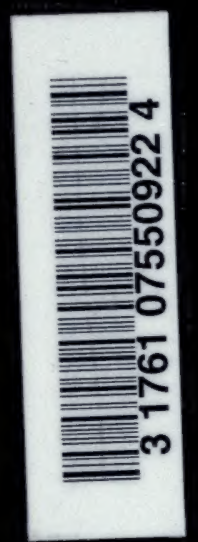

Univ. OF TORONTO LIBRARY 



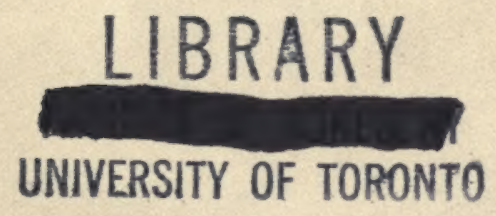


6. 


$$
\text { gorftidge }
$$

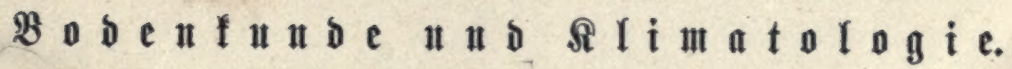


की.

1)

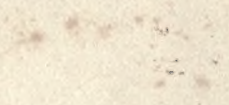

13

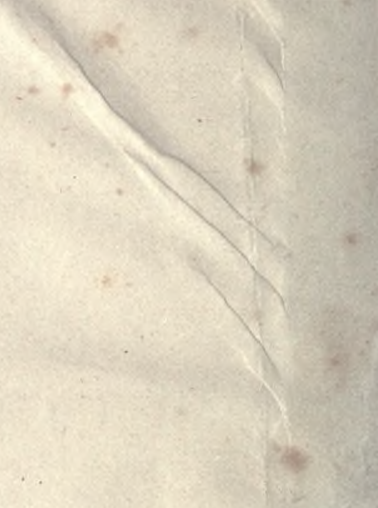

4.

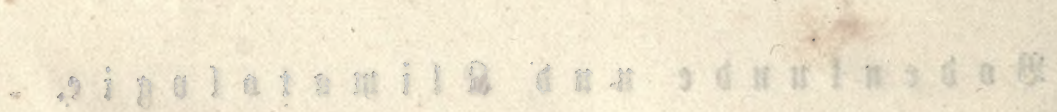

*.

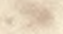
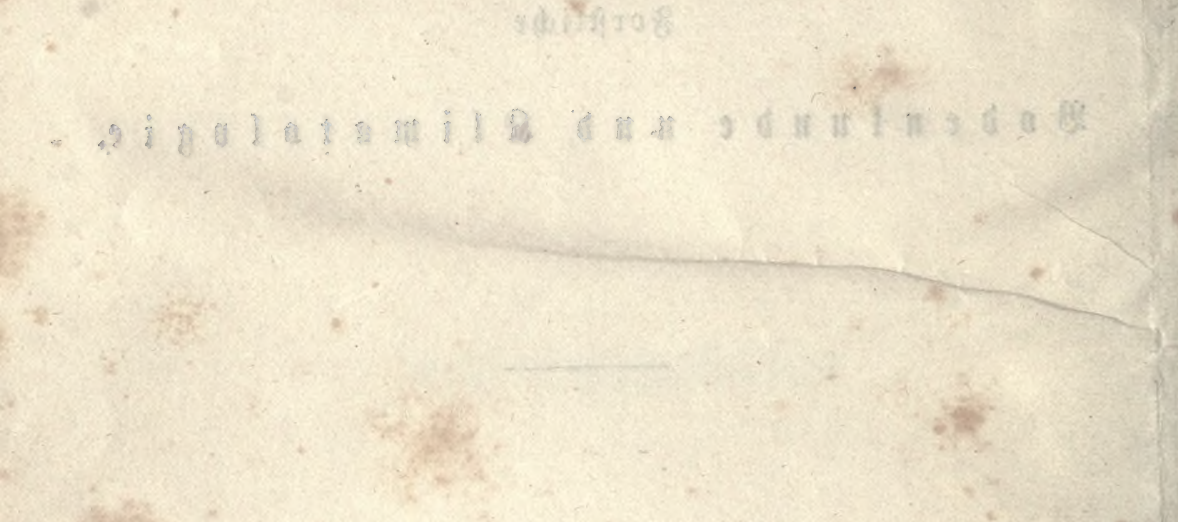

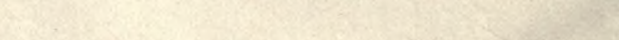

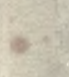

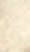

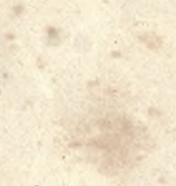

$x^{2}=x^{2}+2$

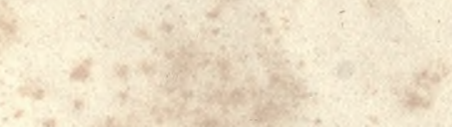

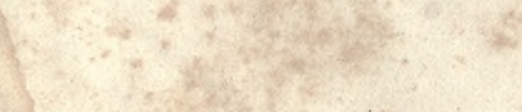

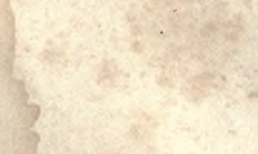
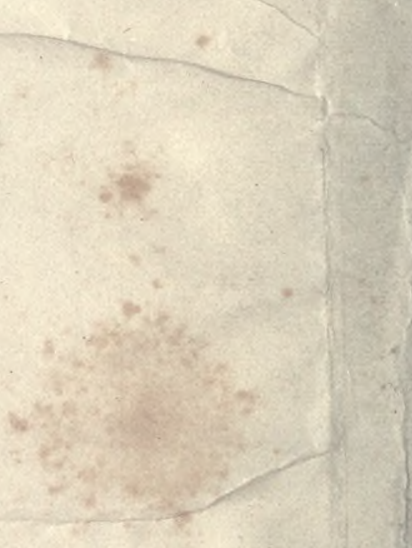


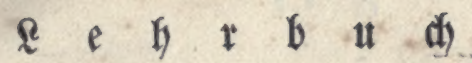

ber

\author{
for itliden
}

\section{Bodenlunio und Elimatologie}

yon

\section{Dr. (A) It a d $\mathfrak{H}$ e yer,}

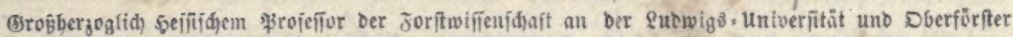
ber Oberförfterei Biefen.

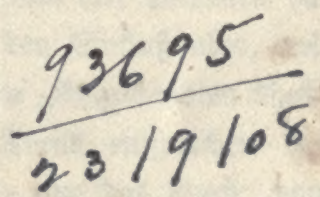

Mit 183 in ben Tert' eingebrucơten 5olzidhnitten, eimer lithographirten ¡đ)warzen uno jowei frarbentafeln.

\section{Cirlagen.}

2) $\mathfrak{f} \mathfrak{i} \mathfrak{g}$ yon 


$$
\begin{aligned}
& s \\
& 598 \\
& 1447
\end{aligned}
$$




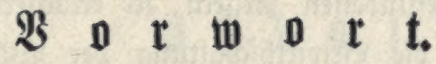

Der $\mathfrak{B e r f a f f e r ~ b e r ~ v o r l i e g e n t e n ~ S c h r i f t ~ i f t ~ v o n ~ b e r ~ \Re n f i c h t ~ a u s g e g a n g e n , ~}$

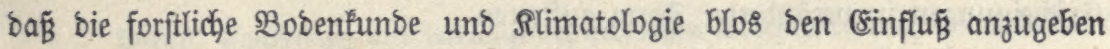

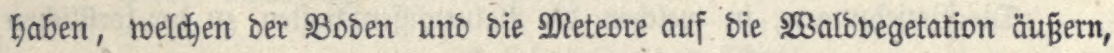

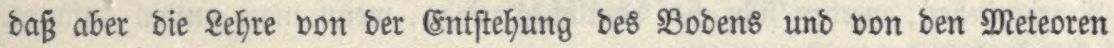
jachgemäß̈ ber Breognofie uno Meteorologie zugetheilt merbe. WSenn er trog= bem bie beiben legtgenannten $23 i f f e n j$ haften in jeiner Sdjrift abgehanoelt

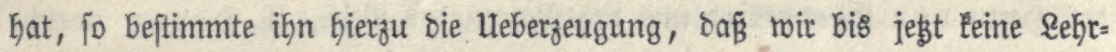
bücher ber (seognofie uno Meteorologie befisten, weldje bem Bebürfniß̧ bes

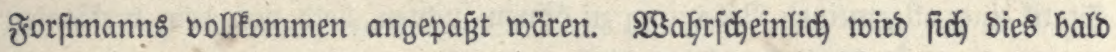

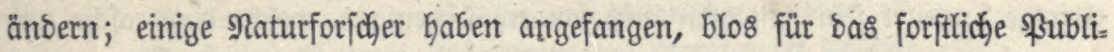

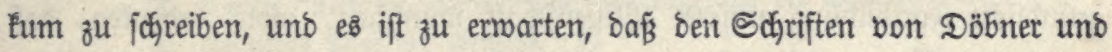

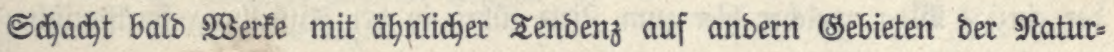
miffenjdyaften folgen werben.

Die \&efre von ber Entftefjung bes Bobens und von ben Meteoren hat

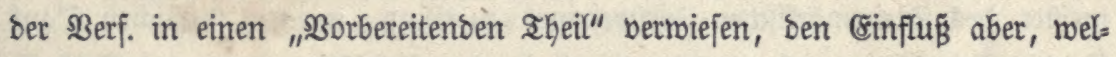

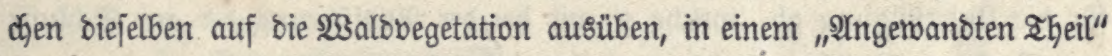
abgeh̆anbelt. Die einżetnen Bücher biejes leģteren Theils entjprechen ben

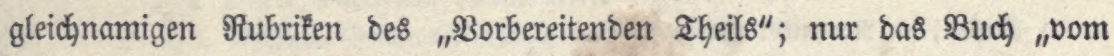
Druct ber \&uft" Eommt blos in leb̧terem bor, meil es Gauptfächlidid wegen bes 3ujammenbangs ber barometrifohen Ericheimungen mit ber Temperatur uno

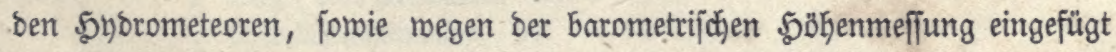

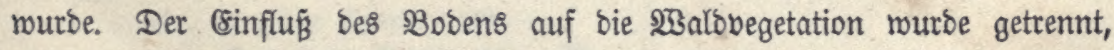

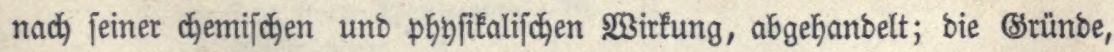
meldye ben $\mathfrak{B} e r f$. zu einer foldhen Sonderung beftimmen fonnten, wirb ber geneigte \&ejec am beften aus bem Buche jelbjt entnehmen.

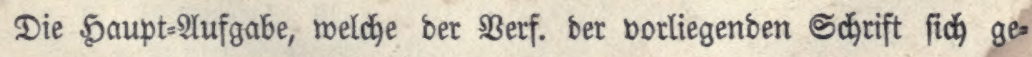
ftellt bat, beftegt barin, bie Naturmififenfdaften in eine engere uno unmittels 


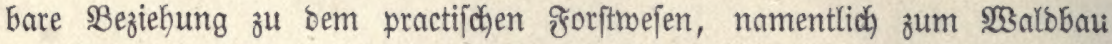
zu bringen, in fo meit lesterer sie forftliç) Bobentunbe uno Slimatologie

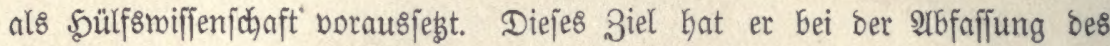
angemanoten Iheils fortwähreno im 2 uge befalter.

Die Naturnifjenjchaften Gaben bisher mebr bazu gebient, bie bereits

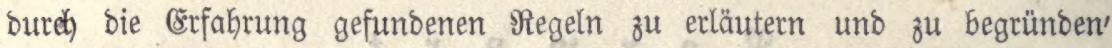

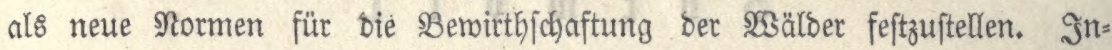

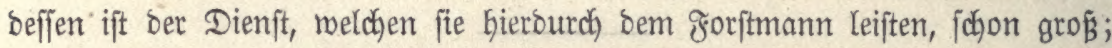
nur Derjenige, welcher bie Urjachen ber (Ericheimungen kennt, ift fick ber

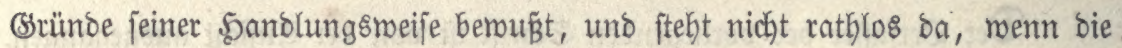
(srjcheinungen in beränoerter Form auftreten.

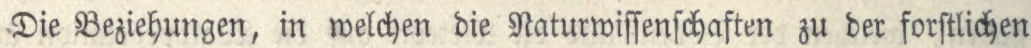
Braçis ftehen, werben fich aber beutlicher zeigen, menn man einmal anfängt, an bie Stelle fufälliger Beobadłtungen, mie fie ber Arugenblid von ungefähr barbietet, genaue ftatijche Unterjuchungen zu jezen. Miochten bie SBemïlfungen

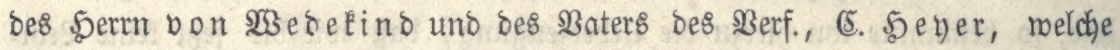
fchon bor Sabren mit bebeutenden pecuniären Dpfern bas ซ̌eld ber forftlichen

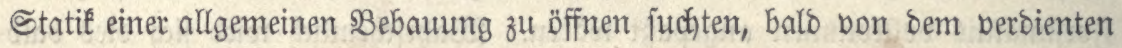
Erfolge begleitet jein; möchten insbejontore Diejenigen, weldhe eine rajche uno

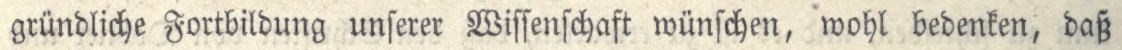

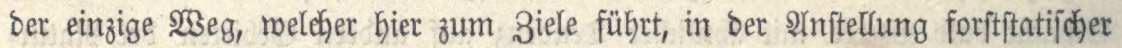
unterjuchungen bejteht.

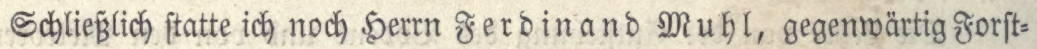
meifter bes Steiermärtijchen grorjtbereines zu Srab, meinen Gerzlichen Dant für bie Unterftübung $a b$, welche er mir bei ber Alusfübrung ber am Schluffe

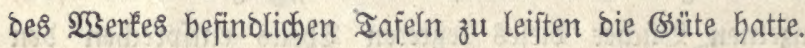

SSiefen, im Roventber 1855.

(S)Ittav Şeuer. 


\section{3) $\mathfrak{n} \mathfrak{a} 1 \mathfrak{t}$.}

\section{Einleiturg.}

Begriff, Cintheilung uno Riteratur ber forftidjen Bobentunbe unb Rlimatologie. S. 1.

Borbereitender $\mathfrak{Z}$ beil.

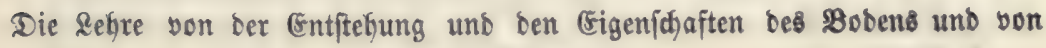
Den IReteoren.

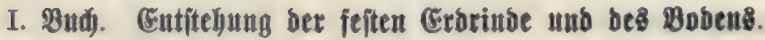

I. भbidnitt. Einleitung.

1. Erf̌ärung bet Erogeftalt. 3.

2. Entĩtebung ber neptunifacen uno plutonif̧en Oefteine. 4.

3. Tertur, Structur, Nbionberung unb \&agerung bet Befteine. 5.

4. Nelative\& IIter ber Gefteine. 7.

5. Berfteinerungen. 7.

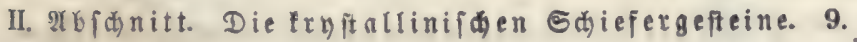

III. Ibidnitt. Die neptunifden ober febimentåren bebilbe bis zur (5) ruppe bes Dilubiums (einfdi.).

1. Einleitung. 12.

2. Draumadengruppe. 13.

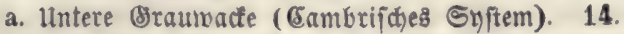
b. Inittlece graumacte (ভilurifotes €nftem). 14.
c. Dbere Draumacte (Debonifiegి Syftem). 14.

3. Steinfohlengruppe. 17.

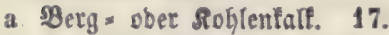
b. Steintohlenformation. 17.

4. \$ermijche Orrtppe. 20.
a. Das Rothe Zobtliegenbe. 20.
b. Supferintiejer. 21.
c. Seçjtein. 21.
d. Bogejenfanbitein. 21.

5. Iriagrgrupfe. 21.

a. Bunter Sanbitein. 21. 
b. Mujdelfalt. 23.

c. Reuper. 24.

6. Juragruppe. 25.

a. Riสริ. 25.

b. Эura. 25.

7. Sreibegruppe. 27.

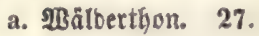
b. Quaberfanbftein. 27.
c. Sreibeformation. 28.

8. Molafiegruppe. 29.
a. Braunlofienformation. 29.
b. Oroblalfformation. 31 .
c. Segelformation. 31 .

9. Cruppe beछి Diluviums. 31 .

IV. भbidnitt. Die plutonifden unb bulfanifden Felsarten.

1. $\mathfrak{A}$ IIgemeines. 33.

2. Oruppe bes Oranits. 34 .
a. Oranit. 34 .
b. Syenit. 35 .
c. Granulit. 36 .

3. Sruppe besి Orünteing. 36.

4. Oruppe be8ి Felfitporphyrs. 37.

5. Oruppe bes MRelaphyrz. 38.

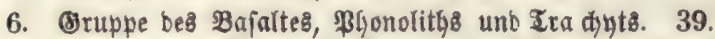
a. Bajalt. 39.
b. \$honolith. 42.
c. Iradjit. 43.

7. Sruppe bet Bulfane. 44.

v. Abj

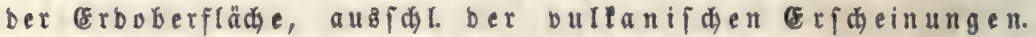

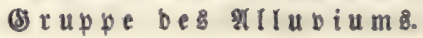

Cinleitung. 46.

I. Rapitel. Bobenbitbung burdh medjanifthe ober phnfifalifdje aräfte.

1. Mirtung ber $\mathfrak{W a ̈ r m e . ~} 47$.
a Die 2 ärme im 2 Ügemeinen. 47.
b. Cinfuß bet $\mathfrak{B a ̈ r m e ~ a u f ~ b i e ~ B e f t e i n e . ~} 50$.

2. Mirfungen ber Sabuete. 52 .

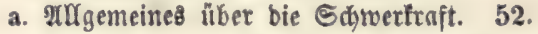
b. Sinfuß ber Sđ̆were auf bie Oefteine. 53 .

Sdhuttfegel. 53. Bergftürze. 54. (Einwirfungen ber flüfie auf ihr Bette

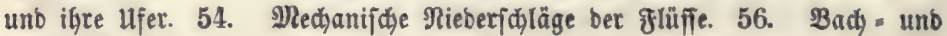
Flupgefđiebe. 56 . Deltabilbungen. 57.

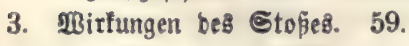

a. $3 \mathrm{~m}$ IXgenteinen. 59.

b. Einmirtung beछి Stoßies auf bie Orefteine. 59 .

Ufernäßle, \&agunen. 60. Dünenbilbung. 60. Flugfanb. 61. 
II. Rapitel. Bobenbilbung burd) organifaçe Siäfte.

1. Bobenbilbung burd Ihiere. 61.

2. Bobenbilbung burdh Pfantzen. 63.

A. Bermefung ber Pfanzen bei vollfannoigem Butritt ber \&uft. 63 .

2. Beftanbtheile bet झfianzen. 63.

b. Die Bebingungen ber Bertwejung. 63 .

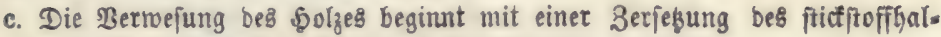
tigen Beftanbtheils. 64.

d. Dorgänge bei ber Berję̧ung ber ftiffitoffbaltigen Beftanbtheile im 5otze. 64 .

e. Die Serjeşung ber fticfifoffbaltigen Subftanz überträgt fich auf bie fict. fitoffireien Beftanotheile beg̊ 5olzeg. 64 .

f. Borgang bei ber Berjęung ber fticfitoffreien Subftungen im \$olze. 65 .

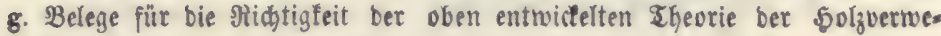
fung. 66.

h. Die Bermejung. Deళి 5olzeళ geht um fo Ianglamer von Statten, je meiter fie vorgeidritten ift. 66 .

i. Beförberungsిmittel ber Berwejung. 67.

B. Berwejung bei Mbjolü ber Rujt. 69 .

C. Berwejung bei unvolftänoigen 3utritt ber \&uft. 69.

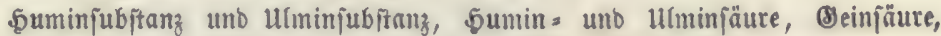
Quelfjäure unઠ Quell

D. Zorfbilbung. 72 .

a Begriff bon Sorf. 72.

b. Bebingungen füt bie Iotîbilbung. 72.

c. Benennung ter Sorfmoore nad̆ ifger äußern Eripheinung. 75 .

a. 5odmoore. 75. $\beta$. Reffelmuore. 75. $\gamma$. SBiejenmosre. 75. d. Deermoore. 75.

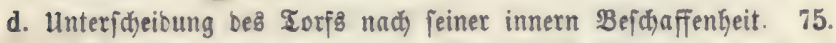

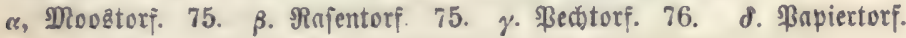

76. є. Briggertorf. 76.

e. Radjwadjen beछి Iorf̧. 76 .

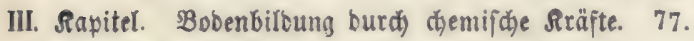

(Berwitterung in engern Sinne bевి 20 ort8).

1. 2rmgemeites. 77.

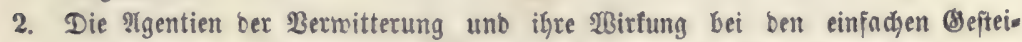
nen. 78.

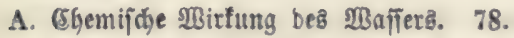

a. Berwitterung burd) Rlupnahme von Rryitallifations. unb Sybratmaj= jer. 78.

a. 2nhybrit. 78. B. Eijenglan. 78.

b. Tuföfung ber Defteine in reinem $2 B a f f e r .79$.

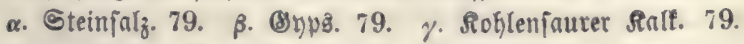

B. Bermitterung burd Drbbation. 80.

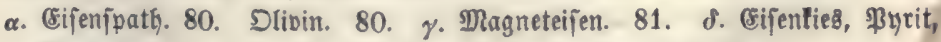
Marfafit. 81 .

C. Bermitterung Durd Deвoxnbation (gtbgabe bon Satterfioff), 82. 
a. Desorybation famefelfaurerer Galze. 82. $\beta$ Entfithung beg Rajeneifen= ftein. 82.

D. Berbitterung burd Sohlenjäure. 84 .

a. $\mathscr{\text { UMgemeine8. } 8 4 .}$

b. Cintvirfung ber Rohlenfẩure aũ fohlenfaurem Salf. 84.

Tropffteine. 85. Salftuff unb Silfịter. 85. Brunnen= unb Filufimai= ier. 86 .

Inbang: Bifbung bes Dolomits. 87.

c. Einmirfung ber Roblenfäure auj Whospthorjaure Salze. 88.

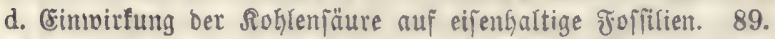

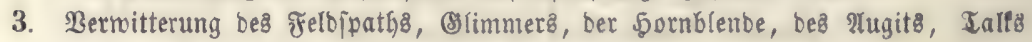
unb ber Riejelgefteine. 90.

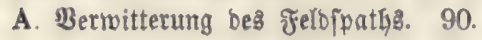

a. Widtigfeit besి Felbipatḩ. 90.

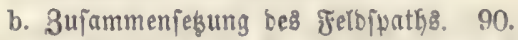

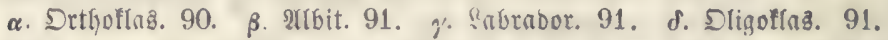

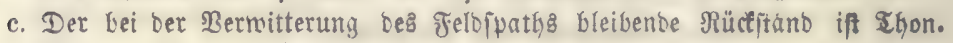
92.

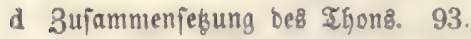

e. Bergleidfung Des Saolins mit frifdyem felofpath. 93.

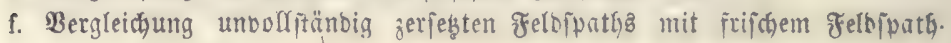
94.

g. Der Felbipath wirb burh Stohlenโäure zerję̧t. 94.

h. Berwitterung Dez গtbit3, Dligoflaję uno \&abrabors. 95.

i. Die Berfebbarfeit ber Felfipathe nimmt zu nit ifrem Ratrongehalt, Felopathe, melche Natron uno Salf z̧ugleich belizen, fino bejonbers leicht attffiliepibar. 96 .

k. Die übrigen Beftanbtheile ber Felbipatbe. 96 .

श्(nhang: SBillung ber Beolithe. 97.

B. Berwitterung Deళ Ofimmerî. 98.

C. Berwitterung ber 5ornblenbe. 99.

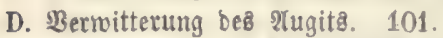

E. Bermitterung Desి Drivinz. 102.

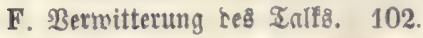

G. Bermitterung Der Riejelgefteine. 103.

4. Berwitterung ber Feläarten. 104.

A. Im भUfgenteinen. 104.

a. Die Serwitterbarfeit einer Felgart hängt von ber Berwitterbarleit i̧rer Beftanbtheile ab. 104.

b Sd)iefrige Bepteine zerfallen Ieid)ter in fleinere Jraguente, als mafinge (septeine. 104.

c. Boröje Bepteine verwittern Yeirhter, ala Derbe. 104.

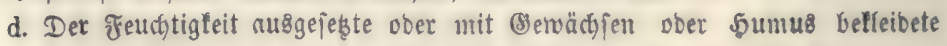
Gefteine berwittern leidjter, alo nacte Felfen. 104.

e. Eifenoxbourhaltige (sefteine verwittern leidjt. 104.

f. Aryftallinifde Bepteine. 105.

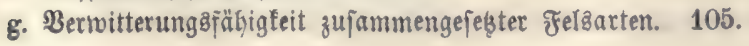


B. Dertwitterung bet Felsarten ingిbeionbere. 106.
a. Jranit. 106.
b. Eranulit. 107.
c. Sycnit. 107.
d. Sneiß̄. 107.
e. Slimmerijiefer. 107.
f. Thonįdiefer. 108.
g. Giraumace. 109.
h. Srünteine. 109.
i. Jelfitporphnr. 110.
k. Delnphyr. 110 .
1. Iradint 111.
m. Bhonolith. 112.
n. Bajalt. 113.
o. \&ava. 114.
p. Sanbiteine. 115.

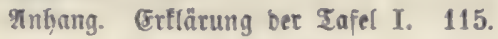

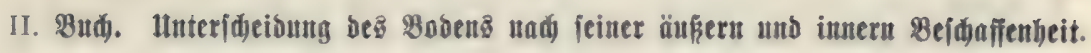

I. Tbiduitt. (5)aracteriftif bes Boben в แa ber Engerfätte. 117.

1. Uriprüngliđje unb fecuntäre lagerîtätte. 117.

2. IB Burzelbobenraum uno untergrunb. 117.

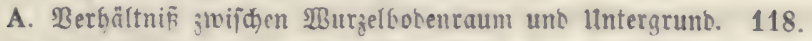

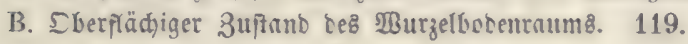

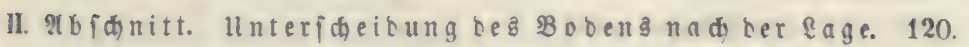

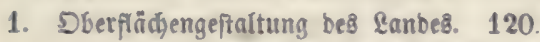

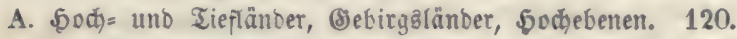
B. รieflänber inछిbejonbere. 120.
C. (5) birgalänber inbefonbere. 120.
D. 5odjebenen inşejonbere. 123.

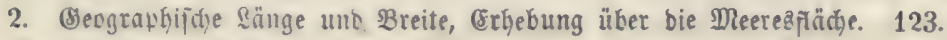

3. Rbbachung. 124.

4. Expofition. 126.

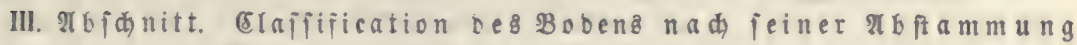
Don ben IIttergefieinen. 126.

IV. शbidnitt. Claffification ber Bobenarten nad ihren bormals tenben Beftanbtheilen. 127.

1. Einleitung. 127.

2. शufzäblung ber Bobenarten. 128.
A. Ihouboben. 128.
B. Lebmboben. 129.
C. Ralfbudent. 130 .
D. Byprboben. 131.
E. Mergelbaben. 132.
F. Ialtboben. 133. 
G. Gijertboben. 133.

H. Sanbboben. 133.

I. \$umusboben. 134.

a. Begriff von \$umus. 134.

b. CintGeilung. 135 .

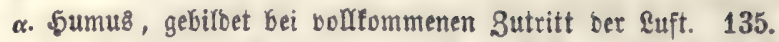

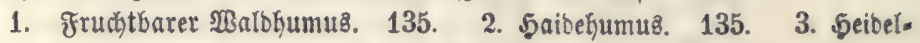
beetgumus. 135. 4. Staubetbe. 135.

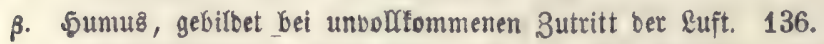

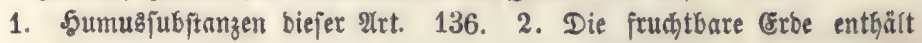
feine ฐumuş̧äuren. 136.

Intyang: Nitrolin. 138.

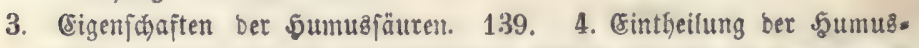
arter, weldie fid bei unvolpänbigen 3utritt ber \&uft zo ben berwes

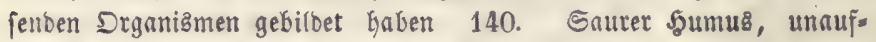

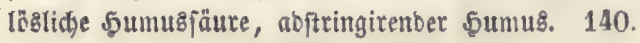

v. Abjanitt. Eraffification bes Bobens nad feinen phyfifalifaen Eigenidaften. 141.

1. Bemidit ber Croarten. 141.

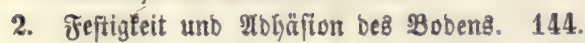

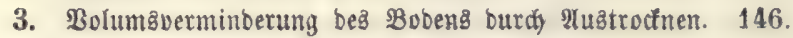

4. Feư⿱⺈⿵⺆⿻二丨
A. Betingungen. 147 .
B. MBafferaufnafmefätiglét. 147.
C. $\mathfrak{B a f f e r z z u t u ̈ c t g a l t e n b e ~ S r a f ̣ t . ~} 150$.
D. Wanferbampfabjorption\&fähigteit. 151.
E. Claffififation bez Bobenz nađ feinem Feudtigfeit8gehalte. 153.

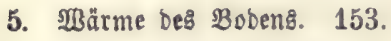

A. Crtwärmung\&̊̄ähigleit. 153.

B. Wärmelgaltenbe Rraft ber Creben. 155 .

6. Sonpitge Eigenif haften besి Bobens. 156.

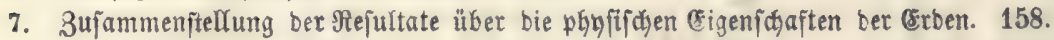

III. Buth. Die Bejtantheile ber Âtutoiphäre. 160.

1. Begriff bon ※tmojphäre. 160.

2. Quantitatives Berłältniß von Enuerfoff uno Stidfitoff. 160 .

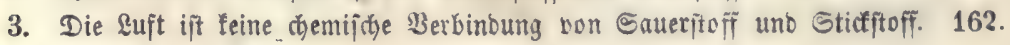

4. Sobjlenfäure. 163.

5. Immoniat. 166.

6. Bafferbampf. 166.

7. SaIpeterjäure. 166.

8. $\mathfrak{R}$ ftittaub. 167.

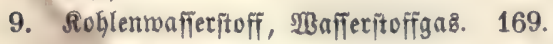

10. Eubiometrie. 170. 
IV. Bud. Ridit.

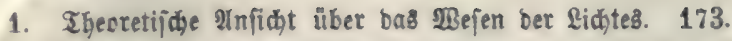

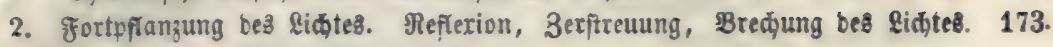

3. Intenfität ber Beleud̆tung. 174.

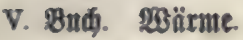

I. $\mathscr{A} B$ đ

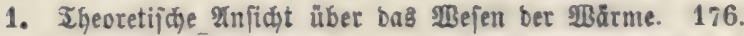

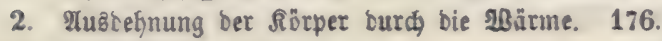

3. Thermometer. 177.

4. Egermometrograph. 178.

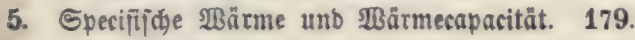

6. Ratente $\mathfrak{B a ̃ r m e . ~} 180$.

7. Fortpflanzung ber 20 årme. 181.

8. Erfalten. 185.

II. भื

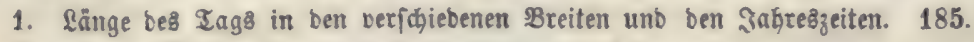

2. Regeln für die Iemperaturbeobacitungen. 188.

3. Directe Beobachtungen über ben Bang ber tägl. Semperatur ber \&uft im Sđjatten. 189.

4. Rejultate ber Beobachtungen über ben (3ang ber tảgliḑen Iemperatur. 194.

5. Dittlere Iagestemperatut. 198.

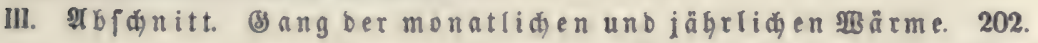

\section{Monatliđe शBärme. 202.}

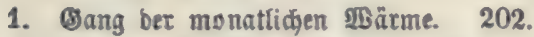

2. Die mitthere 2 Bärme eines פMonats. 202.

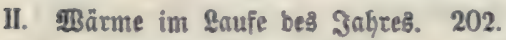

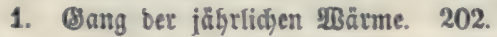
A. श्रgemeines. 202.

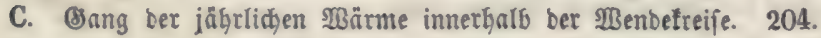
a. Drte an ber Gee baben fühtere Sommer. 205.
b. Drte an ber Gee baben wirmere 20 inter. 205.

B. Drang Der jährlidjen Wärme in ber nörbliđ̆en gemäß̧igten unb \$olargone. 203.

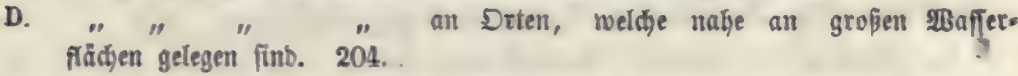

2. Mittlere Jahreatempecatur. Methoben zur Beftimmung berfelben. 207.

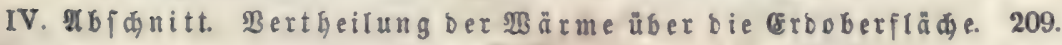

1. Begrifi ber ijotbermif̣đan Rinien. 209.

2. Die DRectêftömungen. 210.

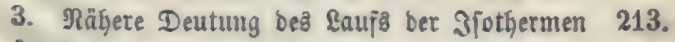

4. Dic Jođimenten. 218.

5. Siptberen. 219.

6. Monatsijotநermen. 220.

7. Iemperatur bes Bobens. 220.

a. Iemperatur ber Bobenvberflādje. 220 .

b. Iemperatur Des Bobens in ber Iiefe. 221. 
8. Iemperaturabnakme mit zunehmenber Erhebung über bie Deerebpäac. 224.
a. Utiacien biejer Temperaturabnafime. 224.
b. Grỉje ber Temperaturabnabme. 226.
c. Febuction ber Semperatur auf Das Meeresiniveau. 228.
d. Sđ)neegrenze. 229.
e. Orleticher 231.

\section{Buti. Bintive.}

1. Begriff unb Benenmung ber SMinbe. 234.

2. (Se)

3. Urjachen ber Winbe. 235.

4. $\mathfrak{L a n t}=$ und Seeminbe. 238.

5. Locale Binbriđatungen. 239.

6. Der Aequatorial = und Der \$olariffiftrum, झaffate. $2: 0$.

7. Die Region ber Ealmen ober Winbfillen. 243.

8. Winbverhäıtnifje in Europa. 243.

9. Temperatur ber Sinbe. 245 .

10. Stürme. 246.

\section{Bud). \$norometeare.}

I. XGidnitt. $\mathfrak{B}$ pu ber $\mathfrak{B}$ erbunitung. 248 .

1. Dunit, Dampf. 248

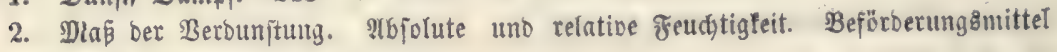
ber Berbunịtung. 249.

3. Spanufraft Der Dinnfte. 253.

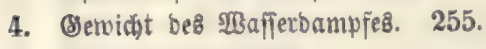

5. 5ngrometrie. 256.

6. Sang ber abjoluten unb relativen Ruftfeudtigfeit im Laufe beछ Ingesి. 261.

7. grang ber abfoluten unb relativen \&uftfeudtigfeit im \&aufe bez Jaদrez. 262.

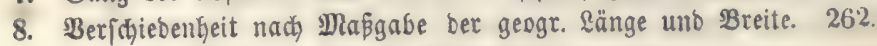

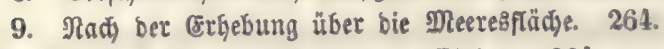

10. Feudtigfeit bei berijiebenen 2 Binben. 264.

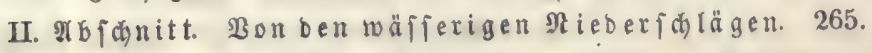

1. Urjađ̧en ber wäfïerigen Rieberfalăge. 265 .

2. Nebel. 266.

3. Wolfen. 267.
a. Entitebung ber $\mathfrak{W}$ olfen. 267.
b. Sdyeben ber isolten. 267.
c. Molfengeftarten. 267.

4. Regen. 270.

5. Sdinee. 270.

6. Бagel. 272.

7. Thau unb গeif. 274.

8. Regenmenge. 277.
a. Begriff. 277.
b. Regenmefier. 277.
c. Einflüfle, weldye bie Regenmenge beîtinmen. 279.

9. Beftanbtbeile beв sheteorwafiers, 286. 


\section{Butd). Cercetricitït.}

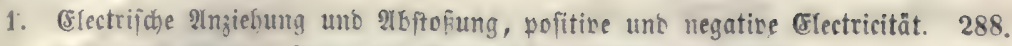

2. Bute uno ihledite Reiter Der (Elestricität, Sfolatoren. 289.

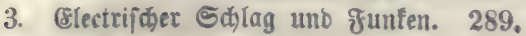

4. urjađjen bet Clectricitätzentroictung. 290.

5. Electricität ber शtmofphäre. 290.

6. Dewitter. 291.

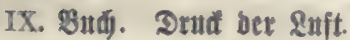

1. Sdiwere ber \&uft. 293.

2. Das Barometer. 293.

3. Rejultate Der B̉eobadtungen an Barometer. 295.

4. Urjacten rer Edtmanfungen Desิ Barometers. 298.

5. Barometrifhe 5öhenmeTung. 299.

\section{Angewanoter Zgeil.}

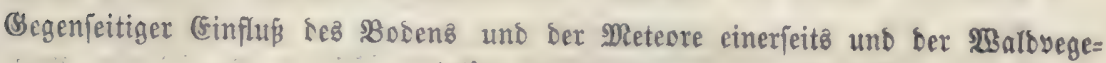
tation anderfeits.

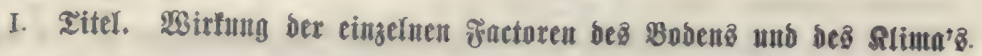

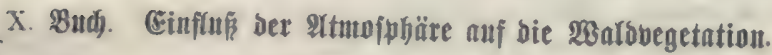

I. Ab fdnitt. Bon ber Reimung. 310 .

1. Beftantbtheile bes Saments. 310 .

2. (6hemifaje Beränberungen, meldye bie Beftanotheile ber Samen bei ber Seimung exieiben. 314.

3. Bebingungen für ben Eintritt be\& Seimacte8. 316 .
a. Saueritoff. $\mathbf{3 1 6 .}$
b. Feudigtigleit. 318 .
c. W̋ärme. 320.

4. Dauer ber Secimfraft. 321 .

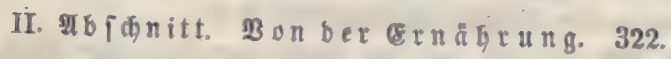

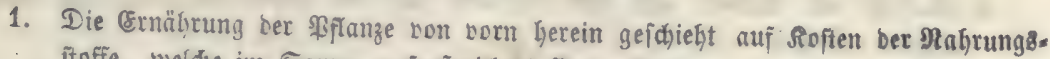
itoffe, welde in Samen aufgejpeichert fint. 322.

2. Beftanbtheile bes \$oTzes. 323 .
a. Structur be8 5olzes. 323.

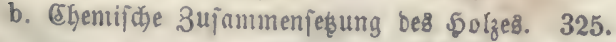

3. uriprung bes foblenptoffes in ber 5olzfajer. 327.

4. (Bej̧ichte ber Entbecfung ber Robjlenjäures-2ffimilation. 330.

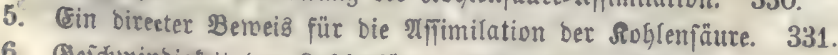

6. Bejđ̆winbigfeit ber Soblenfäure = 26jorption. 332.

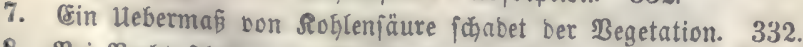

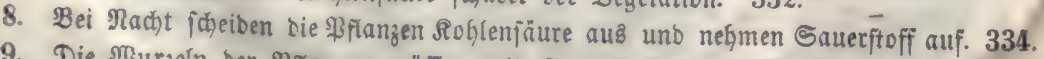

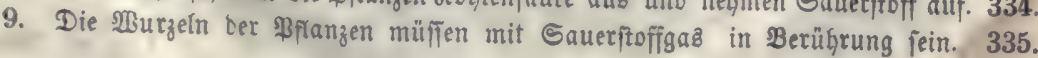




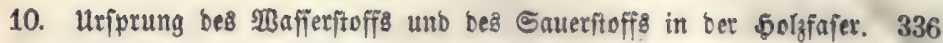

11. Uriprung bes Sticiftoffి. 338

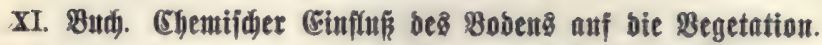

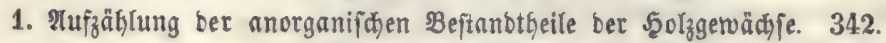

2. Bertheilung ber anorganifhen Stoffe imethalk bet einzelnen Theile ber 5olzges wädje. 343.

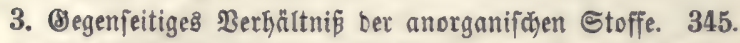

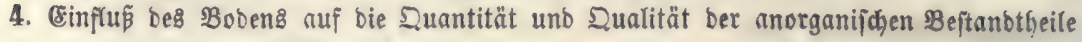
Der \$olzpflanzen. 348 .

5. Uriprung bet anorganifdjen Beftanotheile in ben Begetabilien. 350 .

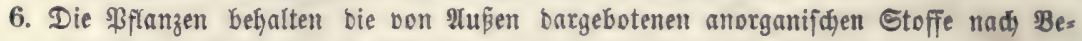

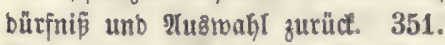

7. Die anorganifjen $B$ eftandtheile in ben Pflanzen finb eine notymenbige Bebingung für bie normale entwicfung berfelben. 353 .

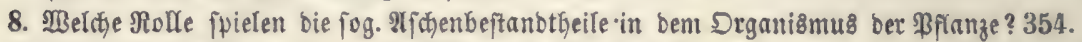

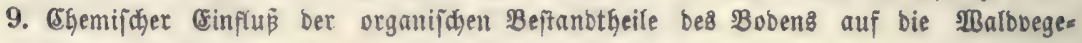
tation. 363.

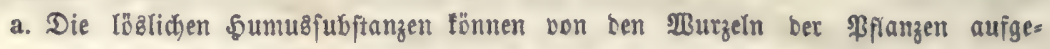
nommen werben. 363.

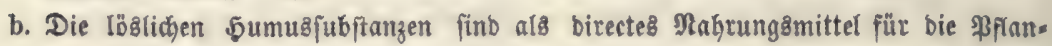
zen obne befonbere Bebeutung. 364.

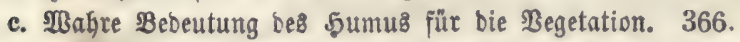

$\boldsymbol{\alpha}$. Die aแ jeiner Berjebung berborgebenoen gasförmigen unb nnorganijøen Stoffe tragen zur Ernährung ber Berädjie birect bei. 366 .

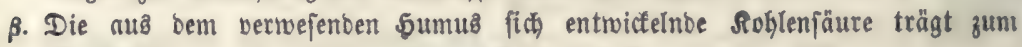

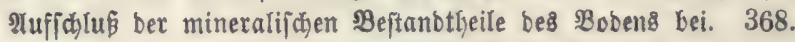

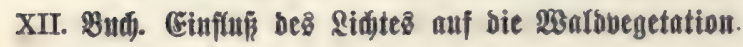

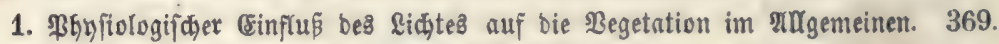

2. Berhalten ber Malbbäume gegen bas Ridut. 372 .

a. Solzarten, weldje in bex Jugenb be8ి Sdjattensి bebürfen. 372.

b. 5olzatten, melaje in ber §ugend Sd)atten extragen. 373.

c. Riđtbebürfnip ber 5olzarten in ben übrigen \&ebensaltern. 374 .

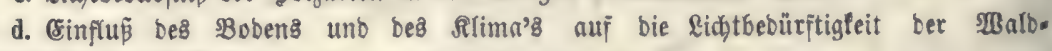
ธลีนแกอ. 377.

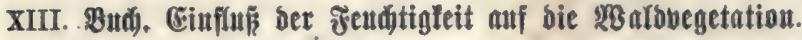

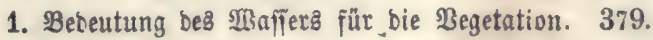

2. Saftieudigfeit. 380 .

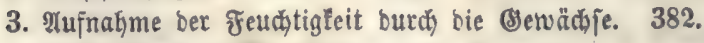

4. Detbunftung ber Bewädje. 383.

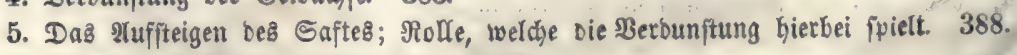

6. Cinfū bes গegens insbejonbere. 393 .

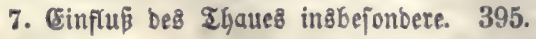

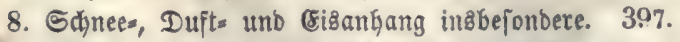

a. Sduneeankang. Die Sđäblichfeit beffelben hängt ab: 398.

$\alpha$. Bon ber פolzart. 398. B. Bon Dem 5olzalter. 398. $\gamma$. Bon ber Deeres. 
Gäbe. \&. Bon Der Expofition uno Dem Minbe. 399. $\varepsilon$. Bon bem bichteren ober liăteren Stanb ber Bäume, Der Walbbebanblungsart 2c. 399.

b. Duft unb Eisిantang. 400 .

9. 5agelfăaber. 401.

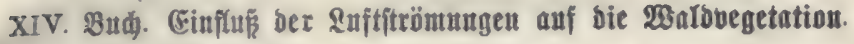

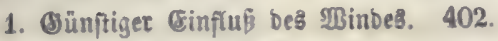

a. Sữtmeçj̄el. 402.

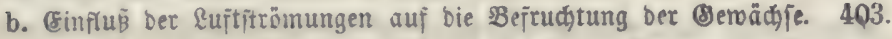

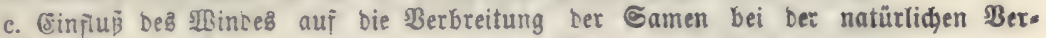
jüngung. 404.

d. Bejeitigung ber Bobennäfie. 404.

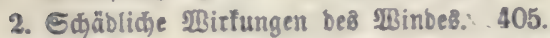

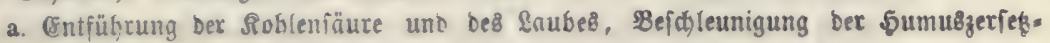
ung. 405.

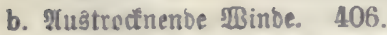

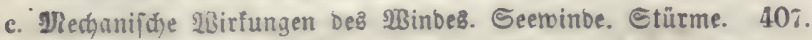

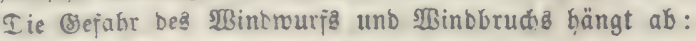

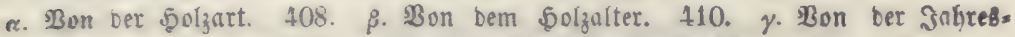

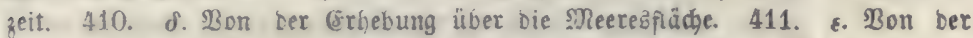

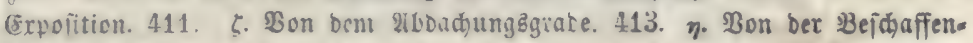

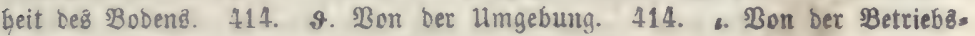
art unb ber 2 balbbebanblung. 414.

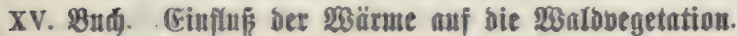

1. Cinleitung. 417.

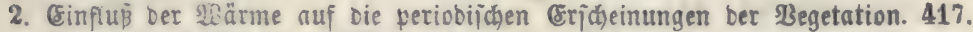

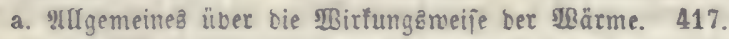

b. Interjưtung, ob bie Effecte ber Wärme ben Temperaturgraben einfad proportional feien. 419.

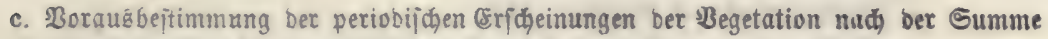
Der Quabrate ber Iemperaturen. 420.

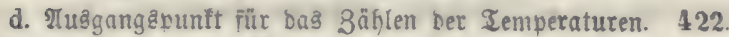

e. Wichtigfeit ber Wärme für baรి গReifen ber frindte. 423.

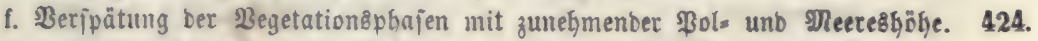

3. Cinfuß ber Wãrme auf bie ફolzmafientrzeugung. 428.

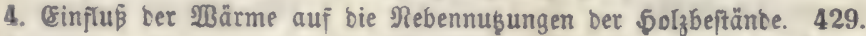

5. Бikge. 430 .

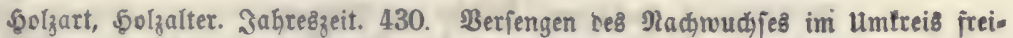

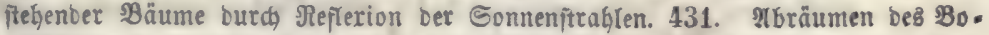

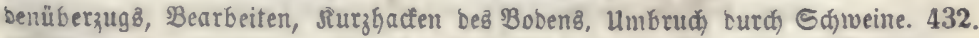

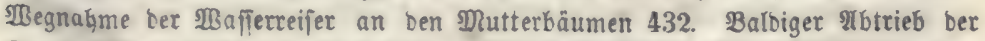

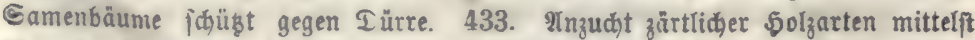
Boranbauz unempfindlider 5olzarten 433. 3m Gdilufie exgogene Bflanzen leis ben Dorgugsmeije bon ter Sike. 433. Rinbenbrand 433. Majregeln gegen bent-

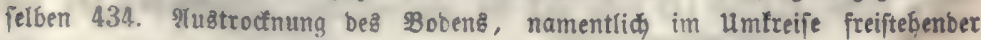
Bäume. 434.

6. Einftup ber Bobenกürme. 435 . 
7. Froit. 435.

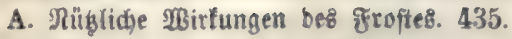

B. Sdaben bezి Frofter. 436 .

a. 2rOgemeines über ben Erfriertob bei Den झfanzen. 436.

b. Umitänbe, von weldien Das Eririeren ab̧ängt. 437.

a. Temperatur. 437.

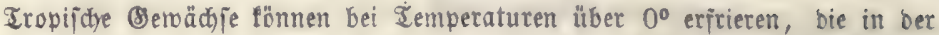

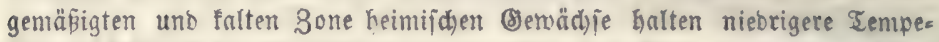
raturen aนs. Sdnedfer Uebergang ber Rälte zur SBärme, uno umgefebrt, idabet am meiften.

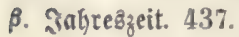

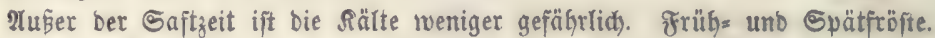
$\gamma$. Iageg్zిeit. 438.

Frïl = uno Sfätronfife treten meif́t furz vor Sonnenaufgang ein. Wärmes auşftrahlung bet grünen Iheile ber Begetabilien.

ข. Mitterung, inßober. WBinb. 438.

Bei besecftem șimnel uno bei berwegter \&uft fino bie fröffe jelten. In.

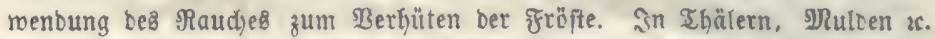

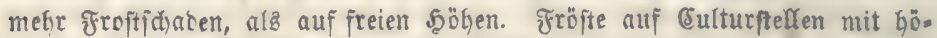

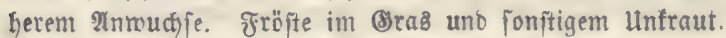

8. 5olzart uno 5olzalter. 440 .

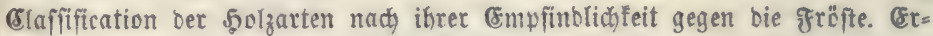
frieten älterer Buçen auf najien Stanborten. Sgerbithieb beim Riebermalb

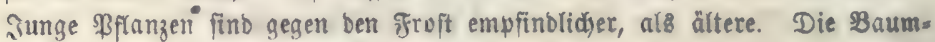
blüthen fino gegen ben froft empfinblid.

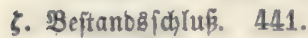

Bäume, weldhe aนв bem Sd)luffe in freien Stano gebracht werben, erfieren

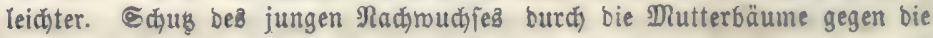
Fröfte. Boranbau von nicht empfinoliden 5olzarten,

$\eta$. Bejdaffentyeit bes Bobent. 443.

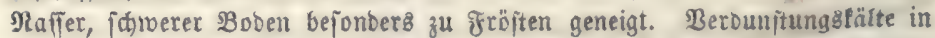
feudten \&agen. Beredjnung berfelben. Stänbige Froftifellen. Frronbirung

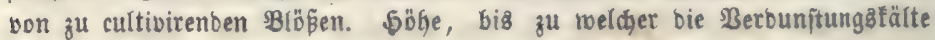
fich exfrectt.

ง. Expofition. 446.

Dits unb Sübofffeiten.

b. Meereвböbe. 446.

Frübfröp̣te in 5odlagen. Fröpte auf \$laten'sి.

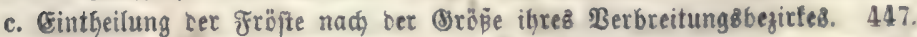
Ranb= unb \&oculfröfte.

d. Froftrifie. 447.

e. Iuøిfrieren ber झflanzen. 449 .

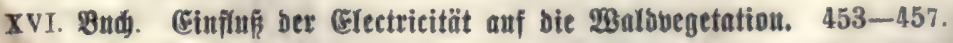

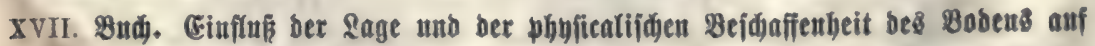
bie 2 Balovegetation.

1. Urjprüngliđạe unb fecunbäre Iagerfâtte. 458. 
2. Burgelbobentaum unb untergrunb. 459.

3. Zieflänber. 459.

4. Debirgslänber. 460 .

5. 5odebenen. 463.

6. Beographif̧̄e \&änge uno Breite, Meereßböbe. 463.

7. अbDaळunig. 464.

8. Cexpofition. 468.

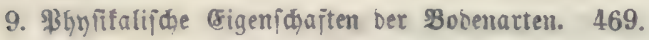

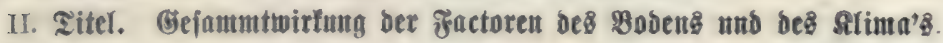

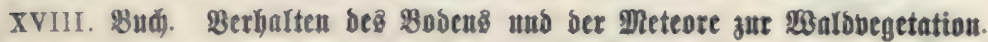
Einleitung. 470.

I. आbidnitt. Begriff ber forftiden StanbortBgüte. 471.

1. Borbemerfung. 471.

2. Iie widitigften Factoren ber Bobengüte fino Jeudtigfeit, Tiefgrüntigreit, locterheit unb sumushaltigfeit. 472.

3. Snbere Injichten über bie Factoren ber Bobengüte. 478 .

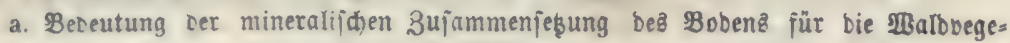
tation. 4.78.

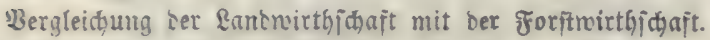

a. Dingung. 479. B. Beacferung. 481. $\gamma$. Bradje. 481. d. Bedfelwirthibaft. 481.

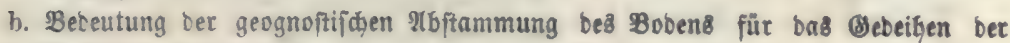
MBalobegetation. 489.

4. Sonítige Factoren ber forftiめen Stanbortsిgüte. 492.
a. शुärme. 492.
b. \&uftfeuڤtigfeit. 495 .
c. Bujtfitiomungen. 495.

II. Tbidnitt. Erfyaltung unb Debrung ber forfliden Stanbort Bs $\mathrm{g}$ uี te. 496.

1. 24u

Theorie ber reinen Beftänbe. 497. Theorie ber geniifdten Beftänbe. 498. Bobens

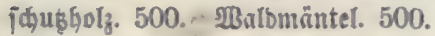

2. Maß̄ ber Beftanosoidte. 501 .

3. T)

4. Umtriebsిzeit. 505 .

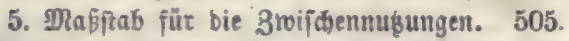

6. Patürliđge unb fủnplidue Berjüngung. 506 .

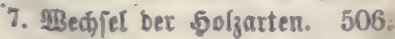

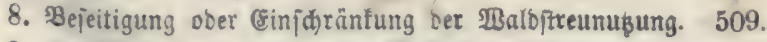

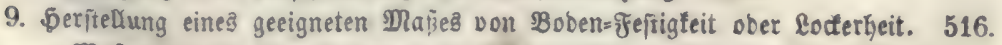

a. Mapregehn zur Berminberung einer übermäß̈igen Bobenlocferbeit. 516 .

b. " " " " allzugropen Bobenfeftigleit. 516.

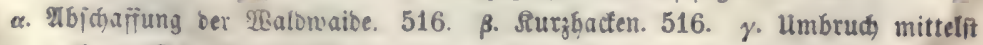
jafmer Sdyeine. 51\%. d. Sainen โes Botens. 517. 5actmalb = uno

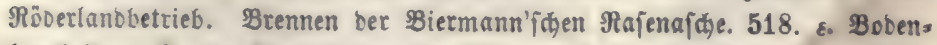

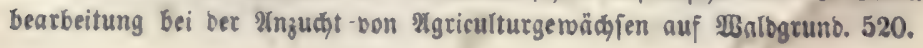


Zemporärer uno ftänbiger $\mathscr{M B}$ albfelbbau. 521.

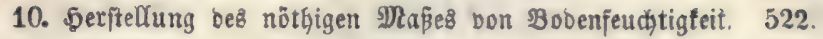

a. Beieitigung einer fđäblidien Bobennäfie. 522.

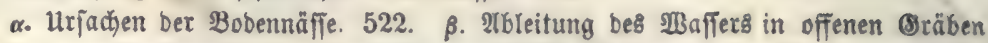

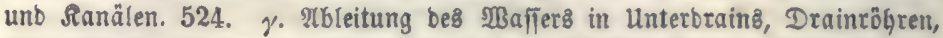
Dber mittelft Berjenfung. 526. d. Sonjtige Mafiregeln zur Berminberung einer alfzugroßien Bobenjeuditigleit. 527:

b. Bejeitigung einer fdablichen Bobentrocfentheit. 528.

III. थb fdnitt. Unterfudung ber jorfitidell Standortsgüte (Boniti= rung). 528.

1. Begriff unb 3nect ber Bunitirung. 528.

2. Berfahren zur Bonitirung. 528.

a. Directe Unterfudung bet Factoren ber Ctanoort8güte. 528 .

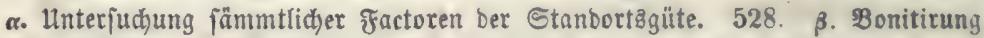
nad Maßjgabe ber demifden 3ujammenfekung bes Bobens. 530.

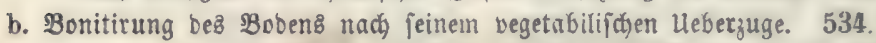

c. Bonitirung bes Bobens nach Maģgabe Deg auf iłm befinolicten 5olzbeftan= beรి. 536.

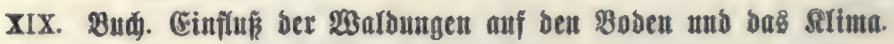

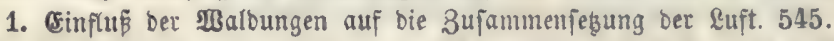

2. " " ." " Temperatur Der Rujt unb bes Bobens. 546.

a. " " " "Sommertemperatur. 547.

b. " " " " "

c. " " " " mitt!ere Jabręిtemperatux. 548.

3. " " " " " " "

a. " " ". " Negenmenge. 553.

b. " " " "ben 2 afferreidgthum ber Duellen, Frĭfe u. Seen. 556.

c. " " "bie Lavinen. 565.

4. Cinfluß ber $\mathfrak{B}$ aldoungen auf bie Winbe. 566 . 


\section{(Eillteitullg.}

\section{Begriff, Eintheilung nno siteratur ber forftliden. Bobenfunbe und slimatolugie.}

\section{Begriff.}

- Die forftliche Bobentunbe und Slimatologie lebren ben mectjeljeitigen

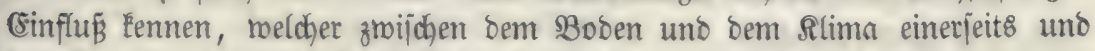
ber $23 a l$ begetation anderjeit\& befteft. Unter "Slima" berjtehen wir mit 2. v. Sumboldt bie Befammtrirfung ber Meteore, unter Meteor (bon

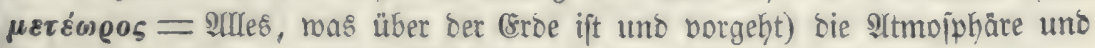
bie in ifr bortommenten Bricheinungen.

\section{Eintheirung.}

Die forftliche BodenEunce uno Silinatologie wiro jachgemä̈̈ in żoei

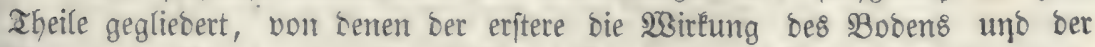
Meteore im Eingefnen angibt, rähreno ber andere fich mit bem (Sefammt=

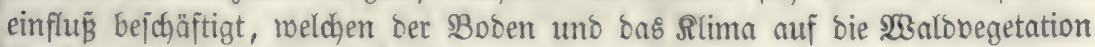
ober bieje auf bie erf́tgenannten ăuß̈ern.

Bei biejer (sintheilung ift bie Renntnifi ber Entitefungsmeife uno ber Fhyfínalijchen unt dyemijhen (sigenichaften bes Bobens uno ber Meteore bor= ausgejegt, uno eigentlich bürften bieje (Segenjtänbe beim Bortrage ber forit= lidhen Bodentumbe unt Rlimatologie nidht abgehantelt merben, weil fie be= reits in bejonbern Theilen ber Raturmiffenjidaften - ber Beognofie uno Mes teorologie - ifre Stelle finden. Da aber basjenige, was ber Frorftmann aus biejen beiben Disciplinen für ben borliegenoen 3mect. zu wiffent nöthig hat, in ben naturwiffenichaftlichen sefrbüchern geröbntich entroeber zu umfangreid, ober zu turz bargejtellt mirb, po erachtet es ber Berfaffer, nad, bem Beifpiel 
2 Begriff, Cintheilung unb \&iteratur ber joriftliden Bobenlunbe unb Rlimatologie.

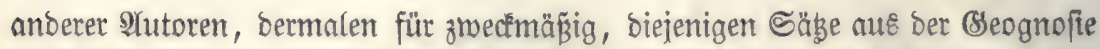
uno Meteorologie, welche in ber forftlicken Bobentunde und Silimatologie $\mathfrak{A n}=$ menbung finben, in einem "Borbereitenten IGeil" vorauszujchiden. Der "ÎAn= gemanote Theil" miro bann unjere 2 Biffenfohaft $j$, wie fie unter 1 . Definirt murbe; enthalten.

\section{Siteratur.}

Sein 3roeig Des Foritfachs ift fo in ber Joumalliteratur bearbeitet mor $=$ ben, wie bie forftliche Bobentunbe uno Rlimatologie. Die Rebrbücher, bon meldyen wir nactjtehend bie beften aufführen, bebandeln mełr basjenige, mas wir in ben "Morbereitenden aheil" verwiejen Gaben.

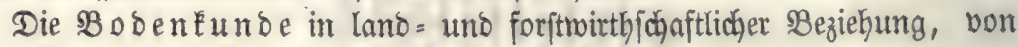
\$. Chr. Бunbeshagen. Tübingen 1830.

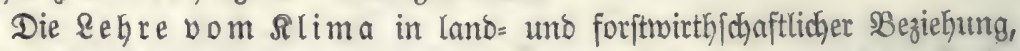
von \$. Ehr. Sumbeshagen, herausgegeben von S. \&. Rlaupredt. Sarts= ruthe 1840 .

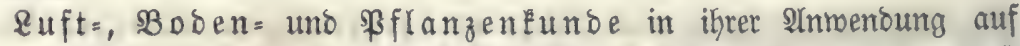

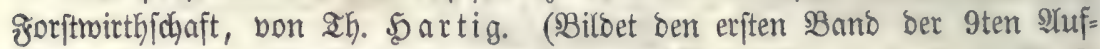
lage bes bon Th. Sartig herausgegebenen "Rehrbucts für F̈ritter" von. (5). \&. Sartig). Stuttgart unઠ :übingen 1851.

Sebirg\& Éube, BDdentunde und Rlimalehre in ifrer Armenbung auf Forftmitthidaft, von (5. (s) rebe. (Eijenach 1853. 
näber fie bem ßole liegen. Denten mir uns, die Eroe fei flüfitg gemefen ஓig. 1.

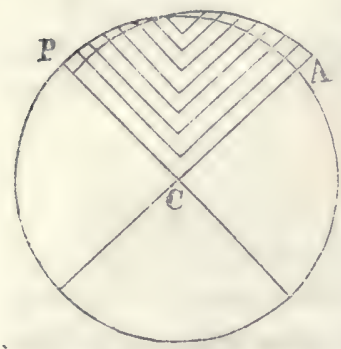
und zerlegen rvir biejelbe in lanter fommunicirente

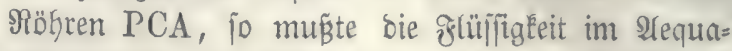
torinlichentel AC Yeichter fein, als im Polarichenéel

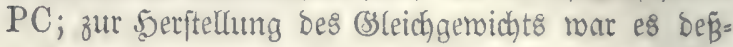

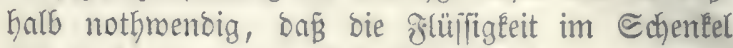
$\mathrm{PC}$ fant uno in ben Echenéel AC eintrat, melcher IImitano beffen Berlängerung zur §olge hatte. Die

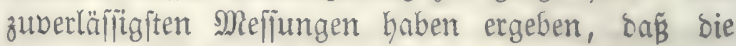

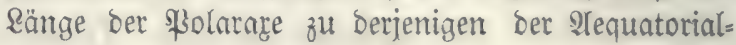
are fich verbălt, wie 288: 289 .

\section{Entitehng ber neptunifinen und plutonilden Gefteine.}

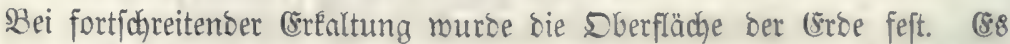

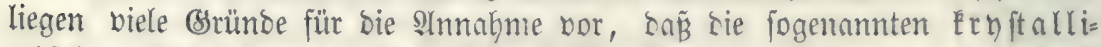
nifhen ङ erfte Erifarmungeprobuct ausmadjen. Tieje (sefteine nurben surdh bas mitt=

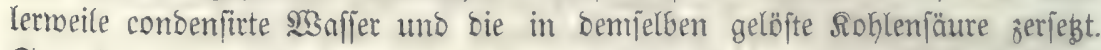

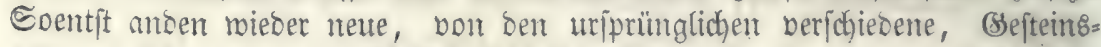

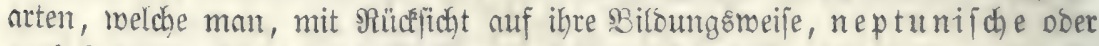

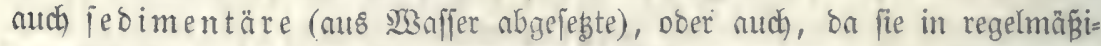
gen Eafichten abgelagert fint, normale Befteine genamnt hat. Die neptu=

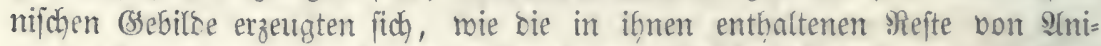

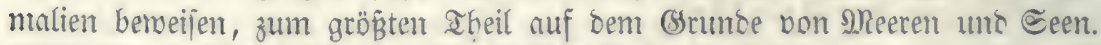

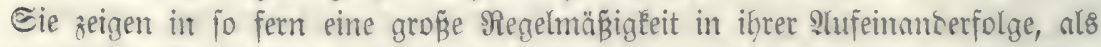
bie relatioe Rage eines jebimentären Bejteins gegen baร anbre immer bie näm=

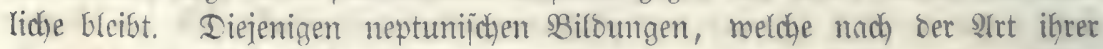
(Entftefung uno ibres fortfommens zu einnoer gebören, hat man, zur leich)=

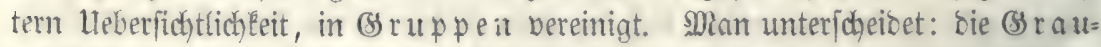
maten=, Eteinfoblen=, Sermifde=, Irias=, Jura=, Rreibe=, Mnlaffe=, Dilubial= und alluvial= Sruppe, mobei von ben älteften

- Gebilsen ausgegangen ift. Die Brmppen zerfallen wieלer in formationen,

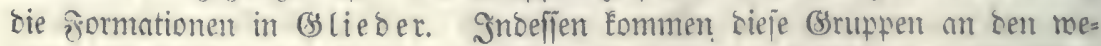
nigiten Drten ber srobe in ber angegebenen Dronung volläählig vor, oft fehlen einzelne (Sruppen ober Gormationen. So trifft nuan 3. B. Die Molaffe nand)=

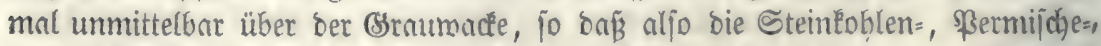
Trias:=, Jura $=$ uno Sireibegruppe nicht autgebiloet fino.

Da bie äufierften Sagen ber Erboberfiäche bei iffer Erftarrung fids zu=

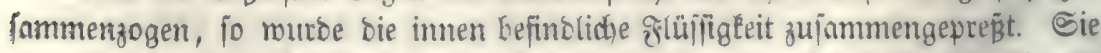
entroidg, inbem ifhr Druct Epalten uno Riffe in ber feften frufte bilbete. Durch biefe Deffunng stang mun nud tropfonr flüiliges 230 fffer ein; biejes berwantelte fids in Berührung mit sem heipen sern in Inmpi, melcher, ver= 


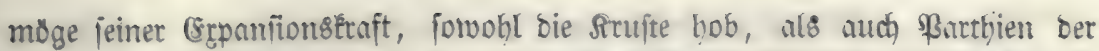

ஓig. 2.

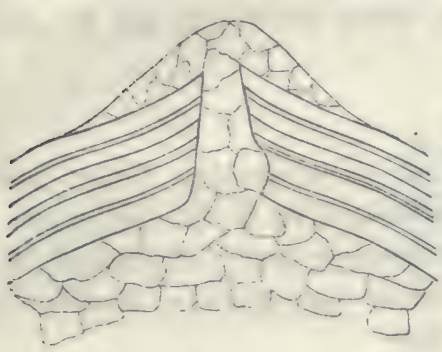

Keiß̌en flüliligkeit an bie Dberflädhe em= porführte. So entitanben bie plutonis iden Eruptiogefteine, bon benen man bie jüngern vultanijoge nennt. 23eil

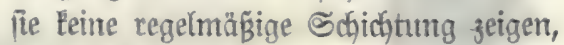
hat man ifnen auch bie sBenenmung "abnorme" Felsarten zugelegt. Die flülïgen Sนšbrïche aus bem (5rcinnern fanten niḑt fämmtlión auf einmal, jonbern in verijhiedenen 3eitcăumen ftatt, uns bie in jebem berfelben ent

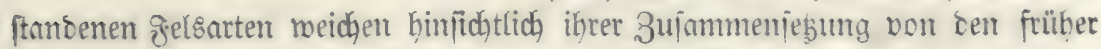
gebildeten ab. Die einmal borhantenen plutonịchen Gejteine gatent wieder Material zur sillsung bon neptumiichen Seiteinen $a b$.

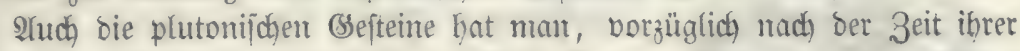
Entjtehung, in Gruppest geichieden. Dieje Bruppen finto, bon ter ältejten

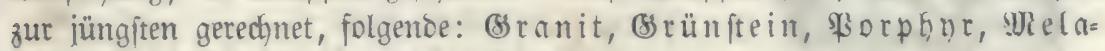
phor, Bajalt, Bulleaniloe (B) bilde.

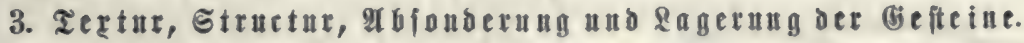

\section{ค. Textur un จ อtructur.}

Die sefteine finto theils einfache (wenn fie mut aus einet uno bers jelben Mineralart beftehen), theils gemengte. Nad, ber S(rt, in meldher bie Theile verbunden fint, unterjeibet man

æiig. 3.

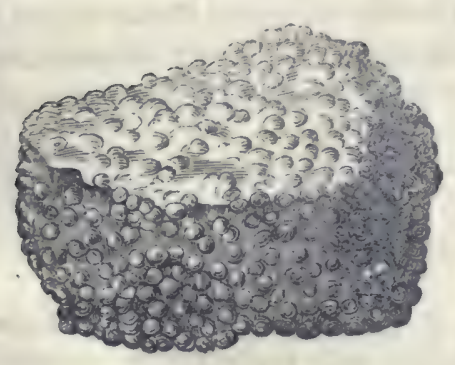

a. Sörnige zectur, wenn bas Beftein aus einzelnen Rörnern zujammengeję̧t ift, beren Ränge, Breite uno \$öbe nicht jebr verichieben ift. 5aben bie Rörner stryftallform, io heißst bas (septein trcy)= ftallinifd); Dolithifd) (łig. 3.) wiro es genannt, wenn bie Römet Hleine sugeln bildoen.

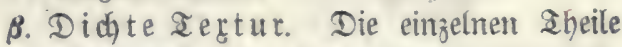
laffen fich mit blog̈em âge nidgt mehr Gerausfinden.

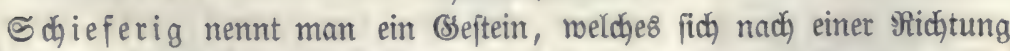
Fin vorzugsmeije leiळht trennen läpt, porphyrartig, wenn aus einer gleich= artigen Brunomafle einzelne Srnjtalle Gerbortreten, blafig, menn \$öhlungen in ifm vorfommen, mandelfteinartig, wenn biefe föhlungen mit einem 


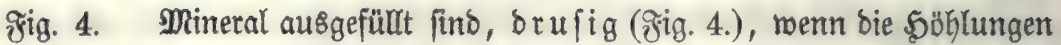
eine Siryftalbelleibung haben, breccienartig, wenn bas (Se= ftein aub edfigen $\mathfrak{B r u c h}$ ftüclen eines andern Befteins fich gebilbet hat, conglomeratartig, menn bie Santen ber Bruchitücé abgerundet find.

\section{b. Ibfon berung formen.}

Biele Befteine zeigen fich in regelmänige Stüde geidhie ben, abgejonbert. Die 2 Gjonderung ift eime grolge von $3 \mathfrak{u}=$ fammenziehung. Dieje fano ftatt beim Brenalten einer heipflüffigen Maffe

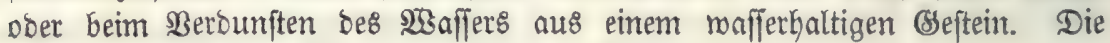
bemerkensmerthejten 2lbfonderungsformen find:

æig. 5.

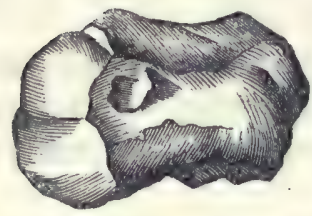

ঔig. 6.

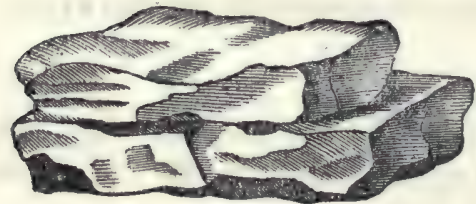

ঔig. 7.

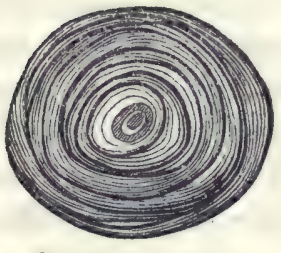

Fig. 8.

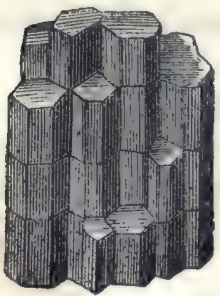

$\alpha$. Die unregelmäßig=maflige, wenn bas se= ftein aus formlojen Stücfen bejteft. Dieje 2łbjon= betungsart finbet fich vorzüglid bei (sranit, Syenit, Srünitein, Borphyr, Melaphyr, Bajalt, Phonolit, Irackyt, $\mathfrak{E} a$ ba.

B. Die plattige, menn bie abgejonber=

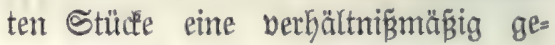
ringe Diớe befitgen, ohne Daf́ gerabe eime bebeutende Rängenausbehnung vor= Ganden ijt.

$\boldsymbol{\gamma}$. Die Augelige; hăufig in Berbinoung mit

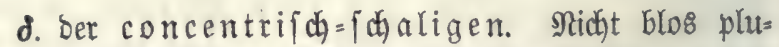
tonifde Befteine (Branit, Borphyr, Baralt u. f. m.), fonoern auth) feoimentäre Bildungen (Graumadee, Sandjtein, Sonps, Ralk) haben bieje Arbjonderumgs:= form aufzumeifen.

ש. Die făulenartige, (જ̛ig. 8. Sajalțäulen).

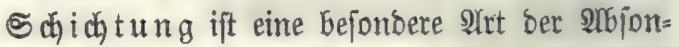
berung, bie am meiften mit ber plattigen ïberein= fommt, fich aber bon biejer baburath unterfojeibet

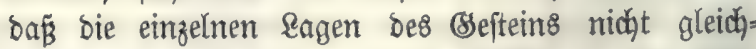
zeitig, jonoern nadh einander gebildot roorben find. Die Schid)ten find entmeber blos burd) Yeere Räume 
Siüfte -, Doer burd \&agen eines andern (Sefteins getrennt. Die Sdjichten

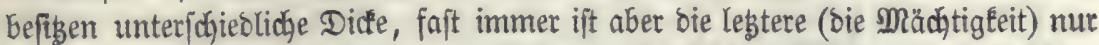

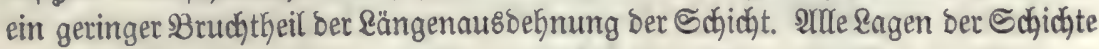
fins, fo lange fie nicht gewaltjam beridsoben murben, einander pacallel.

c. Lagerung.

Æig. 9.

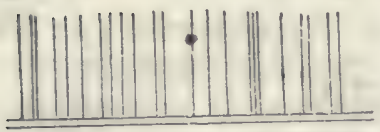

ช̛̀ig. 10.

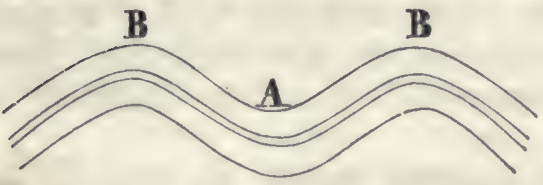

Stehen bie \&agen einer Schicht mit ifrer Eängserftrecung jentrecht auf ber Breite ober Diake einer anbern Schicht, to keipht bie Rage= rung übergreifend. Sint bie Ragen gemun= ben, fo unterjibeibet man $\mathfrak{R u}$ lben (A) uno Sättel (B). Den WBinlel, weldye eine Sdjidyt mit ber \$orizontalen biloet, nennt man ibs æallen,

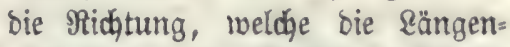
ausbefjnung einer Edhidht einj(jlägt, ify Etreichen; bie Durdjidynitt8: linie ber Sdjichtenfläd) mit ber Sori= zontalen ift bie Streidhungslinie. Die

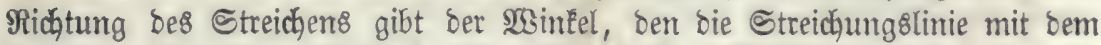
Meribian bilbet, an. Das @treid)en bleibt inmerbalb eines (Sebirgs̊zuges von ber nämlichen geognoftifchen sBejchnffenheit gemöhntlich baffelbe, mähreno bas Frallen bie mannigfachiten SPerjejicbentheiten zeigt.

\section{Rerative grter ber Gefteine.}

Bon mehreten auf einanoer liegenden jebimentären Sdjidjten find ftets bie zu unterfit befinblichen bie ältern, D. h. Die zuerft gebildeten, bie oberen bie jüngern. Die relatibe Rage ber Felsarten gibt baher ein Mittel ab, um ibr

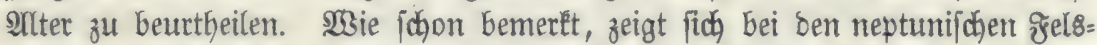

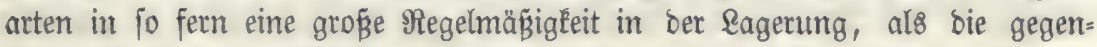
feitige Stellung ber Sdyichten, menn biefe, was inbeffen felten vorfommt, nidht gemaltjam geftört morden ift, immer biejelbe bleibt. So findet fid z. 3 . bie Sreibe ftet8 über ber Srraumacke, nie unter berfelben. Dies kamn audh zufolge ber (Entítef)ungsart ber Sebimentärgefteine gar nidht anders fein, benn

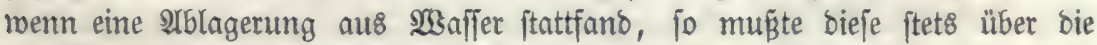
bereits borbandenen Schichten erfolgen, fie connte nidgt unter benfelben Gin= weg fich billoen.

MBenn ein plutonifches Bejtein ein anderes plutonifches ober fedimen=

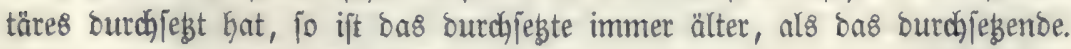

\section{Berfteinerugen.}

Sommen zroi neptunifdse (sefteine von gleidjer ober fefr ähnlicher $3 \mathrm{u}=$ fammenjesung an veridhiebenen Drten vor, uno ift bie Beffimmung bes $2[=$ 
ters aus ben sagerungšberbältniffen nicht möglich, fo bietet bie Senntniß̈ Der Berfteinerungen ober Betrefacten immer ein Mittel zur Fefftellung bez allers bar. Unter biejen berfteht man Refte von Drganismen, meldje blos in ben neptumifchen Bsebildoen fitch porfinten. Sie Eomnten fich bis auf bie

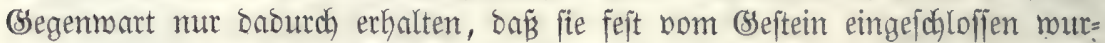
Den, welches bem Saueritoff Der \&uft ben Butritt berwehrte. Daburd) murbe

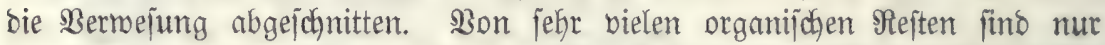
bie formen übrig geblieben; bie organijche Materie ift berjchnunoen, an ifre Etelle traten Mineralien, wie Schmefelleties, Dpal, Ëeuerftein, Sallépath, bidy=

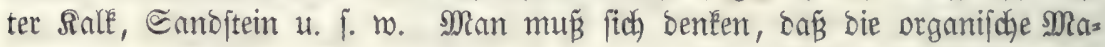

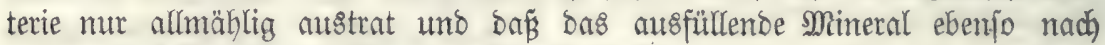

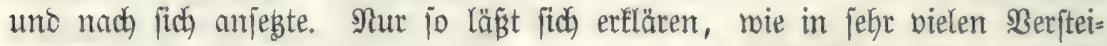
nerungen fomohl bie äuñern Frormen, als auch) bie innere Drganifation (z. B.

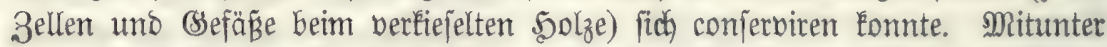

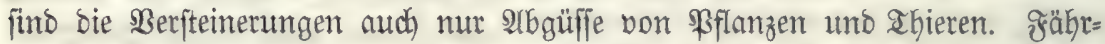
ten bon ๔äugethieren, Bögeln, 2Ymphibien finten fich gleichfalls in Ag güiा̄en.

Mod) am häufigiten hat fich bie organifde Materie von \$flanzen, $\mathrm{bb}=$ mohl mit beränoerter 3 ujammenjebung erbalten; in allen foffilen $\mathfrak{B}$ egetabilien ift bie relatibe Suantität Des Sohlenftoff gegenüber Dem Eauerftoff uno $23 a[=$ feritoff übermiegeno geworden. Foffite Inodyen haben geröbnlich ben phos= phorfauren Sale berwahrt, bie leichter zerftörbare Reimjubftanz bagegen ift ver= idjwunden.

Die zuerit gebildeten sefteine enthalten am menigiten Betrefacten, uno biefe felbft befinten fidh auf einer niebern Stufe ber Drganijation. Se jünger bie

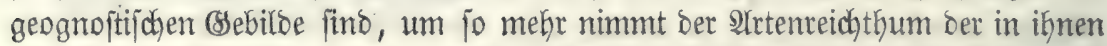
begrabenen Drganismen zu. In ben jüngften Bsebirgsformationen finden fich

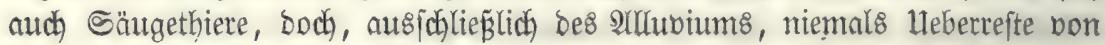

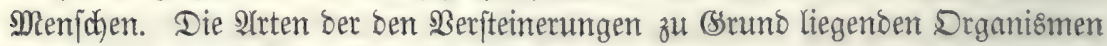
Eommen gegenmärtig nicht mehr auf ber (öroe vor, ment aud bie seichledh)= ter mitunter mit ben noch jebt lebenden übereinftimmen.

Bon Den foffiten Bffanzen und IGieren finden fich Eremplare in Sse= genten, weldhe nach ifyrem gegentärtigen Slima nidht geeignet fein würben,

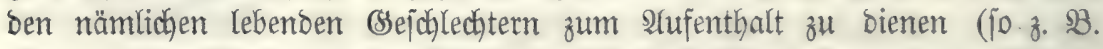
Mammuth's, (Elephanten in Sibirien). Gür bieje Ifyatjadje mangeln bis jest

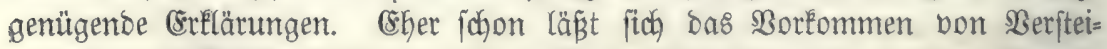
nerungen auf bohen Bebirgen (mie z. 38. im Simalaja auf 16,000' Meeres= höbe) begreifen, ba bas Stubium ber Seognofite ergeben hat, bań in vorge=

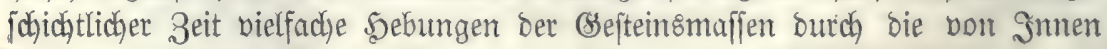
thätigen Siräfte ber Erove ftattfanoen.

Sebe Geftein\&gruppe befigt igre eigenthümliçen 2 Yrten von ßsetrefacten, bie fich in leiner anbern (stuppe ober Formation wiederfintert, bie Berftei= 
nerungen F̈̈nnen Daher, morauf fđjon oben bingemiejen rourbe, zur Beftimmung uno Rlajfificirung, forwie zur altersermittlung ber Bepteine bienen.

Dentsiten find Uleberzüge von (Eijen, Mangan uno anbern Metallorboen in (Sejtalt bon Bflanzenabbrücéen. Sie exjdeinen jomobl im Snnern, als audh) auf ben stuftflädhen ber Bsefteine.

\section{3weiter $\mathfrak{A} b$ fditt.}

\section{Die fryftallinijiden Sdjiefergeiteine.}

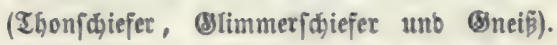

\section{Entftelumg.}

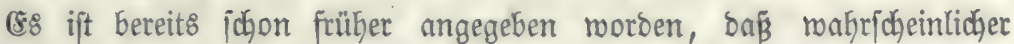

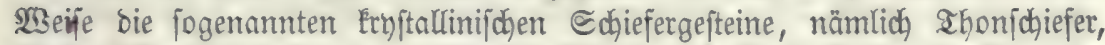

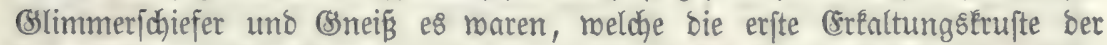

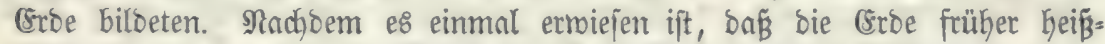
flüflig roar, fo ift man gezmungen, fich nach benjenigeu $B$ Bildungen umzu=, fehen, melche bie erfte folibe Dberfläche ber (stbe ausgemacht haben, uno ba bie Ernftallinijchen Echiefergefteine unter allen neptunijohen Formationen ge= lagert find, fo liegt nidyt\& näher, al\& jene für bas erfte Erftarrungeproduct ơ

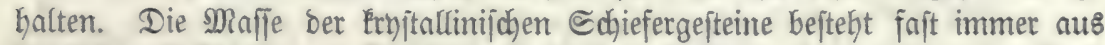
beutlichen Echichten, gerabe 10 , wie fie fid bilden musten, indem ber heip̈=

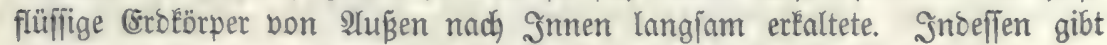

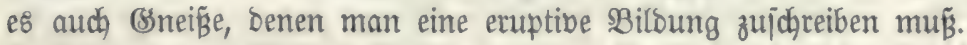

\section{3 ufamenjebug.}

Die Eryftallinifdyen Cdyiefergefteine führen ifye \$Benennung von bem Erty= ftallinijchen (Sefüge. Sie unterjcheiden fich baourch bon ben meiften Gojiefern in ben Sebimentärformationen.

Der (s) neifi bejteht aus gelbipath, Quarz uno srimmer. (5r fitimmt Ginfichtlich jeiner Bemengtheile bolljtänoig mit bem Branit überein, unterjheibet fich aber von bemjelben ourch bie jejiefrige Structur. Der gelds=

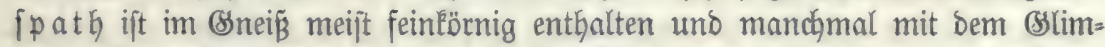
mer auf bas Innigfte berbunden, fo daß̉ beibe mit unberoaffnetem 2luge faum zu unterjcheioen find. Nidht jelten fehlt ber Qunrz gäuzlich. Der (slimmer finot fïh gemöhnlid in abgejonoerten Etraten und bebingt baburch bie Sdhieferung; ift er mehr gleichförmig im '(sejtein zertheilt, jo geht biefes, uno merun außserdem bie jobiefrige Ctructur auffört, in Eranit über. Diejer Heber= zang finbet fonohl allmählig, als auf einmal ftatt. Dft auch) fino im Bneife

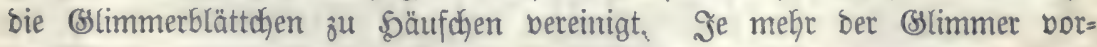
berricht, je abgejonberter in paralleten Edjichten berjelbe borfommt, um fo vollommenter ift bie Sdhieferung. 
Der Slimmerichiefer befteht aus হuarz uno (s) limmer; aud

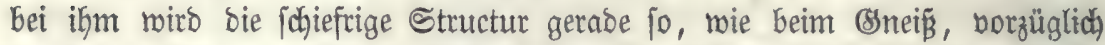

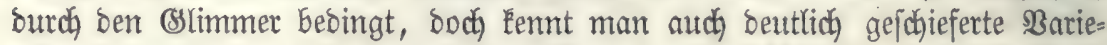
täten biejes sefteins, in Denen ber sslimmer zurücttritt und fogar ganz fehlt.

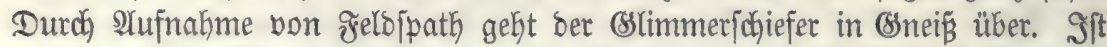
in jenem ber BSlimmer burd, Ialf ober Bhlorit vertreten, fo heifst bns rsefteir Ialk = ober Egloritfdiefer. Der Talejdiefer ift gemöhnlid bödjt fein=

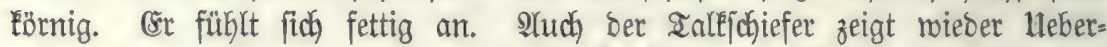

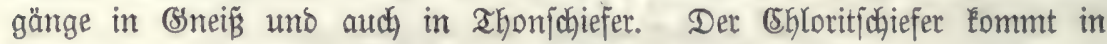

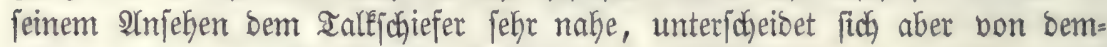
felben burch bie mę̧r grünlidje garbe.

Der Igonjdiefer befteht nach den unterfuchungen bon Saubage aus Ehlorit, einem Ihonerbefilifat, aus Duarz nebjt (Eijen = und Mangan= oryofybrat, benen Eleine Mnengen geldipath uno SSlimmer beigemengt, fino. 3iemlich richtig brüctet fich bie 3ujammenfebung bes a ahonjichiefers auch folgen= bermafen aus: er hat bie stementarbejtandtheile des (Sneipes plus. Ialf.

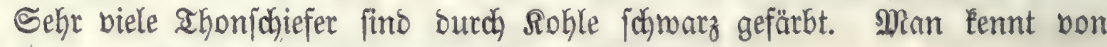
unjerem Beftein folgenoe ausgezeichnete Barietäten

a) ben Dadfidiefer. Dünte Flatten, meldye mieber aus ganz, feinen

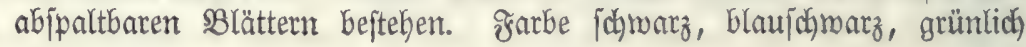
ooer grau.

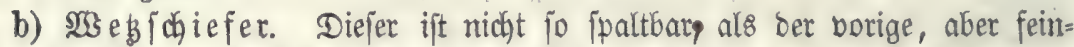
körniger. (er beftefyt porberrichent aus Riejelerbe. Bon Frabe ift er Geller. (sr geht häuftg in Dachjobiefer über.

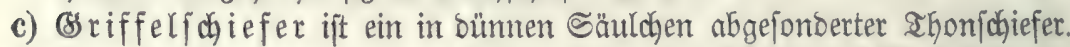

d) Frud tichiefer. Sn bem Bseftein finden fich fobluarzgrüne oflecten von Der Sröß̄e einer simje.

Der Ihonjojiefer geht in Talfichiefer, Bhloritfdiefer, Bneis, Brimmer=

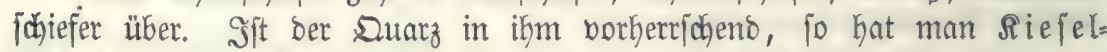
idjiefer. Diejer bridgt gewöhnlidy beim Zerjelagen in Paralleltrapezen.

In ber (Sraumadengruppe fommen Thonjohieferarten vor, weld)e benen ber borliegenton Bruppe fehr ähnlich find, fich aber burch reniger fryftalli=

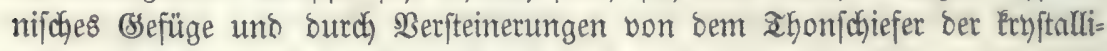
nifden Sdjiefergeiteine unterfocioen.

\section{Rebengefteine.}

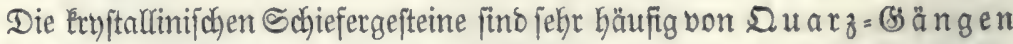
uno Schnüren burchzogen, moburch bas (sefteit ein geabertes $2 \mathfrak{n}$ jehen erhält. 230 hl in ben jeltenften Fällen mag bas Material ber Duarzgänge aub bem heifffüffigen (Erbinnern emporgebrungen fein, biel mahridgeinlicher ift $e \&$, baf bieje (Sänge uno Sdhnüre auf neptunifdem $23 e g e$ entifanoen fino. Mit auf= gelöptem Riejelfäurebybrat belabenes 2 Bnffer fiderte in bie Spalten bes (se= 


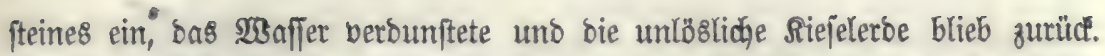
Die Quarzidnüre zum menigiten, weldye oft nur in samellen bon ber Diởe

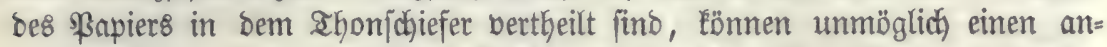
bern Urjprung Gaben. Aluf Rluftflädhen funbet fid nicht jelten aud koklen=

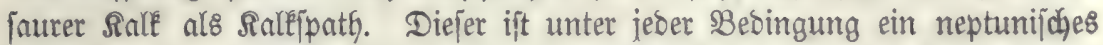
\$roduct und mahriffeinlich aus Dem Thonjhiefer jelbjt burd, Den Bermitter=

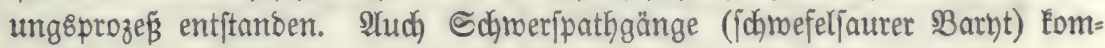
men im Ihonfobiefer vor.

Uréalk ober E⿱

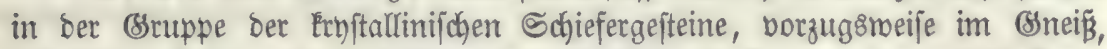

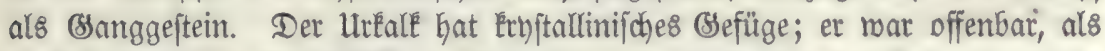
er fid billoete, in feuerflüffigem 3uftande. Durdh ftarten Druof murbe er ge-

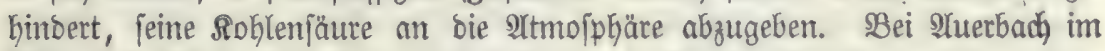
Doentralde fommt ein bebeutender Bang ber 9 rt im Bneifis vor.

\section{Bergforment.}

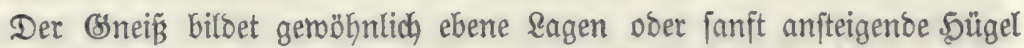
mit rellenförmigem 3uge, boch ift er aud bon S(bluchten burdjiegt, weldhe

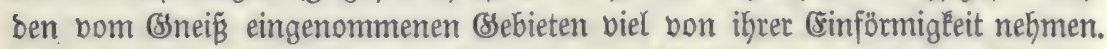
Der Eneif tritt bismeilen eruptio auf uno erjheint bann in berben Broden.

Der (Slimmerjofjiefer zeigt eine idhon unregelmäß̈igere Dberflächengeftal= tung, als ber Bneiß̈, mit weldhem er inbeffen bie wellenförmige Beftalt ber Söhen gemein hat. Die Shäler im Sslimmerjojiefergebiet find nod forroffer

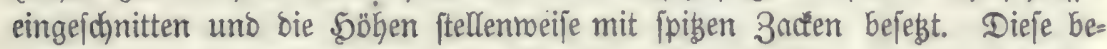

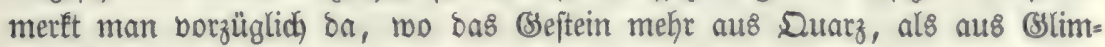
mer befteht.

Der Ihonichiefer vereiniat bie Frormen ber vorgenannten beiben Befteine.

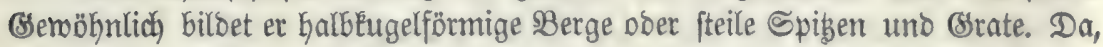

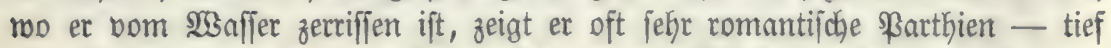

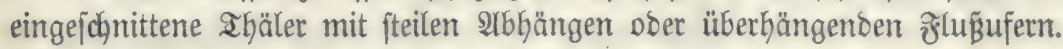

\section{Berbettug.}

Die Erbftallinifłen Schiefergefteine nefmen fehr bebeutente (Sebiete auf ber Croe ein uno fommen. nidyt blos in Buropa, foubern auch in 2yiten,

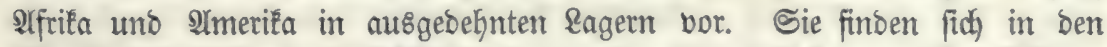

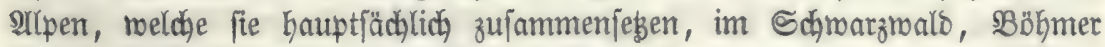

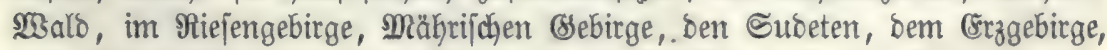

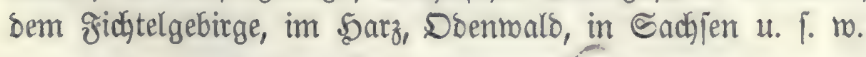

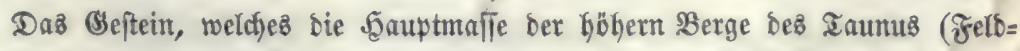

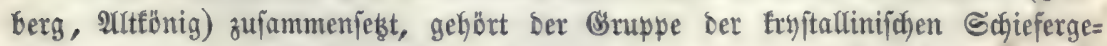
fteine an, wenn aud feine näłern Beziefyungen zu biejen noch nicht binlänglich erfannt finto. Borbem hielt man ę für einen Ostimmeridjiefer, in weldjem ber 
(S)limmer burch) Iaff vertreten jei, bis sijt auf Den geringen Bittertegehalt auj=

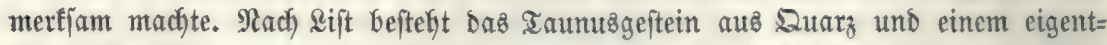

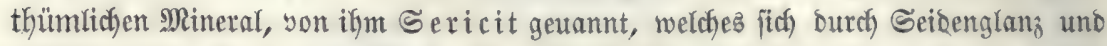
grünlidy weipe Farbe auszeidynet. Der Sericit fonmt ftellenweife audi) in Derben Mafien vor.

\section{Metamorpbismus ber fryfarrinifuen Sdiefergefte tue.}

Die auffallenoe Structur, fomie bie Ulebergänge, meldhe bie Eryjtallinilichen Schiefergefteine in anbere Felsarten, oft in ganz allmähligem Berlaufe zeigen,

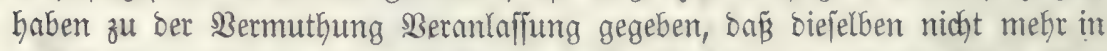
Der* ZuFammenjebung vor uns liegen, weldye fie bei iffer urfprünglidjen (Ent= ftehung befaß̧en. Biele ber ausgezeidhnetiten Beologen nefmen baher an, Daß̉ zmar bas urjprüngliche Material ber fraglichen (Sejteine in nichts anderem,

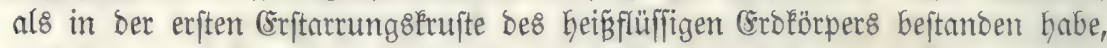
baß̈ bagegen Daffelbe im Berlauf ber ungeijetren 3eiträume, melche von ber erften Bonfolibirung Der (Erboberfläche bis zum gegenmärtigen Beitpunlet ber= floffen fino, mannigfachen Beränderungen uno (sinflüffen ausgejebt gewejen fei. Arls biejenigen Rräfte, welche-biefe ßeränberungen betwirften, werben bald

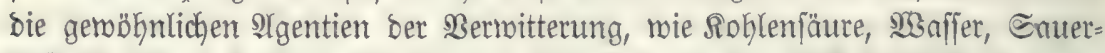

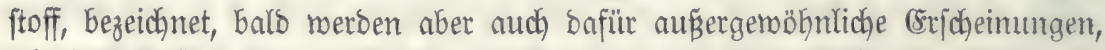

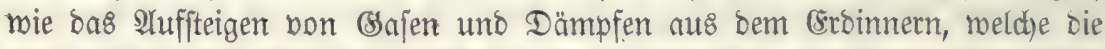
ganze Maffe bes Brefteins burdbrungen haben jollen, zu Sülfe gentommter. Sedenfalls läfit fohon ber sehalt an Rohle, ben bie Shonfohiefer oft gantz an iłrer Dberfläche żeigen, auf bedeutende. Beränderungen, welche Das uriprüng=

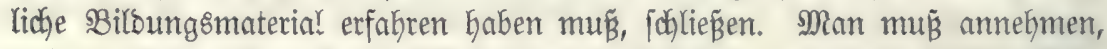

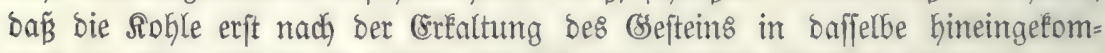
men ift, benn bei einem Gohen Siggras unb bei Segenmart von Metalloryben

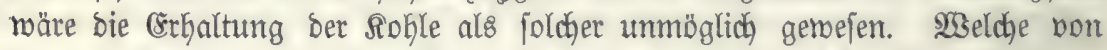
ben oben angegebenen Sypothejen bie ridhtigere jei, bies ift jujwer zu ent=

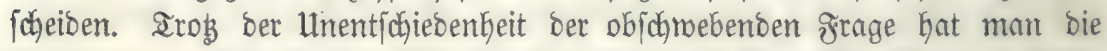
Benennung: "Érnftallinifhe Schiefergefteine" fehr häufig mit: "Metamorphiịche

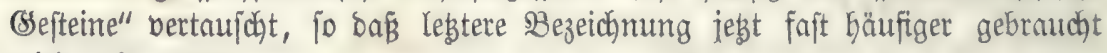
miro, als exftere.

Dritter $\mathfrak{A}$ b

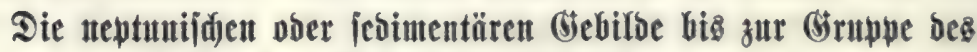 Diluviums (einifl.).}

\section{Einleitung.}

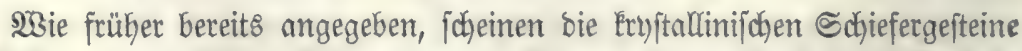

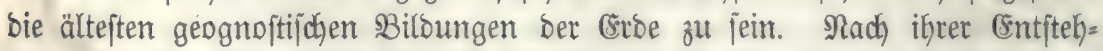
ung fanden nachmeislich biele Sebungen und Sentungen bes Randes ftatt bie Bertiefungen füllten fidh mit Waffer an uto bitbeten Meere unt Eeen, 


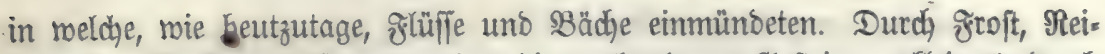
bung bes 23 nffers u. F. m. murben bie borhandenen (Sejteine zertleinert, burd)

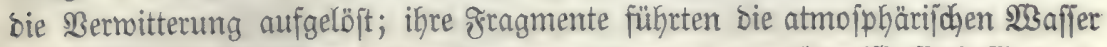

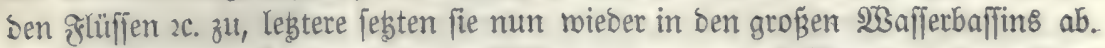

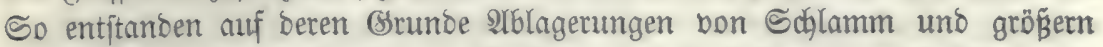

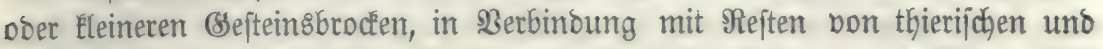
pflanzzlichen Drganismen, welche entweder in biejen Meeren und Seen gelebt hatten, ober bom sande her in fie Ginein geffynemmt wurben. Die erbigen

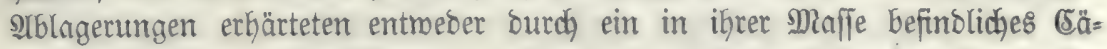
ment (Riejelerbe, Ralk, (sijenoryd u. 1. m.) ober Glos in Folge bes Drudf8 ber über ifnen Lajtenoen $\mathfrak{B a f f e r j a ̈ u l e . ~ \Re a c h ~ b e r ~ B e j đ a f f e n h e i t ~ b e s ~} \mathfrak{W}$ afjers, wel= dhes in biejen Eeen $2 c$. enthalten roar, unterjecioet man, mit 3uhülfenabme

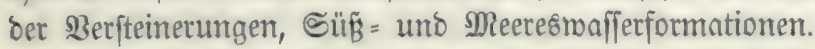

Die Befteinsbiloungen onuerten inoffen nidat immer bis zur vollfänbigen STuffüllung bes $\mathfrak{W}$ afferbafilins fort, oft murben fie burch Sebungen unterbrodjen, welche ben ভee in einen Berg boer 5ügel bermanoelten. In

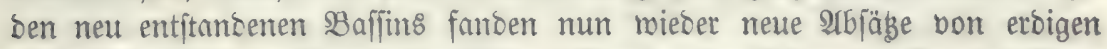
Eubitanzen ftatt, roährend bie höber gelegenen \&ocalitäten in ihrem frühern Beftano blieben. Dutch abermals enteute Eenkungen wurben mun wieber bie regten in Eeen, burch 5ebungen bie erftern in Berge umgenandelt. Daker

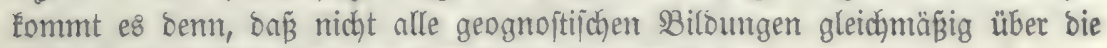
sorbe bertheilt finto, fondern mir hie uno on auftreten.

Llriprünglich muß̧ten alle abgejesten Ėdjichten eine horizontale sage einneftmen; biefe murbe aber bielfach) geftört, theils burd) bie fobon borbin erroähnten, von Elie de Beaumont mit grogerer Bejtimmtheit ausgeprodhenen

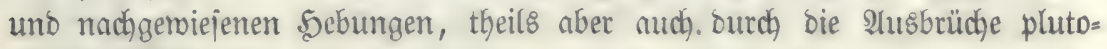
nijocher Beiteine.

WBir mollen nun die geognoftijdgen (Sruppen, bie mir in Frormationen

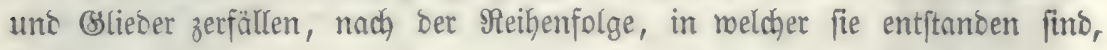
betradbtert.

\section{Gี}

Dieje zerfällt in brei frormationen: bie untere Braumacfe ober bas $5 \mathrm{am}=$ brijhe Enftem, bie mittlere. Graumadie ober bas Eilurijhe Syjtem, uno bie Dbere Sraumacke Doer bas Debonijohe Eyjtem.

Die in ber Braumadengruppe borfommenden Befteine fint Schiefer uno Sanditeine (von äbntidyer Zujammenjebung, mie ber Ifonjchiefer), Riejel= fohiefer, Ralk, 2hnthracit, Dolomit u. ¡. ro.

Die Bergformen ber Braumadé find burd) iłhre (sinförmigkeeit aus=

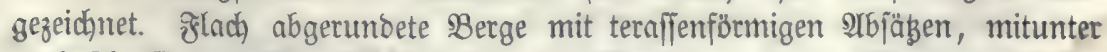

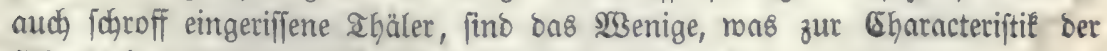
Dberfläh)engeftaltung biefer Befteinsogruppe bienen Énn. 


\section{a. untere cora wade (Cambrifbeb Onftem).}

Die älteiftent neptunifolen Sebilbe, weldhe fid) aus ber 3eritörung ber

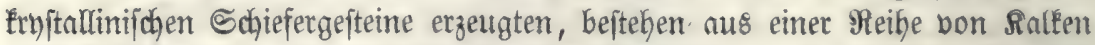

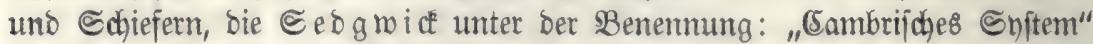
vereinigte. Diefe Formation ift bis jest borzüglich in Englano nachgemiefen morden, in Deutjichland fommt fie gleidjfalls vor, ift aber nod nicht jtreng bon ben übrigen frormationen ber Braumade getrennt morben. Die Ralte bes (Eambrif̧d)en Snftems befizen in England keine bebeutende Mächtigkeit,

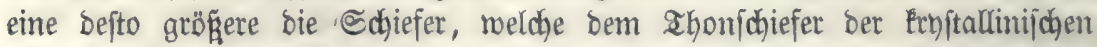
Schiefergefteine in ifrer 3 ufammenjebung jehr nabe kommen, fich aber von

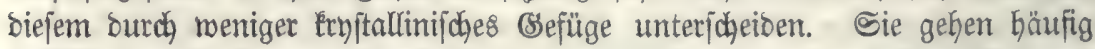

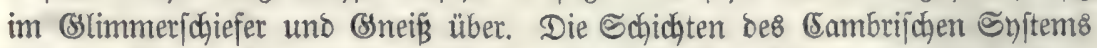
befinden fich Durchneg nicht mehr in ihrer urjprünglichen horizontalen sage; fie fallen meift febr fteil, in sitglanto faft fenterect ein. Betrefacten Eommen in ben Sefteinen biejer frormation mur jefre wenige bor.

Neuere Beologen bereinigen bas (Eambrijche Enftem mieber mit ber fol= genton Formation.

\section{b. Mittlere Eraunade (Ellurifhes Onftem).}

Die Frormation ber mittlern Sraumade, bon $M$ urdijon als Siluri= fohes Syftem bezeichnet, reift fich unmittelbar an bie vorkergekente an, un= terfdeibet fich aber von berfelben vorzüglich burch andere Rngerung ber S(hjich)=

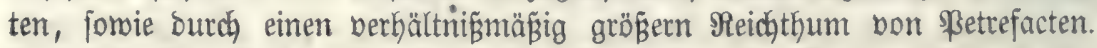
Das Cilurifche Enjtem ift bejonders in Englano ausgebildet, mojelbjt es eine beträçtliche Mäătigkeit befigt. Alber auch in ben \$yrenäen, in ber Bretagne,

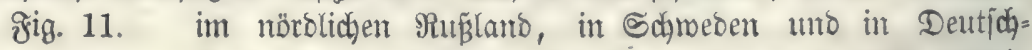

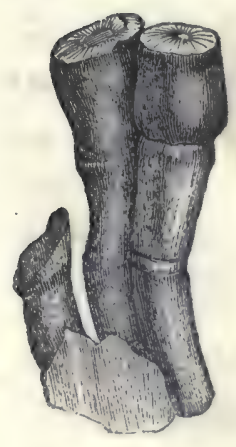
lant fommt es bor, obgleidy e\& bier nodh nidyt gebörig von ber folgenden frormation gefondert roorden ift. Im Sarz, an ber (sifel und in $\mathfrak{B o ̈ h m e n ~ r o l l ~ m a n ~ S e f t e i n e ~ a u f = ~}$ gefunden baben, melche ben Silurij̧⿻n Sojichten (sng= lants entipredyen jollen.

Die gelzarten biejes Syjtems bejtehen, mie bie bes vorhergebenden, aus Sdhiefern nno Ralfen.

Bon Betrefacten fübren wir an bon Sorallen: bie (sejc)lechter: Limaria, Cyathophyllum (æig. 11.) (caespitosum), von Bradjiopoden Lingula, Terebratula (unguis, interplicata), Orthis (virgata, grandis) bon Bafteropoben Litorina striatella, bon (Eephalopoen: Orthoceras duplex.

\section{e. Doere Grantade (Debontidges Evftem).}

Das Devonifche Euftem enţält bie nämlichen (Sefteine, wie bie beiben vorbergebenten Formationen. (Sraumadenjanbftein, (Sraumadenfjuiefer, Sinlfe, 


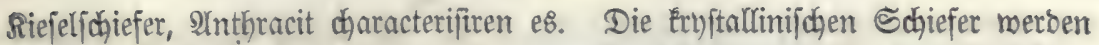
jeltenter, an ifre Stelle treten conglomeratartige SBiloungen. Untergeorbnet tom. men aud Eager von Mergel uno Dolomit vor.

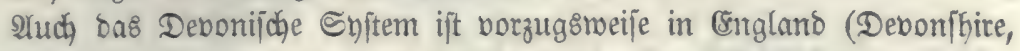
Daber ber same) entwicfelt uno erreicht dort eine Mächtigleit von über

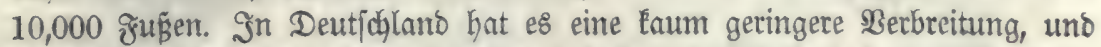
höchit wahrfheinlich gehört ein Theil Des Sarzes uno bas jogenannte Rhei= nijobe Hebergangsgebirge vorzugsmeije ber Dbern (Sraumade an, wenn aud)

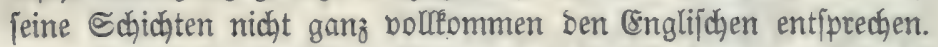

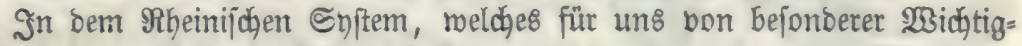
keit ift, Gat man folgenbe Unterabtheilungen biejer grormation unter/djieben.

\section{E. ben Opiriferenfanbitein.}

(5r ift befonbers entmictelt am sibein, im sabnthale, im Dill = uno

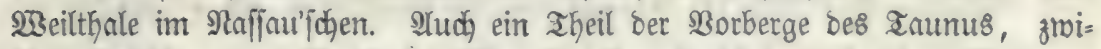

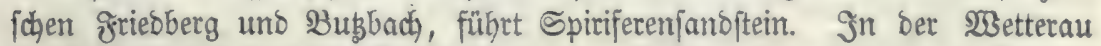
ift biejes sejtein gleidyfalls verbreitet.

Die Bstieber bes Epiriferemjandfteins beftehen hauptjächlich aus jefre grob= Ë̈rnigen Braumacten, in Denen Quarz vorwaltet, fomie aus shonjichiefern von mebr ober minoer fryftallinijchem Ssefüge. Salke fommen nur felten bor.

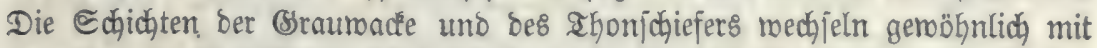
einanber $a \mathfrak{b}$; fie befinden fich Durdhgängig in einer bon ber Gorizontalen abroei=

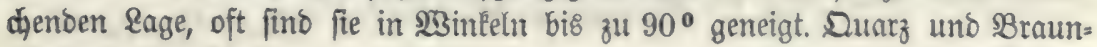
eijenftein fint bäufig anzutreffen.

ঔig. 12.

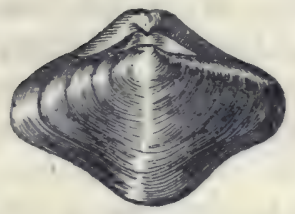

Die ßetrefacten gehören größ̈tentheil\& ber gramilie

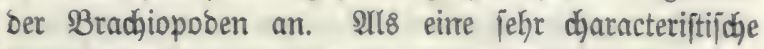
Berfteinetung mag hier Spirifer macropterus-Goldf. genannt merben.

Die Mädhtigeeit biejer frormation beträgt in ben Rheingegenten an 1000 ₹üe. Der Spiriferenjanto. ftein bildet flacthügelige Brebirge; inbeffen entfteben in

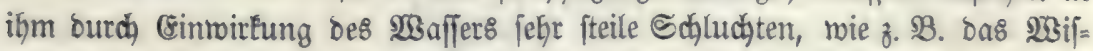
perthal, bas \&ahntbal bon Balbuinjtein an bis nach CEgrenbreitftein Gin, bas sRheinthal von St. Boar bis $B$ onm.

\section{B. Etringocepbalenfalt.}

Dieje Formation ift aubgezeidjnet burch) bas \$orkerridhen bon bidaten, im Brudd iplittrigen Ralken, weldge burdh Eijen = uno Manganorì oft mar= morartig geftreift find. Der Ralk ijt jefr rein, er hat nur menig Bittererbe uno Spuren bon Riejelerbe, ahonerbe uno Alléalien. Cein SBorfommen be=

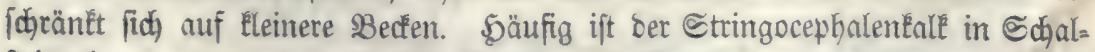

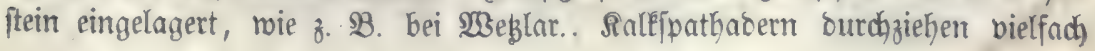


bas Bef̣tein; aud auf ben Sluftflächen findet fich Salfipath, mabridgeinlid etft im Raufe ber Bermitterung entitanden.

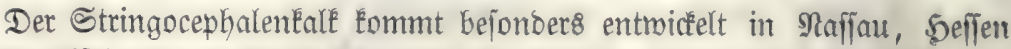
uno ber (sifel vor; er findet fich aud im Sarze.

Æig. 13.

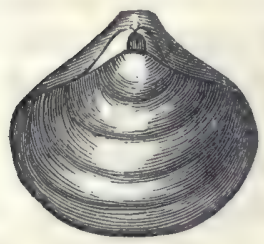

Die characteriftijd)e Berfteinerung für biefe fromation ift Stringocephalus Burs tini Defr. (æ̧ig. 13). (sinzelne Sialefelfen be= fteken nur aus ßolypen, z. B. Calamopora polymorpha.

(sin weiteres (slied biefer frormation ift ber Dolomit, eine Berbinbung bon Foblen= faurer Ralkerbe mit kohlenjaurer anlferbe.

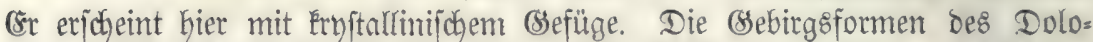

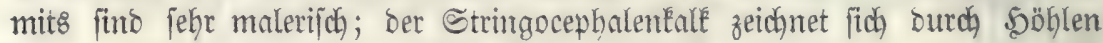
ณuรి.

Die Salfe Der eben betrachteten Frormation finto von Edjiefern begleitet, bie man nach der in ifnen borḱommenden Cypridina serratostriata (5 ypr $i=$ binenfdiefer genamnt bat. Die Sdjichten fino meift jebr geneigt uno be=:

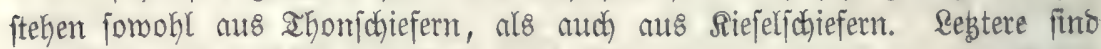
ganz bejonbers reichlich von Ralk = uno Suarzabern burchzogen. Die (onpri=

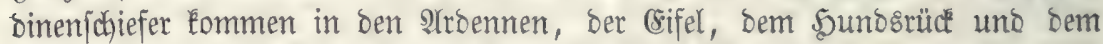

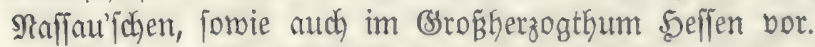

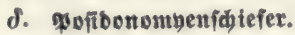

Die Shefteine biejer grormation find mieber Sale, Braumadfen=Sanditein, Sdjiefer uno Sdjieferthon. Reל̧terer bejteht aus einer mehr eroigen, als ftein= artigen Maffe von gelber ober bläulicher Farbe; oft ift er burd) Rokle fohmar.

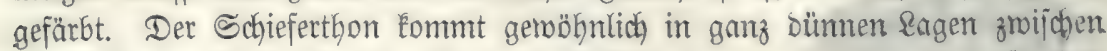

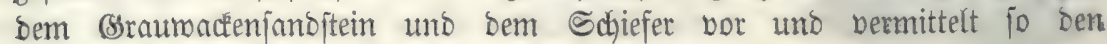
Lebergang biejer beiben Befteinsarten.

Sluch ber ßofitonombenjofiefer befigt mur nody an ben menigiten Drten

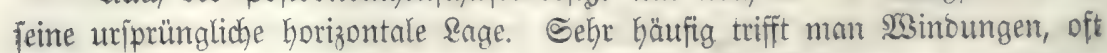

gig. 14.

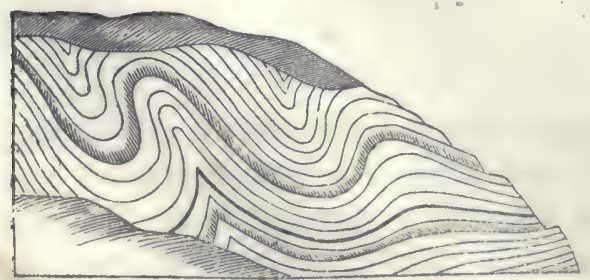

ftoff erhalten, ber ben in mitunter nidut unvebeutenoen Eagern norfommen=

fint bie Sdjichten ganz umges ftürat uno neigen jich in verfojics benen $2 \mathfrak{B i n t e l n}$ gegen bie நori= zontale.

Det \$folitonombenichiefer ift vers

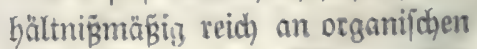
Reiten. Bon Den Rffauzen hat fich ïbrigens fait nur ber Soblen= oen Inthracit bilbet. 
¡ิig. 15.

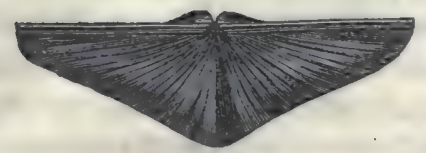

Bon Retrefacten nemuen wir diejenige S(rt, welche ber Fromation die Benennung verliefyen Kat, nämlidy Posidonomya Becheri. Die Bflanzentefte- im ßoftonomnenichiefer rüfren bon $2($ cotylebonen Ker, unter Denen Calamites Suckowii Kertorzuheben ift.

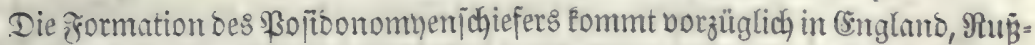

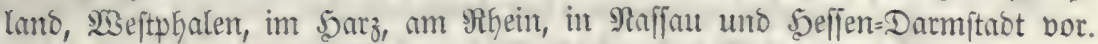

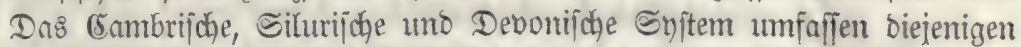
Bebilide, meldhe SWerner unter bem Namen "llebergangigebirge" bereinigt hat. In Englano tritt als ein jehr bemerkensmerthes Stieb des Devonijdyen Enftems ter alte rothe Eandftein anf, bon weldhem Barallelbiloungen in

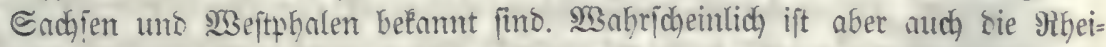

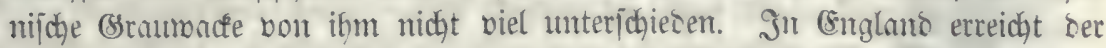

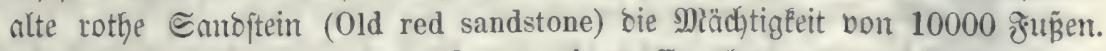
Das Bejtein befteht borługsmeije aus einem (Eonglomerat, melches bie näm= licken frragmente, wie bie Braumadée entḩält. Mit bemfelben wechjeln Engent von Mergeln unঠ Ralłen.

\section{Gteiufobrengrupp.}

Die Eteinkohlengruppe umfǟt zrwei jormationen:

\section{a. Den Bergefle ober foblentalf, aud enctinitentall,}

megen der barin vorfommentben \$etrefacten gentannt. (5r befteht hauptäa(t)=

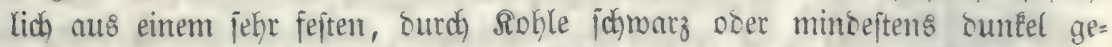
fäıbten Raleftein, oer oft Bitumen enthält uno cann beim Zerichlagen einen

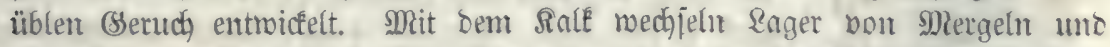
Ganofteinen. In tem Ralejtein Eonmen midht felten fetterfteinatige Brodfen,

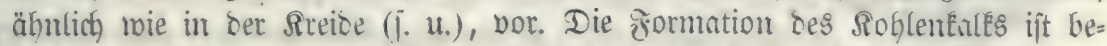

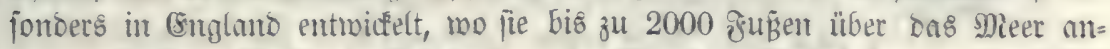

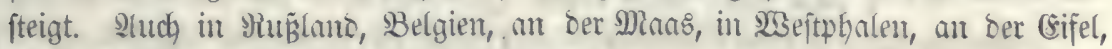
bei . Facken, an ber $\Re$ uhe tritt biejelbe auf.

ঔig. 16.

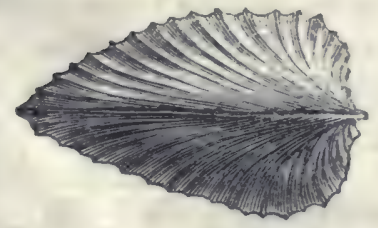

Bon Berjteinerumgen nemen wir sie Bes $=$ ichledyter Pentatrematites, Poteriocrinus, Actiniocrinus, Productus, Spirifer (glaber æig. 16).

(Sinige Sheognoften erfemen den Sohlentenlf nicht als eirte jelbitftänoige formation an, jonbern betrachten ifn alı ein (3)lieb ser folgenoen fror= mation.

\section{b. Dic etciatorrenformation.}

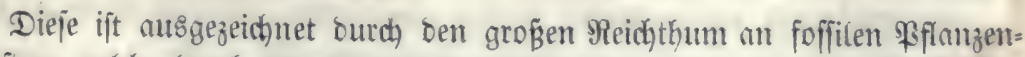
ïberreiten, welche burdh Den Bermoberungeprozeź in sie jogennunte Eteintoble 
umgewanbelt worben fino, , Die gegenwärtig aus Dem Jnnern Der (Erbe ges monnen und als sirennmaterial bemubt mirc. Die Pflanzen, meldje bie Stein= Eoblen bildeten, find lauter untergegangene Arten, ber Mefirzabl nach ICoty)= lebonen Doer Monocotyleoonen, Dicotylebonen fehlen, mit SYusnahme ber

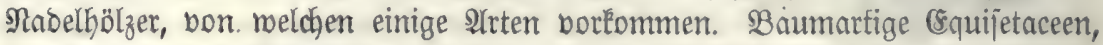

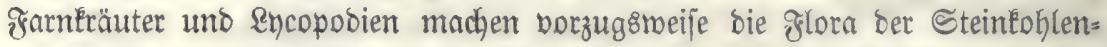

Æิig. 17.

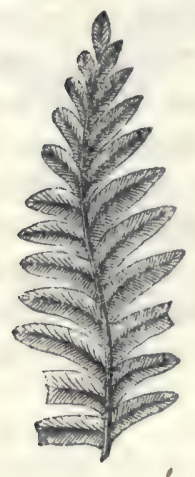

æig. 18

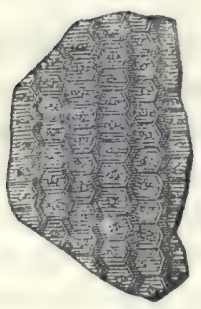
formation aus. Bon Equijeten ift fu nennen bas Bese

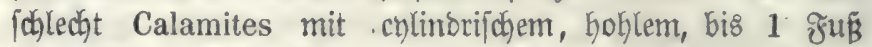
bicfem Stamm ohne 2lefte, bon rarnţäutern die ßrenera Sphenopteris, Odontopteris. Neuropteris, Pecopteris (aquilina ঔ̊ig. 17.) und Cyclopteris. Da\& (seid fect)t Sigillaria (hexa-

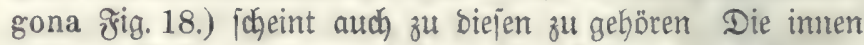
bohlen Sigillarienftämme haben oft eine Ränge von 50 ช̛u=

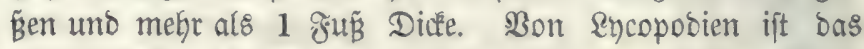
(Sefoblecht Lepidodendron mit piralförnig geftellten \$3latt= ftielnarben ausgezeichntet. Aluch Balmen hat man in ben

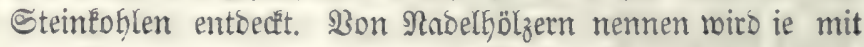
ben Afraucarien berwanoten (seichlechter Voltzia uno $\mathrm{Al}=$ bertia.

Daß́ bie Steintohlen aนళ Pflanzen entftanden feien, Larüber fann nicht ber geringite Zmeifel beftehen. Cine an= bere orrage aber ift bie, auf welche 2 Beife bie Itmmandlung ber Rflanzenfajer in bie fefte fdywarze uno bichte Maffe (bie Steinéohle hat ein fpecifiches servidyt bon 1,3) et=

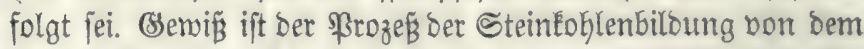
ber gemöbnlichen Bermejung unterfajieden. Reinenfalls hatte bie \&uft volftändigen 3utritt, fonft mürbe der $\mathfrak{S B}_{\mathrm{S}}$ ffer=

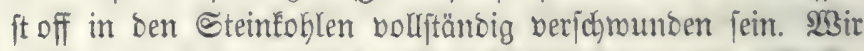

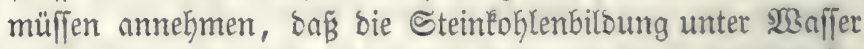
Dber unter einer bicfen \&age bon (Erbe bor fich gegangen jei.

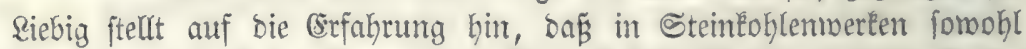
Cumpfgns, als auth Sohlenjäure angutreffen finto, bie Theorie auf, bie Ctein= fohle habe fich aus ber Solzfajer etzengt, intem fid) ভumpfgar, Roblenjäure und $\mathfrak{B a f j e r}$ bon berjelben getrennt Gätten.

গach (5ary Rulfac ift bie Formel bes 5olzes $=\mathrm{C}_{36} \quad \mathrm{H}_{22} \quad \mathrm{O}_{22}$ Giervon $a$ b 3 ๔umpfgas $=\mathrm{C}_{3}-\mathrm{H}_{6}$

$$
\begin{aligned}
& \text { " "3 23affer }=\mathrm{H}_{3} \mathrm{O}_{3}
\end{aligned}
$$

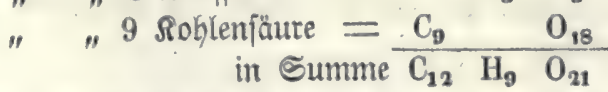

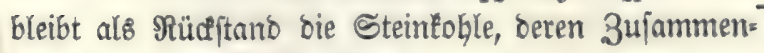
pegung fid burdh bie Formel: ausbrïct. 


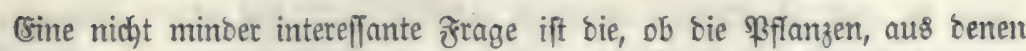
bie Steinfoblen entítanben finto, an ber gegenwärtigen \&agerjitätte ber legteren

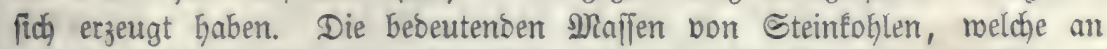
manchen Drten zujammengehäuft fino, joheinen nidgt für bieje Înnabme zn

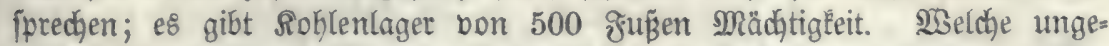

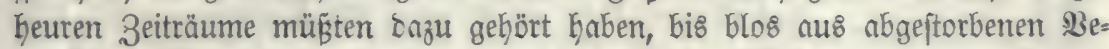

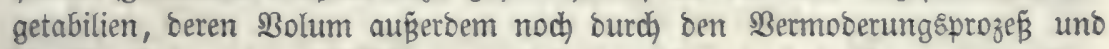
ben Druaf ber obern ๔ajidhten berminbert murbe, fo hohe sngen fich bilden

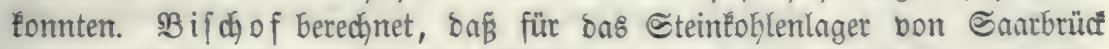
bazu ein 3eitraum von über 10 Millionen Sahren erforberlich gemejen jein

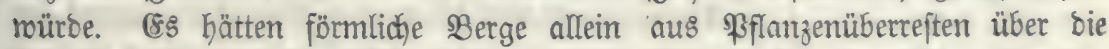
Dberfiäche bes B̧obens fidh erheben müffen. Iubersem mechjeln aber bie Steintoblenflöbe ftets mit Ragen bon (Erbe (Ihon, \&ehm, Sand), Deren Bil= bung unerelärlich ift, menn man bie Steintoblen mur für ben \$umus eines

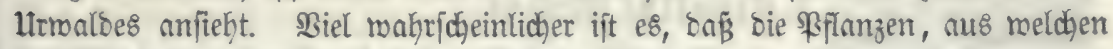
bie Steinfohlen entifanben fino, in Becten, Seen u. 1. w. zujammengeidnrwemmt murben, baß̈ fie aljo von jogenanntem Ireibholz Kerrübren, wie ế nodh Geut

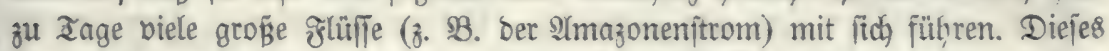
Ireibfolz fonnte fich fo lange am Epiegel bes Waffers idnmimment erhalten,

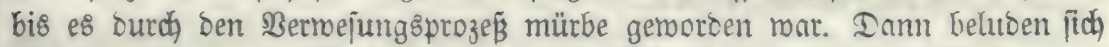

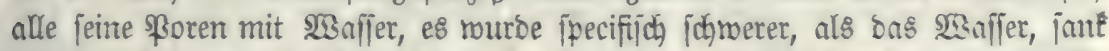
unter und rutbe in bem Geegrunb begraben. Man barf übrigens nidjt

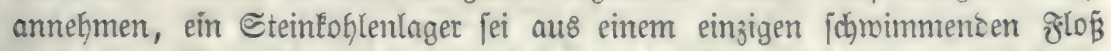

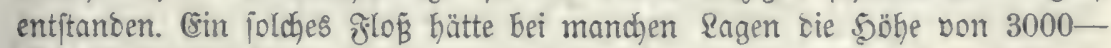

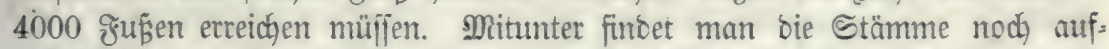

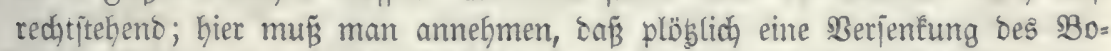
bens jtattfand, mie fie die (Sejhichte ber Bsognofie häufig nadjgemiejen hat. Biele Eteinfoblentager mögen auch wohl aus aorf entitnnoen jein. Zür bieje lann man baher eine Orzeugutg auf if̧rer gegentwärtigen Rngerftätte ans nehmen.

Wisie idton angegeben, befinten fich in ten Steintohlenlagern ertige

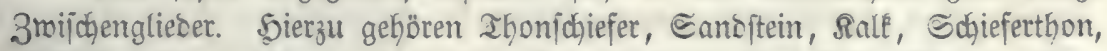
plaftiocher Ihon, sebm uno ๔ant. Die einzelnen Steintoblenflöge etreichen,

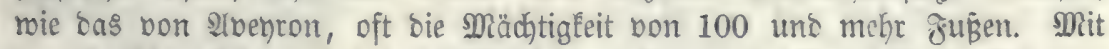

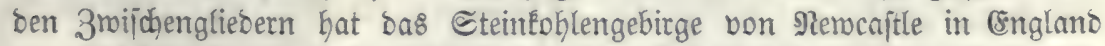

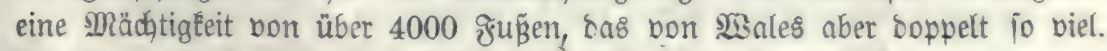

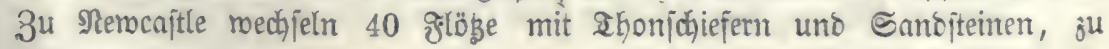
SD:on8 115 đlöge.

Die Eteinfohlenformation ijt über alle Iheile ber (Erbe, jelbjt über bie

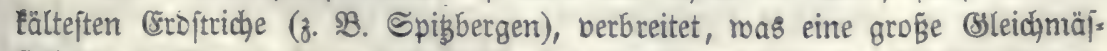
figeit bes Slima's in ben betidhiebenen 3onen zur 3eit ber Steintoblenent-

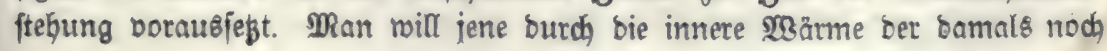




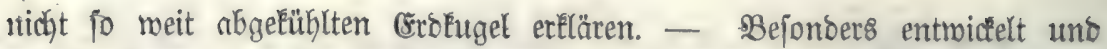
mächtig fommt die Steinḱphlenformation in England vor. In Deutichland finbet fie fich bei 2 achen, an ber $\Re u b r$, bei Steuznach,

ซึig. 19.

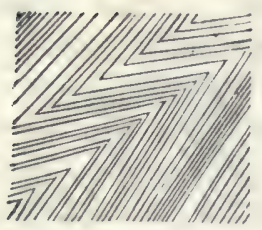

ફૈig. 20.

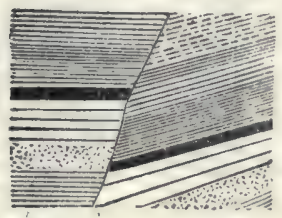
Sarbrüd uno in Sdjlefien. Sn Den (Sorbilleren reichen bie Steinf́blenlager an bie ๔d)neegrenze (bis zu 13000

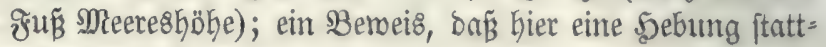
gefunden hat.

Die Alblagerungen ber Steintoblenformation find ge= möhnlich Gorizontal; boch trifft man auch Mulben uno ธättel.

Die einzelnen Schidhten eines Steintohlenlngers ber= raufen nicht immer parallel; jefrr häufig tommen Zicázact= bilbungen unt 2 erwerfungen ber Schichten vor.

\section{9ermifoe Grappe.}

Dieje Bruppe füfrt ifre Benemunng bom Srouber=

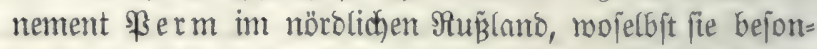
bers ausgebilbet ift. Sie umfant folgenoe Fromationen:

\section{a. Das शtothe gobtliegenbe.}

(S8 bejteht hauptjächlich aus einem fajt immer jeb̆r grobërnigen, con=

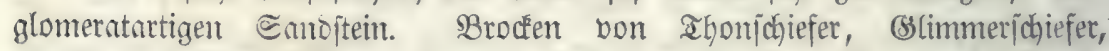

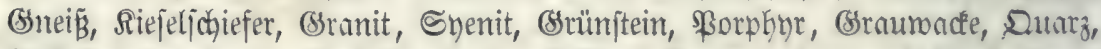
Salk find burch ein eijenhaltiges ober Ealfiges (Cement ober auch burch frag= mente ber eben genamten Bejteine berfittet. Die vorberrichenoe garbe biejes (Eonglomernts ift bie blutrothe bis rothbraune, feltener bie grünliche poer graue. Die Echichten bes Sandjteins find oft burdh Bänfe von rothem Echie= ferthon getremnt. Diejer erreicht mandymal eine bebeutende Mäa)tigleit un jegt fid) bis in ben Sandjtein fort. Regterer geft bismeilen in förmlidyen

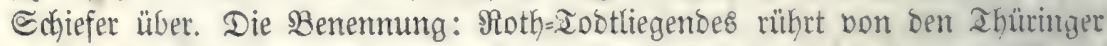

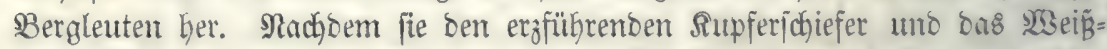

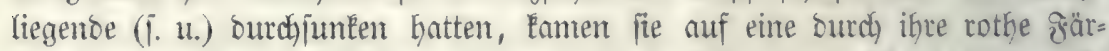
bung ausgezeichnete Edjichte erzfreien (tobten) Ssefteins, meldye sons sirgentse

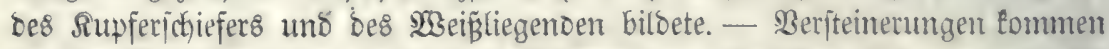
in :Rothliegentoen nur mentige vor. Etämmte von ähnlichen SBäımten, mie bie oer @teintohlenformation, finten fich in verfiejeltem 3ujtanto.

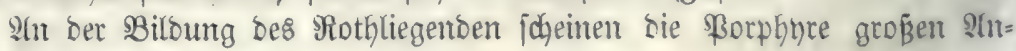
theil gebabt zu haben.

Uleber bem Rothliegenden befintet fidy an mandjen Srten ein Eant= fteii von ber nämilichen Bejchaffenheit, aber von Kellerer Fratbe, tas joge-

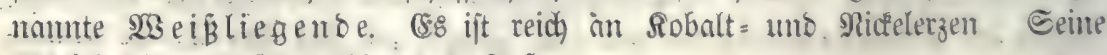
Märdigfetr geht felten über 100 juß̃e. 
mengehalten werben. Sach bem Sitt richtet fich auch zumeift die Farbe bes

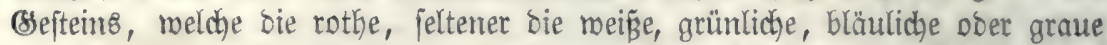
ift. Die Farbe ift nicht immer einförmig, oft mechfeln Gellere uno bunElere Fartbien mit einander, jo baß̧ bas Geftein ein gebänoertes Arnjegen erbält. Dodh findet bie Streifung nicht immer in einerlei Simne mit ber Schichtung ftatt. Der bunte Eandjtein ift feinënniger, als ber Bogejenjanoftein, bod hat man von erfterem audh groblërnige Barietäten; zumeilen find Felbit bide Duarz= brocken ober Ihoutelumpen in ifm enthalten; menn bieje ausgemajohen mer= Den, entftehen Söblungen in bem Seftein. Der bunte Santoftein fommt in bickern unt bümtern Schichten vor, bie mit einanber abrwedbjeln uno bäufig burch) Eagen (slinmmers getremt fint. Die Fejtigeit bes Bef̧teins ift eine febr berfatiedene; einige Sorten erfärten erft an ber suft, andere bejteben blos aus

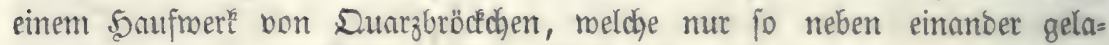
gert fint.

(sin fehr d)aracteriftifjes (s)lieb ber Formation bes bunten Canbiteins fint Ragen bon rothem 2 hon, melche gemöhnlich bald über ober unter einer Reihe von Gefteinsjefichten befindlich fint, bald aber audh mit lebtern ab= mectjeln. Diejer Ifyon füblt fich zart an; er ift ftaré bon (sijenoryd burdh)=

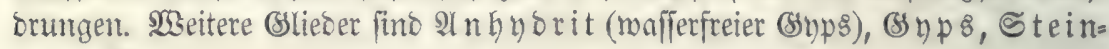
ialz, Mergel.

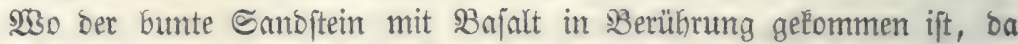
hat er (mie am $23 i l$ benftein bei Bübingen in DEerheffen) mitunter bie fäulen= artige 24bjonberung mit Dem $B a j a l t$ gemein.

Der bunte Sambjtein bildet gewöhnlidh, wo er in geringen Maffen auf= tritt, Eegelfärmige Berge mit fteilen 2165 ängen unס ift bann oft mit lofem,

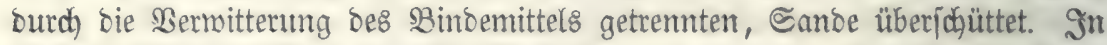
größ̈ern Maffen bilbet er meite \$rlatenu's uno plumpe, abgerundete Berge,

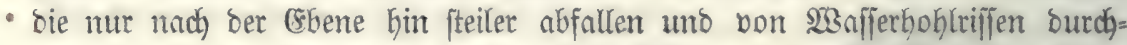
gogen fint. Sm Doenmald ift ber öftlicje IGeil bes bunten Sanditeingebirge\& eben und fanft abgeflacht, ber mejtliche dagegen fteil. YIn ber Sarbt findet bas

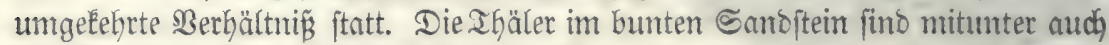

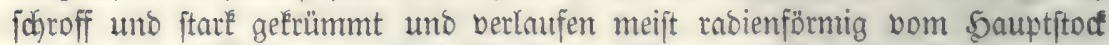

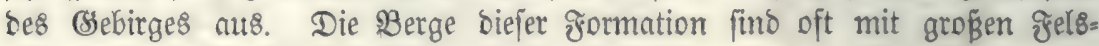
blödén überbectt.

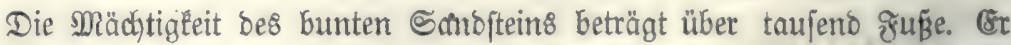
freigt im Sdymarzmald bis zu 3600, im Speffart bis zu 1400, an ber 23 erra

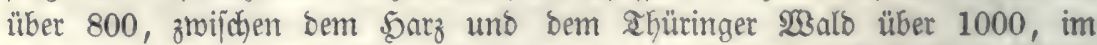

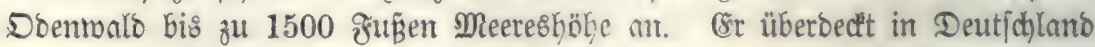

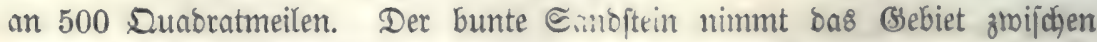

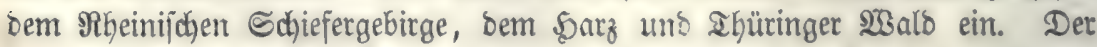
aröß̈ere Theil von Rurbeffen gehört biefer grormation an, bie fid auß̧erbem 


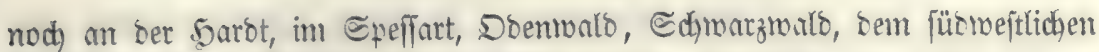
sheil bes githtelgebirges u. 1. m. findet.

Drganifde Refte fint im Sanzen felten

ฆig. 22.

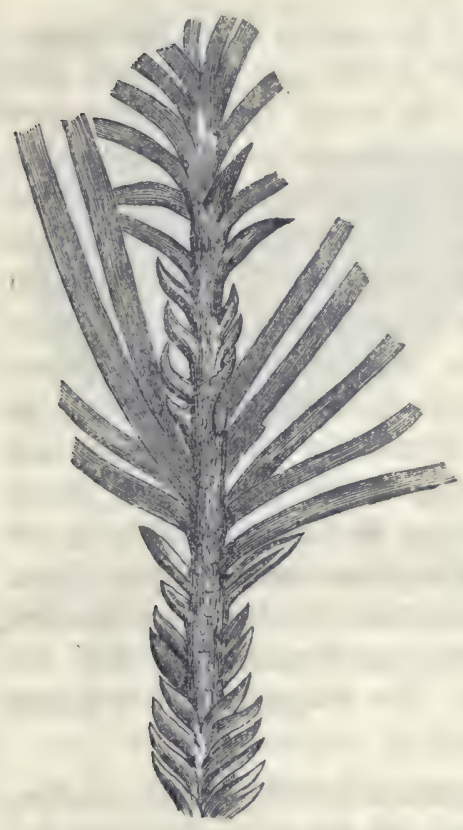
in biejer fromatien, als einige ber bezeid)= nenopten Petrefacten mögen Voltzia heterophylla (grig. 22.) Calamiles arenaceus, Aethophyllum speciosum genannt mer= Den. IGierfäbrten haben fich im bunten Sanoftein wohl erfalten.

\section{b. Der פufóttalt.}

(Ex beftebt aus einem bläulidben ober grauen, meift bünnjwiefrigen Raleftein, in welchem an manthen Drten grope Quan= titäten verfteinerter Muicheln borformmen, Daber ber Same. Sntefien ift bas seftein nicht übetall jo reich an \$etrefacten, uno es gibt jebr bielen Rale, melcher zufolge jeiner Ragerung in bieje grormation gehört uno bod gar Eeine Mufcheln enthält. Der Salle ift mitunter rellenartig gebogen, ba= ber ber Name $\mathfrak{B}$ ellentéalé.

Der MujchelEall füfrt als untergeoro=

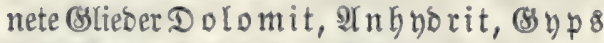
und Steinjalz. So befinden fich z. B. Die bebeutenden Steimfalzlager von 23 imp fen in biejer frornation.

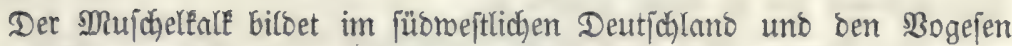
zujammenbängende fich) fanft abflachende, mit rellenförmigen (Erbebungen bes

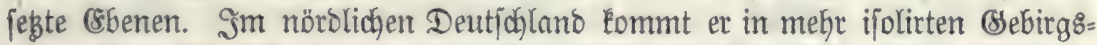
żügen bor, bie nicht jelten ziemlich) fteil abfallen. Die shäler biefer ssebirgs: formation find, mie bie ber borkergehenden, meift eng uno fteil.

Die Berbreitung bes Muichelealles geht nidht fo meit, als bie bes bum=

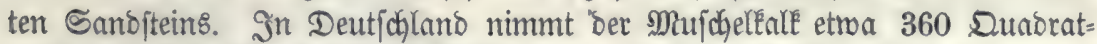

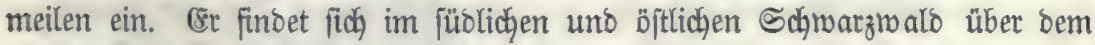
bunten Sandftein bis zu einer Söhe von 2300 Fufen, im Doentwald bis

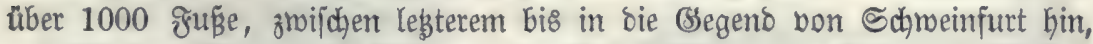

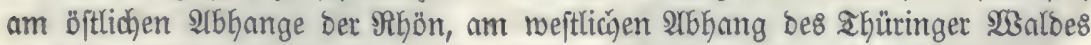
uno bes Fichtelgebirges, am Reinethal in ber Begento bon ssöttingen, im noromeftlidhen unઠ nörolichen aheil bez Sarzes, in Den Bogefent uno im Sarbtgebirge. 
तìiz. 23.

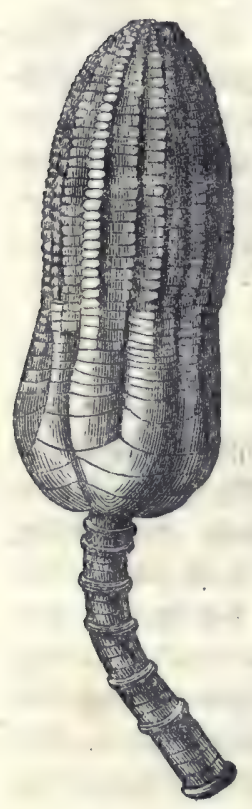

Bon Betrefacten, an senten bieje frormation biel reicher ift, als bie bes bunten Eandfteins, nemen wir fol= gente: Enerinites liliiformis (ð̊g. 23.), Ceratiles nodosus, Delthyris flabelliformis, Pecten laevigatus.

\section{e. Aeuper.}

Der Seuper ift ein in Den untern Ragen feinëörniger, in ben obern bagegen mebr grobërniger, gewöhntich gelb=

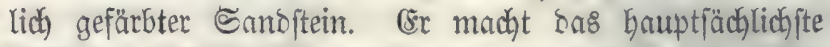
(Stieo Der nach ifm benannten Frormation aus. Mit biejem Sanditein Eommen Ragen bon Mergeln, die meift eine grüne Doer rötfliche Farbe befitgen uno fohiefrige शrbfon= Derung zeigen, por. Sunps, ভteinfalz; Dolomit, Âthyorit finten fich ebenjo in biejer, wie in ben beiben vorkergeh= enoen frormationen. Der Reuper ift borzüglich dyarac= terifirt Durch bie fogenannte RettenÉoble. Cie befteht zu unterft aus gefchiefertem, bituminöjen Ihon, ber nach uno nach in eine fofrnarze eroige Soble mit mattem sBruch übergeht. Die Rettenḱkhle hat zu geringe Mäbtigkeit, als bá̉ fie z̆ Brennmaterial abgebaut werben könnte. Shrer chemijchen 3ujammenjebung nach) iteht bie Rettentéble zmi= fhen Der Eteinfoble uno ber Brauntoble. Mit Der Rettentohle medffeln Rager von Mergelfohiefer. Der Reuperjanoftein liegt ftet8 über ber Rettentoble.

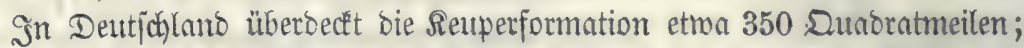
jie nimmt aljo nidht jo bebeutente Bebiete ein, als ber bunte Ganojtein und

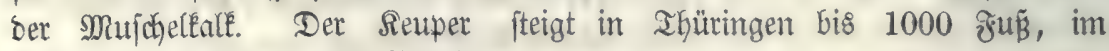
Schmarzmald bis zu 2400 ซutuen an.

Der Reuper bilbet flach hügelige SSegenden, boch finto bie Arbhänge ber Berge meift jteil, meniger ba, wo Der Mergeljojiefer vorkerrfat. Die Sieuper= formation findet fich in Schroaben und Franten, im norbmejtlichen Deutid)=

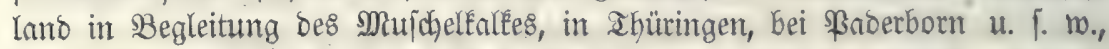
ferner noroweftlich vom 5arz bis in bie Umgebung von Dsnabrück, am meft= lichen Arbhang ber Bogejen.

jig. 24.

In $\mathfrak{B}$ etrefacten ift ber Reuper nidit reidjer, alo ber Mujchelérlf. Frolgente nennen wir als bezeidnende: Gervillia socialis (ङig. 24), Equisetum arenaceum, Mya matroides, Pterophyllum Jaegeri. 


\section{Suragruџp.}

Dieje, weldhe eine etraas geringere Berbreitung, als bie Triagrgruppe be= fitst, theilt fich in folgende grormationen:

\section{*. $2 \operatorname{tas} 8$.}

Die Siasformation befteht aus salfen, Schiefern unb ๔anbiteinen. \$on

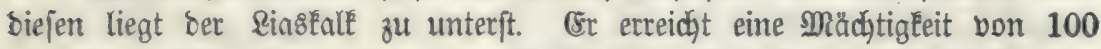
§ig. 25.

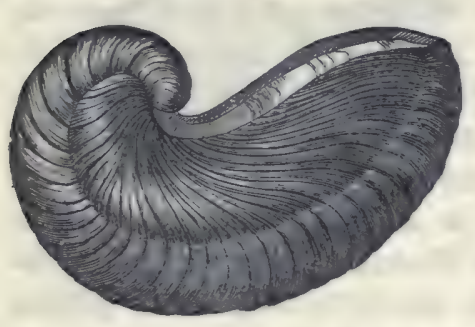

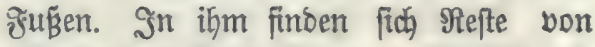

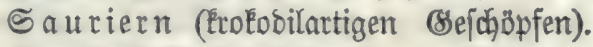
Det Riablale if fehr reich an Bitumen. Bejonders Eezeidnend für ifn ift bas $\mathfrak{B o r}=$ Eommen von Gryphaea arcuata (ङig. 25.) in unzähligen (Exemplaren. Der Riašală finoet fich, auper in (5nglano uno grant=

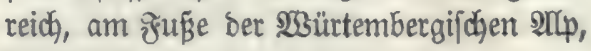
bei $\mathfrak{B a j e l ~ u . ~ ๆ . ~ w . ~}$

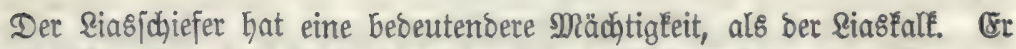

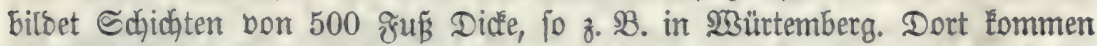

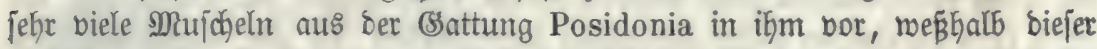

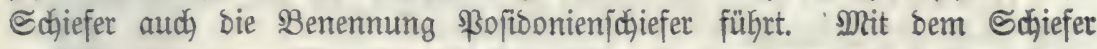

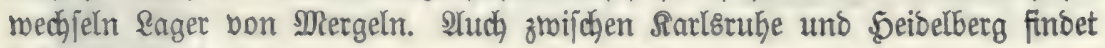
fich) ber Riasfidjiefer.

Der Riasfandjtein ift bas oberfte sslies ber Riasformation. (Er fommt

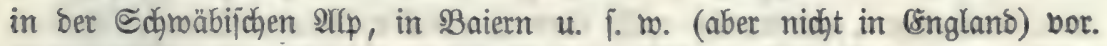

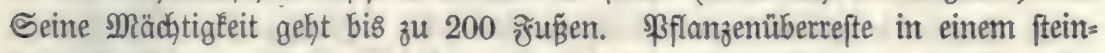
fohlenähnlichen 3uftande fino bem Riaşanditein eigen. Die Sauptmaffe biejes Sejteins bilben compacte Mergel.

Der Rias formirt flachbügelige Begenden.

\section{b. รura.}

Æig. 26.

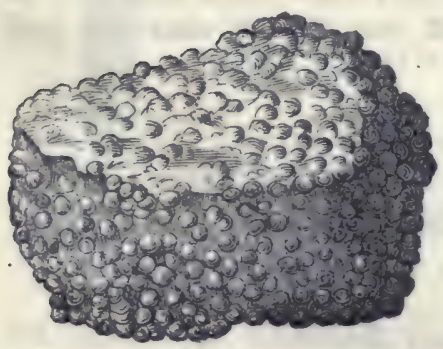

Das dharacterifitifge Beftein biejer For= mation ift ber fogenannte Surafale, ein erbjengelber oder bläuliojer Salfftein von feל̧ feinem Sorn, aus beffen reineren Barie: täten bie lithographifjen Steine gefertigt

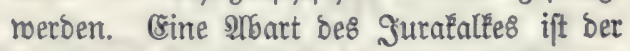
Dolithentalk. Diejer beftegt aus Sötrnern bon ber Bröbe einer (Erbje, bie buth ein Halkiges (Sement berlittet finto. Daber bie Benennung ( $\mathrm{r}$ rbjenftein). Man Gielt fie früber für berfteinerten giidgrogen uno nannte befs= 


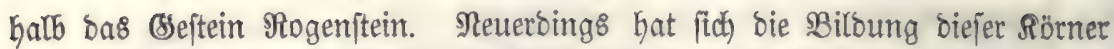
erElärt; Diejelben erzeugen fich nämtlich nod) gegenträrtig an manchen Drten.

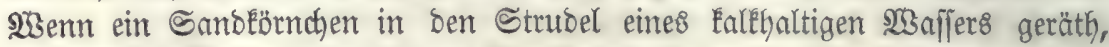
fo erhält es fich in biejem einige Zeit jofmebent, nobei fith fo lange Ralé um baffelbe Gerum anjegt, bis jeine Edjmere jo bebeutend geworben ift, baß̈ ber Strubel es nidft mehr zu tragen vermag uno es zu 30 Doen fintt. Şier nun merben bie Rörner berlittet.

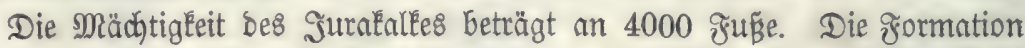

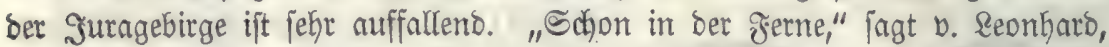

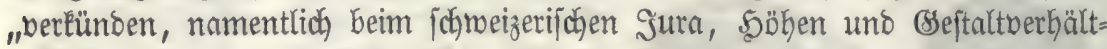
niffe eine, bon nachbarlicken Bergreigen mejentlich berichiebene, 3ujammen= fesung Des Innern. (Sinem gewaltigen Damme gleid), fteigt ber erhabene Rütfen ber ausgebebnten Maffe mit faft umunterbrochener (Sinförmigleit bon

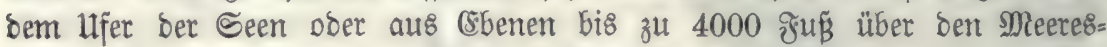

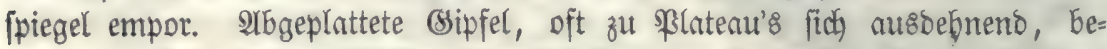

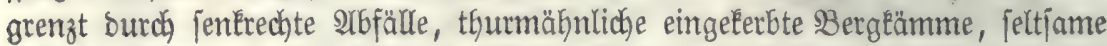

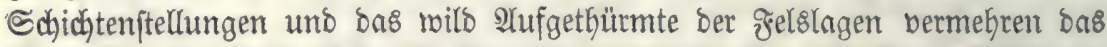

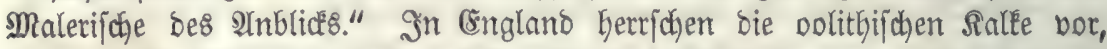

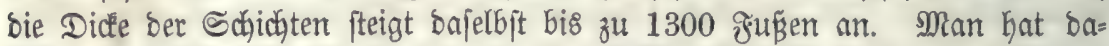

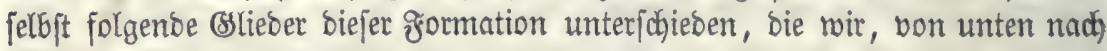
oben gerectynet, anfübren.

\section{a. Interer Dolitb.}

Befteht aus mergeligen, oft glimmerfaltigen Sanofteinen ober aud Lofen Gandlagen, in weldhe nach oben hin Salke fich einorängen, bis bas ganze Geftein in einen berben Saltitein übergeht. Säufig fint bie Dolithe biejer Schidjten eijenjđülfïg.

\section{B. Drforbtbon.}

3u unterft in biejem SSlied liegen mergelige, eijentyaltige Salfe, bann

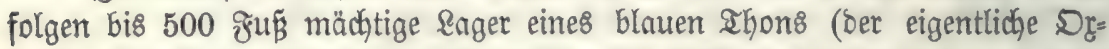
forbthon), hierauf Sand und Sanditeine mit Kalfigem Binbemittel und end= lich ber (Eorallentalé (Coral-rag), ein, wie fohon ber stame andeutet, an Corallen reidjer Salffitein, Der in ber SSegeno von Drforo etwa 150 Эuß Mächtigleit erlangt.

\section{$\boldsymbol{\gamma}$. Stumeribger Ebon.}

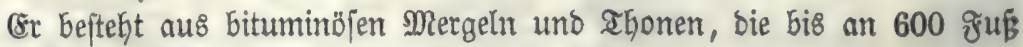
mäbtig find uno bie uno ba BraunÉohlen entfyalten.

\section{d. \$ortianberate.}

\$Gn fegen vorzugsmeije hellgefärbte derbe Sanofteine zujammen, bie mitunter oolitbifich, zumeilen erbig uno zerreiblich fint uno nidot felten fiejelige 
5oncretionen enthalten. Baumptämme fommen in Dorjetshire, mandjmal noch in aufrechter ๔tellung, im SPortlandéale vor.

In Deutidjland fint nidht alle (Slieder fo ausgebildet wie in Ongland.

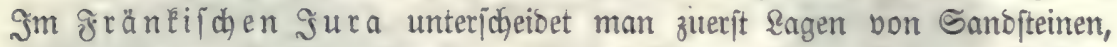
bie Dem untern Dolith entipreçen, Fierauf Ifyon, äquivalent bem Drford=

Æig. 27.

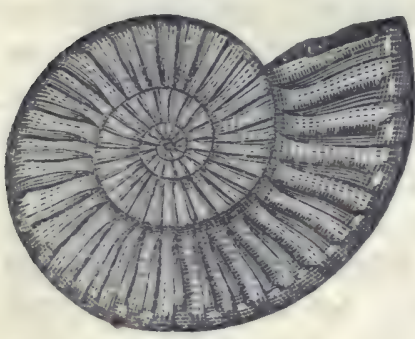

‡̧ig. 28. thon, und endlich bedeutende \&agen eites vielfach von Corallen burdyzogenen Raléfteins. Die Dolomitbiloung tritt im beutiden Gura

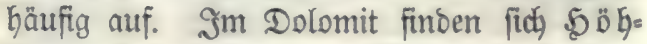
Len, mie biejenigen bon Muggenborf, Sai= Lemreuth und Streitberg. Steinjalz uns (5yps fint ftets Begleiter ber Surajifichen Be= bilbe.

Bon Petrefacten fübren wir an: Pecten disciformis, bas (Gejęlecht Ammonites (A. Bucklandi, §ịg. 27), Das (seidjledjt Belemnites (B. giganteus, ஓig. 28.).

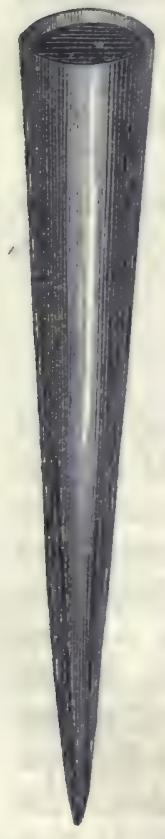

\section{Ereibegruppe.}

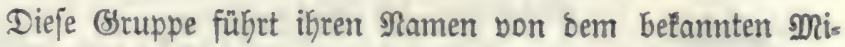
neral Sreibe, melches in ber oberften grormation borfommt. Die Sreibegruppe ift über groß̈e Ränderftreçen hin berbreitet. Sn (Europa fennt man fie in Englano, Franfreidh, Spanien, Sta= lien und in Deutidgland. Man theilt fie in brei formationen.

\section{a. Der פBdbert bon}

if: bie unterfte von biejen. Bejontere 9lusbiloung hat er in Fingland exlangt, boch finden fich $\mathfrak{B a r a l l e l g e b i l \delta e ~ i n ~} \mathfrak{B e j t p h a l e n ~ u n d ~}$

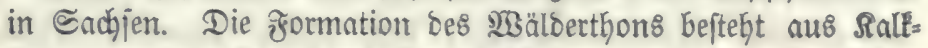

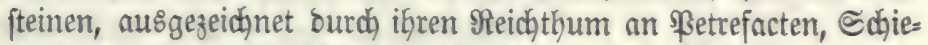
fertfyonen, lojen eijenjchüjifgen Sanblagen, Sanditeinen und Iho=

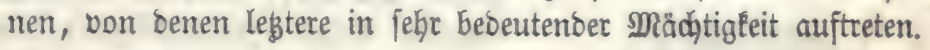

\section{b. Duaberfanbein.}

Dieje Formation befteht vorzugstreije aus einem jehr कa racteriftichen Ganditeine bon beller (gelblicher ober grauer grarbe, ber gemöhnlich eifenjojüfitg ift. Der Quaberfandftein führt jei=

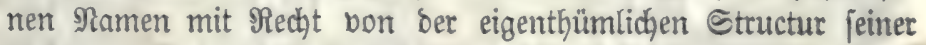

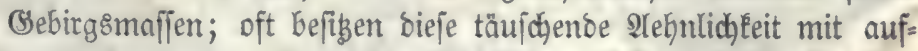

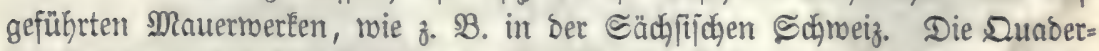

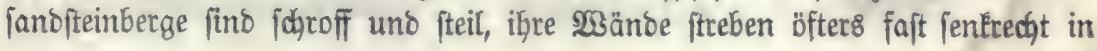


ærig. 29.

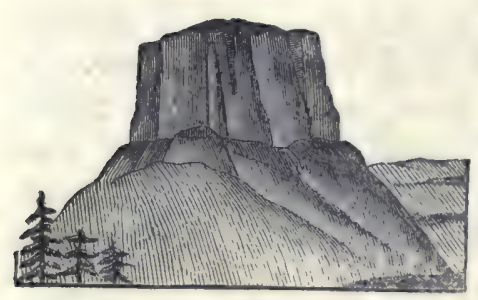

bie 5ỏke. (ærig. 29, Silientein in ber

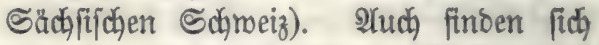
mitunter einzelne freiftehende Säulen bon geringer Dide, aber befto größserer நöhe. Đöblen ober Serwölbe von unbedeutenber Arusbefyung fommen im Duaberjanoftein: gebirge vor (Ruhftall, Brebijatthor in ber

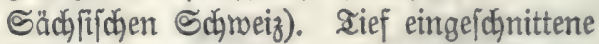
Schludyten fint bem Duaberjandftein ber Sächjifchen Schmeiz befonders eigen.

İm Şarz (Teufelsmauer bei Blanḱenburg) treten mebr loje SBlödé bon be= Deutenden Dimenfionen auf. Das Material bes Duaberjanditeines in Deutich=

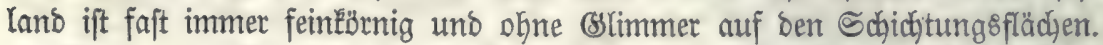

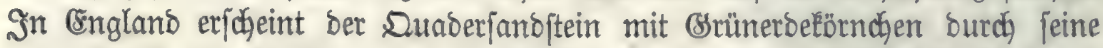
gange Maffe Gin Surchorungen, weşhalb man bort bas Beftein (5) rünjand nennt. Sm beutfdjen פuaberjanditein Eommen bieje Brünerbefïrndjen felten uns wur an mandjen Drten bor.

ชุig. 30.

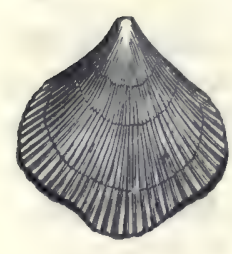

3mifden bem Duaberjandftein finbet fich in Sactjen ein eigentfjümlidjer mergeliger Rall in plattenförmiger $2 \mathbb{b}=$ fonberung, ber \$lă ner.

Der Sarpathenfanoftein gehört gleidfallis in bie eben betrachtete Formation.

Betrefactern: Pinna tetragona, Terebratula octoplicata (§ig. 30.), Ammonites Rhotomagensis, Scaphites aequalis.

\section{c. Die setbeformat to}

if tharacterifirt burd bas Bortommen ber belannten Streibe. Diefe befteht

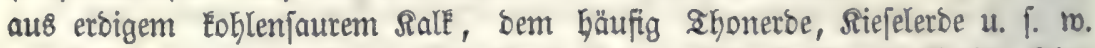

Æig. 31.

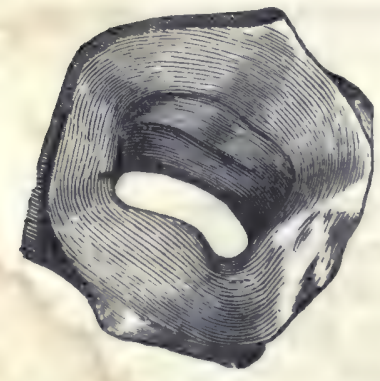

beigemengt fint. Die Streibe conftituirt Eeine boben Bsebirge, fondern nur Plateaus ober einzelne grelfen (Injel Rügen). Riejelige (5on= cretionen - Feuerfteine uno Dpale - Eom= men in Sreito febr bäufig bor (ð̧ig. 31. ein

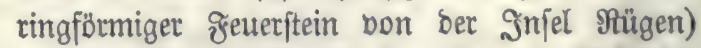
und find für biejelbe febr bezeidnend. Nidgt fel= ten enthält die Sireibe (stüneroelörnchen. Die Sireibeformation findet fich fehr mädhtig in reng= Lano, granlreich, 2Beftphalen., im nörbliçen Deutjchland, in Belgien u. 1. w. entroidelt. 
รig. 32.

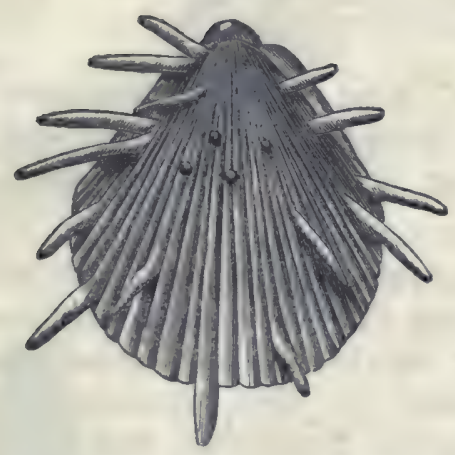

ßettefacten: Ostrea serrata, vesicularis, Spondylus spinosus (ঔig. 32.) Terebratula carnea, Pecten quinquecostatus, Belemnites mucronatus.

\section{Molafegrapde.}

a. Die $2 x a$ antobrenformation

umfafit eine Reibe bon (sebildon, weldhe in ifrer \&agerung unmittelbar auf bie Rreibe= formation folgen. Sie entbalten ungebeure Schichten bon plaftichem, grau ober grün=

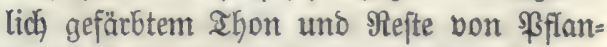
zen, beren Bermoberung fomeit vorgefdritten ijt, Da je fie eine braune ober

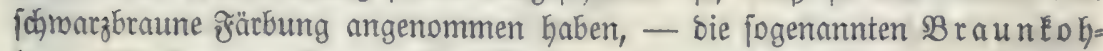
Len. Sie ftammen ifrer größ̈ten Maffe nach, bon bif́otylebonifchen Bäumen

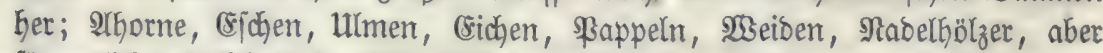
fämmtlich mit Keiner ber jegt lebenden 2Yrten übereinjtimmenઠ, bilbeten bor= zugsmeije bie Baumbegetation ber Brauntoblenformation. \$3on mandjen

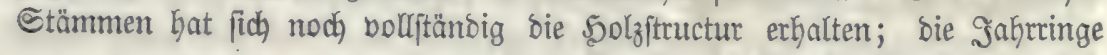

§ig. 33.

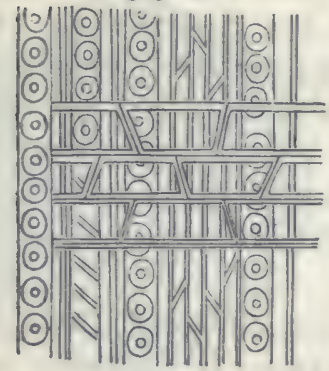
und 5olzzellen Eönnen jẹ̆ häufig ganz beutlid unteridjieben weroen. (ङig. 33. (Fin હdanitt

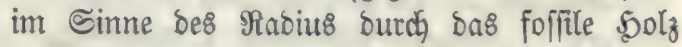
von Pinites ponderosus.) YUuf die $\mathfrak{3} 3 a b m e h=$ mung hin, baß̃ Sohlenjäure ftets in Den Braun= bohlenlagern fich findet, hat Riebig folgende febr mafricheinliche Shyptheje ber Brauntohlenbildung gegrünbet. (5r geht von ber belannten $3 \mathfrak{u}$ am= menjełung ber \&aubacher $\$$ Brauntoble aus, weldhe enthălt

$$
\begin{array}{lr}
\text { Sioblenitoff } & 57 \cdot 28 \\
\text { Swafferitoff } & 6 \cdot 03 \\
\text { Sauteritoff } & 36 \cdot 10 \\
\text { Siche } & 0 \cdot 59 \\
\hline & 100 \cdot 00
\end{array}
$$

und mofür fich bie frormel $\mathrm{C}_{33} \mathrm{H}_{21} \mathrm{O}_{16}$ bered)net. Dieje leitet siebig aus

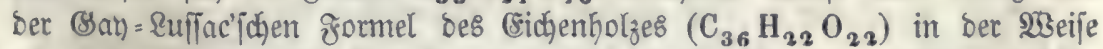

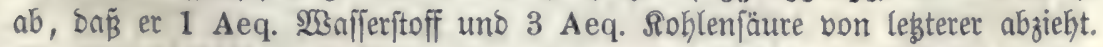

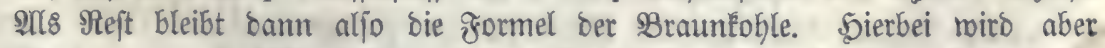
angenommen, baß́ bie \&uft wenigitens fo viel 3utritt zu Der Brauntóble hatte,

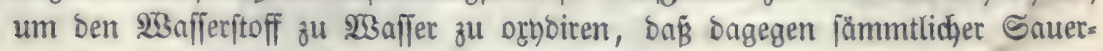
ftoff ber Sohlenfäure mis ber Solzfafer felbjt Gerrübre. 
Formel bes 5olzes

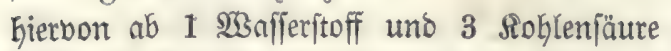
bleibt alb Rejt Brautntoble

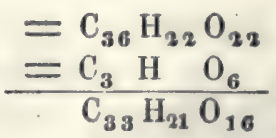

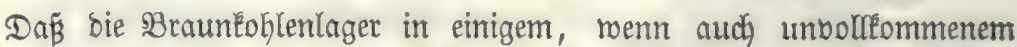
3 ujammentyang mit ber \&uft jtehen, hat bie Beobadjtung nachgetwiejen; auch führen bie Tagmafler, welche von oben her zu Den Braunloblen Ginabfideen, immet suft mit fich.

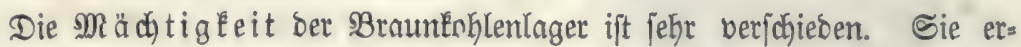

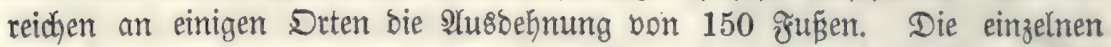

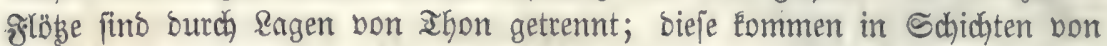

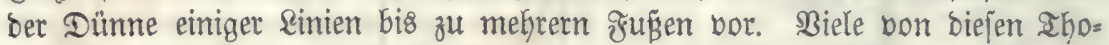
nen fint unter bem Einfluffe der bermodernoen Braunteblen ifres sijen= gebaltes beraubt worben; fie eignen fith bann borzüglich zur \$orzelfanberels tung. Bejonbers gilt bies bon benjenigen Igonen, melche burch ifre ganze Maffe hin mit Fragmenten bon Braunétblen burdibrungen uno baburch bun= Eel gefärbt fino.

Die Ueberlagenung Der Braunfohlen mit ahon ift unzmeifellgaft bie Ur= facje ifrer Brfaltung gemejen. Durch ben Ihon murben bie Solzitämme bon

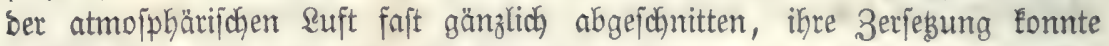
baker nur in fehr geringem Mafpitabe von ftatten geben. An manchen $D r=$

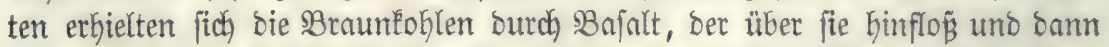
erftarrte. (Enubach), Meipiner). Durdh Den Keifflüjfigen Bajalt murben bie Ehone mitunter gebacken, Stborücé von Sfflanzentheilen conjerbirten fich in Folge diejes Umitanbes bis auf bie gegenmärtige Zeit (NÄnzenberg in ber 2Betterau). 2(4uch die Brauntohle felbft erlitt in Berübrung mit bem Bajalt Beränberungen; fie erjcheint an ben contactftellen gerabezu in soble ber= randelt.

Die bebeutende Mächtigleit bieler Braunḱbhrenlager beutet Darauf hin,

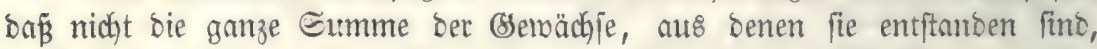
an ber gegenwärtigen \&ngerfitätte fich erzeugt babe; mir müffen bier, mie bei

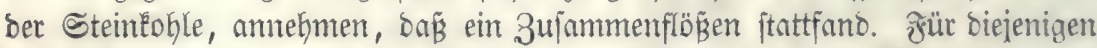

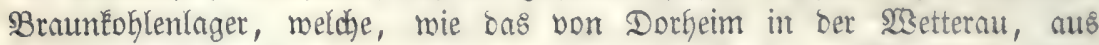

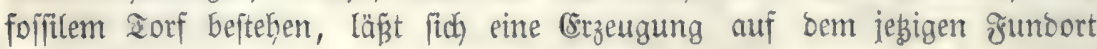
zugeber.

Die Braunfoblen find immer bon Steinjalz, Shps, Sdyrefeleijen, Sdinefelcalcium uno ânun begleitet.

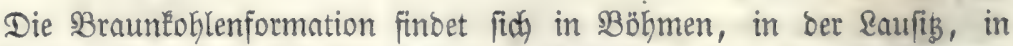

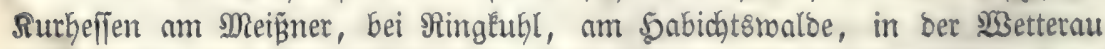
(Salzhaujen, - Dorheim, Eanggönв, \&aubach), im :Beftertwalbe uno noch an bielen anbert Drten. 


\section{b. Grobiglfformation.}

Sie ift jünger als bie eben betrachtete Braunfohlenformation und befteht haupt= (ächlich aus einem Derben, im Bruch rauben Salêtein bon Geller gelbliç,er ober grauliçer Fiarbe, ber, an bielen Srten burd einten ungebeuren Reichthum von foifilen Mujcheln nusgezeichnet ift. Unter biejen find bie Bejchlechter

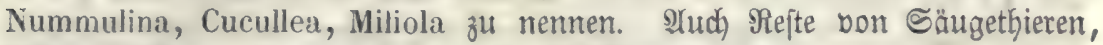
Fiichen, Bffanzen lommen in ber Brobéalfformation vor.

Der Srobéalé confituturt Eeine hohen Berge, er füllt mebr Æig. 34. Bajfin's uno BBecten aus. Mainz, Raffel, Paris u. T. m.

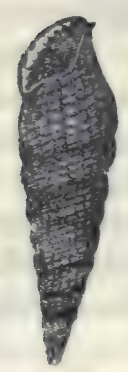

ßetrefacten: Cerithium plicalum (ঔ̊ig. 34.), Litorinella acuta.

\section{e. Tegerformation.}

Iuch bieje entbält einzelne Brauntoblenlager, boch bon

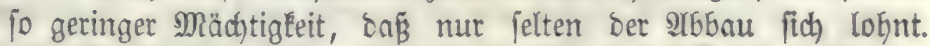
Tie ausgezeichneten Bslieser biejer Fुormation find Ihone (ber fog. Tegelthon in Böfmen Gat ber formation ben Namen ber=

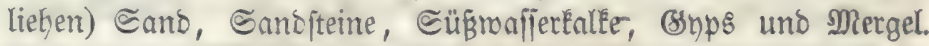
Yluch bie jogenannte $\Re$ a gelfluke, ein in ber Cedneiz in bebeu=

গิig. 35.

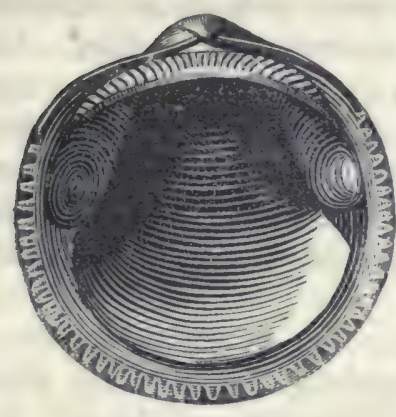
tenoer Mächtigleit auftretences Conglomerat, fojeint ifrem arter nad) in bie vorliegenoe Fुor= mation zut gehören. Die Bebilbe ber Tegelfor= mation fommen in Englano, frranfreich, BB̈h = men, bei :rsien, Mainz, Ealjel bor.

ßetrefacten: Petunculus pulvinatus (§ig. 35.), bie (sejhlechter Helix, Bulimus, Palu-

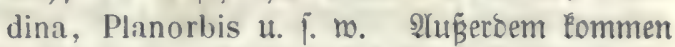
mehrere, zum Theil mahrhaft gigantijche Wrir= belthiere, mie Mastodon, Dinotherium, Megatherium bor, beren Snocken man ziemlich vollitänbig erbalten fano.

\section{9. (1) rupde beb Dilutumb.}

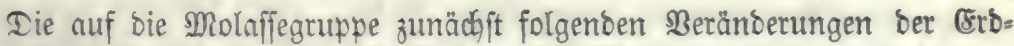
oberflädhe nennt man die Diluvialbilloungen. Cie fanden theils unter bem

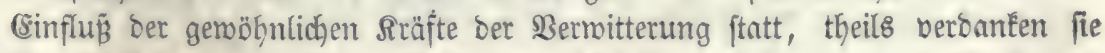
ifre Entftefung gemaltigen Fluthen, meldhe burdh Sebungen uno Sentungen

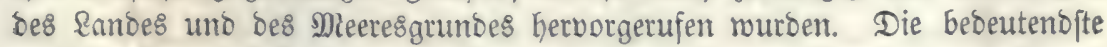

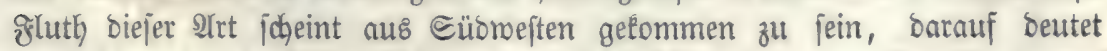
venigitens. bie in biejer Richtung zugejpigte Bsejtalt Der meijten Continente

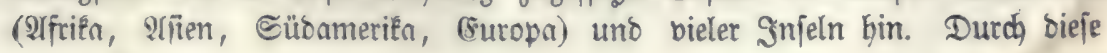


Fłuthen murben Sheile ber bereit8 vorhandenen Bejteinsarten bislocirt uno in manḑen Begenden zufammengehäuft. 3mei merEmüroige frormationen

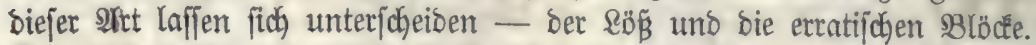

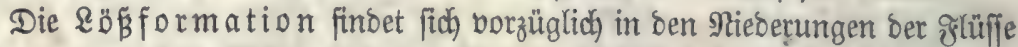
und an ben flachen Rüften mandjer Meere, boch ift fie auch über größjere

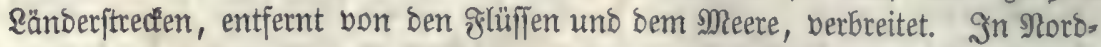

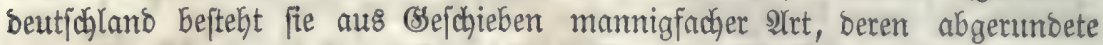
Form beutlich Darauf Ginmeift, baf fie in benegtem 23 affer an einander gerie=

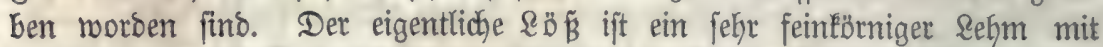

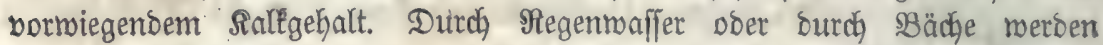
faft jenfrechte Sdjichten bon ifm abgelöpt, baher bie Benemnung. Der Röß

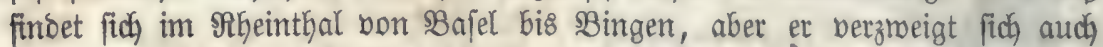

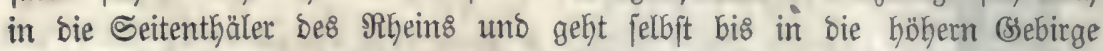
Ginauf, in Denen er freilich nur nefterweije borḱommt. Bezeidyneno für ben

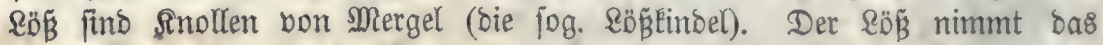

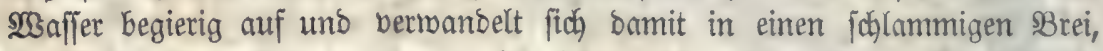

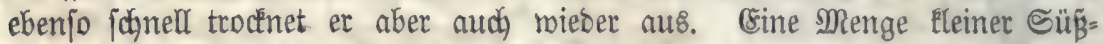
raffercondinlien findet fich in ben Eöpablagenungen.

Reben bem eigentlicken \&öß Fommen noch Bejchiebe, Rolliteine uno bergl.

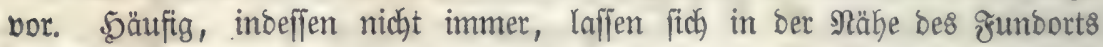
biefer Sefofiebe die Muttergefteine auffinoen, bon Denen fie ftammen. Defters

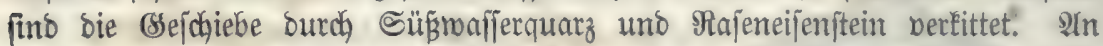

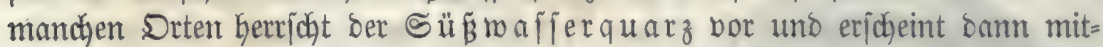
unter in grofen, bon \$öhlungen burchzogenen Blöcken, bie mie angefreffen

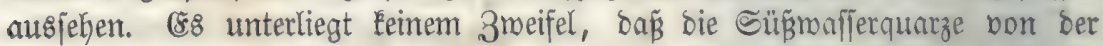
3ermitterung felbjpathartiger Befteine Gerrüfren. Die Roblenjäure, gelöjt in Waffer, fojied aus biefen bie Riejeljäure ab; legtere wurbe vom $23 a f f e r$ fort= gefülyrt unto jammelte fich local an.

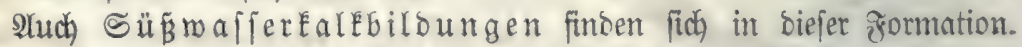

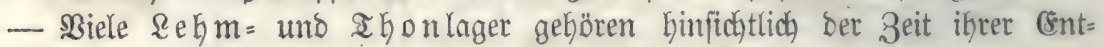
ftebung ber Diluvialperiobe an. Daffelbe gilt bon Snochenanthäufungen, bie fid in mandyen 5öblen finten.

Die Shejchöpfe Der Diluvialzeit find höher organifirte Arten; berichiebene Săugethiere von mitunter riejenmäß̈iger (Sröß̈e, beren Gebeine nodh jegt an bielen Drten ausegraben werben. Sallas fant in Den Eisablagetungen

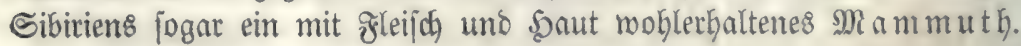


ฆ่เg. 36.

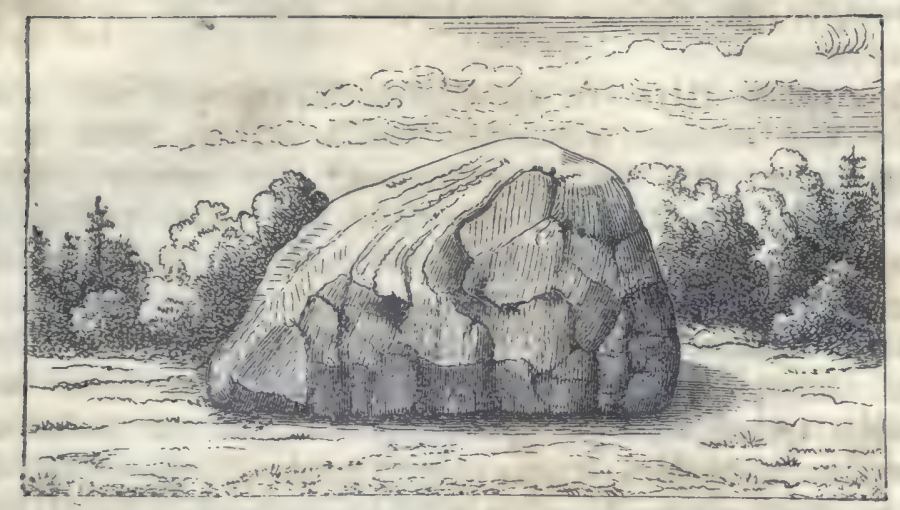

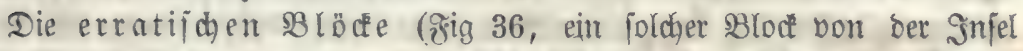

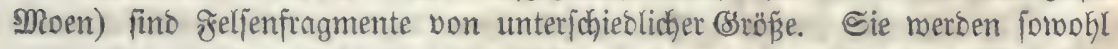

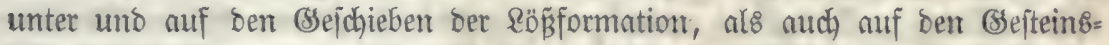
bildungen früferer geologiīcher ßerioben angetroffen. §ont immer fino aber bie Muttergefteine, bon weld)en fie ftammen, bon ber gegenmärtfgen Bager= ftätte biejer Blödfe meit entfernt. Co ift bie ganze Rorboeutiche Ebene

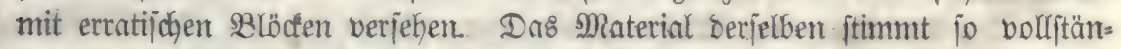

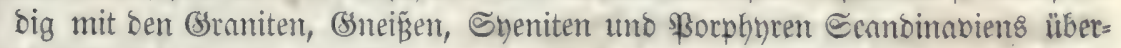

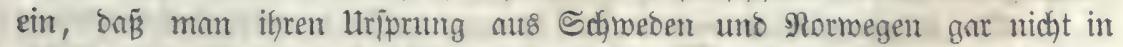

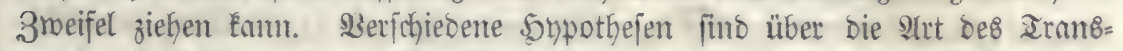
ports aufgeftellt morden. Die Beobndytung, oní in mandhen Ihälem. ber

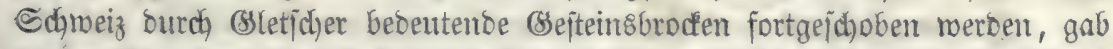

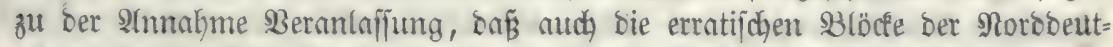
ichen (Ebene auf biejelbe 2 Seife aus Ccandinnvien hinmeggefithrt morben feien.

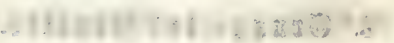

Bierter $\mathfrak{A} b$ fintt.

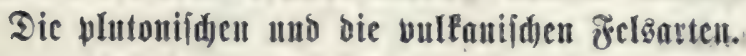

\section{Arrgeneites.}

Diejenigen そretzanten, meldhe ifren ltrprung aus einer feuerflüifigen Maffe herfeiten und babei enuptio auftreten, zeigen Keine regelmäsäige Ed)ich)= tung, wie bie neptunijd)en, ober audh felbit wie bie Erbjtallinijohen Schiefer=

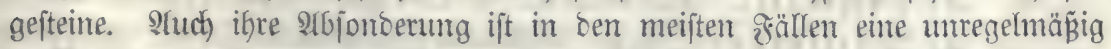

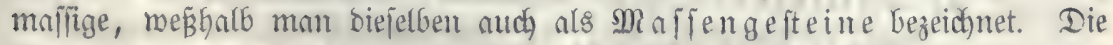

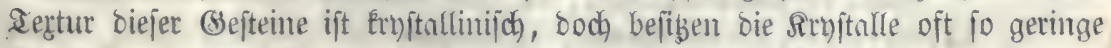

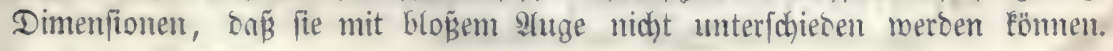




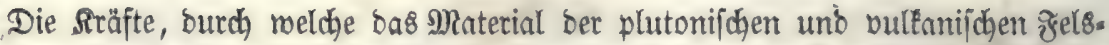
arten burd bie feite (soblenfte emporgetrieben nurbe, fino bereits Seite 4. angegeben worben.

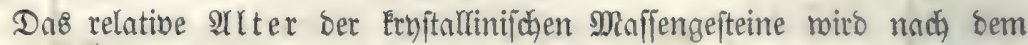

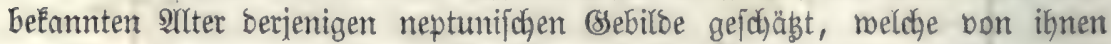
burdjejegt morben fint. Bei biejem Borgange fano entrober Sdjmelzung, ober Alufrichtung, ober Umitülpung Der lebtern itntt. Das burchlebte Bejtein

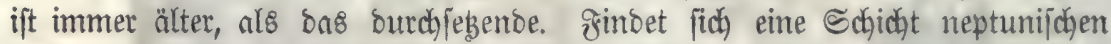
uriprungs über ein plutonifobes Sseftein gelagert, uno ift erftes von lebterm nicht Durdjorungen worden, fo ijt bas jebimentäre Beftein jünget als bas plu= tonifhe. Hebrigens fanten bie Sruptionen ber Sefteine legterer Art nicht

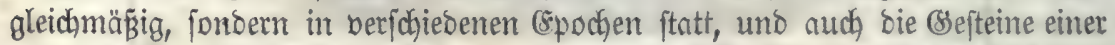

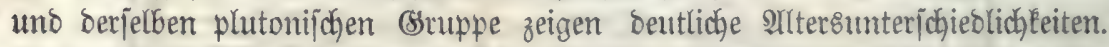
2luch bie Mafjengefteine Gaben fich mitunter gegenjeitig burdhjebst; man Gat

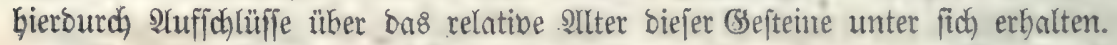

Die MRaffengefteine müffen, zufolge ifres IIrjprungs, frei pon \$setrefacten fein. Went man bennod, mandjmal, miemohl in jeltenen fällen, Berfteine=

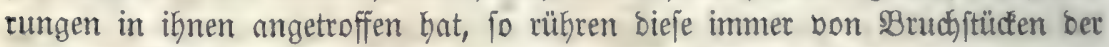

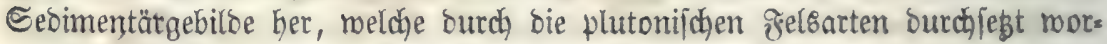
ben fint.

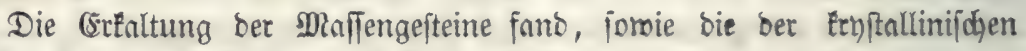

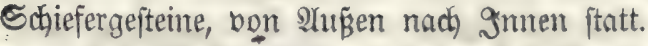

Die Maffengefteine nehmen im Banzen nicht jo ausgerureitete Bebiete ein, alo bie feoimentären Bsebilbe. Dft treten fie nur in Etöcfen ober Bää= getr auf.

In bem folgenben merben wir nun bie einzelnen plutonifchen uno bul= fanifichen Felsarten nad) ifrem alter abhandeln, wobei roir von ben zuerft gebildeten zu ben jüngern übergehen.

\section{2. (5)}

In bieje redhnet man brei §̧elsarten, beren relatibes al(ter nod nich)t gebörig ausgemittelt rooben ift, ben seanit, Syenit uno (5) ranulit.

a. Der Granit.

\section{c. Buiammenfeвung.}

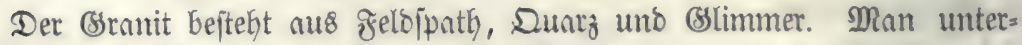
jolseibet folgento Mrbarten:

1) Brotogyn. (sr enţält anle anftatt bes Blimmers.

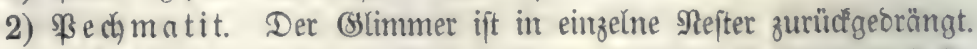

3) Sd)riftgranit ift ein \$echmatit, in weldgem Duarz und gelds

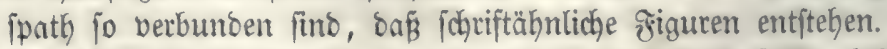

4) Breifen ift ein (Sranit, in weld)em ber geldipath fehlt, bejteht aljo blos aus Dunrz uno Blimmer. 
Der Branit erfheint grob = uno feintërnig. Dft treten einzelne Sirns ftalle in fo bebeutenden Dimenfionen Gerbor, Dan baburdy bas Beftein ein porphbrartiges 2njehen erfält.

\section{B. Betbrettung.}

Der Branit furbet fich in Deutichland in Den Arpen, im Siejengebirge,

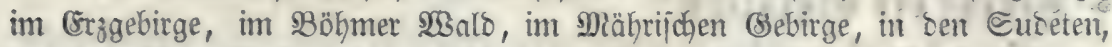

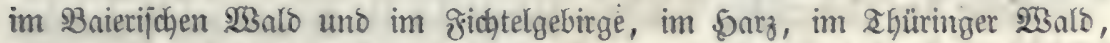
im Spefiart, Doentwald uno Schmarzmald.

\section{j. Wergformen.}

Diefe find höb)ft mannigfad)er 2rt. Im Allgemeinen bilbet ber Branit Sn, mo er mit bebeutenoen Maffen auftritt, plumpe, abgerunoete Berge; nlif biefen aber uno ba, wo er nur in Element Parthien erjobeint, zeigen fich

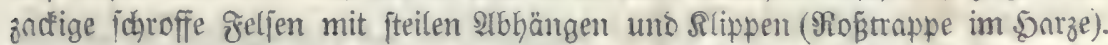

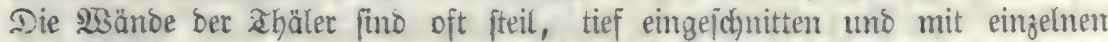

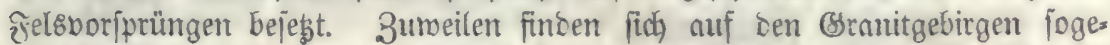

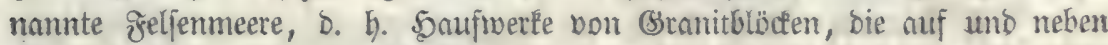
einander liegen, wie im Fichtelgebirge, im \$B̈hmermalb u. F. w. Sibgerum= bete Blöcfe biejer 21rt nemnt man audh 230 olljäcfe. Die Branitberge: fint ge= möhnlich) mit jogenanntem (sranitgrus bebeçt, b. i. in Eleine Erocfen zer= fallener Branit.

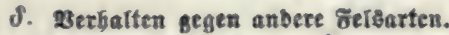

Bon (Branit fund mur bie ältern Sebimentärgeftente (nevfit ben Erluft

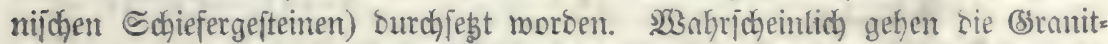

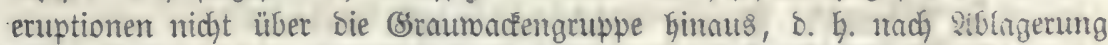
Siejer Sruppe fyörten bie Sraniteruptionen auf. Daß̉ ber Sranit bei feinem Derbortcetent an bie Eropberflädje oft ichon jo meit abgefiilflt war, um

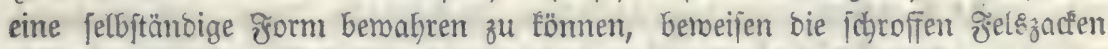
auf ben Bsipfeln vieter Berge. Dann hat ber Branit aber audy mieder in

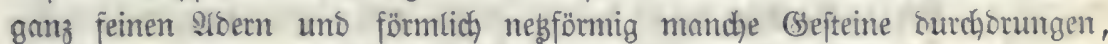
mas mieber auf eine Dünffüffigkét zur Zeit jeiner ßerbreitung in siejen Bse=

ftemen Ginbeutet. Durchjebungen von (Braniten burch Branite gehören - fei=

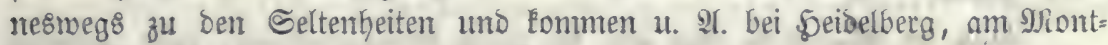
blanc (Durchjesung von (Sranit burdh Protogin) nor.

\section{b. Der eyentt}

$\alpha$. befteht aus zeldipath und 5ornblende. Durd siuptatinte

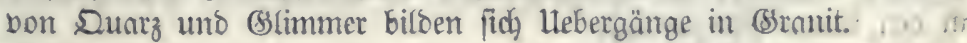

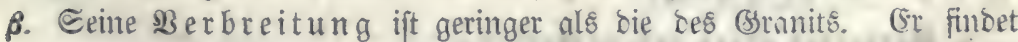

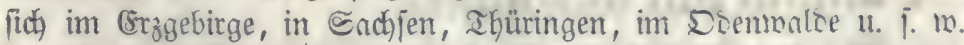

$\boldsymbol{\gamma}$. Die Bergformen bes Syenits furo einfacher als bie bes (Sranits. (sin Feljermeer von Branitblöefen findet fids bei ileidgentonch im Soentwalbe. 


\section{$\therefore$ e. Det Gratult}

enthält blos gelbipath uno (s) limmer, häufig aud seranaten, und be=

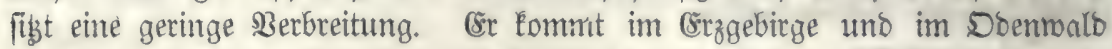
(Barlebajen) vor. Der Branulit konjtituirt nur bügeligę \&ano.

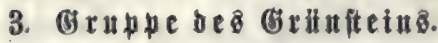

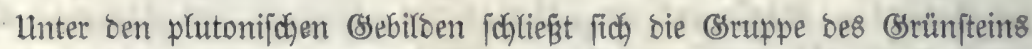

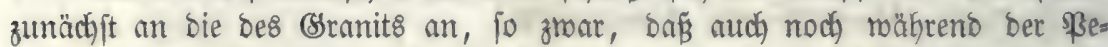

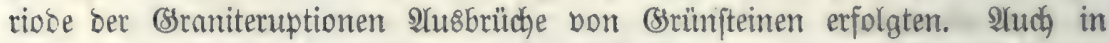

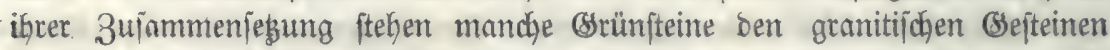
(insbejontere Dem Syenit) jefr nafe.

\section{- Die Gefteine ber orŭneingruppe finb folgenbe:}

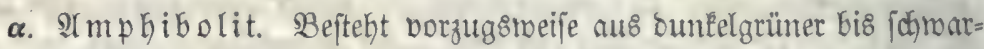

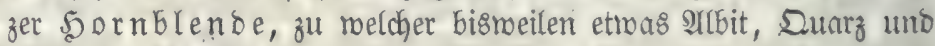
(S) immer Ginzutommen.

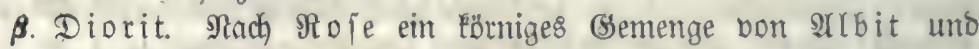
Sornblente.

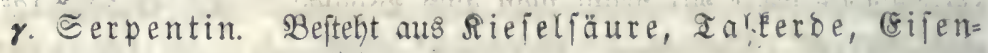
orybul uno 20 affer.

d. Babbro. Rörniges 2lggregat aus \&abrabor ober ๔auffurit und aus Diallag oder Smaragoit.

e. Syperit. Enthält Syperithen uno $\& a b r a b o r$ in Eörnigen semenge.

ร. EElogit. Entbält Smaragoit uno (sranat.

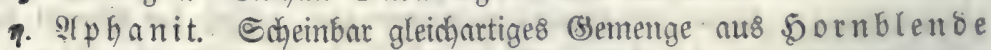
unu atbit.

4. Diabas ober eigentlicher (Grünftein. Sïnige8. Semenge

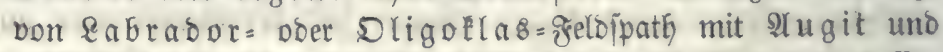
(5) hlorit. Bine stbart bes Diabajes ift ber Sd)alftein, bon beffen

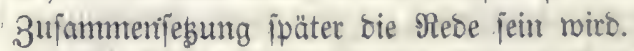

\section{b. Berbettung.}

Nuch) bie (sinunfteine fino über bie ganze (Ẽtoe verbreitet, boch nehmen fie nicht jo bebutende Bsebiete, wie bie Befteme ber Branitgruppe eir. Eie

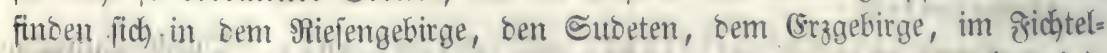
gebirge, in 5anrz, im Noobargebirge, im Doenmald, in Naffau (હchalitein), in Sen alpen (Eerpentin).

\section{c. zerbalten begen anbere cefteine.}

Bon ben (stünfteinen find nadyweistidy bie frtytallinifdyen edjieferge=

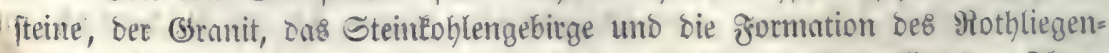
Den ourdjeght moroen. Sehr merEmüroige Beränoenungen erlitt ber Thon= 


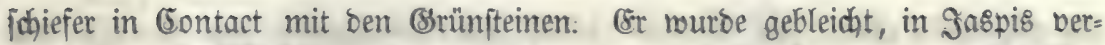
mantolt unt vielfad) gebogen uno gemunten. Dabei brang ber heipfiüjige Srünftein oft in ganz Dünnen Ramellen zmijhyen bie Engen bes shonichiefers ein. Salé, in Berührung mit Brünfteiu, nahm kryjtnlliniīches Bsefüge, ๔ant= ftein bie bei bem Brünjtein bäufige majîtge, Enollige, kugel= unঠ jäulenförmige

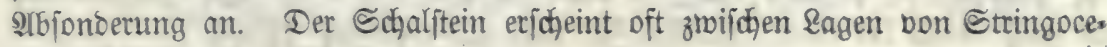

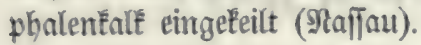

\section{d. gergformen.}

Die Brünfteine treten über Der Crebe jelten in größ̈ern Maffen auf, jons bern fommen mehr in Eleinen Ruppen zu Tage. Dagegen find viele andere gSefteine, namentlich Erbjtallinifche Edjiefergefteine, burch (brünftein geboben worben, uno es ift in biejem Falle bie Dberflädjengeftaltung burdh bie Brün=

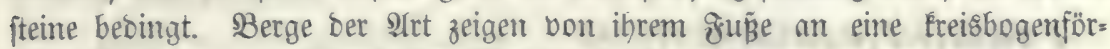
mige Afnjteigung, währeno ben (Sipfeln bie (Beitnlt von flachen Siegeln eigen

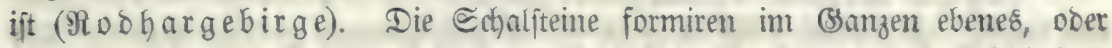
Doch nur bügeliges Rano. Der Gerpentin foll in $\Re$ ǘtand uno Sibirien Gebeutende Berge zujammenjeben.

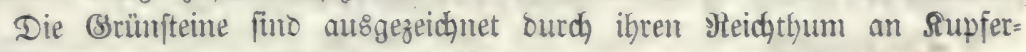
unc (sijenterzen (

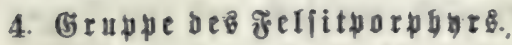

a. Bufammenfesung.

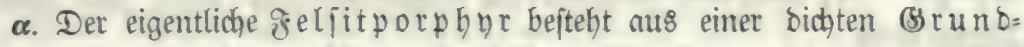
mafie uno aus eingemadjenen Strytallen (Einjprenglingen). Die (Snumbmaffe ijt ein joheinbar gleichartiges, hödjit inniges Bemenge von gel bo ipath, Quarz uno Blimmer, bie Einjprenglinge bejtehen aus Rrtjtallen von benjelben Mineralien, aljo gleichfalls geldjpath, Duarz uno sstimmer. Se nadjoem eintes ober bas anoere bout biejen borferridt, nent man ben \$orphyr: Felo/patfporphyr: Duarzporpfyr, (scimmerporphur.

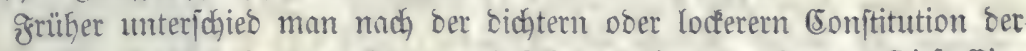

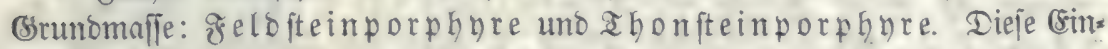
theilung muß terung beruht, fallen gelaffen werden.

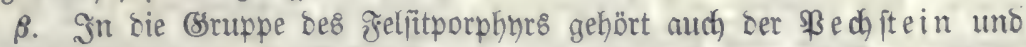
gachfteinporphyr. Dieje befteben aus ber in eiranoer gefloffenen Maffe Des \$porphurs.

Die Porphnte fino jebr mejentlich charafterifitt ourdy bas Bortonmen von oft ungebeuren (5onglomeratmaffen, meldhe entitanden find ourch (Sinmir= fung ber SBorphyre auf febimentäre Bejteine. So bejteht das Eonglomerat im Schrorzmallo und ben Bogejen aus Broden von Porphys und rothem Sandjtein nebft rothem ahon. Diejes Cónglomerat geht ganz unmerflida in 
ben Sanbftein über. In Sahjen bejteht bas (5onglomerat aus ßorphtre und

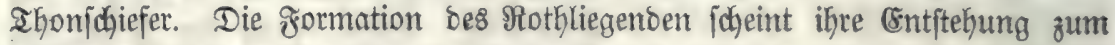
größ̈ten Theil den \$porphyren zu verbanken.

Die bei ben \$orphyren gewöbulityen शrbjonberungsformen finto neben ber maifitgen bie kugelige, plattige uno fäulenförmige. (58 giebt Săulen von

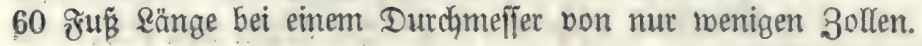

\section{b. 28еxвеitung.}

Der Borphyr findet fich allenthalben, boch felten in grö Bern zulammen= bängenden Bebieten. In ben Allpen, in Tyrol, im Sdjwarzmald, ben $\mathfrak{B D}=$ geien, an ber Nake bei Ireuznach, im Doenmald, im Shüringer NBald, im

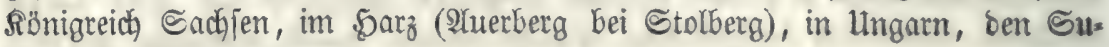
Deten, im Riejengebirge.

\section{c. Berbaltenzu andern eefeinen.}

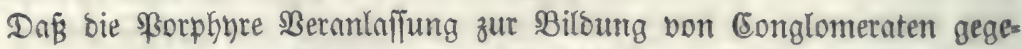
ben haben, ift joeben ermäbnt roorben. Durdjegzungen anorer Bejteine bon Seiten bes Sforphyr. hat man bielfach beobad)tet uno zmar beim Branit,

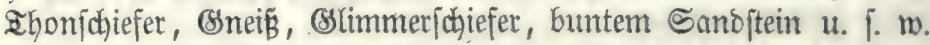

\section{d. Bergformen.}

Der \$orphyr bilbet feltent abgerunbete Berge, fondern meift einzelne

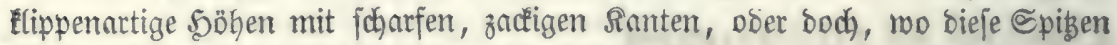

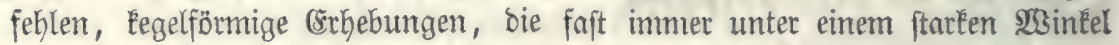
anfteiger. Dis einzelnen \$orphyrberge erjheinen sabei ijolint und ohne $3^{u=}$ fammenţang.

\section{Grapde bes grelaburs.}

\section{Bufem menietgug.}

2uch ber Melapfyne befteht aub einer (srundmaffe uns aus Ein= iprenglingen. Ueber erftere ift man nod) nicht redht im Rlaren. Sie foheint

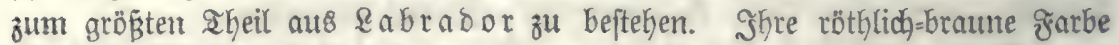

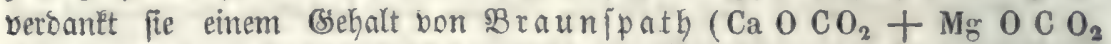
$+\mathrm{Fe} O \mathrm{C} \mathrm{O}_{2}$ ). Sit fie grüntolich gefärbt, fo rührt bies bon (5 hlor it Ger.

Die Eimfprenglinge fino wakrideinlich nur \$roducte ber Bermit= terung. Sie bejtehen aus Braumpath, Salefpath, Sdjweripath u. โ. w. und fommen in form von Manbeln bor. Dex Melnphyr ift ftellentweife vollftändig

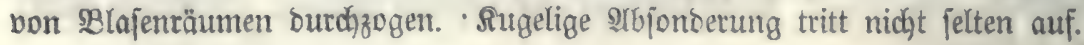

\section{b. Bexbeitung.}

\$n ben ausgebehnteften Mafjen commt ber Melaphyt in ben 9lpen bor, wojelbft er viele febimentäre (sefteine gefjoken bat. (5r fteht bort in

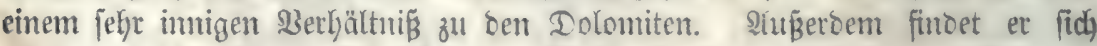

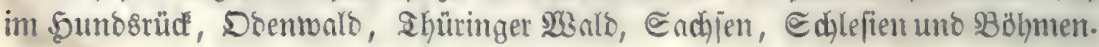




\section{e. Bergformen.}

Sn ben झlpen bildet ber Melaphyr ba, mo er zu Tage tritt, anfehnliche, abgerunoete 2 Berge. Sm übrigen Deutichland nimnt er meift ebne Engen ein, aus benen fid einzelne Suppen erbeben.

\section{Du}

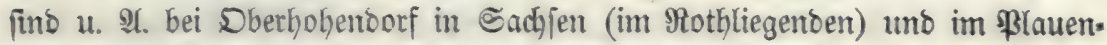
fhen Brunbe bei Dresben (im Styenit) bemert norben.

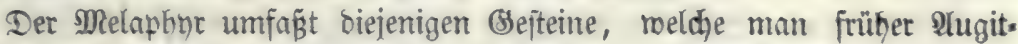
porphyr, Manbelitein, Irapp, arappmandelitein genannt hat.

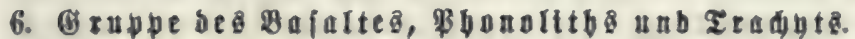

\section{- Bafalt.}

\section{a. Bufammenięุung.}

Rach neutert Unterfudungen befteht ber Bajalt aus \&abraborfelb. ipath, Augit, Magneteijen uno einem wafferbaltigen abonerbea

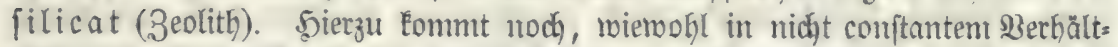

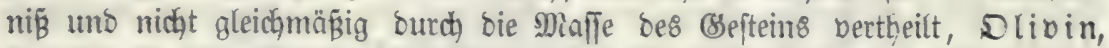
ber jomohl in miErojcopilich Eleinen Sartifeln, als in slumpen von ber

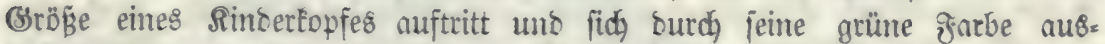
zeidynet.

Der 3 a jalt ift ftellemweije gantz uno gar ron mefye ober weniger grofien

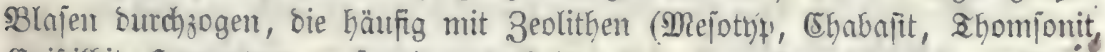

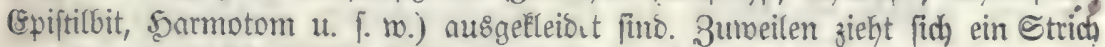
von größern Blajen burch das Elemtöcherige Gejtein binturdh.

3ig. 37.

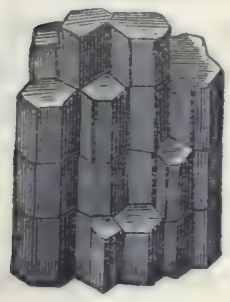

ঔig. 38.

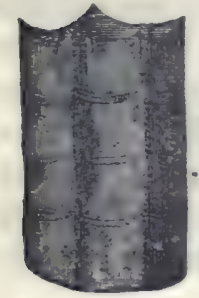

Dreten bie einzelnen Beftantotheile fo auseinans

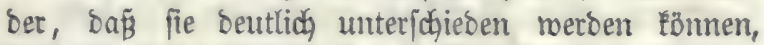
jo heipt bas Beftein Dolerit, fint pie bagegen

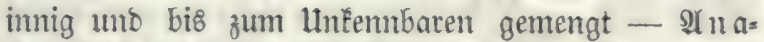
mejit. Nicht jelten ift $\Re$ ep Gelin ein ß3egleiter bes Dolerits (Rakenbucfel im Doentoald).

(Einte ber häufigiten $\mathfrak{A} b j$ onberungsformen bes $\mathfrak{B a}=$ faltes ift bie prismatij fäulenförntige mit fünf ober jechs હeitenfläd)en (ঔ̊ig. 37.). Die Didfe ber ธäulen idjmantt bon mentiger als einem 3oll bis zu mefreren

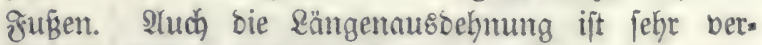
[ádiedent. Meift finto bie Säulen gegliebert, zumeilen

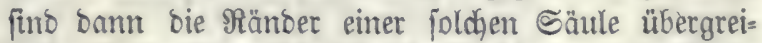
fend, jo baßi bie obere glädje berjelben eine Bertie.

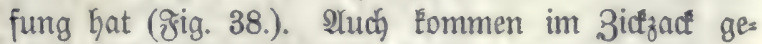
bogene Säulen bor. Die Säulen fteḩen nidat inmer fentredyt auf bie crtboberfläche, isnoern geben bäufig 


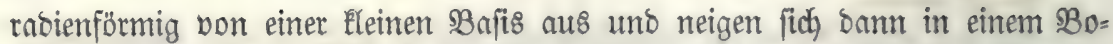

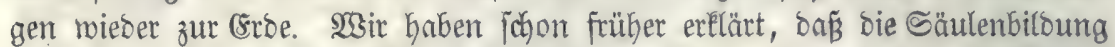

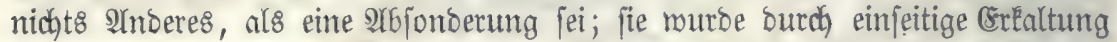
ber Keipfflüiflgen Maffe Gerborgenfen. Sntoeflen jegt bie fäulenförmige Arbjon=

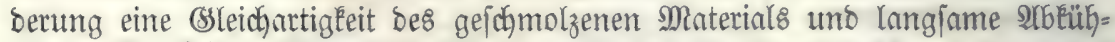
hung vornut. In Srtant unto Frantreich befteht bie Dberflärłye groß̈er \&än= berjtrecfen nur aus ben Röpfen folcher Bafaltfäulen; fie bildon bie pogenann= ten Riejentönme. Daß̧ ber Bajalt in Berübmung mit buntem Sanditein aud Den lebtern zur 2rbfonberung in Säulen veranlafste, Gaben wir bereits an

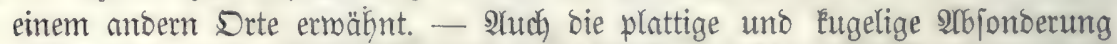
tritt beim Bafalte nicht felten auf; am Gälfigiten Eommt aber bie unregel= mäв̈ig maifige vor.

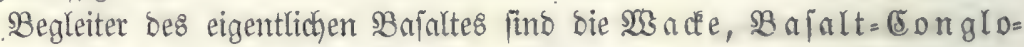

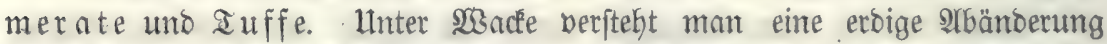

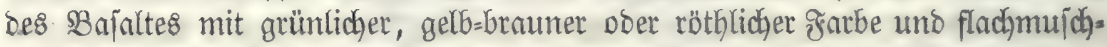

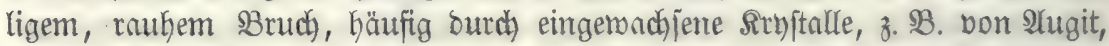
Magneteijen, Sstimmer, Sornblentoe, Jelojpath ein porphyrartiges Alus/ehen

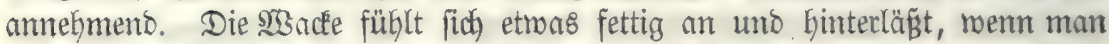

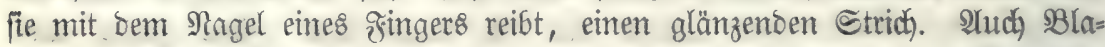
jenräume, zum Iheil mit Ralêppath, Irrngonit ober zeolithartigen Mineralien ausgefüllt, Eomnten in Der WSade vor. Db biejelbe eine uriprüngliche Billoung ober ein ProbuEt ber Bermitterung bes Bajaltes fei, ift noch zmeifelhaft. She=

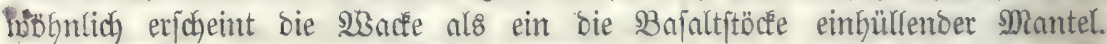
Sie conftituirt mitunter beträd)tliche sebirgsmaffen. - Der $\mathfrak{B}$ a $\{$ altt uff bat

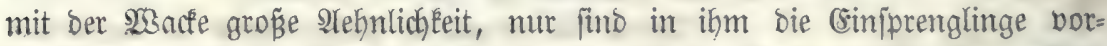
herrichent, uno bie 23 acke madyt nur ben Teig, burch meldyen fie berfittet merben, aus. Brryält das ßBindemittel bie Dberhano, jo geht ber হuff in

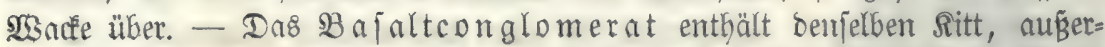

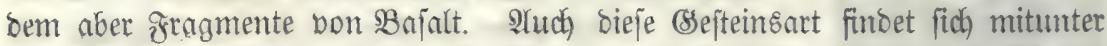

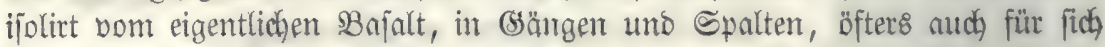
altein Heinere Berge zufammenjebend.

Der Bajalt ift bon Earbe Eohlichmarz, blaufdymarz ober grïmidmarz. Die blafigen Baritäten befiben gewöbnlich bellere (graue, röthliche) Färbung.

\section{B. Berbrettung.}

Die beiben größten $\mathfrak{B a j a l t l n g e r ~ i n ~ C u r o p a ~ b a b e n ~ b i e ~ S l u b e r g n e ~ u n d ~ b a s ~}$ Bogelzgebirge aufzumeijen. Afunerbem kommt ber Banalt in Eleinen Ruppen burch fait alle sebirge hin zerftreut vor. Sn größ̈̈erer Säuftigleit erjobeinen bie (Eruptionen bes Bajaltes in Dem (sebiete zwijchen Der (sifel uno Dem (Erz=

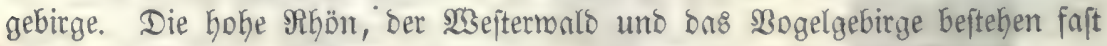
ganz aus Bajalt. Böbmen bejigt eine fehr groß̈e 3ahl von Bajaltéuppen.

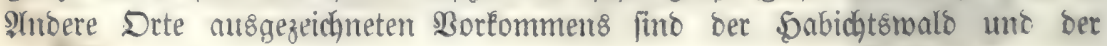




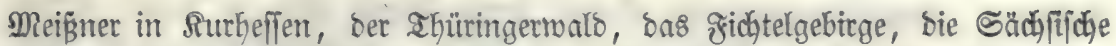

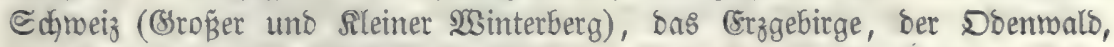
bas Siebengebirge bei Bom, die Eifel, ber Raijerftubl im Breisgau. - Der

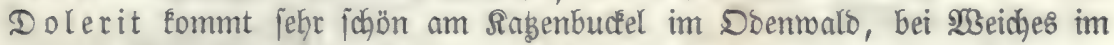

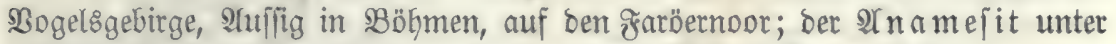

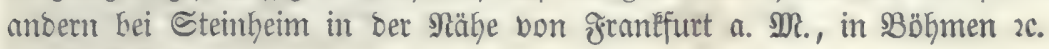

\section{$\gamma$. 3ergformen.}

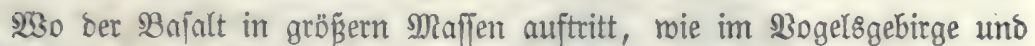

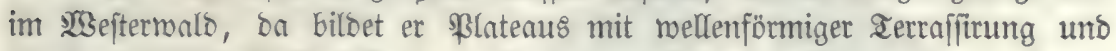
meniger atsgezeidhneten Exizen. Das ganze (Sebirge etjcheint als ein Rugel=

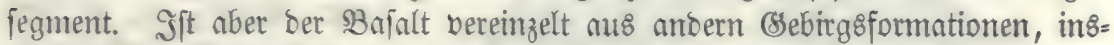
bejondere ben jeoimentären, Kerborgebroden, fo zeigt er eine bon ber borigen

§ig. 39.

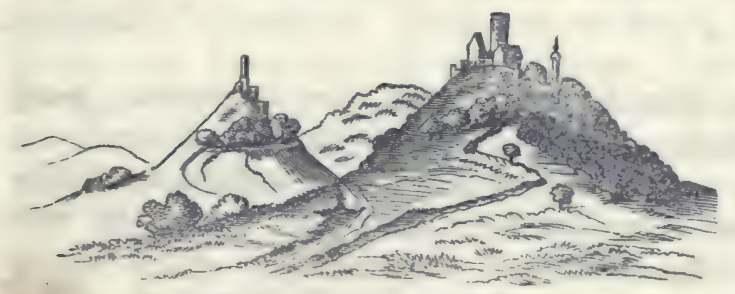

d. Berbalten zи anbern Oefteinen.

ganz verjofiebene bejtal= tung; feine $\mathfrak{B e r g e}$ finto nămliđa alsobann auffal=' lent kegelförmig (尺̊ig. 39, bie $\mathfrak{B a j a l t e ́ e g e l ~ ( s ) e i b e r g ~}$ und Beğberg bei (sieß̧en) und băufig ift beren Spige aus nad) oben bin cons vergirenoen Săulen zu= fammenge ejst.

Der Bajalt burchjebt alle jebimentären Schichten, mit 2Yusnahme ber Diluvialgruppe, ferner alle bis jest aufgeführten plutonijden Bepteine. (sriftere find bnourch an ben Berührungsftellen bäufig umgeänoert morben. Sand=

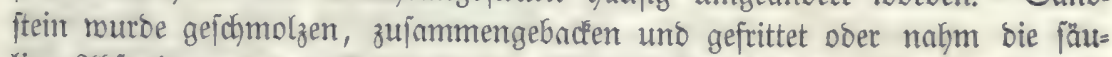
lige 216jonderung bes $\mathfrak{B a j a l t e s}$ an; Ihon und Sdjeferthon wurbe in eine ziegelartige, Ihonichiefer uno Sraumade in eine fteingutäbnliche Maffe ber= wandelt uno gleichfalls nidht felten jäulig abgejonoert, Braunfohlen berḱohlt.

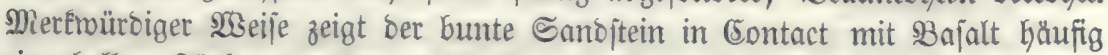

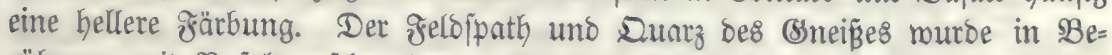
rübrung mit $\mathfrak{B a j a l t}$ gejchmolzen. Alte bieje Ihatjachen reijen umwiberleglich

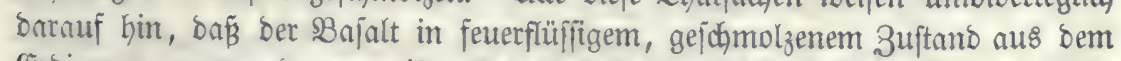
Sroimern emporgebrungen ift. Der Bajalt hat viele \&efynlickleit mit ber \&ava

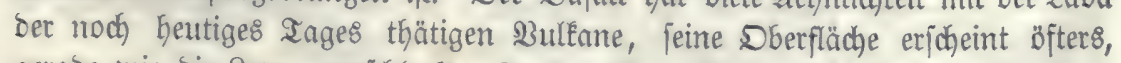

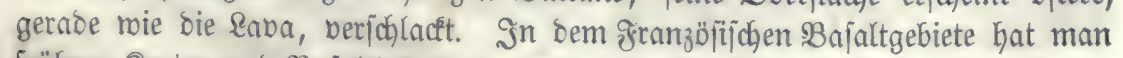

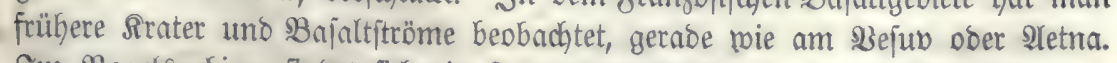
Im $\mathfrak{B}$ ogelsgebirge findet fich ein jogenanntes Feljenmeer, weldyes aus unge=

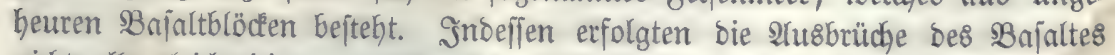
nidht alle gleidhzeitig; es laffen fidh berjobiebene Perioben in benjelben unter= 
[đjeiben. Durchjegungen bon $\mathfrak{B a f a l t}$ burch $\mathfrak{B a f a l t}$ fino an vielen Drten z. B. Bei Rauterbach im Srob̆herzogthum Seffen, aufgefunden morben. IUf bie Beziefungen bes Bajaltes zur BraunÉbhlenformation wurbe fdyon früher aufmerkfam gemadht.

ஓ̊ig. 40.

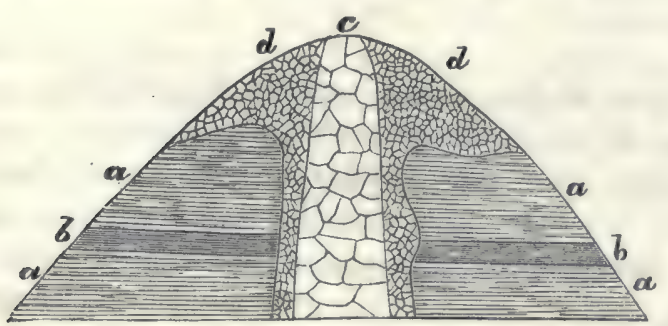

Ulı [pecielles ßeipiel für bie Durdjeģungen jeoimentärer Biloungen burdi $B$ a jalt fübren wir ben Biegentopf am 5abichts: malb ant $a, a$ in orig. 40 . be= beuten Brauntoblen = ałon uno Sano, b, b סas eigentliche Brauntoblenla: ger, c compacten $\mathfrak{B a}$ alt, d $\mathfrak{B a j a l t c o n g l o m e r a t . ~}$

\section{b. Wonolitb.}

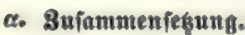

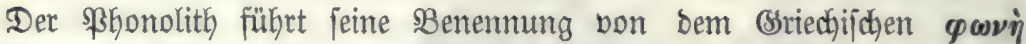
= Rlang und $\lambda l$ dos = Stein; zu Deutjch heist aljp Bhonolith Rlingftein; bieje Bezeidynung rührt babon Ger, weil bie \$latten biejes Befteins beim $\subseteq$ d)la= gen mit bem \$ammer einen bellen Ion bören laffen. (5r beftebt aus einer Sorunomaffe mit Sinfprenglingen. Eritere ift aus einem $\mathfrak{\Omega} a l i=\Re a t r o n f e l \delta=$ fpath und einem 3eolith zujammengejezt. Die Cinjprenglinge werben von glaftgem grelbfpath, Den man Sanibin nennt, gebildet. Dex \$hono: lith bejigt meift eine graue Jarbe, boch Eommt auch bie gelbgraue unb röth= liche bor. Sine für ben Phonolith bejonber8 characteriftijche 2lbjonberungs: form ift bie plattige; boch finbet fich aud) bie fäulige, kugelige ıno am häufig= ften bie unregelmäzig maffige Die \$Bbonolitbplatten find oft fo düme, baf́s fie, twie Sdjiefer, zum Dadbecken benubst werben. Drujentäume fino nur felten mit 3eolithen ausgetleibet.

\section{B. Berbreitung.}

Der \$honolith nimmt nicht jo bebeutente Strecten Ranbes ein, wie ber Bajalt; indeffen findet man ifn in einzelnen Ruppen burch bas ganze Bajalt=

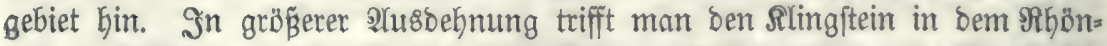

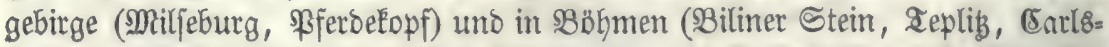

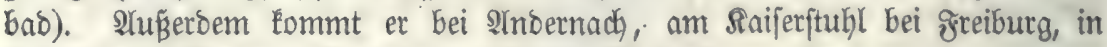
Sdjottlano, Ungarn, Spanien, auf Teneriffa u. f. r. bor.

\section{$\gamma$. Bexgformen.}

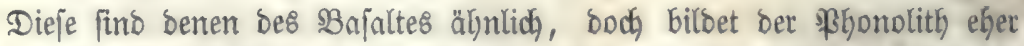

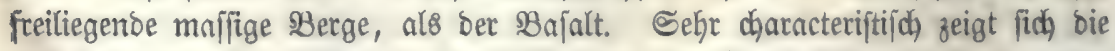
Bergform bes \$3honolith8 an ber Miljeburg; bon fern gejeben gleidit fie einem 


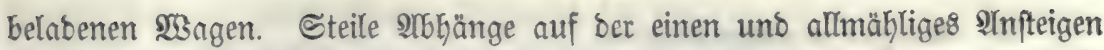

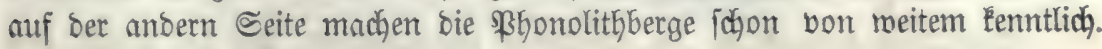

\section{d Berbalten au anbern Gefteinen.}

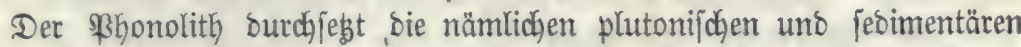

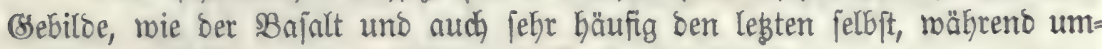
gekefyrt Durchjebungen von \$honolith burch Bajalt feltener vortommen. Des: balb if jener aud mabricheinlich in ben meiften öăllen bas jüngere Beftein. Sanbfteine unb Thone baben in Berührung mit bem Rlingftein bie beim $\mathbb{B a j a l t}$ bejchriebenen $\mathfrak{B e t a ̈ n d e r u n g e n ~ e r l i t t e n . ~ S u f f e ~ u n t o ~ E o n g l o m e r a t e ~ f i n t e n ~ f i c h ~ i m ~}$ \$̧onolithgebiet feltener.

\section{c. $\boldsymbol{x} \boldsymbol{r a n d t}$.}

\section{a. Buโammenfęุung.}

Die Srumbmaffe bes Tradyts befteht aus Magneteifen unb geldpath; in biefer finten fidh (siniprenglinge von Eanibin. Rebterer befigt zuweilen jegr

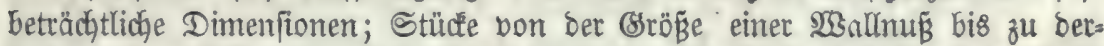
jenigen einer ßomeranze find nichts feltenes. Die garbe bes aradyts ift die nämliche, mie bie bes \$honolith8. Seltenere Bimprengfinge find \$ornblenbe

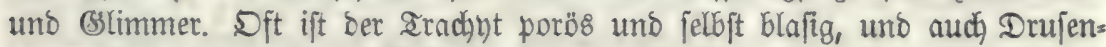

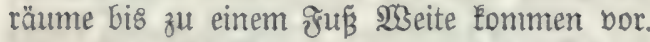

Die Nifonderungsformen bes Irachyts find bie unregelmäfig maffige, fäulige, platten = uno auch nohl bie Eugelförmige, bod) trifft man bie fäulige

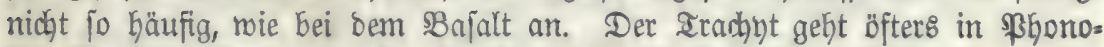
lith über. 2Uuch von Irachnt Eennt man হuffe und Eonglomerate.

\section{ק. Berbreitung.}

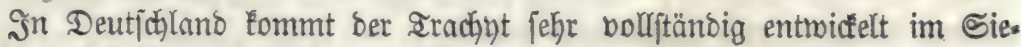

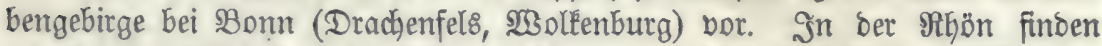

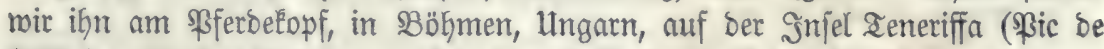

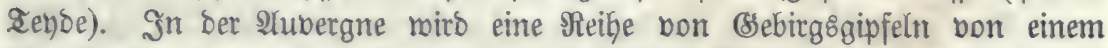
bem Iradint berwanten Beftein, bem Domit gebildet (Buth be Dome). Mit

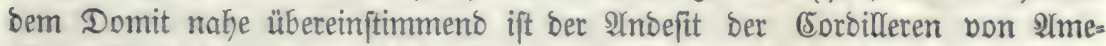

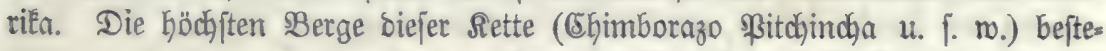

əิig. 41.

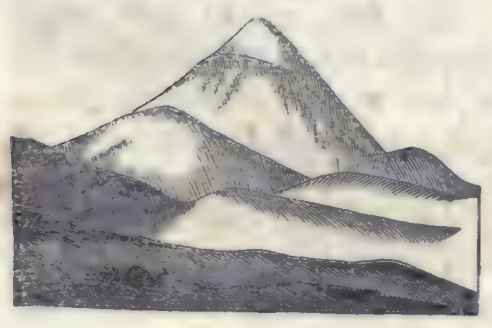
ben aus Alndefit. Aluch ber Dawalaggiri in Iffen foll ein sradbytberg fein.

\section{\%. Dergformen.}

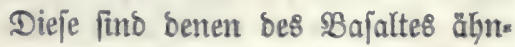
lich, nur mehr bom $=$ und glocten $=$ als les

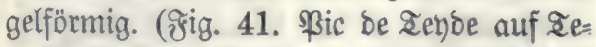

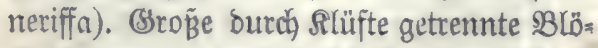
de Eommen ziemlich häuîtg im Gebiete bes Iradints vor. 


\section{Berbalten zu anbern Gefteinen.}

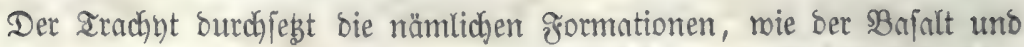

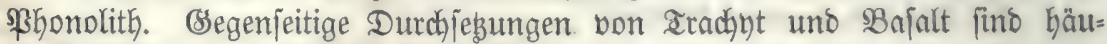
figer, als von aradynt uno .\$bonolith.

\section{7. 암ape ber $\mathfrak{B}$ It ane.}

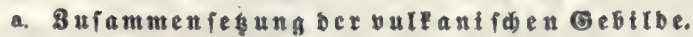

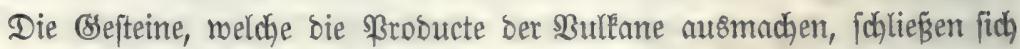
in ifrer 3ujammenjegung jehr nake an Bajalt, shonolith und Irachyt an.

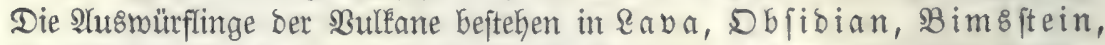

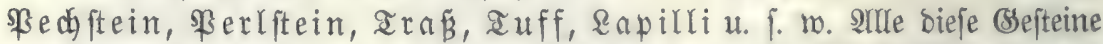
find Doppelfiticate von kiejelfaurer Igonerbe mit kiefelfauren arlkalien ober kie= feljaurem salf.

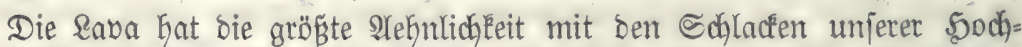
öfen. Der Dbfibian befibt bas Ânjehen eimes fdymarzen, auch robl blauen,

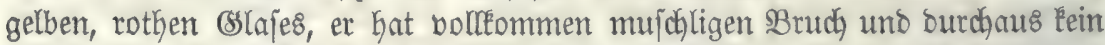

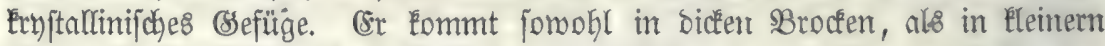
Sörnern bor. Dft ift ber Dbfitbian ganz und gar bon größern und Hleinern Blajen burchzogen; man nennt ihn alebann Bimsftein. Diejer fohnimmt wegen

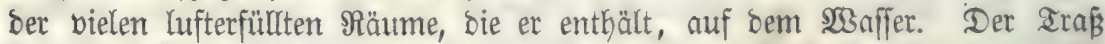

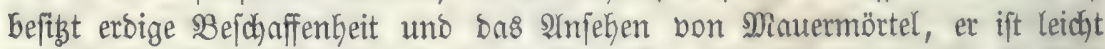
zerreiblich. Man Eann ifn als erbigen Iradyht betradyten. Die sapilli finto Fleinere Fragmente Der \&ava; oft befteten fie ganz aus 21ugit ober Magnet=

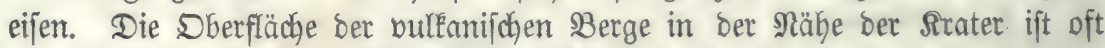

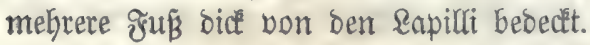

\section{b. serbrettung.}

Man untericheibet bie Bulfane in erloficene uno noch thätige. Bon lebteren finden fich in Deutfolano Keine; Dagegen hat man unzmeifellyafte

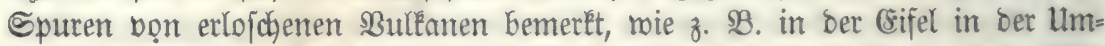

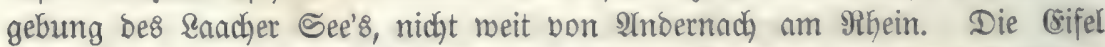

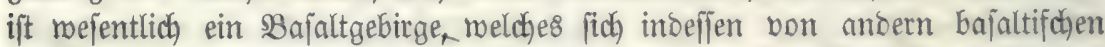

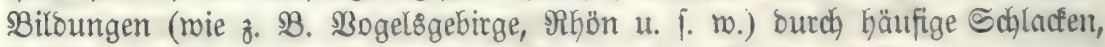
Dbfibian, Bimsftein u. \%. m. unteridheibet. Die Eifel enthält viele ausge=

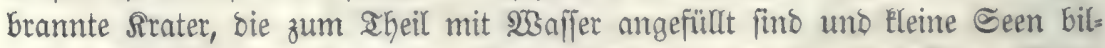

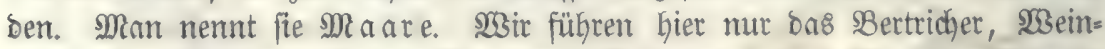

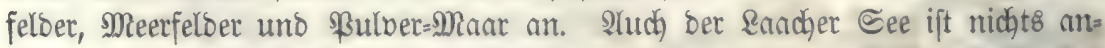
beres, als ein fold)es Maar. Bielfad) ift ber Boben in ber (sifel mit Sprün= gen burdhzogen, aus meldjen Sioblenfäure ftrömt. - (sin anderer bemerfens: wertber etlofhener Bulfan ift ber Sammerbühl bei \&ger in BB̈hmen. 2Benn

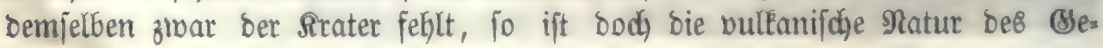




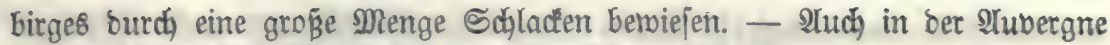

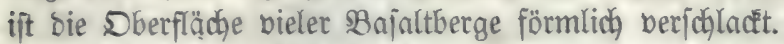

Bon ben nod) jest thätigen $\mathfrak{B u l f a n e n}$ unterjdeibet man nach ber 9 rt ihrer Berbreitung mieber (5entral= uno Reifenvulkane. Zu erfteren

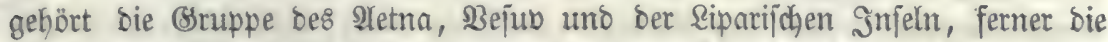

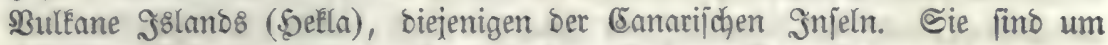

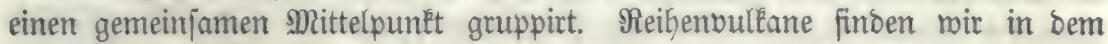

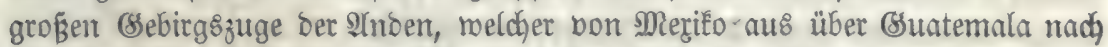

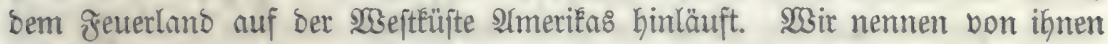

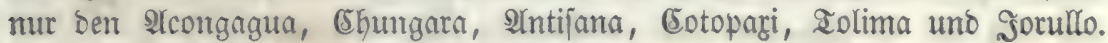
2uch die Snjel Sapan enthält Reihenvuléane.

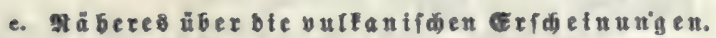

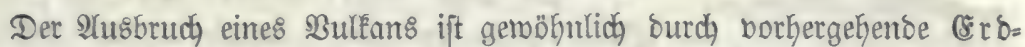
beben angebeutet, rolḑe in einer wellenförmigen (orkebung uno Sentung Der Grboberfläche befteben unঠ fich in Den meiften ₹ällen meit über Das von

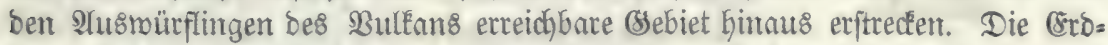
beben richten Gäufig bebeutende Beritörungen an. (Erobeben von Riffabon im Эabr 1755.)

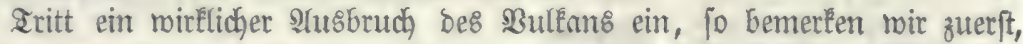

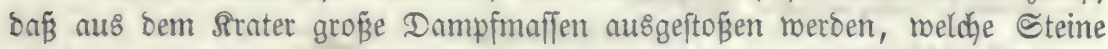

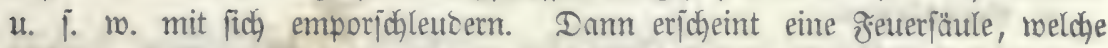
Göchit mabricheintich von entzünbeten brennbaren (Sajen Gerrübrt, Gierauf folgt

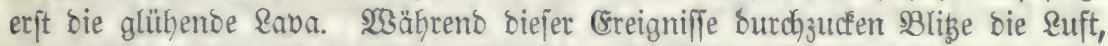

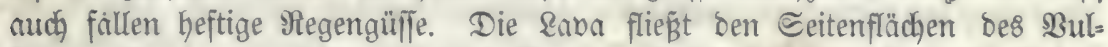
kans entlang uno erknitet erft nach längerer 3eit. Dft miro fie von ausిge=

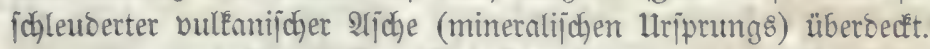

Die menigiten Bulfane fino fortwährent in IGätigkeit, oft bergeben von

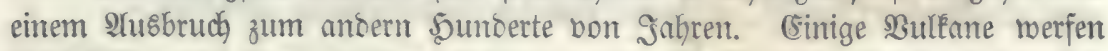

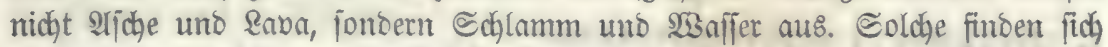

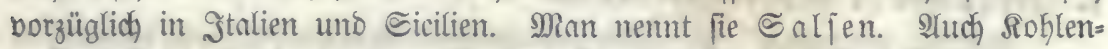

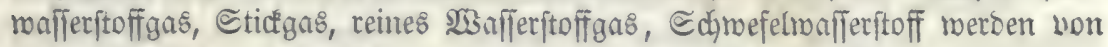
einigen $\mathfrak{B u l f ̈ a n e n ~ e n t r o i c f e l t . ~}$

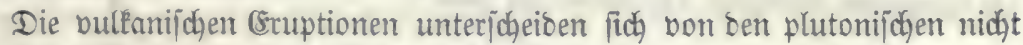

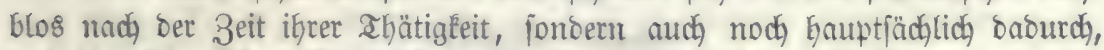

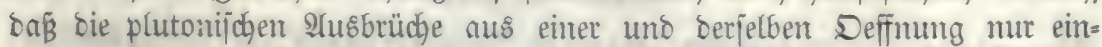

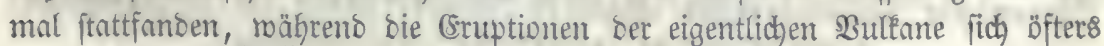
mieberholen.

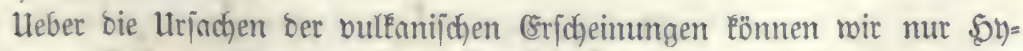
pothejen aufitellen. Da, wie twir päter fehen merben, bie 233 ärme von Der

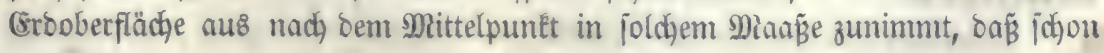


in einer Siefe von etra 12 Meilen fämmtlide Metalle uno aud bieñenigen

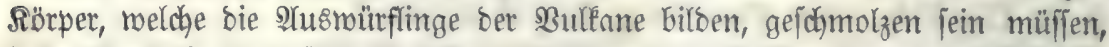

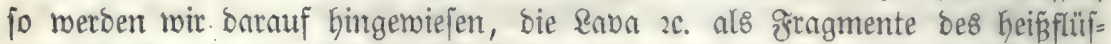
figen Ertberns anzunefmen. Die bebeutenten Duantitäten von 23 afferbampf,

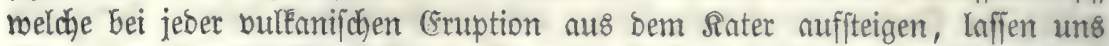

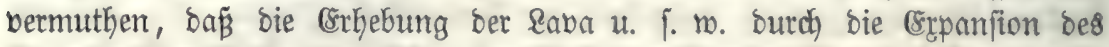

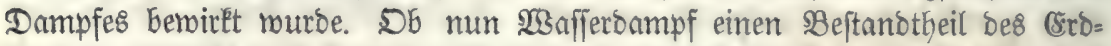

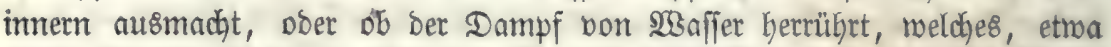
burdh Spalten, aus bem Meere u. 1. m. zum Geiß̈en (stoboben hirtabfickette,

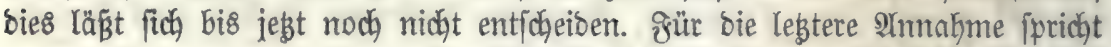

§ig. 42.

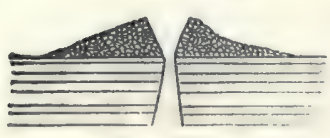

ஓig. 43.

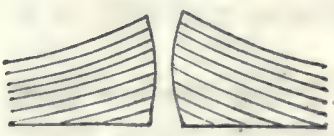

4. Bergformen.

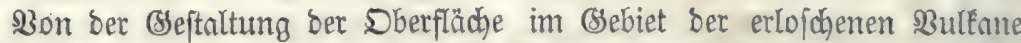
war bereits unter b bie Rebe. Die SSipfel ber ausgebrannten und noch thäs tigen $\mathfrak{B u l f a n e ~ f i n d ~ m e i f t ~ K e g e l f o ̈ r m i g , ~ a ̈ h n l i c h ) ~ D e n t e n ~ b e s ~ B a j a l t e s . ~ S f t ~ i f t ~ e i n ~}$ foldyer Segel nod) einmal mit einem Sall umgeben, gebildet burdh (sinfturz eines aheiles Der Siratermano. Bei den nod thätigen Bulfanen miro die (Seftalt Der Dberfäache Des Rraterberges bei jebem Sfusbruch Durch Sebungen

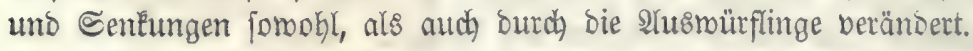

\section{Berbalten za a abern Befteinen.}

Bultane Durchfeben alle bisher betrachteten meptunijonen uno plutonichen

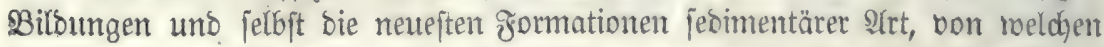
im folgenoen Albjhnitt bie Rebe fein wirb.

\section{Z̧ünfter 2tbidnitt.}

\section{Die auf bie Diluvialgruppe folgentben Berünternugen ber Eroblerflähtse,

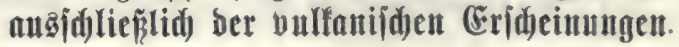

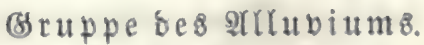

\section{Cinlettut th.}

Nach Der Ablagerung Der bebeutenden Manfen von Ries, Rebm, Rößs,

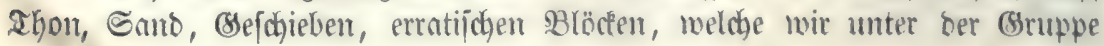


Des Diluviums betradjtet Gaben, war bie (Erobberfläche fortwäbrento neuen Beränberungen atsgejebt. Dieje ziehen fid) bis in bie gegenmärtige Zeit hin= ein - mann nennt fie Altruvionen. Dbgleich biejelben auf allen aheilen ber (Erboberfläche fich bemerken laffen, fo ftehen fie bod) in ber Bröfige bes Effect8 ben Beränderungen, weldhe bei ber Bildung ber bisher betradjteten

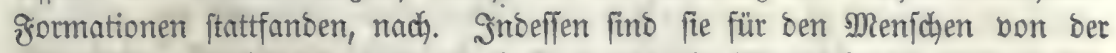

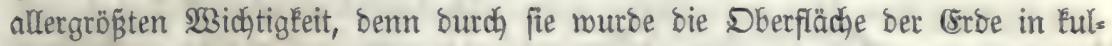

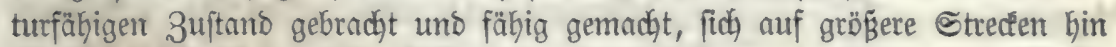
mit (serwächjen bebauen zu laffen. (88 ift bie Billoung bes 21cfer = uno 23alt=

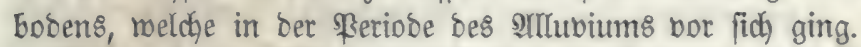

Der Boben ift ein \$robuct ber 3erfleinerung Der Befteine. Diejelfen fint im saufe ber 3eit in eine etoige, zerreiblictje, formbare Maffe zerfallen, in benen man häufig nodh orngmente bes Muttergefteins finbet.

Man nennt ben Frozeß, in Folgen beffen bie Felsarten in Boben ver:

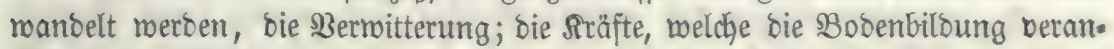
laffen, unterfdgeibet man in
a) medanifore ober phyitifalifice,
b) demijo uno
c) organifige.

Erfes Rapitel.

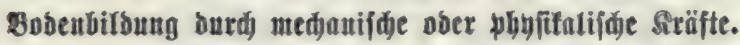

Unter ben phyfifalifchen Itäften, melche bei ber 3erfleinerung ber Bse fteine thätig waren uno es noch fino, fpielen bie $\mathfrak{S}_{3} a ̈ \mathrm{rme}$, bie Sdjwere und

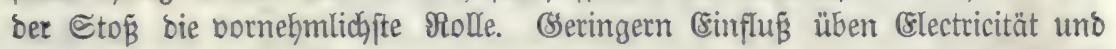
Magnetismus aus.

\section{WBirtung ber 2 ärme.}

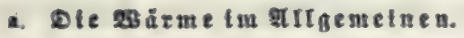

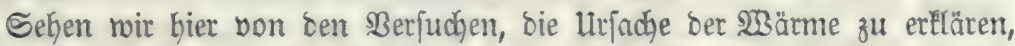
ab, unb balten wir nur iffe erjcheinungen in 10 meit feft, als fie uns bier

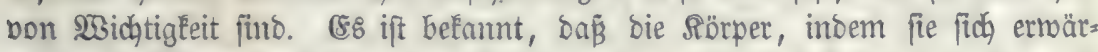

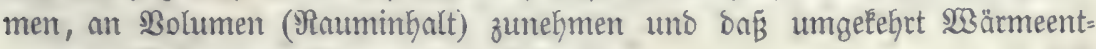

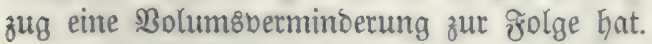

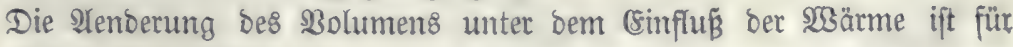
jeben Sörper eine andere. 
ซ̊ig. 44.

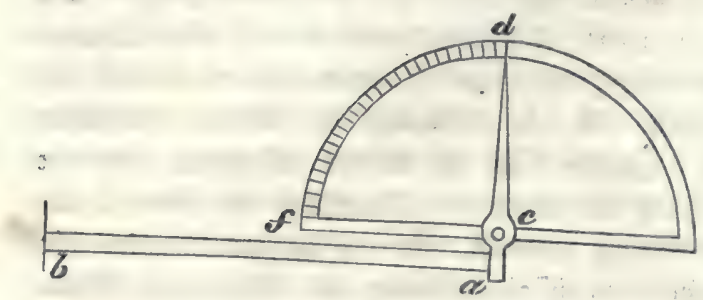

Um bie श̂turoehnung, meldje bie Rörper unter bem

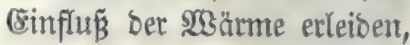
zu mefien, Eann man fich bes 2Tpparates (æig. 44.) bebie= nen. Der Rörper wirb in Form einer Stange a b zroi= fiden eine feite WBiberlnge b und Den Eürzern $\mathscr{N}$ trm ac eines S. Sebels gebracht, beffen

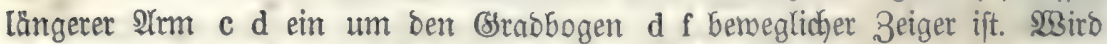
ber Sïrper a b erroärmt und behnt er fich nus, fo verjajiebt er mur ben Se=

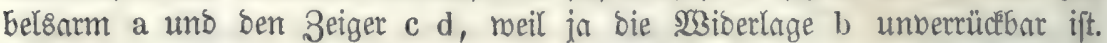

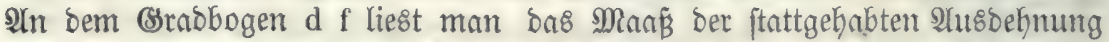

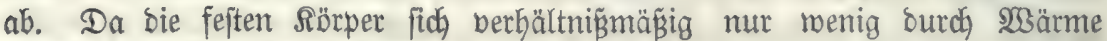
ausbefnen laffen, fo muß̈ man ben 3eiger e d recht groß̈ nehmen, Damit bie Bolumsvermebrung ftärker in bie 2hugen fällt.

Nach Der angegebenen Methode bat man gefunden, Daß̧ S5las von 0 bis $100^{\circ}$ (Eelj. erroärmt, um $\frac{1}{1200}$ feines urjprünglichen Bolumens fich aus= Defhnt. BBringt man aljo eine Bshasftange die z. BB. 1200 3oll Ränge bei ber Iemperatur bon $0^{\circ}$ befibt, auf bie Iemperatur $100^{\circ}$, fo bat fie nun eine Ränge bon 1201 3ollen. Die Bejteine befnen fich bei meitem nicht fo ftark

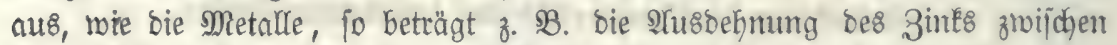

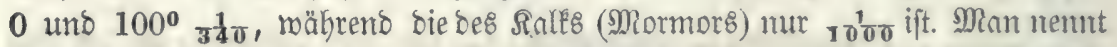
ben 3 Brutch, mit meldhem man bie urfprüngliche Ränge eines Rörpers multi=

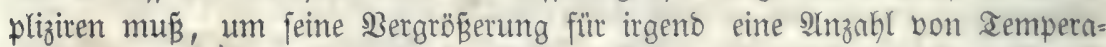

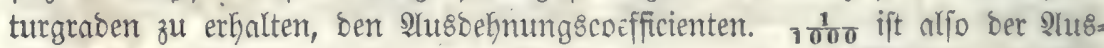
behmungscoefficient bes Marmors für sen Temperaturunterfhied von 0 bis 100 sraben.

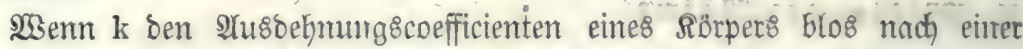

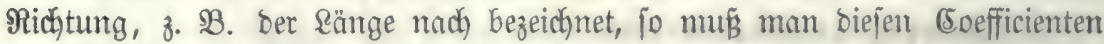
breimal nehmen, wenn man bie Aนtsofhnung bes Rörpers nad) feinem ganzen

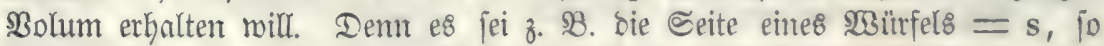

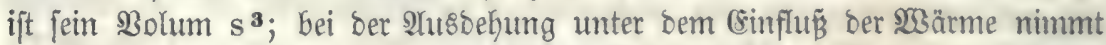
jebe Seite uno s. $k$ zu; ifre ganze Ränge ift bemund $=s+s k$ uno ons $\mathfrak{B O}=$ lum $=(\mathrm{s}[1+\mathrm{k}])^{3}=\mathrm{s}^{3}(1+\mathrm{k})^{3}=\mathrm{s}^{3}\left(1+3 \mathrm{k}+3 \mathrm{k}^{2}+\mathrm{k}^{3}\right)$.

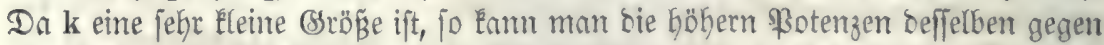
bie niebern vernad)läfïgen; es bleibt aljo mur $\mathrm{s}^{3}(1+3 \mathrm{k})=\mathrm{s}^{3}+\mathrm{s}^{3} 3 \mathrm{k}$

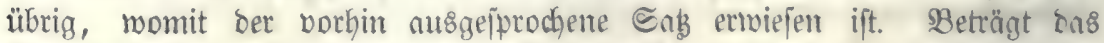
Bolumen eines 9Marmormilnfels 1 Rubifzoll bei ber Iemperntur vou 0 Bra= ben, uno wirb ber 233 trfel anf 100 Sirnoe erroärmt, fo nimmt fein Bohum unt 1. 3. $\frac{1}{\operatorname{sov\sigma }}=\frac{3}{1000}$ Rubilígolle ริu. 


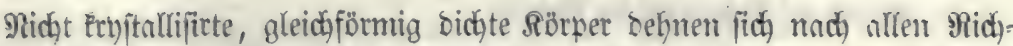

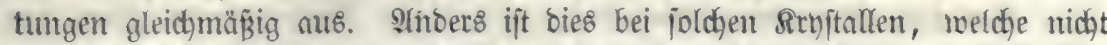

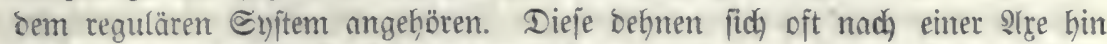

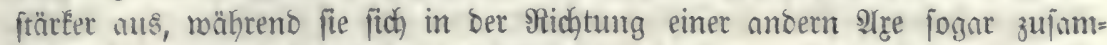
menziehin. Co behnt fich ber Saleipath von $0-100^{\prime \prime}$ in Der Richtung ber

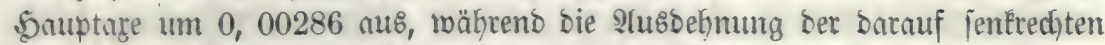

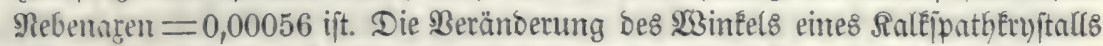
Enm baburch bis auf $81 \% 3$ Minuten anfteigen. $23 e n n$ man eine gemöhnlidye Sd)we= felftange, roie fie im 5anbel vortommt, in Der Sant erwärmt, fo vernimmt man ein beutlidjes Siniftern; es rührt von ber ungleichen Nusbehnung ber

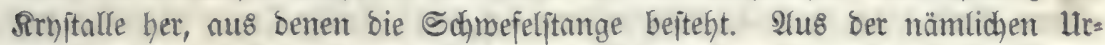
fache brechen fehr häufig bie Arren an Eocomotiven ab. Das uriprünglich

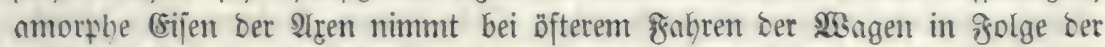
fortgejebter zitternoen Bemegung fryftallinijokes Gefüge an.

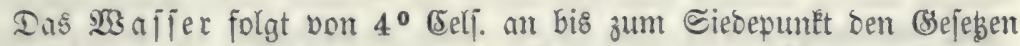

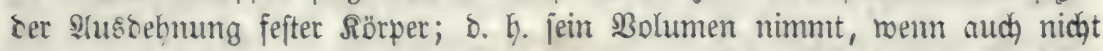

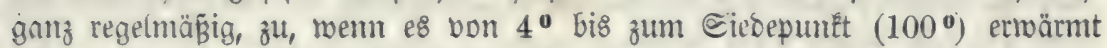
roiro. Dugegen zieht e\& fich, menn e\& unter $4^{\circ}$ erfältet mirt, nich)t meiter zu=

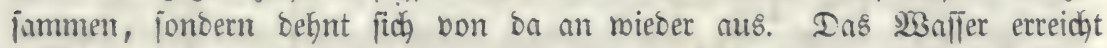

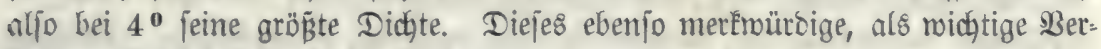

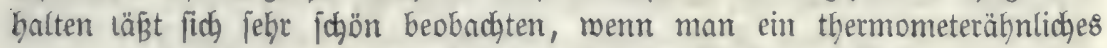

ซૈig. 45.

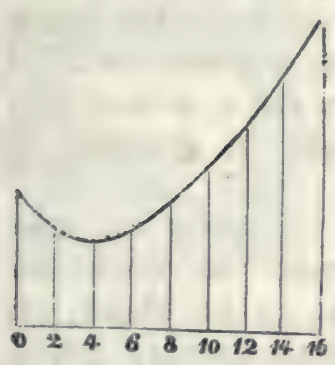

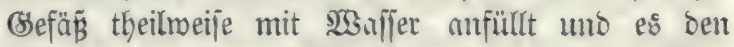
Iemperaturen bon 8 biš 0 Grenden ausję̧t. 23on $8^{0}$ bis $4^{0}$ fällt bas $2 \mathfrak{M n f e r}_{\text {, von }} 4^{0}$ bis $0^{0}$ jteigt es mieber in bie 5öhe. Die nebenturtehende Curbe

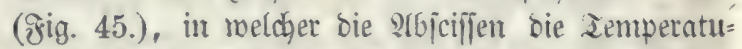
ren, bie Drbinaten bie benjelben entiprect)enden $\mathfrak{S B}_{\text {nIfer }}$

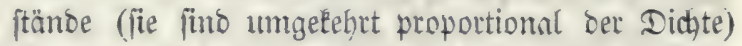

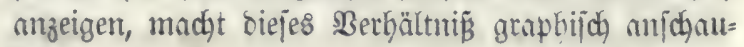
lich.

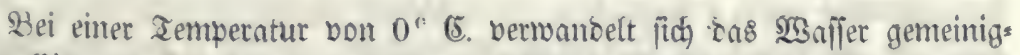

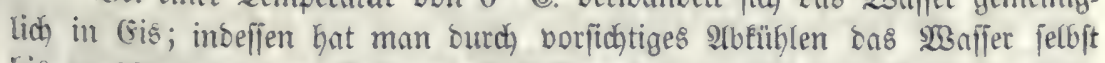
bis zu $10^{\circ}$ unter bem (Sefrierpunft flüffig erhalten. (Sis bon $0^{\prime \prime}$ nimmt einen

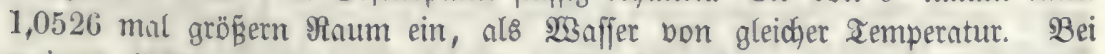

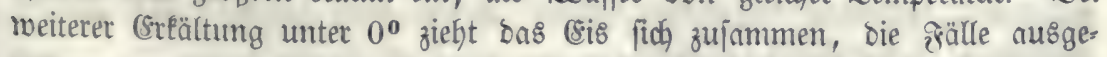

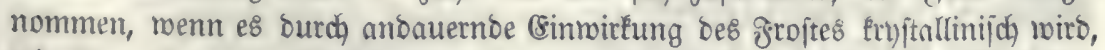

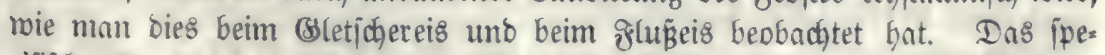

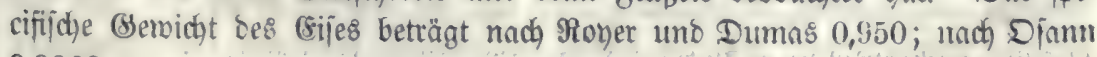
0,9268 . 


\section{b. Cinfu| Der :3ärme auf bie Gefteine.}

24u8 ben oben angegebenen (stidjeinungen bei Tempernturberänderungen

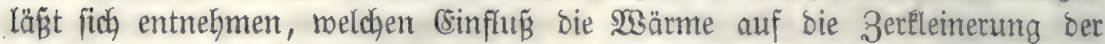

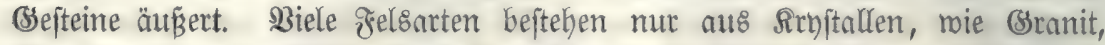

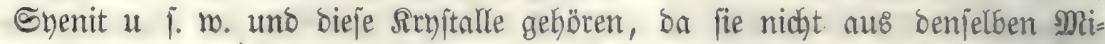

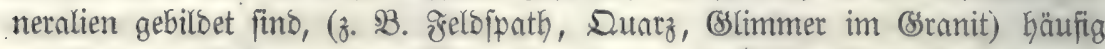

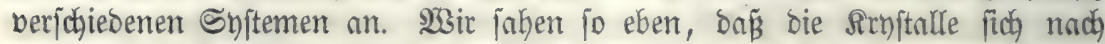
jeber Arge ungleich ausbehnen, roent ifre Iemperatur fid änoert. Da bieje Yusbefnumg mit unwiberftehlicher semalt bor fich) geht, fo mur bas (seftein berften. In ber IGat finben mir fajt alle grelsarten mit feinen Riiffen burch)=

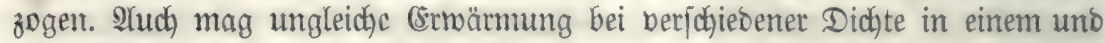
Demjelben Beftein bäufig Beranlafiutg zum Bntftehen von Spalten uno feinen

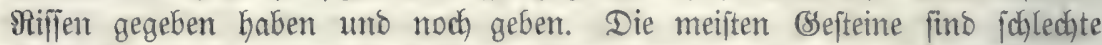

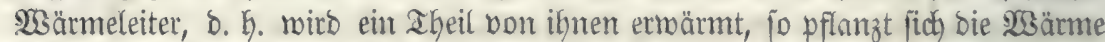
auf bie biejem zunädbft liegenten Theile nur langjam fort. Der wärmere Theil

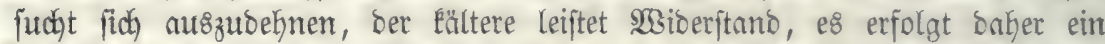
Beriten, geraos $[0$, wie wir es wafhnehmen, wenn wir ein gemöfnliches Irinté glas auf ben Keif̈en Dfen ftellen.

Bifdi of hat bie Borofität ber Befteine butch mefrere jebr finnreiche Berjuche nachgemiejen. (Er żerjalug einige Säulenbajalte vom Menbeberg bei

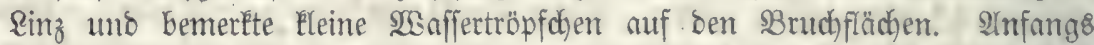
bermuthete er, eв feien Regentropfen, überzeugte fich jeboch jogleich, baßis bem nicht jo jei, benn ber Simmel war keiter uno bie Iropfent zeigten fich auch)

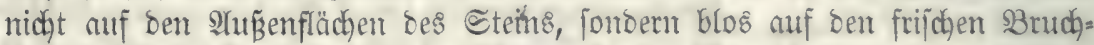
fläbyen. Sïggerath Eatte diejelbe Beobachtung an ben Bajalten bes Unfler

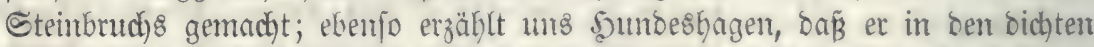

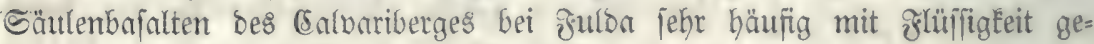
fütlé Drujentäume gejunoen babé.

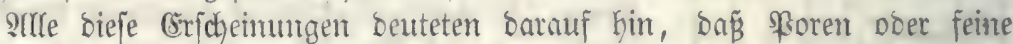
Epalten in ben $B$ afalten vorbanoen maten, surdy welche das sisaffer ein= brang. Bijofof unterfuchte mun auch) anoere (Bejteme, als ben Bajalt, auf ifre Borofität. Dazu bebiente er fich folgentoer Reaction. Ia er bie Bemer=

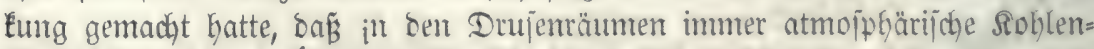
fäure fich anjammle, fo übergon er bie (Sefteine, welche er auf ifre Forofität

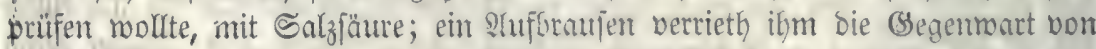

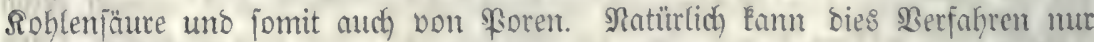
bei foldhen (Sefteinen angemantot werben, meldhe nidht ichon in iffer 3ujam= menfeb̧uı Soklenfäure enthalten.

Gine anbere, von Bijchof angegebene Methode, um bie Forojität ber sefteine nachzumeifen, ift folgende. (Er legt bie Ctüufe in ein mit jelir ver=

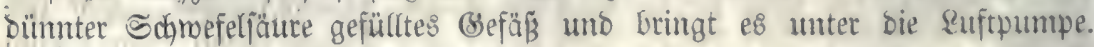

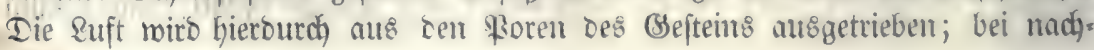


berigem Sinzuleiten bringt bie burch ben \&uftorud gepreşte Säure mit Be=

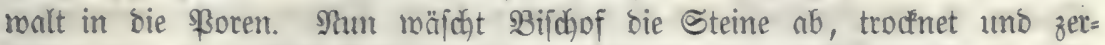

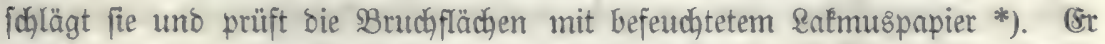
hat jo gefunden, dañ bie Iradhnte bes Ciebengebirges bis auf $1-1 \frac{1}{2}$ 3oll Diefe bon ber Cäure butchbungen rutroen, aljo porös waren.

Sudfom bat nach einem andern Berfahren ben Sibiriichen Sdyriftgranit uno aus Dem Granit bon Rarlsbå ftammende Exemplare von Felojpath, meldhe augen noch ganz gejumb uno frijo eridgienen, unterjucht uno nud in biejen feime Riffe gefundent.

23ie wir in ben vorigen arbichnitten gejehent haben, fino einige Beiteins: arten (8. B. Melaphur, BRãalt, Bhonolith, Irodgnt, Dolerit u. i. m.) mit Drujentäumen berjeben, welche fịch iohon bei ber urnfänglichen Biloung

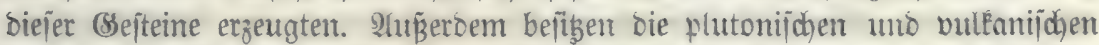

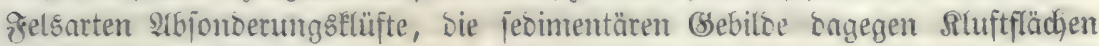
grvilidyen ben Sdyidhten.

Somokt in bie feinen Piffe, als in bie Mtbjonbetungs = unt Sdjichtungs:=

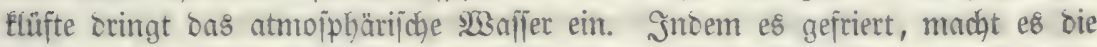
Sejteine berften. Der Borgantg ift folgenter.

ìg. 46.

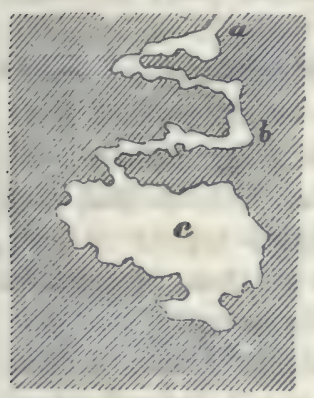

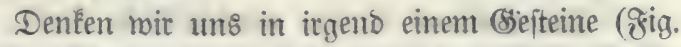

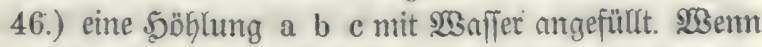
bie Iemperatur ber \&uft finft, io merden zuerit bie äusern Ragen bes ๔teins, bie ber \&uft zunächit aus: gejest find, abgefüblt; bas $\mathfrak{B B} a f f e r$ gefriert baher zu=

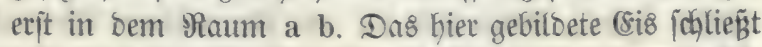

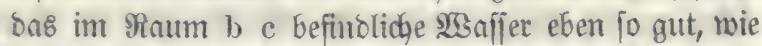
bie fteinerne $\mathfrak{S B}_{\text {and }}$ ber Druje ab. Schreitet mun bie Rälte nach Dem Imnern bes Cteins bor, fo gefriert aud bas 23 affer in be und Debnt fid babei, wie wir. miffen, 1.0526mal aus; wäre ber Haum ab frei, fo

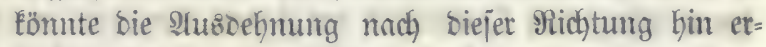
folgen; $\delta a$ ab aber gejoloffen ift, jo miro ber Stein gejprengt. Serabe eben=

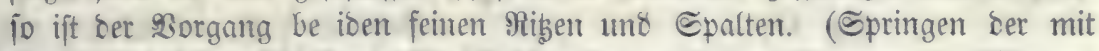
einem Ctöplel berichlofienen (5lasflajchen in ungeheizten 3immern im $23 i n t e r$.

Der Effect, Den bie Eišbilloung hinfichttich) Der 3ertrümmerung ber gel= jen kerborbringt, ift mirflich) grofantig. Sarr bemerten mir ifyn in ben (5e=

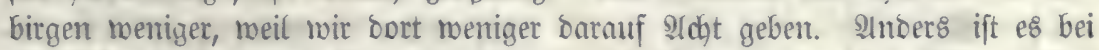
fünftid's zugehauenen Eteinen, bie einen beftimmten 3roed erfülfen follen. (mie z. B. Brenzfteinen, Monumenten ac.). Dieje merben mefy controlitt. ISie viele Brengfteine werben mun aber burd) ben grojt (GiEbiloung) abge=

*) Dieję nirt befanntliơ turợ Căuren gerīttiet. 


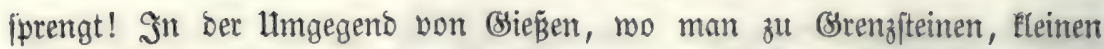
Säulen an ben Banquet\& Der Shauffeen u. f. m. Blafigen Bajalt bermentet,

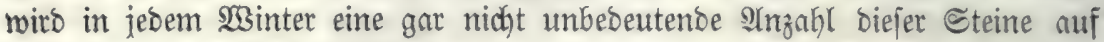
bie angegebente $\mathfrak{W} 3$ eife ruinirt.

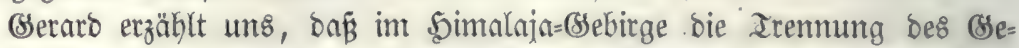

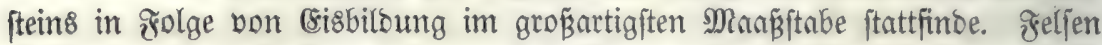
von bebeutendem Umfange nurben losgefprengt, (Srund und Boben ber Päffe in weldhen fidh jene Freljen finten, waren mit ungeheuren bantwerken joldher Trümmer bebecțt.

\section{Wirfugen ber Sdimere.}

\section{n. extgemeines über bie Edberfraft.}

Die Sdhnere ift eine Sraft, meldje bie Rörper nadh bem Mittelpuntt Der

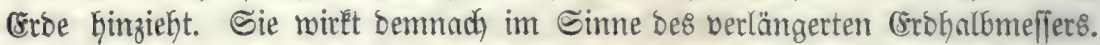
Die gallridytung eines in ber 8 uft befindlidjen Rörpers ergibt fidd, wenn man feinen ๔djwerpunft mit bem Mittelpuntt ber (Erbe burch) eine sinie verbintoet.

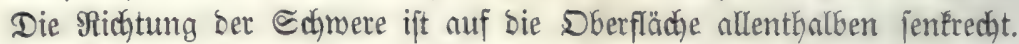

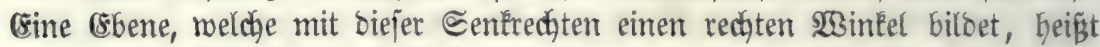
eine நorizontalebene.

Die Sdywere ift eine continuirliche Rraft; D. h. fie wirgt in einem fort.

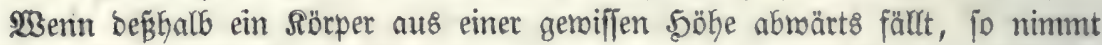
jeine (sejphinbigfeit immer 'zu.

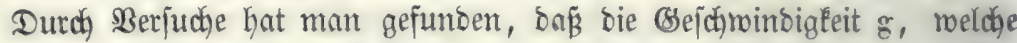
ein fallentoer Sörper nach Berflǘ bon einer Sełunoe antehnten uno beibebalten würbe, wenn bon ba an jebe meitere Cinwirkung ber Edymere auf=

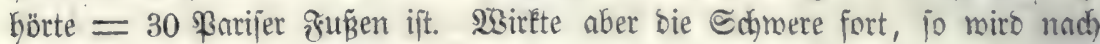
ILblauf ber zmeiten Eecunbe bie erlangte (Sejchmindigkeit boppelt jo groß̈,

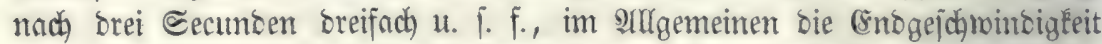
$v$ nach 2 blnuf von $T$ Cefunden Tmal jo gró̈ jein, aljo $v=g T$.

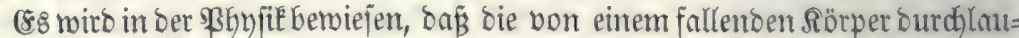

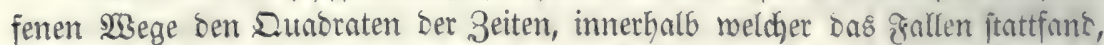

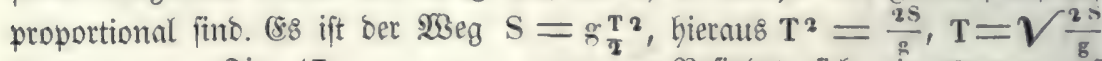
Æig. 47.

Befinoet fich ein Rörper alif einer idjefen (Sbene A B, bie mit ber ఏorizontalen A C einen $23 i n t e l$ C A B $=\alpha$ billoet, (\$ig. 47.), jo wirt

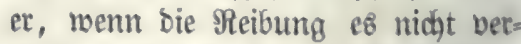
Ginoert, abmärt\& gleiten. Die ङchtwer= fraft bes Rörpers, weldje ourdi D F vorgeftellt ift, roirt jentredst auf bie Sorizontale A C; zerlegen mir bie= jelbe in eine Rraft D E parallel uno eine Iraft D G jenfred)t zur fojiefent (5tene, fo wirb erftere bas bernt: 
gleiten bes Rörpers nach A hin bemirken; ba inteffen biefe Staft nur ein Theil ber gefammten Sdymere bes Sörpers ift, fo Eam bas Serabgleiten nicht

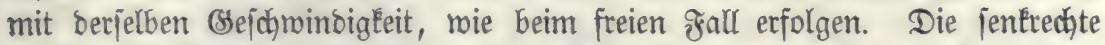

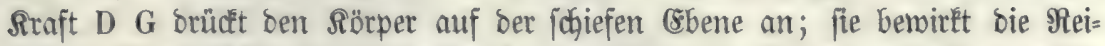

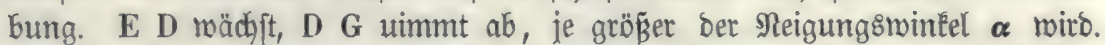

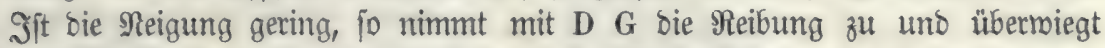
baburch bas Beftreben ber Sraft D E; Der Rörper Lann nidgt Gerabgleiten; er bleibt auf ber ichiefen Bbene liegen.

\section{b. Einfuf ber Odbwere auf bie Oefteine.}

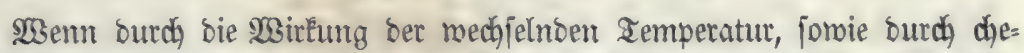

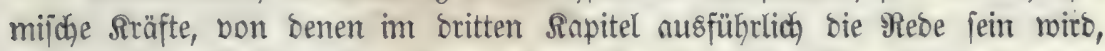
bie grelfen in Hleinere arümmer zerfallen find, fo rollen bieje, fobald fie nidjt auf einer horizontalen ober bod einer bon biejer menig abweidyenben (56ene

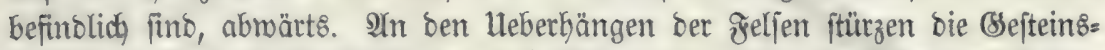
brodken feneredht in bie Tiefe, an Den Nbbängen gleiten fie über bas Beftein

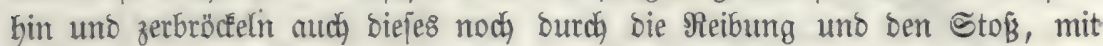
weldyem fie es treffer. Se meiter ein foldher (Sefteinsbrocken abroärts rollt,

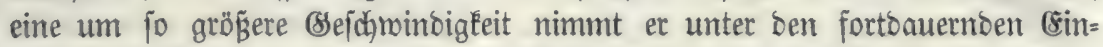
fluźs ber Schnere an; er fann baburdh jelbft bei Eleiner Maffe eine bebeutenoe

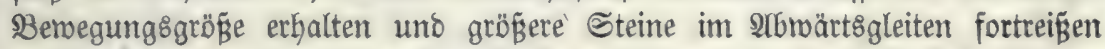

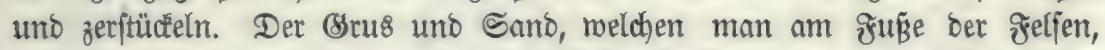

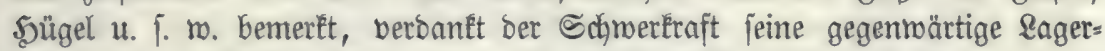

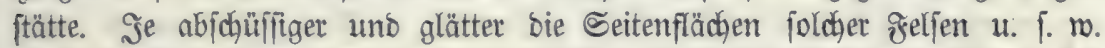

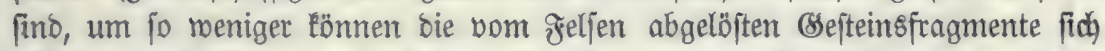

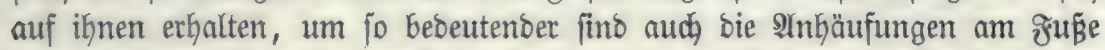
ber greljen.

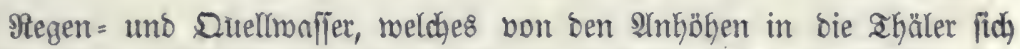
exgießst, trägt gleichfalls zum Iranşport Der Bejteinstrümmer mejentlich bei, uno zroar forohyl ourch ben Stofi, ben e8 auf biejelben, angeregt burdy bie

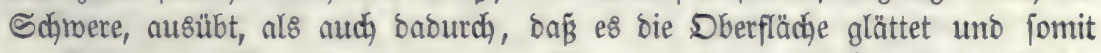

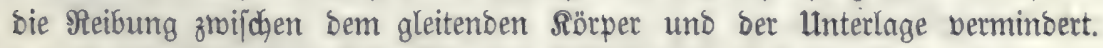
In legterer Beziehung fino (sis und Sdynee von noch gröferer Bebeutung, als bas flüfige 23 affer.

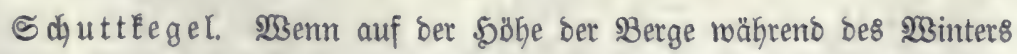

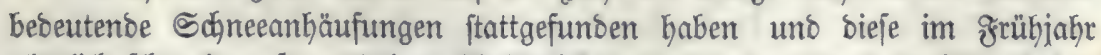

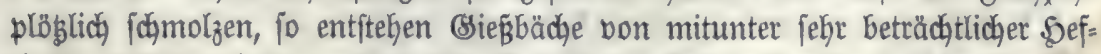
tigkeit. Dieje fodieben mit grofier Benalt bie Befteinsbroden, weldhe ihnen in 
jig. 48.

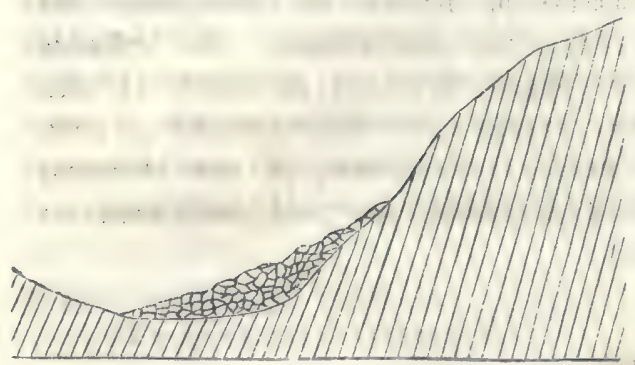

Dem $\mathfrak{W}$ eg ftehen, abrört8, Laffen biejelben aber im Thale am ơuß bes $\mathfrak{B}$ erger Kiegen. So bilben fich bie Schutttegel (今̈ig. 48.), melche man in foft allen Ge=

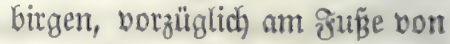
Sohlrifien, bie ben 2 Silbbäctyen zum Bette dienen, findet. Sn ber Sdymeiz, in Syrol, im Jitra fommen bieje Sdyuttleget be= jonbers käuftg vor.

Bergftürze. Wenn ein Sügel ober Berg ats Feljen befteft, fo zer= Heinert fid) immer zuerfit bie Dberflädje beffetben; nadher erit bringt bie $\mathfrak{B e r}=$ witterung nad) bem Snnern bor. Denten wir uns bie fefte Maffe eines Bergs

วิig. 49.

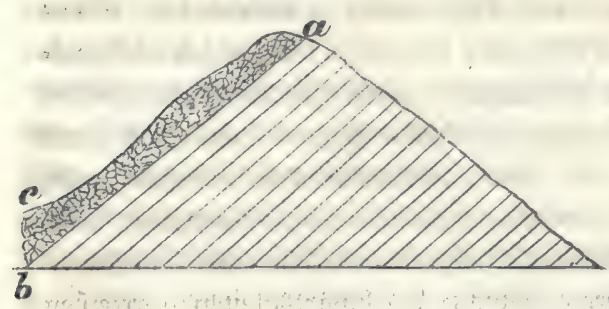

mit SSerölle ober aufgejhyemm= tem \&ano bebectt, welches für Regen $=$, Ect)nee $=$ ober Duell= waffer burchbringlich. ift. Die Dberflädje ab (જ่ig. 49.) bes fe ften (Befteins roits in biejem ærall job)(üpfrig gemadjt werben und bie aufgelagette weidhere Maffe a e abroärts rutịchen. Die nämliche

(sricheimung tritt aber johon bann ein, wenn bie Unterlage von unburchlnffen= bem Ihon gebildet wirb. Co entitehen bie gefürçteten Bergftürze. Beéannt

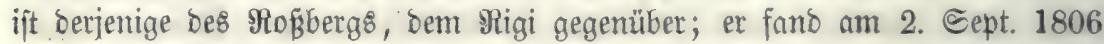

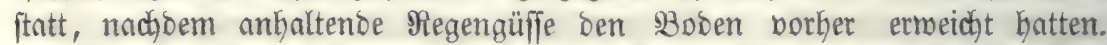

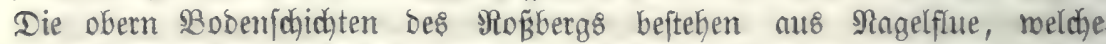

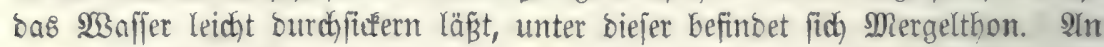

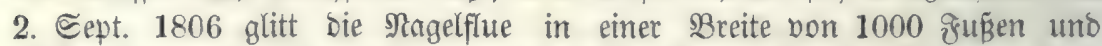

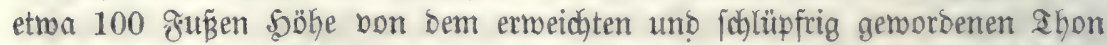
ab. Die Maffe mäls̆te fich auf bie Dörfer Bolbau, Buffingen uno büllod

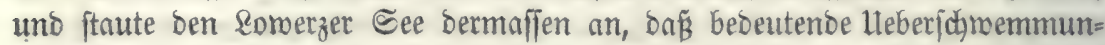

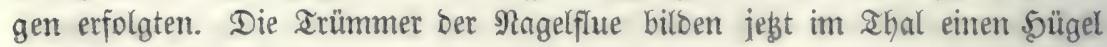
von 200 ₹ußen ఏöke.

Einoirungen ber Flajie auf igr Bette und igre ufer.

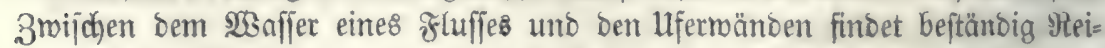

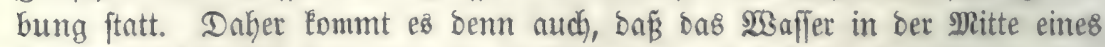

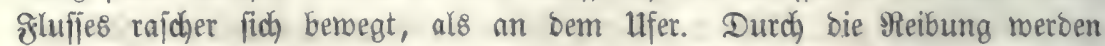

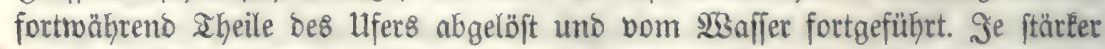

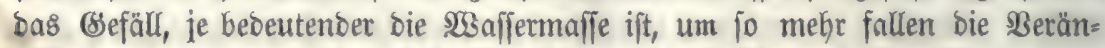

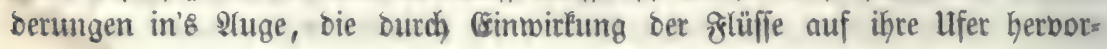




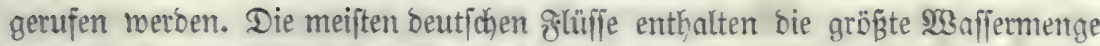

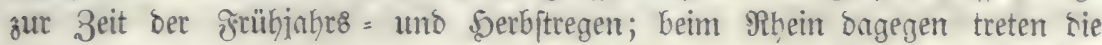

ঋig. 50.

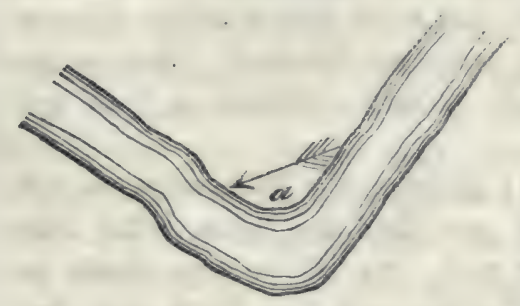

lleberidfmemmutngen in Sonmter ein wenn ber Schnee in ben Illpen, wo

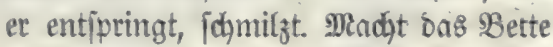
eines §itifes eine ftarke Rtünmung, jo'

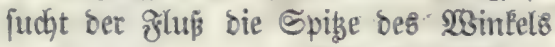
a (厃̣̊. 50.), Den bie Ufermänbe biloen, abzultofien; baburch wirb bie Ränge bes Bettes verringert, zugleidy aber autich ber glus reisenoer gemad)t, weil mun aud) fein Befälle zunimmt. Steine, Sant

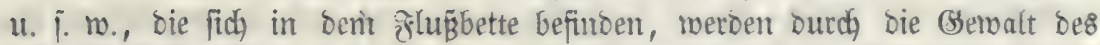

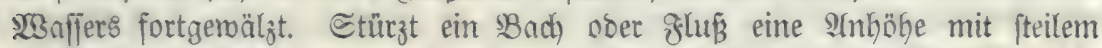
Fall hinab, fo höhlt er bie Etelle, an weld)er bns 23 nffer auffichlägt, aus; bas

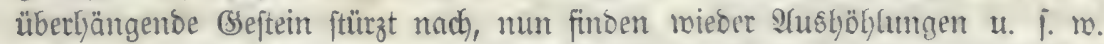

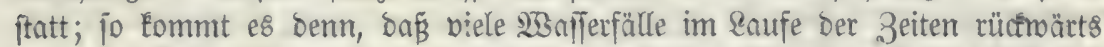
jđyreiten. Ein jefr eflatantes ßeijpiel bon biefem Borgange liefert uns bnв

马urü defdreiten ber Fälle des Riagara. Sine ber grofartigften

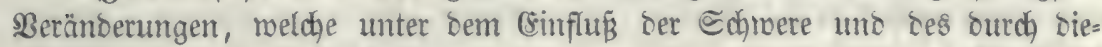
Æig. 51. jelbehervorgenufenen Fall : Riagara , Erie See

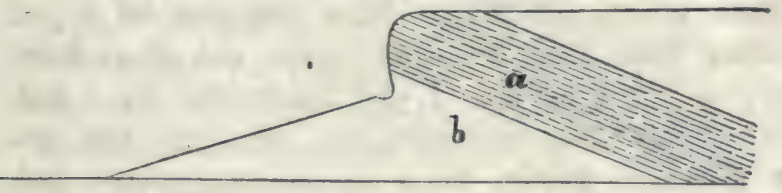

Dntario See Ctoี̉es bes 23 ấ fers nod, gegenroärt= tig ftattinoet, er= blicfen wir im gort= rütefen ber Ringara= fälle. (જ̊ig. 51.) Der Ningara bilbet bes fanntlict bie Ber= binoung bes Erie = mit ben Dntario= See in Norbamerifa. Beibe fino etra 12 Stunden bon einanoer entfernt; Der Niveauunterjojied beträgt 330

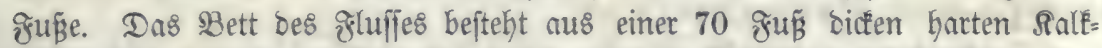
fteinplatte a; unter biejer befinoen fid roeidjere હchiefer bes Silurifhen હy=

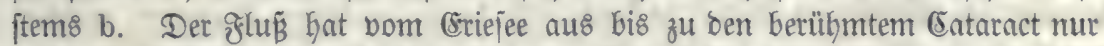

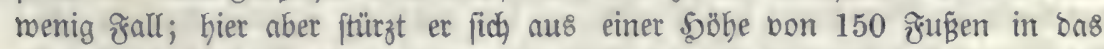

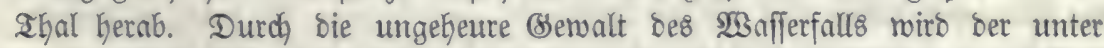

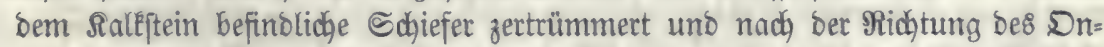
tario fortgefüfyrt; Der $\mathfrak{W}_{3}$ afferfall ergieß̈t fich Dann über bie unterminirte Rall"=

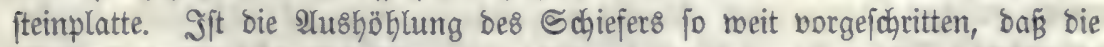
ßlatte Das (semidjt des Stromes nidjt mehr zu tragen vermag, fo löst fie

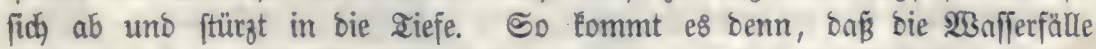

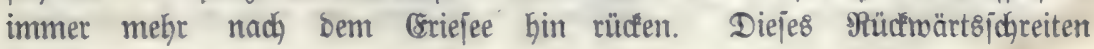


joll jährlich gegen 4 Fuß̈e betragen. (s\& miro exit bann aufhb̈ren, wern nidjt

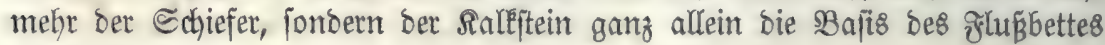
ausmact)t.

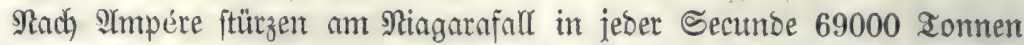

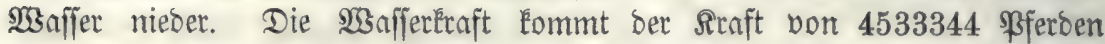
gleich, ift etwa $19 \mathrm{mal}$ größzer, als. bie gejammte Irieberajt, über meldhe

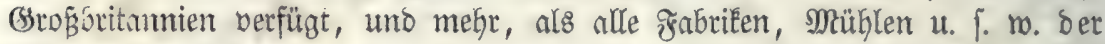
Welt treiben müroe.

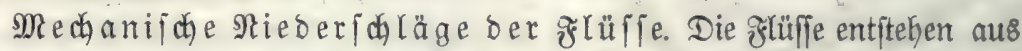

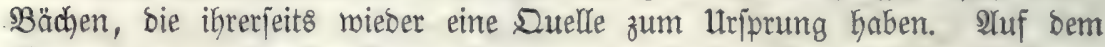

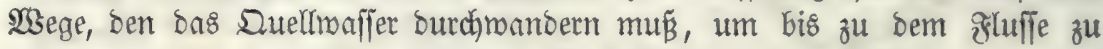
gelangen, belabet es fich mit feinen Erotheildchen aus bem Bette ober ben uferwänoen ber $B$ äche. Treten ftarke Regengüffe ein uno ift ber Boben in bem Sebiete eines Fłuffes lehmig, fo werben bie Bäche getrübt. Das Regen= maffer ftürzt über bas bebaute Rano bin, fdrwemmt bie (sroe fort und füfrt fie in bie Bäd)e, zulebt auch in bie Flüffe Ginein. Feinere Iheildyen bon ge= ringerem abjolutem (Semicht merben vom $\mathfrak{B a f f e r}$ getragen; fie Gleiben in ifm

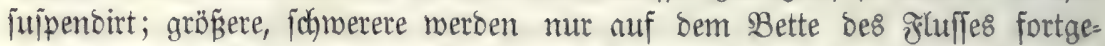

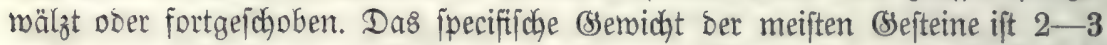
mal größzer, alb. bars bes $23 a f f e r 8 ;$ fie verlieren aljo etwas meniger, als bie Sälfte ihres (Semichtes im $23 a$ affer Darin liegt bie Urjactje ifrer verbältnifs=

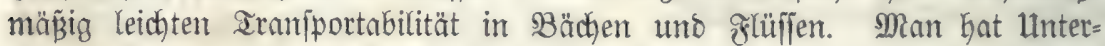

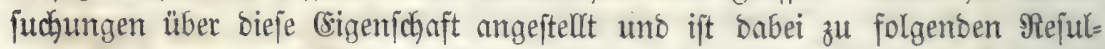
taten gelangt. (s: bleiben unberweglich) liegen: feiner ๔d)lamm bei 3 30ll

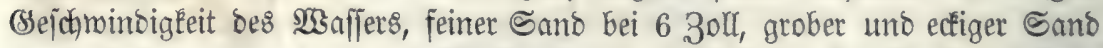

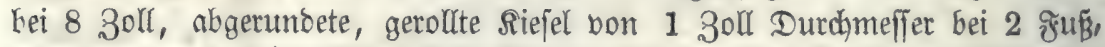

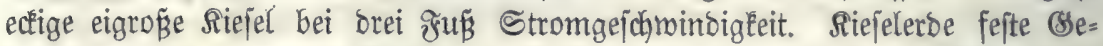
fteinsbrocken merben im fließentoen $\mathfrak{K a f f e r ~ i m m e r ~ a n ~ e i n n o n o e r ~ g e r i e b e n ~ u n o ~}$ baburd abgerumbet, auth wenn fie fich nidft bon ber Stelle berogen. Im Rhein vernimmt man beim Untertauchen ganz beutlich ein Sniftern in Folge bes STneinnderichlagens der Riejel. Davon rührt aljo bie abgerundete grorm

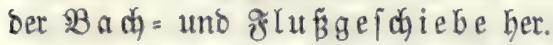

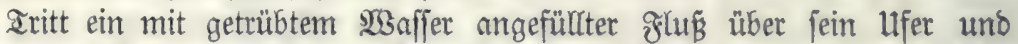

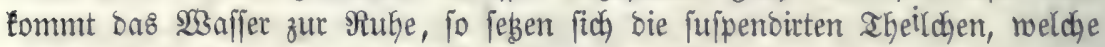

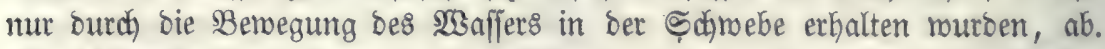
Sie überziehen bann bas an bie æłüffe zc. angrenzende Brelände in Beftalt

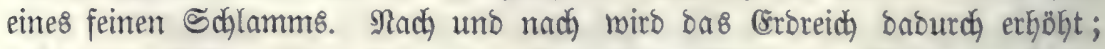

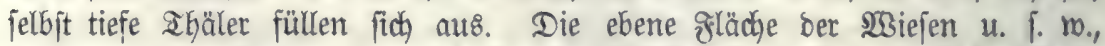

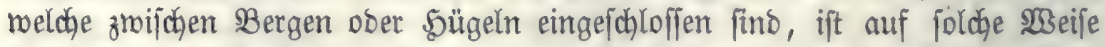

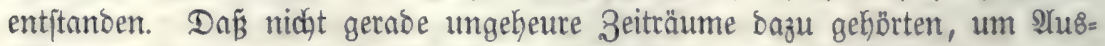
füllungen biefer 2 rt zu bewerfftelligen, betweift folgenoe Beobachtung. Nake

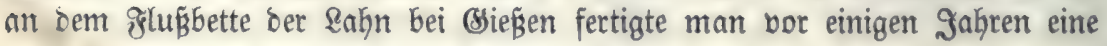




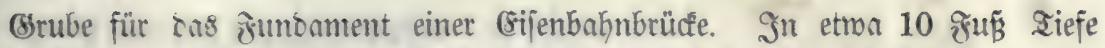

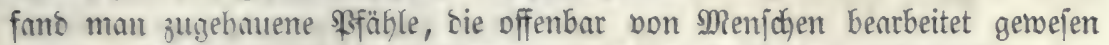

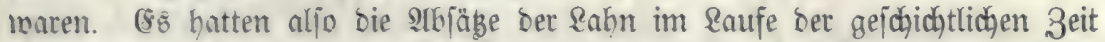

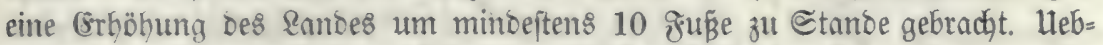

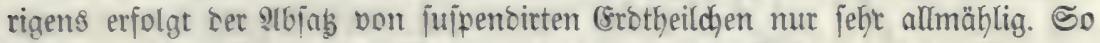
Eann man das 2 Saffer Der Rhone noch 6-7 engl. Meilen weit im Meere an jeiner F̧ärbung erfennen; Der Chinefif h) Meerbujen wiro in feiner ganzen

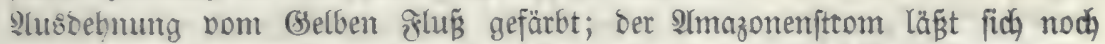
300 engl. Meilen von jeiner Müntung Deutlich vom Meere unteridgetoen. Der

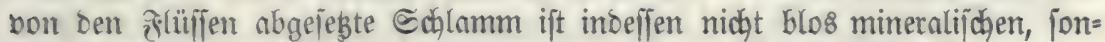

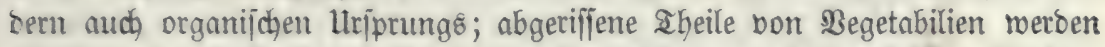

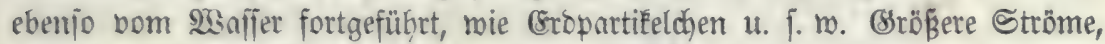
wie Der Intazonenifrom, Drinoco uno Miffiffippi transportiren jogar grofise

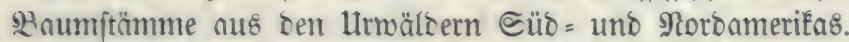

Die Berölle und Beidhiebe, meldge in bie \&lüffe Gineingeführt merben uno in benjelben mit bem (Eintritte jeber ftarêen f̊luth reiter manoern, er=

§ig. 52.

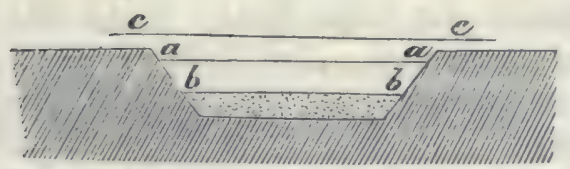

Göben nach uno nach dn ほlußbette. Bezeidynet (§ig. 52.) a bie Rinie bes

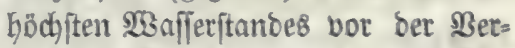
fanoung, io miro, wenn die Âtuffül= lung bes Flupgetts burch (sejchiebe u. โ. w. neuerdings bis b reidat, ber

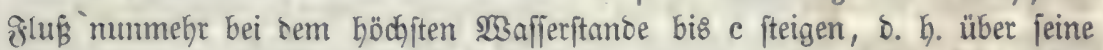
Ufer treten. Dadurch entftehen Heberichmemmungen. Sebes Mittel, weldhes

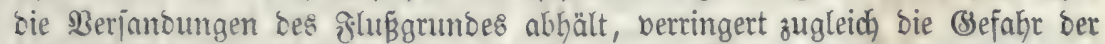

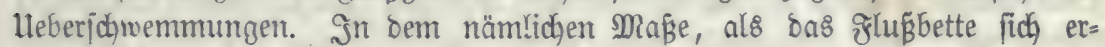

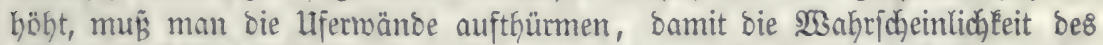
(Sintritts von lleberjobremunumgen nicht vermebrt nerbe. Durch fortgejebste Berjantungen uno Uferbauten ift bas Bett bes $\mathfrak{B}_{0}$ über bie (sbene ber Rom=

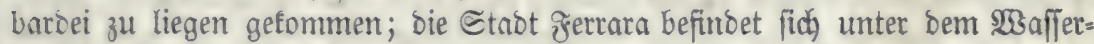

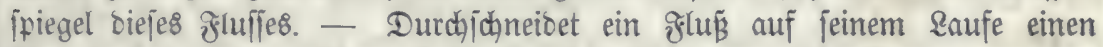

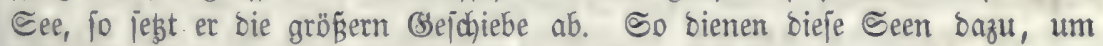

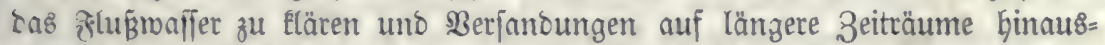

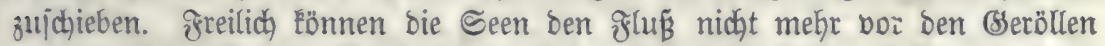

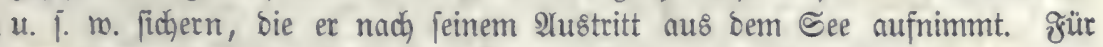

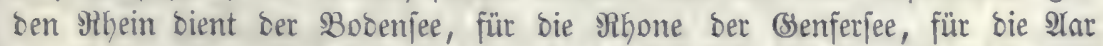

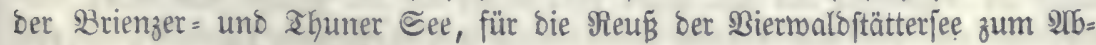
jab ber feften Beftanotgeile.

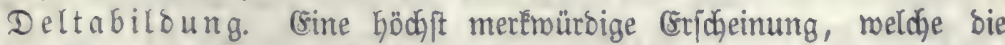
meiften größ̈eren ๔tröme und jelbft auch Eleinere glüffe zeigen, find bie Delta'sి.

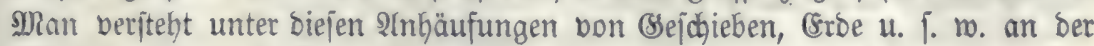

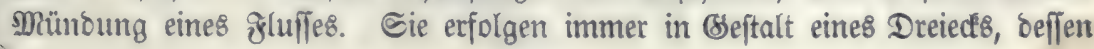


Æ̛ં่. 53.

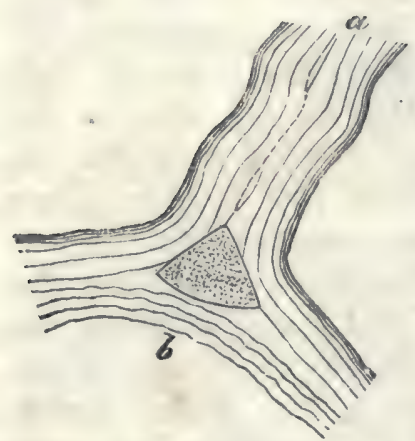

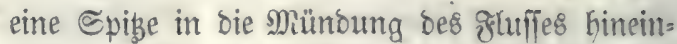
ragt, uns führen ifre Benennung bon ber 9 lefun=

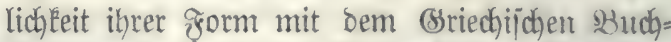
ftaben Delta (d). Sie entftehen in folgender

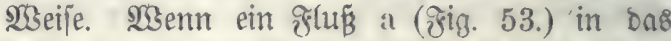
Meer b Doer in einen Gee einmündet, jo miro jein $\mathfrak{B a f f e r}$ aufgejtaut, e\& fommt in Rube; bie im $23 a f j e r$ juppendirten Iheildyen, weldye nur burch) bie Berwegung im Sdymeben erbaiten mur=

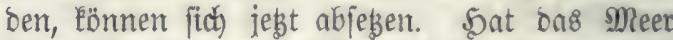
zugleich (sbbe uno Fluth, fo wiro bas $2 B a f f e r$

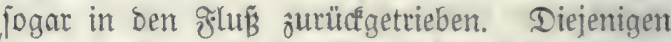
głüfie, welche an ifrer Münoung Kein rufiges Meer finden, bitben auch, wie z. $\mathfrak{B}$. Der 2lmazonenjtrom, Kein Delta. STn Der Münoung biefes Fluffes geht bie heftige Aquatorialitrömung in ber Michtung

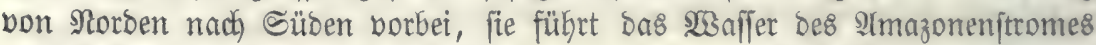
fogleich in bas offene Meer.

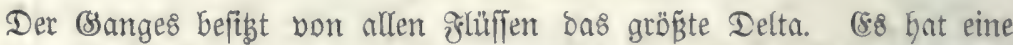
Ränge von 320 Silometern uno ift faft ebenfo breit. Das Delta bes Mriffi=

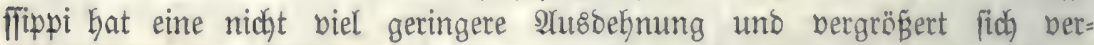
bältnifmäfsig am ftäreften von allen Deltn\&, borzüglich burch) Baumptämme,

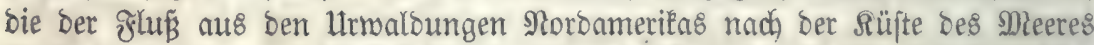

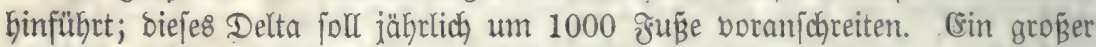

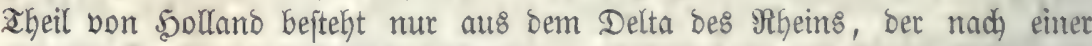

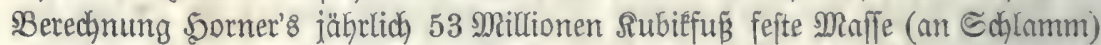

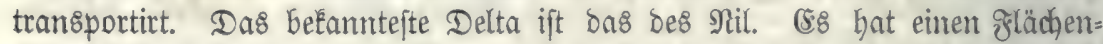
raum von 400 Duabratmeilen. Seine Epige liegt bei Rairo. Der ine

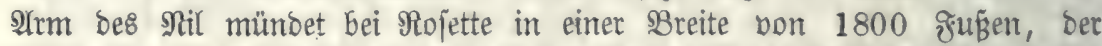
anbere 2 rrm bei Damiette in 900 F̆uñen Breite in Das Mittellänoiiche Meer

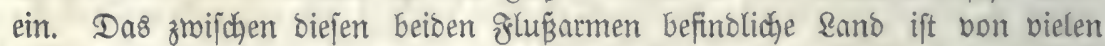
Sinälen burchjonnitten. Bor bem Delta, längs der Rüjte bes Meeres hin, lăuft ein $13 a$ all bon Ealkigem Sanoftein. 21nfangs Sulli fteigt bas 233 affer

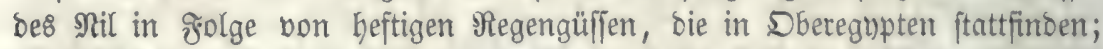
ber höchfte 2 anfferitand tritt gegen (snbe Geptember ein. $23 a ̈ h r e n \delta$ diejer

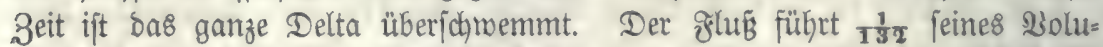

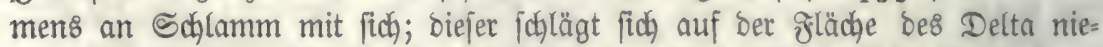
Der; Daburdh bat fich biejelbe feit Infang cer chriftichen 3eitrechnung um

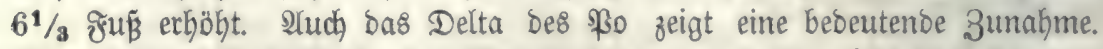
Die Stabt Abria Gatte in ben $\Re$ ömerzeiten einen Safen, jegt liegt fie etwa neun Stunben bom Meere entfernt. 


\section{EBirfungen be stopez.}

\section{a. ริm 20rigemeinen.}

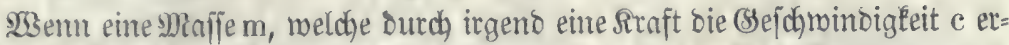

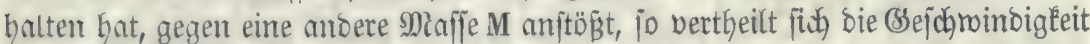
c, oie jeoem Theilchen von m innemohnt, anf bie beiden Maffen $\mathrm{m}+\mathbf{M}$; es rejul=

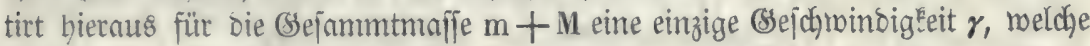

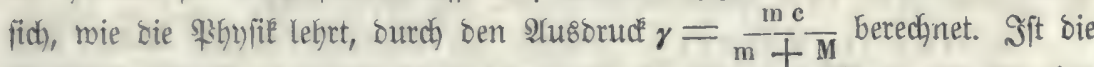

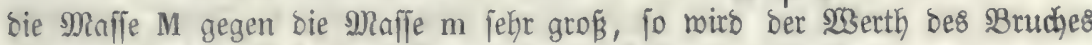

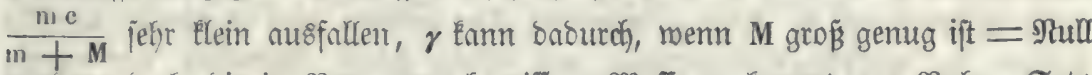

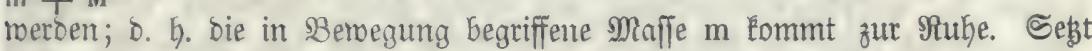
fich aber Den beibent berwegten Maffen ein $23 i b e r f t a n \delta$ entgegen, ber bie $\mathfrak{B e}=$ megung zloar nicht momentan auffören macht, fie aber boch bon Secunde zu

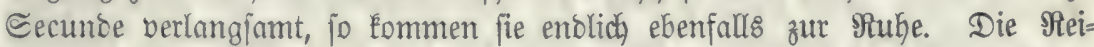
bung, bie fich inmer erzeugt, menn bie Dberfächen zmeier Sörper auf einan= Der hingleiten, wirlt in biejer $2 \mathfrak{B} e i j e$; fie ift es, meldye bie Betwegung Der Rör=

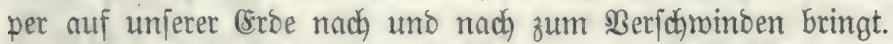

3on Den Siäften, welche Bervegungen verurjachen, haben wir bereits

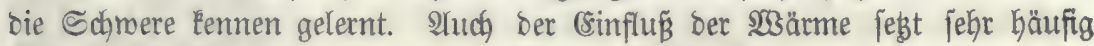
Materien, insbej. Die \&uft und bas $\mathfrak{W a f f e r}$ in Bemegung. Die $\mathfrak{B i n b e}$ find

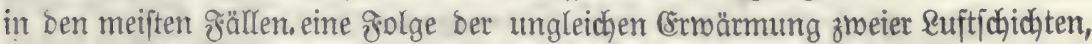
wie mir päter ausfüfhrlich nachmeijen merben. YYuch bie Meeresftrömungen,

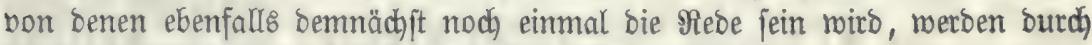
bie locale Crrmärmung bes Meermafiers herborgerufen.

Eine conjtante $3 B$ enegung befizt bas Meerwaffer in ber (sbbe und Fluth.

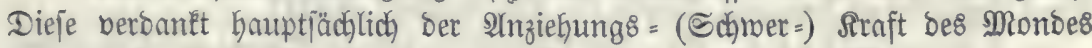

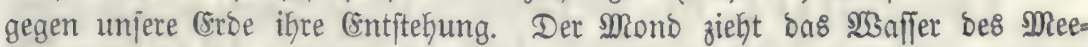
res hinter fich her. Sechs Stunden lang entfernt fith bas $\mathfrak{W a f f e r ~ b o n ~ b e n ~}$ Riuften, bas ift bie (sbbe, Gierauf fteigt es wieber fects Stunden lang, und

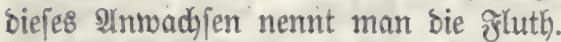

Die WBinbe und Ctürme fezen bas Meer ebenfalls in Betwegung; fie

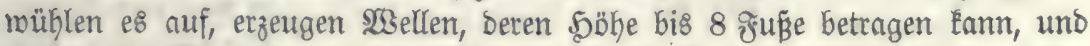

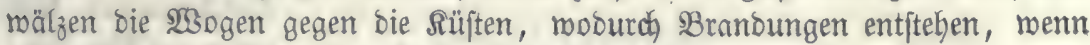

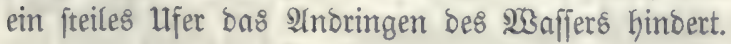

\section{b. Einwirtung bes Otopes a}

Unterböhlung und 2 bflachung der Meerescüten. Dab ent= reober Durdh Winde und Stürme, Dber burdh bie Fluth in Bemegung ge= feşte Meer reibt beftänoig an ben Rüften. Beftehen legstere aus ģelfen von weicher Bejchaffenbeit (z. 28. Sireibe, Sanoftein, Schiefer) fo werben fie unter=

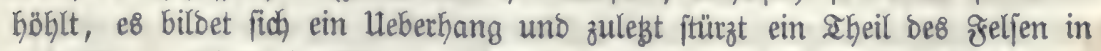

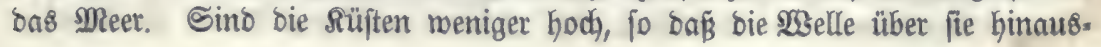


folagen fann, fo berid)afft ifnen bie fluth nach und nach eine geringere

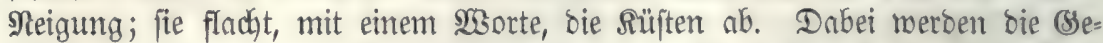
fohiebe, meldhe auf bem Sanoe liegen, Durdy bie gluth hinauf=, ourd) bie (86be heruntergemälzt, an einanber gerieben und zerfleinert. (sin eigenthümliches

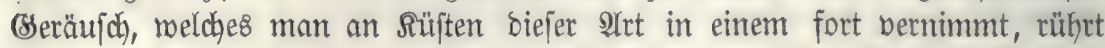

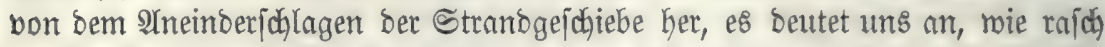
die Zerfleinerung biejer (Sefteinsbrodéen vor fith geḩen mußs.

ufermälre, \&agunen. Befteht ber Meeresboden aus Sano, Ries

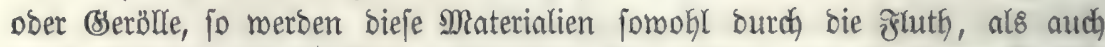

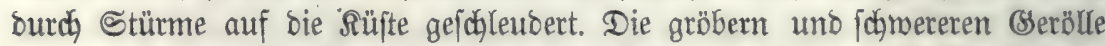
oringen an meiteften landeinmärt\&, unঠ bilden Sägel, Ufermälle, ber feinere,

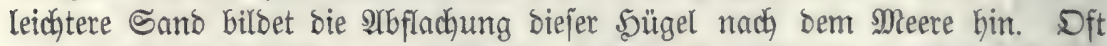

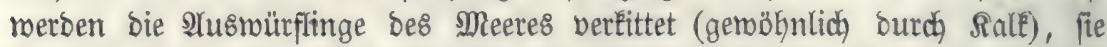
formiren bann einen fejten Damm, Der ben Zerjtörungen ber Meeresmogen

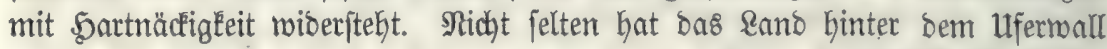

\section{₹̛ig. 54 .}

\section{Meer}

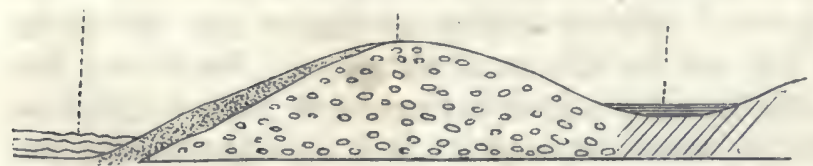
eine Bertiefung, Die mit 13 affer anges füllt ift, bieje $23 a$ j= jerbebălter nennt man Ragumen. (३ïg. 54.) gant an allen Meere\&Eüften finben fich fowohl bie llfer= wăle, als auch bie Ragunen. Die frifde Rehrung und bie Rurifde Rehrung in Der Ditfee fino Ufermälle im grofartigften Mafitabe; bie hinter

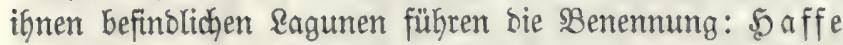

Dünenbiloung. Bon ben lferwälten find bie Dünen mohl zu unter=

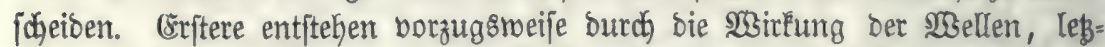

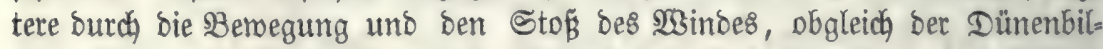
bung immer bie frormation eines Ufermalles vorausgeft. Unter ben Dünen

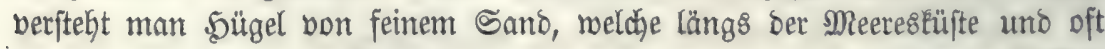
§iंg. 55.

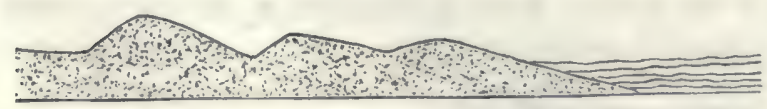

in mehreten Reiben Gintereinanoer bin= zieben. (Fiß. 55.) Der 233 ind treibt ben Sant immer meiter

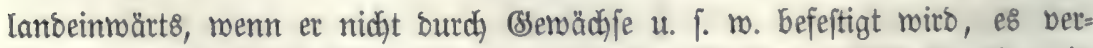
fóninben baburch bie Dünenhügel an mandjen Stellen, während andere in meiterer Entfernung bom Meere aufgebaut merben. Zur Dünenbildung barf ber Sand nidft zu fdymer fein, damit ifn ber MBind nod fortfüfren Eann. 100 Der größ̄ten Sanblörner, an ber Dänifchen Süfte gejammelt, mogen 6662600 Milligranme. Die Arbfladjung ber Dünen nadh bem Meete bin betrăgt 
gervöbntich $5^{0}-10^{\circ}$; lanbeinmärt8 fallen die Dünen viel fteiler $a b$; die $\mathfrak{B}:=$ ichung beträgt hier fajt conftant $30^{\circ}$, böchjtens $40^{\circ}$. Die Şöhe ber Dünen

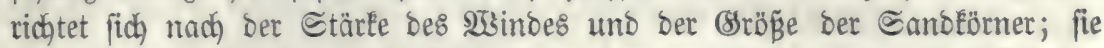

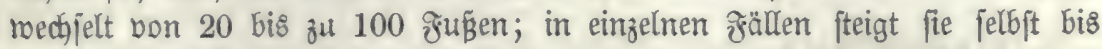

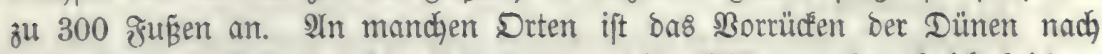
Dem Snnern bes \&anbes jefr bebeutend; an ber Rüjte von Franlreich bei bem Snštogner Meerbujen beträgt e\& 60-72 ซ̌uß̉e im \&aufe eines Jabres.

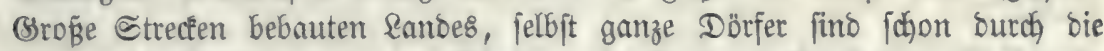
Dünen überjđüttet rorben. "MRimijan, ein Dorf im Departement bes Ean=

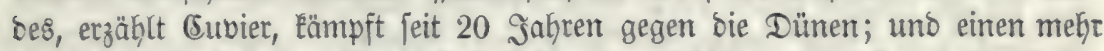

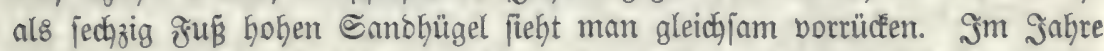
1802 verbreiteten fïch bie Seen Ginter ben Dünen über fünf fdg̈ne \&ano=

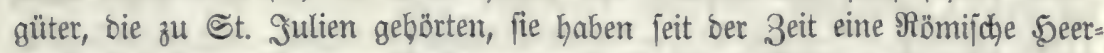

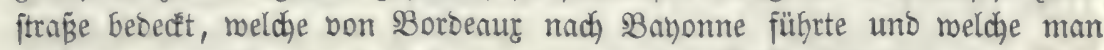
nod) bor ungefähr bierzig Jnhren jah, wenn bie 23 affer niebrig waren. Der 9loour, ber einft bei Bieur Boucaut flö̧ und am (5ap Breton in's Meer fiel, hat jeinen \&auf um mef̧r, als tnujeno Ioijen veränbert." Die Dünen in

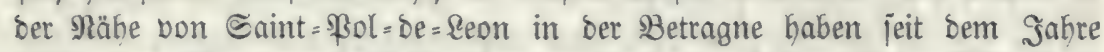

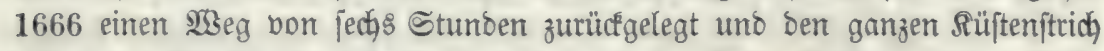
mit einem Santomeere bebect, aus, bem nur noch bie Spizen einiger Rirch= thürme unt Ramine herbortagen. Blie be Beaumont.

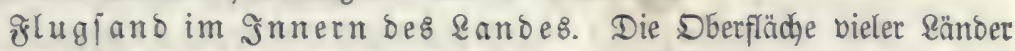
befteht aus \&agen von Sano, Der häufig Dem Meere feinen Hrjprung ber=

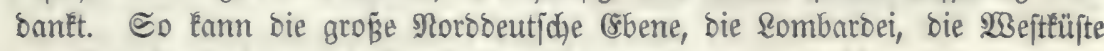
bon Frantreid) (zum aheil) als ber Boben eines nun nidht mebr borhan=

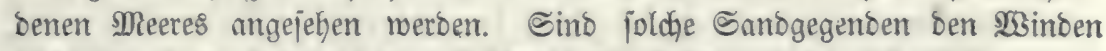

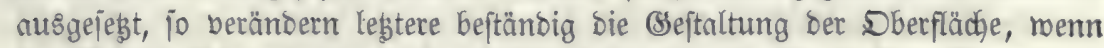

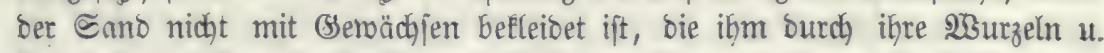
1. m. eine größ̈ere (5onjiftenz verleihen. Der Sano wirb bon einem Drte zum andern vermeft und überbecit, ebenfo mie ber Dünenjant, auch folche Ränder= ftrecfen, melche urjprünglich) Keine ๔andlager entfielten. (Seroöhnlich) geht bie Berjanoung von ben jogenannten Eandfeblen aus. Dieje fino Sügel, beten

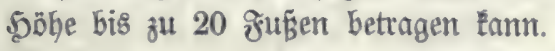

\section{3 weites Rapitel}

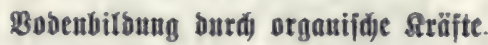

Die Drganismen, weldhe entroeber eine Neugeftaltung ber Erobkerfläche, Doer aud eine Beränberung ber bisherigen Bejtalt berfelben Gerborrufen, ftam= men forohkl aus bem Thiet = als audh aus bem Pflanzenteid $)$.

\section{1, Bobeubiroug oitrib Thicre.}

Dbgleich bie Reiber aller berenbeten und berweften Ihiere in fo fern auf

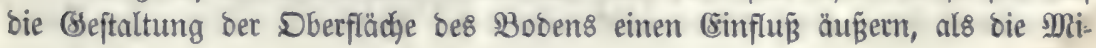


neralbeftanotheile der Reichname biefe Dberfläche erhähen, jo fint es body mut

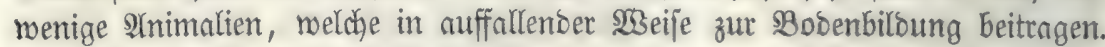
Bon bejonberer Sicichtigleit fino:

\section{a. Die snfuforten.}

Dieje find miErofcopifch Eleine SWejen uno ftehen auf einer fehr nieberm Stufe ber (Entwidelung. Sie leben jomohl in jü̈̈еm, als auch in gejalzenem

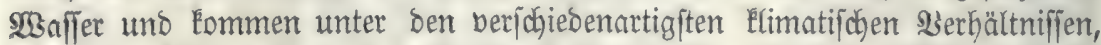
bei ber gröften Sibe und Siälte, ja felbft im (sije noch) fort. Shre Bermehr= ung, bie bei einigen SYrten burch blop̉e Iheilung ftattfindet, ift eine ungeheure. gür uns baben mur biejenigen Snfuforien Sntereffe, Deren (gallertartiger) Rörper mit einem $\mathfrak{B}$ nzzer aนళ Riejelerbe umgeben ift, wie bie Bacillarien mit ben Irten: Galionella, Navicula, Bacillaria, Xanthidium, bon ifnen follen

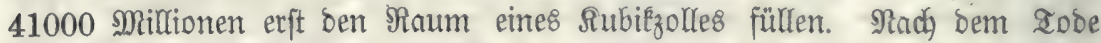

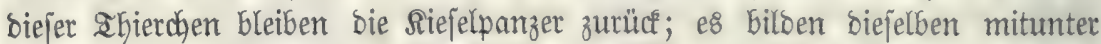
fefr beträchtliche Ânfäufungen. So foll nach Esbrenberg ein grofier Theil ber

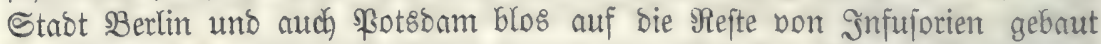
jein. Sn ber \&üneburger Şaibe fand mant ein 250 Sdjritt lange\&, 150 ङdhritt

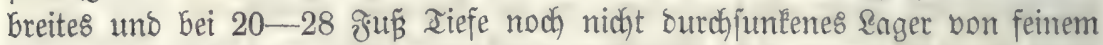
Sand, ber fich al\& ein Iggregat bon Snfujorienteften herausftellte. Neuere Unterjuchungen Baben ergeben, Daf́s Der Trippel, Bolirjchiefer, Die Riejelgufr, mandhe Jeuerfteine u. . . w. Blos aus Snfuporienpanzern bejtehen. Dies gilt auch bon ber gemeinen Sreibe. Arther હchlamm vour Ieichen, Bräben u. j.w. enţält Snfujorien in grober Menge.

\section{b. Die Rarallen.}

Die Sorallen gehp̈ren zu ber Slaffe Der 3oophntert. Sinige Sirten, auf

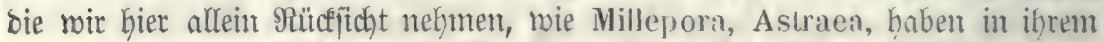
Snnern eine fteinige Maffe, welche borzugerweije nts fohlenjautem Rale be= fteft. Diefe İjiere leben im Meere; fie heften fict) entmeber an eintem ofelien

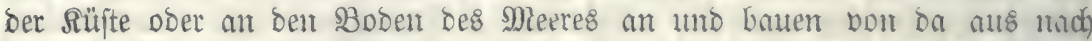

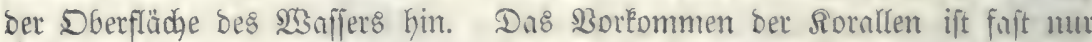

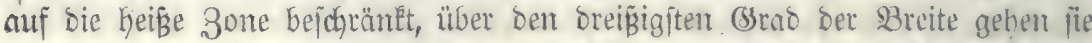

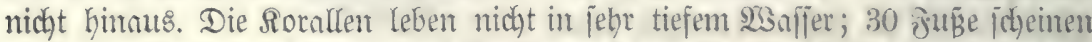

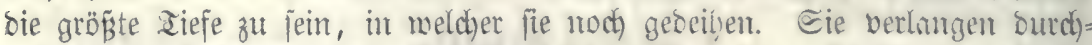

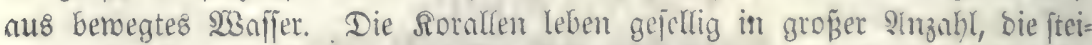
nermen Maffen, melche fie Ginterlaffen, bilden bie jogennmuten Rorallentiffe.

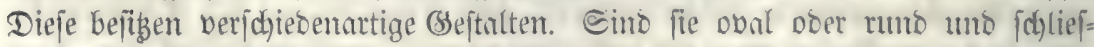

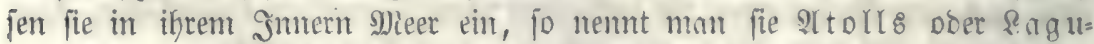
nenriffe, befinbet fich in Der Mitte eine Snjel ober Injelgruppe, jo heipen fie Dammriffe, zieben fie parnllel mit ben Rüften, fo verden fie $\&$ üften= riffe genannt. - Die Rorallen bemirten oft bie (Entfehung von Injeln. Menn fie nämlid eine geroiffe Mieeresftreffe niggegiengt Gaben, uno legtere von Sant, 


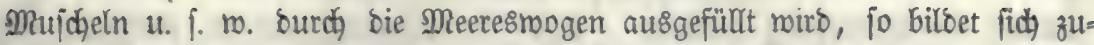

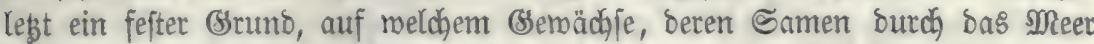

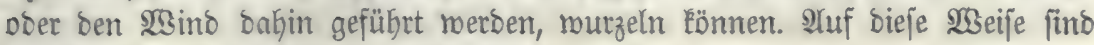
viele Snjeln in ber Sübjee entitanoen.

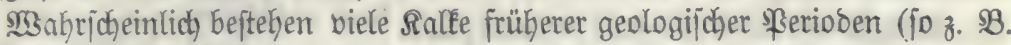
ser Etringocephalentálf im Debonifchen Enjteni) nur aus Rorallenäften, bie fpäter burda Snfiltration bon Ealebaltigem $23 a$ j]er vertittet wurden.

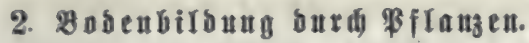

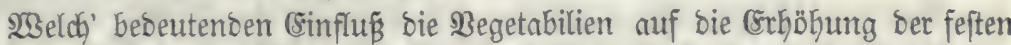
Erorinde in frühern geologifoben ßerioben äuß̈erten, Gaben wir bei ber Stein= Fohlen= uno Braunfohlenformation gefehen. Altein noch gegentoärtig tragen

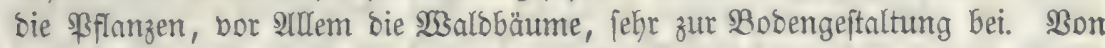
ben Felocrescentien gilt bies meniger, weil ber Ranomirth ben gröpten Theil ber jäbrlichen \$roouction entrotet uno vom gelbe Ginmegnimmt. In ben 23 aldungen bleibt bagegen entweber bie ganze Quantität bes jährlich abfallen=

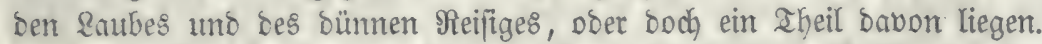

Die $\mathfrak{B e r a ̈ n b e r u n g e n , ~ m e l d h e ~ i n ~ D e n ~ a b g e f t o r b e n t e n ~ T h e i l e n ~ b e r ~ B e g e t a = ~}$

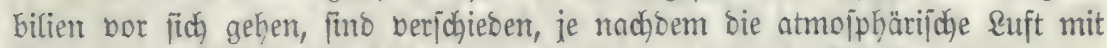
ifrem Eauerftoff 3utritt hat, ober mehr ober reniger abgeichloflen ift.

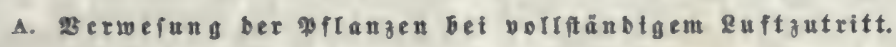

a. Beftunbthetle ber \$ilanzen.

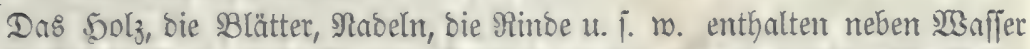

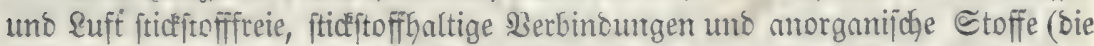
fogenamnten $2(j$ d)enbeftanotheile); bie eigentliche \$olzfajer befteht bei reifem . Solze aus ber jogenannten Eelluloje, sieje ijt fticfitofffrei, uno ber intruftiren=

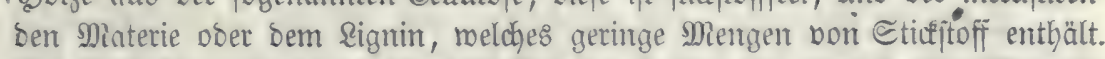

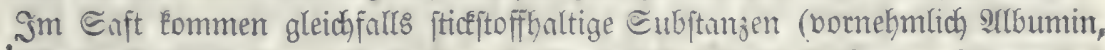

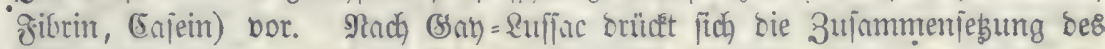
(sid)entyolzes burch bie frormel

$$
\mathrm{C}_{36} \mathrm{H}_{22} \mathrm{O}_{22}
$$

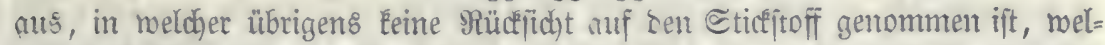

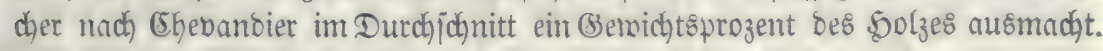

\section{b. Die sebingungen ber Berwefung}

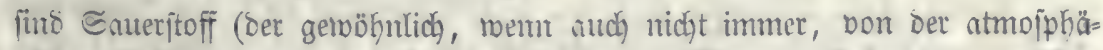

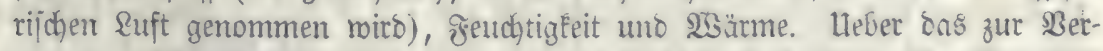
wejung nöthige నemperaturminimum liegt mur bie Beobndgtung Boujïngault8

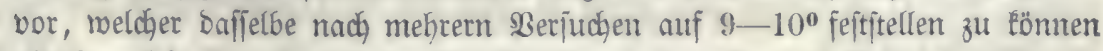
glnubt. Die Ângabe anoerer Edyriftiteller, wie z. B. von Bronn, nach wel= them bie Temperaturgrenzen für Sen 3 erwejungsprozé zroijchen 5" uno $30^{\circ}$ liegen, beruken mur auf Mutḩmä̈ungen, aber nidht auf wirklichen Beobradd=

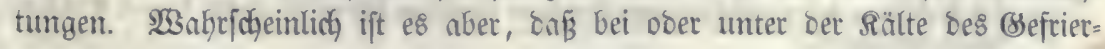




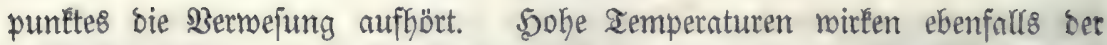
Berwejung entgegen, meil bei ifnen bas in ben Pffanzen befindlid)e 253 affer

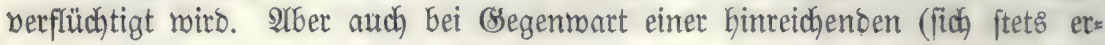

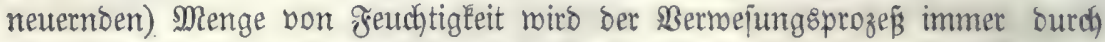
Den Cintritt bes Siebepuntês unterbrodjen.

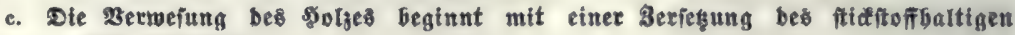 Beftanbtbetres.}

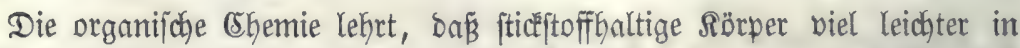
ifre Elementarbejtanotheile zerfallen, als fticfitofffreie, movon wahrịcheinlich bie complizirtere $3 \mathfrak{u}$ jammenjegung erfterer die Urjache ijt. Man fat jogar

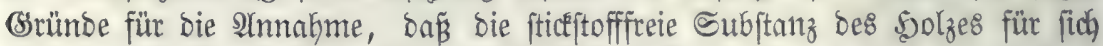
allein gar nicht ber Bernefung fähig fei. Alle Solzconjerbationsmethoden, relche bie Zeriebung des fticéftoffhaltigen Rörpers im \$olze aufheben, machen

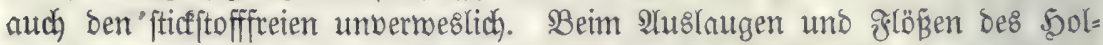

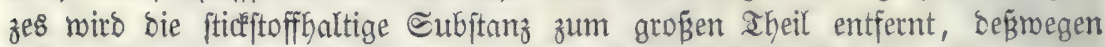

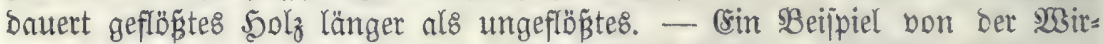
hung fticiftoffhaltiger Subjtanzen auf ftidfitofffreie liefert bas Stärkemehl, wem man es mit Rleber (Dem fticfitoffhaltigen Beftandtheil Der (setreibejamen) behandelt. Das gemöbultiche Stärfemehl entgält nur eine geringe Beimengung yon fticéftoffhaltigen organifchen Rörpern. WBenn man es mit $2 \mathfrak{B a f f e r}$ zu einem

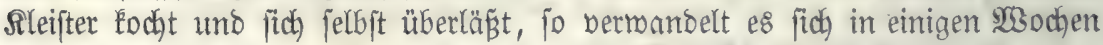
unter sontmicflung bon Rohlenfäure uno 2 anfferftoffgas in Setumelzucfer; aber in Berührung mit Rleber uno bei einer Temperatur bon $60^{\circ}$ geht Das Etärkes mebl fodon in adjt Stunoen in Rrïmelzuteer über.

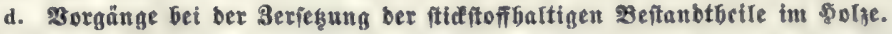

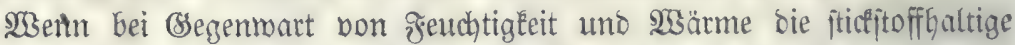
๔ubjtanz Des $50 l z e s$ oon Dem ๔auerftoff in Singriff gentommen wiro, jo ent= mickelt fich Rohlenjäure uno 23 afler. Der Etiçitoff jelbjt lommt gleichzeitiis in Freifeit. Or tritt entweder unberbunden als (Sas aus; biejer Fall ereig=

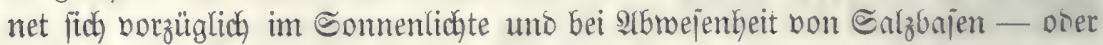

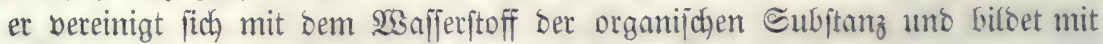

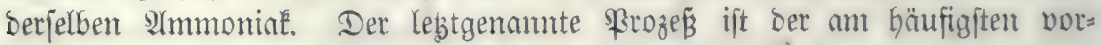
kommente. Sino aber ftarke Bajen in Ginteidjenoer Mienge zugegen, mie

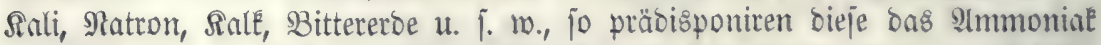
jur Bildung von Salpeterjäure, melche fict) mit ben Bajen veteinigt. Đ̧äufig

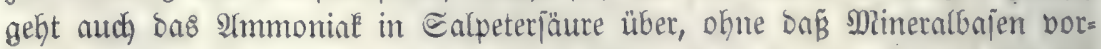

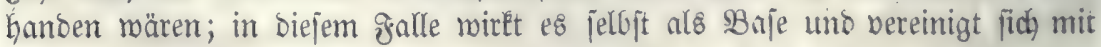
ber erzeugten Säure.

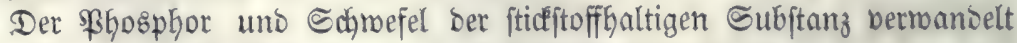
fich in \$boaphormafferftoffgas uno in Sdymefelwafferitoffgas.

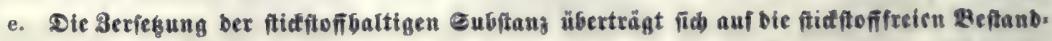
theife be go golzes.

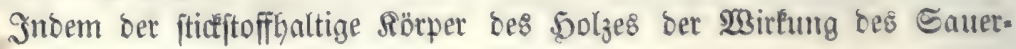




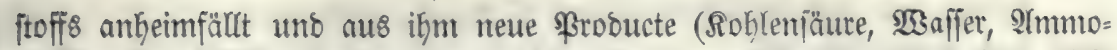
nial u. . w.) fid entwideln, wird feine 3ujammenjebung aufgeboben. Die

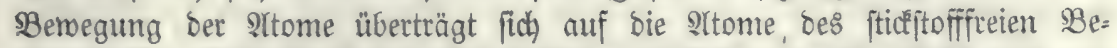
ftandtheils. Daburdy werben bieje befähigt, theils unter fidh, theils aud mit bem Saueritoff ber suft ober anderer fauerftoffhaltiger Sïrper Berbinoungen einzugeben.

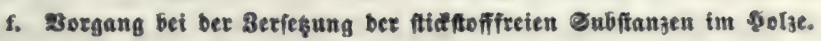

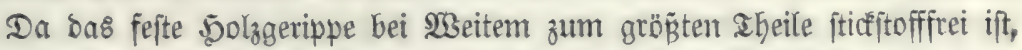
jo haben mir es hier reest eigentlich mit ber 3erjegung bes 5olzes zu thur.

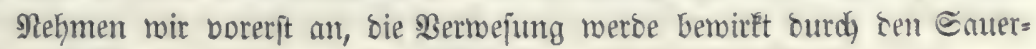
ftoff Der Euft.

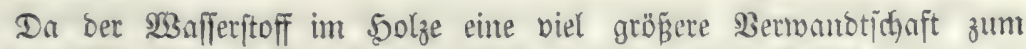

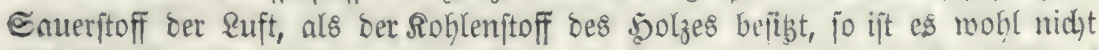

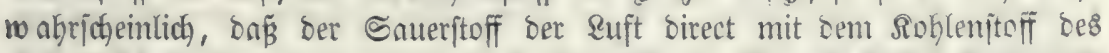
ఏolzes fich verbinbe; es tritt vielmegr fichertich ber Emerftoff ber \&uft zuerft

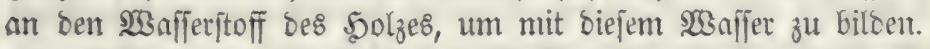

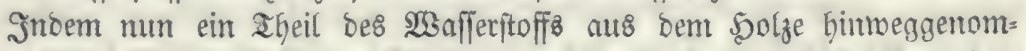

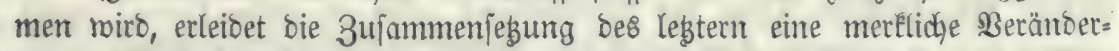
ung. $23 a r$ nämlich vorher Der Sauerftoff uno $23 a f f e r f$ toff im $50 l z e$ im $\mathfrak{B e r}=$

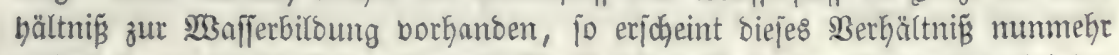
aufgehoben; ein Theil bes ๔aueritoffs ift bisponibel geroorben. Da bei ber Berwejung des \$olzes immer aud ber Sauerjtoffgehalt bes leģtern abuimmt,

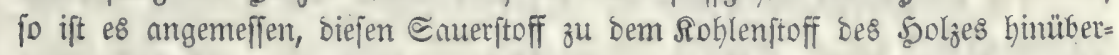

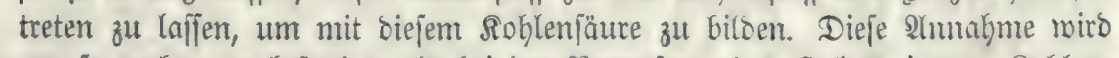
um fo mehr gerechtfertigt, als bei ber Bermejung bes Solzes immer Sohlen= fäure entroictelt mirs.

Siernach mären arjo bie erften \$robucte der ßerwejung bes \$olzes

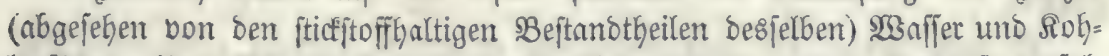
lenjäure. Utm aber ben $\mathfrak{B e r w e j u n g s p r o z e s ~ i n ~ f e i n e m ~ g a n z e n ~ B e r l a u f e ~ v e r f o l = ~}$

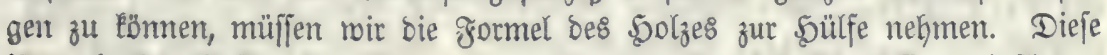

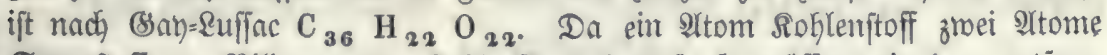
Sauerftoff zur Bildung von Rohlenfäure beonrf, jo miüfen wir bem entjpre:

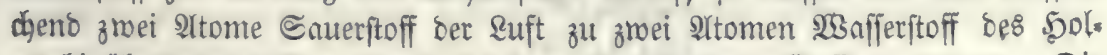

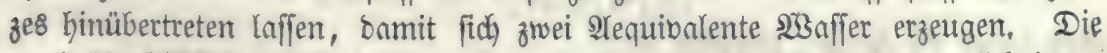

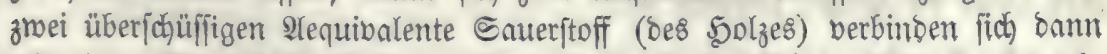

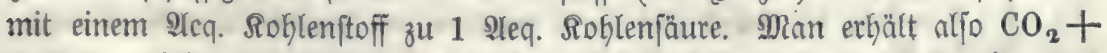
2 Ho. Ziełen mir bieje bon ber grormel bes Solzes ab, jo jehen wir, was im Rücfftano bleibt:

\section{Zrormel bes 5olzes}

\begin{tabular}{lll}
$\mathrm{C}_{36}$ & $\mathrm{H}_{22}$ & $\mathrm{O}_{22}$ \\
$\mathrm{C}$ & $\mathrm{H}_{2}$ & $\mathrm{O}_{2}$ \\
\hline $\mathrm{C}_{35}$ & $\mathrm{H}_{20}$ & $\mathrm{O}_{30}$
\end{tabular}

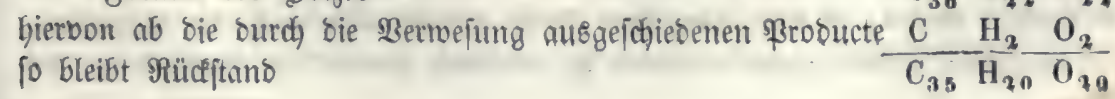


Denfen wir uns, ber 9 ustritt von $\mathrm{C}_{2} \mathrm{O}_{2}$ finbe aber= mails ftatt, ziehen wir aljo ab, jo bleibt $\frac{\mathrm{C} \quad \mathrm{H}_{2}-\mathrm{O}_{2}}{\mathrm{C}_{34} \mathrm{H}_{18} \mathrm{O}_{18}}$

Die Zerjebung des Solzes in der angegebenen 1 Seife kann ber Theorie nach io lange vor fich gehen, bis aller Eauterftoff uno $\mathfrak{3 a f f e r i t o f f ~ a u s g e t r e = ~}$ ten ift. Da bie 22 2leq. Sauerftoff bes frifchen 5olzes 11 அeq. Soblenftoff bebürfen, um mit ifnen 11 Sohleniäure zu bilben, fo blieben alfo $\mathrm{C}_{25}$ als

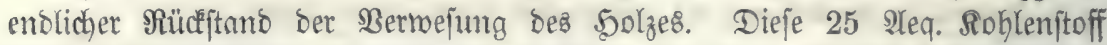
werten fick unberändert erhalten, weil bie Soble bei gemöhnlidjer Iemperatur feine Berbindungen mit andern Rörpern eingeht; Den $\Re$ feft $\mathrm{C}_{25}$ nennt Riebig "Mober".

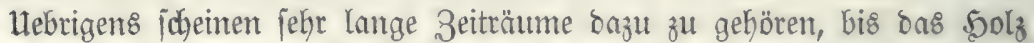
gämzlich in Mober fich bermandelt Gat. Denn bie meifze zerreibliche Maffe aus im Gmnern faulen, biele Gunbert Safre alten, (sichen ift gewöhnlict) nur um

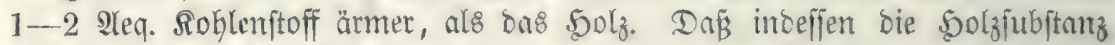
wirklich im saufe ber Zeit auf Moder reouzint werben kam, Davon geben uns Die Enger bon Braphit (fajt bolleomment reinem Rohlenjtoff), Deren organija)er

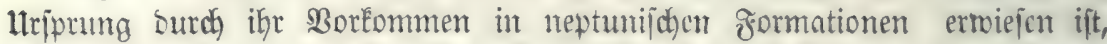

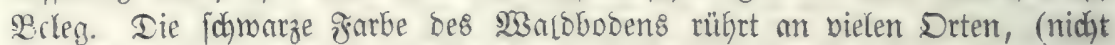
immer) von organifchem Rohlenttoff her, melcher gleichfalls als Mober ange= fehen werben fann.

\section{Relege für bie \$idhtigfeit ter efen entwidelfen Theorie ber \$olgberweitung.}

Die Unteritellungen, melche wir fo eben bezüglich, bes ßrozeffes bei bet

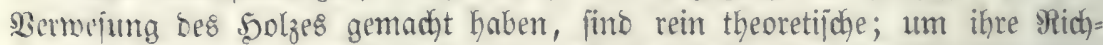
tigflit nad)zumeijen, müffen mir bie borbin burch jucceffive Eubtraction bon $\mathrm{C} \mathrm{H}_{2} \mathrm{O}_{2}$ bon $\mathrm{C}_{36} \quad \mathrm{H}_{22} \mathrm{O}_{22}$ enthaltenen formeln mit ben burch mirfliche llnterjuct)ung gefunbenten formeln bon in 3erjebung begriffenem 5olze ber= gleidyen.

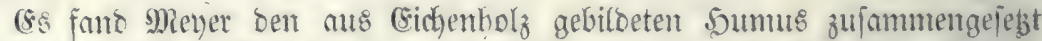

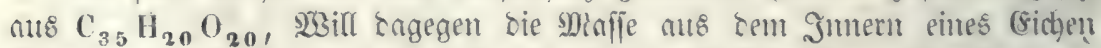

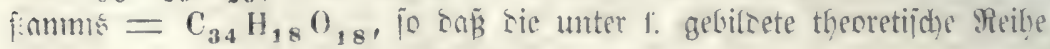

$$
\begin{aligned}
& \mathrm{C}_{36} \mathrm{H}_{22} \mathrm{O}_{22} \\
& \mathrm{C}_{35} \mathrm{H}_{20} \mathrm{O}_{20} \\
& \mathrm{C}_{34} \mathrm{H}_{18} \mathrm{O}_{18}
\end{aligned}
$$

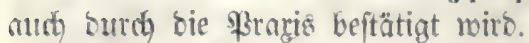

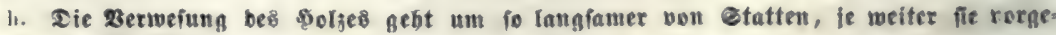 fobritten ift.}

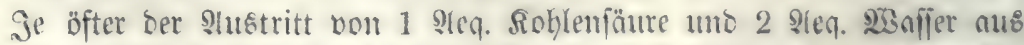

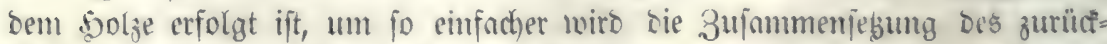

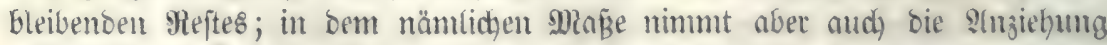

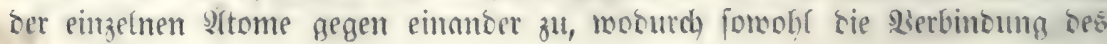




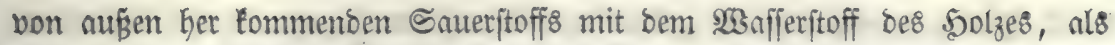

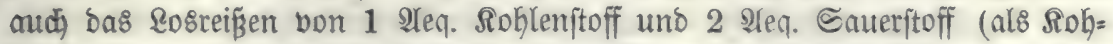

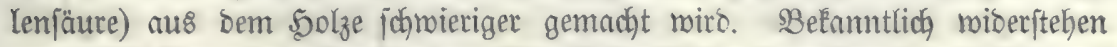

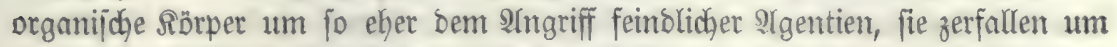
fo mentiger leidyt in ifje (stementarbejtanotheile, je einfacher ifje 3ujammen=

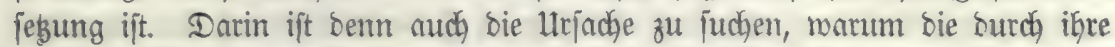

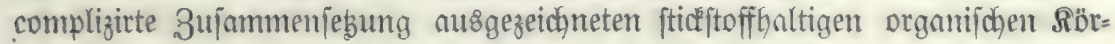

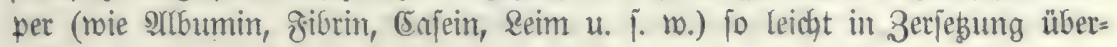
gehen.

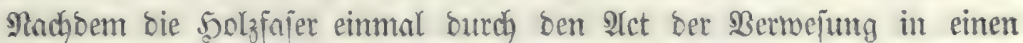

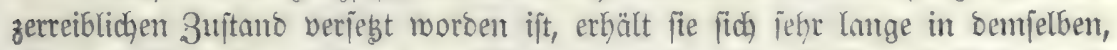
ohne merklich) Dunntitäten bon Soklenfäure abzugeben. Sa es jicheint, als

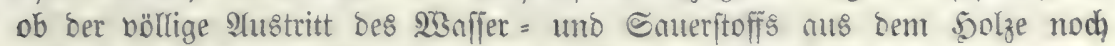
nicht in hunbertent, felbit taufenten bon Sabren erfolgen Ë̈nte. Dent reinen

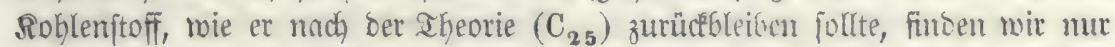

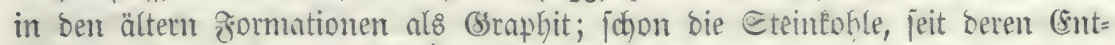
ftefung vielleidyt Millionen von Sabren verfloffen find, und aud bie Braun= Fohle, entbalten neben Soblenftoff noch Sauerftofi uno 23 afferftorf.

\section{Beförberungemittel ber Berweiung.}

23ie unter 2 benterft worden ift, find Saueritoff, $23 a ̈$ ăme und Feud)= tigfeit Bebingungen ber Bermefung. Eorgt man bafür, baß́ biefelfen in er= höhtem Mañe vorhanden fint, jo wirb bie Berwejung beichleumigt.

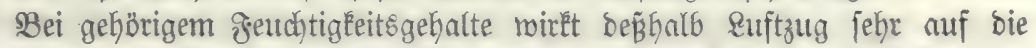
Berwejung eir. Itm jesen vermejenden Rörper bilbet firs eine Sidjichte von Sohlenjäure, melche bie atmoiphärifiche suft mit ihrem Eamerftoff abjchlieñt. Durch Den \&uftzug (20int) wirb bieje Sohlenjäure entfernt, an ibre Stelle

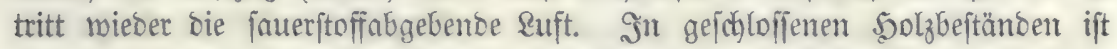

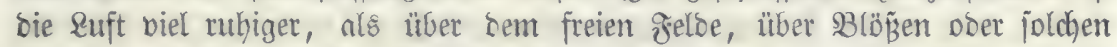
Flächen, auf Denen Eabler Afbtrieb ftattgefunden hat, uno auch rubiger, ats in

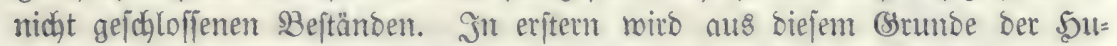

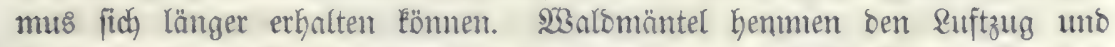

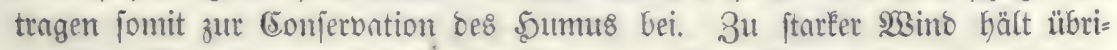

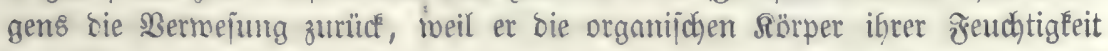
bernubt.

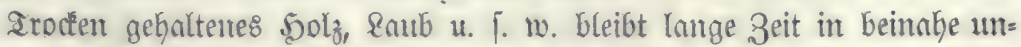
veränoertem 3uitmo, wie man an Miobeln, eingemauerten Balfen 2c. fieht.

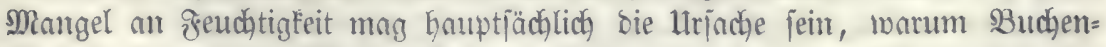

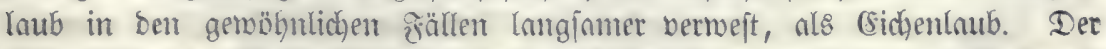

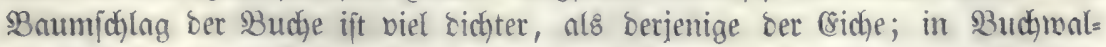

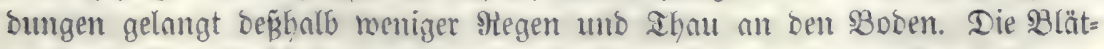

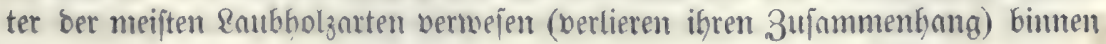


1-2 Jabren, währento in gejchloffenten Sudyentwaldungen bas abgefallente

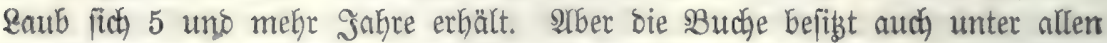

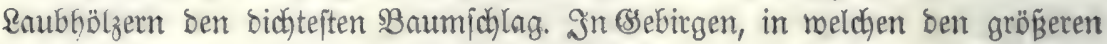
Theil bes Safres eine nebelfeuchte Ruft herrfdyt, verweit (mie im Bogelsge= birge) tas Budjenlaub in 1-2 Sahren, aljo eben fo ichnell, wie bas (sichen=

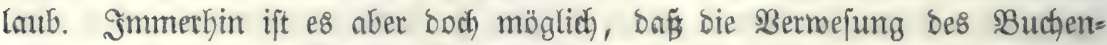
laubes much nodh burdh andere Hrjachen, meldye in jeiner Tertur, jeinen Eaft=

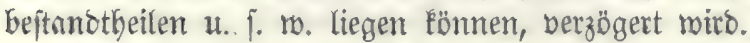

Nabeln verwejen im Sonzen langjamer, als saub; aber auth bei ben

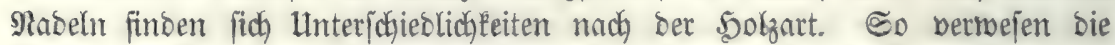

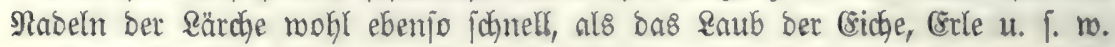

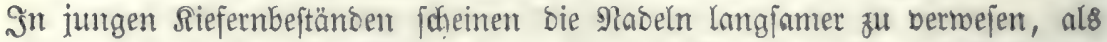
in ältern, was ofne Zneifel in bem größern Schluß ber jüngern Riefernbe= ftänoe, butd) welchen, wie curch bns Rnubbach Der Buthe, Der Regen abge=

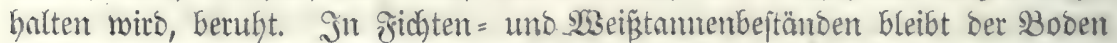

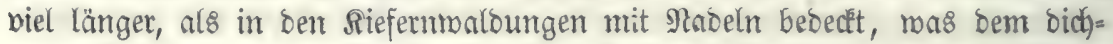

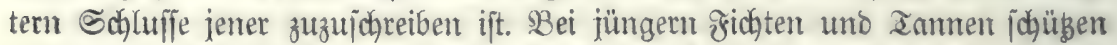
bie bis zum Boben berabhängenden 2Nepte bie abgefallenen Nabeln gegen Be=

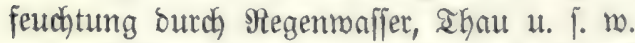

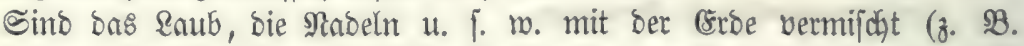

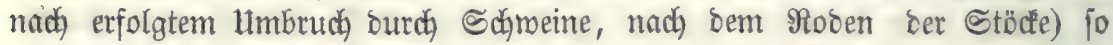
bermejen biefe Subjtanzen um jo eher, je loderer ber Boben ift, mobei mir

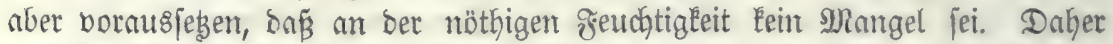
verzegrt fich ber 5umus fonneller in Sand $=$ als in ahouboden. Die Boben= lockerung, weldye ftattfindet, wenn ber Waldboben zeitmeife ber lanomirth= fdyaftlichen Bemugung überlaffen wirb, Gat immer eine Bejchleunigung ber Berwelung zur Folge.

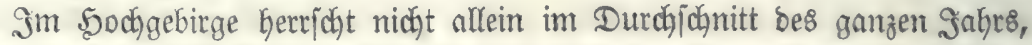
jonbern auch in best Sommermonaten eine geringere Iemperatur, als in ber (sbene. Def̈regen ichreitet auch bie Bermejung bes abgefallenen Baum=

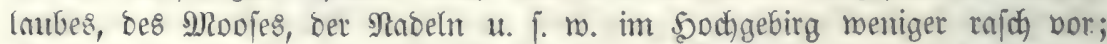

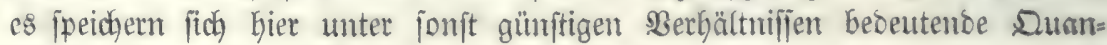
titäten von Sumuı auf.

Die Bermejung ocs 50 hes bängt ficherlich aud von ber Didhte feiner

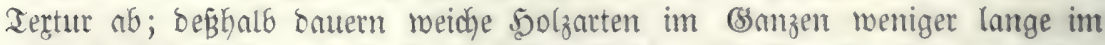
greien aแ8, als harte. Dod) gilt biejeళ Befes nidjt für alle \$olzarten; bas

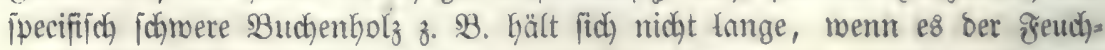
tigleit uno \&uft ausgejegt wird.

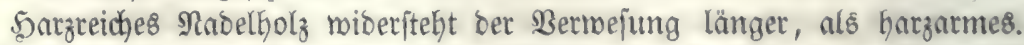

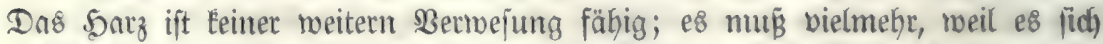
aus dem Ierpenthinöl burd Saueritoffaufnahme gebilbet hat, fobon at8 ein

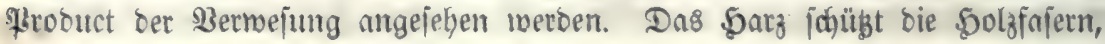


meld)e es umgibt, gegen ben 3utritt ber \&uft. $13 a d$ s, Gerbjäure, Iorffäure,

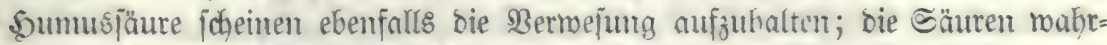

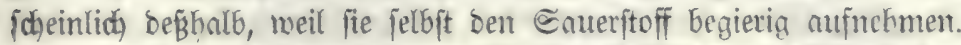

Die im Saft entbaltenen SllEalien beföroen die Berneejung; einmal

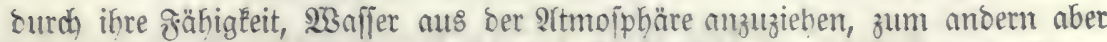

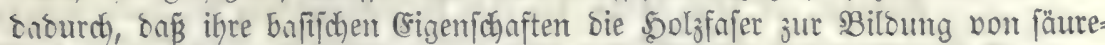
artigen Rörpern berantaffen. Rebteres gilt aud) non Een alfalijden Erben.

\section{B. Berweing beim abidu垈 ber Ruft.}

(sigentlich) ift bie Euft bei ber Berwejung niemnls bollftänoig ausge=

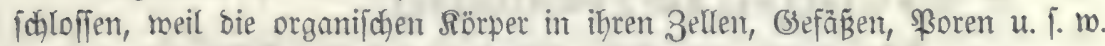
inmer etwas \&uft enthalten. Indeffen ift bie Menge biejer \&uft gering.

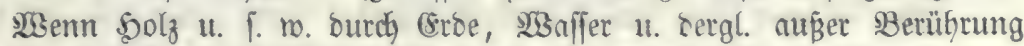

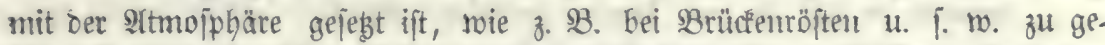

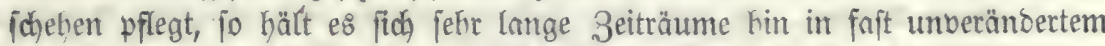
3uftande; exft nadh Inujenten bon Sahren ninmt bie Oberfläche eines joldjen

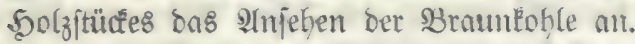

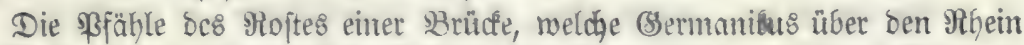
(d)lngen lief́, fano man wor Eurzer Zeit nod) ganz roohl erbalten. Etämme,

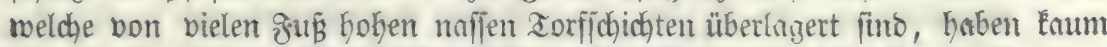

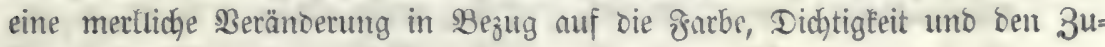
fummentyang bes 5olzes extitten.

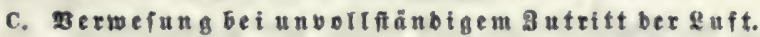

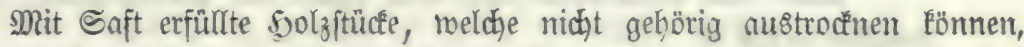
(8. B. reil fie nicht entrinbet worben fint) nefymen in ifrem Surtern eine Dumélere (graue, fodmärzlidje) garbe an, werben mürb uno berlieren igre (5on= fijtenz. Man nemut biejen Sict ber freimilligen Zerjezung bes 5olzes: bas Berjtocen. (s\& Fommt borzüglich bei aufgeflaftertem bicépaltigem Solze uno an foldhen Drten vor, welche nicht bintreicheno bem Euftzug exponirt find.

2lud) bie abgeitorbenen intern 5olzlngen von noch lebenden $\mathfrak{B a ̈ u m e n}$ fino bäufig bem Berftodéen unterworfen, Bei biejen geht bie urfprünglidje

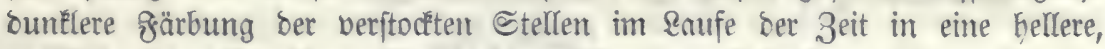

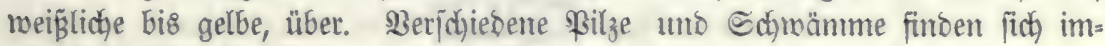

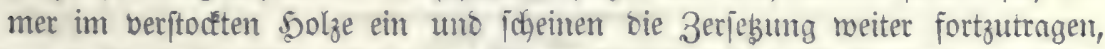
menn fie nuch) nicht als tie primitiven Urjachen bes Beritocfents angejehen werben Pbunen.

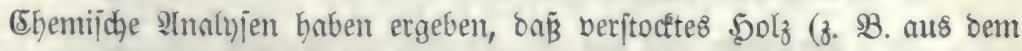
Innern von Bäumen) eine 3 ujammenjegung befist, welche fich burch bie

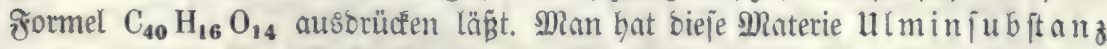
genannt. Sie ift bielfachen Beränterungen unterworfen, je nadhoem Ml(kalien, Feudjtigkeit uno Sauerftoff auf fie einmirken können. Unter Umitänoen, beren Bebingungen aber nodh nicht gebörig ermittelt morben fint, geht bie ltlmin= 
jubjtanz in ફuminjubitang $\mathrm{C}_{40} \mathrm{H}_{15} \mathrm{O}_{15}$, Ulminjäure $\mathrm{C}_{40} \mathrm{H}_{14} \mathrm{O}_{12}$, Suminfäure $\mathrm{C}_{40} \mathrm{H}_{12} \mathrm{O}_{12}$, Beimjäure $\mathrm{C}_{40} \mathrm{H}_{12} \mathrm{O}_{14}$, Quelljätre $\mathrm{C}_{24} \mathrm{H}_{1_{2}} \mathrm{O}_{\mathrm{L} 6}$, Queljąz=

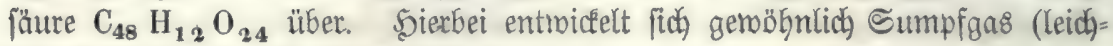
tes sohlentorferftoffigas $=\mathrm{CH}_{2}$ ).

(Sentauer, als beim Sgolze, hat man bie Heberführung fer Utminjubftauz in bie fogenannten f̧umuşäuren beim Buffer unterfucht. Diefer liefert, wenn man ihn mit Säuren unઠ Bajen nad) einantoer behanbelt, bie nämlidjen

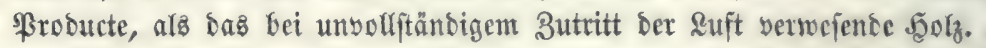

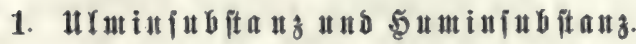

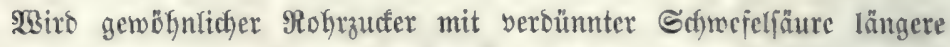
3eit bei eirer unter bem Sicbepunt liegenden Ientperatur crmärmt, fo ver= wantelt ex fid in eine braune untöslidfe Materie, welche fowohl ifrem

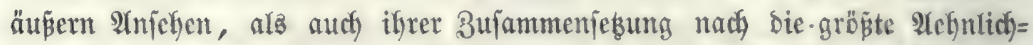

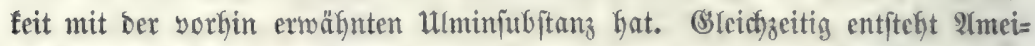
fenfăure uno 2 affer. Man fann jich Denfen, auz 7 भeq. Rohrzutfer bitbe=

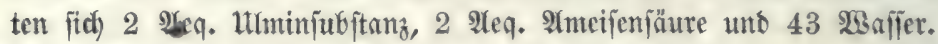

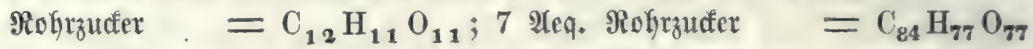

Ulminiubjtanz $=\mathrm{C}_{40} \mathrm{H}_{16} \mathrm{O}_{14} ; 2$ $\mathrm{Aeq}_{\text {. Ulminfubitanz }}=\mathrm{C}_{9_{0}} \mathrm{H}_{32} \mathrm{O}_{28}$

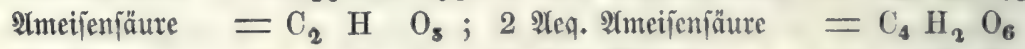
פaffier = $\mathrm{H} 0 ; 43$ 2eq. פEaffer $=\mathrm{H}_{43} \mathrm{O}_{43}$ Summe $=7$ Rohrzucter $=\mathrm{C}_{84} \mathrm{H}_{77} \mathrm{O}_{77}$

Sodyt man bie Ulminjubftanz nod) weiter mit Ect)ncfelfäure, fo ver wandelt fie fich in

$$
\text { Guminjubitanz }=\mathrm{C}_{40} \mathrm{H}_{15} \mathrm{O}_{15}
$$

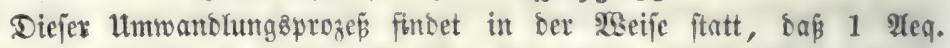

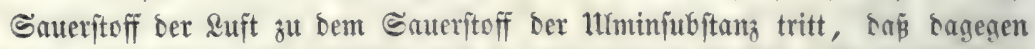

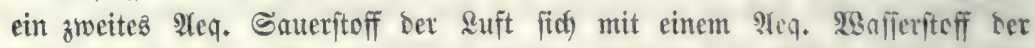

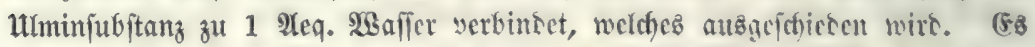
ift näm(tich)

$$
\begin{aligned}
& \mathfrak{u l m i n j u b j t a n z}+0-\mathrm{H}=\text { Sumimfubjtanz ober } \\
& \mathrm{C}_{40} \mathrm{H}_{16} \mathrm{O}_{14} \\
& \frac{-\mathrm{H}+\mathrm{O}}{\mathrm{C}_{40} \mathrm{H}_{15} \mathrm{O}_{15}}
\end{aligned}
$$

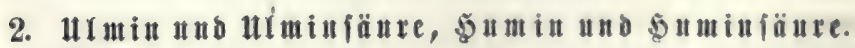

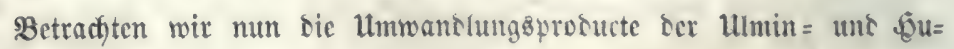
minjufitanz.

A. $u \mathfrak{n}$ infubitanz.

Befandelt man biefe mit fochentem foblenjaurem Ratron, fo entfteht

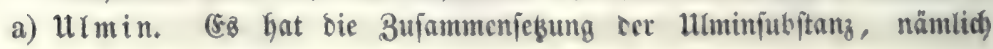




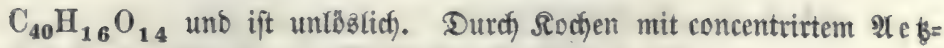
natron geht

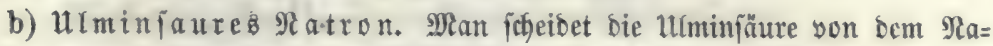
tron Durd, 3ufąs yon Sdywefelfäure ab; nämtich

$$
\text { Ulminiảure }+\left(\begin{array}{l}
\Re \text { atton } \\
\mathrm{SO}_{3}
\end{array}\right.
$$

Die Umminfäure wird in Dem yorliegenten Falle als cine braune gal=

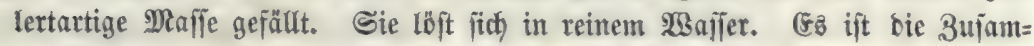
meniekูung bex

$$
\text { urminfăure }=\mathrm{C}_{40} \mathrm{H}_{14} \mathrm{O}_{12}
$$

Man fant fie jid entîtanden benten aus bem Ulmin, yon weldyem zwei

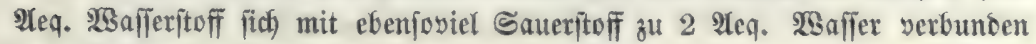
und abgecofieben haber.

\section{B. ธุนminโubitan.}

Behandelt man biefe mit fohlemiaurem Satron, fo bilbet fid

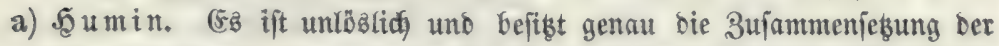

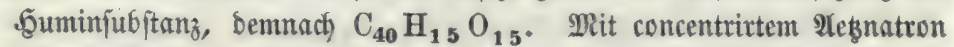

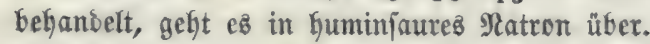

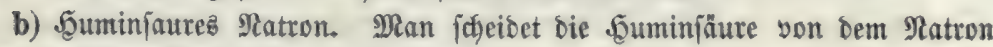
mittelift Schwefeliäure ab.

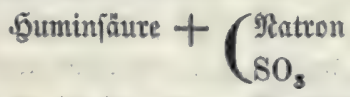

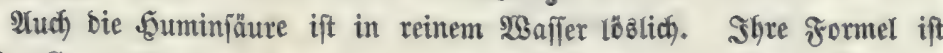
$\mathrm{O}_{40} \mathrm{H}_{12} \mathrm{C}_{12}$.

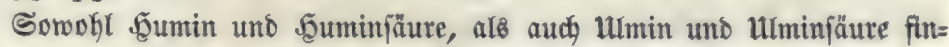
Den fid in ber Ratur, obwobl ber Hebergang bes f̧uminz in Şuminfäure

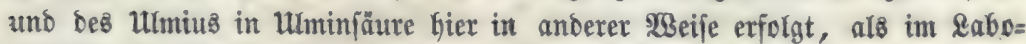

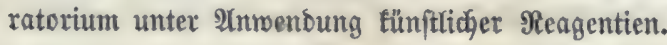

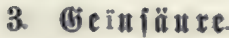

Die huminfauren Salze gehen unter ber (sinmirtung ber Sauerforf:

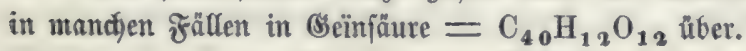

\section{Duerriăue แแ Duerriatäure.}

Beibe find von Berzelius in Quellen gefunden worben; fie fdyeinen je=

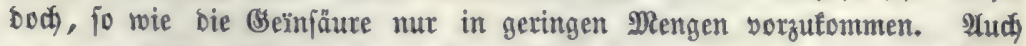
treten bie beiben Säuren neben ફ̧uminfäure auf. In reinem 3ujtande fennt man fie nod) nidjt, weil fie nidjt yon anhängendem 2(mmoniaf befreit wer= ben tô̆nten. 
(ss ift bie 3u[ammenjęung

$$
\begin{aligned}
& \text { des Quelläurefyorats }=\mathrm{C}_{24} \mathrm{H}_{12} \mathrm{O}_{16}+3 \mathrm{OH} \text {. } \\
& \text { bes Quellabjäurebyorats }=\mathrm{C}_{48} \mathrm{H}_{12} \mathrm{O}_{24}+2 \mathrm{OH} \text {. }
\end{aligned}
$$

\section{Torfbitoung.}

\section{a. Begrifi von Torf.}

Det Torf bilbet fich nus abgeitorbenen unt megr ober weniger ber 3er= febsung bei unvolftänbigem \&uftzutritt anheimgefallenen Pflanzen. Säufig tommen bierzu auch noch Mineralftoffe, mie Sano, ahon, \&ehm, Salk, Eijen= Kies, Esijenvitriol, Blnuteifenerde, Eijenodfer u. T. m.

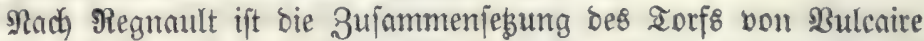

$$
\text { mit ardue ofne aridge }
$$

\begin{tabular}{lrr} 
Sohlenitoff & 57.03 & 60.40 \\
Wafferjtoff & 5.63 & 5.86 \\
Sauerjtoff & 31.76 & 33.64 \\
ajder & 5.58 & - \\
\hline & 100.00 & 100.00
\end{tabular}

\section{Gierfür berect)net fid) biegrormel $\mathrm{C}_{1 \mathrm{j}} \mathrm{H}_{21} \mathrm{O}_{13}$.}

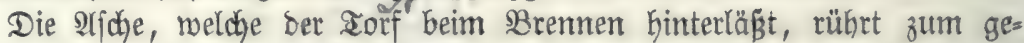
ringften Theil bon ben Bffanzen Ker, aus benen ber Torf entitanden ift, ift

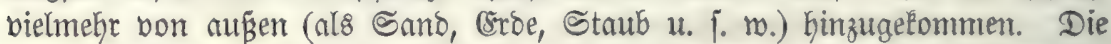

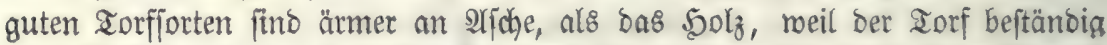

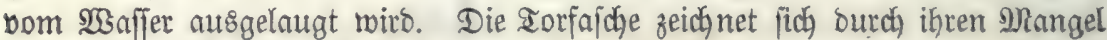
an Eoblentaurem siali aus.

Biele Iorfarten entfalten audh harzige und madysantige Stoffe, beren Nienge im Durdjpditt 1-2 Prozente beträgt.

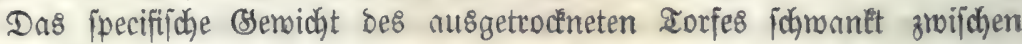
0,3 un 0,9 .

ACle Iorfarten enthalten \$ımtinjäure, Quell = uno Quelliab̧äure.

\section{b. Bebingungen für bie Torfbitbung.}

Somokl bie dhemifdhe 3u[ammenjebung bes aorfs, als nudh Das Bor= fommen ber Suminjäure, ber Duell = unb Quelfaj̧äure benten barnuf hin,

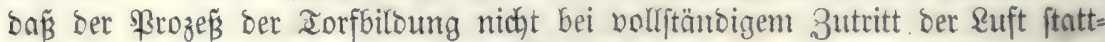
finbet. Denn im lestern Falle müroen bie gennnnten Säuren fehlen, c.ud

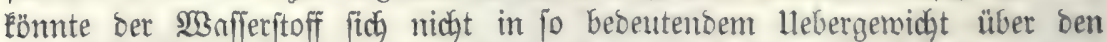
Sauerfoff erbalten baben. $933 a b r j$ feinlich finoet beim Torfe bie Bermejung

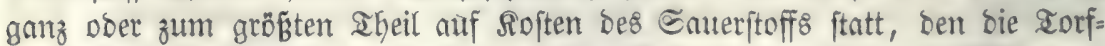
pflanzen jelbft befïben. Bergleichen wir näınlich bie vorfin entwidelte grormel

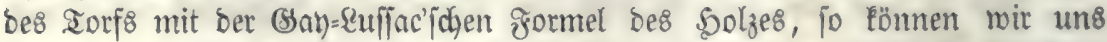
Den erftern entitanden benten burdy Nurstritt bon 5 STequibalenten Soblenjäure unto 1 2leq. 23affer 


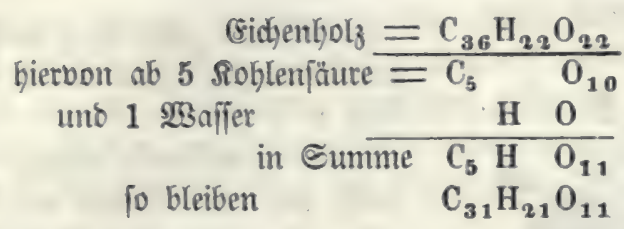

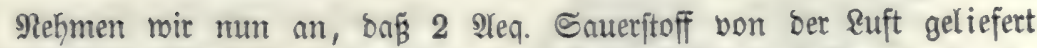
worben feien und fügen wir biefe bem fo eben erbaltenen $\Re e f t e$ zu, fo er= gibt fidw

$$
\mathrm{C}_{31} \mathrm{H}_{21} \mathrm{O}_{13}=\text { Iorf. }
$$

Saupt|ächlich ift es ftagnirendes 230 affer, welches bie suft bei ber $2 B i l=$

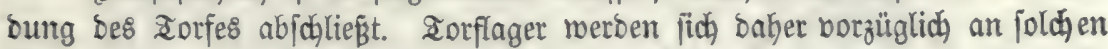
Drten erzeugen, welche zmar nody eine hinreichenbe aemperatur zur Entroid:

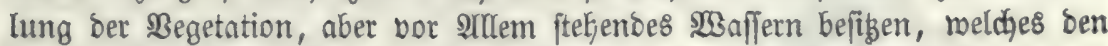

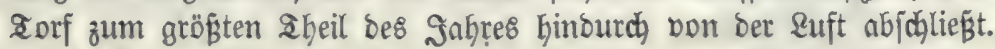

Borzüglid) geeignet für bie Dorfbilbung fint \$odgebirge, in benen einess

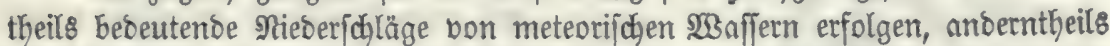
aber aud bie niebrige Iemperatur ber \&uft ein rajhes Berbunften biejes Waffers berhindert. Finden fich an joldten Drten Jetsarten, melche aus

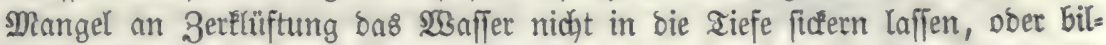
bet Dajelbft IFon *) einen undurdhlaffenden IIntergruno, io ftauen fich bie 2Baffer an und verurfachen Sümpfe. In biefen madj]en Pflanzen, meift

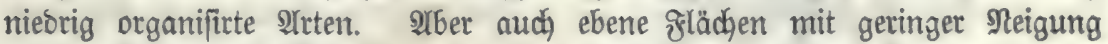

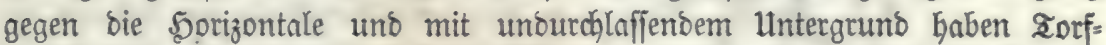
lager aufzumeifen. Cinige ber getwöhnlichften borfommenten Sumpfgetwädje fint.

Erica tetralix, Calluna vulgaris, Vaccinium uliginosum, Vaccinium Oxycoccos, Vaccinium vitis idaea, Andromeda polyfolia, Empetrum nig rum, Ledum palustre, Salix rosmarinifolia, Eriophorum vaginatum, gracile, berffiebene Carex-2̂Arten, wie Carex paludosa, stricta etc., Ranunculus, Nymphaea, Alisma, Hydrocharis, Sagittaria, Potamogeton, Callitriche, Hippuris, Ceratophyllum, Chara, Lemna, Drosera, Juncus, bet=

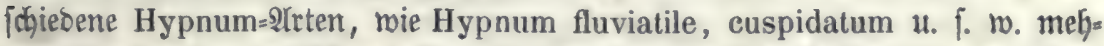
rere Equiseta; bor 2 UKem aber bie Battung Sphagnum mit ben Irten

*) Unmittelbar auf Igout bemerlt man bie wenigiten Iorflager, in ben meiften Fällen finben fï biejelben auf Sanb, unter weldjem in einiger Tiefe ber Igon bin. fitreidyt. 
Æ̊ig. 56.

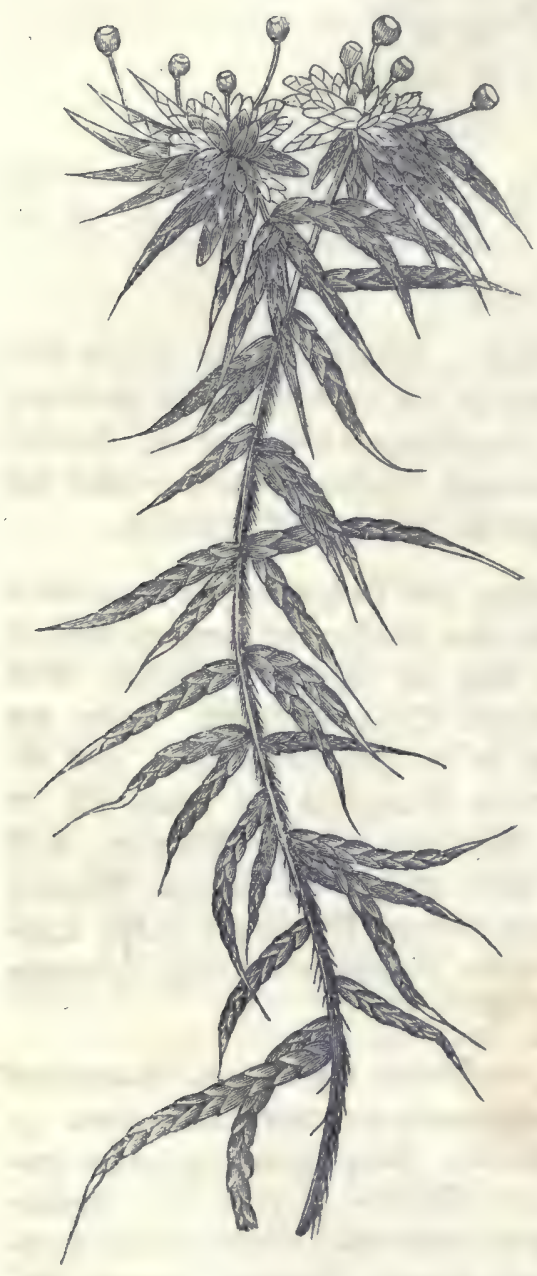

cymbifolium (す̊ig. 56.), molluscum, squarrosum, acutifolium, cuspidatum u. . . w.

Dieje Pflanzen exzeugen fich $10=$ mobl auf Dem SBoben ber Sümpfe, als auth auf ber Dberfläche bes Traj" ferb. Sie finken, menn fie im Serbft abfterben, entweder auf ben $B$ oben be8 Sumpfes, ober taudjen bod) po meit

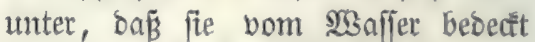
fint, ober merben entid von ben Serbjtwaffern überitaut. ఇad Ford)= Gammer foll in Dänemaré bas $23 a$ adj8 thum ber grösten Torfmoore nicht felten in ber $\mathfrak{2 B e i j e}$ bor fid gehen, baß̧ bie Dberflădje eines See's fich mit einer Moosbecfe überzieht, roldje

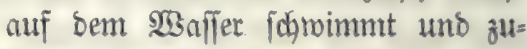
meilen fo bick mirt, dafis fie einen Menidjen zur Rotb tragen Eann. Det= gleidjen. Moore Geip̌en "Sangejact" im Munbe bes Bolfes. W3ino uno ঔłuth führen Sand und Schlamm über bieje Mroosbecfe hin, ber auf ifyr entitehenoe Maridjboden wiro immer bicker. (\$Bronn, Bejdjidgte ber Matur. II. 351).

Shnimmente Snjeln von Iorf, bie in ber ebert angegebenen 23 eije fid billoen, finbet man übrigens nod) an vielen andern Drten. "In bem Seroauer See in Breugen befant fidh lange eine jurwimmenbe Iorfinjel, io

groß̈, baß 100 Stüc Bieh barauf maibeten. Sie wurbe 1707 in mefrece

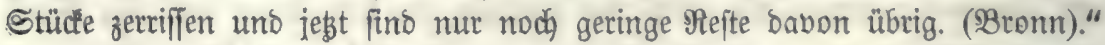

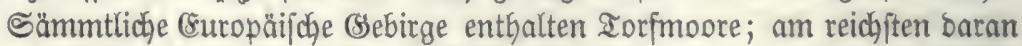
ift bie grofe (sbene, welche fich bon Belgien und Solland an Den Rüiten ber

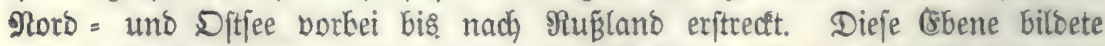

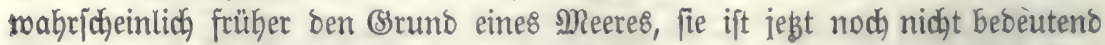
über Dem Meeresfpiegel erhaben uno befït Demnach bie geeignete Bejdaffen=

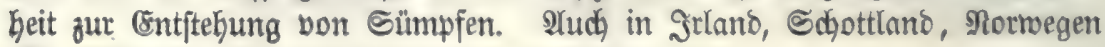
und Sdhweben Émmen bebeutente Iorimoore bor. 
Snt tou Bbenten ber शequinoctinlgegenden fehlt ber Torf gänzlich, wahr=

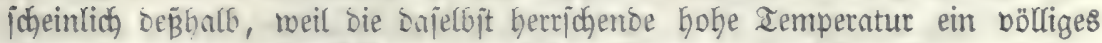
Bermejen ber zur Iorfbiloung tauglichen \$flarzen berwirlt. Sur auf bem Plateau ber Qfnten, wo bie mittlere Iemperatur nicht über $8^{\circ}$ bis $10^{\circ}$ (c) be= trägt, fan Bouñutgault ๔een mit হorjgrumঠ.

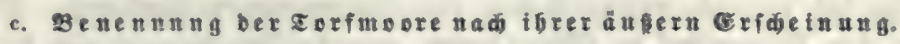
Man unterfidgetoet:

a. Sodjmoore. Rachibem eine Bertiefung, ein Sumpf burdy Torf aus= gefüllt morben ift, findet in bielen gällen noch eine fortgejegte Torfer= zeugung ftatt, troboem, baßj jegt bie Bflanzen nicht mebr bon einem

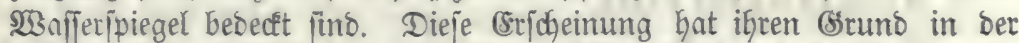
(capillarität ber Torfmoore; es miro beftänoig $23 a$ ffer auః ber হiefe auf=

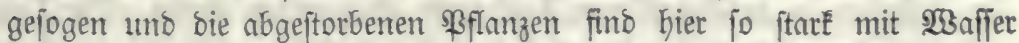

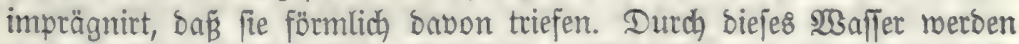

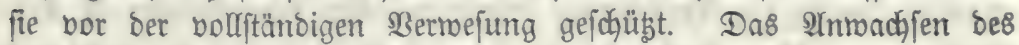

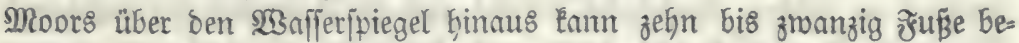

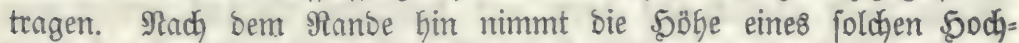
moors ab, meil hier bie (5npillarität biel geringer, als in ber Mnitte ift.

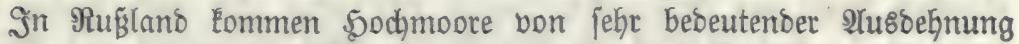
bor; fo foll bas Torfmoor, weldyes bie nöroliche Rüfte âfiens be= grenzt und angeblid, 300 MReilen \&änge und 100 Meilen Breite be fight, als, ein 5odymoor angejehen werben fünnen. Der Boben bet Torfmoore ift menig frudjtbar; feine Begetation befteft geroblynlid aus einzelnen verErüppelten Riefern, SBirken uno $23 e i b e n$.

B. Reffelmoore. Sier ift ber Sorf in eine Eeffelartige Bertiefung zmijchen

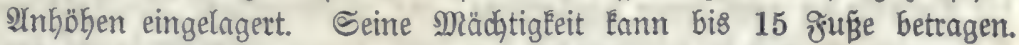
Dft ift ber Reffel burch Den Iorf boljtändig ausgefüllt. Die Baum= vegetation biejer Moore ift eben[o, wie bie ber Scocymoore, gering; ba= gegen liefern fte Brab unb $2 B a i b e$.

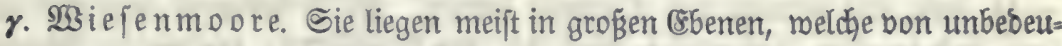

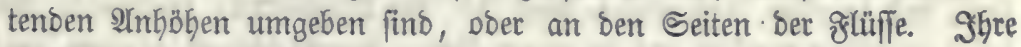
2lusbehnung ift geroöhnlich größzer, als biejenige ber Reffelmoore.

d. Meermoore. Diefe befinden fich an ber Rüjte bes Meere8.

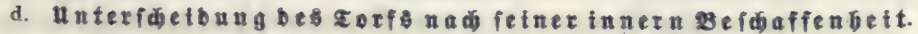

Je nach ber Dertlidýeit gibt eb eine zahlloje Menge bon Iorfarten. Die ఏaupteltaflen berjelben find folgente:

a. MNDostorf. (sr bejteght borzüglich aus den Stengeln uno Blättern von Sphagnum, meldhe der oben bejobriebenen unvolftänbigen Bermejung antyeimgefalten find. Seine grarke ift mandhmal ganz bell, wie bie bes frijchen Moojes.

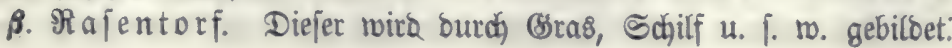


r. Bechtorf. Er ift mit Erobarz imprägnirt uno hat einen nuiळeligen sinuof.

d. Bapiertorf. (5r bejteft aus vermoderten Blättern, Moojen, Bras u. f. w. und lägt fid in bünne Sdjichten tremten.

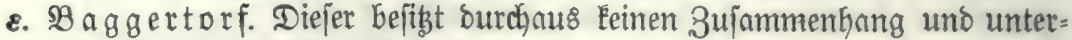
jotheibet fich baburch mejentlich von ben vorgenannten Torfarten. Man formt ben Baggertorf in Rlöge, wenn er ted)nijđ)e Bermenoung finden foll. Der Baggertorf Eann als ein organijđer Schlamm angejehen werben.

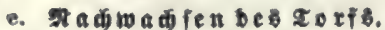

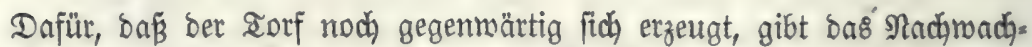
fen beffelben in ausgejtodenen Torflagern johlagenten Beleg. Die Dunntität

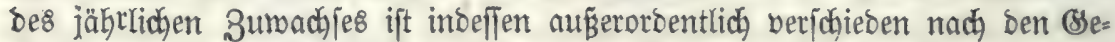
mächjen, melche zur Torfbilbung beitragen. N(m bebeutenoften ift bas Nach= wadjen bei jolchen Torflagern, rolche aus Sphagmum=2lrten bejtehen. Dieje Pflange treibt nämlich aus einem und Dempelben Stengel immer neue 2lefts chen und 23 ürzeldhen, fobald Der untere Theil abjtirbt. So Eann man in manchen Iorflagern Sphagnum=Stengel bon zehn uno mehr ơǚen \&änge

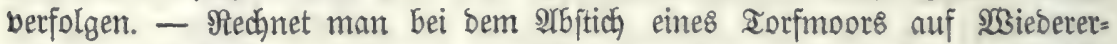
zeugung bes Iorf8, fo hat man vor artem barauf zu jehen, baß̧ ber aorf nicht

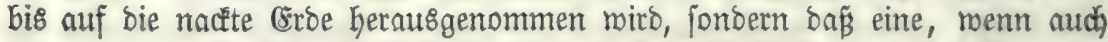
Dünne, Torfiohle erbalten bleibt. Mit bem 216jtich bes Moors barf nur ein temporäres, kein gänzliches 2lbleiten bes zur Torfbildoung unumgänglich nöthi=

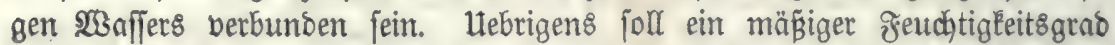
Die হorffilloung weit mehr begünftigen, als volnénmmene Heberfdyemmung.

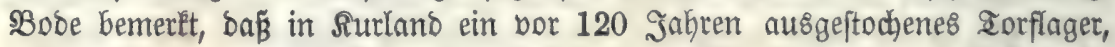

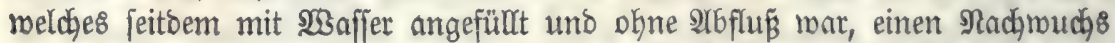

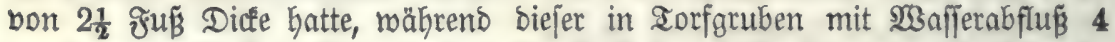

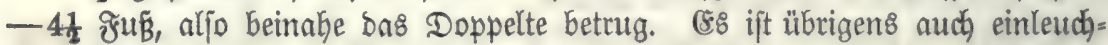
tend, bafi in einer blos naffen \&age bie zur Torfbildung geeigneten Pflanzen beffer vegetiren werben, als in eitrem See. 3wedtmäpigig ift e8 auch, bie Bege.

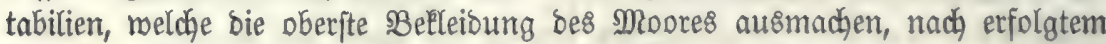
2Afjtich auf bie ftehenbleibenbe Soble auszubreiten.

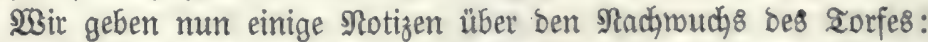

Im Sabre 1804 wurbe ein Iorfftich zu (Sundolzen am Bobenfee er= sffnet; nady Berlauf von 22 Sabren hatte fich eine neue Torflage bon $2 \frac{1}{2}$

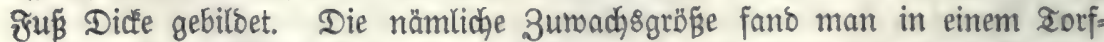
lager zu (sayenhofen. (Mayer) Ban Marum beobachtete, baß̧ in einem $\mathfrak{B}_{\text {affer: }}$

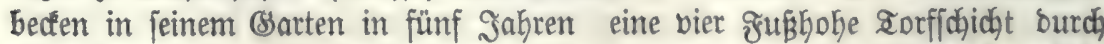
Conferba ribularis (?) uno Myriophyllum entftano. - Nady be Suc ftidst

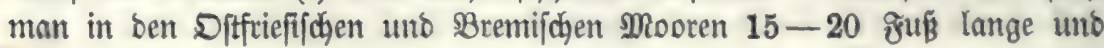




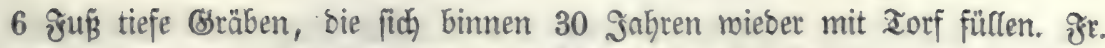

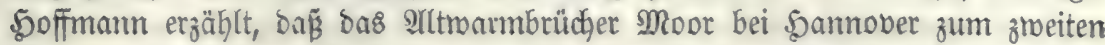

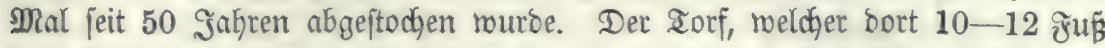

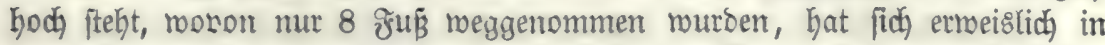

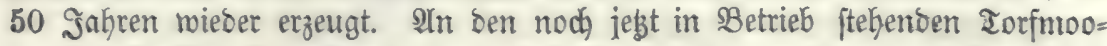

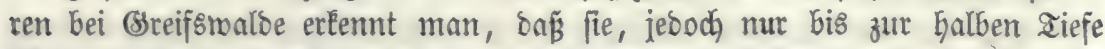
idjon einmal abgeftochent roorben fino; "Der in Den früherent Brruben faft bis

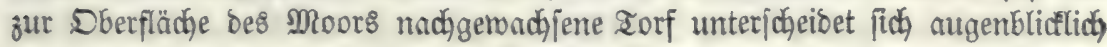
von bem barunter liegenten burdh getbere Farbe uno geringere Didate. -

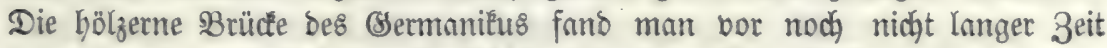

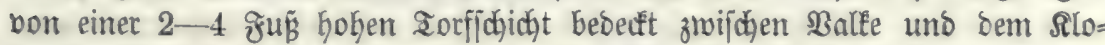
fter $\mathfrak{x}$ er $\mathfrak{A}$ pel im Drenthe=Departement der Niederlande. (Bronn).

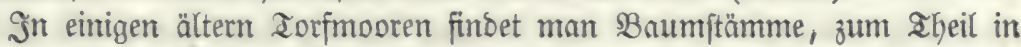

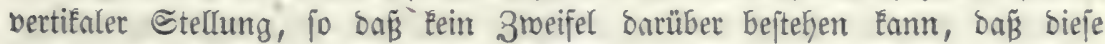
Etämme in bem Boben bes Moore\& jelbjt murzelten uno ppäterhin burch ben nadjwadjenten Torf eingehüllt murben.

\title{
Drittes Sapitel.
}

\section{פobenbilsungurd demifde Aräte.}

\author{
(2Rernitterung im engeren Sinne resి $\mathbb{B}$ ortes).
}

\section{1. भiff gemei ite?.}

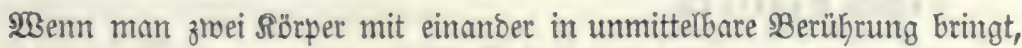

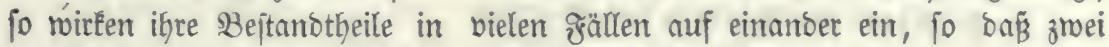
neue sörper entiteken, weldye bon ben urjprünglich borhandenen wefentlid

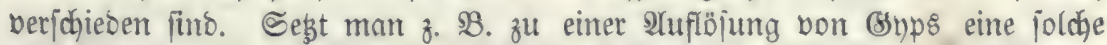

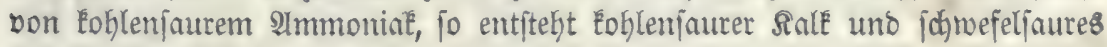
İmmoniatét.

$$
\begin{aligned}
& \mathrm{SO}_{3}+\mathrm{CaO} \\
& \mathrm{CO}_{2}+\mathrm{AmO}
\end{aligned}
$$

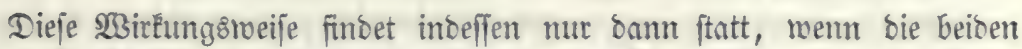

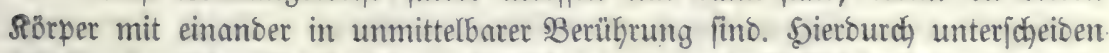

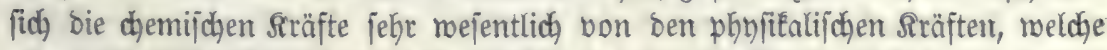

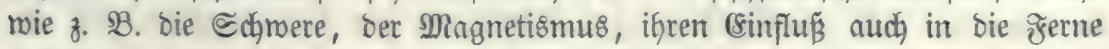
ăแถึern.

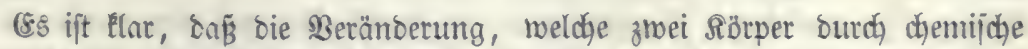

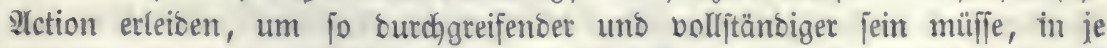
innigeter Berüfrung bie beiben Sörper fid befinden. Diejes Berhältniß̈ wiro bann am meiften erreidht, wenn bie beiben Rörper eine redyt großße Dber= fläche befïgen. Cino fie z. BB. flüiffig, fo fönnen fie fich) ant allen Bunften

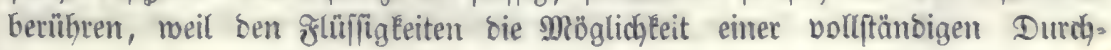


bringung gegeben ift. Defimegen bringt ber Ehemifer biejenigen Subjtanzen,

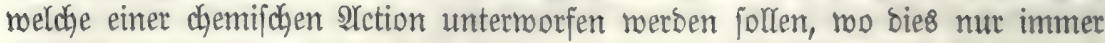
thunlich ift, in 2 tuflöpung.

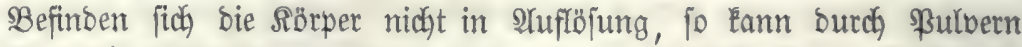
ifre Dberflädye vermefrt merben.

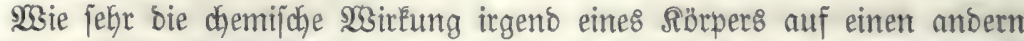

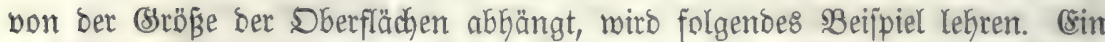
Subiezoll rifen, beffen Seite 1 3oll lang ift, befizt im Sanzen eine Dberfläche von 600 Quabratlinien (bec.) malzt man biejen Cubilzoll in ein 3 lech bon 1 sinie Didfe aus, fo ift bie Dberfläche bes Yesten mefy als 2000 Qua= bratlinien großs. Gifen berbinbet fich mit bem Sauterftoff an jeiner Dberflädje

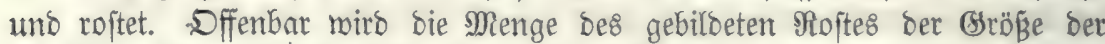
Dberfläche proportional fein, fich bemnach bei ben eben genannten frormen wie $600: 2000=6: 20$ verfalten. Bsibt man aber bem sijen bie Beitalt

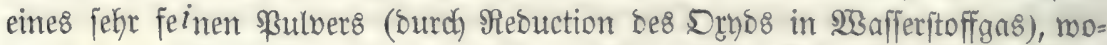
burch) feine Dberfläche auferorbentlich) bermehrt miro, fo entzünoet e\& jid an ber \&uft, indem es fich an allen Punften mit bem Sauerfoff berbinbet uno verbrennt volritänoig zu Drtyd.

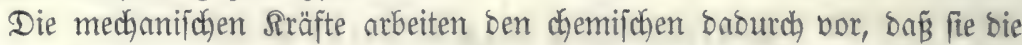

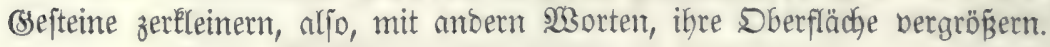

\section{Die Agentien ber Bertitterang und inte 2 irfug bei bencin= fathen Gefteinen.}

A. Cbemifide 28 irtunb Des 2 affers.

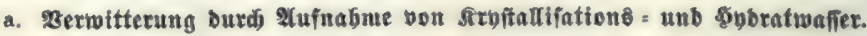

Berbinoungen von $\mathfrak{B}$ afen ober Säuren in bejtimmten Berbältniffen mit

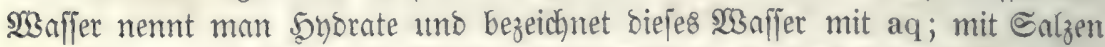
Doer 5 boraten berbunbenes 23 nffer, melches bie Sirbjtallgeftalt bebingt, nent man Rryftallmafler. $(\mathrm{OH})$

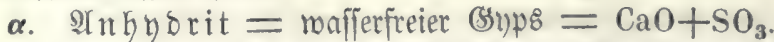

or fommt in vielen neptunifchen Formationen, Gouptfäd)lich in ber Iri=

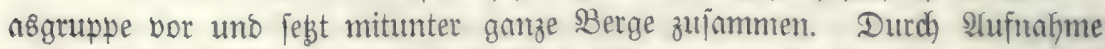
bon 2 צreq. Marfer bermandelt er fich it (Styps $=\mathrm{CaO}, \mathrm{SO}_{3}+2 \mathrm{OH}$. Sier

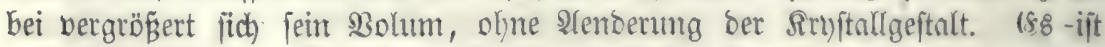
mabricheinlid, baf́ bie meiften (5ypfe aus Snfubrit nuf die eben angegebente

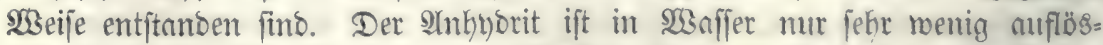

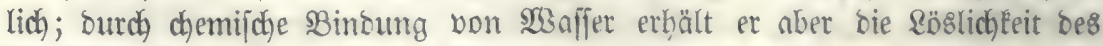

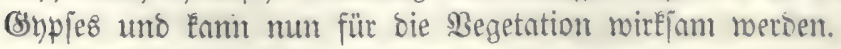

B. Eifenglanz $=\mathrm{Fe}_{2} \mathrm{O}_{3}$

finbet fich in vielen Sseftemen, z. B. Solfe, Brnumade, Echjefer, borzüglich

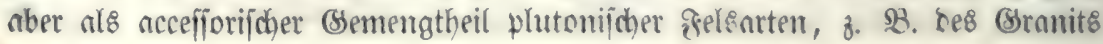


Durd 2tufnabme von 230 affer geht ber rijenglanz in

$$
\text { Brauneijenftein }=2 \mathrm{Fe}_{2} \mathrm{O}_{3}+3 \mathrm{aq}=\text { (Sijenorbohyorat }
$$

über.

\section{b. Tuftöing ber cefteine in reinem soffer.}

Die meiften Mineralien befigen eine nux geringe \&öslich'eit in reinem

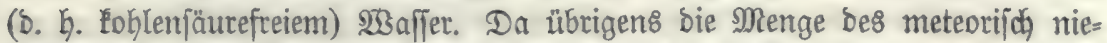
berfallenden $23 a f f e r s$ nidjt unbebeuteno ift (nad) Sdjübler fallen auf 1 ßreuß̈.

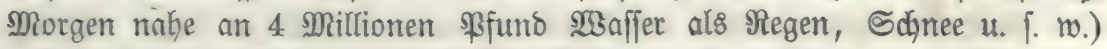

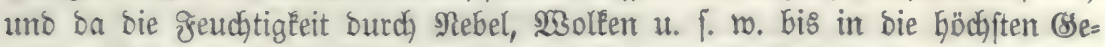
birge geführt miro, fo fino bie ßeränoerungen, welche bie Bsefteine unter bem

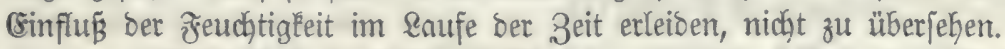

$\boldsymbol{\alpha}$. Steinfalz $=\mathrm{ClNa}$. Es Eommt in fejr bebentenden Maffen im

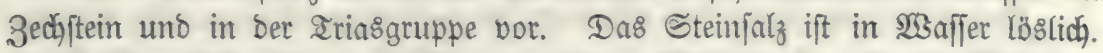

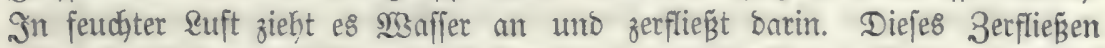

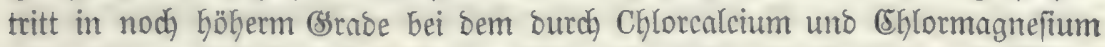
verunteinigten Salze eir. In mandjen Segenden, z. B. in ben sfuffifichen Steppen ift ber Boben auf groge હtredfen hin mit Steinfalz imprägnirt.

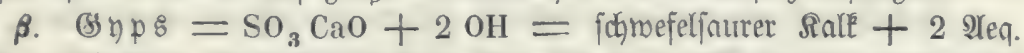
23affer. Die Farbe bes (sypjes ift meift meißs ober rötblid, aber audh grau

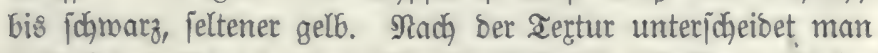

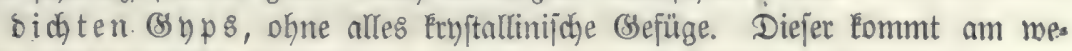
nigiten bäufig vor;

blätterigen (syps (graueneis),

fajerigen (syps,

ĭfaumartigen (syps (Bergmebl).

Bon allen fotwefeliauren Ealzen tritt ber Gyps in ben größten Maffen nuf. Gr kommt in Den ältern jebimentären Frormationen bom Old red Sandstone an aufmärtร vor. Im häufigften fintot man ifn in ben formationen bes 3edjpteins uno ber Iringgruppe; hier ijt er ein fajt nie fehlenter BBeglei= ter bes Єteinjalzes. Sn ber Formation bes bunten ๔anbjteins wechjellngert er oft mit ben befannten rothen Thonen. STud) in ber untern s(btbeilung Des Reupers ift Der Bsyps Gäufig in Begleitung von IDlomiten anzutreffen.

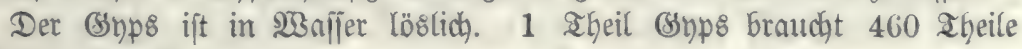
Waffer zur 2luflöpung.

\section{$\gamma$. Soblenjaurer $\mathfrak{R a l l}=\mathrm{CO}_{2}, \mathrm{CaO}$.}

Sines der verbreitetiten (Sefteine uno in überau groß̧en Maffen vorfommento.

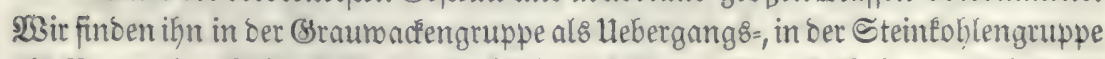

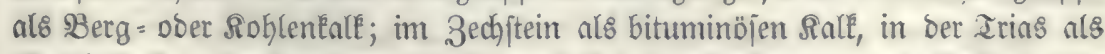

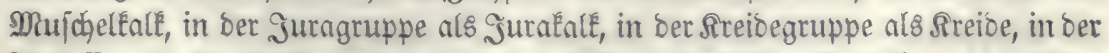

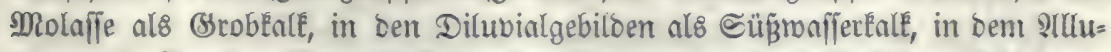

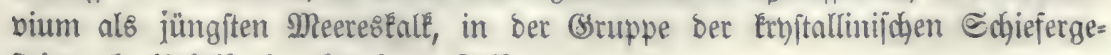
fteine als Urlalt ober törnigen Salk. 


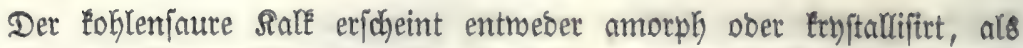
Saleppath und 2Yrragonit. Bon Den Rryftalfformen bes erftern lennt man über 300 Barietäten; fie laffen fich inbeffen alle auf bas ßibomboeber, wel=

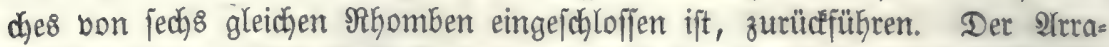
gonit weicht in feiner Sryftallgejtalt mejentlich bon ber Itrform bes Salfipaths $a b$, unterfacheibet fich bon biejem aud burch gröpere Särte und ein bebeuten= beres ipecifiches (servidit.

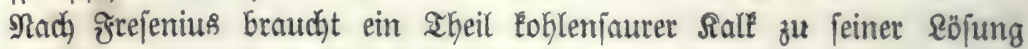
10601 Theile reinen (Éblenfäurefreien) $\mathfrak{1 3 a j f e r ళ . ~}$

\section{B. Berwitterug burd D xybation.}

a. Eijenipath $=\mathrm{FeO}, \mathrm{CO}_{2}=$ kohlenfaures sijenorboul.

Der sifenfpath finoet fich mitunter in fo grósen Maffen, dä́ er (wie in ber (Segend von Siegen) zur Bereitung bes Stahls berwandt miro. Seine Farbe ift gelblich, ex ift Gärter, als ber Ralejpath. Mitunter fommt er in

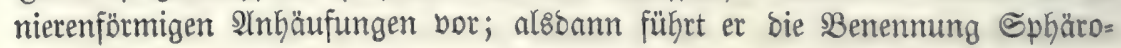
fitorit.

Der sijenjpath berliert allmählig jeinen sebalt an Soblenjäure, bas

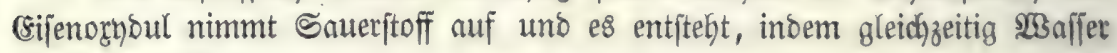
gebunden miro,

$$
\text { Brauneifenjein }=2 \mathrm{Fe}_{2} \mathrm{O}_{3}+3 \mathrm{aq} \text {. }
$$

\section{B. Dlibin.}

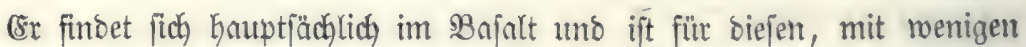

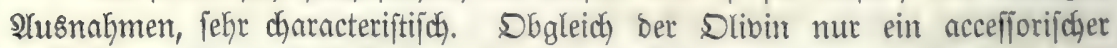
Beftanotheil bes $B$ afaltes ift, fo lommt er boch in ben meiften safalten in

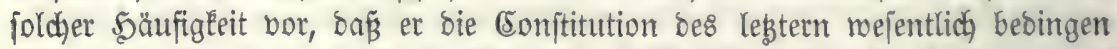

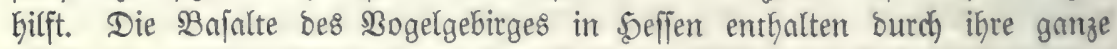

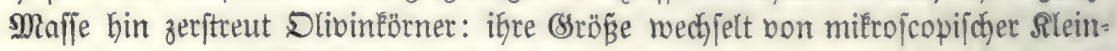
Geit bis zu ber Sröñ̈e eines Sinbertopfs.

Der Dlivin ijt für bie Berwitterung bes Bajaltes von um fo größerer W3idhtigkeit, als er, ferbft leicht zerjebbar, bie 3erftörung biejez (Sefteing Gaupt=

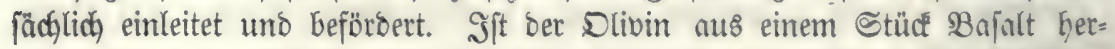
ausgemittert, fo erjheint e\& nun butch uno burd) mit brujenartigen Räumen verjeken, in welche bas $\mathfrak{W a f f e r}$ einzubringen, uno, inbem es gefriert, bieje= nigen (srjheinungen Gerborzubringen bermng, weldhe wir früber ausfütyrlich betradytet baben.

Man Kennt zwei Barietäten bes Dlivins - Den eigentlidjen Dlivin und

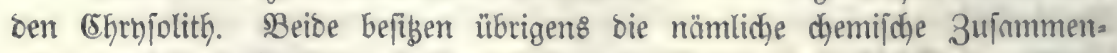
jeģung. Die mejentlichen Beftantheile bes Dlivins fint Siefelfäure, Mags

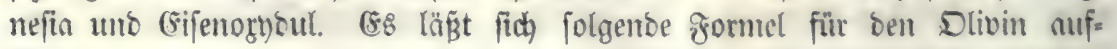
fitellen: 


\section{$10\left(3 \mathrm{MgO}, \mathrm{Si}_{3}\right)+3 \mathrm{Fe} 0, \mathrm{SiO}_{3}$}

welcher als prozentifobe Зu[ammenjesung entipricht:

$$
\begin{aligned}
& \text { Siejelfăure . . . 41,19 } \\
& \text { Zalterbe . . . 5 50,27 } \\
& \text { (8ijenornoul } \frac{.88,54}{100,00}
\end{aligned}
$$

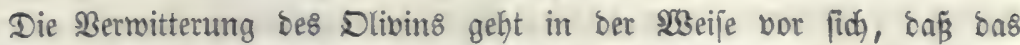

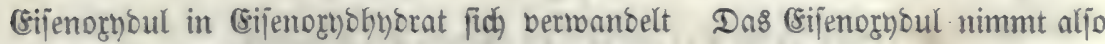
fomohl Sauerftoff, al\& 2 affer auf. Dabei miro bas Mineral gelb bis braun und zerfällt in eine zerreibliche, erbige Mafje.

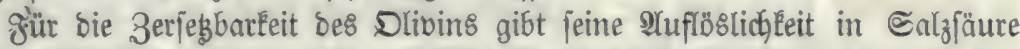

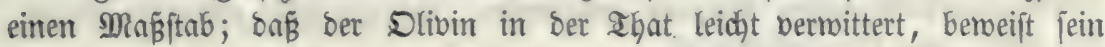
Borlommen im $\mathfrak{B}$ ajalte bes $\mathfrak{B}$ ogelşgebirges. Dort gebören nämlich bie un= zerfesten Dlibine zu ben Seltenkeiten.

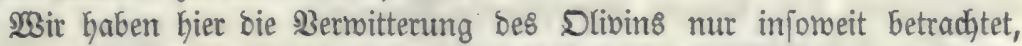

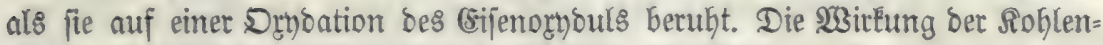
fäure auf biejes Mineral merben wir jpäter abhanbeln.

r. Magneteifen $=\mathrm{FeO}+\mathrm{Fe}_{2} \mathrm{O}_{3}=$ Eifenoryouloryd.

Das Magneteijen, weldyes fich burdh bie sigenidjaft, Das Bijen anz̧u= ziehen auszeidhnet, finbet fid vorzüglid, im $\mathfrak{B} a j a l t$, zu beffen mejentlichen,

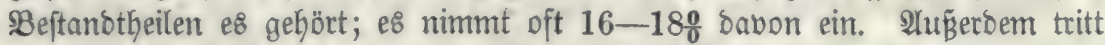
aber bas Magneteijen nody im Sradynt, in ben Eaven und als accefforifder

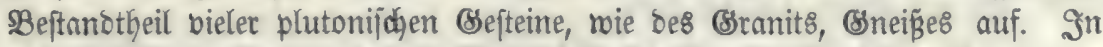
bielen regenden fommt es als Magneteifenjand bor, entftanden aus ber Ber=

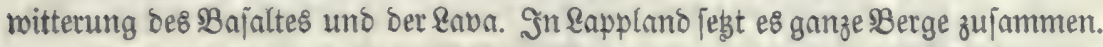

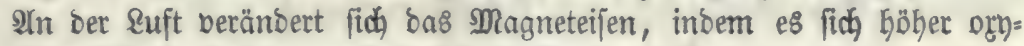
birt. Das Gifenorgbul vermandelt fich in Dryb.

\section{Magneteifen $\left.=\begin{array}{l}\mathrm{Fe} 0+\mathrm{Fe}_{2} \mathrm{O}_{3} \\ \mathrm{Fe} 0+\mathrm{Fe}_{2} \mathrm{O}_{3} \\ 0 \text { der Luft }\end{array}\right\}=3\left(\mathrm{Fe}_{2} \mathrm{O}_{3}\right)$.}

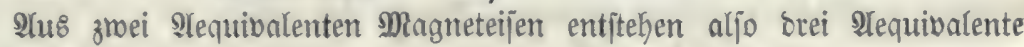
Bijenoryo.

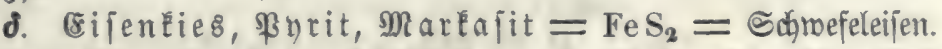

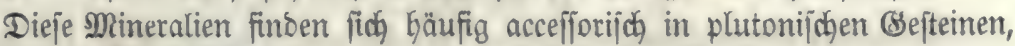
Бejonbers aber auf RTüften.

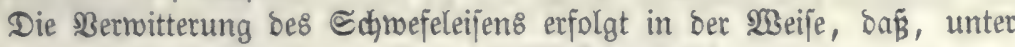
gleidjzeitiger Yrbjheibung bon 1 2leq. Sdjwefel, 1 Aleq. Saueritoff zu bem Gijen unb 3 2lev. Sauerjtoff zu bem reftirenden Sdymefel treten, roburdh jdgrefelfautes sijenort)oul (sifenvitriol entjtebt

$\mathrm{S}$$$
\left(_{\mathrm{O}_{3}}\right)=\mathrm{S}+\mathrm{FeO}, \mathrm{SO}_{3} \text {. }
$$ 
Diefe Berbinoung tann aber nicht für fich befteben; fie beonarf zu ibrer

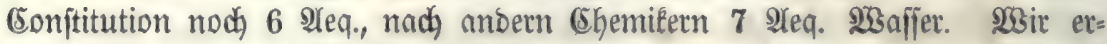
balten aljo aus bem sifenties

\section{$\mathrm{Fe} 0, \mathrm{SO}_{3}+6 \mathrm{OH}$ ober $70 \mathrm{H}$.}

Durch bie 2 ufnafyme von $\mathfrak{B}$ affer wiro bas uriprüngliche Bolumen be\& (sijentiejes bebeutent bermehrt. Die golge biejer Bolumsberänoerung ift ein Berften ber Felzarten, in weldhe Der sijenties eingefprengt mar.

\section{Berwitterung bur d Desิorbbation (Fbgabe von Gauerfofi).}

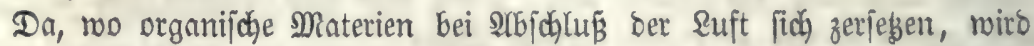
ber Sauerftoff theils aus ber organijdhen Subjtanz jelbit, theils aber audh von nnoern fauerftoffhaltigen Sörpern genommen. Sez̧tere fino entrober sBajen, ober Salze mit Sauerftoffiäuren.

$\alpha$. Desorybation formefelfaurer Salze (Eijenbitriol, Gyps,

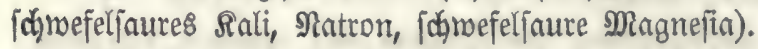

Die Desorybation beruht hier barin, onß́ jomohl ber Säure, als ber Baje Sauerftoff entzogen mirb, moburct Sdjwefelmetalle entiteben. Das

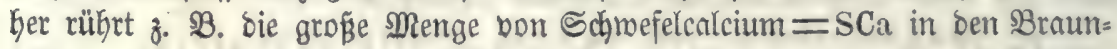

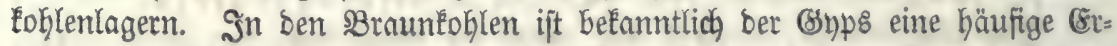
fdeinung. Err gibt zur Berwejung ber Brauntoblen 4 Seq. Sauerftoff her; es entiteft Sdjwefelcalcium $\mathrm{SO}_{3}, \mathrm{CaO}-40=\mathrm{SCa}$. In ben Sraun=

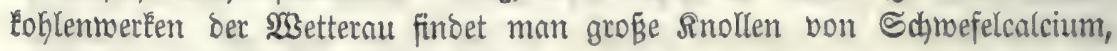
welche fich aus Gups gebilbet baben.

AYn ber \&uft orybiren fich bie Sdymefelmetalle wieber zul fohnefeljmuren Salzen; ift aber Rohlenfäure uno $\mathfrak{S a f f e r}$ zugegen, fo werben fie zerjeģt. (5:8

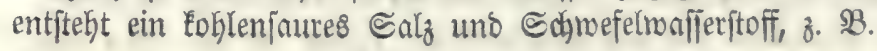

\section{$\mathrm{SCa}$$$
\text { ( }{ }_{\mathrm{H}} \mathrm{CO}_{2}
$$

Sommt ber Sdjwefelwafferitoff mit ber \&uft zujammen; fo wiro ber Schmefel abgeichieben, indem gleichzeitig 2 baffer fich billoet

$$
\begin{aligned}
& \text { S ) } \\
& \text { O Det Euft. }
\end{aligned}
$$

Sn vielen Brauntohlentbergmerken Der SBetterau findet man oft finger:

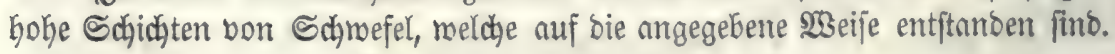

\section{B. Entfegung des Rajeneifenfteins.}

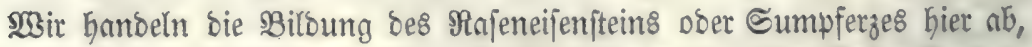

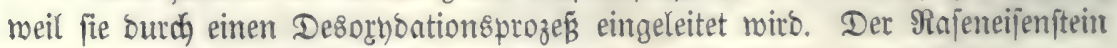
gehört ber 2AChuialgruppe an uno bilbet fich gegentwärtig nodh, wie Sautsmann, menigitens für Sdłweben, nachgemiejen Gat. Der Rajeneijenftein Eommt jo= wohl in einzelnen sroden uno slödéen, als aud) in ganzen Bänten vor, 
melche entweder bie Dberflähe bes BBobens bilben, Dber in geringer Diefe

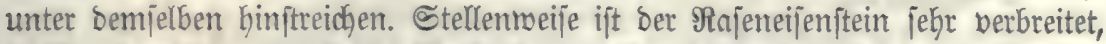
in Norbdeutjolano, z. B. in Medfenburg gibt es ganze Diftricte, Deren $\mathfrak{B}_{e}=$

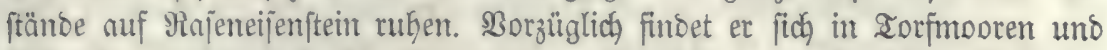
Sümpfen, baber aud bie Bentennung: Suntpferz. Sicht felten bietet ber

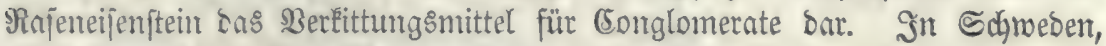
im Dsenwalbe u. \%. เo. Benust man ifn auf Gijen.

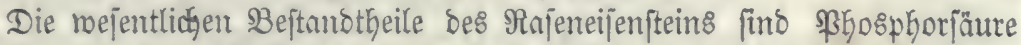

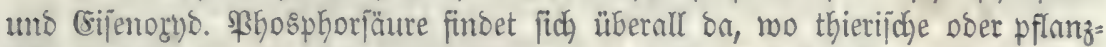
lidge Drganismen berwejen, wie aljo borzugsmeije in Cümpfen. Das Eijen=

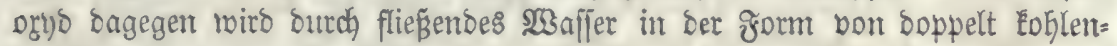
fautem rijenogrybul zugefüfth.

Das Eijenorboul finoet fich in ber Natur biel jeltenter, als bas (sijen=

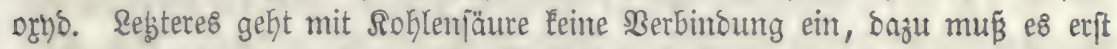
zu Dryoul reduzirt werbeu. MBie Sintler beobachtet hat, find es vorzüglid organiiche Subftanzen, welche dem (sijenonyd einen IGeil feines Sauerftoffs

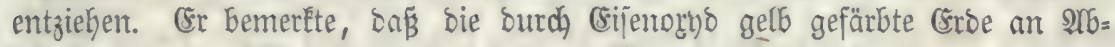

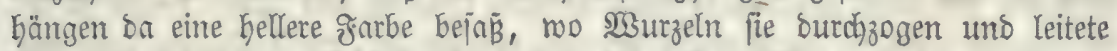

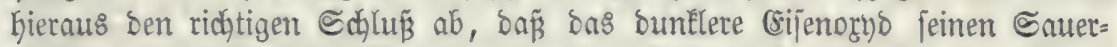

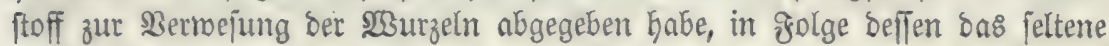
(Gijenoryoul entítand: $\mathrm{FeO}$

\section{Fe 0 - Drg. Subjtanz.}

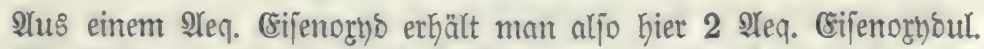

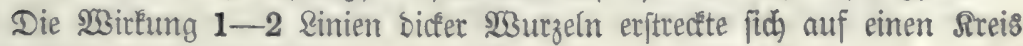
von 1-2 3oll Durdfmeffer.

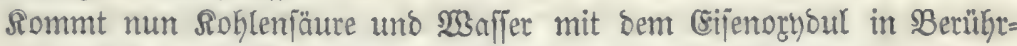

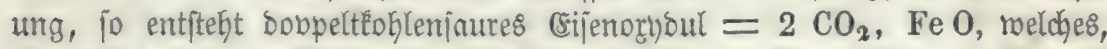

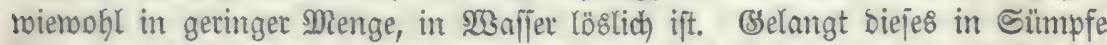
Doer an anbere Srte, an benen \$3bsphorjäure fich vorfintet, fo verbintoet fich lestere mit bem Eijenorybul, mobei biejes gleidzzeitig Enuerftoff aufnimmt uno wieser in (sijenorlyo übergeht. Eo entifteht alfo phosphorjaures sifenoryo.

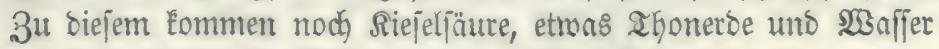

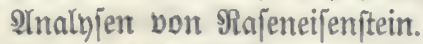

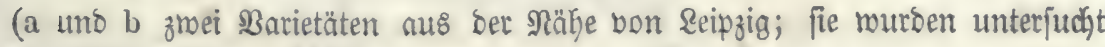
von (Eromann).

\begin{tabular}{|c|c|c|}
\hline $\begin{array}{l}\text { rijenorys } \\
\text { Manganortyo }\end{array}$ & 51.00 & 60.50 \\
\hline \$5овฺ For[äure & 10.99 & 9.57 \\
\hline Riejetfăute ... & 9.20 & 5.95 \\
\hline Ebonerbe & 0.41 & 0.73 \\
\hline 9KZoflar & 28.80 & 23.95 \\
\hline & 100.50 & \\
\hline
\end{tabular}




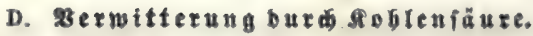

a. Allgemeines.

Mitteljt ber ftarken Säuren, meldje wir in ben Enbaratorien Earfellen, unb unter Arnwenoung bon Gohen Temperaturen find mir im Stanbe, fait fämmitlid)e Mineralien uno (Sefteine in ifre einfacheren Beftandtheile zu zer=

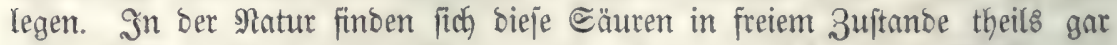
nidht, theils in fehr geringer Menge uno auk̈erbem berbünnt mit 23 affer bor. Dennoch) erleioen bie (Sejteine Dort bie nämlichen Betänoerungen, wie in unijern $\mathbb{R}_{n}=$ Garotorien unter ber Crinmirkung ftarker Säuren. In ber Natur werben bieje burch bie Rohlenjäure bertreten, weldje in ifyrem Berbalten gegen bie Metalle als

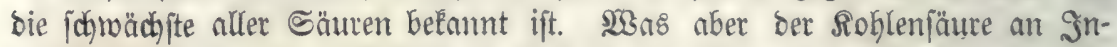

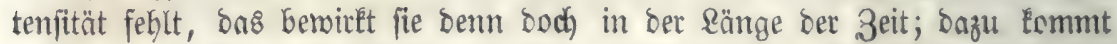

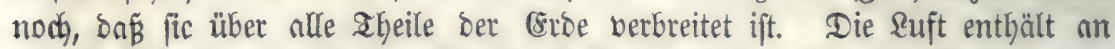
uno für fich einen conftanten Befyalt an biejer Säure; was bie Pflanzen bei ifrer Ernährung Dabon abjorbiren, wiro Dutch Den Berwefungs = ober Ber=

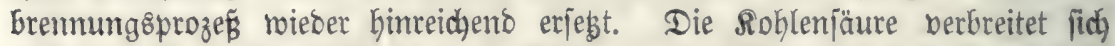

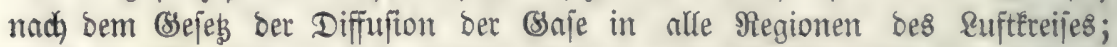
fie findet fich jelbit auf ben höbjten Bergen. Sn $\mathfrak{M B}_{3}$ ffer gelöft bringt fie in bie feinjten Spalten ber Befteine ein und bemirft fo eine Berjegung jelbjt in

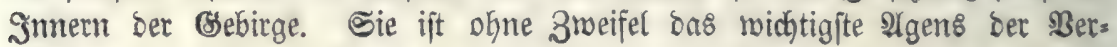
witterung.

\section{b. Cinwirtung ber Aobienfäure aul tobienjauren Ralf.}

Die Berbreitung bes foblenjauren Rale's murbe bereit\& ङ. 79. be=

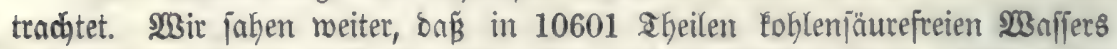

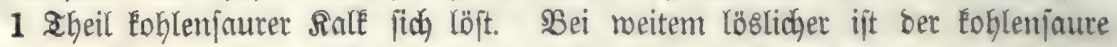

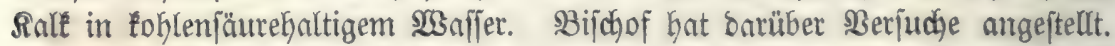
2(uf ber Bleimeigffabrił zu $B$ urgbrohl murbe Sohlenjäure in grofie mit 4-6

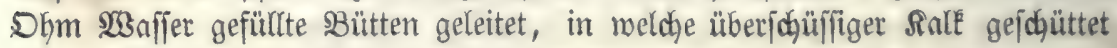
war. sijatiof erbielt folgende Rejultate.

Ingemanoter Sale

Dauer bes Durd) = Sn 10000 Theilen $23 a$ fifer waren ftrömens Der $\Re 0 h=$ meutraler Eohlenjaurer $\Re a l^{k}$ auf= ไenjäure

1. Nreibe

1 Stunde

2. besigl.

2

3. Desgl.

3 " " gelöpt

4. burd) ซällung aus einem Ralle= jalze Dargeftellter Sale

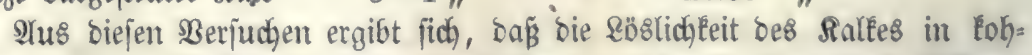

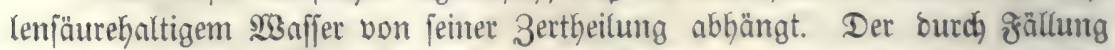
aus einem Ralkjalz Dargejtellte Ralk hat bie Bejtalt eines \$Bulwers, ex befigt eine jefr grof̧e Dberfläd), weldłe mit ber Soblemjäure in Berührung treten

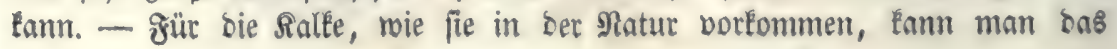




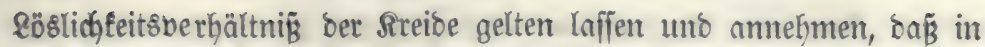

10,000 Theilen foblenjäurebaltigen 2 Baffers 10 Theile neutraler foblen=

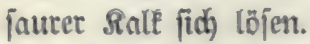

Uebrigens löst fich nidgt bet neutrale Eoblenjaure Salt als joldher, in bem

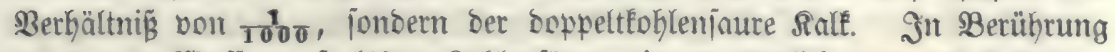
mit ber in $\mathfrak{B}$ nffer aufgelöften $\Re$ ohlenïäure nimmt nämlid, Der einfach fohlen= faure Ralé nod) ein $\mathfrak{A} e q$. Roblempäure nuf.

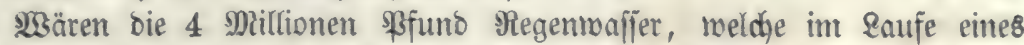
Sahres auf einen heff. Mlorgen ( $1 / 4$ Sectare) nieberfallen, vollfommen mit Rohlenjäure gejättigt (was indeffen nidjt ber grall ift), jo ruuroen biejelben 4000 \$runo fohlenjauren Ralf aujăulöjen bermögent.

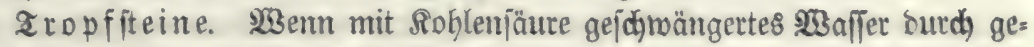
borftene Ralffeljen burdjficfert, jo löft ę, wie erwähnt, Salé nuf uno etweitert

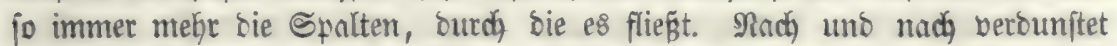

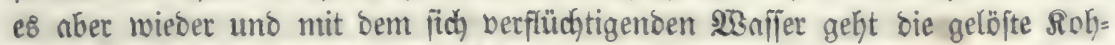

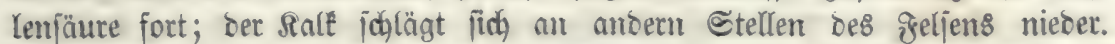

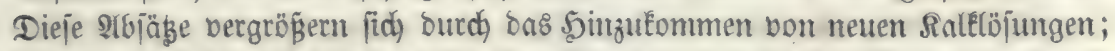

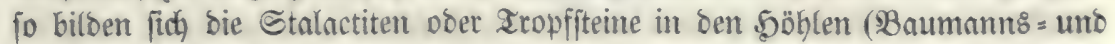

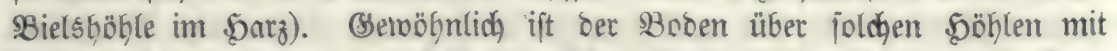
einer Decte bon \&flanzen beflleidet, meldye, wenn jie verwejen, Rohlenjäure

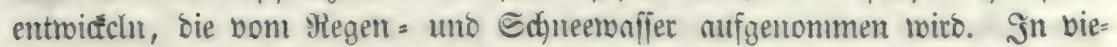
Ien Bejteinen, bejonters benjenigen, weldge Salf enthalten, wie \$ajalt, Snenit,

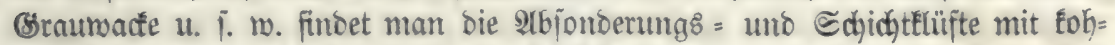
lenfautem Ralf befteibet, oft jogat gänzlich nuвgefüllt. Dieje Ralfabjäbe futo in ähnlidjer $23 e i j e$ mie bie 2 ropffteine, entftanden.

RalEtuff un RalEjinter. Biele Quellen belizen idjon bei ifrem

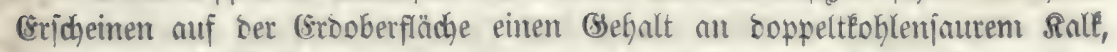

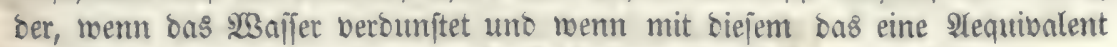
sohlenjäure entweidy, als nettraler Éblenjaurer Sialé fid nieberjojlägt.

$$
\frac{\mathrm{CO}_{2}+\mathrm{CaO}}{\left|\mathrm{CO}_{2}+2 \mathrm{Ba}_{\text {aler }}\right|}
$$

So entitehen Saltetuif uno Salffinter. WBie (8. Roje bemerlft, jegt jich berjelbe aus Ealten Duellen ftets in Der Beftalt des Ralejpatys, aus beipen bagegen in berjenigen bes Srrngonits $n$ b.

Ungeheure Mengen bon Ralejunter liefern bie Cartsbader Duellen. Die $50^{\circ}$ (5. warme Dutle von ๔nu gilippo im Brobherzogthum Dosfana hat einen Bergrïten von 24 bis 30 Metern ந̋̈he uno einem Rilometer \&änge von Ralefinter aufgebäuft. Bei Sivoli conjtituirt ber Ralftuff (Irnbertin)

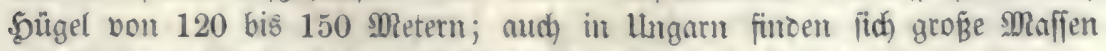

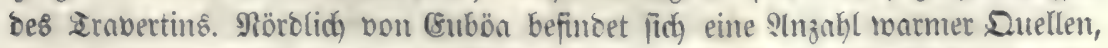
beren jece einen Đüget von Salfiuter um ibre Seffmung abgejegt bat. Eo bat firch ein eleimer Bergaug gebiloet, Der nabe an 20 Metern über sas 


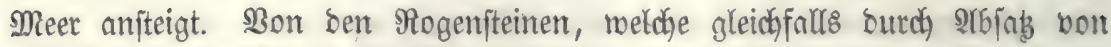
Eoflenfaurem Ralé aus Duelfen entitanoen fino uno nods entíteben, kaben wir fibon früher gehandelt.

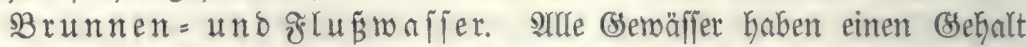
an Eohlenfautrem Rale. Diejer ijt als boppeltéoblenjaures Salz in Röfung. Da ber Salf fo weit berbreitet ift und aud) bie Roklenfäure nirgenos fehlt, jo pind überall bie Bebingungen vorbanoen, unter benen bie Bserwäffer Salk aufnelymen fönnen.

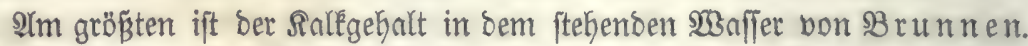
Bon jenem rübren bie Bobenabjäge in ben Rochgefdirten her, bie man ge=

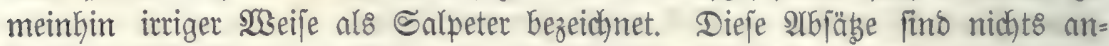

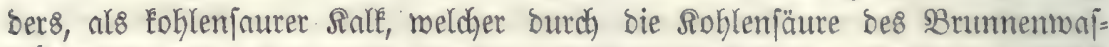
fer's gelöft war, aber butch bie beim Rochen ftattfindende $23 a r l u n g$ zugleid) mit ber Sohłenjäure ausgetrieben nurbe. Das Rochen bietet baher ein Mittel

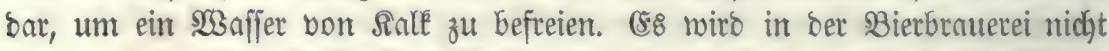

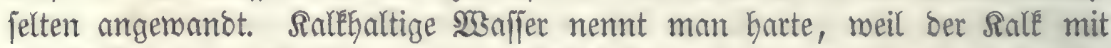

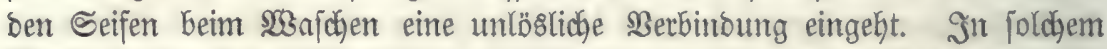

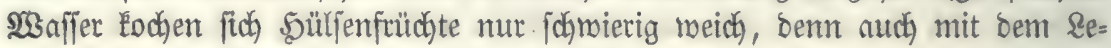

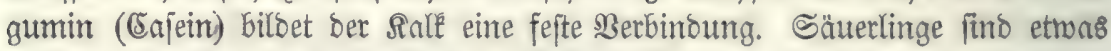

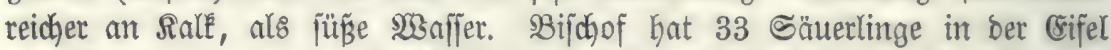
unterjucht uno barin bis 0,0006 Theile Rale gefunden.

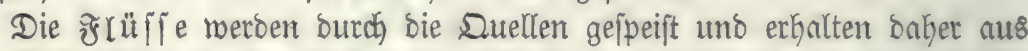

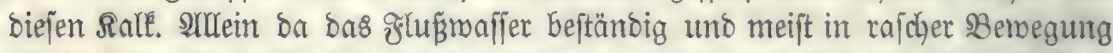
ift, fo miro bie Rohlenfäure auвgetrieben uno ber unlöвtiche neutrale Eohlen=

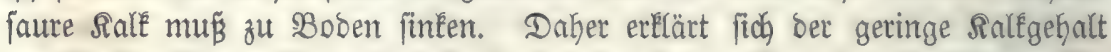

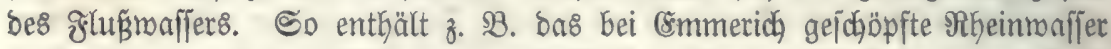
noch nicht $\frac{1}{100000}$ an Eoblenjautrem Sinle. Şe weiter ein ơluß in jeinem sauf fortfor)reitet, um fo mebr nimmt fein salégebalt ab.

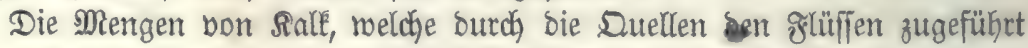
werben, find nidyt unbedeutend. Bijdjof Gat barüber intereffante Berechnut=

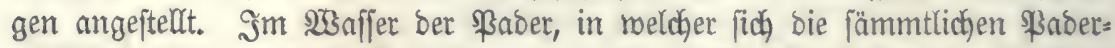

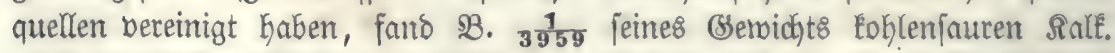
Nach angeftellten Meffungen beträgt bie Menge bes in einer Mimute fort=

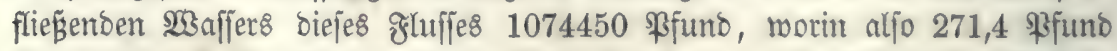

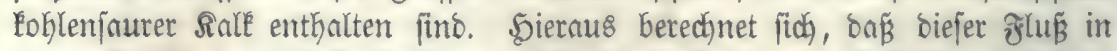
einem Sabre einen Ralfmürfel von nake 93 ₹uß Seite Dem SSebirge entzieht.

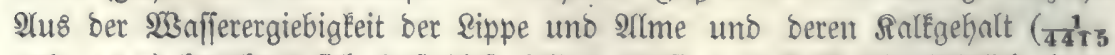

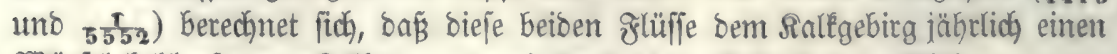

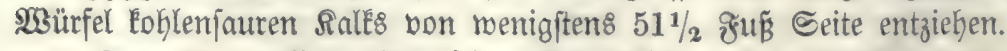

Das Meerwaifer erhält feine Mnineraljalze ohne 3rweifel zum größ̈ten รheil burdh bie ซ̛tüfle. 
Fubang. Bildung bes Dolomits.

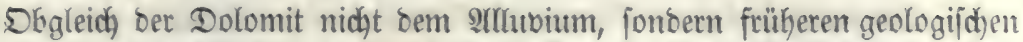
gormationen angebört, io wollen wir feine Billoung bod hier abhandeln, weil fie gleidj) am auf einem Berwitterungeprozeffe beruht, bervorgerufen burch bie Cimbirkng Der Sohlenjäure nuf magnefiabaltige Salfée.

Der Dolomit ift ein Doppelfalz, befteheno aus tohlenjaurer Sinlferbe uno Eohlenjaurer Magnefia, nach ber Frormel $\mathrm{CO}_{2}, \mathrm{CaO}+\mathrm{CO}_{2}, \mathrm{MgO}$. Da\& 3erifiene, Fufgeblähte, Berftörte in ber Structur bes Dolomits hat von jeher bie Sseologen bejdyäftigt. Man ichien Zmeifel barüber zu Kegen, ob ber Dolomit eine neptunijaje Bilbung fei, Denn Der ganze Character ber Dolomitgebirge beutet mehr

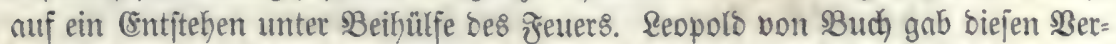

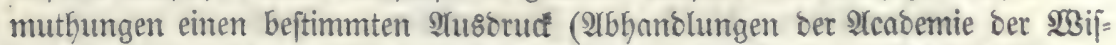
jenjidfaften zu Berlin aus Den Gahren 1822 und 1823); er erflärte Den Do=

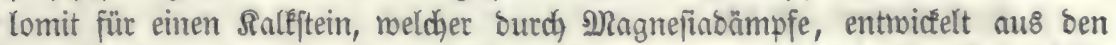
2ugitporphnren, in ein neues Beftein, Den Dolomit, umgewandelt roorben fei.

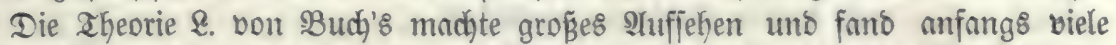

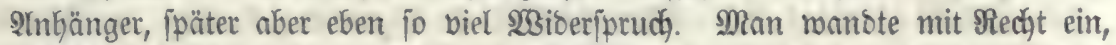

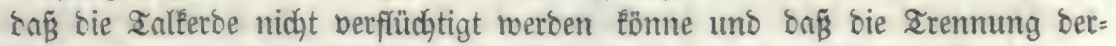
jelben von ber Riejelwerbintung im Melaphye und bie nadh herige ßeceinigung mit bem tohlenjauren Silf zrwei (srjhjeinungen feien, bon weldyen bie eine

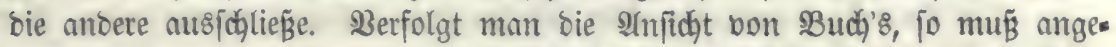

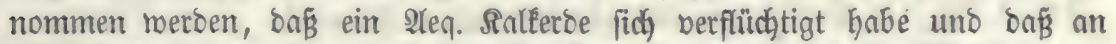

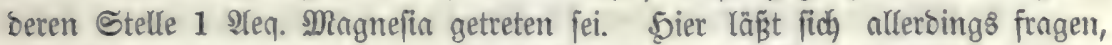
ob benn bie Sibe, weldhe bie Berflühtigung ber Ralkerbe bemirtte, geftattet

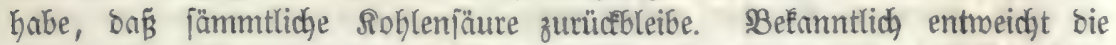
Sohlenjäure beim Salebrennen fđjon in einer Semperatur, bei weldher bie Ralle=

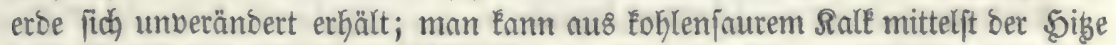
wohl bie Rohlenfäure, aber nidyt bie Salkerbe verflüdtigen.

(5s bleibt Daber immer viet mabrfdjeinlidger, baf̈ ber Dolomit auf naffem

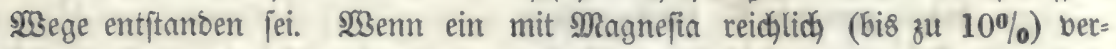

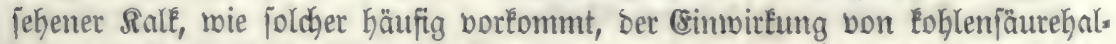
tigem 23 affer ausgejegt ift, to mirb jowohl bie Ralferbe, als aud bie Magnefia

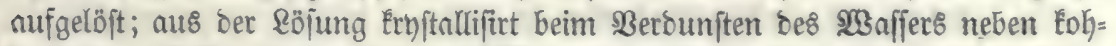
Lenfautem Salf (a) ein Salz, weldhes mefyr Magnejia enthält, als bas ur= iprüngliche Mineral. Diẹes ๔nlz ift ber Dolomit. Neue Uleberiftömungen von tohlenjäutrehaltigem $\mathfrak{2 B n f f e r ~ l o ̈ j e n ~ m u n ~ b e n ~ E o h l e n j a u r e n ~ S a l t ~ ( a ) ~ a u f ~ u n o ~}$ führen ifn fort, währento ber Dolomit, als ein jebr fodner lösliches ๔alz zu=

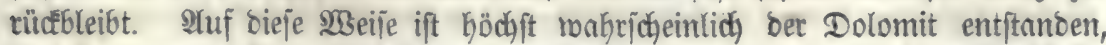

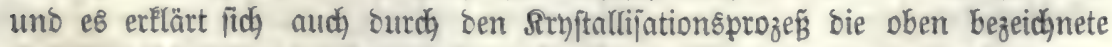

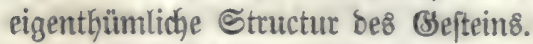

Det Dolomit verwittect langjam, viel langjamer, als ber tohlenfaure 


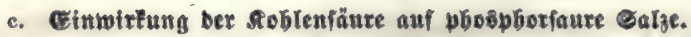

Die phosphorjauren Mineraljalze fommen in Der Matur in geringer Menge

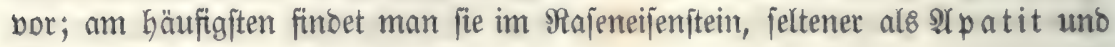
$\mathfrak{M a}$ a wellit.

Der $\mathfrak{A}$ patit ift eine Berbinoung von 3 श्:eq. Gafifd phosphorjaurem Salf mit 1 YYeq. (Shlorcalcum Dber mit gluorcalcium. Die Gormel ift bemnady für ben (5)lorapatit: $\mathrm{Ca} \mathrm{Cl}+3\left(3 \mathrm{CaO}, \mathrm{PO}_{5}\right)$ für ben gluorapatit: $\mathrm{Ca} \mathrm{Fl}+3\left(3 \mathrm{CaO}, \mathrm{PO}_{5}\right)$

Mandymal ift aud (5)lorcalcium mit Fłtuorcalcium gemengt.

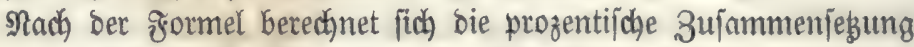
Desి Bhlorapatits

(6) Lorcalcium 10.62

\$ho 8 phorjaurer Rale 89.38

ఇach) Bifdoof löft fich

1 Iheil $\mathfrak{A p a t i t}$ Des Fluorapatits

Fłtuorcalcium 7.69 \$ho

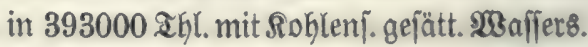
" " nach ftarkem Schütteln in 96570 " " "

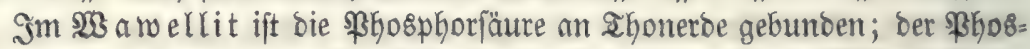

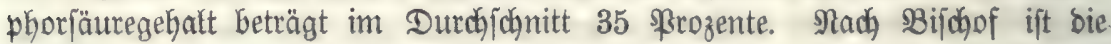
phosphorjaure Ifyonerbe in Eoblenjäurehaltigem $23 n$ ffer, miemohl in äuperft geringer Menge, löвlich.

Die Snodjen enthalten über 50 ßrozente bafijo phosphorjauten Rall $\left(3 \mathrm{CaO}, \mathrm{PO}_{5}\right)$ in $\mathfrak{B e r b i n}$ ung mit phosphorjaurer Mngnefin.

Bifdhof\& Unterjuchungen über bie \&ö8ticheeit be8 phosphorjauren Salte8 in ben Inodyen ergaben:

1 Ifeil gebrannte Sinochen, weldye meb= rere Sahre gelegen unt wieber Soblen= fäure angezogen hatten, gepulvert, braud = ten zur \&öjung 2823 Ifl. mit Sobleni. gefätt. 23 afferళ.

1 Sheil frifde Dajentenochen, geidart, 4610 " " "

" - " beşgh, nadjoem fie 18 Tage lang in mit Rohlenjäure gejättigtem $\mathfrak{2}$ affer gelegen hatten 4030

"... besgl., als ђobelfpähne, eben io lange in $203 a f j e r$ gelegen, 2981

". getochte Dojfenthodjen, eben io lange in $2 B$ affer gelegen, 3643 " " " " " " "

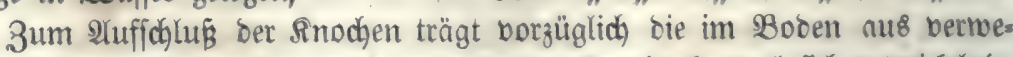

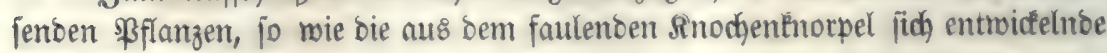
Sohlenfäure bei.

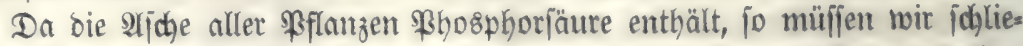

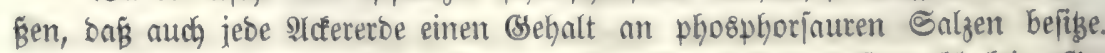

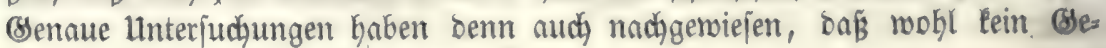


ftein, weldyes zur Billoung ber Addeterbe beittagen Eann, frei von \$hosphor= fäure ift; fpeciell wurbe fie unter Andern in ber Rreide, im Mujchelénlé, DD=

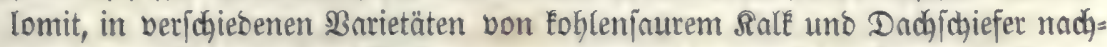
gemiejen. SSenn, wie vielfach) angenommen wirb, bie kohlemjauren Salkée ber

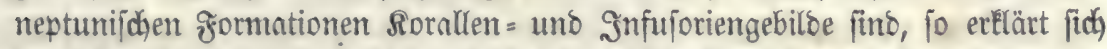
ber \$hosphorjäuregehalt biejer Salfe jebr leidyt, benn in oen Snfujorien bat 5. Roje phosphorjauren Sarle mit Bejtimmtheit nachgemiejen und in ben Ro=

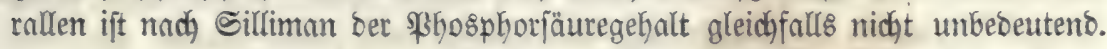

\section{SPoriten Mabreporen "alftreen}

Roblenjauter Rale

$$
89,9-95,4
$$

$92,8-95,1$

$91,1-96,6$

Pho ॄ̋ hate u. Fluorüre $\quad 0,7-2,1 \quad 0,5-0,9 \quad 0,3-2,1$

Drganifiche Miaterie

$2,1-9,4$

$4,3-6,6$

$3,2-8,3$

\section{d. Cinwirtung ber Roblenfäure auf eifenhaltige zofflitien.}

Dnะ Cijen ift in Der Natur ïberaus berbreitet, es fommt in allen fry)=

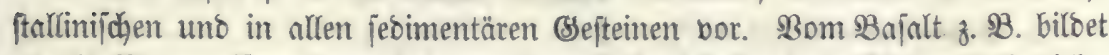

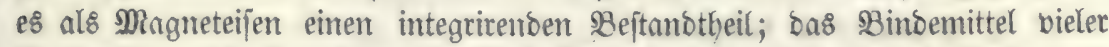

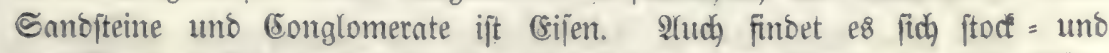
gangförmig in jefr groß̧en \&agen, oft befteben ganze Berge nur ats (sijen=

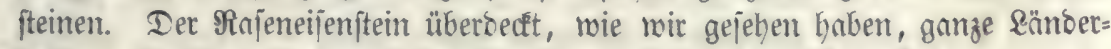
frriche. Die bemerkenstwerthejten Borkommentheiten bes (sijens fint:

1. Eijenory $=\mathrm{Fe}_{2} \mathrm{O}_{3}$, als Bijenglanz, Bijenglimmer, Rotheijeniftein, Roth= eijenocfer.

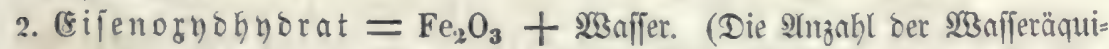
valente fedmanft bei den veridchiedenen Barietäten), als Brauneijenjtein, Brauneijenoder, Belbeijenftein; Bohnerz.

3. Sdnefeleifen (berichiebene Mingen (sijen unt Sdymefel), als magnet= kies, (Eijenties, Strahlfies u. \%. w.

4. Scheferjaures Eifenoryoul $=\mathrm{SO}_{3}, \mathrm{FeO} \cdot \mathrm{f} 6 \mathrm{OH}$ ober $7 \mathrm{OH}$ $=$ rijenbitriol.

5. Roblenjaures Eijenozybul $=\mathrm{CO}_{2} \mathrm{FeO}$ als (sijenjpath uno Sphä= rofítertit.

6. \$hosphorjaures Eijenoryd, im Rajeneijenftein.

Diejenigen von biejen 3etbindungen, weldhe, mie ber (sijenvitriol, nicht

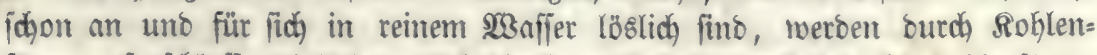

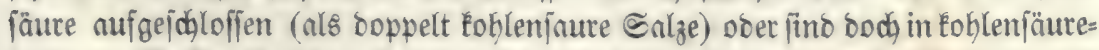
haltigen 23 affer löslid). Damit übrigens oas (sijennthyo in Berbinoung mit

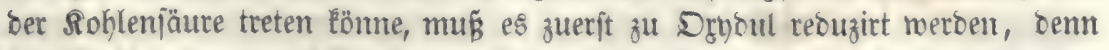

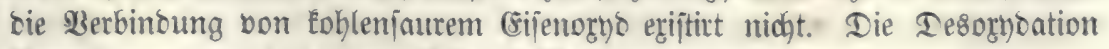
übernehmen bermejente organijche Eltfifangent.

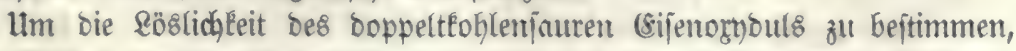

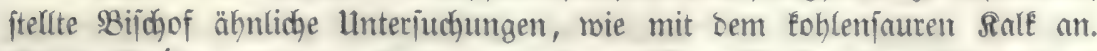
Sphärofiberit murbe gepulbert, in mehrere Dhni 13 affer eingerüfrt uno 9 


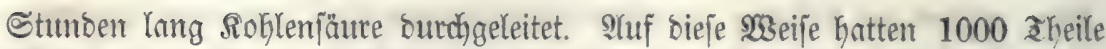
23 affer 6,0755 Ibeile fohlenfaures Eijenoryoul als Bicarbonot aufgelöft.

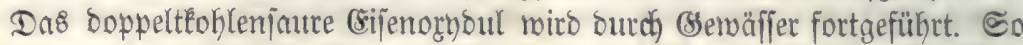

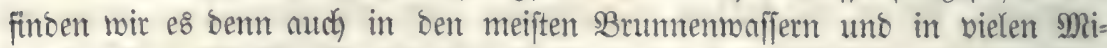
neralquellen (Staflwaffern). Sn Berüfrumg mit ber \&uft, ober wenn bas

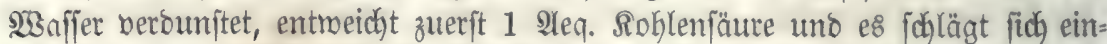
fach Eohlenfaures Eijenoryoul $=\mathrm{Fe} 0, \mathrm{CO}_{2}$ nieber. Diejes berliert unter gleidy)= zeitiger Drybation bie Sohlenfäure und nimmt bann nod 230 nfer auf, mo=

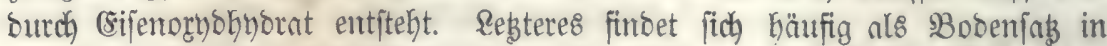

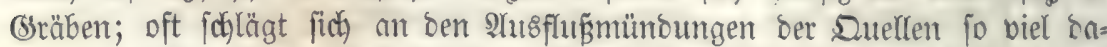

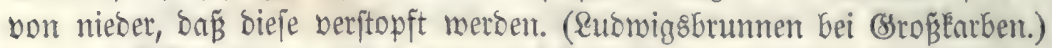

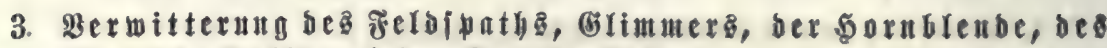 A 4 it}

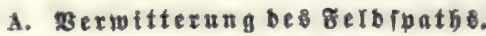

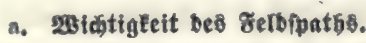

Bon allen Mineralien Gat ber geldpatpath ben bebeutenoften Binflǘ nuf bie Bilfung bes Bobens getabt, weil er in faft allen Sefteinen uno baz̆ in

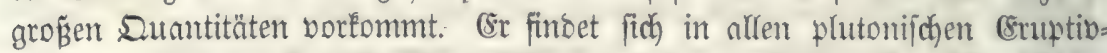
gefteinen; bon ben fryftallinifdyen Sdhiefergefteinen enthalten ifn ahonjofiefer und Bneip. Die Braumacee, ber alte rothe Sandftein, bas alte rothe Toot=

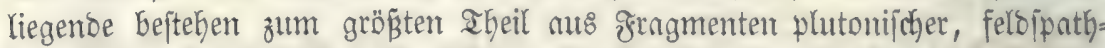
führenter Bsefteine. Biele Sanditeine entfalten ein thoniges Bindemittel, wel=

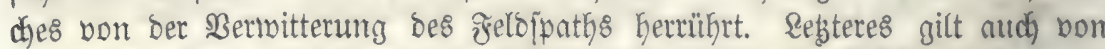
bem meiften Ifon und \&ehm in \&lubium und andern geognofitichen Sratppen.

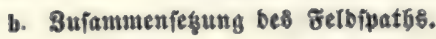

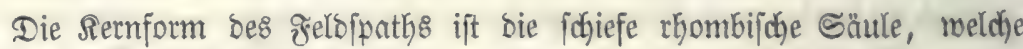
bon fechs rfyombifdyen flächen begrenzt mirs.

Der Gelbjpath ift ein Doppelfalz, beftehento ans eimem Kiejeljauren snteali

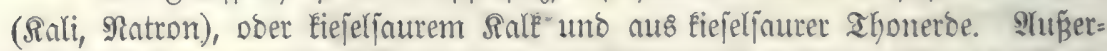
bem enthält ber gelojpath ntod, geringere Mengen von ceifen=, Mangan = unto Ialferbe. Sn neuerer Beit hat man auch einen unbedeutenton Befhalt an

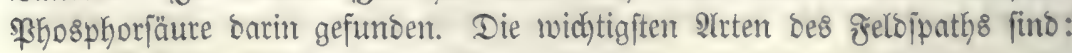

a. Det Dethoel'as.

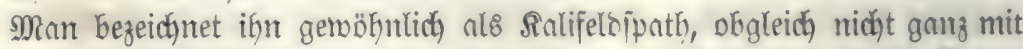

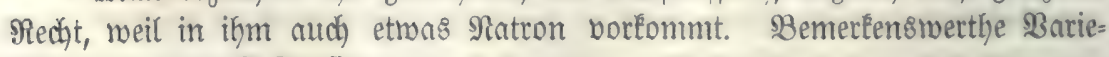
täten bes Drthollajes finto:

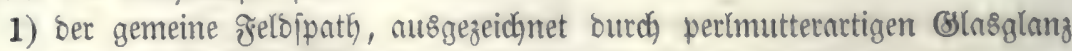
ober burch Silberidhein.

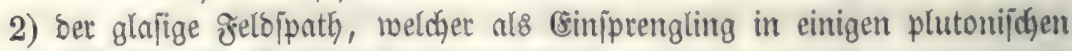
Sefteinen (8. S8. Dem Iradbyt) auftritt. 
Die iceale 3ujammenjegung bes Drthollajes ift:

\begin{tabular}{ll} 
Siejelfäure & 65.21 \\
Ihonerde & 18.13 \\
Sali & 16.66 \\
\hline & 100.00
\end{tabular}

Giefür Ferechinet jich bie frormel

$$
\mathrm{SiO}, \mathrm{KO}+3 \mathrm{SiO}_{3}, \mathrm{Al}_{2} \mathrm{O}_{3}
$$

ק. Der $\mathscr{U l}$ bit,

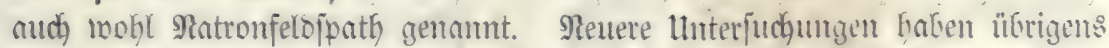

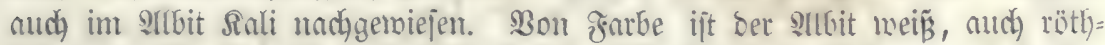

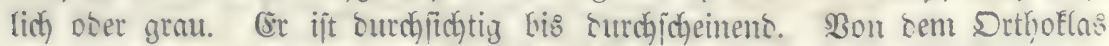
untericheitoet er fich auffalleno surdh fecterartige @treifung feiner Blätter(ngen.

Die ibenle 3ujammeniegung bes artbits ift:

\begin{tabular}{lr} 
Riejel[äure & 69.09 \\
\&honerbe & 19.22 \\
Ratron & 11.69 \\
\cline { 2 - 2 } & 100.00
\end{tabular}

Diejer 3ujammenjełung entipricht bie grormel

$$
\mathrm{SiO}_{3}, \mathrm{NaO}+3 \mathrm{Si} \mathrm{O}_{3}, \mathrm{Al}_{2} \mathrm{O}_{3}
$$

r. Rabrabor,

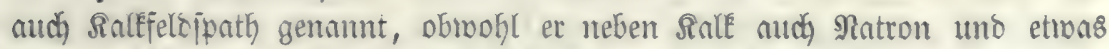

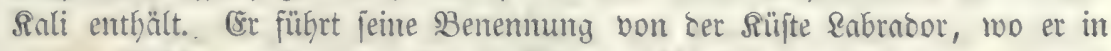

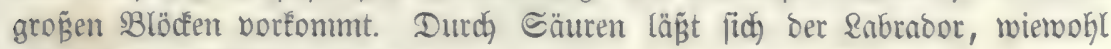
niḑt ganz vollitändig, zerję̧en.

Die ibeale 3ujammenjegung ses Eafrabors ift

$$
\begin{aligned}
& \text { Лiejel[äure } 53.42 \\
& \text { Ifonerbe } 29.71 \\
& \text { Salferbe } \quad 12.35 \\
& \text { Natron } \frac{4.52}{100.00}
\end{aligned}
$$

Sierfür berecthnet fidh bie Frormel:

$$
\begin{aligned}
& \mathrm{SiO}_{3}, \mathrm{NaO}+\mathrm{SiO}_{3}, \mathrm{Al}_{2} \mathrm{O}_{2} \\
& +3\left(\mathrm{SiO}_{3}, \mathrm{CaO}+\mathrm{SiO}_{3}, \mathrm{Al}_{2} \mathrm{O}_{3}\right)
\end{aligned}
$$

d. Drigoelas (oder Natronipodumen).

Ier Sligoflas mar früher meniger beadhtet, weil man ifyn mit ten an= bern Feldipathen bermectjelt Gatte; neuere Beobadjtungen baben ergeben,

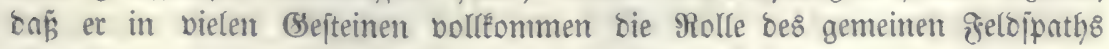
einnimmt.

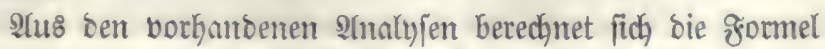

$$
\mathrm{Si}_{3}, \mathrm{NaO}+2 \mathrm{SiO}_{3}, \mathrm{Al}_{2} \mathrm{O}_{3} \text {. }
$$


uno biernach ift bie ibeale 3ujammenjegung bes Dligotelnjes

\begin{tabular}{lr} 
Riejelfäure & 62.64 \\
IGonerbe & 23.23 \\
Natron & 14.13 \\
\cline { 2 - 2 } & $\mathbf{1 0 0 . 0 0}$
\end{tabular}

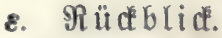

Etellen wir bie für bie æeldojpathe erbaltenten grormeln zujammen, fo erbalten wir

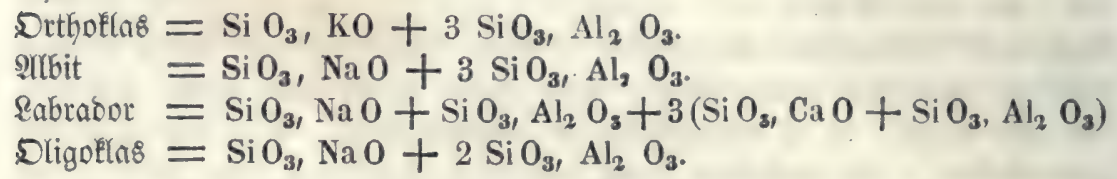

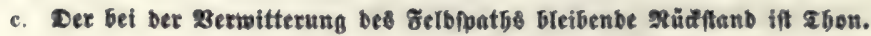

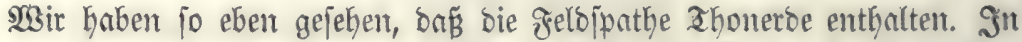

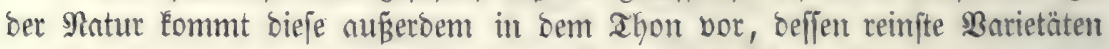
bie Porzellanerde und der Raolin find. Die meijten ahone ftanment bon zer=

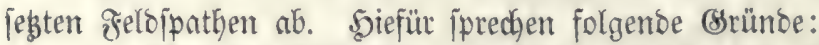

$\boldsymbol{\alpha}$. Mant hat Fetojpathe aufgefunden, welche ganz die Siryftallform biejes Minerats bejaß̧en, aber in ifrer 3ujammenjegung in jo meit veränsert waren, als zwar bie Duantität ber ahonerde fich gleich geblieben war, ongegen ber Bsebalt an Riejeliäure, Allealien oder Ralk abgenommen hatte. Die 3ujanmen. Fegumg biejer Felojpathe hatte fid berjenigen bes Rnolins genähert.

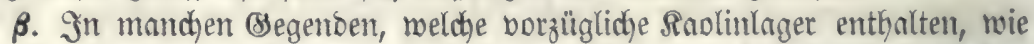

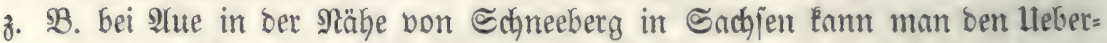
gang bes grelbjpaths in ahon jehr bentlich wabunehmen. Die pbern \&agen De\& Bodens finto fajt reiner Ravlin, bann fommen Sdjidyten, weldye fid) burd,

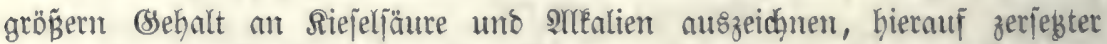
Frelbipath in ber Sityftallform biejes Minerals. - Ein äbnlidjes Borḱontmen

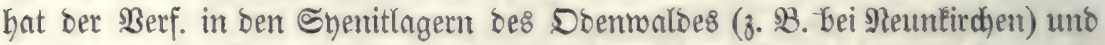
im Branit (bei Darmitabt), fo wie im 5arz (am sBrocen) beobrdatet. (8r fonnte ben Hebergang Des Feloppaths in biejes Ssejtein in Dhon unt Rebm (eine

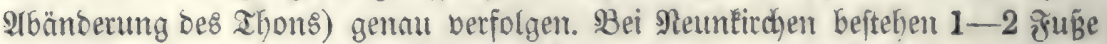

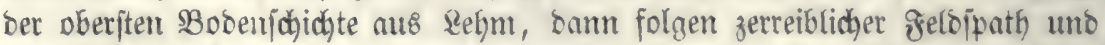
Sornblende, hierauf bie nämlid)en Minteralien, aber in biafern Brocten; ju

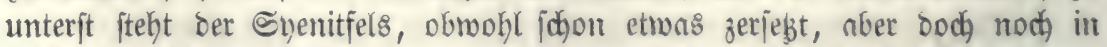

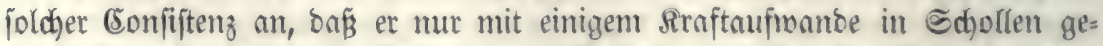
trennt werden kamm. - Bejonders auffallento zeigt fich ber llebergang res

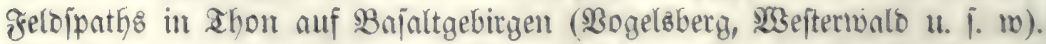

DnE jtellenmeije jefr ausgedefnte Borfommen von Snndingern, an De=

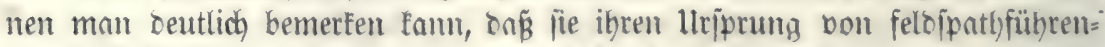

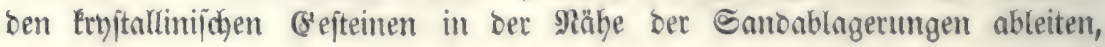


Deutet barauf Gin, baß̈ ber F̧elbjpath entfernt worben jei. weber in näherer, noch in fernerer Umgebung biejes Santes Felbipathlager,

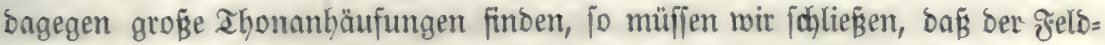

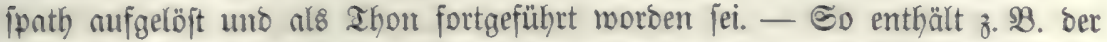

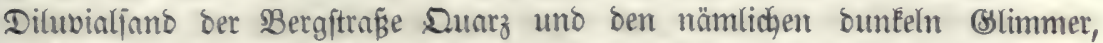
melcher ben Branit bes Doentwalbes und bejonbers ben in ber Unigegent von

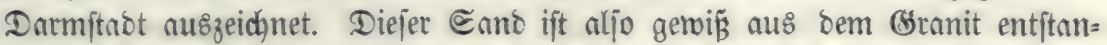
Den. Aber wohin ift ber ģelofpath gefommen? (ar fintet fich ebenfalls nidit

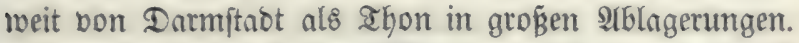

$\boldsymbol{\gamma}$. Die aus ferbjpathführenoen Bejteinen berborkommenoen Quellen ent=

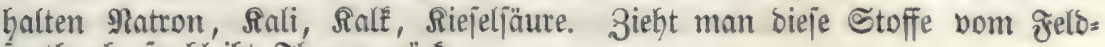
Ipath $a b$, jo bleibt İyon zurüct.

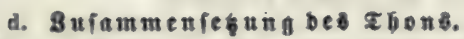

Es: ift eben angedeutet worben, baß Raolin bas endlidge Product ber 3erfebung Der geldpathe jei. Inteffen findet man ben Raolin nicht fo häufig. Thon und Sebm bagegen treten faft überall und in groß́en Maffen

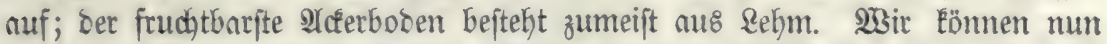

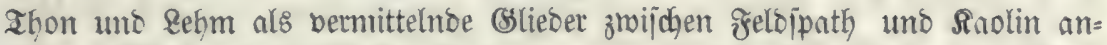
jehen. SBir werben alsballo erläutern, warum ser Saolin fo jelten in grö̈ß̈ern Eagern exjodeint.

Fordhbammer hat für ben Raolin bie Formel

\section{$3 \mathrm{Al}_{2} \mathrm{O}_{3}, 4 \mathrm{SiO}_{3}+6 \mathrm{OH}$}

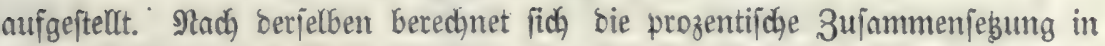

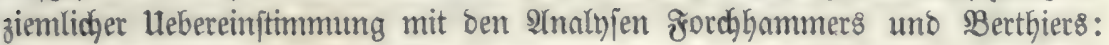
Siejelīäure $\mathbf{4 7 . 0 2 8}$

ahonetoe 39.233

23 affer $\quad 13.739$

100.000

Uebrigens enthalten jelbit jehr reine Saoline uno \$orzellanerben immer

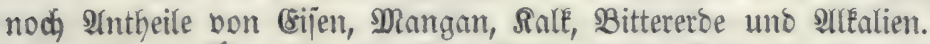

\section{e. zergleidung be sta oling mit bem frifden gelbipatb.}

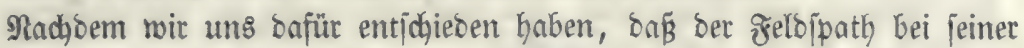
3erjesung zulegt in Raolin übergehe, 10 haben wir nur bie frormeln biejer beiben Minteralien von einander abzuziegen, um die \$robucte zu erhalten, soldye bei ber 23ermitterung bes Jelbjpatţ8 frei werben.

Da wir annehmen müj]̄en, baş bie Ihonerbe nicht aufgelöft merbe, jon=

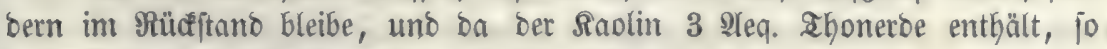
verbreifachen roir bie grormel bes łeloppaths.

$$
\begin{aligned}
3 \text { Felopath } & =3 \mathrm{Al}_{2} \mathrm{O}_{3}, 9 \mathrm{SiO}_{3}+3 \mathrm{KO}, 3 \mathrm{SiO}_{3} \\
& =3 \mathrm{Al}_{2} \mathrm{O}_{3}, 12 \mathrm{SiO}_{3}+3 \mathrm{KO} \\
1 \text { saolin } & =3 \mathrm{Al}_{2} \mathrm{O}_{3}, 4 \mathrm{SiO}_{3} \\
\text { e8 ift aljo fortgefubrt worben } & 8 \mathrm{SiO}_{3}, 3 \mathrm{KO}
\end{aligned}
$$




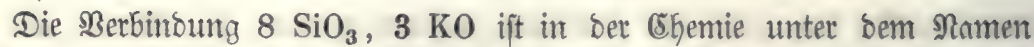

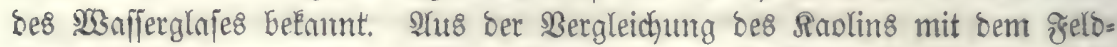

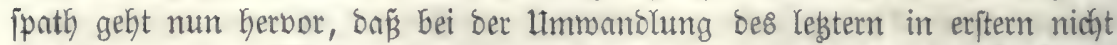

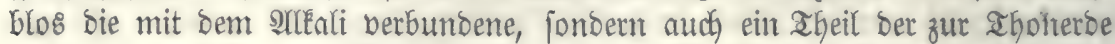
gebörigen Riejelfäure entfent twirb. Der Rrolin bilbet fich aljo nidjt etroa

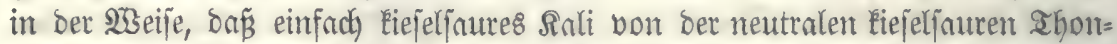

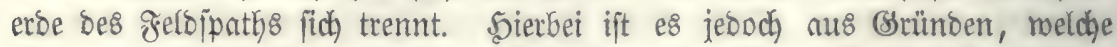
fpäter entwicfelt werben, angemeffen, zu unterftellen, Daß̌ zur Billoung be\& Rnolins keine von ber mit bem Sinli verbunbenen Riejelfäuré verwanot werbe,

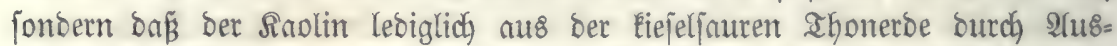
treten eines Theils der Riejeljäure uno 2 hufnahme von $\mathfrak{B}$ affer entftanden jei.

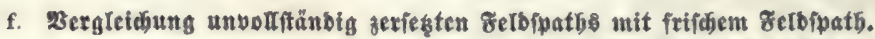

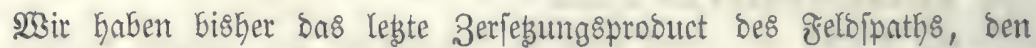

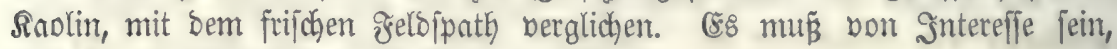
auch Die 3roijchenitufen in's âge zu faffen.

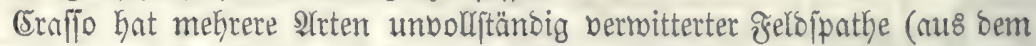
rotken अorphyr von Şmenau, bem (Sranit bon Rarlsbas nto bem Syenit

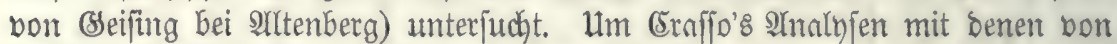

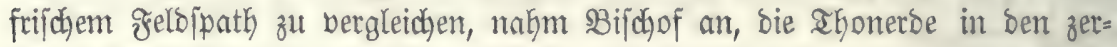

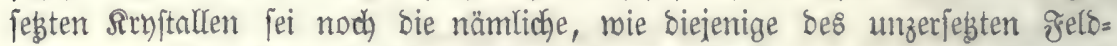

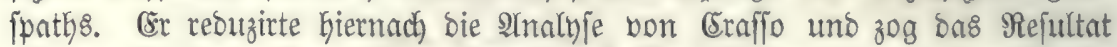
von Der 3u[ammenjebzung bes Drthoflajes ab. Man erbält alsoant und menn

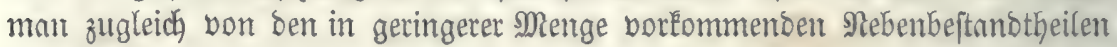

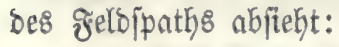

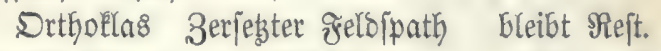

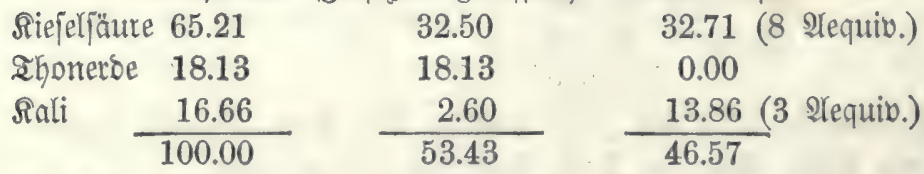

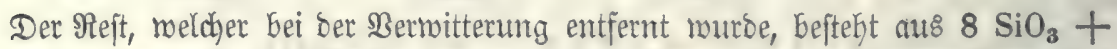

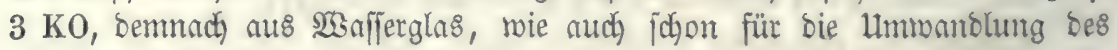
Felopatys in Sirolin gefunden wurbe.

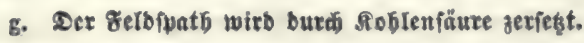

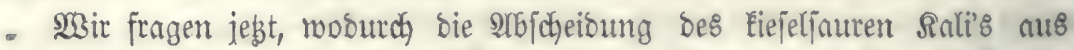

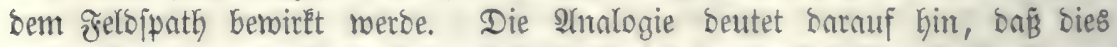

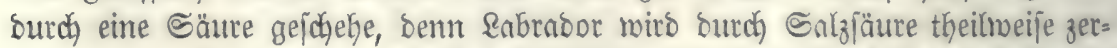
jebt, und auch bie übrigen Felbjpathe werben von ber kodjenden Säure etrons angegriffen.

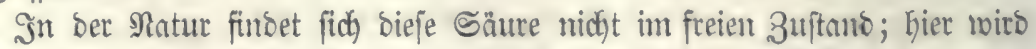
ifre Stelle von ber Rohlenfäure eingenomnten. Diejer müffen wir in ber

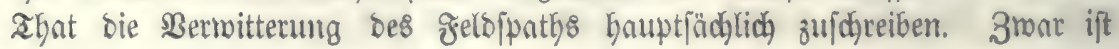




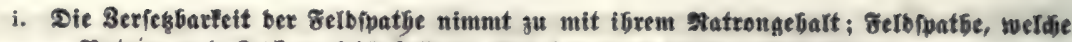
Matrón unb Salf zngleid befigen, finb beionber reidit aufídicfibar.

Wenn wir uns ein Urtheil barüber bilben mollen, welche Itrten bon

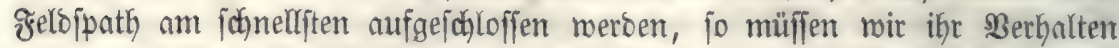

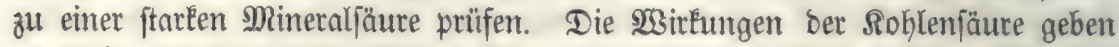
nämlich), meil fie nur in Hleinem Masftabe erfolgen, nidht augenblicflid einen beutlid) mahrnefmbaren \&ffect; fie meroen erjt nad längerer Zeit fichtbar.

Drthollas mirb mur in feingepulvertem 3uitanoe uno nad) monatelangem Sodgen bon Salzfäure angegriffen, Allbit uno Dligofllas wiberftehen ber Säure

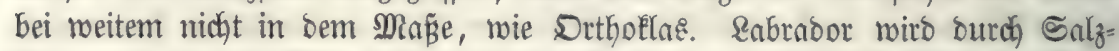
fäure auch in ber Rălte, jeboch nicht volljtänoig, zerjeģt. Dligothlns enthält immer etroas Salf $(2-4 \%)$, objhon nidjt fo viel, als \&nbrabor $(12 \%)$. Sier= aus geht benn bie Richtigkeit be\& Dben nusgeiprochenen Sabes herbor.

Sn Hebereinftimmung hiermit ftefen bie Rejultate ber Unterjuchuugen

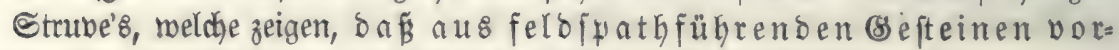
gugsmeife Natron extrabirt berbe. Strube fant

Sali Ratron

1) Sn einem \$honolith bom Rotheberge bei Brür, im fri=

josen. 3ujtand

in Demfelben, verwittert

$3.45 \% 9.70 \%$

5.44 " 3.26 "

2) In einem andern Pronolith, frifi

3.10 " 6.69 "

in bemfelben, berwittert

3) In einem Bajalt, frifd

6.68 " 3.80 "

in Demjelben, berwittert

1.35 " 7.35 "

$2.62,2.31$ "

\section{k. Die übrigen Beftanbtbeile ber ซึelbipatbe}

fint, wie vorhin angegeben, Magnejia, Mangan, Csijen, uno \$bosphorjäure.

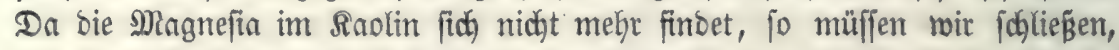

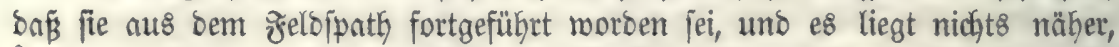

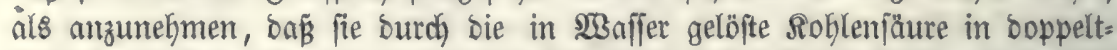
foblenjaure Magnefia berwanbelt uno bann bom $\mathfrak{W a f f e r}$ aufgenommen wor= Den jei. Das Magnefíabicarbonat ift etroas löslidjer, al\& bas Ralébicarbo= nat; 10000 Theile $2 \mathfrak{B a f f e r s ~ l o ̈ j e n ~ n a ̈ m l i c h ~ u n g e f a ̈ h r ~} 13$ Theile neutrale fohlen=

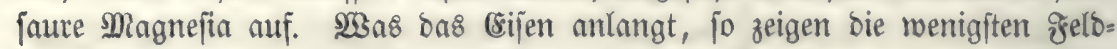

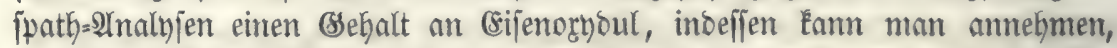

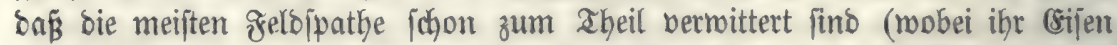

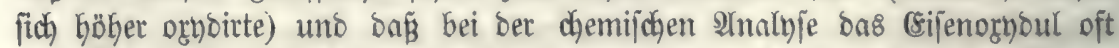
für Dryo genommen wurbe, was um jo weniger befremoen fann, als bet

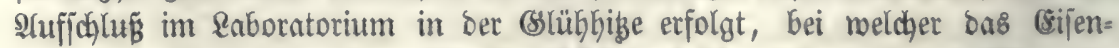

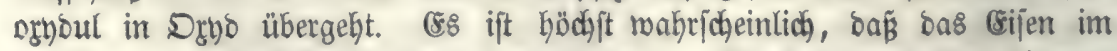
Jeldipath uriprünglid, als Drboul entfalten ift. 23enigftens beuten bie ber=

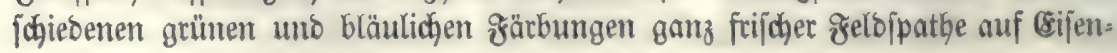




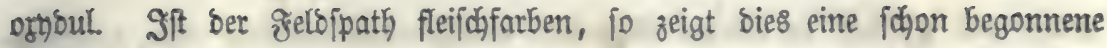
Drbbation an.

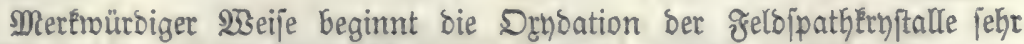

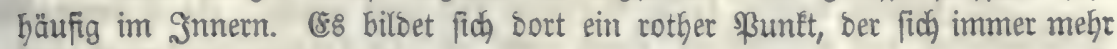
vergröfípert.

Aluch bas Mangan mag in bem frijdyen Felbipath nur in ber frorm von

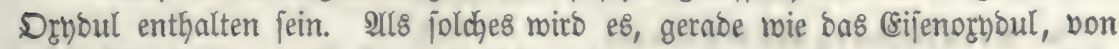

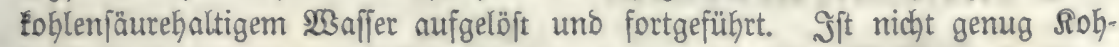
lenjäure, Dagegen ๔auterftoff vorbanden, fo gebt das Manganorhoul in Man= ganoryobybrat über. Diejes Eam bann wieber burch organijage Stoffe re= ouzint roetben.

Die \$35osphorjäure ift im greldipath entweber an Salf ober an Ihon= erbe gebunden. Die beiben phosphyorjauren Salze löjen fich, wie oben ange= geben, in Eohlenjäurebaltigem $\mathfrak{M a}$ affer.

An

Unter ben 3eolithen verjteht man MNineralien, welche ben Felojpathen nake bermandt find, fich aber von ifiren characteriftijo surdy einen bejtimmten

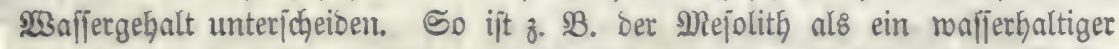
\&abrabor zu betrachten. Zieht mant nämlich von bem Mejplith jein Şaffer $(12 \%) a b$, jo zeigt er fajt bolftänoig die 3ujammenjeßzung bes \&abrabors: \&abrabor. Mejolith

\begin{tabular}{lrr} 
Riejeljäure & 53.42 & 53.35 \\
RGonerde & 29.71 & 29.67 \\
Salt & 12.35 & 10.97 \\
Ratron & 4.52 & 6.01 \\
\hline & 100.00 & 100.00
\end{tabular}

Die 3eolithe find überaus berbreitet; fie madjen einen conftanten $\mathfrak{B C}_{\mathrm{e}}$

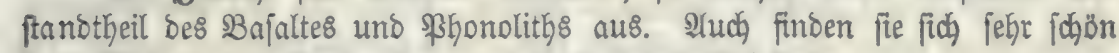
Eryjtallipirt in ben Drujentäumen, Gejonders des $\mathfrak{B} a j a$ ltes.

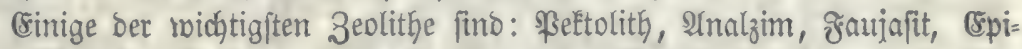
ftilbit, Chabajit, Mejottpp, Rehuntit, SBrebezit, Ihomjonit, Sarmotom, DRe= polith.

Heber Die Entftehung Der 3eolithe hat man zmei Infichten.

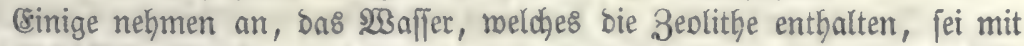
ben keikflüfigen (Sejteinen, in Denen bie Zeolithe fich finden, aus bem Groinnern keraufgetommen, aber burd ben Drud ber Befteinsmafje jelbft zurücige= Galten uno bor bem (Entroeidyen in Dampfform gejhüzt roorben.

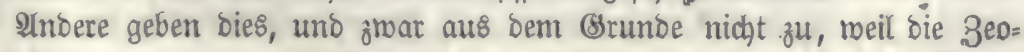
lithe fich auch ganz an ber Dberfläche ber Jelsarten finben, ro kein Druck

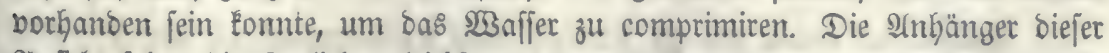

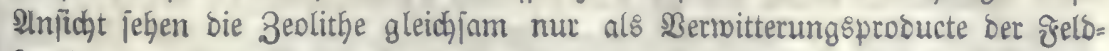

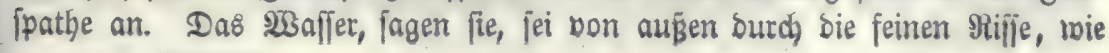


Foldie bon Bifdy of an vielen Sejteinten nadjgetwiejen worben fint, Gineinge= Eommen.

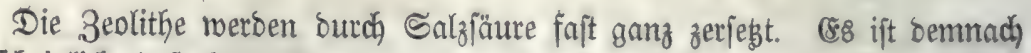

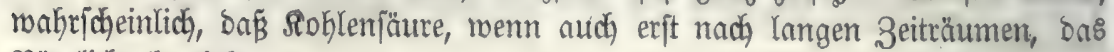

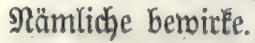

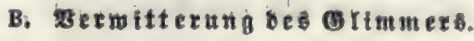

A. Bortommen.

Der (slimmer, ein bem gieldipath nake bermanotes Mineral, ift gleidh

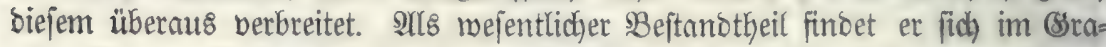

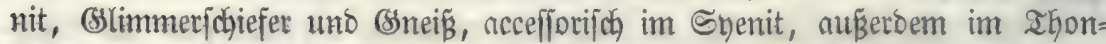
ichiefer, in ber Broumade und in bielen Sanditeinen, bie ifn zum Theil ftro tenförmig, zum aheil burch bie ganze Maffe Gin zerftreut enthalten. (s)immer

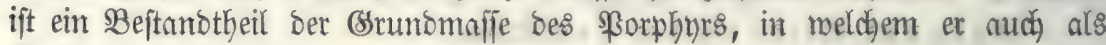
Sinjprengling vorkommt. Die ßarallelftructur bieler idfieferiger Befteine miro burch) Ragen von (slimmet bebingt.

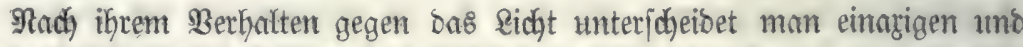

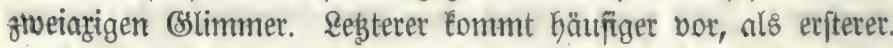

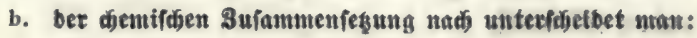

a. Sialiglimmer.

ק. Magneftaglimmer.

$\boldsymbol{\gamma}$. Rithionglimmer (Repiodith).

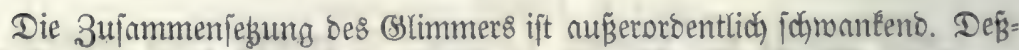
balb befist man auch Eeine allgemeine formel, melche für alle (Stimmerjorten

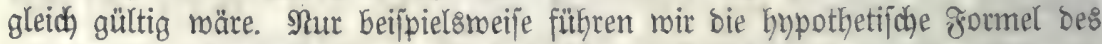

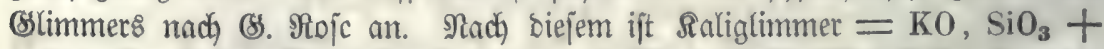
$4\left(\mathrm{Al}_{2} \mathrm{O}_{3}, \mathrm{SiO}_{3}\right)$, Magnefíaglimmer $=3(\mathrm{MgO}, \mathrm{FeO}, \mathrm{KO}) \mathrm{SiO}_{3}+\left(\mathrm{Al}_{2}\right.$ $\left.\mathrm{O}_{3}^{\prime}, \mathrm{Fe}_{2} \mathrm{O}_{3}\right) \mathrm{SiO}_{3}$. Der Repibolith Gat für uns Eeine Bebeutung, meil er nur jefre jelten vortommt.

Misie bie Felofpathe, fo fins aud bie (stimmer Doppelfalze bon Riejel= fäure verbunben mit einet Baje bon ber 3u[ammenjegung RO (mie Rali, Sitbion, Magnefía, Salé, (Eifenoryoul) uno Riejeljäure, berbunoen mit enter

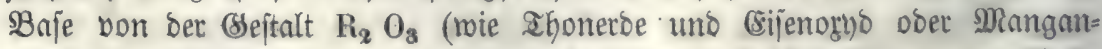

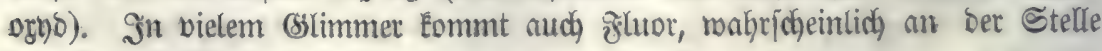
bes Sauertoffs, vor.

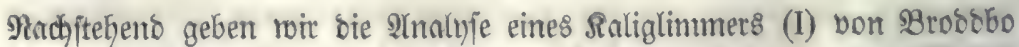

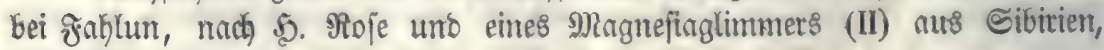
stady Staproth. 
I : II

\begin{tabular}{|c|c|c|}
\hline Siejel[äure & 46.10 & 42,50 \\
\hline Ehonetoe & 31.60 & 11.50 \\
\hline (sijenorbs & 8.65 & 22.00 \\
\hline MRanganogty & 1.40 & 2,00 \\
\hline Talferbe & - & 9,00 \\
\hline Sali & 8.39 & 10,00 \\
\hline 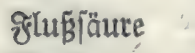 & 1.12 & - \\
\hline NBaffer & 1.00 & - \\
\hline (க)lüboerlujt & - & 1.00 \\
\hline
\end{tabular}

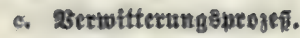

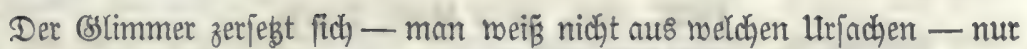

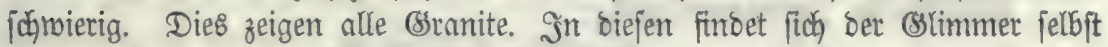
bann nod, menn ber grelofpath fohon roeich uno zerreiblich getworben ift, faft unveränoet. (slimmer, weldher ein anfgequollenes 9 Injehen angentommen uno jeine Spaltigkeit berloren bat, ift jojon roeit in ber Berwitterung vorgeidjritten.

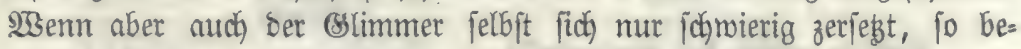
günftigt er boch on, wo er jtratenförmig zroifden ben Sdjidjten auftritt, ganz

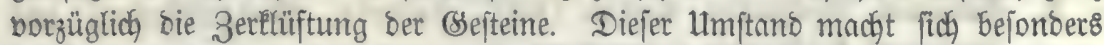

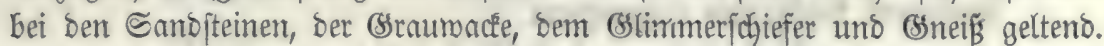
(58 baften bie Schichten an ben mit sslimmer belegten Stellen nicht feft auf=

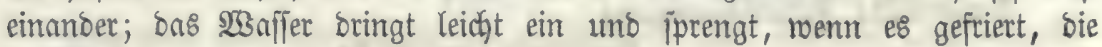
Schichten von einanber.

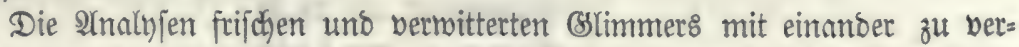
gleidhen, um baraus Den \$organg bei Der Berwitterung biejes Minerals zu

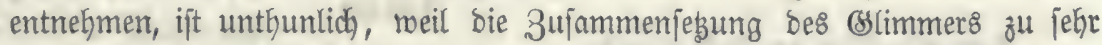

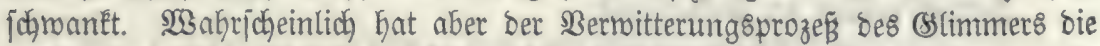

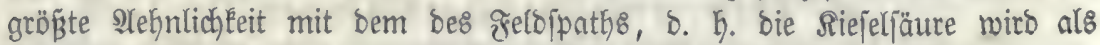
Shyorat und in Berbinoung mit Rali entfübrt, Magnefia, Sifen, Mangan wet=

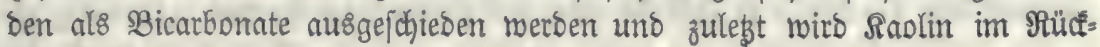
ftans bleiben.

\section{Ferwitterunger \$ornblenbe.}

a. Borlontmett.

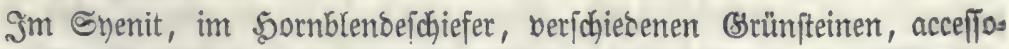

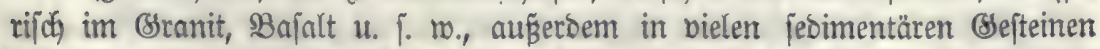

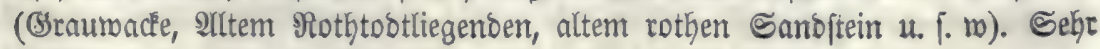
werbreitet.

b. Sufammenfeह̧นก! .

Dieje läpt fich burch bie allgemeine Formel $\mathrm{RO}, \mathrm{SiO}_{3}+3 \mathrm{RO}, 2 \mathrm{SiO}_{3}$ 
ausbrücfen. Man Gat zrei 2rrten von 5ornblenbe unterjobieben - thonerbe= freie und thonerbehaltige.

a. Thonerbefreie 5ornblenden.

1. Neutrale kiejelfaure Ralketbe uno zweiorittel kiejelfaure Inlferbe =

$$
\mathrm{CaO}, \mathrm{SiO}_{3}+3 \mathrm{MgO}, 2 \mathrm{SiO}_{3}
$$

Diejer Formel entipricht bie 3ujammenjęung

$$
\begin{aligned}
& \text { Siefelfäure }=60.50 \\
& \text { Salferbe }=12.43 \\
& \text { Ialferbe }=27.07 \\
& \hline 100.00
\end{aligned}
$$

Sierber gebören Sremolit, Strahlftein, Srammatit.

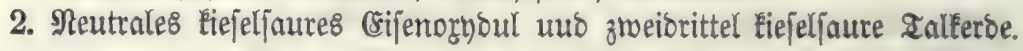

$\mathrm{FeO}, \mathrm{SiO}_{3}+3 \mathrm{MgO}, 2 \mathrm{SiO}_{3}$

ßrozentijche 3 ujammenjesung:

$$
\begin{aligned}
& \text { Riejelfäute }=58.79 \\
& \text { Ialferbe }=26.31 \\
& \text { sijenoz̧oul }=14.90
\end{aligned}
$$

Sierher gebört ber Alntophnllit.

3. Neutrales kiejelfaures Natron (Rale, Talkerbe, Manganoryoul) uno smeiorittel fiejeljaures (sijenorbbul.

$$
\mathrm{NaO}, \mathrm{SiO}_{3}+3 \mathrm{FeO}, 2 \mathrm{SiO}_{3}
$$

Prozentijøe 3 ujammenjęung:

$$
\begin{aligned}
& \text { Riejelfäure }=50.34 \\
& \text { (sifenorybul }=38.30 \\
& \text { ఇatron } \frac{=11.36}{100.00}
\end{aligned}
$$

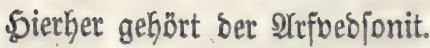

B. Thonerbehaltige \$ornblenben.

Dogleid) ber Thonerbegehalt biejer \$ornblenden jefr verjojieben ift (et

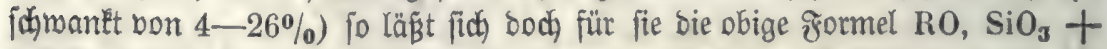
$3 \mathrm{Ro}, 2 \mathrm{SiO}_{3}$ benugen, menn man annimmt, bẩ bie Siefeljäure burch bie

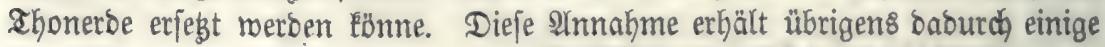

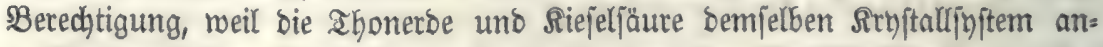

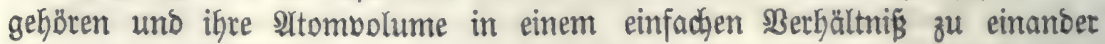
ftȩ̧en.

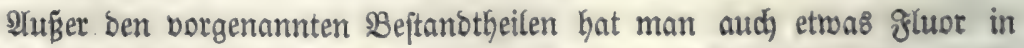
ben \$ornblenten gefunben.

\section{c. Bertwitterungôprozef.}

Heber bie Bertwitterung ber Sornblenbe liegen menige Beobadhtungen

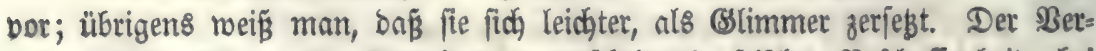

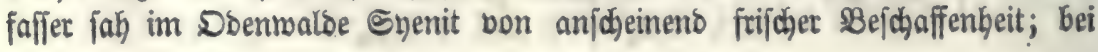




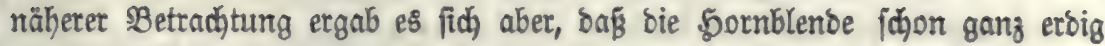
unt zerreiblich getworben war.

Ifonerbehaltige 5ornblenden mögen bas mit ben Felbjpathen gemein

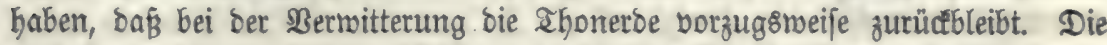

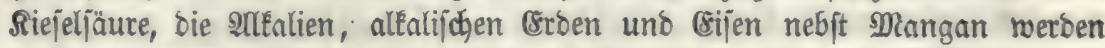
entführt, menn nicht bie beiben legten fich Göher orgboiren. Daffelbe gilt audi, abgejehen von ber Shonerde, für bie thonerdefreien Sornblenden.

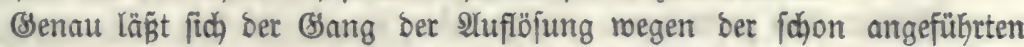
verichiebenartigen 3 ujammenjebung ber 5ornblente nidjt berfolgen. Man hat nämlich Darüber Eeine Bsemiß̈G

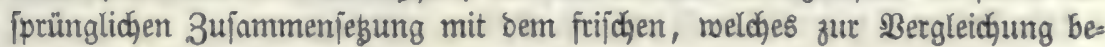
mubst wirb, ibentifd mar.

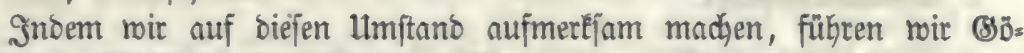
ichen's und Mabrelfs 2rnalyje einer frijchen und berwitterten इornblente vom

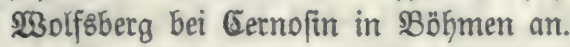

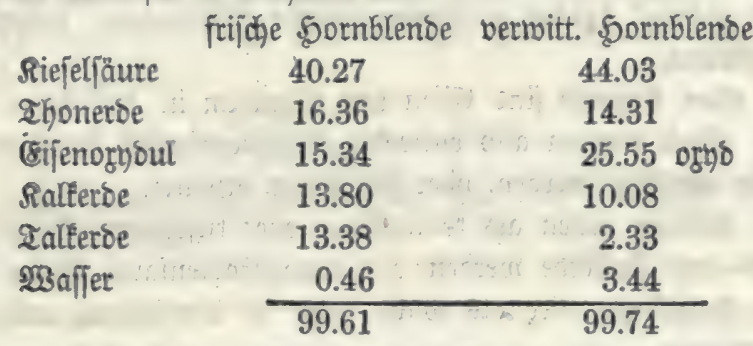

Şie man fieht, hat ber Esehalt an Salferbe und zalferbe abgenommen, mähreno bas Bijen in eine Köhere Drydationsftufe übergegangen ift.

\section{Berwitterung beต थugitร.}

\section{a. Bortommen.}

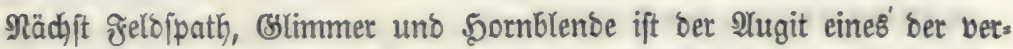
breitetiten Mineralien. 2Ir mejentlidger Bejtanotheil fommt er in mand)en

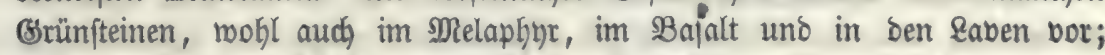
auserbem fintet er fich fragmentarijo in vielen feoimentären sejteinen.

\section{b. Bufammenieţung.}

Sn feiner dhemijohen (5onjtitution ift ber Augit ber Sornblente fo ähn= lich, baß̈ man in neuerer 3eit berjucht wurbe, bie berjojiedene Irbjtallgejtalt

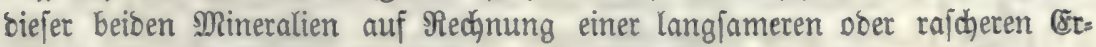
faltung beim Hebergange aus bem geidhmolzenen in ben feften 3uitano zu bringen. Snbeffen hat man audh beim 2lugit, fowie bei ber Sornblenbe nöthig,

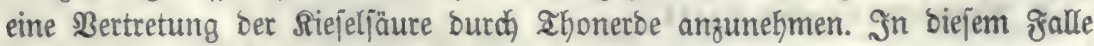
nürbe bie Formel ber 2 ugite $3 \mathrm{RO}, 2 \mathrm{SiO}_{3}$ fein.

Plud ber Arugit fommt mit uno phne shonerbe bor, 


\section{a. Ihonerbefreie $\mathfrak{A}$ uite.}

Sierher gehören: Diopfito, Malaḱolith, Sedentbergit.

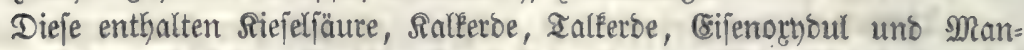

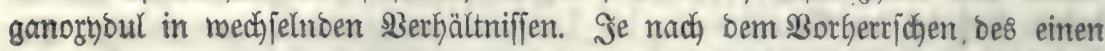

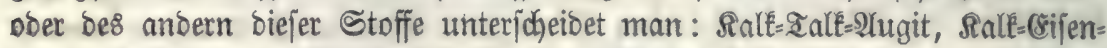

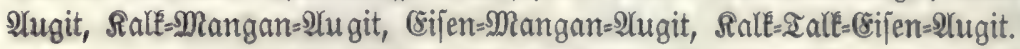

ק. Zhonerbehaltige 2 ugite.

Sierher fino zu rechnen: Dex gemeine 2lugit, Diallag uno Shperfthen. Dieje enthalten, neben ahonerbe, alle Bejtanotheile ber thonerbefreien AYugite.

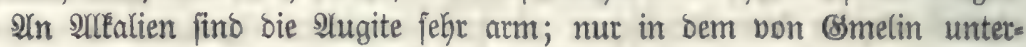
juchten fanden fich ungefäbr $3 \frac{1}{2} \%$ an Sali uno Natron.

\section{e. Berwitterungôprozef.}

Ueber biejen hat man, wegen ber jahmankenten 3ujammenjekung bes

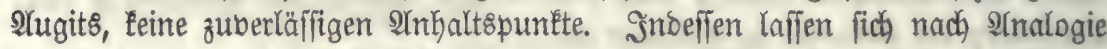
ber Zerjęung anderer, ähnlich zujammengejegter Mnineralien, folgente Muth= maß̈ungen auffitellen.

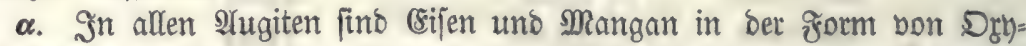
bul enthalten. Dieje merben aljo entweoer als BBicarbonate burd Eohlenjäure=

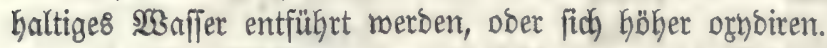

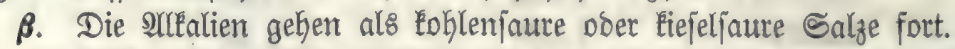

$\gamma$. Zalle $=$ und Salkerbe werben als boppeltéblenjaure Salze austreten.

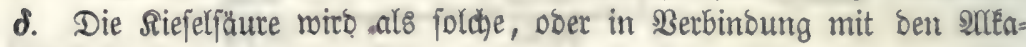
lien entführt weroen.

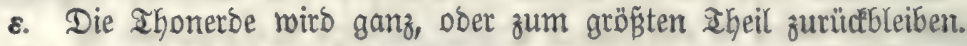

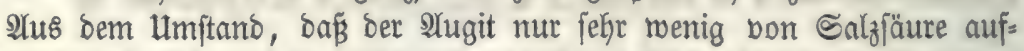

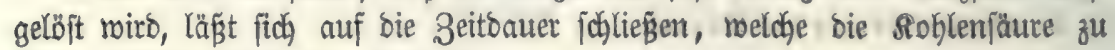
jeiner völigen 3eriegung braudgt.

\section{E. Berwiterung bes Ditvits.}

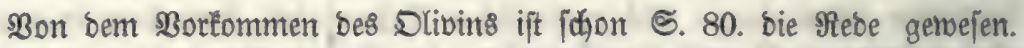
(5.8 murben bort bie $\Re$ eränberungen abgehandelt, meldje ber Slivin burdh

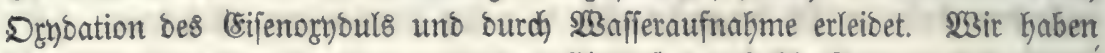

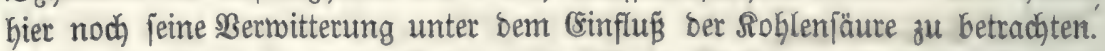

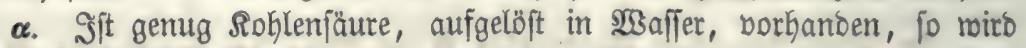
bas Eifenorybul bes Dlivins als $B$ Bicarbonat entfübrt.

B. Die sBittererbe geht gleichfalls ars boppelttohlenjaures Salz fort.

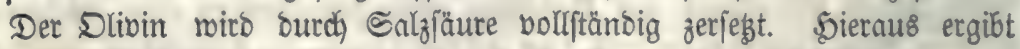

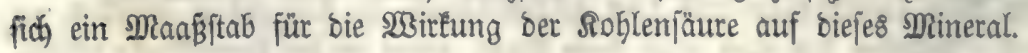

\section{F. Berwitterun bes Ialts.}

a. Botfoumen.

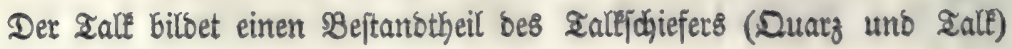




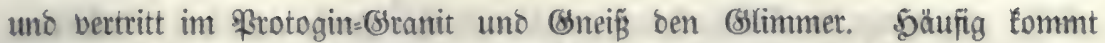
aber auch) ber Ialt jelbitțtänoig in größ̈ern Maffen vor. (Er fühylt fich fettig, ähnlidid wie Seife, an.

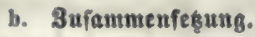

Die wejentlidjen Bejtanotheile bes Inales find Riejelfäure und Bitter=

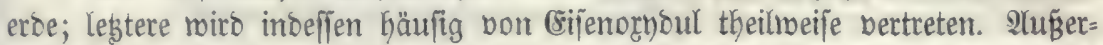

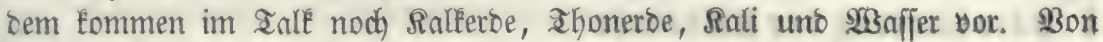
biejem meif́ ntan aber noch nicht, ob e\& ein mejentlicher ober zufülfiger

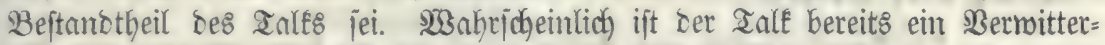

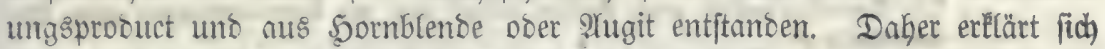

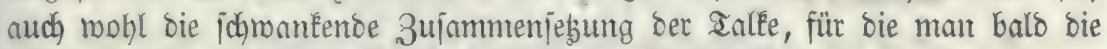
frormel $\mathrm{SiO}_{3}, \mathrm{MgO}$, bald $5 \mathrm{SiO}_{3}, 6 \mathrm{MgO}$ aufgeitellt bat.

Dem anlf nahe bermanot ift ber chlorit; nur tritt in biejem bie Thonerbe als mejentlicher Bejtanotheil auf. Bon bem Chlorit Gat man znei

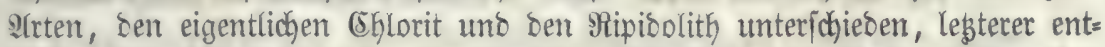

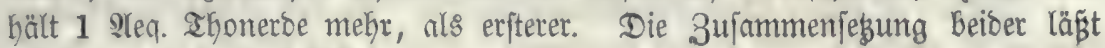
fidi) aber burch bie grormel

$$
3 \mathrm{RO}\left\{\begin{array}{l}
2 \mathrm{SiO}_{3} \\
2 \mathrm{Al}_{2} \mathrm{O}_{3}+3 \mathrm{OH}
\end{array}\right.
$$

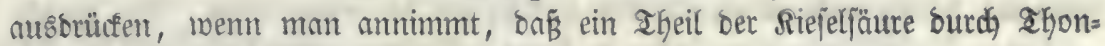
erbe vertreten werben fönne.

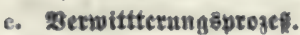

Die Bermitterung bes Inlées fommt jo giemlich) mit berjenigen bes

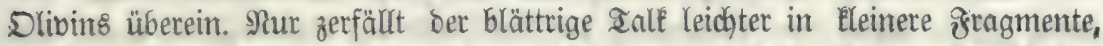
al\& ber Dlivin, währeno legterer etwas leidjter von Rohlenjäure aufgejd) miro.

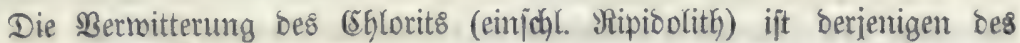
Felojpaths ähnlich; die Bajen vou ber form RO werben als boppeltéleblen. jaure Salze aufgelöjt, ober nudh, wenn fie (sijen unt Mangan find, höher orgy= sirt. Die Riejeljäure miro als \$̧borat in jreiłeit gejegt.

\section{G. Siefelgefteine.}

3 biefen redhnen wir alle biejenigen Bejteine, in benen Riejelerbe ohne

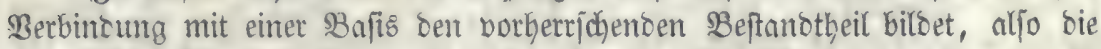

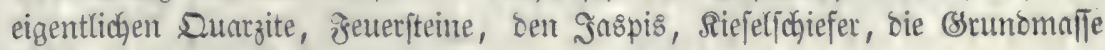
vieler Gantiteine ut. \%, m.

Die reime Riefeleroe löft fich, wiemohl in jefr geringer Menge, in Ebylen=

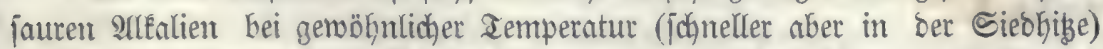

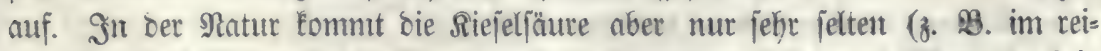
nen \$Bergeryftall) ganz rein bor; meijt ift ifgr etwas (sijen uno MRangan bei= 


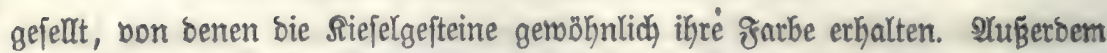
fommen in ben meiften Sefteinen biefer Sruppe Spuren bon Ehonerbe, Ralk:

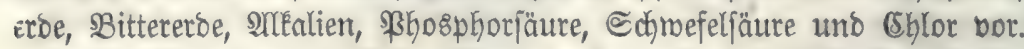

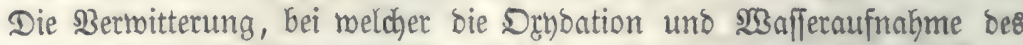

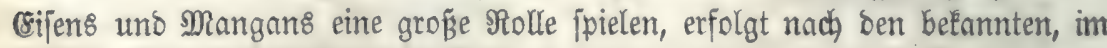

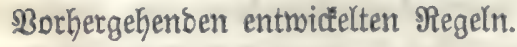

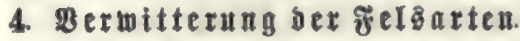

A. ริm xirgemetuen.

a. Die Berwitterbartet einer Feløart bängt von ber Berwitterbarlett tbrex se ftanbtbeile ab.

So zerjest fid zum Beifpiel ein Snenit, befien Felojpath \&abraoor iff, leichter, als ein Eyenit mit Drthollą).

b. Odiefrige Cefteine zerfallen Ieidite in Eleinere Fragmente, ars mantige Oefteine.

Sierauf ift früber fołon Gingemiejen morben. 21n ben Sohichtungsflädhen Gängen bie Befteine nicht po fejt zujammen. Dringt bas 2 saffer in bie Spal= ten uno gefriert, fo werden bie Sdjidjten von einandergeprengt uno zertrüm=

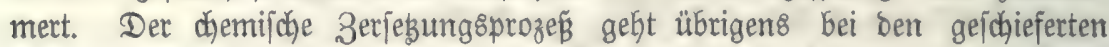
Frelsarten häufig nidht fo fojnell von ftatten, als ber med)anijche. So zerfällt 子. B. Der Riejeljobiefer fehr leicht in Eleinere Stücke, aber bieje erhalten fith lange Zeit unberänbert, neil bie Srunbmaffe bes Befteins Duarz ift.

c. Forōfe Cefteine verwittern Ieidjter, als berbe.

Dies erlelärt fich ganz einfad aus ber grofien Dberflädje foldher (Se= fteine. Sene bietet bem Snuerftoff ber Euft uno ber Sohlenjäure. mehr AYn=

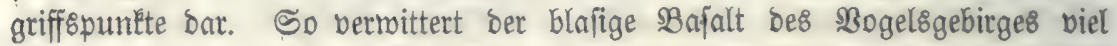
jăneller, als ber biçte Säulenbajalt; ber mit vielen Blajenräumen berjełene Melaphyr von Darmftabt vermittert in bei weitem Kürzerer Zeit, als bas berbe Beftein aus ber nämliçen Begeno.

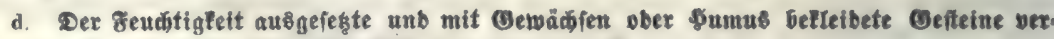
wittern leiditex, als nadte gerien.

3u Diejem Saß̧ liefert befonders das Berfalten ber gelsarten in ben Bebirgen ben Beleg. Freiftehenoe vegetationslofe Sutppen erfalten fich Jahr=

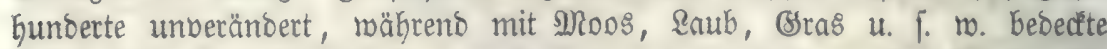

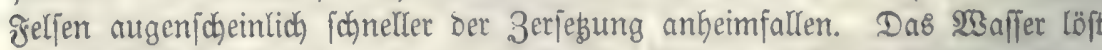

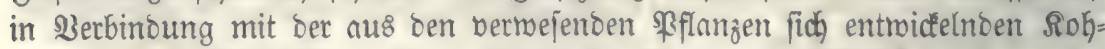
Yenjäure bie meijten Mineralien auf, wie int Borigen ausfüfrlid nad)gemiejen worben ift.

C. Etienoxbutbaltige Oefteine verwittern Ietat.

Das rijenorgoul hat bas Bejtreben, in Dryo überzugeben. So zer: 


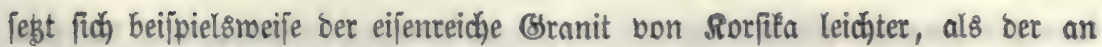

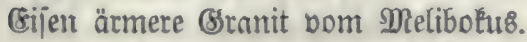

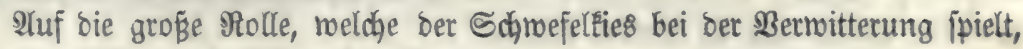
madhen roir hier nodimals aufmerfjam.

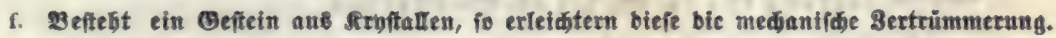

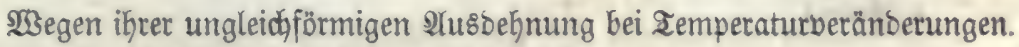
SBir verm eifen in biejer Beziehung auf S. 49.

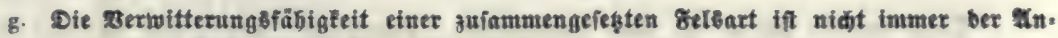
zabi threr Beftanbtbeile proportional.

Den entgegengejesten ๔ał hat Sunberhagen ausgejprochen. Die bon bemjelben angeführten Belege fino aber teinestwegs entidheibende Bemeife. So beruht bie lunberänberlidjleit ber reinen Riejelgefteine (Duarge u. f. w.) nidgt

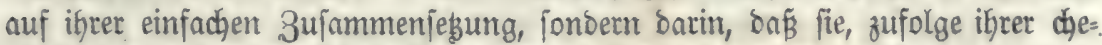

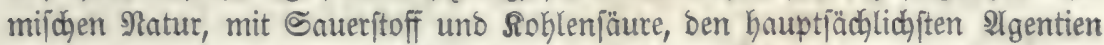
ber $\mathfrak{B e r m i t t e r u n g , ~ P e i n e ~ B e r b i n o u n g e n t ~ e i n g e h e n . ~ ( E n t h a ̈ l t ~ b e r ~ D u a r ~ f r e m o = ~}$ artige Bejtandtheile (Eijen, Mangan u. i. m.), fo erleidhtern bieje allerbings bie Bermitterung, aber nidat biejenige der Riejeljäure, blos fie jelbjt zerjesen fich, weil fie zu bem Sauerjtoff Berwandtida aft haben. Dieje Rebenbejtand: theile bermittern aber eben jo leidht, renn fie nicht im Bereine mit freier Rie= felerbe vortommen.

Andere Behauptungen, weldje Sumbeshagen zum Belege feiner Âtridut

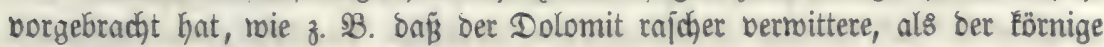
Rale, find vollfänoig unricytig.

Dagegen laffen fich biele BBeipiele bafür anführen, baß̉ die Complenität

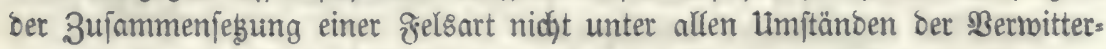
ung günjtig fei. So zerjebt fich ber aus vielen (Elementen beftehenoe Slimmer

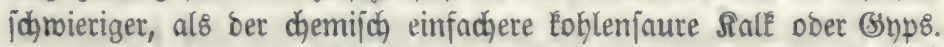

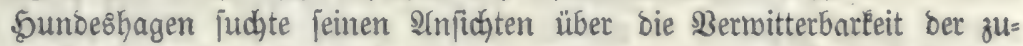

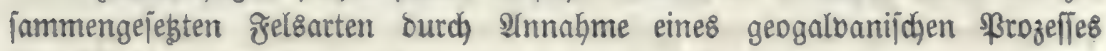
eine Stüge zu geben.

Man weiß̈, baß́ bei ber gegenfeitigen Berührung ungleidjartiger \&ïrper

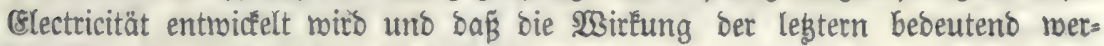
ben Eann, wenn man bie ungleichartigen Rörper zu einer Rette oronet. Sun=

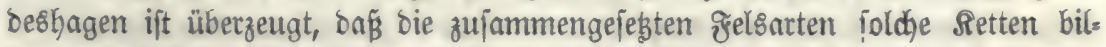
ben uno daß́ die (Stectricität, welche ourch biejelbe erregt wiro, eine 3erjebung ber Ealge in Bajen uno Säuren uno der Drtbde in bas betreffende Rabical

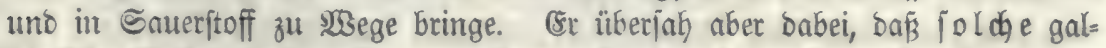
banijhe Ströme, wie ex fie bermuthet, nodh nirgends nadjgemiefen jino, ober baś biejelben auch nur bei einer bejitimmten regelmäß̈igen Dronung ber BSlie= ber einer Rette auftreten, Eeinesnegs aber Dann, wenn bieje (s)lieber bunt burd) einanoer gemürfelt find, nie bies in Den Felsarten ber Fall ift. Sebenfalls 


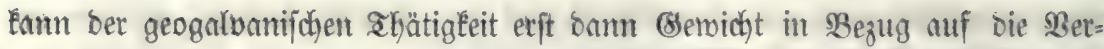
mitterung beigelegt merben, wern genauere llnterjuchungen über biefelbe nach)= gewiejen Gaben, baß̌ fie mirflich bejtehe.

\section{B. Bermitterung ber geborten im sefonberen.}

a. Oranit.

\section{a. 3uiammenjegung.}

Dieje murbe fobon S. 34. angegeben. Siernad) bejteft ber Branit aus

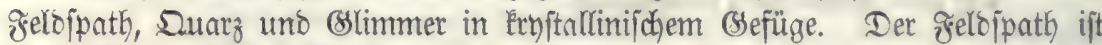

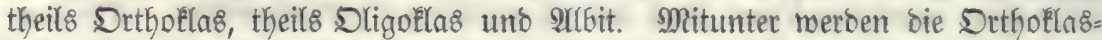
Förner von Mlbit ober Dligoflas mie von einer bünnen Sdjale eingehüllt. Der SSlimmer ift Rali = ober Magnefiaglimmer, mur in feltenen Fällen Eepibolith.

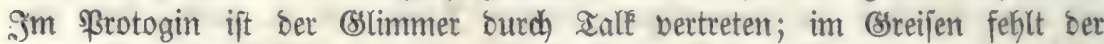
Gelbjpath.

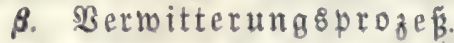

Diejer jebt fid aus ber Bermitterung ber einzelnen sBeftandtheile bes Branits zulammen. Dabei fpielen bie accefforijosen Minernlien im Branit, wie Inlk, BGlorit, Sornblenbe, Bijenglanz (Eijenglimmer), Magneteijenerz, Sranat, Binit, Iutmalin, Irpatit u. f. w. uno unter biejen bejonders bie Bifen=

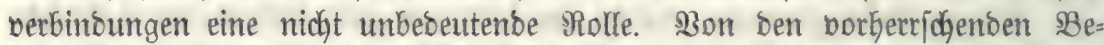

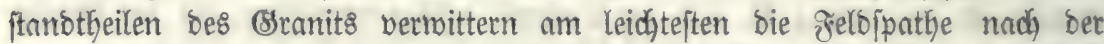

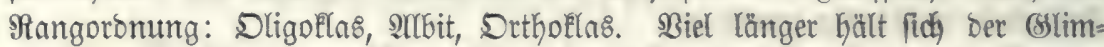
mer. Die Bernitterung bes Duarzes befteht hauptiächlich in ber Drvoation Des bemiflben beigemengten (sijenorybuls.

Der Ninfang in ber Berwitterung bes Eranits manifeftint fid) burd)

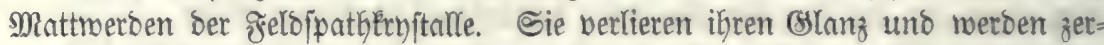
reiblich; zulegt gehent fie in eine Eaolinartige Mafle über. Doch bauert biefer

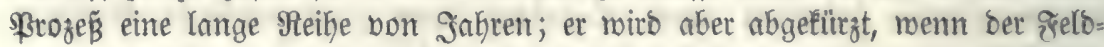
[path biel Cijen entbält. Dft ijt ber Feldipath ichon ganz eroig gemorden, räGrento man an bem Duarz uno Sslimmer knum eine Spur ber Jer/ebung wabrnimmt.

WBenn bet grelbjpath feinen 3ufammentyang verloren bat, fo zerfälit bas Geftein zuerft in bidere Brocken, Dann in Aleinere frongmente (Branitgru8).

(sinige (Sranite vermitten leidht, anoere fdhwerer, ohne baß̧ fich immer

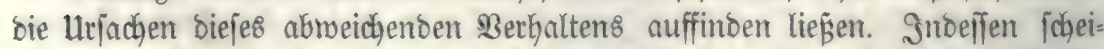

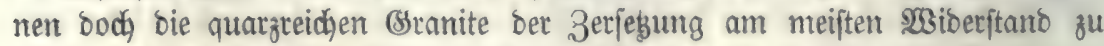
leipten.

\section{$\gamma$. Die Berwitterung8prooucte}

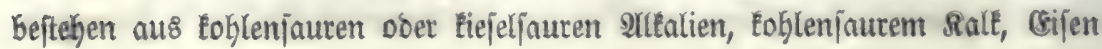


uno Mangan uno Eohlenjaurer Magnefía, freier Riejelfäure, jojwefel = uno phosphorjauren Salzen, Sijen = uno Manganoxybhyorat.

\section{b. Branulit.}

a. 3 uammenjesung.

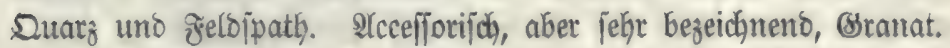

B. Bermitterung.

Dieje icheint, nach ben Beobadytungen, Die ber Berfaffer im Doentwald zu madjen Selegentheit hatte, ichnieriger, als bie bes Granit\& won ftatten zu gehen.

\section{c. Eyentt.}

a. 3 iammenjeģung.

Det Gelbpath ift meift Drthollas, ober Eabrator. Sligoflas uno afl= bit fommen jeltener bor. Nack) Deleffe befteht ber Syenit in Den 30 gefen aus 5ornblento und aus zmei Feldjpathen, nämlich Drthoflas uno Ŝnbefiu (in leșterm 5\% Ralle, 2\% Rali, $7 \%$ Ratront).

\section{B. Die Berwitterung}

bes Syenits hat mit ber bes Sranits, in weldhen ber Syenit häufig übergeht, Bieles gemeinjam. A4ud von diejem Beftein gibt e8 $\mathfrak{B a r i e t a ̈ t e n , ~ b i e ~}$ fäneller, uno andere, nelche leichter bernittern.

\section{d. Eneif.}

a. 3 uammenjegung.

Die bes (3ranits, aber mit idjieferiget Structur.

B. Bermitterung.

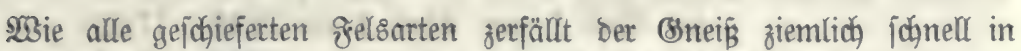

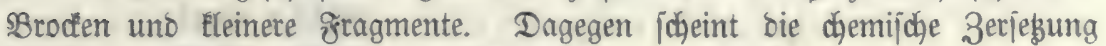
langjamer, alø beim Branit zu erfolgen.

\section{e. Grimmeríditefer.}

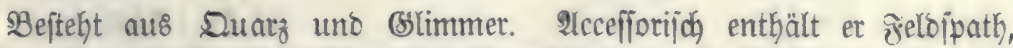

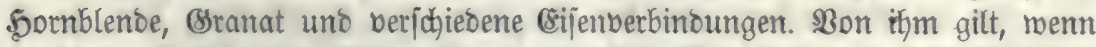

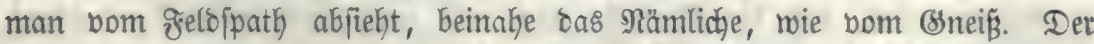

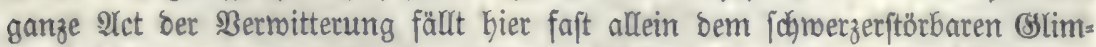
mer anbeim. Dod) liefert ber sstimmerjobiefer oft einen jebr mürben un nidjt felten aud) tiefgrïnoigen Boben. Binige Bsimmerjojiefer idjeinen jogat leichter zu verwittern, als ber sineif. 


\section{f. Eboniditefer.}
a. 3ujammenjebung. (ธ. ธ. 10.)

atke bis jeşt unterjuchten Ihonidjiefer enthalten 2 Baffer, idjeinen baker, ba lebteres auch in ben zunäd)ft ber Erooberfläche liegenoen Schichten bor= fommt, zum Theil johon ber Bermitterung ankeimgefallen zu jeir. Biele Ihonjobiefer braujen mit Säuren, fie enthalten Eoblenjauren Sale, roeldyer fid

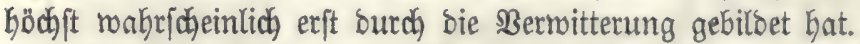

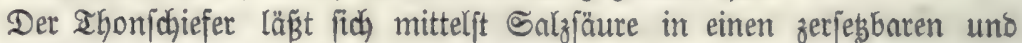
uno unzerjegbaren sheil trennen. Beibe enthalten Riejelfäure, Thonerbe, rii= Fenorbb, Mangan, Ralkerbe, Ialferbe, Rali und Roble.

1) Der burch Salzäure zerlegbare Iheil hat fo ziemlich bie 3ujammenjegs

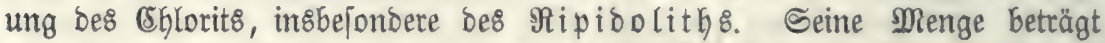
$10-30 \%$. (\&r ift alz ein feiner Staub burch bas ganze (seftein verbreitet und bebingt, neben ber Soble, vorzüglich) die zarbe beffelben. Die grün=

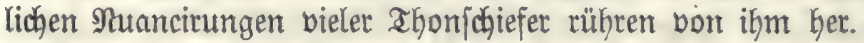

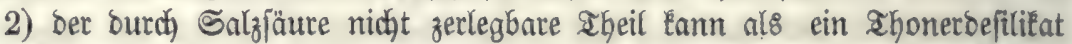

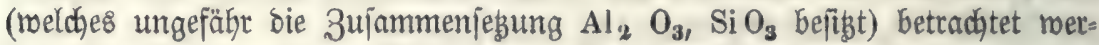

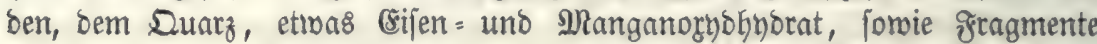
von Jelojpath uno Bsimmer beigemengt fino. Die Duantität Des Duarzes

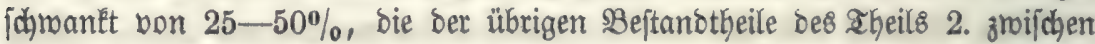
30 und $50 \%$.

Da bie 3ujammenjebung bes Thonjohiefers fo febr beränoerlid ift, jo laffen fidh şormeln für benjelben nidht nohl aufftellen.

\section{B. Berwitterungsprozé̈.}

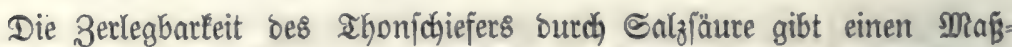

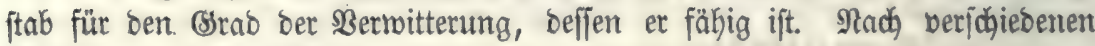
Itnalyjen verbalten fich

bet Theil 1 fum aheil $2=28,98: 71,02$
$30,53: 69,47$
$29,73: 70,27$
$3,216: 76,39$
$24,48: 75,52$
$25,31: 74,69$

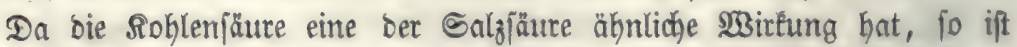

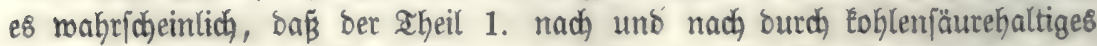
Wanjer aufgelöft uno fortgeführt merben Kann. Die Bermitterungsprobucte

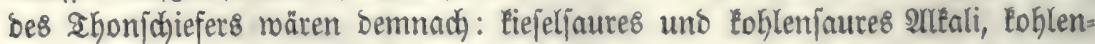
jaure Ralterbe uno Magnefĭ, freie Riejeljäure, tohlenjaures Eifen = uno Man= ganogybul und (sifen = und Maganorybbybrat. 
Die meiften INnalyjen geben bas (sijen im Zhonjojiefer als Drbo an. In= beffen facheint biejer Stoff aud häufig al\& Drybul vorzutommen. In biejem

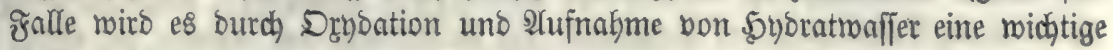
Rolle pipielen.

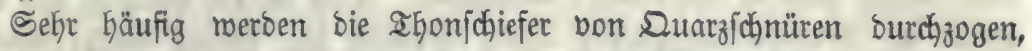
weldhe wohl nur als ein ßerwitterutgsprobuct angejehen werben bürfen. Wie

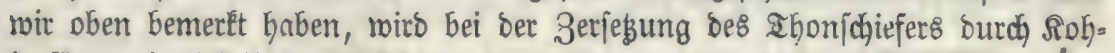

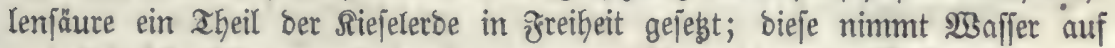

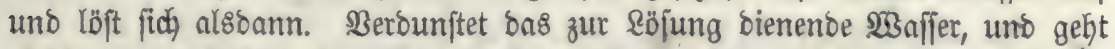
gleichzeitig auch oas chemijch gebundene $23 a f f e r$ Ginneg, fo bleibt unlöslidje Siejelerbe zurüaf.

\section{$\mathrm{SiO}_{3}+$ Laq.}

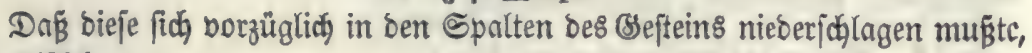
ift begreiflid.

B8 bebarf laum nod, einer Bemertung, uno bie Benennung be8 §hon=

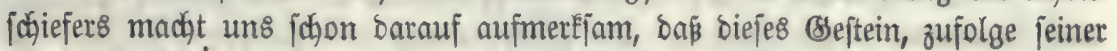
Structur, febr' leidjt von einoringendem $\mathfrak{B a}$ afer geêlüftet wiro.

\section{Graumadte.}

Sie fommt ars Braumadenjobiefer uno als Braumactenjanoftein vor uno ftimmt, abgejehen von bem grö̈ern Duarzebart, in ifrer 3ujammenjegung

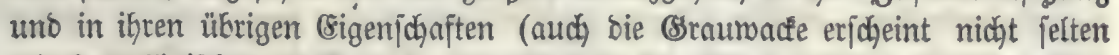

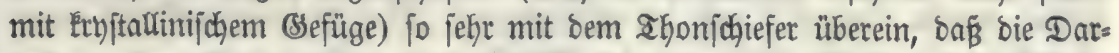
ftellung ifrer Bernitterung nur eine MBieberholung bes über ben Ihonjwiefer Bejagten fein müroe.

\section{h. Grünftit.}

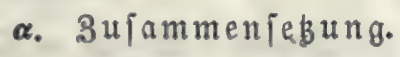

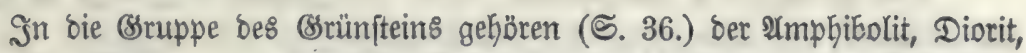
Serpentin, Brabbro, ber eigentliche Brünjtein ober bie Diabaje, ber Schaljtein,

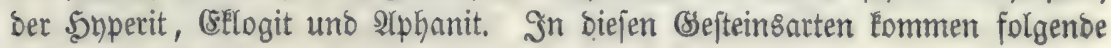
Mineralien bor:

1. Felofpath, (Rabrabor, 2rtbit, Sauffurit, Sligoflas).

2. Jornblente.

3. 2ugit (Diallag, syperithen rc.)

4. Ehlorit.

5. Rallpath.

\section{ק. Die Berwitterung}

Der voritehenden Mineralien Gaben mir früher iळon betradjtet. Die \$robucte ber Bermitterung Der Brünjteine iegen fid aus oenen ifrer Bejtanotheile zu|ammen.

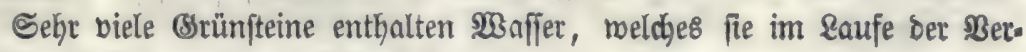
mitterung aufgenommen zu haben idgeinen. 


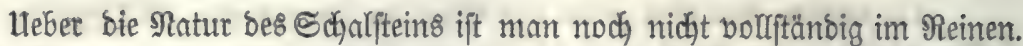
(ơr entfält mundliche, oft erbfengrofie Rörner bon Salejpath. WBabricheinlich

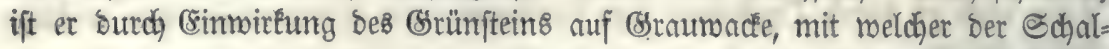
ftein immer zugleich vorfommt, entftanden. Dafi bei ber SBildoung bes Cobal= fteins. ein Bermitterungsprozef́ thätig gerwejen jei, barauf beutet jejon ber sebalt an Eohlenjaurem salf hin.

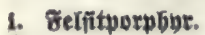

ж. Bufammenje⿻̧一ng. (ธ. 37.)

Fetopath, Quarz uno Bstimmer bilden bie Brunomafie uno (Einjpreng= linge. $3 \mathfrak{u}$ ben accefforifden Beftandtheilen gehören \$ornblenbe, Eijenties, Eijenglanz, Bijenrahm, Magneteijenerz.

B. Bermitterung sprozę̆.

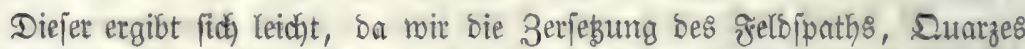
uno Simmers bereits Eennen. Die Bermitterung bes \$orphyrs beginnt ge=

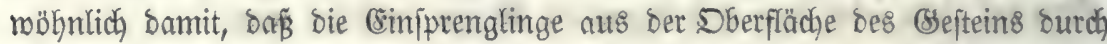
groft 2c. 2c. gehoben merben." In bie Deffmungen bringt mun leidgt Fohlen=

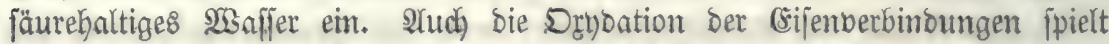

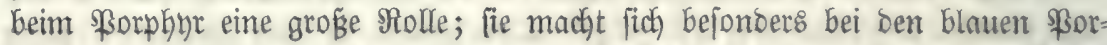
whyren bemerlbar, meldhe alsonnn eine röthliche ₹arbe annehmen. - Schon

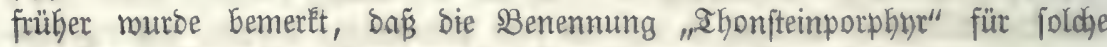
ßorphyre gilt, welebe fohon von ber Berwitterung gelitten haben.

\section{k. Melaplint.}

a. 3ujammenje⿻̧ung. (ङ. 38.)

Der Melaphyr ift ausgezeidynet burdh bent gänzlichen Mnngel an Suarz. (Er vermittelt ben Hebergang pon ben \$orphyren zu ben Bafalten. Beolithe lommen indeffen felten im Melaphnt bor. Alccefiorijche Beftandtheile, des Melaphyrs fint: Bifenglinmer, Salefpath, Braunjpath, Eijenglanz, Eijenrafym, Bifenipath.

\section{B. Bermitterung.}

Sie fällt zum grösten Theil mit berjenigen des \&abrabors zulammen,

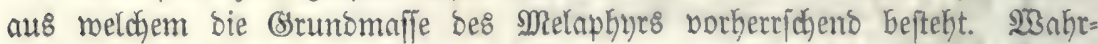

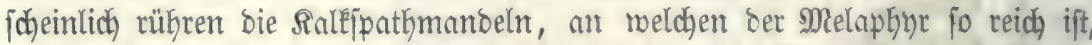
mur yon ber Zerjęung bes \&nbrnonrs Ger, während ber \$Brnumipath gleichzeitig aus den Bejtandtheilen Des Rabradors und des (Ehlorits finch gebildet hat. Die Blafige Structur Des \$Melaphnrs begünftigt jeine Berwitterung ausnebyment.

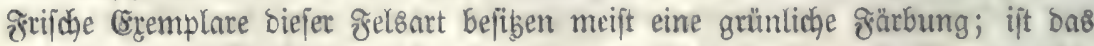
Geftein in Der Zerfebung ichon weiter vorgejchritten, io geht jene in eine rothe ober braumrotbe ther.

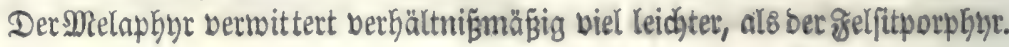




\section{Iradjpt.}

a. 3иүammenjesung.

Der Iradyyt läs̆t fich mittelft Salzäüure zerlegen.

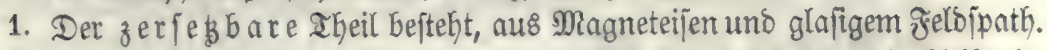

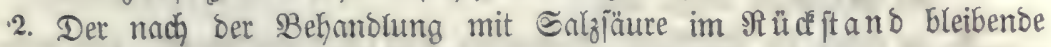

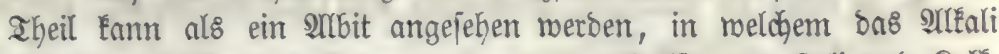

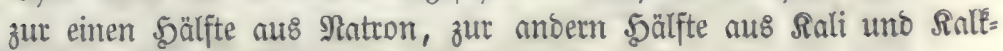
eroe befteht.

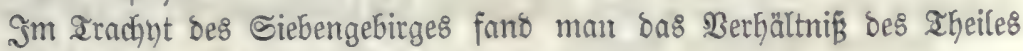
1. zum Iheil 2 , wie $12,51: 87,49$ und zroar:

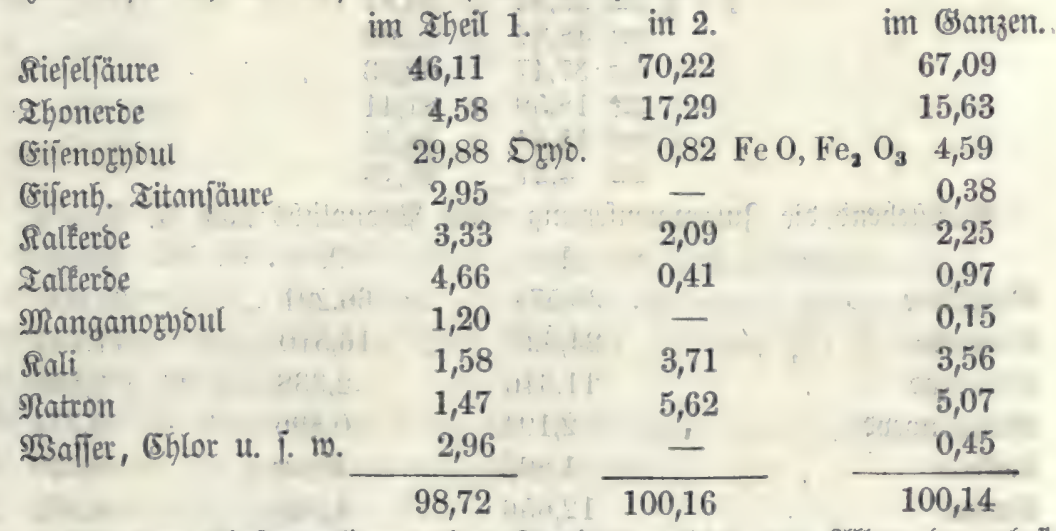

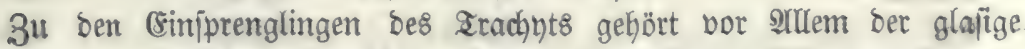
Felbjpath Doer Sanibin, außier biejem Eommen Sornblente, Sslimmer, Sranat,

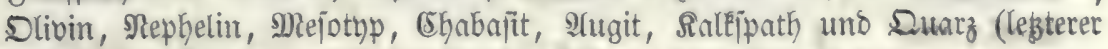
jelten, am häufigiten noch im Iradynt bes Siebengebirge\&) bor.

Domit ift eime Slfart bes aradyt, weldye in ber Slubergne (Puy de

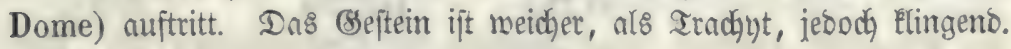

\section{B. 2erwitterung.}

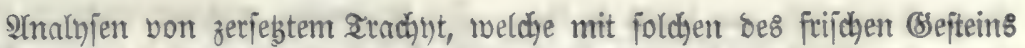
verglidjen rerben fönnten, find noch nidyt angeftellt rooroen.

Die in ber ssumomaffe bes Iradjyts eingeiprengten Sanibintryftalle

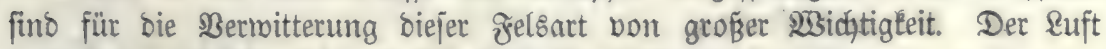

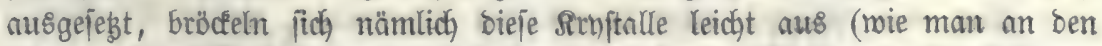

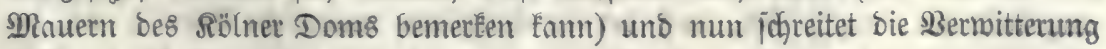
raich) vormäts.

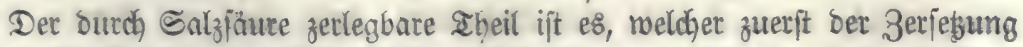
Durch) Rohlenjäure anheimfällt. Die poröfe Structur viełer Iradhyte erleidgtert

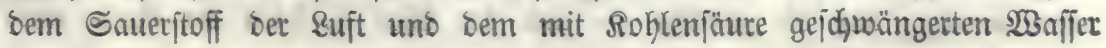
ben 3utritt. 


\section{m. ॠbonorit5.}

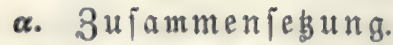

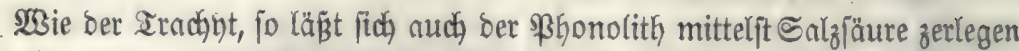

1. in einen zeolithartigen Bejtanotheil, ber ungefähr bie 3 ufammenjegung bes Mejptyps befigt und

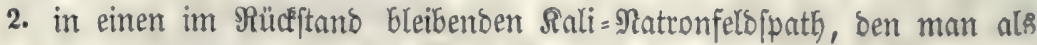
Sanibin anjeben tann.

Das Berhältníz Des Zeoliths zum Feldpatpaty ift nidht conftant, was roabridgeinlich baher rührt, weil ber. Zeolith fich leichter zerjebt, als Der Felojpath.

Mefrere 2Tnalyjen ergaben

$$
\begin{aligned}
1: 2 & =55,33: 44,87 \\
& =48,97 \quad: 51,03 \\
& =37,47 \quad: 62,53 \\
& =18,59: 81,41 \\
& =15,84: \\
& =44,16
\end{aligned}
$$

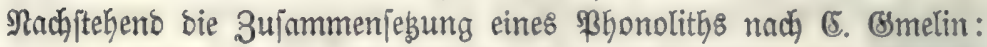

1.

Riejeljäure

Shonerbe

(Eijenorbo

Mangonoryd

Salferbe

Natron

Sali

Iitanjăure

Wañer uns

Drg. Subftanz
38,574

24,320

11,346

2,194

1,802

12,656

3,079

0,620

4,614
2.

66,291

16,510

2,338

0,896

Spur

4,960

9,249
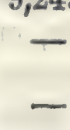

Sanzes.

61,901

17,747

3,806

0,774

0,029

6,182

9,006

0,098

0,666

\section{9,295}

100,294

99,478

Im Phonolith fommen von 3eolithen in Drujenräumen vor: 2Ypo= phyllit, Bhabafit, Eomptonit, Desimin, Ratrolith, Anatcim. Dlibin uno

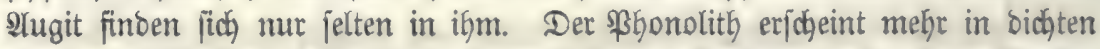
compacten Maffen, Dagegen ijt igm iøjeferige Structur uno plattenförmige Albjonberung mehr eiger, als ben übrigen plutonij̧̄en g̈elsarten.

\section{B. Bermitterung.}

2Yu einer 2Ynalnje eines verwitterten \$honoliths, weldje (5. Smelin angeftellt hat, ergibt fidh, bañ ber in Salzjäure unlöslidge zheil 1. bei ber Berwitterung faft gar Keinen \$eränterungen unterliegt, währent ber in Salz= fäure lösliche Iheil 2. nidht blos Riejeljäure, Rale, Rali uno SRatron, jondern auch etroas von feiner Ihonerbe abgibt. Regteres Eann nidjt befremben, wenn man errägt, bǻ bie Zeolithe - uno ber Ifyeil 1. Tpielt bie Folle eines foldhen - bon Salzjäure zerjęt merben. 


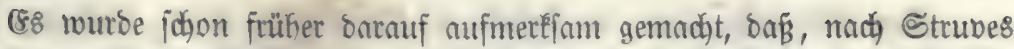
Entbeatung, bon ben Allfalien borzugsmeije bas satron nusgejohieben mirb. Der \$honolith berwittert, einzelne Fälle ausgenommen, im Banzen leicht.

\section{n. Safalt.}

a. 3uүammenґевung.

Der Bająt befteht (ธ. 39.) aus Enbrabor, AYugit, Magneteijen uno einem

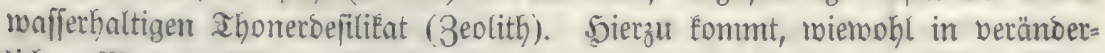
lichen Mengen Dlivin ober (Shryjolith. In einem Bajâlt vom æridhtelgebirge fano man bas Berbältniż biejer MRineralien folgendermaß̧en:
1. $\left\{\begin{array}{l}\text { Magneteifen } \\ \text { Dlivin } \\ \text { 3eolith }\end{array}\right.$
11. 54
$\left.\begin{array}{r}\text { 8. } 30 \\ 27.94\end{array}\right\}$
2. $\left\{\begin{array}{l}\text { Rabrabor } \\ \text { Alugit }\end{array}\right.$
47. 78 .
21. 34
30. 88
52. 22 .
100. 00

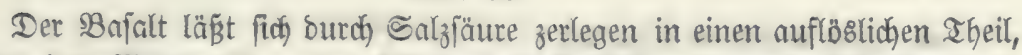
welcher bas Magneteijen, ben Dlivin uno 3eolith uno etras \&abrabor um= faß̄t, unס in einen unauflöslichen Theil, weldher den Reft des \&abrabors uno ben 2 ugit in fid begreift.

Der Bajalt ift ausgezeidynet sutrdy bas Borkemmen bon 3eolithen, ex ift reicher an biejen, als jebe andere plutonijche Felsant.

ק. Bermitterung.

Bon den Beftandtheilen bes Bajaltes bermittert vorzüglich leichtber

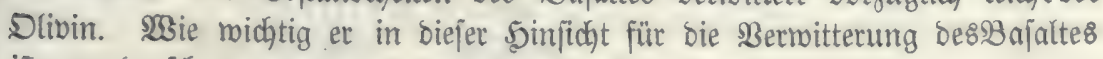
ift, nurbe jobon angebeutet.

Rächft Dem Dlivin zerjegst fich am frütejten ber zeolithartige Bejtanotheil

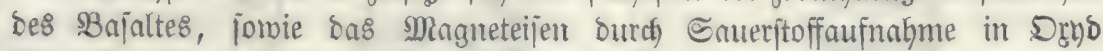
übergeht. Dann folgen ber Rabrabor und Stugit.

Ebelmen bat friichen uno vermitterten Bajalt von einerlei §unoftätte analyfitt uno gefunoen:

\section{Siejalfäure \\ Sitanjäure \\ Shonerbe \\ Manganorno \\ (sijencrybul \\ zalterbe \\ Salferbe \\ Ration \\ sali \\ Şaffer}

frijo, $B$ ajalt. 45,9

1,0

16,2

0,3

13,0

6,3

10,3

3,6

1,2

$\frac{2,4}{100,2}$ bermitterter $\mathfrak{B a j a l t . ~}$

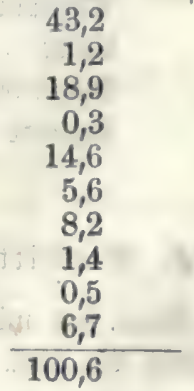

5eber, Bobentunte. 


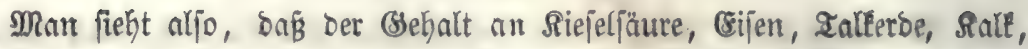

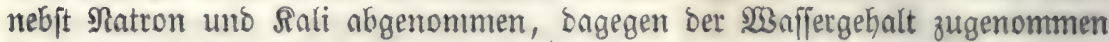

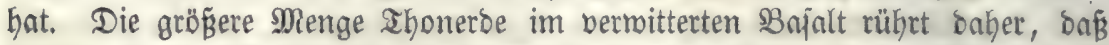

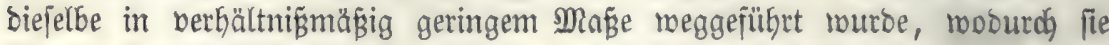
fich relatio anfäufen muşte.

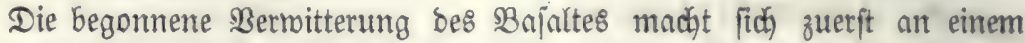
gelben lleberzuge bes Befteins bemerťbar, ber an Säulen oft bamnscirt er=

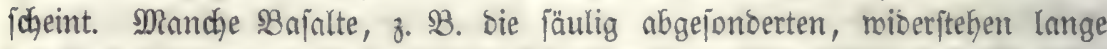
ber Bermitterung, andere zerjegen fich fohneller. Nicht jelten bemertit man, bafï ganze Feljen in Eleine, hajel = bis wallmügrofie Trümmer zerfallen find. Biełe Ihone bes Diluviums uno ber Molaffe berbanken bem Bajalte ibre Entjtehung.

Der blajige $B$ ajalt wirb b̈ters bei ficton weit vorgejhrittener Bermits

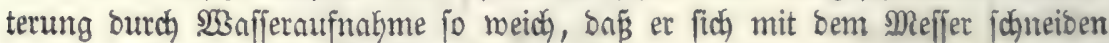
läğt. $2 \mathfrak{n}$ ber Ruft erbärtet er wieber.

\section{2ava.}

a. 3 uюmmenjebung.

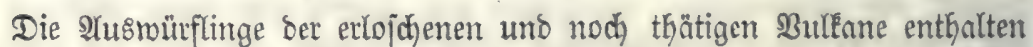
fo ziemlich bie nämliçen $\mathfrak{B}$ ejtandtheile, wie ber 2 Bajalt, nur ift ber in bet \&ava borkommende Felojpath nidyt blos \&abraoor, jonbern auch Dligollas. Iugit und Magneteijen, aud Dlivin, Kommen in allen Eaven vor. Die

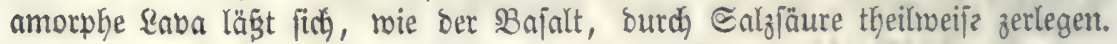

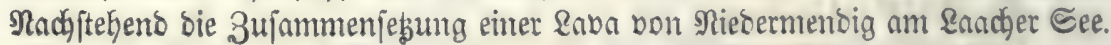

Durch હalzfăure zerjeşbar. nicht zerjeb̧ar.

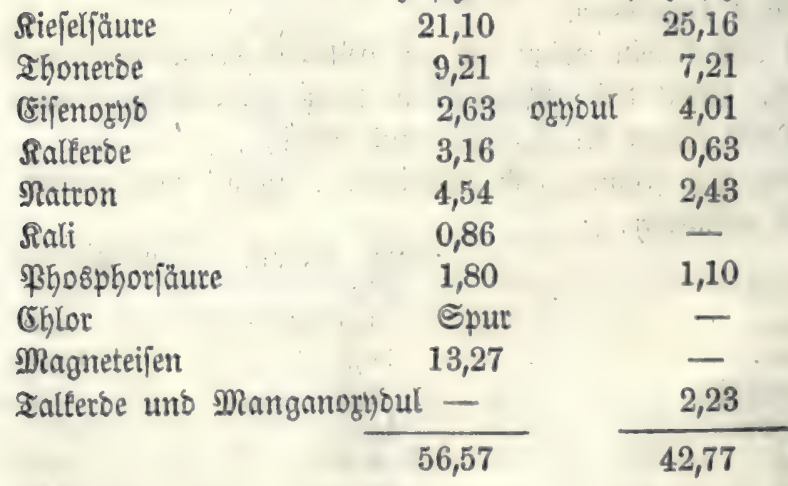

\section{ק. Berwitterung.}

Diefe. Gat mit berjenigen bes Banaltes bie gröpte Aehnlichteit. Sur vermittert die \&ava viel jdyneller, als ber Bajalt. Sin Stalien, am Bejub 


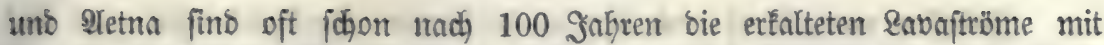

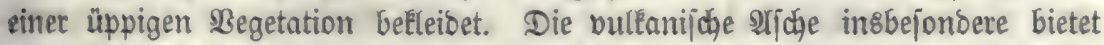
regen ihrer 3ertheilung ben 2Igentien bie ßerwitterung viele 2lngriff\&= puntte bar.

\section{p. Canbfieine.}

a. 3uүammeniegung.

Die Smojteine bejtehen entweber aus ben bernitterten Irümmern anderer

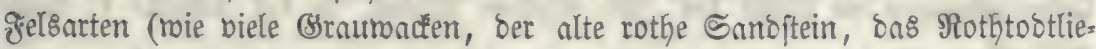
genoe, viele Sandfteine ber Iria $8=$ und Rreibe $=$ (Sruppe) ober pie find burch

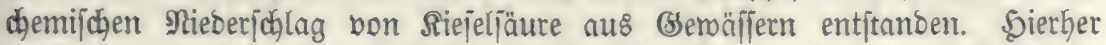
gebören wahricheinlich bie meiften bunten Sanojteine, ber Quaberjandjtein,

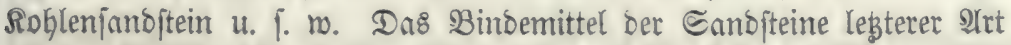

1. fehlt entweder ganz, uno bie einzelnen Quarzëbrter find in biejem Falle nur zujammen gefittet,

2. ober ift Riefelerbe,

3. Dber Ralferoe uno Zalferbe,

4. Doer ahon,

5. Doer (Eijen in Den beiben Drybationsftufen, vorzüglich aber als Dryo.

\section{ק. Diermitterung.}

Die 3erfebung ber conglomeratartigen Sanofteine ergibt fich aus bem

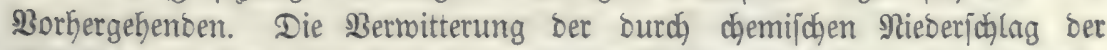

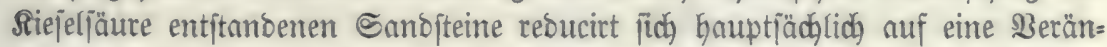
berung in bet 3ujammenjebung bes Binbemittels. Salk uno anle uno Eijen=

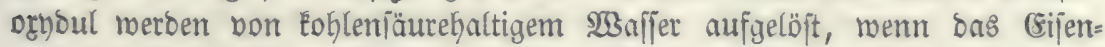
prybul fich nicht böher orybirt; aus bem Ihon, ben wir nut als ein unvoll= ftänoig zerjętes felojpathartiges Mineral anjehen bürfen, merben Riejeliäure,

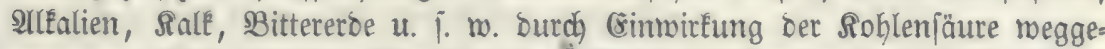
nommen. Die jhiefrige Structur ber Eandfteine Eommt ifrer mechanijojen 3ertrümmerung febr fll ftatten.

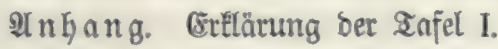

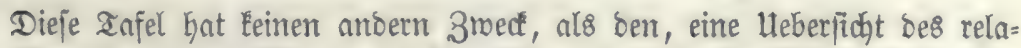

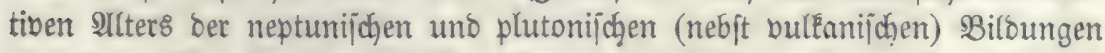

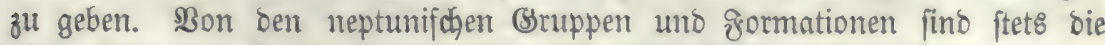
obeten jünger, al\& bie unteren; bei ben plutonijogen unb vulfanijogen (bes

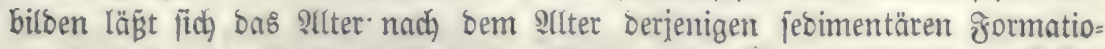

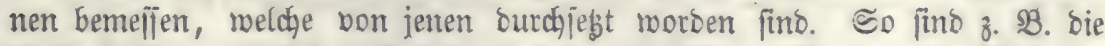

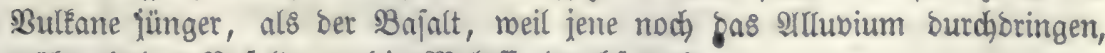
rährend ber Bajalt nur bie Mrolaffe ourchjegt hat. 
Inteffen mangelt es noch jebr an verbürgten Beobadtungen, um bas

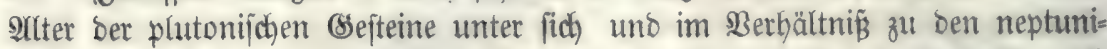

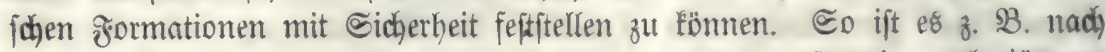

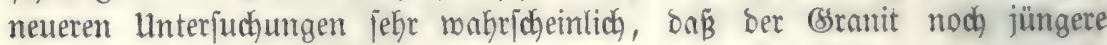

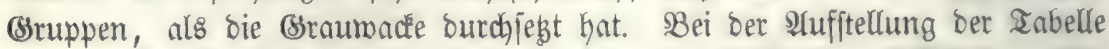
I. hat man fich vorzüglich an bie 9 rngaben bon Bernbard (5ptta gehalten, meldye bas Rejultat einer umfaffenden Reibe bon Beobadjtungen fint. Der geneigte \&ejer wirb gebeten, Diejenigen AYenderungen, relche fich burds conjtatirte Unterjudjungen im \&aufe ber 3eit ergeben follten, in ber Iabelle I. nad)= zutragen. 


\title{
3 weitcs $\mathfrak{B}$ u
}

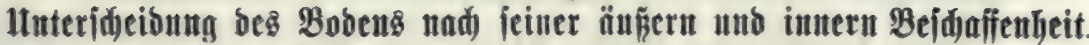

\author{
Erfer Xbidnitt.
}

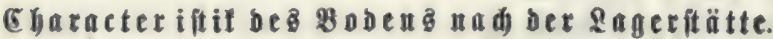

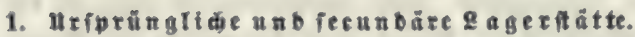

Der aus den Befteinen Durah Den Bertwitterungsprozé̈ entitandene $\mathfrak{B D}=$

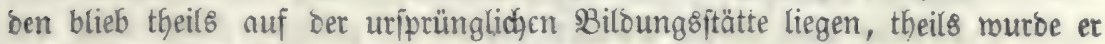

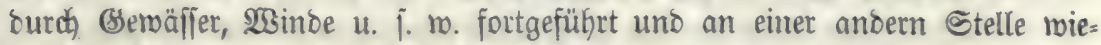

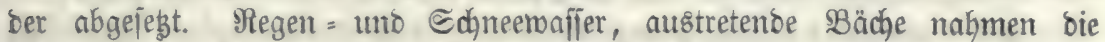
leidgter benoglidgen Jragmente Der zerjegten (Befteine mit fid) unto lieǵen fie

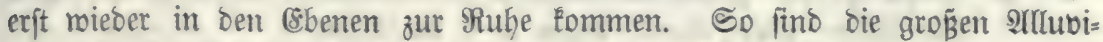

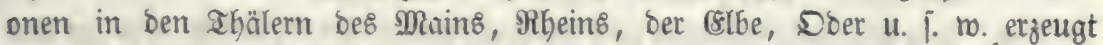
morben. Co ftammen die grofien Thonlager ber WBetterau in Seffen bon zerjegtem $B$ ajalt aus Dem $\mathfrak{B}$ ogelsgebirge ab.

Siernady Eann man den Boben eintheilen

a) in joldjen, weldjer fid nod auf feiner uriprünglidgen Billoungsiftätte befindet;

b) in foldhen, meld̆ger eine fecunoäre \&agerfiätte eingenommen hat.

Den Boben Der eritgenannten 21rt bezeidhnet man aud wohl als ose $\mathrm{e}$ birggfoben. Dieje Benennung jollte übrigens fallen gelaffen merben, weil fite

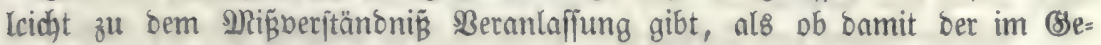
birge befindlidge Boben gemeint fei. Den Boben auf fecundärer sagerjtätte

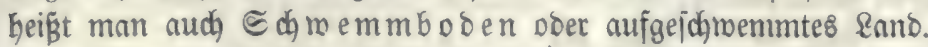

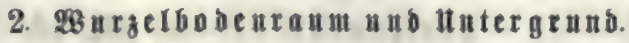

Diejenige Bobenjofichte, weldje die Bflanzen nod mit ifren 133 urzeln burdforingen, nennen mir ben 2 zurzelbodentaum, bie unter diejem liegenden Sdjidgten ben untergrumb. 2noere begeidgnen ben 234 zelbobentaum als 


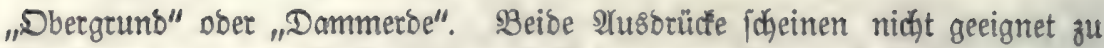

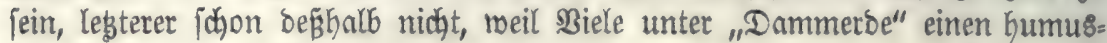
baltigen $B$ oben verfteben.

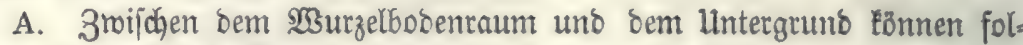
genbe Berbältniffe ftattfinden

a) Beibe find gleidartig uno grat ङัเg. 57.

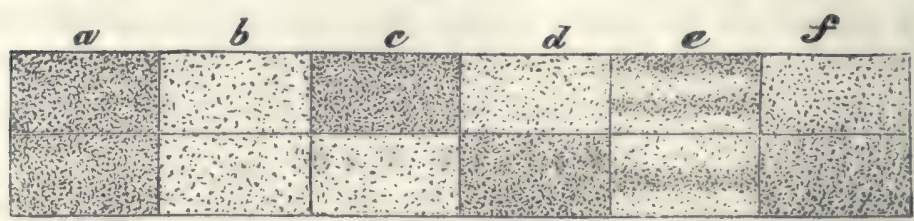

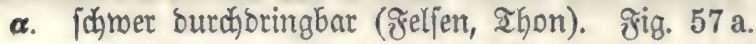

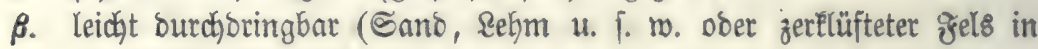
ber Iiefe.) §ig. $57 \mathrm{~b}$.

b) beibe find ungleidartig.

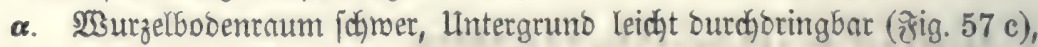
8. SB. menn Thon über Sand liegt. Diejer frall fommt in ber Natur

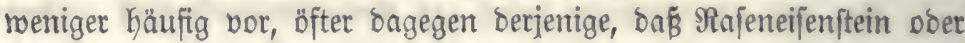
Drtitein über grofie Strecten Rande\& in geringer Diefe unter ber

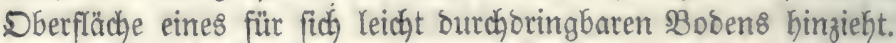

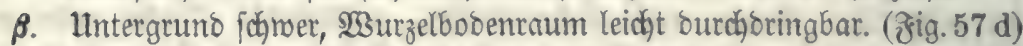
Diejer ift ber genobhnlichite frall. Br" tritt ein, wenn f. BB. Ehon Doer Ferfen unter Sano, Refm u. j. r. liegen.

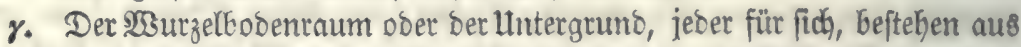

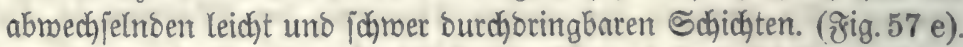

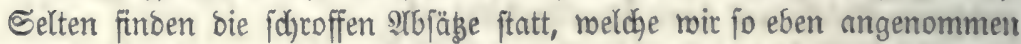

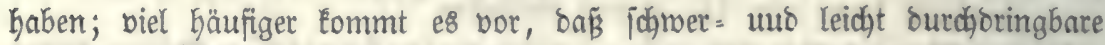

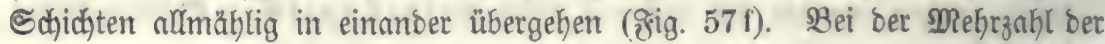

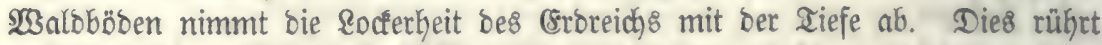
zum Theil bon Dem größ̈ern Drud her, meldhem bie untern Sdjidgten ausge= feģt find; bann werben aber auch bie okem Bobenlagen mebre burch ben פu= mus, burch ben 13 interfroit uno burch bie dyemijoge Bermitterung gelodert.

Bilden getjen ben untergruns, jo ift es jehr midjtig, wie bie Sdjichten einfallen. Man unteridheibet

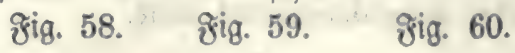
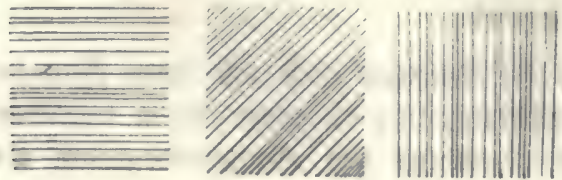

horizontale (poblige) Fig. 58. geneigte (fladye) §ig. 59. und ienéredute (jaigere) Jig. 60. Stellung ber Edjidten. 


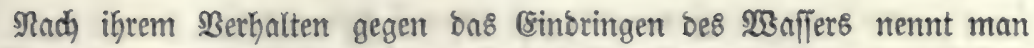

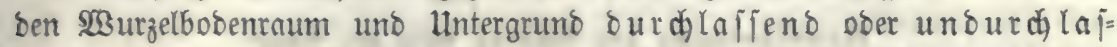
jend. Binen unourdalaffenben lintergruno liefern plajtijdjer If on, nidjt zet= flüftete Feljen, ober eine borizontale uno oft aud eine geneigte Stellung bet

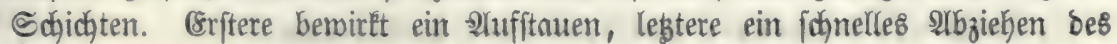
:Bafferళ.

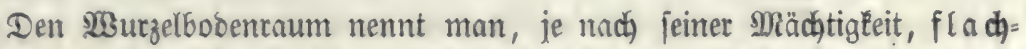
grünoig ober tiefgründig. Dieje Bezeichnungen fino aber relatib, fie

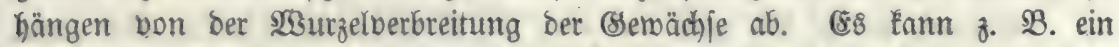

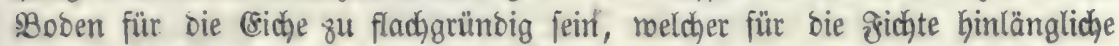
হiefgrünoigkeit befiłt.

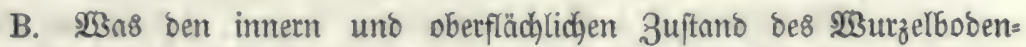
raums, abgejeben vom Untergrunbe, anlangt, fo laffen fich folgenbe Unter= (d)

a) SRact Geif́t ber Boben, wenn ifm jebe Belleioung burdh (5e: räable fehlt, wunt mirb ex genannt, wenn ein aheil ber obern Bobenterume

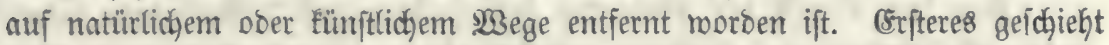

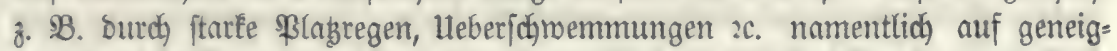

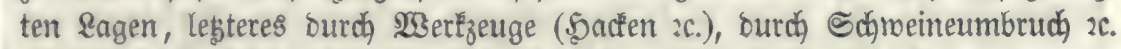

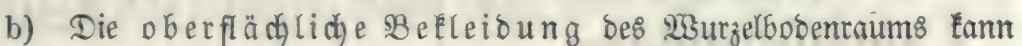
burch Bsemächje mannigfocher Pirt betwirlt merben. Sinjichtlich ber Frorftcultur,

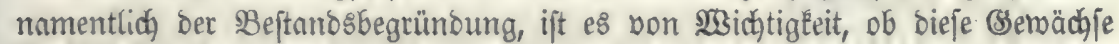

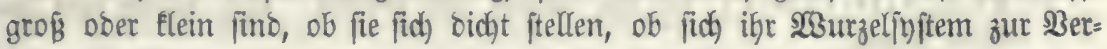
filzung neigt $2 c$.

Die getwöhnlichen Sträud̆er, welche mif dem 2 Balbboden bortom=

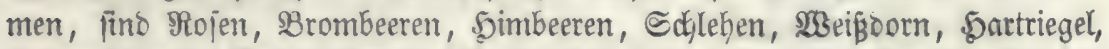

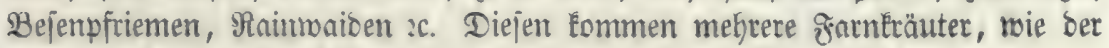
Slolerfarn, an Brößze fait gleich).

Zu ben niedrigen Sträudern (jogen. (Erofträudhern) gehören: bie Snibe, mehrere Bacciniumarten, wie bie \$eibel = und bie \$reißelbeeten, bann bie भlpenröschen in \$ochgebirg :c. Sie leben gejellig, ftellen fidh febr bidht und verfilzen mit ben $\mathfrak{2} 3$ urzeln ben 3 oben.

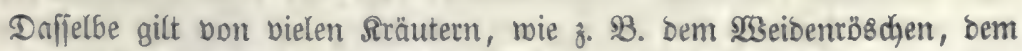
rothen Fingerhut-ıc., \&räjern, Simjen, Binjelt zc.

3on ben Moojen ftellen fich zroar bie 2lftmooje uno bie Sumpfmooje

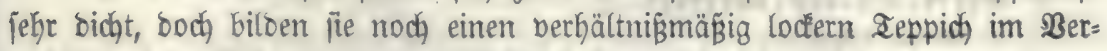

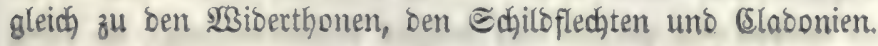




\section{3 we ite $t$ \& b i d $n$ it t. \\ Interidjeidung bes Bobens nadj ber Sage.}

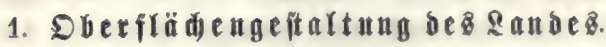

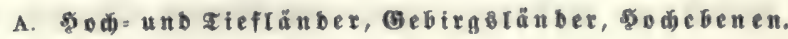

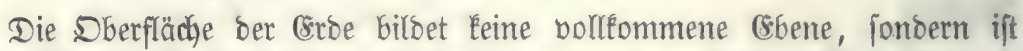

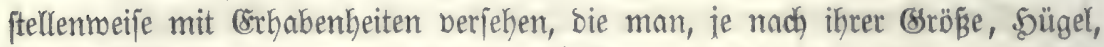
Berge, Sebirge nennt.

(sbenen, melche fidh nicht viel über bie Meeresfläthe erheben, ober jogat nod) unter berjelben liegen, nennt man aiefländer, im Gegenjał zu ben 5odĭläbern.

(Fin Tiefland ift $\mathfrak{3}$. B. Die Rombarbei, Ungarn, Folland uno Belgien, ein grojer Theil yon Rupland - eit (5od)lant: Schweben uno Rormegen,

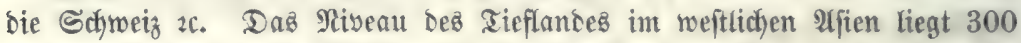

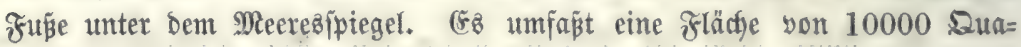
bratmeilen.

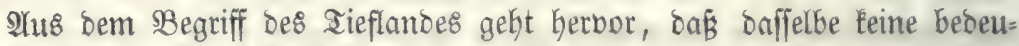
tenden (Erfb̈hungen des Bobens entyalten Eam. Die Sodhlänoer bagegen Ë̈nnen jowohl mit einzelnen Serborragungen berjehen fein (\$sebirgslän=

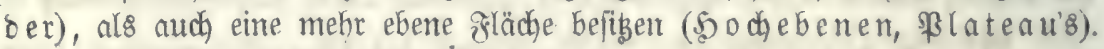

B. Diefrander insberonbere.

Man unterictyetbet

a) Rüftentieflänoer, an ben Rüften bes Meere\&. Cie Gaben eine ge= ringe $B$ reite.

b) Stromtiefländer, längz des Stromlaufes uno żmar entweder auf beiben ufern, ober mut eines derfeiben umfaffent. Beifpiet: ons Strom=

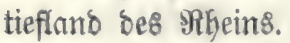

c) Zieflănoer im Binnenlande. Sie fint die ausgebehnteftent. (Un= garn, Norbbeutiche (sbene). Dft exitredfen fie fid) quer burd) einen (Eon= timent bon einer Meereşüfte zur andern bin.

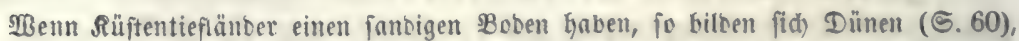

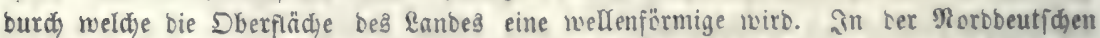

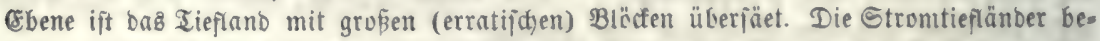

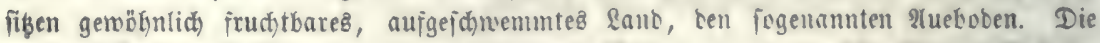

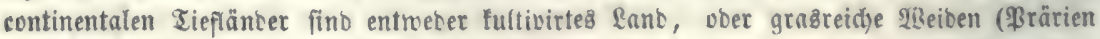
in Norbamerifa, Eanos unb \$ampas in Sürmmerifn) ober regetationsarne Eteppen, ober

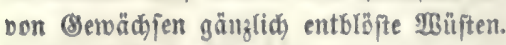

\section{c. Gebirgoräner in befonbere.}

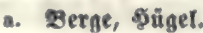

Die (sebirge merben von 5ïgeln uno 23ergen zujammengejeßst, bie burch Sabluchten uno Ihäler von einnnoer getrennt finc. Die bemerfensmertheften Formen ber (sinzelberge laffen fid, folgentormaß̈en flaffificiren: 
a. bie legelförmige, wie fie öfters beim sajalt vorf́ommt.

B. Die parabolijiche Form. Der Berg hat bie Geftalt eines paraboli=

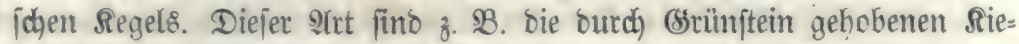
felichieferberge in Seffen unt $\mathfrak{W}$ eftphalen.

$\boldsymbol{\gamma}$. Die parallelepipedijal Frorm. Die Seitennänbe des Bergs fteigen fenfrecht ober boch beinake jentrecht in bie Şöhe, ber sipfel ift abge= plattet. Dieje Frorm befiben biele Runderjandftemberge ber Gächilijhen Sibureiz.

d. Die Eugeljegmentige. Die Dberflähe bes Bergs Gat die Beftalt Des Mantels eines Rugelfegntents. Dieje frorm tritt jehr häufig auf; fie ift z. 8 . ben Bajaltbergen, weldge fich aus brjaltijchen Maffenge= birgen erkeben, eigen.

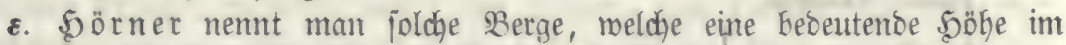

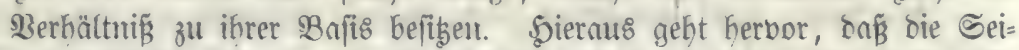

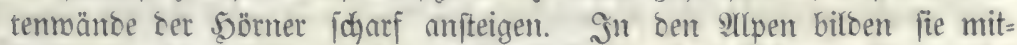

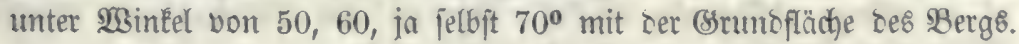

\section{b. Gebirge.}

a. Begrenzungs=Rinieu und gräden der Gebirge.

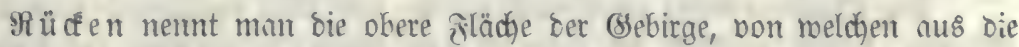

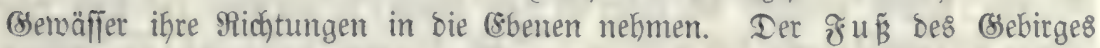

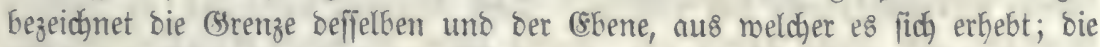

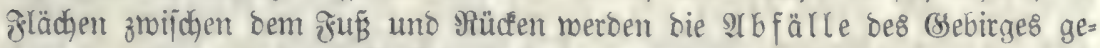
nannt. Rebtere fint gemöhnlich nad ber einen Ceite bin fteiler, als nad)

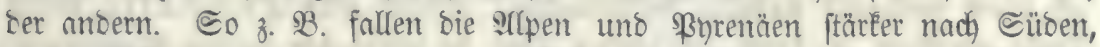
als nach গorden, bet Doemwald und Edymarzmald, besgleidyen bie Bebirge

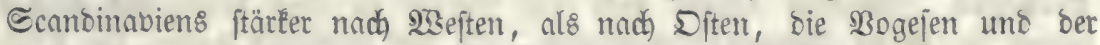

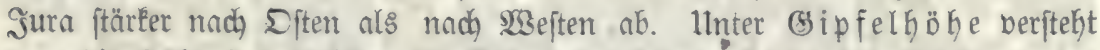

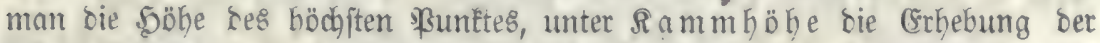

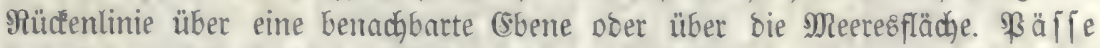

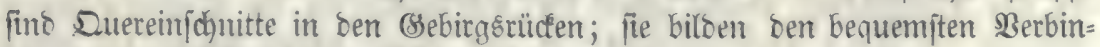

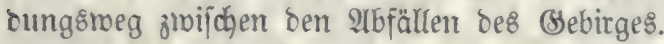

B. Bolumenbertheilung ber Bebirge.

Man untericheibet Rettengebirge, welche eine gröpere Erftrectung in ber Ränge, als in bet Breite haben, uno Majfengebirge, bei benen bieje beiben Dimenfionen nicht biel bon einamber beridjieben fint.

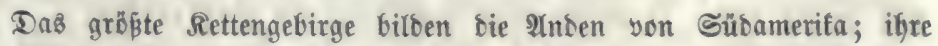
Lånģ่erftrectung betrăgt 900 Meilen bei einer Breite yon ungefăhr 15

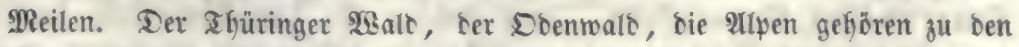

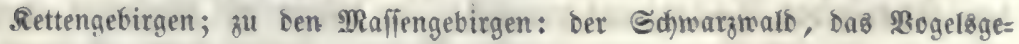
birge, ber $\mathfrak{S}$ efternalt. 


\section{$\boldsymbol{\gamma}$. Die Richtung ber \&ebirggetten ift entweber}

1. eine parallele, wie beim Doenwalbe. Doer

2. eine tran8verfale. Bon ber 5auptlängserjtrectung bes sebirge\& aus Imifen nach beiben Seiten Gin parallele Sietten, beren stidftung auf bie bes Bsebirgbrüctens ganz ober beintabe rechtmintlig ift. Beifpiet: Die थlpert.

3. Sine rabienförmig bivergirende. Die Retten berlaufen, me bie Mabien aus Dem Mittelpunft eines Rreijes, Dod) Ënnen bie einzelnen

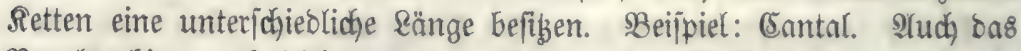
Bogelsgebirge, obgleich) mehr zur (Sruppe ber Maffengebirge gehötento,

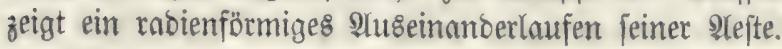

\section{c. Eלăler, छdiludten.}

Die Thäler find rinnenförmige (simfdhnitte im SSebirge. Shre (Entitef)=

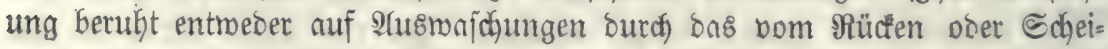
tel ber Berge abfliefiento $\mathfrak{B a j f e r , ~ o b e r ~ a u f ~ b e r ~ B i l d u n g ~ b o n ~ S p a l t e n ~ i n ~}$ Folge einer crthebung ober Sentung bes \$Bobensి.

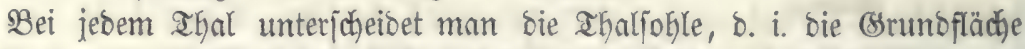
ber Rinne, unọ die Seitenmände ober das (S) ănge bes Thars.

Die Thaljohle befigt gemöbnlidy ba, mo bas ahal entipringt, eine geringe

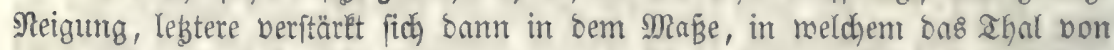

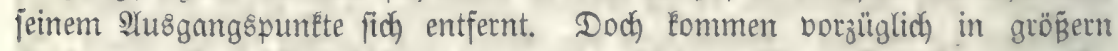

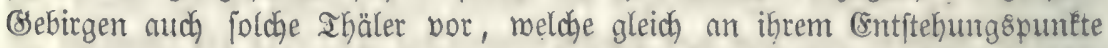
eine beocutende seigung befizgen. - Dft miro das (Sefälle ber Ihaljohle plögs=

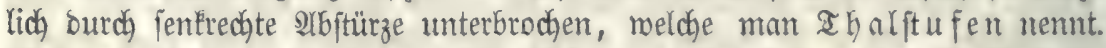

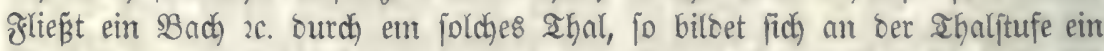
Wafferfart. Zumeilen ninmt aud bns Befälle an einer Stelle bes Thates mieber zu; ift bie Steigung bebeutenber, als bas vorherige fallen ber Ihal= fohle, jo entiteht binter ber Steigung thalaufwärts ein Cee ober Teidy.

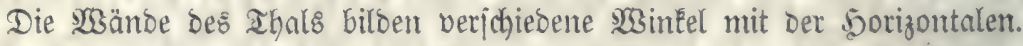
(58 gibt Ihalgehänge, welche unten faft rechtminelig an bie Thaljoble ftoken, währeno ifgr oberer Theil abgefladht ift uno ebenjo häufig fommt ber umge= Eefrte frall vor. Se enger bie Thäler find, um fo fteiler erheben fid gemöhn= lich bie sebänge.

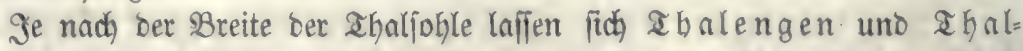
weitungen untericheiben. Beibe gehen oft in einander über. Sat bie Thal=

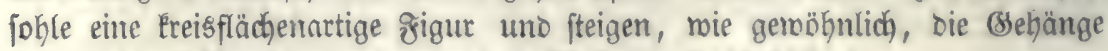
fteil in bie Söhe, io nennt man bas ghal ein seflelthal.

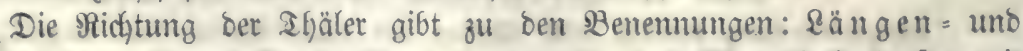
Duerthäler Beranlaffung. Jene (wie z. B. Das Sihonethal) laufen mit

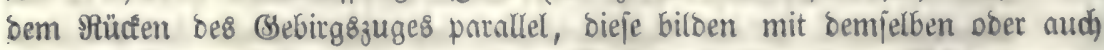

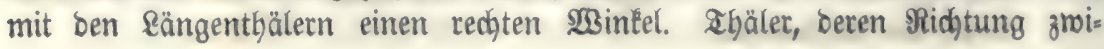




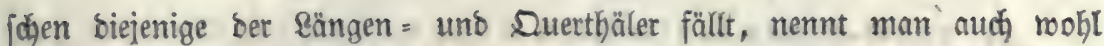
biagonale abäler. Beginnt ein Ihal am Rücen bes (Sebirges unt ję̧t es

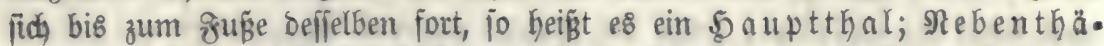
ler fino foldhe, weldhe in ein \$anutthal einmünoen. Die \$öhe burdh weldhe

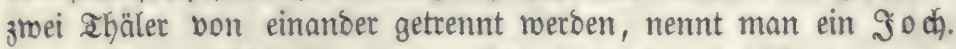

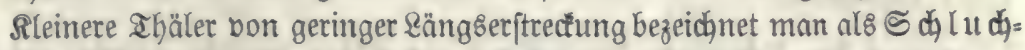
ten ober Rlingen. Sin bet Sdymeiz keift man fie auch robh a ofel.

\section{Sodebenertingefonbere.}

Unter einer 5odjebene (einem $\mathfrak{B}$ (ateau) verfteft man eine ebene faläd)e

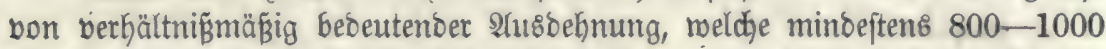

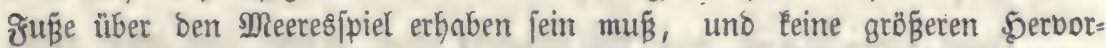
ragungen (Berge) enthalten barf. Die Rängen = unઠ 2 reitendimenfionen ber Sodhebenten k̈nnten eben jomohl gleich, als berjojieben fein. Die Plateau's

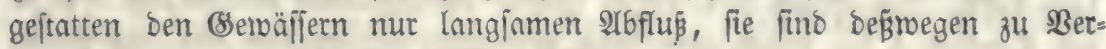
jumpiungen und zur Torfmoorbiloung fehr geneigt.

ख3iro ein ßlateau burd, ein Iieflano begrenzt, jo fteigt e8 aus biejem genöhnlid, nicht allmählig, fondern in teraffenförmigen 2 tbjäben auf.

Deutichland Gat mehrere nidht unanjebnlidge \$odyebenen, wie z. $\mathfrak{B}$. Die

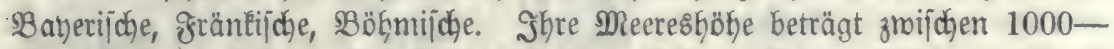

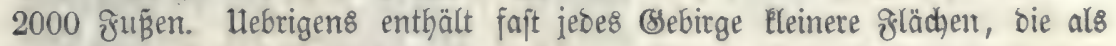

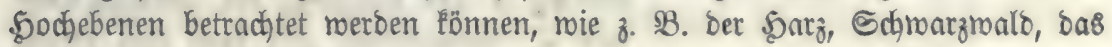
$\mathfrak{B o g e l}$ gebirge (Dbernalb) u. i. w.

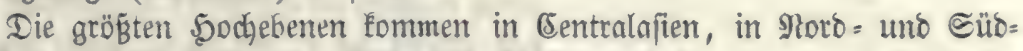

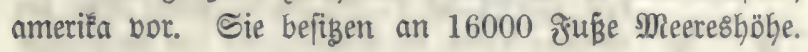

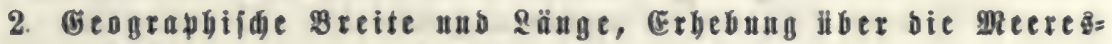 fläđe.}

Die Sage eines Drtes auf ber Erooberfläche wirb bejtimmt:

a. Durdh feinen Afbitano vom 2lequator; man nennt biejen 2lbjtano bie geographijd) Breite ober Polböhe, rechnet fie nördlich uno jüblich vom 2 (equa= tor uno brüatt fie in Sraben, Minuten uno Eecunben aus, inbem man fid)

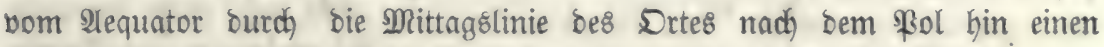

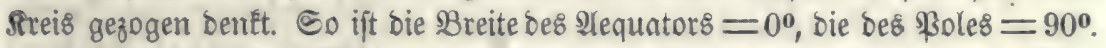

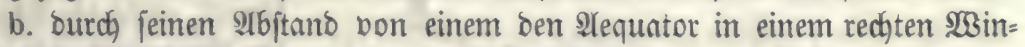
fel jäneibenben Salbfreije, meldhen man gewöhnlich burdh bie Snjel gerro ge= legt bentt. Siernad, unterjojeibet man öftliche uno mejtlidje $\& a ̈ n g e$. Uleb=

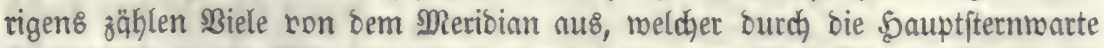

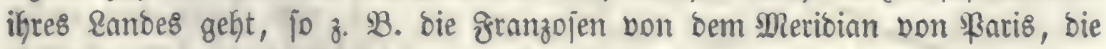
(Engländer bon bem Meribian von Streentoich) aus.

Ueber bie Metfoben zur Beftimmung ber \&änge uno Breite einę

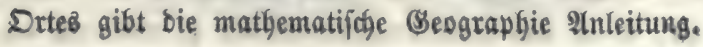


c) burd-jeinen fenéredten 2tbftand von ber Meeresfläde Dber beren horizontaler Berlängerung. Man nemnt biejen Mbitant

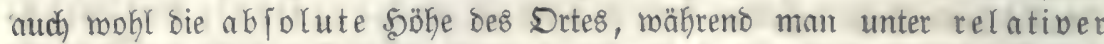
5öbe den jenfrechten $26 j$ tano bon ber Sorizontalebene eines benadjbarten Drtes verjteht.

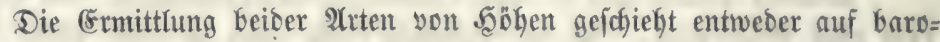

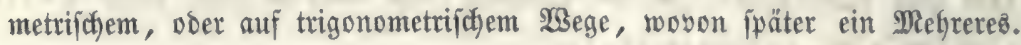

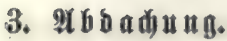

\section{a. gegrift.}

Unter biejer begreift man die Neigung einer gräche ober sinie gegen

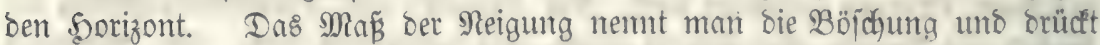
bieje burch einen Bruch) aus, beffen Zähler bie fenterechte (sntfermung A B ei= nes \$unttes A ber flähe ober sinie über einer horizontalen CD, auf melche

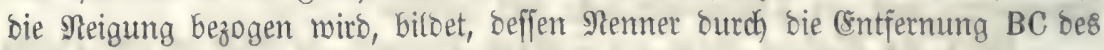
ฆิig. 61.

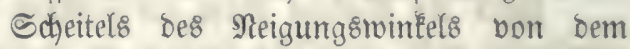

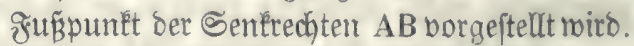

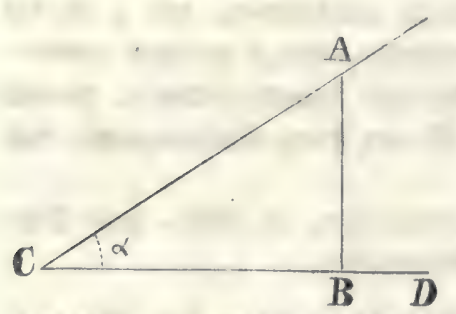

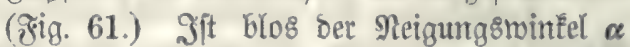
bef́annt, jo erhält man bas sBöjchungsver= Gältnifís in Det Inngente des Neigungsimin=

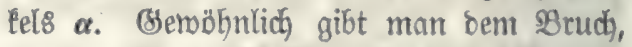

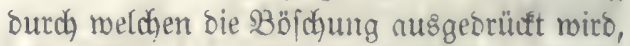
ben 3 ăblet $=1$. In biefem æalle roirb bér Renmer Durct) tie (Sotangente bes Neigungs: winteets $\boldsymbol{\alpha}$ gebilbet.

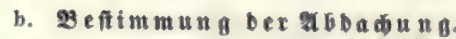

Dieje erfolgt am genaueften mit Sülfe einer 23 afferwage, ober einte Theoboliten, beffen \$öhenÉreis mit einer Möhrenlibelle verjęyen ift. Sat man bieje Injtrumente nicht zur 5̧ano, jo leiftet folgenoes Berfahten oa, wo es Æig. 62.

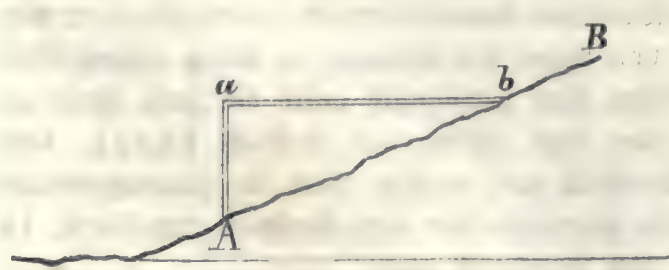
nid)t auf grope (senauig: feit anlommt, gute Dienfte.

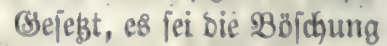
Det \$rergivanto A B ftimmen. (§ìg. 62.) Man begebe find auf Den PunEt A uno balte eine (mög= lidjit lange) Ratte ab von betannter Ränge borizontal

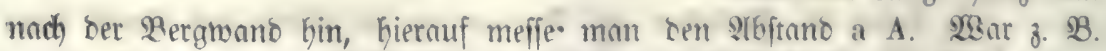

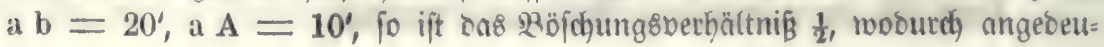




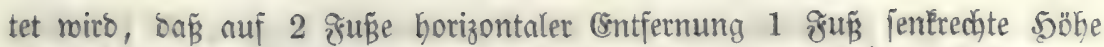

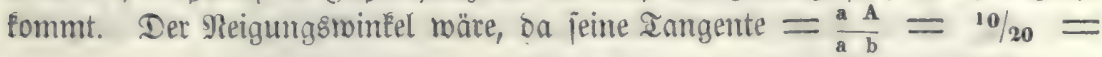
0,5 ift, $20^{\circ} 34^{\prime}$,

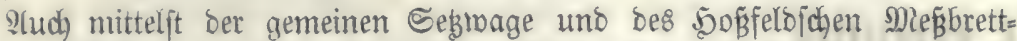

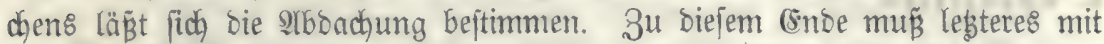

\section{J̛ig. 63.}

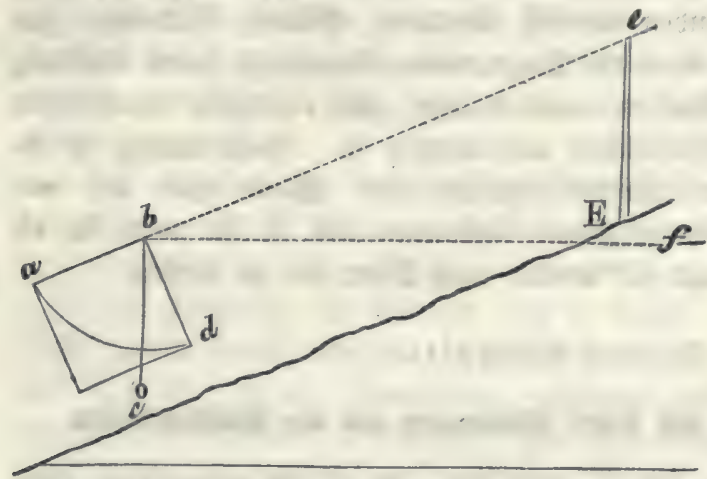

etrem Brabbogen: ver= iehen ïein. Sn E (æig. 63.) bringt man einen Stab an, uno mertt fidy auf demijelben einen ßunlt e, beflen Söhe über $\mathbf{E}$ gleid) Der böhe ift, in weldyer bas Aluge a bes $3 \mathrm{Be}=$ baditers über bem sooden fich befindet. Man vifitt num über bie obere Sante bes Brettchens bin, bis man ben Puntt e in ber Betlängerung biejer ßinte

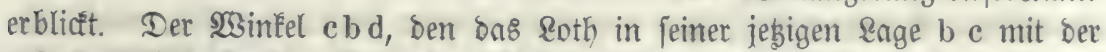

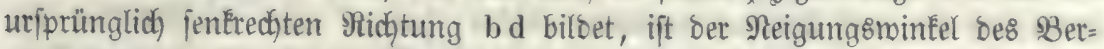
ges. Denn es ift ebd $=$ floc $=1 \mathrm{~s}$; zieht man bon beiben fbd $=$ fbd $a b$, jo bleibt ebf $=$ cbd.

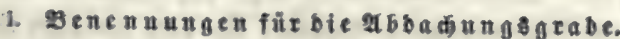

Bilbet Die Dberfläche des Bobens mit bem Sorizonte einen 2 Binfer von 1 -5 0 , jo nennt man bie Neigung janft abhängig,

"5-100, " " " " mäвig fteil,

"10-150, " " " " " " fteir,

". $15-200$, " " " ", ,... jefr fteil,

" $20-40^{\circ}$," " " " aúperorbentlid fteil.

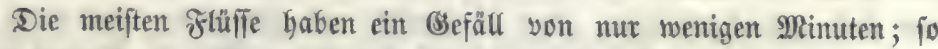

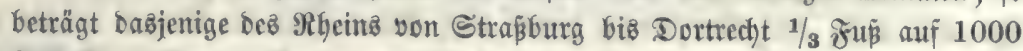
Fuß Stromlänge, alfo etwa 1 Mimute 8 Secumben. Steigt baв đ̧efäll biz auf mehrere (Strade, fo entiteht fojon ein SGaflerfall.

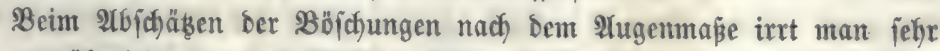

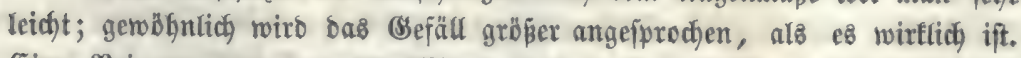
(Eine Neigung bon nur 10 Minuten ober $1 / 349$ ift für bas $\mathscr{2}$ uge fojon

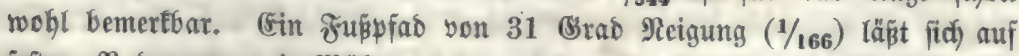
feftem Boben mur mit Mehhe erfteigen; über 37 Srab (1/133) Reigung hin=

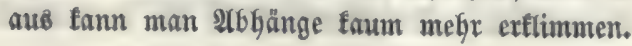


In Frantreich bat man als Maximum ber Reigung für Ç̧aufeen $1 / 2_{0}=2$ G5rab 52 Minuten angenommen. Die gröpte Steigung ber

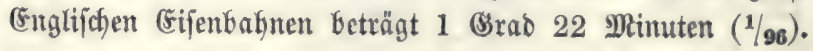

\section{Expofition.}

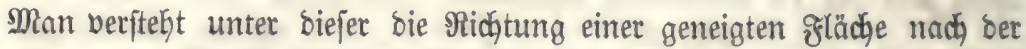

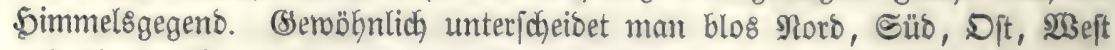

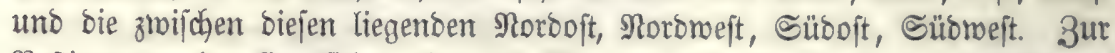

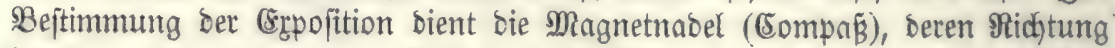
inbeffen nicht genau bon Norben nach Süben geht, fonbern periobifosen Sdymantungen um bie Meribianlinie untermorfen ift. Ssegenwärtig ift bie

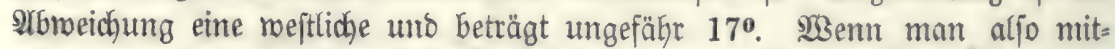
telft eines (Eompajfes bie Simmelsgegend beftimmen will; fo hat man fich bie Ridgtung ber Magnetnabel um $17^{\circ}$ meiter nad, Diten hin ju Dentéen.

\section{Dritter $\mathfrak{A} b$ 西nitt.}

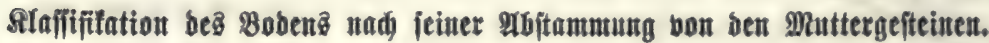

1. Die Crrfahrung, baß̧ fämmtliche Bobenarten, abgejehen bon ibren organijchen Bejtanotheilen, aus ben Befteinsarten entitanoen fino, meldje ur= fprünglid bie fejte Brorinbe zufammenjesten, hat zu einer Slaffifiéfation Der Bobenarten nad) ifrer Albitammung bon ben Muttergefteinen Beranlaflumg

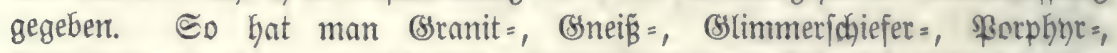
Bajaltboben u. f. w. unterjbieden. Dieje (sintheilung läpt fich nicht bei allen Bobenarten burdyführen, weil bon ben wenigiten befant ift, bon weldyen Be=

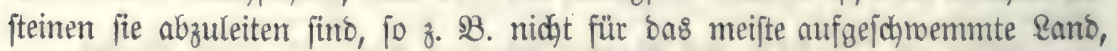

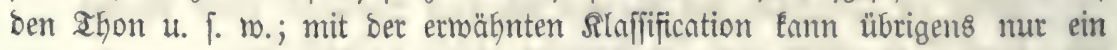
jebr allgemeiner Begriff von ben (sigenjohaften ber Bobenarten gemonnen werben, und zroar aus folgenten (stünden:

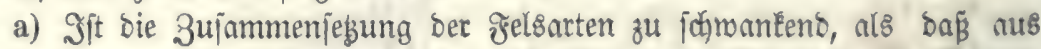
irgento einer von ifynen immer ber nämlidje Boben fid bilden ë̉nnte. Co ents Gält z. B. Der sranit oft fajt nur Qunr

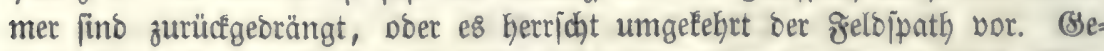
jegt aber auch, bas Berbältniß̈ biejer orei Mineralien im (Sranit bleibe überall eines uno baffelbe, fo zeigen Dods wieber bie Felofpath = uno stimmer=

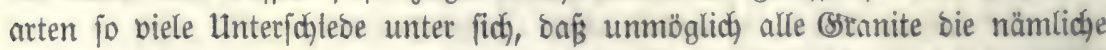

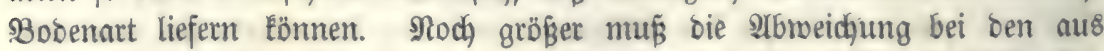
Sornblente ober 2fugit zujammengejesten Felsarten jein, weil von biefen bei= ben Dineralien tyoneroefreie uno thonerbehaltige Barietäten beftehen Dft

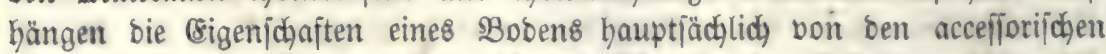
Bejtanbtheilen bes Muttergejteins ab; wie jeht aber ber (Sebalt an biejen bif

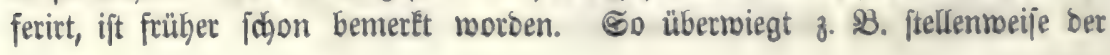


Slivin im Bajalt alle übrigen Beftanotheile biejer jelsort, währen an an= Dern Drten ber Dlivin fajt gänglich fehlt. Dit enthält ber bunte Sanoftein nur zujammengefrittete Quarž̋̈bner ofne Bimbemittel; ein anderes Mal herricht lesteres (z. 23. als rother Ihon) ganz unto gar bor, jo bas aud nicht ein

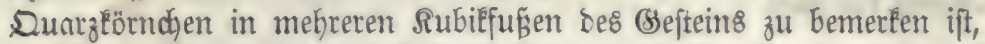

b) liefert eine und biejelbe ફ̧elsart, je nad) Dem (Srab ber Bermitter= ung, in meldfem fie fich befinbet, fehr berjofiebene Bobenarten. Salten roir

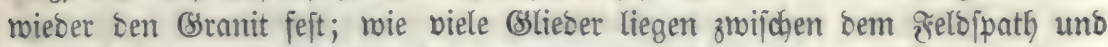
Rnolin! ఏat Der Felbjpath eben angefangen, erbig uno zerreiblid, zu merben,

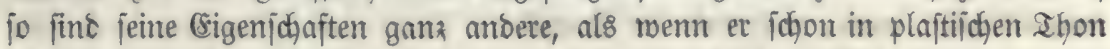
übergegangen ift.

c) Bleiben bie \$robucte ber Berrvitterung einer §etsart nidjt immer

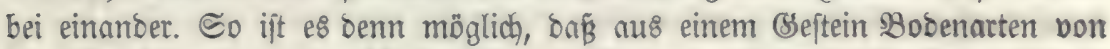

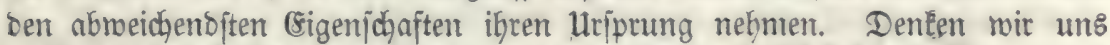
8. 3. Der Jeloppath Des Branits gebe in Saolin ober Dody in Ifon über uno biejer merbe burch 2 saffer meggefdymemmt, jo entfteht auf ber einen Seite aus bem Granit ein Ihonboden, rährento auf ber anbern Seite ein aus Quarz uno (Slimmer zujammengejester Sanoboben fich bilbet. Bbenjo Enn

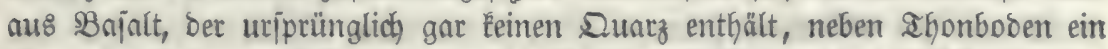

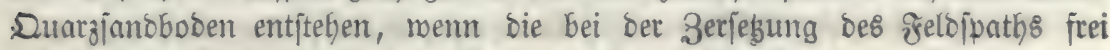
merbende Riejeljäure in unlöslichem 3ujtano fich abjojeibet. Biele Quarz=

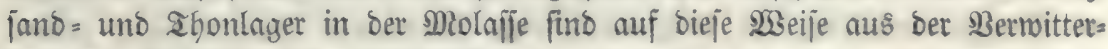
ung bes Bajaltes herborgegangen.

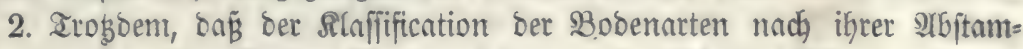
mung von ben betreffenden Muttergếteinen viele Schwierigkeiten entgegen= ftehen, funbet man biejelbe boch fäufig angewantot uno fie. Gat audi), wenn man fie mit gehöriger Borfidht uno innerhalb ber richtigen Brenzen gebraudht,

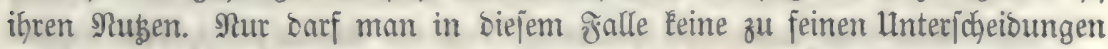
madjen uno bie Bezeidjnungen ber Bobenarten nur nadh ben Sauptgefteinen

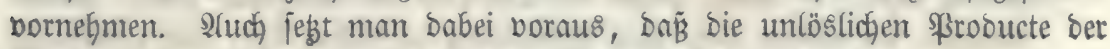
Berwitterung an ber Ragerjtätte be\& Muttergejtein\& berbleiben.

\section{Bierter $\mathfrak{A} b\left[\begin{array}{l}\text { ditt. } \\ \text { inten }\end{array}\right.$}

\section{Slaniffiftation ber Bobenarten nă igren vorwaltenben Beîtandtheifen.}

\section{Einleiturg.}

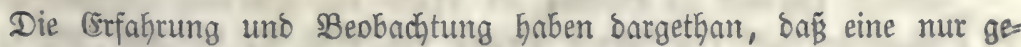
ringe Arnabl bon Mineralbejtandtheilen als vorherrid)ende Ingrebienzien

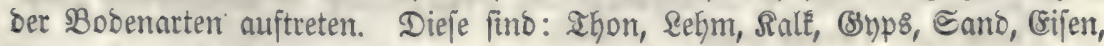
Magnefia unt Şumus. Se nachbem der eine ober ber anoere bon biejen Beftandtheilen vormaltet, fpridyt man bon SGonboben, Rebmboben, Sanbbo=

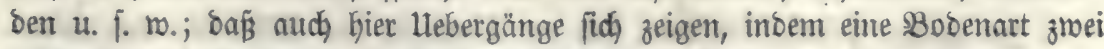
biejer Sauptbeftanotheile in gleidjem MRaß̉e enthält, liegt auf ber \$ano. 
2. Folgende Bobenarten find nach ben angegebenen Momenten unter. fofieben worben:

\section{A. TGonboden.}

\section{a. Begrif von Tbon.}

23ir madjen Gier noç)mals Darauf aufmerkjam, baß̃ man unter Thon nicht Thonerbe, fondern zerjegte felbjpathartige Mineralien verfteht. Se nadh=

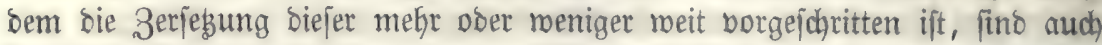
bie (sigenfichaften bes ahons ambere. Der reinfte Raolin z. B. enthält gar

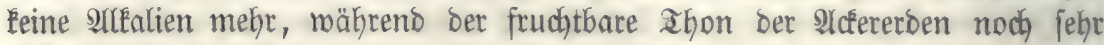
biel von biejen befitst. Durdh bie Cultur miro ber Ifon nady uno nach in Ravlin umgemandelt, weil bie Pflanzen bem Ifon bie 2llkalien und altalijchen Errben entzieben.

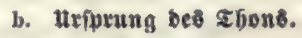

Illle Diejenigen Befteine weldhe thonerbebaltige Mineralien befigen, ênn= nen Thonboben liefern; io z. SB. Der Sranit, wenn er arm an Quarz ift, ober biejer burch 23 afferfluthen bon ben 3 ermitterungsprobucten bes Feld=

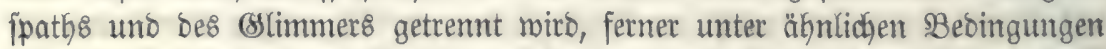
Der Syenit, Srünjtein, Erelfitporphyr, Melaphyr, Bafalt, Bhonolith uno Ira

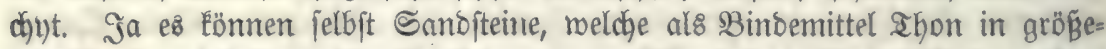
rer Menge enthalten, zur Entftebung von Ihonboben Beranlaffung geben. In biejem gralle mur eine Trennung bes Thons von bem. Sand bor fidh gehert.

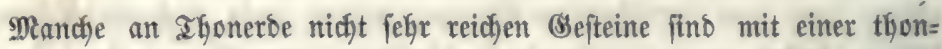

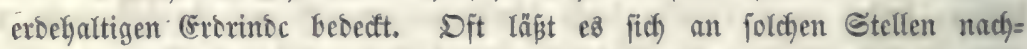
meifen, Dap bie Ihonerbe nidjt yon anbern \&ocalitäten herbeigefühyt morben ift. Man famn baher nur annelymen, ba funden habe, in Folge beffen bie Ihonerbe im Raudftant blieb. Soldhe (Sefteine, an welefyen man bicje (Ericheinung beobachtet hat, find unmentlid) Raffe, auch felbit, wenn fie mur $1 \%$ Ihonerbe befiben. Der Ralf wurbe

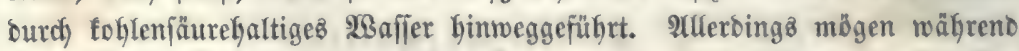
biejes 3 organgs Iaujende von Sahren verflofien fein. Man wirb indeffen

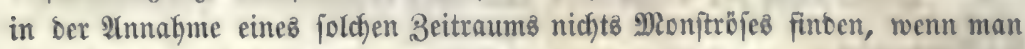

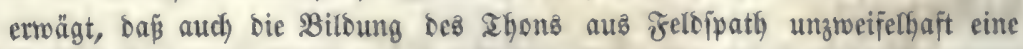
ungeheure 3ahl yon Jahren erforbert hat, felbjt futr ben Fall, bap in vor=

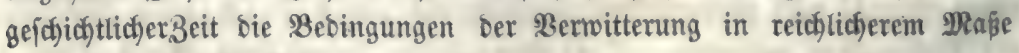
vorbanben gewefen jeien.

\section{e. Bortonumen Des Tดons.}

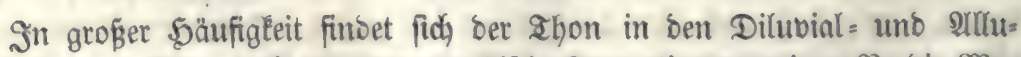
vialbilbungen; allein aud ältere geognopitijase grormationen, wie z. B. bie SMlo= 
Iafle, Steibe, ber bunte Ganbftein U. F. w. Gaben mitunter bebeutenoe ahon= lager aufzumeifen.

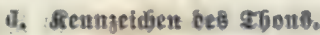

Der Ifyon befizt gemöhnlid eine weifliche, bläuliche oder graue, ift et

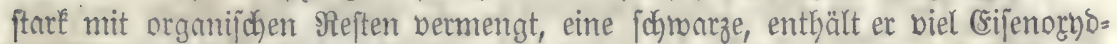
Gyorat, eine rothbraune orarbe.

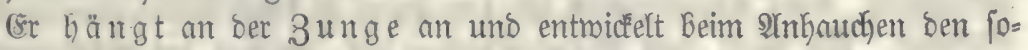

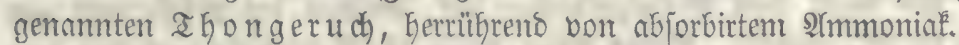

Der eigentlidje IFon befindet fid in einem 3uftande febr feiner Ber= theilung. $23 e n n$ man eine thonerbebaltige froe mit $23 a f f e r$ antütyrt, jo blei= ben bie Ifyontheildyen in biejent fuppendirt, während bie gröbere, fonmerere (stoe,

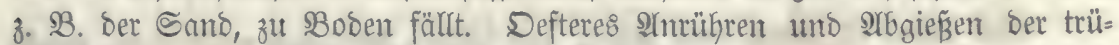

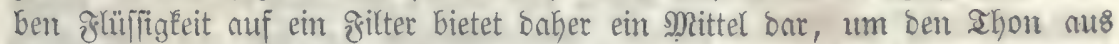
einter Sronat bolfitübig zu entfernen uno jomit feine Menge zu bejtimmen. Man nennt bieje Dperntion bas ๔dlämmen.

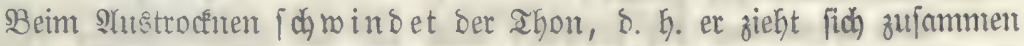

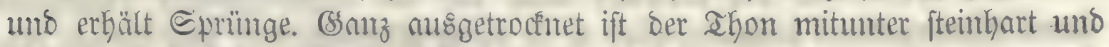

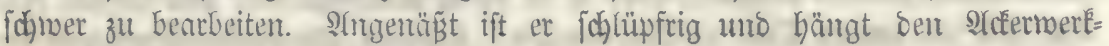

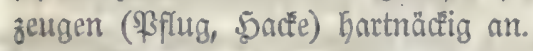

Man nemt ben Ihon plaftifd, formbar, weil er fict eneten und in be=

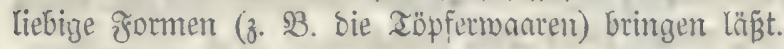

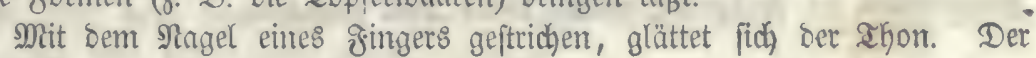
Strich ift gläızeno unঠ eben.

\section{e. Trten bes ฐgonbobent.}

Se nadh ber Reingeit bes $\mathfrak{I}$ hons unterfheibet man

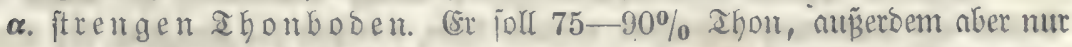

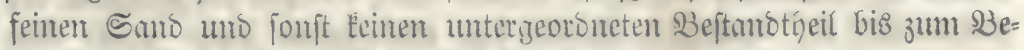
trag von 5-10\% enthalten. (Jumbeshagen.)

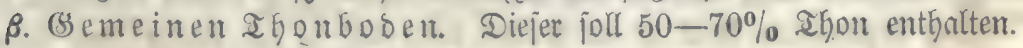

\section{B. debmboben.}

ส. 2 egriff.

Inter Refm berfteht man eire Mnengung bon Ealefyaltigem ahon mit

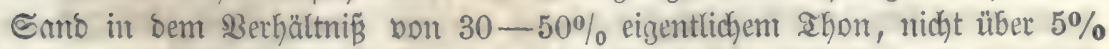

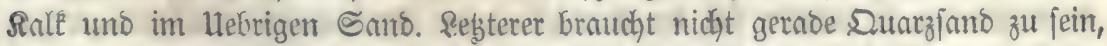
er bejteht meijt aus unzerjegten zrngmenten bes (Sefteins, aus werkfen ber Rebm fich gebildet hat.

\section{b. Eintbeitung bes debmbobens.}

Man unteridheibet

a. ftrengen Refmboden mit $50-65 \%$ reinem Refm;

B. gemeinen Refmboden mit $35-50 \%$ reinem sebm. 


\section{c. Renugeidien bes selimos.}

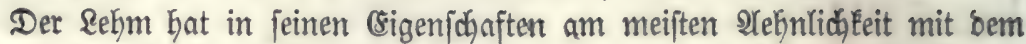

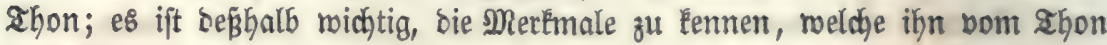
unterjobioen.

Der Sehm ift nidyt fettig anzufüblen, ex glättet fich unter bem Na=

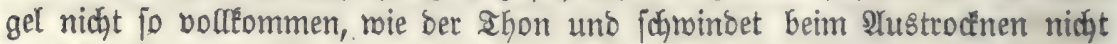
beträchtlich. Sehr djaracteriftijoh für ben Rehm ift jeine rothbraune bis braune

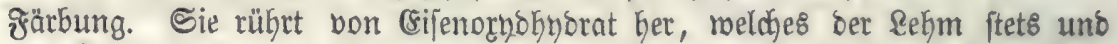
zraar etma zu $5 \%$ enthält. Diejes (sijen, forwie die Santbtyeile verleifen bem \&ehm bie Eigenfduaft einer geringern Formbarkeit.

\section{d. uriprutug besీ Rebmo .}

Der Refm ift, gleich Dem Ihon, aus polchen Felzarten entftanben, weldhe thonerbebaltige Mineralien führen. $23 a b r j d$ einlich bat fidh aus ifm zuerft

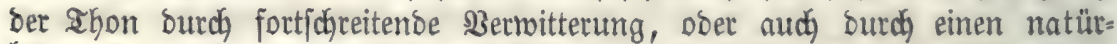
lichen Sd]lämmprozé̉ gebilbet.

Der Rehm fann fich entweoer nodh auf ber urjprünglichen \&agerftătte

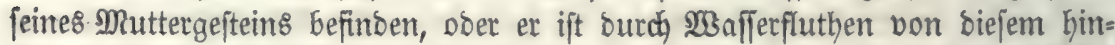
reg und an andere Drte geführt worben. Regteres gilt insbejonoere von ber

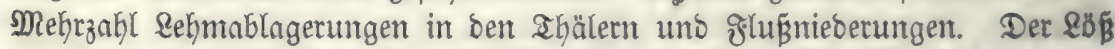

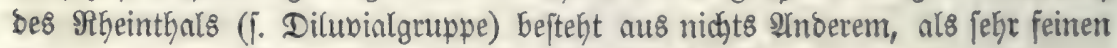
grngmenten ber Gelsarten, weldye biejes I Ihal einfaffen.

\section{c. Salt5oben.}

\section{A. Begrifi.}

Heber bie Menge loklenfauren Salfe, weldhe exforberlich ift, bamit ein

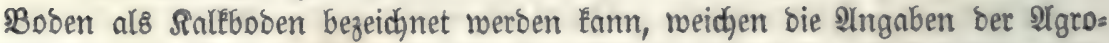
nomen fehr ab. Sdü̈bler fajreibt ben Bobentarten biejer Slaffe über $20 \%$ Rale zu, rähreno nach 2 nnoern ber Saléboben $30-75 \%$ babon enthalten joll.

Der toblenjaure Salf ift im Boben entweber in ber ơorm bon Eleinen Steinchen uno ธand, ober in ganz fein zertheiltem 3uftand enthalten, wie

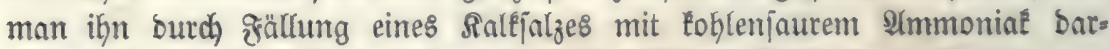

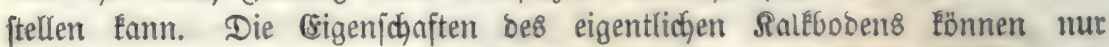
burch biejen fein zertheilten Salé bejtimmt werben. Nimmt man blos lepteren

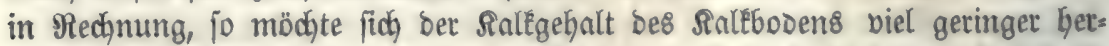
ausftellen, als oben angegeben ift. Ueberbaupt fällt bie MRehrzabl ber Ralls böben mit ben \&egmböben zujammen.

\section{b. uriprung beo fatebobent.}

Der Salleboben Eann fich aus allen eigentlichen Salf̈gefteinen, bom Ut= uno Hebergangsfale Gerauf bis zu ben Salkjojichten ber efluvialformationen

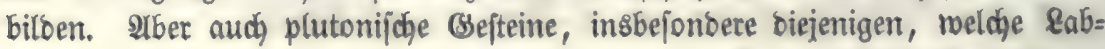


rabor enthalten, unb Sanbfteine mit taltigem Binbemittel fỏmen zur Gntftebung bes Ralťbobens beitragen.

Schon in ber Rebre von ber Berwitterung wurbe gejeigt, baßi ber Ralf aus ben Bejteinen burd, Eoblenjäuref̧altiges $23 a$ affer als boppeltéb hlenjaures

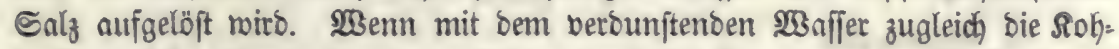

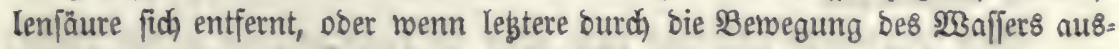
getrieben roiro, fo fallägt fich neutraler koblenjaurec Salé in Bsejtalt eines feinen Pulbetø nieber.

Sebre irrig ift bie 2lnficht, als ob aller $\mathfrak{B o b e n}$ auf Saltégeftein auch im= mer Salffooden jein müffe. Soldher Boben Eann von andern Drten ber auf biejes Beftein angejdnemmt roorben jein. Ilber, wenn bies audh nicht ber

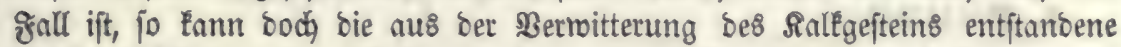
Groe jo viel an andern Beftandtheilen auß̧er Salk enthalten, baß̈ fie gar nidjt

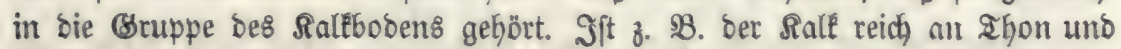
Siejelerbe und babei ber Heberriejelung Durch 2 affer ausgejebt, jo wirb fich biel eher ein \&ehmboben aus bem Saltgejtein erzergen.

\section{c. Rennzeidjen bes saltbobensos.}

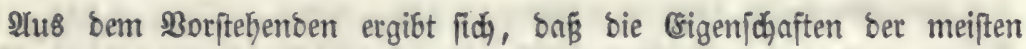
Saltböben mit benten bes Reלmbobens zujammenfallen. Der Salleboben braujt,

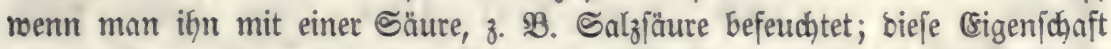
zeigen aber audh nod anbere Böben, weldbe feinen Salf, aber toblemjaure Magnefía ober fohlenjaure alkatien befïben.

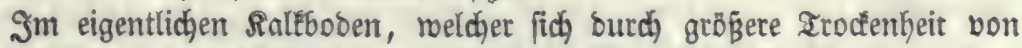
bem Rehmboben unterjheibet, zerjegt fich ber Dünger ziemlid, id̆nell, weil er

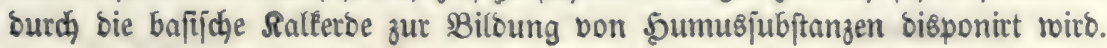

\section{d. Cintbetiung.}

Se nadiom Ihon, Rehm ober Sano bem Raltboben in größzern Men. gen beigemijobt ift, unterjojeibet man
$\alpha$. Shonigen Raleboben,
ק. Rebmigen Ralfboden (bie meiften Ralfböben),
$\gamma$. Sambigen Raltboben.

\section{Gygboben.}

\section{a. segriff.}

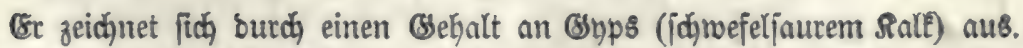
Der Syps fautn in biejer Ortbart entweber in form eines feinen ßulpers, ober in gröbern Iheilḑen entḩalten jein.

\section{b. Hefprung bet Gypơbobens.}

Det Gyp8boben entitebt Gauptjächlich aus ber Berwitterung bes (8upjes

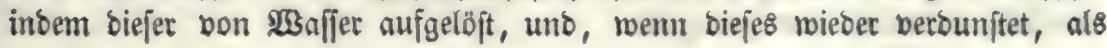




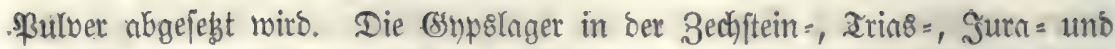
Molaffegruppe geben vorzüglich zur Bildung von Bsypstoben Beranlaffung. Diejer entfteft aber audh, wenn forwefelfaure Salze auf toblenfaure Salze einmirten.

\section{c. Etgenīaptent.}

Bom (5ypsboden gilt, was audh fichon für ben Salleboben gefagt murbe;

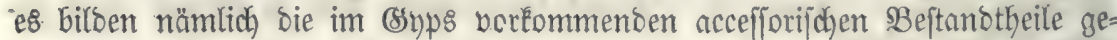

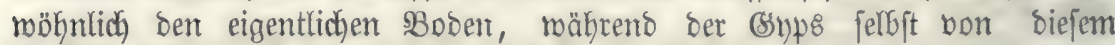

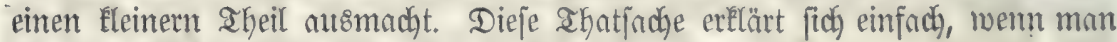

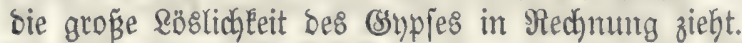

\section{E. mergelbober.}

\section{a. esentifi.}

Unter Mergel berifeht man einen Fallebaltigen ahon ober Sefm, ber= mengt mit Sant. Folgento SInalyjen geben bie Bufammenjegung von fieben

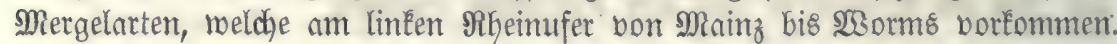
Sohleni. Sinlé $\begin{array}{lllllll}12,275 & 14,111 & 18,808 & 20,246 & 25,176 & 32,143 & 36,066\end{array}$ Sokłenj. Mngnefia Sali 0,975 ๔puren 1,228 $0,087 \quad 0,082 \quad 0,092$ 3,211 2,223 $1,544 \quad 1,106$ NBafler Ifon, Sand, (Eijenturydo $\begin{array}{lllllll}2,036 & 2,146 & 2,111 & 1,311 & 1,934 & 1,520 & 1,555\end{array}$ 2lmmoniat

$$
\begin{array}{rrrrrrr}
84,525 & 82,830 & 76,827 & 74,325 & 69,570 & 64,214 & 60,065 \\
0,0047 & 0,0077 & 0,0988 & 0,0768 & 0,0736 & 0,0955 & 0,0579 \\
99,9027 & 99,1767 & 99,1648 & 99,3608 & 99,0816 & 99,6175 & 99,0129
\end{array}
$$

\section{b. urfpeung.}

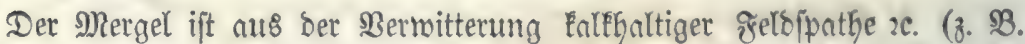
bes \&abrabors), ober thonbaltiger Salfe entitanoen. (5r tann aber auch burda

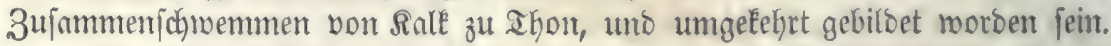

Der Mergel fommt in bielen frormationen, nicht felten fogar al8 eit nusgebilbetes uno midytiges sstied, vor. So in ber Sraumacenteruppe, wo er mit Salk = uns Eandfteinen abmechjelt, in ber Eteinfoflenformat.on, ber Formation Des Rupferjofiefers (biejer ift ein, bäufig mit Rupfererzen verjebener

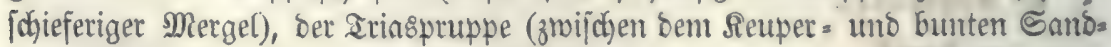

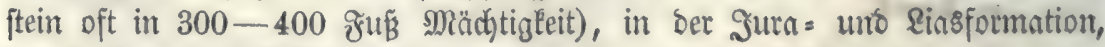
ber Steibegmuppe (多länermergel).

\section{c. Stennjeldien.}

Der Mergel brauft mit Săuren wegen feines Bsebnltes an Fohlents faurem Sile. (Er ift zum Ihyeil gejdjiefert, theils tritt er ftaubartig auf. \&egs= terer ballt fid, menn er befeuditet wirb. Bon Farbe ift ber Mergel grau, rötblid̄, bräunliç, ober graugelb. 


\section{d. Cintbeilung bes mergelbobeno.}

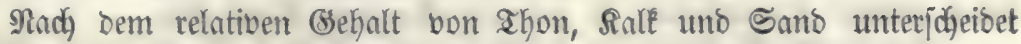
man:

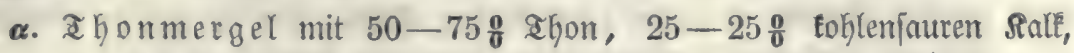
$0-5 \%$ Santo.

B. Ralémergel $0-10 \%$ Sant.

$$
10-25 \frac{0}{6} \quad \text { " } 75-90 \%
$$$$
\text { " } 1
$$

\%. Sandmergel bis

$10 \frac{0}{8} \quad 10-50 \%$

n $50-75 \frac{0}{8}$ ธand.

\section{F. ₹aItboben.}

a. Begriff.

(Er joll menigftens $10 \frac{0}{0}$ Eohlenjaure Magnefía enthalten. (\$unbeşagen).

b. Urfprung.

Der Taleboben entiteft vorzüglich aus Nugit=, Sornblente=, SSlimmer= uno (Shloritgefteinen. Dolomite möchten feltener, als man genöbnlich annimmt, Inléboben lieferm, weil ber Dolonit jefr foyner berwittert.

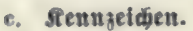

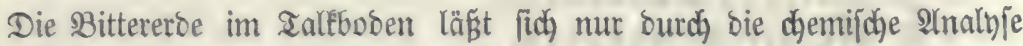
nadhroijen.

\section{Q. Etientoben.}

\section{a. Begrifi.}

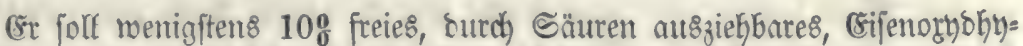
brat enthalten (\$unbeshngen). Eprengel forreibt ifm 15-30\% Eifenogtyo zu.

\section{b. Hefprung.}

Der Bijenboden Eann aus allen eijentgaltigen Befteinen entjteben. Er fintet fìch bäutfig auf fecunoörer sagerftätte.

\section{c. Sienณzeiden.}

Braunrothe färbung uno rauber Brud

\section{H. Canbboben.}

\section{a. 23egriff unb Entfebung.}

Man berfteft unter Sandboben eine foldhe Groart, in reldyer hödjiftens 108 abfolämmbare aheile, im übrigen aber Sano, enthalten finto.

Det Snnto entfteft entweder burch unvollftänoige Berwitterung ober

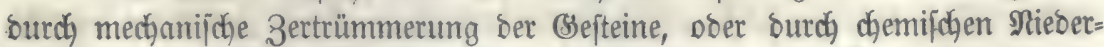
fa)lag von getwiffen Minernljubftanzen (Siejelerbe, Ralk, Eijen zc.), weldje in

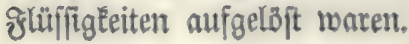


Die Größ̈e ber Sanblörner barf eine Sinie nidat überfdreiten; baben fie etras ftärfere Dimenfionen, fo geht ber Sano in Sies über.

Der meifte Sanbboben hat fich nidłt auf jeiner gegentwärtigen \&aget:

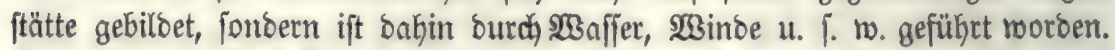

Die am häufigiten borkommenden Sanoarten fino:

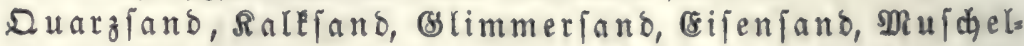
fand (aus zertrümmerten Mujchetn an ben bejtaben bes Meeres) u. โ. w.

\section{b. Seunzetdien}

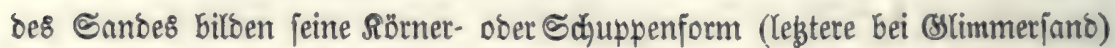
unb jein geringer 3 ujammentang. Die übrigen sigenjđaften bes Sanbes werben in ber golge nambaft gemadjt merben.

\section{c. Eintbettung bes ฮanbbobens.}

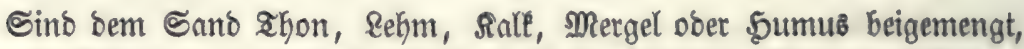
fo unterjheibet man, wenn bieje Stoffe in jo beträdhtlichen Mengen auftreten, bas fie bie sigenidaften bes Sanbbobens theilmeife aufheben:

a. Thonigen Sanbboben,

ק. Sehmigen Sanbboben,

r. Aaltigen Sandboben,

d. Mergel=sanbboben,

e. Бumolen $ธ$ andboben.

Nimmt aber ber Sand in bem ahon=, \&ehm=, salts, Metgels uno \$u= musboben eine mebr untergeoronete Stelle ein, jo jegt man biejen Bobenar= ter bas 230 ort janbig bor; man pricht aljo in biejem gralle von janbigem

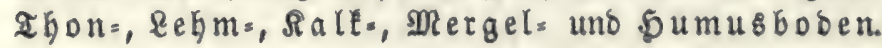

\section{Sumudboben.}

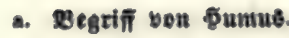

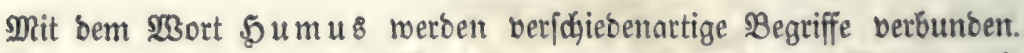
ธaufiure berfteft unter bemjelben bie ersige, jhmargbraune Materie, mit meldjer abgeftorbene Theile von Begetabilien bebect find, nadjoem fie einige 3eit an ber \&uft gelegen haben. Schübler unb mit ifm bie meiften 2lgros

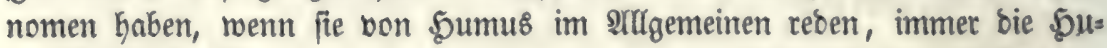
musfăuren im \$ruge.

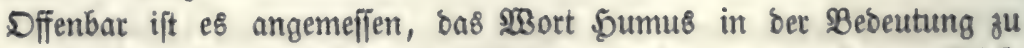
nebmen, weldje ifm ber Banbwirth uno ber Frorfmann unterlegen. Dieje

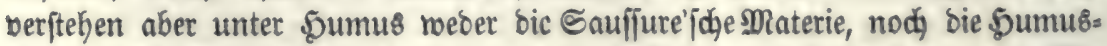
fäuren alleiu, fonbern fie begreifen unter bemjelben alle in Zerjęung begriffes

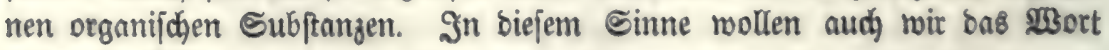
ছumus etf̌lären. 


\section{b. Einfbettung.}

Se nadibem ber Sumus bon \$flanzen ober von Shieren ftammt uns nach ben \$flanzenarten, fomie nach ben lumftänben, unter welden bie $\mathfrak{B e r}=$ wejung vor fich geht, ijt aud bie Dualität bes șumus unterichieblich. (ss Iaffen fid folgenoe Eintbeilungen madjen:

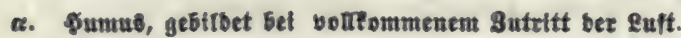

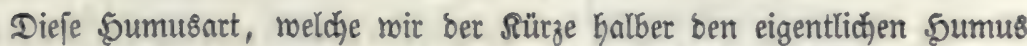
nenten rollen, if am meiften berbreitet. Sie entiftebt hauptjächlich burch bie abgefallenen Blätter uno Nabeln ber $\mathfrak{B a ̈ u m e ~ u n \delta ~ S t r a ̈ u c h e r , ~ b u r c h ) ~ b a s ~ b e n ~}$ Boben in Nabelwaldungen bebectente Moos uno butch anbere frautartige (Ses

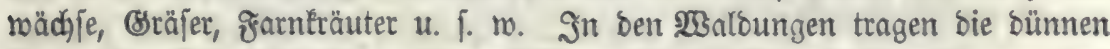

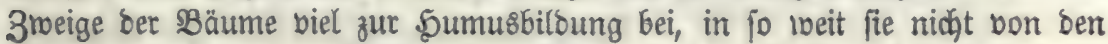

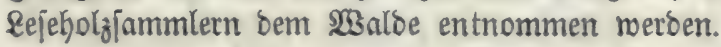

Der bei bollfommenem \&uftzutritt aus abgeftorbenen $\$$ flanzen erzeugte 5umus reagirt reber als Säure, nodh als Baje; er fteht in feinem demis foden Berfalten ber ఏolzfafer, aus ber ex fid gebilbet bat, am nädjpten uno ftimmt mit biejer um jo mebr überein, je meniger bie Berwejung vorgejdrit=

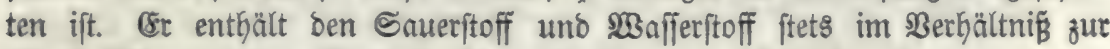

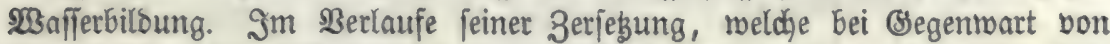

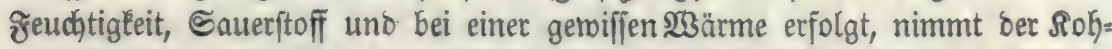
lenjtoffgehalt, gegenüber bem Sauerftoff uno 23 afferftoff, relatio zu. Daher

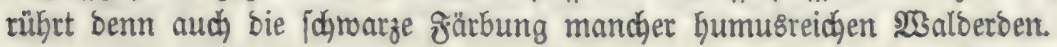

Bon bem eigentlidjen 5ूumus laffen fich wieber folgenbe Mlobificationen unterjdgeiben :

1. Der fruchtbare 23 al Nabeln, Moos $2 \mathrm{C}$.

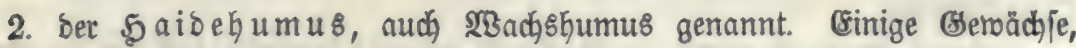
zu benen vorzüglich bie 5aiben (Calluna vulgaris unઠ Erica Tetralix)

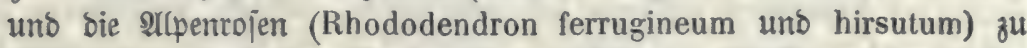

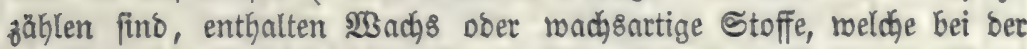
Berwejung ber Solzfajer fid nur menig verändern. Sprengel will im

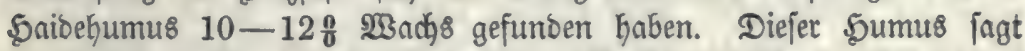

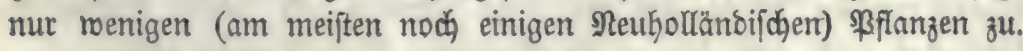

3. ber ఏ̧eibelbeethumuв, gebilbet aus Vaccinium Myrtillus uno Vaccinium vitis idaea, tommt in jeinen (Eigenjajaften Dem \$aibehumus fehr nahe.

4. Die Stauberbe. Sie entfteft aus mefreren gledten, von benen wir Cenomyce (Ach.) rangiferina (Cladonia rangiferina Hoffm.) §ig. 64., 


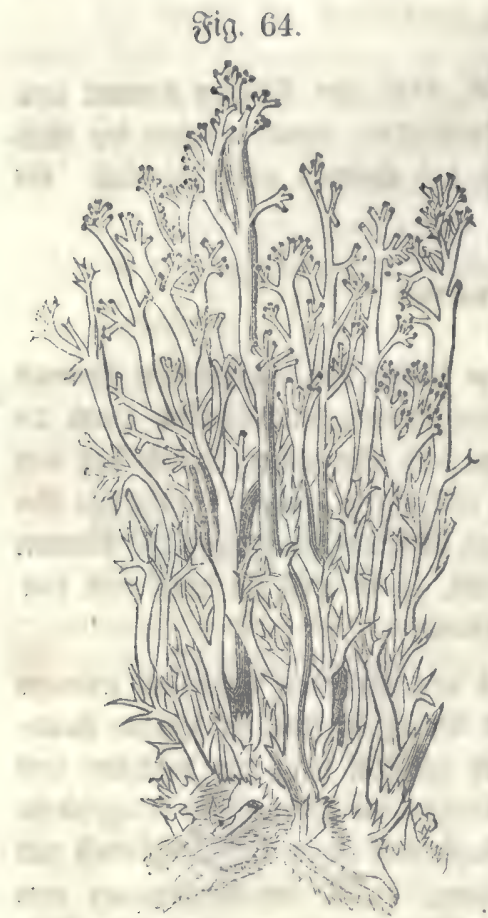

C. pyxidata, uncinata, subulata, formie Peltidea(Ach.) apthosa, canina, horizontalis, polydactyla nemnen, uno zeict)net fict), mie fojon die Benemung fagt, burch ftaubartige Bejd)nffentheit aus. Die Stauberbe ift ge= möhulidy trocfen unto daber bem Sebeifen Der .5olzarten nicht föroerlidj.

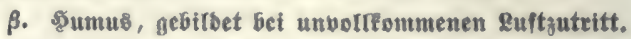

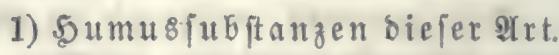

2renn organijobe Rörper bei unvoll: ftänbigem 3utritt ber Ruft bermejen, fo bil= ben fid), wie wir früker gejeben baben, ut=

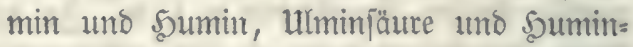
fäure, Seinfäure, Duelfäure uno Duelfabs= fäure uno viele moere, noch nidgt näher be=

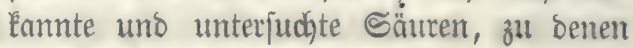
unter antern bie Torffäure gefjört. Berbe= fäure bält fich an ben Drten, weldhe ber

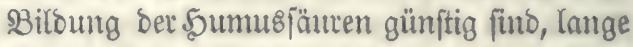
in unzerjegtem 3 uftanto, räbreno fie an freier \&nft und bei Segenwart einer angemeffenten SWärme zuerft burch Sauteritoffaufnathme in

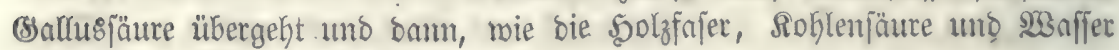
entrwictelt.

2) Die frudtbare (5roe enthält keine 5umusfäuren.

Biele Algronomen find ber Âtficht, Der \$umus der futhtbaren

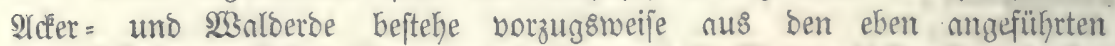
Sumusfäntren; babei machen fie bie Unterftellung, bie dibgeftorbenen Drganis-

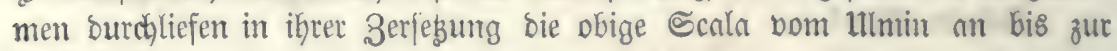
ฉuérjabjüure.

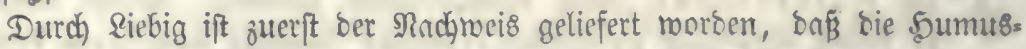

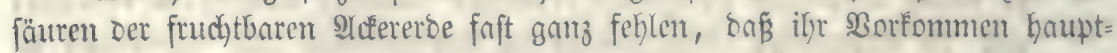

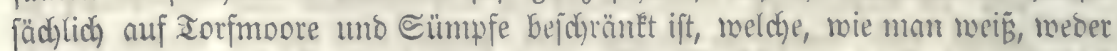

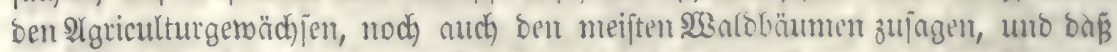

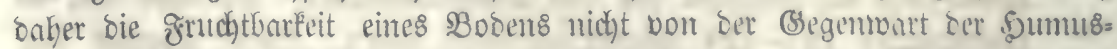

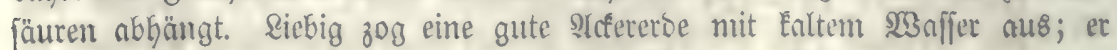
fand, bnßं nod) nicht $1 / 100000$ an organijoger Materie gelöft twurbe.

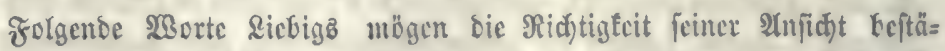
tigen. "Die Iropffteinböblen in Fromfen, in sor Ungebung son Baircuth,

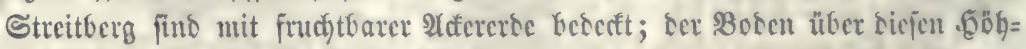

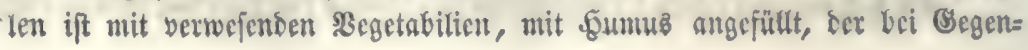




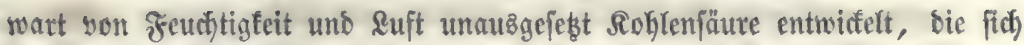
in Regentwafter loft.

Das mit Roblenfäure angefdyängerte Regentwaffer fitfert burch Den

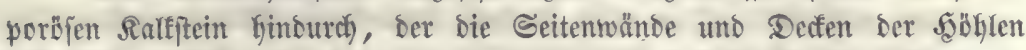

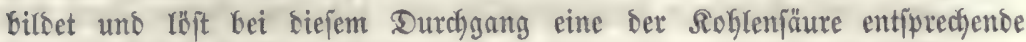
Menge yon toblenjaurem Raft auf.

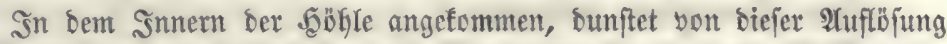
ธaล গูa

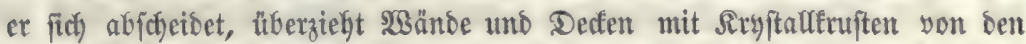
mannigfactiften Formen.

Atn wenigen Drten ber (Erte vercinigen fich) aber in gleichem (orade,

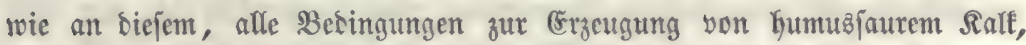

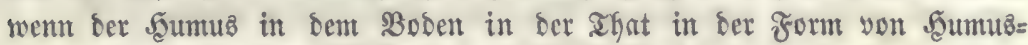
făure vorbanden wäre.

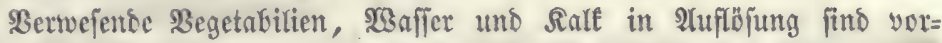

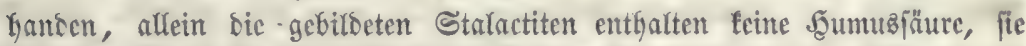
find glänzend weiß ober gelflict), zum Ifyeil burdffichtig, wie Ralffpath und

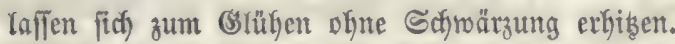

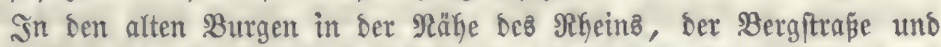

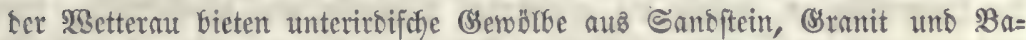
falt aufgefült, cine äfnlidge (Eridgeinung, wie bie Sarfföflen bar.

Diefe Benölbe oder Seller find bedectt mit einer mehrere Fuß biffen aage von Dammerbe, in ber fich verwejente $\mathfrak{B}$ egetabilien befinten. Daz Regenwaffer, weld)es auf biefe B̈stwölbe fäft, nimmt bie gebildete Rohlen= fäure auf, ficfert burch bie (Erose Gindurdh, löft burd) feinen Rohlenfäurege= Galt ben Raltmörtel auf; bieje AUflöfung verounftet auf Der Snnenfeite ber

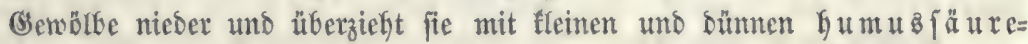
freien Stalactiten.

(5z find bies aber surd) die Ratur gebaute Filtrirapparate, in benen

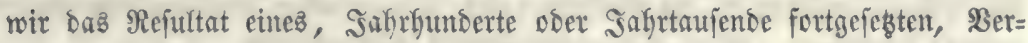
fuches yor शtugen haben.

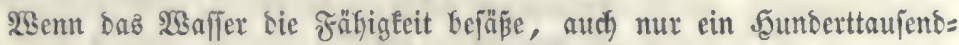

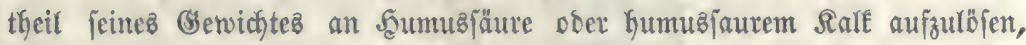

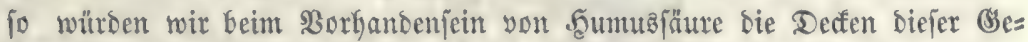
wörbe und Şöhlen bamit überzogen finten, alleit man ift nidgt im Stande, audi) nur bic fleinjte Spur bavon wahrzunehmen. SSenn man zulebst $\mathfrak{c r}=$

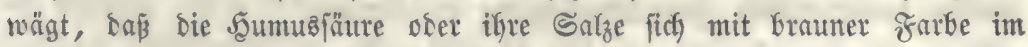

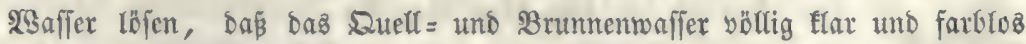
ift und beim Scrdampfen nur Salze, bie burd) Mineralfäuren gebildet fint,

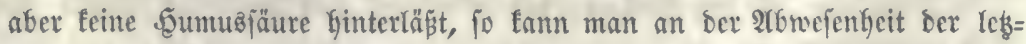

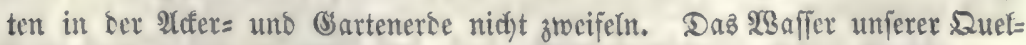
Ien und Brunten ift Rigenwaffer, weldjes burd Den Boben ficfernd feine 


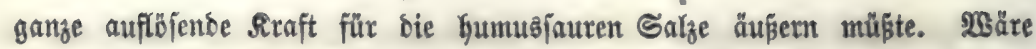
Gumusfaures Sali in bem Boben vorfanden, fo müpte alles Quell = uno Brunnenwaffer, in einer gewiffen Riefe gejammelt, bejtimmbare Mengen $D a=$ son enthalten, allein jelbjt in Dem, fohlenjaure Arfatien enthaltenben, Sel= terjer unt Facthinger Mineralwaffer, bie auz bem Boben einer jumpfigen

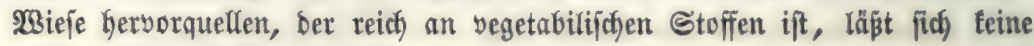
Spur ફூumuहิ|äure nadjweifen."

SBßenn trobgom Sprengel, Mulder, Sermann und andere (Shemifer in faft allen Aldererben Sumusfäure gefunden haben, fo berubt bies lebiglich in ber bon biejen Sinalytikern angewanoten Mietbooe zur Darjellung ber Su= musfäure. Sie laugten nämlich bie zu unterjuchenden (Eroen mit bohlenjau= ren Allealien bei geröbntidher Temperatur, ober in ber Siedfize aus und jojlu= gen bas gebilbete humu\&faure AllEali mit einer Säure nieber, z. $\mathfrak{B}$.

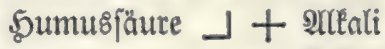 \\ Sdhwefeljäure.}

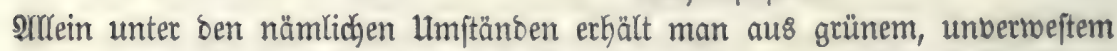

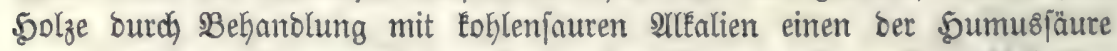
ganz ähnlichen Rörper, weil bie infruftirenbe Materie auf ber Snnenfläche ber

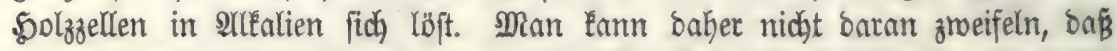

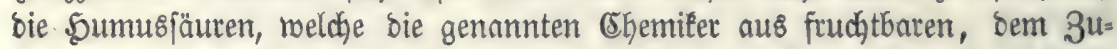

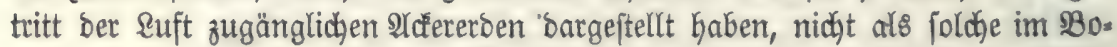

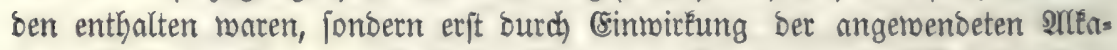
lien auf bie im Boben vorfindlidjen SRefte von Drganismen gebildet nurben.

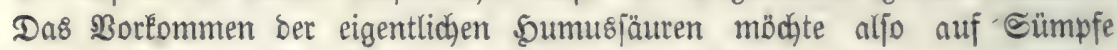
uno Torfmoore ober ïberfaupt foldje Drte bejacänlt bleiben, in roeldgen ber Saueritoff ber Ruft nicht gehörig ou bem berwejenoen sörper gelangen Eann.

Anthang. Nitrolin.

Sermann will aus faulem 5olze eimen ftidiftoffbaltigen Sörper abgeidhies ben baben, weldfen er als sitrolin (aus nitrogenium uno lignum zujammens

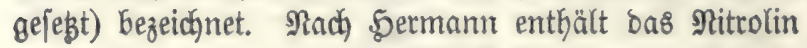

$$
\begin{array}{lr}
\text { Rohlenjtoff } & 57,20 \\
\text { SBajferjtoff } & 6,32 \\
\text { Sauterftoff } & 24,28 \\
\text { Sticfitoff } & \frac{12,20}{100,00}
\end{array}
$$

reldyer procentijhen 3ujammenjezung bie Frormel

entipriaht.

$$
\begin{array}{llll}
\mathrm{C}_{56} & \mathrm{H}_{40} & \mathrm{O}_{18} & \mathrm{~N}_{5}
\end{array}
$$

Sermanu ift ber 21nficht, ber Sticfitoff bes গitrolins merbe aus ber Euft genommen.

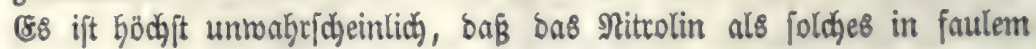


5olze enthalten fei; ba 5ermann baffelbe burdh Behanolung bes \$olzes mit

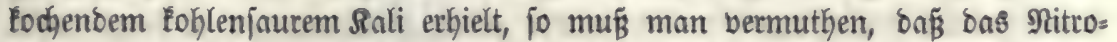
lin erft burd) bie (sinnirthung bes Sali's auf bie \$olzfajer gebilbet morden

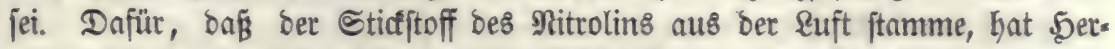
mann feinen Betweis geliefert; biejer Stiđftoff ftammt entweber von 2lmmo=

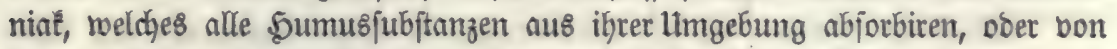
ben proteinartigen Stoffen im $50 l z$ uno in bem Safte beflelben.

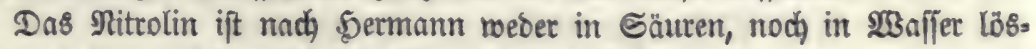
lid) und beritgt nod) beutlich bie Structur bes \$olzer.

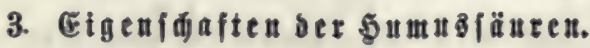

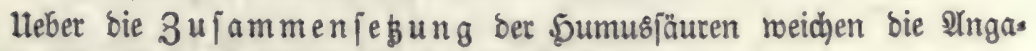
ben ber (6hemifer auserorbentlid) $a b$. (8s fanben

Eprengel in ber 5umuşăure aus Torf

$$
\text { Soblenitoff : }
$$

$$
\text { bargeftellt ......... . . 58,00 } 2,10 \quad 39,90
$$

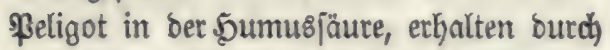

3ujammenjajmelzen von Säge|pähnen

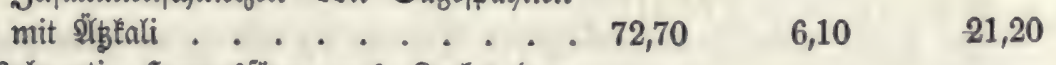

Inalaguti, ફumusfäure aus 3ud̛̃er bar=

geftellt . . . . . . . . . . . . $57,60 \quad 4,70 \quad 37,70$

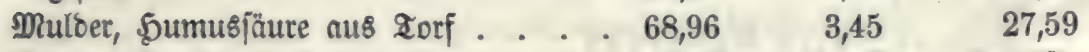

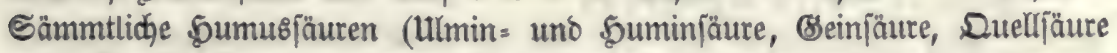

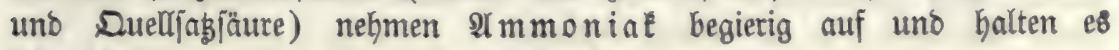
jehre fejt.

Die rigenjhaften ber 5umusfäure finto am genaueften bon Sprengel

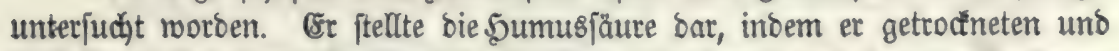
gerriebenen Sorf mit IImmonial bigerirte uno bann aus bem entitanoenen

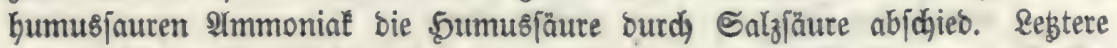

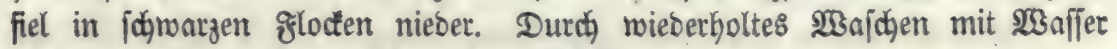
reinigte ex fie bon bet anjängenden ๔alzfäure.

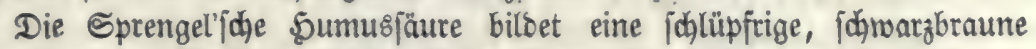

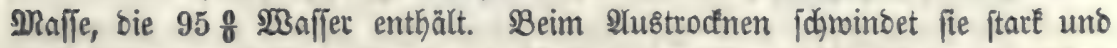
geigt bann mujdheligen $B$ rud. 1 aheil biejer Säure löpt fid in 150 I gei-

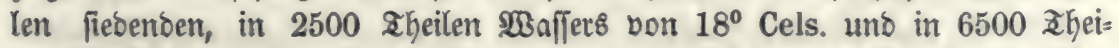

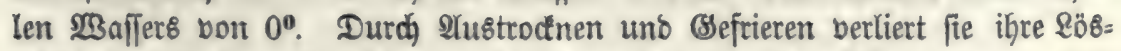

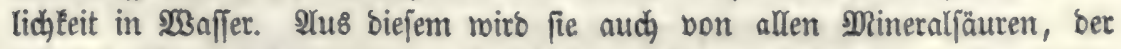
\$hosphorjăure ausigenommen, abgejhieben. Ân ber suft verweft fie, inbem fie Sauerftoff aufnimmt, mobei fie, mie bie நolzfajer, Rohlenjäure und $23 a j=$

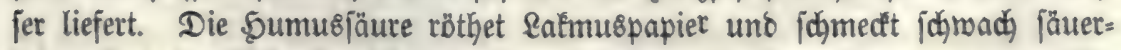

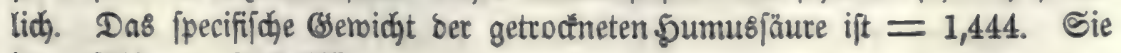
ift unfäbig, gă tryftalifiten. 
Die Sumusfăure geft mit Den meiften Bajen Berbindungen ein. Die

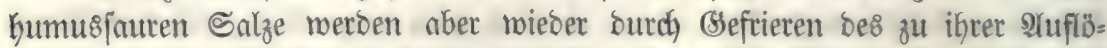
fung bienenden 23 affers zerlegt, nobei bie Säure als ein unauflösliches \$uls ver zu sooben fällt.

Artealifare Salze.

Die Salze, meldye aus ber Berbinoung ber Sumusfäure mit ben 2rléa= lien entiftehen, find viel löslicher, at8 bie Sumusfäure jelbft; 1 Ibeil Salz bes

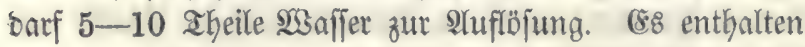

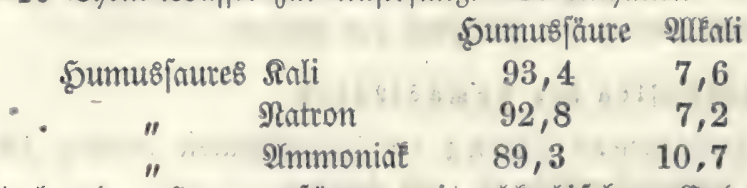

ธalze der Sumusjäure mit alkalijón Erden.

Bon biejen haben nur ber humusfaure Rale uno bie humusfaure Mag=

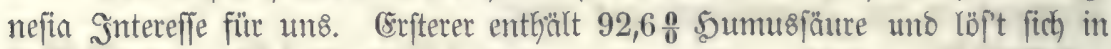

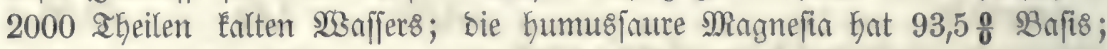
fie bebarf zu ifrer Röfung nur 160 Theile Ealten $\mathfrak{3 a f f e r 8 . ~}$

Sumusfaure $\mathfrak{x h o n e r b e . ~}$

Sie befibst einen Şumusfäuregefalt bon $91,2: 0$ und ift in 4200 ahei=

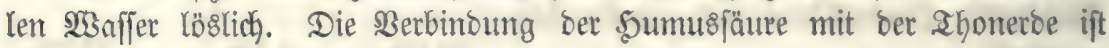
eine febr innige.

Ђ̆

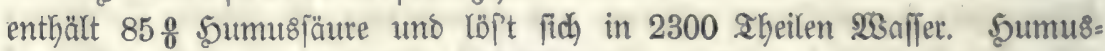
faures Bijenoryoul ift bei reitem löslicher.

5umus โаนres Manganorybul

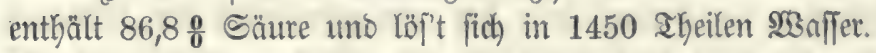

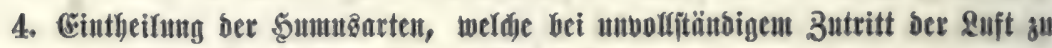

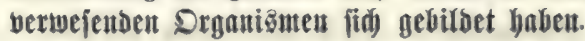

Bon ben bisfer gemadhten (Sintbeilungen fann folgenbe beftehen bleiben:

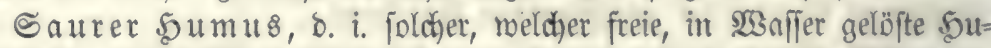
musfäure enthält. (Ẽr findet fid nuf fefr naffem Boben, in Sïmpfen, auf Iorflngern, 4. 1. w. Maan erkennt ifn an ber braumen gärbuntg be६

una

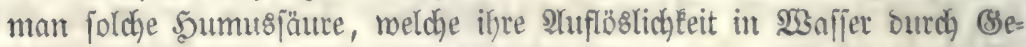
frietert ober Âtżtrodnen verloren hat.

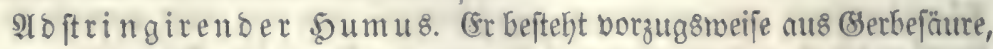

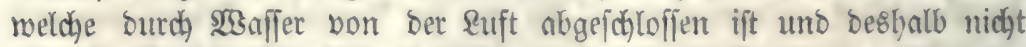
bermejen Eann. Albgefallenes (Erlen= und Cidjenlnub gibt unter ben ge=

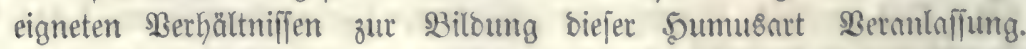
Hebrigens irren Diejenigen, weldge glauben, ber sumus in ben Eidgen= 
maldungen fei frets ein abftringirentoer; überall on, no ber SBoben nicht mit ftngnirentom 23 afjer bebecft ift, verweft bie Berbejäure in jefre kurzer Zeit.

Die von melgreren Agronomen gewäblten weitern (Fintheilungen in

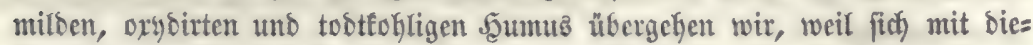
fen Alubbrütfen feine Begriffe verbinten Iaj]en, weld)e bem gegenwärtigen

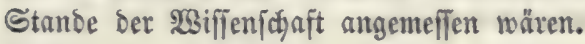

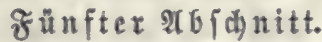

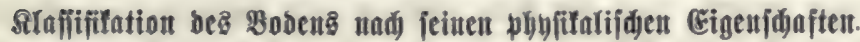

\section{Getwidit bet (exbarten.}

Borbemertung.

Die Beftimmung bes (semidyt8 einer Eroe Eann man entwebet

a. Blos auf bie fefte Maffe berfelben, oder

b. auf bie in einem gewiffen Bolumen entfaltene Eromenge beģieben.

Siemach unteridfeibet man bas ipecififdse (seridht (a.) und bie Bse= widhte gleidger $\mathfrak{B}$ olumina (b.). Seghtere fint um befimillen für bie Ilgro= nomie bon bejonberer Bedeutung, weil man, wenn berichiedene Erden hin= fichtlich ifres (semidhts berglichen werben follen, immer gleidye \$aummengen berjelben im 2Yuge hat, ohne babei bon ben leeren saäumen zrijdgen ben cropartikeldyen zu abjtrabixen.

\section{A. Epezififdes Eew idst.}

Das einfachite Berfahren zur Beftinmmung beffelben ift folgendes:

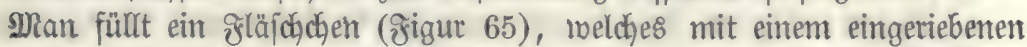

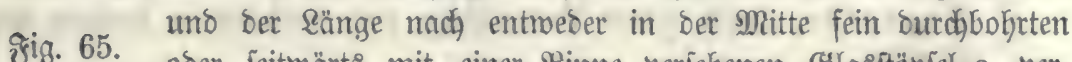

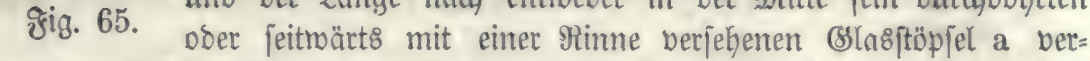

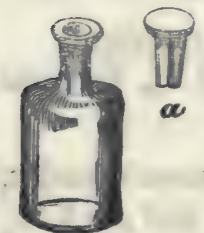

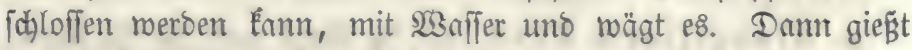
man bas $\mathfrak{W a f f e r ~ a u s ~ u n t ~ b r i n g t ~ b i e ~ z u ~ u n t e r j u d j e n t e , ~ g e w o = ~}$

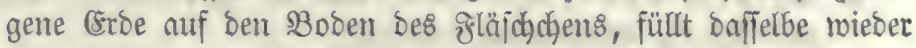

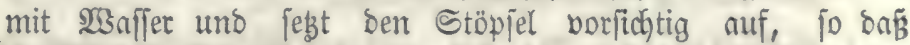

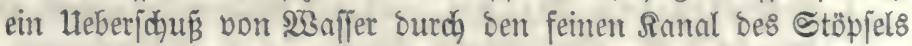

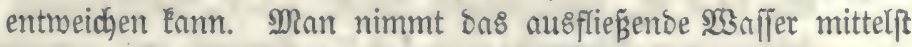

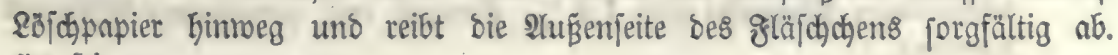
Cร) jei

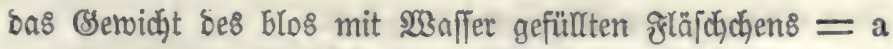

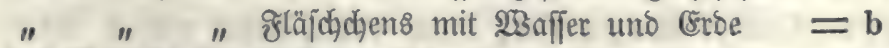
Sas servicht der trodfenen (stoe

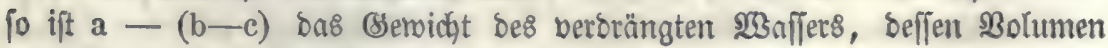
gleich) bemjenigen ber Erbe ift, uno

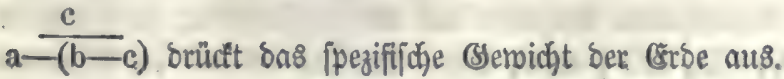


(s8 jei z. B. $a=100, b=93, c=5$ Eramme, io ift c

$a-(b-c)$

$=2,4=$ bem ppezifijc)en Servidgt ber zu unterjudbenden Erbe.

\section{B. Oewíle gleider Boluminaber Exben.}

IIm bieje zu erfabren, bringt man bie (8rbe in geometrifich einfache

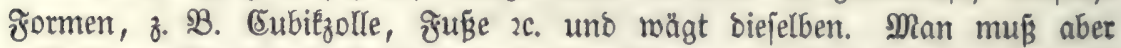

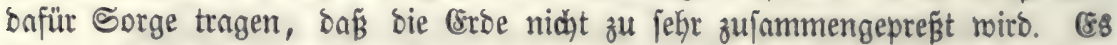
ift von Intereffe, bie corde in trockenem und naffem 3ujtand zu unterjudien.

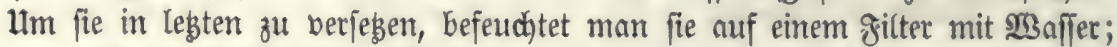
als böllig burchnäfst tann bie croe bann angejeken werben, wenn fie bas

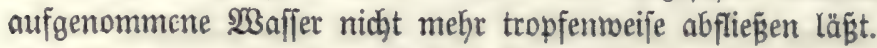

\section{c. Nefultate einiger unterfudungen über bas gewi crbarten}

berbanten wir Sdyübler. (Er operirte mit folgenben Subjtanzen:

a. $\mathfrak{a} a \mathrm{rz}$ and,

b. Saltiand,

c. feiner pulverförmiger Ralterde, aus gebranntem Ralferbalten, weldyer burdh langes Riegen an ber Ruft wieber in bollfommen loblens jauten 3 ujtanઠ übergegangen mar.

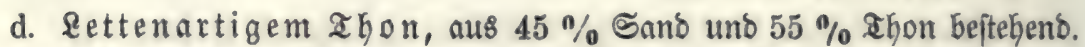

e. Eehmartigem Ihon, mit etra $24 \%$ Sand und $76 \%$ ahon.

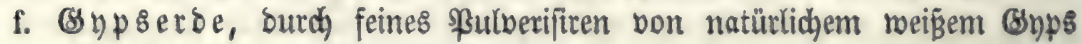
erhalten.

g. Slayartigem ahon, $10 \%$ ธanb und $90 \%$ Thon enthaltend.

h. Reinem Ihon, obne Sanb, aus $58 \%$ Siejelerbe, $36,2 \%$ Ihonetbe und $5,8 \%$ (sijenosyoul beftegent.

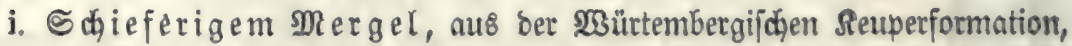
mit $84,8 \%$ eijenthaltigem shon, 6,5\% Eohlenjaurem Rale, 7,2\% Foflenjaurer Magnefia und $1,3 \%$ weniger eng gebundenen Eifenobsto bejteheno.

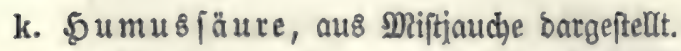

1. Sohlenjaurer $\mathfrak{R} a g$ nejia, buth) Präcipitation mittelft Arlealien aus ibren 2luflöjungen in Săuren erbalten. Die fo von Sçübler barges ftellte Eohlenjaure Magnefia Gat inbeffen Keinesmegs biejenige 3ufam= menjesung, wie bie im Boben vortommende. Sene ift nämlid einte Berbinoung von tohlenjaurer Magnefía mit MRagnefitabyorat, entiprecheno

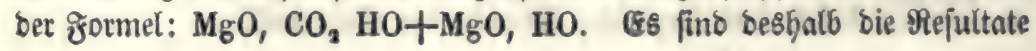




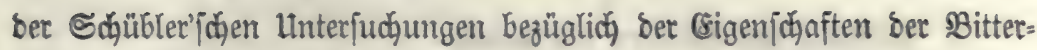
erbe reggelafien worben.

m. Reidte, frudtbare, fकrmarze gartenerbe, befteheno aus $52,4 \%$ Ibyon, 36,5\% Duarzjano; 1,8 Salfiano; $2,0 \%$ Salketbe uno

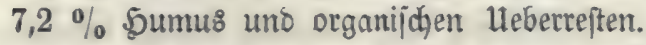

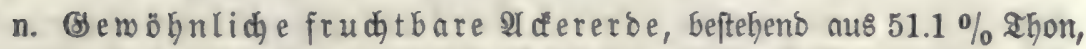
$42.7 \%$ Duarzand, $0,4 \%$ Sinlejand, 2,3\% Salterbe und $3,4 \%$ 5umus uno organijaten Ueberreften.

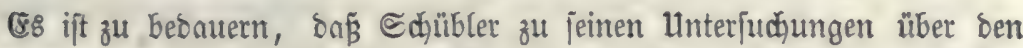

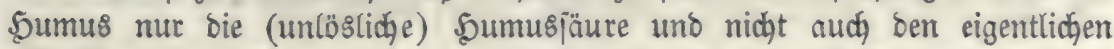
23 ald humus (welchen er als "organijhe Heberrejte" bejeichnet) vermentet hat.

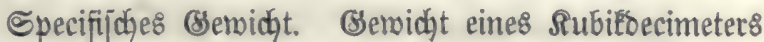

Brbarten.

\section{Raltiano}

Duarziano

Sups, gepulbert

IYon mit $45 \%$ Sand

Ifyon mit $24 \%$ ভano

Thon mit $10 \%$ ธanb

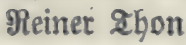

geiner Foblenj. Salle

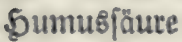

(Sartenerbe

Qlcfererbe

Edjiefr. Diergel

$$
\text { 23affer }=1
$$

Eroe. Rilogramme.

Bei $60^{\circ}$ - getrodinet. Ingenås̆t.

$\begin{array}{ll}2,722 & 2,085 \\ 2,653 & 2,044 \\ 2,331 & 1,676 \\ 2,601 & 1,799 \\ 2,581 & 1,621 \\ 2,560 & 1,423 \\ 2,533 & 1,376 \\ 2,468 & 1,006 \\ 1,370 & 0,632 \\ 2,332 & 1,449 \\ 2,401 & 1,537 \\ 2,613 & 2,048\end{array}$

2,605

2,494

2,350

2,386

2,194

2,156

2,126

1,758

1,428

1,744

2,810

2,600

\section{Dtofuffon ofefer gefultate.}

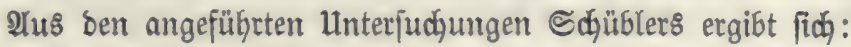

a. Der Sand ift jomohl trodéen, als naß̉ bie jchnerfte von allen Bobenarten und von ben Beftantotheilen zujammengejebter Böben.

b. Die Shonarten find um jo leidgter, je meniget Sano fie enthalten.

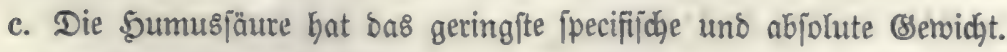

d. Die beim \&anomann gebräuchliche Benennung eines fdymeren ober Yeich= ten Bobens fann fid weber auf bas pecifiche, noch auf bas abjolute

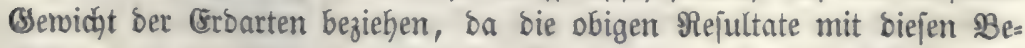

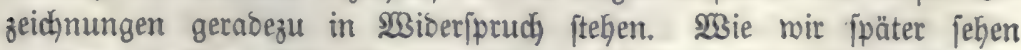
werben, beruben bieje Benennungen auf ber größ̈ern ober geringern Confiftenz ber, Groen. 


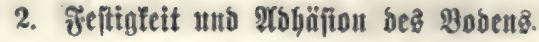

\section{A. Eeftigett.}

a. Begriff.

Unter ber Zeftigleit ober Confiftenz eines Bobens verfteht mant sen :3us fammentyang feiner einzelnen Theile. Sie äupert fich burdh ben 2B3iberjtand, ben ber Boben foldhen Snftrumenten entgegenfest, mittelft beren man ifjn zu

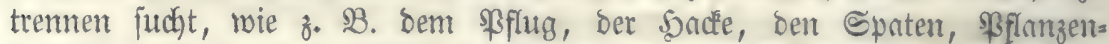

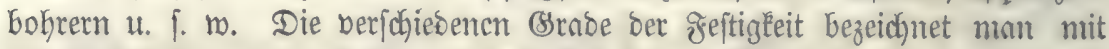

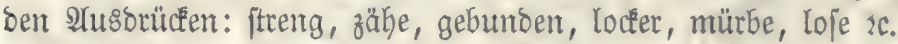

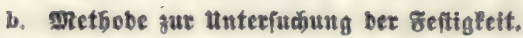

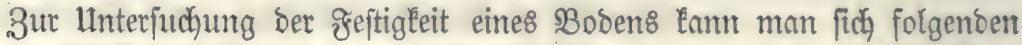
2lpparates bebienen.

2łus einer lunterlage a (æig. 66) erbebt fich ein Iräger bc, nuf Æig. 66.

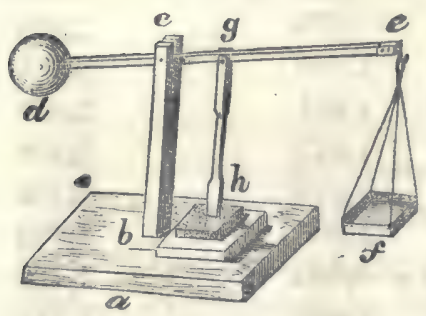
welchem ein Sebel de ruft, an beffen einem Enoe eine \$leifugel d befeftigt ijt, rähreno

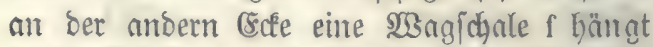
Diejer Sebel bient als $\mathfrak{W a g b a l l e n t ~ u n o ~ n i n u m ~}$ to lange eine freie sage ein, als bie Sctyale f nidht mit (serwidyten belaftet wirb. Bei g ift ein unten fpatelförmiges (sijen og h mittelít eines ๔tiftes in ben Şebelsarm de 10 befeftigt, baf es fich frei berwegen fann uno immer lotfrecht fängt, wenn audh ber Sebelsarm felbft feine \&nge verändert. Diejes patelförmige Gijen gh ift zun Durbjfdyneiben ber auf einer Blatte liegenden Eroe beftimnt.

Man gibt lebsterer bie from eines \$arallelpipebons mittelft einer $\mathfrak{B o r}=$

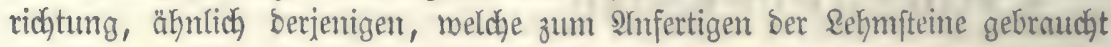
wiro.

Itm baร Maß̧ ber Feftigéeit-einer Crobe zu beftimmmen, legt man in bie

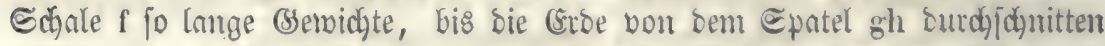
worben ift.

\section{B. Wobäton bes 20 o}

๑. Begriti .

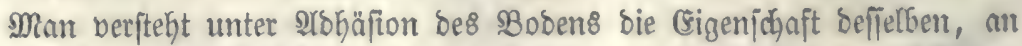
ancern Rörsern, nit melchen er in Berüfrung gef́ommen ift, nnzubängen. Sie ift wichtig für bie Beacferung. Crrbarten, weldhe ftart an ben \$flug, bie

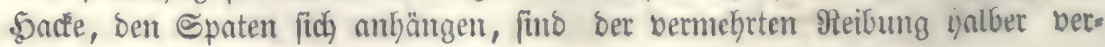

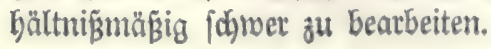


b. Unter'

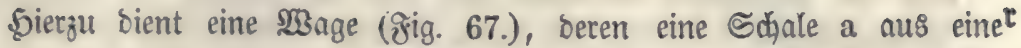
§ig. 67.

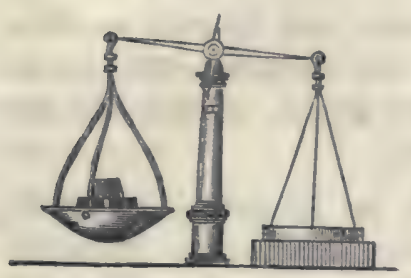
Sdkeibe bon Solz doer rijen (ben zu ben

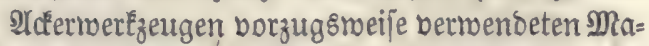
teralien) bejtejt. Man jeşt bie Schale a auf

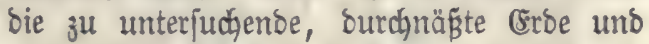
legt auf bie Schale b fo lange (Servidate, bis a bon ber Eroe getrennt wirb.

b.

a.

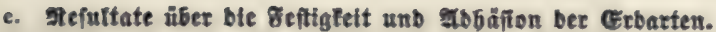

æreftigleit

im trocenen

Groarten

Quarzianto

Saltiano

Geine Eoblenj. Salterbe

(S)ps, gepulbert

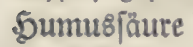

Thon mit $45 \%$ Sand

ITon mit $24 \%$ Sanb

ITon mit $10 \%$ ธand

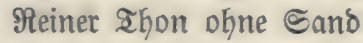

Bartenerbe

श्थdeterbe

Sdjiefriger Mergel

gejęst. 3 uftand, bie bes

Ihon $=100$

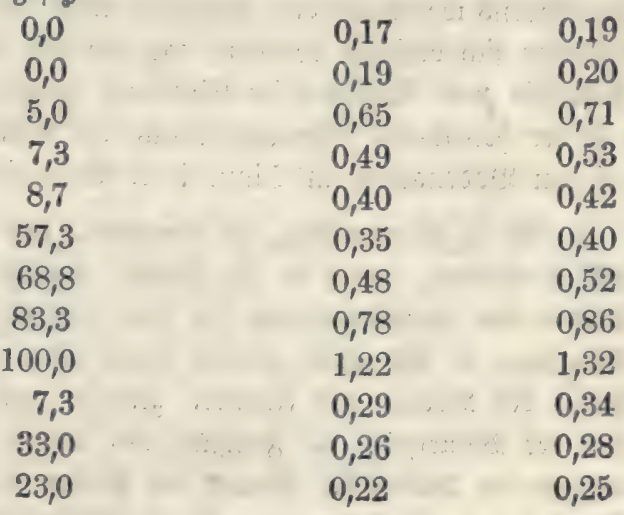

Nobăfion an eine Flädje von 1 Duabratbecimeter. sijen $\mathrm{S}_{\mathrm{SO}} \mathrm{lz}$. Rilogramme.

0,42

0,40

0,52

86

1,32

,34

0,25

\section{d. Distuffion ber Meruitate.}

2us ber vorftehenden 2abelle ergibt fich Folgenies:

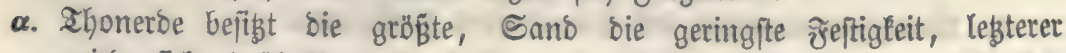
miro fich befihalb auch leichter bearbeiten laffen. Die geftigéeit ber Sumusfäure ift gering; menn Sdÿbler einen Berfudy mit bem getoöhnlichen insifferenten $\mathfrak{K}_{3}$ ald bumus angeftellt Gätte, fo würoe et beffen Jejtigkeit gerwiß̈ größ̈er gefunden haben, bern bie zu bem obigen

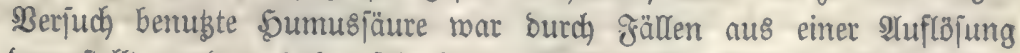
bargeftellt morben, baher jefr fein zertheilt, währens ber aus verwejtem 


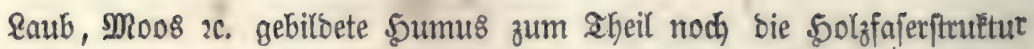
beipht, aljo jebenfalts mehr 3ujammenting hat. Sn ber ahat nimmt auch ber Forjtmann allgemein an, Daßí ber Sumus die Grtreme ber Bobenfeftigéeit bermittle, alfo einem locferen Boben mehr geftigkeit und einem feften Boben mebr soderbeit berleibe.

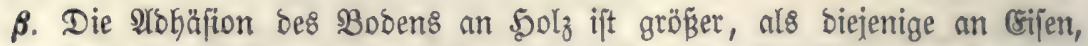
was fomohl von ber größern Dberfläche bes verbältniß̈mäßig rauken

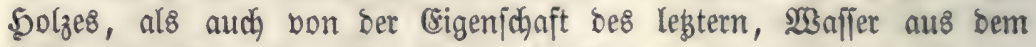
Boden fdynell in fich aufzumebmen, Gerrübrt.

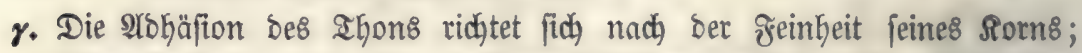
feine Ralkerbe zeigt eine größ̈̈ere 2robäfion, als mandje Ihonarten.

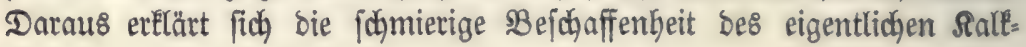
bodens.

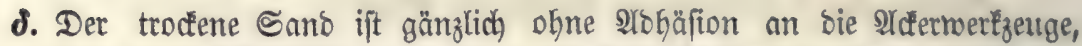

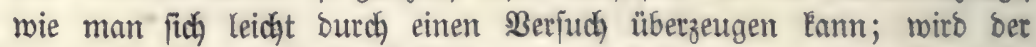

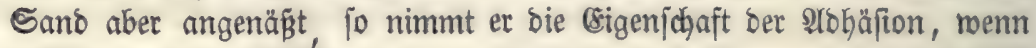
auth in getingem Máse an.

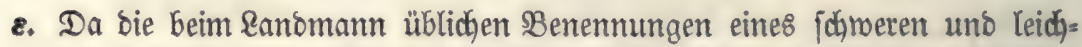
ten Bobens reber auf bas fpezififdhe, noch auf Dns abjolute Betwidht ber Eroarten fitch beziehen Ë̈nnen, Dagegen mit ber größjeren ober geringern

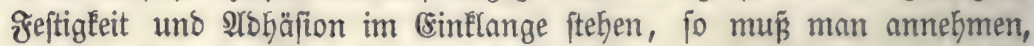

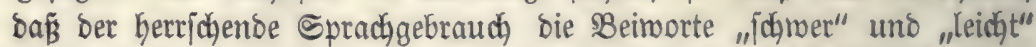

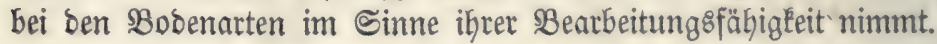

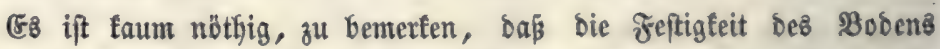
fid) vermindert, went ex im feudiden Buftanto vom froft getroffen wirb.

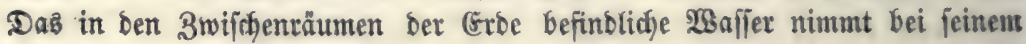

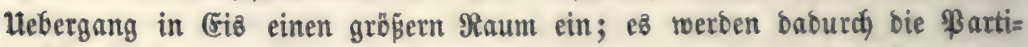
feldjen bes Bobens son einander getrennt uno zerfleinert. Sdjübler fant,

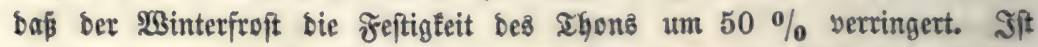
bagegen ber Boben bei Fintritt beß Froftes trocten, fo erleibet feine Fefitg=

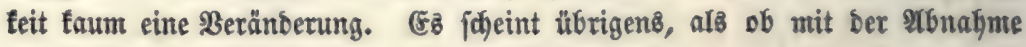

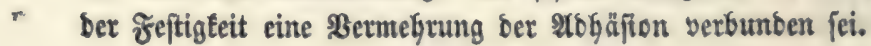

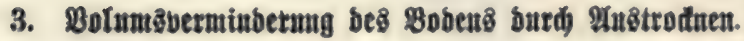

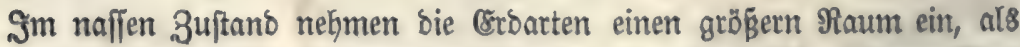

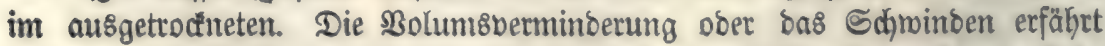
man burdi) Meflung ber Dimenfionen, weldje bie regelmäßig geformte (robe erft um naffen uno bann im trod"nen 3ujtano befïbt. Sdjüblet erbielt bei feinen unterjuchungen folgenbe Iejultate: 
1000 Raumtbeile geben 1000 Raumtbeile vermindern

Quarz= und Raltjand, Ginps 1000

Jreiner foblenfaurer Salle

Shon mit $45 \%$ Sano

Shon mit $24 \%$ Sant

Shon mit $10 \%$ Sand

Reinet Ifon ofne Sand

ฐุumusfäนเe

Bartenerbe

Qddererbe

Sdilefriger Mergel
950

940

911

866

817

800

851

880

965 ibr Bolumen um

0 sheile.

50

60 "

89 "

114 "

183 "

200 "

149

120

95

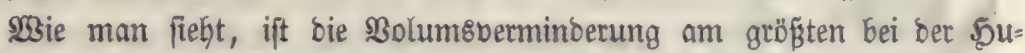

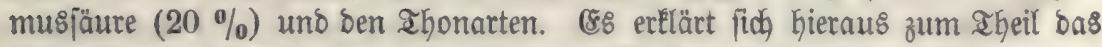

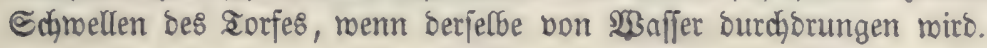

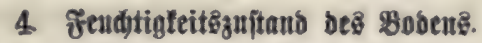

\section{A. Bebingungen.}

Der freudhtigkeit8zuftano bes Bobens hängt $a b$ :-

a. zunächft bon ber Menge $\mathfrak{W a f f e r , ~ w e l d j e ~ b e m ~ B o b e n ~ z u r ~ 2 l u f n a f m e ~ i n ~}$

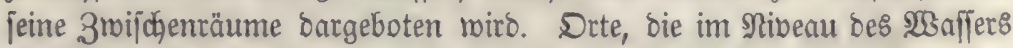

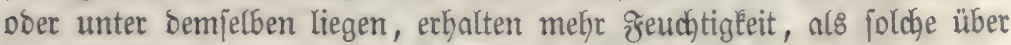
Dem 23 afferjpiegel, weil bei leģtern bas 23 affer nach Den ticfer gelege= nen ßunÉten abfliejen Eann. Soldhe Begenden, meldhe reidh an mete=

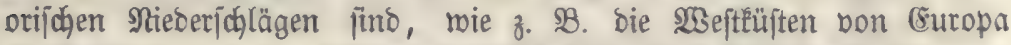
5odjgebirge u. f. w., beftzen ebenfalls öfter einen feudyten 30 ben.

b. Davon, ob bas aufgenommene $23 a f f e r$ bem Soben aud berbleibt.

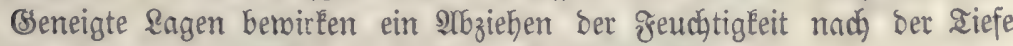
Gin; Sonne und 2 Sind begünjtigen bie Berbunjtung.

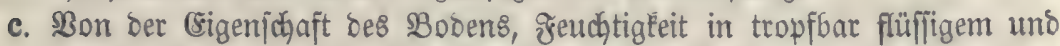
gasförmigem 3uftand in fich aufzunebmen uno biejelbe zu halten. Dieje Eigenfobaften verbienen eine näbere sBetrachtung.

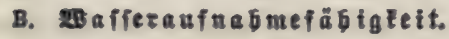

a. Begrifi.

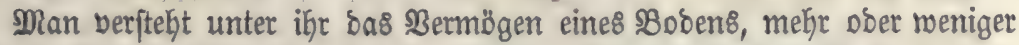

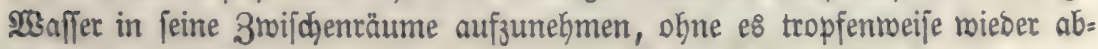
fliegien zu laffen.

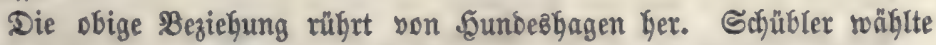

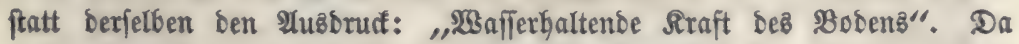

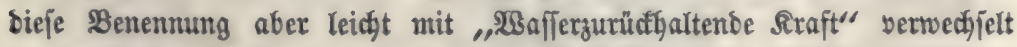

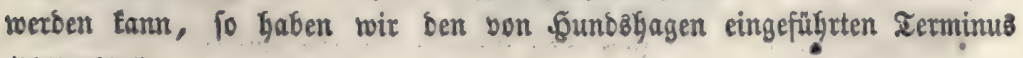
borgezogett. 


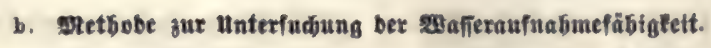

Æig. 68.

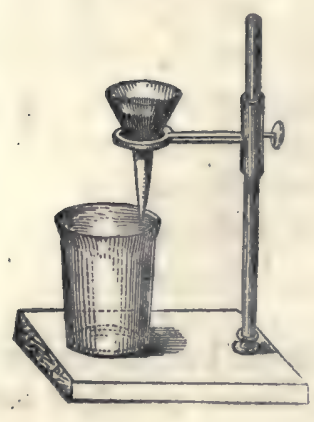

Man bringt etra $20 \mathrm{Srm}$. Crrbe (nicht zu viel, weil fonft bas 2 Baffer burch ben Druc ber (Erbe ausgeprepst roiro), naçbem fie bei etron 20$30^{\circ}$ längere 3eit hinburdh getrocfnet morben ift, auf

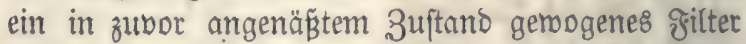
(ङig. 68.) uno giept bann 2 affer auf bie (Eroe. So= bald bas $\mathfrak{X a f f e r}$ nidjt megr tropfenmeife abfliest, wiegt man sie Eroe fammt bem filter.

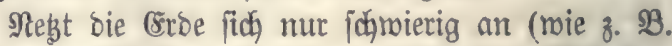
mandje Mergel, welche fich mit 23 affer zulammen= ballen), jo ift es rathjam, biefelbe, ehe man fie auf

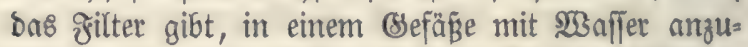
rühren unઠ Damn beffen Inthalt auf oas filter zu fpüblen.

Die burch bas aufgenommene $\mathfrak{B a f f e r}$ bewirlte Bewidjtsvermehrung ber

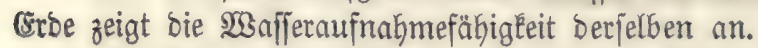

Die Rechnung wird folgendermañen gefüfrt:

Serwicht ber getrocineten Erbe $=\mathbf{a}$

(semidat bes angenåfiten §ilters $=\mathbf{b}$

(Semidat bes angenäften ßilters uno ber naffen croe $=c$, fo ift nufgenommenes $\mathfrak{B}$ affer $=\mathrm{c}-(\mathrm{a}+\mathrm{b})$.

(8s jei 子. B. $a=20, b=5, c=35$, fo ift $c-(a+b)=$ $35-(20+5)=35-25=10 ;$ und 100 semichtstbeile (Erbe baben 28,6 Theile 2 affer aufgenommen.

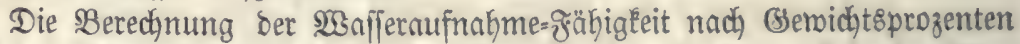

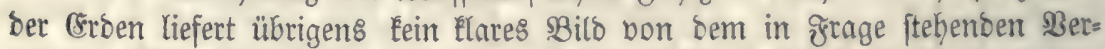
balten. WBir find nidht getoohnt, ben Boben feinem (Setrotht nach anzujehen;

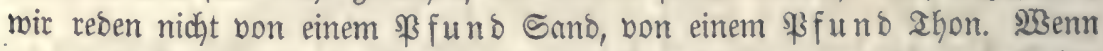
wir zmei $B$ obenarten in Bezug auf ifre (sigenid)aften bergleichen, fo baben mir immer gleiche Bolumina im Aluge. Dies gejdjeht aud immer, roenn von

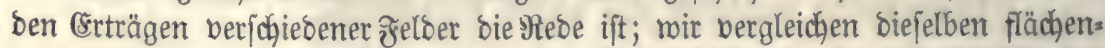

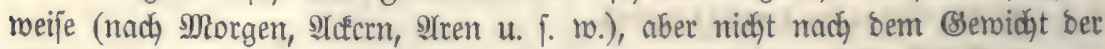

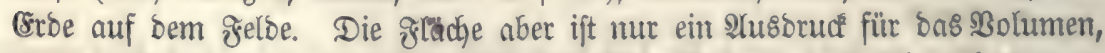
vorauछgejeșt, on

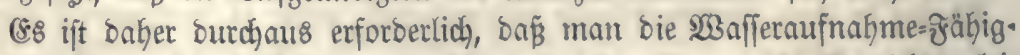
feit ber Crrben auf bas Bolumen berfelben bezieft. Da mir bie semichte gleis der Rolumina ber Eroen Eennen, fo geftaltet fid bie Rebuction ber Berwidhts=

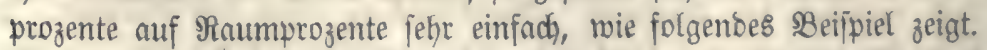

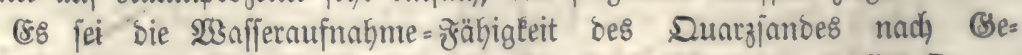
widhtsprozenten $=25$ gefunben worben; on ein Rubilbecimeter nafien Duarz=

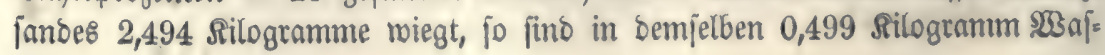


jet entfalten $(125: 25=2,494: x=0,499)$. Da eine Bramme $=$

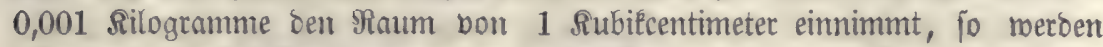
aljo in 1 (c00 Rubifcentimetern (= 1 Rubif́secimeter) bes naffen Sanos 499

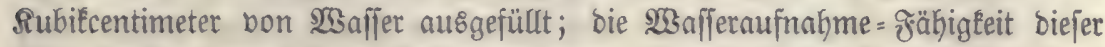

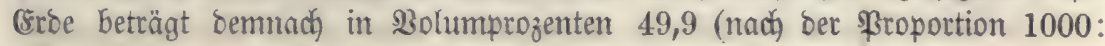
$499=100: x=49,9)$.

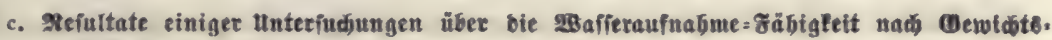
unb Bolumprojenten.

23afferaufnahmefähigkeeit. 1 Rubif́becimeter ber angenäß̧ten SSewichts = Bolum = Eroe entbält Silogramme

Eroarten.

Duarziano

Ralkjano

(5yp8, gepulpert

Ihon, mit $45_{0}^{0}$ ऽand 40

Ihon, mit $24 \frac{0}{0}$ Sand 50

Zhon, mit $10 \frac{0}{6}$ ธano 61

Reiner Thon ohne " 70

ซreiner Fohleni. Sialf 85

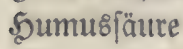

Bartenerbe

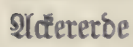

Sdjiefriger Mergel 34

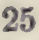

29

27

190

89

52
Prozente.

\section{d. Discuffiton biefer Mefultate.}

a. $\mathfrak{B o n}$ allen Beftantheilen bes Bobent zeigt ber Sand bie geringfte $2 \mathfrak{3 a j =}$ feraufnalyne: gäffigéeit. Das günjtigere ßerhalten des Salējands, gegen=

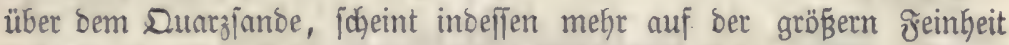

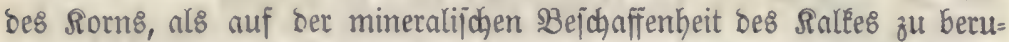

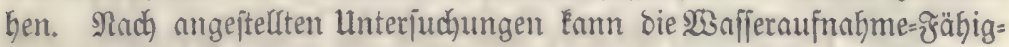
keit bes grob́f̈̈rnigen Santoes fich bis zu $20 \frac{0}{0}$ bermindern, während fie bei febr feinem ๔and bis auf $40 \frac{0}{0}$ fteigen Eann.

$\boldsymbol{\beta}$. Die Bupseroe zeigt ein bem ๔ande ähnliçes Berbalten; bies fann nicht

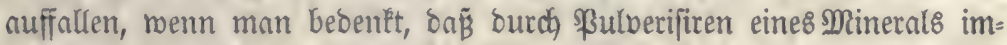
mer nut eine 2 ret Sant erzeugt mit'b.

$\boldsymbol{\gamma}$. Der Ifon nimmt um fo mefr 2 affer auf, je weniger Sano er entfält.

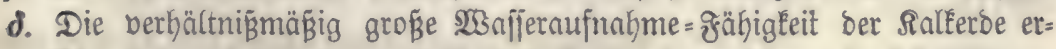
Elärt fich aus dem feinzertheilten 3uftand, in tweldyem fie fich befindet. Da ber Ralkjand hierin ber Ralf̈erte, wie fie zu ben obigen Berfudjen

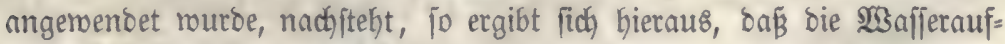
nahme = g̈ähigfeit eines Ralêtobens je nach ber frorm, in neldyer ber sale fidh befindet, jefte beridieden fein tann. 


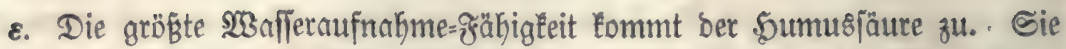
mirb übrigens in biejer (sigenjhaft nod) bon bem bei bollemmenem

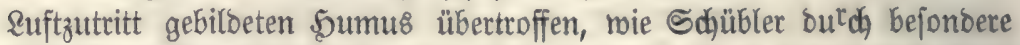
Berfuthe nadjgemiejen hat. 100 Theile ber feinen, burdh faules $50 l z$ in alten Bäumen gebilbeten forbe follen fogar gegen 200 und gewiffe

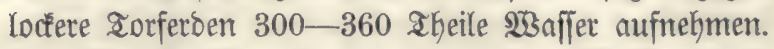

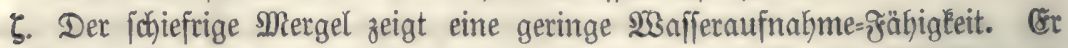
Eann baher bemught werden, um eimen $\mathfrak{B D b e n}$ rärmer uno trodher zu madjen.

\section{c. 20 affergurubaltenbe seaft.}

\section{a 3egriti.}

Man verfteht unter ber mafferzüübaltenoen Rraft eines Bobens bie (sigenjhaft beffelben, mehr ober weniger ichnell auszuttoctnen.

\section{b. Pethobe zur unterfudung ber wafferzurud haltenben staft.}

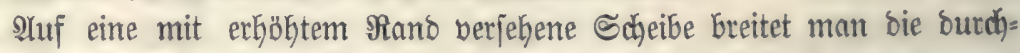

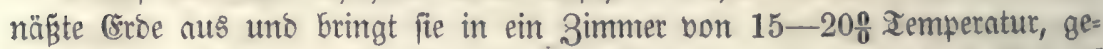

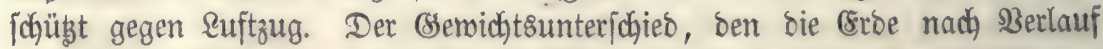
bon einigen Stunoen zeigt, gift bie Menge ber berbunjteten Feuchtigleit an.

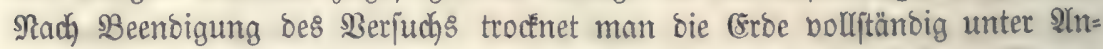

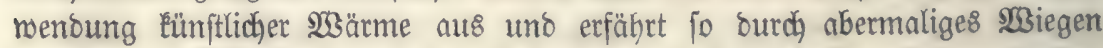

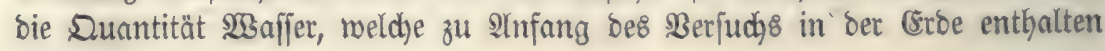
mar. 68 jei is. $\mathfrak{B}$.

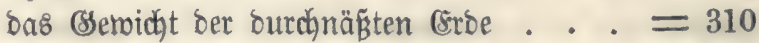

$$
\begin{aligned}
& \text { berjelben (stoe nad) } 24 \text { Stunben }=260 \\
& \text { ber völlig aurgetrodineten corbe }=200
\end{aligned}
$$

fo mar bie "Menge des in 24 "Stumben verbunjteten

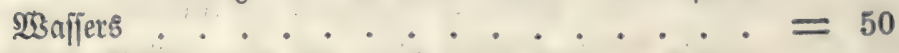

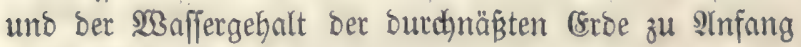

Des $\mathfrak{B e r j u c j s}^{2}$. . . . . . . . . . . . $=110$.

Bon 110 Iheilen $\mathfrak{B}$ affers fino alp 50 aheile verounftet, bas madjt $45,5 \%$.

c. Refultate einfger untexfudungen über bie wafiergurüdbaltenbe fraft.

Die Eroen rurben auf einer Flädje von 10 Duabratzoll ausgebreitet, man randte bon jeber gleidje (Semidhtsmengen (200 Bran) an. Die Iem= peratur bes 3immers, in weldjem ber $\mathfrak{B e r j u t h}$ borgenomment murbe, betrug $18^{0}, 75$ Cels.

Eroarten.

Duarziand

Saltjand
Bon 100 abeilen abjor= birten 23 anfers betoun= fteten bei $18^{\circ}, 75$ in 4 Stumben
Bom 100 Theilen aufge= nommenen $\mathfrak{1 B}$ affer8 bet= Dunfteten 90 Theile bei $18^{0}, 75$ in 4 Stunoen 4 Minuten 4 " 44 
(3)p8ి, gepulvert

Thon, mit 458 Santo

בhon, mit 248 Sand

Ihon, mit 10: Sano

Peiner Ihon ohne Sano

greiner Rale

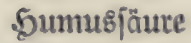

Sartenerbe

शafererbe

Sddiefriger $\mathfrak{R e r g e l}$
71,7

52,0

45,7

34,9

31,9

28,0

20,5

24,3

32,0

68,0
5 Stunoen 1 Minutent

$\begin{array}{rrrr}6 & \text { " } & 55 & \text { " } \\ 7 & \text { " } & 52 & \text { " } \\ 10 & \text { ". } & 19 & \text { " } \\ 11 & \text { " } & 17 & \text { " } \\ 12 & \text { " } & 51 & " \\ 17 & \text { " } & 33 & \text { " } \\ 14 & \text { " } & 49 & " \\ 11 & \prime & 15 & \text { " } \\ 5 & \text { " } & 53 & \end{array}$

\section{d. Diøenfion biefer Fefultate.}

a. $21 m$ idhnelliten trodnen bie Sambarten, fowie ber idjiefrige Mergel und ber SSyps nus; man nennt fie barum hisige Böben.

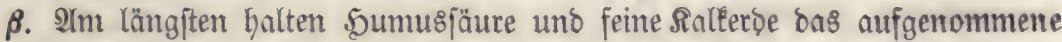

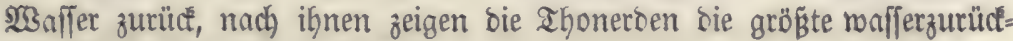
baltenoe Siraft.

$\boldsymbol{\gamma}$. Die (Eigentidaft ber Eroarten, bas nufgenommene $23 a f f e r$ langfam zu berounften, fteht mit ber 23 afferaufnahmefähigéeit jo lange in gleidłem

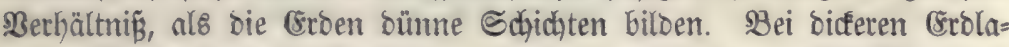

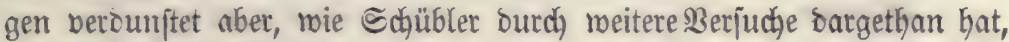

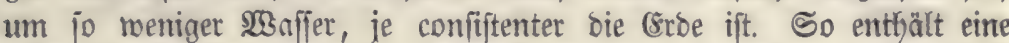
naffe, jollside Ihonjididyte nady Berlauf von einigen 2 agen immer nodh

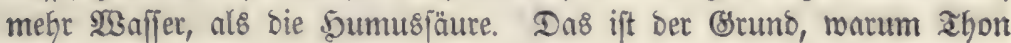
ben jogenamnten "Ealten" Boben bilbet.

\section{2Bafferonupfabforptionsfäbiglcit.}

\section{a. Begriff.}

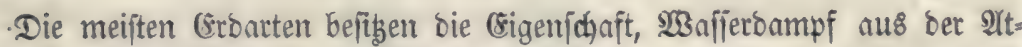
mojphäre aufzunefymen uno an ifrer Dberfläche zu berbidaten. Nad) allgemein

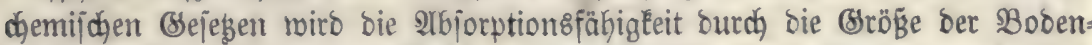
benoberfläche, mit andern $230 r t e n$, Durch Den Grab ber Zertheilung, in rel= dhem bie Erofrume fid, befinbet, bebingt.

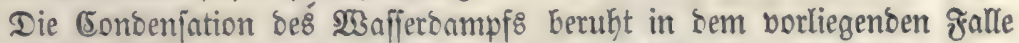

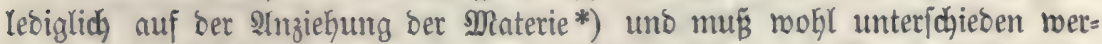

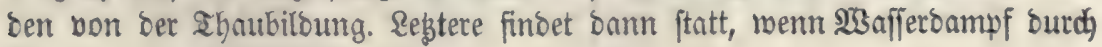

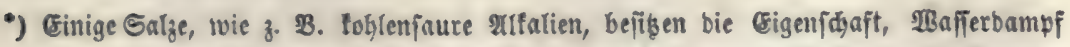
anzugieben unb benielben, nabbem ex fich berbihtet gat, feftzubalten. Sic fommen aber in ben meijten Böben nur jęr fpärliđ vor, fo baj̃ bie @röße ber Abjorptions. fähigleit burळ fie tณum merfliq geänbett werben fann. 
Berüfrung mit Eältern Sïrpern in feiner Iemperatur Kernbgeftimmt unb ba= burch berbichtet wiro.

\section{b. Mretjobe zur unferidjung.}

Man breitet bie getrodthete (srbe auf einer Scheibe a b aus, weldhe über Æig. 69.

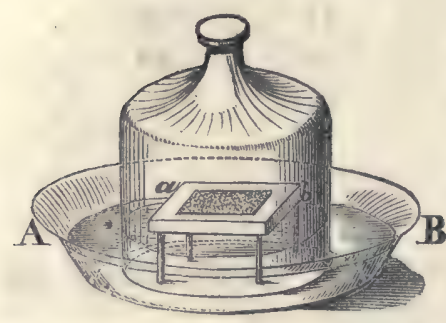
einem 23 afferbefälter A B auf rrägern ruht. Heber bie Scheibe mirb eine Brlngglode geftülpt, welche noch in bas $\mathfrak{B a f f e r}$ Ginein reicht. Die Eroe roiro vor bem Berjuche uno nach VIblauf einer gemiffen Stundenzahl ges rogen; bie Ssemichtszunahme gibt bie Menge bes abforbirten $\mathfrak{2}$ affers an. Der Berjuch muf́, menn er praftifacte sBebeutung Gaben foll, bei gemöhnlidyer remperatur $\left(15-20^{\circ}\right)$

vorgenommen werben.

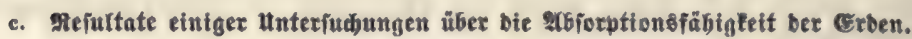

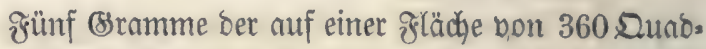
ratcentimeter aubgebreiteten Broe abjorbirten in 12 Stunden 24 Stumben 48 Stunben 72 Stunoen

Eroarten.

\section{Quarzand}

Silejano

(3)ps, gepulbert

Thon, mit $45 \frac{0}{0}$ Sand

IGon, mit $24 \frac{0}{0}$ Sand

FYon, mit $10 \frac{0}{0}$ Sand

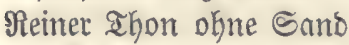

Geiner foblenjaurer sialf

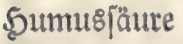

Sartenerbe

2Cüererbe

Sdjiefriger Mergel

\section{Eentigramme.}

$\begin{array}{rrrr}0,0 & 0,0 & 0,0 & 0,0 \\ 1,0 & 1,5 & 1,5 & 1,5 \\ 0,5 & 0,5 & 0,5 & 0,5 \\ 10,5 & 13,0 & 14,0 & 14,0 \\ 12,5 & 15,0 & 17,0 & 17,5 \\ 15,0 & 18,0 & 20,0 & 20,5 \\ 18,5 & 21,0 & 24,0 & 24,5 \\ 13,0 & 15,5 & 17,5 & 17,5 \\ 40,0 & 48,5 & 55,0 & 60,0 \\ 17,5 & 22,5 & 25,0 & 26,0 \\ 8,0 & 11,5 & 11,5 & 11,5 \\ 12,0 & 14,5 & 15,5 & 15,8\end{array}$

d. Disluffion biefer sifultate.

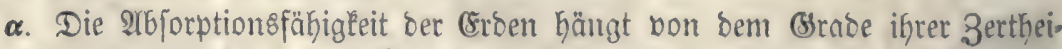

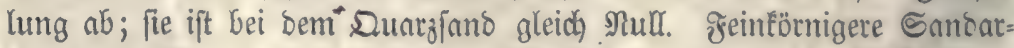
ten (zu weld)en ber bei ben obigen Berjuchen angenante Salfjarto ge=

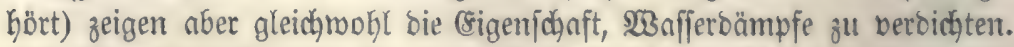

B. Die 2rfforption ift beim $B$ eginn bes Berjuct)s am ftärfften; fie nimmt bann fortwähtend $a b$ unt ift nach) einigen angen beenbigt. W3erben bie

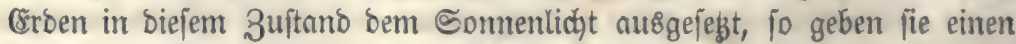
Iheil ber aufgenommenen greudigtigleit wieber ab. 


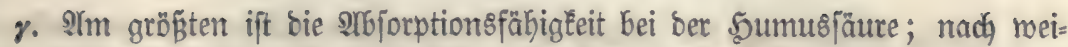
teren Berjutchen ift fie indeffen für ben gemöhnlichen erbigen 5umus

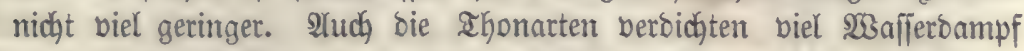
an ifyer Dberflädje. Shnnen fteft in biejer Seinficht ber feine kohlemjaure Sale uno ber jofiefrige Mergel ziemlich nake, rähreno ber gepulberte (Syps mehr mit Den Canbarten übereinfommt.

\section{E. Craffification bes 20 o}

Man nennt ben 2 boden

a. Sürr, ment er, zerrieben, bei \&uftzug ftaubt. Die geringe žeudtigteits=

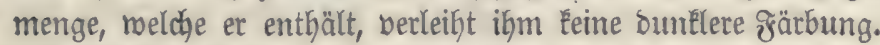

b. troden, wenn er zroar nidft ftabt, aber audh Eeine buntlere färbung befitgt.

c. frifd, went er beim 3ujammenorücten in ber Santo Spuren von

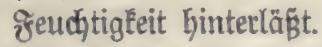

d. feudbt, menn bas $23 a f f e r$ beim $3 u$ ammenorücfen tropfenmeije $a b=$ fliefit.

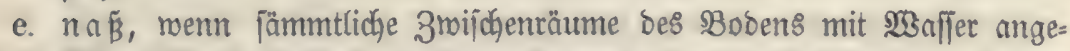
fülut find, fo Daß̧ es bon einet Kerausgenommenen Sdyolle burdh fein

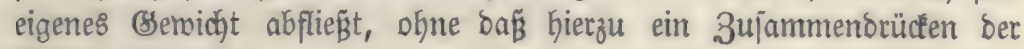
orroe nöthig twäte.

\section{2Bärme be פoben}

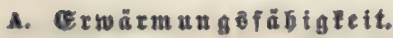

\section{a. Begriff.}

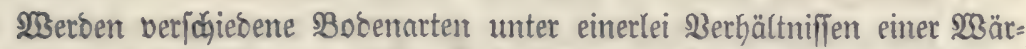
mequelle, z. B. ben Sonnenjtrablent, ausgejebt, fo nebmen biejelben nidht alle bie nämliche remperatur an. Şe höher eine (Eroart bei gegebener Tempera= tur fich ermärmt, um jo größ̈er ift if̧e "(srroärmungsfähigleit".

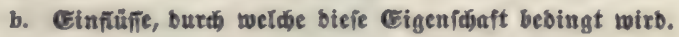

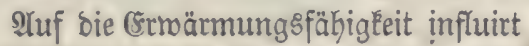

$\boldsymbol{\alpha}$. Die [pecifijめe $\mathfrak{B a ̈ r m e}$ jeber Eront. Man verfteht unter jener bieje= nige $2 \mathfrak{B a ̈ r m e j u m m e , ~ m e l d h e ~ n o ̈ t h i g ~ i f t , ~ u m ~ b i e ~ T e m p e r a t u r ~ b e r ~ ( s i n f e i t ~}$ bes Bolums, ober bes Bemidgts Groe um 1 Brab zu erhöhen. Llebri= gens iit ber Unterjđjed in ber fpecifichen 2 särme ber Bobenarten fo

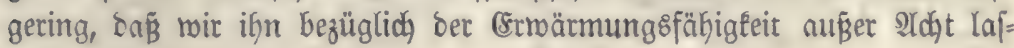
fen tönnen.

ק. Die §arbe bes Bobenళ.

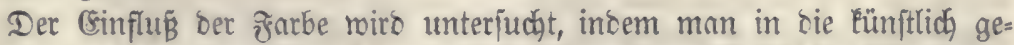

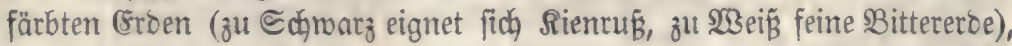
Thermometer eingräbt und an biejen die Iemperaturerhöhung, melche Die Sonnenftrablen bewirken, beobadhtet.

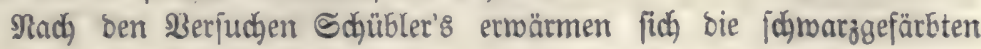




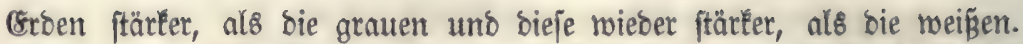
Die Iemperaturunterfichiebe biejer brei Farben betragen 1-8 Brabe. W3erben bie ver/dyieben gefärbten (8rben aud) ftunbentang bem Sonnen= licht ausgejest, fo erreidhen fie bod nie biejelbe Iemperatur; bie Keller= gefärbten (stoen bleiben immer kubler, währeno bie fdymarzgefärbten fid) am meiften erhigen.

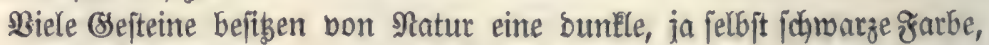

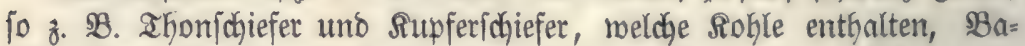

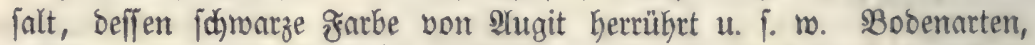

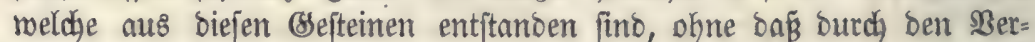

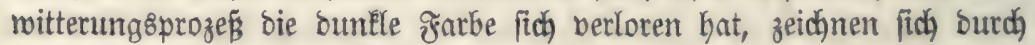

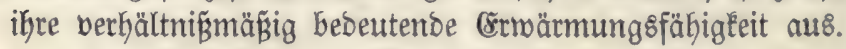

$\boldsymbol{\gamma}$. Die Fe uthtigeit bes 28 Dents.

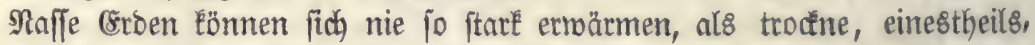

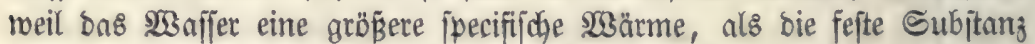
bes ßobens befipt, anterntbeils aber aud beshalb, weil ein Iheil der

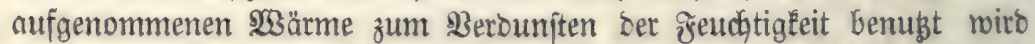
uno beshalb für bie (Errärmung bes Bobens verloren geht. Die burch) die Berounjtung des 23 nffers entiptehende בemperaturetmebrigung bet naffen Crobe gegenüber ber trodfenen beträgt 5-7 (Srabe. Sietaus geht

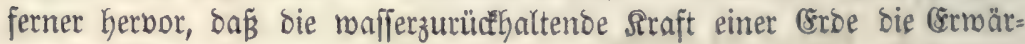
mungళ्f̣ähigkeit beeinträhtigt.

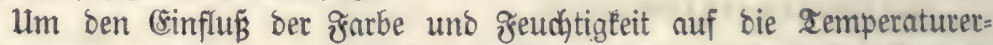
böhung ber (rrben zu ermitteln, brad)te Schübler biejelben in rsefäb̆e von 4 Quabratzoll Dberflädhe unt $\frac{1}{2}$ 3oll riefe uno jegte fie, theils künftlid) gefärbt, theils mit Belaffung ihrer natürlid)en zarbe, in naffem uno trodenem 3uftonto bem Sommenlicht aus. Die Berjudge murben

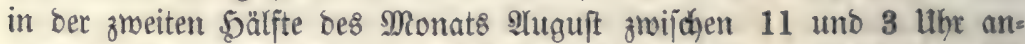
geftellt, währeno bie Zemperatur ber \&uft im Sdhatten grwijdhen $22^{\circ}$ bis $25^{\circ}$ wechjelte.

Eroarten:

Duarzano, hellgelblichgrau

Raléfano, meiśliç)grau

(5np8, reiß̈grau

ahon, mit $45 \frac{8}{0}$ Sand, getblidy 36,7

Ihon, mit 24: Sano, gelblid 37,2

Reinet Ihon, ohne Sand,

gelblichgrau

Bläulichgrauer Ifon (mit
37,4

37,4
Temperaturmarima ber oberften Crojidjidte bei natürtiç gefärbter Dberfläche, nafle Erose trodne Corbe.

$\begin{array}{ll}37,2 & 44,7 \\ 37,4 & 44,5 \\ 36,2 & 43,6 \\ 36,7 & 44,1 \\ 37,2 & 44,5\end{array}$
bei troufenter Groe, bei weiker, johwarzer Dberfläctse.

$43,2 \quad 50,9$

$43,2 \quad 51,1$

$43,5 \quad 51,2$

$42,4 \quad 49,7$

$42,1 \quad 49,5$

$10 \%$ Sand)
44,6

44,6

$41,9 \quad 49,1$ 


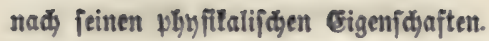

\begin{tabular}{|c|c|c|c|}
\hline Salf, weî́ & 35,6 & 43,6 & 43,1 \\
\hline 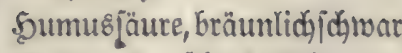 & 39,7 & 47,4 & 42,5 \\
\hline Gartenerde, fđjwärzlichgrau & 37,5 & 45,2 & 42,4 \\
\hline Alcfererbe, grau & 36,9 & 44,2 & 42,0 \\
\hline $\begin{array}{l}\text { Schiefriger Mergel, bräun= } \\
\text { lid,troth }\end{array}$ & 38,7 & 46,2 & 42,4 \\
\hline
\end{tabular}

d. Die $\mathbb{R} a g e$.

Den Cinflußi ber geographijden Ränge uno Breite, jo wie ber Meere\&. höhe auf bie (trwärmung bes Bobens werben wir fpäter abhandeln uno hier nur bie (Strpofition unt Alboachung Gerünffichtigen.

Die Intenfität ber (Ermärmung einer Fläd)e burd) bie Sonnenftrah)= len ift bem ๔inus bes 2 Binféts proportional, unter weldgem biefe Strab)= len bie glädhe treffen.

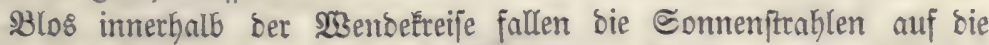
Sorizontalebene jentrect)t auf; in allen übrigen ßreiten nefmen fie eine

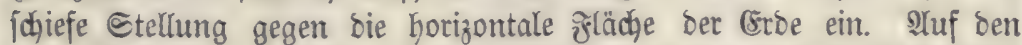
Seitenflädhen ber Şügel uno Berge bngegent fallen die Eomnenftrablen meniger fodief auf; ja fie fönnen, je uach Ler Sahres= unt Ingeszeit

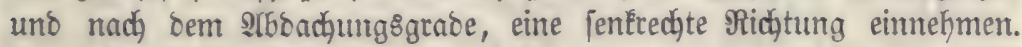
Sn ber Mitte bes Commers fteft bie Sonme gegen 12 uhr ungefähr $60^{\circ}$ über bem Sorizont; Gat nun eite Bergmanto eine Arbbadhung bon 30 Braben, po roirb fie surd, die Sonnenftrahlen in einem rechten $23 i n=$ ซig. 70.

fel getroffen. (ङ̈ig. 70.) Dieję Berbältniß̈ finbet bei freileren (Eint)ängen aud jĭgon im

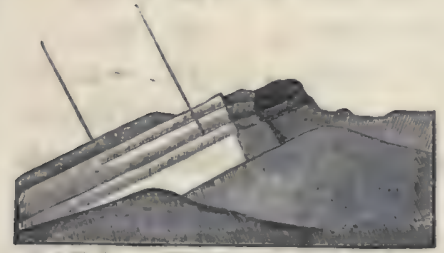
Borjommer und nod im Nadjommer ftatt. Sübjeiten (reine ๔üb=, Sübojt= und Sübrweft=

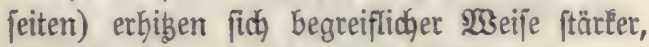

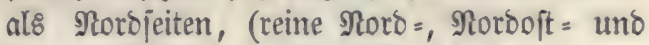

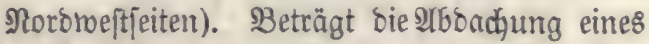
nördliçen Cintyangs $60^{\circ}$, jo wirb bie (8rbe, menn bie Conne $60^{\circ}$ über bem Sorizont fteht, eben nur bon ben Sonnenftrahlen rafitt, bei tieferent Stano ber Sonne aber gar nidat mehr bon beren Strahlen getroffen. Sm $23 i n t e r$, menn bie Conne oft nur $20^{\circ}$ über ben Soorizont fich erhebt, erf̧alten rein nörolidje

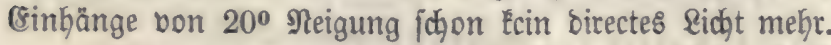

\section{B. 2ärmebaltenbe firaft ber Erben.}

\section{a. 23 egriff.}

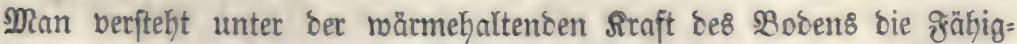
feit beffelben, nad) erfolgter Etroärmung bie angenommene Zemperatur längete 3eit fu bewatiren.

\section{b. Metbobe zur tnterfudjung ber wärmebaltenten straft.}

Dieje beftefht ganz einfach barin, baß̈ man gleidje Bolumina (z. $\mathfrak{B}$. Srismen) ber (Erben anfertigt, fie erroärmt unb burdh ein in bie zu prüfente 
(Erbe tauthenoes ahermometer bie Temperaturabnabme neben ber Zeit, imer= Galb weldyer biefelbe erfolgt, beobaditet.

\section{c. Meiultate.}

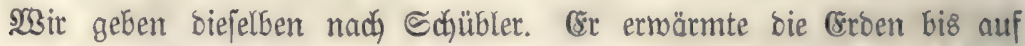
$62^{\circ}, 5$ und beobachtete in einem geidhloffenen 3immer bie Zeit, weldye fie be= burften, um bis auf $21^{0}, 2$ fich abzufühlen; bie remperatur ber suft in bem 3immer betrug $16^{\circ}, 2$. Die croen murben in blecherne Befäpe bon $595 \Omega$ biécentimeter Jinfalt gebradat.

23 ärmehaltenoe Ränge ber 3eit, mährento meldher Sraft, bie bes 595 Subitecentimeter fich bon Raléfandes $62^{0,5}$ bis auf $21 \%, 2$ abeühlten, $=100$ gejest. renn bie Temperatur ber umge=

Eroarten.

Saltéand

Quarziano

(3ips, gepulbert

Ifon, mit $45 \frac{0}{6}$ Sano

Thon, mit $24 \%$ Sand

Ifon, mit $10 \frac{0}{0}$ Sano

Seiner Ifon, ofne Sano

Zeiner fohlenj. Salt

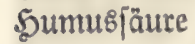

Sartenerbe

श्रctererde

Sdyiefriger Mergel
100,0

95,6

73,8

76,9

71,8

68,4

66,7

61,3

49,0

64,8

70,1

98,1 benten \&uft $=16^{0}, 2$ betrug.

3 Stunoen 30 Minuter.

\begin{tabular}{|c|c|c|}
\hline 3 & " & 20 \\
\hline 2 & " & 34 \\
\hline 2 & $"$ & 41 \\
\hline 2 & " & 30 \\
\hline 2 & " & 24 \\
\hline 2 & $"$ & 19 \\
\hline 2 & " & 10 \\
\hline 1 & " & 43 \\
\hline 2 & "' & 16 \\
\hline 2 & $"$ & 27 \\
\hline 3 & " & 26 \\
\hline
\end{tabular}

\section{d. Discufítion biefer Mejultate.}

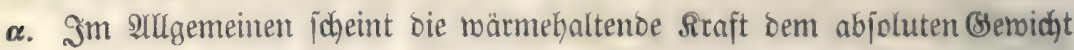
Der Eroen proportional zu jein.

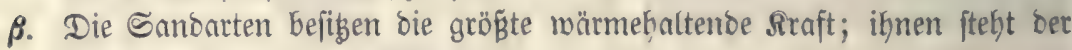
fdiefrige Mergel am nädjiten.

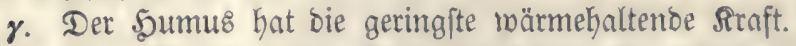

d. Die wärmebaltende Sinft ber Thone ift geringer, als bie bes Canbes, aber größ̈er, ats bie bes รృumus.

\section{Sonitige (E⿱一𫝀)}

23on biejen berbienen genannt zu merben bas galbanif

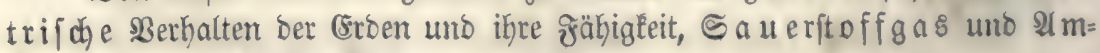
monia $\mathfrak{k}$ an ifhrer Dberfläche zu berbichten.

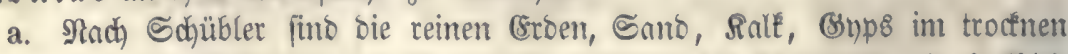

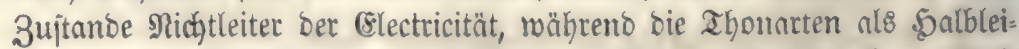
ter uno bie zujammengejesten thonhaltigen (Eroen als johroad)e Salblei=

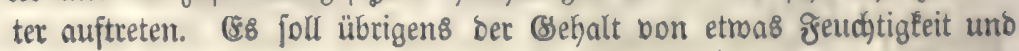




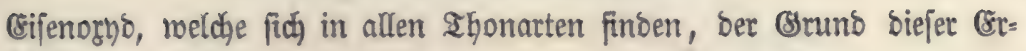
idgeinung jein.

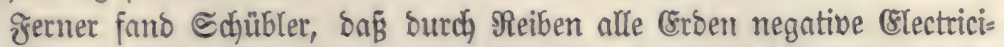
tăt entroidéln, reenn man trodfene länglidje Stüdfe berjelben mit einem Meffer fodabt und bie feinen abjpringenden aheildyen unmittelbar auf bie

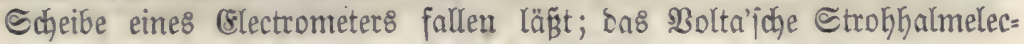
trometer zeigte bei biejem Berfahren gewöhnlich Divergenzen von $4-5$ Braben. (sis, auf biejelbe 2lrt behandelt, gab pofitive Electricität.

b. Im naffen 3ujtand befigen alle Erbarten bie Eigenjofaft, Sauer ft off=

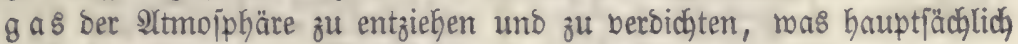
auf einer djemijhen Berwandtid)aft bes Drygens zu mefreren Beftano= theilen ber (Eroen (Sumus, (sijen= uno Manganorybul), aber auch auf

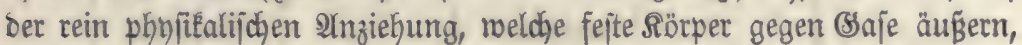
beruben fann.

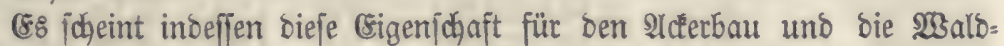
mirthjdjaft obne \$Bebeutung zu jein.

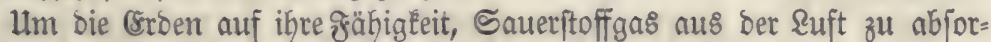
biren, zu prüfen, brachte Sdjübler biejelben in mäß̊ig befeuchtetem $3 \mathrm{u}=$ ftanbe in gläjerne Flajchen. Nadybem lestere mehrere Tage einer Semperatur von $15^{\circ}-18^{\circ}$ ausgejeßzt roaren, unterjuchte Sdaübler bie suft in ben glajken auf ifren Sauerftoffgehalt. (5r fand

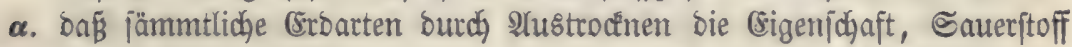
z̆ abforbiren, einbüfen.

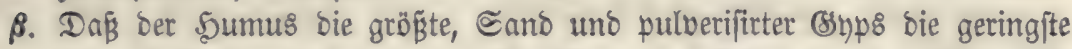
Eauerfoffabjorption zeigen. Die Ihonarten ftehen in ber Mitte zroi= iohen Sand und Sumus; fie abjorbiren um fo mehr Saueritoff, je we= niger Sand ihnen beigemengt ift.

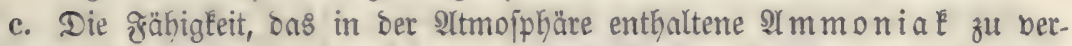
bidgten, ift vorzüglid, bem Ihon, Dem Mergel uno bem Sumus eigen.

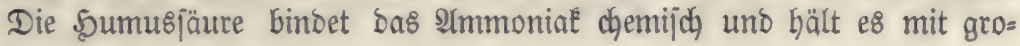
fer Begierbe feft.

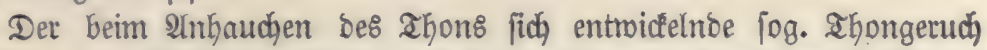

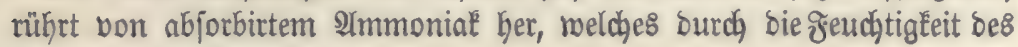
2tḩems ausgetrieben wirø.

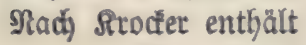

Mergel $\frac{5}{100 \sigma}$ bis $\frac{1}{10}$ Prozent Ammoniat,

Sehm $\frac{104}{1000}$ bis $\frac{170}{1000} "$ " "

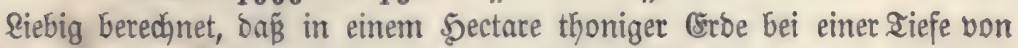
25 Eentimetern 10000 Silogramme, in einem ganz fanbigen Terrain bagegen nod) über 2000 Rilogramme reines 92 mmonial enthalten fint. 


\section{Bujammenftellung ber Rejultate, zu weldyen bie Unterjudjungen}

\begin{tabular}{|c|c|c|c|c|c|c|c|}
\hline \multirow[b]{2}{*}{ Grbarten. } & \multirow{2}{*}{$\begin{array}{l}\text { Epecififdies } \\
\text { Ectidit. } \\
\text { wafier =1 }\end{array}$} & \multirow{2}{*}{ 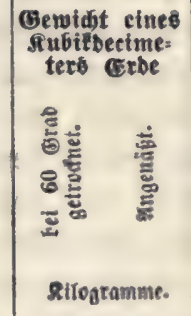 } & \multirow{2}{*}{$\begin{array}{l}\text { Oeftiglett im } \\
\text { trofnent guftand } \\
\text { bie bes ghuns } \\
100 \text { gefeßt. }\end{array}$} & \multirow{2}{*}{\multicolumn{2}{|c|}{ 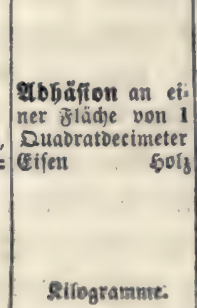 }} & \multicolumn{2}{|c|}{$\begin{array}{l}\text { Bolumblvernin } \\
\text { Derung burd } \\
\text { Gubtrodnen. } \\
1000 \text { Paumtheife }\end{array}$} \\
\hline & & & & & & 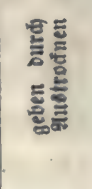 & 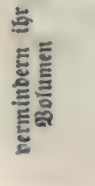 \\
\hline Suarziand & 2,653 & $2,044 \quad 2,494$ & 0,0 & 0,17 & 0,19 & 1000 & 0 \\
\hline $\begin{array}{l}\text { Sarkjano } \\
\text { shon mit } 45 \frac{0}{0}\end{array}$ & 2,722 & $2,085 \quad 2,605$ & 0,0 & 0,19 & 0,20 & 1000 & 0 \\
\hline $\begin{array}{c}\text { Sano } \\
\text { Shon mit } 248\end{array}$ & 2,601 & $1,7992,386$ & 57,3 & 0,35 & 0,40 & 940 & 60 \\
\hline $\begin{array}{l}\text { Sand } \\
\text { Shon mit 10: }\end{array}$ & 2,581 & $1,621 \quad 2,194$ & 68,8 & 0,48 & 0,52 & 911 & 89 \\
\hline $\begin{array}{l}\text { Sand } \\
\text { Reiner Ihon }\end{array}$ & 2,560 & $1,4232,156$ & 83,3 & 0,78 & 0,86 & 866 & 114 \\
\hline $\begin{array}{l}\text { obne } \text { ธand } \\
\text { ofeiner Eoblen= }\end{array}$ & 2,533 & $1,3762,126$ & 100,0 & 1,22 & 1,32 & 817 & 183 \\
\hline $\begin{array}{l}\text { faurer Ralé } \\
\text { (Sepulvertet }\end{array}$ & 2,468 & $1,006 \quad 1,758$ & 5,0 & 0,65 & 0,71 & 950 & 50 \\
\hline (S)p8 & 2,331 & $1,6762,350$ & 7,3 & 0,49 & 0,53 & 1000 & 0 \\
\hline $\begin{array}{l}\text { 5umısfäure } \\
\text { Бेchiefriger }\end{array}$ & 1,370 & $0,632 \quad 1,428$ & 8,7 & 0,40 & 0,42 & 800 & 200 \\
\hline Ḿpergel & 2,613 & $2,048 \quad 2,600$ & 23,0 & 0,22 & 0,25 & 965 & 95 \\
\hline $\begin{array}{l}\text { Gartenerbe } \\
\text { Qdaterbe }\end{array}$ & $\begin{array}{l}2,332 \\
2,401\end{array}$ & $\begin{array}{ll}1,449 & 1,744 \\
1,537 & 2,810\end{array}$ & $\begin{array}{r}7,6 \\
33,0\end{array}$ & $\begin{array}{l}0,29 \\
0,26\end{array}$ & $\begin{array}{l}0,34 \\
0,28\end{array}$ & $\begin{array}{l}851 \\
880\end{array}$ & $\begin{array}{l}149 \\
120\end{array}$ \\
\hline & & & & & & & \\
\hline
\end{tabular}




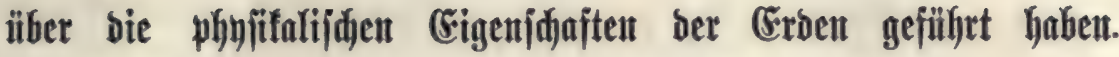

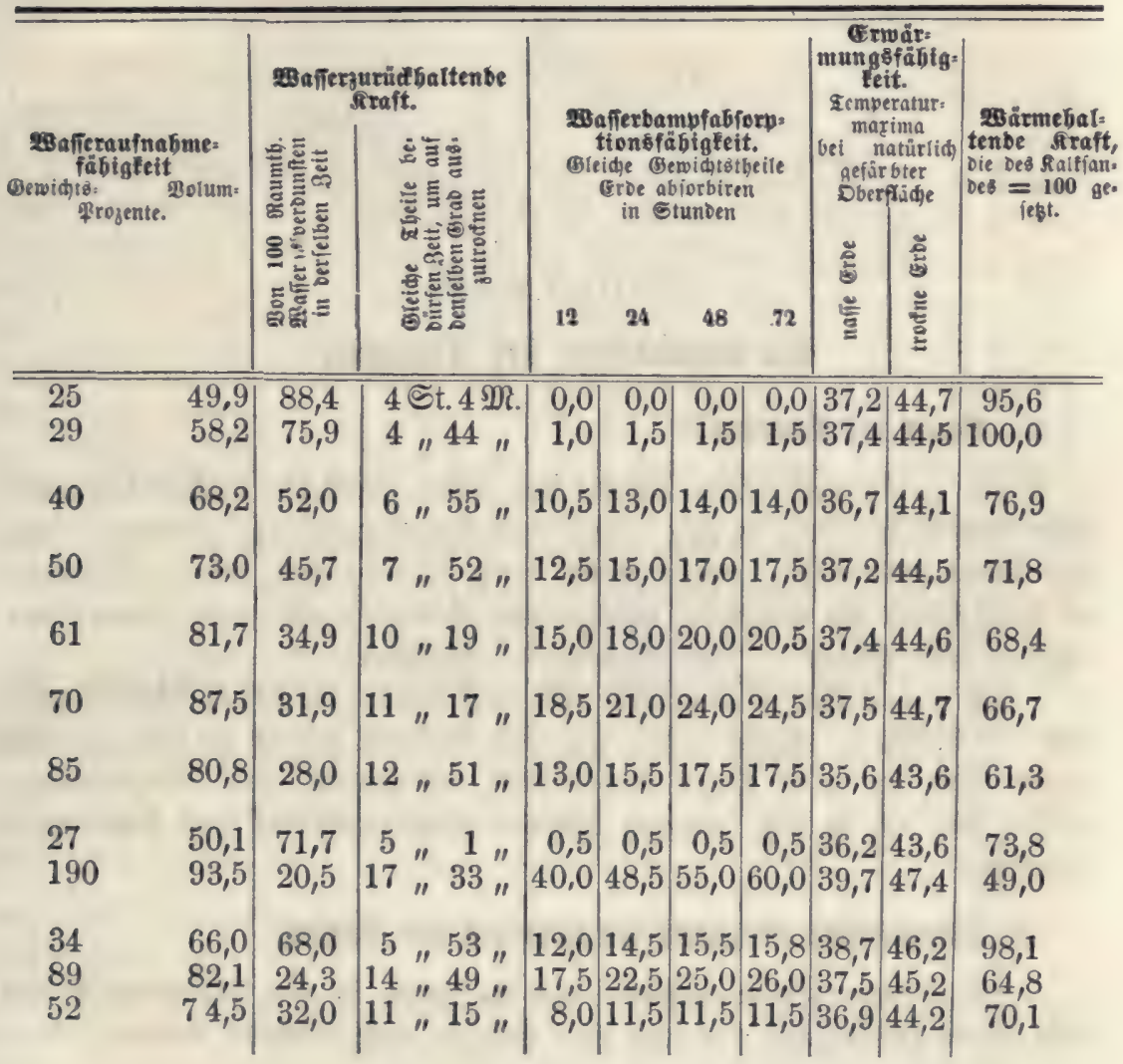


Drittes 23 ud.

\section{Die Beftanotheile ber Atmoiphäre.}

\section{Begriff von IXtmoiphyäre.}

Die gasförmige sülle, weldye ben feften (Erblörper umlleibet, nennt

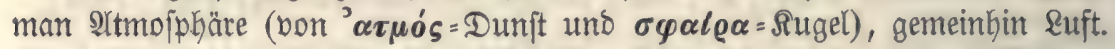
Sie bejteht aus Sajen (weldhe meber burch) Druck, noch burch Yrbtühlung

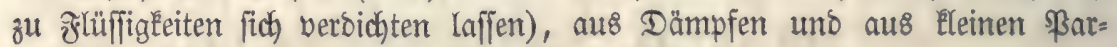
tifeldyen fefter Rörper - bem jogenannten \&uftftaub.

Die wejentlichen Beftanotheile ber Ruft billon bie beiden Baje Snuer=

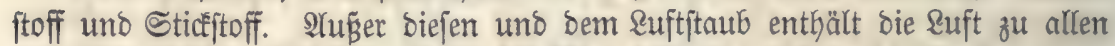

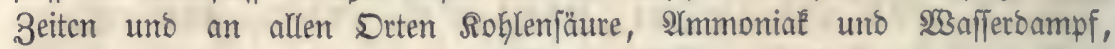
feltener uno nur in fehr getingen Mengen Sohlenwafferftoff und freies $2 \mathfrak{W a f =}$ jerftoffigas.

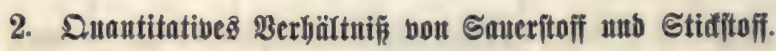

Die Menge bes Sauerftoffs uno Sticfftoffs in Der Ruft kann forobl

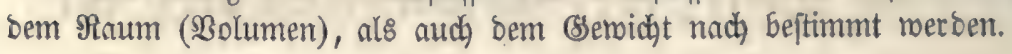

css fanien

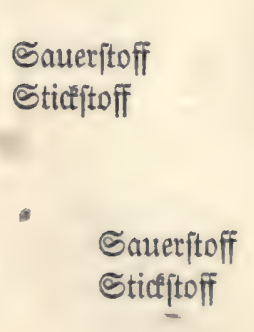

\begin{tabular}{|c|c|c|}
\hline ธณuโโนxe. & Brumnet & \\
\hline 21,05 & $78,07\}$ & Bolumtheile. \\
\hline 78,95 & $78,93\}$ & \\
\hline 100,00 & 100,00 & \\
\hline
\end{tabular}

Dumas unธ Bouाingault.

$$
\left.\begin{array}{r}
23,07 \\
76,93
\end{array}\right\} \text { Ssewichtstbeile. }
$$

Punbet man bie obigen Zablen auf ganze Stellen $a b$, fo ergibt fid bie 3ujammenjegung ber suft, wie folgt: 
Samertoff

Stiuftoff
In SRaumtbeiten

21

79 in Servichtstheilen

23

77

\section{0}

Die 3ujammenjebung ber \&uft joheint, was ifren Sauerjtoff = und Stid= ftoffgebalt anlangt, allermärts über bem fejten sanbe bie nämliche zu fein. (say) \&uffac fand bie bon feiner \&uftreije aus einer Söbe bon 21000 \$3ar. अuB̈en nitgebrachte \&uft gerabe jo bejhaffen, mie bie \&uft von \$aris. \&benjo

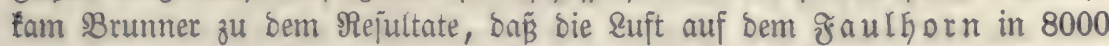

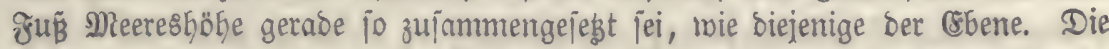
\&uft auf bem $\mathscr{Y}$ ntijana (in 16600 \$ar. §.) uno auf bem Mont (5eniø

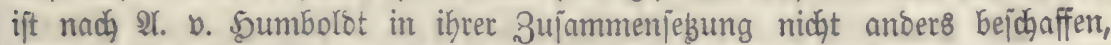

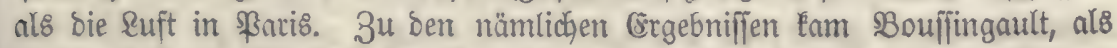

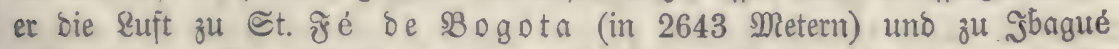
(1333 Meter Neeresb̆öhe) analnfirte; für Bogota fand er $20,65 \%$ und für

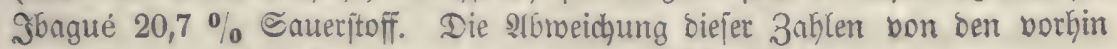
angegebenen liegt in ber (Stenze ber unvermeiblichen Jehler.

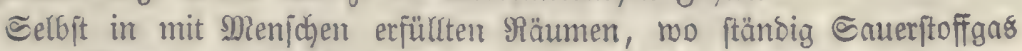

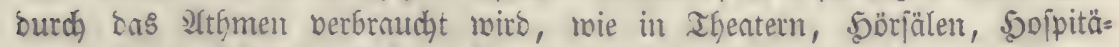

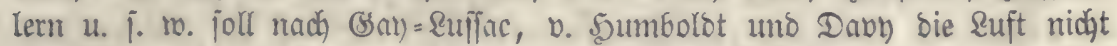

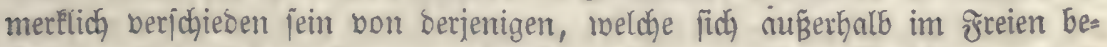

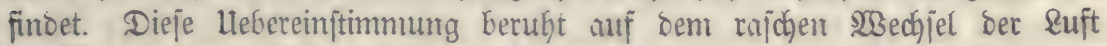

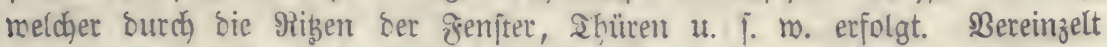

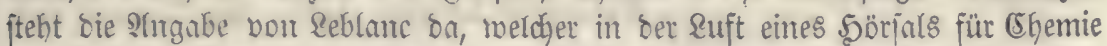

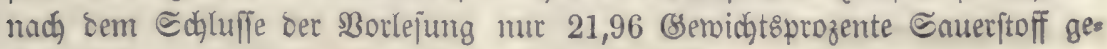
funben baben will.

Die in 23 a jer gelöjte Suft enthält $32 \%$ Sauerftoff uno $68 \%$

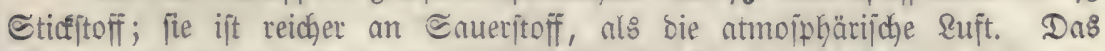

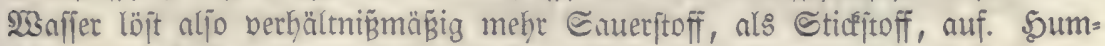
bolot uno (say)= \&uffac fanben

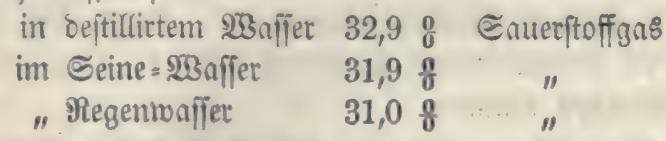

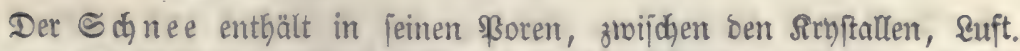

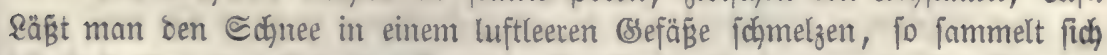
bie \&uft über bem Edhneemaijer an. Sauाँure, Sentebier uno Boufingault unterfuchten bie \&uft im Edfnee bon ben Arpen, bem Shimborazo uno im Edynee von ßaris, fie fanben mur 16-19\% Cauerftoff, was nicht auf=

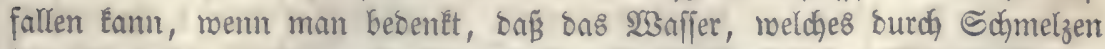

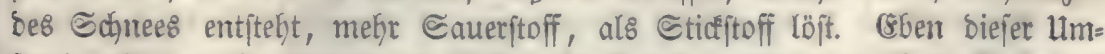

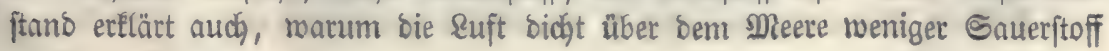




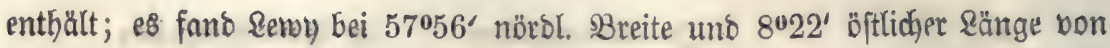
Baris nur 22,57 o Sauerftoff, bngegen bie \&uft in Ropentagen gerabe po

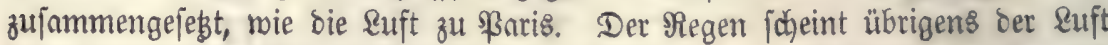
Feine beträchtlidge Menge Sauterftoff zu entzieken, menigftens fanoen Dumas und Bouffingault bie 3u[ammenfebung ber suft nach anhaltendem Negen ganz normat.

श्ud bie $\&$ uft über Sümpfen foll nidht meniger Saueritofi entbalten, als biejenige auf ben Bergen:

Die Bergleidung ber älteren suftanalyjen von Shanéro uno v. Sums Bolot mit Den neuern bon Dumas uno Bouffingault hat ergeben, Dañ bas

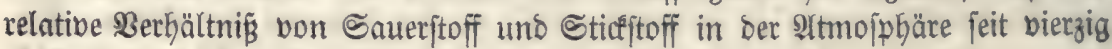
Jahren fich nidjt geänoert hat.

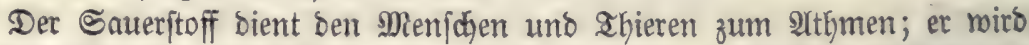
außerbem von abgefforbenen Drganismen berbraucht, wenn bieje faulen ober vermefen. Den SBerluft, weldyen bie suft bierburch erleidet, gleidjt aber mieber

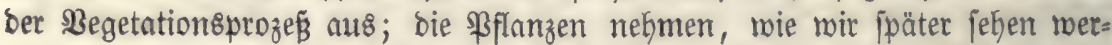

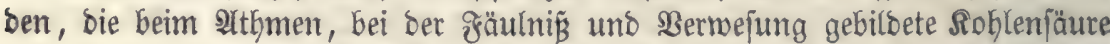

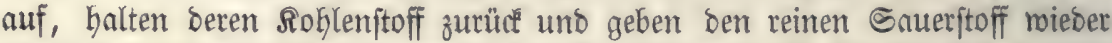
au8. Alber wenn felbjt ein Srjas bes Sauerjtoff's burch bie Begetation nicht

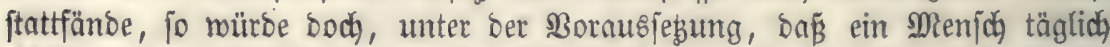

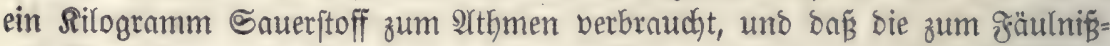
uno Berwejungsprozeß berwenbete Sauerjtofmenge bas breifache ber bon 1000 Millionen auf ber Crobe lebenden Menjchen betrüge, nach झlblauf eines Sahr= Gunberts bie \&uft nur $\frac{1}{134000}$ Sauerftoff berloren Gabe, mie Dumas mit

Sđărfe nadygemiejen hat.

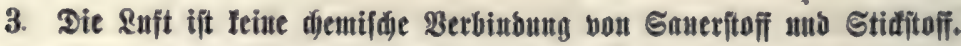

כ̧ü biejen ऽałs gibt e\& folgende Bemeije:

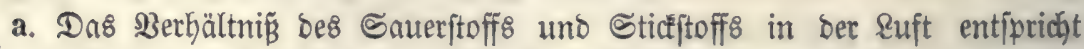
nidht ben dyemifosen ÂAequibalentenzahlen. Denn in biefem Falle müßsten auf 23 ssemichtstheile Sauerfoff nidht 77 , jonbern 40,48 Be= wichtstheile Sticfiftoff tommen.

b. Stellt man künftich ein semenge bon Saueritoff und Stiofitoff nach ben nämlidyen Berbältniffen her, wie bieje beiסen Braje in ber \&uft ent= Galten fins, fo erfolgt keine Bolumsverminberung, weldhe man bods ftet8 rahtnimmt, wenn żwei saje in einem anbern 20 bumtberbältniffe als von $1: 1$ fid verbinden.

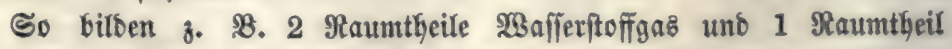

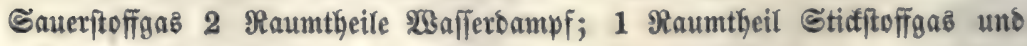

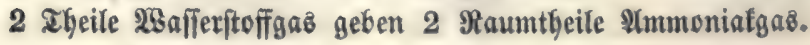




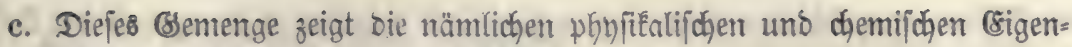

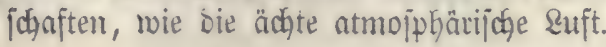

\section{Sohłeniäure.}

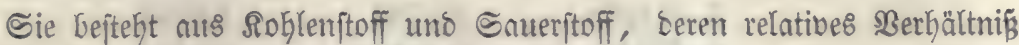

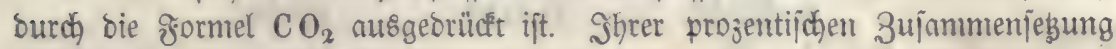
nadh enthält bie Soblenjäure:

$$
\begin{array}{r}
\text { Rohlenftoff } 27,27 \\
\text { Saueritof } \quad 72,73 \\
\hline 100,00
\end{array}
$$

Wenn Sauterftoff mit Rohlenftoff zu Sohlenfäure fich verbintot, fo nimmt

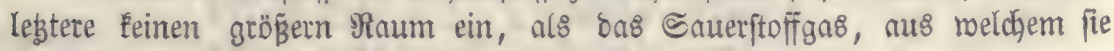
entftanten ift.

Die Roblenjäure ift bei gemöhnlichem \&uftoruct ein (sas. Ş̧r ipeci=

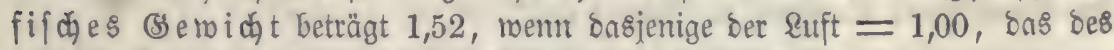
Saueritoff: $=1,1057$, bas bes stichitoffes $=0,972$ ift.

Bei einem Druck von 36 Itmojphären läğt fiç bie Sohlenjäure zu

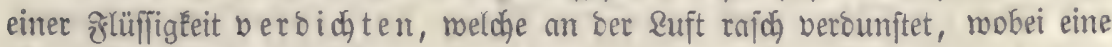
fdyneenrtige Maffe fid biloet.

Die Siohlenjäure lö ft fich in 2 Bnffer a uf. Diejes nimmt ftet\& bas gleidge Bolumen bon ihr auf, einerlei, ob siejelbe in sidytem ober bünutem 3uftanto fidh befindet. Berbichtet man bie Sohlenjäure burdh Drud (ohne fie in ben flüfligen 3ujtand zu bringent) uno löst fie bann in 2 Gaffer, fo enthält bies aljo um jo mehr bavon, je ftärfer ber angemendete Druc war. Bomfommen

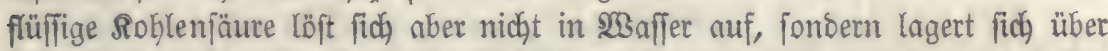
bemjerben, auch nach borkerigem હchütteln ab.

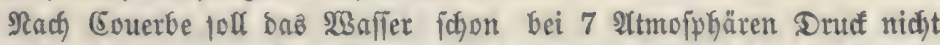

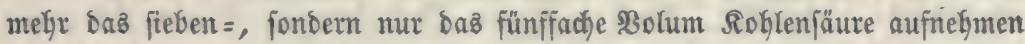
und überhaupt bei noch Gäherem Druct bie abjorbirte MRenge Säure immer fleiner ausfallen.

Die Siohlenjäure verbindet fich mit vielen şajen zu ๔alzen, bon benen

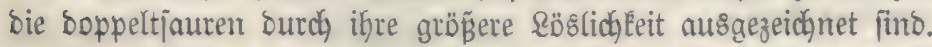

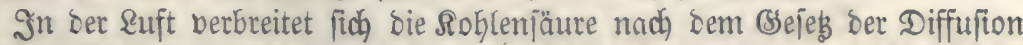
ber saje nach allen アrichtungent bint; obgleich fie jelbjt johlwerer, als bie \&uft ift, fo bringt fie bod) aufwärts bis zu ben beträchtlichften \$̧öhen.

Der Rohlenjäutegehalt ber \&uft ift übrigens vielfachent und fortwährenoen Sdjwankungen unterworfen.

अbends ift mehr Rohlenjäure in ber \&uft enthalten, als am $\mathfrak{M i t t a g e , ~ w a s ~ b a h e r ~ r u ̈ h r e n ~ m a g , ~ w e i l ~ m i t ~ b e m ~ B e r j d h i n d e n ~ b e s ~ h e l = ~}$

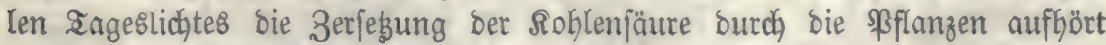

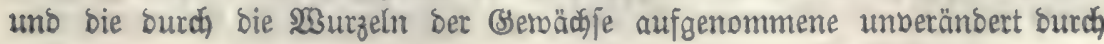




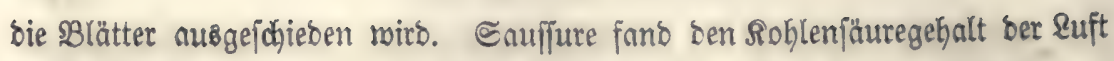
in Bolumprozenten :

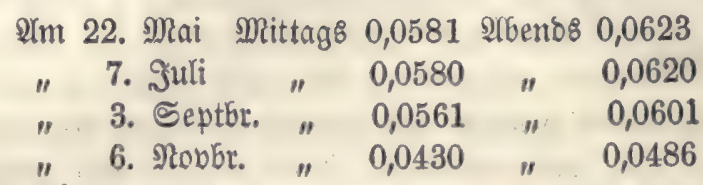

im Durchjßnitt wie $21: 23$.

gm Sommer enthärt bie suft mehr Sohleniăure, als im

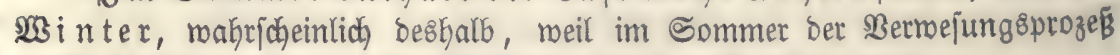
burch Die böhere Temperatur befdileunigt mird. Sauffure fand

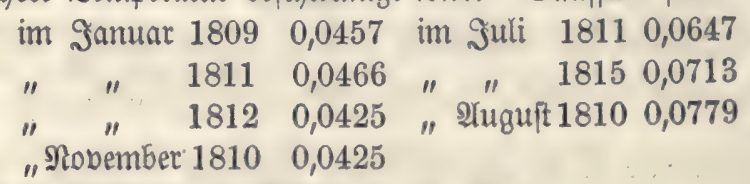

Im Durchfanitt Sommer zu $\mathfrak{\text { Binter }}=7: 6$.

Heber bem Meere bejibt die suft viel reniger Soblen.

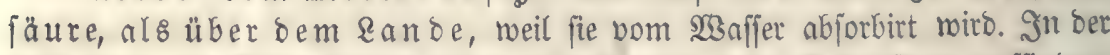
\&uft über ber Dftfee fonnte man nur Sputen bon Soblenjäure auffinden. Uleber bem atlantichen Dcean fan'́ Remy) Die Ruft bei Inge reicher an Soblen=

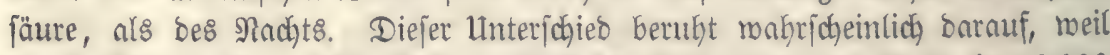
bie im Meerwaffer gelöfte \&uft mebr Sohlenfäure (12-19 Iheile in 10,000 Bolumtbeilen \&uft) entfält uno weil bei Iage burd) bie @onnenmärme etwas bon biejer 8 uft entbunbent wirb.

Die $\mathbb{R} u f t$ a uf Den Bergen enthält Rohlenjäure.

Dies beftätigen bie Unterjuchungen, melche Gaujfure mit \&uft angeftelit Gat, bie er auf Dem Montblanc fanmelte. Stud in ber von (Bay)= Ruffac bei

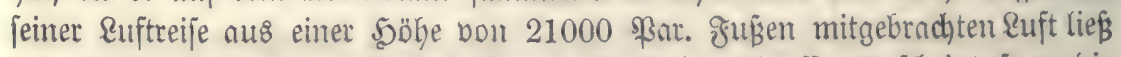

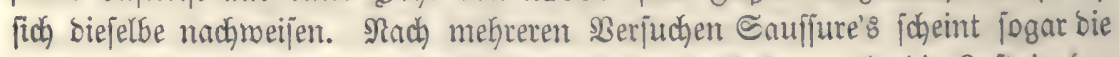
\&uft auf $B$ ergen etwas mehr Sohlenjäure zu entharten, als bie suft in ber (Sbene. Br fanto in Bolumprozenten

auf bem Col de Faucille $0,0443 \quad 0,0454 \quad 0,03690,0360 \quad 0,0422 \quad 0,0395$ (963) Meter über bem (senfer

$$
\text { See.) }
$$

zu Chambeisy

$\begin{array}{llllll}0,0414 & 0,0415 & 0,0387 & 0,0322 & 0,0355 & 0,0315\end{array}$

Die Gauffureichen (Erfabrungen funo in neueter Zeit burds Serot) und Schlagintweit beftätigt worden. (Srf̧terer fand

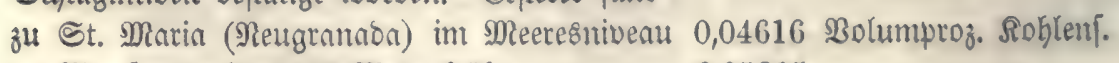

子̆ Monjerrate in 3193 Meter \$öbe . . . . 0,05215

3̆ Bogota "2645 " . .... 0, 0,04994

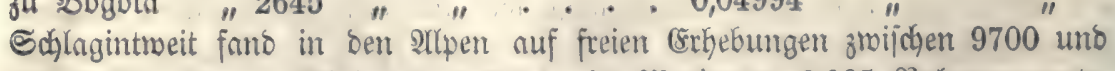

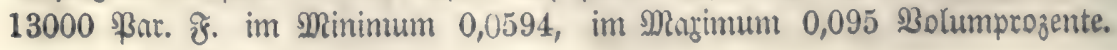




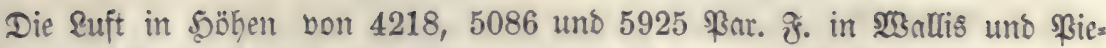
mont enthielt rejp. 0,0497, 0,0480, 0,0475 Bolumprozente Rohlenjäure.

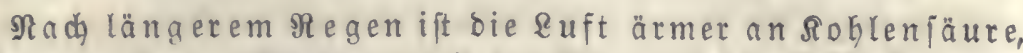
als bei trocenem 23 etter, reil bas Regenmaffer bie Rrhlenjäure auf= löft. Nach ftarl em $\mathfrak{i}$ ha foll bagegen bie relative Menge berfelben in ber

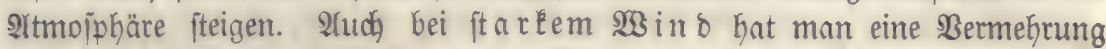
ঠ̣es Rohlemäuregehaltes der suft bemerkt.

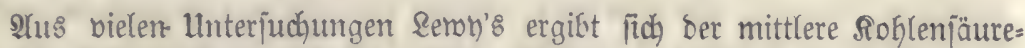

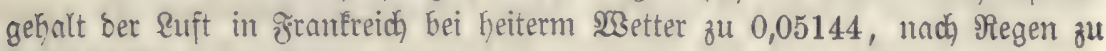
0,03586 Bolumprozenten.

Die \&uft in ben 3 rifdenräumen bes 30 bens ift reid an Iohlenjăure.

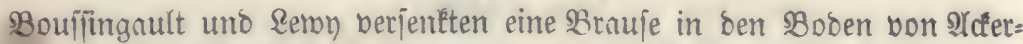
Iant 30-40 Eentimeter tief; bie Euft wutroe mittelft eintes langfam mirfents ben Alpirntors aufgejogen. Sie fanoen in terjelten 22 bis $23 \mathrm{mal}$ fo viel

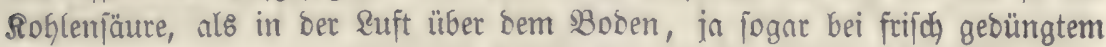
Ranbe $245 \mathrm{mal}$ jo biel.

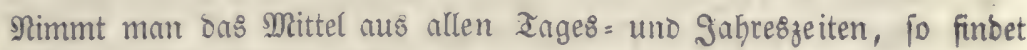
man, baß in 10000 aheilen Ruft

\section{Bolumtbeile uno \\ 8 Ssetwichtstbeile}

Sohlenjäure enthalten finઠ, was 0,05 Bolum $=$ uno 0,08 Semidhtsprozente ausmacht.

Q uellen ser $\Re$ oble njäure. Man muß́ ammehmen, baß̉ fohon zur 3eit ber Sraumadengruppe eine gemiffe Dunntität Soklenfäure ber Sitmojphäre eigenthümlich war, benn bamals gab es fichon Pflanzen, und bieje beburften

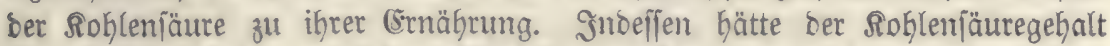

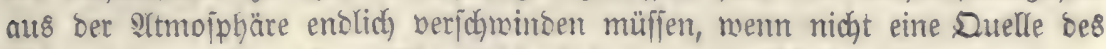

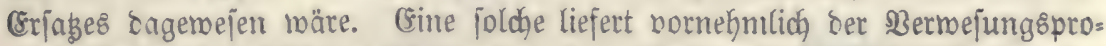

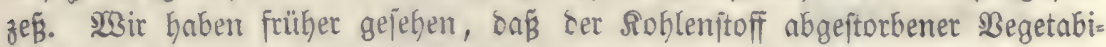
lien in Roblenjäure fid berwandelt.

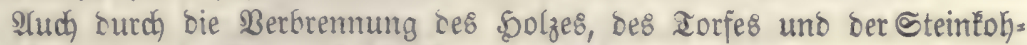
len wirb eine groß̉e Menge Rohlemäure ber \&uft zugeführt.

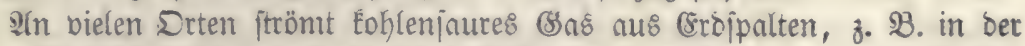

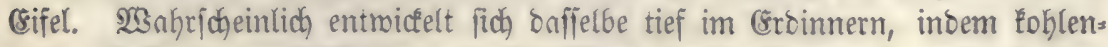

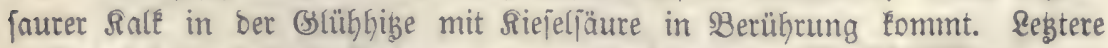

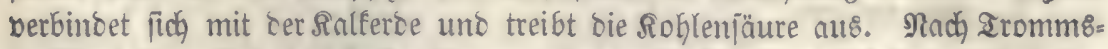

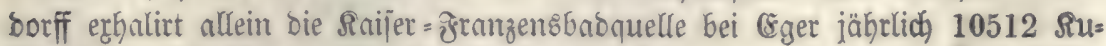

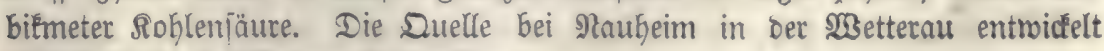
täglidh 3160 Rubiêmeter Rohlenjäure. 


\section{Tammonial.}

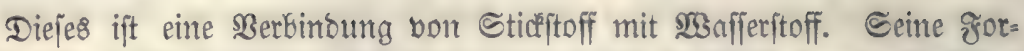
mel ift $\mathrm{NH}_{3}$. Es\& Eommt in ber Natur faft immer in Berfindung mit ๔äu= ren, bornefmilich mit Sohlenjäure - in legterem Falle als anderthalb Eoblen=

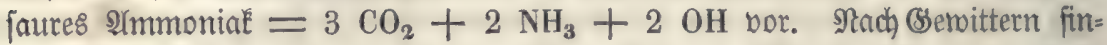
bet fich aud falpeterfaures âmmonine $=\mathrm{NO}_{5}+\mathrm{NH}_{3}+\mathrm{OH}$ in ber \&uft. (Es erzengt fich nämlich, menn bie Funken bes sitiges burch bie feuchte Ât= mojphäre folagen, Salpeterfäure, meldye fid mit bem Immoniak berbinoet.

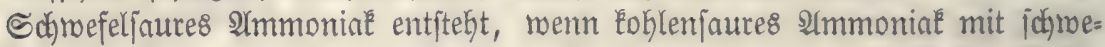
ferfauren Salzen, z. B. mit Syps, in Berülyrung Eommt. Die beiben sBajen taujd)en bann ifge Săttren um.

$$
\begin{aligned}
& \mathrm{SO}_{3}+\mathrm{CaO} \\
& \mathrm{CO}_{2}+\mathrm{NH}_{3} .
\end{aligned}
$$

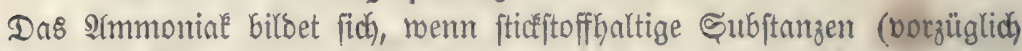

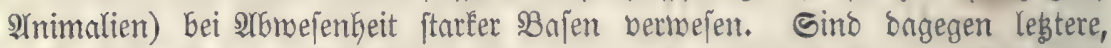

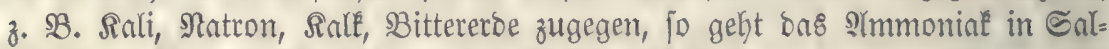
peterjäure über, weldye fich mit ben $\mathfrak{B}$ ajen berbinbet.

(sinige Riorper, wie Thon, Mergel, Şumut, fint nusgezeidnet befăfigt, श्ummonial an ifrer Dberflädhe zu verbichten.

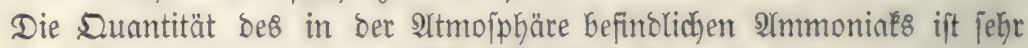
gering; nach Bräger foll in 100000 IGeilen Ruft 1 Theil Srmmonią ent= Galten jein.

Regen = unঠ Sdyneemoffer zeigt immer Spuren von 2Ymmonial. Das

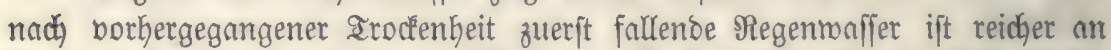

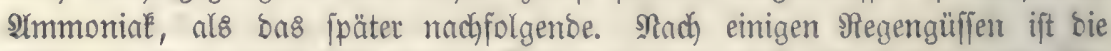

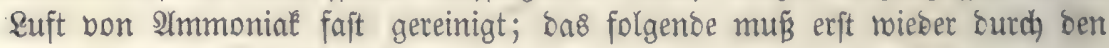
žäulniß̈prozeß́ geichaffen werben.

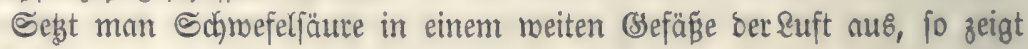
fie fich ballo ammoniallfaltig.

\section{2Banierbampf.}

Bon biefem merben wir päter, bei ber Bettadhtung Der Sybrometeore, ausfühyrlid Ganbeln. Borerft mollen mir mur bas bemerfen, bnß bie suft zu allen 3eiten uno an allen Drten $\mathfrak{B}$ afferbampf entfält. Ceine Dunntität medjelt aber mit arages = uno Sabreszeit unt ift nuch nach ber gengraphi= fhen \&änge uno Breite verjhieben.

\section{Salpeteriäure.}

Sie fintet fich borzüglid) mut nach (semittern in ber Altmoiphäre; bei biejen erzeugt fie fidh, mie früher fidon angegeben mutbe, bann, nem bet

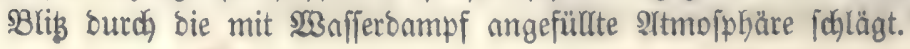


Die Duantität ber Salpeterjäure in ber \&uft ifit immer unbebeutenb uno

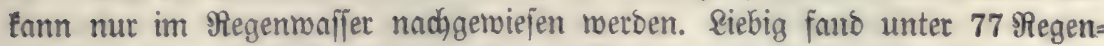
roaffern, bie in ber Nähe von Bief̧en nufgefangen rourben, mur 19 falpeter: fäurehaltig, bavon rührten 17 von (Semitterregen her. In ben ourdh häufige uno ftarfe Gemitter ausgezeidyneten 2(equinoctialgegenoen foll, nad, Bouffin= gault, bie \&uft reicher an freier Salpeterjäure jein.

\section{Suftitaub. (Ferolitgen.)}

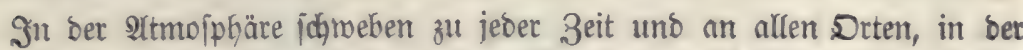
(Sbene uno auf ben Bipfeln ber Berge Hleine, nur bei ftarler Beleuchtung fichtbare feite \$artileldhen, weldhe nidhts anoers, als losigeriffene Theile bon

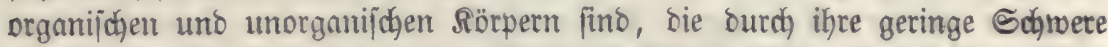

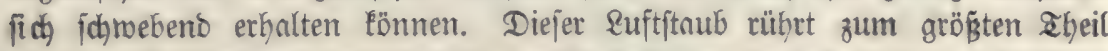

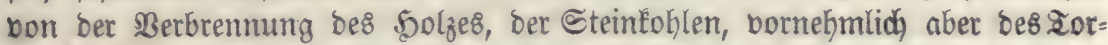
fes her. Durch ben \&uftzug, auf sojten beffen bie Berbrenmung ftattinoet,

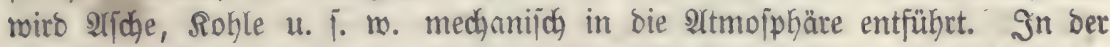

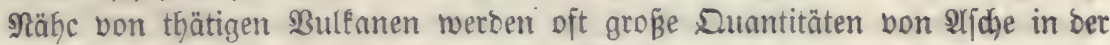
Iuft rahgrgenommen, bie bei ftarkem $\mathfrak{W}_{3}$ ino mitunter fefr weit transportirt metben. So trieb die গlf

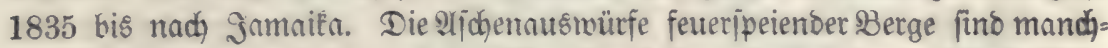

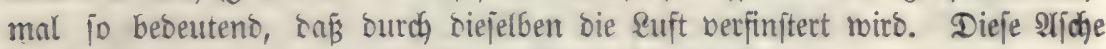
trägt mitunter zur Bobengeftaltung jefhr wejentlid) bei.

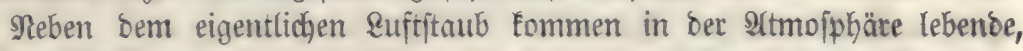

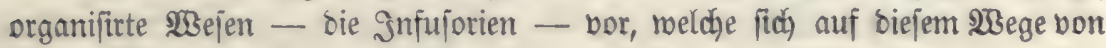
einem Drt zum anbern verbreiten.

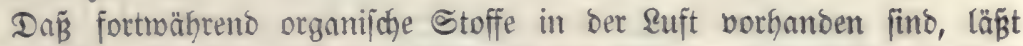

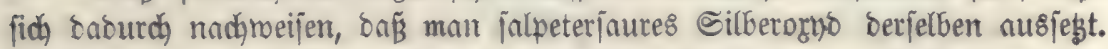

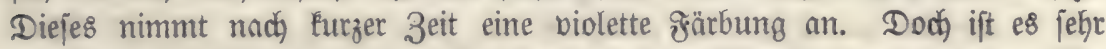

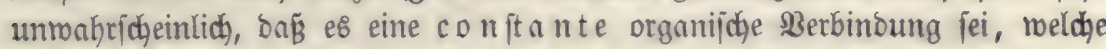

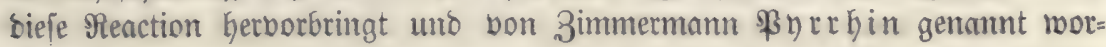
ben ijt.

Der nadytheilige (sinfluñ ber Sümpfe uno Moräjte auf bie Gefuntheit

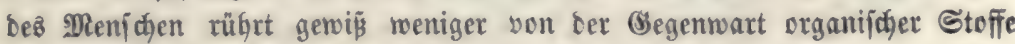

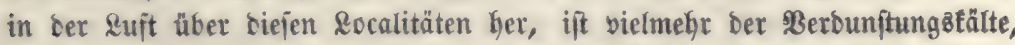
bie überall an ftehenten Bewäijern auftritt uno ber gró̈en DRenge Sohlen=

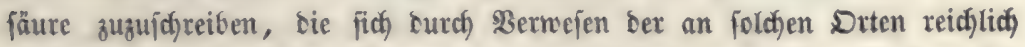
sorbanbenen organijidgen Rörper erzeugt uno bei mangelnbem \&uftzug fid anhäuft.

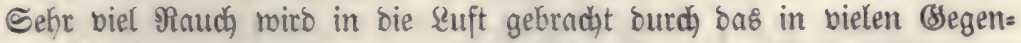

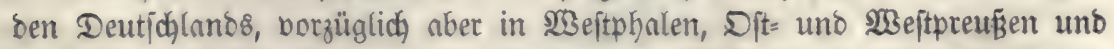
in Sollano übliche Bremten ber Iorfmoore. Sidjerlidy ift biejes bie ßeran=

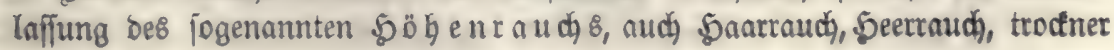


Nebel u. โ. m. genamnt. Sebermann Eennt biefe Brifheinung. Sie tritt ge= möhnlid im Borjommer ein. Bei heiterem $\mathfrak{B}$ etter uno nolkenlojem Simmel

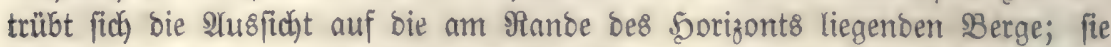
fehen aus, roie bon einem graugelben flor umzogen. Die Sonne fotheint

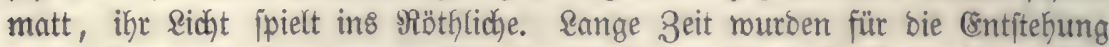

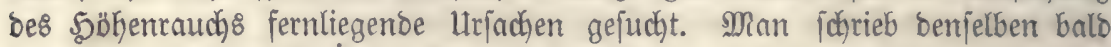

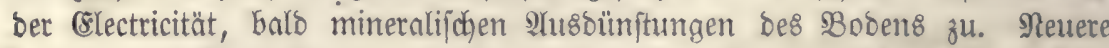

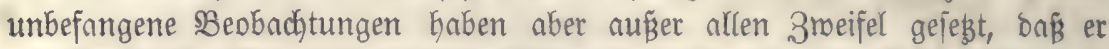

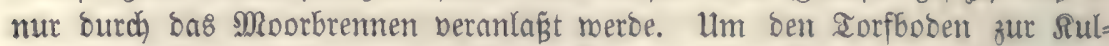

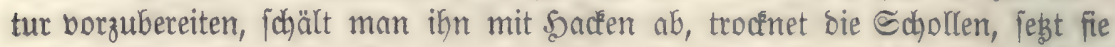
auf Saufen und zündet fie an, robei man ein BBrenten berjelben mit lidłter

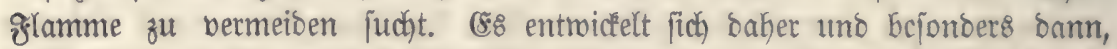

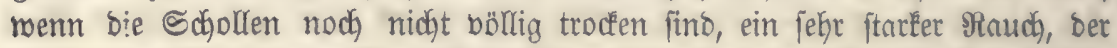

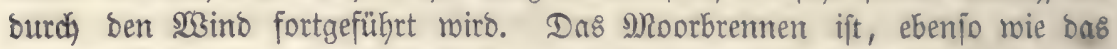
Hebertanobrennen uno Sdjmoren ber Sactroaloungen, fojon feit fefor langer 3eit üblid); in ben Sactmaldungen bes Doenmaldes 'Ennnte man es idjon

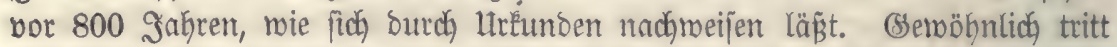

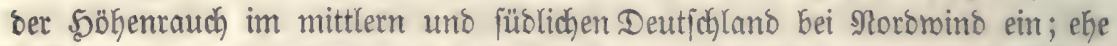
biejer zu rokhen angefangen hat, zündet man in ben Moorgegenden bie Schol= len nicht gern an, weil fie erft butch) Den Norbmino gebörig getrodenet nerben.

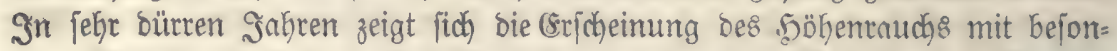
berer ๔tärke, meil bann das Moorbrennen borzugsmeije leicht bon હtatten

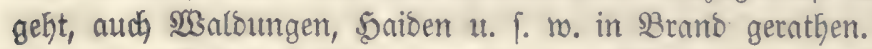

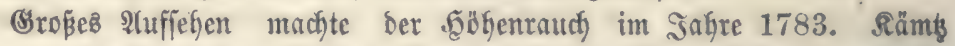

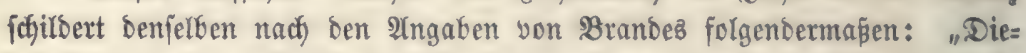

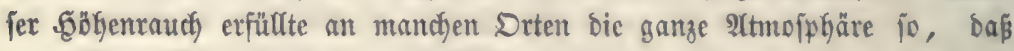
man Ǒegenftänte, weldfe sux $\frac{1}{4}$ Meile entfernt waren, an mandjen Tagen entrober gar nicht, doer wenigftens nur blau und nebelig fah. Die Sonne

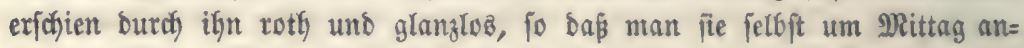
fełgen fonnte; gegen bie 3eit bez 2 Uuf= unt Unterganges verbarg fie fid,

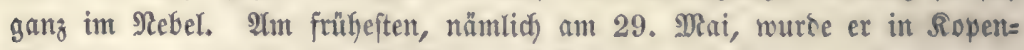
fagen beobadtet, wo eine Reitye von Geitern rarmen Tagen soraubigegan= gen war. Sier trat or alfo nady beiterm sisetter ein, währeno er an ben meiften Drten nady) einem (Senoitter fam, an einigen Drten nach einem fal=

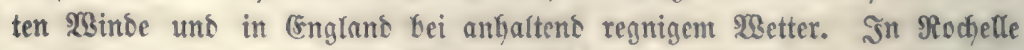
murbe er am 6. unt 7., in Dijon an 14. Iultiub beobaditet, nadflet aber

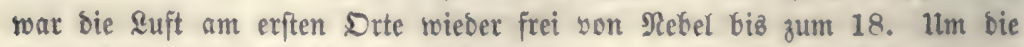
Mitte bes Suniuz ift bie eigentliche 3eit, wo ex fich faft allenthalleen auf einmal zeigte, inbem er żwifacen ben 16. und 18. Sunius in ben meiften Gegenden yon Deutichtant, Frantreid) uns Stakien beobaditet wurte, am

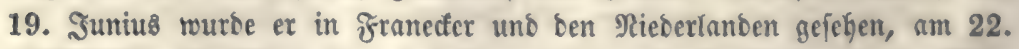
in Spybberg in Rorwegen, am 23. auf bem St. Botthard und in Dien, 
am 24. in Stocffolm, am 25. in Mrobtau, gegent Enbe bes Sumius in

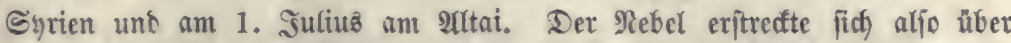

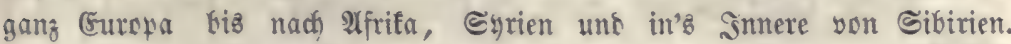

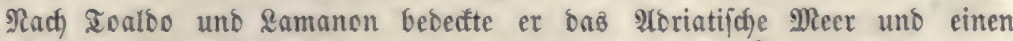

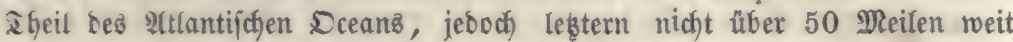
yom Rande. Dagegen erzählt yan Swinden, daß ein yon Rorwegen nad f̧olland fabrenter Schiffer, Der am 19. Suniuß Dort abreifte unt am 2.

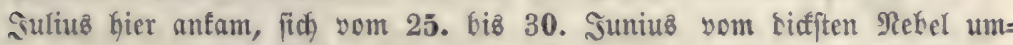
geben fanto. Int (England mar ex eben fo bid, als auf bem Continente.

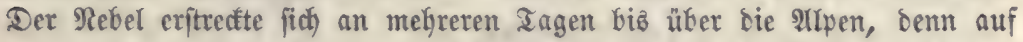

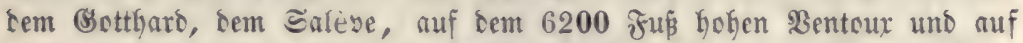

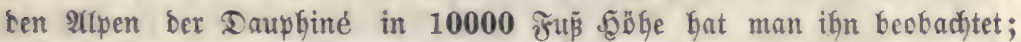
Soch) Gat man zu andern Beiten bie Spizen Der Alpen Darüfer Geryorragen febten, währent ihr Juß serbect war. In einigen (Segenten fodeint ex nid)t fo hod gejtiegen zu fein, benn Marcorelle fagt, fei Rarbonme Kabe

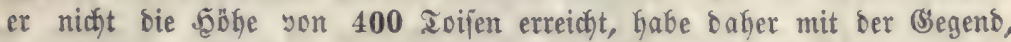
wo Serwitter entitehen, in feiner Berbintung geftanden, uno biejem $\mathfrak{l t m}=$ ftante müffe man

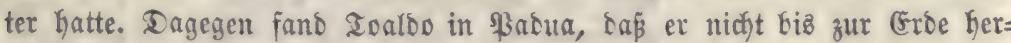

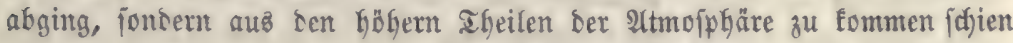

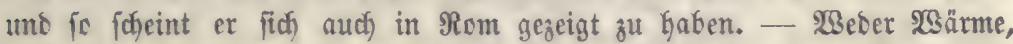

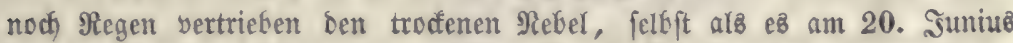
in Franecfer to Geftig regnete, $\mathrm{Da \beta}$ ę in einer halben Stunbe 20 dinien

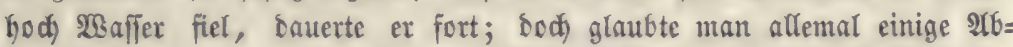

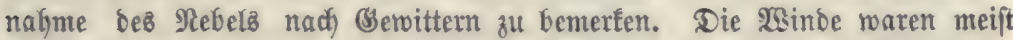
nörolid, aber an vielen Drten berrichte fajt in ber ganzen 3eit 2 Sinojtille."

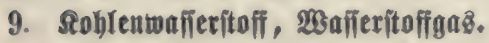

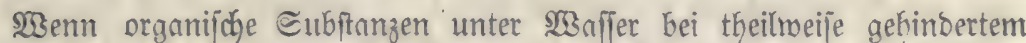
Suftzutritt bermejen, jo erzengt jich leichte\& Sohlenwafferftoffgas $=\mathrm{CH}_{21}$ audh Sumpfluft gentannt. Diejes, fo wie bas jobmere Sohjlentwafferftoffgns ober bas ölbilbenoe $5 a s=\mathrm{CH}$ entmeichen auch bei unvollftänbiger Berbrennung Der Бeiz= uno Reuthtitoffe. Bouffingault will ben Roblenwafferftoff in ber suft, wenn audh in fefr geringer Menge, gefunsen haben. Mafferitoffgaв

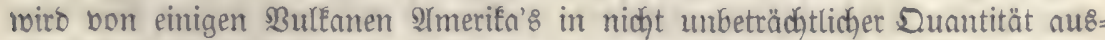
geftogen. Slber jofon in einiger Entfernung von biejen Sultenten Ennn man es nicht mehr in ser suft nadymeijen. Durdh ben silis mirb es eben jo we= nig, wie bas Rohlenmofferftoffgas berbrannt, weil bie grop̉e Menge bes bane= ben befindlidgen ๔aueritoff= uno Stidgajes bem entzünbeten brennbaren (saje

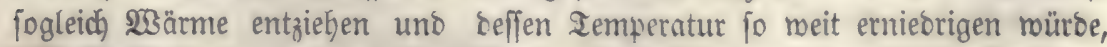
baß̉ bie $\mathfrak{B}$ erbrennung ftoden müß̄te. 


\section{Cunbiometrie.} theile.

Unter biejer berfteft man bie Unterjuchung ber \&uft auf ihre Bejtano.

a. Um ben Sinuerftoffgehalt zu ermitteln, gibt e\& folgende Berfabren:

a. Bolta'\& (\&ubiometer (જig. 71.) befteft aus einer grabuirten Röhre; ơंg. 71.

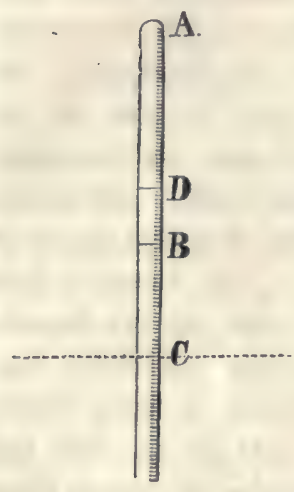
bie in ifre enthaitene \&uft, welche auf ifren Sauerftoff = gehalt zu unterjuchen ift, bat man burdy Quecfill= ber gepperrt. Zu bem anfänglich vorbandenen \&uft"

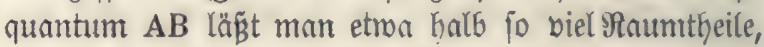

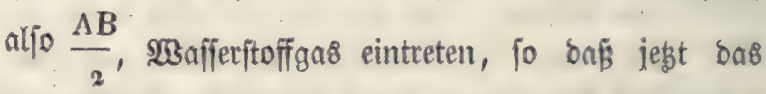

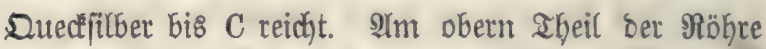
find zroei ßlatinorähte eingejd)molzen, um einen elec= trifchen gumfen in bas Bsemenge von 23 afferftoffgas uno \&uft Gineinfolagen zu laffen. Daburdh wirb ber Mafferftoff entzünbet, er berbrennt mit bem Sauer= ftoff zu 2 Baffertompf, welcher an ben abgeéliblten

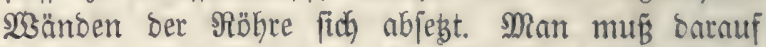

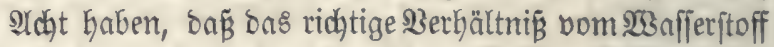
zum Sauerftoff getroffen merbe. Sat man zu renig 23 afferjtoff hinzugege= ben, fo wiro nidjt jämmtlicher Sauerftoff verbrannt; eine zu großse Menge von

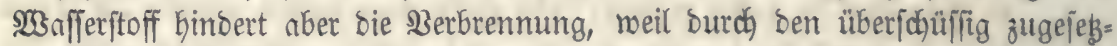

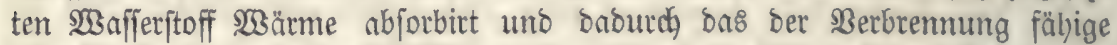

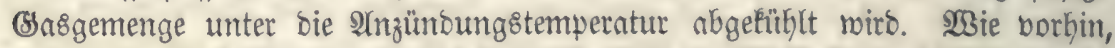
fo wirb aud) bei bem gegenträrtigen \$ुerfuch bie Glüffigéeit burch ben Iruct

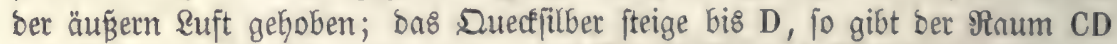
bns Bolum bes berfintoundenen Sauerjtoff= und $\mathfrak{W a f f e r f t o f f g a j e s ~ a n . ~ D a ~ b i e j e ~}$

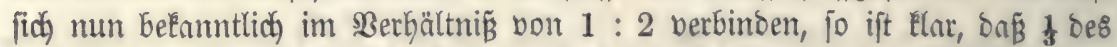

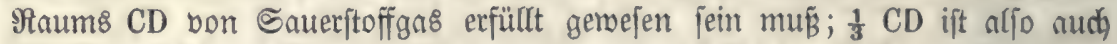
bie Menge Sauterjtoffgas, weldhe in ber zu unterjuchenoen \&uft enthulten wat.

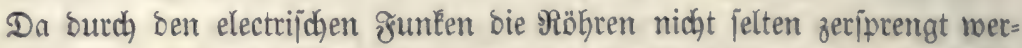
Den, fo Gat man folgende Miethobe angemandt, weldye biejen Uebelitano bejei=

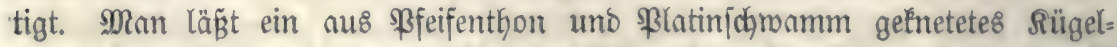

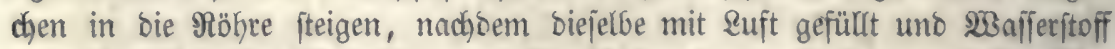

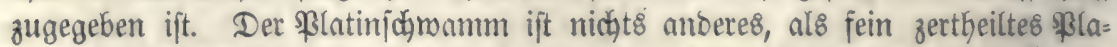

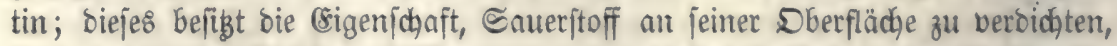

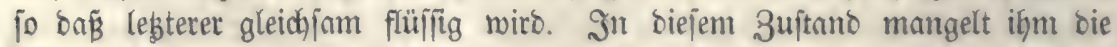
Repulfïberaft und er berbinoet fidh nun bei gewöhnlidger Iemperatur mit bem 33afferftoff zu 13 affer.

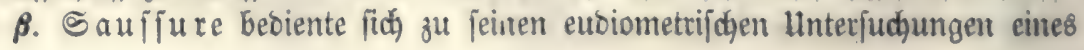


mit einem 5abnen berfhloffenen BIasballons; in biejem befanben fich

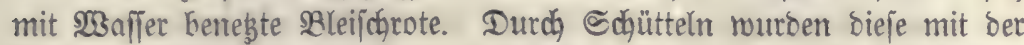
Euft des Ballons in innige und miederbolte Berüfrung gebradht; fie orty= birten fich. Shun D̈ffnete Eaujure ben Sabnen unter 13 affer; bie Menge W3affer\&, weldhes an ber Stelle bes (zur Drybation bes Bleie\& vermende= ten) Sauerfoffis getreten war, gab ifm ben Sauerftoffgehalt ber zu prü= fenben Euft an.

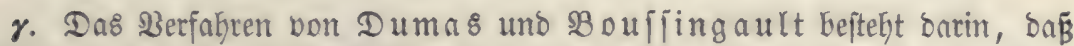
Æ̊ig. 72.

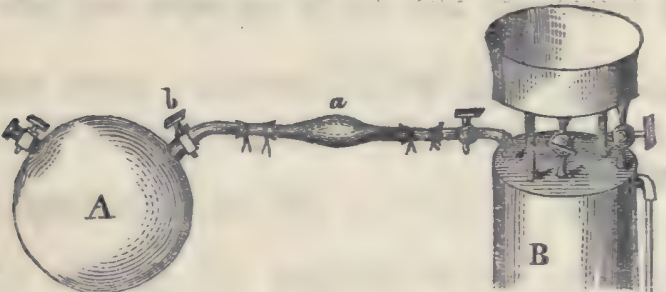

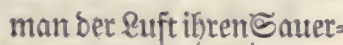
ftoff mittelft glühenden Supfers entzieft. Sebtes res befinbet fid in ber

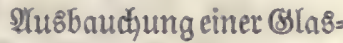
röbre(g̈ig.72.), weldhe mit einem luftleer gemadjten Ballon A in Berbinoung

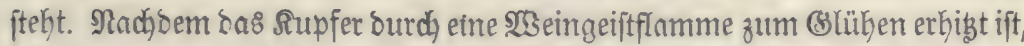
D̈ffnet man bent \$afhn b; mun frömt die suft über ons Supfer uno gibt fämmt=

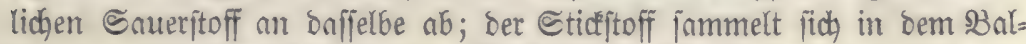
Ion A. Die Ssetwichtzzunabme bes Rupfers gibt bie Menge bes ๔auer= ftoffs an. Damit man aber miffe, meldyem Suantum \&uft biefelbe ent= fpridat, läß̈t man lebstere aus einem Bsajometer B von befanntem räum= lidjen Snthalt ausftrömen.

b. Den Stidfoffgehalt geben bie fänmtlichen zur seftinmung bes Sauerftoff's angemenbeten Berfahren ebenfalls an, rem man bie \&uft borber bon ifren Nebenbeftandtheilen gereinigt bat. Ien $N_{3}$ afferbampf

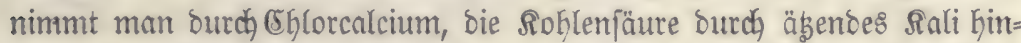

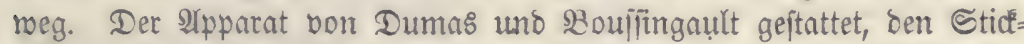
ftoff forohl zu roiegen, als zu meffen. Zu lez̧term muв aber ber räum=

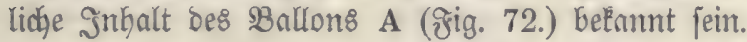

c. Soblenjäure. Zur Beftimmung biejes Bajes Eann ber Alpparat æig. 72. benubst werben, roen man ifm nod eine ausgebrudyte (Slastöbre c beigibt. Sn a wird Sebzallé uno in e mit Sdywefeliäure befeudateter

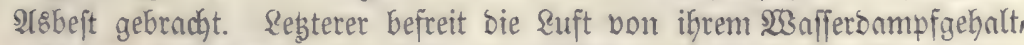

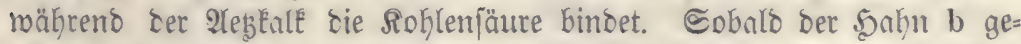

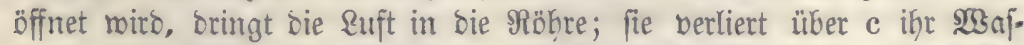

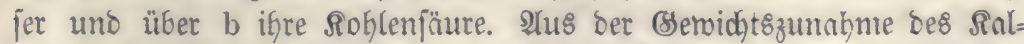
ke\& ergibt fid) Ser Roblenfäuregebalt ber \&uft für ein Bolumen gleich bem bes Brefägę $A$.

d. Immoniak. Ceine Menge ift jo gering, baß̈ e\& mur im Regenwaj= jer mit Sidgerkeit quantitatio nachgerwiejen merben fann. Man bampft 


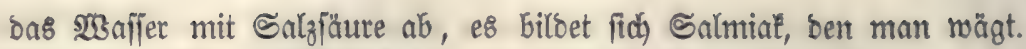

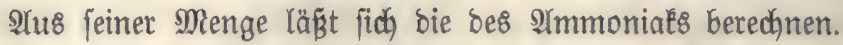

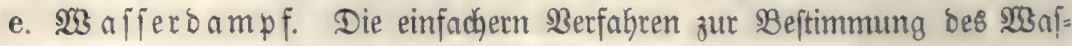

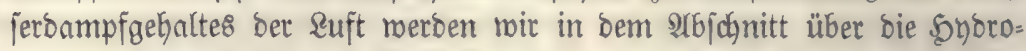

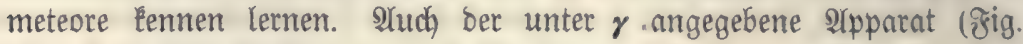
72.) Ennn zur (rrmittelung bes $\mathfrak{B}$ afferbampfes bienen. Man hat ben mit Schmefelfäure befeudhteten Arbeft vor uno nach bem Durdhgang ber 8 uft zu wiegen.

f. Salpeteriäure. Ģte quantitative Beftimmung ift eben fo miffich,

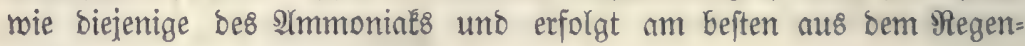
waffer.

g. Sohlentofferftoffgas und $23 a f f e r f t o f f g a s$ merben nadgemies

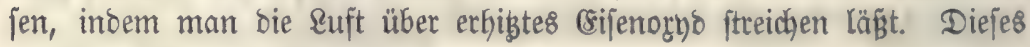
roiro ofu Metall reoucirt. 


\section{$\mathfrak{B i e r t e 8} \mathfrak{B} u \dot{\alpha}$.}

\section{$8 \mathrm{i}$ i $\mathrm{t}$.}

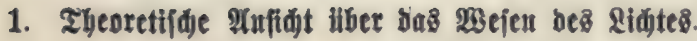

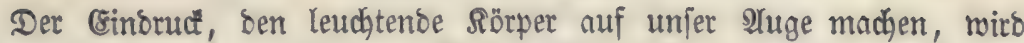

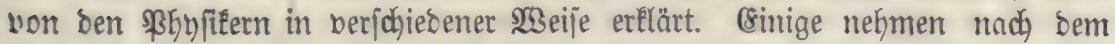

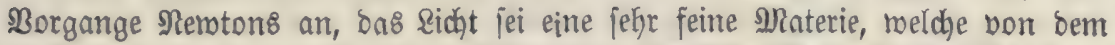
leudtenden Sörper nach allen Ridytungen ausfliege (\&manationshypo=

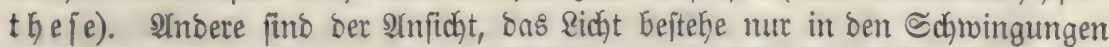
einer foldhen Materie, bie burdh den ganzen WBeltraum verbreitet jei. Sie nennen biefelbe 2lether. Der leudatenoe Rörper verfege rebstere in Sdyming= ungen, äfnlid benjenigen, welche ein tönender Rörper in ber \&uft berwirlt;

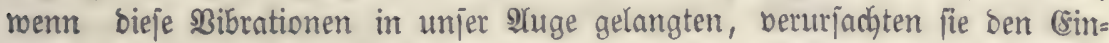

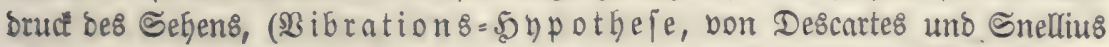

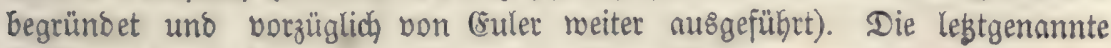
(srtlärungstroife fdheint bie ridłtigere zu jein.

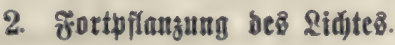

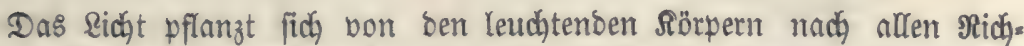
tungen hin in geraben sinien fort. Trifft es auf antere Rörper, fo mirb es entroeber reflectirt, ober, wenn es ber Sörper burch jeine Maffe hin paffiren

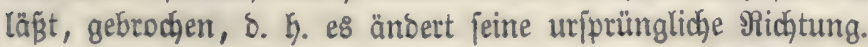

§ig. 73.

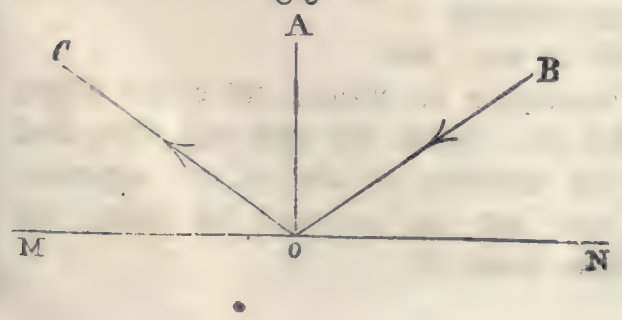

Die Beobadytung hat barge: than, daßs Det Sinfallsmintel BOA, meldyen ber auf eine flädbe MN auffallento Ridatftrabl BO (ঔig. 73.) mit ben Eimfallstoth AO (๖. দ. Der Senfredaten auf MN) bilbet, gleich bem গtes flecrionsmintel $A O C$ ijt. Der 


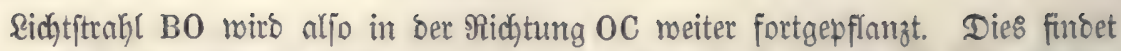

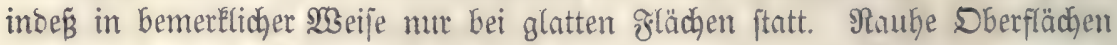

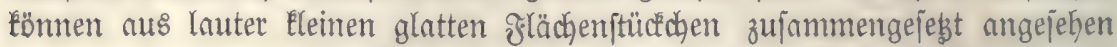
merben, von benen jeber das sidyt für fidh reflectirt. Weil aber bie 9 (nzahl

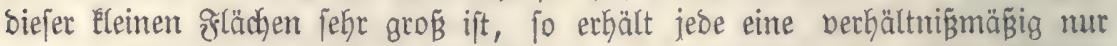

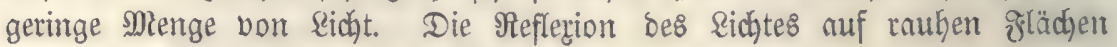
nennt man bie 3eritreunng beffelben.

ஓig. 74 .

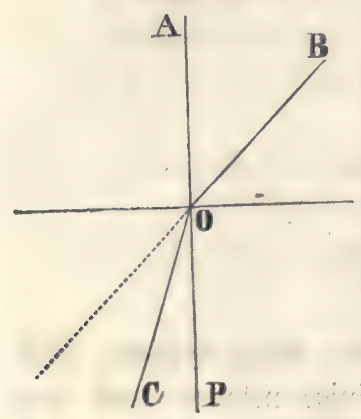

Baffitt ein Ridjtiftrahl BO (જig. 74.) aus einem ourchfichtigen-Mesium ein mberes, ebenfalts burch)= fichtiges von gröperer Dichte, fo wirb er ge= brochen uno zroar dem (sinfallelothe AP genähert, 10. Dañ er jest bie Richtung OC einjolägt. Dieje bebält er fo lange bei, nle fich bie Didjte bes Mebiums niḑ̆t änbert.

\section{Sutenfitüt ber Belentidunty.}

a. Die Stärêe ber Beleudtung einer §lähe nimmt im $3 e r=$ Gärtuiṕs des auadrates ber Entfermung, in melder bie gräche von dem leudtenden sunete jid befindet, $a b$.

Æ̛ig. 75.

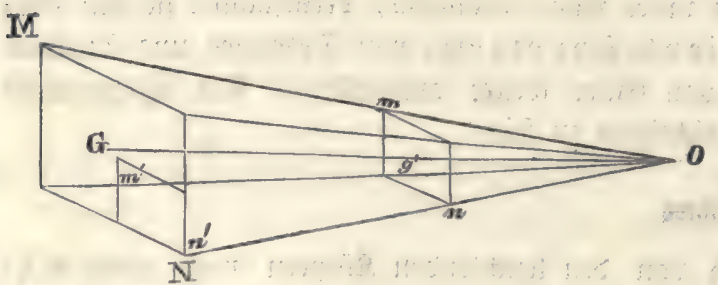

(88. Jei in 0 (ङ̈g. 28) bie Ridytquelte, bort ibs gehe eine beftimmte MRenge sidyt aนย:. Die Glădi) MN erfält im šnzzen ebenio: viel Ridyt, als $\mathrm{mn}$, obgleids fie weiter von 0 entfernt ift. âtein bie sidytmenge

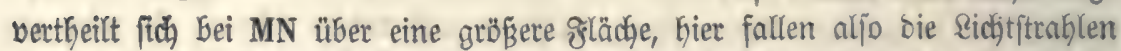
nicht fo nake neben einanoer, als auf $\mathrm{mn}$, modurd, notfwendig bie Intens

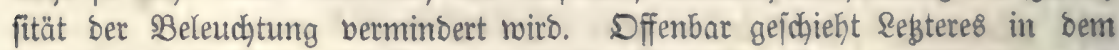

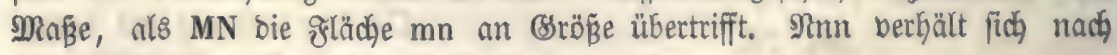
einem befannten Sage Der ETementargeometrie.

$$
O \mathrm{~g}^{2}: \mathrm{OG}^{2}=\mathrm{mn}: \mathrm{MN} \text {. }
$$

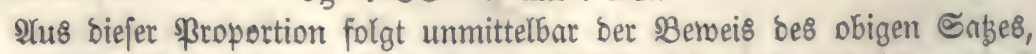
benn was für bie ganze ģlädhe MN gilt, beziejt fich aud auf jeben aheil

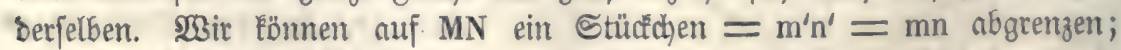
bie Beleuch)tungsintenfitäten bon $\mathrm{m}^{\prime} \mathrm{n}^{\prime}$ uno $\mathrm{mn}$ berbalten fid oaker, wie Sie Quabrate ifrer Entfetmungen vom ßunťte 0 . 
b. Die Stärle ber Beleudutung einer Fläde ift bem Sinus

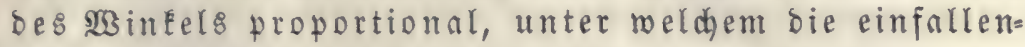
ben sidfteralen die gläde treffen.

76.

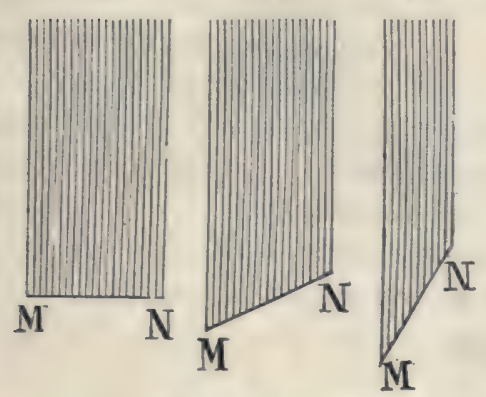

ঔi 79.

78.

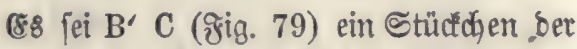
auf eine gegebene Fläche MN auffal= len, je jujiefer biejelbe gegen bie Ctrah= len geridftet ift, ergeben bie ₹iguren 76, 77, 78. Das Maß́, in welchem Die Beleudhtungsftärlée abnimmt, ergibt fïh) aus ซolgenoem:

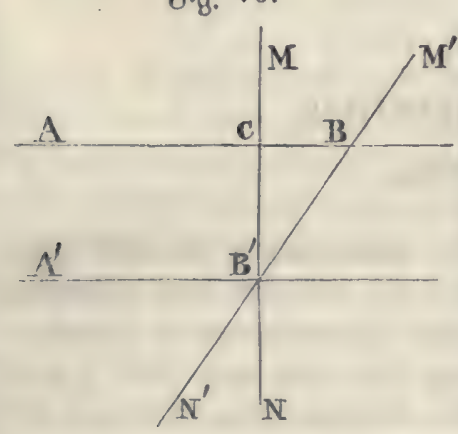
gräche MN, jo Elein, daß̉ die sichtjtrablen

$$
\begin{aligned}
\mathrm{BB}^{\prime}: \mathrm{B}^{\prime} \mathrm{C} & =1: \sin . \mathrm{CBB}^{\prime} \\
& =1: \sin \cdot \mathrm{A}^{\prime} \mathrm{B}^{\prime} \mathrm{N}^{\prime},
\end{aligned}
$$

meil $4 \mathrm{C}^{\mathrm{BB}^{\prime}}=4 \mathrm{~A}^{\prime} \mathrm{B}^{\prime} \mathrm{N}^{\prime}$ ift. A $C, A^{\prime} B^{\prime}$, welche baffeltbe treffen, als pa= rallel betradytet werben tönnen. Wirs bie

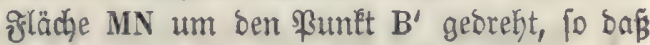
fie mun bie \&age $\mathbf{M}^{\prime} \mathbf{N}^{\prime}$ einnimmt, fo fällt biejelbe Richtmenge, welche früher bem oflä= chenftülf $B^{\prime} C^{\prime}$ zu Theil murbe, auf bie Fläçe BB'. Die Intenfität ber Beleucjtung vom $\mathrm{BB}^{\prime}$ ift barum Eleiner, als biejenige bom $\mathrm{B}^{\prime} \mathrm{C}^{\prime}$ weil $\mathrm{BB}^{\prime}$ größ̈er, al8 $\mathrm{B}^{\prime} \mathrm{C}$ ift. (5s verbält fic

Bezeichnen wir Doher bie Beleuchtungsftärfe von $\mathrm{B}^{\prime} \mathrm{C}$ mit a, fo ift bie

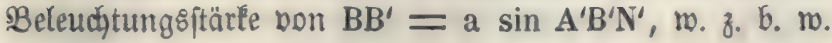




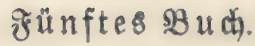

$\mathfrak{B}$ ärme.

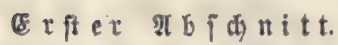

Bon ber $\mathfrak{B}$ ärme im Arrgemeinen.

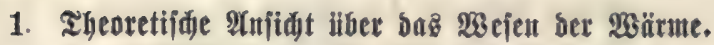

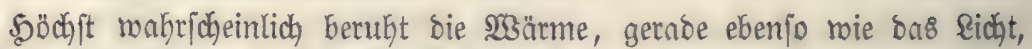
in ben Schningungen eines 2 (etbers, bod) ift e\& bis jest nod) nidyt gelungen,

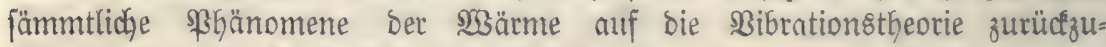

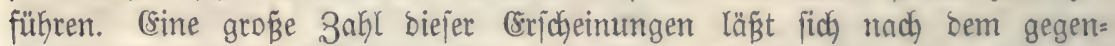

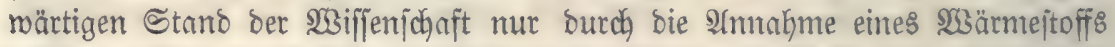
erklären. Man benlt fich unter biefem eine ätherartige hödhft feitre, bie Sïrper leidyt Durchoringende, unfichtbare Materie ohne (semidgt.

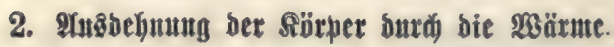

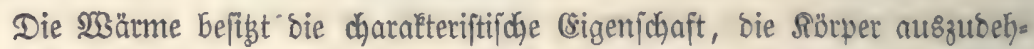

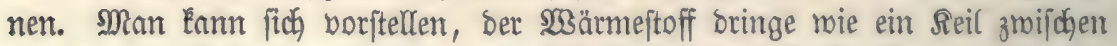
bie fleinften sheildyen (Ŷtome) eine\& Rörpers uno treibe fie auseinander.

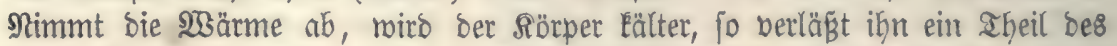
Wärmeftoff8, die Altome nähern fid einanoer wieber und bas Bolumen bes Rörpers verminoert fich.

(88 ift foh früher (ङ. 48.) nadhgeniejen morben, Daß̊ ber Roefficient

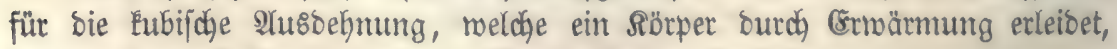
breimal jo groß́ ift, als berjenige für bie lineare $2(u s \delta$ blynung.

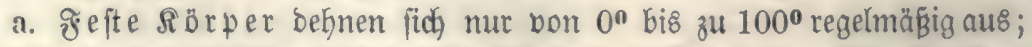

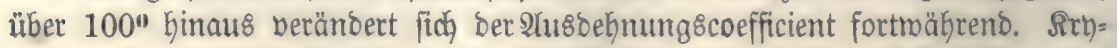
italle, weldhe nicht bem regulären Syftem angefören, zeigen aber (d)on un=

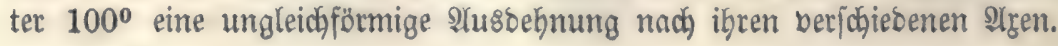




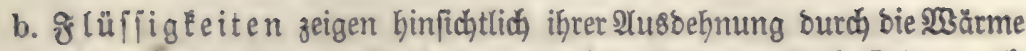

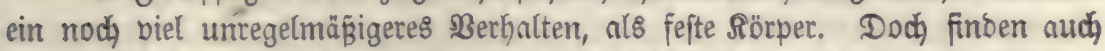

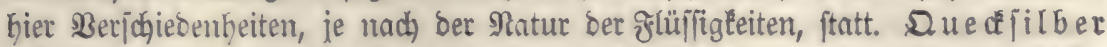

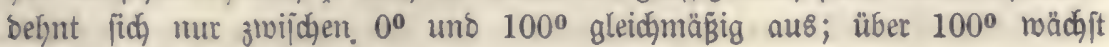
fein $\mathfrak{A}(48 \delta$ ehnungscoefficient.

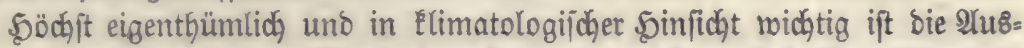

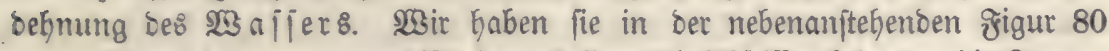

(ङ̈ig. 80.)

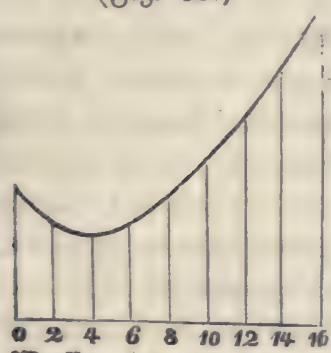
graphijd bargeftellt. Die 2lbiciffen bebeuten bie Tempe=

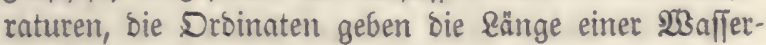

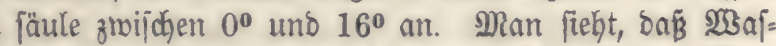

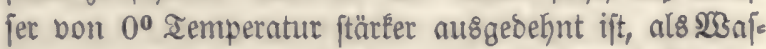
fer bon $4^{0}$, ber Alusbehnungscoefficient bes 23 nfer8 ninımt aljo bon $0^{0}$ bi\& $4^{0}$ (genau $\left.4^{0}, 108\right) a b$. Da bie Didjte eines Sörpers fich bermintert, rem er aus:

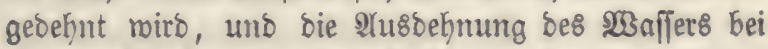
$4^{0}$ an fleinften ift, fo geht hieraus herbor, bafis bas

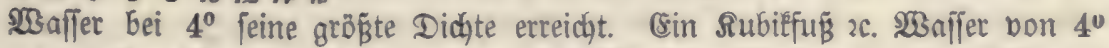

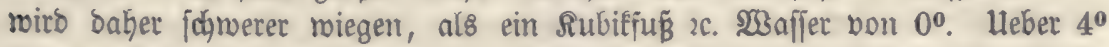

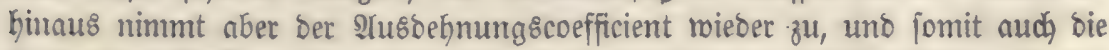

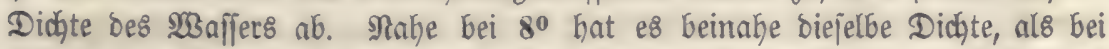

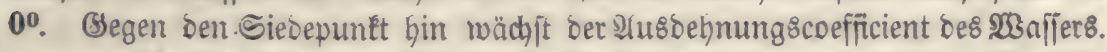

c. Die ss aje behnen fich bei gleidher Demperaturzunahme faft gleidmäbig nus; nur biejenigen, melche fich zu f̧lüfifigeiten verbidjten laffen (bie Dämpfe)

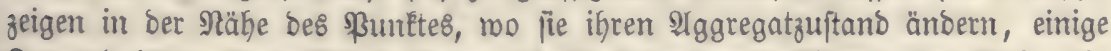

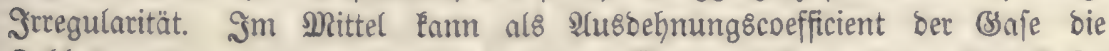
3ał $0,00366=\frac{1}{2} \sqrt{3}$ genonmen werben. $23 e n n$ bie Temperatur eines Bajes

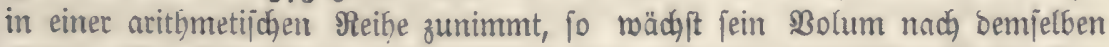

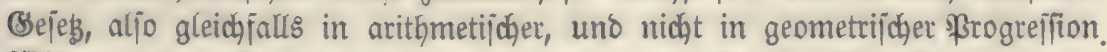

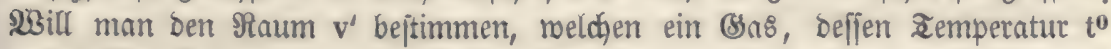
unt beffen Bolum v beträgt, bei ber Temperatur $\mathrm{t}^{\prime 0}$ einnefmen miro, fo muß bies nach Der Proportion:

$$
\begin{gathered}
273+t: 273+t^{\prime}=v: v^{\prime}, \text { aus weldger } \\
v^{\prime}=v\left(\frac{273+t^{\prime}}{273+t}\right) \text { folgt, }
\end{gathered}
$$

gejöghen.

\section{3. ¿lyermometer.}

Borridgtungen, weldje bazu bienen, um semperaturen zu beftim= men, nennt man Shermometer. Da bie Sörper, wenn fie ertwärmt werben, fich ausbehnen, io fann bas Maß́ ber Solumsvermefrung zur SBeurtheilung

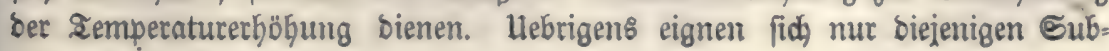


ftanzen zroedmäßig zu Ihermometern, beren Bolumen gleidjmäß̈ig mit ber Temperatur mächft, mie bies z. B. Bei bem Quecffiltber zmijhen bem Befrier= punft und bem Siebepuntt beళ 2 Gaffers ber gall ift.

Das Dutecfiltberthermometer befteht aus einer. mit Duecfiltber gefülten oben geidhloffenen, unten mit einer kugelförmigen 2tusbaudjung berjefenen

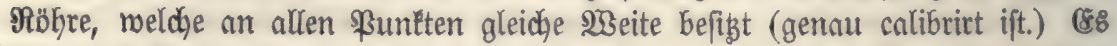
hat zroei fejte ßunkte. Den einen erfält man, wenn bas Injtrument in ¡đjmelzendes sis eingetaucht wiro; man bezzichnet ifgn mit 0 uno nennt ifn Den Sefrierpuntt. Den anbern \$untt gibt bie Berlängerung Der Duectfitber= făule an, wenn man bas Ihermometer ben Dämpfen von fiebentem 2 Saffer

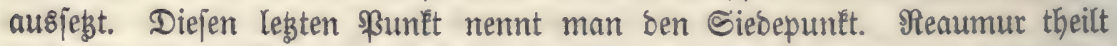

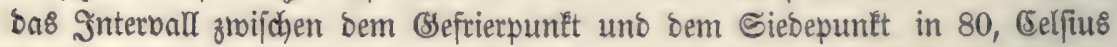

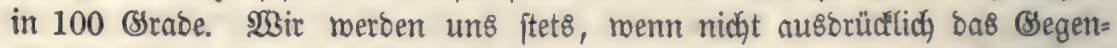
theil bemerlt wirb, ber Cerfius'idsen Eintheilung (ber centefimalen) bebienen.

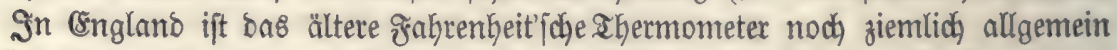

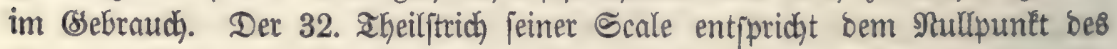

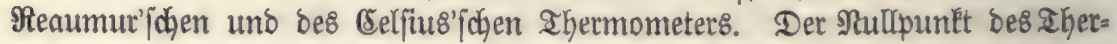
mometer\& bon Fabrentheit liegt $32^{\circ}$ unter Dem sefrierpunt; er rourbe burd Eintauchen bes Inftruments in eine Mnijchung bon Sdynee und Salmial be=

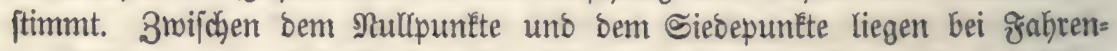

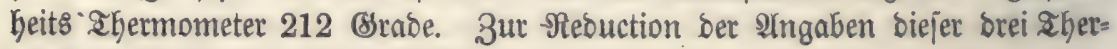
mometer bienen folgenbe (sleidhungen

$$
\begin{aligned}
& \mathrm{n}^{0} \mathrm{C}=\frac{4}{5} \mathrm{n}^{0} \mathrm{R}=\left(32+\frac{9}{6}\right)^{0} \mathrm{~F} \\
& \mathrm{n}^{0} \mathrm{R}=\frac{5}{4} \mathrm{n}^{0} \mathrm{C}=\left(32+\frac{9}{4}\right)^{0} \mathrm{~F} ; \\
& \mathrm{n}^{0} \mathrm{~F}=\frac{4}{8}(\mathrm{n}-32)^{0} \mathrm{R}=\frac{5}{8}(\mathrm{n}-32)^{0} \mathrm{C} .
\end{aligned}
$$

Da bas Suecfitlber bei $-45^{\circ} \mathrm{C}$ erftart, fo Eam bas auedfitberthermometer nur bis etwa $40^{\circ}$ benubst merben, für $\mathfrak{2 e m p e r a t u r e n ~ u n t e r ~} 40^{\circ}$ nimmt man ein $\mathfrak{2 3 e i n g e i f t t h e r m o m e t e r . ~}$

\section{Thermometrograph.}

So heipht ein Snftrument, weldhes bie Beftimmung ber bödhften uno nieb= rigften Iemperatur rährento eines gemiffen Zeitabjohnitts baburdh erleidgtert, bafis auf ifm bas צRarimum forobhl, als auch bas Minimum firitt bleiben.

ฆิเg. 14.

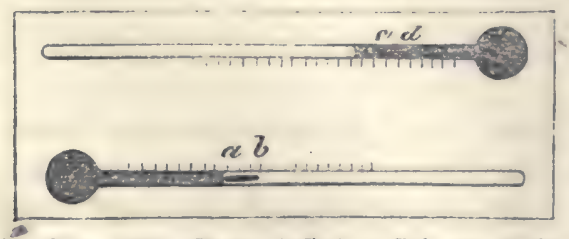

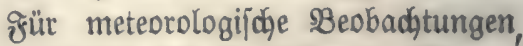
empfieglt fich ber folgente ahermo= metrograph (ð̊ig. 14.)

3wei zhermometer find auf eine Platte aufgeheftet. Das eine, zur (Erforid)ung Des Magimums beftimmt ift mit Duedfitber gefült. 2rm ende

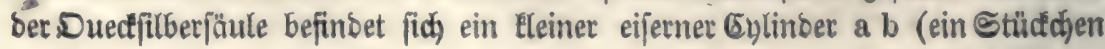




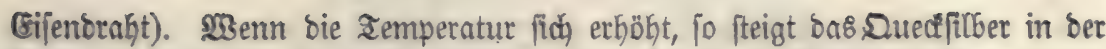
Röhre uno ichiebt ben (sijen = (Sylinber vor fid her. Ninmt bie Iemperatur

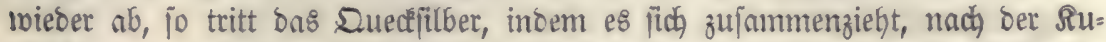

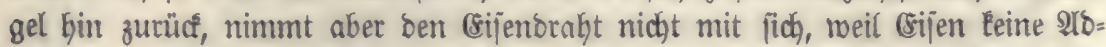

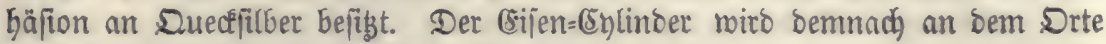
be8 Semperaturmatimums liegen bleiben.

In ben zweiten IGermometer befindet fid $\mathfrak{B 3 e i n g e i f t ~ a n f t a t t ~ D u e d f i t b e r . ~}$ Die Stelle bes (sijen = Eylinoers wiro hier von einem sstafftäbothen ed einges nommen, beffen beibe (snoen mit Inöpfdhen berjehen find. Das Stäbchen

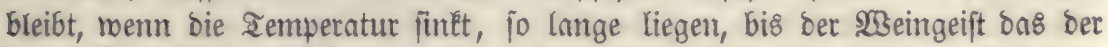

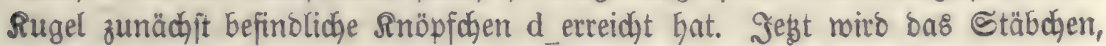
menn bie Temperatur nod) weiter fïh erniebrigt, bom 2 Beingeift nachgezogen,

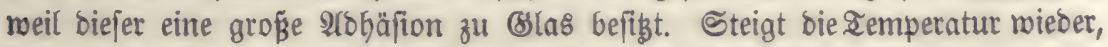

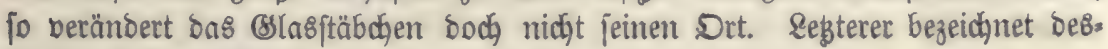
wegen bas Minimum ber Temperatur.

Ulm ben Ihermometrographen zu neuent (sebraudje Gerzuridjten, neigt man ihn auf bie linke Ceite; es fällt alsbann ber Eijen=(E)linber auf bas

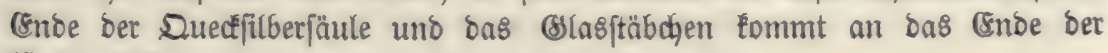
Sweingeifţăule zu liegen.

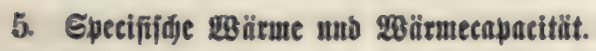

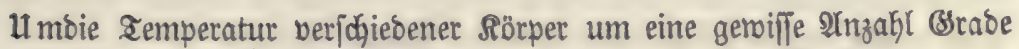

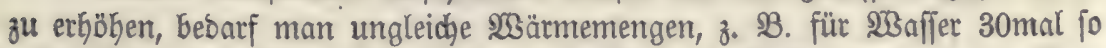
biel, als für Duecfiltber. Man jagt beshalb, bas $\mathfrak{3 a f f e r ~ h a b e ~ e i n e ~ g r o ̈ ß e r e ~}$

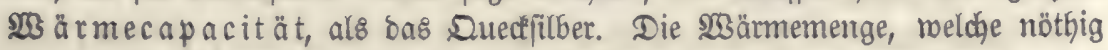
ift, um bie হemperatur irgeno einer Subjtanz un $\mathbf{1 0}^{0}$ zu bermebren, nennt man ifre ipecifijche $\mathfrak{W a ̈ r m e . ~ M a n ~ b e z i e h t ~ b i e j e l b e ~ a u f ~ b i e j e n i g e ~ b e s ~} \mathfrak{3}$ aj=

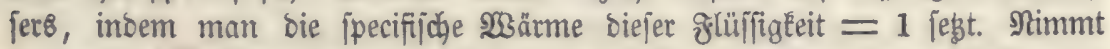

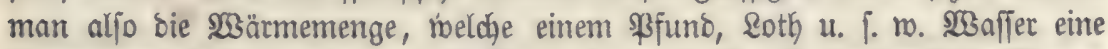

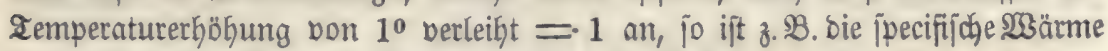

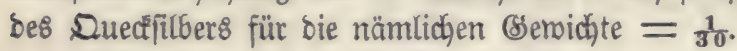

Braud man, um bie zemperatur bon g Serwidytstheilen eines Sörpers um $t$ Srabe zu erhöhen eine ${ }^{3}$ ärntemenge $=m$, jo ift für ein Benidat $g^{\prime}$

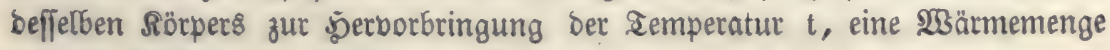

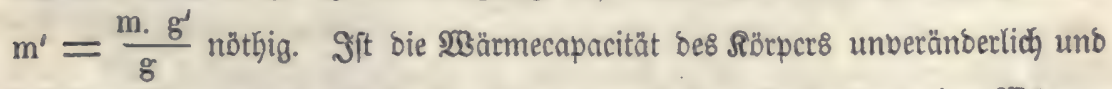
foll feine Iemperatur auf $t^{\prime}$ gebradgt werbell, fo berwirlt Rejteres eine $23 a ̈ r m e=$ menge $\mathrm{m}^{\prime \prime}=\frac{\mathrm{m} \mathrm{g}^{\prime} \mathrm{t}^{\prime}}{\mathrm{g} \mathrm{t}^{\mathrm{t}}}$

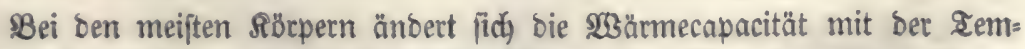

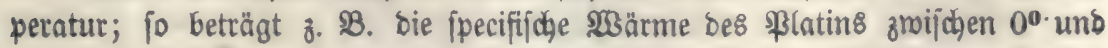




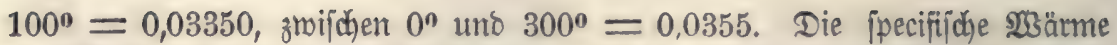
Des $\mathfrak{2 3 a f f e r \& ~ b l e i b t ~ f u ̈ r ~ b i e ~ I e m p e r a t u r e n ~ b o n ~} 1-20^{\circ}$ comftant, bon $20-100^{0}$ ift fie $=1,0127$.

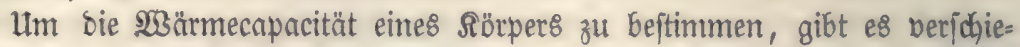
bene Metyoden. Eine Don biejen befteht Darin, dä̈ man ben Rörper, beffen

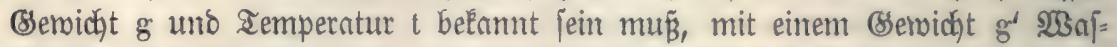
fer von ber Iemperntur $t^{\prime}$ zu[ammenbringt uno bie Mitteltemperatur $\mathrm{T}$ ber

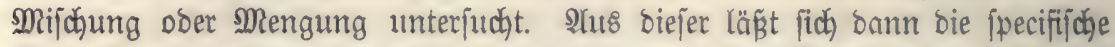

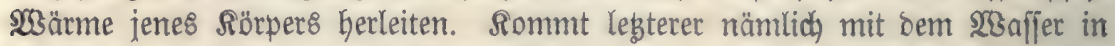
Berüfrung, fo gibt er an baffelbe $\mathfrak{B a ̈ r m e}$ ab ober nimmt folche auf, je nadh= Dem feine Temperatur höher oder niebriger, als biejenige bes 23 affers ift. Die Temperaturen gleichen fich auf bieje $23 e i j e$ aus. Nefymen mir an, baß̈ roäh=

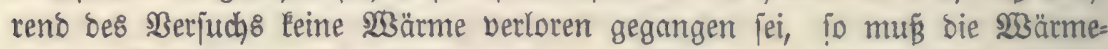

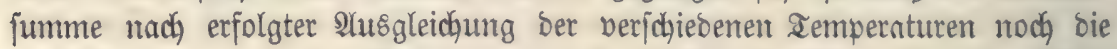

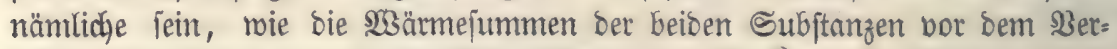

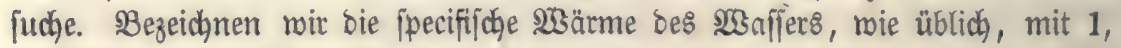
biejenige bes fraglichen Sörpers mit s, fo ift

$$
\begin{gathered}
\mathrm{T}\left(\mathrm{gs}+\mathrm{g}^{\prime} \cdot 1\right)=\mathrm{gts}+\mathrm{g}^{\prime} \mathrm{t}^{\prime} .1 \text {; hieraus } \\
\mathrm{s}=\frac{\mathrm{g}^{\prime}\left(\mathrm{t}^{\prime}-\mathrm{T}\right)}{\mathrm{g}(\mathrm{T}-\mathrm{t})}
\end{gathered}
$$

Sätte man z. $\mathfrak{B} .10$ Pfuno $\mathfrak{3}$ affer von $20^{\circ}$ mit 2 Pfuno Duedfftber

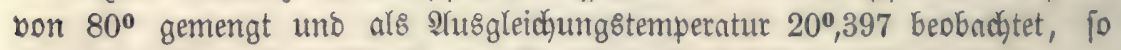
wäre, menn man bieje 2 Serthe in obige frormel einführt

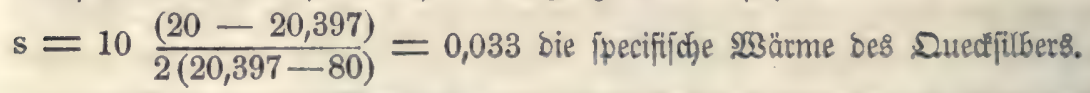

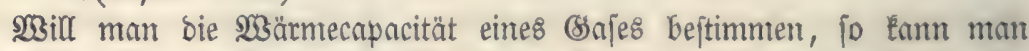
entweber annefmen, jein Bolumen werbe butd) einen mit ber Semperatur wadbjenben Druck auf einerlei Niveau erfalten, ober es lafte auf thm ein con= ftanter Drưf, meldher bern (Saje geftattet, fich auszubehnen. Snllegterem galle

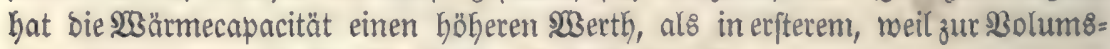
bermełrung an uno für fich. 933 ärme erforberlich ift.

\section{Satente 20 ärme.}

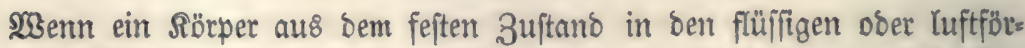

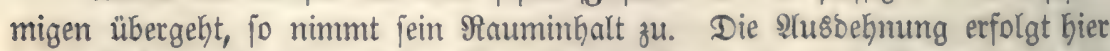
burch $\mathfrak{B}_{3}$ ämeaufnafme. Man Eann fid) bie Sache fo vorftellen, als menn

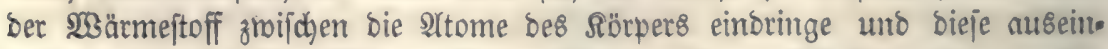
ander treibe (2.) Die SGärme aljo, weldhe ein $\Omega$ örper abjorbirt, wenn er fei= nen 2 ggregatzuftano änbert, wirb bazu verwentet, um bie Altome auseinanber gu halten. Sie fann burch, das IGermometer nid, wahrgenommen weroen, uno wiro beshalb latente $\mathfrak{3 a ̈ r m e}$ genannt. 
खुenn man 1 sf Maffer ron $79^{\circ}$ (genall $7^{\circ} \frac{1}{4}$ ) mijcht, fo jollte (nach 5) eine Mitteltempera= tur von $\frac{0^{\circ}+79^{\circ}}{2}=39^{\circ}, 5$ entiftehen. Dies ift aber nicht ber gall. Man erfält 2 Pfun $\mathfrak{W}$ affer von $0^{0}$. Die 79 WBärmeeinheiten, weldhe bas $\mathfrak{B} a[=$ fer bejaß́, murben baher blos zum ๔athmelzen bes rijes bermanot, uno ba

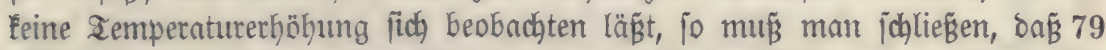

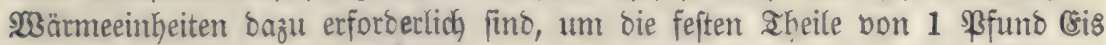

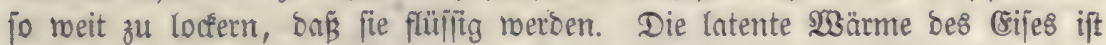
aljo $=79$. IIm 1 Pf

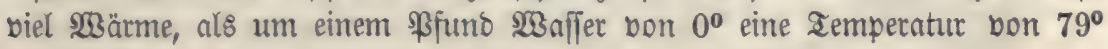
zu extbeilen.

WBiro eine gemiffe Duantität $\mathfrak{B}$ affer längere Zeit nuf bem Siebepuntt

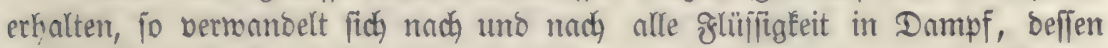

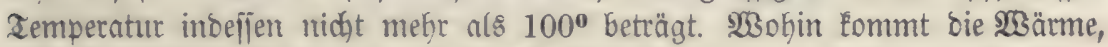
weldje die Dampferzengung erforbert? Cie miro bağ bermentet, um bas grö= Bere Bolum, welches Der Dampf einnimmt, Kerzuftellen. Dieje 2 Gärmemenge

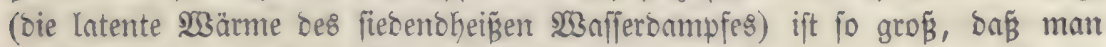
mit berjelben bas gleiche (Semidat 23 affer von $0^{\circ}$ aulf $536^{\circ}$ ermärmen lönnte.

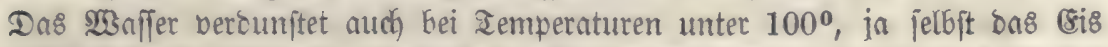
berounjtet; bie Dämpfe entmeichen mit ber Iemperatur, weldhe bas 23 nffer ober Cis befigt, aus dem fie fid) gebilbet haben. Snoffen bleibt fich bie la=

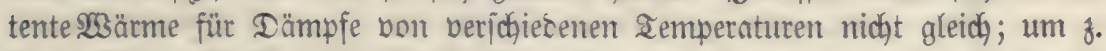
3. 1 Rilogr. 23affer bon $50^{\circ}$ in Dampf von $50^{\circ}$ zu vermandeln, ift fo biel

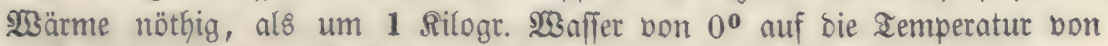

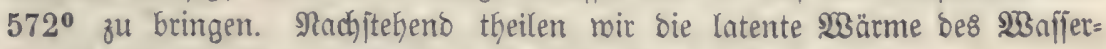
onmpfes für bie Temperaturen bon $0^{\circ}$ bis $200^{\circ}$ mit.

$\begin{array}{cc}\text { Semperatur. } & \text { Satente } \\ 0^{\circ} & 606 \\ 50^{\circ} & 572 \\ 100^{\circ} & 536 \\ 150^{\circ} & 501 \\ 200^{\circ} & 464\end{array}$

\section{Fortpflaugung ber 2 ärme.}

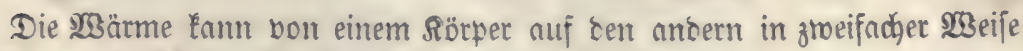
Iibergehen, nämlich) burdh Reitung uno burch) Strahlung.

\section{a. Leitung bex æärme.}

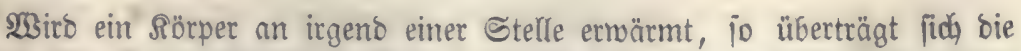
Wärme von einem Sheildben zum anoern burdh Reitung. Man Eann fid 


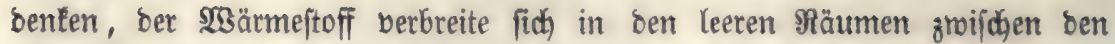

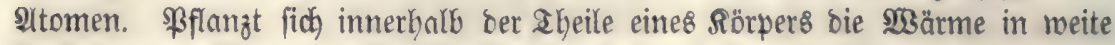
contfernung von ber erroärmten Stelle fort, fo nennt man biejen sïrper einen guten Reiter, mie z. B. bie Metalfe. Sdjlechter leiten fidjon bie Steine uub Eroen, 5olz; zu ben fajlechteften \&eitern gehören W̧olle, Geibe, Stroh, trocienes Raub uno Moos.

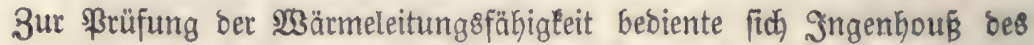
əิ่า. 81.

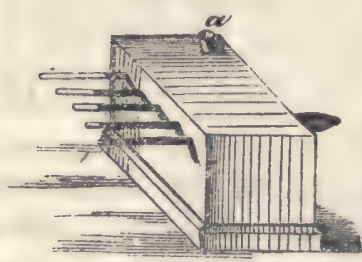
neben berzeidjneten 2 pparates. In einem Saften, iwelcher burch bie Deffnung a mit beig̈em 23 affer gefüllt werben tann, find bon berjhiebenen Siör= pern angefertigte Stäbe eingelaffen, beren Dber= flächen man mit $2 \mathfrak{B a c h s ~ u ̈ b e r z o g e n ~ b a t . ~ \Re a d ̧ = ~}$ bem bas 23 affer eingefüllt ift, errärmen fich bie rinoen ber Stäbe, welche in bas $23 a f f e r$ himein= ragen; bie $\mathfrak{S a ̈ r m e ~ p f l a n g t ~ f i c h ~ n a c h ) ~ b e r ~ \Re i c h t u n g ~}$ ber Cunben um to weiter fort, je beffer bie Stäbe bie 203 ärme leiten. Dabei

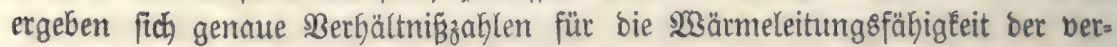

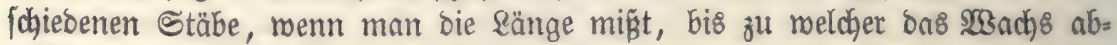
gejamolzen ift. Bseję̧t, eв jeien die Stäbe von Silber, Supfer, Bijen, ßBor=

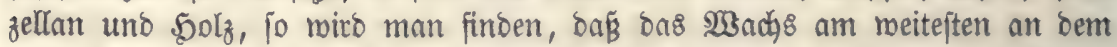
Silberjtab, fujon etwas weniger an sem Rupferitab, noch weniger am \&ijen,

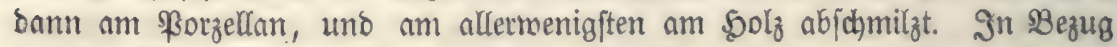
auf ifre 233 ärmeleitung8fähigkeit folgen fict) aljo bieje vier @ubftanzen in ber nämlichen Dronung in weldyer wir fie borbin aufgeführt haben.

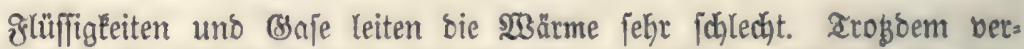

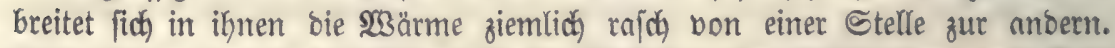
Dies rübrt aber blos baher, weil bie Iheildyen ber głüffigleiten und şaje

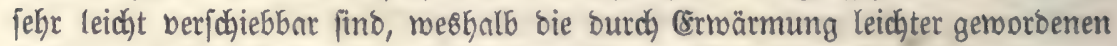

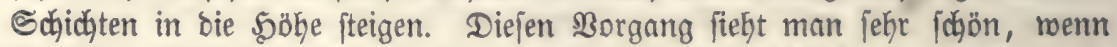

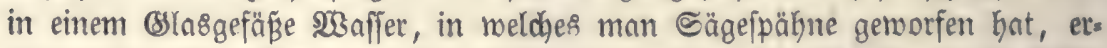

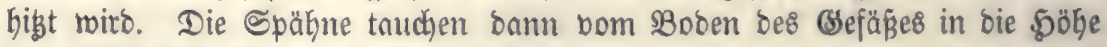

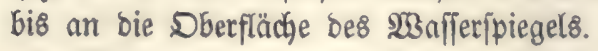

Waffer leitet bie 23 ärme viel beffer, al\& trodene \&uft. Die $\mathfrak{B a ̈ r m e s}$

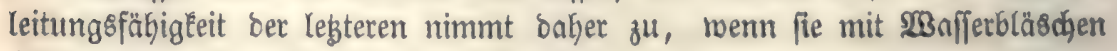

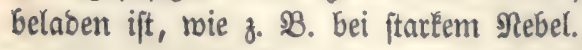

\section{b. *åneftrabไung.}

Die $230 ̈$ äme tann fich bon einem Sörper auf ben anbern birefft über= tragen, ohne baß̧ ein zrwifdhen biejen Sörpern befindliches Mittel bie \&eitung 


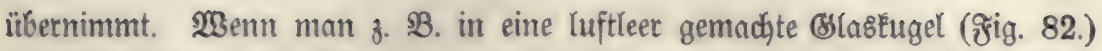

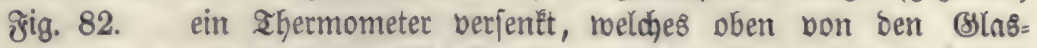

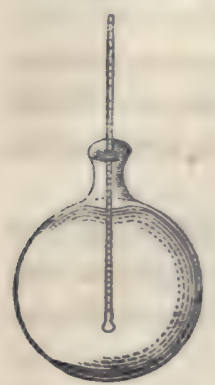
wänben feft umidjloffen ift, uno bann bie untere Fflädje ber

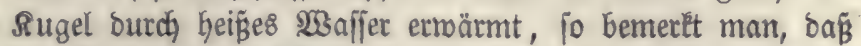
bas Queçiflber im Thermometer fteigt. Die Orträrmunglann aber hier nidjt burch Reitung bes (Jlajes an ber Stelle, wo es bas Thermometer betühtt, Gewirft worben jein, benn

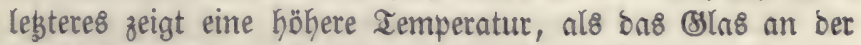
Berbinoungsftelle. Man fagt in Dem oben angegebenen

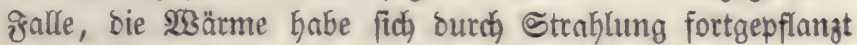

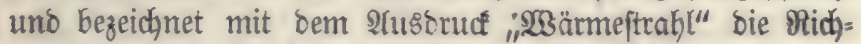
tung bon bem erwärmten $\Re$ örper zu ber $2 \mathfrak{B a ̈ t m e q u e l l e , ~}$

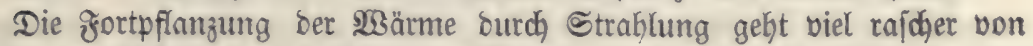
Ctatten, als biejenige burdh Reitung. $23 \mathrm{cmn}$ man in einiger 8ntfermung von einem Geigen Dfen ein Thermometer anbringt, fo fteigt beffen Temperatur viel häher, als bie \$emperatur ber \&uft, weldhe Den Dfen umgibt; hiervon Ennn ntan fich leidht überzeugen, inoem man plöblich) einen Edbirm bor ben Dfen ftellt und vor biejem bie Semperatur ser \&uft befimmt. (58 ift jebr

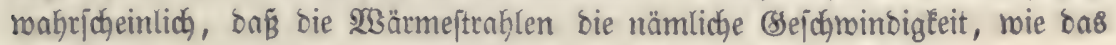
sicht bejizgen, meldhes 70000 Meilen in einer Secunbe burdaläuft.

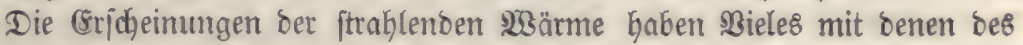
sidjtes gemeinjam. Co unter 2 (noerm:

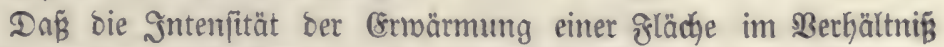
bes Sunbrates ber Entfernung, in reldher bie Fläd)e von ber $23 a ̈ r m e=$ quelle fidf befindet, abnimmt.

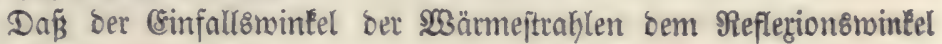
gleich ift.

Daß̉ bie Stärke der Errmärmung einer fläche bem Sinus bes

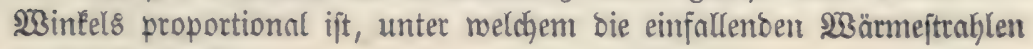
bie gläçe treffen.

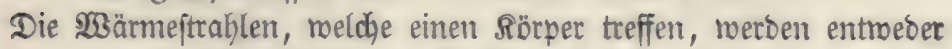

$\alpha$. Durdggelafjen. Subftanzen, weldhe bieje Eigenidhaft befigen, nennt man binthermane, im Begenjabs fu ben athermanen, benen fie feflt. Der biathermanfte Rörper ift bas Steinjalz. Doch läjt es nidjt fämmtlidge $2 \mathfrak{B a ̈ r m e f t r a h l e n ~ p a f f i r e n . ~ M a n ~ f a n o , ~ \delta a ß ̉ ~ v o n ~} 100$ Iheilen ber

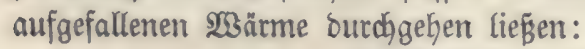

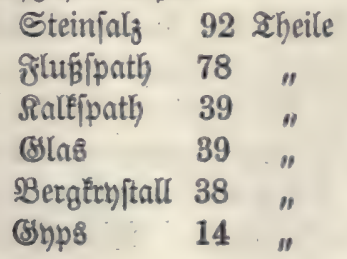




\begin{tabular}{|c|c|}
\hline Xlaun & \\
\hline (slimnter & 20 \\
\hline (sis & 6 \\
\hline
\end{tabular}

Die nod übrigen 8 aheile werben vom Steinjalz nicht abjorbirt (benn e8 tritt Éeine merfliche (Ermärmung Deffelben ein), fonbern reflectirt. Diefes

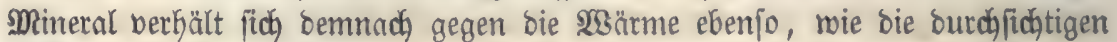
Rörper gegen bas sidjt.

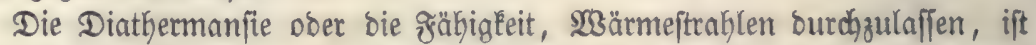

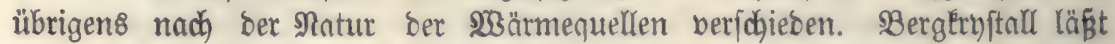
von ben Strahlen einer Rnmpe $38 \%$, bon denen eines glühenden \$latinbrahtes mur $28 \%$ paffiten.

B. Reflectirt. Die athermanten Rörper merfen um fo megr bon ben

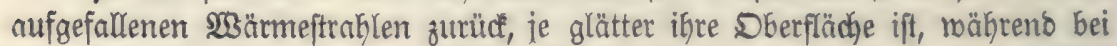

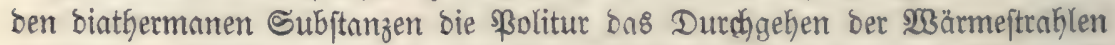
erleidatert. Stellt man zmei metallene 5obljpiegel einanoer gegenüber uno bringt man in Den Bremmpunt bes einen eine glühente Sohle, fo entzünoet

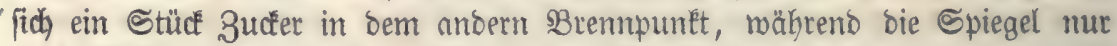
unmerflich erroärmt merben. Bei rauken Dberflächen finbet, gernoe wie beim Sidat, eine Diffufion ber $\mathfrak{B}_{3}$ ärmejtrablen ftatt; $\delta$. h. Dieje reerben nad' allen Seiten hin untegelmäßsig zeritrent.

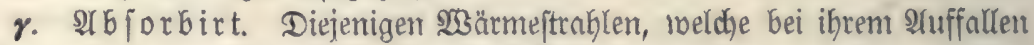
auf irgento eine Subftnnz nidjt burdhgelnffen ober reflectirt merben, bienen fur crrnärmung ber Subftanz uno werben fomit abjorbirt. (58 ift flar, bañ

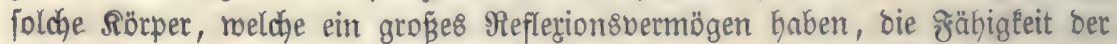
Utborption in geringerem Maßje befizen; Kei ben athermanen Subftanzen

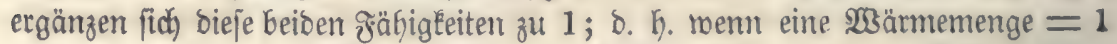
auf einen Siorper auffält, 0 ift bie reflectirte. $\mathfrak{B a ̈ r m e j u n m e ~}+$ ber abjor= birten $=1$. Dies ergeben auch folgenoe durd) Berjudbe ausgemittelte $\mathfrak{B e r}=$ Găltniß̧ząlen

$\begin{array}{lr}\text { Mreffing } & \text { Reflerion8 } \\ \text { Silber } & 100 \\ \text { 3inn } & 90 \\ \text { Stabl } & 80 \\ \text { Slei } & 70 \\ \text { Sienrui } & 60\end{array}$

216jorptionsoermögen.

100

90

80

70

60

0
0

10

20

30

40

100

Die abjorbirte 23 ärme breibt nicht in Den Sïrpern, fonbern wirb mieber ausgeftrahlt, wenn bie ltmgebung eine niebrigere zemperatur bejigt. D as Iusfrahlungsbermögen ift bem Abforptionsbermb̈gen pro=

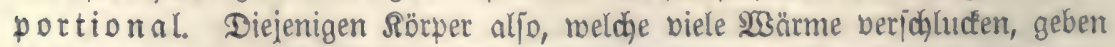

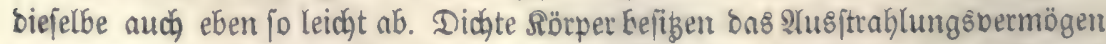

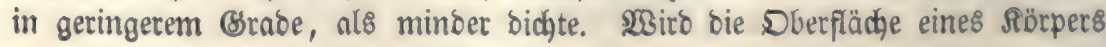




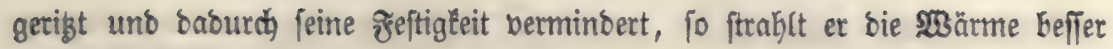
aus, als' borker.

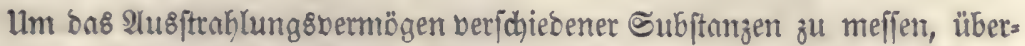
zieht man bie Seiten eines hohlen Metallmürfels, mit einer bünnen Sdhidft

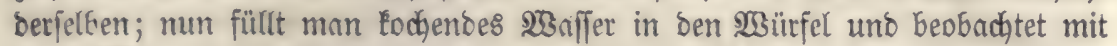
einem Shermometer bie Temperatur in gleichem Albftand von jeber Seitenflädje. (88 ergab fict)

\begin{tabular}{|c|c|c|c|}
\hline für Sienruß & bก8 & 2イเిftrahlung8̊vermögen & $=100$ \\
\hline " Bleitweiß & " & $n$ & $=10$ \\
\hline நauโenblaje & " & $"$ & \\
\hline surdae & " & $"$ & $=$ \\
\hline " Summilact & " & $"$ & \\
\hline " blankes INetah & II , & $"$ & \\
\hline
\end{tabular}

Die grünen 3 lätter ber Bremädje füt vorzugsiveife zur Abjorption ber

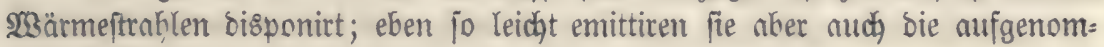
mene $\mathfrak{3}$ ärme.

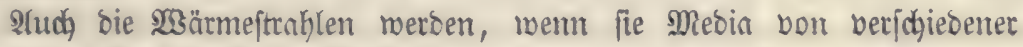
Didjte zu pafficen baben, gebroctjen.

\section{Ertalter.}

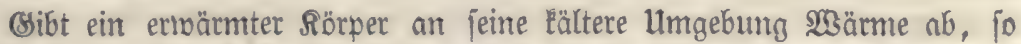

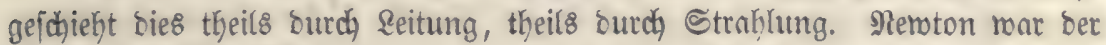

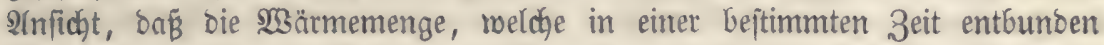

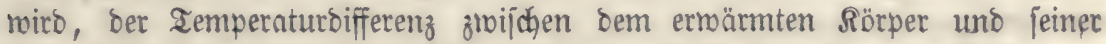

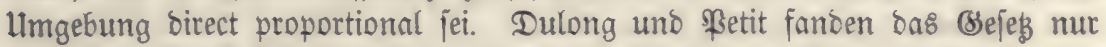
bis $40^{\circ}-50^{\circ}$ beftätigt. Ueber biefe Brenze hinaus geft bas Ertéalten meit idneller von ftatten.

Bei einer Temperatur bon finft bas ahernometer in einer Minute un

$\begin{array}{rr}240^{\circ} & 10^{\circ}, 69 \\ 220^{\circ} & 8^{0}, 81 \\ 200^{\circ} & 7^{\circ}, 40 \\ 180^{\circ} & 6^{\circ}, 10 \\ 160^{\circ} & 4^{0}, 89 \\ 140^{\circ} & 3^{0}, 88 \\ 120^{\circ} & 3^{\circ}, 02 \\ 100^{\circ} & 2^{0}, 30 \\ 80^{\circ} & 1^{0}, 74\end{array}$

3 weiter 2 bi nitt.

Gong ber tägliden Iemperatur ber $\&$ uft.

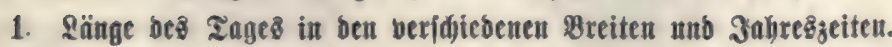

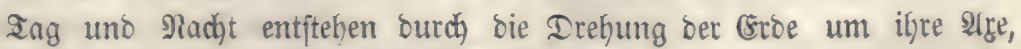
weldye fie in vier uno zroanzig ๔tunten vollenoet. 


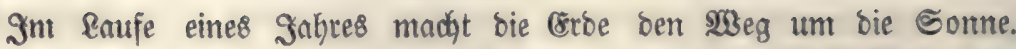

ซึig. 83.

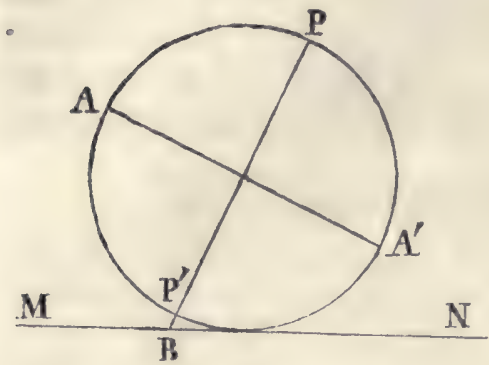

Määrend biefer 3eit ift bie Dauer bes Ings unb ber Nadht in unjern Brei= ten beftänoigen Beränoerungen unter= morfen, bie Gauptjädylich barin iłren

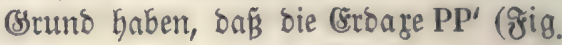
83.) , eine fofiefe Stellung gegen bie sbene ifrer umorefungsbahn MN ein nimmt, welche fie rährent ber Dauer des Sabres beibehält. Dieje Neigung gibt ber $\mathfrak{N B i n k e l ~ P B N ~ a n ; ~ f e i n e ~ B r o ̈ ß ̈ e ~}$ beträgt gegenrwärtig $66^{\circ} 32^{\prime}$.

Die Brobabn bildet eine bon ber Figur bes Sireifes menig abtweidjente Ellipfe, in beren einem 8 rennpunft bie Somne ftebt.

Da bie Sonne jo jefre weit von ber (srbe entfernt ift (im Mittel unge= fäbr 21 Millionen Meilen), jo Eönnen bie Sonnenftrablen al\& unter fid) und mit ber 85ene ber Srobahn parallel angejefen werben. Sntmerbalb bes saufes

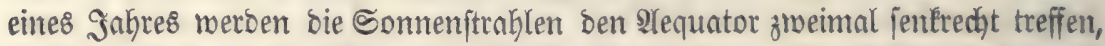
es finbet bies am 21. März nnठ 23. September ftatt. SIm tiefiten unter bem 2equator ftegt bie Sonne am 23. Dezember, am höbhften Den 21. Juni.

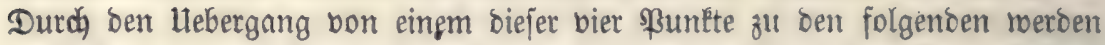
bie Gabreszeiten gebilbet. SBetrachten mir nun ben Stano ber Sonne in bent vier Sahrezzeiten.

\section{a. \$inter.}

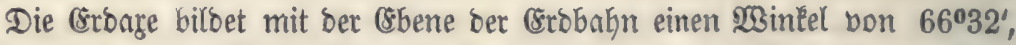
ber 2 lequator $\mathbf{A A}^{\prime}$ ( Figur 83.) madjt baber mit berjelben 8sbene einen 26intel $=90^{n}-66^{\circ} 32^{\prime}=23^{\circ} 28^{\prime}$. Da bie Sonnenftraflen parallel mit ber (Erobabn einfallen, fo biloen audh fie bei bem tiefften Stano ber Sonne (am 23. Dezember) mit bem 2 equator einen $\mathscr{Y}$ sintel von $23^{\circ} 28^{\prime}$.

\section{ซึig. 84.}

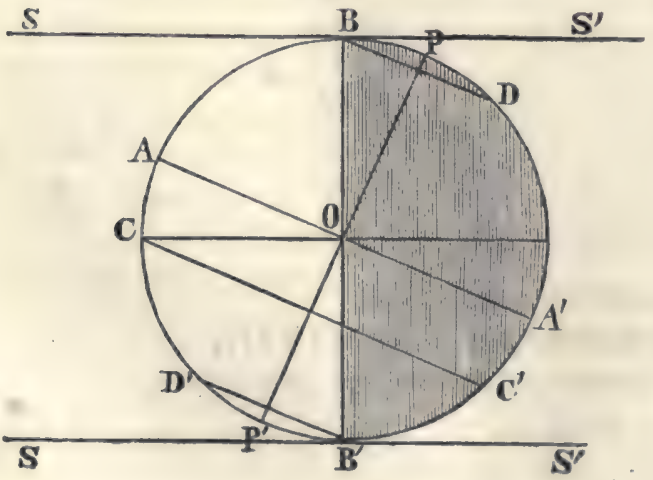

Die Cró tann annäberungstweije für eine Sugel genommen merben; bie Sonnenftrablen bilben eis nen Cylinoet, weldyer bie (5roe in bem größten strije

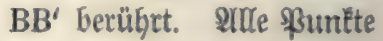
ber Crobe, weldye bon bie= fem Streife nady ber Sonne bin - gewenbet liegen, wers ben aljo erbellt jein, wäb= rento bie hinter $\mathrm{BB}^{\prime}$ befino= lidje salblugel buntel ift. 
3ieb̆t man burdi $\mathbf{P}$ uno $\mathbf{P}^{\prime}$ mit $\mathbf{A A}^{\prime}$ bie Parallelen $\mathrm{BD}$ un $\mathbf{B}^{\prime} \mathbf{D}^{\prime}$ To grenzen bieje zroei Rugeljegmente ab. Das obere miro bie nörolidge SBolar=3one, bas untere bie fübliche \$olar=3one, BD roiro ber nöroliche, $B^{\prime} D^{\prime}$ Der fübliche \$lolarfreis genannt.

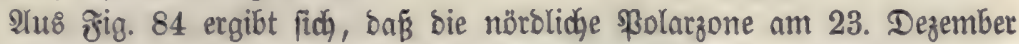
24 Stunden lang Radjt, bie fübliche Polarzone ebenjolange Ing hat. Die

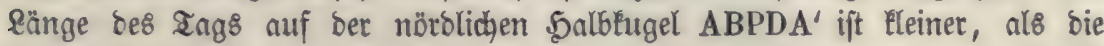

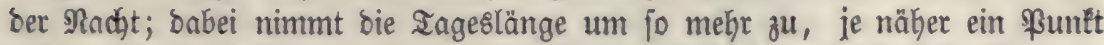

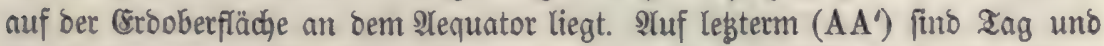
Nacht einanber gleidh. Bom 2lequator an nad bem Sübpol P hin nimmt bie Tagerlẳnge wieber zu.

Segt man butch) ben Bunft C, wo bie Sonnenftrahlen bie (stbe redht= minflich treffen, einen mit ber (Erbbahn parallen streis $\mathrm{CC}^{\prime}$, fo ift biejer ber MBenbetreis bes Steinbocts.

SWinfel C O B $=\mathrm{A} 0 \mathrm{P}=1 \mathrm{R}$; ziegt man von Beioen.

$$
\text { " } \frac{\mathrm{A} O \mathrm{~B}=\mathrm{A} O \mathrm{~B}}{\mathrm{~A} O \mathrm{C}=\mathrm{B} O \mathrm{P}} \text { ab, io bleibt }
$$

Die (Entfermnng bes ßolarkreiję BD vom $\beta 0$ l P betrâgt bemnach) $23^{\circ} 28^{\prime}$.

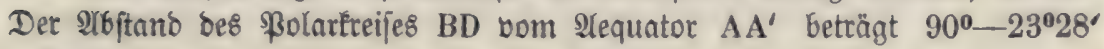
$=66^{\circ} 32^{\prime}$.

b. Eonuter.

2fm 21. Juni baben wir bie entgegengejesten Berbältniffe vom 23. Des ริig. 84.

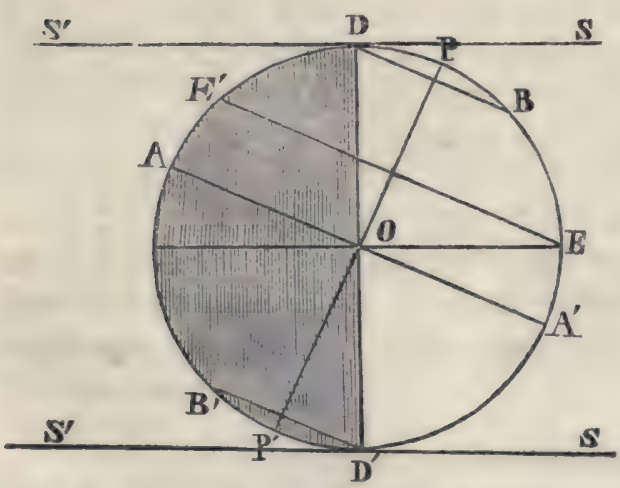
zember, wie gig. 84 . beran" ichaulicht. Die fübliche ßolatgone bat an biejem Iage 24 Stumben lang Nacht, bie nörb= liche Polarzone 24 Stumben lang Iag. Puf ber noblidien 5albetugel ift bet Tag länget, auf bet füblidgen bagegen

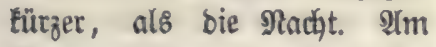
2equator bauert ber Tag roie= ber, wie borbin, eben fo

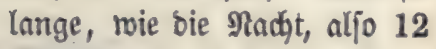
Stunben.

Regt man burdh ben \$unlt E, wo bie Sommenftrablen bie Eroe redht= mintelig treffen, einen mit bet (robbahn parallelem steeis EE', fo ift biefer ber

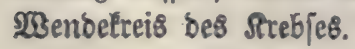

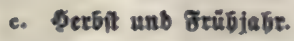

2im 23. September uno am 21. März fallen bie Sonnenftablen fent" 


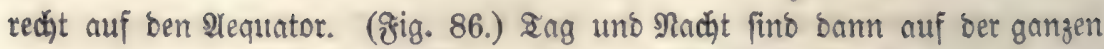
Æ̛ig. 86.

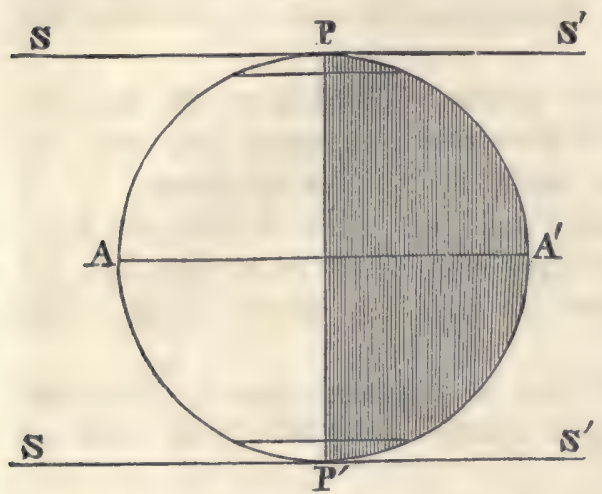

(Erbe gleid). Nur bie beiben Buntte P unt: P am $\$ 30 t$ bas ben, weil jie eben noch bon ben Somnenftrablen rajitt werben, 24 Stunden lang Tag.

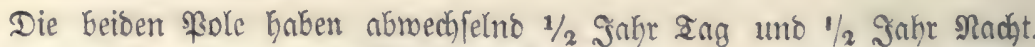
Die Dauer bes Inges für verfabiebene Breiten zeigt bie nadjfthenbe anbelle.

Monat

Dauer bes Tages in ber Breite von

$$
\begin{array}{lllllllll}
0^{\circ} & 10^{\circ} & 20^{\circ} & 30^{\circ} & 40^{\circ} & 45^{\circ} & 50^{\circ} & 60^{\circ} & 70^{\circ}
\end{array}
$$

\begin{tabular}{|c|c|c|c|c|c|c|c|c|c|}
\hline รanuar & $12,0 \quad 11,5$ & 10,9 & 9,6 & 9,5 & 9,0 & 8,4 & 6,4 & - & \\
\hline grebruar & $12,0 \quad 11,7$ & 11,5 & 11,2 & 10,6 & 10,2 & $.9,9$ & 8,9 & 6,8 & \\
\hline März & $12,0 \quad 12,0$ & 11,9 & 11,9 & 11,8 & 11,8 & 11,7 & 11,6 & 11,3 & $"$ \\
\hline 2tpril & $\begin{array}{lll}12,0 & 12,1\end{array}$ & 12,4 & 12,8 & 13,1 & 13,3 & 13,6 & 14,3 & 15,8 & " \\
\hline Dai & $12,0 \quad 12,5$ & 12,8 & 13,5 & 14,3 & 14,7 & 15,3 & 16,9 & 21,5 & " \\
\hline Suni & $12,0 \quad 12,6$ & 13,2 & 13,9 & 14,8 & 15,4 & 16,1 & 18,4 & 24,0 & " \\
\hline গ̦uli & $12,0 \quad 12,5$ & 13,1 & 13,7 & 14,5 & 15,1 & 15,7 & 17,7 & 24,0 & " \\
\hline Îuguft & $12,0 \quad 12,3$ & 12,5 & 13,1 & 13,6 & 13,9 & 14,3 & 15,3 & 17,6 & $"$ \\
\hline September & $12,0 \quad 12,1$ & 12,1 & 12,2 & 12,3 & 12,3 & 12,4 & 12,6 & 12,9 & " \\
\hline Detober & $12,0 \quad 11,6$ & 11,6 & 11,3 & 11,0 & 11,0 & 10,6 & 9,9 & 8,6 & " \\
\hline Nobember & $12,0 \quad 11,1$ & 11,1 & 10,5 & 9,8 & 9,8 & 8,8 & 7,2 & 3,0 & " \\
\hline ezember & $12,0 \quad 10,8$ & 10,8 & 10,1 & 9,2 & 9,2 & 7,9 & 5,5 & - & \\
\hline
\end{tabular}

Unter ber $B$ reite von $67^{\circ} 19^{\prime}$ bauert ber längfte Tng 30 Iage, unter $69^{\circ} 34^{\prime}$ Breite 60 Iage, unter $73^{\circ} 5^{\prime}$ s 8 reite 90 Inge, unter $7^{\circ} 38^{\prime} \mathfrak{B r}$. 120 Iage, unter $82^{\circ} 55^{\prime} \mathfrak{B r} .150$ Iage, unter $88^{\circ} 38^{\prime}$ SBr. 180 Iage unt $90^{\circ} \mathrm{SBr}, 6$ Monate.

\section{Regeln fïr bie Temperaturbenbantungen.}

ख3enn man ben şang ber täglichen Temperatur ber \&uft nittelft des

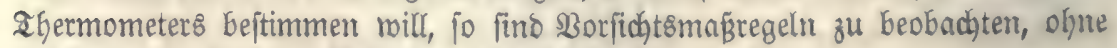
weldye bas gefundene Rejultat nicht ridytig fein mürbe.

a) Drs Ihermometer Darf nicht birect von ber Eonne befajienten werben. Demn in biejem farlle gibt es nicht die 23 ärme ber Ruft, jondern bie remperatur an, wethe ifym jelbjt burdh bie aufgefallenen Sonnenjtrablen 
extheilt wirb. Dieje if aber immer höber, als jene, roeil bas şlas mehr

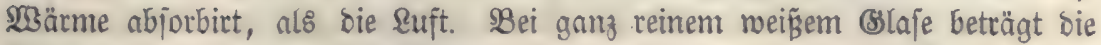
Differenz immer nod einige Brabe.

b) Ias Inftrument barf nicht in Sinmmer bängen, meil in einem

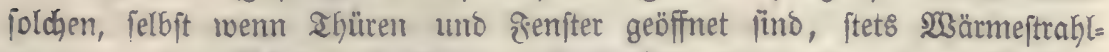
ung von Den $23 a ̈ n d e n$ ftattfindet. Beobactet man von einem Srebäube aus, fo muß bas Thermometer auf ber 9lorbfeite beffelben in einer ziem= lichen Entfernung von ber 23 ant angebracht jein. Stegt ein Saus gegen=

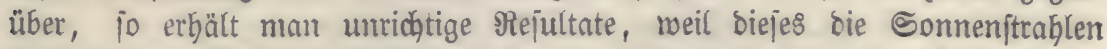

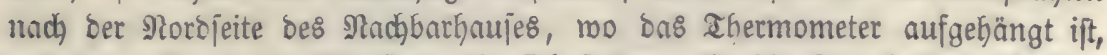

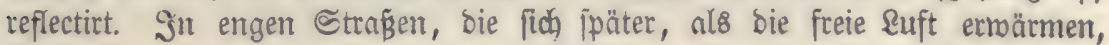
joll man gar keine Temperaturbeobachtungen zu bem angegebenen 3wed"e bornebmen.

c) Da\& Thermometer barf nicht zu nake am Boben angebradht fein.

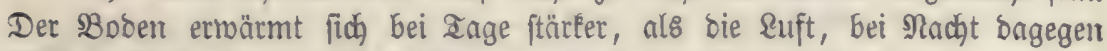
füblt er jidch mefr ab. Das Ihermometer wirb aljo bei Iage bie Zemperatur

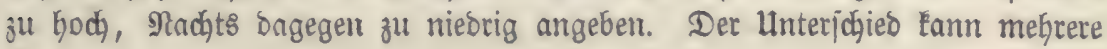
Brabe betragen.

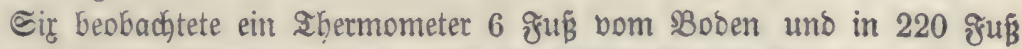
böbe auf einem Ihum; ex fant, baß̉ bie hödffte Iagestemperatur am $\mathrm{BD}=$ Den 70,9 , nuf bem Ihum nur 70,1 , bie niebrigfte Iemperatur am Boben $2^{0}, 6$, auf bem ahum $3^{6}, 1$ betug.

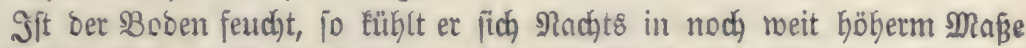

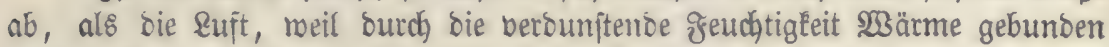

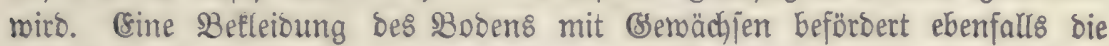
Berbunftung uno jomit bie Erniebrigung der Iemperatur. Daniell bradgte

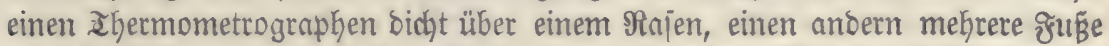
über bemjelben an. Der Unteribied in ben Eleinften şerthen beiber Sinjtru= mente betrug nad, bem Mittel breijähriger Beobachtungen im

\begin{tabular}{|c|c|c|c|c|c|}
\hline anuar & $1^{0}, 9$ & April 3,4 & Șuli & 3,0 & Detober \\
\hline & 2,6 & Mai & 9ługuft & 2,9 & গobember \\
\hline März & 3,1 & Suni 2,9 & September & 2,0 & Dezember \\
\hline
\end{tabular}

\section{Directe Beobaditnngen iiber ben G̈ang ber täglidjen Temuerntur ber \&uft in Sdjutter.}

Die älteften \$eobadjtungen find biejenigen, weldje (5Giminello in \$abua in ben Sahren 1778-1780 mit Unterbrechungen angeftellt hat. Sie exftredfen fich auf bie Dauer bon 16 Mronaten. Mit Nusnahme bon 12 uthr bes Machts bis Morgens 4 Uhr, währents weldher Zeit nur eine Beobachtuutg ftattfant, wurbe bas Ihermometer alle Stumben abgelefen. F̧ü bie feblen=

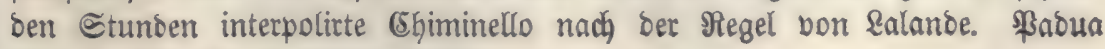
fiegt in $45^{\circ} 23^{\prime}$ nörolidger $\cong r e i t e$. 
Die exften genauen Temperaturbeobadjtungen nady Bhiminello murben

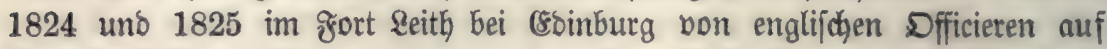
Bremiter's Beranlaffung unternommen. Fort Reith liegt in $55^{\circ} 58^{\prime}$ nörol. Breite.

Borzügliḑe Beobadtungen über ben (Sang ber tăglidgen 23 ăcme in

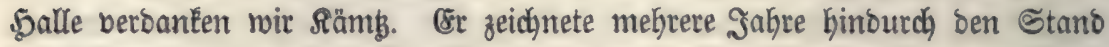

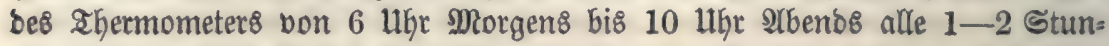

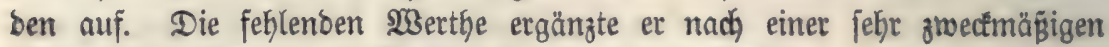
Snterpolationsformel. Salle liegt in $50^{\circ} 31^{\prime}$ in Breite.

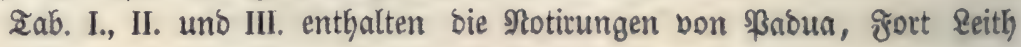
uno balle. 


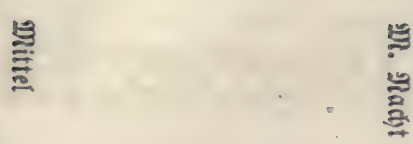

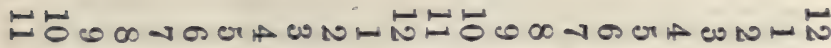

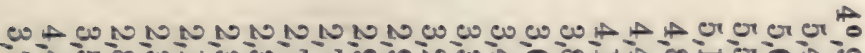

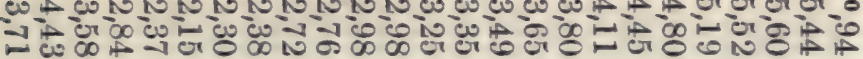

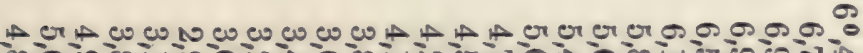

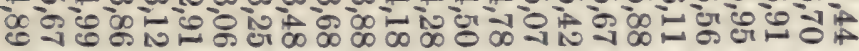

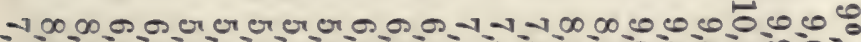

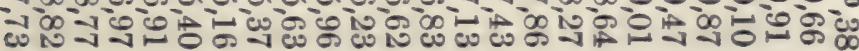

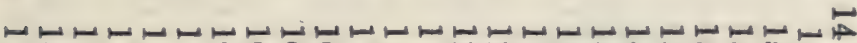
w

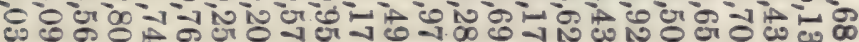

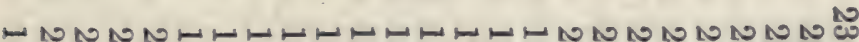
๑ NSNM

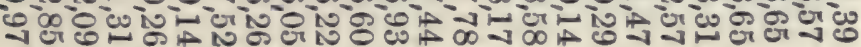

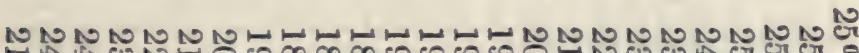

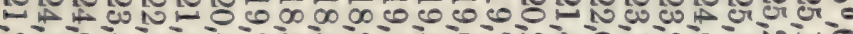

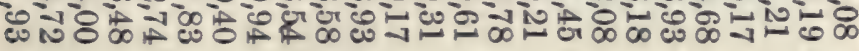

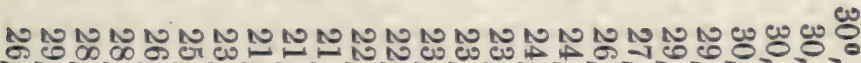

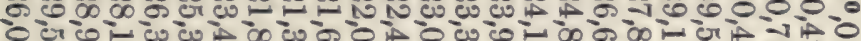
O

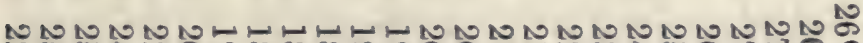

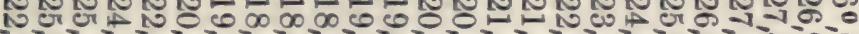

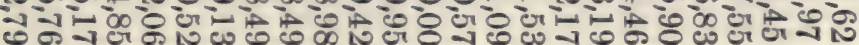

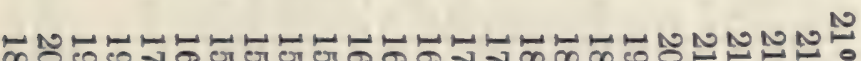

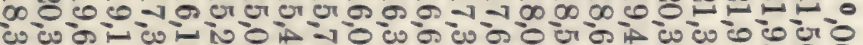
w

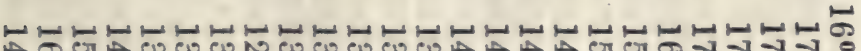
\& F

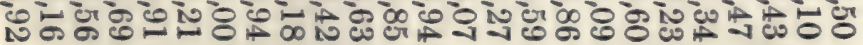

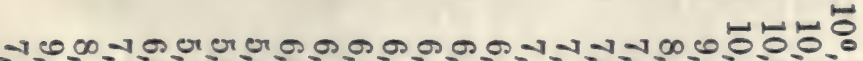
U A vi a 


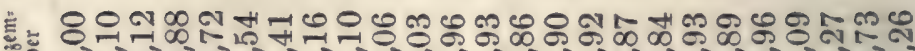

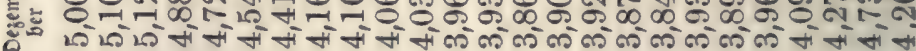
$\dot{\Xi}$

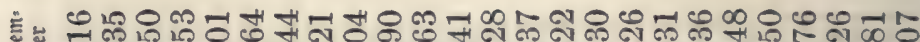

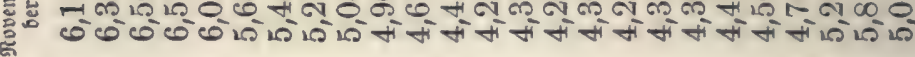

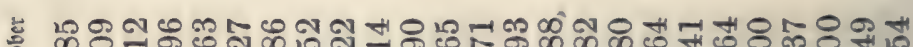
o.

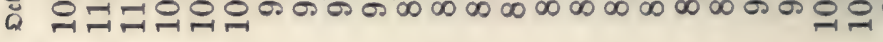

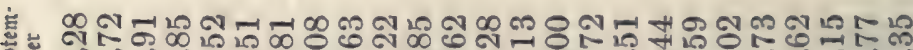

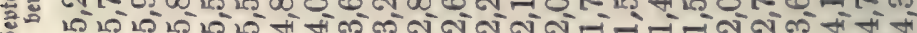
(6)

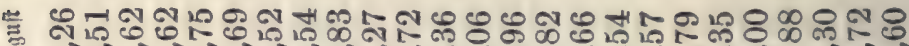

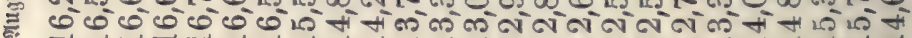

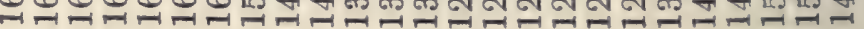

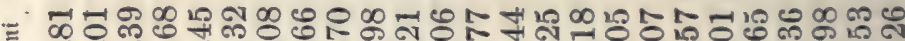

इ แल

난ㄷㅇㅇำ

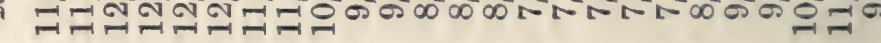

= 규ำ

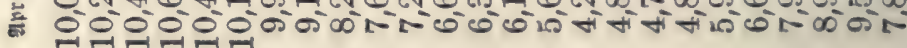

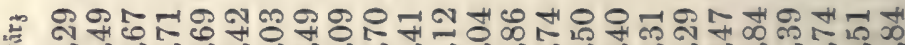

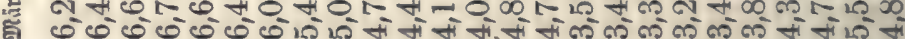
늘

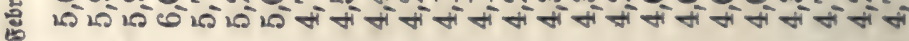

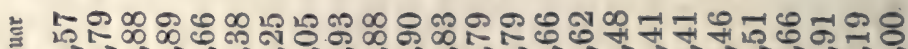

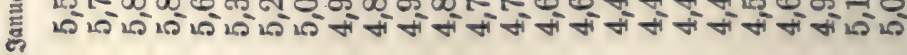

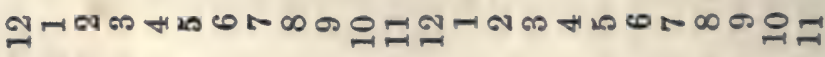
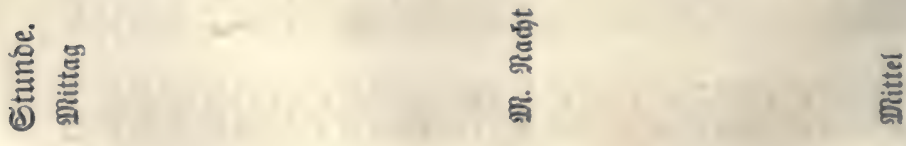
$\frac{1}{2}$

Ш

$1|1| 1|1| 1|1| 1|1| 1|1| 1|1| 1$

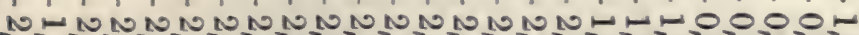
ध一

竞

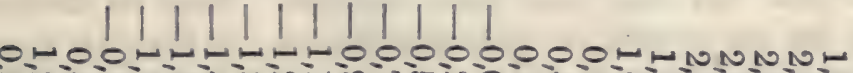

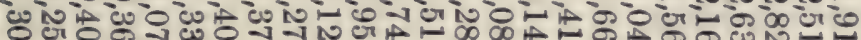

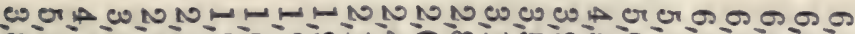

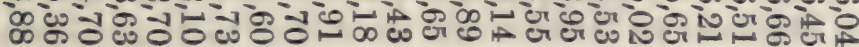

$\frac{3}{2}$

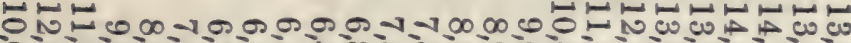
-

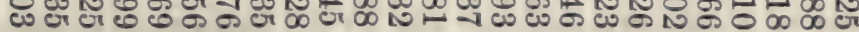

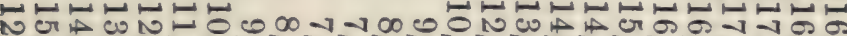
-

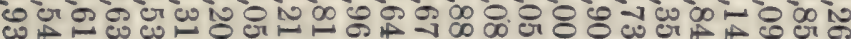

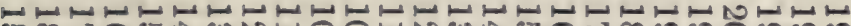
or $\infty$ a Nis wil in

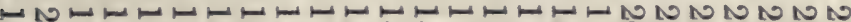

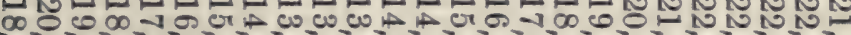

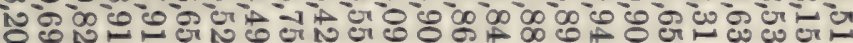

- 0 O

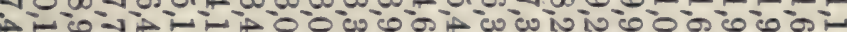
-

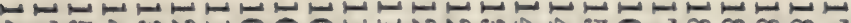

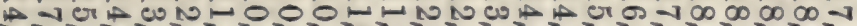

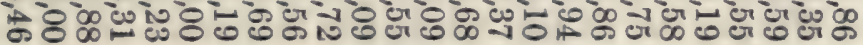

-

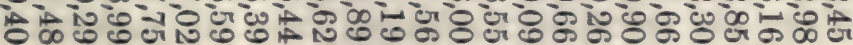




\section{Mefultate ber Beobadjtungen iiber Den B̧ang ber täglidien Zemperatur.}

Die roidjtigften ærolgerungen, relche fich aus ben 3ahlen in ben bor= ftebenben Iabellen zieben lafjen, fint bieje:

\section{Die Ienueratur fteigt von Eonnenaufgang an bi8 วur böळften Bonuenböbe.}

Diejes Rejultat war von born berein abzujehen. Denn bie Sonnen=

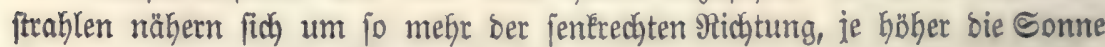
über ben 5orizont emporiteigt.

Inteffen gilt ber obige Sab nur bann, wenn man bon vielen Beobacts= tungen bas Mittel nimmt. Berbecken $\mathfrak{M o l f e n}$ zeitmeije ben Simmel, ober tritt plöblich ein Ealter Ruftitrom ein, fo Eann furz vor Mittag bie Zemperatur fim ten, mähreno fie bon Sonnentaufgang an geftiegen ift.

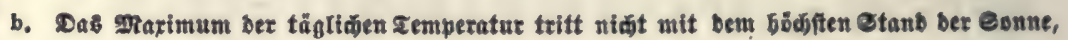
probern etwas päter ein.

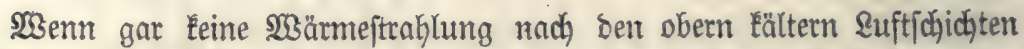
ftattfänbe, fo müpte bie Iemperatur fortwäbrend fteigen. Sach Nufgang ber

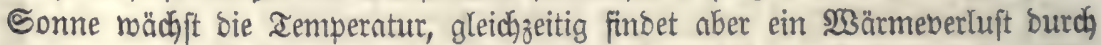
Strahlung ftatt, Deffen SSröge ber Temperaturhb̈he faft gerabe proportional ift. So lange bie zugeführte 233 ärme bebeutender ift, als bie Arusftrablung, nimmt audh bie Iemperatur zu. Da aber bie Somne nad 12 Mbr wieber nad bem

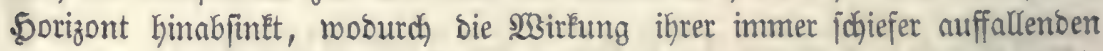

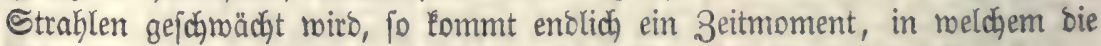

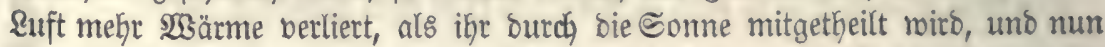

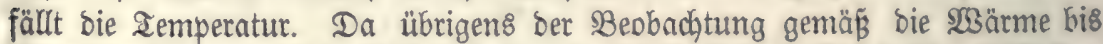
12 uhr fteigt, fo mus bies auth noch einige Beit nach 12 uhr gejojehen, Demn bie Sonne ftebt furz bor 12 ubr eben fo hod) an Sinmtel, als in bem

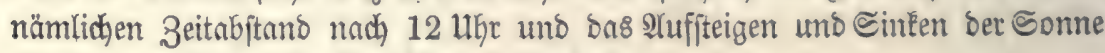

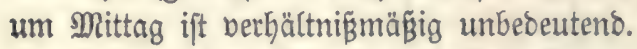

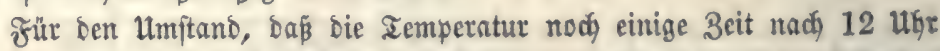
fteigt, hat man fehr abweidjenbe Ǧrtlänungen. (Eine yon bicjen fupt ba=

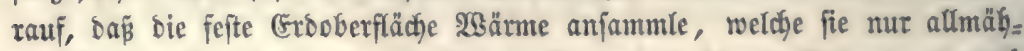

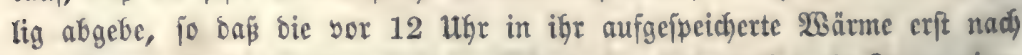

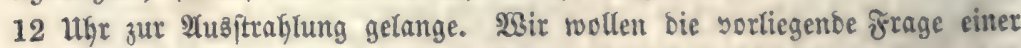

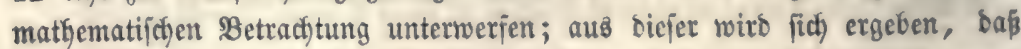
nad) 12 Uhr eine 3unahme ber Iemperatur aud) banu erfolgen mü, wenn ber 90 od gar feine $\mathfrak{W a ̈ r m e ~ a n ~ b i e ~ \Re t m o f p h a ̈ r e ~ a b g i b t . ~}$

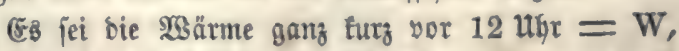

bis 12 Uthe exfolge ber 2 ärmtę̧wađ̆ $=\mathrm{x}$,

10 if bie 2Bärme นm 12 นtดr

$=\mathrm{w}+\mathrm{x}$. 
fieryon nimmt bie Strahlung einen Iheil Ginweg, meldjer ber yor= Gandenen Temperatur proportional ift. Damit wir aber bei biejer Annahme feinen Feffler begchen, müffen wir bie 3eit, in welcher bie Iemperatur W ftattinbet, ganz furg yor 12 $\mathfrak{H}$ hr Iegen.

(5) ift aljo Auzftrahlung $=\frac{w+x}{a}=\frac{w}{a}+\frac{x}{a}$,

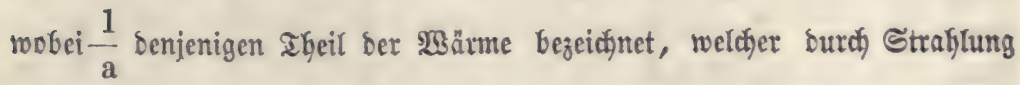
verioren geht. Da wir wiffen, Dap bie Temperatur furge 3eit yor 12 uthr bis zur Culmination ber Sonne fteigt, to muß $\frac{W}{a}+\frac{x}{a}<x$ jein.

Rentent wir $\mathrm{x}-\left(\frac{\mathrm{w}}{\mathrm{a}}+\frac{\mathrm{x}}{\mathrm{a}}\right)=\mathrm{q}$,

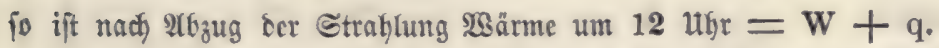

DFienbar erfolgt furze 3eit nad) 12 Uhyr ber nämlidje 3umadjs $\mathrm{x}$, ber

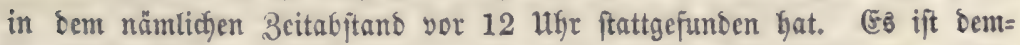
nad)

Iemperatur furze 3eit uad $12 \mathfrak{u g r}=W+q+x$;

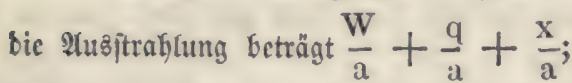

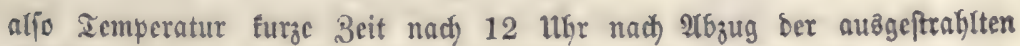
ISărme

$$
\begin{aligned}
& =w+q+x-\frac{w}{a}-\frac{q}{a}-\frac{x}{a} \\
& =w+q+x-\left(\frac{w}{a}+\frac{x}{a}\right)-\frac{q}{a} \\
& =w+q+q-\frac{q}{a} \text { weil } x-\left(\frac{w}{a}+\frac{x}{a}\right)=q \text { gejebs nurbe. }
\end{aligned}
$$

Ez ijt offenbar q größerer, als $\frac{q}{a}$, semmad) $q-\frac{q}{a}$ pofitiv.

Nennen wir $q-\frac{q}{a}=r$, fo ift

Iemperatur furze Beit nad) $12 \mathfrak{u b r}=\mathrm{W}+\mathrm{q}+\mathrm{r}$; es war aber Iemperatur turze 3eit yor 12 uhr $=W+q$

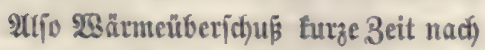

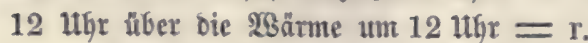

Da wir bei ber yoritefyenton Betrachtung gar teine Rüfficht auj bie

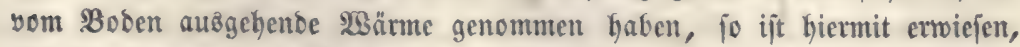
Dap bie Temperatur nach Ser (Culmination ber Sonne nod) einige 3eit ftei=

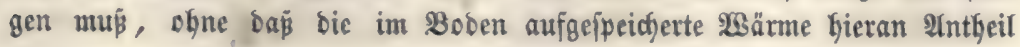
nimutut. 
Die হabellen I., II. unঠ III. ergeben für ben (sintritt bes täglichen NRaris mums bet Iemperatur:

\begin{tabular}{|c|c|c|c|c|c|c|}
\hline Monat & & bua & Forth & Eeith & & \\
\hline Januar & & Uht & & Ihe & & thet \\
\hline そ̌ebruar & 3 & $"$ & 3 & $"$ & 2 & $"$ \\
\hline März & 3 & $"$ & 3 & $"$ & 2 & $"$ \\
\hline 2lpril & 3 & $" \prime$ & 3 & $"$ & 2 & $"$ \\
\hline Mai & $2-3$ & $"$ & 4 & $"$ & 3 & $"$ \\
\hline Şuni & 2 & $"$ & 3 & $"$ & 3 & $"$ \\
\hline İuli & 2 & $"$ & 5 & $"$ & 3 & $"$ \\
\hline श्रนgupt & 3 & $"$ & 4. & $"$ & 3 & $"$ \\
\hline September & 3 & $"$ & 2 & $n$ & 2 & $"$ \\
\hline Detober & 3 & $"$ & 2 & $"$ & 2 & $"$ \\
\hline ఇobember & 2 & $"$ & 3 & $"$ & 2 & $n$ \\
\hline December & 2 & 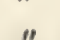 & 2 & " & 2 & " \\
\hline
\end{tabular}

Das Marimum ber tägliçen Temperatur tritt aljo in ben Sommermo:

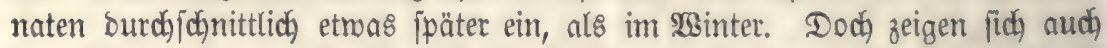

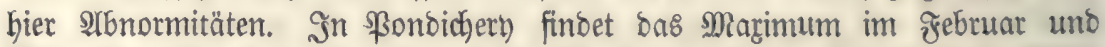
März Bormittags zroijchen 9 uno 10 uhr ftatt, weil um bieje Zeit ein tühler Seeminto bie Temperatur ermäß̈̈gt.

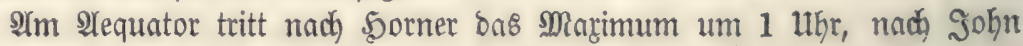
Davy zur Mittagszeit ein. \$umbolbt beobadatete e\& in Cübamerifa um 2

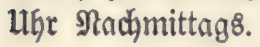

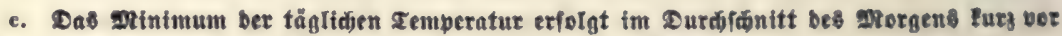
Eonnenaufgang, im 20inter etwa früber, als im Eonmex.

In nebelreidyen Gegenton finft bie remperatur aud oft nod kurge Zeit

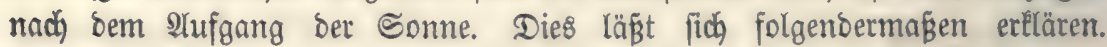

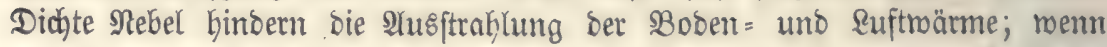
mun Morgens frühe bie Rebel von ber Sonne aufgelöft merben, jo findet plöglich eine $\mathfrak{B}$ ieberausftrablung nach bet freien SItmojphäre Gin ftatt.

\section{d. Die Temperaturveränberungen von Etunbe эu Etunbe befolgen leine genau arttbue:} tiffbe शteibe,

meil bie 3unabme ber Temperatur bem Sinus der Sonnenböhe, bie 21bnahme bagegen ber jebeŝmal ftattfinoenden Temperatur proportional ift.

গach) Den Beobachtungen in \$abun jteigt im jährlichen Mittel bas Ifyer= mometer

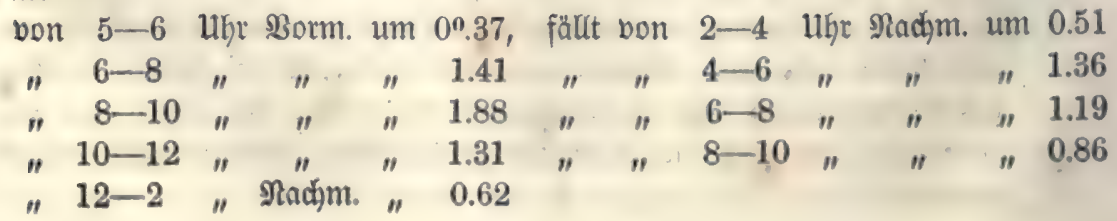


fällt von $10-12$ lth̆r Naçm. um 0.60

$$
\begin{aligned}
& \text { " " 12-2 " Borm. " } 0.52 \\
& \text { " " 2-4 " " " } 0.48 \\
& \text { " " 4-5 " " } 0.07
\end{aligned}
$$

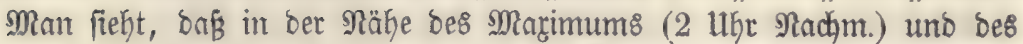
Minimums (5 11hr Borm.) Steigen und Fallen wentiger rafd von Statten geft, als in einiger (Entfernung von biejen beiben Buntten. Der Bang ber Demperatur befolgt alpo bas in ber reinen Mathematié längit beĺannte Beję,

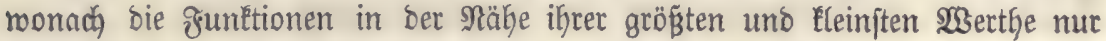
allmäblig z̆u= uno abrefymen.

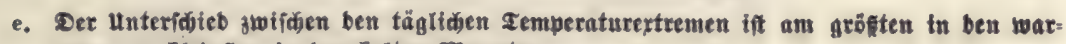

\begin{tabular}{|c|c|c|c|c|}
\hline & Babua & Forth \&eith & Salle & Büridy \\
\hline Sanuat & $3^{0,45}$ & 1,48 & 1,36 & $4^{0.0}$ \\
\hline Februar & 4,04 & 1,98 & 4,22 & 4.7 \\
\hline März & 4,94 & 3,42 & 5,06 & 6.5 \\
\hline April & 5,50 & 5,88 & 7,90 & 8.2 \\
\hline Mai & 7,60 & 4,77 & 9,33 & 9.5 \\
\hline Suni & 6,67 & 4,63 & 9,26 & 8.7 \\
\hline Suli & 9,39 & 5,38 & 9,21 & 9.5 \\
\hline श)guft & 9,06 & 4,21 & 8,92 & 8,3 \\
\hline September & 6,92 & 4,47 & 8,03 & 7,3 \\
\hline Dctober & $.4,53$ & 2,71 & 6,77 & 6,3 \\
\hline Rovember & 5,17 & 2,24 & 3,45 & 3,5 \\
\hline December & 4,11 & 1,28 & 2,09 & 3,3 \\
\hline
\end{tabular}
men, an Eleinften in ben Falten Mtonaten.

Dies ergibt folgende Heberficht:

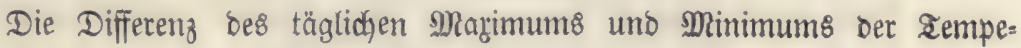
ratur ift

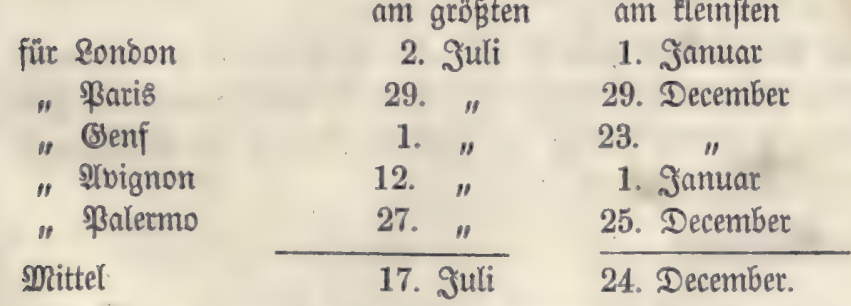

Sn ber ßolargone ift ber Unterichied ber täglichen Temperaturertteme

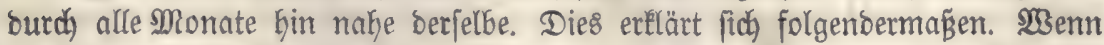
im Sommer bie Sonne gar nicht ober mur hurze Zeit unter ben \$orizont tritt, fo kann beinahe gar leine Arbfühlung ber artmojphäre ftattfinden; unto menn im 2 Binter bie Sonne gar nidgt Dober nur kurze Zeit über ben Sorizont 
fteigt, fo fann wieberum feine Srwärmung erfolgen. Somit bält fich ber lin= terjhieb ber (Ertreme in allen Sabreszeiten nahezu gleid).

3ur Beptätigung biejes (sejęes biene die folgende Tabelle, weldhe bie Differenz ber monatlidyen Temperaturidhwantungen für (snontekis $\left(68^{\circ} \frac{1}{2}\right.$ ก. 3 .) in Rapplano angibt.

\begin{tabular}{|c|c|c|c|}
\hline Sanu & 4.96 & guli & \\
\hline Febrt & 4.96 & Âguft & \\
\hline März & 7.16 & September & \\
\hline 2lpril & 5.40 & Detober & \\
\hline Mai & 3.91 & Robember & \\
\hline Juni & 4.03 & December & \\
\hline
\end{tabular}

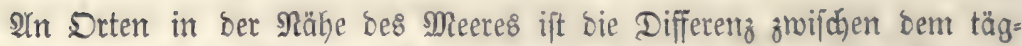
lichen $\Re$ arcimum und Minimum Hleiner, als im Binnenlanbe. Das Meer et= roärmt fïch, wie wir fpäter fehen merben, bei

ซig. 87.

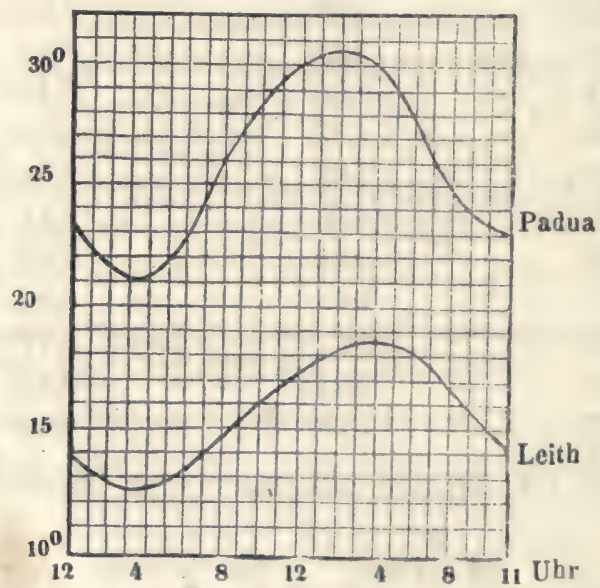

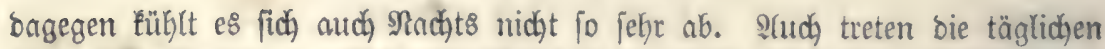
Temperaturegtreme am Meer etmas fpäter ein, wie bie nebenanftefyento gra=

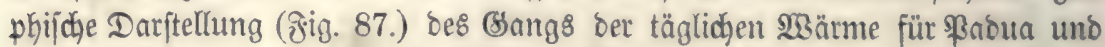
Fort Reith in bem Monate Suli zeigt.

\section{Mittlere నageștenuperatur.}

\section{Eegriñ.}

WBit Gaben im vorigen ßaragraphen gejehen, baß̈. bie Temperatur im \&aufe eimes Tages fortwährent fich änbert. Theilt man aber bie Zeit von 24

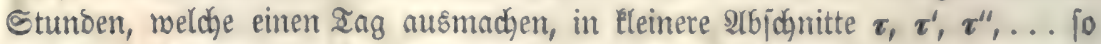
fann innerhalb biejer bie Temperatur $t, t^{\prime}, t^{\prime \prime}, \ldots$ als ftationär angenommen

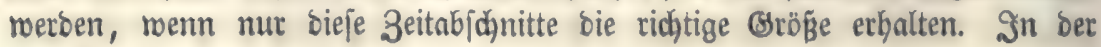




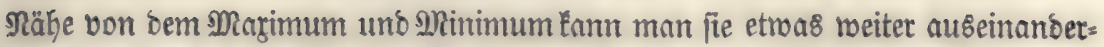
legen, meil an biejen Pumtten bie Temperatur nur allmählig zu= ober abnimmt.

Run babe man beobaditet:

raăhrento ber Zeit $\tau$ bie Temperatur $t$

" " " " $\quad \tau^{\prime \prime} "$ " " $\quad \mathrm{t}^{\prime \prime}$ uno jo fort,

To ift bie ๔umme aller Temperaturen trährent eines Tages

$$
=\tau t+\tau^{\prime} t^{\prime}+\tau^{\prime \prime} t^{\prime \prime}+\ldots \ldots
$$

Bejęst, bie aemperatur jei innerbalb 24 Stunben $e_{i q u}$ uno biejelbe uno $=\mathbf{T}$

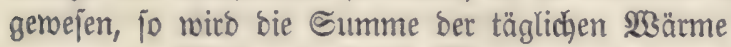

$$
=\mathrm{T}\left(\tau+\tau^{\prime}+\tau^{\prime \prime}+\ldots . . . . .\right.
$$

fein. Saben (1. uno (2. gleidgen 23erth, fo folgt aus

$\mathrm{T}\left(\tau+\tau^{\prime}+\tau^{\prime \prime}+\ldots \ldots\right)=\tau \mathrm{t}+\tau \mathrm{t}^{\prime}+\tau^{\prime \prime} \mathrm{t}^{\prime \prime}+\ldots .$.

$\mathrm{T}=\frac{\tau \mathrm{t}+\tau^{\prime} \mathrm{t}^{\prime}+\tau^{\prime \prime} \mathrm{t}^{\prime \prime}+\ldots}{\tau+\tau^{\prime}+\tau^{\prime \prime}+\ldots}$

T nennt man bie mittlere angestemperatur. Dieje gibt uns aljo an, roie grof́ eine (eingebildete) conftante Temperatur fein muß̈, bamit bie $23 a ̈ r m e=$ jumme im Raufe eines Iages gleid) berjenigen fei, meldbe fich ergibt, wenn Der afermometerfand fortwähreno fich ändert.

\section{b. Metbobe zur Beftimuung ber mittleren Iagestemperatur.}

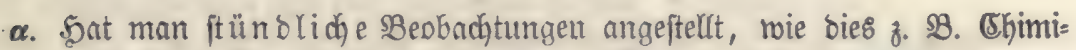
minello für ßabua, Säms für Soalle gethan haben, fo erhält man aus (Sleichung (3. unmittelbar bie mittlere Iemperatur bes rages, wenn man in jener $\boldsymbol{\tau}=\tau^{\prime}=\tau^{\prime \prime}=\ldots . .=1$ jest. Es ift bann

$$
T=\frac{t+t^{\prime}+t^{\prime \prime}+\ldots}{24}
$$

Man erhält aljo nus ftünolidgen Thufzeidynungen bes ahermomes ters bie mittlere ragestemperatur, wenn man bie beobadhteten Iemperas turen abbirt uno bie erhaltene Summe burd 24 bibibirt.

So ift : B. Die mittlere Ingestemperatur bes Monats Mai zu Salle $=(16,26+16,85+17,09+17,14+16,84+16,35+$ $15,73+14,90+14,00+13,05+12,08+10,88+9,67+$ $8,64+7,96+7,81+8,21+9,05+10,20+11,31+12,53$ $+13,63+14,61+15,54): 24=12,93$.

$\boldsymbol{\beta}$. Die halbe Summe ber beiben tägliden Iemperatureg= treme gift bie mittlere angestemperatur ziemlid, genau an, wie fol= gente Heberfidt, entnommen aus ben Beobadhtungen Chiminello's, jeigt. 
Padua.

Mebium aus 24 Meoium aus bem

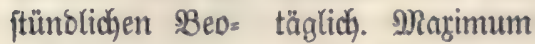

\begin{tabular}{|c|c|c|c|}
\hline & bachtungen & uno Minimum & Differenz \\
\hline Sanuar & $3^{0}, 71$ & $3^{0}, 84$ & $+0^{0}, 13$ \\
\hline grebruar & 4,89 & 4,93 & $+0,04$ \\
\hline Mårz & 7,73 & 7,63 & $-0,10$ \\
\hline 2lpril & 13,03 & 12,95 & $-0,08$ \\
\hline Mai & 19,97 & 19,85 & $-0,12$ \\
\hline Suni & 21,93 & 21,88 & $-0,05$ \\
\hline Şufi & 26,06 & 26,04 & $-0,02$ \\
\hline Áuguft & 22,79 & 23,02 & $+0,23$ \\
\hline September & 18,38 & 18,51 & $+0,13$ \\
\hline Detober & 14,92 & 15,20 & $+0,28$ \\
\hline ఇobember & 7,73 & . 8,33 & $\begin{array}{r}0,60 \\
+0,6\end{array}$ \\
\hline December & 3,84 & 4,35 & $+0,51$ \\
\hline
\end{tabular}

Durch 2 nnwentung bes Thermometrographen wiro bie Serleitung ber mittleren Ingestemperatur aus ben täglichen Iemperatureçtremen auperordentlid, erfeidjtert, fo baß fie in ber Ihat jeber andern borzuzie= Gen ift. Die arbreichung bon bem raabren Mittel beträgt nach ifgr im Durchidgnitt nod nicht 0,2 (serab.

r. Beobadtung ber angeszeit, um relde eine ber mittlern Tagesmärme gleidhe Iemperatur ftattfindet.

Diejes $\mathfrak{B e r f a h r e n ~ m u ̈ r b e , ~ m e n n ~ e \& ~ f i c h ~ a l s ~ p r a c t i f i c h ~ e r m i e j e , ~ b e n ~}$

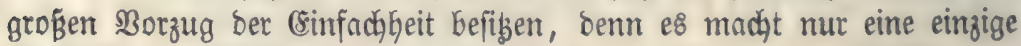
Beobachtung nöthig.

Rämb hat bie 3eit genauer berechnet, um weldhe bie mittlere $2 a=$ gestemperatur in Proun uno \&eith eintritt und folgende $\mathfrak{W}_{\text {erthe ge }}$ funben:

\begin{tabular}{|c|c|c|c|c|}
\hline & \multicolumn{2}{|c|}{ Morgen } & \multicolumn{2}{|c|}{ शrbento } \\
\hline & Pabua & Eeith & Babua & Seith \\
\hline . & uht & $116 \mathrm{r}$ & uhr & $115 \mathrm{r}$ \\
\hline Januar & 10,2 & 10,3 & 8,7 & 7,8 \\
\hline Z̆ebruat & 10,1 & 9,9 & 9,7 & 7,2 \\
\hline März & 9,6 & 9,9 & 9,2 & 8,6 \\
\hline Ipril & 9,5 & 9,0 & 9,1 & 8,8 \\
\hline Mai & 7,6 & 9,0 & 7,6 & 9,0 \\
\hline Şuni & 7,4 & 8,8 & 7,1 & 8,6 \\
\hline Şuli & 7,5 & 8,7 & 7,1 & 8,9 \\
\hline Q̃uguft & 8,2 & 8,8 & 7,4 & 8,5 \\
\hline September & 8,8 & 9,1 & 7,9 & 8,2 \\
\hline Detober & 9,4 & 9,2 & 7,5 & 6,8 \\
\hline Rovember & 9,2 & 9,6 & 6,6 & 7,7 \\
\hline Decembet & 9,6 & 9,5 & 7,5 & 6,2 \\
\hline
\end{tabular}


SBie man fieft, weidjen bie Stunben ber mittlern Iagestempera=

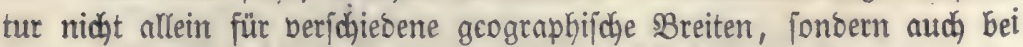
einem und Demjelben Drt interbalb ber verjediedenen Monate von ein=

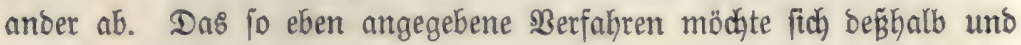
außerbem nod) aus bem (srunde menig empfehlen, weil c8 bas forgs jame 2 fbmarten einer beftimmten 3eit erforbert. Die (8rmittlung biefer Zeit, reldhe für jeben Dot eine andere ift, legt Die Senntniß des (Sangs ber täglichen Iemperatur boraus. Şat man biejen aber einmal bejtimmt, jo erhält man bie mittlere Temperatur ganz einfach nady ber Methobe unter $\boldsymbol{\alpha}$.

d. Man nimmt aus mefrern Beobadutungen, weldye an veridhiebe= nen Tagesftumben angejtellt roorben fino, bas Mittel uno corrigirt bie=

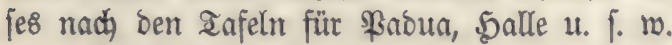

(58 jei z. B. für einen Drt $x$ in Deutjhlano an irgeno einem

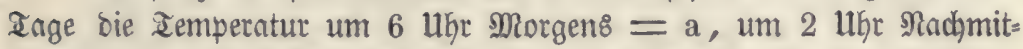
tags $=b$, um 9 uhr âtbenos $=c$, für Salle uno bie nämliçen Iagesftunden $=\mathbf{A}, \mathbf{B}, \mathrm{C}$ gefunoen werben, fo ijt bas Mittel aus ben erften srei Beobachtungen $=\frac{a+b+c}{3}=d$, aแร ben brei leğten für \$alle $=\frac{A+B+C}{3}=D$. (\$8 jei bie wahre Mnittels temperatur von Salle $=\delta$, jo ift $\delta-\mathrm{D}$ ber pofitive ober negative Unterjchied, weldgen man zu d fügen muю um bie richtige Mitteltem= peratur für ben Drt $\mathrm{x}$ zu erhalten.

Sejebt, es wäre an einem Tage bes Monats ๔eptember a $=$ $12.12, \mathrm{~b}=18.30, \mathrm{c}=15.36$ gefunden worben. Nach Iabelle III. beträgt für Salle $\mathrm{A}=11.19, \mathrm{~B}=18.59, \mathrm{C}=14.10$; aljo ift $\mathrm{d}$ $=15.26, \mathrm{D}=14.63$; ef iff $\delta=14.46$, bemnact) $\delta-\mathrm{D}=-$ 0.17 ; biejen $\mathfrak{M B e t t h}$ zu $d=15,26$ nobirt, gibt bie wahre Mitteltempe= ratur bes Drtes x zu 15,09 ar.

$23 e n n$ man mit Eeinem Ihermometrographen berjeken ift, fo leiftet bas eben bejdyriebene Berfahren gute Dienfte. Doch muß́s man in ber Qluswahl ber હtunden, an weldgen bie Beobadjtungen anzuftellen find,

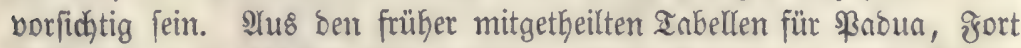

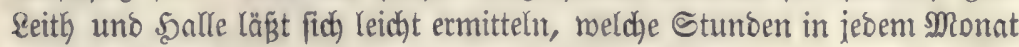
zu berartigen Dbjerbationen am meiften fid) eignen. 


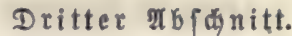

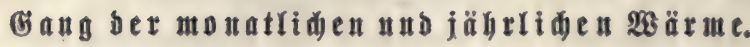

\section{Menatlidge 23 ärme.}

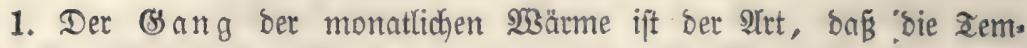
peratur bon Sinfang bes Monats bis zum Ende beffelben entroeber ifteigt

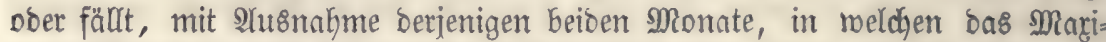
mum ober Minimum ber jäfrliçen $\mathfrak{x a ̈ r m e ~ e i n t r i t t . ~ D e r ~ n o r m a l e ~ ( S a n g ~ b e r ~}$ monatfichen remperatur ergibt fich indefien nur aus mebriäbrigen Beobad)= tungen, in weldhen fich einzelne Srregularitäten ausgleichen.

2. Die mittlere $\mathfrak{S}_{3}$ ärme eines Monats findet man am ge=

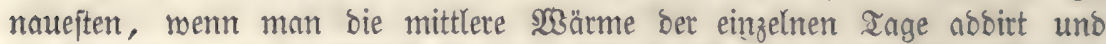

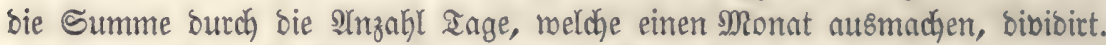

Die mittlere Iemperatur eines 9 Monats medjelt bon Sabr zu Jahr; fo war z. $B$. Der Februar im Sahr 1849 in unfern Gegenden jefr Ealt, ber nämliche Monat im Safre 1850 nuffallent gelino. Utm bas ridgtige Mittel zu erbalten, nimmt man baher aus mehrjährigen Beobachtungen ben Durchj) (d) nitt.

\section{23 ărme im $\&$ aufe seb găbre\&.}

\section{Goug ber jübrlidjen 23 ärme.}

\section{A. Wgemeines.}

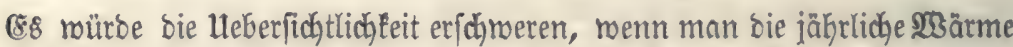
bon $\mathfrak{x} a g$ zu Iag berfolgen rollte; man nimmt beşhalb bie mittlere monat=

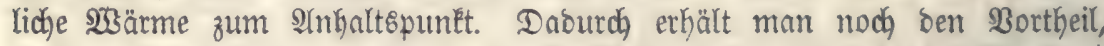

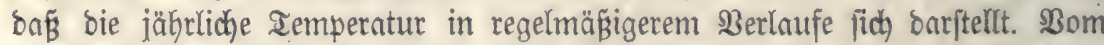
rein theoretijđen Stanopuntt aus betrachtet, follte man meinen, bie Wärme

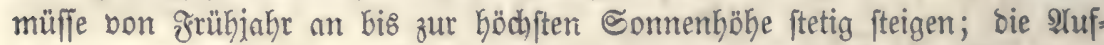

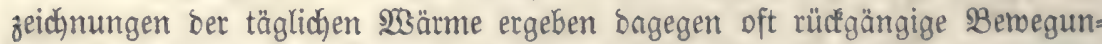
gen, bie von mandhen zufälligen Störungen, z. B. SBinben, Itegentagen u. f. m. Gerrühren. In bem monatlichen Mittel gleidjen fich bieje शtbnormitäten aus.

Nach ber fo eben empfoblenen Methode erbält man arjo eine graphifdge

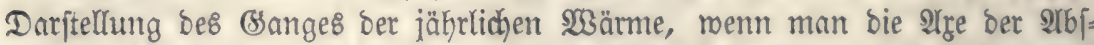
ciffen in 12 gleidge Theile, entiprechend Der $\mathfrak{A}$ (nzahl ber Monate, zerlegt, in Den Theilumg8punten Droinaten erhebt uno biefen eite foldhe Eänge gibt, melche ber Temperatur ber betreffenden Monate proportional ift. Inoeffen barf nidht überjehen werben, baß̈ bei biejer Darftellungsmeife bie wabren Marima uno Minima ber jährlichen Iemperatur ausfallen. Um fie fichtbar zu madjen, ras in Elimatogijdjer Beziefung mitunter roichtig ift, muß eine bejonoere (Eurve verzeichnet werben. 


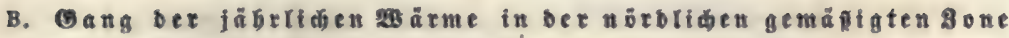 un in ber n bैrblidien}

a. Das Minimum ber Temperatur tritt nicht mit bem niebrigiten Ctand ber Sonme (23. Dezember) ein, fonderm fältt etmons fpäter, bei= nabe in bie Mitte bes Sanuar. Die Urjache biejer (srjocheinung liegt $b a=$

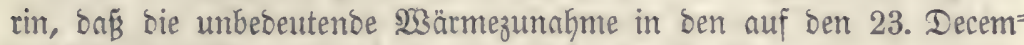
ber folgenden Ingen burch bie biel ftärfere 2 (usftrahlung übermogen wirb.

Der fältefte Iag tritt ein:

in Enontefis am 20. Sanur; in Upjula am 16. Sanuar;

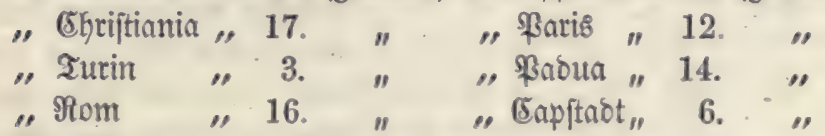

Im Mittel am 13. Sanuar.

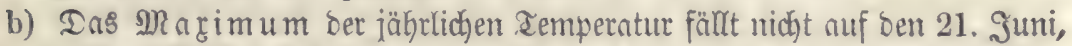
an meldyem Inge bie Eonne ifren hödjpten Etanto erreicht, fonbern in

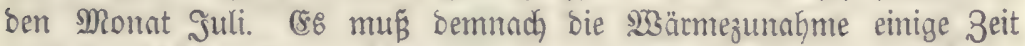

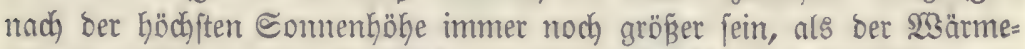

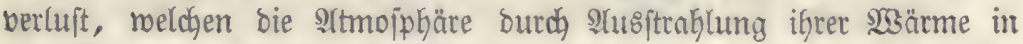
ben $\mathfrak{B e l t r a u m}$ erfährt. (Es läß̈t jīh) gerabe 10 , wie wir e\& für ben Eintritt bes tägliçen నemperaturmaçimums gethan hnben, ber Beneeis

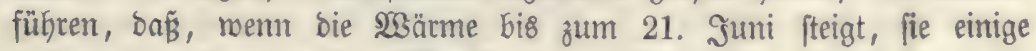

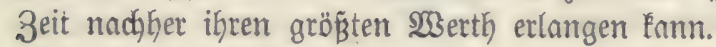

Der wårmfte $\mathfrak{I a g}$ tritt ein:

in Enontefis am 26. Suli

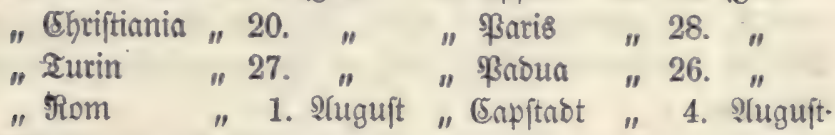

Im Mittel am 27. Suli.

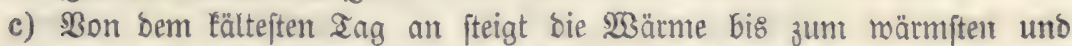
uno kehrt barauf mieder zur Iemperatur bes Eälteften Inges zurüct. IIm geringiten ift bie Aenberung ber $\mathfrak{B a ̈ r m e}^{2}$ in Der Nähe ber beiben Temperatureştreme.

‡iı. 88.

J-A, A.S, S. O, O-N, N.D, D.J
Die Berzeidynung ber neben ftehenten ஓig. 88. berfuntlicht bas relatibe Steigen uno ₹allen ber Temperatur in einzel= nen Mionaten. Die erite Dr= binate gibt alt, um roie viel bie mittlere remperatur bes Jebruar biejenige des Ja muat übertrifft, bie folgenden zeigen ebenjo bie Temperatur= bifferenzen ber übrigen Monate. 


\section{c. Gang ber fäbrliden 20 äre innerbalb ber genbefreffe.}

Fig. 89.

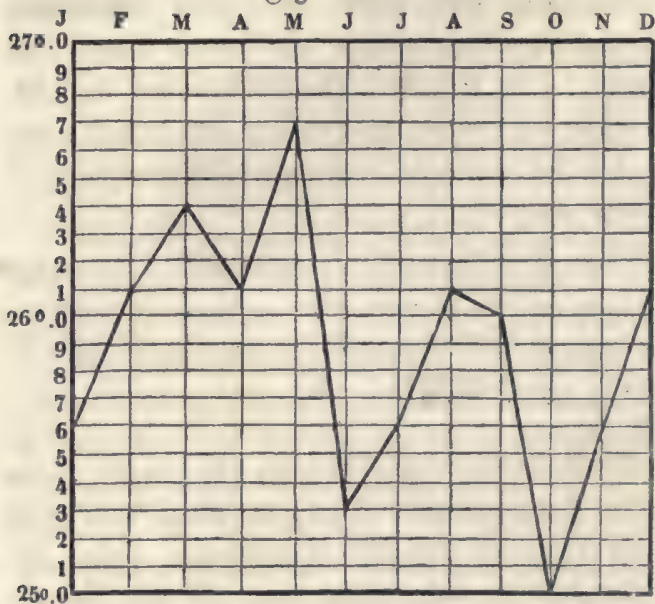

Die Temperatur in ber Geipen 3one follte, ba bie Sonnen= ftrablen zneimal bes Sahres auf jeben Dort jentredyt ein= fallen, znei Marima haben. Die Sybrometeore, weldye in= nerfalb ber michtige Rolle ipielen, änoern aber biejen bsang ber Iempe= ratur, wie er fid aus ber Theorie ergibt, wejentlich $a b$, wie bie Bergeidynung in Fig. 89. für Batabia $\left(6^{0} 12^{\prime}\right.$ [übl. 8 reite) augenicheinlich macht.

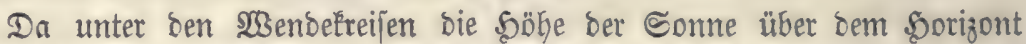
währeno Den Sahreszeiten nidht jo jehr bifferirt, alz in ber gemäß̈igten un

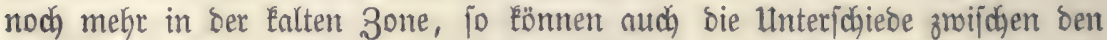

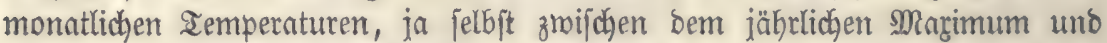
Minimum dajelbft nicht jo bebeutend fein. In ber Ihat jehen mir aus gig. 89, Daß́ bie Temperatur bon Baatabia fich zmijchen $25^{\circ}$ uno $26^{\circ}, 7$ berwegt. Dagegen fano Sarty bei feiner Norbpolerpebition al\& Göchften IGermometer=

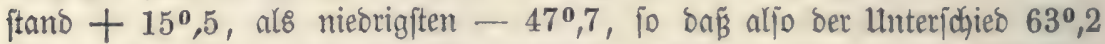

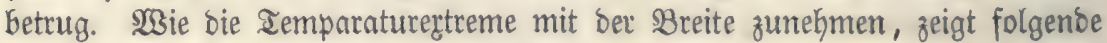
3u|ammenftellung.

Drt.

Cumana

grunchal auf Mabeira $\}$

Rom

Stoctholm

Enontefis in sappland

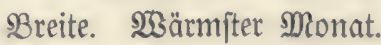

$$
10^{0} 27
$$

$32^{\circ} 37^{\prime}$

$41^{\circ} 53^{\prime}$

$59^{\circ} 20^{\prime}$

$68^{\circ} 30^{\prime}$

$$
29^{\circ}, 1
$$

25,0

17,8

15,3
Eältefter Monat. Unteridojieo.

$$
26^{\circ}, 7
$$$$
2^{\circ}, 4
$$

17,8

6,4

5,6

19,4

5,1

22,9

18,1

33,4

\section{Gang ber jäbrlíben 20 äre an Drten, welde nabe an grofen gaffer: ráden gelegen itub. Geeflima.}

Da bie \&uft mur ungefähr ein Drittel bon ber 203 ärme ber Conmen=

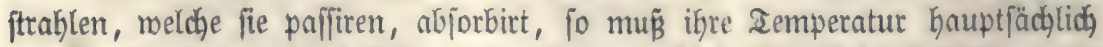
bon ber (strwärmung bes sBobens Gerrilthren, weldyer forwohl burdh \&eitung, als

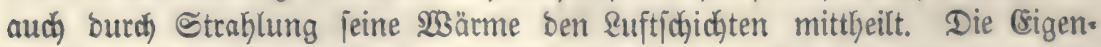

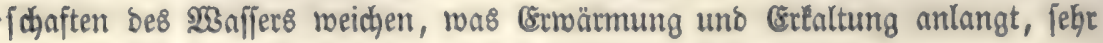


mejentlid, bon benen bes feften Sobens ab; Gieraus folgt, baßs Drte an ber See anders temperirt jein werben, als Drte im sBinnenlanoe. Da bie Ruft über Dem Meere nidht ftagnirt, fonbern burch. WBinbe bon einer Stelle zur

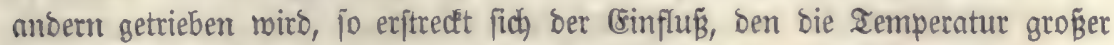

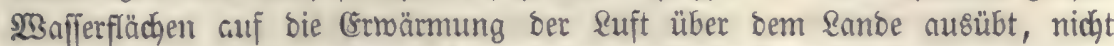
blos auf bie Rüptengegenoen, fondern ift oft noch in weiter Entfernung bon

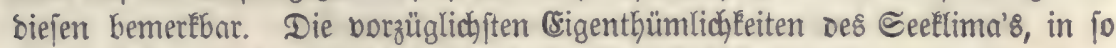
meit baffelbe burch bie $23 a ̈ r m e$ bebingt mirb, find folgende:

a) Drte an ber See haben in ben Sommermonaten eine geringere \&uftemperatur, als Drte im Binnenlande, weldye mit jenen unter gleider 8 reite liegen - und gwar aus folgenden (s) rünon:

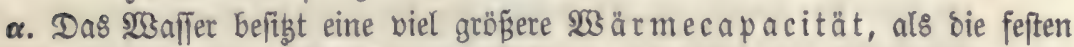

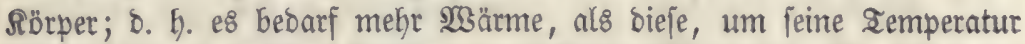

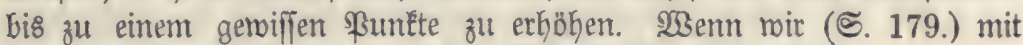

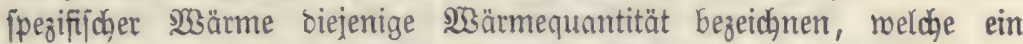
Rörper aufnefmen $m u \tilde{B}$, bamit feine Semperatur um $\mathbf{1 0}^{0}$ fteigt, io et= forbert:

\begin{tabular}{|c|c|}
\hline Wुaffet & 1.0000 \\
\hline Siallipath & 0.2170 \\
\hline 2trragonit & 0.2018 \\
\hline Dolomt & 0.2179 \\
\hline (3)yp & 0.2728 \\
\hline Arbular & 0.1861 \\
\hline 2nbit & 0.1961 \\
\hline Rabrabor & 0.1926 \\
\hline Irugit & 0.1938 \\
\hline Bergertyftall & 0.1894 \\
\hline Euft & 0.2669 \\
\hline sobkenfäure & e 0.2210 \\
\hline
\end{tabular}

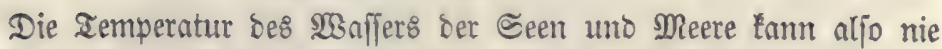
fo hoch fteigen, als biejenige bes feften \&anbes. Die nämliche $\mathfrak{S B a ̈ r m e}=$

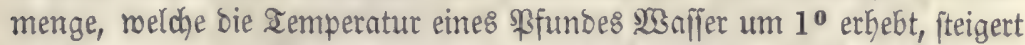

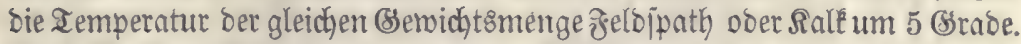

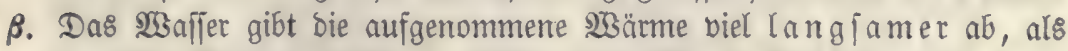
Der fefte Bobent. Resterer befibt ein größ̈eres Strahlungsivermögen,

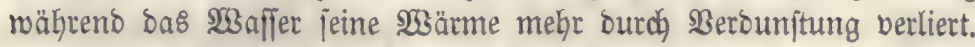

b) Drte an ber See Gaben rörmere Winter, als Drte im Binnenlande.

Die Urjacten biejet Bricheinung fint folgende:

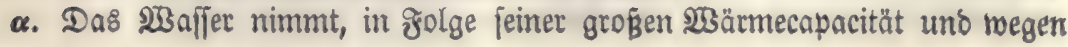




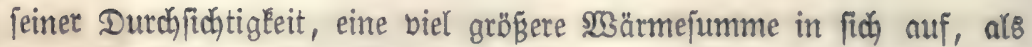
ber fefte Boben. Die Märme ber Sommenftrahlen wiro nut an ber

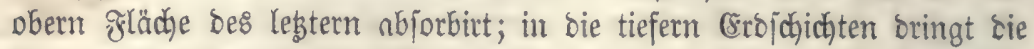
Temperatur nur mittelft Reitung vor. Dagegen gelangen bie Somren=

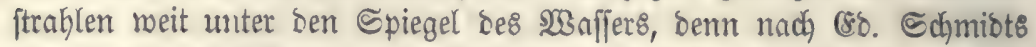

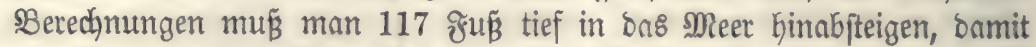
bie Eonne nidjt beller erfdjeint, als ber ßollmono.

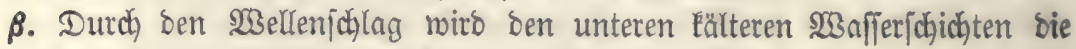
Temperatur ber oberen rärmeren fdhnell mitgetheilt.

$\boldsymbol{\gamma}$. Da bie Temperatur bes $\mathfrak{B}_{\mathrm{S}}$ fers, wegen feiner hohen $\mathfrak{3 a ̈ r m e c a p a c i t a ̈ t ~}$

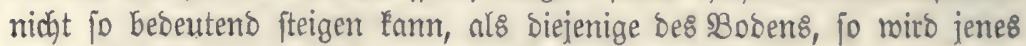

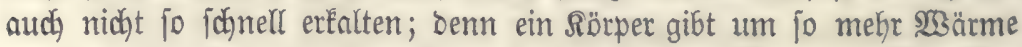

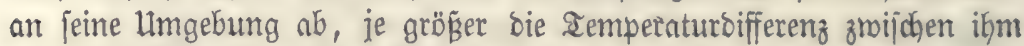
uno biejer limgebung ift. Ifuferbem befigen aber aud bie feften Sïrper

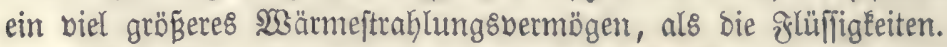

Ât8 allem Diejem folgt, daß́ zmar bie Cee fich lnugamer er= wärmt, als bas \&ano, bagegen aber aud bie einmal angenommente Temperntur biel länger, jelbjt bis in ben $23 i n t e r$ binein, beibehält. Sie gibt ifre 203 ärme erft in ber Eăltern Sahreszeit wieber $a b$, und zwar mittelft ber $\mathfrak{B}$ afferdämpfe, weldye fich burch bie Berbunftung

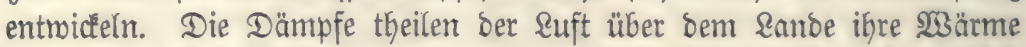
mit, roenn fie mit ifr in Berüfrung fommen, ober fie berbidgten fidh zu Regen, Der ben $\Re$ oben erroärmt.

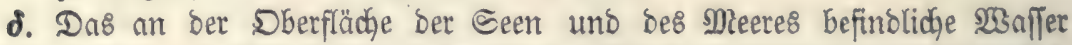
erfaltet uno finft Dann, meil jein fpezifijches (semicht zugenommen Gat, nach ber Tiefe himunter; bafür fteigt aus biejer rärmeres 233 affer in

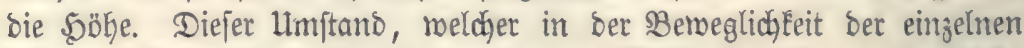

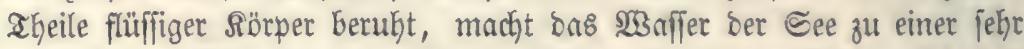

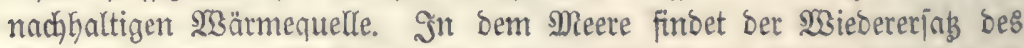

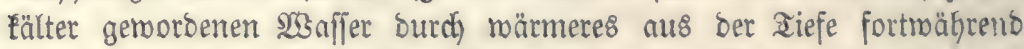
ftatt, weil bas jpesififhe (semidht bes Meeresmaffers zunimmt, nem jeine Iemperatur funft. Das jü̈е $23 a$ ffer ber Eandjeen leijtet einen

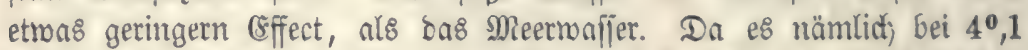
jeine größ̈te Didjte erreidyt, fo wirb an Dem Brunbe eines joldgen ๔ees das wärmere $\mathfrak{B a f f e r ~ ( b o n ~} \mathbf{4}^{\mathbf{0}}, \mathbf{1}$ ) fich auffalten, roähreno über ifm Eälteres, aber fpezifijich leidyteres 230 affer fich befincet.

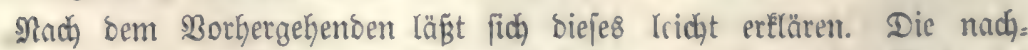
ftehenbe Heberficht für ßaoua (im Binnenlande) und Reith (an ber See) zeigt

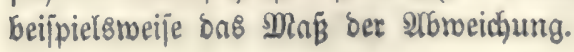


C3ang bet monatliđen unb jăhrliden DBårme.

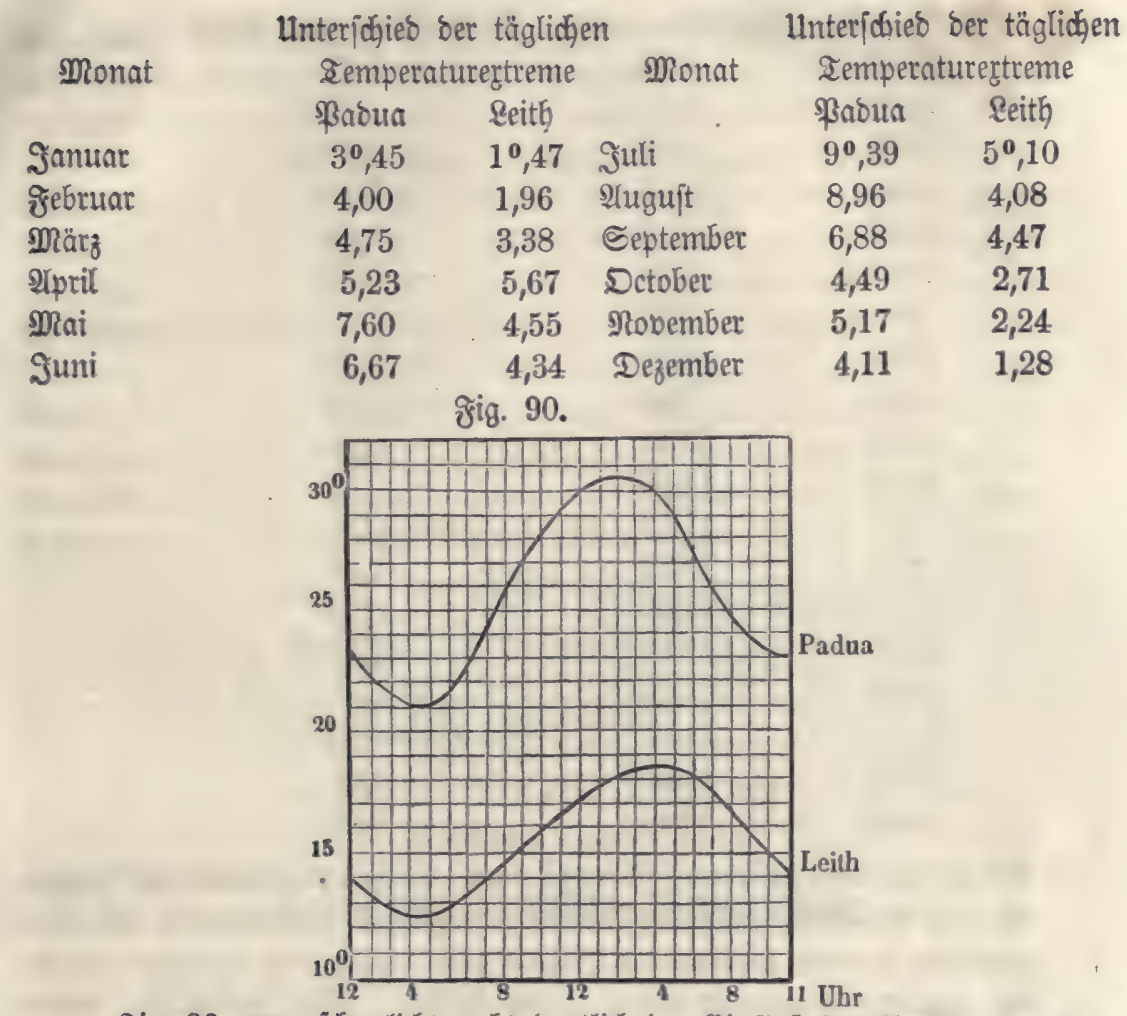

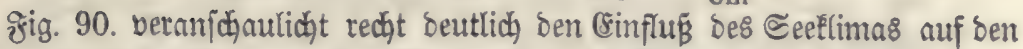

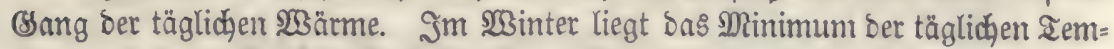
peratur nicht jo tief, Dagegen bas Marimum höher bei Drten, weldje Seeflima Gaben.

\section{Mittlere Săreåtemperatur.}

Die Methooen zur Befitimmung ber mittlern Jahrestemperatur fins folgenoe:

a) Man abbirt bie mittlere Temperatur jebes Inges burd bas ganze Jahr Gin und theilt bie Eumme burdh bie $2(n$ zahl ber Inge (365). Das nämliçe Rejultat ergift fich, inoem bie Summe ber mittleren Montat=

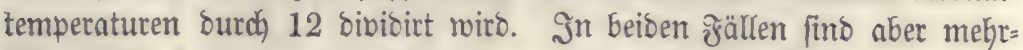
jährige Beobachtungen nöthig, menn bie gefundene 3 ahl bie richtige fein foll, benn bie mittlere Temperatur eines und beffelben Monats meicht in verichiedenen Jahrgängen oft gänz̧lich abs. Irogbem ift aber ber gehler bod nidht jehr bebeuteno uno überfteigt jelten bie Bröge von 1,5 Srad.

Man fano für Paris bie mittlere Jahrestemperatur, berechnet aus

21 Beobaçtungen $=10^{\circ}, 81$ un

im Sahr Sahrestemperatur 2氏breidung vom Mitter

$\begin{array}{rrr}1806 & 12^{\circ}, 08 & +1,27 \\ 1807 & 10,76 & -0,05\end{array}$


im Jabr Snhrestemperatur SYbweichung bom SRittel

$\begin{array}{lrr}1808 & 10,35 & -0,46 \\ 1809 & 10,64 & -0,17 \\ 1810 & 10,62 & -0,19 \\ 1811 & 11,97 & -1,16 \\ 1812 & 9,89 & -0,82 \\ 1813 & 10,24 & -0,57 \\ 1814 & 9,80 & -0,31 \\ 1815 & 10,49 & -1,41 \\ 1816 & 9,40 & -0,40 \\ 1817 & 10,41 & -0,58 \\ 1818 & 11,39 & -0,31 \\ 1819 & 11,12 & -1,00 \\ 1820 & 9,81 & -1,29 \\ 1821 & 11,06 & -0,41 \\ 1822 & 12,10 & -0,34 \\ 1823 & 10,40 & -0,86 \\ 1824 & 11,15 & -0,63 \\ 1825 & 11,67 & \end{array}$

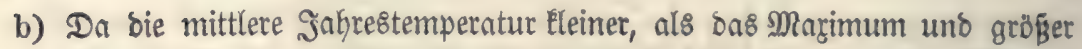

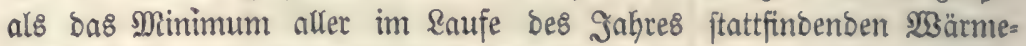
grabe ift, jo mú zmeimal bes Jahres eine Temperatur herrfchen, weldge ber mittlern Safyestemperatur gleid, Eommt. Den 3eitpunkt, menn biejes gejojieht, fand man

für Enontekis am 28. Alpril uno 22. Dettober

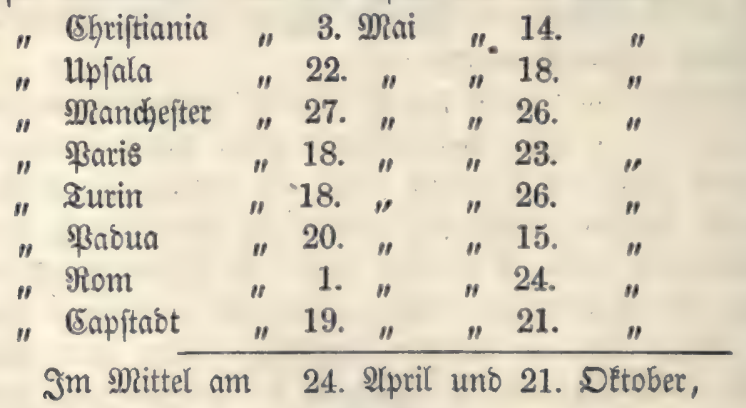

aljo im legsten Drittel biejer beiben Mionate.

Siernus ergibt fich benn ein abgetürztes $\mathfrak{B}$ erfahren, um bie mittlere Sabrestemperatur zu bejtimmen. Man beobadatet nämlid, blos bie Iem=

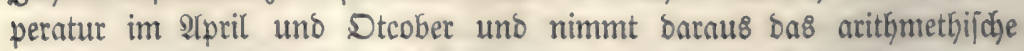
Mittel. Dod müj]en bie Beobachtungen mefjece Safre fortgefegt merben.

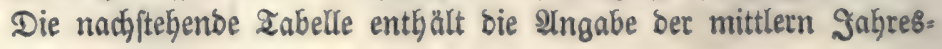




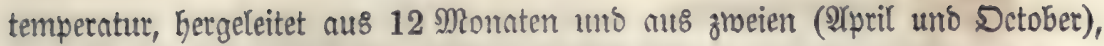
forie ben Unterjojieb zmijhen beiben Berechnungen.

Drte. Mittel aus Mittel aus

12 Monaten. $\quad$ Ipril u. Dctober.

\begin{tabular}{|c|c|c|c|}
\hline Berlin & $7^{\circ}, 93$ & $7^{0}, 30$ & $+0,63$ \\
\hline శulba & 8,28 & 8,50 & $-0,22$ \\
\hline Zübingen & 8,68 & 9,00 & $-0,3$ \\
\hline Mtündgen & 8,80 & 9,10 & $-0,3$ \\
\hline 5amburg & 8,90 & 8,55 & 0,3 \\
\hline Erfutet & 8,08 & 8,60 & 0,4 \\
\hline ranffuct a. $\mathfrak{M}$. & 9,83 & 9,60 & 0,2 \\
\hline tuttgart & 10,00 & 9,75 & 0,2 \\
\hline รürzburg & 10,41 & 10,90 & \\
\hline
\end{tabular}

Man kann bemnach bie mittlere Gabrestemperatur für einen Drt, an Sem man blos im Alpril uno Dctober Beobachtungen angeftellt Gat, herleiten, wenn man bie obige Differenz für einen benadjbarten Drt, weldye nach [einer \&age zc. mit Dem borigen übereinjtimmt, kennt.

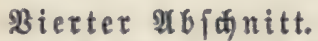

\section{Bertheilung ber $\mathfrak{B a ̈ r m e}$ iiber bie Erote.}

\section{Begriff ber Sipthermijäen Linien.}

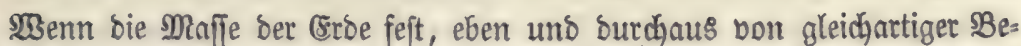

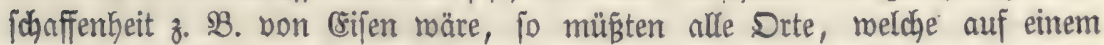

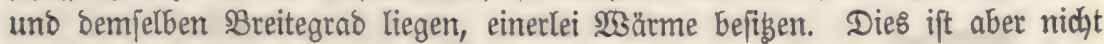

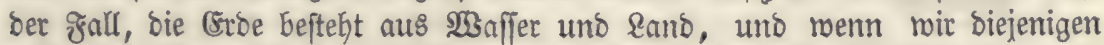
\$unťte ber (Erboberfläche, weldye gleiche mittlere Sabrestemperatur haben, mit Sinien verbinten, To bemerken wir, bnß̈ bieje fajt nirgenos mit ben \$arallel= Ereifen zujammenfallen. Şumbolot Gat zuerft bie Berzeidynung foldjer Rinien,

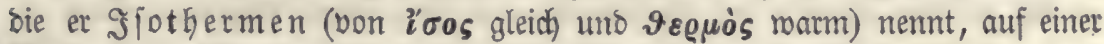
(5)arte ausgeführt.

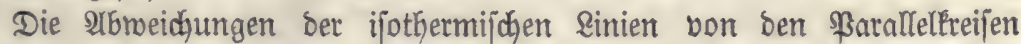

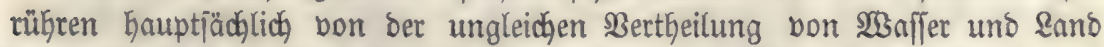
her. WBir Gaben früher gejehen, baś bieje beiben Subftanzen meber in ber

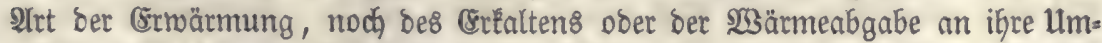

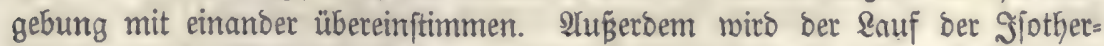

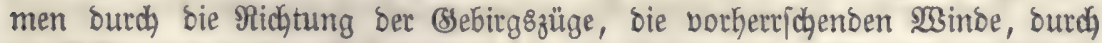
bie Shbrometeore, ganz bejonbers aber burch bie MReeresftrömungen bedingt, meld') lebstere mir nun etwas näber betraçten mollen, ba bon ifnen früher nod nidjt bie Rebe war. 


\section{Die Mceregึtrionungen.}

Die Maffe bes Meeres wirb nicht blos burch bie 2 Binbe und ben $23 e l l e n=$ fohlag berwegt, es gibt conftante Strömungen mitten im Meere. Man Eann fie

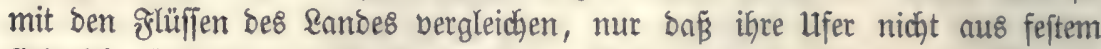

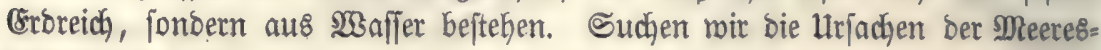
ftrömungen auf.

In ber (Segent bes arequators, wo bie Sonne zroimal im Sahr pent=

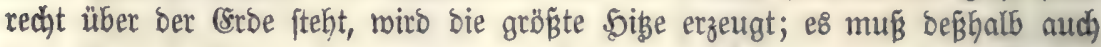
bas Meer Dort eine Iemperatur annegmen, welche bie in anoern Breiten überfteigt.

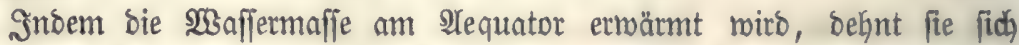
aus, fie erlangt eine gröpere \$öbe. Sebtere bebingt nach bem Sejeb ber

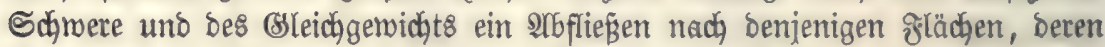

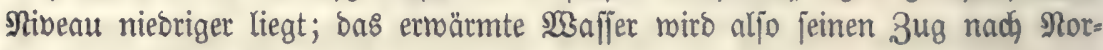
ben uns Süben nehmen.

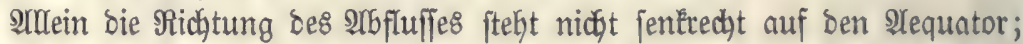

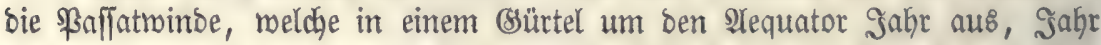

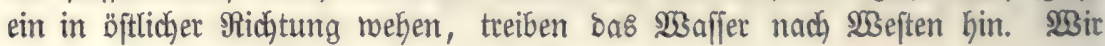
merben jpäter ausfüfrliç von biejen WSinden reden.

\section{A. Hequatorialfiom im Stlantifón Decan.}

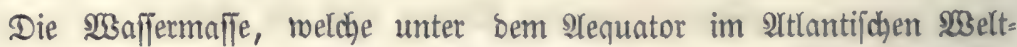

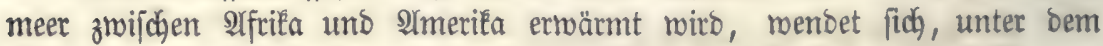
Ginfluf́ ber ßaffatminde zuerít rein weftlich. Sobald fie an bie Süjte bon

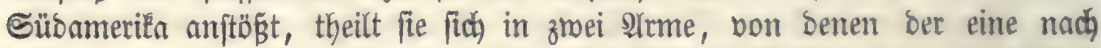
Rorben, ber andere nach Süben jeinen \&auf nimmt.

\section{a. Oolffitom.}

Der nöroliche Âtrm verfolgt zuerft bie norbojttiche Süfte von Sübamerif́a,

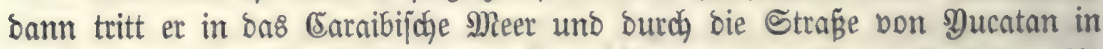
ben Merikanifdyen Meerbujen ein, beffen Rüften er fortmäfyreno begleitet, bis

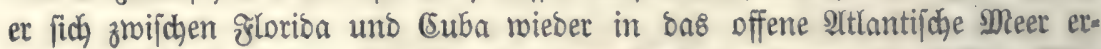

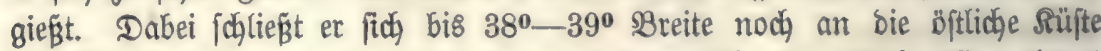
von Norbamerifa an; bon bort an menbet er fich aber bfttick. (Er gelangt

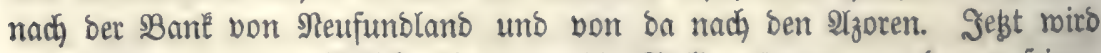

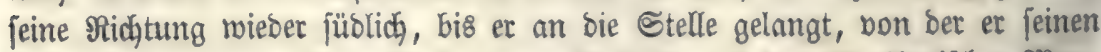

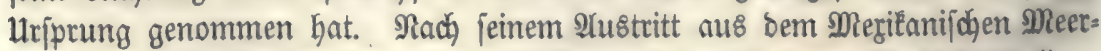

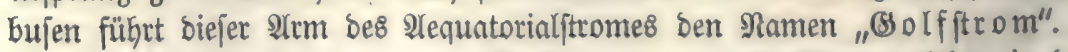

Dodh nicht bie gejammte 23 affermenge bes Bolfftroms lehrt in Den

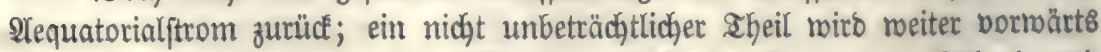

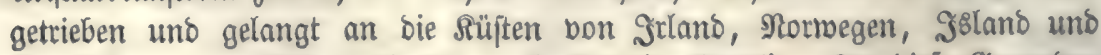

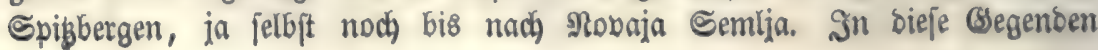


bringt ber Bolfftrom Früchte aus füblichen Slimaten unb groß̈e Nengen von Ireibjolz. Im fünfzebnten Sahrbunbert murben Reidhname von Snbianern

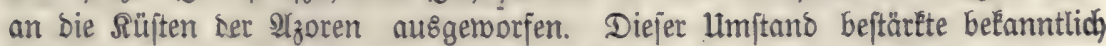

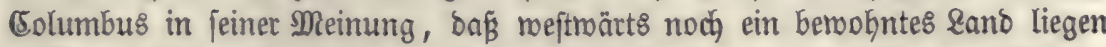

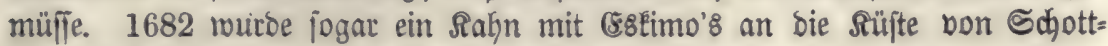
land getrieben.

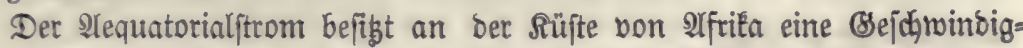
leit von 10 geographijohen Meiten in 24 Stunoen (bei ben Injeln St. Iho=

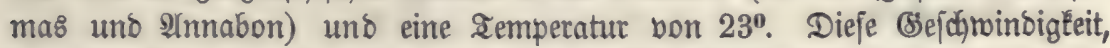
bermehrt fid aber, je weiter er borbringt, weil bejhleunigente Stäfte auf fie einmirken, währeno bie Iemperatur bes Strommafferళ gleidjfalls fteigt. IIn

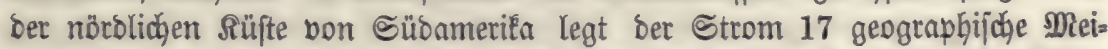

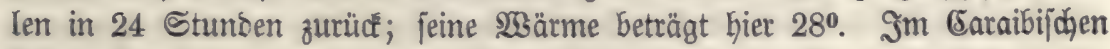
Meere foll jeine Semperatur auf $32^{\circ}$. fteigen (Berghaus), was aber zu bes zmeifeln ift.

Sobald Der Bolffitrom in bas offene Meer eintritt, nimmt jeine Breite

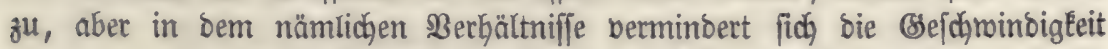

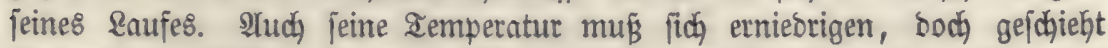
bies nur allmählig; in $40^{\circ}-41^{\circ}$ nörolichen 3 reite beträgt fie noch 22,05 ,

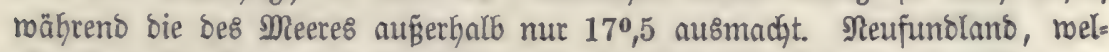

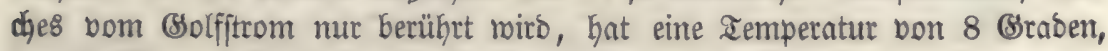

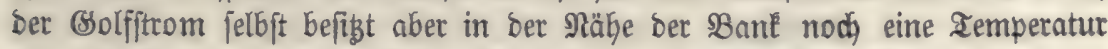
von 16 Graben; baher entitehen bie bicfen, unourd,fichtigen Nebel, mit benen

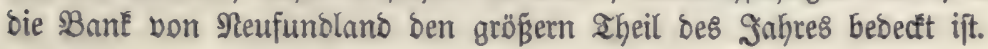

\section{b. Brafiliantide Otrömung.}

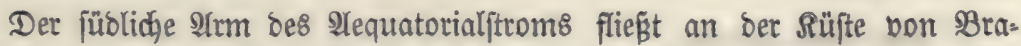

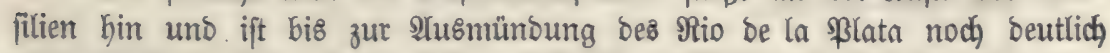
wahrnehmbar. Sierauf wenbet er fich aber p̈ftlich uno geht um Das Bor= gebirge ber guten soffinung berum.

\section{B. Raltmafferfírme in quantifien Dcean.}

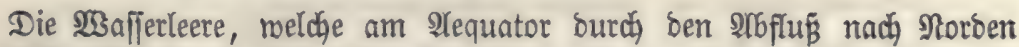

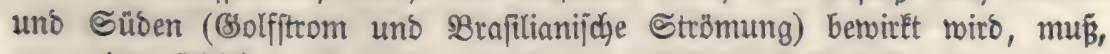

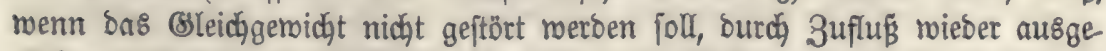
glidjen werben. (sin poldyer fintet theils in ber Siefe bes Meeres, theils aber aud) an beffen Dberflädje ftatt.

\section{a. 2abzaborfitem.}

Das nörolidge Cismeer jentet einen Strom Ealten $13 a f f e r 8$ nach bem Siben hin. Er ift in ber Begend bon Spibbergen bemerfbar, paffirt mit

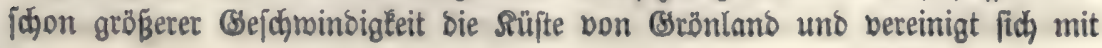




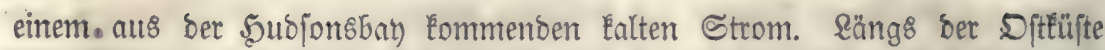

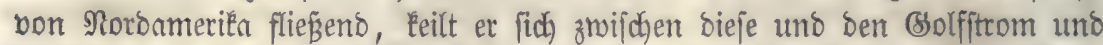

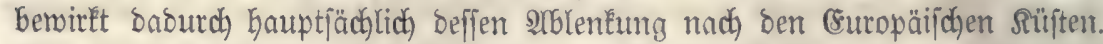
Der \&nbraborftrom fest fich bis zum 40ten Breitegrab fort; in manchen Sah)=

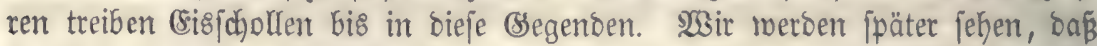

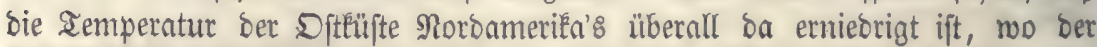
Raltwafferitrom fliefit.

\section{b. Cutneaftrom.}

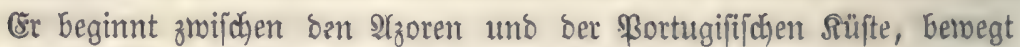

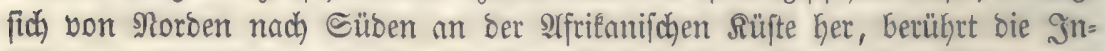
feln bes grünen \$orgebirges unt biegt bann in ben Meerbufen von Bruinea eir, wo er fidh mit bem Alequatorialfitrom vereinight. Da ber Butuneaftrom an feinem Utrprung mit bem Bsolfftrom in Berbinoung fteht, fo vermittelt ex ben

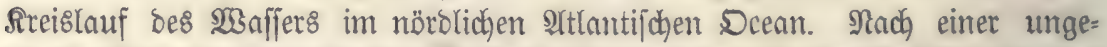

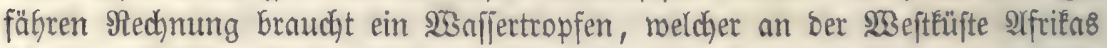

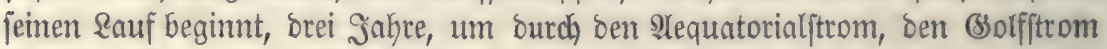

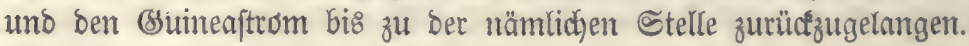

\section{c. Sapftrom.}

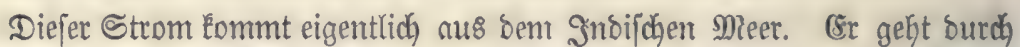

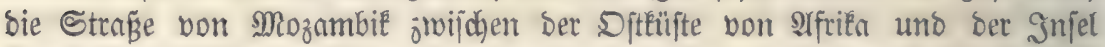

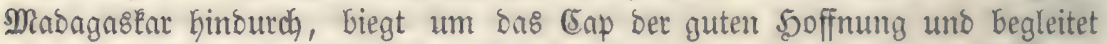

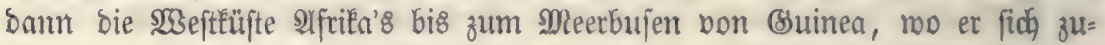

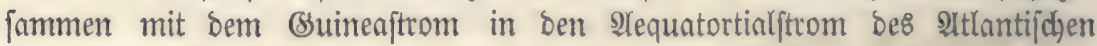
Dceans ergieğt.

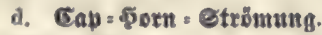

Sie entiftegt im füblichen (sirmeer, geft am Cap Sorn borbei uno

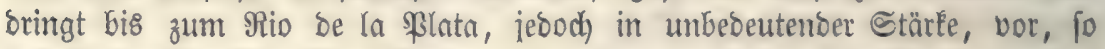
baßj fie ber Brafilianif̧chen Strömung gerabezu entgegengejegt ift.

\section{20armer ifequtorialftom im coroden Decan.}

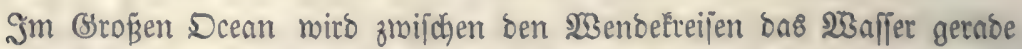
fo errwärmt, wie im Ntlantijchen 23 eltmeer; bie $\mathfrak{P a f f a t e}$ treiben e\& in ber

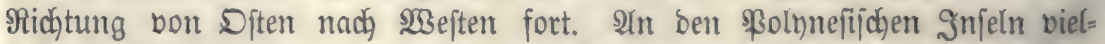
fach zeriplittert, gelangt biejer Strom [übroärt8 in bas Snoijd) Meer, räh)= reno er nach నoroen hin bie Sïften von Sapan befpült.

\section{Saltwafierftỏme in Erof́en Deean.}

Die burd ben श्Tequatorialftrom im Sropen Dcean verurjadjte $23 a f f e r=$

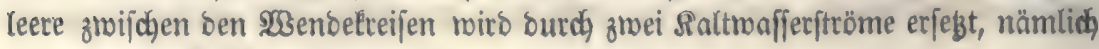


a) Surd) bie Meriéanifde Strömung.

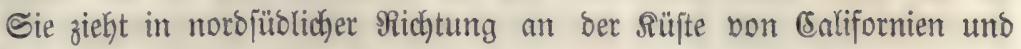
Mlerifo vorbei.

b) Durd ben grog̈en $\mathfrak{B e r u f t r o m}$.

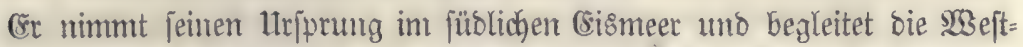

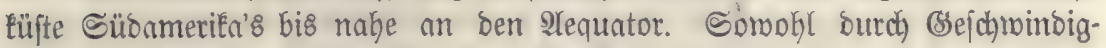

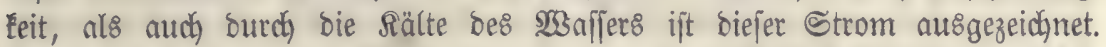
5umbolot fand in ber Breite von Eallao feine semperatur gleich $15^{0}, 5$,

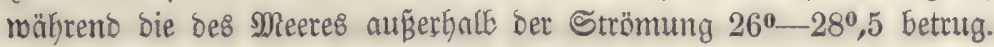

\section{Mälyere Deutung beß saufa ber Sipthermen.}

Senn man eine Rarte anfieht, auf weldyer bie ijothermijchen Sinien verzeichnet find, fo bemerft man folgenoes:

a) Sn der Rähe des âdeqators fomie im allgemeinen auf ber fübliden 5̧albugel ftimmen bie Şothermen

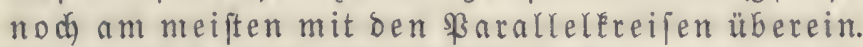

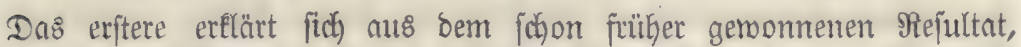

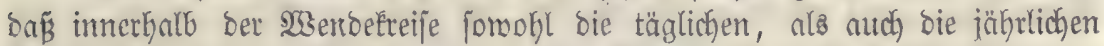
Temperatureģtrente nicht fo meit auseinanoerliegen, al\& in Der gemäpigten 3one. Berichiebentheiten in ber (stroärmung bes Meeres uno bes fejten \&an= be\& fönnen baker bort aud nidht jo bebeutend merben.

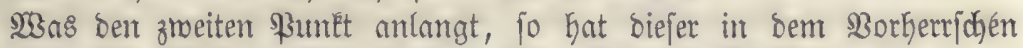

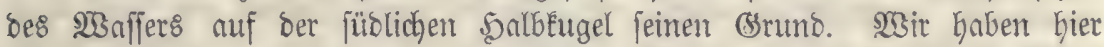

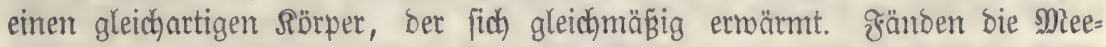
resftrömungen nicht ftatt, fo würben bie Sjothermen auf ber füblichen Salb= fugel, foroit fie nicht über bas sand gehen, böllig mit ben Paralleléreifen zujammenfallen.

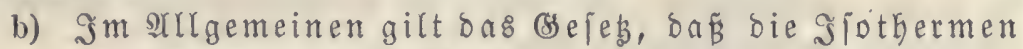
im Jnnern ber geftländer jidj jenten, dagegen im Meere wieber böher fteigen.

Dies mill nidjts anders jagen, als baß̈ unter einerlei Breite bie Ruft über Dem Meer eine größ̈ere mittlere Sabrestemperatur bat, als Drte auf bem

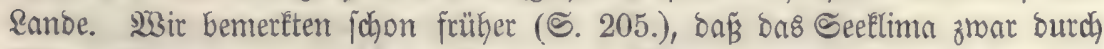

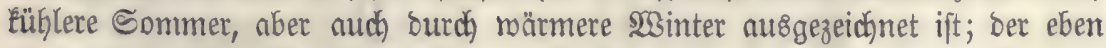
angebeutete Berlauf Der Siothermen beweift, baßs bie Iemperaturerniebrigung

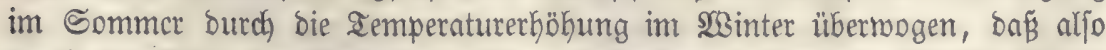
burch bie sähe ber See ber mittlern Sahrestemperatur ein höherer $\mathfrak{B}$ erth vertiegen witr.

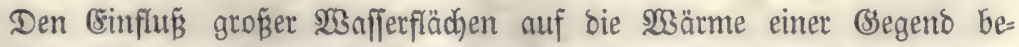
mertt man fefre beutlich an ben grofien Seen im Snnern storbamerila's. 
Sn bet Nähe biejer Seen hebt fid bie Sjotherme von $5^{0}$ in auffallenber Mreije; fie fälut nach) bet Dittüfte diefer Continentes um 36 Meilen.

c) 2Rgejehen bon einigen Störungen, beren Utradje wir in ben Mee= resftrömungen etbliafen, gehen die siothermen an ben Wefteüften ber continente und Jnjeln böber binauf, als an ben Dit ü f̈ten, $\delta$. h. Die $\mathfrak{W}$ ejteüften haben unter glei= cher geographif cher Breite eine Göhere mittlere Эahrestemperatur, als bie Dithüiten.

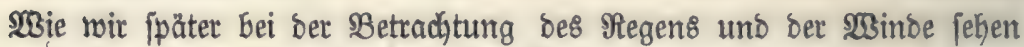

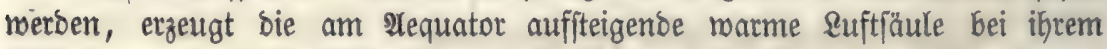

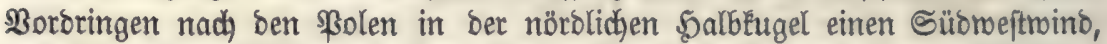

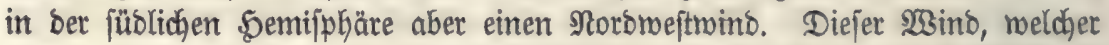
aus ben heifeften Begenden ber (Eroe ftammt, befibt eine hoke Temperatur.

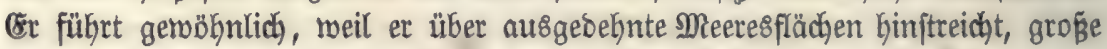
Mengen von greudutigkeit mit fich, benen gleidjfalls eine Göhere Temperatur eigen ift.

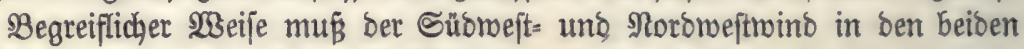

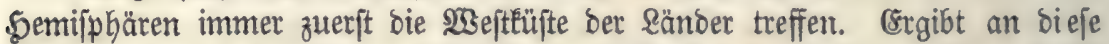

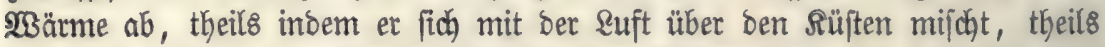

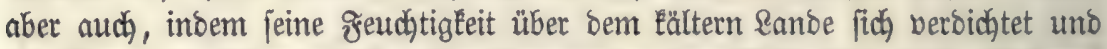

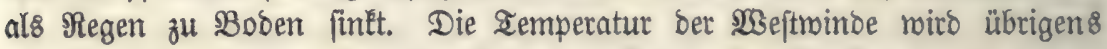
um fo mebr erniebrigt, je weiter fie in bas Innere ber Continente borbringen, uno wenn hoke Bsebirgstücten fich ifnen entgegenftemmen, an benen fich bie Freuchtigkeit vorzugsrmeife abjeşt. So ift es zum Beifpiel mit bem Ural,

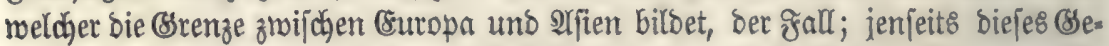

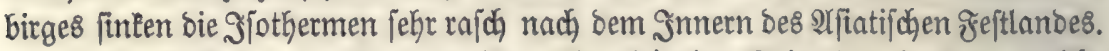

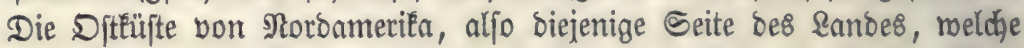

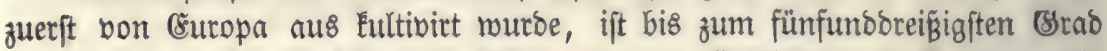

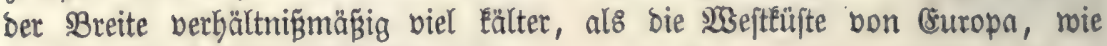
bie folgente 3 uโammenjtellung zeigt.

\begin{tabular}{|c|c|c|}
\hline \multirow{2}{*}{ 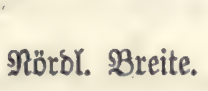 } & Ditfuite von & 2Befttüfte v \\
\hline & Sorbamerito & a. Europa. \\
\hline $25^{\circ}$ & $24^{0}, 30$ & $22^{\circ}, 71$ \\
\hline 30 & 22,44 & 21,40 \\
\hline 35 & 18,54 & 18,68 \\
\hline 40 & 12,94 & 16,91 \\
\hline 45. & 5,94 & 13,38 \\
\hline 50 & 1,90 & 10,68 \\
\hline 55 & $-1,76$ & 7,97 \\
\hline 60 & $-5,60$ & 4,99 \\
\hline 65 & $\begin{array}{r}-960 \\
-\quad 96\end{array}$ & 0,65 \\
\hline 70 & $-15,70$ & 0,10 \\
\hline 75 & $-18,9$ & \\
\hline
\end{tabular}


Norbametifa verbantt bie Göhere Iemperatur feiner Dfttüfte bom fünf=

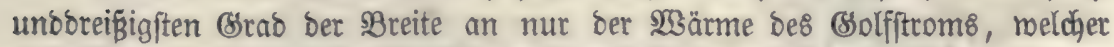

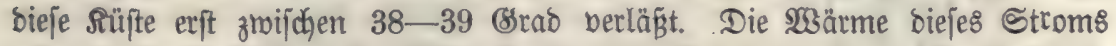
trägt, neben berjenigen ber Sübmejtminbe, audh jefrc biel zur Göheren aem=

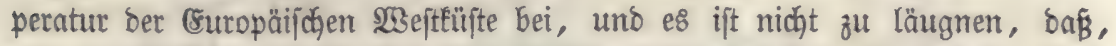

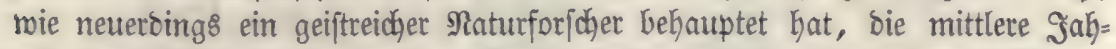

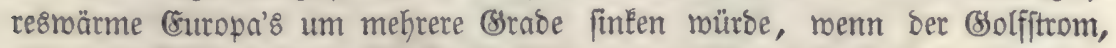
etroa mittelft eines Durdjitichs der \&anoenge von Banama, einem Albfluf in ben Brofien Dcean finden pollte.

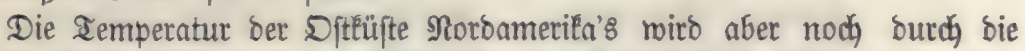
sälte be\& Rabraborftrome\& beprimirt. Sn manchen Jahren bringt biejer jefr

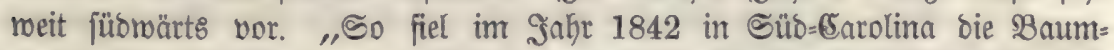

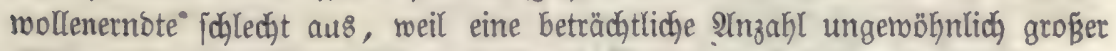

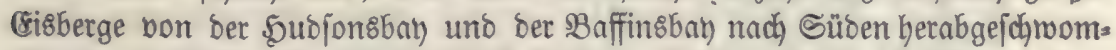
men mar und bie See, forwie bie \&uft in jemer Begend fefr abgekült Gatte."

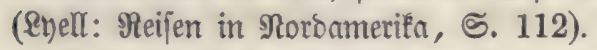

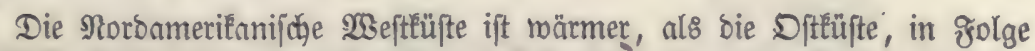
ber Cinmirkung ber Sübmeftrinoe. Doch gilt bies nicht für bie nieberen Breiten. Seier zeigt fich eine (rrföbung ber mittlern Sabrestemperatur zu

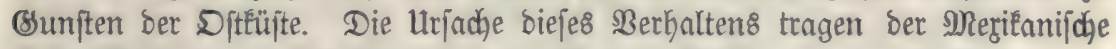

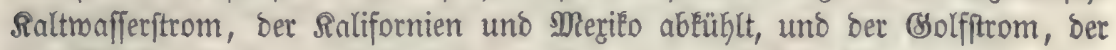

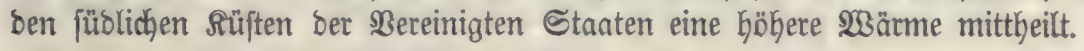

¡olgenbe 3ujammenftellung gibt an, unter weldjen Breitegraben bie beiben Rüften Sorbamerifa's von ben Siothermen gefdenitten werben.

$\begin{array}{ccc}\begin{array}{c}\text { Sotberme } \\ \text { von }\end{array} & \text { 2Bejthijfe } & \text { Dittüfte } \\ 25^{\circ} & 15^{\circ} 42^{\prime} & 22^{\circ} 00 \\ 20 & 2743 & 3138 \\ 15 & 3615 & 3748 \\ 10 & 4509 & 4045 \\ 5 & 5328 & 4526 \\ 0 & 6238 & 5230 \\ -5 & 7452 & 5937\end{array}$

Ituch) bie Temperatur Cübamerif́n's jeigt eine stomeidfung bon ber

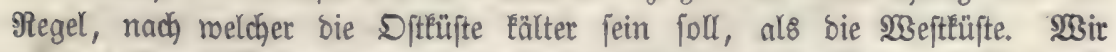

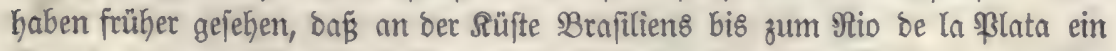

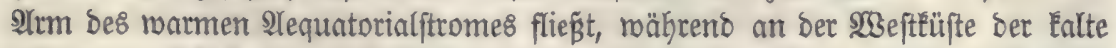

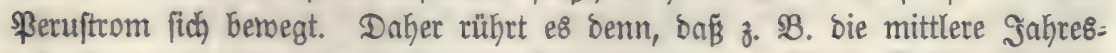

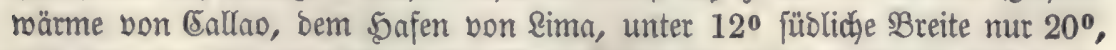

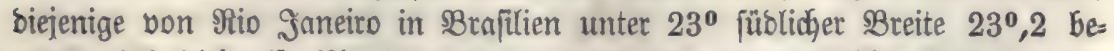

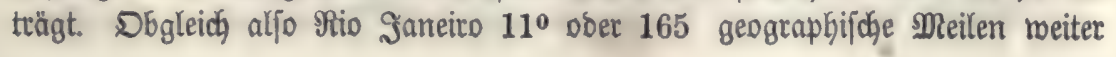


bom Slequator entfernt ift, als Sima, hat es boch eine um $3^{0}, 2$ hỏhere Sah. restemperatur, aโs bieje8.

In Europa bieten Norwegen uno Sd)weben eine borzüglidge Belegen=

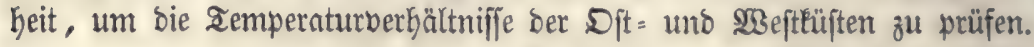

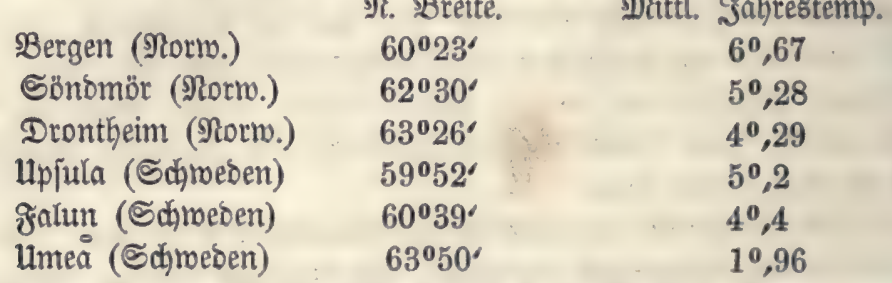

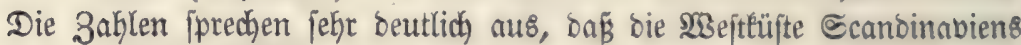
wärmer ift, al\& bie Ditthifte.

d) Der $\mathfrak{M}$ ärme= 2 equator - fo nennt man biejenige sinie,

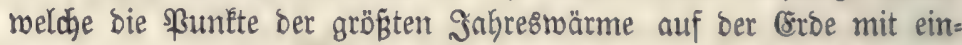
ander verbindet - fällt nidht mit bem Ero= $\mathbb{A} e q u a t o r$ zujammen.

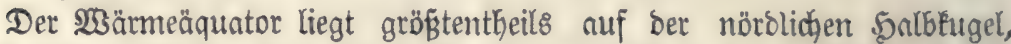
wabricheinlid besfalb, weil bieje mefyr \&ano enthält, als bie füblidje Semi=

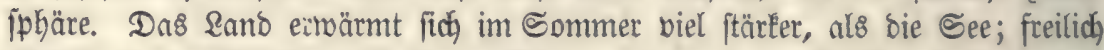

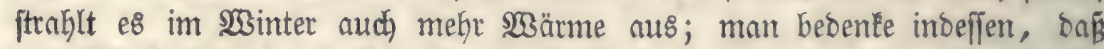
biejer Berluft in ber heifien 3one nicht bebeuteno fein Enn, weil Dort bie Iemperaturen beళ Commerళ uno 2 Binters nur um einige \&rabe bifferiren.

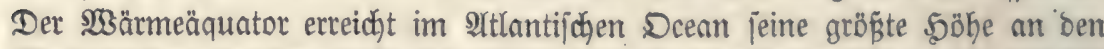

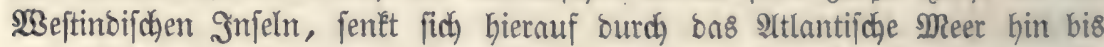
an bie Süfte von Buinea, fteigt roieder in bem innern Iffrifa, bon 100 aus er fid) bis faft nach Dftinbien auf gleidyer Söbe bält, fällt bei ben Moluccen, wo er ben (Erbäquator fohneibet, unter meldem er bis $155^{\circ}$ mejtlich von \$aris

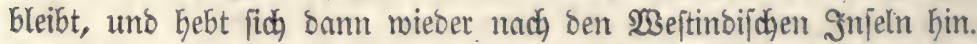

Die mittlere aemperatur bes terreftrifchen $\mathscr{Y}$ equator\& beträgt $28^{\circ}, 3$, wobei

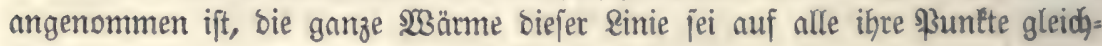
förmig vertheilt.

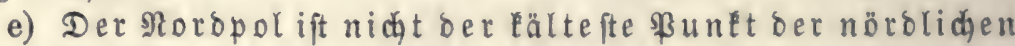
5albét.

(8z Bejteht vielmehr, nach Dove, ein Eältefter flect, weldjer im Jahres:

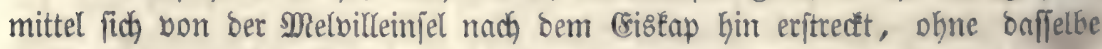
zu erceichen oder ben $\mathfrak{F o l}$ zu berillfren. Bom Sanuar zum Suli nandert ber

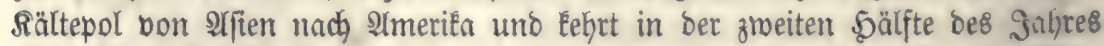

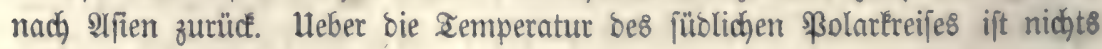
Räberes betannt.

Brewiter nahm zroei Rältepole an; einer befinbe fich im Rorben yon Imerifa und habe einte Iemperatur von $-19^{\circ}, 7$, ber anbere über 2 fien 
mit - 170,2. 3u biejer unterftellung gab ber Umitand \$erantajiug, baß

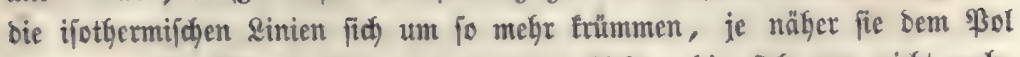

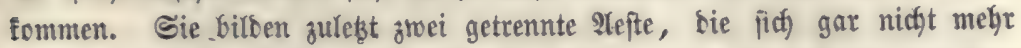

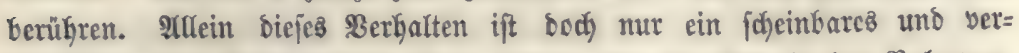
fajwinbet, wie Dove gezeigt Kat, wenm man bie Erbe in ber Polarpro= jection verzecidjnet und sie STothermen Ginreidjenઠ verlängert.

f. Die aemperatur ber fübliden \$albengel ift niebriger, als bie ber nöroliden.

3ur Bergleidqung mögen folgenbe 3ahlen bienen:

S̃ahresträrme.

\begin{tabular}{|c|c|c|}
\hline Breite. & Rörol. БalbÉugel. & Sübliche நalbäugel. \\
\hline $0^{0}$ & $26^{0}, 5$ & $26^{0}, 5$ \\
\hline 10 & 26,6 & 25,5 \\
\hline 20 & 25,2 & 23,4 \\
\hline 30 & 21,0 & 19,4 \\
\hline 40 & 13,6 & 12,5 \\
\hline
\end{tabular}

Dieje Ifyatiadje murbe fojon früher geahnt, ift aber erjt in ber legten

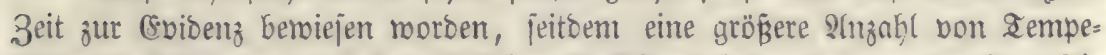
raturunterjuchungen auf ber jüblichen Salbeugel befannt gemorden ijt. Die geringere $\mathfrak{B a ̈ r m e}$ ber jüblidjen Șemijphäre wollte man anfangs von ber fürzern Dauer ifyres Sommers berleiten. (Der Unterjohied beträgt ungefähr

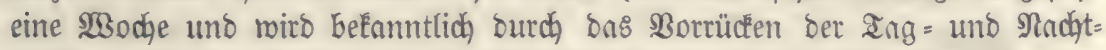
gleichen und bie Benegung ber 2lbfibenlinie ber Sommenbahn berwirft, ver=

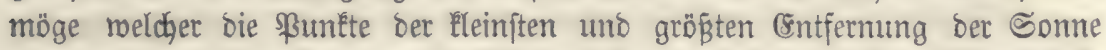

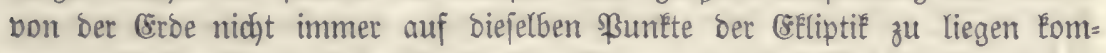
men). Dod) (d)eint biejer Umftand nidjt von grofier Bebeuturg zu fein.

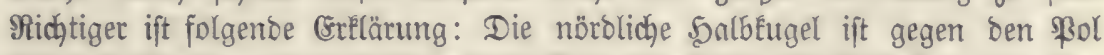

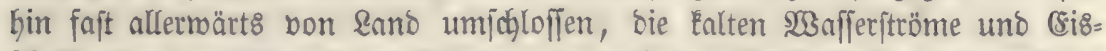

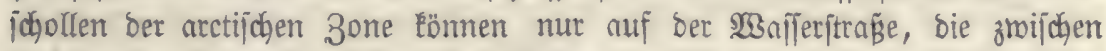

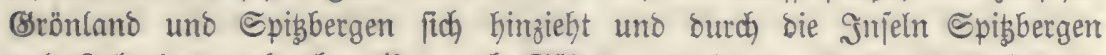

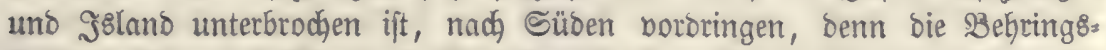

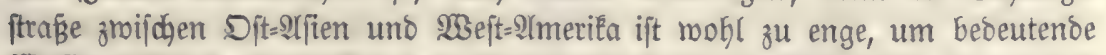

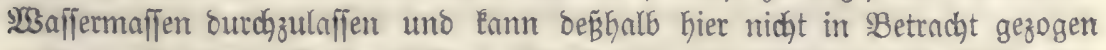
merben. Dagegen ift ber Süben übernll frei; bie Crisberge des Silbpolar= meeres fönnen ungefindert bis an ben Ylequator borbringen, unt bie nad Süben zugefpigte Seftalt bes alten uno des neuen (Entinentes, meldye von

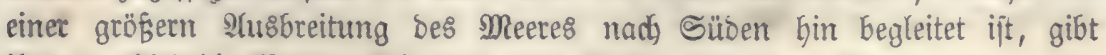

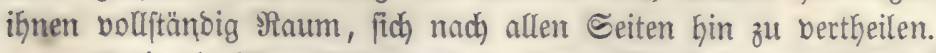

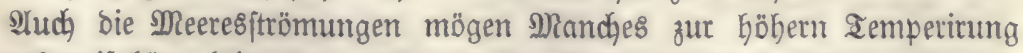
unjerer Semiipthäre beitragen. Der warne Aequatorialftrom bringt nämlid) jeiner gröBern Maffe nad̆ in nörolidge Eegenten; ein $\mathfrak{A r m}$, ber jüblidh gebt, 


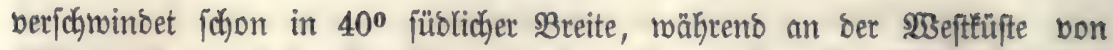

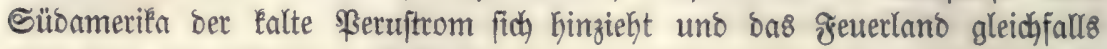
von einem \$olariftom umpült ift.

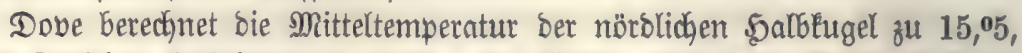

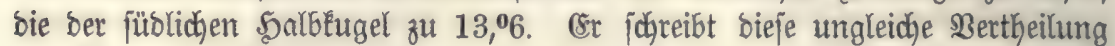

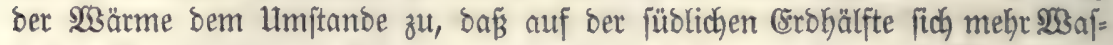
jerbampf entwiçele, weldjer borzugsmeife auf ber nörblichen Salblugel zur

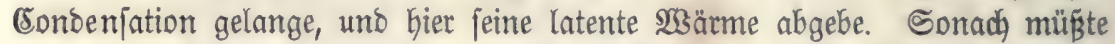

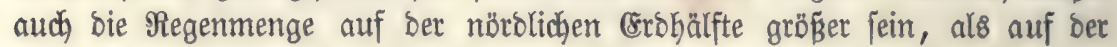
füblidfen.

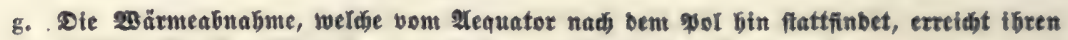
böbiften

Sie betrăgt

grwif $0^{\circ}-10^{\circ}, 10-20,20-30,30-40,40-50,50-60,60-70,70-80,80-90$ $\begin{array}{lllllllll}\text { Semp. (5r. }-0^{\circ}, 12 & 1,4 & 4,2 & 7,4 & 8,2 & 6,4 & 7,9 & 5,1 & 2,2\end{array}$

Anmerkung. Die Mitteltemperatur ber ganzen Erbe finDet Dove $=14^{0}, 6$ (Eelj. Die Bejammtmärme, melche an ber (Erooberfläche das

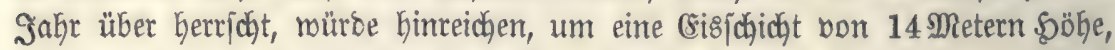
mit weldyer man fich bie (srbe bebectt zu benken hat, zu fojmelzen.

\section{Die gionimenen.}

\section{a. Begrifi.}

All8 wir bie STothermlinien zogen, betradyteten wir bie Bertheilung ber

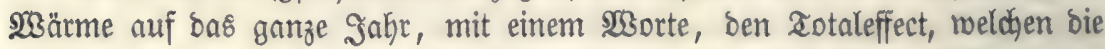
S3ärme erzeugt, wenn man bie Temperaturen ber verjdhiebenen Sabrezzeiten auf einanber ausgleidat.

Dieje Darjtellungsmeije verid)afft uns alleroings einen Heberblid über bas STima im sanzen, in fo fern biejes aus bem 3ujammenwirten verjobie=

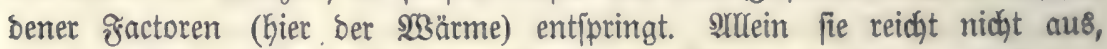

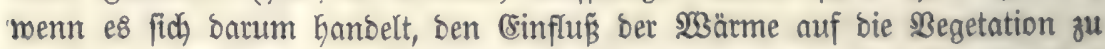
ermitteln. Das (Sebeifen ber (serwäh)je hängt nämlid, viel weniger von ber mittleren Sahrestemperatur, al\& bielmehr von ber Wärme ber Jahreszeiten ab.

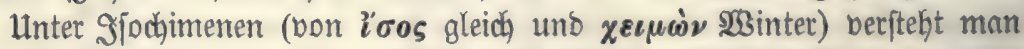

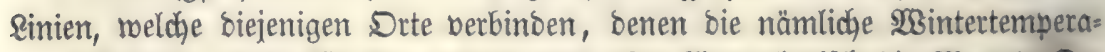

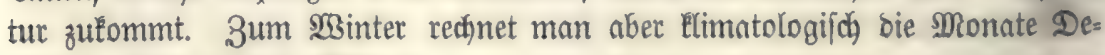
cember, Jamuar uno ซebruat.

\section{b. Rauf ber รึด ดimenen.}

Man Eann bie STodhimenen als Curben bezeidynen, welche ben Siotfet: men ähnlich find; nutr finben wir bei ben erftern alle füblichen $\$$ Biegungen viel 


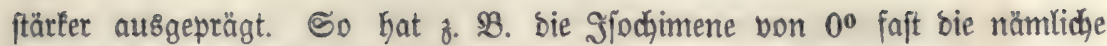

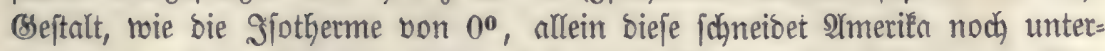
halb ber grofien Seen, jene erft in Eabrabor. Beibe heben fich an ber Süjte von Norwegen bebeuteno norbroärts uno finken bann wieber im Snnern von

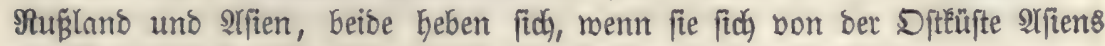
zut $\mathfrak{W}$ efttüfte 2 merita's menten.

Im İnnern ber Feftländer biegen fich bie Şpochimenen ftark nach bem

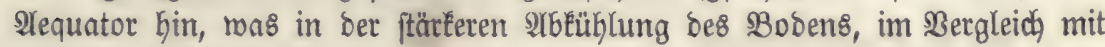
Det See, feinen \&runo hat.

\section{Siotheren.}

\section{a. Begrif.}

Sīotheren nennt man bie Sinien, welche Drte mit gleicher Sommerwärme verbinben (bon 9 źpos ๔ommer). 3um Sommer rechnet man Elimatologild bie Monate Suni, Suli uno Âguít.

\section{b. Sauf ber Tiotberen.}

Da bie STorfimenen im Snnern ber (Sontinente fidh nadh bem Yequator biegen, bie Siothermen aber nidht fo tief herabjinten, jo müffen an ber refpec= tiben 5ebung ber lestern bie Şotheren fduld fein. In Der That finden wir,

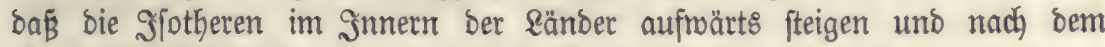
Sheete Gin fid jenfen.

So hat bas burdh jeine berhältnißmäß̈g hohe mittlere Gahrestemperatur ausgezeichnete Englano fulblere Sommer, als viele Drte in Scanoinavien, weldye $10^{\circ}$ nörolicher gelegen fint.

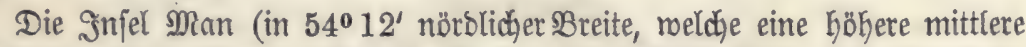

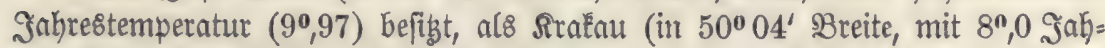
resmärme), hat bod eine geringere Sommertemperatur $\left(15^{0}, 1\right)$ als Drontheim

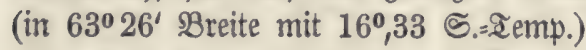

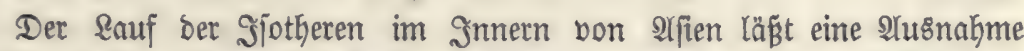
von ber borbin aufgeftellten $\Re$ tegel wabrnehmen. Sie beginnen nämlich bort roieber etroas zu fallen. Dies rüfht bon ben Ealten \&uftttrömungen ber, weldje

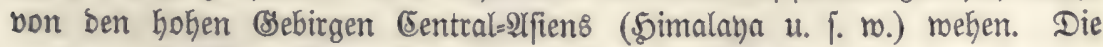
aus bem Snbijhen Meere fommenten Sübrofitminbe jeben an ben fdneebes

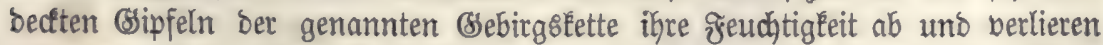

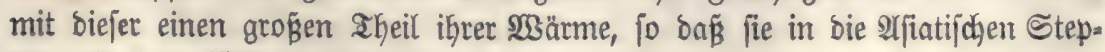

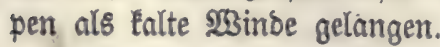

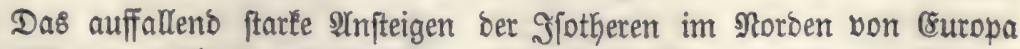

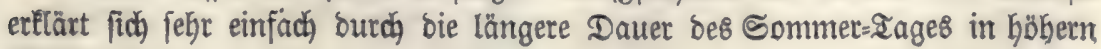
Breiten. 


\section{Monatoijothermen.}

a. Begrif.

Unter ben Monat8ifothermen verfteht man Rinien, welche die Drte glei= dher monatlicher $\mathfrak{W}_{3} a ̈ r m e$ verbinoen. Dieje, von Dove eingeführte Benenmung

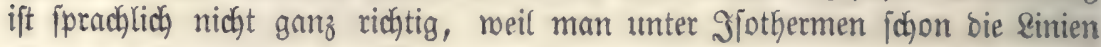
gleicher Эahresmärme begreift.

\section{b. Lauf ber Dtonatbifotbermen.}

थuf bie Brundlage einer größzern STrzahl von Zemperaturbeobadjtungen un mit Ђülfe bon Snterpolationen hat Dove ben \&auf ber Monat8ifother= men bargejtellt. Dieje Rinien (c)liešen fich, was bie Eälteren Monate betrifft,

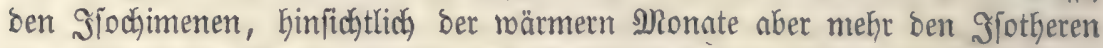
an. Die \&inien für bie ફlerbjt= uno grühlingsmonate bilden bie llebergänge zrwijdhen beiben.

\section{Temtperatur be: Bobenเి.}

\section{a. Iemperatur ber Bobenoberfläđ̆e im Eonnenídicin.}

Die Crroe erwärmt fich bermöge ifrer groß̧en 2łbjorptionsfähigkeit für bie Sonnenftrablen viel ftärker, als bie \&uft, welḑe ben lebstern größ̈tentheil\&

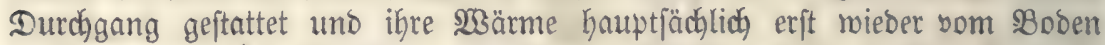
Durch Seitung ober Straflung empfängt. Cchübler ftellte Darüber Beobad)=

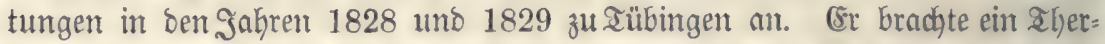

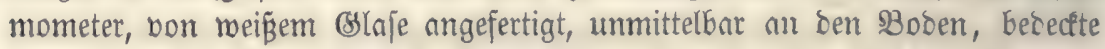
aber beffen Rugel eine \&inie ftark mit (5roe. Die Angaben biefes İnitrumen= teళ nurben zroijeden 12 uno 1 uhr notit.

\section{Temperatur}

ber Erooberflädhe ber Ruft

Monate im Sonmenjdyein im Schatten Unteridjied

Sanuar

gebruar

12,2

30,1

Mărz

37,5

Iptil

$-4,1$

6,1

16,3

IMai

Suni

Suli

8,1

24,0

शruguit

Septembet

Dctober

November

29,4

December

Mittel

49,7

55,1

59,7

63,5

16,5

\section{4,5}

48,7

19,6

24,0

27,4

20,5

20,0

33,2

27,1

6,0

4,5

35,5

22,6

2,0
35,7

36,1

34,0

28,7

21,1

18,1

$17,1^{\circ}$ 


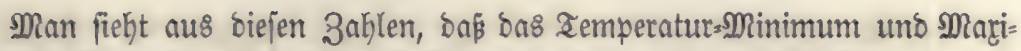
mum bes SBodens, wie bas der Ruft, in ben Jamun und Suli fällt.

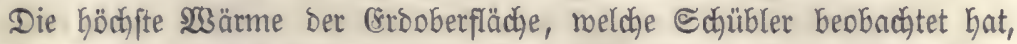
fiel auf ben 16. Suli bes Sabres 1828; fie betrug $67^{\circ}, 5$ (5elf. bei $25^{\circ}, 6$ suft=

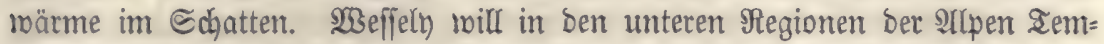
peraturen bis zu $65^{\circ}, 0$ in ben oberen bis zu $40^{\circ}$ beobadjtet haben.

\section{B. Temperatur bes sodeno in ber Tiefe.}

Die Dberfläche bes sobens wird fomohl burch die Sonnenftrahlen, als

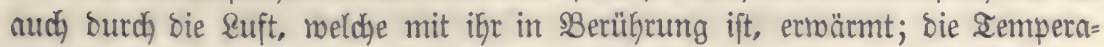
tur yflangt fich ourch Reitung bis in bie tieferen Bobenjofichten fort. Da nber

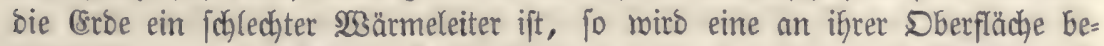
rirfte Iemperaturerföhung fid nid)t momentan ben untern Sdjidyten mit=

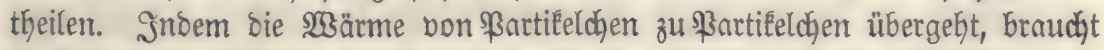
fie 3eit, und zwar um fo mefr, je weiter ber ßunft von ber Dberfläd)e ent= fernt ift. Daher Eommt e\& benn, Daß́ eine an ber Dberfläche des Bobens

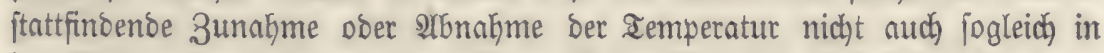
ber Tiefe rahrgenommen wirb. So wiro ber Eintritt bes täglichen Iempera= turmarimums ber Ruft 1 Decimeter unter ber Bobenoberfäche 3 Stunben päter bemeret. In nod größfern Tiefen bleibt bie Temperatur um einen meit längern Zeitraum hinter ber \&ufttemperatur zutüć. (\&\& fano Duetelet in Brũỵel

in ber Iiefe von

$0 \quad$ Metern
0,19
0,45
0,75
1,00
3,90
7,80

das jährl. MRarimum das jährl. Minimum

\begin{tabular}{|c|c|}
\hline am 22. Suli & 23. Januar \\
\hline " 27. " & 3. Jebruat \\
\hline " 31. " & 11. " \\
\hline " 5. 2Uaguft & 22. \\
\hline "8. " & 25. \\
\hline " 12. Dctobet & 22. Slpril \\
\hline "12. December & 18. Suni \\
\hline
\end{tabular}

In einer Tiefe bon 8 Metern treten bemnady bie jähtl. Temperatur = Marima und Minima fajt ein bolles Salbjabr fpäter ein, als an ber Dberfläche bes Bobens. Doch verurjacken auth bie Materialien, aus benen ber 230 ben be= fteht, einige Unterjhiebe, wie man aus Den nadjitebenoen Beobadjtungen von Frorbes in cosinburg erfieht.

Bobenart. Das Iemperaturmarimum trat ein
in 1,0
1,9
3,9
7,8 Metern Ziefe

Sanbjtein am 5. 2Tugujt 19. 2luguft 11. September 11. Robember

Dolerit am 6.

Sano

am 31. Suli

2. Sept.

17. Dctober

24. Y)uguit 7.

8. Januar

30. December

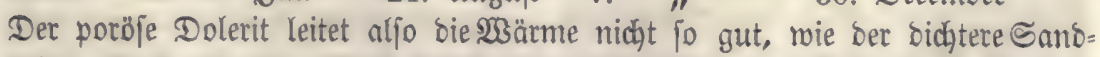

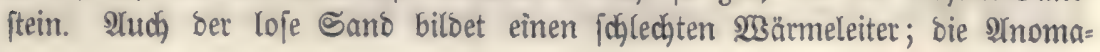




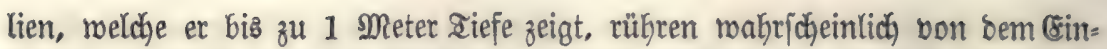

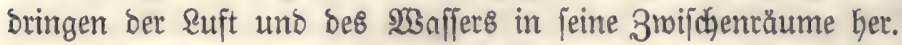

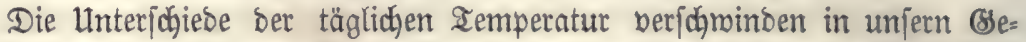

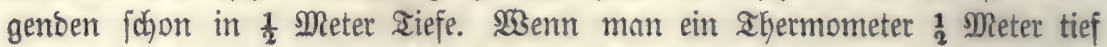
in ben sBoden einjentt, fo hält fich biejes bon einem $2 a g$ zum andern ftatio=

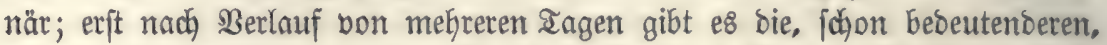
Iemperaturberänderungen an. Sn ber Siefe von 1 Meter berjojwinden felbft bie wödjentlichen uno in 2 Netern bie monatlichen Iemperaturbifferenzen.

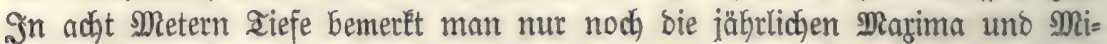
nima und in 20-24 Metern Gleibt bie Temperatur bas ganze Jabr Gindurch eine und biejelbe. Im Reller bes Dbjerbatoriums zu \$aris befindet fich 27,6 Mleter unter Der Sberflähye bes Bodens, ein Thyermometer, melches 1773 von Saboifiter bort aufgejtellt wurbe uno jeit biejer Beit fortroähreno bie conftante Iemperatur bon $11^{\circ}, 82$ zeigt. Snnerbalb ber Iropen trifft man aber idgon in einer Tiefe bon $\frac{1}{2}-\frac{3}{4}$ Metern eine conftante Iemperatur an.

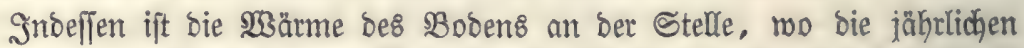
Yenderungen berjdyminden, nidht gleich ber mittlem Safrestemperatur ber \&uft an ber Bobenoberfläche. Die Bobenwärme behauptet einen etmas grö=

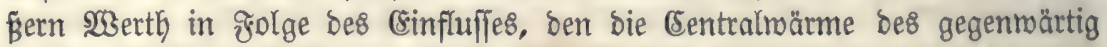

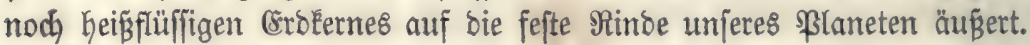

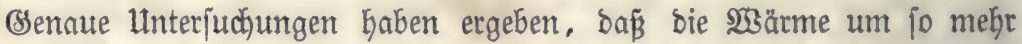
zunimmt, als man fich), von ber (Erobberflädje ausgeheno, bem (Eromittelpun Et năhert.

So fand man in Bofrlöchern zu \$regny bei \&enf (\$regnty liegt 1400

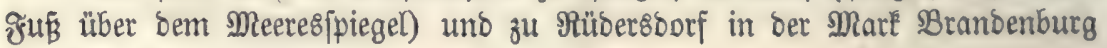
folgense Temperaturen:

Tiefe unter ber

Bobenoberfläcje

\begin{tabular}{|c|c|c|c|}
\hline & Meter & $9^{0}, 750$ & \\
\hline 9 & $"$ & 10,500 & \\
\hline 19 & $"$ & 10,625 & \\
\hline 31 & $"$ & 11,000 , & \\
\hline 62 & $"$ & $11,875\}$ & \\
\hline 93 & $"$ & $13,125\}$ & 1,250 \\
\hline 124 & $"$ & $14,212\}$ & 1,087 \\
\hline 155 & $"$ & 15,250 & 1,03 \\
\hline 186 & $"$ & $16,312\}$ & 1,062 \\
\hline 211 & $"$ & 17,250 & \\
\hline
\end{tabular}

Unter $=$ Diefe unter ber

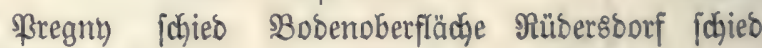

\begin{tabular}{|c|c|c|c|}
\hline 0 & Meter & $8^{0}, 50$ & \\
\hline 25 & $"$ & 10,00 & \\
\hline 62 & $"$ & $13,44\}$ & 1,4 \\
\hline 93 & $"$ & $14,93\}$ & 14 \\
\hline 124 & $"$ & 10,36 & 1,4 \\
\hline 155 & $"$ & $17,75\}$ & 1,3 \\
\hline 186 & " & $19,12\}$ & 1,3 \\
\hline 217 & " & 20,79 & 1,6 \\
\hline 248 & " & $22,34\}$ & 1,6 \\
\hline 273 & " & 23,50 & \\
\hline
\end{tabular}

23 ir fehen aljo, baf bie Temperatur in gerabem $\mathfrak{B e r b a ̆ l t n i f f e ~ m i t ~ b e t ~}$

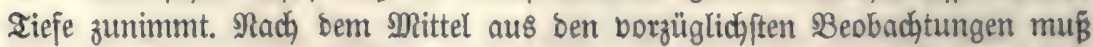

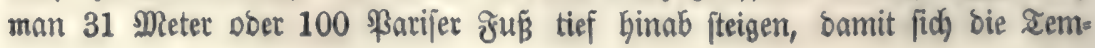


peratur um $1^{0}$ (Eelj. erböbe. Dod) finbet man audh Unterjobiebe, je nach ber

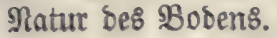

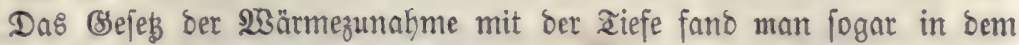
gefrornen Boben von Saluź in Cibirien beftätigt. Die mittlere Sabreastem= peratur beträgt bajerbit $-9^{n}, 7$; im Sommer thaut ber 9 Boden nur bis zu $\frac{3}{4}$ Metern Siefe auf. Sm Sahr 1830 legte (5rmann hier einen Brunnenjohacht an, ber aber erft 1837 beendigt rutro. Man fand

$$
\begin{array}{lrlll}
\text { in } 15 & \text { Metern } & \text { Iiefe } & -60,9 \\
\text { " } 23 & \text { " } & \text { " } & -5,0 \\
\text { " } 36 & \text { " } & -2,5 \\
\text { " } 116 & \text { " " } & -0,6
\end{array}
$$

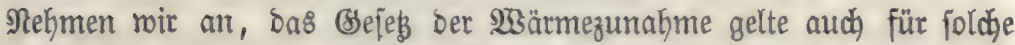
Siefen, bis zu welchen man noch nidht gelangt ift. Beredhnen wir Giemad,

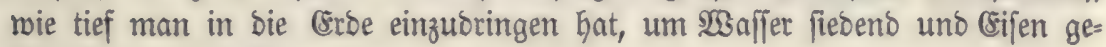
jömolzen anzutreffen.

Der Siebepunkt bes $\mathfrak{W a f f e r}$ liegt bei $100^{\circ}$. Bejebt, bas $\mathfrak{W}$ affer an ber Erooberflädje Gabe eine Temperatur von $0^{\circ}$, fo mürbe in $31.100=3100$ Me=

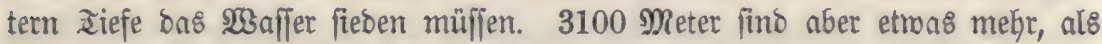
eine babe Meile. - Das (sijen jomilgt bei $1200^{\circ}$; um an ben $\mathfrak{s u n l t}$ zu ge= langen, ro biejes geidjieht, müß̈te man aljo $31.1200=37200$ Mpeter (etras über fünf Meilen) tief unter bie (Srooberflädje hinabzufteigen haben. Man

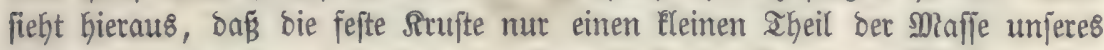

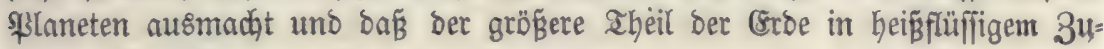
ftande fich befinten mußs.

Da bie remperatur bes 3 obens in einiger Tiefe $(20-24$ Metern) fta= tionär ift, fo hat man borgejhlagen, bie mittlere Jahrestemperatur eines $\mathrm{Dr}=$ teళ aus ber Iemperatur jeiner Duellen, bie aus einer joldben Tiefe auffeigen, abzuleiten. Diejes Berfahren, obgleidy e8 nur eine einzige $B$ eobadtung ex= forbert, if indeffen nicht jefy empfehlenstwerth, benn es madjt fids in ber

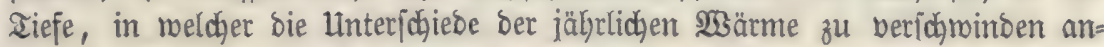
fangen, içon ber Binflü ber innern (Eromärme gelteno, wie aus ben nachfte= benben Beobachtungen Quetelets in Brüffel erfichtlich ift.

$\begin{array}{ccc}\text { হiefe } & & \text { Jahresmittel } \\ 0 & \text { Mleter } & 9^{0}, 90 \\ 0,58 & \prime & 9,71 \\ 1,38 & \text { " } & 10,07 \\ 2,21 & \prime & 10,31 \\ 3,08 & \text { " } & 11,16 \\ 12,00 & \text { " } & 11,99 \\ 24,00 & \text { " } & 11,88\end{array}$

Dann Eann man aber nie barüber volftändig berficjert fein, ob benn bie Duelfe mirlelid, aus der oben bezeidgneten, Dber aus einer größ̈ern Doer ge- 
ringern Tiefe comme. Im exftern Falle mütbe bie Quelle eine Therme und

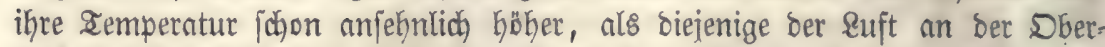
fläche Des Bobens fein; im andern ひ̆alle aber erfielte man, ie nach ber $\mathfrak{B e}=$ obadjtungszzeit, fdrwankenbe Iemperaturen. Das $\mathfrak{B a f f e r}$ Der gemöhnlidjen Senébumnen eignet fich am allermenigften baz̆, um aus feiner Temperatur bie mittlere Jahresిmärme eines Drteళ Gerzuleiten; Diefe Snumnen merben bon Iagmaffern geipeift, beren Iemperatur übernus veränberlich ift.

Da unter ben Tropen fojon in einer Iiefe von $1 / 2$ biz $3 / 4$ Metern bie Temperatur des Bobens conftant ift, fo lä̧̆t fich in biejen Begenden bie mitt= lere Iafrestemperatur nod) am exften burch Beobadjtungen ber Iemperatur Des Bobens ermitteln. Die meijten Temperaturangaben, melche uns Boujīin= gault und \$̧umbolot für Drte ber Geiésen 3one mitgetheilt baben, fino auf biejem $\mathfrak{2}$ Bege etlangt worben.

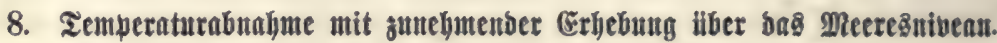

\section{a. Iriadjen biefer Iemperaturabnabme.}

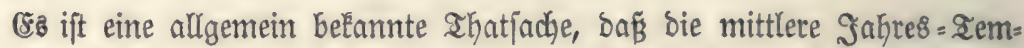
peratur um fo mefr abnimmt, je weiter man fich von ber (Erboberfläche in

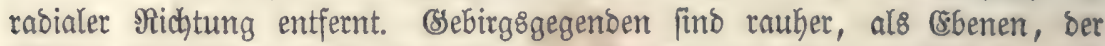
S3inter ift in ifnen nicht allein ftrenger, fonbern er beginnt aud früber uno fört fpäter auf. Unter bem 2 requator gibt es $\$ 3$ erge, welche mit etwigem

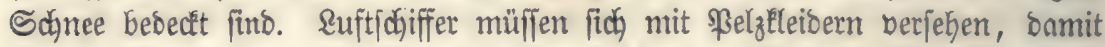

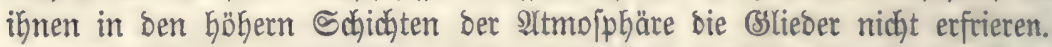

Die Temperaturabnafyme mit ber rrbebung über bie Meeresfäche läßt fid folgenber Maßjen ertlăren.

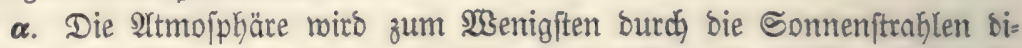
rect ermärmt, da fie nur einen geringen Theil ber $23 a ̈ r m e$, welche bieje Strah= len begleitet, abjorbirt. Nach ben Hnterfuchungen von ßoutllet gelangen wes=

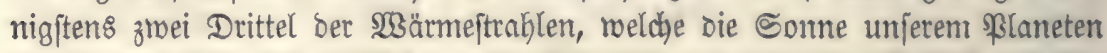
zujendet, nuf bie (Erooberfläche. Die Ruft errärmt fich Gauptjäblich auf $\Omega_{0}=$ ften ber lestern. Die höhere Temperatur, meldge bie (srbe annimmt, theilt fich ber \&uft, bie mit ifr in Berührung fich befindet, burch \&eitung und ben ents ferntern Sdjidhten burdj Strablung mit. Wir haben aljo bie (Erboberfäche als bie Gruptiäd)lidjte $23 a ̈ r m e q u e l l e$ für bie 2 ttmojphäre anzujeken.

Dentéen wir uns bie (šrbe von lauter concentrijd)en, ifrer Dberfläche parałkelen Flächen umgeben, jo merben bieje um jo meniger ftark burdo bie von ber ertbe ausigehenden Strahlen erwärmt werben, je weiter fie von bem

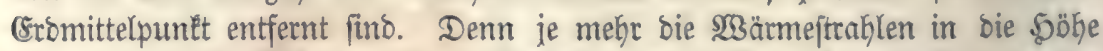
Dringen, um fo ftätéer bivergiren biejelben. Das Maß́ ber Errmärmung für zmei jolche gläh)en ift bem Quabrate ifrer (Entfernungen bom (Eromittelpunft

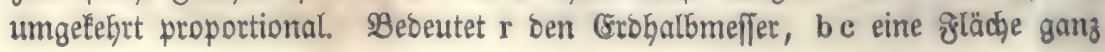


ঔig. 91.

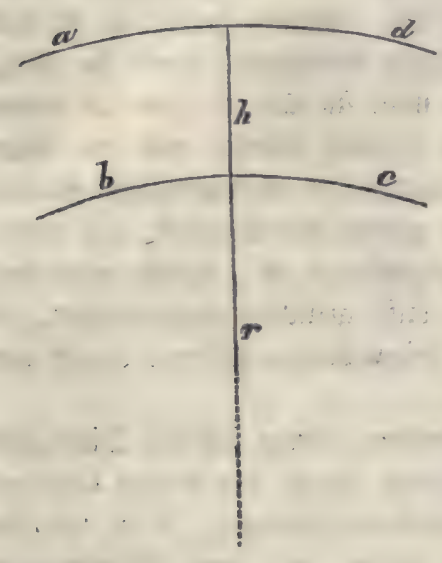

Găltnif mito matje ant Niveau bes Mreeres, ad eine Fläche in einer entfernung $h$ von ber vorigen, po verbält fich bie (struärmung ber §lädje be z̆u Serjenigen ber Flädje ad

$$
=(\mathrm{r}+\mathrm{h})^{2}: \mathrm{r}^{2}=\mathrm{r}^{2}+2 \mathrm{rh}+\mathrm{h}^{2}: \mathrm{r}^{2}
$$

uno, roenn wir $h^{2}$ als jebr Hein im Berbalt=

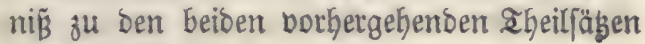
vernachlä|figgen

$$
=\mathrm{r}^{2}+2 \mathrm{rh}: \mathrm{r}^{2}=1+\frac{2 \mathrm{~h}}{\mathrm{r}}: 1
$$

Der Crobhalbmefier am 2lequator ift $=6376851$ Metern; es jei $h=4000$ Metern, fo ift $\frac{2 h}{r}$ $=\frac{8000}{6376851}=0,00125$ uno Das obige $\mathfrak{B e r}=$

Man fieht, dä́ biefe urjache für fĭd allein bie rajdye 2lbnabme ber Tempe=

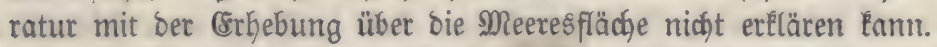

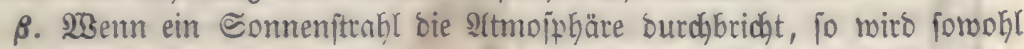
ein Theil jeiner leudatenden, als auch jeiner wärmenden Siraft abjorbirt, uno zroar ift bie Abjorption um jo ftärfer, je bichter ber Iheil ber 2rtmojphäre ift, weldhen er burdioringt. Die untern \&uftidbichten fino bie bidhteften, weil auf

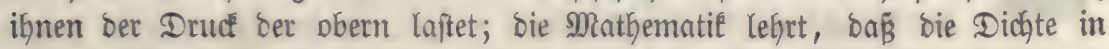

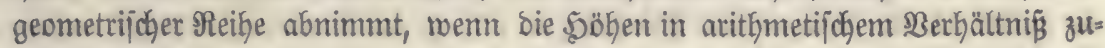
neל̧men.

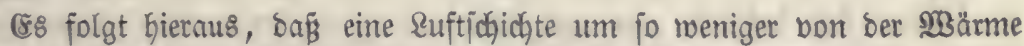
Der Sommenftrablen abjorbirt, je weiter fie it vertifaler Ridjtung von ber

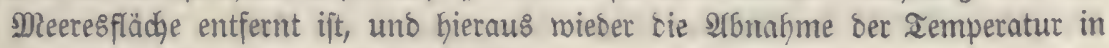
ben höbern Regionen bes \&ufttreijer.

Inbeffen ift hiermit wohl bie größ̈̈ere Rälte in ber \&uft felbft, aber nicht

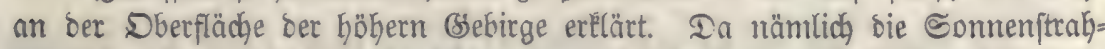
len auf biejent meniger gejobroädht anlangen, al\& in ben tiefer liegencen (5be= nen, fo foltte man eher betmuthen, baß die remperatur auf Bergen höber jei, als am গiveau bes Meeres. Dies ift aud in einter Beziehung wirtlich Der Fall. $23 e n n$ man an einem und bemjelben Tage bei Geiterem Simmel bie Rugel ei nes ahermometers in einer Dieflage und nuf einem Sebirge ber

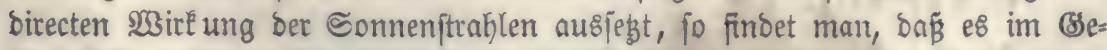
birge böber fteigr. Im ๔ohatten beobachtet, zeigt es bagegen eine geringere

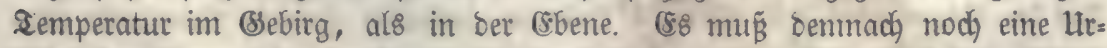
fache ber Temperaturabnahme mit zunehmender Meereshöhe beftehen. Dieje möchte mohl in grolgentem beruhen. 


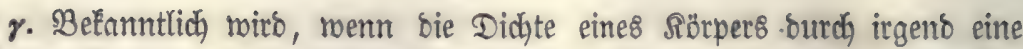

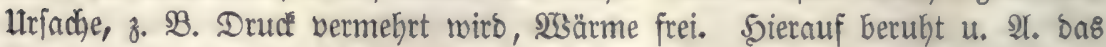

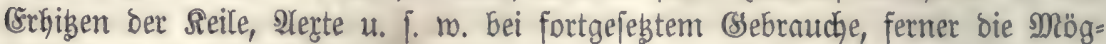
lichkeit, zwei Solźftüçe zu entzünoen, wenn man fie längere Zeit an einan= ber reibt. Die Saje verfalten fich in biefer Simficht ebenjo, wie bie feften Sïrper, wie mittelft bes pneumatifden Feuerzeuges nachgemiefen merben kann. Sn einen (oylinber von Metall paşt genau ein Stempel, an beffen

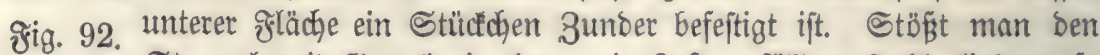

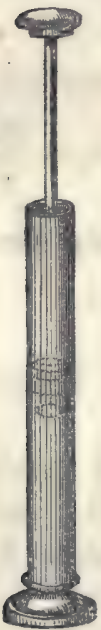
Stempel mit SSemalt in ben mit \&uft gefültten 5oblcylinber, fo mirb bie Suft comprimirt und bie freigemorbene $23 a ̈ r m e$ bringt ben 3unber วิum grlimmen.

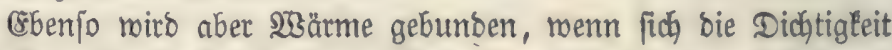

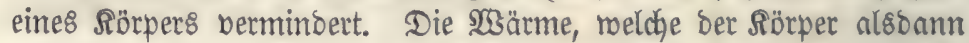
aufnimmt, bient aber nur zur Bolumsvergrög̈erung, D. দ. um bie Altome bon einander entfernt zu Galten; mit bem IGermometer Enn fie nidjt wabrgentommen werben. \&uftquantum in bem oben bejdriebenen (Eylinber (æig. 92) burd) Den Stempel fperit und nun plöglid) Den legten eine Strecfe meit

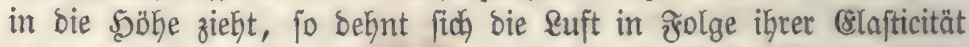
au\&, ifyc 30 lumen vermebrt fich, aber in Demjelben Moment finft

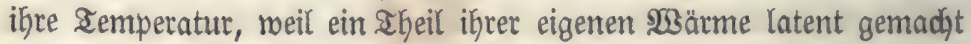
wirb.

\$33enn bie am Boben befindlichen \&uftichichten burch bie Sonne, bie Strablung ber Eropberfläche u. 1. w. erwärmt werben, jo fteigen

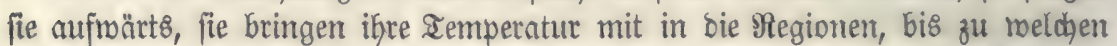
fie fich erbeben. 2⿰亻⿱丶⿻工二木

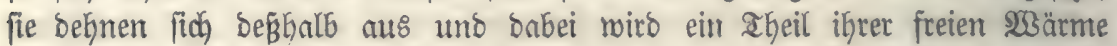

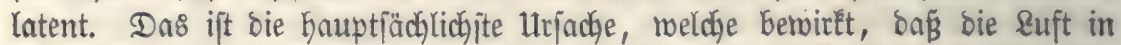
ber \$öhe niemals die $\mathfrak{3 a ̈ r m e ~ b e f i ß z e n ~ E ́ n n , ~ w i e ~ i n ~ b e r ~ T i e f e . ~}$

\section{b. Erŏfle ber Temperaturabna fome.}

Die SD̈he, um welche man aufivätts fteigen muß, bamít bas Ihermo.

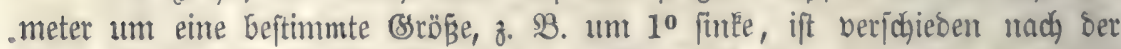
Inges= uno Safireszeit, nad, Der geographipdyen SBreite unt Ränge, ber Con= figuration bes sodens, ber Umgebung ic.

a. ₹agezzeit.

Sierüber liegen Beobadhtungen bor, weldhe im Montat Suli auf bem (Col bu (séant (in 3330 Metern) uno zu berjelben 3eit in Bsenf uno Cbas mouni angejtellt wuroen. Die Brö̈̌e ber (Erhebung, weldge erforderlich ift, bamit bas Igermometer um $\mathbf{1 0}^{0}$ Celj. finke, fano man 


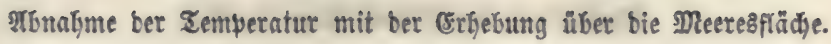

\begin{tabular}{|c|c|c|c|c|c|c|c|c|}
\hline & tunde & & (5rthe & Suntg & & Stunoe & (refhebr & ung \\
\hline 12 & MRittag) & 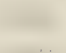 & 148 & Meter & 12 & (Mnadft) & 171 & Meter \\
\hline 2 & . n & & 140 & $"$ & 2 & (nadg $M(n$.) & 189 & \\
\hline 4 & " & $\because \ldots$ & 142 & " & 4 & " & 210 & " \\
\hline 6 & $\because-$ & $\because$ & 141 & $"$ & 6 & " & 195 & "I \\
\hline 8 & . & : & 143 & $n$ & 8 & $"$ & 180 & " \\
\hline 10 & & $\because$. & 157 & $"$ & 10 & $"$ & 160 & \\
\hline
\end{tabular}

श̂tus diejen 3ahlen geht hervor, baß̈ bie nöthige (5rhebung um 2 uhr bes Nachmittags am Eleinften ift, aljo zu Der 3eit, in reldjer bas Marimum

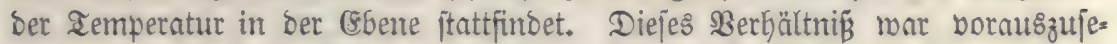

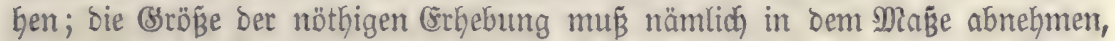

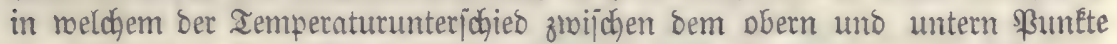

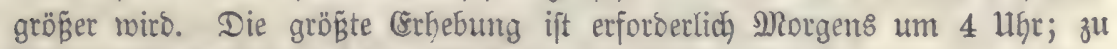
biejer Zeit tritt im Suli bas Minimum ber Iemperatur ein.

\section{B. Jabrezzeit.}

In ben kältern Monaten muß man höher fteigen, bamit bie Tempe= ratur um $1^{0}$ finfée, als in Den wärmeren Monaten. Beobadqungen bon

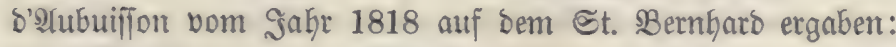

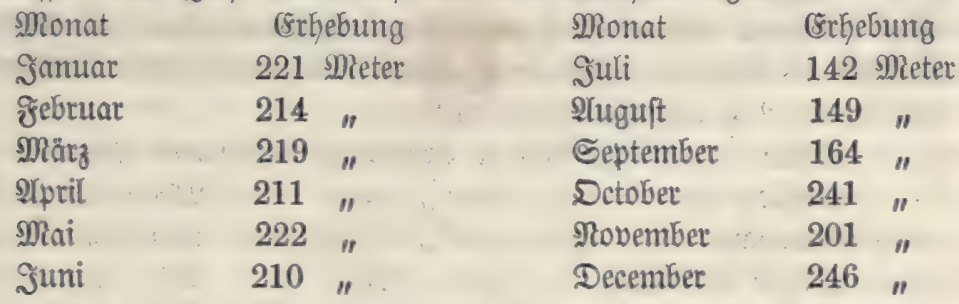

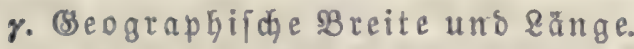

Dieje üben in io fern einen (sinflur auf bie Eemperntutabnabme mit Der Erhebung über bie Meeresfläche aus, als bie Crrmärmung ber untern unt Dbern Ruftichichten für berichiebene Drte eine andere ift, je nach ben WBinden,

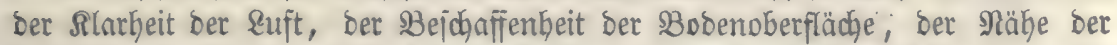

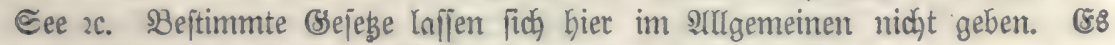
fano bie nöthige Esthebung für $1^{0}$ Temperaturabnathme:

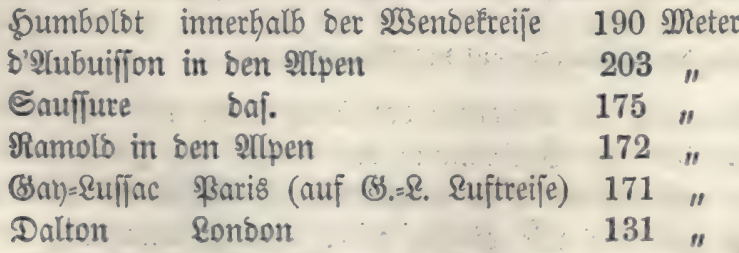

Silauprecht theitt für Deutichlanto insbejonbere folgentoe Angaben mit (Alimatologie 150, 151): 


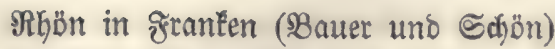
Speffart (Rlaupredht)

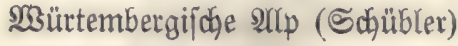

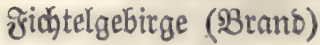

ঔichtelgebirge (NBeiß)

Sachjen. Dbermiejenthal

" I্Altenburg

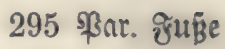

404

398

339

419

512

440

507

Die Beobachtungen Sumboldt's immerbalb ber Yequatorialgegenoen baben

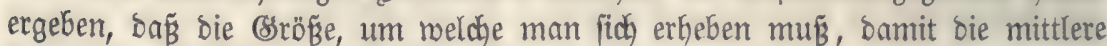

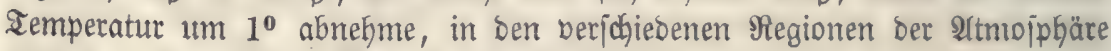
nicht bie nämliçje ift. (st fano nämlich

von 0 bis 960 Meter Die nöthige Grthebung 164 Meter

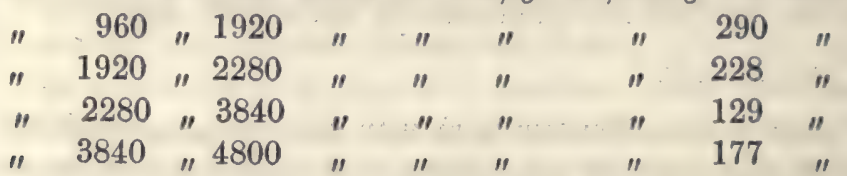

d. Configuration bes Bobenz. Umgebung.

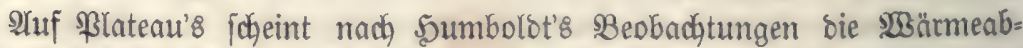
nafme nicht io raich bon ftatten zu gehen, al\& auf ijolitten Bergent. (58 fand berferbe nämlicty auf ben Sochebenen von

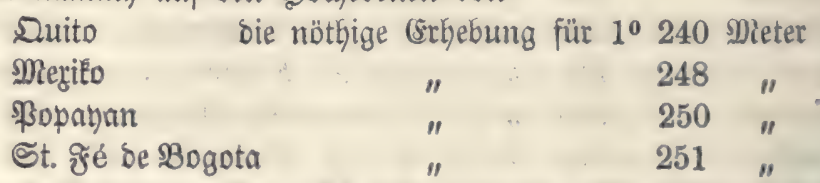

Dieje Errjcheinung erelärt fich fehr einfach. (sin fpiger ifolitter Berg

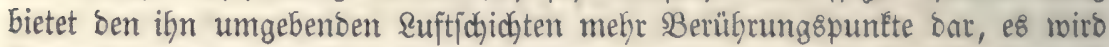
ifm burch bieje beftänoig $\mathfrak{3}$ ärme entzogen, wenn auch idjon bie Dberfläche

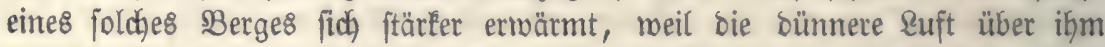

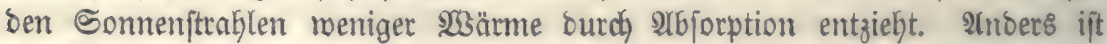
e8 mit ben \$slatenu'8. STud auf ihnen nimmt ber Boben eine böbere Temperatur an, allein bie \&uft ift Gier länger mit ber größern Bobenober= flädje in Berührung und erwärmt fid baher nad uno nady.

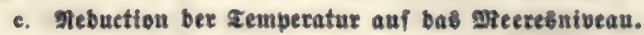

Die Renntnif ber Albnakme ber Temperatur mit ber 5ähe ift bon ber

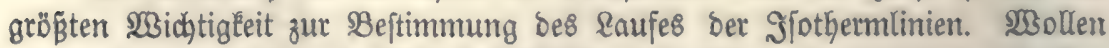
roir bie Temperatur ztoeier Drte bergleichen, fo müffen roir biefe unter gleichen Berbältniffen arjehen; wir bürfen alfo, unt zu ermitteln, in mie weit bie Siothermen bon ben \$aralfellereifen abmeidjen, nidjt einen \$unlt in meeres:

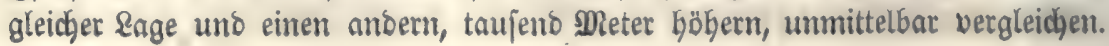


Det Einfadbeit Falber rebuzit man bie Iemperaturen am beften auf bas Niveau bes Meeres.

Um die Redhnung bornehmen zu fönner, muв man aber für ben be= treffenten Drt sie Söhe ennen, weldhe ber Temperaturaknahme bon $1^{\circ}$ entipricht. Diejelbe beträgt $\mathfrak{z}$. $\mathscr{B}$. für Quito, beffen mittlere Temperatur 15\%,6 ift, 240 Meter; Quito liegt 2914 Meter über Den Meeresfpiegel; Da auf 240 Meter $1^{0}$ Temperaturabnatime fommt, jo Eann man fid benéen,

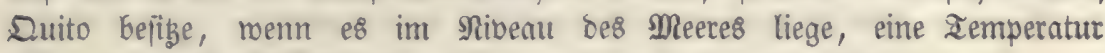
won $15^{0}, 6+\left(\frac{2914}{240}\right)^{0}=15^{0}, 6+12^{0}, 1=27^{0}, 7$.

\section{d. Edneegrense.}

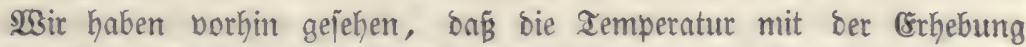
über bie Meeresflädhe abnimint; felbft unter Dem Ylequator Énn man, renn

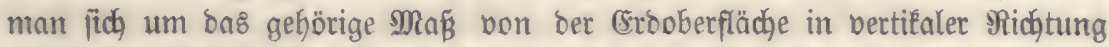

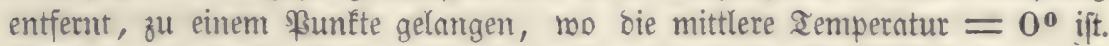

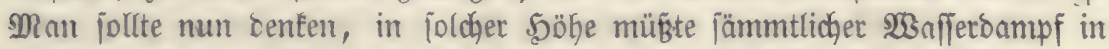
ber Ruft gefrieren, fejt werden und Edynee ober Bis bilden.

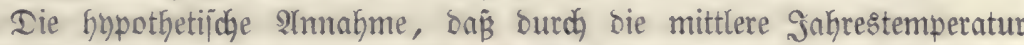
vont 0 Srno bie Echneegrenze bejtimmt werbe, ift aber, wie bie 3 Beobachtung ergeben Kat, nicht ridatig; benn man Kennt Drte, seren mittlere Jahrestem. peratur unter $0^{0}$ liegt und bie trobsem im Sommer ganz frei bon Sdyneefint.

Dffentar i it bie Sommernärme in joldgen Begenden, beren Demperatut

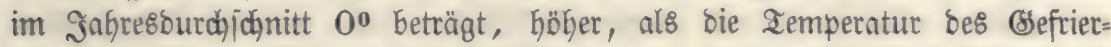
punttes. 23enn aljo aud hier im 23 inter uno aud, wohl im grühling uno Serbit Schnee fällt, io miro biejer bod, menigitens zum Theil, im Sommer megidhmelzen. (s\& hängt baher bie ๔aneegrenze bon ber Söhe ber Sommer= temperatur und bon ber Menge bes gefallenen ๔dunee's ab. Man Eann

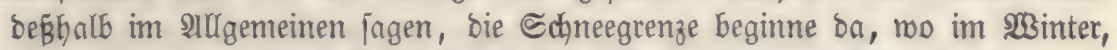

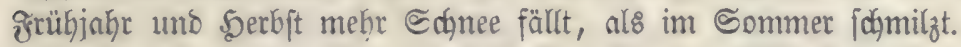

Sit die Sommermärme fo hoch unc ber Sdneefall fo gering, baí fämmitlidher Sdynee im Sommer bergeht, jo Eann ein Drt aukerbalb ber Sdhneegrenze liegen, ofgleidy jeine mittlere Sahrestemperatur meniger, als $\mathbf{0}^{\circ}$

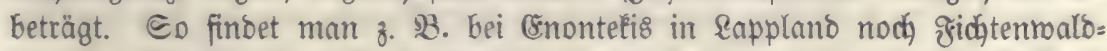
ungen, e\& rirb dajelbft -ntod) (Setreibe gezogen, obgleid) bie mittlere Jahres= temperatur $-2^{0}, 7$ ift. Waäre ber Boben bns ganze Safhe über mit Sdgnee bebeckt, fo mitroe es unmöglid, fein, ifn zu bebauen.

Daß̉ bie Sdyneegrenze am 2requator höher liegen muß́, als in ber ges mäßigten uno in ber kalten 3one, ift begreiflic), bem wie oft kann man bort, no bie mittlere Jahrestemperatur $28^{\circ}$ beträgt, 200-300 Meter (mittlere Err= hebung für bie হemperaturabnahme um 10) zurüdlegen, bi\& bie Temperatur auf 0 srab gefuntent if. 
Sm Snmern ber Eänoer rüaft bie Sdineegrenze gemöhnlid böher auf= wärt8, al\& an ben Rüften. Dies rührt einestheils baher, meil bie Sommer= temperatur im Binnenlanoe höher ift, anderntheils aber von bem größ̈ern Sd)neefall an ben Rüjten, weldjer ber Meeresfeudjtigfeit feinen urjprung veroantit.

Normegen bat befanntlich) bei gleicher Breite eine böhere mittlere Snh=

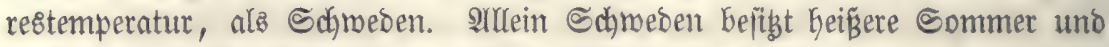

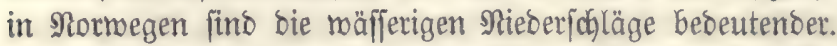

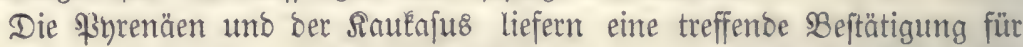

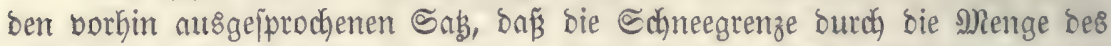
gefallenen Sdhnees beftimmt merbe. Sbgleidy bie mittlere Sabresmärme in ben Porenäen Göher ift, als im Saukajus, fo liegt boch in bem erftgenamnten Sebirg bie Schneegrenze 2000 Fü tiefer. Dies rübrt baher, weil in ben

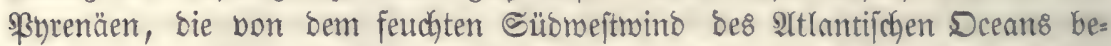

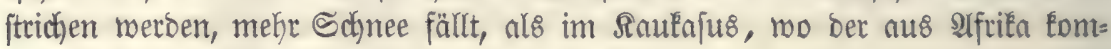
menbe Sübmeftwind trocfen ift.

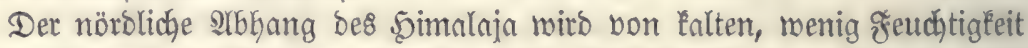
mit fich füfrenben, 23inben getroffen, Der fübliche 2lbhang bagegen von ben Mouffons, weldje bas sndifdye Meer paffitt uno fids auf biejem mit

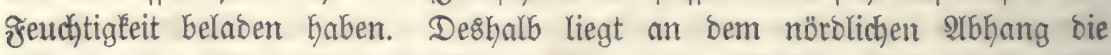

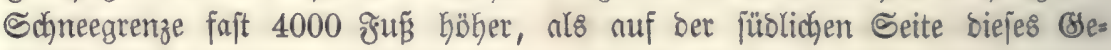
birgşzuger.

Iuf ifolirten Bergen geht bie Sdhneegrenze gewöhnlid höher binnuf,

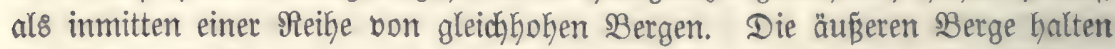
bie Sonnenftrablen ab; aud mirb bie remperatur burdh bie grofien Sdynee= mafjen eines ganzen (sebirgsfyftems erniebrigt.

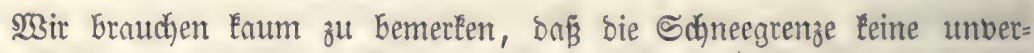

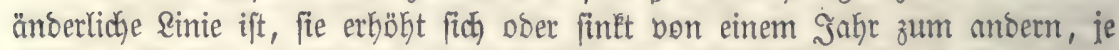
nach ber Maffe bes Sdneefalls und ber Sähe ber Sommertemperatur. Ulm bie mittlere Sdjneemenge zu beftimmen, muв man beşalb nus mebrjährigen

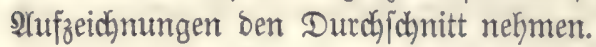

ख̧enn man fich bom Alequator aus weit genug nad) Norben ober Sü= ben hin begibt, fo lommt man.enblid) zu einer Region, wo bie Sdyneegrenze im Meeresnibeau liegt. Die Sinie, weldye bie Srenze bes emigen Schnees in meeresgleidyer \&age auf ber nörolichen Salblugel bezeidynet, geht bei Spits= bergen bis etra $80^{\circ}-81^{\circ}$ ber geogr. SBreite hinauf. Heber Iffien uno Imerifa fentt fie fich bebeutend Gerab. Da bie fübliche Dalbëugel überbaupt kälter, als bie nöroliche ift, fo trifft nuf jener bie Cdneegrenze audj früher im Mrees resnibeau ein, wahrjheinlich zrijchen $67^{\circ}-71^{\circ}$.

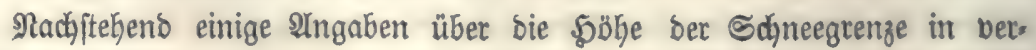
fajiebenten Breiten. 
Bietjōer.

231

Breiten.

Bei Ruito

SBreite

\$ultén Purace

$0^{0}$

Buiftan Iolima

$2^{\circ} 18^{\prime}$

Sierra Rebaba bi Meriba

$4^{046}$

$8^{0} 5^{\prime}$

श्रbrfitinien

$13^{\circ} 10^{\prime}$

Meçito

$19^{\circ}$

Simalaya, nörol. शlbhang

$31^{\circ}$

Sinou"usho fübl. शnb bang

$31^{\circ}$

Sierra Rebaba be Branaba

$34^{\circ} 30^{\prime}$

Sdnneegrenze in Metern.

(Etna

$37^{\circ} 10^{\prime}$

4824

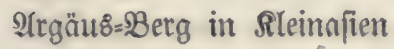

$37^{\circ} 30^{\prime}$

4688

4670

4550

4287

4500

5067

$38^{\circ}$

Mratat

$39^{\circ} 42^{\prime}$

3956

ßyrenåett

$43^{\circ}$

3956

3410

2905

3262

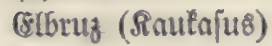

$43^{\circ} 21^{\circ}$

4318 (?)

2llpent

$46^{\circ}$

2728

3372

थltai

$50^{\circ}$

2708

1070

Bulfan Sdjebelutich (Aleuten)

1600

1460

$59^{\circ} 40^{\prime}$

1364

$60^{\circ} 55^{\prime}$

1560

$60^{\circ} 62^{\circ}$

936

$65^{\circ}$

1266

$67^{\circ}$

1072

$70^{\circ}$

$71^{0}$

120

Snjel Mageroe

$80^{\circ} 81^{\circ}$

0

\section{c. Die Gletifiter.}

Die Sdfneegrenze bilbet üGerall eine ber Sorizontalen ziemlidy parallele Sinie. Bon ber Єdyneegrenze aus ziefen fich aber (sismaffen bis weit in bie Ihäler hinab - man nennt fie (s)leticher.

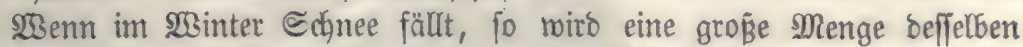

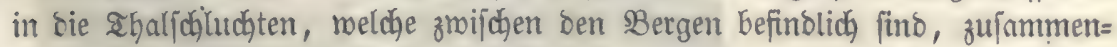
gemeft Diefer Schnee bleibt aud im Eommer liegent, weil ifn bie Sonne, gehinbert burch bie Bergränbe, nidht erreidjen kann. YYuf ben \$Bergen ba=

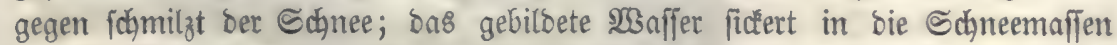

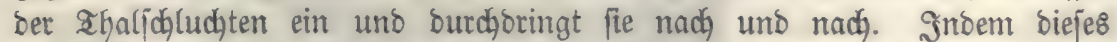

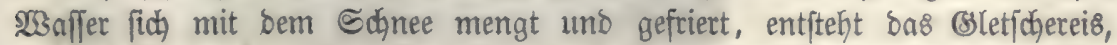
melches fich burch geringe Cpröbigleit uno Ërniges (sefïge bor bem genöhn= lidłen (sije auszzeichnet. Die Sïrner, in meldhe bas Bletidyereis beim Zer=

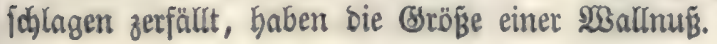


Das meifte (sletfidfereis ftnmmt aber bon bem girn ab. Diefer finbet

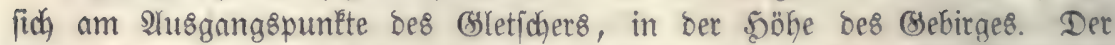
Zirn bejteft aus rundlichen, erbjengrofen Sörnern von (sis. Sie bilben fick (d) on nach einigen Ingen aus bem frijchgefalfenen Sdhnee. Der girn wiro burdh bie Berwegung bes (sletichers, bon meldyer wir fogleid, reden wollen,

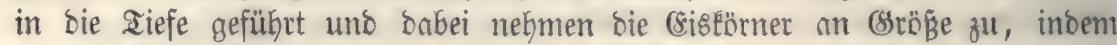
mefrere fich berbinoen.

Die (Sletjcher reichen mit ifrem (snde bis in bas Gebnute \&anb hineint,

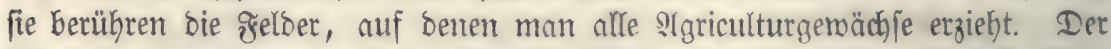
Brinbelwalogletjcher im Berner Dberlano geht bis 1000 Meter über bie Mlee= resfläche hinat.

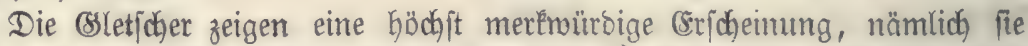

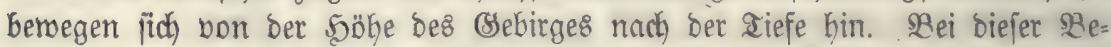

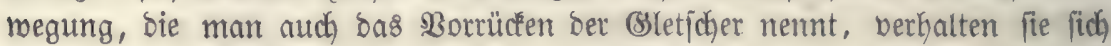

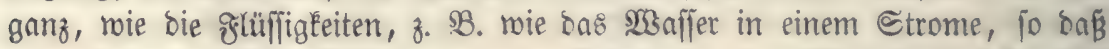
man fie in ber That Ciffiftrome nennen fann. Sn ber Mitte bemegt fid bas

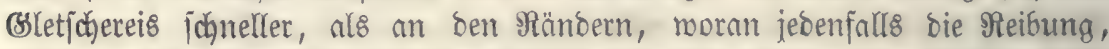

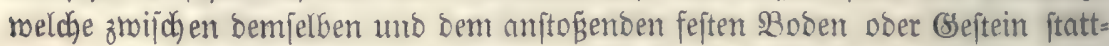

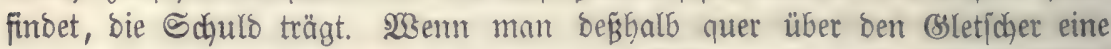
gerabe Sinie gieft, bie zu ber sängenare beffelben rechtrointelig ift, jo bilbet biefelbe nath einiger Zeit eine Curbe; bie beiben (snben am Ranbe bleiben

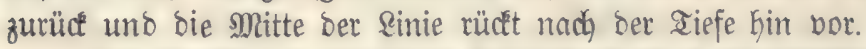

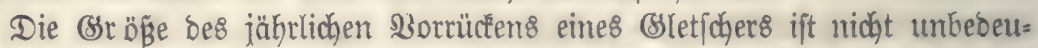
tent; fie foll an 100 Meter betragen Ëönnen. Sm Somnter und bei raarmem

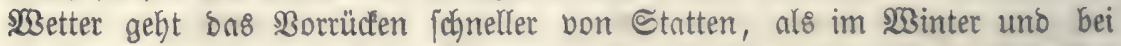

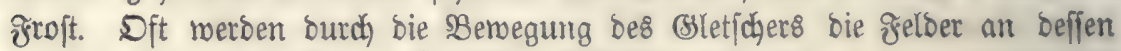
unterem conde berbect unt baburch ber cultur entzogen.

$\mathfrak{3 e n n}$ am $\Re$ ande be\& (stetjchers Freljen fich befinoen, io fallen oft Stücfe von biejen auf bns Bis und merben bann von bemielben weiter ge. tragen. $\mathfrak{A m}$ untern (snoe im \$hal bleiben fie liegen, menn bas sis jetmilat. Man nennt bie Sdutt= baufen, weldye bierdurd entiteben, Moränen.

ฆ̊ig. 93 .

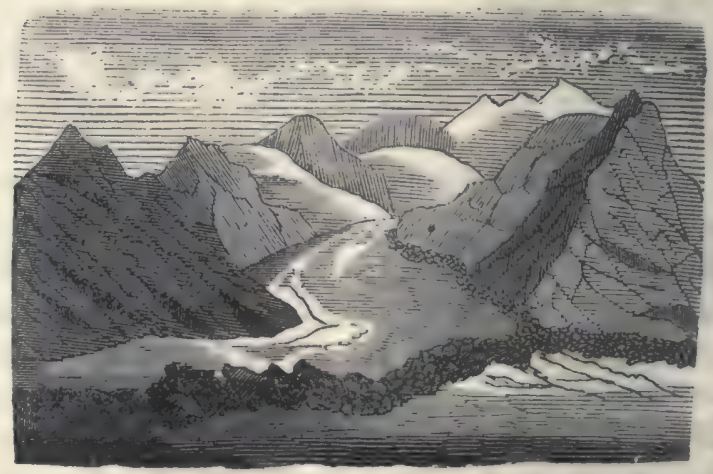

Bon ben (Ertlärungen, weldhe über ba8 Borrücen ber (Steticher gegeben worben find, hat rookl biejenige am meiften für fidd, weldye fie von 
ber eigenen ङdhwere biejer ungeheuren, auf einer geneigten (Sbene befindichen, Eismaffen ableitet. Ia\& von ben Bergen lonmente $\mathfrak{B}$ affer bringt bi\& zur

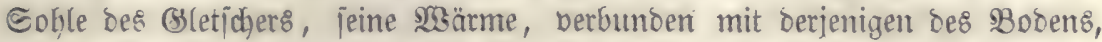
auf meldyem ber (Sletider ruft, löft bas (sis auf. Sadjoem ber 3u[ammen= bang zroijchen bem (sis uno ber llnterlage nufgetioben morben ift, beginnt

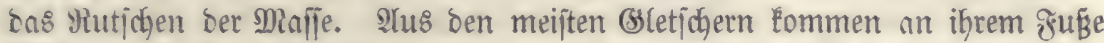
Bäche, oft von bebeutenoer Stärfe, Gerbor. Durch ons fortwäfrenoe llm= ervftalliftren bes (sijes bei jeber Iemperaturberänberung miro bie Beroegung ber Maffe exleichtert.

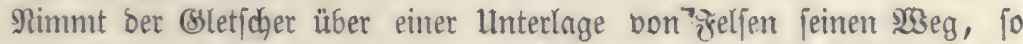
ziehen bie Steine, Molljẗlfe u. j. w., welche immer in bas SSletjchereis ein= gefroren find, jłurchen in ben Feljen, jo baßj fich an biejen ber song früherer (sletidger beutlid berfolgen läßst.

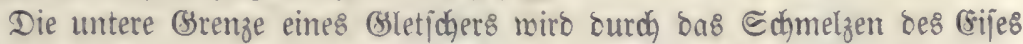
in Eommer bebingt. Sn marmen Sommern tritt bieje Brenze zurïr, in Ealten forreitet fie vor.

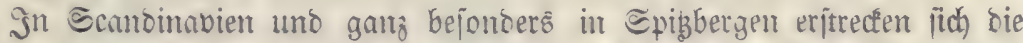

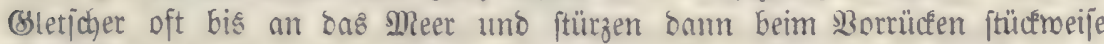

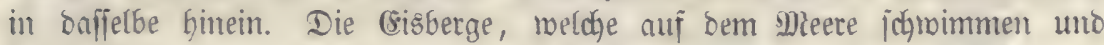
Durch Etrömungen oft bis in niedere $\$ B$ reiten getrieben nerben, bejtehen zo

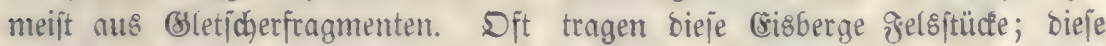
noch gegentoärtig zu keobachtende Ihatjache gibt vielleidyt über ben Irnnsport

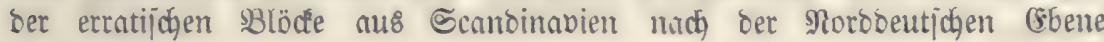
2ufichlup. 
Sedifter 20 ud.

\section{2 i it is $\mathrm{e}$.}

\section{Begriff utb Benenmung ber 2 Binbe.}

Bine in Bewegung begriffene Basmaffe nennen wir einen 23 int. 23 ir

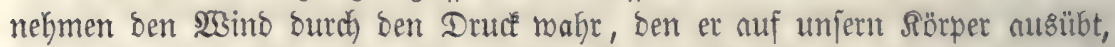
fo wie butch bie Bemegung hängenter und fatwebender Segenftände, roie o.

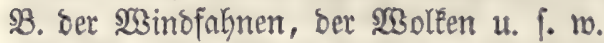

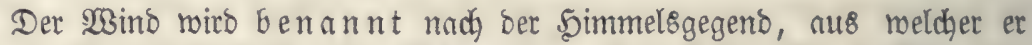
fommt, nicht nach berjenigen, welche er zu erreichen ftrebt. (sinen $233 i n \delta$, ber

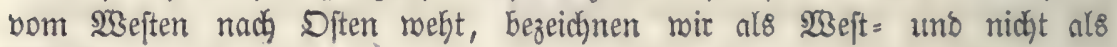
Ditwint.

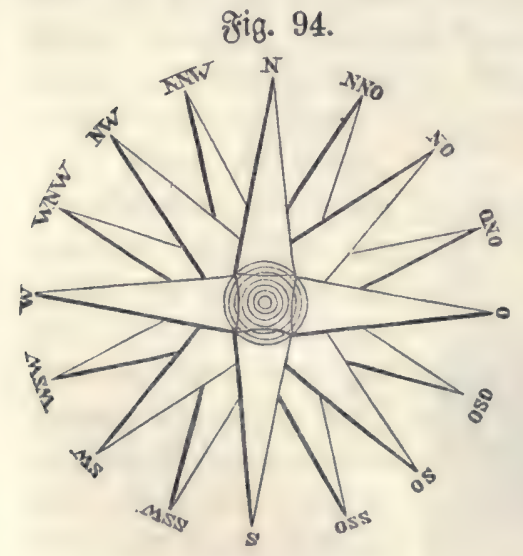

Die Benennung ber 2 Binbe, mie

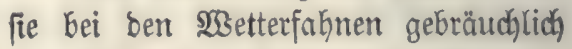
ift, zeigt bie nebenjtefente $\mathfrak{W B i n}_{\text {brofe. }}$ (§̊ig. 94.) ชึu bie Metereologie wäre es am zroedmäbigiten, menn man bie $23 i n b r i c h t u n g$ in Sraben bes Sireijes ausbrüctte, ber bie vier 5immelsgegen= ben verbinoet.

3ur Beftimmung ber 23 in or i d $)=$

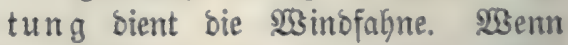
man biefe mit einer langen 2 rge in $2 \mathrm{Ber}=$ binoung bringt, weldye in bas 3immer eines ssebäubes hinuntērreicht uno einen 3eiger hat, fo expart man fich bas

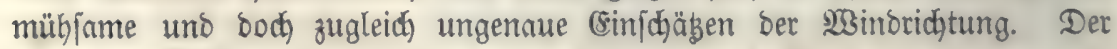

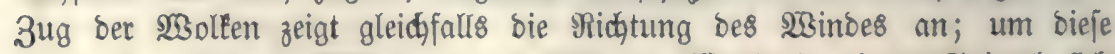

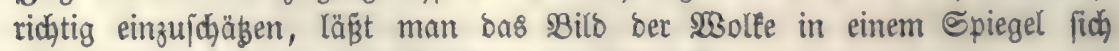

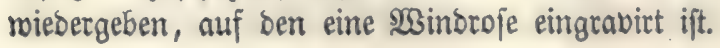




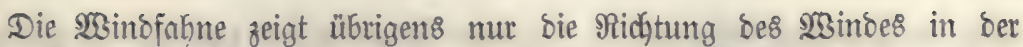
Region an, in relcher fie aufgeited ift. Säufig wehen in ben obern \&uft=

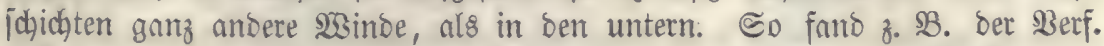

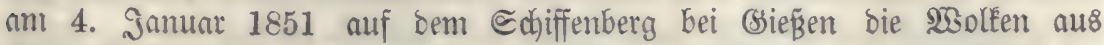

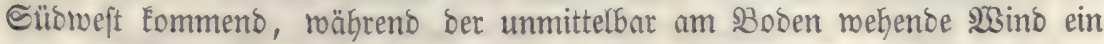
rein norböptlicher mar. Rämb füfrt in jeiner Metorologie I, 161 mehrere

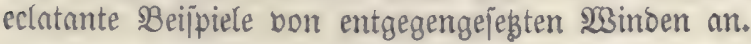

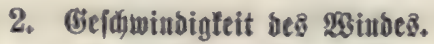

3ur Meffung ber Srejchninsigkeit bes $23 i n d e 8$ bienen bie fogenannten

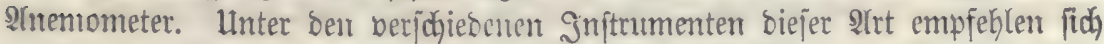

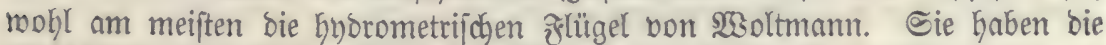

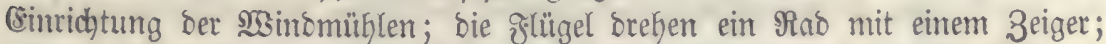
legterer gibt bie : Inzahl ber Umbrefungen nad) Berlauf einer gemiffen Zeit an.

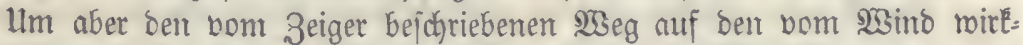

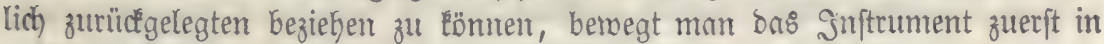
rubiger \&uft mit einer befannten Beichminoigkeit uno fieft nad), um mie viel ber 3eiger in ber 3eiteinheit borrü ${ }^{*}$.

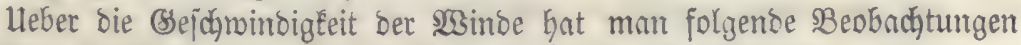
gemadht.

(Ein faum roahrnehmbarer:3ino legt in ber ๔elunbe einen

" eben

" angenehmer

"Lebhafter

" ftarter

" Geftiget

"Sturm

" Geftiger Stum

"Drtan

Der ftärf́pte Drtân

\begin{tabular}{|c|c|c|c|c|c|}
\hline$"$ & $n$ & $n$ & $n$ & $n$ & H \\
\hline$n$ & $n$ & $\prime \prime$ & $n$ & $" \prime$ & "l \\
\hline$" 1$ & "I & $" \prime$ & $\eta$ & $" \prime$ & $\prime \prime$ \\
\hline$" n$ & $\|$ & $"$ & $\prime \prime$ & $n$ & $n$ \\
\hline "I & $n$ & $n$ & $n$ & $" \prime$ & $n$ \\
\hline$" \prime$ & $" l$ & $\|$ & "I & $" \prime$ & $n$ \\
\hline 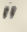 & $" \prime$ & $"$ & $n$ & $n$ & " \\
\hline$"$ & $n$ & 's & $\|$ & $"$ & $n$ \\
\hline$\prime \prime$ & $\|$ & $n$ & $n$ & " & $" 1$ \\
\hline
\end{tabular}

\section{Itrađjett ber $\mathfrak{2 B i t t b e . ~}$}

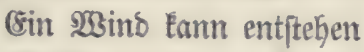

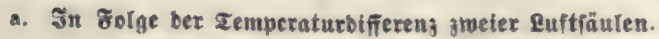

Æig. 95.

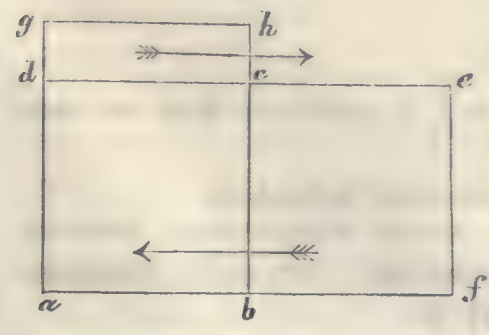

Nebymen mir an, bie beiben \&uftiäu= len a b c d uno b c e f belïgen gleidjes Bolum, (Semidgt, gleidge remperatur und 5öke. Nun werbe bie Säule a b c d erroärmt, 3. 98. Dutdy bie Sonne; fie bebnt fid) auв bis $\mathrm{g} \mathrm{h}$ uno ein Theil von ifgr fliegt über auf $c$ e. Segt ift aber bas (Sleid)gemidat geftört, benn im Qnfang maren bie beiben \&uftidjichten gleid, johtwer; 
nach) eingetretener (srroärmung auf ber einen Seite hat bie anbere Säule einen Theil ber \&uftmaffe bon ber benadjbarten erbalten, ohne felbit etmas

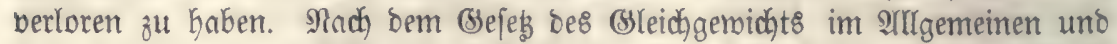

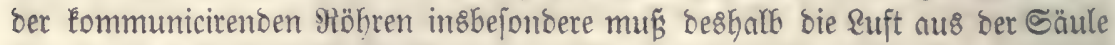
b c e $f$ nach $e d$ hinüberftrönien. WSir haben bafer zmei einanoer ent= gegengefeste 23 intoe; bie warme suft fliept oben uno bie falte unten jeit= märts $\mathfrak{a} \mathfrak{b}$.

(sin 2 eijpiel von ber eben angefüfrten Entftehungsart ber 2 Sinbe fieht man im Sleinen, wenn man ein sicht einem Dfen näbrt. Unten, nake am Boben neigt fid bie flamme. Dem Dfen zu, oben, nad) ber Deafe bes 3immers bin, wentet fie fidc) von ibm ab.

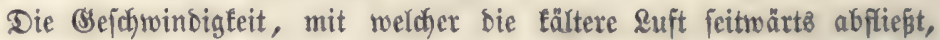

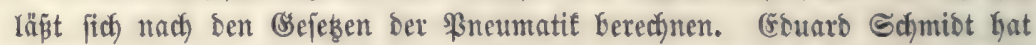
bics in jeiner Mathematijacn und Bhyjifichen (Seographie II, 334) gethan. Da bie Entwitflung żiemlidy meitlöufig ift, fo beid)ränten wir uns barauf,

- bloz bie Rejultate, zu Denen Sdjmibt gelangt ijt, mitzutheilen uno verweifen

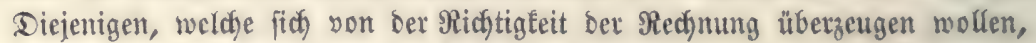
auf bas yorfin angefüfrte dehreuch).

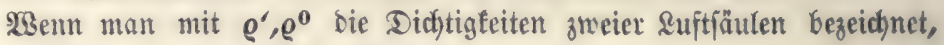

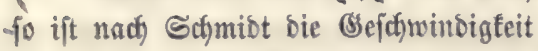

$u=\frac{Q^{\prime}-Q^{0} .}{Q^{0}} 1215$ Par. Fuß́, ober, wern $\mathrm{p}^{\prime}, \mathrm{p}^{0}$ die Barcmeter= ftänoe vorftellen,

$\mathrm{u}=\frac{\mathrm{p}^{\alpha}-\mathrm{p}^{0}}{\mathrm{p}^{0}} \cdot 1215 \mathfrak{B a r}$. $\mathfrak{⿰ u}$.

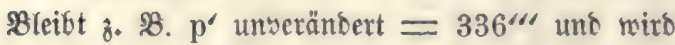

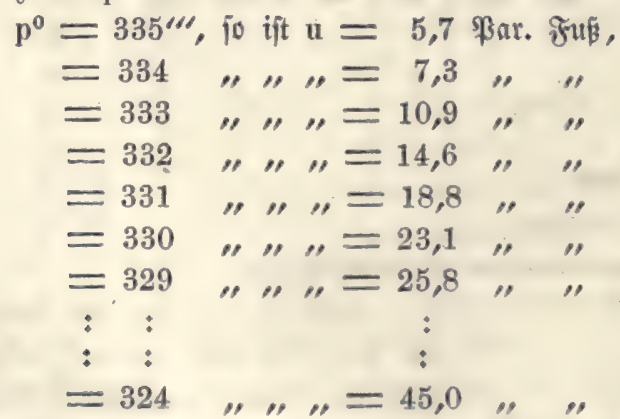

Fälut aljo bas Barometer um 1 3oll, fo entifteht cin $\mathscr{B}$ int mit ciner (stejchwindigteit yon melgx ars 40 Fupen.

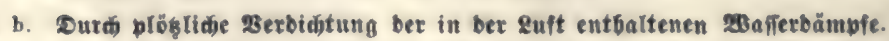

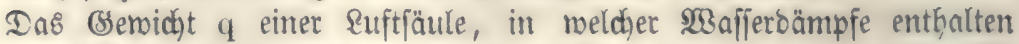

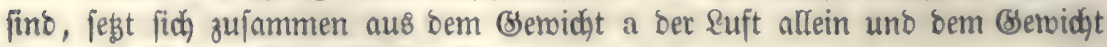
b bes $2 \mathfrak{3 a f j e r b a m p f e s . ~ ( 8 s ~ i f t ~ a l j o ~} \mathrm{q}=\mathrm{a}+\mathrm{b}$ 
Berjdminbet $b$, inbem ber Dampf fich zu 2 Baffer berbidjtet, fo bleibt nur nodh $a=q-b$.

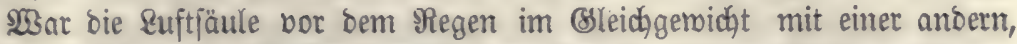

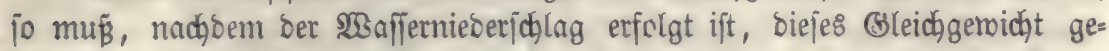

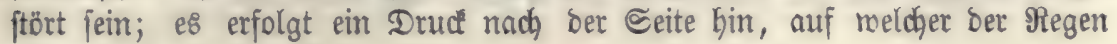
gefallen ift.

Dod) muß̈ bie Quantităt ber in ber \&uft befindlicfent Feudjtigfeit

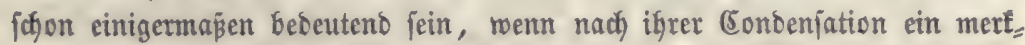

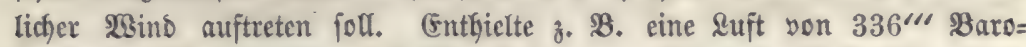

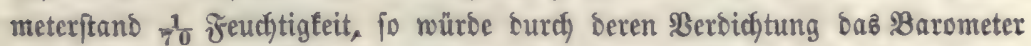
auf 331 " finfen. Sisăre gleid)zeitig an einem anbern Drt ber Barometer= ftand $336^{\prime \prime}$ nnd an Eeiben Drten bie remperatur gleidy, fo entfitübe ein

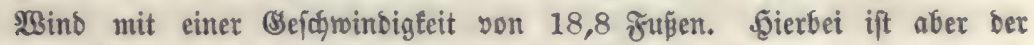
niemals eintretende Fall angenommen worben, Daß mit bem Regen jämmt=

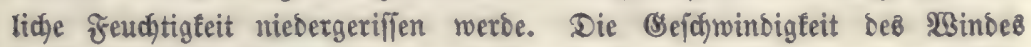
fann aber bodh bebeutento werden, wenn, wie bieb gewöbntid ber Fall ift,

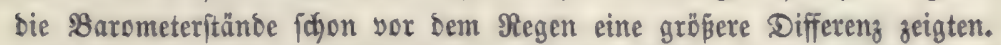

AIm 15. Dezember 1850 fano in uno um Bieß̌en ein Sturm ftatt, Der

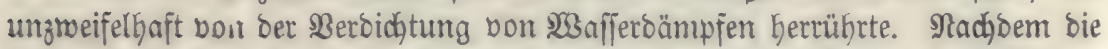

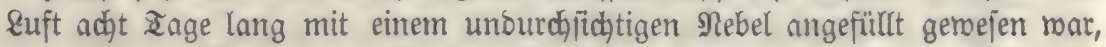

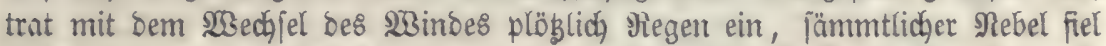
zu Boben. In ber Nacht entfano ein Keftiger Sturm, ber fich exjt gegen Morgen legte. $\mathfrak{A m}$ 16ten zeigte fich, in §olge Der ßerounftung, wieber ఇebel, am 17 ten regnete es von ఇeuem uno an 18ten ethob fich abermals ein Sturm bon beinahe berjelben Seftigleit, weldye ben Sturm bom 15ten ausigezeidjnet hatte.

Entfteht ein WBino, fo wirb er früher an einem Drte bemertbar, ber in

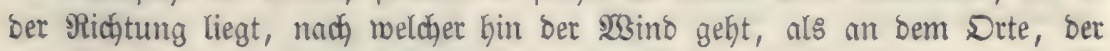
in ber ßichtung liegt, aus welcher ber $23 i n \delta$ Eommt.

Franelin rourde einjtmals unt 7 uhr âbends in Philabelphia burch

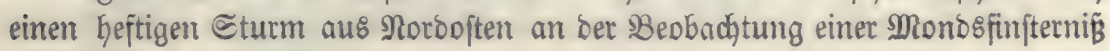

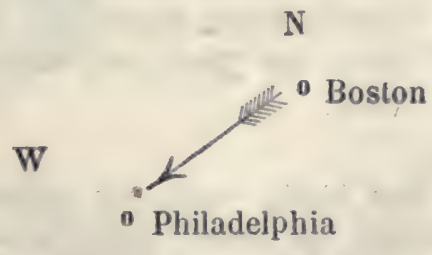

0

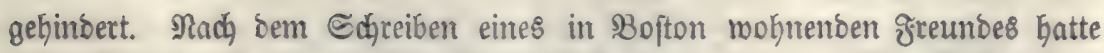
biejer Sturm erft um 11 ubr jeinen Unfang genommen. Afber SBofton liegt 


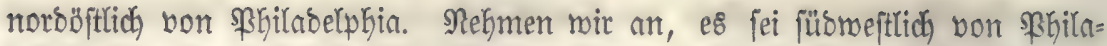
belphia ber Druc ber Ruft Dutch irgend eine Utrache verminbert worben, fo mufite natürlich bie \&uft früher von \$\$Gilnoelphia, als von Bofton au\& zuftrö= men, beshalb war ber Sturm an jenem Drte eher bemertbar.

\section{Ranto= Httb Sectuintie.}

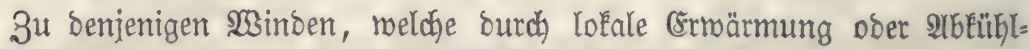
ung ber \&uft entifteben, gefören bie Rano = und Seeminoe.

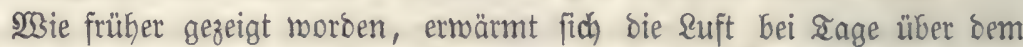
sande meit ftärker, al\& über ber See. Sie mirb alfo bort aud mehr ausge=

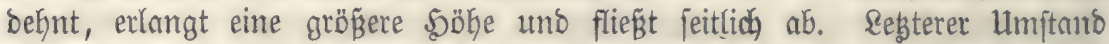

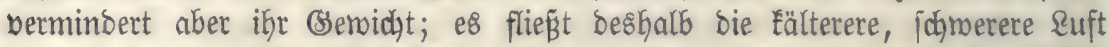

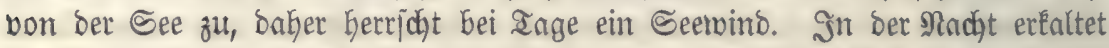

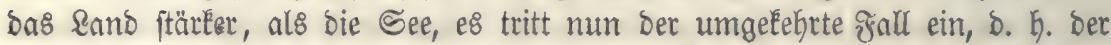

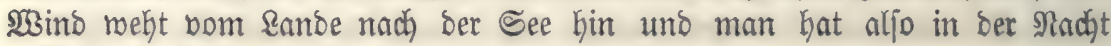
einen \&anbmint.

Da zur (Ermärmung ber \&uft burch) bie Sonne 3eit nöthig if und ba bie Abküblung nidyt auf einmal, fonbern nad und nach bor fich geft, fo zeigt fich ber Ceemino nidyt pogleid) nadh Eommenaufgang, fonsern erft 1-2 Stunden ipäter. Sbenjo tritt ber Ranomind erit einige Stunden nach) Sonnenuntergang ein.

Unter ben Iropen befïgen bie \&and = und Seetwinde eite größ̈ere Seftig= Eeit, als in hökern Breiten, wo man fie oft mur mähreno bes Sommer\& be=

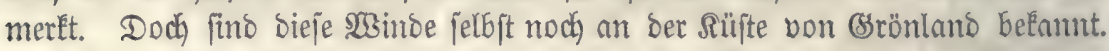

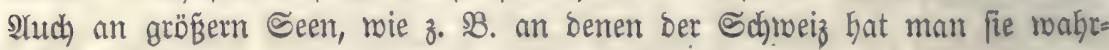
genommen.

Freiliegende Snjeln im Meere genię̧en bei Inge einen Seetwino, ber rabienförmig vom Meer nach ifrem Mittelpunlte Ginläuft. Znoei biantetral

ஓig. 96.

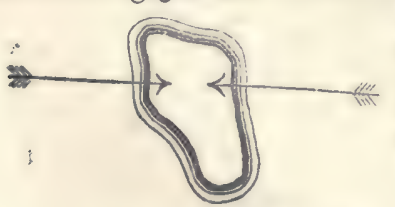

gegenüberliegenbe Drte ber Jnjel haben desfalb birect entgegengeleste 233 inbe ( Oigur 96).

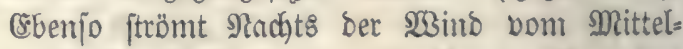
punlt ber Snjel aus rabienförmig über bas Meer.

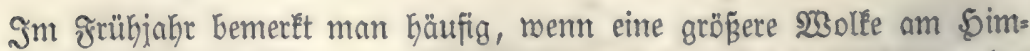
mel fich benegt, eine Eridyeinung, bie einterlei utracke mit ber Entiftefung ber Eano = und Seeminde bat. Man mag von irgent einer Seite in bas Bereich

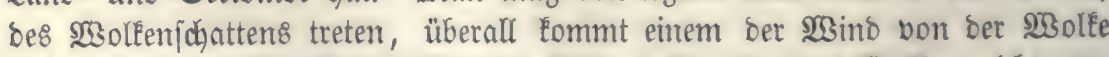
aus entgegen. Die\& rübrt baher, weil bie suft unter ben 2330 lfen nicht bon ben Gomnenftrablen getroffen wiro uno be8balb falt bleibt. 


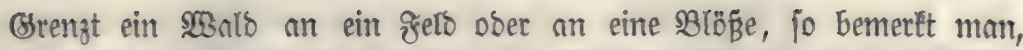

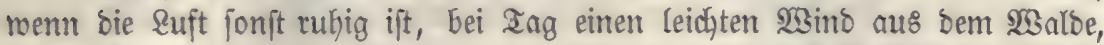

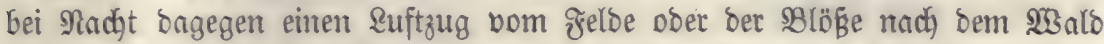
Fin. Nach Dem jo eben Borgetragenen kann man fich bie Urjache biejes 2 Bin= bes leidht ertlăren.

Die Moufions im Indifjen Meere fallen robl aud in bie Gruppe

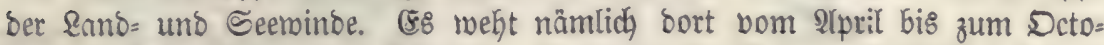

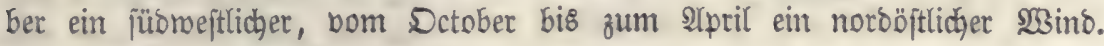

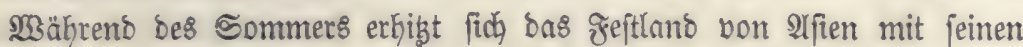

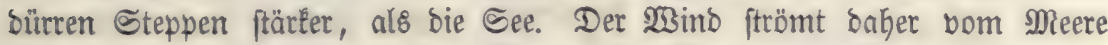

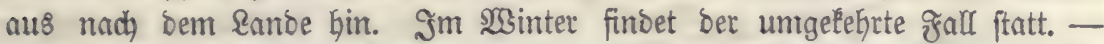
Doch änbert bie eigentbümliche Configuration ber Inbijoben \$albinjeln bie

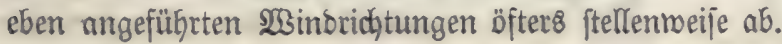

\section{Socafe 2Binbridutumgen.}

Sohe Bebirge, tief eingejohnittene shäler geben oft ben \$Binben eine

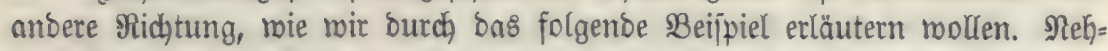

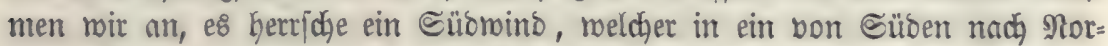
ben berlaufendes und bann nady Diten hin fid fortfebendes ahal eindringt.

ซ̊ig. 97.

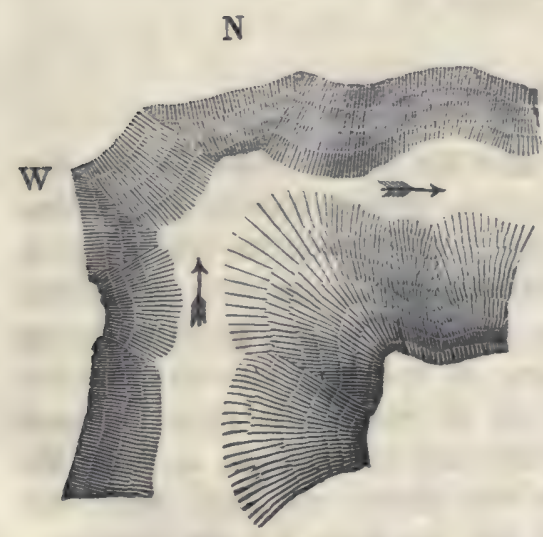

$\mathrm{S}$ Der $\mathfrak{W i n}$ prallt an ber norbroärt8 vorgejdobenen : aber ftets neue suftmafjen nachfols gen, To juchen bie zuerjt angelangten einen 2 (usweg uno finden biejen in

0 bem Biftichen 3weig bes Ifates. Die Bemogner beffelben empfinben Daker ben urpprüngliçen Sübminto als $\mathfrak{B}_{\text {ejtrint. - }}$

In Bebirgen, wo ber Miberfant, ben eine hohe Bergmand bem $21 \mathrm{t}=$ prallen bes Windes leiftet, oft nod)

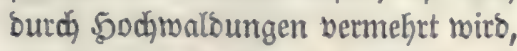
melche bie Rämme uno Bipfel bebecfen, uno wo bie Ihăler verjhite bene Richtungen einbjalten, mirb bie auf sem flachen \&anbe berrichende \$3inoridjtung immer abgeänoert. Daber

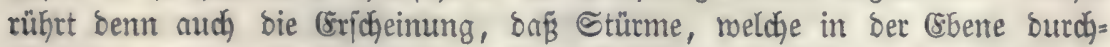

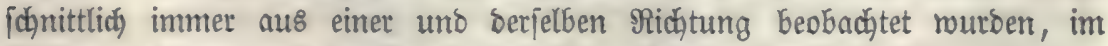
(bebirg aus ganz anderen நimmelsgegenden kamen.

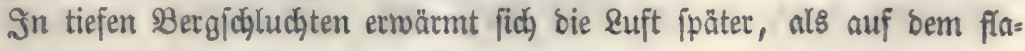




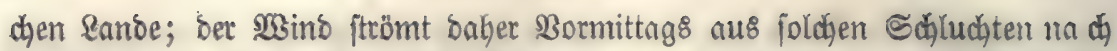

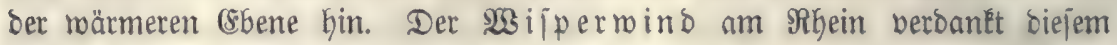
Ümitande jeine Entitehung.

ঔ̊ig. 98.

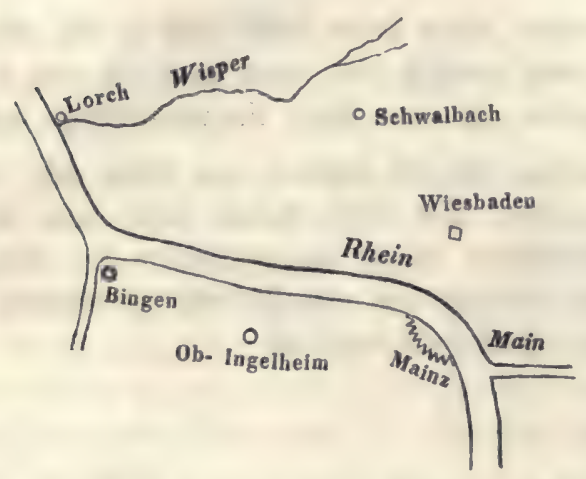

Bei \&ordh münbet Das ahal

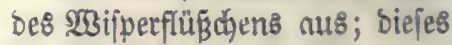

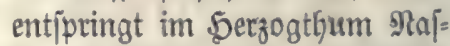

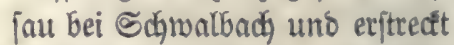
jidy in einer sange bon etroa fieben Stunben in ber Pidutung von Norboft nach, Sübweiten. (SB hat hohe Ufer, bie tief in bie Bergmaife bes হaunus ein= gejunitten fino. Die Strablen Der Sonne tönten bes Mporgens nicht bis auf Den Brund bes Wiiperthales gelangen; bie Iem=

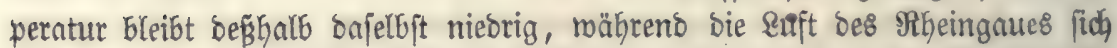
fohon ermärmt hat. Die kalte \&uft ftrömt baher aus bem WBijperthal ben

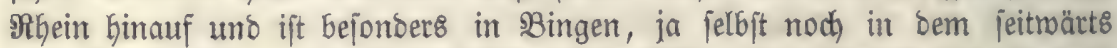

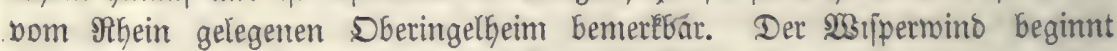
nach Sonrenaufgang unઠ hält ungefäbr 8 Stunden lang an; alsoann hört er auf, weil nun auch bas $\mathfrak{B i p p e t t b a l ~ e r m a ̈ r m t ~ i f t . ~}$

\section{Det Requatorial= unb bet Bolarlufititrm, $\mathfrak{B a f f a t e}$.}

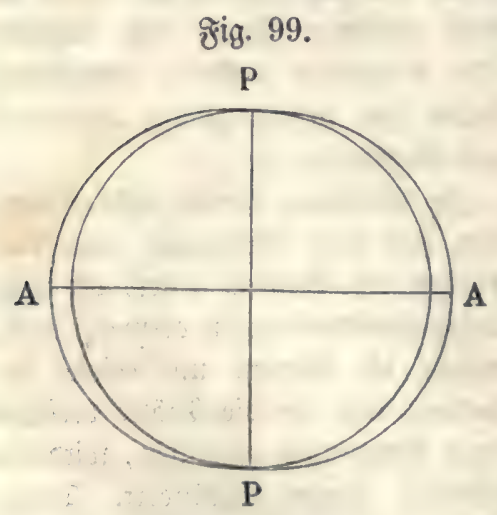

Wie wir bei ber Refre bon ber ßer= theilung Der 233 ärme über die (stooberflärye gejełen Gaben, herridyt die größte Sibe in Der Bsegend Des \&equatorz A A. Die \&uft

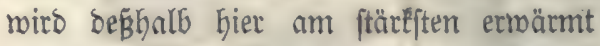
merben; igr jpecifiches (semidat nermintoert fich und fie fteigt in bie Söhe. Darurdh vermebrt aber bie \&uftjäule in biefer (se= geno igre \&änge, ein aheil biefer \&uft nirb nach ben Solen P P Gin abfliejen.

Die etrărmte \&ufft bebălt, inbem fie nad, Noro uno Sü vorbringt, lange 3eit bie am 2lequator herrichento LIm= brehungsgefdninoigleit bei, fie nimmt nur langjam bie ben höhern Breiten

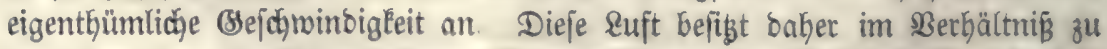

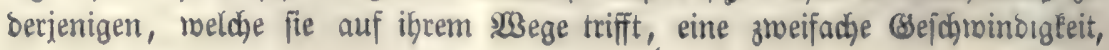


§ig. 100.

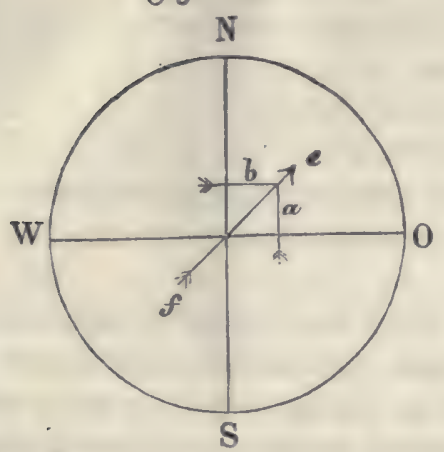

Э̊ig. 101.

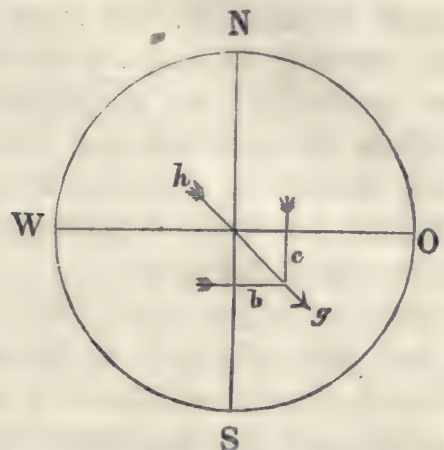

einmal eine polche in ber Ridjtung bon Süben nach Norben a auf ber nörb= lichen Salbêtugel ober von Norben nach Süben c auf ber jüblichen Salblu=

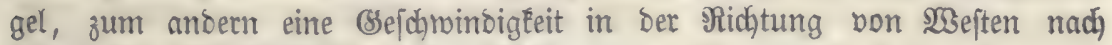
Dften (b). Da fie biejen beiben Midjtungen nidjt zugleidh folgen Enum, jo

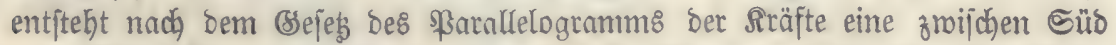

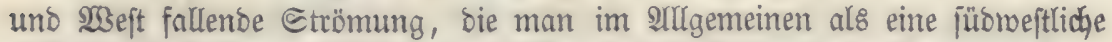
ef (ð̊ig. 100) bezeichnet. Senau ebenị ergibt fich aus bem 9 lequatorialluft=

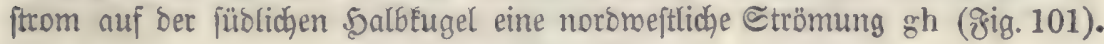

Db bie Richtung biejes \&uftftromes eine mehr nörblidhe (rejp. jübliche) Doer reftliche jei, hängt einmal bon ber (sejdjwinbigfeit $a \bar{b}$, mit rolcher bie

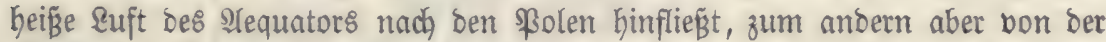
Bröß̧e ber Utmorehungsgejchmindigkeit ber \&uft in ben verfdhiebenen geogr. Breiten.

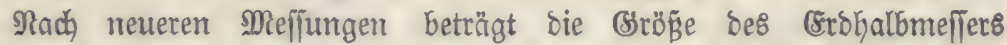
am Requator 6376851 Meter uno ber Umfang Der (5rbe 40067054 Meter. Die (sroe bregt fich um fich jelbft in 24 ๔tumben $=24.60 .60=86400$

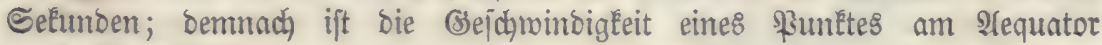
$=\frac{40067054}{86400}=464$ Meter. §ür eine anoere Breite ift Der Salbmeffer $r$ bes

Æ̊ig. 102.

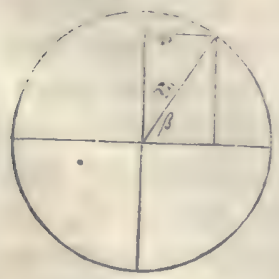

bab Barometer plöglid um 3 ßar. sinien fäut. 6eper, Bobentunde.

Parallelleifes $=\mathrm{R} \cos \beta$, menn $\beta$ bie Breite bezeich) net, Der Parallelfreis felbft ift $=2 \pi \mathrm{R} \cos \beta$. Mittelft

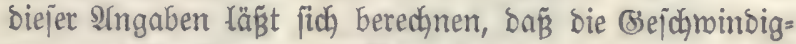
Keit eines $\Re_{3}$ untes in $30^{\circ}$ Breite in einer Setunbe $=402$ Meter, in $60^{\circ}$ Breite $=232$ Meter ift. 3 mij und $60^{\circ}$ Breite ift bemnach ber burchichnittlidje Unter= jojied in ber Umbrefungrgeichmindigkeit ber \&uft für $\mathbf{1}^{0}=5$ Metern, und bieje Bejofnindigkeit ijt gerabe jo grofi, als bie eines 233 intoes, weldyer fich erzengt, menn 
Da bie Sonte fich nientals aus bent Bंereiche ber sMendetreife entfernt

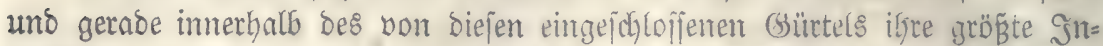

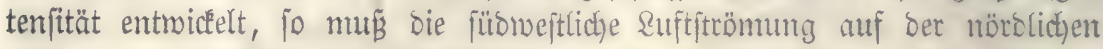
uno bie noromeftliche auf ber jüblid)en .̧albugel beftänbig im 3uge jein.

$23 e n n$ aber bie suft pom Sequntor nach den \$olen bin abfließ̈t, io

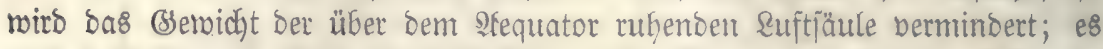

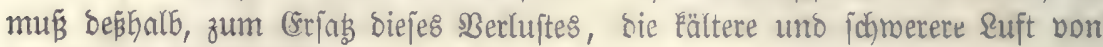
Den beiben ßolen zuftrömen.

Dieje hat auf Der nörolichen Semifph häre urjprünglich bie Richtung bon Nord nad Süb; allein, ba fie ifre geringpre Umbrehungsgejdymindigkeit nach ben nieberen Breiten mitbringt, fo wirb fie dajelbft gegen bie suft, meldhe eine größ̈ere (Der niebern Breite entiprechenoe) Itmorebungsgejchminoigkeit be-

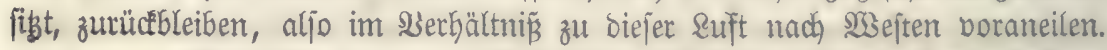
₹̊tg. 103.

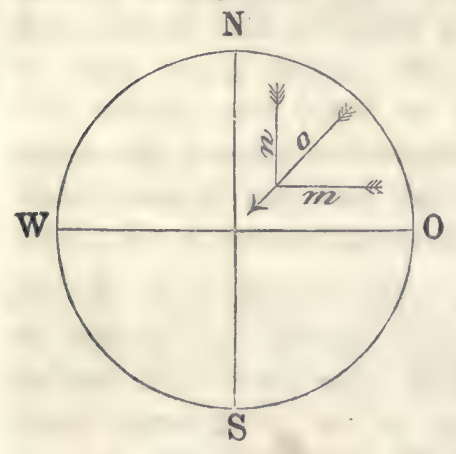

Ás biejer p̈ftliçen (m) uno ber urjprüurg. (ich) nörolichen :Richtung (n) rejultirt nadh bem Seeps bes \$arallelogramms ber Rräfte eine norböftliche Sichtung (o) bes ßolar= froms auf ber nördlichen \$albugel.

Ebenip erzeugt ber \$olaritrom auf ber füblidgen Salbugel eine füböftlidge Strömung.

Man nennt bie betoen Cestermähnten SBinbe: \$allate.

2Yuf Den exiten 2lnblid Gin follte man mokl glauben, auf der nöroliçen Şalbüugel

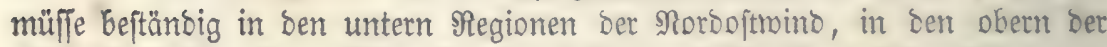
Silbneftmint meken. Dies ift aber nicht ber fiall. Der Sübneitmind er=

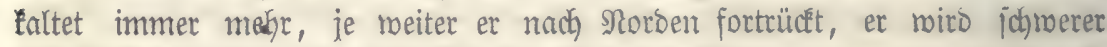
uno finft herunter, bis er endlidy ben Boben erreicht.

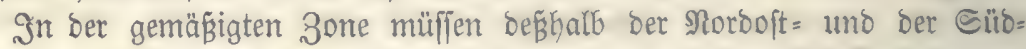
weftwint einanber begegnen, uno es hängt bon ber relativen Etärke bes einen Doer bes anbent $a b$, weldyer bon ifnen bie Dberherridyaft behalten joll. (Ss

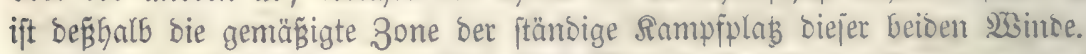

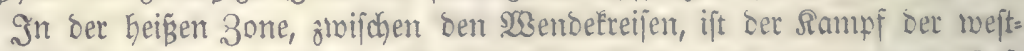

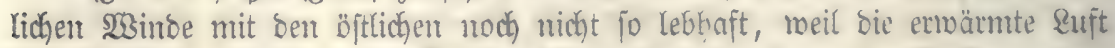

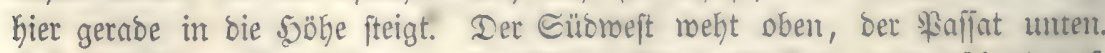

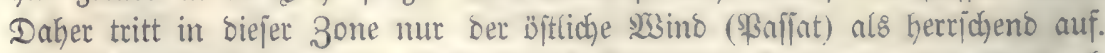

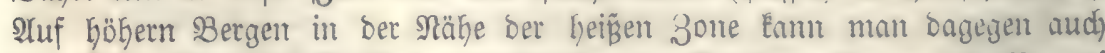

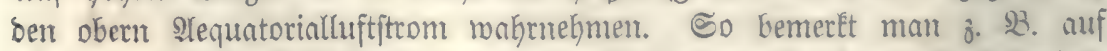

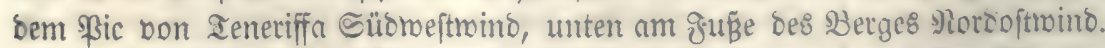

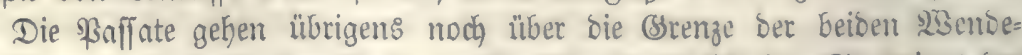

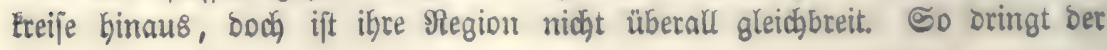




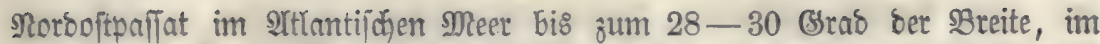
Brog̈en Dcean fagezen nur bis jum 25. (Srad vor. Sm Commer liegt auf

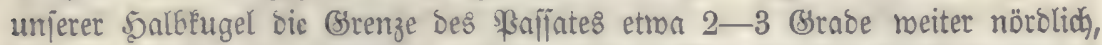
im 23 inter ebent jo viel meiter jütlict). Die \$affate finto jecoch erft in einiger Entfermung bom sanbe wafinebmbar.

\section{Die Region ber Carmen nder 2 sinditiffen.}

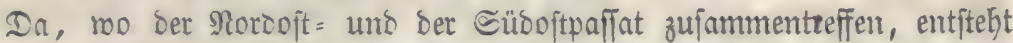

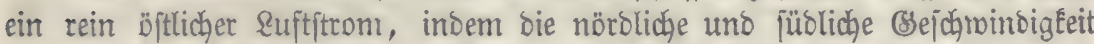
jich gegenjeitig aufbebt. Altein biejer rein öftliche Etrom ift menig bemerlEbr,

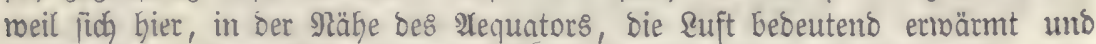

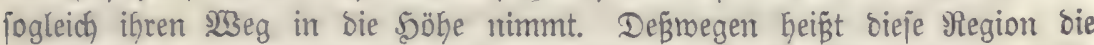

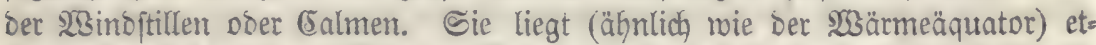
mas nörblich vom terreftrijchen Slequator und umfaßit einen sürtel bon etwa

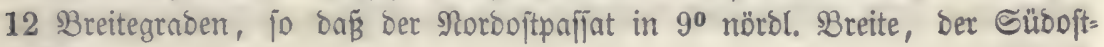
pajpat in $3^{0}$ fübL. Breite beginnt.

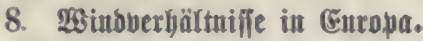

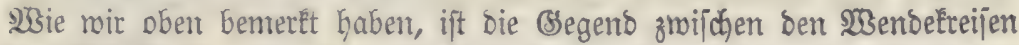

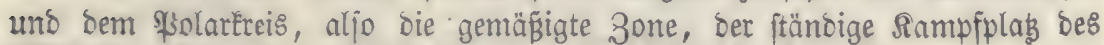

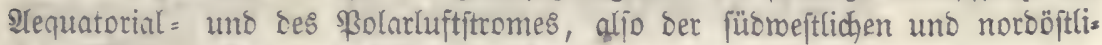

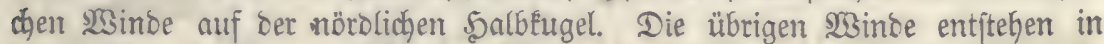

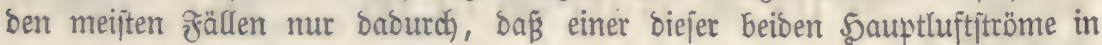
ben anberen überjpringt. Dabei hat man bie \$3eobadjtung gemadht, Dnß̈ ber

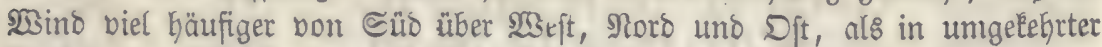
Dronung rechjelt. Das Bejeb der 13 indodrehung erflärt jïd) ganz ein=

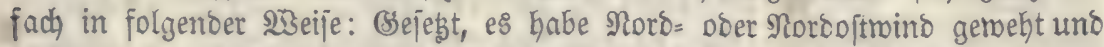
biejer merbe nun ourch einen Gübneftrinto verbrängt, jo wirb leğteter immer

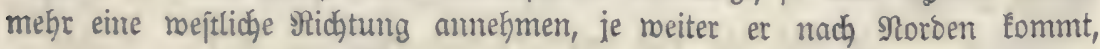
ฆiฺ. 104.

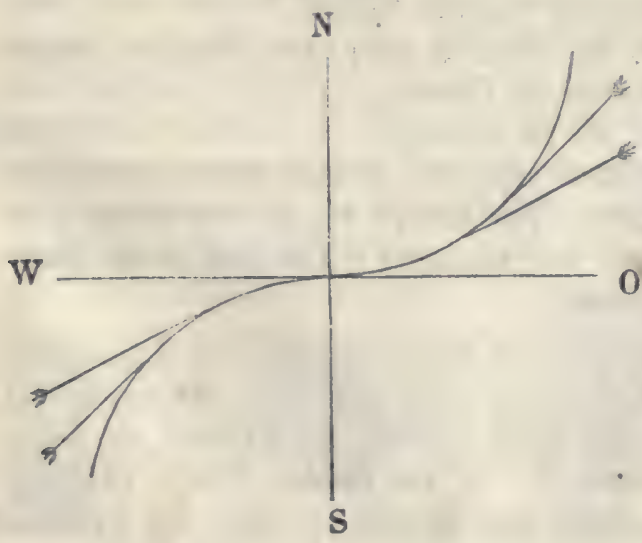
benn er beiligt eine größ̈ere ulmorehungsgejdhminoigleit in Sinne bon $\mathfrak{B g e f t}_{\text {nad }}$ Dft, als bie \&uft it höberen Brei= ten. Räít aber jest ber wefts lidge suftfrom nad und tritt an jeine Ctelle bet Norboft, fo wiro lesterer ben $\mathfrak{2}$ ejtrinin nicht plöblich, fonóern nur alls mählig verorăngen uno eళ miro, nad) bem sejes bes şaralles logramms bet Sträfte, juerft

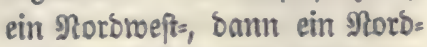
bind entftehen uno zulegt exft 
ber reine Norboft auftreten. Diejer nimmt aber, je meiter er nach Su=

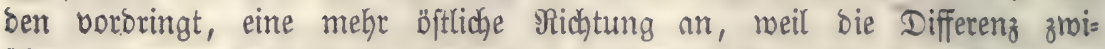

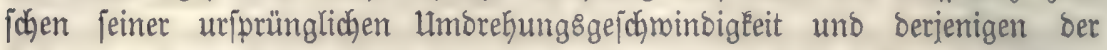

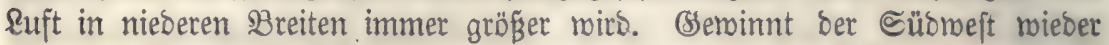
über ben Norboft bie Dberhano, jo treten, efje ber reine Sübneft zum $\mathfrak{B} 0 \mathrm{r}=$

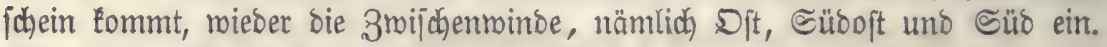

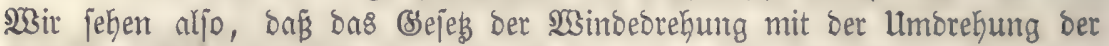

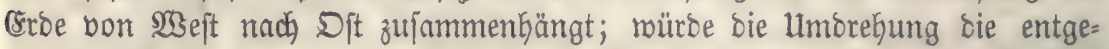
gengefezte, aljo bon Dit nach $23 e j t$ fein, fo fände gemís auch bie Drehung

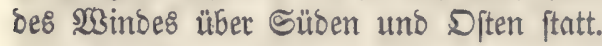

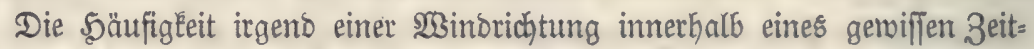
abichnittes bleibt fich für bie berjojiebenen Eänoer (suropa's nicht gleich. Durch)

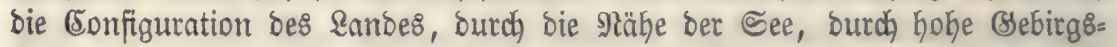

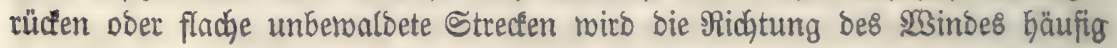
mobificitt.

Die nachftehente Tabelle gibt an, wie oft unter 1000 NBinben ber Norb,

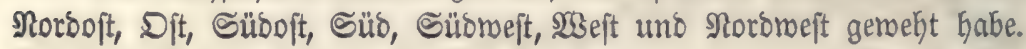

\section{Summe}

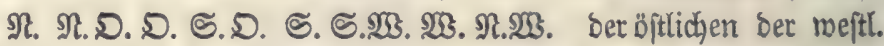
Minde

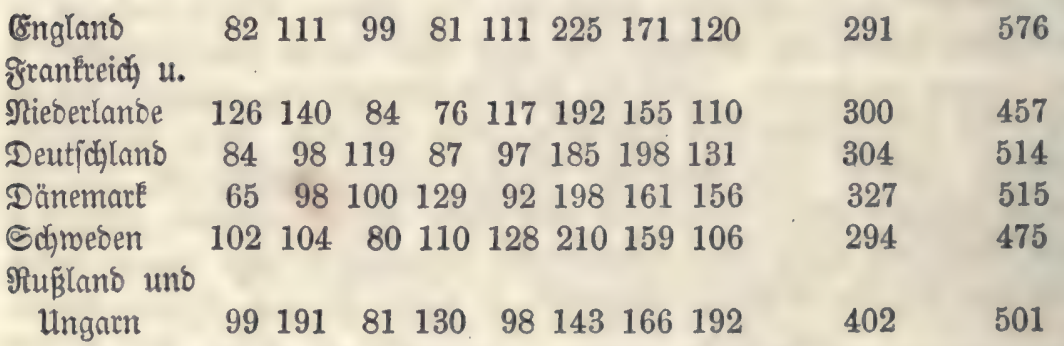

IIn bieje 3ahlen tnüpft Sdjoum folgende ๔dłlüfle:

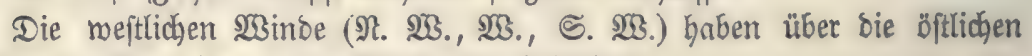

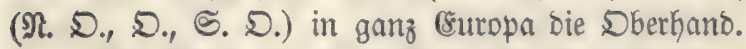

Der $23 e f t r i n \delta$ ift häufiger, als ber Diftrino.

Das Ulebergctwidht ber wefftidyen gegen bie biftlichen 23 inbe nimmt vom

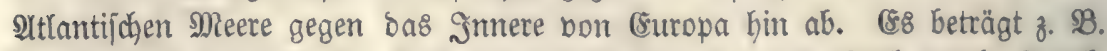

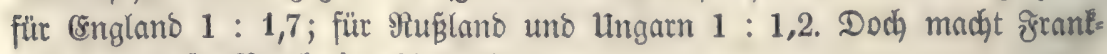

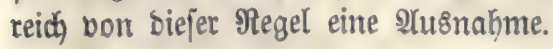

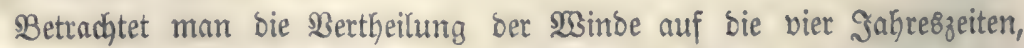
To ergibt fich, baß̧ im meftlichen und mittlern Iheil von Norbeuropa bas uebergemidgt ber weftliḑen über bie öftlichen $23 i n t e$ im Sommer viel bebeu=

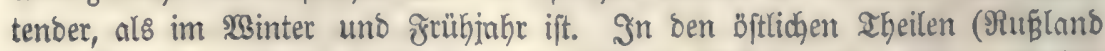
und Schneden) faheint biejes Dagegen nidht ber gall zu fein. Die weftlichen 


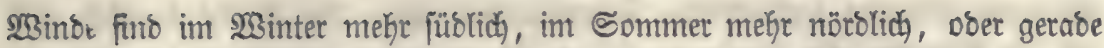

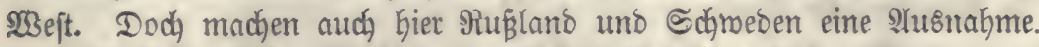

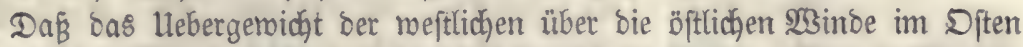

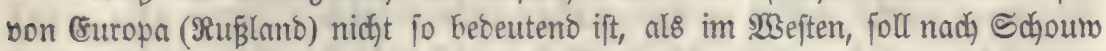

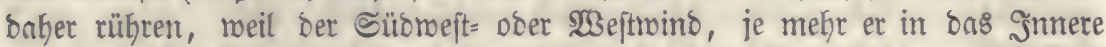
Des (suropäijhent Continents porbringt, um jo mehr in feiner Stärfée ge=

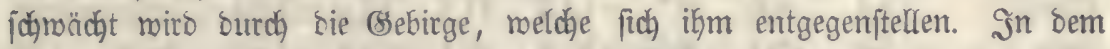

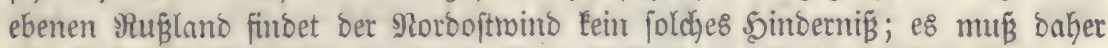

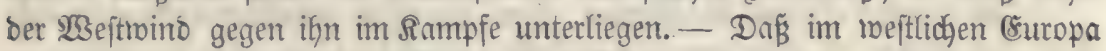
im Sommer bie meftlichen $23 i n b e$ bie b̈ftlichen übermiegen, foll in ber ber=

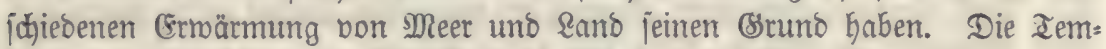
peratur bes 3 obens fteige im Commer böher, als bie bes Meeres, es werbe

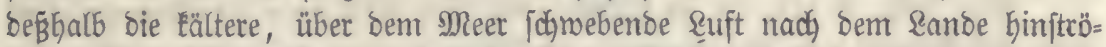

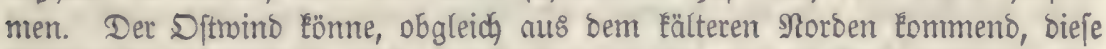

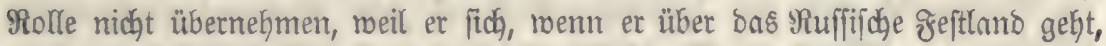

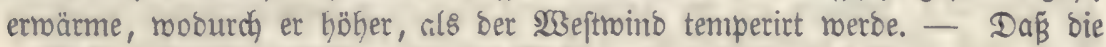
mejtlichen 23 into im $2 B i n t e r$ mebr jüblid, merben, als im Sommer, wo fie

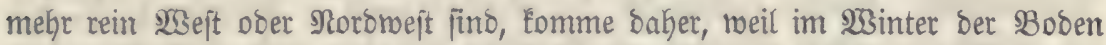

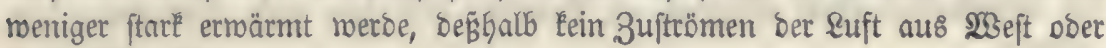
sorbmeit nöthig jei.

\section{Iemuperature ber 2 Bitbe.}

Die $233 i n b e$ bringen bie Temperatur ber Begenden mit, aus meldyen fie

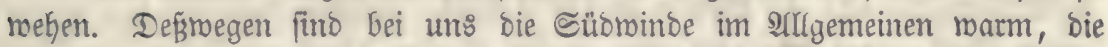

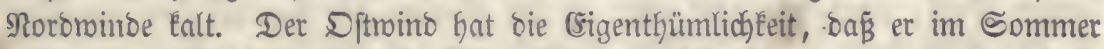

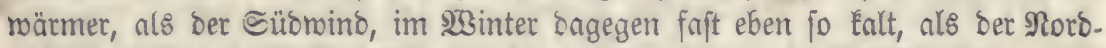

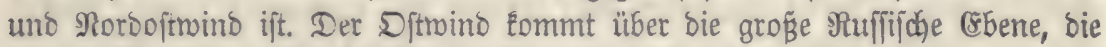

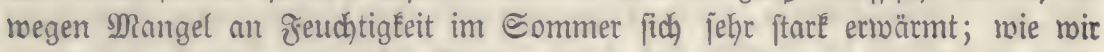

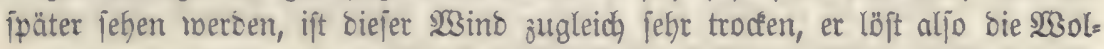
Een auf uno ftellt eine reine, ungetrübte Ruft her. Die Sonnenftrahlen kön=

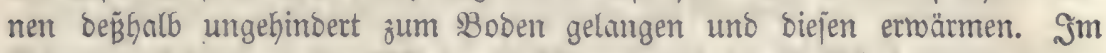

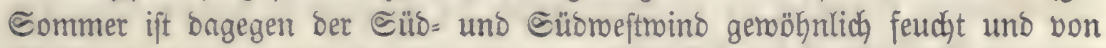
$230 l$ fen begleitet, meldge bie Strablen ber Somme bon ber (Erbe abhalten. Da mun bie rrobberfläche im ๔ommer mehr $\mathfrak{3 a ̈ r m e ~ v o n ~ b e r ~ S o n n e ~ e m p f a ̈ ı g t , ~}$

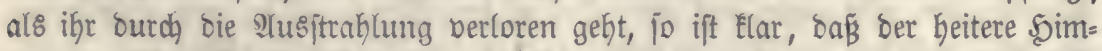
mel, ben ber Ditmino herftellt, einé lehr ftarke (Ermärmung ber \&uft herbei=

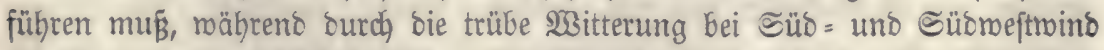

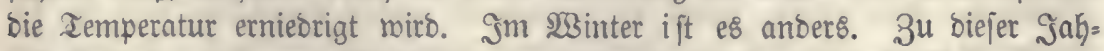

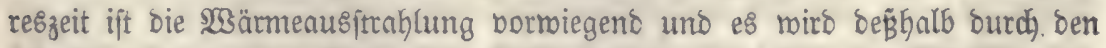
bebecten Simmel bei ๔üठ = und Eübroftroinden bie Erbe vor Ertaltung ge= forügt.

Die nachftełende, für Carliruhe entworfene, Iafel gibt bie bei bén ber= 


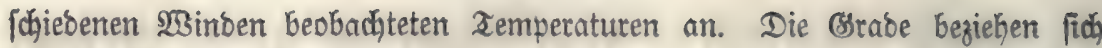
auf bie Reaumur'iche Scale.

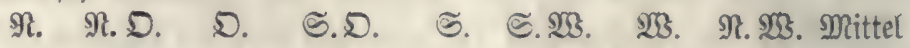

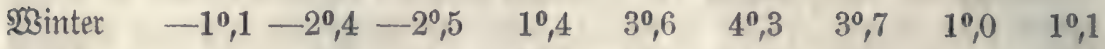
$\begin{array}{lrrrrrrrrr}\text { Frülyling } \quad 9,4 & 9,2 & 11,4 & 13,9 & .13,7 & 11,7 & 10,8 & 10,4 & 11,3\end{array}$ $\begin{array}{llllllllll}\text { Sommer } & 17,9 & 19,3 & 21,0 & 20,1 & 19,4 & 19,1 & 19,2 & 18,5 & 19,4\end{array}$ $\begin{array}{llllllllll}\text { 5erbjt } & 9,4 & 8,6 & 9,7 & 11,0 & 11.5 & 11,4 & 11,4 & 10,8 & 10,5\end{array}$ $\begin{array}{llllllllll}\text { Jabr } & 9,5 & 9,1 & 9,5 & 10,9 & 12,1 & 12,5 & 11,8 & 10,9 & 10,8\end{array}$

\$m פBinter, menn bie Sonne, ifres niebrigen Standes Kalber, meniz

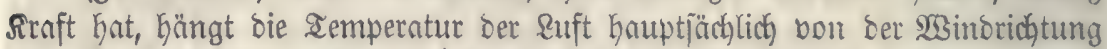
ab. Dody fommen aud wohl sinomalien bor. Eo brachte z. 23. Der antal= tende Sübroint im $\mathfrak{2 3 i n t e r ~} 18 \frac{44}{4} 5$ jehr kaltes 23 ettèr.

Der beipe SiroccD in Stalien umo ber Solano in Epanien fino wohl mit Unrecht bon Dem Samum ber SSüjte Saharn abgeleitet worben. Da Der Cirocco fid nicht auf berjenigen Rüfte ber Snjel Sicilien, melche Iffrila

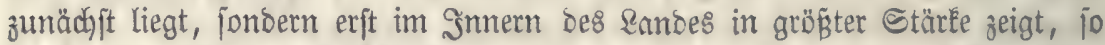

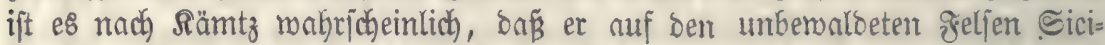
liens entiteht. (sbenjo erzeugt fich ber Eolano wohl in Spanien jelbit, bej= jen ausgedefnte bürre Steppen im Sommer eine jebr bohe Iemperatur an= nebmen.

\section{Stiime.}

Die Geftigften Stürme (DrÉane, Sourratans, Suragans), melche eine

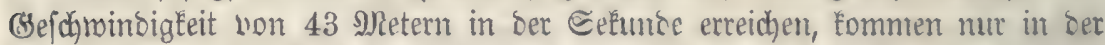
Geiß̈en Zone, ganz. Gejontors aber in Der Region ber (5nimen vor, rojelbjt fie ifre centftefung ber plöglid)en Berbichtumg bes 23 afferdampfes, mit mel= dhem bie suft in biejen Segenden ftarḱ belabent ift, berbanten. Dieje Drtane

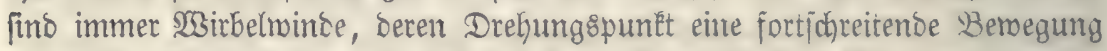

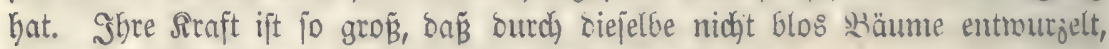
jondern jelbjt fteinerne \$̧äujer umgenorfen metben.

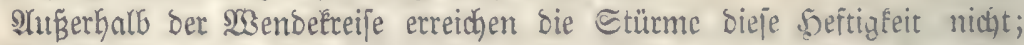

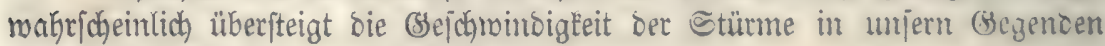
niemals 30 Meter in ber Sek̂noe.

S̄n ber gemäpigten 3one treten bie Stürme norzüglich jur 3eit ber Yequinoctien, aljo gegen bas lebste Drittel ber Monnte Miärz uno Eeptember,

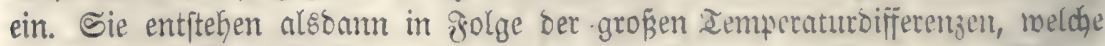

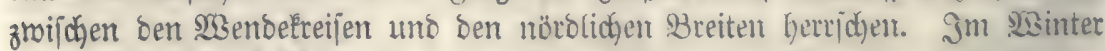
erfaltet bie Altmojphäre, forwie ber Boben it umjent Segenten uno in Der

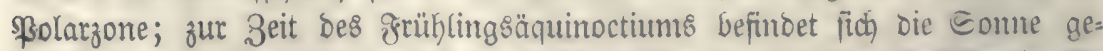

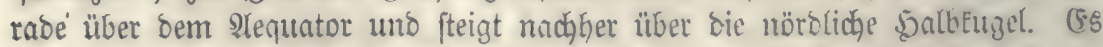

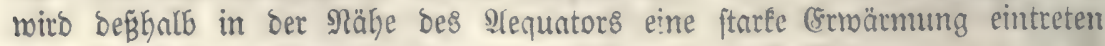
uno jowohl bie erbizte \&uft mit groper (Setwalt nach sorben, als audh bie 
Ealte Ruft von ben Rolen nad) Sem Sequator Ginftrömen. (58 entipinnt fich)

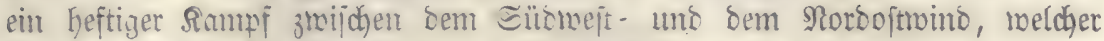

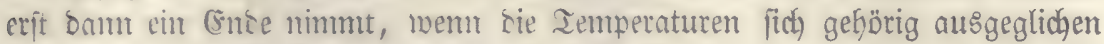

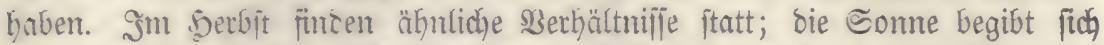

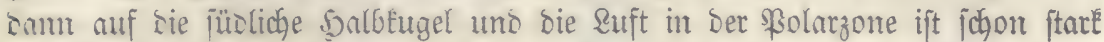

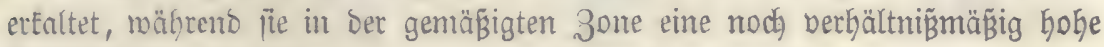
Temperatur befauptet.

Die ftäıfịten Etürme fomnten in Deutichlano aus füorneftlicher, meftli=

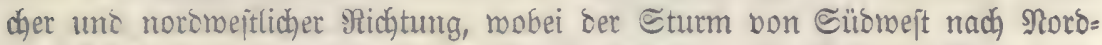
wejt jïh) steht. Sn Silitenlänbern gehen bie હtütme nber ftetร vont MReere aus.

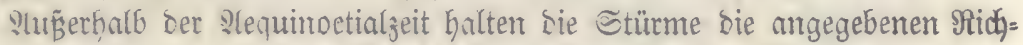
tumgen nicht inmer ein. So mar z. \$3. Der Keftige ङturmmino im Suli 1841,

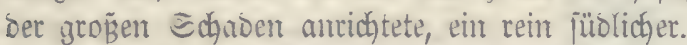

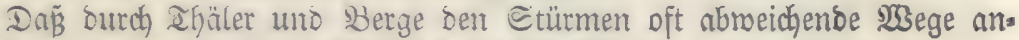
gewiejen meroen, haben mir jobon früher ermähnt. 
Siebentes $B$ ud.

\section{S I) i t \\ (E) rifer Tbidnitt. \\ Bon Der Berounfung.}

\section{Dumit, Dampf.}

Die flüffigen, ia jelbft aud) viele fefte Rörper, kefigen bie (sigenidtaft, bei gemiffen Iempernturen in ben gasförmigen 3uftano ilberzugehen. Iritt

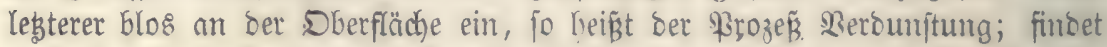
er aber burch bie ganze Maffe ber glüfigteit ftatt, jo nennt man ifn Ber= bampfung. Inoeffen untericheibet weber ber gemöfultidhe, noch ber iviffens

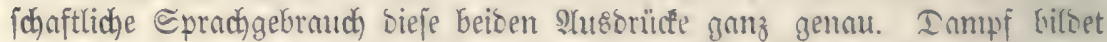

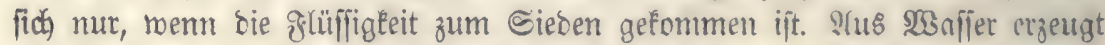

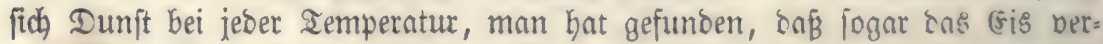
bunftet.

\section{Mak ber Berburtung.}

Die Menge Dunft, meldye in einem gemiffen Raum, ł. S2. pintem Su=

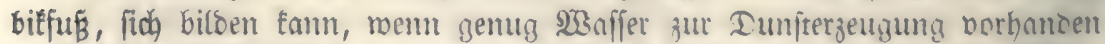
ift, hängt blos bon ber Temperatur biejes Raumes ab umo nimmt nit biejer,

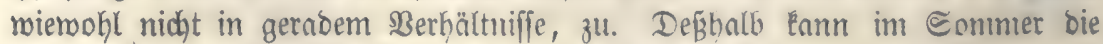
\&uft biel mebr æreudatigkeit nufmehmen, als im 23 inter.

Die nachjtehenoe Ueberficht zeigt, wie viel $\mathfrak{W}$ afferbampf bei ben angeges benen Iemperaturen in bem Raume eines Rubilmeters bödgitens enthalten fein tann. 
Semperatur Sewidat bes Dampfes (Sramme.

$\begin{array}{rr}-20^{\circ} & 1,5 \\ -10 & 2,9 \\ 0 & 5,4 \\ 10 & 9,7 \\ 20 & 17,1\end{array}$

ঔig. 105.

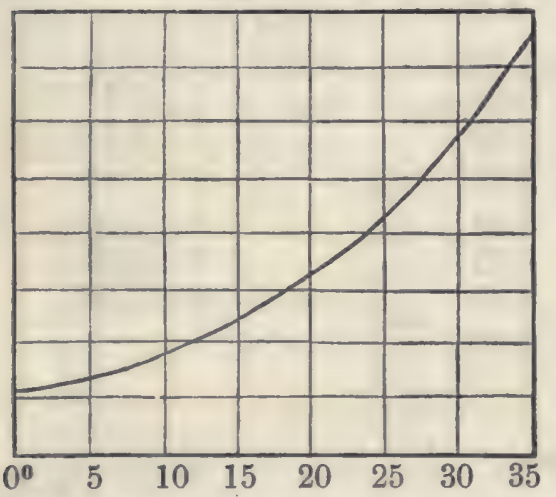

In neben ftebenter §ig. bedeuten bie 2 biciffen bie Temperaturen, bie Droinaten bie größ̈te \$lenge Dumft, weldye bei biejen aemperaturen aufs genommen werben lann. Wrie man

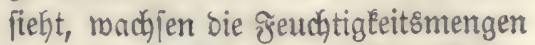
in viel ftärǩerm $\mathfrak{B}$ erbältniffe, als bie Temperaturen.

(sntfält die suft gerabe fo viel Freuchtigkeit, als pie bei ber beftekten= ben Temperatur aufzunehmen bermag, fo jagt man, fie jei gejättigt. Sit bie Menge $x_{3}$ affer, meld)e berounjtent Eam,

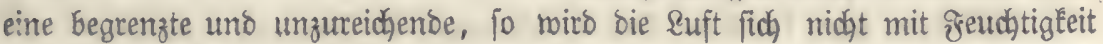
fättigen tỏnnen.

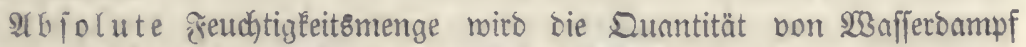
genannt, welche ebent gernoe in ber suft befindid ijt. Unter relatiber

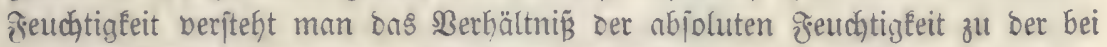
set betreffenoen Iemperatur überbaupt aufnebmbaren Dampfmenge, aljo zu

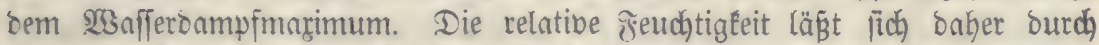
einen Bruch nusoritcfen. (5s jei z. B. Die Temperatur $=10^{n}$ unto es jeien in einem CubiEmeter Suft 5 Gramnte Dampf enthalter, fo ift bie relatibe

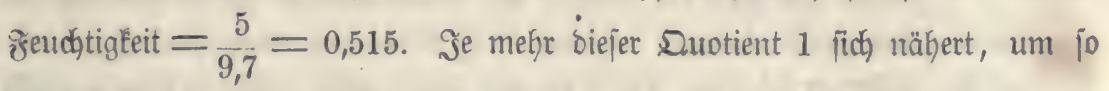
feuchter ift bie \&uft, um fo näher ftebt fie aljo bem Sättigungspunfte; ift bet Quotient flein, jo jagt man, bie \&uft jei trodfen.

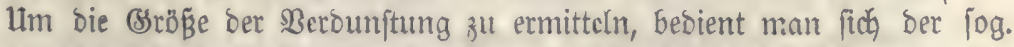
It mometer, b. h. Berbunjtungsinteffer. Daร Snftument beftebt ganz ein= fach aub einem (sefäße, neld)es mit einer હcale verjehen ift uno mit $23 a f f e r$

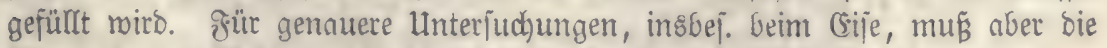
Menge ber verflïchtigten jeuchtigéeit burdh ons (Benvicht beftimmt werben.

Die Berounjtung wirb befördert

\section{a. burd) \$äนme.}

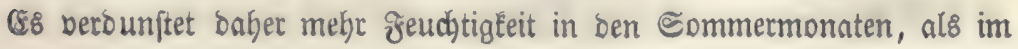


Frübling, Serbft und 23 inter, mebr im Sommenjdyein, ar\& in bem Edjatten. Die folgentoen Berfuche von Edjübler und Etnrể geben ons Berbältnip̌s ge= nauer an.

Monat im Sdjatten : im Sonnenjoyein

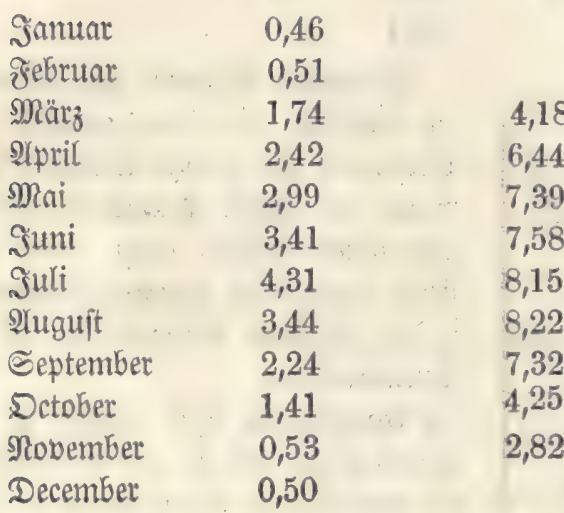

Berbältuifís von

$\mathrm{a}: \mathrm{b}$

\section{b. Duxd Berminberung Des Ruftsudet.}

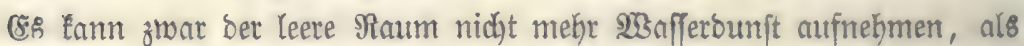
ber lufterfüllte; allein in Yesterm berbunftet bas $\mathfrak{M}$ affer bei meitent nicht jo idhnell, als in erfterem, reil sie Suft bie auffiteigende SRemegung bes Dumites Ginbert. Dieje funbet im Luftleeren sRaume mit einer (Sej̣chnindigkeit von 500 -600 Metern in ber Selunto ftatt. Se bünter aljo bie \&uft ift, um io ras fajer mirb bie Berdunftung bon ftatten geben. Iefbalb berflühtigen bie

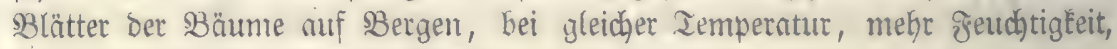
als in ber tiefer gelegenen sbene.

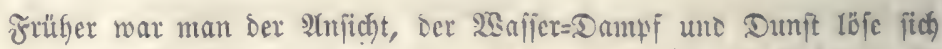
in ber \&uft gerade fo auf, wie cin fejter Rörper in cinter Flüfifigfeit, aljo

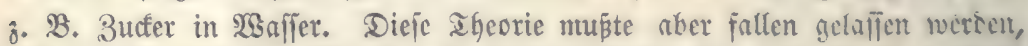

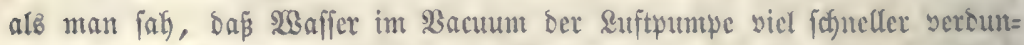

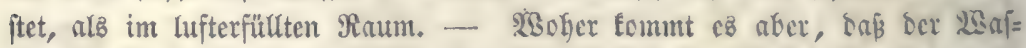
jerbampf, befien fpecificiches Gewidft $=0,62$ ijt, wenn mant saz ber suft

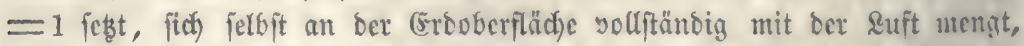

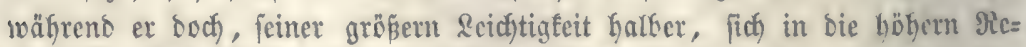
gionen ber 2tmofphäre begeben follte? Diez rüthrt von ber ungleidjen fpe=

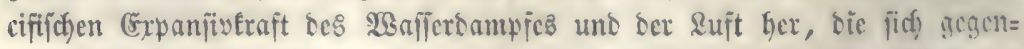

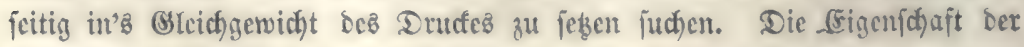
(Baje und Dämpfe, fich) yolfịtändig mit einander zu mengen, nennt man Difipuin. 


\section{c. Dưচ Ruttung.}

Kasun ein feuchter Sörper längere Beit mit der \&uft in Berührung ift, lo nimmt Diejelbe fo viel Dumpt auf, als ber Gerrjhenten Lemperatur entipricht, nachfer fyört cie Sierdunftung auf. WBirb aber bie mit geuchtigkeit ge|ättigte

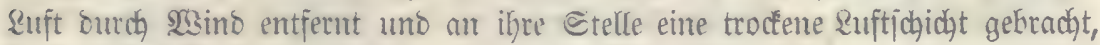

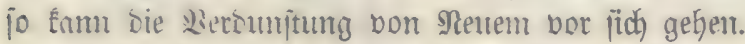

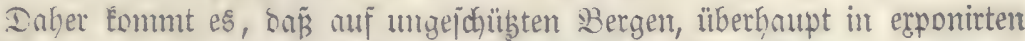

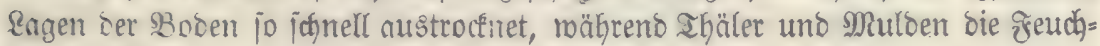
tigfeit viel länger Galten.

Die winse Geförbetn die Berounftnung un jo mehr, je ftärf́er fie mehen umo je trodenter pie funt. Echüblet fant die Mlenge des innerbalb 24 Stun= bent berbuniteten 2 Baillers, bei $1 \square$ jü Dberfläche:

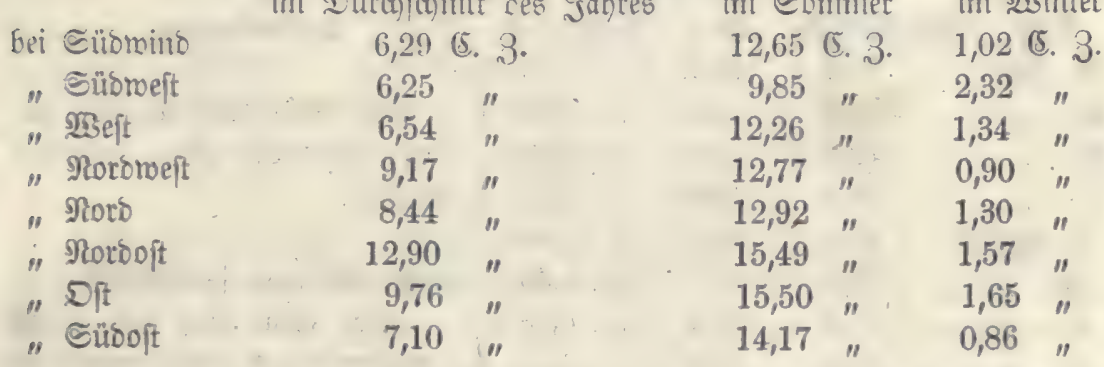

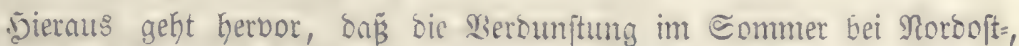

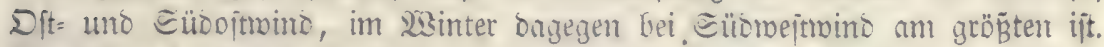

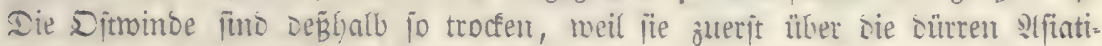

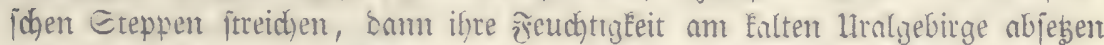

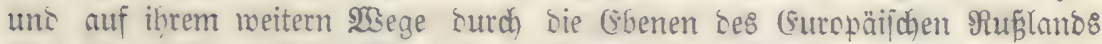

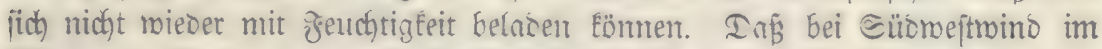

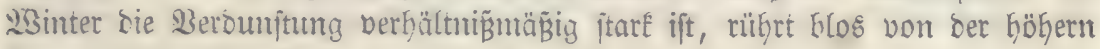
Temperatur diejes 2 Binbes her.

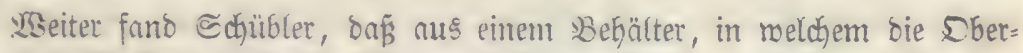

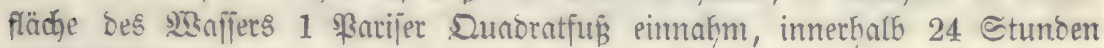
verbuniteten

\begin{tabular}{|c|c|c|c|}
\hline im $23 i n t e r$ & $\begin{array}{c}\text { bei mincịtillem s:setter } \\
0,98 \text { Eubitzolle }\end{array}$ & $\begin{array}{l}\text { Gei minto } \\
3,91\end{array}$ & \\
\hline " Fิtübling & $8,51 \quad \prime$ & 11,68 & " \\
\hline "Sommer & 11,92 & 19,84 & I \\
\hline " Serbft & 6.57 & 14,94 & " \\
\hline im ganzen Sabp & 6,65 & 13,32 & \\
\hline
\end{tabular}

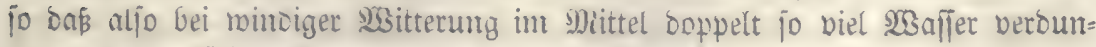
ftete, als bei నSinojtille.

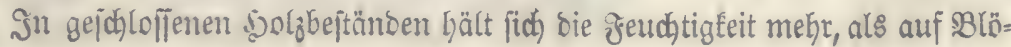




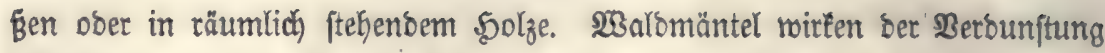
entgegen.

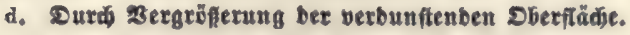

Dies ift an und für fich Elar; benn bei ber genöhnlidyen Berbunftung entrwičeln fich Keine Dämpfe im Sinnern, fonbern mur an ber Dberfläche ber głlüfitigkeit.

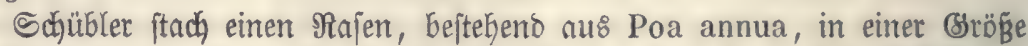

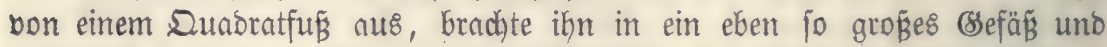

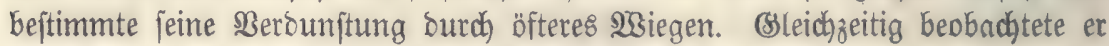

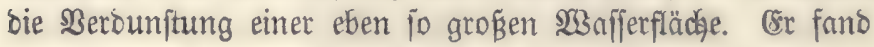

\section{bie 3erbunftung in 24 Stunden}

\begin{tabular}{|c|c|c|c|c|}
\hline Iag & Şafferfläche & Grna & Berbältniñ & Bemerḱungen. \\
\hline 28. Şuli & 10,3 & 37,3 & $1: 3,61$ & \\
\hline 9. 11 & 15,7 & 44,0 & $1: 2,80$ & 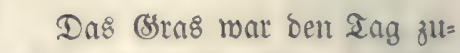 \\
\hline$"$ & 12,8 & 35,4 & $1: 2,77$ & bor, ben 27. Suli, begoffen \\
\hline 31. " & 17,2 & 43,9 & $1: 2,55$ & worden. \\
\hline 1. शYuguit & 17,4 & 46,9 & $1: 2,69$ & \\
\hline 2. " & 28,3 & 47,7 & $1: 1,65$ & Geif́, MittagE + 240,2 R. \\
\hline 3. & 17,0 & 15,1 & $1: 0,88$ & Das Brab fing ben 3. zu \\
\hline 4. & 21,8 & 37,5 & $1: 1$, & welten an, e\& wurbe am 2 Ubend \\
\hline & 9,9 & 17,4 & & biefes Tag8 auf' neue begoi= \\
\hline 6. & 5,3 & 11,5 & & jen, woburch es fich exbolte, \\
\hline & 16,4 & 27,6 & $1: 1,68$ & nur einzelne 3 lätter ftarben ab. \\
\hline
\end{tabular}

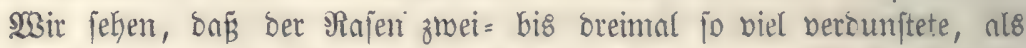
eine gleid grof̧e $\mathfrak{B a f f e r f l a ̈ c h e ~ u n d ~ E ̈ o n n e n ~ u n s ~ b i e ̨ ~ m u r ~ b u r c h ~ b i e ~ g r o ̈ f ̧ e r e ~}$ Oberfläche des (Grajes, melche ocr \&uft mehr Berührungspunte Darbietet, erêlären. Hebrigens berbalten fich, nicht alle Pflanzen jo mie bie Bräjer, bon

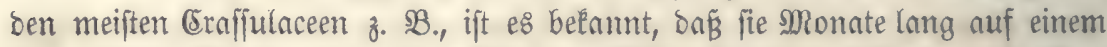

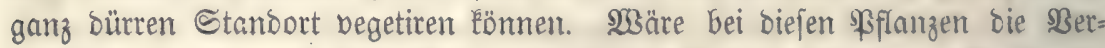
bunftung fo grosi, als beim Sraje, fo mürben fie bald ifre eigene Eaftfeudh= tigkeit verloren baben uno abjterben.

Die Berounftungsfähigkeeit Der $\mathfrak{H}$ flanzen bängt von ifrer innem Ierctur und ganz bejonbers bon ber Bejchaffenheit Ser (Epibermiz ah. Torb fann

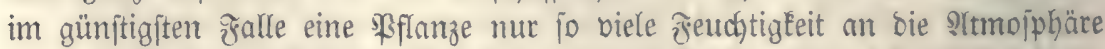

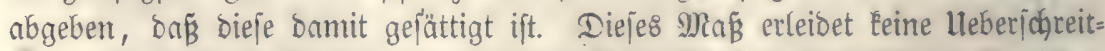

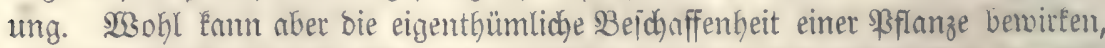

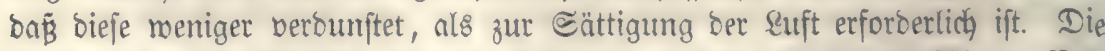

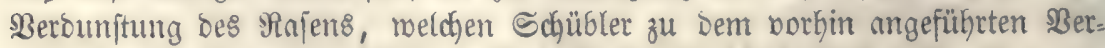

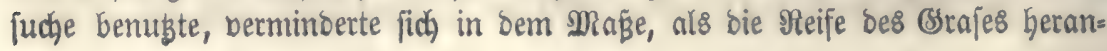




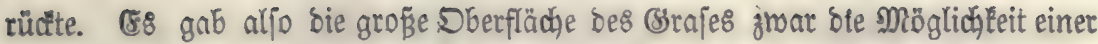
ftarfen $\mathfrak{B e r b u n f t u n g} a \mathfrak{b}$, Dod mar biejelbe nicht bie einzige Bebingung Gierfür.

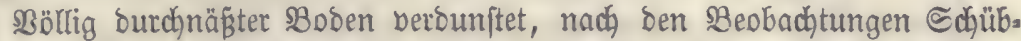

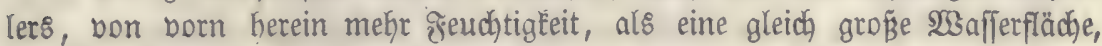
reil, mie ๔chübler jefr ridjtig bemerlt, bie unebene Dberfläcje bes Bobens ber \&uft mehr Berührungspunlte Darbietet. Sobald aber ber Boben ober=

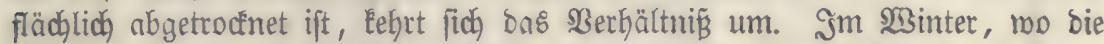

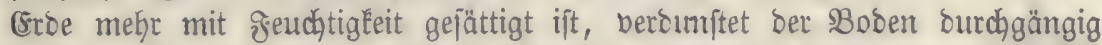

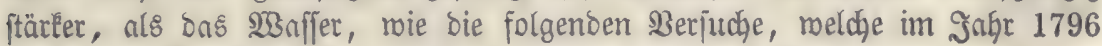
im botanijenen Barten zu Benf angejtellt murben, ergeben.

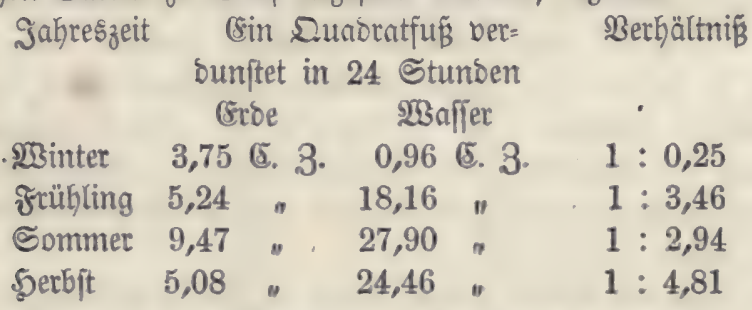

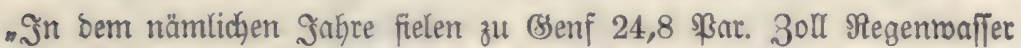

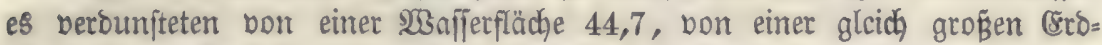

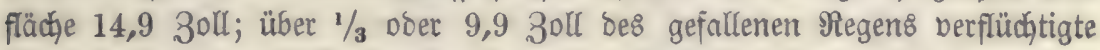
fich baher nicht burd, Berounftung von ber (Srofläche, jonbern lief bon bem (Erbreich ab, ober brang in bie Tiefe, wo es zur silloung von auellen ober zur (Ernäbrung von Begetáilien vermanot merben Eonnte." Schübler.

\section{e. Durb Irodenbeit ber \&uft.}

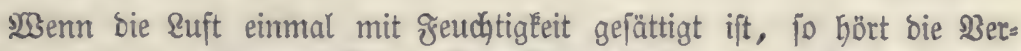
bunftung auf. Se trockener aljo bie Altmojphäre ift, um jo mehr freudhtigkeit

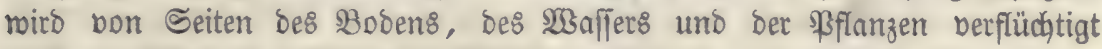

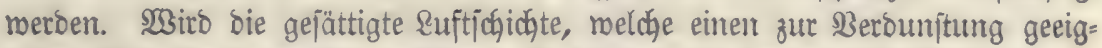

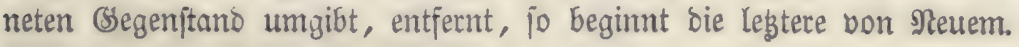

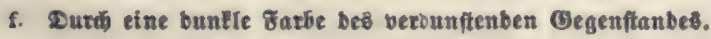

Dunfel gefärbte Sörper ermärmen fich ftärfer; enthalten fie in igren

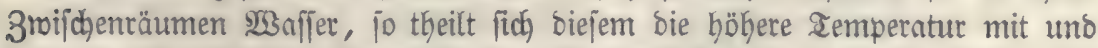
e\& verdunjtet ichneller. Deshalb ift 2 . $B$. Durch Rohle, organijoche Refte ober (sijen bunfel gefärbter Ihon im âtgemeinen trockener, als weißßer ober grauer Thon.

\section{Spantrajt ber Dintite.}

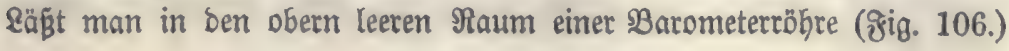




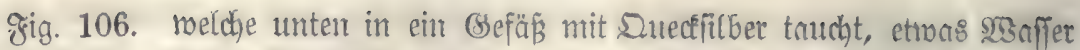
treten, fo beroumftet ein Sheil beffelben augenbicictich uno es

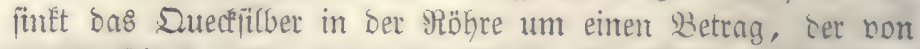

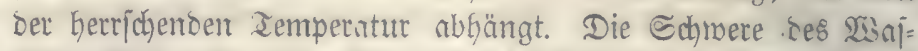
jers unt des Dampfes faum nidjt bie Urjache biejer (stidjeinung

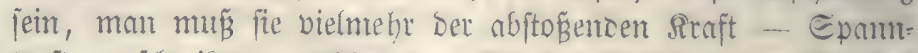

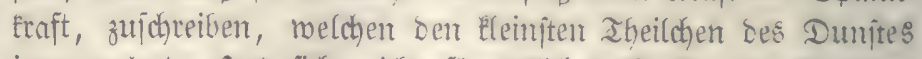

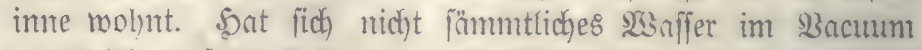

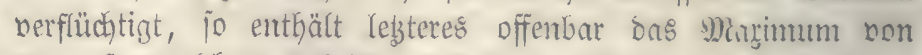
Immp, melchen es bei ber beitehenten Iemperatul auphefiment

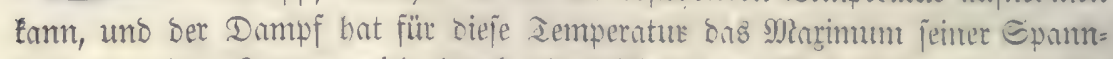

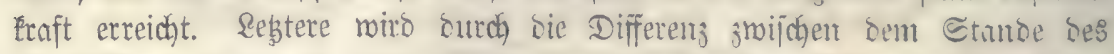

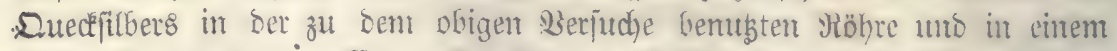
anbern Barometer genteffen. $\Xi_{D}$ beträgt $\hat{\jmath}$. BB. Gei einer Temperatur von $10^{\circ}$

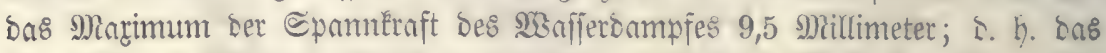

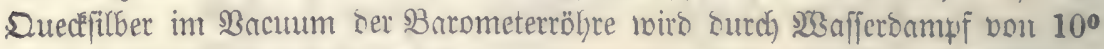
um 9,5 Mitlimeter Gerabgebrüdit.

Iautht man bie Röhre etwas meiter in ba\& Suedfitber ein, jo wirb

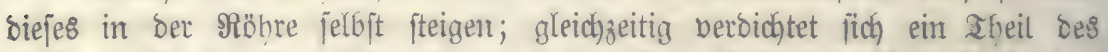

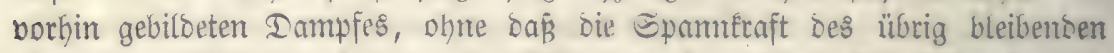

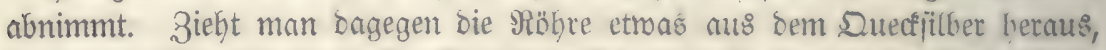
fo erzeugt fid mehr Dampf, allein ebenfalls ohne slenderung Der Epamteraft.

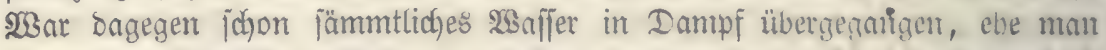
bie Yebstermähnte Mantipulation vornafim, io berminoert fid sie Epamteraft Des Dampfes. Damit aljo ber NSafferbampf bei irgento eirter Lemperatur sas

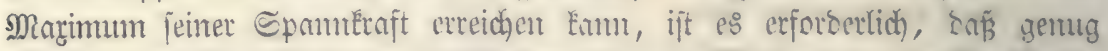

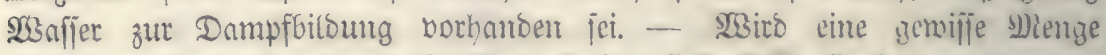
Dampf ermärmt, fo nimmt bie Spamtenft deffelbent zu, jie Eomunt aber mur

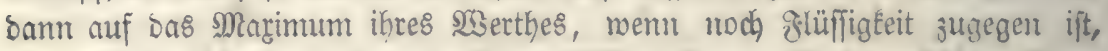
aus welcher fich fo biel neuer Dantpf bilben Eam, al\& Der erböbten Tem= peratur entipricht.

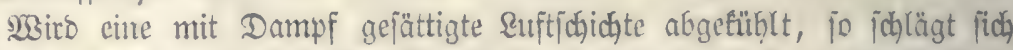

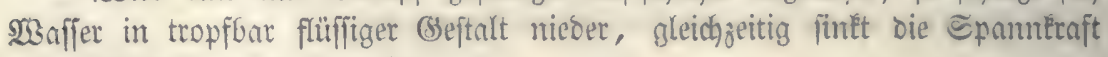
Des zutüdб́teibenton Dampfes.

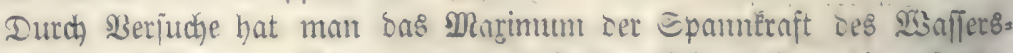

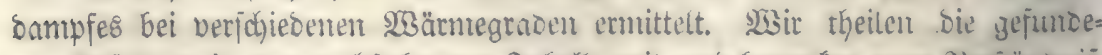

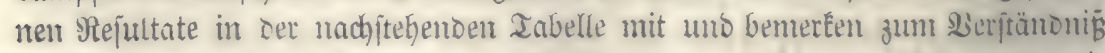

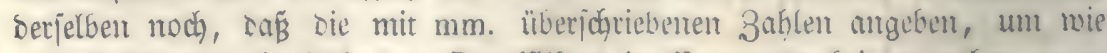

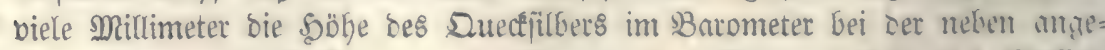
fügten Iemperatur fintt, wemr im Bacuun bes Barometers jo viel waifier= Dantpf fich befindet, als biejer Haum bei jenter Iemperatur aujzutehmen vermag. 
Temperatus Gr. Epannkraft Temperatur Gr. Eparnfraft

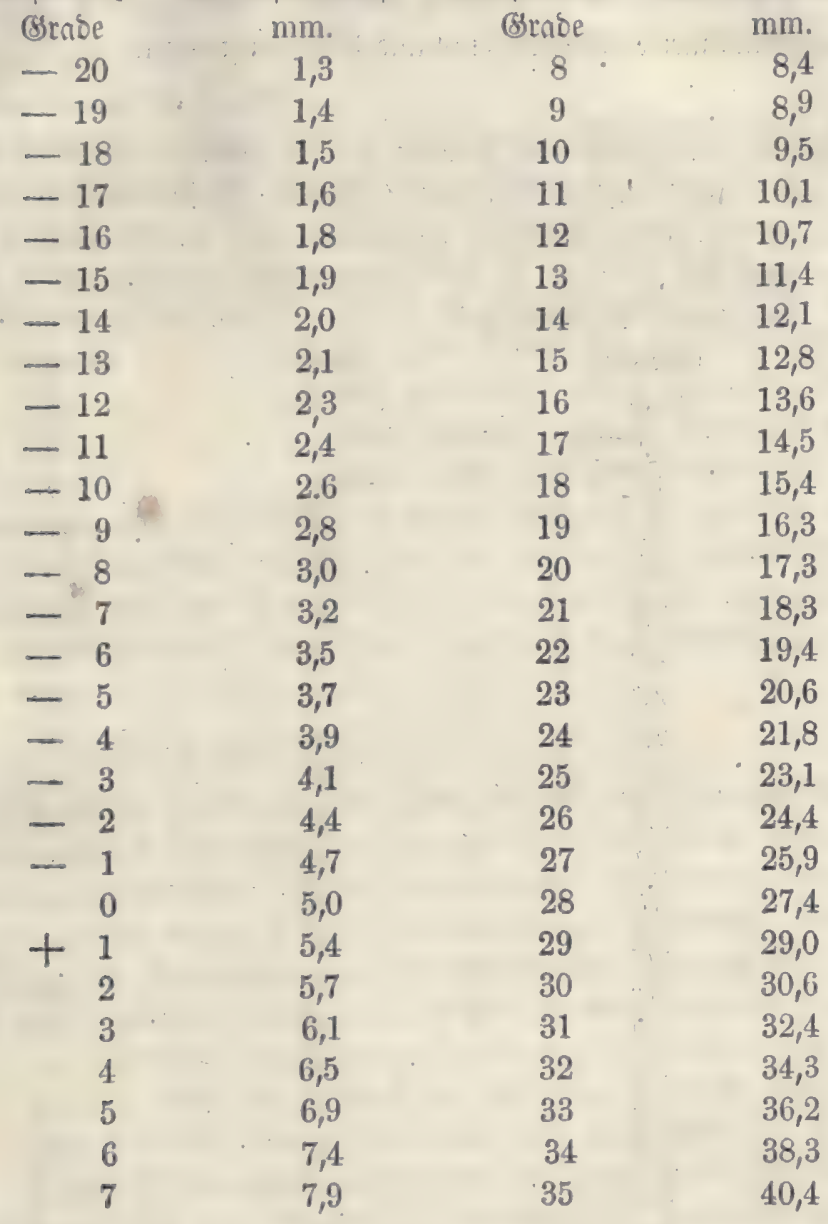

\section{Gemidat be 20 afierbanufe?.}

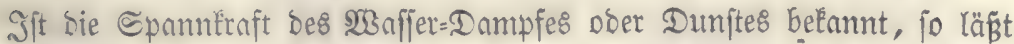

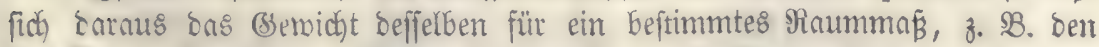
Subifmeter, bered)nen. (ss niegt nämlich) ein Subitmeter Suft bei $0^{\circ}$ Tent= . perntur und 760 Mim. Barometerftand 1299 Srammen. Da Der 23 afferonmpf bei gleicher Iemperatur und gleidjem Barometerjtano mur 0,62 vom (Semicht Der Suft Gat, fo miegt ein Subifmeter 23 afferoampf nur 1299. 0,62=805,38 (Sramme. SBei einem Mm. Spant leaft beträgt diejes Bremidat $\frac{805,38}{760}=1,06$ Gramme. Bon $0^{0}$ bis to befunt ficth Der Dampf im Berbältnißs von $1: 1+0,00366 t$ 


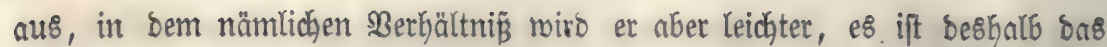
Senicht eines Eubifmeters Damipf Gei to uno b Barometerftano $=\frac{1,06 \mathrm{~b}}{1+0,00366 \mathrm{t}}$ Sramme.

Radfitegento theilen wir eine rabelle mit, in meldjer angegeben ift, wie

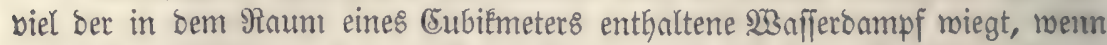

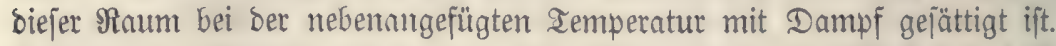

Iemperatur (Servicht bes in 1 C. $M$. Iemperatur (semidjt bes in 1 (5.M. entbaltenen $\mathfrak{M a}$ afferbampf:

\begin{tabular}{rrrr} 
Srabe & Sramme & Srabe & Sramm \\
-20 & 1,5 & 8 & 8,7 \\
-19 & 1,6 & 9 & 9,2 \\
-18 & 1,8 & 10 & 9,7 \\
-17 & 1,9 & 11 & 10,3 \\
-16 & 2,0 & 12 & 10,9 \\
-15 & 2,1 & 13 & 11,6 \\
-14 & 2,3 & 14 & 12,2 \\
-13 & 2,4 & 15 & 13,0 \\
-12 & 2,6 & 16 & 13,7 \\
-11 & 2,7 & 17 & 14,5 \\
-10 & 2,9 & 18 & 15,3 \\
-9 & 3,1 & 19 & 16,2 \\
$-\quad 8$ & 3,3 & 20 & 17,1 \\
-7 & 3,5 & 21 & 18,1 \\
-6 & 3,7 & 22 & 19,1 \\
-5 & 4,0 & 23 & 20,2 \\
-4 & 4,2 & 24 & 21,3 \\
-3 & 4,5 & 25 & 22,5 \\
-2 & 4,8 & 26 & 23,8 \\
-1 & 5,1 & 27 & 25,1 \\
\hline 0 & 5,4 & 28 & 26,4 \\
+1 & 5,7 & 29 & 27,9 \\
2 & 6,1 & 30 & 29,4 \\
3 & 6,5 & 31 & 31,0 \\
4 & 6,9 & 32 & 32,6 \\
5 & 7,3 & 33 & 34,4 \\
6 & 7,7 & 34 & 36,2 \\
-7 & 8,2 & 35 & 38,1
\end{tabular}

\section{5. \$ngrometrie.}

Die Sngrometrie hat zum 3rueảe, bie abjolute Menge bes in einem

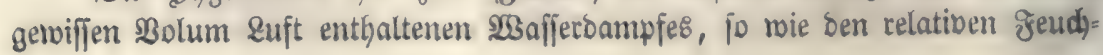




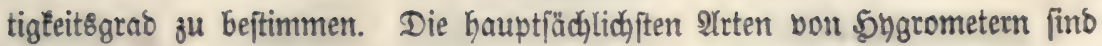
folgende:

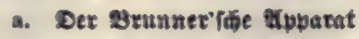

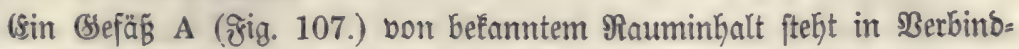

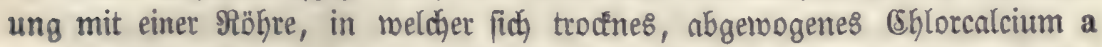
§ì. 107.

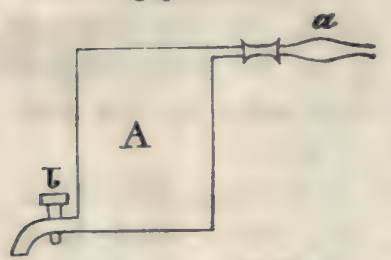
befindet. A ift mit Del gefült; jobald ber şahn b geöffnet rito, fließst biejes $a b$, inoem bie

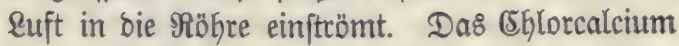
hält alle reuchtigleit ber \&uft zurüct, menn man nur bafür forgt, baß̈ bas Del nidat zu iddnell abflieğt. Nach Beenbigung bes $\mathfrak{B e r}^{*}$ jucher ergibt die Bemidhtżunahme des Ehlor= calciums, mie biel Sאßfferdampf in einem \&uftraum A enthalten mar.

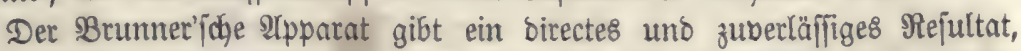
ift bagegen megen bes Zeitaufwanbes, den jebe einzelne unterjudjung exfor=

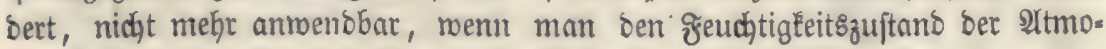
[phäre öfters, 8. 38. täglich, ermitteln will.

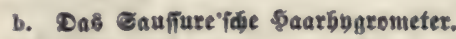

(sin burch Ralilauge ober burdh शether von ben anjängenden grett= theildaen befreites Menjđentyan wirb mit bem einen (snoe um eine Rolle a

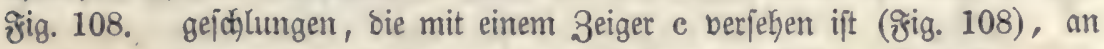

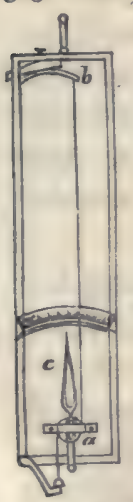
bem anoen Ende an einem Iräget b befeftigt. Das ફaar hat bie (sigenjogaft, fich in feuchter \&uft auszubehnen, in trockener bagegen zu berkürzen. Beioe Zujtänoe macht ber Zeiger an einem jeitrörts angebraditen Brabbogen bemerflidy. IIm eine Scale für biejes sygrometer zu conftruiren, bringt man es zuerft in einen mit $\mathfrak{B a}$ ajerbampf voljtänoig gejättigten uno bann in eiten

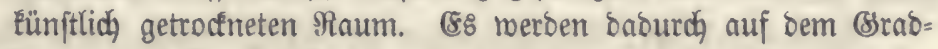
bogen zrwei Bunfte figirt werben, die man mit 100 und 0 be=

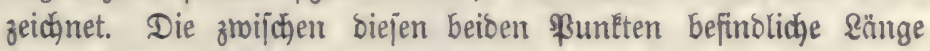
wiro bann in 100 srabe eingetheilt.

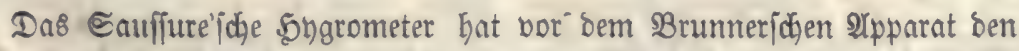

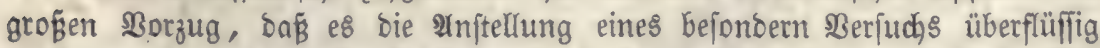

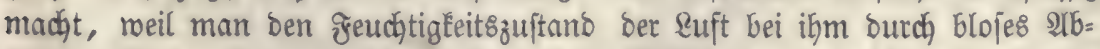

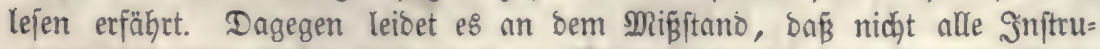
mente biejer 2 rt gleichen (sang haben. Diejer änoert fich jogar bei einem uno

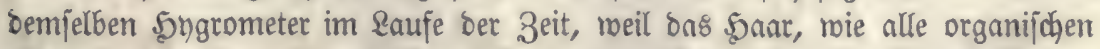

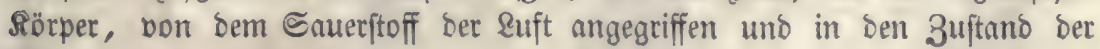
Bermejung verjest wirb. 


\section{c. Danieft's ฐggrameter.}

Whir Gaben oben gejehen, Daß́ e\& für jebe Temperatur ein Maçimum

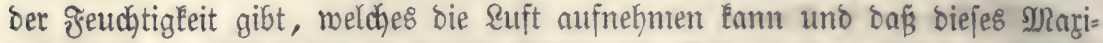
mum mit ber Iemperatur mädjit. Befigt bie \&uft die Semperatur $t$ und ift fie nicht mit Feudhtigkeit gefättigt, fo gibt es jeben falls eine niebrigere ₹em=

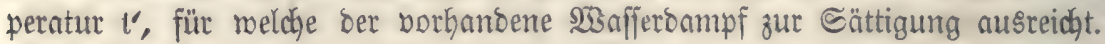
(Es hanoelt fid baker nur barum, $t^{\prime}$ ausfindig zu machen. Sift bies geidjeben,

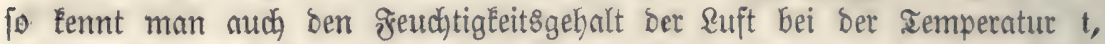

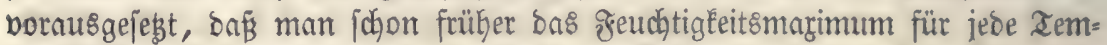

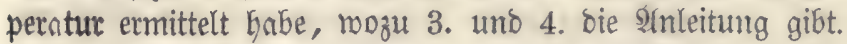

Daniell hat einen Slpparat erbacht, melcher zur Beftimmung bon t' bie=

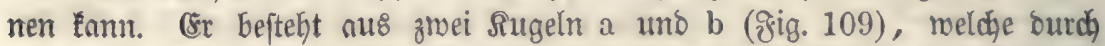

Æig. 109.

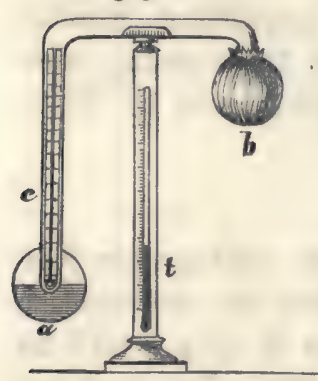
eine Slabstöhre berbunben find. Die Sugel a ift sur Sälfte übergoldet un๖ mit IYAether gefülrt; b ift mit Mouffelin ummiçelt. Iräufelt man auf die Sugel b etroas 2lether, [o berbunjtet biejer jegr

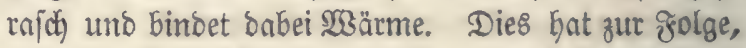

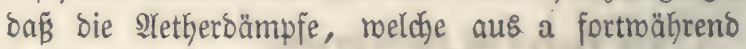
auffteigen uno nadj b überbeftilliren, fich berbidaten. (s:s erzeugt fich beshalb neuer Dampf in a uno ber

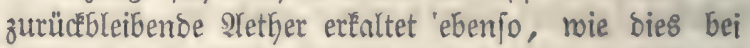
Der Rugel b ber そ̧all war. Sif die Temperatur von

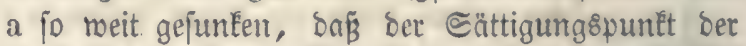
Euft, weldye a umgibt, um etrons weniges überfohritten miro, fo ichlägt fich

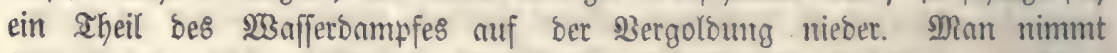

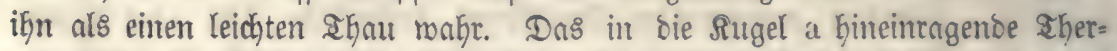
mometer $c$ gibt bie Temperatur an, bei weldyer bie \&uft igren Sättigungspuntt erreidjt Gatte.

Rebmen wir an, bie Iemperatur ber \&uft, meldye butch bas auf bent Träger befindlidye ahermometer 1 beftimmt wiro, fei vor bem $\mathfrak{B e r j u c h e ~}=20^{\circ}$

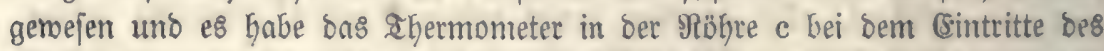
$\mathfrak{W a f f e r}=$ Dampf $=$ Nieberichlags auf a eine Temperatur von $10^{\circ}$ angezeigt, fo

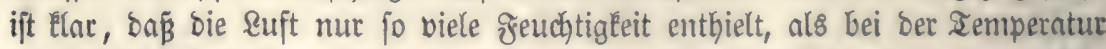
von $10^{\circ}$ zur Sättigung Gingereidjt hätte. SYlus ber unter 4. mitgetheilten Tabelle exjehen roir, Daß̧ ein Rubiłnteter \&uft bei $20^{\circ}$ im Marinum 17,1

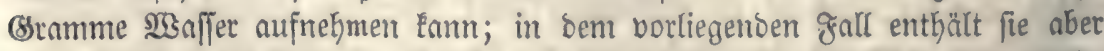

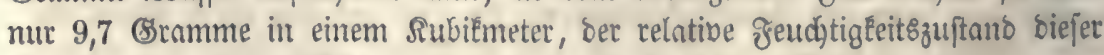
Euft ift bemnach $=\frac{9,7}{17,1}=0,57$, ober fie ift etras mehr als zur \$älfte gejättigt.

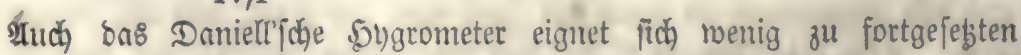
Beobachtungen, weil jebe Beftimmung Des Feuditigertsogehaltes ber \&uft mittelft biejes Snjtrumentes bie Anjtellung eines eigenten, zeitraubenden $B e r-$ 
juches nöthig macht. Sft bie Ruft meit von ifjem Sättigungspunfte entfernt,

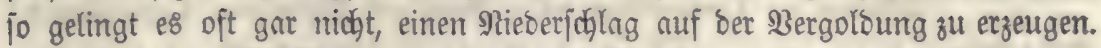

Bon Den Mig̈ftänden ber bis jegt bejchriebenen \$ygrometer ift frei

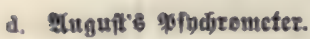

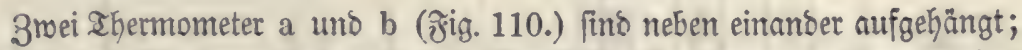
bie Sugel bes ahermometers a ijt mit Mouffelin überzogen, meldger in bas ஓig. 110.

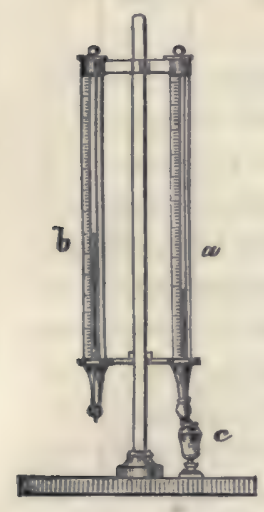

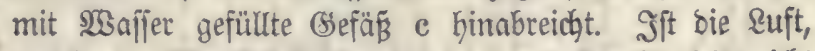
weldhe bie Mouffelinhülle umgibt, mit greudhtigleit nicht gejättigt, fo wiro ber Mouffelin einen aheil bes $\mathfrak{B a}$ afer8,

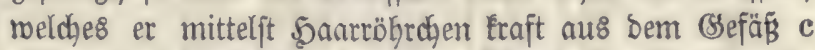
emporzieft, berouniten, uno zmar mirb bie Berbunftung um fo ftärker jein, je weiter bie suft vom Sättigungs= punte entfernt ijt. BBeim llebergang bes 2 Baffers in Dampf ober Dunf́t finoet aber eine Binoung von $\mathscr{B a a r m e ~}$ ftatt, it grolge Deren bas Ihermometer a finlt. Der

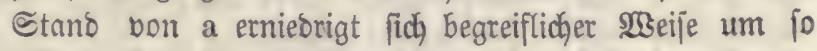
mełr, je ftärker die Betounjtung, ober je weniger bie Euft mit đ̧eudjtigkeit gejättigt rar. Sank f. B. bas ahermometer um $5^{0}$, fo entbält bie \&uft meniger $\mathfrak{S a}[=$ jerbampf als wenn es nut um $3^{\circ}$ fintet.

Die Denge ber berounfteten Feuchtigkeit roiro - fo kann man obne

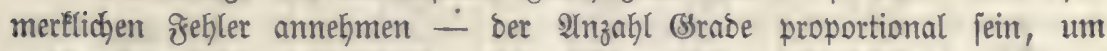
welche ber Stant bes నhermometers fich erniebrigte. Sit d bie Differenz zrwi|jhen ben beiben Ihermometern, jo läß̈t fich, bie Menge ber berbunfteten

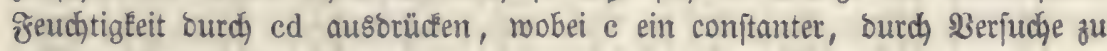
Eeftimmenoer Factor ijt.

Die Dampfmenge W, welche bie \&uft zunädhft ber Moufferingülle ent= bălt, lebt fiç) bemmady zujammen

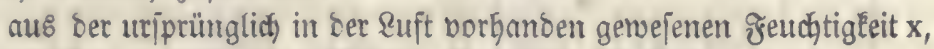
aus ber neueroings gebildeten Quantität $\mathfrak{N a f f e r \delta a m p f ~ e d . ~}$

C8s ift jonad)

$$
\mathrm{w}=\mathrm{x}+\mathrm{cd}, \mathrm{x}=\mathrm{w}-\mathrm{cd} \text {. }
$$

c 5at man burdh Berjuche $=0,65$ gefunben.

(58 jei z. B. Die Temperatur bes trodfenen ahermometers $(a)=15^{\circ}$, bie bes naffen $(b)=10^{\circ}$, fo ift $d=5, W=9,7$ (fiege 4.), ed $=5.0,65=3,25$, $x=9,7-3,25=6,45$ un relative Feudgtigleit $=\frac{6,45}{13,0}=0,49$.

Man Gat Tabellen im Boraus berechnet, aus Denen fich jogleid, ber Feuditigkeitggebalt ber \&uft für eine beftimmte Differeng ber beiben Shermo. meter entnebymen läğt. Geite 260 entyält eine folche Sabelle. 


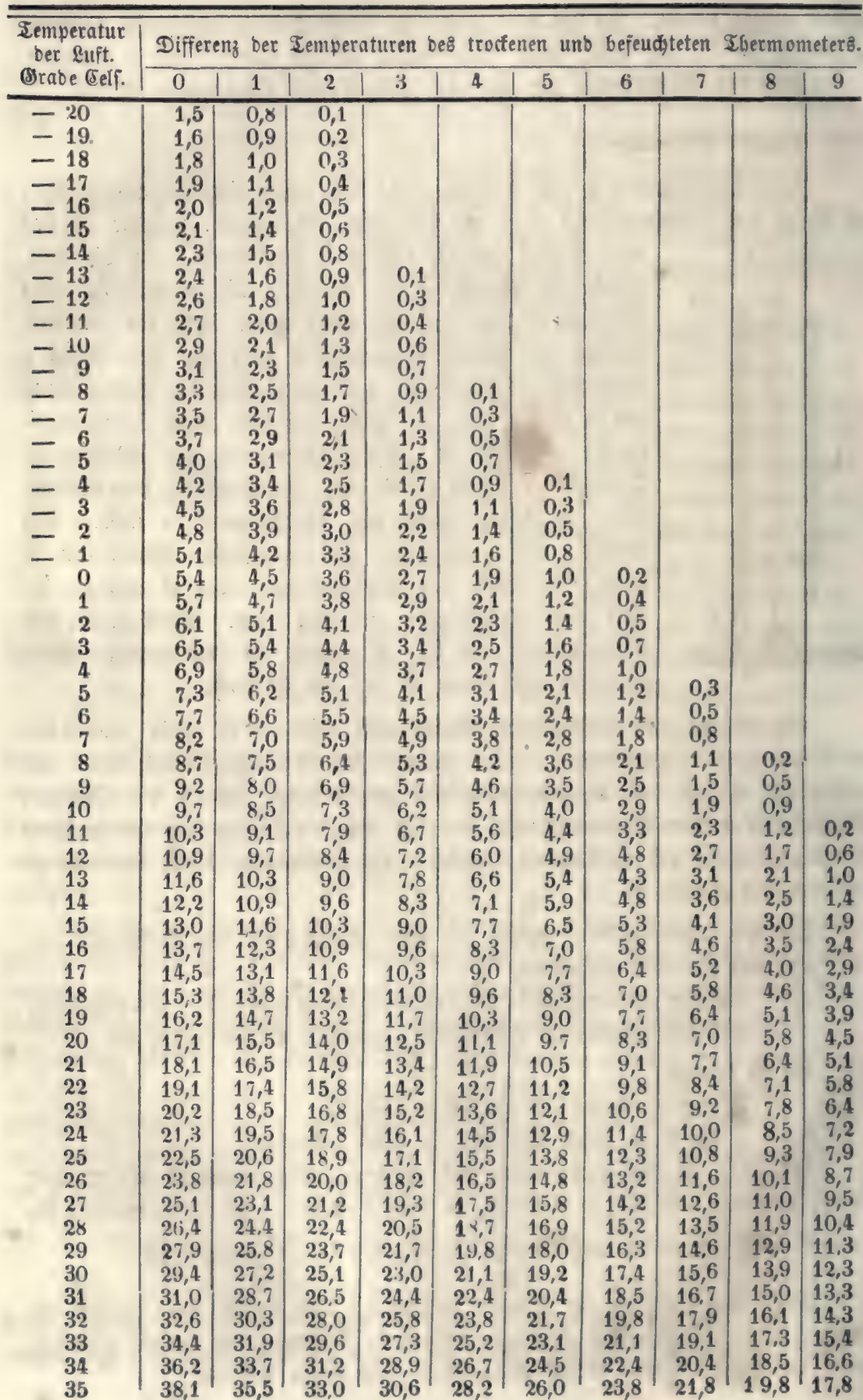




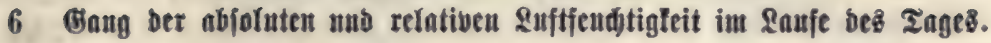

\section{a. Fbiolute Feuditigleit.}

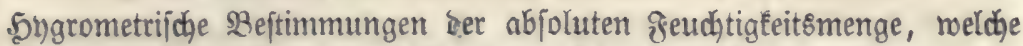
bie \&uft im \&nufe bes Inges enthält, Gaben folgende rejejeşe ergeben:

a. Im $\mathfrak{B}$ inter findet Das Minimum ber abjoluten Dampfmenge zur

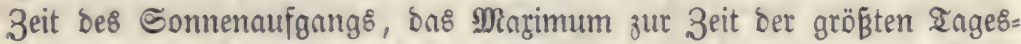
wärme, aljo einige Stumben nadh Mitting ftatt. - Diejes \$erhältniß̈

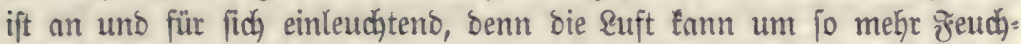
tigḱeit aufnehmen, je höher ifre হemperatur ift. Sinflt bie $\mathfrak{W}_{3}$ rme gegen Abeno bin, fo muß̈ fid ein Iheil bes Dampfes in bor \&uft nie= berjhlagen uno bies bauert bie ganze Nacht himburdh bis zum Sonnen= aufgang fort.

ק. Im Sommer treten einige Inomalien ein, weldye burch ben einige 3eit nact) Sontenaufgang fidc erhebenden roarmen Buft from herborgerufen wer= Den. Das Minimum ber abjoluten Dnmpfmenge findet zroar aud bei Son=

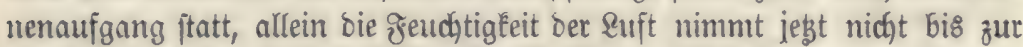
3 eit ber höchjten angesträrme, jonoern nur fis 8 ober 9 uhb zu. Nadh

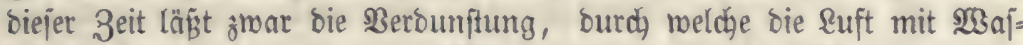
ferbampf gejdynängert mirb, nidjt nad) - jie fteigert fid bie(mefyr mit zunehmender Sonnenböhye - allein bie größ̋ere (Ermärmung auf ber

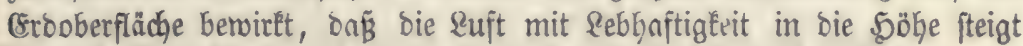
uno bie Dünfte mit fich reifst, moburch fich bic geuthtigkeit an ber Erboberfläche, wo wir Geobachten, berminbert. (5s tritt beshalb um

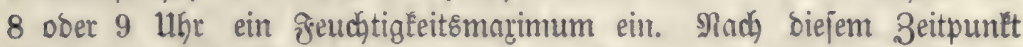
fängt bie Erooberfläche twieber au, zu erÉnlten uno bie Suftfeuchtigkeit an berjelbell nimmt wieber zu, incem ber aufiteigende Suftitrom nad)=

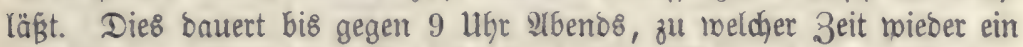

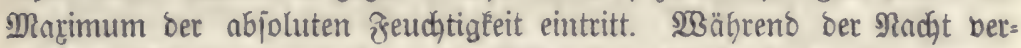
minoert fich bie \$Berbunjtung in jolge bes Sinfens ber remperatur

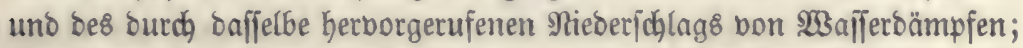
bies onuert bis Sonnentaugang, wo, wie wir oben bemerfłt Gaben, ein Fetıdtigleitominimum eintritt.

Im Sommer finten aljo zroe Minima uno Marima ber abjoluten Feuchtigkeit ftatt; bie beiben erftern ftellen fich bei Sonnenaufgang uno

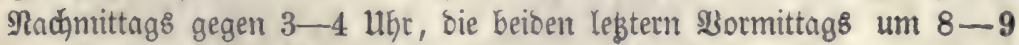
uno श्aents gegen 9 uhb ein.

\section{Relative ซeuচtigkeit.}

Man berjteht unter biejer bas B̉erhältnif́ ber in ber \&uft wirllich bor=

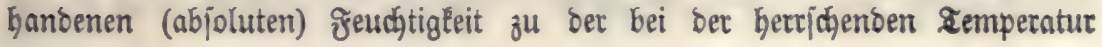


überfaupt aufnefmbaren. S̈e größ̈er bie relative Feudhtigfeit ift, um fo meni=

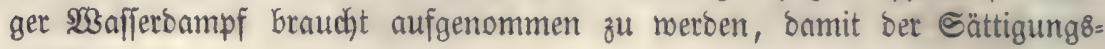
puntt eintritt.

Dbgleich ber abjolute శeuchtigkeitżgehalt ber \&uft im Sommer größzer, als in ben übrigen Safhrezzeiten ift, fo berridst bod) im Sommer eine gerin=

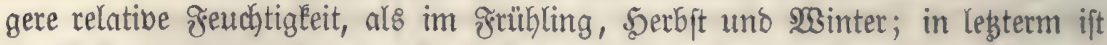
bie \&uft burdjichnittlich am feudjtejten. Diejes ßerbältniß erllärt fich ganz

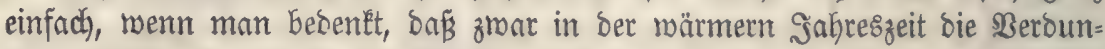
ftung ftärkêt ift, als in ber Fältern, Dafi bagegen bei ber Göhern Iemperatur

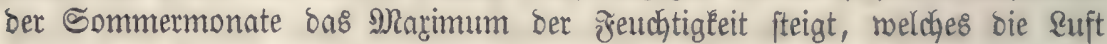

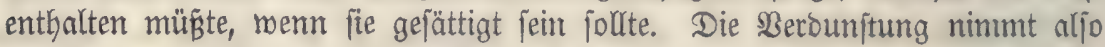
im Sommer nicht in gleichem Maß̉e, wie bie Iemperatur zu, fonbern bleibt Ginter biejer zurüd.

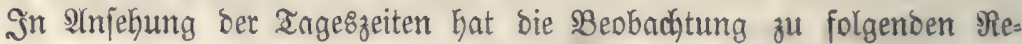
jultaten geführt. Die gröp̈te relative Feuchtigkeit tritt in allen Monaten bei

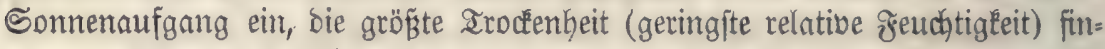
bet z̧ur 3eit des tägliḑen Iemperaturmarimums, aljo einige Stunden nadh Mittag ftatt.

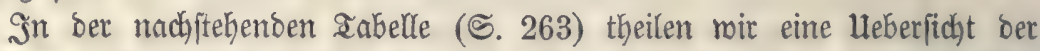
abjoluten und relativen æeuchtigéeit mit. Sic rüfrt bon bem berbienjtbollen Rämb Ker uno gilt für ben Beobndhtungsort Salle. Die Spanntraft deళ

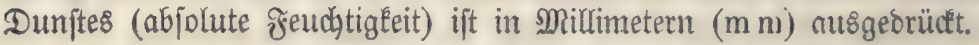

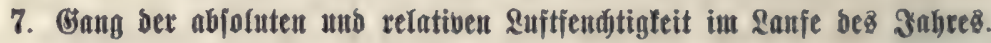

Sierüber find unter 6 , b fdhon einige Ŷndentungen gegeben morben.

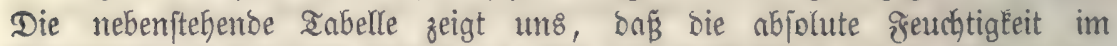
Sanuar am Eleinften ift, bon ba an bis zum Jutli fteigt une nachber mieder bis zum Sanuar fällt. Die relative Feudjtigleit erreicht ifr Mininum im

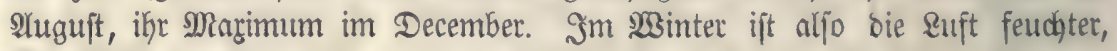
als im Sommer.

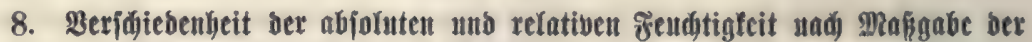 geographifiden Qüuge and Breite.}

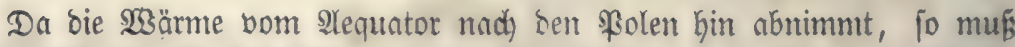
aud ber abjolute Fettdigleitsgebalt ber AYtmojphäre um fo Eleiner werben, je

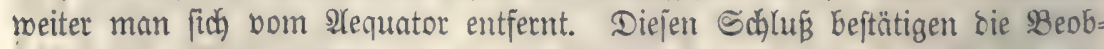

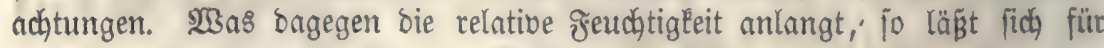
bieje keine jo allgemeine Regel aufftellen. Sie hängt gar jebr bon bem Um=

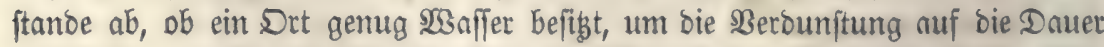

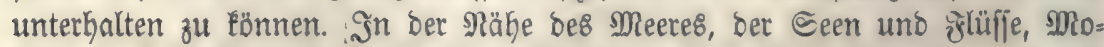
răfte 2c. ift bie Ruft feudjter, als im 8 Binnentande. So zeidjut fidh 8.38 . bie 


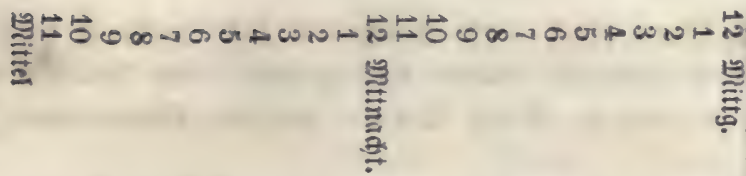

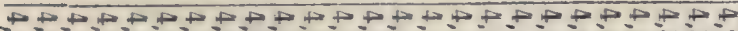

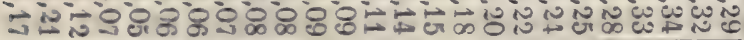

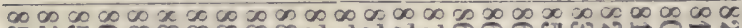

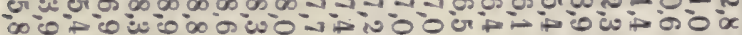

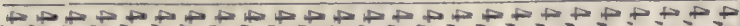

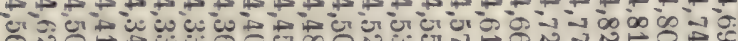

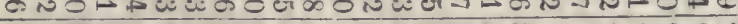

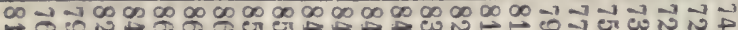

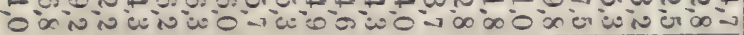

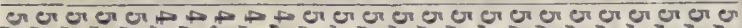
EN

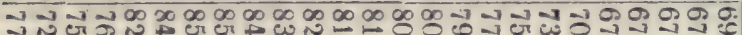

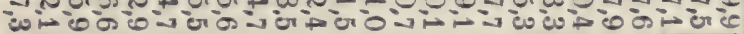

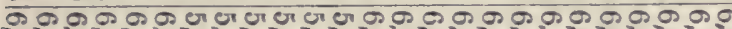

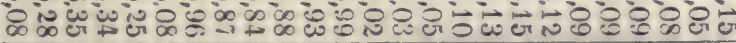

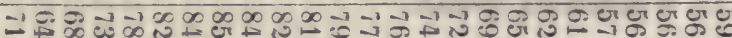

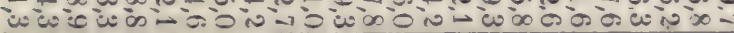

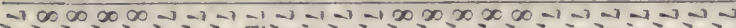
윰

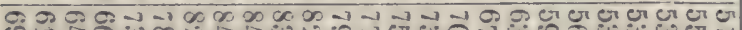

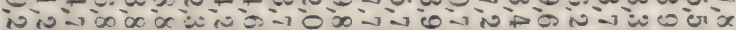

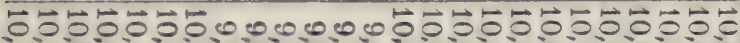
N

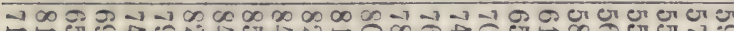

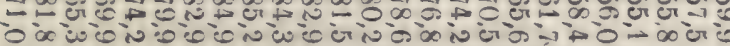

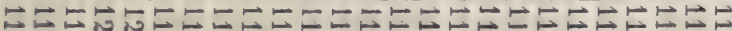

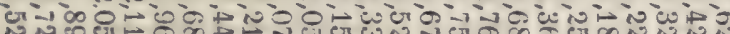
N क्ष

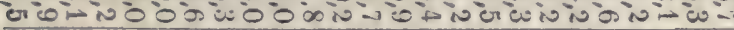

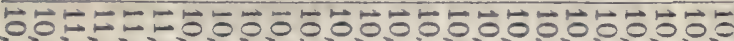

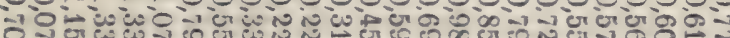

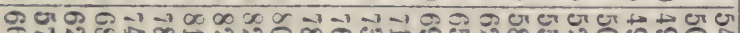

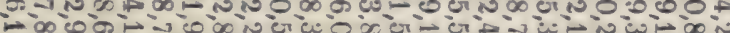
cob $000000000000000000000 c$

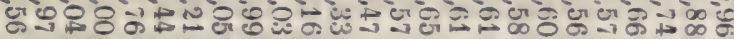

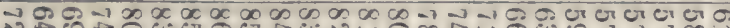

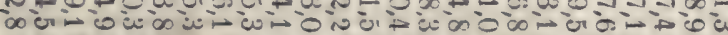

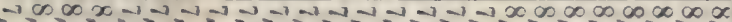

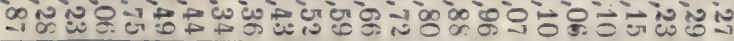

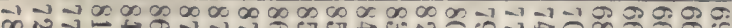

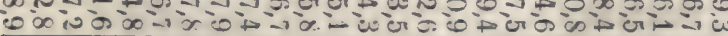

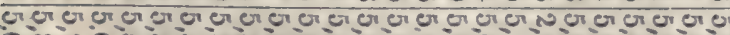

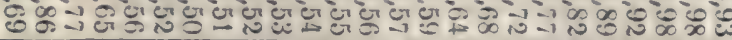

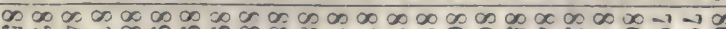

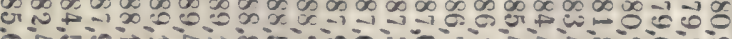

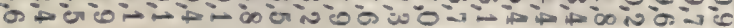
erererer er er er er ner er ererer er er verererer

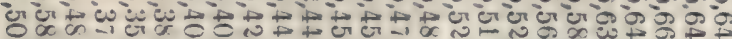

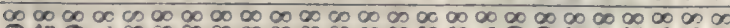

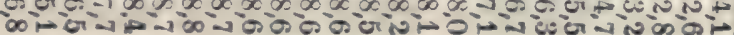

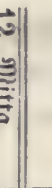

Mbiolute geud tigfeit

Nelative foud: tigteit

भbjolute ซีeuต, tigfeit

Relative geud. tigfeit

Mbiolute Jend. tigfeit

Relative Bend). tigleit

wojolute geudi) tigfeit

greIative Feud): tigfeit

ॠbjolute seudj. tigteit

ReIative geudh: tigteit

Mbiolute Fend: tigfeit

PRelative feuds tigfeit

Mbfolute geud) tigleit

Relative ₹end = tigfeit

आbiolute Eeud: tigfcit

Relative Jeudja tigkeit

ॠ6ivinte geud: tigfeit

Relative geuch tigfert

*oidute gend. tigfeit

relative Feudo tigfeit

Mbiolute ซีenक tigt: it

Relative Frud. tigleit

भbfolute feud. tigfeit

Relutive geuc. tigleit

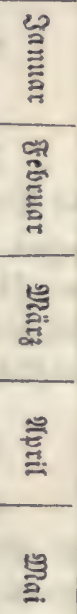

异

巳一

를

Q

0

E

궁

过

$\theta$

룰 


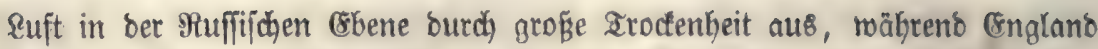
bas ganze Sahr findurch einer jehr feuchten \&uft genieß̈t. (sin ähnliches $2 e r=$

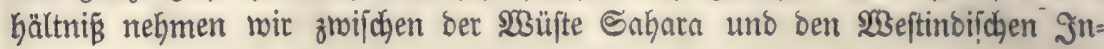
feln wahr.

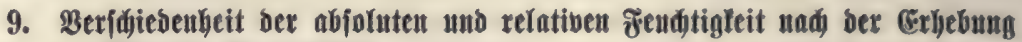 iiber bie Mneereşflädje.}

Der abjolute Frenchtigfeitsgehalt ber \&uft nimmt mit ber Spöke ab, wie bie Beobadtungen ber Meteorologen nadyeifen; bie relatibe Yreudhtigleeit ba=

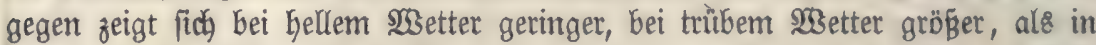

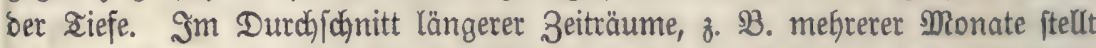

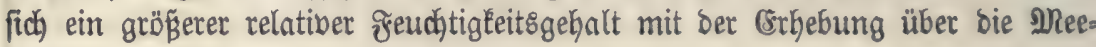

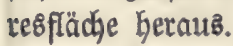

\section{0. Żenthtigfeit bei verídiebentu 2 sinben.}

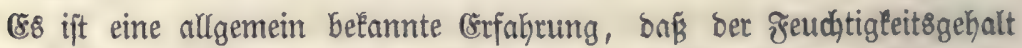
ber \&uft mit bem 2 Winbe wedhjelt. $23 i r$ haben aud hier mieder zroijden $a b=$

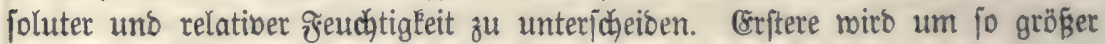

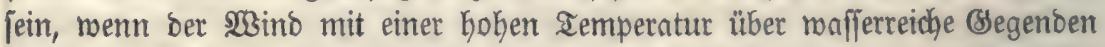
hinzieft, meil er in biejem fralle biel Dampf aufnehmen fann. Die relatibe

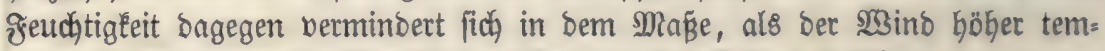
perirt if nno menn Derjelbe über mafferarme Rocalitäten ftreicht.

Sn Deutjhland find im Sommer storoweft, Sübneft und 23 eft bie

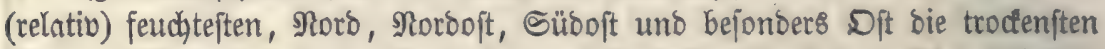

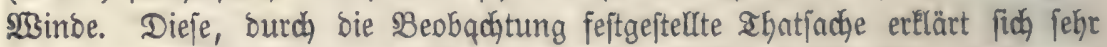
einfach aแs Demjenigen, ro ratur ber $\mathfrak{B}$ inde bemerft nurbe. Sm Sommer ift nämlich bas Snnere be\&

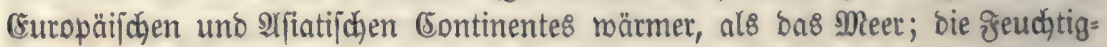
Feit, welche ber Dftwino aus 2rfien mitbringt, fegt er an bem hoben Uralge= birge $a b$, ohne jie auf jeinem fernern \&aufe wieber zu erbalten, ba bie Milliiche

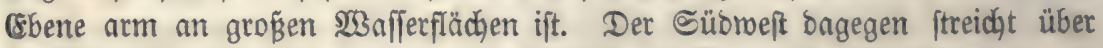

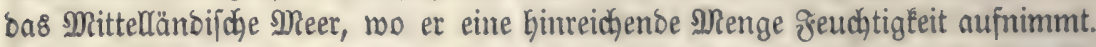
Dieje tritt relatio um fo ftärfer heroor, als ber Sübrweft im Sommer beinahe um 2 srabe tübler, al\& ber Dftwind ift. Nodh feuchter ift ber bom sitlanti=

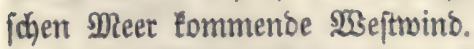

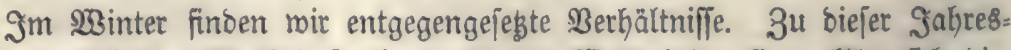

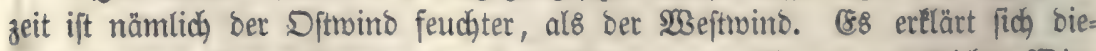
fes aus ber nieberern Iemperatur ber p̈ftlichen, gegenüber ben weftlichen $\mathfrak{B B}_{\text {in }}$ ben, woourdy ber Ihaupunlt jenter Gerabgeftimmt wirb.

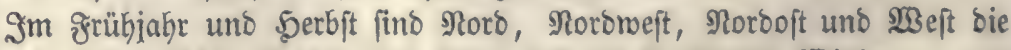

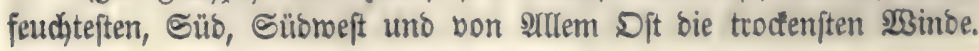


Die nadjftekenbe, nuf bierjäbrigen Beobadgtungen beruhente 3 uјam= menftellung von Säms gibt bie relatibe freudjtigleeit ber adgt 5auptminbe in ben verjojiebenen Safreszeiten an. Der Beobadjtungsort ift \$alle.

\begin{tabular}{|c|c|c|c|c|}
\hline & 23 inter & ร̌tůŁling & Sommer & Serbf \\
\hline Noro & 89,5 & 75,0 & 67,6 & 78,7 \\
\hline Norboft & 91,2 & 72,3 & 67,4 & 82,6 \\
\hline Dit. & 92,6 & 66,9 & 61,3 & 75,7 \\
\hline Süboft & 85,5 & 71,4 & 66,3 & 79,2 \\
\hline Süઠ & 83,0 & 70,3 & 67,4 & 76,2 \\
\hline Sübrwett & 81,9 & 70,3 & 69,9 & 78,6 \\
\hline NBeit & 80,9 & 71,7 & 71,4 & 80,6 \\
\hline Norblwett & 83,2 & 73,4 & 68,8 & 82,7 \\
\hline
\end{tabular}

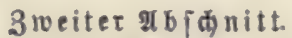

Bon ben wäferigen Rieberidrägen.

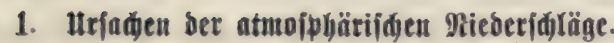

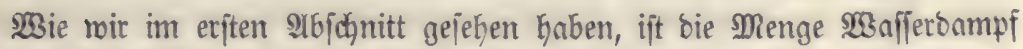

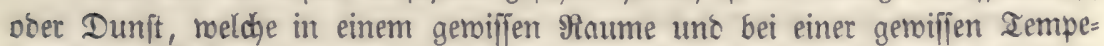
ratur fich biltoen Eann, eine genau begrenzte. F̧ür jese হemperatur gift e\& ein

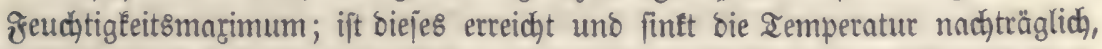
10 mus ein Sheil bes Dampfes in ben tropfbar flüfigen ober feften 3 uftano uีbergeben.

巨o enthält 子. 28. ein Rubifmeter \&uft bei $20^{\circ} \mathfrak{X}$ ärme im Marimum 17,1 Sramme $\mathfrak{3 a f f e r \delta u n j t , ~ b e i ~} 10^{n}$ bagegen nur 9,7 (Sranme. Wirb bie bei $20^{\circ}$ gejättigte \&uft auf $10^{\circ}$ erkältet, jo müjen fíd bemnad $17,1-9,7=$

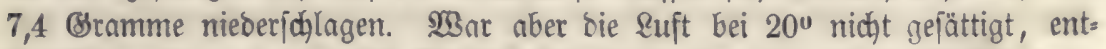

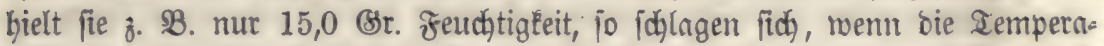
tur auf $10^{\circ}$ fintt, nur $15,0-9,7=5,3$ Sramme nieber. (Entfielt entolid) bie Buft bei $20^{\circ}$ Temperatur 9,7 Bramme Dunft, fo wiro in ben angenom=

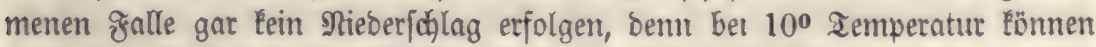
fid) gerabe nod 9,7 (Gr. Feudigligeit in ber \&uft auffalten.

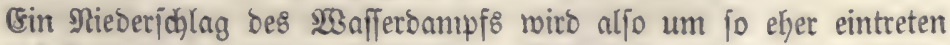

a) je mebr ber in ber \&uft befindlidje $\mathfrak{M a f f e r \delta u n f t ~ b e m ~ b e i ~ b e r ~ b e t r . ~}$

হemperatur möglichen Marimum gleidyfommt,

b) je größ̨er bie Temperaturerniebrigung ijt.

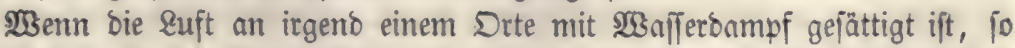

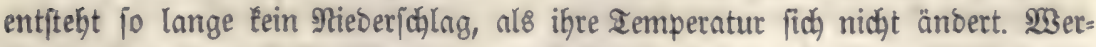
ben bagegen zmei Ruftmaffen von verjdjiebener Iemperatur mit eintander ber= mengt, fo jegt fich augenbliaflid ein Ibeil bes Dampfes ab. Denn bie bet= 


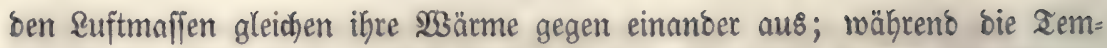
peratur ber einen fteigt, nimmt fie zeuchtigkeit auf, melche fie von ber anoern, Deren Temperatur fällt, empfängt. Da aber bie Dampfmenge, meldje fich in einem gegebenen Bolumen \&uft im Marimum aufhalten kann, in ftärf̌etem Maß̃e, al\& die Temperatur zunimmt, fo muß́ bie roärmere \&uftmaffe bei ber 2lusgleichung auf bie Mitteltemperatur viel mehr æ̌euchtigfeit abgeben, als bie uriprünglich Eältere \&uft bebarf, um bei ber YYusgleid)ungstemperatur bon

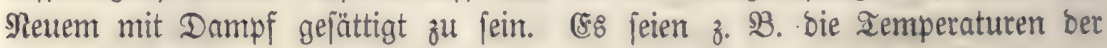
beiben Ruftmaffen $20^{\circ}$ und $10^{\circ}$; nach exfolgter Mengung baben fie bie ge= meinjuaftlidje Temperatur bon $15^{\circ}$. Die \&luft bon $15^{\circ}$ nimmt Gierbei eine Dampfmenge von $13,0-9,7=3,3$ Srt. pro $\mathbb{S}$. Meter nuf, bie Ruft von $20^{\circ}$ gibt $17,1-13,0=4,1$ Sr. p. $\Omega$. $M$. $a b$, aljo toeroen $4,1-3,3=0,8$ (5r. $\mathfrak{3 a j [ e r b a m p f ~ p . ~} \Re$. M. ausgefdjieben.

\section{Nebel.}

WSenn aus irgend eitter ber vorbin angegebenen Utradjen bie Suft fich

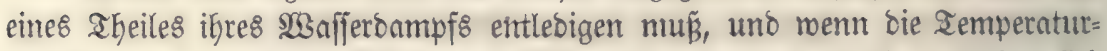
erniebrigung, weldhe Gierbei ftets eintritt, nidjt bedeuteno ift, fo bersichtet fich) Der 23 afferbampf in Gseftalt Hleiner Blä\&djen, weldhe innen mit \&uft gefüllt fino. Sdjweben viele foldje Bläschen nahe neben einander in ber suft herum, fo nennt man bas rsanze Mebel.

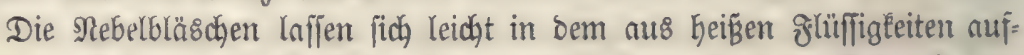

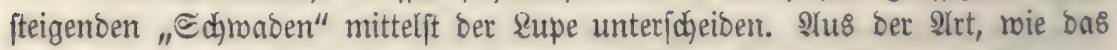
sicht vou ifnen reflictirt miro, gelnng e\&, ifren Durdymeffer zu beftimmen,

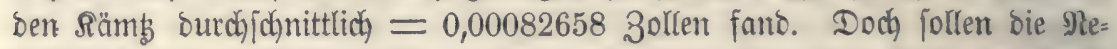

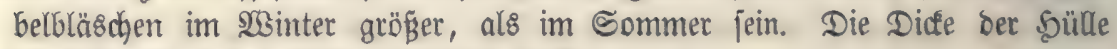
beträgt nađ) Rrałenjtein 0,00002530 lle.

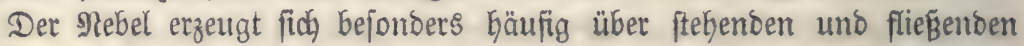
Gerwäffern, Sümpfen und überbaupt über naffem ober feuchtem \$BDoen un

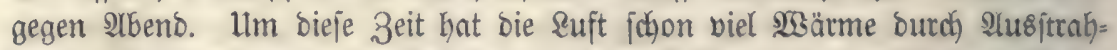
lung berloren, wäfreno bie Temperatur bes $233 a f j e r 8$ nakezu biejelbe geblieben

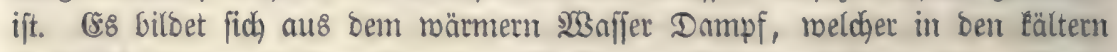

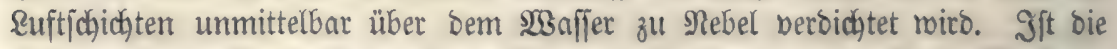

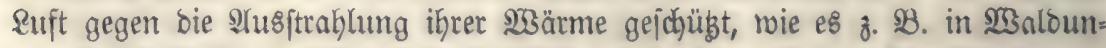
gen ber Fall ift, fo billot fich oft jelbịt auf feuditem Boben Eein Rebel.

Blöß̈en oder jüngere Bejtänbe in Tieflagen, welche von höherent Ŝn=

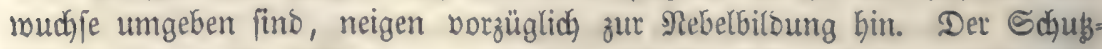
beftand Gemmt bie Enftbernegung, burdh weldye bie Ë̈ltere \&uft an foldhen $\varepsilon_{0}=$ calitäten von wärmerer erjest werben Ë̈mute. Die bem NBinozug esponirten

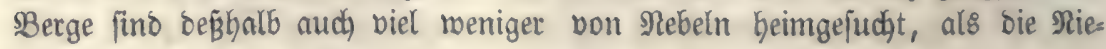
berungen.

Eänoer in ber Nähe ber See leiben in ber Eältern Snhreşzeit mehr von 
Rebelwetter, als Drte im Binnenlanbe. Das Meerwaffer bält bie im ๔om=

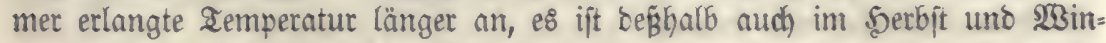
ter wärmer, al\& bå \&ano. Die Dämpfe melche fidy auళ bem Meermaffer

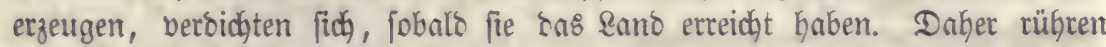

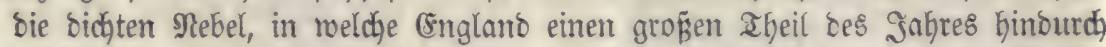

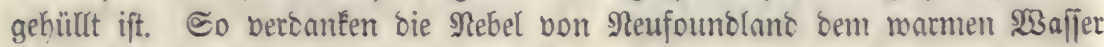
Desీ rolffitromes igre (Entítehumg.

\section{EDoffen.}

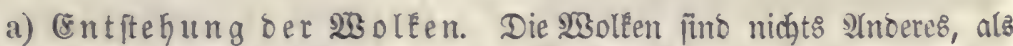

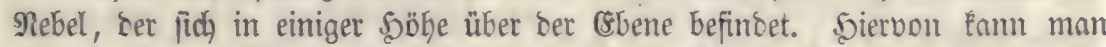
fidi) am beften überzengen, menn man ein Bebirge bei trüfem 2 getter be= fteigt. Man fiebt fidh bann oft in bie Mitte einer Mebelmaffe berjebt, bie von

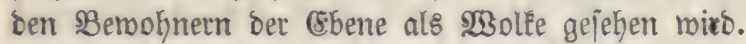

Die 230 olfen entifefen aus ber Feuchtigfeit, welche fids nus bem 30 on,

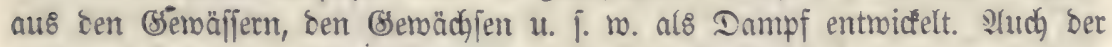

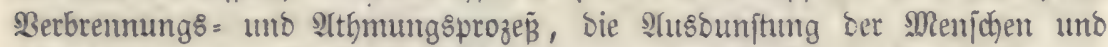
Ihiere bilden eine Duelle für bie Crzeugung bon $\$ 3$ afferbampf. Diejer, mag er num von ber einen ober ber andern Urjache Kertühren, fteigt megen feines

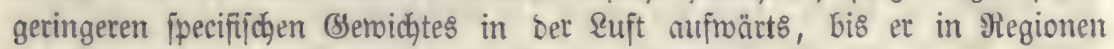
gelangt, beren niebrige Temperatur ihn zur Berbichtung zmingt.

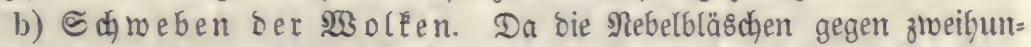
bertmal jofnerer fino, als bie \&uft, jo müffen fie jogleid, nach ihrer (Entjtehung nad) Der (Erboberfläd)e hin fallen. Dies gejojiebt auch) unter allen llmitänben,

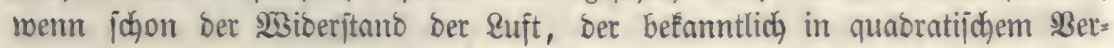

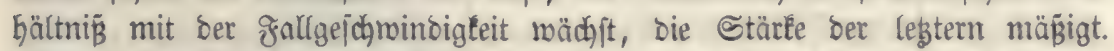
2 Sarum erbalten fich aber, Eam man fragen, bie $230 l$ leen in ber Sdjwebe? Dies beruht auf ber höhern Iemperatur ber untern Ruftjchichten. Eobald bas

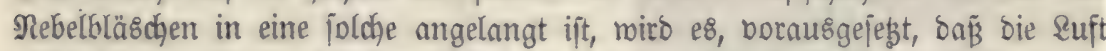

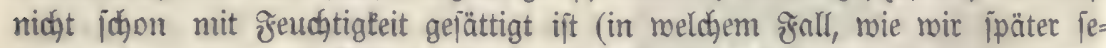
Gen werden, Regen einttitt), wieder in Dampf berwandelt, Der abermals jeinen

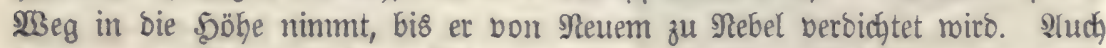

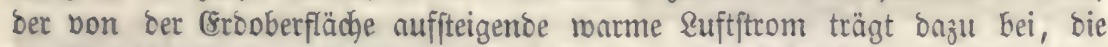

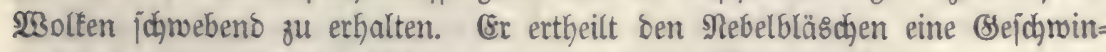
bigkeit in eintem ber Fallrichtung entgegengejegten Sinne.

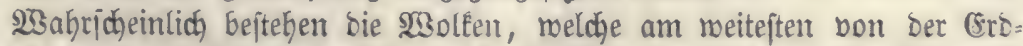

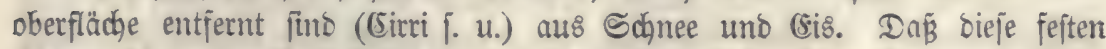
Sörper fich in ber \&uft jujpendirt erhalten Eönnen, berubt auf ben nämlichen

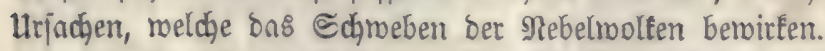

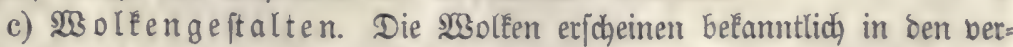
fajiebenartigiten Formen, bod) ftehen bieje in jebr genauem 3ujammentang

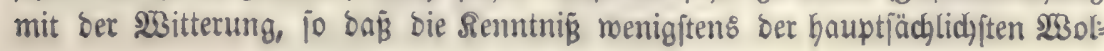


fengeftalten für bie Meteorologie bon 23 idjtigleit ift. Die nachftehenoe (6laf= fification verbanfen wir 5omart.

§ig. 111.

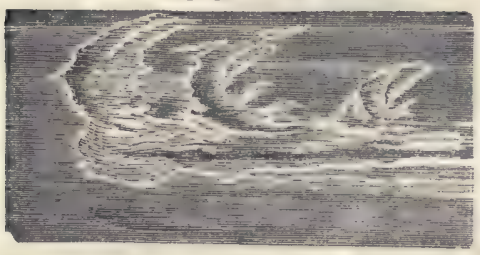

a. Die Gebermolle - Eirrus.Sie befteft nus zarten meipen Streifen, bie entweber einander parallel laufen ober etruas gebogen fint uno an ben crnoen getwöhnlich bivergiren, fo baßz bieje bas

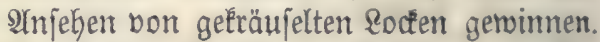
Die Fredernolke ift gewöhnlidy am meiteften bon ber (srobberfläche entfernt, nach ben Meffungen von Dalton uno Siäms ftęt fie oft in 20000 Fus \$öke, mo, wie wir wiffen, bie Iemperatur unter ben ssefrierpunlt gejunken ift. Deß̈megen müffen mir aud annefmen,

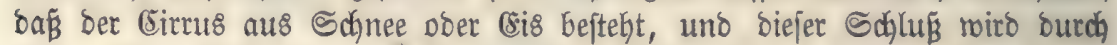

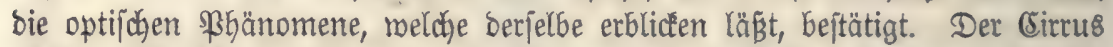
rüctit gemöhnlich mur langiam bom ßlage, mas ebenfalts auf jeine weite cont=

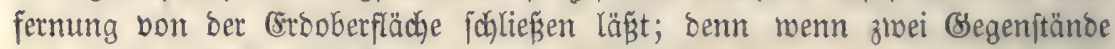

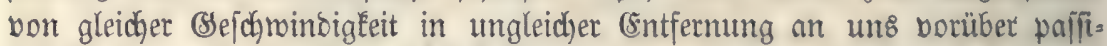
ren, fo fheint ber uns zunädjit befindlidje eine gröBere Bejdyroindigleit, als

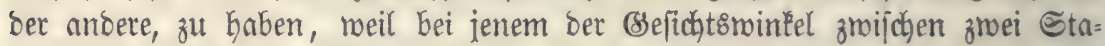
tionen fiç) in ber nämlichen Zeit um einen größzern Betrag ändert uno wir

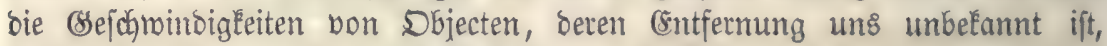

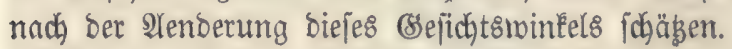

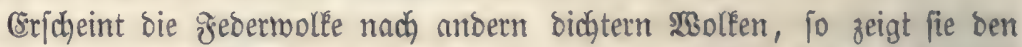
(sintritt bon gutem $N_{3}$ etter an; tritt fie aber nach anbalteno beiterm Simmel

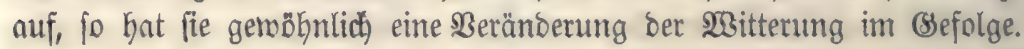

ஓig. 112.

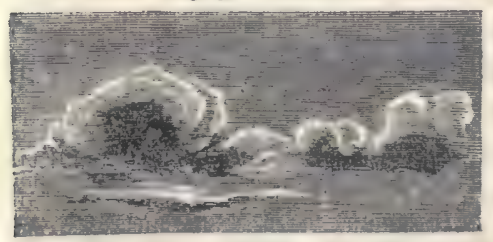

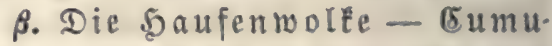
I Galbéugelförmig mit einer ber 5orizontalen parallelen Brunofläcţe. Die Sautenmolte hat einen bumkeln, oft ganz idymarzen siern, aber kelle, oft burd) bie Sonnen= ftrchlen bergolbete siänber. \$äufen fich

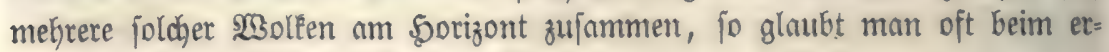
ften 2 nblict ein fernes Bebirge zu jehen.

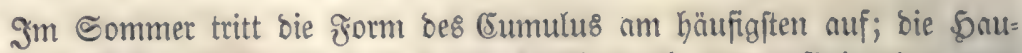
fentoolke entiteht zu biejer Sahreszeit vorzüglich burdh ben aufiteigenton mar= men \&uftftrom, ber bie Dünite rajd) mit fid in bie \$口obe nimmt, bis fie fidf

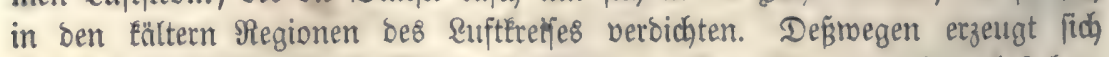
bieje $\mathfrak{Z}$ olkenart meijt bes Miorgens, bleibt ben ang über an Simmel ftehen, indem fie fortwähreno wädjft uno finft gegen 2abeno, wenn ber auffeigenoe suftiftom nachläg̈t, herunter, robei fie fich in ben särmern \&uftichichten auf: 


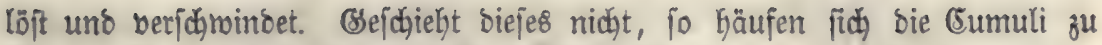

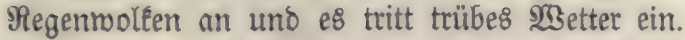

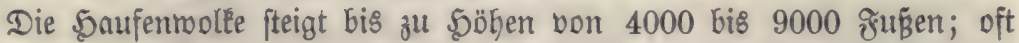
feht fie aber viel tiefer, namentlid bes Arbends, wo fie bis ofu 3000 gunen

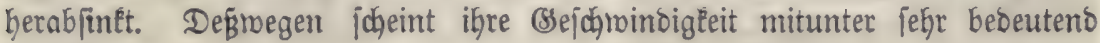
ơ jein.

Æig. 113.

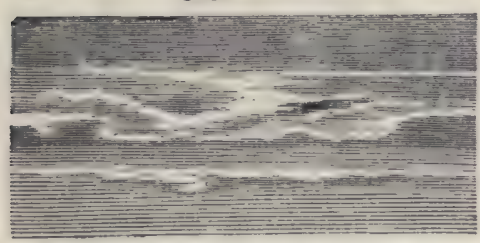

$\gamma$. Die Sdiditentolke - Stras tus. Sie hat mit ber rebernolle einige Yehnlidłleit, unterjabeibet fich aber von biejer burch ifre grö̈̈̈re Didhte uno burdh Duntlere Farbe. Dabei bejitst fie eine grö= Bere Rängenausbehnung, fo bá̉ fie fich mie ein langet Stretfen ausnimmt, bet mit ber Sorizontalen parallel verläuft. Dft berbedt fie ben 5̧orizont ganz, bejonberళ in feudaten abälern und Nieberungen, und läp̈t ben obern IGeil bes Simmels frei. Die Edjichtenmollee erfjebt fich nicht fo hod), mie bie Jje=

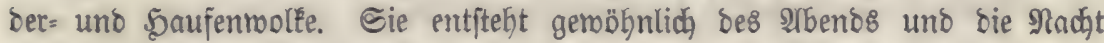
finourd, aud bei Iage nach semittern.

§ig. 114.

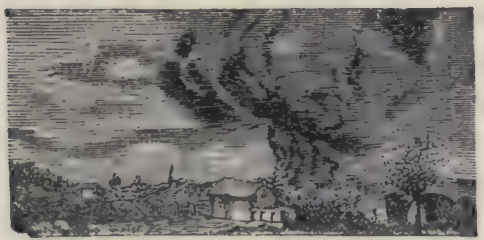

d. Die Regenwolke - Nimbus. Sie befibt eine eintönige, graue Doet blau= graue, nach unten hin buntlere Färbuntg uno bertwajdenten, unbeutlidsen Saum, forvie eine unregelmäpige, bod, maffentafte

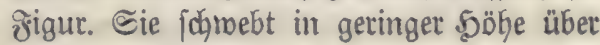
ber Crrooberfläche.

Die biş̧er aufgefüfrten $\mathfrak{B}_{0}$ léengeftalten jinto nicht immer fo icharf aus= geprägt, als wir fie eben gejujildert haben, jegr oft geft eine frotm in bie anbere über. Die bemerfentswertbeften Zroijd)enjtufen find:

§ig. 115.

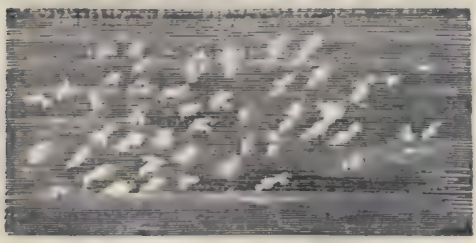

8. Die feberige \$aufenrolke 厄irro $=\nwarrow u m u l u s .-$ Sie befteht aus

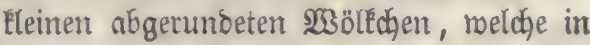
größ̄erer 2nnzahl neben eimander gelagert fino. Man Eamm fich voriftellen, fie jei aus ber Febermolfe burdh 3ujammenballen ber Sajern entitanden. Jin ber Bolfspipradhe

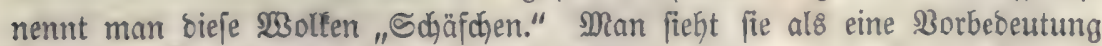
für bas lăngere Inhalten bon heiterm $\mathfrak{W}$ etter an. 
ชั่g. 116.

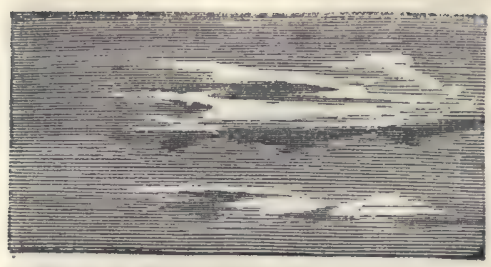

Æig. 117.

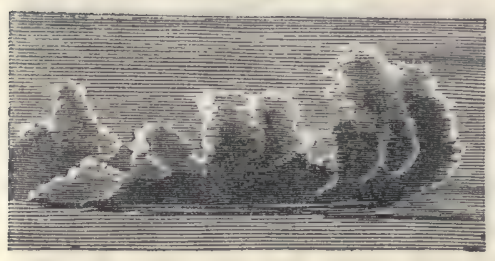

ל. Die feberige Swidtenmolée (cirro=Stratu\& (ङig. 116). Sie bilbet einen Gorizontalen Streifen, Der aber nicht, wie ber Stratus, bicht ift, fonoern aus Inuter fleinen fogmalen unter fid paralle=

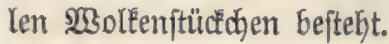

$\eta$. Die geididtete 5aufenrolle - Eumulo= Stratus. (§ig. 117). Sie befteht aus aufeinandergethürmten 2030 l= kenmaffen von größ̈erer \$öhe, als sruno= fläche, bie obere ßarthie ift überfängeno. Man Eann fie fid aus ber Bereinigung mehrerer Saufentoolken, über relche Cirro= Strati gelngert fint, entitanden benten.

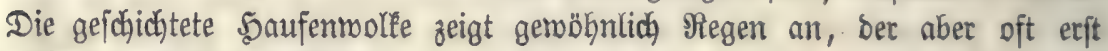
nach einigen Iagen erfolgt.

\section{Regen.}

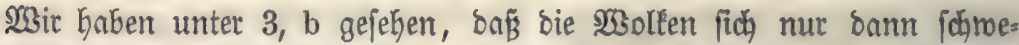

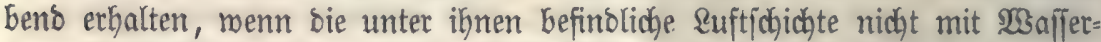

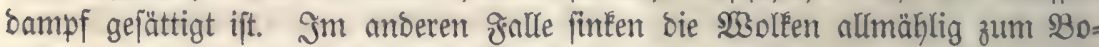
Den Gerunter, Dabei vereinigen fich mehrere Nebelbläschen zu einem Iropfen

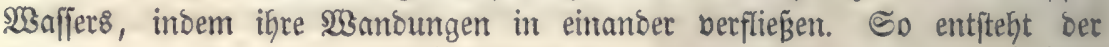
Regen.

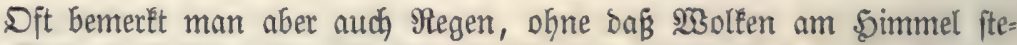
hen. Diejer fall tritt bann ein, wem eine warme gejättigte \&uftid bidjte mit

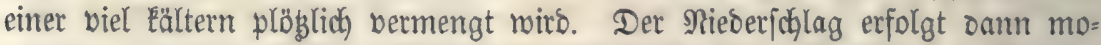

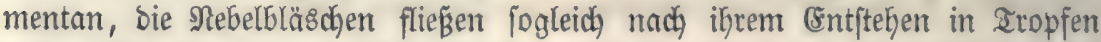
oujammen. Der Regen ofne $230 l$ ken tritt am bäufigften im frübjabr auf, wenn Der Kalte ßolarftrom mit bem viel wärmeren 2lequatorialftrom Eämpft.

Im Aleinften find bie Regentropfen in bem jogenannten Staubregen, größ̈er fchon in bem mefrece Inge anoauernoen Sanoregen, am gröpten in Dem \$laskegen.

\section{Sdinee.}

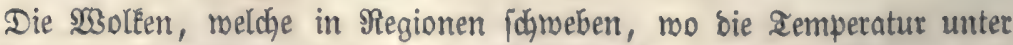

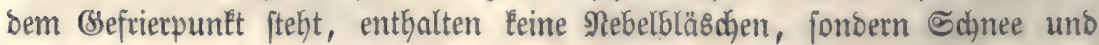

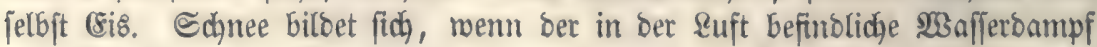
gefriert. WSie wir früber gejeben haben, enthält bie \&uft jelbjt bei Iempera= 


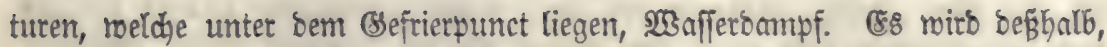
wenn sie Iemperatur fo weit finft, baß Edhee entfteft, nidgt mehr Dampf

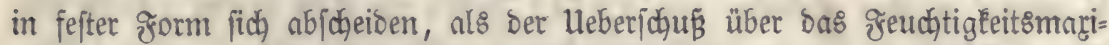
mum beträgt, weld\}e\& fid bei ber Gerridjenden Iemperatur in ber \&uft auf= Galten Eann. Durdh einen Edjneefall verliert alfo bie Euft keinesmegs ifre

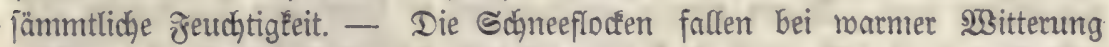
größzer aus, als bei Ealter, fie beftehen aus Hleinen nabelfōtmigen Sityftallen, beren frorm bem heragonalen Enjtem angehört. (Semöhnlid) jtofien feçs

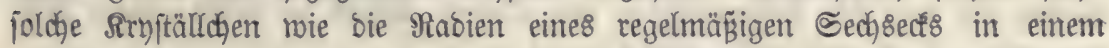

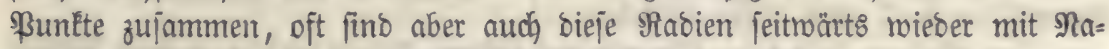
beln bejest, jo bá bie mannigfaltigften sejtalten entitehen. Fig. 118 enţält Æig. 118.
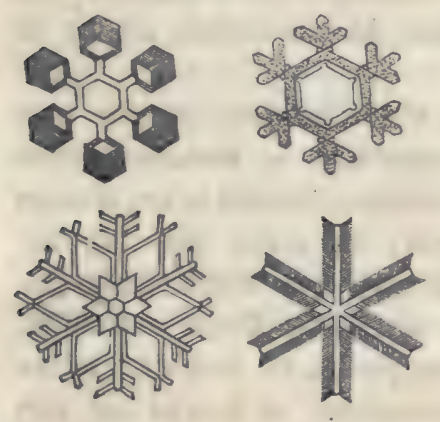
einige berjelben nach einer von Score8by entworfenen 3eidhnung.

Da bie Menge Feuchtigleit, weldye bie Ruft aufzunebmen bermag, mit ber $\mathfrak{E}$ em= peratur räadjt, fo mús aud bie Menge Sdhnee, weldhe in ber 3eiteintheit, 8. B. in

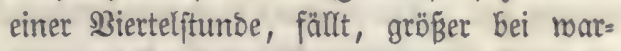
mer, als bei Ealter $\mathfrak{N}$ itterung fein, uno in bet IGat beftätigt bie Beobadbtung biejen ङ઼̆luణ́.

(Sleidje (semidhtsmengen Schnee lie= fern beim Schmelzen gleiche Duantitäten NBafler; Gillot man aber von bem Sctynee, io mie er gefallen ift, gleiche Bolumina, fo erfält man beim rgauen beffelben

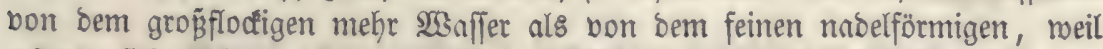

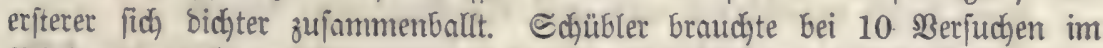
Minimum 10,1; im $\mathfrak{M}$ arimum 22,3, im Mittel 14,1 Raumtfeile હdhnee, um 1 Raumtheil 23 affer zu erzengen. Eine 14 3oll bohe Sdyneelnge wiro alfo bein Sdymelzen im Mittel eine 23 afferichidjte von 1 30ll 5ähe geben.

Die Menge bes fallenben ๔ahnees nimmt mit ber orrbebung über bie

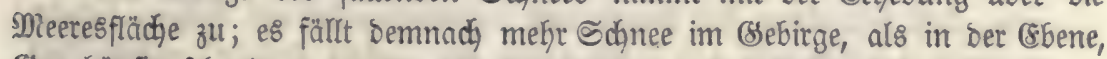

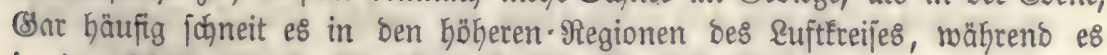
in ben Iieflagen regnet; sie Edfneefloden fajmelzen bann, ehe fie an bie

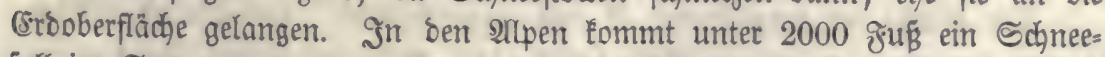
fall im Sommer nie bor, mähreno bei 4000 bis 5000 Jüen MRereshöbe bes reits Eein Monat mehr idyneefrei ift. Die Sïutentänber (Europa's, welche ben feudtwarmen Cübrweftrinden ausgejebt fino, Gaben bei gleicher Meereshöhe uns gleicher Breite mefr Sdjneefall, als das Snnere unjeres continentes.

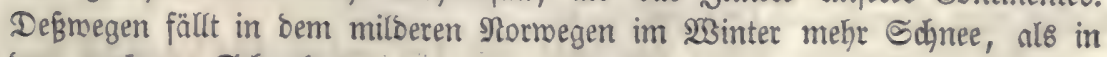
bem raukeren Sdjweben.

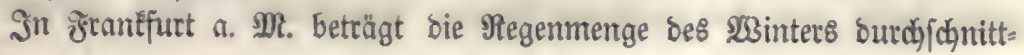




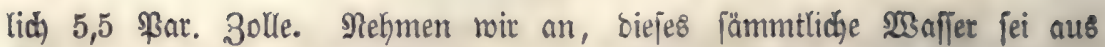
Schnee entifanden und biejer ben ganzen $23 i n t e r$ Gindurch liegen geblieben,

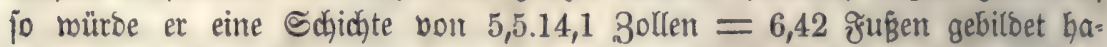
ben. Dod) Gäuft fidh in ber (segend bon orranffurt ber હdhnee felten höber,

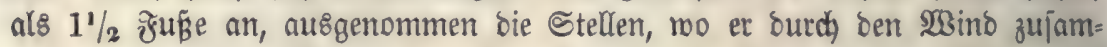

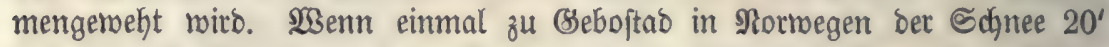
hoch lag, fo ift bies, nach D. Buch), nur ein ertremer Fall; an ben süften

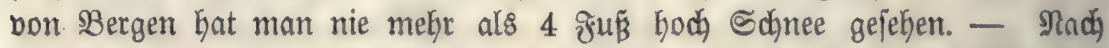
Meffely foll aber bie Sdyneelage in ben Defterr. Arlpen bei 5000-6000 ơน

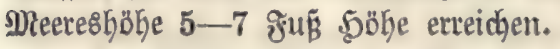

Im Sebirge fällt beim (sintritt ber kältern Sahreszeit ber Sdgnee früher

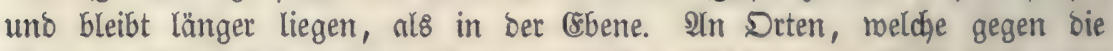
Sonne geidjübt find, mie z. B. an nöroliç)en 2 rbjängen in Sdjluchten, im

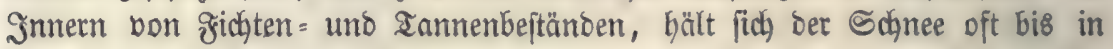
Den Sommer Ginein.

In ben भlpen, borzughlich aber in ben Polargegenoen, bemerlt man

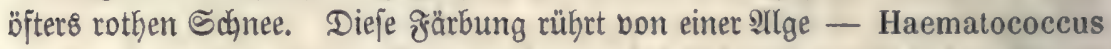
nivalis, her. "Die abjolute Alequatoralgrenze bes Sdjnees etreidyt in ben (8benen bes alten continents jojmerlich ben 30 ten (stab; im neuen abet faft ben

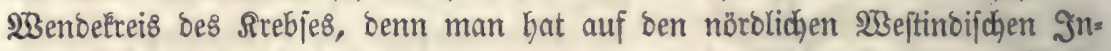
jeln seifpiele von Sdhnee gehabt; menn man aber folche Derter ausfichließ̈t,

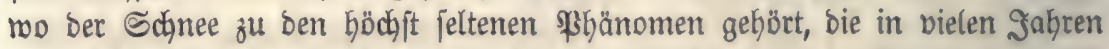
gar nicht eintreffen, io Darf man bie Requatorialgrenze in (suropa auf $40^{\circ}$, in Ilmerifa auf $30^{\circ}$ bejtimmen". Sdjoum, Pflanzengeographie, 386.

\section{6. ફagel.}

Bom Sagel unteridheibet man zwei Mrobificationen, nämliḑ

a) Die Sraupeln, runblidje, bis ztwei Sinien grof̈e, Sörperçen von

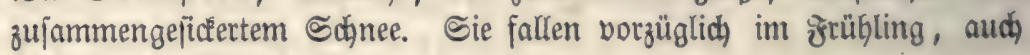
mohl im 5erbft uno $\mathfrak{W}$ inter.

b) Den eigentlid)en \$agel. (Er ftimmt barin mit ben Sraupeln überein, bá̧ jein Sern faft immer aus zu[ammengeballtem Sdinee bejteht,

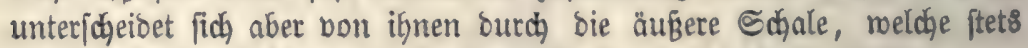
(sis ift. Dft wechjeln auch concentrijhe (sis = uno Echneejdjidyten.

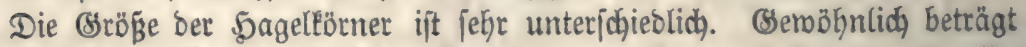
fie zomei Rinien, aber es ift fajon நagel bon mehreren 3olfen Durdameffer gefallen. Bei bem 5agelmetter, meldhes 1822 bie Hmgegeno von Bonn ver-

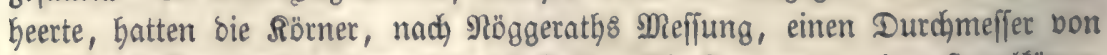
$1-1 \frac{1}{2}$ 3ollen uno rogen bis 13 \&oth. Die remperatur ber ફageltërmer betrågt nach ßouillet $-0^{0}, 5$ bis $-4^{0}$.

Die Sagelwolken laffen fich) leidht bon ben andern $\mathfrak{B S}_{\text {ollen }}$ outch bie graue garbe nno bie zerriffenen Ränber unterjdeiben. Sie fogneben in. 
getinget Şöhe über ben Boben uno laffen oft, aud fwon ehe ber Sagel

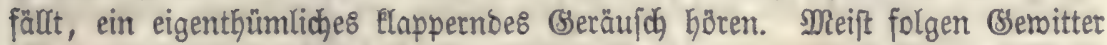
auf ben sagel.

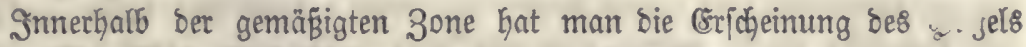

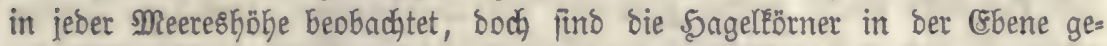

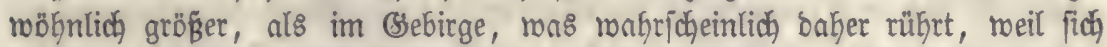

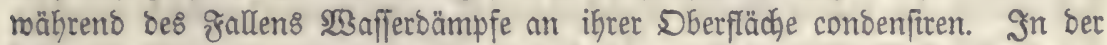
heiß̈en 3one tritt ber sagel in meeresgleicher \&age aufiserorbentlict) felten auf, Dfter geigt ex fird im rebirge.

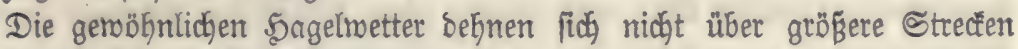
\&anbes aus; fie bejdgreiben einen Streifen, ber viel länger, als breit ift. ఏagelmetter, wie das non 1788, weldjes Jrtanfreich in einer \&änge von 100

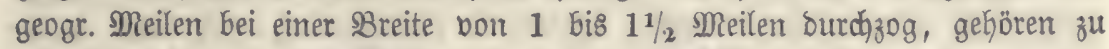
ben Seltentheiten. Manche Drte fino Dem Sagelichlag vorzugsmeije ausgeję̧t, fo Daß̉ fie fajt aljährlich babon betroffen rerben.

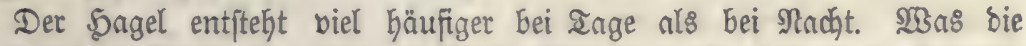

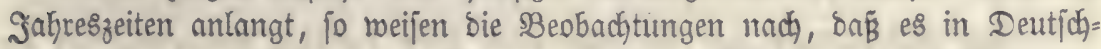

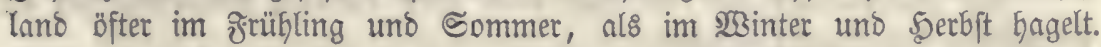

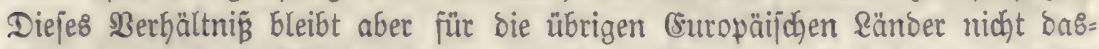

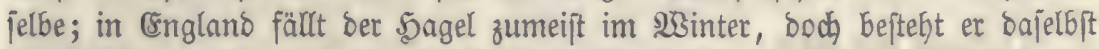
vorzüglid, aus Sraupeln; nudh in Deutichlant fommt ber eigentliche Sagel mehr im Sommer bor, mähreno im frühjahr mehr sraupeln fallen.

Entftehung des \$agels. Die ältern \$fyfíter bielten den Sagel

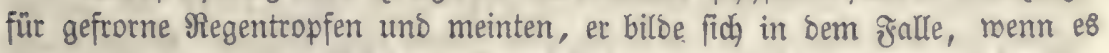

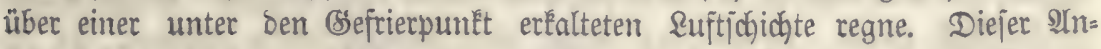
ficht fteht in jo ferne nichts entgegen, als es in ber That zumeilen borkommt,

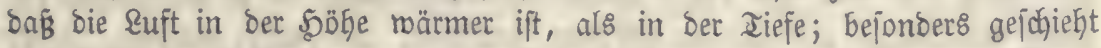

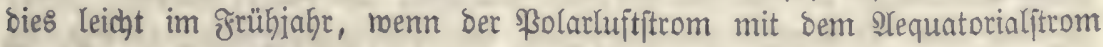
Eämpft; burdh bie swinde merben bann beibe mit eitander vermengt. Itnridgtig

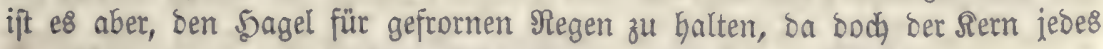

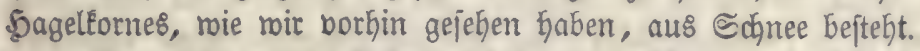

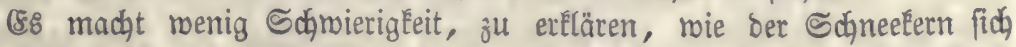

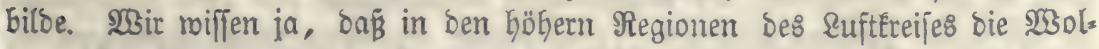
Een nicht mefr aus Nebel, fondern aus Sdynee ober (sis bejtehen. (ss brau= dhen baher nur bie Sdjneefloden, etwa unter bem (sinflü einer böhern rem= peratur ober bes 13 indes, fid zujammengutallen, uno bie Sdaneeferne find fertig. Sicht jo leicht ift aber bie Beantwortung ber Orrage, noker bie mitunter fo bebeutenbe Crismaffe fomme, welche ben Echneekern umgibt. Solta Gat

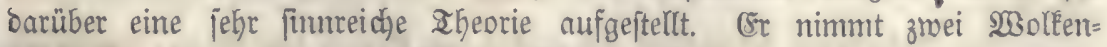

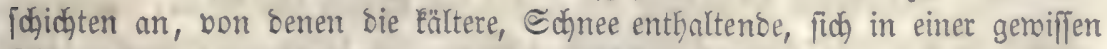

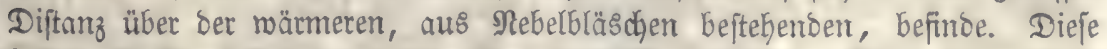

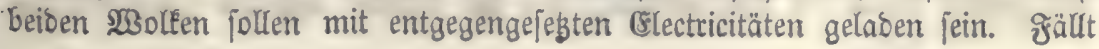


nun, fo fagt Bolta, eine ๔dineeflodfe aus ber obern 23olfe zut untern hernieber, fo fegt fich bie Jeudhtigfeit ber Yegtern an ber Eäftern Sdaneeflocfe ab und gefriert gleichzeitig; Das Rügeldyen, melches fich gebildot hat, berißst

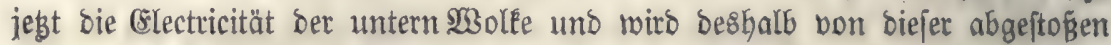
und ber obern $\mathfrak{W}_{3}$ olke wieber genähert; Gier angeḱtommen, finlt jeine Iempe-

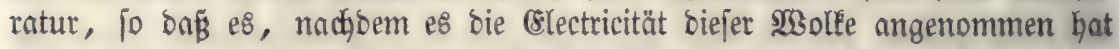

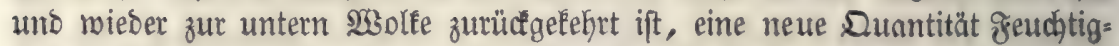
keit in Sis verwandeln Ennn. Der Brozér foll fo lange bauern, bis bas

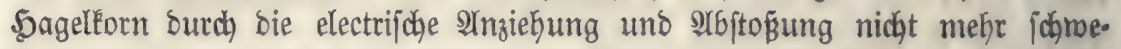
bent erhalten werben Fann uno wegen feiner vermebrten Sdgmere zu Boben fintert.

Man fieht auf ben exften Rliat bie Schnädhe biefer Theorie ein. Menn

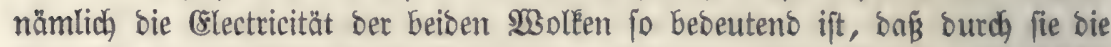
Sagelëbrner unaufbörlich in Berwegung gehalten rerben fönnen, fo müfte nothroendig eine 2Yusgleichung ber beiben (STectricitäten erfolgen, wie wir bieß 8. $\mathfrak{B}$. bei ben Semittern beobadyten.

Die Meteorologie hat bis jegt noch feine baltbare Errflărung für bie (Entjtebung des sangls gegeben.

\section{Thaน แกธ Meif.}

Die \&uft enthălt zu allen Zeiten $\mathfrak{B}$ afferonmpf. \$3iro fie unter bie Iemperatur bes Sättigungspunttes abgefühlt, fo erfolgt, mie mir gejeken

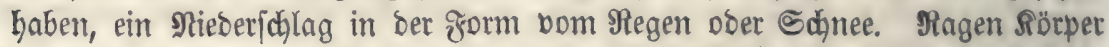
in bie \&uft binein, welche nus irgeno einer Urjache ftäréer erfalten, als bie Euft jelbjt, fo wirb bie \&uft, weldje mit biejen Sörpern in Berührung ift,

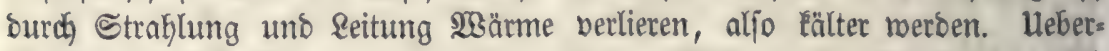
idhreitet babei bie remperaturerniebrigung ben Sättigungspunft, fo fest fid Der Wुafferdampf biejer \&uft an ben kältern Rörpern ab. Man nennt ben

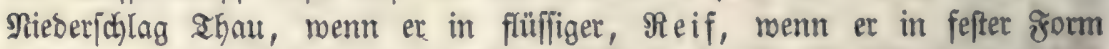
erfolgt. Doch ift es burchaus faljw, ben Reif als gefrornen Ihau anzufeben, weil bei ber Reifbilbung Der $23 a f f e r \delta a m p f$ unmittelbar aus bem gasförmigen

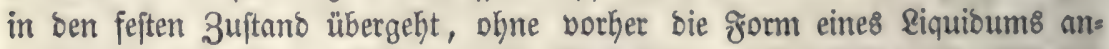
genommen zu haber. Sinft aber bie Zemperatur nad) erfolgter Thaubiloung auf ober unter ben Befrierpuntet, jo entfteht ber \&isangang, an ben SBäumen, ober bas (3) latteis, nuf bem Boben, boch erzengt fich bas leptere aud bei förmlidjem Regen, wern bie Temperatur bes Sobens unter $0^{\circ}$ ftegt. .

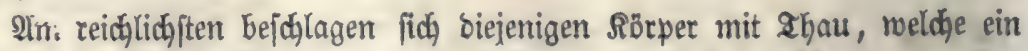

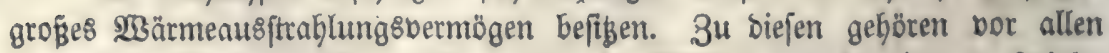
bie grünen aheile ber Begetabilien, wie bie $\mathfrak{B l a ̆ t t e r ~ u n b ~ b i e ~ j u n g e n ~ I r i e b e . ~}$ 


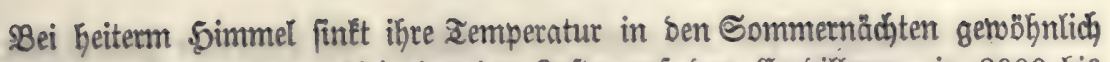
2 bis 3 brabe unter biejentige ber \&uft; auf ben Corbilleren, in 2000 bis 3000 MRetern über bem MReer beobachtete \$Boufingault beim Graje jogar eine Temperaturentiebrigung von 5 bis 6 (sraben, was wahrjejeinlich ber

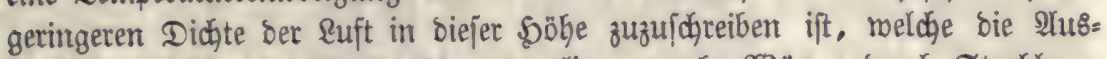

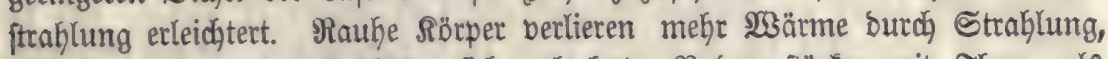

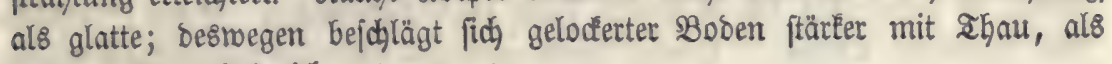
unbearbeitetes Groreidy.

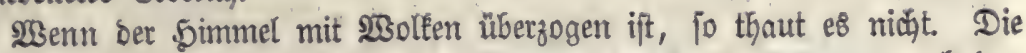

ชั่g. 119.

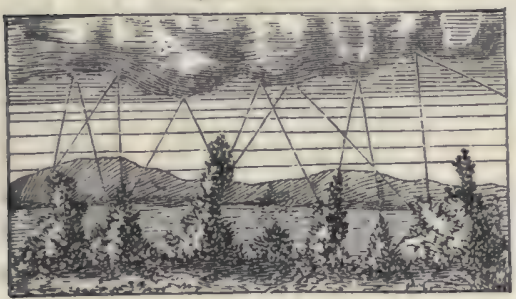

NGärme, welche die Pflanzen nadh ben Gökern Sdjichten ber AYtmophpäre hin ausftrablen, wiro bon ben $2 B_{\text {olfen }}$ auf $=$ gefangen uno wieber nach ber (Ero= oberfläç) zurüctigemorfen. (尹̈ig. 119.) Die Iemperatur ber \$flanzen fann

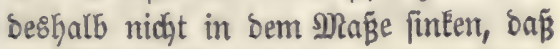
ber Ifaupunft eintritt.

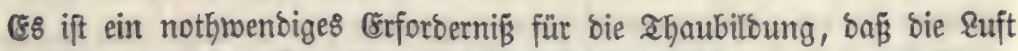

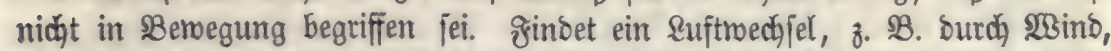

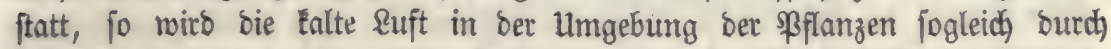
märmere berorängt; bie leģtere kommt bann aud̆ mit ben Pflanzen felbjt in

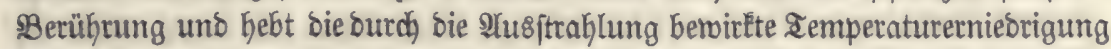

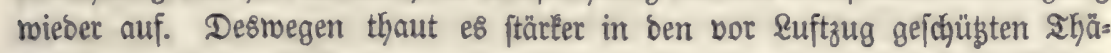
ไetn, als auf ben \$̧ס̋hen.

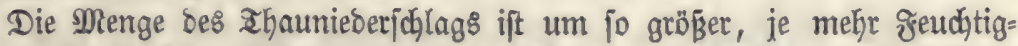

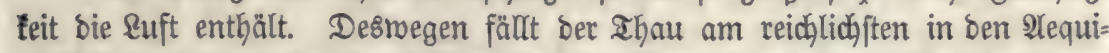

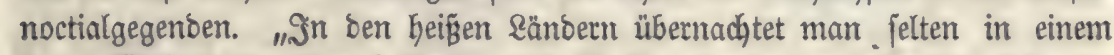

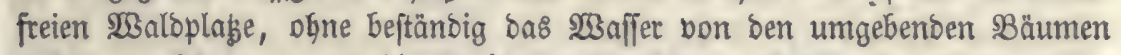
riejeไn zu Gören, wenn bie Nadht ber Strablung günjtig ift. Unter vielen

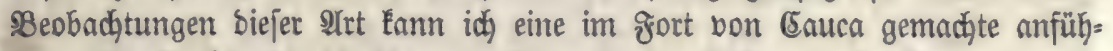

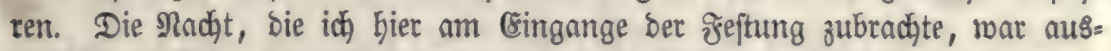

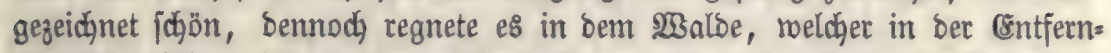
ung von einigen Mletern $\mathrm{lag}$, febr ftark, uno man fonnte bei ftattfindenoem Monojdgeine von ben obern 3reigen Der Bäume bas 2 Saffer Gerabriejeln fegen. - In ben Steppen bon San Martin bielt es mir oft fobrer, behufs

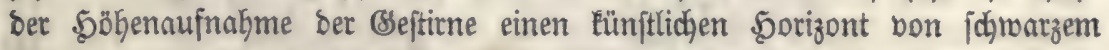
Blaje anzumenden, in bemjelben 2lugenblicfe, wo ber Ilpparat unter ben freien

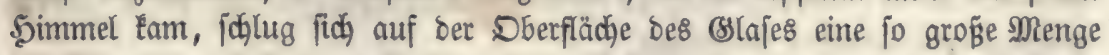

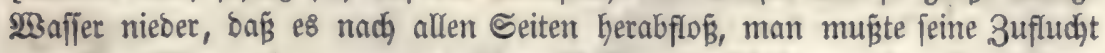
zum Ouedfitber nehmen, um von bem Sejtitne, weldhes man eben beobadjtete, ein פild zu erbalten." \$Bouffingault. 


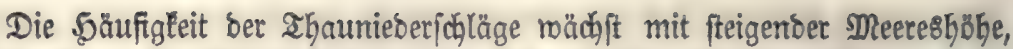
Dagegen nimmt bie Mnenge des zhaumaffer: in eben Dem Mape ab.

Der eigentliche Ifyau bilbet fich nur burch Berbicjtung bes in ber \&uft

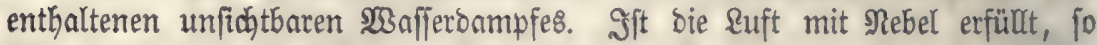
(क)lägt fich biejer an kälteren ssegenftänoen oft gerabe fo nieber, mie ber

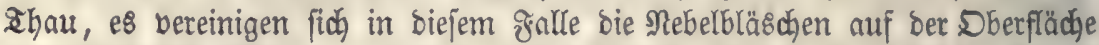

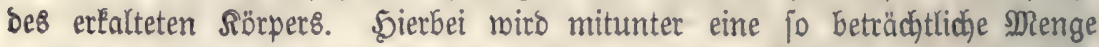
tropfbar flüffigen $\mathfrak{W}$ affers gebillbet, $\delta \cap \tilde{B}$ 子. $\mathfrak{B}$. unter $\mathfrak{B}$ äumen ein förmlicher

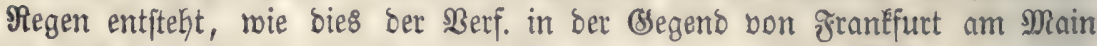
gar oft beobadatet hat. Einige Striche an ber regenlojen Rüfte von şile

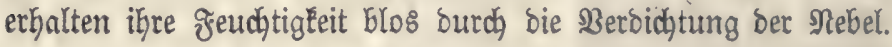

IIm bie Menge bes ahaues zu befitimmen, bebient man fid, ber foges nannten Drofometer. Die einfachjte Borrichtung biejer Arrt befteft in einem umgeftürzten \$oblekegel bon ladirtem ober berzinntem Blech, beffen engere Deffmung in eine grabuirte BSta8̊röfre reicht. Diejes Snjtrument, auf

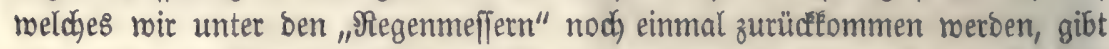

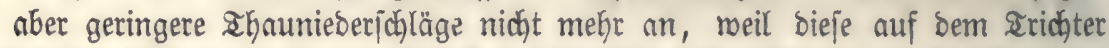
bängen bleiben; will man biejelben beftimmen, jo trodenet man bie greuditig= keit mit, borker gemogener, SBaumwolle ab uno berechnet bie Menge bes

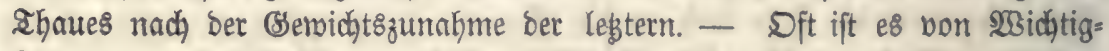

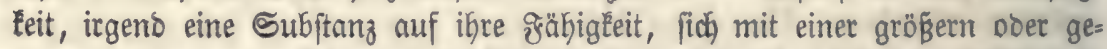
ringern Menge von Ihau zu bejollngen, zu unterjudjen; in biejem gralle legst man ben betreffenden Sörper, nadbem man ifn geroogen hat, auf eine me= tallene Unterlage und roägt ifn nach Beendigung bes \$erjuches nochmals.

Ueber bie Quantität ber Ihaunieberjaläge fint bis jest noch) wenige unterjuchungen angejtellt worben. Flnnguergues fand, wie uns ๔dübler mittheilt, im Sabre 1823 zu Bivier im füblidjen grtankteich bie Mentge des

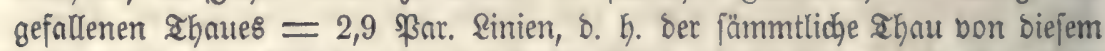
Sahre würbe eine Sdjidjte von 2,9 Rinien \$öhe gebildet Gaben. (5:8 thaute im Jahre 1823 zu Bivier an 125 Iagen bie mittlete Menge bes an einem Iage

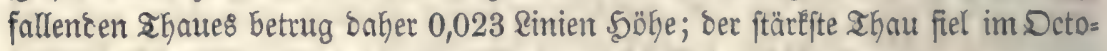
ber, wo leine Menge an einzelnen Ingen 0,04 sinien Şß̈he betrug; in ganzen

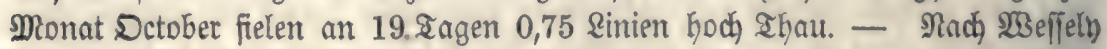
beträgt bie aus zefnjährigen Beobadtungen beftimmte Dhaumenge zu Brab 0,03 bis 0,19 , im Mittel 0,12 SKiener 3olle, ober $0,4 \%$ bes atmojphärijosen

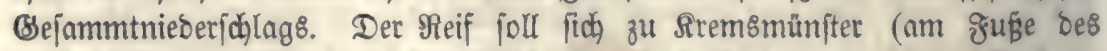

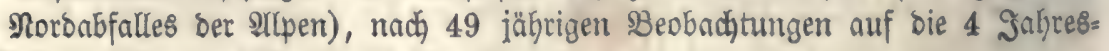
zeiten folgendermapeen bertbeilen 


\section{Sommer 0,06 \\ Serbft 5,60}

Sn Braz fiel im Raufe von 21 Jahren

ber lez̧te Reif am 30. März (Min.) uno 21. Mai (Mar.) - 25. Mipril (Mittel.) " erfte " " 17. Sept. (Min.) " 20. 囚ov. (Mar.) - 14. Dct. (Mittel.)

Sn urjern Begensen ift bas Ihaurnafjer burch jeine Reinheit ausges

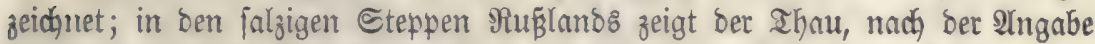

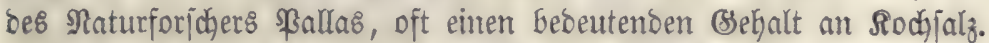

Der 5onigthau, mit melchent bie Blätter bon manchen Pflanzen,

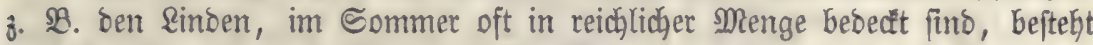

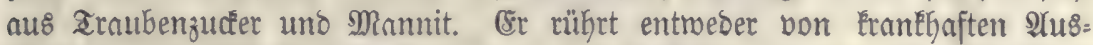

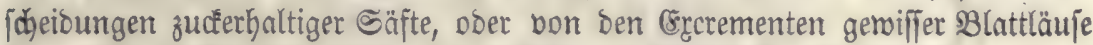

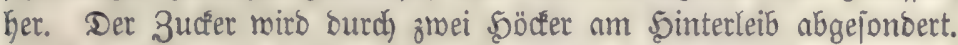

Det jogenannte Me hlthau foll aus Eleinen \$ilzen beftehen.

\section{Regenuenge.}

\section{a. Begriff.}

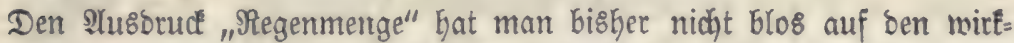

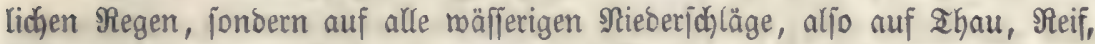
Schnee z. bezogent. Alud wir mollen bas 230 ort in biejer Bebeutung neb̧men.

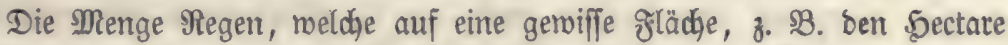
ben Morgen, im Raufe eines Gabres, Monats ober Inges getommen ift, miro

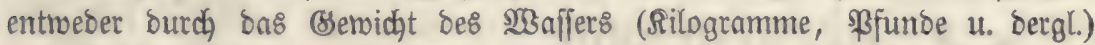

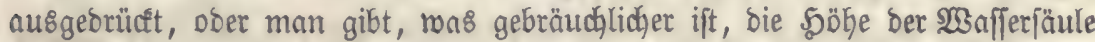
an, welche bie gejammte Regenmenge einnehmen mürbe, wenn von berjelben

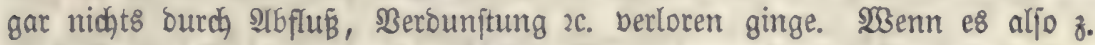

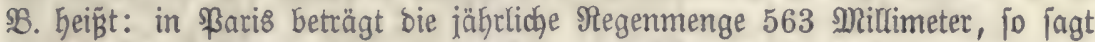

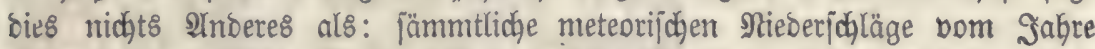

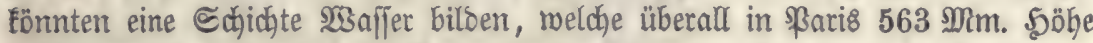

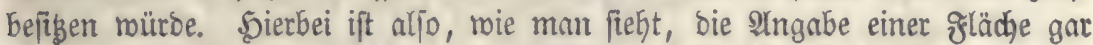
nicht nötfig. 2)

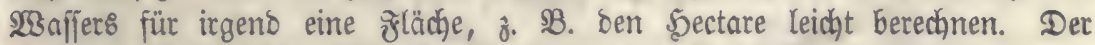
Sectare enthält $100 . \quad 100=10000$ Duatratmeter; Die Regenmenge pro Sectare beträgt aljo 10000. 0,563=5630 Subifmeter, ober, Da ein Rubitmeter 23 affer $=1000$ Silogramme miegt, 5630000 Rilogramme.

\section{b. Negenmetier.}

Regenmeffer, Dmbrometer, werben bie Snftrumente genannt, metterft

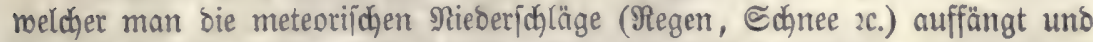

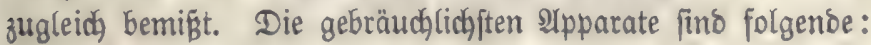


a. Regenmeffer mit grabuiter srasobre.

ซ̛ig. 120.

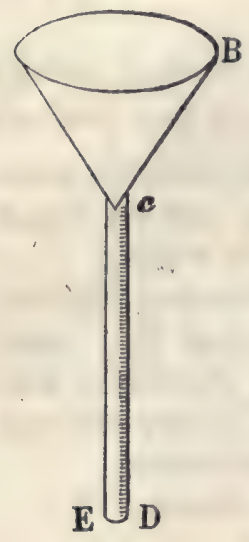

(sin von lactirtem Bled) gefertigter 2ridjter, beffen obre $\mathfrak{W}$ eite AB befannt ift, (gig. 120.) fteht burdh bie enge Deffrung bei c mit ber grabuitten BSIastöbre cD in Berbinoung. Der Regenmeffer wirb an einem freien

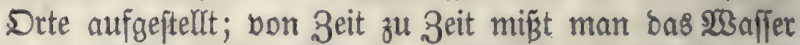

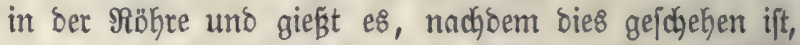
aus. Sat fich ber Iridgter mit Schnee gefülut, fo roiro biefer mittelft einer zubor gemeffenen Duantität marmen Waffers gejdjmolzen, wenn man nicht borzieht, ben arpparat ins 3immer zu nehmen uno ben Sdynee bier aufthauen zu Laffen. SBei Reif Eann man warten, bis ifn bie Tage 8 o ober Sonnenträrme flüfig madht. Die

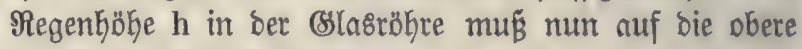
Frläche ber grichteröffnung bezogen meroen; bies gejdjieht inbem man $h$ mit $\frac{A B}{D E}$ multiplizint, wobei DE ben auerourdymeffer ber siöhre vorftellt; e8 ift alfo bie wirllidje Regenböhe $h^{\prime}=h . \frac{A B}{\overline{D E}}$ Dem aridjter fann

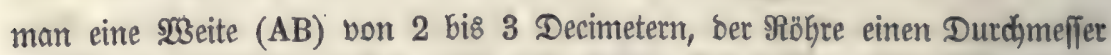
von 1-2 Centimeter geben. Um bei ftarḱen Sdyneefällen leine Berlufte zu erhalten, wiro auf Dem Triḑter nody ein $1 / 2$ Meter boher cylinoerförmiger Quffä, gleichfalls bon ladiutem Bled), angebracht.

\section{B. Б口orner's Regenteffer.}

Diejes Injtrument enthält, mie bas borige, einen Iridjter $p$, weldjer

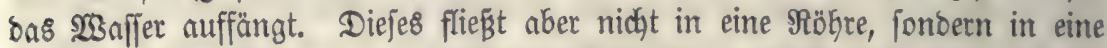

ซig. 121.

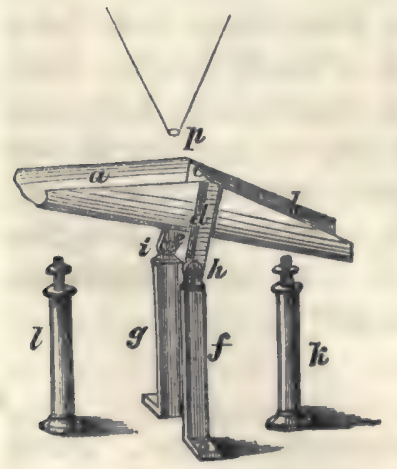
meffingene Schaufel a, welche von einer andern, eben fo gropen Sdyaufel b burdh bie Duer= fijeibemanto c getrennt ift. (ङig. 121.) Die beioen Sdjaufeln ruhen vermittelft ber Stäbchen d und e auf ben Trägern $f$ und $g$. SBei $h$ und i befinden fidy semerbe, weldhe eine auf: unt niebergehende Betwegung forohl ber Sdjaufel $a$, als auch bon $b$ geftatten.

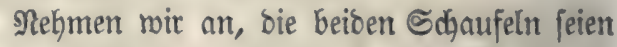
aus ber horizontalen \&age gebradht norben, uno

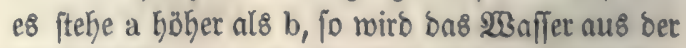
Tridyteröffrung $p$ in bie Schaufel po lange ftrö: men, bis fie bie Hebermucht erfält und fich in

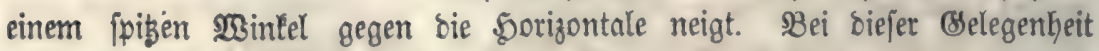
giegit fie aber ihr $23 a$ affer aus, biejes läuft auf ben Boben einer sammer 
in weldher bie Sdhaufelvorridhtung aufgeftellt ift. Num fteht bie Schaufel b böher, als a, fie fülth fich ebenfalls nady uno nach mit $2 B$ affer, bis audy fie

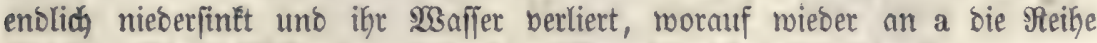

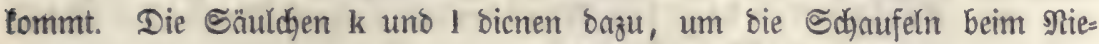
bergeben zu arretiren uno um bie Stellung ber Sdjaufeln fo zu corrigiren,

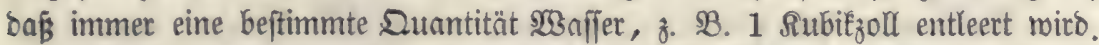

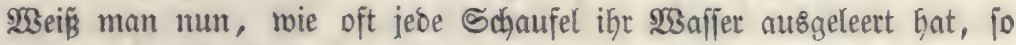
lennt man audh die Regenmenge, weldhe in ben Prichter gelangt ift. (88 Ganbelt fich aljo nur nod barum, jede niebergebenoe Bemegung ber Schau= fein aufzuzeidjnen uno biejes kann bas Snjtrument leidft jelbjt berrichten. In ber Ihat haben wir hier in ber Sdywere bes 23 affers eine Rraft, melche eben jo ben 3eiger eines 3ifferblattes in Beroegung zu icsen vermag, roie biejes burdh bas (servidht an einer Uhr gejdjeht.

Die $21 n z a h l$ bes Fallens bet beiben Sdjiffdyen, auf bie eine und bie andere Seite, wirb Durdh znei 3ahnräber bon gleidjem Durchmeffer gezählt, von benen bas eine bicht hinter bem andern befindlich ift. (Fig. 122.) Mit ঔig. 122. Dem (Sharnier $i$, meldhe8 fejt an e hängt, ifit ein Saken

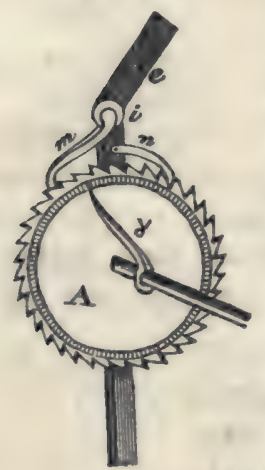
$m$ berbunder. Sintt mun bie Schaufel $a$, fo zieht bet

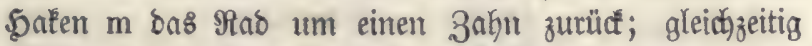

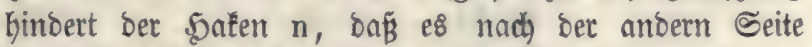

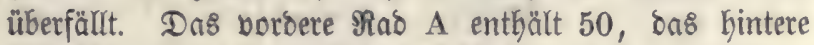

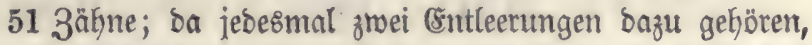

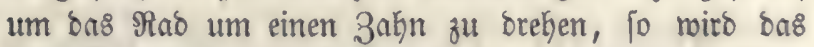

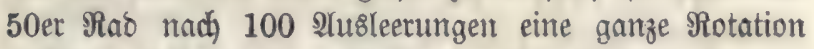

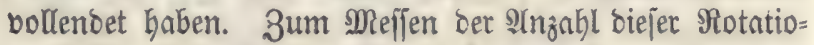
nen bes 50er Rabes bient das 51er Tad. Diejes ift feit mit ber Arce, weldje ben Zeiger $\boldsymbol{\gamma}$ trägt, unto bem

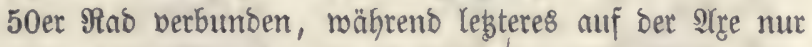
ganz lofe figt; on ein Safeen nun ftets einen $3 a$ hn

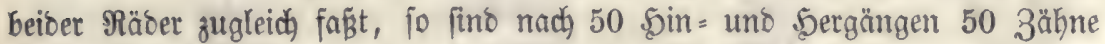

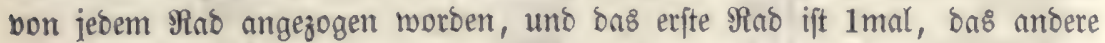
nur somal herumgegangen. Dies gift ber Zeiger $\gamma$ z̆ erfennen, indem er

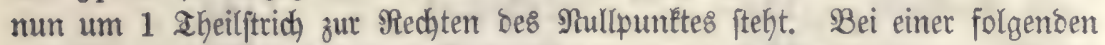
Rotation bes 50er Rabes rüatt er nieber um 1 Theilftridh fort 2 c. Somit fönnen aljo 5100 2Hušleerungen abgetejen merben. Sierin liegt in ber Ihat

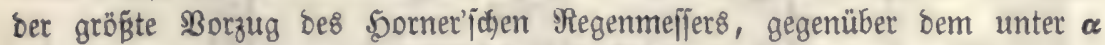

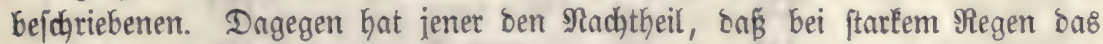

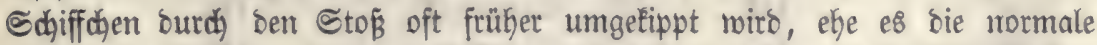

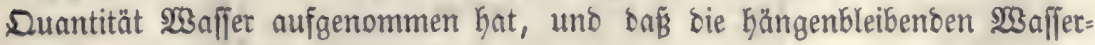
tropfen Unridatigleiten veranlaffen.

\section{e. Cinflüfe, weIde bie Alegenmenge beftimmen.}

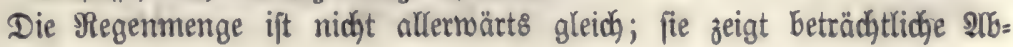




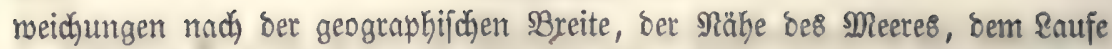

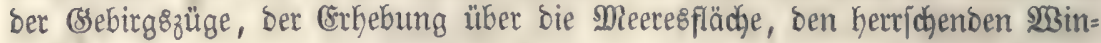

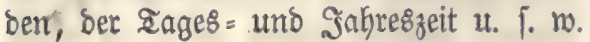

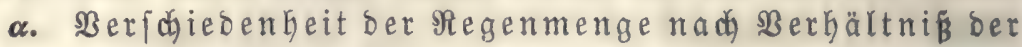
geographifden $B$ reite.

Sieft man von ben Störungen $a b$, meldhe bie übrigen, eben ange=

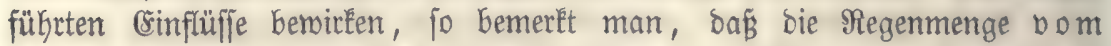

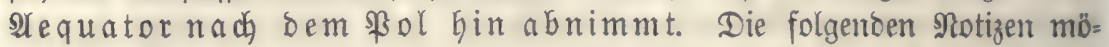
gen zum Belege bienen.

\begin{tabular}{|c|c|c|}
\hline reite & Drte & \\
\hline $12^{\circ} 02^{\prime}$ & Snjel Srenaba & 2844,9 \\
\hline 1856 & Bombay & 2350,0 \\
\hline 2309 & Sabanna & 2320,7 \\
\hline 2957 & Nem = Drleans & 1270,0 \\
\hline 3246 & (5Garlestoron & 1210,9 \\
\hline 3843 & \&iffabon : & 685,5 \\
\hline 4450 & Bordeaur & 650,0 \\
\hline 4846 & Stuttgart & 629,3 \\
\hline 5231 & Berlin & 530,1 \\
\hline 550 & (5opentyagen & 468,4 \\
\hline 5951. & 11pjala : & 392,4 \\
\hline
\end{tabular}

Regentage. Die Anzabl ber Regen, weldhe im Raufe eines Jahres

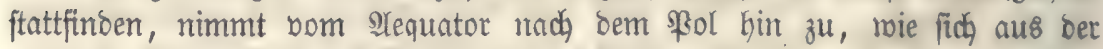
nachjtebenoen 3ufammenftellung von Schübler ergibt.

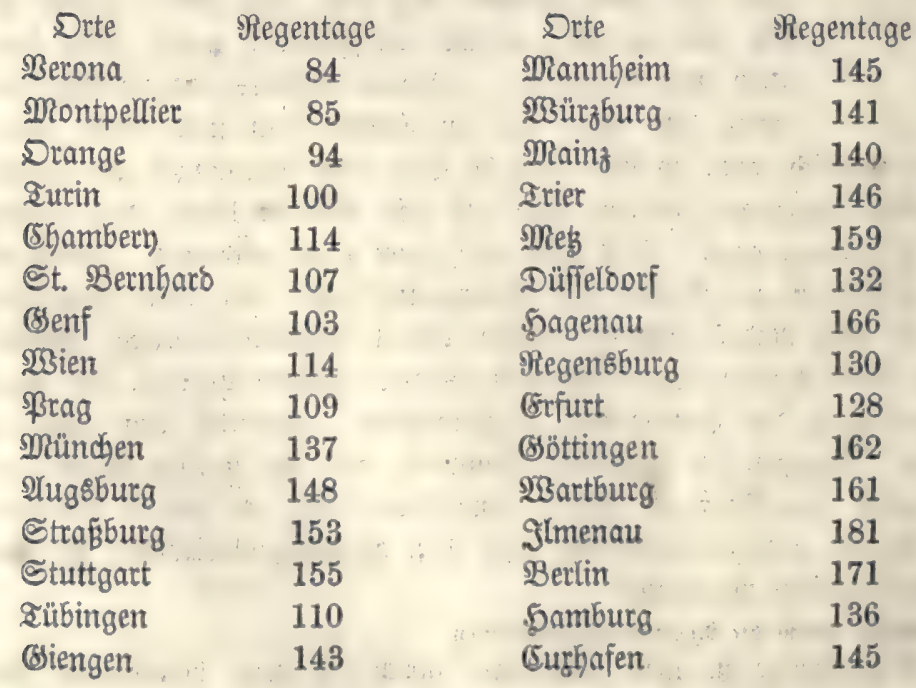




\begin{tabular}{|c|c|c|c|}
\hline Drte & Regentage & Drte & Negentg \\
\hline Gena .... & 178 & Rotterסam & 187 \\
\hline 3rũ & 164 & Drosftaut & 168 \\
\hline üntirchen & 157 & ßeter86urg & 181 \\
\hline
\end{tabular}

Didigfeit bes Regens. Da bie Regenmenge mit bet Breite $a b=$

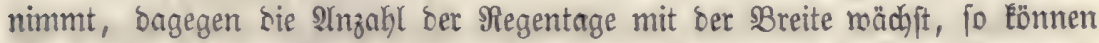

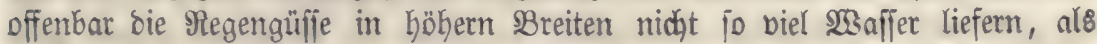

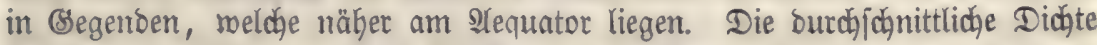

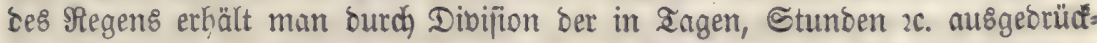

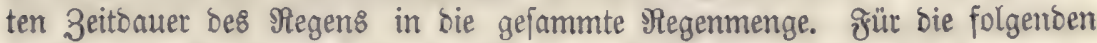
Drte ergibt fich bie aus bem jäfrliç)en Durdjphnitt ermittelte Didgte bes Re= gens, wenn man biejenige von ßetersburg $=1$ lest:

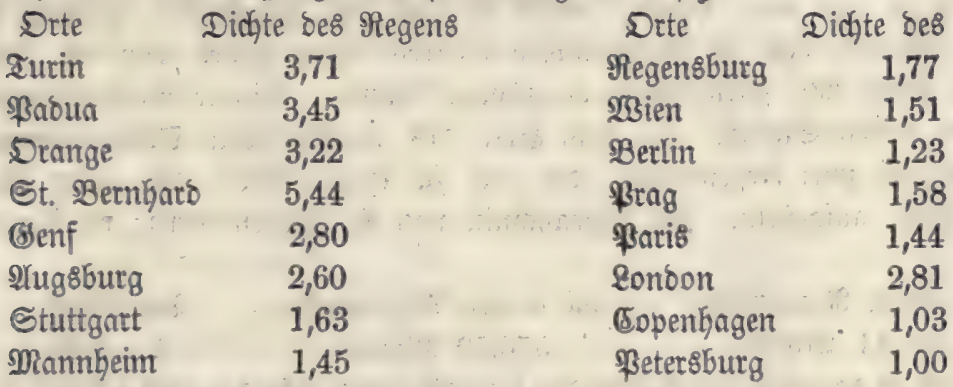

ק. Einflǘ ber Seenähe auf oie Regenmenge.

Drte, welche am Meer liegen, merben bon ben feuthten Geeminden

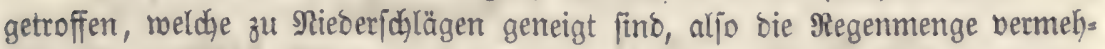
retr. Se weiter bie $\mathfrak{B i n}_{\text {be }}$ in bas $\mathbb{E} a n \delta$ borbringen, um jo troctener werben

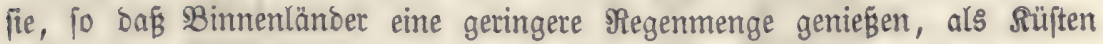

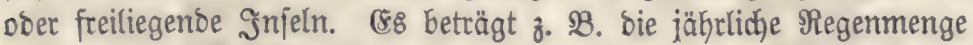

an ber $9 \mathfrak{B}$ eftểüte Englanos

$$
915,5 \text { Mineter }
$$

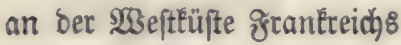

650,0 an ber Dittüfte Conglanos

686,7 Mrmeter

in Sdyweden

$$
\text { in } \begin{aligned}
& 476,6 \\
& \text { Ruk̆lanto }
\end{aligned}
$$

364,1

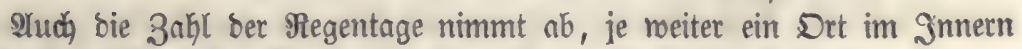

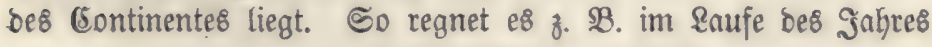

in \$eter\&burg $181 \mathrm{mal}$
"Mrosfau 168 " Rajan 90 "
" Jatubl 60 "

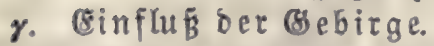

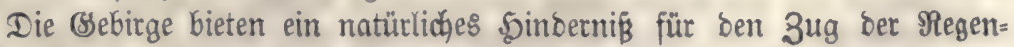
roolfen bar, fie laffen ignen 3eit, ihre freudjtigkeit abzujegen. Daber fommt 


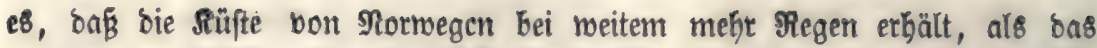
jenjeits ber sijölen liegente Edgroeben. Bergleidhen wir beifpielsmeife bie Regenmenge von Bergen uno Stodtholm.

\section{Bergen \\ 2250,4 Mmeter \\ Stodholm \\ 518,8 Mmeter}

Heberall, wo ein \&ano bon Bebirgen burdhidnnitten wito, finben fids oft ganz nake bei einanber Rocalitäten, an benen bie Regenmenge uno zroar

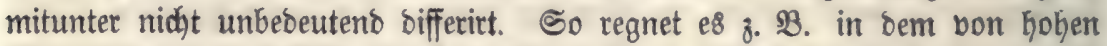

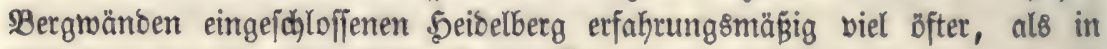
bem frei gelegenen Mannbeim.

\section{d. Einflǘ Der (Erhebung über bie Meeresfläde.}

Da e\& nur bann regnet, roenn bie \&uft mit శeudjtigleit gejättigt ift,

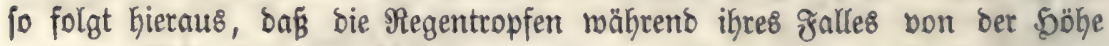
nach ber Tiefe fid fortwährend vergröß̈ern müffen. Directe Beobadjtungen

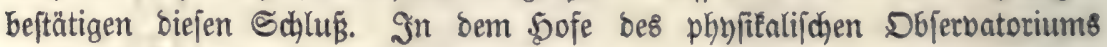

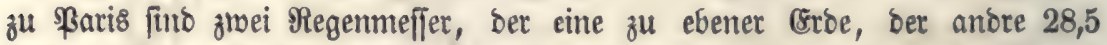
Meter höher, aufgeftellt. Im Durdhidgnitt von 22 Jahren betrug bie Fegens menge

im obern Regenmețer

507,41 Mmeter

im untern Regenmeffer

2̧etbåltnißß

576,79 Mmeter

$1: 1,36$

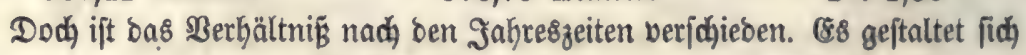
für ben obern

untern

\begin{tabular}{|c|c|c|c|c|}
\hline & 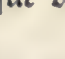 & \multicolumn{3}{|c|}{ 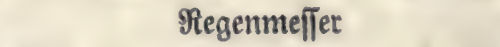 } \\
\hline im $\mathfrak{B B i n t e r}$ & $=$ & 1 & : & 1,006 \\
\hline " grtübling & $=$ & 1 & : & 1,004 \\
\hline "Sommet & $=$ & 1 & : & 1,016 \\
\hline$"$ Derbit & $=$ & 1 & : & 1,015 \\
\hline
\end{tabular}

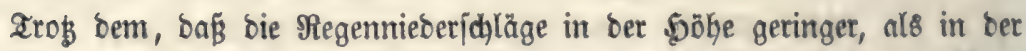

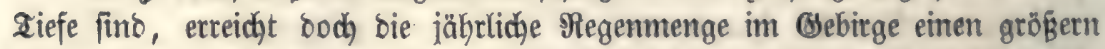
Betrag, als in ber Ebene. (8s fann bies blos baherrühren, weil es bort meht

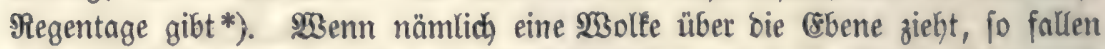

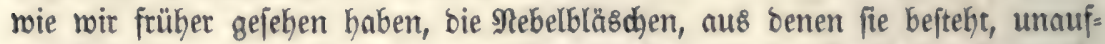

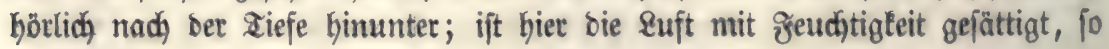

*) Dber weil hier ber Regen längere Beit anbält. Die Meterelogen follten niळht bles bie Iage notiten, an benen es regnet, fonbern zugleid bie Beitbauer bemerfen, währenb weldjer eళ̊ geregnet hat. In manden Bebirgen mit grober Regenmenge ift bie 3abl ber Regentage von ber in ber Ebene menig veridieben. IMan hat

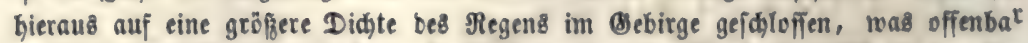

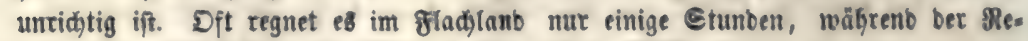
gen an bemielben Iage im Bebirge gar nidgt nadjläpt. 


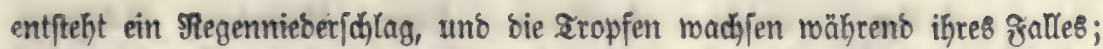
Gat aber bie \&uft in bet Siefe ben Ihaupunct nod nidht erreidat, fo lỏit fid

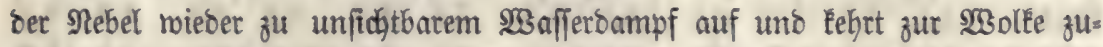
rüct, wo ber lestere fich bon neuem berbidhtet. Im Bebirge ift bie Iempera= tur niebriger, als in ber robene, bort finbet basి fallenbe গebelbläscthen bieje marmen, bom Ihaupunct entfernten Ruftidjidgten niḑt fo bäufig, al\& in bet

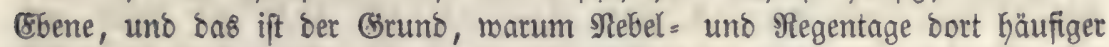
eintreffen, als bier. (88 mangelt an vergleichenden Notizen über bie 3abl ber

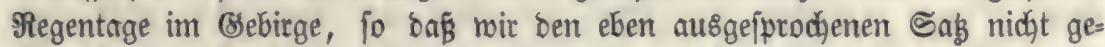

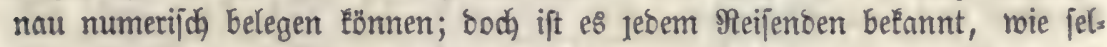

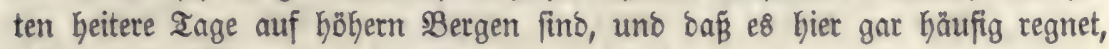
rähreno bie (Ebene blos bedectten Simmel bat.

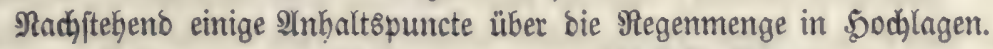

\begin{tabular}{|c|c|c|c|c|}
\hline Drte & ఏöhe & & Säbrliçe & Regenmenge \\
\hline \&egernjee & 730 & Deter & 1331 & Mmeter \\
\hline $\begin{array}{l}\text { St. Bernfard } \\
\text { Greubenitaot im }\end{array}$ & 2474 & $"$ & 1601 & $n$ \\
\hline Sdgwarzmalo & 700 & $"$ & 1545 & " \\
\hline & 256 & $n$ & 678 & " \\
\hline 233ürtemberg & $\left\{\begin{array}{l}430 \\
728\end{array}\right.$ & " & $\begin{array}{l}742 \\
977\end{array}$ & " \\
\hline
\end{tabular}

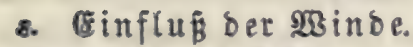

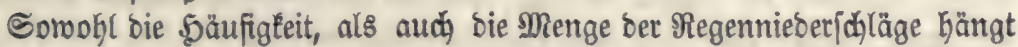

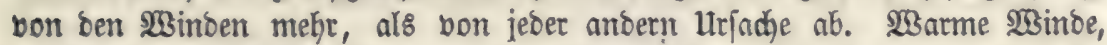
weldhe ifren \&auf über Meete ober grögere Seen genommen baben, fint be=

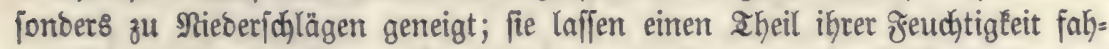

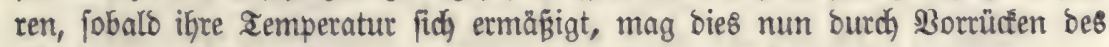

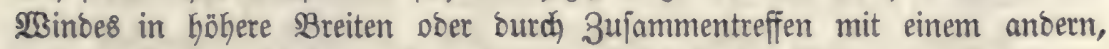

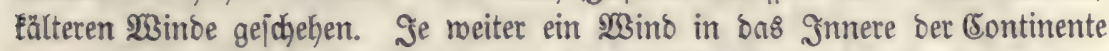

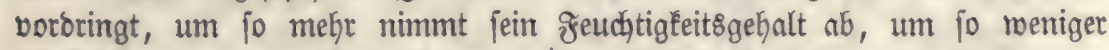

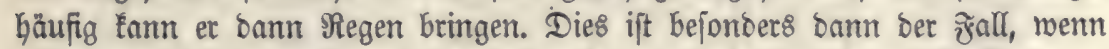
Det WBint höhere Bebirge pafirt hat, auf benen jein Behalt an 2 Bafferdampf

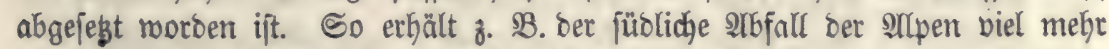
Regen von ben Sübminden, als ber nöroliche.

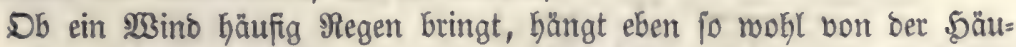

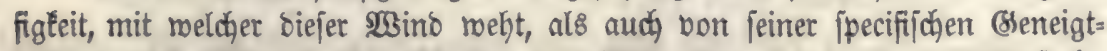
heit zu Rieberjळlägen ab. Die lestere erfährt man, menn man unterjucht,

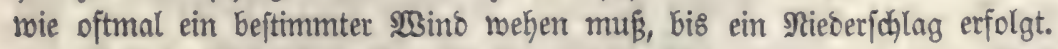

Die nadfftehende Iafel gibt für mehrere Drte unter a an, wie oft unter

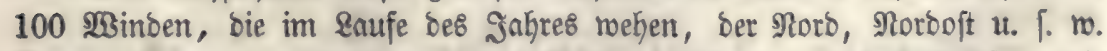
Fegen, Sdjnee 2c. bringen; in Der Spalte b bagegen ift aubgeworfen, wie

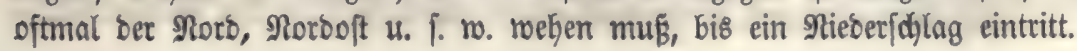




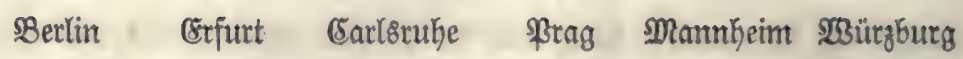

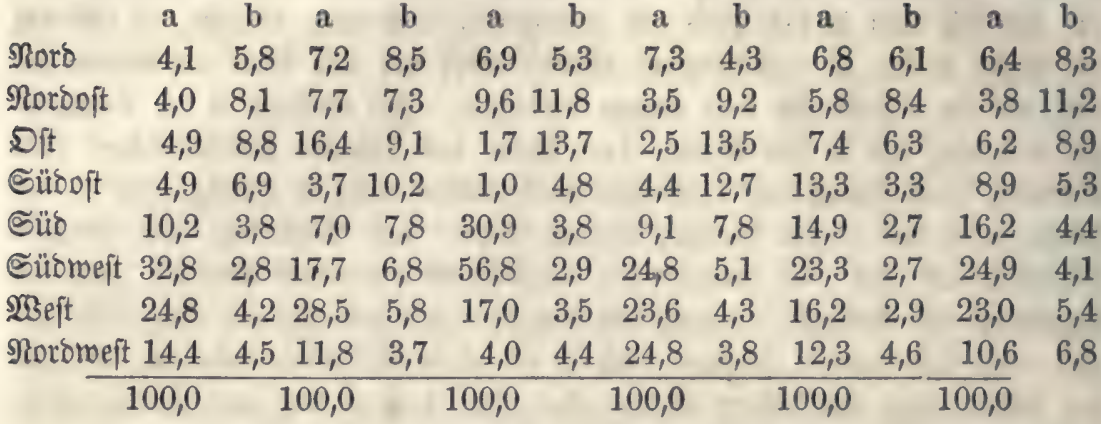

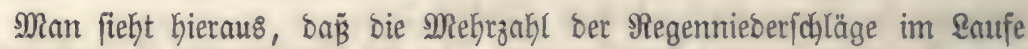

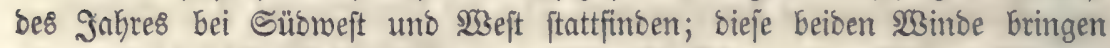

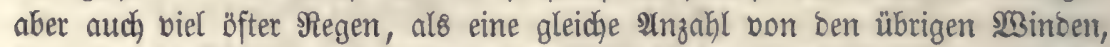
benn fie braudjen z. B. in Bertin mur 3 bis 4 nal (Spalte b) zu weben,

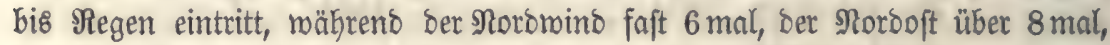
ber Dft beinake 9 mal zu wehen hat, ehe ein Nieberfolag erfolgt.

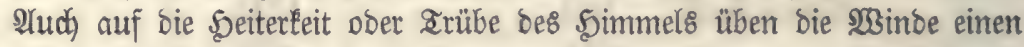
regelmäß̈igen Einflǘ aus. BBeobachtungen z̆ Ropentagen ergaben folgente Rejultate, mobei mieber in Spalte a ausgemorfen ift, wie oft bon 100 W3in= ben jeber Der 8 Sauptminbe heiteren, bemölften ober überzogenen Simmel bringt, währeno bie Spalte b zeigt, wie oft jeber ber genaunten 23 inbe we=

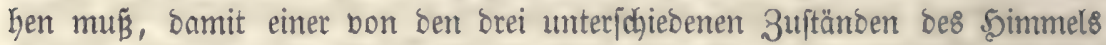
eintritt.

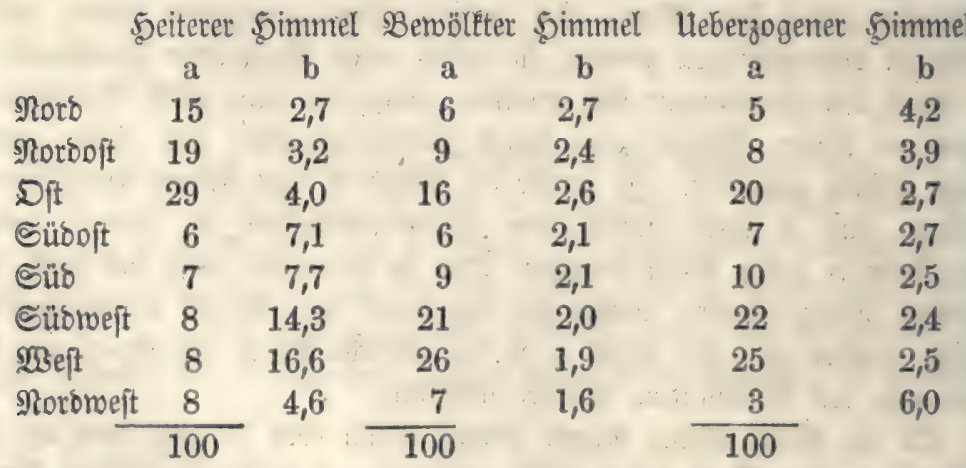

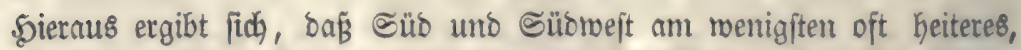

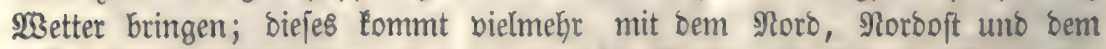

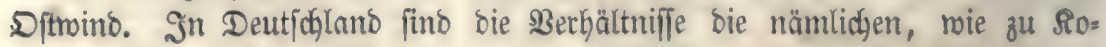
pentagen.

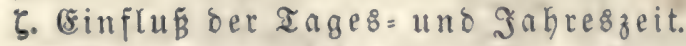

In Curopa regnet es burchidanittlich am Tage, in ben 2requatorialge: 
genben mehr bei Nadjt. So fand Boufingault zu șarmato im Safje 1837 bie Regenmenge

$\begin{array}{lcc}\text { im Monat } & \text { an } \text { Iage (Mmeter) in Ser Nadjt (Mmeter) } \\ \text { Detober } & 34 & 151 \\ \text { Nobember } & 18 & 208 \\ \text { December } & 2 & 159\end{array}$

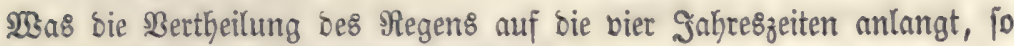

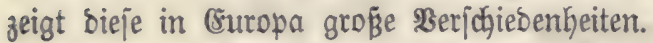

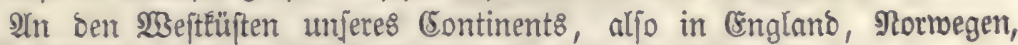

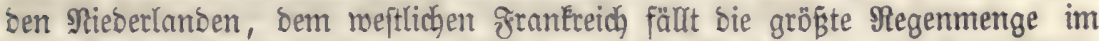
5erbft, mas rahbricheinlich baher rüfrt, reeil bas im ๔ommer erwärmte Meer feine Temperatur bis in ben 5erbft Finein bemahrt uno in biejer Jahreszeit

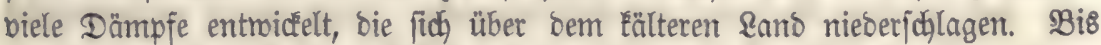

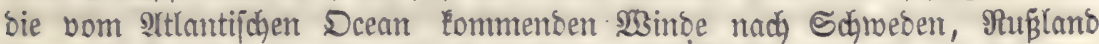
uno Deutichlano gelangen, find fie eines grofenen afeils ifrer Feudjtigkeit be= raubt. In ben jo eben genannten Rändern, forwie in Dänemark̂ fino Dagegen bie Sommerregen vorkerrfheno. Sm fïblichen Stalien uno frantreich ift bie

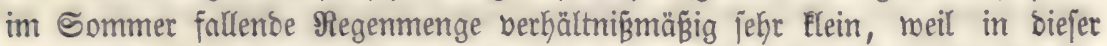

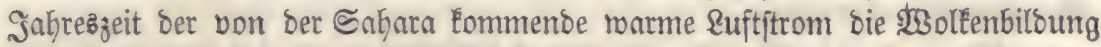
verfinbert; bagegen erreidjt in biejen \&änbetn bie Regenmenge bes Serbftes

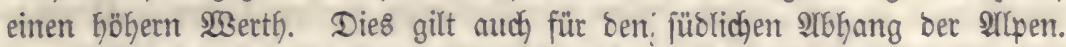

Die nadjftehende Tabelle gibt bie Zahlenverbältnifje für bie \$3ertbeilung

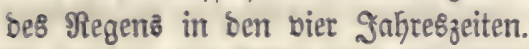

Regenmenge in Millimetern.

\begin{tabular}{|c|c|c|c|c|}
\hline عãnธet & WHinter & Irübling & Sommer & Serbit \\
\hline 23eptliches Bngland & 239,6 & 171,0 & 221,6 & 283,3 \\
\hline Deftliches Englanto & 166,5 & 145,0 & 171,1 & 204,1 \\
\hline 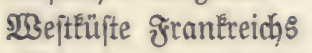 & 185,7 & 140,9 & 170,2 & 246,5 \\
\hline $\left.\begin{array}{c}\text { Sübliches granfreich) } \\
\text { uno Stalien }\end{array}\right\}$ & 195,2 & 194,2 & 133,2 & 291,7 \\
\hline 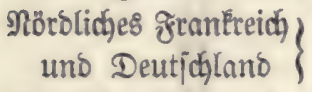 & 126,5 & 148,0 & 229,7 & \\
\hline $\begin{array}{l}\text { Scanbinabien } \\
\text { (ausidbL Rornegens) }\end{array}$ & 81.4 & 761 & & \\
\hline Ruglano & 40,3 & $\begin{array}{l}10,1 \\
59,9\end{array}$ & $\begin{array}{l}170,1 \\
166,7\end{array}$ & \\
\hline
\end{tabular}

SSie wir oben gejehen haben, regnet e8, unter fonft gleichen umftän=

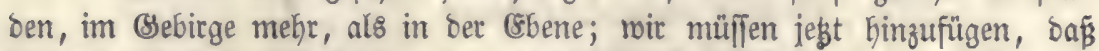
Der Heberidgus Gruptiädjlidy auf ben Sommer kommt.

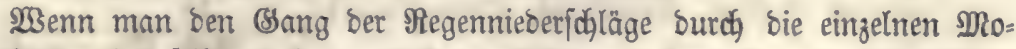
nate eirres, Doer jelbft mefrerer Safje verfolgt, fo bemertt man viel größ̈ere

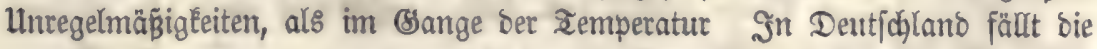
geringite Regenmenge an einigen Drten im Samuar, an anbern im December 


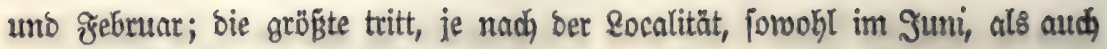
im Sult uno \$luguft ein.

Die 2 affermenge, meldhe bei einzelnen Regengüfifen fălut, überfteigt mandymal ben jäbrlidgen Durdj/dynitt um bas Bielfadje. So beobadjtete man zu Bombay (jäfrl. Regenmenge 2380 Mmeter) an einem Tage im Sabre 1819 einen $\Re$ Regenfall von 162 Mmetern; zu Brüffel fielen am 4. Suni 1839 in brei Stunden 160 Mmeter.

\section{Beitandtheile bę Meteorwafiers.}

Das Regen=, Sdjnee und Thaumaffer enthält nidat blos reines 23 afjer,

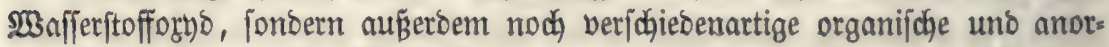
ganijobe Subitanzen, welche in ihm entweber gelöpt, ober blos fuppenoirt finb, und zum größ̈ten Theil aus ber Ruft ftammen. Dod) ift eళ wahridgeintid, bấ einige bon biejen Stoffen jơon in bem 2 baffer enthalten waren, aus be=

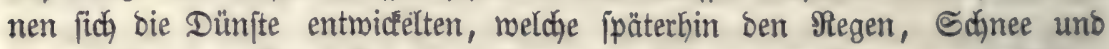

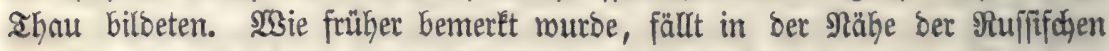
Salzjeen falziger Thau; es muß baher ein falzhaltiger Dunjt aus biejen Seen

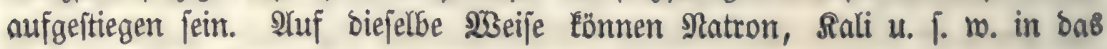
Meteorwaffer gelangen.

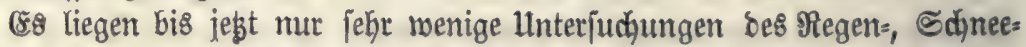
waffers u. \%. w. vor, audh haben bie IInalytifer bie berjojiebenen Mobifica=

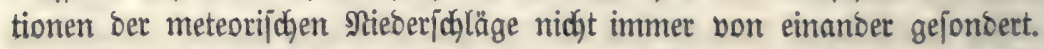

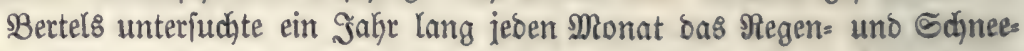
waffer auf jeinen Bsebalt an feften Beftandtheilen unb beredgnete bieraus uns

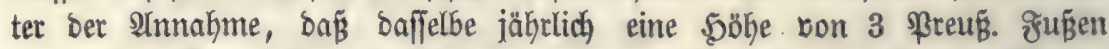
$=0,9417$ Meter bilbe, bie Bejamtmenge an fejten Stoffen für ben Mragoes

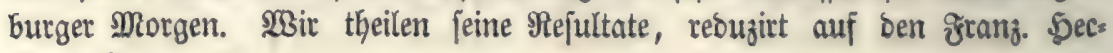
tare mit.

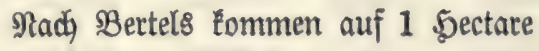

\begin{tabular}{|c|c|c|c|c|c|c|}
\hline soblenjaure & Salferoe & . & . & & 78 & silogramme \\
\hline " & Salterbe & . & . & & 51 & " \\
\hline Sochjalz & 然 & . & . & & 67 & " \\
\hline Syps & . & . & . & & 51 & $"$ \\
\hline (Eifenoysto & . & . & . & & 22 & $n$ \\
\hline 2launerbe & & . & . & & 21 & $"$ \\
\hline Riefelerbe & . & . & . & & 43 & " \\
\hline Drganijue, & Stiçitoff & entbaltenoe & siorper & & 75 & $"$ \\
\hline Sali, als to & blenjaure8 & bereçnet & .. & & 38 & $"$ \\
\hline Bertujt (Eok & lenj. $\mathfrak{A}$ & toniaf́, ఏoun & mแริ|äนเe) & & 19 & $"$ \\
\hline
\end{tabular}

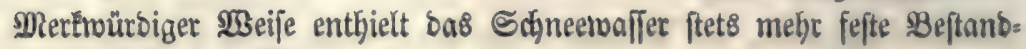
theile, als bas Pegentwaffer. 


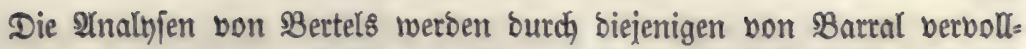

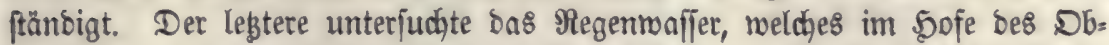
jervatoriums zu ßaris vom erften Suli 1851 bi\& zum 30. Juni 1852 gefalfen war. शady SBartal fommen auf 1 Sectare

\section{6,3 Iilogramme Salpeter ăure}

13,8 " $\quad$ 2tmmonial.

Det Stia̛fitoffgehalt beträgt

12,5 Rilogramme füt bie Salpeterjäure.

10,0 " "Das $\mathfrak{2}$ "

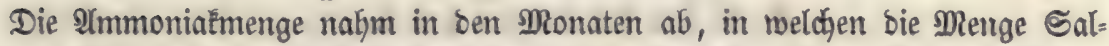

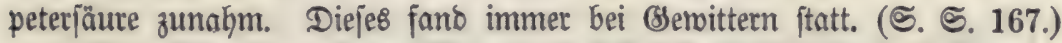

Die Mlenge bes Cblors betrug 11 Rilogramme. Diejes entipridjt 18,1 Silogrammen Sodjalz, aljo bebeuteno meniger, als Bertels gefunden bat.

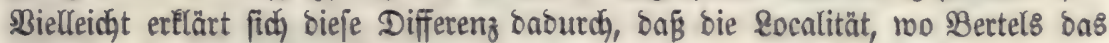

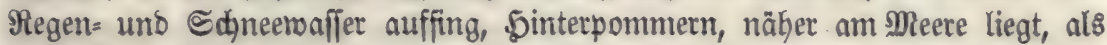

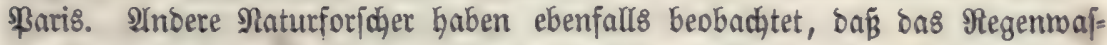
jer in Bregenden am Meere biel mehr Rodjjalz enthält, als im Binnenlanoe.

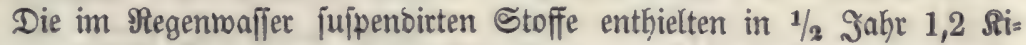

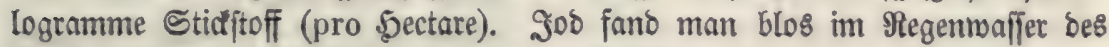
Suni, uno zroar 150 Milligramme pro \$ectare.

Dualitative 2 inalyjen, relche im Eaboratorium zu Biepen angeftellt rour= Den, haben auker ben vorgenannten Stoffen noch \$hosphorjäure, freie Soh= lenjäure, Ratron uno Mangan nachgetwiejen. 


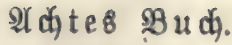

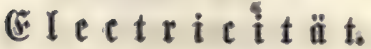

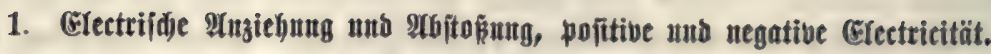

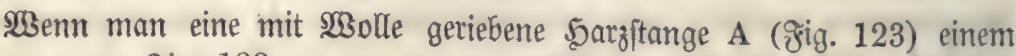
ஓig. 123.

5ollumbermarlftügetchen $a$, weldhes
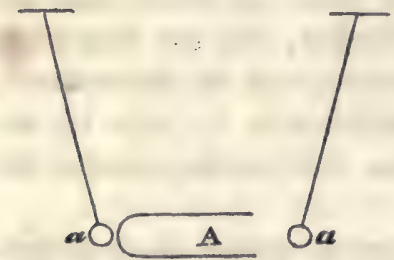
an einem Seibenfaben nufgebăngt ift, nähert, fo beobaditet man, baß̧ bas siugeldyen yon bem 5arz an= fangs angezogen, bann aber abge= ftogien wirt. Det nämlidue Borgang zeigt (id ), menn anftatt ber Sarz= eine (Slasftange genommen wirb.

sRringt man aber bie (3lasftange an bie Stelle ber Şarzitange, nachbem bas sügelchen bereits von biejer abgejtogen worben ift, jo roiro man finden, Daß̧

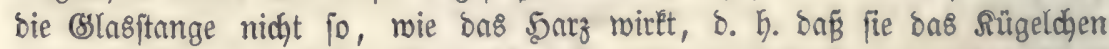

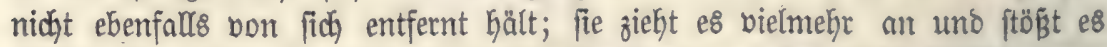
mieber $a b$, gerabe jo, wie wenn bie Sarzftange borker nicht thätig geme= fen wäre.

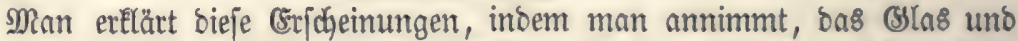
Sarz enthielten eine feine, unwägbare Materie, bie (Electricität, weldhe fich in zroei veriddiebenen 3uftänoen, bie al\& "pofitio" und "negativ" bezeidanet wer= Den, ăußern E⿱艹

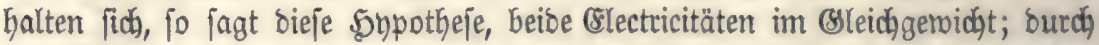
bas Reiben werben fie von einander getrennt; beim Sarze tritt bie negatibe, beim BSIaje bie pofitive an bie Dberfläble ber Stange. Man nimmt nun meiter an, Daß̈ Sörper, welḑ̧e mit ungleidjnamigen (šlectricitäten behaftet fino, einanoer anziehen, währent bie gleidjartigen (slectricitäten einanber abftoß̈en. SBirb Die mit freier negatiber Electricität berjehene \$arzftnnge bem 5ollun=

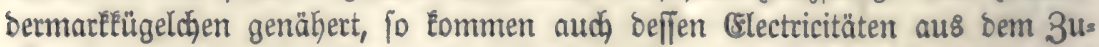

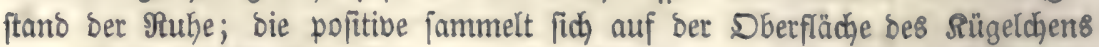
an; es wiro bep̧alb baffelbe von ber Sarzftange angezogen; nachoem bie sBerührung erfolgt ift, gleidht fich bie pofitioe Blectricität Des Sollundermarks

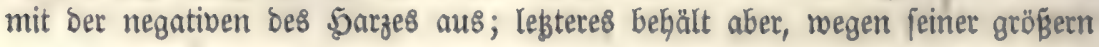




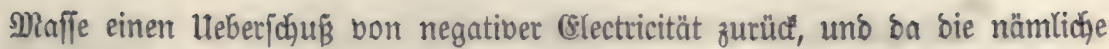
Slectricität jest im sollunbermarffügeldyen frei vormaltet, fo miro biejes ab=

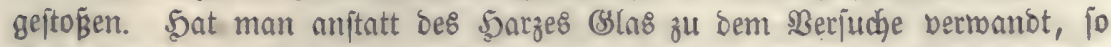
fino blos bie \&lectricitäten, relche nach eintanber auftreten, bie entgegentge= jegten bon ben fo eben angenommenen. Wito ongegen bie sslasftange bem Rügelḑen erft Dann genähert, nachbem e\& bereits bon ber Sarzftange abge= ftoß̌en morben ift, io wirb es von jener angezogen, benn bas \& sas enţält pofitive, bas Rügeldyen negative Electricität.

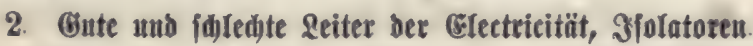

WBiro ein Sollunbermarkëügeldyen an einem Metalloraht, anftatt wie vorhin an einem ๔eibenfaben aufgehängt, uno nähert man nun bent Rüget=

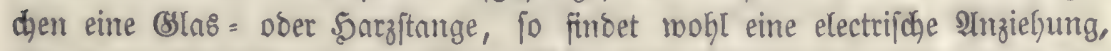

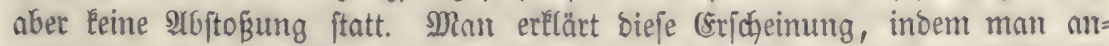
nimmt, bas Metall bejį̧e bie (sigentidaft, bie frei geroorbene Electricität bes

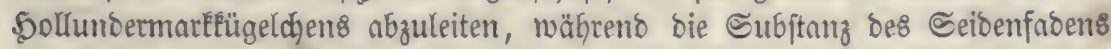

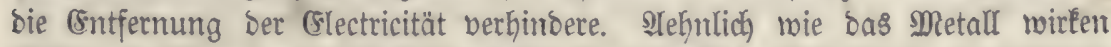

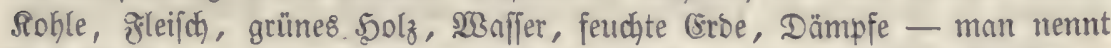

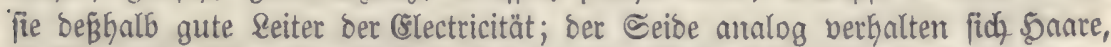

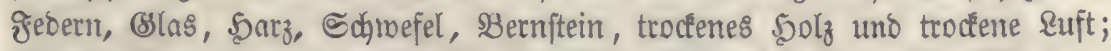

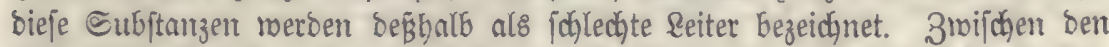
guten uto fohlechten \&eitern jtehen bie Sarbleiter; zu biejen gefjören u. a.

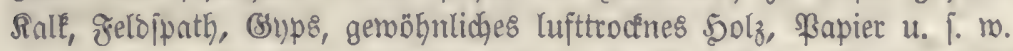

Sit ein electrijo gemorbener Reiter (z. B. (sijen) mit einem Nidjtleiter

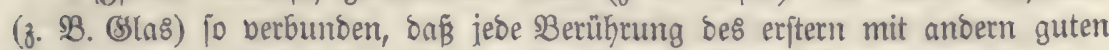
\&eitern unterbrodjen miro, jo berfindert Ser Nichtleiter bas (sntroeicyen ber (Electricität. (St roird, wem er zu biejem 3roede bient, Sjolator genarnt.

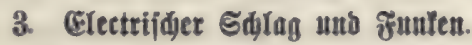

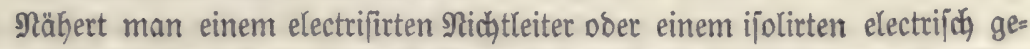
worbenen \&eiter ben Snöchel eines Fingers ber Samb, jo füflt man ein @te= dhen in bemjelben, weldjes zu einem förmlichen ๔chlnge merben kann, wenn

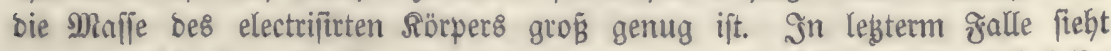
man zugleidh einen ช̛unkeen überjpringen; in ber Dunfelbeit laffen fich felbjt

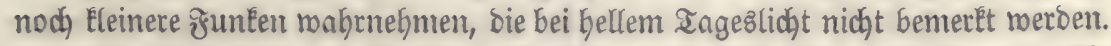

Durch) bas eben befdriebene Berfahren ober burdh unmittelbare Berüb= rung Fann einem electrifitrten Sörper nach) und nad) alle (slectricität entzogen merben. গ̉ährento biejelbe aber bei guten Reitern bon einem einzigen \$uncte

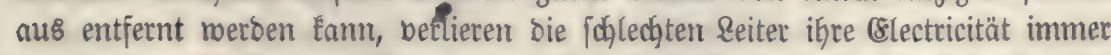
nur an ber Stelle, roo fie zu bem ableitenton Begenjtano überjpringt; um

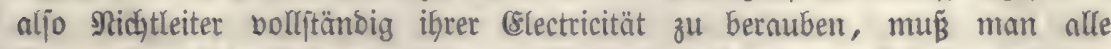
Buncte ibrer Dberfläbje mit \&eiten in \$erbinoung bringen, o. B. eine getiebene

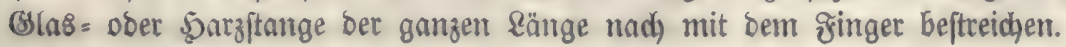




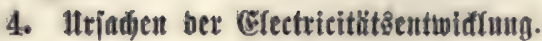

Die Electricität Eann in ben Sörpetn burdh mannigfacje llijachen er= regt werben; bon biefen Gaben für uns nur bie Reibung, bie Berbampfung uno bie Berbrenumg Intereffe.

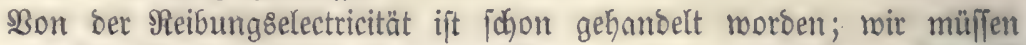

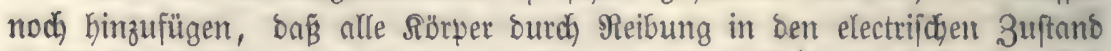

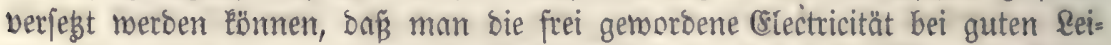
tern aber nur Dann ranfrnimmt, wern fie burd SFolatoren geidjübt fino. -

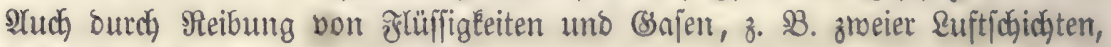
fann Electricität entroicfelt werden.

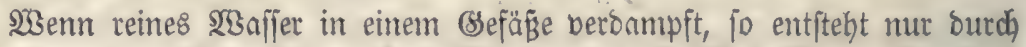

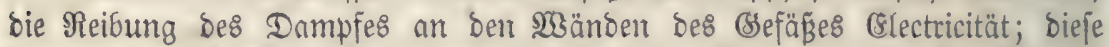
tritt um fo reichlicher auf, je enger bie Deffunng ift, aus melcher bie Dämpfe

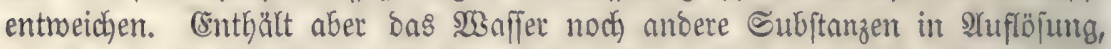
bon benen es fich bei ber Berbamffung trennt, fo mirb. fojon allein burch

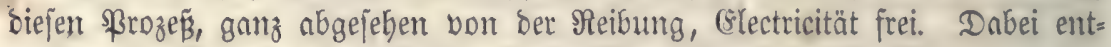

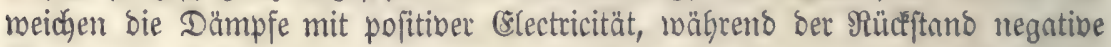
(slectricität zeigt.

Bei allen djemijchen Berbintoungen uno Berjebungen tritt eine (5ntwict=

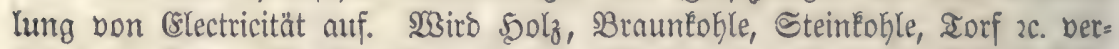
brannt, fo bilden fid) Mafferbampf und Sohlenfäure, beibe mit pofitiver (Slec= tricität; bie झ्ञfche, forwie bie nicht berbramte Rohle ericheinen mit negativer Electricität belaben.

\section{Cêfetricität ber शిtmoiphäre.}

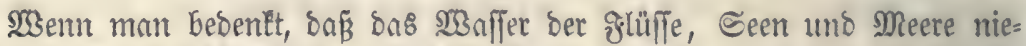
mals rein ift, fonbern immer nufgelöpte ๔alze entbärt, wemn man meiter er= rägt, weldje ungeheute Mengen von Brennftoff nuf ber (8rbe conjumirt

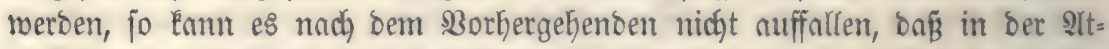
mofpgäre zu allen Zeiten freie Electricität gefundent miro. Dieje ift bei நeites rem Simmel ftet8 pofitio.

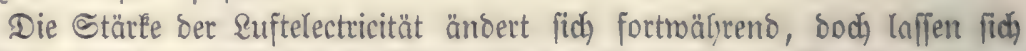

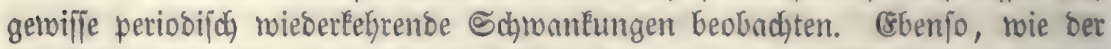
Wafferbampfgehalt, zeigt bie electrifhe Spanmung zmei Marima uno groei Minima. Die erjteren treten einige Stunben nad) bem Somnen= 2ufgartg uno Ulntergang, bie legtern ebent fo biel vor biejen Geiben Momenten ein.

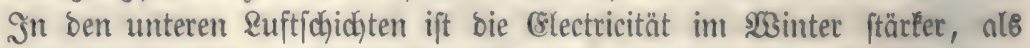
im Sommer; bie obern \&uftidjichten zeigen bas entgegengefeste ßerbaltent.

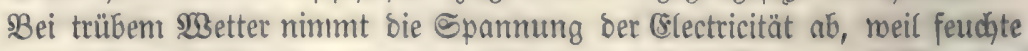

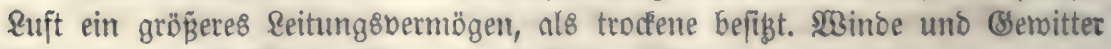
ftören ben regelmäß̈igen Bsang Der Euftelectricität.

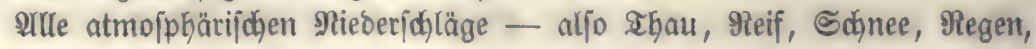


vorgüglich aber ber Sagel - find electrijch, besgleichen ber sebel und bie

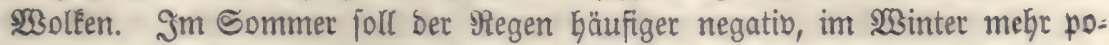
fitio electrijof fein. Der Nebel und bie 230 oleen entfyalten faft immer pofitive EStectricität.

\section{Getwitter.}

\section{a. Urfachen Der Gewitter.}

Daß̧ bie beim Bsemitter nuftretenten (Eridyeinungen, wie sBlis, Donner,

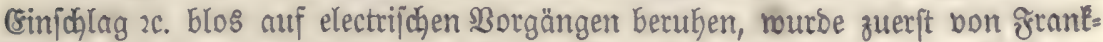
lin in überzeugenber $23 e i j e$ bargethan. (5r ließ im Sahr 1752 zu \$hilabel= phia einen gewöhnlichen Dradłen, beffen Sdhnur bon Sanf und angenäfit, aljo leitend, am untern (Enbe aber bon Seibe (ifolirend) war, aufiteigen. Nad, = bem eine Bemittermolfe in das Bereid) bes Dradjen gelommen war, erhielt

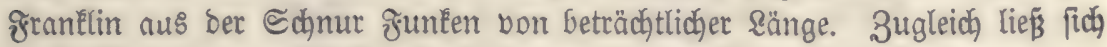
ein Sniftern ḩöten, ähnlich bemjenigen, weldges man bernimmt, wenn man

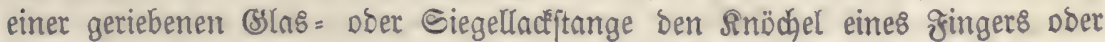
Fonf̣t einen Reiter nähert.

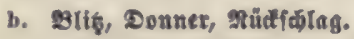

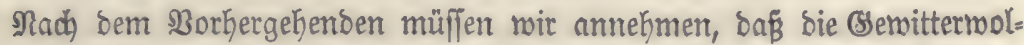
ten viele freie Electricität enthalten. Dieje miro aber auf bie Electricität ber=

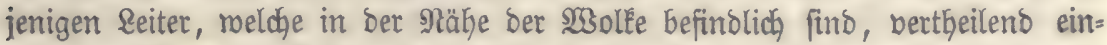

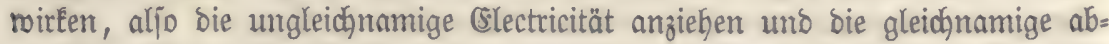

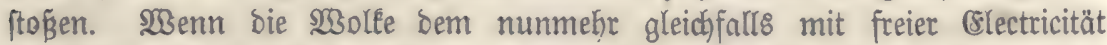
bebafteten Sörper fich Gimreidyeno genäbert hat, fo vereinigen fid beibe Glec=

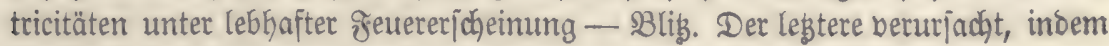
er bie \&uft erjoyüttert, ben Donrrer.

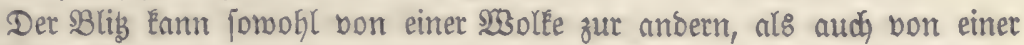

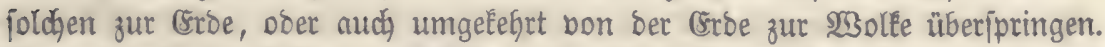

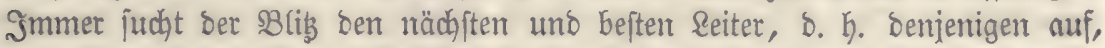

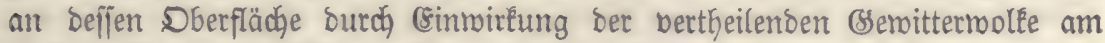
meiften Electricität fich angejammelt bat. Sirchen, hobe grüne SBäume wer=

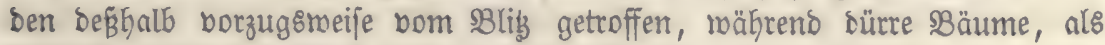
Nichtleiter, von bemjelben mehr berjchont bleiben.

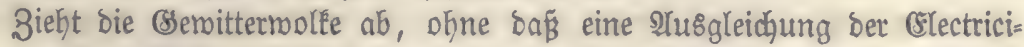

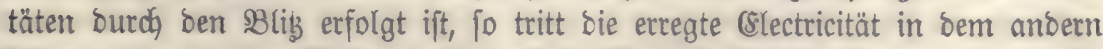

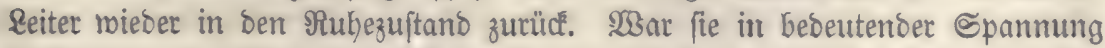
borbanoen, fo exfolgt auf biejem \&eiter eine wahynebmbare Grichütterung, bie

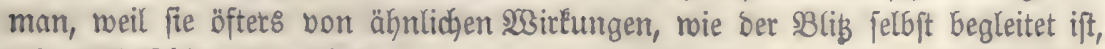

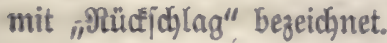

\section{c. Oeograpbifide Berbreltung ber Eewitter.}

श्ञm Gäufigften treten bie Getwitter in ben tropijd)en Bsegenden, nament. 


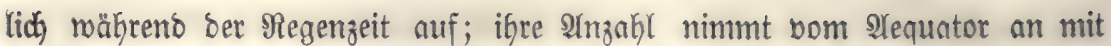
ber wachjenten Breite, miemohl in Éeinem regelmäß̈̈gen Berbältmiffe, ab. In einem Sahr ereignen fich burch /chnittlid) (Semitter

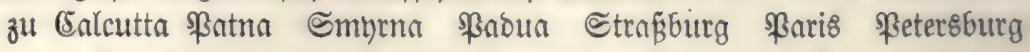
$\begin{array}{lllllll}60 & 53 & 19 & 17,5 & 17 & 13,8 & 9,2\end{array}$

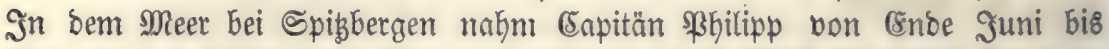

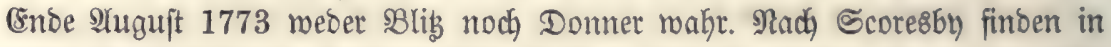

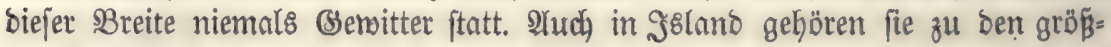
ten Seltenheiten.

In einem uno Demfelben Drte bleibt bie 2 (nzahl ber BSemitter zraar

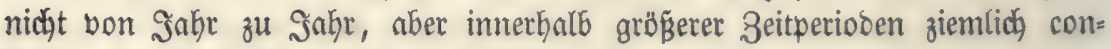
ftant. So beobachtete man zu ßaris

von 1785 bis 1805 Durchichnittlich jährtich 12,2 Bervitter

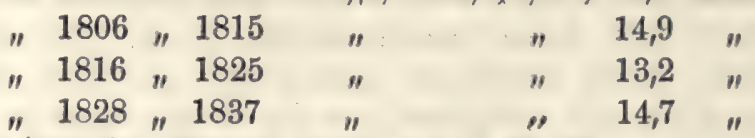

Die jäbrlichen Ertreme gingen von 6 bis 22 .

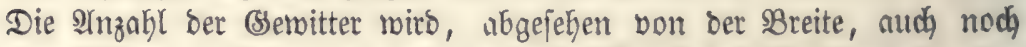

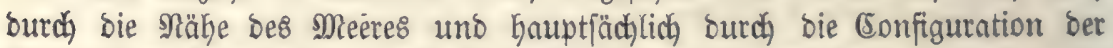
Bobenoberflädhe beftimmt. Bröfsere Berge halten bie (Semitter nuf, ober zer=

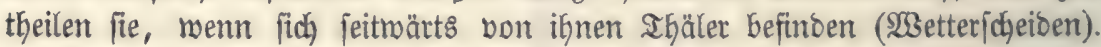

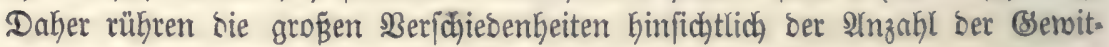
tertage in einem und bemfelben sanbe. So baben z. $\mathbb{B}$.

\&üneburg Berlin Erfurt Mannbeim 21ug86urg Mündyen 2 ß3ien
20,2
$17,2 \quad 14,1$
20,8
22,4
22,7
16,0

BSmitter.

In Deutfoland fällt die Mehrzahl ber Bemitter in ben Sommer. Die Bertheilung auf bie bier Sahreszeiten brücten bie folgenten 3ahlen im groß̧en Durd,jobnitt für viele socalitäten annäberno aus. Son 100 (Semittern fom= men auf

$\begin{array}{lr}\text { Den } 2 \text { Binter } & 1,9 \\ \text { Den ØrüG)ling } & 22,4 \\ \text { Den Sommer } & 67,7 \\ \text { Den நerbft } & 8,0\end{array}$

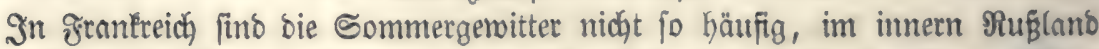

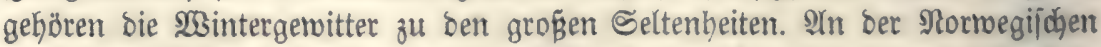

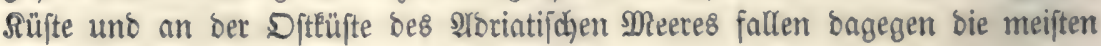
Bemitter in ben $\mathfrak{M}_{3}$ inter.

In ben Altpen foll bie $3 \mathfrak{n}$ hl ber Gemitter mit ber Crhebung über bie Meeresfläche zunehmen. Sn Dell \$odhbergen geht ber Serwitterregen, bejonbers in \$ुerbft, oft in Schnee über. 
Neuntes Bud

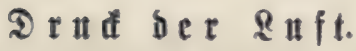

\section{Edfwere ber Ruft.}

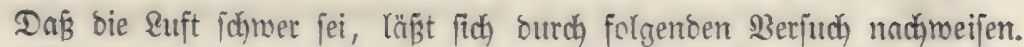
Man fülle eine BSIn\&rögre bon etma 82 (Eentimetern Eänge, weldhe an eintem

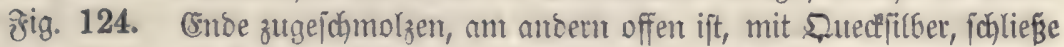

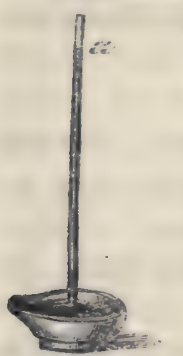
bie Deffnung mit bem Finger, Drehe bie Röhre um uno taudhe

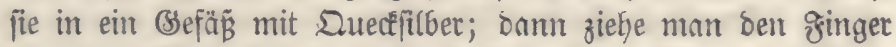

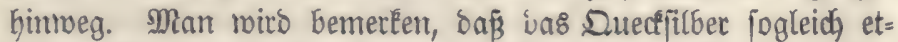
må fältt, ohne bis zu dent Spiegel bes Dutecfiftbers im Bse=

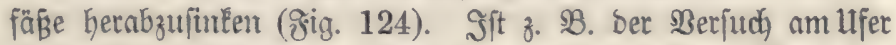
bes Meeres angeftellt worben, î bält bas Duedfitber eine 5ö̆je bon ungefähr 76 (Eentimetern (760 Mmetern) ein.

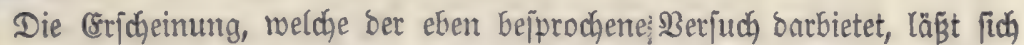
mur burdh bie Edjmere ber \&uft erÉ(ären. Die legstere laftet utämlid) auf bem

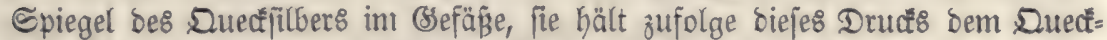

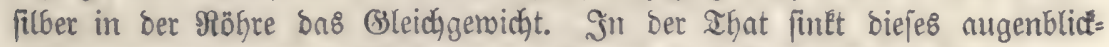

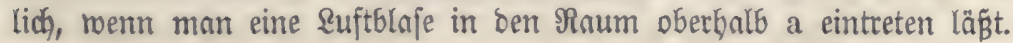

\section{Dฉดื Barometer.}

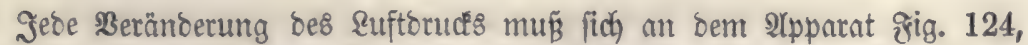

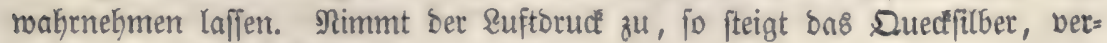

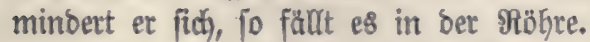

3u meteorologijachen Beobadhtungen bienent bie jog. Barometer, weldye nid)ts anders, als Modificationen bes §nftrumentes §ig. 124 fint. Man unterjdyeibet Sefäß̈barometer uno Seberbarometer. 


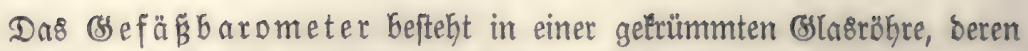

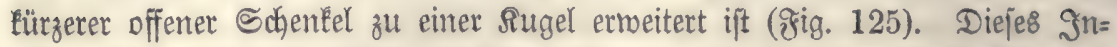
Fig. 125. Ftrument taugt inbeffen nicht fu gariz gennuen BBeobadjtungen,

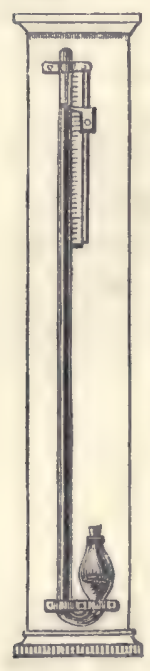

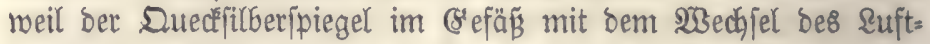
bructé feine Söhe änoert. Fällt nämlid bas Queçfilber in ber

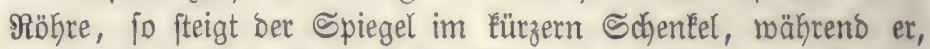

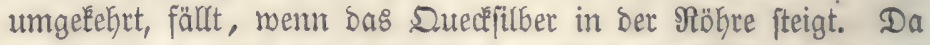

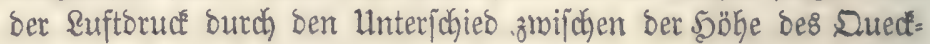
filbers in beiden Sdjenkełn gemeffen mirb, fo erhält man aljo immer einen grejler, wenn ber Rullpunct ber Scala nicht genau mit bem Spiegel bes Suedijtlbers im Bsefäfze übereinftimmt. Die Größ̨e biejes frehlers vermindert fich aber in bem Maß̈e, als

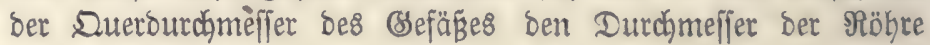
übertrifft.

3u ganz genaten $\mathfrak{B}$ eobadytungen, wie fie insbefonbere für Garometrifhe Şöhenmeflungen nöthig find, bermenbet man bas நeberbarometer (ひig. 126). (\&\& unter/deibet fich von bem be= fäß̈barometer baburch, baß̃ ber kürzere Schenkel gleiche 233 eite mit bem längeren befiłt.

gig. 126.

Die Söhe Der Quedfitlberjäule fann bei bem Seberbarometer auf verjchiedene $23 e i j e$ gemefjen merben, je nachoem bie Scala ber= foriebbar ober feft ift.

Sm exftern Falle ftellt man ben sullpunct ber Scaln in eine Sinie mit Dem Nibeau bes auecffitbers im Kurzern Sdjentel uno lieft

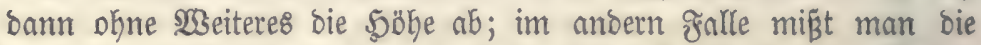
Söhe ber beiben Spiegel uno jubtrahirt die gefundenen (Bröß̈en. Dieje Regel gilt aber nur bann, wem ber Rullpunct ber Scala un-

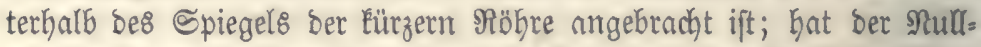
punct, wie bei vielen Barometern biejer SYrt, feine Stelle zmijchen

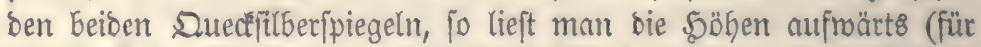

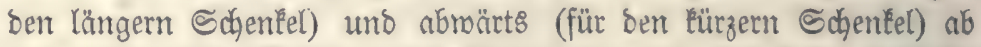

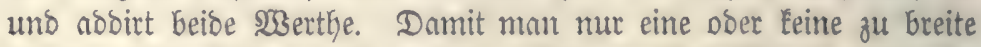
Scala nöthig Gabe, gibt man bem längern Echentel eine sBiegung in ber Mitte, wie sig. 126 zeigt. (SBarometer mit ber/dhiebbarer (Slastöhre find nicht zu empfehlen.)

Der beobachtete sBarometerfand bebarf einer Correctur megent bes Cin=

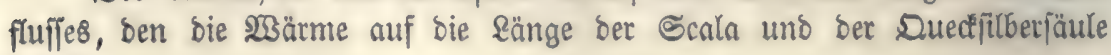
aนธีนีbt.

Da bie Scala mit zunehmenber Temperatur fid ausbehnt, fo miro fie bie \&ănge ber Duediflberfäule bei böheren Zempernturen geringer angeben al\& bei niebrigern gemperaturin. IIm übereinftimmenoe 2Tngaben zu exhalten, 
briict man bie Ecalenlänge für eine beftimmte Iemperatur nuళ, uno ba ber normale $\mathfrak{W e t t h}$ bes neuftanzö|ij legen wollen, nur für bie Iemperatur von $0^{0}$ gilt, fo rebuziren mir bie Eänge ber Scaln auf bie Temperatur bon $0^{\circ}$.

Gerob̋hnlich ift bie Ccala ber Barometer von Meffing angefertigt; biefes Metall befut fī für $1^{\circ} \mathrm{C}$. um $\frac{1}{54000}$ feiner \&änge aus; eine \&änge pon 54000 Mag̈einkeiten (8. 28. Mmetern) wiro beshalb bei ber Iemperatut von $t^{0}$ gleid) $54000+t$ Mañeinbeiten jein. Sit $\beta$ ber Fei oer Zemperntur $t^{0}$ mit= telft einter meffingenen Ecala gemeffene SBaconteterftano, fo piro er fich für bie aemperatur voll $0^{0}$ in $\beta^{\prime}$ tmänbern und biejen findet man nadh ber \$roportion

$$
\begin{aligned}
54000: 54000+t & =\beta: \beta^{\prime} ; \text { bierauв } \\
\beta^{\prime} & =\frac{54000+t}{54000} \boldsymbol{\beta}
\end{aligned}
$$

Ift bie ๔cala nuf Łns (Blas ber 2 Rarometerröhre eingeäbst, fo Eann bie

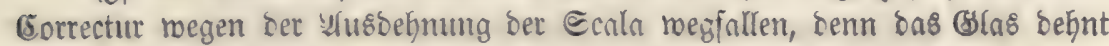
fich) für $1^{\circ} \mathrm{C}$. nur um $\frac{1}{116100}$ feiner \&änge aus.

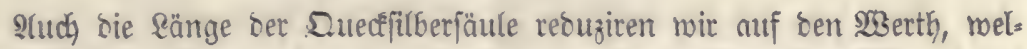
dhen fie bei ber Temperatur bon $0^{0}$ Gaben würbe. Das Quedfiflber behnt (id) für $1^{\circ} \mathrm{C}$. um $\frac{1}{5550}$ feiner \&änge nus; eine Quedfitberfäule von 5550

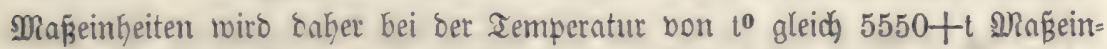
beiten getworben jein; ift $\boldsymbol{\beta}$ wieder ber beobachtrte Barometerftano, fo findet man ben für sie Temperatur $0^{\circ}$ geltenten butch die Proportion

$$
\begin{aligned}
5550+t: 5550 & =\boldsymbol{\beta}: \boldsymbol{\beta}^{\prime}, \text { bierauษ } \\
\boldsymbol{\beta}^{\prime} & =\frac{5550}{5550+\mathrm{t}} \boldsymbol{\beta}
\end{aligned}
$$

\section{Mejurtate ber Beobnditungen aut Barometer.}

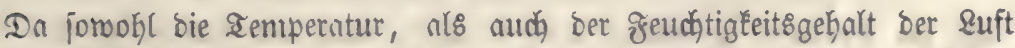
fich fortmährend ändert, fo foum bns sBarometer nicht immer ben nämlichen

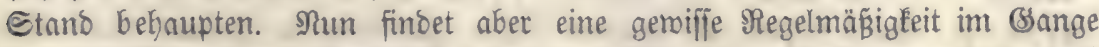

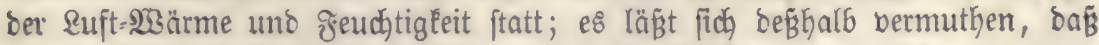

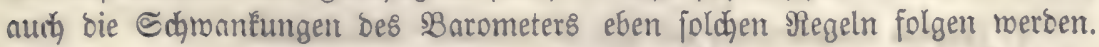

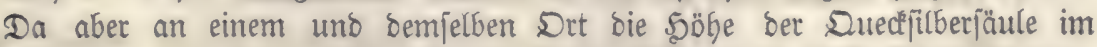
Barometer um einen biel geringern Betrag fich ändert, als bei bem Ihermo= meter, fo mús man eine grö̈̈ere 2 Inzahl bon barometrifajen Beobadjtungen 
anftellen, um in ben erbaltenen Mittelwerthen bie regelmäsigen Sorbmantungen gegenüber ben unregelmäßigen beutlich herbortreten zu Inffen.

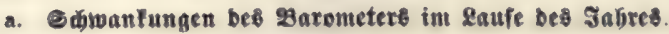

Die Beobadbtung Gat ergeben, baß̈ ber Barometerftano innerbalb 24 Stumben zmeimal einen höd)ften uno zmeimal eimen nieorigften 23 erth erreicht.

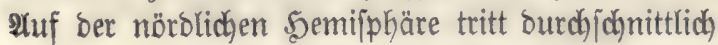

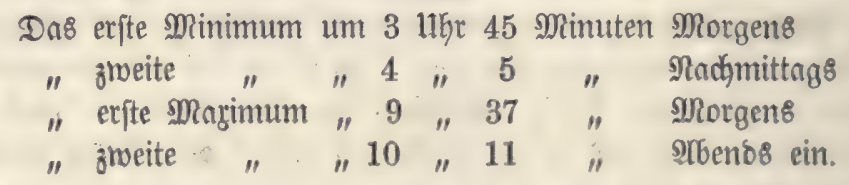

Dies find bie Mittelwerthe; berfolgt man ben 3 nncometerftand burd bie

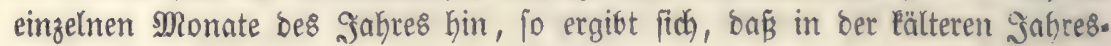
zeit bas erfte Minimum uno bas erfte Marimum etwas päter, bas zrweite Minimum uno bas żbeite Marimum etroas früher ftattfinoen, als in oen rärmeren Monaten.

Die (8rößze, um weldye bie Sdhwantungen Des Barometers fid betwe= gen, nennt man ifre Amplitube. Dieje nimmt im Sommer einen Göhern

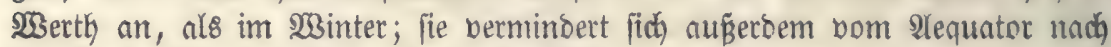

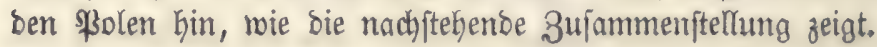

$\begin{array}{cccccc}\text { Drte } & \text { Sima } & \text { Eairo } & \text { Mailano } & \text { Æraneffurt a/M. } & \text { Stbo } \\ \text { Breite } & 12^{\circ} 03^{\prime} & 30^{\circ} 02^{\prime} & 45^{\circ} 28^{\prime} & 50^{\circ} 08^{\prime} & 60^{\circ} 27^{\prime}\end{array}$

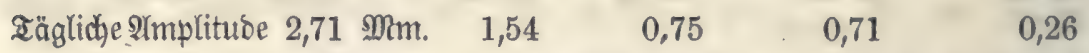

In grö̈Berer Brthebung über bie Meeresfläche veridymintet bas zmeite Minimum uno bas erite Marimum, fo baß̈ hier nur ein Minimum uno ein Marimum im Saufe von 24 Stunben eintritt. Shud) bie 2 (mplitube ber täg= lichen Schmantung ift auf hökern Bergen geringer, als an tiefer gelegenen

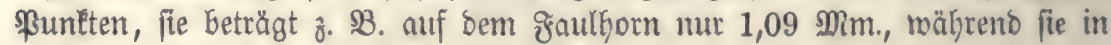
3ürich $=1,56 \mathfrak{M m}$. ift.

\section{b. Mtonatidie Edwantungen.}

Die 2lmplitube ber monatlidgen Edfmantungen ift im SMinter größ̈er, als im Sommer, fie nimmt bom शlequator nady den \$olen Gin zu. Diefelbe

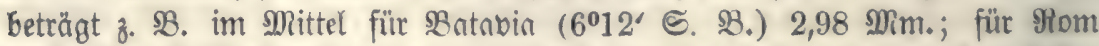

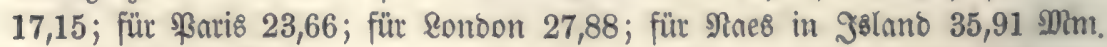

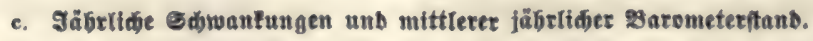

Berfolgt man bns Barometer burdh ben Rauf eines ganzen Sabres, io

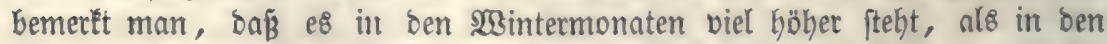
Sommermonaten. In Den höhern Breiten, auferbalb ber Iropen, zeigt ber 
Barometerftant zmei Marima, int Samuar ober Februar uno September ober Detoker, bon benen aber bns erftere biel jtärfer ausgeprägt ijt, als bas lebtere;

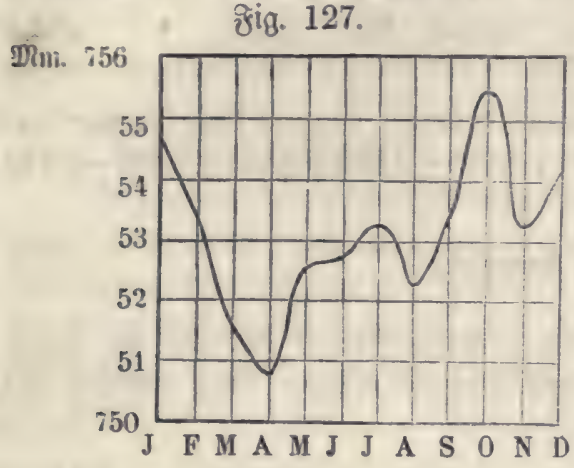
die Minima treten in ben Sommer= monaten und in Nobember ein, in ben erfteren wieber biel bentlicher, al8 in bem leştgenaunten Monat, wie fich aus ber nebenfitehenden

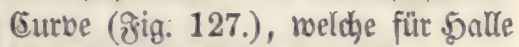
gilt, etieken lăß̈t.

Die Implintoe oer jährlichen Edłrontung wächif bom 2lequator nadi) Dem $\mathfrak{B}$ ol biut, bie IImplitube bes Sommets ijt Eleiner, als bie beร 23 inter8.

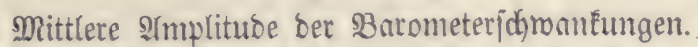

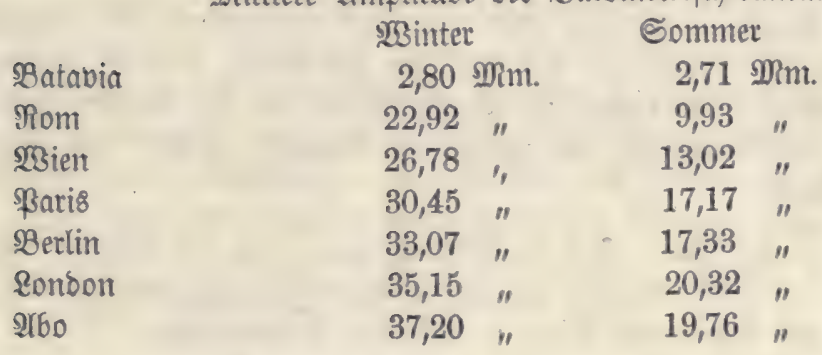

Der jäfrliç)e mittfere Bancometerftano ijt unter bem stequator am Elein= ften, er nimmt bi8 zu $30^{\circ}-40^{\circ}$ Breite zu uno bann mieber noch bis etwa $70^{\circ}$ Breite $a b$. Bielleidft jteigt er mun gegen ben $\mathfrak{B o l}$ hin, boch liegen noch

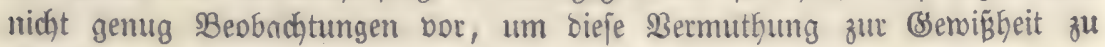
machen.

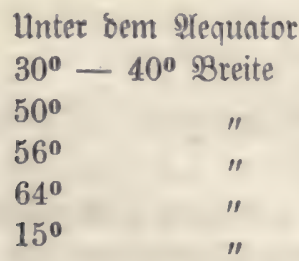

Mittlerer $\mathfrak{B a r o m e t e r f t a n d}$

758 刃meter

762 bis 764 "

760 "

758 "

$\begin{array}{lrl}\text { (Reifiavig) } & 752 \quad " \\ \text { (Injel Melville) } & 758 \quad "\end{array}$

\section{d. Barometerftanb bet ben verfobiebenen grinben.}

Benbadhtet man neben bem Stand bes Baronneters zugleich bie 13 ind $=$ richtung, io nimmt man bald einen auffallenten 3ujammentiang zwifdjen

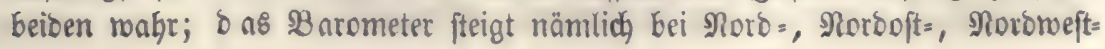


uno Dftrint, es fällt bei Süb, Sübrweft, uno Süboft, wie bie folgenben Bepbachtungen, weldbe zu \$aris angeftellt wurben, zeigent.

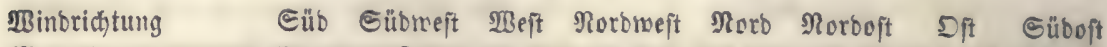
Mittl.Barometerftanb 752,757 753,227 755,950 758,412 759,776 759,672 757,221 754,300

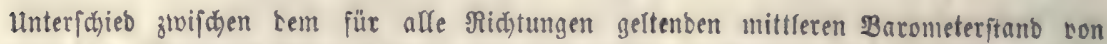
756,414 Mm. $-3,657-3,187-0,464+1,998+3,362+3,258+0,807-2,114$

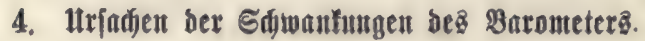

Das 3 Brometer gift nichts 2rnberes, als ben Trudf ber üfer ifm lnften=

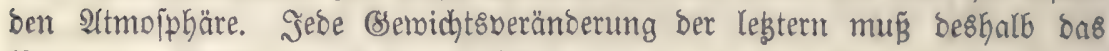
sarometer fteigen ober finten madjen.

Unter ben Urfachen, von melchen ber Stant bes Barometers abfängt,

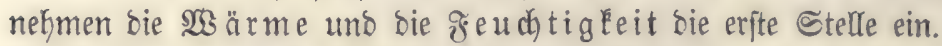

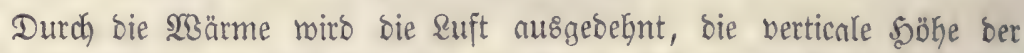

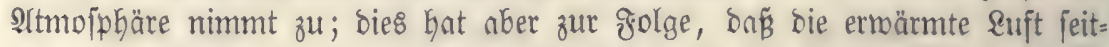
lic) abfliegt. (88 bleibt aljo an ber Etelle, mo bie Iemperaturerföhung ftatt= fano, eine suftmaffe von geringerem (semidgte zurn̈d, bas sBarometer miro bier fintert.

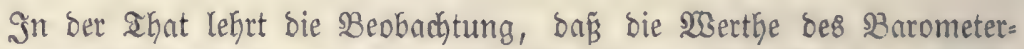
und Thermometeritandes einander gewöhnlid entgegengejest fint; menn aljo 3. B. Das Barometer fteigt, fo fällt bas Ihermometer.

Denéen mir uns die suft pon ifrem 23 afferbampfgebalt befreit, fo

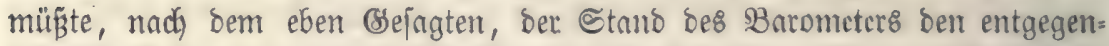
gefesten Bang bon bent bes afermometers einfalten. $23 e n n$ wir bagegen bei ben $\mathfrak{B}$ arometer im $\mathfrak{Q} a \mathfrak{u}$ e bes $\mathfrak{I}$ ages nidht ein Max̧imum uno Mini= mum, wie beim ahermonteter, fonbern beten ztweie wahrnehmen, fo fann bieje Annomalie mur von bem 23 afferbampfáebalt herrühren. Diejer zeigt in

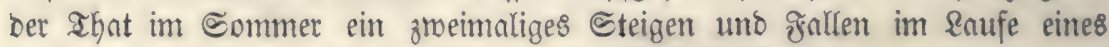
Inges, gerabe fo wie roir es Geim Barometer beobadyten.

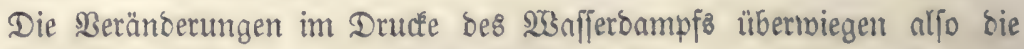
Beränderungen im Druct Der trocfenen $\&$ uft.

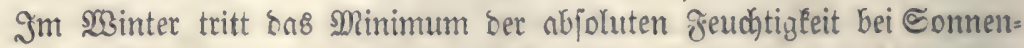

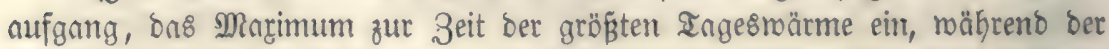
Drucf ber trocfenen euft gerabe zul ben entgegengelebten Tageszeiten feinen Eleinften umo größ̈ten $23 e r t h$ erreich)en müß̈te. Qlus ber (Sombinntion bes Drudes von $23 a f l e r \delta a m p f$ und trớner \&uft gehen hier zmei tägliche Magima

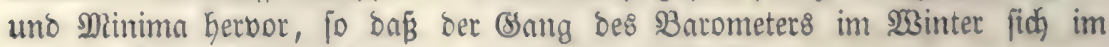
Wejentlidjen nidjt bon bem im Sommer unterfajeibet. 


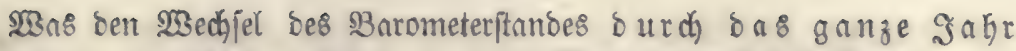

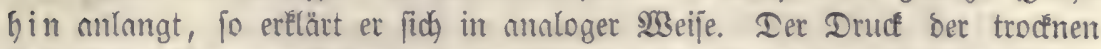

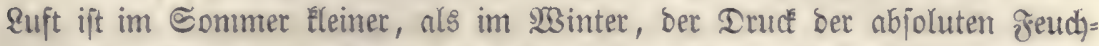

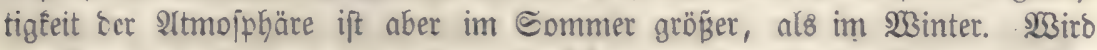
ber Inute bon beiben abbirt, fo ergibt fid ber unter c bargejtellte eigenthüm= liche Brang bes sBarometerfanbes.

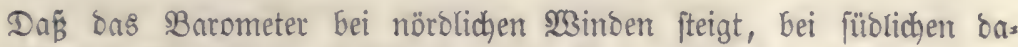

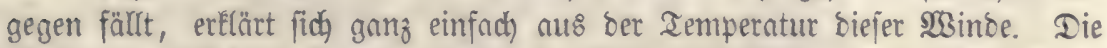
füblichen \&uftftrömungen fint mätmer, als bie nörolid)en, e\& wirb bei ifnen

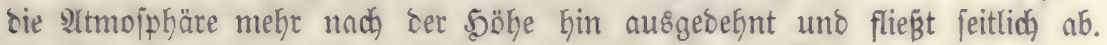

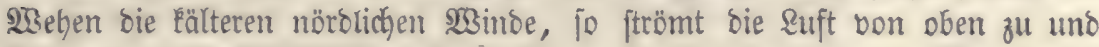

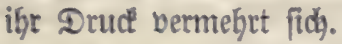

Rod) ein umptano ift es aber, bem man das bebeutende Fallen bes

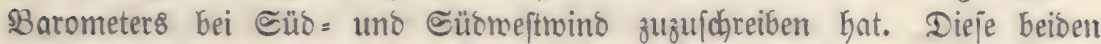

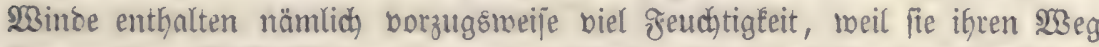

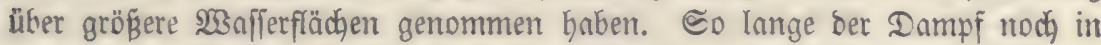
prpandirtem 3uftand in ber suft fofmebt, bermehrt er bie Spanneraft ber

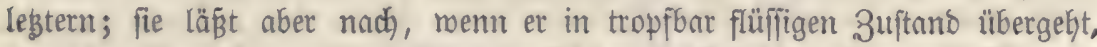
benn ber Dampf nimmt, nadjoem ex fid conbenfirt hat, einen biel Eleineren

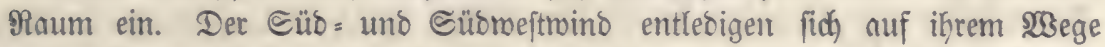

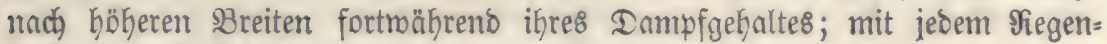
guffe, ben fie bringen, muß̈ baher bas 2 arometer finten.

\section{Barometrifije 5öhenuefinug.}

Das Barometer gibt Ien Drut ber \&uftfäule an, meldje über bem

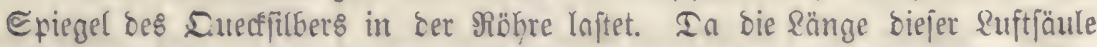

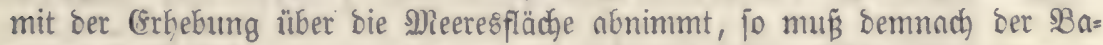
rometerftano finfen, menn das Snftrument bon einemt tiefer gelegenen nad)

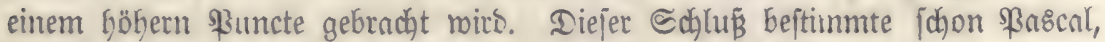

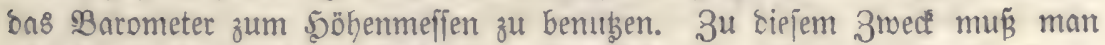

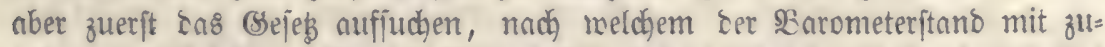

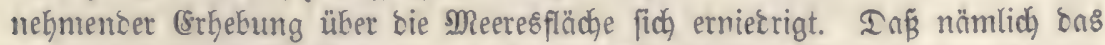
Frallen ber Quecfitlberjäule für gleidhe \$öheninterballe nicht bas näntliche fein

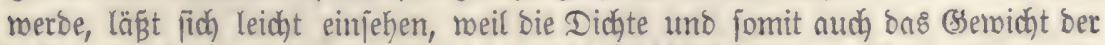
Ruft von unten nach oben Gin fid) nidht gleichbleibt, fondern fortmäbreno $a b=$ nimmit. In meldjem Mafie berminbert fid aber bas Bemidjt ber Ruft in ber

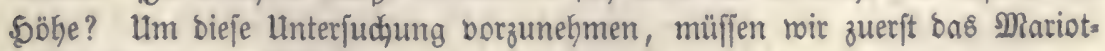
te'ide sejes entroideln. 
a) Mariottéfices derej.

Fig. 128.

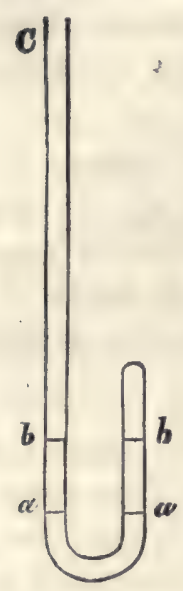

Wenn man in eine gebogene Blasiöbre (ङ̈ig. 128.),

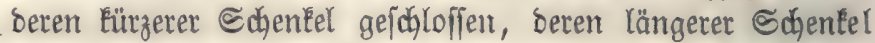

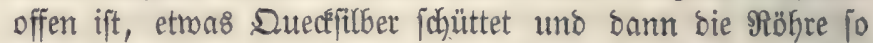
neigt, baß̧ etrons \&uft aus bem kürzern Sdjentel in ben längern übertritt, fo Eann man e\& bafin bringen, baß̈ bas Duecfittber in beiben Schenfeln bei a gleidy bod ftebt. Die suft in bem Eürzern Schenfel ift aljo jebt blos bem Drua Der Artmojphäre nusgejegt. Schüttet man nun meiter Qutect= filber zu, jo zieht fid bie suft in bem fleinern Schenel auf ein geringeres Bolumen zurücé. Beobachtet man ben Quects fitberftano in Dem längern Schentel, nachbem bie suft in bem Fürzern biz b, aljo auf bie Sälfte ifres urfprünglidłen Rnume\& zurüdfgebrängt morben ift, fo wito man finden, bas bie Söbe bC ber Quedfitberfäule gleidy bem eben kerrjoben: ben Barometerftande, aljo z. $\mathfrak{B} .=760 \mathrm{Mm}$. geworben ift. Unter bem Drude bon zmei IYtmojphären nimmt aljo bie

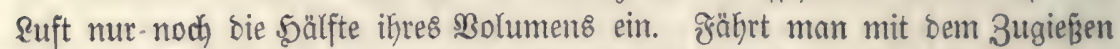
bon Quecfititber fort, fo ergibt fich, Dañ unter bem Druct bon $3,4,5 \ldots \ldots$

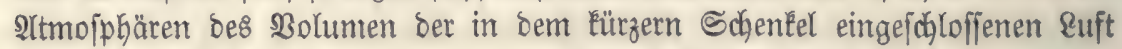
nur noch $1 / 3^{3}, 1 / 4,1 / 5 \ldots .$. bes uriprünglichen beträgt.

Sierall folgt, bas Sejes: bie Bolumsyerminderung einer com: primirten suftmaffe ift bem Drude, meldier auf ihr laftet, proportional.

Unterjuchen mir jegt bie Didyte ober bas Bsemidgt ber comprimirten

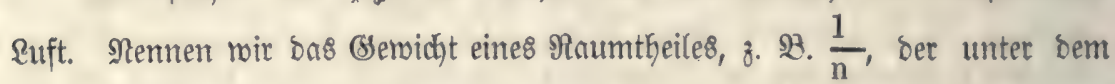

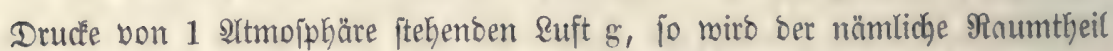
unter bem Drucke von $2,3,4 \ldots$. Nttmofphären $2 \mathrm{~g}, 3 \mathrm{~g}, 4 \mathrm{~g} \ldots$ miegen, benn er entbält ja jebst $2 \mathrm{mal}, 3 \mathrm{mal}, 4 \mathrm{mal} \ldots .$. po viel suft, nls bei 1 attmojphärenorud. (Ss geht aljo Gieraub Gerbor, da B̈ bie Did, te, ober bas (semidt eines gleiden $\Re$ a umtheils suft bem auf ihr laftenden Drude proportional ift.

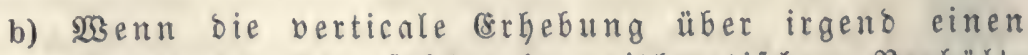
Bunct ber atmoiphäre in arithmetifoem Berfält= niffe zuninmt, fo nehmen bie Barometerfänbe in geometrifdem Berbältnifje ab. Bemeis.

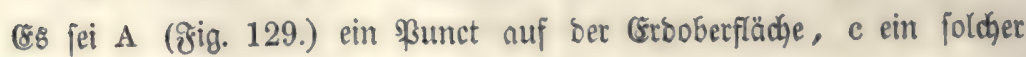




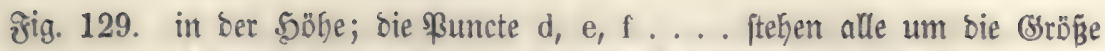
$\mathrm{h}$ von eitanoer ab. Die Barometerftänoe in c, d, e, f, g. . . . feien $B, B_{1}, B_{2}, B_{2}, B_{4} \ldots \ldots$

Dbgleich bie Dichte ber Suft bon unten nady oben abnimmt, $g-\mathrm{B}_{4}$ io fömen wir bodh bie Dichte berjelben innerbalb jeber einzelnen Edjichte, 8. $\mathfrak{B}$. innerbalb cd als gleidjbleibent nnuehmen, wenn f - $\mathrm{B}_{3}$ wir mur h einen gebörig fleinen $2 \mathfrak{3 e r t h}$ geben. Nun ift

e $+B_{2}$ ber Ruftichichte ed de ef $f g$.... (Servidit $\quad \mathrm{B}-\mathrm{B}_{1} \mathrm{~B}_{1}-\mathrm{B}_{2} \mathrm{~B}_{2}-\mathrm{B}_{3} \mathrm{~B}_{3}-\mathrm{B}_{4} \ldots \ldots$

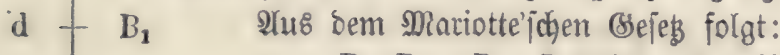

$\mathrm{B}-\mathrm{B}_{1}: \mathrm{B}_{1}-\mathrm{B}_{2}=\mathrm{B}_{1}: \mathrm{B}_{2} ;$ bieraus $\mathrm{BB}_{2}-\mathrm{B}_{1} \mathrm{~B}_{2}=\mathrm{B}_{1}{ }^{2}-\mathrm{B}_{1} \mathrm{~B}_{2}$,

$\mathrm{BB}_{2}=\mathrm{B}_{1}{ }^{2}$.

$\mathrm{B}_{2}=\frac{\mathrm{B}_{1}{ }^{2}}{\mathrm{~B}}$

A

Ferner if nach bem nåmlicłen (Sejes

$\mathrm{B}_{1}-\mathrm{B}_{2}: \mathrm{B}_{2}-\mathrm{B}_{3}=\mathrm{B}_{2}: \mathrm{B}_{3}$; Gieraus

$B_{3}=\frac{B_{2}^{2}}{B_{1}}$, und, wern man für $B_{2}$ feinen eben gefundenen

$=\frac{\mathrm{B}_{1}{ }^{3}}{\mathrm{~B}^{2}}$

(56enjo finoet man

$$
\mathrm{B}_{4}=\frac{\mathrm{B}_{1}^{4}}{\mathrm{~B}^{3}} ; \mathrm{B}_{3}=\frac{\mathrm{B}_{1}^{5}}{\mathrm{~B}^{4}} \therefore \ldots .
$$

(ss ift alio

für bie \$öbe

$\mathrm{Ac}$

Der 8 arometerftano

B $\quad \mathrm{B}_{1} \quad \frac{\mathrm{B}_{1}{ }^{2}}{\mathrm{~B}} \quad \frac{\mathrm{B}_{1}{ }^{3}}{\mathrm{~B}^{2}}$

$\mathrm{Ac}+4 \mathrm{~h} . .$.

ober auda

B $\quad B_{1} \quad B_{1}\left(\frac{B_{1}}{B}\right) B_{1}\left(\frac{B_{1}}{B}\right)^{2}$

$\frac{\mathrm{B}_{1}^{4}}{\mathrm{~B}^{3}}$

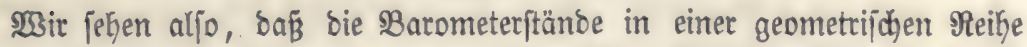
abnehmen, wenn bie Söben in einer aritgmetijden Reige madjen, woburdh unjer obiger Sab erwiejen ift.

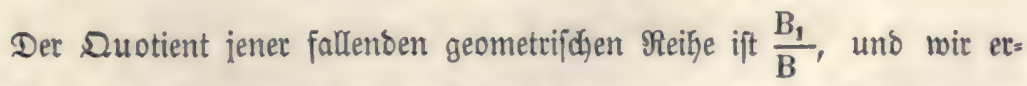

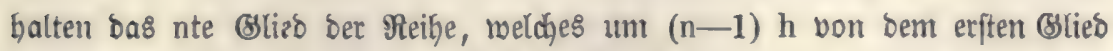
$a b$ teght, wenn wir siejes mit $\left(\frac{B_{1}}{B}\right)^{n-1}$ multipliziren. 
c) Ableitung einer Formel für bie barometrifde bु̈ben= mefโung.

8i่. 130

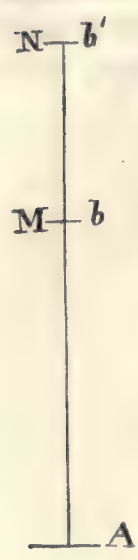

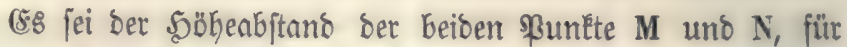
meldye man burch rireliche Beobachtung bie Sarometerftänoe b unto b' gefunden Kabe, zu beftimmen. (ङ̈ig. 130.)

Seben wir zu biejem 3medfe b als bas erfte, b' als bas nte (slieb einer Reifje an, fo merben nach Dem Dbigen zroijchen $M$ und $N$ gernoe $(n-1)$ h liegen. Nun ift

$$
b^{\prime}=b\left(\frac{B_{1}}{B}\right)^{n-1}
$$

Refmen wir auf beiben Seiten bie Rogaritymen, fo ift $\log . b^{\prime}=\log . b+(n-1)\left(\log . B_{1}-\log . B\right)$, Gieraus $n-1=\frac{\log \cdot b^{\prime}-\log \cdot b}{\log \cdot B_{1}-\log \cdot B}$

Multiplioiren mir bie beiben BSlieber biefer (8)eichung Durch A $\quad \mathrm{h}=\mathrm{h}$ jo ift

$$
(\mathrm{n}-1) \mathrm{h}=\frac{\log \cdot \mathrm{b}^{\prime}-\log \cdot \mathrm{b}}{\log . \mathrm{B}_{\mathbf{1}}-\log . \mathrm{B}} \mathrm{h}
$$

(sss ftellt aber $(n-1)$ h bie gefuchte söbe MN vor, meil zufolge unjerer vorberigen Almmabme $n-1$ sufticjichten, jebe von ber Diafe $h$, zmijojen $M$ uno N liegen. (Es ift aljo audy

$$
M N=\frac{\log \cdot b^{\prime}-\log \cdot b}{\log \cdot B_{1}-\log \cdot B} h=\frac{\log \cdot b-\log \cdot b^{\prime}}{\log \cdot B-\log \cdot B_{1}}
$$

In biejer seleidyung fint $b^{\prime}$ und $b$ Surdh bie Beobaditung gegeben, $h$ bebsutet eine \$obke, um weldje man fid erfeben mußs, bamit ber Barometer=

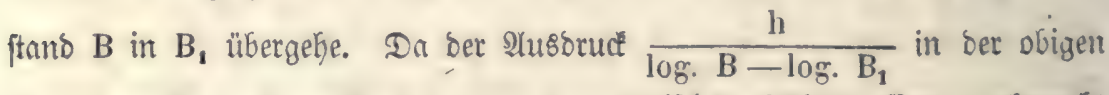
Formel conftant ift, aljo kei jeber barometrifden 5öhenmeffung gebraudjt wiro, fo Eann man ign ein für alle $\mathfrak{M a l}$ berechnen.

গun hat man gefundert, baßs man fidf am Meere, wo ber 33arometer=

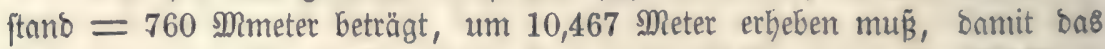
Barometer um $1 \mathrm{Mm}$. finft. Es ift aljo $\mathrm{h}=10467 \mathrm{Mm}$.; und $\mathrm{B}=760 \mathrm{Mm}$.; $\mathrm{B}_{1}=759 \mathrm{Mm}$. unt

$$
\begin{aligned}
& \frac{\mathrm{h}}{\log \mathrm{B}-\log . \mathrm{B}_{1}}=\frac{10467}{0,0005718}=18305 \text { Meter und } \\
& \mathrm{MN}=18305 \text { (log. b }-\log . \mathrm{b})
\end{aligned}
$$

d) Correctur ber beredneten Sobe wegen ber aempes ratur und oem æeudtigleitsgehalt ber $\&$ uft.

Nur bann, wenn bie Zemperatur ber \&uft $0^{0}$ beträgt, reidht eine 
Crhebung von 10,467 Metern hin, um bas Barometer um 1 Mm. fallen ou madjen. Dat bie suft eine böhere aemperatur, fo ift fie aud leidjter, uno es wito bann h einen gröвetn 23 erth, als $10,467 \mathfrak{M}$. annefment. Die

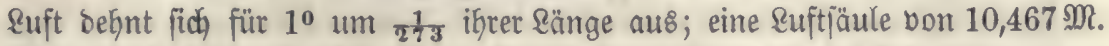

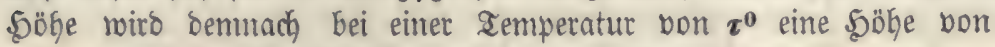

\section{$10,467\left(1+\frac{\tau}{273}\right)$ erlangent.}

Nimmt bie remperatur ber \&uft bon M nadh $\mathbf{N}$ hin $a b$, wie bies ge= wöbntid Der Fall ift, fo ätbert ber Duotient $\frac{\mathrm{h}}{\log . \mathrm{B}-\log \mathrm{B}_{\mathbf{1}}}$ fortwäbreno

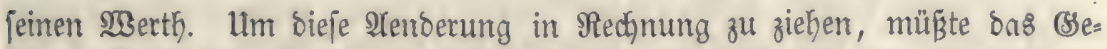
fes, nady weldjent fie erfolgt, belamut jein. Da bies nber bis jebt nidjt ber Fall ift, io hilft mant fich in ber 23 eije, baß̉ man antimmt bie $\mathfrak{B}_{3} a ̈ r m e$

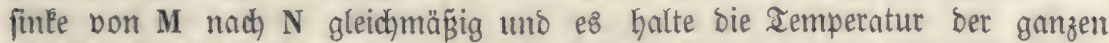
Euftidyidhte MN bas Mittel aus ben Temperatuten $t$ und $t^{\prime}$ ber Beobach)=

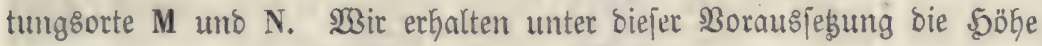

$$
\begin{aligned}
& \mathrm{MN}=\frac{10467}{0,0005718}\left(1+\frac{1}{2} \frac{\left(t+t^{\prime}\right)}{273}\right)\left(\log \cdot \mathrm{b}-\log \cdot \mathrm{b}^{\prime}\right)= \\
& \mathrm{MN}=18306\left(\frac{546+t^{\prime}+t^{\prime}}{546}\right)\left(\log \cdot \mathrm{b}-\log \cdot \mathrm{b}^{\prime}\right)= \\
& \mathrm{MN}=33,526\left(546+\mathrm{t}^{\prime}+\mathrm{t}^{\prime}\right)\left(\log \cdot \mathrm{b}-\log \cdot \mathrm{b}^{\prime}\right)
\end{aligned}
$$

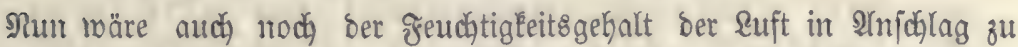
bringen, inbem bie Brö̈ße von $h$ wechjelt, je nachoem bie suft ntehr ober

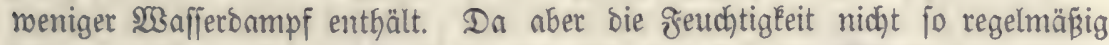
mit ber \$öbe zu= ober abnimmt, al\& wir bies bei ber 2 särme unterftellen

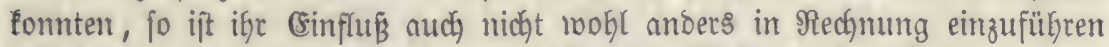

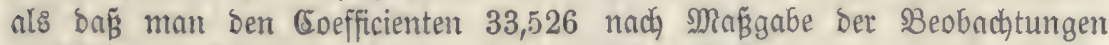
mobifizint, welche man bei ber barometrijchen Mefiung bon geometrijoh be=

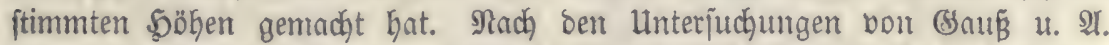

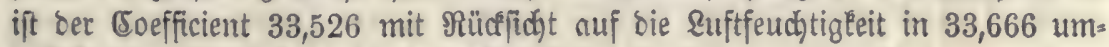
guänoern, uno e\& lautet nun unjere Formel

$$
\mathrm{MN}=33,666\left(546+\mathrm{t}^{\prime} \mathrm{t}^{\prime}\right)\left(\log . \mathrm{b}-\log . \mathrm{b}^{\prime}\right)
$$

e) Correctur ber beobaditeten Barometerftäno wegen

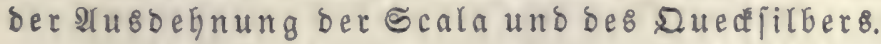

Die beobachteten Barometerftänbe b umb $b^{\prime}$ Eebürfen einer Correctur

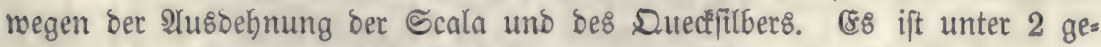

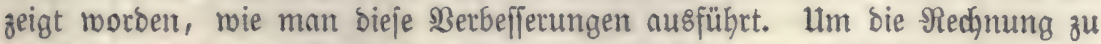
erleidgtern, hat man ãbellen (ङ. 304) entworfen, aus meldhem bie beiben

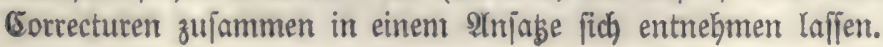


Barometrifde 5obenmefiung.

\begin{tabular}{|c|c|c|c|c|c|c|c|c|c|}
\hline 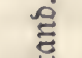 & \multicolumn{8}{|c|}{ Sorrectur für Die Semperatur von } & \\
\hline $\begin{array}{l}\text { D } \\
\text { E⿱艹 } \\
\text { ही }\end{array}$ & $1^{0}$ & $2^{0}$ & $3^{0}$ & $4^{0}$ & $5^{0}$ & $6^{0}$ & $7^{0}$ & $8^{0}$ & 90 \\
\hline & & & & & & & & & \\
\hline $\begin{array}{r}600 \\
05\end{array}$ & $\begin{array}{l}0,097 \\
0,098\end{array}$ & & $\begin{array}{l}0,29 \\
0,29\end{array}$ & $\begin{array}{l}0,38 \\
0,38\end{array}$ & $\begin{array}{l}0,4 \\
0,4\end{array}$ & & 0,6 & & 872 \\
\hline 10 & 0,098 & 0,197 & 0,295 & 0,394 & 0,492 & 0,591 & 0,689 & 0,788 & 0,886 \\
\hline 15 & 0,099 & 0,198 & 0,298 & 0,397 & 0,496 & 0,596 & 0,695 & 0,794 & 0,893 \\
\hline 20 & 0,100 & 0,200 & 0,300 & 0,400 & 0,500 & 0,600 & 0,700 & 0,800 & 0,901 \\
\hline 25 & 0,101 & 0,202 & 0,303 & 0,403 & 0,504 & 0,605 & 0,706 & 0,807 & \\
\hline 30 & 0,102 & 0,203 & 0,305 & 0,407 & 0,508 & 0,610 & 0,712 & 0,813 & 0,91 \\
\hline 35 & 0,102 & $0^{\prime} 205$ & 0,307 & 0,410 & 0,512 & 0,615 & 0,717 & 0,820 & 0,922 \\
\hline 40 & 0,103 & 0,207 & 0,310 & 0,413 & 0,516 & 0,6 & 0,723 & 8,826 & \\
\hline 45 & 0,104 & 0,208 & 0,312 & 0,416 & 0,520 & 0,625 & 0,729 & 0,833 & 0,937 \\
\hline 50 & 0,105 & 0,210 & 0,315 & 0,420 & 0,524 & 0,629 & 0,734 & 0,839 & 0,944 \\
\hline 55 & 0,106 & 0,211 & 0,317 & 0,423 & & & & 0,8 & \\
\hline 60 & 0,106 & 0,213 & 0,320 & 0,426 & 0,533 & 0,639 & 0,746 & 0,852 & 0,959 \\
\hline 65 & 0,107 & 0,215 & 0,322 & 0,429 & 0,537 & 0,644 & 0,751 & 0,859 & 0,966 \\
\hline 70 & 0,108 & 0,216 & 0,324 & 0,433 & & & 0,757 & 0,8 & \\
\hline 75 & 0,109 & 0,218 & 0,327 & 0,436 & 0,5405 & 0,654 & 0,763 & 0,871 & 0,980 \\
\hline 80 & 0,110 & 0,219 & 0,329 & 0,439 & 0,549 & 0,658 & 0,768 & 0,878 & 0,988 \\
\hline 85 & 0,111 & 0,221 & 0,332 & 0,442 & 0,553 & 0,663 & 0,774 & 0,884 & 0,995 \\
\hline 90 & 0,111 & 0,223 & 0,334 & 0,445 & 0,557 & 0,668 & 0,780 & 0,891 & 1,002 \\
\hline 95 & 0,112 & 0,223 & 0,336 & 0,449 & 0,561 & 0,673 & 0,785 & 0,897 & 1,010 \\
\hline 700 & 0,113 & 0,226 & 0,339 & 0,452 & 0,565 & 0,678 & 0,791 & 0,904 & 1,017 \\
\hline 05 & 0,113 & 0,228 & 0,341 & 0,455 & 0,569 & 0,683 & 0,797 & 10 & 1,024 \\
\hline 10 & 0,115 & 0,229 & 0,344 & 0,458 & 0,573 & 0,688 & 0,802 & 0,6 & 1,031 \\
\hline 15 & 0,115 & 0,231 & & 0,462 & 0,577 & & 0,808 & 0,923 & 1,039 \\
\hline 20 & 0,116 & 0,232 & 0,349 & 0,465 & 0,581 & 0,697 & 0,813 & 0,930 & 1,046 \\
\hline 25 & 0,117 & 0,234 & 0,351 & 0,468 & 0,585 & 0,702 & 0,819 & 0,936 & 1,053 \\
\hline 30 & 0,118 & 0,236 & & 0,471 & 0,5 & 0,707 & 0,825 & 0,943 & 1,060 \\
\hline 35 & 0,119 & 0,237 & 0,356 & 0,474 & 0,593 & 0,712 & 0,830 & 0,949 & 1,068 \\
\hline 40 & 0,119 & 0,239 & 0,358 & 0,478 & 0,597 & 0,717 & 0,836 & 0,955 & 1,075 \\
\hline 45 & 0,120 & 0,240 & 0,361 & 0,481 & 0,601 & 0,721 & 0,842 & 0,962 & 1,082 \\
\hline 50 & 0,121 & 0,242 & 0,363 & 0,484 & 0,605 & 0,726 & 0,847 & 0,968 & 1,089 \\
\hline 55 & 0,121 & 0,244 & 0,365 & 0,487 & 0,609 & 0,731 & 0,853 & 0,975 & 1,097 \\
\hline 60 & 0,123 & 0,245 & 0,368 & 0,491 & 0,613 & 0,736 & 0,859 & 0,981 & 1,104 \\
\hline 65 & 0,124 & 0,247 & 0,370 & 0,494 & 0,617 & 0,741 & 0,864 & 0,988 & 1,111 \\
\hline 70 & 0,124 & 0,249 & 0,373 & 0,497 & 0,621 & 0,746 & 0,870 & 0,994 & 1,118 \\
\hline 75 & 0,125 & 0,250 & 0,375 & 0,500 & 0,625 & 0,750 & 0,876 & 1,001 & 1,126 \\
\hline 80 & 0,126 & 0,252 & 0,378 & 0,504 & 0,629 & 0,755 & 0,881 & 1,007 & 1,133 \\
\hline 85 & 0,127 & 0,253 & 0,380 & 0,507 & 0,633 & 0,760 & 0,888 & 1,014 & 1,140 \\
\hline 90 & 0,127 & 0,255 & 0,382 & 0,510 & 0,637 & 0,765 & & 1,020 & 1,148 \\
\hline 95 & 0,128 & 0,257 & 0,385 & 0,513 & 0,641 & 0,770 & 0,898 & 1,026 & 1,155 \\
\hline 800 & 0,129 & 0,258 & 0,387 & 0,516 & 0,646 & 0,775 & 0,904 & 1,033 & 1,162 \\
\hline
\end{tabular}


Die QYnwentung biejer Iabelle wirb fich am beften butch ein Beifpiel zeigen Inffen.

3u Siefent murbe am 13. Mtai ein Barometerftano bon 747,5 Mimetern beobad)tet. Die Iemperatur bes Quectiflbers im Barometer uno ber més fingenen Scala gab ein am Snjtrument befindliches agermoneter zu 180,6 ant. (5s wäre nlio, wenn wir bie Ränge ber Scala auf bie Iemperatur bon 00 rebuizen, bet 23 arometerjtano.

$$
\frac{54000+18,6}{54000} \cdot \quad 747,5=\frac{54018,6}{54000} \cdot \quad 747,5=747,758
$$

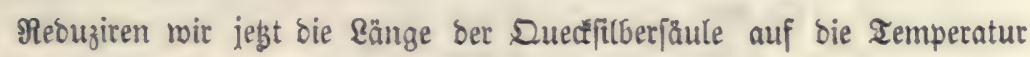
von $0^{\circ}$, jo ift

$$
\frac{5550}{5550+18,6} \cdot 747,758=\frac{5550}{5568,6} \cdot \quad 747,758=745,26 .
$$

ชübren mir nun bie beiben Correcturen auf einmal mit \$ulffe unferer Tabelle aus. Dazu juchen wir zuerft in ber mit "BBarometerftanio" überiohries benen Bertifalipalte 747 auf, uno netmen, weil bieje $3 a$ hl fid nicht findet, bie zunädhftliegenbe 745 . Danu fabren wir in ber Sorizontalipalte, beren exftes Blied $\mathbf{7 4 5}$ bilbet, fort uno nehmen bie Correctur für 10. Dieje beträgt 0,120 ; bieje 30 hl multipliziren mir mit 10 , um vorecft bie Correctur für $10^{\circ}$ zu erbalten.

Reģtere beträgt aljo

1,200

Sn ber nämlidłen Spnlte finden wir bie Correctur für $8^{n} \quad 0,962$

uno für $00,6=0,721 \cdot 0,1=$

Die Bsejanımtberbefferung für $18^{0}, 6$ beträgt aljo

$-\frac{0,072}{2,234}$

Dieje ziehen wir bon Dem beobachteten Barometerjtand $=747,5$ \meter ab und erhalten bam ben corrigirten Barometerfand $747,5-2,234=745,266$. Die Eleine Differenz von 0,006 rüfrt baher, weil wir in unjerer Iafel für 747,5 gernbezu 745 Gaben gelten laffen, twährent, um gant genau zu verfă)= ren, bie 2 serthe für 747,5 mittelft Interpolation zmifonen 745 uno 750 bätten gefudgt merben müfien.

Riegt bie beobadjtete remperatur unter $0^{\circ}$, fo mus, menn man fich ber Sülfstabelle bebient, bie Correctur nicht fubtrabirt, fondern aboirt werben.

\section{f) Beifpiel einer barometrifaen 5öhenmefiung.}

Ulm ein SBeifpiel bon ber Ânmentoung urjerer frormel zu geben, wollen

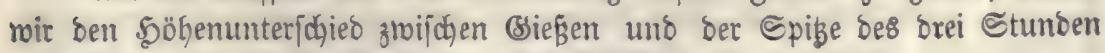
bon biejer Єtabt liegenten Dünsberges beredynen.

2m 13. Mai beobachtete man

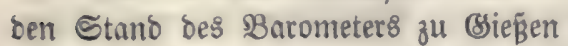

$\mathrm{b}=747,5 \mathrm{Mm}$.

"seser, Bodentunice.

auf Dem Dün8berg

$b^{\prime}=717,0$ " 
bie Iemperatur bet Scala und bes Duecfillbers im Barometer

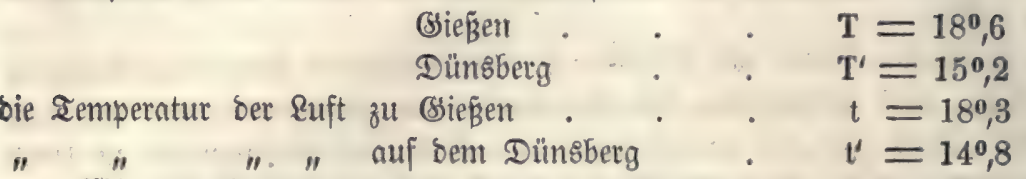

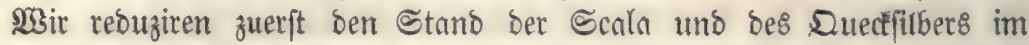

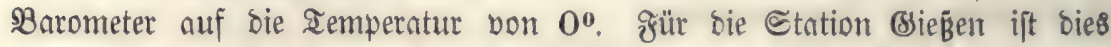
bereit\& oben gefchehen, wir fanoen . . b $b=745,266 \mathrm{Mm}$.

Für ben Barometerftano der Station Dïnsberg beträgt bie Correctur:

$$
\begin{aligned}
& \text { für } 10^{\circ} \ldots \ldots 1,150 \\
& \text { " } 5^{0} \ldots \ldots .0,577 \\
& \text { " } 0^{0}, 2 \ldots \ldots 0,023 \\
& 3 \text { u[ammen } 1,750
\end{aligned}
$$

Daber corrigirter $B$ arometerftano $=717,0-1,750=715,250 \mathrm{Mm}$.

Cs: ift aljo ber gejuchte 5öhenunteridjied

$\mathrm{MN}=33,666(546+14,8+18,3)(\log .745,266-\log .715,250)=$

$$
=33,666 \text {. } 579,1 \text { (log. } 745,266-\log .715,250) \text { und }
$$

log. $M N=\log .33,666+\log .579,1+\log .(\log .745,266-\log .715,250)$

$=2,5416660$, aljo

$\mathrm{MN}=349$ Meter.

g) Einridtung ber zur \$öhenmefiung beftimmten Baro= meter.

Bon ben berfjiebenen Barometerjorten eignet fich allein bas \$eber:

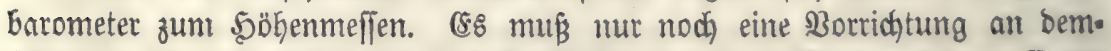

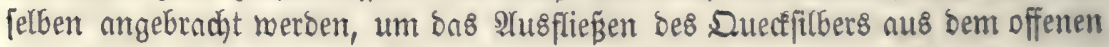
Schenfel beim হransport zu berbüten.

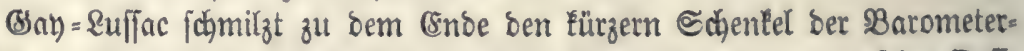

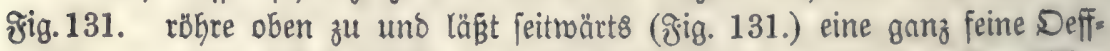

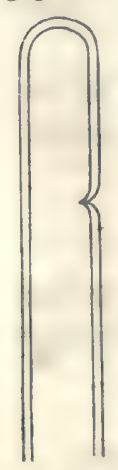
nung, burch melche zroar bie suft eintreten, aber bas Quectifltber nidjt entroeidyen Eann. Beim Transport kehrt man bas Snitru=

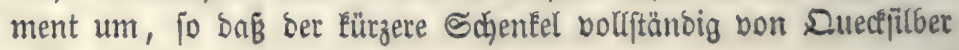
erfüllt ijt.

(sine anbere Borridytung, meldje gleidffalls jehr gute Dienfte leiftet, ift folgenoe. Die Röbre bes Eürzeren Schenfels befteht aus

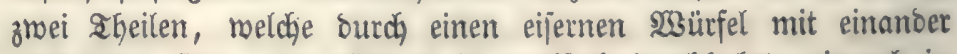

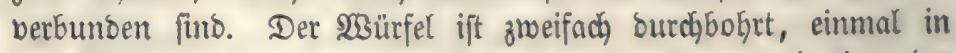
Der Riçtung ber Baronteterröhre (um bie Communication ber beiben Iheile des kürzeren Schentels herzujtêlen), zum nnoern

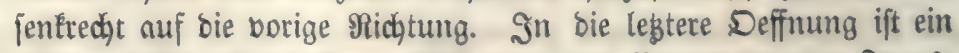
eijerner babn eingelaffen. WBill man bas Barometer zum Irans: 
port berridhten, io neigt man e8, bis bas Suedfitber ben langen Schentel

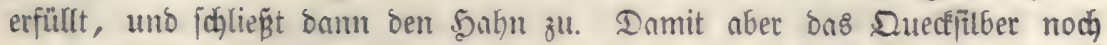
etroas Epielraum babe, wenn e\& fich bei zumebmenber 233 ärme ausoebnt, ift an bent Theile bes \$anhns, weldher fich innerbalb ber Durchbohrung bes

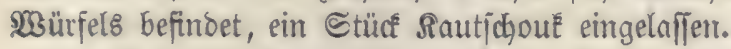

Sebes gute Barometer entbält nod, ein Shermometer, um bie Tempe= ratur ber Scala und bes Quedfitbers in ber Barometerröhre zu beftimmen.

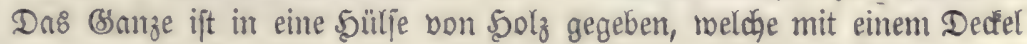
beriobloffen werben tamn.

ஓig. 132.

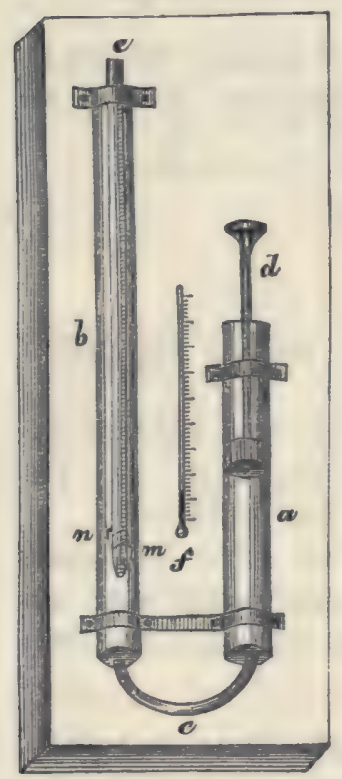

\{bgefürtes Barometer bon Ropp. Diejes Snittument arbeitet nidyt mit ber Bentaig= Eeit, wie das borhin beidgriebene Seberbarometer; ongegen hat e\& ben Borzug einet gröfern Trans= portabilität, weil eร์ mur 0,3 Meter lang iit uno fich

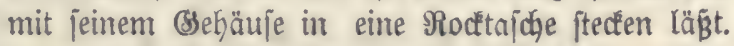

Das Sopp'idye SBaronteter (Æ̊ig. 132.) befteft

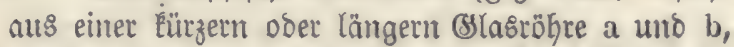
melche burdh eine gebogene engere Röhre e von bemielben Material berbunden fint. Sn bie Röhre

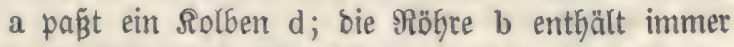
nod) eine engere (s)Instöhre e, weldye 6 Centimeter vou ifrem untern (snde mit eitrem \$latinoraft um= widelt ift, beffen eirte Spibe $m$ ein menig tiefer, als bie andere $n$ fteht. Die Röhre e ift grabuirt. 3 wijchen a uns b befindet fich ein lleinez I Ther= mometer $f$, welches noch $+50^{\circ}$ uno $-30^{\circ}$ anzeigt.

Die siögre c ift mit Ruecfitlber gefüllt; biejes ringt audh nody eine Hleine Etrecfe mit in a uno b binein. Sieht man ben Solben $d$ in bie Şöhe, io tritt bns Duecffilber aนร b gänzlich Gernus und b füllt fich mittelit ber Deff= nung bei e mit \&uft. Drücât man jebt ben fiolben d wieber abıärt\&, fo

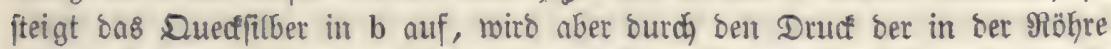
b eingejoloffenen suft (bie nicht entroeichen fann, weil b oben feft berftopft

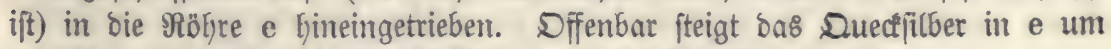

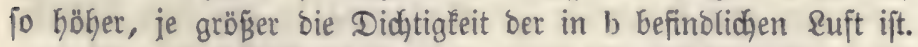

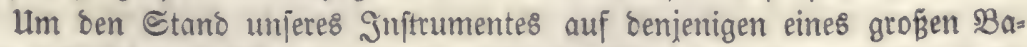

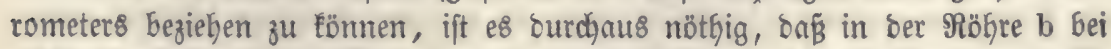

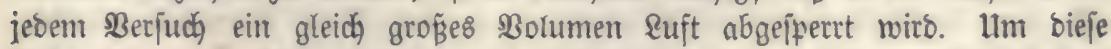
Bebingung zu exfüllen, brücłt man ben Solben fo reit abroärts, bis ber Spie= get bes Suedfitber's in bet siohre b bie Spige $m$ erreidyt und lieft bann bie

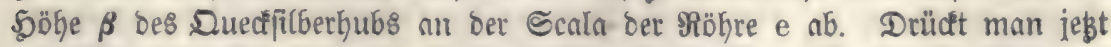
ben Rolben nodjmals etwas tiefer, fo tommt bas Ruectfltber in ber Robre b 
bis an bie Spige n zu ftehen, greichzeitig fteigt es aber in e etwas Göher als bas erfte Mal, nämlich biz $\beta^{\prime}$. So geftattet alfo bie $\mathfrak{B}$ orridytung ber zmei Spizen, zmei fich controlirente Meffungen kutz Ginter einnnoer yorzunehmen.

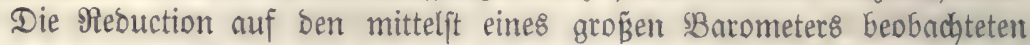

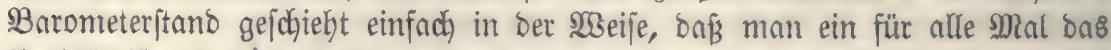

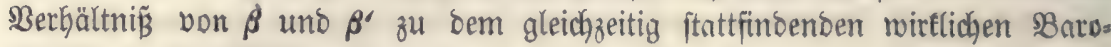
meterftano B feftitellt. $\quad(8 s$ ipt

$$
\begin{aligned}
& \beta . c=B, c=\frac{B}{\beta} \\
& \beta^{\prime} \cdot c^{\prime}=B, c^{\prime}=\frac{B}{\beta^{\prime}}
\end{aligned}
$$

Sätte man nun ein anderes Mal an bem Sopp'iajen Snftrument ben Stano bes Duecffitbers in ber Röhre e gleich $\beta^{\prime \prime}$ uno $\beta^{\prime \prime \prime}$ gefunden, fo roäte ber wirkliche Barometerjtand

$$
\begin{gathered}
\mathrm{B}^{\prime}=\mathrm{c}^{\prime} \beta^{\prime \prime} \text { oder } \mathrm{c}^{\prime} \beta^{\prime \prime \prime}=\frac{\mathrm{B}}{\beta} \beta^{\prime \prime} \text { ober } \frac{\mathrm{B}}{\beta^{\prime \prime}} \beta^{\prime \prime \prime} \\
\text { unь } \mathrm{B}^{\prime}=\left(\frac{\mathrm{B}}{\beta^{\prime \prime}}+\frac{\mathrm{B}}{\beta^{\prime}} \beta^{\prime \prime \prime}\right): 2
\end{gathered}
$$

Die Coefficienten e uno $e^{\prime}$ theilt ber Mechaniés, von weldhem bas Injtru= ment bezogen wiro, mit.

Das Sopw'fdye Barometer ift geröbntid) auf ein hölzernes Brettchen be= feftigt, welches zugleidh ben Decíel eines Räftchens biloet. ßật man ben Decfel ein, fo befinbet fich) Der (8lasిapparat int Intern bes Siätchens.

Da bas abgefürzte 8 arometer ben \&uftoruck nur bis auf 2-3 Mmeter genau angibt, io ift es zur Beftimmung Eleinerer Söhendifferenzen nidht an= menbbar; gröB̈ere laffen fich mit ifm mur bann ermitteln, wenn man fidh einen F̌ehler von 20 bis 30 Metern gefalten laffen will.

h. Negeln für bie zum 3 twea ber 50 bentheflung anzuftels lenden barometrifaen Beobachtungen.

WBir Gaben oben gejełen, Daß̧ Der Stanto des \$arometers fortwährenden Sdfwantungen unterworfen ift. Coll bie mittelft biejes Snftrumente8 abge: leitete \$öbendifferenz zweier Drte ifrem rabren $\mathfrak{M}_{3}$ erthe entiprechen, fo ift es

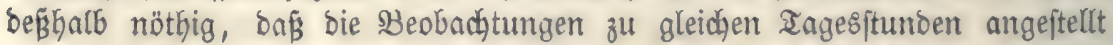
werben. Steht aber mur ein $B$ arometer zur $\$$ Berfügung, fo eile man jogleich) von bem einen Drte zum andern uno bringe, svern ber Unterichied zwijhen ben Beobachtungszzeiten beträchtlich) ift (. B. mebrere Stunden beträgt), eine nach bem täglichen (Sang Des 3 arometers zu bemeffente Correctur an ber einen ober anbern Beobadytung an.

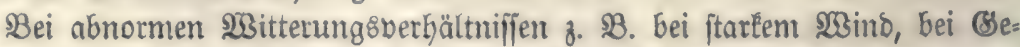

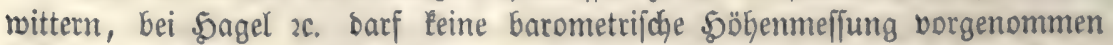
rerben, meil unter biejen Umftänben bie Edmere ber über ben Geiben Reob. 
adhtungsorten laftenden \&uftiaulen nicht blos von ber Meereshähe $a b=$ bängt.

Das genauejte $\Re e j u l t a t$ erfält man immer, menn man ben mittlern jäbr=

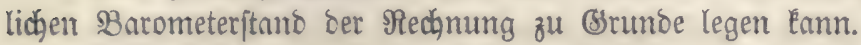

SBenn blos eine Doer nut wenige Beobnchtungen angeftellt werben tön= nen, Donn bürfen sie beiben Drte nidat roeit bon einander entfernt liegen, weil man jonjt nicht barïber berjichert jein Earn, ob nicht zur 3eit ber BBeobad)= tung verjhiebene 23 itterungsoerhältniffe an ben beioen Etationen geberridht

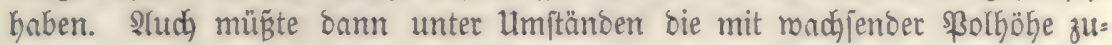
neymente Sdymere ber \&uft in Rechnung gezogen merben. Die ßerminterung,

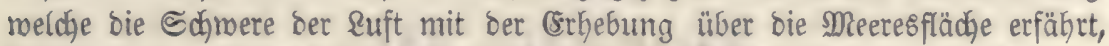
Eamm immer auß̈er IIdat gelnffen rerben, weil bie Söhendiftanzen, meldhe wir meffen, nicht jo beträchtlich fino, Daß̈ bie Bernachlä|ligung biejer Beränberlich)=

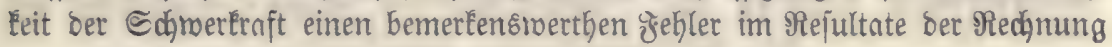
zu verur 


\title{
Angewanoter Theil.
}

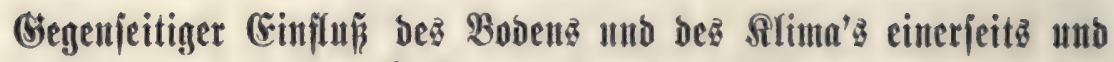
ber $\mathfrak{R a l b u e g e t a t i o n ~ m o e r j e i t . ~}$

\author{
Eriter Iitel.
}

\section{Birfung ber eitzeluen Factoren bes Bobets und bes Rlima' \\ 3ehntes 3 u (t).}

Cinflu: ber Atmofphäre auf bie $\mathfrak{B a l b u e g e t a t i o n . ~}$

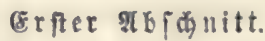

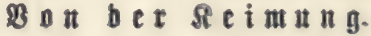

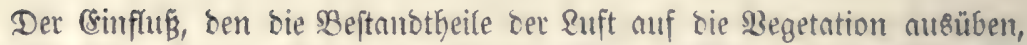
madyt fich idhon bei ber Seimung geltent. Man berftebt unter siejer biejenige Entwiatung bes Cament, weldhe bie sntitebung einer neuen \$ffanze zur golge hat.

\section{Beftanbtheile beฉి Sณment.}

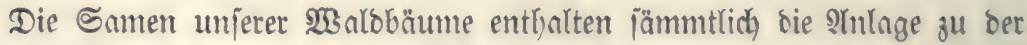
neuen Pflanze, Gefteheno in Dem 23 ützelden (Radicula) uns ber Stanin: Enoppe (Plumula), meldye aber Gäufig nidgt beutlid) ausgebiltet ift unt fid

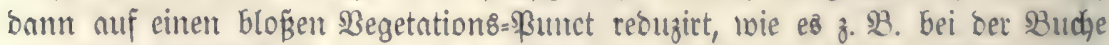

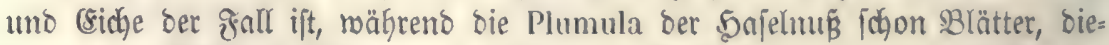

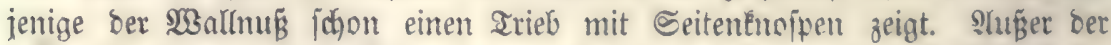

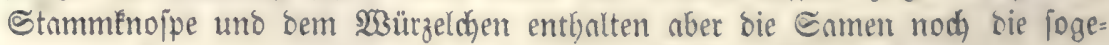
naunten Samenlappen ober (Soty)lebonen, uno bieje füllen bei mandjen Sa=

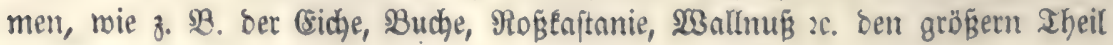




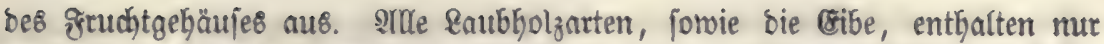

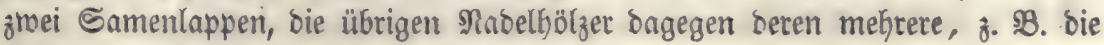
Riefer und Ianne 5-7, bie Pridyte 6-10.

Würzeldgen, Stammennope uno Samenlappen fino bet mandjen Samen nod) einmal von eirer weidjen, weif́en ober gelblidjen Schidgte, bem Sa

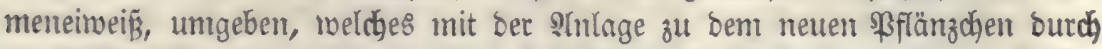

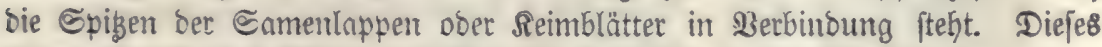

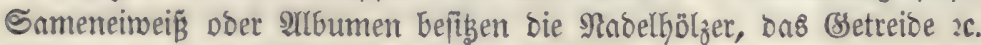

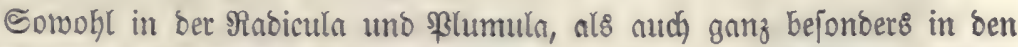

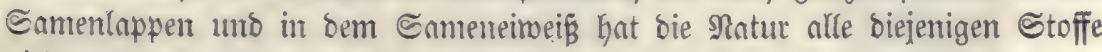

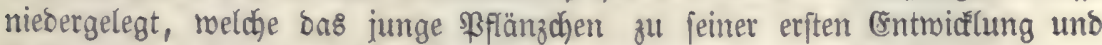
fo lange beonrf, bis esి fich jelbittiändig ernähren fann. Dieje Stoffe fino:

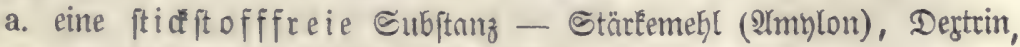
Doer in beren Bertretung ein Del.

b. eire ft iff off

ஓ่̊g. 133.

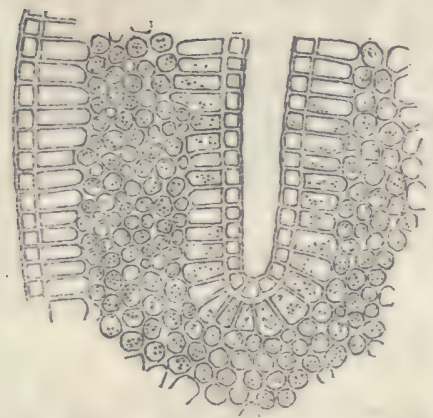

Das Stär temehl lommt in größ̈ter Menge in ben Eamenlappen ber nidft b̈lfal=

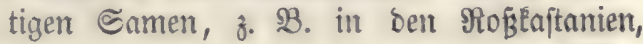
Sicheln vor, ofue baj̈ es in jenert ganz fehlte. Die (Sotylebonen ber Budhe, von benen grig. 133 ein Eleines ๔tücớchen bei 200 maliger Bergröß̌etung zeigt, enthalten eine nicht un= beträd)tlicf) Menge Amylon; es ift bier in Den Zellen zerftreut in Eleinen Siugeldhen ents Galten; bie in unferer Figur burch fantrarze

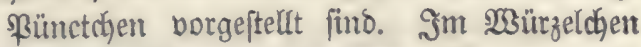
ber Budjel bagegen nimmt Daz CtärÉemehl nur einige genau begrenzte $3^{\mathrm{el}=}$

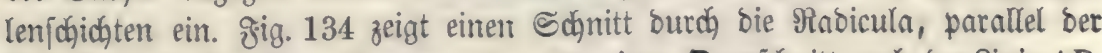

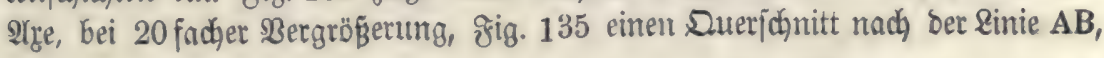
§ig. 134.

ชิ่า. 135.
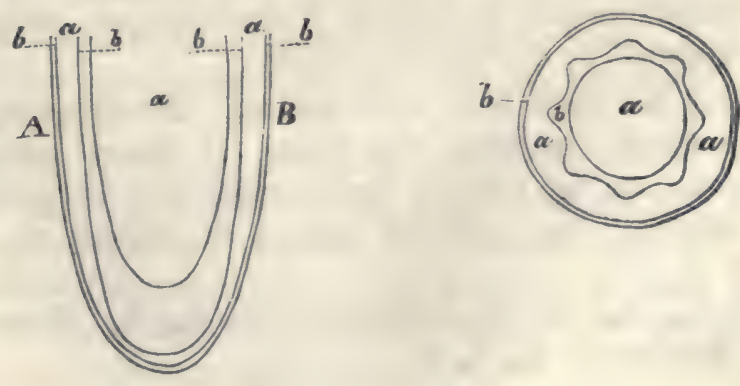


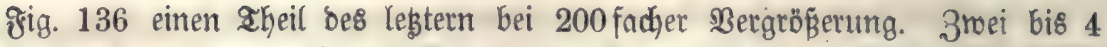

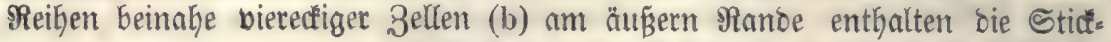

ঔig. 136.

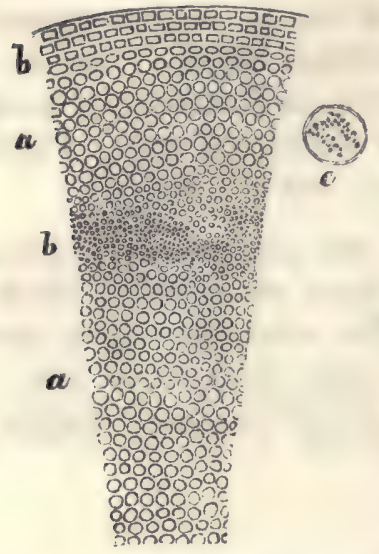

ftoffmaterie, Dann Eommen viele fajt Ereistunbe Bellen $a$, in melchen fich Stärlemehl befindet (c zeigt eine folche Belle mit Stärfemehlërnern, ftär= Eer bergrößgert). Siernuf folgen bie biel Eleinern fogenannten Cambiumzellen b, weldye mieber mit fticéftoffhaltiger Materie gefüllt füo uno bann wie=

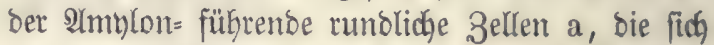
bi\& zum Mittelpuntt erftrecfen.

Die ફrormen, unter welden bas Stärk̈emehl in ben Samen auftritt, fino überaus mannigfach. In ber Buchet z. $\mathfrak{B}$. erjobeint e\& in jefre Heinen

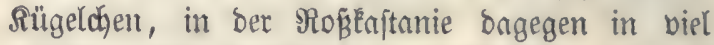

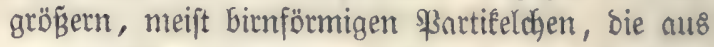
concentrija) gelagerten Schidgten zu befteben jofeinen.

Das Etärfemehl ift eine Berbinoung von Rohlenftoff, Sauerftoff und

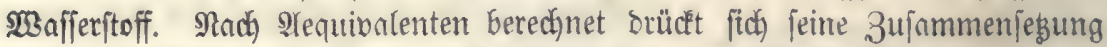
burch bie formel $\mathrm{C}_{6} \mathrm{H}_{5} \mathrm{O}_{5}$ aus. Eauerftoff uno 2 Bafferftoff fino alfo in

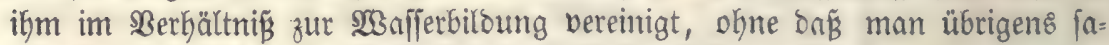

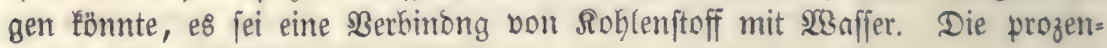
tijobe 3ujammenjesung ift:

$$
\begin{array}{lr}
\text { Sohlenitoff } & 44,91 \\
\text { Malferitoff } & 6,11 \\
\text { Saueritoff } & 48,98 \\
\hline & 100,00
\end{array}
$$

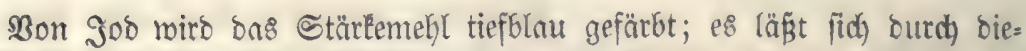
fe8 Reagens febr leidgt in ben \$flanzen entocéent.

Das Dertrin fhliegt fich in feiner 3ujammenjebung an bas Stärle= mebl an; ber prozentif(he Bsebalt an Rohlenftoff, Snuerftoff unb 23 nfferftoff ift genau der nämliche; bagegen zeigen bie Berbintungen, welche bas Degtrin mit andern Sörpern eingeht, bie boppelte Sfequibatentenzafl, weß̈halb man bie Formel Des Dertrin's $=\mathrm{C}_{\mathbf{1 2}} \mathrm{H}_{\mathbf{1 0}} \mathrm{O}_{\mathbf{1 0}}$ ïhreibt.

Die Dele fint theils fette, theils flüthtige. Die Brundinge bon erite=

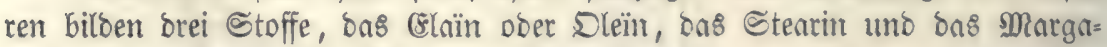
rin. Man nimmt an, baß̉ diejelben Berbinoungen einer ๔äure mit einer $\mathfrak{B a}$

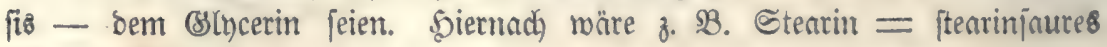
Bsincerin. Es ift

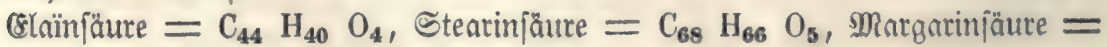
$\mathrm{C}_{68} \mathrm{H}_{68} \mathrm{O}_{6}$, slycerin $=\mathrm{C}_{3} \mathrm{H}_{4} \quad 0$. 
Die fetten Dele theilt man in troctnende uno nidjt trodtnente. $3 \mathfrak{u}$ er=

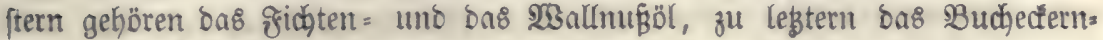

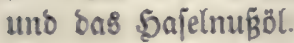

Bon ben flühtigen Delen unteridheibet man fauerjtofffreie uno jauerftoff: haltige. Unter ben fauerftofffreien Delen, seren 3ujammenfegung ourch bie frornel $\mathrm{C}_{5} \quad \mathrm{H}_{4}$ ansgebrüctt ift, berdient ganz bejonders dns Terpentfinöl we= gen jeires fyäufigen $\mathfrak{B o r t o n m e n s ~ g e n a n n t ~ f u ~ w e r b e n . ~ D i e ~ S n m e n ~ b e r ~ \Re a s ~}$

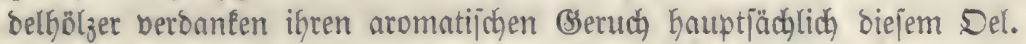

Das Del ift, wie bas Ânulon, in Bellen eingejdylofien. (88 tritt in biejen in um to größ̈erer Menge nuf, je mehr bns 2immlon fehlt. Die Zellen Der (Sotylebonen Ler Budgel fint gang mit, einem bellgelben Del erfüllt, bie Samen der Nadelhölzer nit einen mehr meip̈lichen Del.

Die ftilfit offhaltigen Materien, weldye in ben Eamen vorfommen, gehören in bie (Sruppe ber ßrotëntörper. Sie beftehen aus Rohlenftoff, Sau=

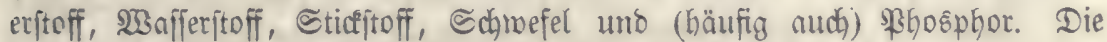

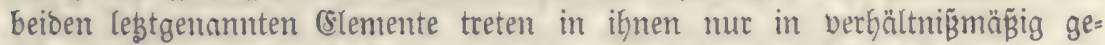
vingen Suantitäten auf, fint aber mit ben brei übrigen Bejtanotheilen fo feft berbunten, baß́ man fie nidgt bon ignen tremen fann, obne bie 3ujammen=

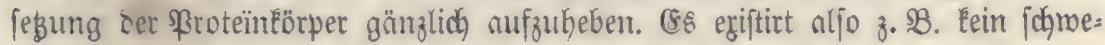
felfreie8 Proteïr.

Sn ben ธamen finoen jich bie \$roteintërper theils als eime Ërnige Ma= terie in ben Zellen (namentlich ben an bie Camenjichale angrenzenoen) abges lagert, theils gelöft in bem Bellaft vor. Sie laffen fieds in beiben Fällen leidat an ber rojenrothen fartbe erlennen, weldhe fie annebmen, wenn man fie

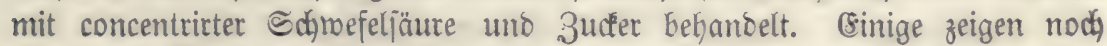

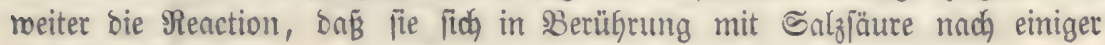
3eit blau fătben.

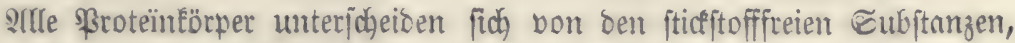
relche mil borfin aufgefübrt haben, fefre mejentlich burdh ifgre complizirte $3 u=$

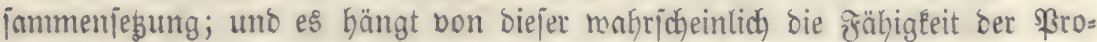

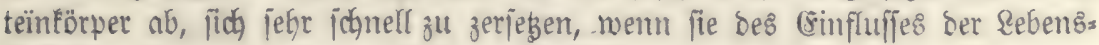
fraft beraubt uno mit ber Ruft in \$erbinoung gebracht werben (Berlegen ber Eamenidjale von ofrüdten, Zerquetid)en ber Bellen ac.)

Die roidtigften Sroteïntërper, roeldye in ben હamen vortommen, fino folgente:

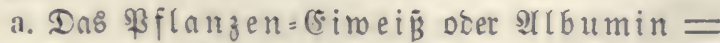

$\mathrm{C}_{400} \mathrm{H}_{310} \mathrm{~N}_{30} \mathrm{O}_{120}+\mathrm{P}+\mathrm{S}$, mobei aber $\mathrm{P}$ uno $\mathrm{S}$ blos tie Begen=

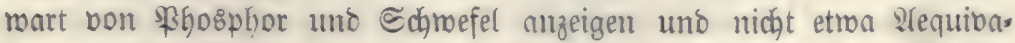
lentenbergältniffe voritellen follen. Dns 2lbumin ift löstich in Wafier, gerinnt aber bei einer Iemperatur bon ungefähr $70^{\circ}$. (58 fommt por= züglich in ben b̈lthaltigen ธamen bor. 
b. Das Pflanzentafeïn Dber ber Bflanzenfäfeftoff unteridgeibet fich bon borigem jeiner djemifichen 3ufammenjebung nadj nur burch

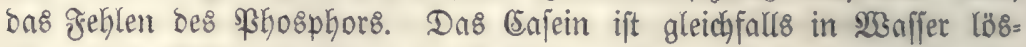
lich; beim Erbigen gerinnt bie Âflb̈|ung aber nidjt, fonbern zieht nur eine Sant an Der Dberfläh); Durch bie Shjleimbaut bes Rälbermagens

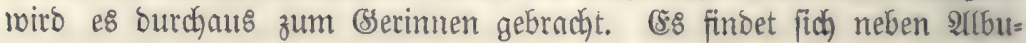
min in Den blfaltigen Samen z. B. Den Sajelnüfien, aber auch in ben

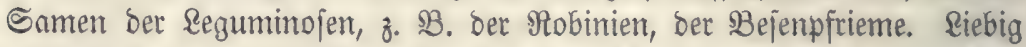

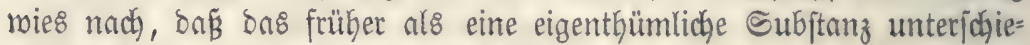
bene Regumin mit bem Enjein ibentija jei.

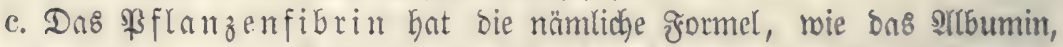

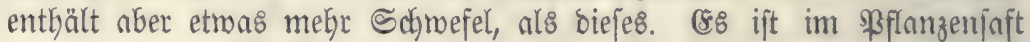

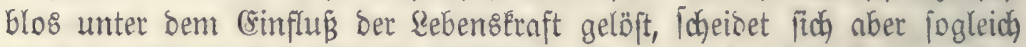
in Form eines gelatinöjen Nieberjhlags ab, menn ber betreffente \$flan= zentbeil zerftört, aljo z. B. Die Zelle, in ber es entfalten ift, geöffuet miro. Das gibrin fommt in gröpter Menge in ben Samen ber Cerea= lien neben Pflanzenleim vor, weldher ifm Elebente (sigenjahaften ber= leift, meB̈Galb e\& bemn aud) Rleber genannt wirb. Der spflanzen= lein theilt bie 3ujannnenjegung des gibrins, er ijt in 233 affer unlöslidw. Sn ben blfaltigen Samen tritt er böufig neben sllbumin auf.

IIm zu zeigen, in weldyen Qunntitäten bie borbemerkten Stoffe in Dest Gamen yortommen, theilen mir bie AYnalyjen Der (sidjetn uno ber Rog̈Eâtnnie mit.

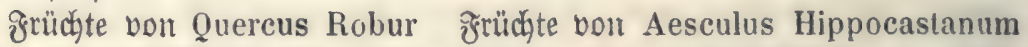
mact) Brande

\begin{tabular}{|c|c|}
\hline Stärłemehl & 20,28 \\
\hline Pflanzenleim & 18,00 \\
\hline (serbfäure & 2,8 \\
\hline grafer & 7,15 \\
\hline $\left.\begin{array}{l}\text { Ertractivitoff } \\
\text { uno } \mathfrak{B a} \text { a jer }\end{array}\right\}$ & \\
\hline
\end{tabular}
nach. Бermbftäbt

\begin{tabular}{|c|c|}
\hline Stärkemehl & 35,42 \\
\hline CEimein̈, & 17,19 \\
\hline (S)ummi & 13,54 \\
\hline ซ̌ettes Del & 1,21 \\
\hline Frajer & 19,78 \\
\hline Ertractivitoff & $\frac{11,45}{98,59}$ \\
\hline
\end{tabular}

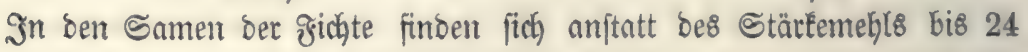
Brozente Del.

\section{Chentifđe Beränberungen, welde bie Beftanththeile ber Samen bei ber Seimung erteiden.}

Bei einer gewiffen Iemperatur, uno wemn bie Samen mit Feuthtigleit uno Sauerftoff in Berüfrung fich befinoen, beginnt eine mertwüroige Ber= änoerung mit ben Stoffen bor fid) zu gehen, meldge in ben Samen abgela= gett fint.

Der Saurertoff, mag biejer nun aus ber \&uft, ober irgentwo anbers 


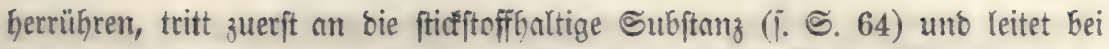
ifr einen Zerjęungeprozeñ ein, währeno bie ftidéftofffreien Materien, wie

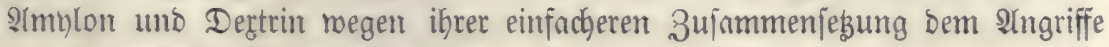

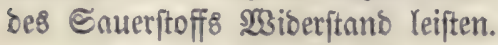

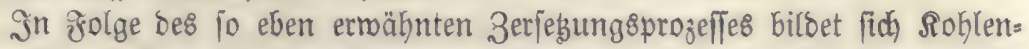
fäure. Die Ruft, melche die Santen untgibt, änoert bnbei ifgr Bolumen nidgt,

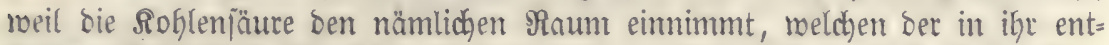
Galtene હaueritoff für fich bebauptet baben würbe. Der Sticfitoff der \$ro=

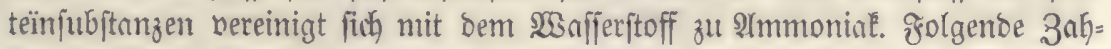
len, welche fich aus einem Berjutie ergeben, den Bouffingault mit (Erbjen

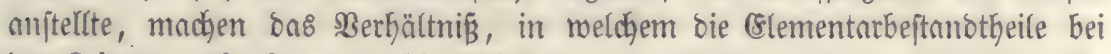
bet Reimung abnebmen, anjodjaulid.

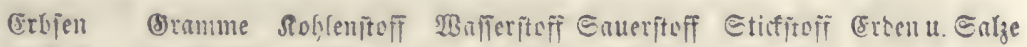

\begin{tabular}{ccccccc} 
bor dem Reimen & 2,237 & 1,040 & 0,137 & 0,897 & 0,094 & 0,069 \\
nady Dem Reinten & 1,075 & 0,472 & 0,065 & 0,397 & 0,072 & 0,069 \\
\cline { 2 - 7 } Berluft & $\mathbf{1 , 1 6 2}$ & 0,568 & 0,072 & 0,500 & 0,022 & 0,000
\end{tabular}

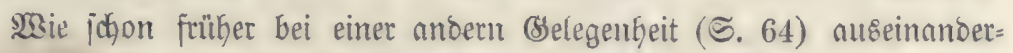
gejegt murbe, überträgt fid bie sewegung, in weld)e bie sitome des fticfitoff= baltigen Iörpers burch die Berbindung mit bem Saueritoff gerathen, auf bie

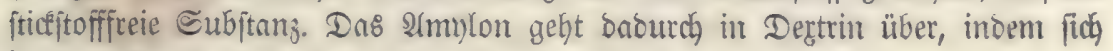
je zmei :lequibalente Des eriterent vereinigen.

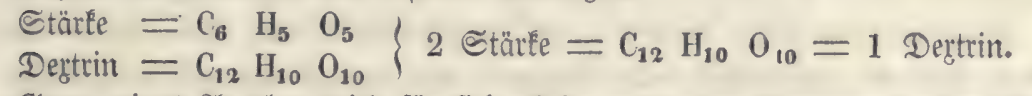

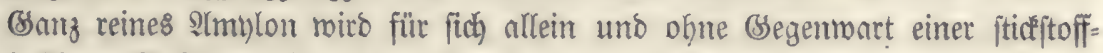
baltigen ๔ubjtanz niemale in Dertrin berwandelt.

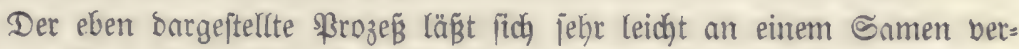

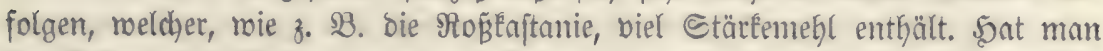
ber Rintanie bie Bebingungen zur Reimung gegeben uno unterjutht man bie=

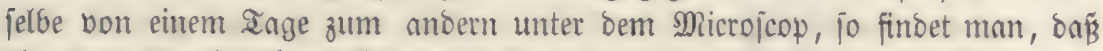
bie 3ahl ber Stärkentebltörner nad) und nach abnimmt und bnß an ifre Stelle eine johleimige Subitanz, Dertrin, tritt.

Unmittelbar aus bem Dextrin Eann fid) bie Membran zu neuen Bellen entmicfeln, benn bieje befïgt genau bie 3u|ammenję̧ung bon jenem, nämlich) $\mathrm{C}_{12} \mathrm{H}_{10} \mathrm{O}_{10}$.

Int ben Dlhaltigen Samen ift bas S(mblon burdh Del bertreten. S(uch biejes geht unter bem Cinfluffe ber fticfftofffaltigen Subjtonz in Dertrin über.

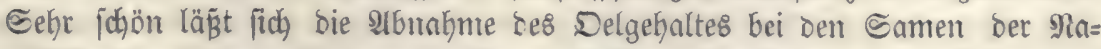
belhölzer berfolgen; íchon einige Inge, nadjoem bie Seimung eingeleitet wor=

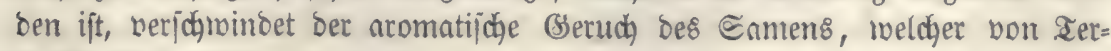
penthinäl berrübrt.

In einigen હamen, 8. B. benjenigen ber Betraibenrten erfährt bą 
Derttin nod) eine weitere Beränberung; es vermanbelt fiç unter शrufnabme bon zreien Plequibalenten $\mathfrak{B}$ affer in Iraubenzuder.

$$
\begin{aligned}
\text { Degtrin } & =\mathrm{C}_{12} \mathrm{H}_{10} \mathrm{O}_{10} \\
2 \text { 23affer } & =\mathrm{H}_{2} \mathrm{O}_{2} \\
\text { Traubenzuder } & =\mathrm{C}_{12} \mathrm{H}_{12} \mathrm{O}_{12}
\end{aligned}
$$

\section{Bebingutnen fiir bent Cintritt Des Seimacte?.}

Dieje murben bereits unter 2 angegeben. Sie find Eauerjtoff, J̌euth:

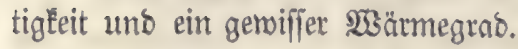

\section{a. eaueriton.}

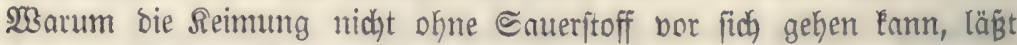
fich aus Dem Borkergehenoen (2) entnefmen. Der erfte S(ct bes Reimpro= zeffes bejteft ja immer in ber 3erjebung ber fticfitoffhaltigen હubjtanz, mas auf Roften bes Sauterftoffs geidjieht. Die Enmen werben aljo muth in einer

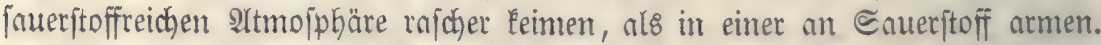

IIm jeben keimenten Santen bildet fich), wie oben bemertt vourbe, eine Scfichte Soblenfäure, herrühreno von ber Zerjebung ber fticfitoffhaltigen Ma= terie. Dieje Rohlenfäure mengt fich nur langfam mit ber umgebenton \&uft, fie fdhließst Den Samen von ber Berüfrung mit bem Sauerjtoff ber leştern ab. Sebes Mittel, welches geeignet ift, bie bon bem Samen entrwictelte Soh.

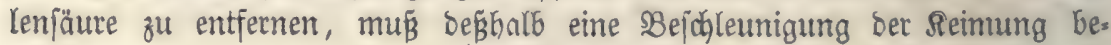
mirferer.

Saufintre mants zu biejem 3inec gebrannten (jeiner soblenjäure be= raubten) Sall an. Er brachte bie Samen unter eine (Slnglglodfe und ftellte neben fie eine Edyale mit Salte. Die Samen Keimten hier viel fojneller, als ohne bieje Borrichtung, unzweifelfaft aus bem Brunoe, weil ber Salk bie fith) entroicfelnoe Soblenjäure begierig aufnimmt.

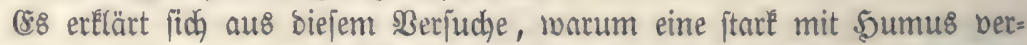
leste Eroe, welche jonjt jo mohlthätig auf bie Begetation wirlt, für Den Reim=

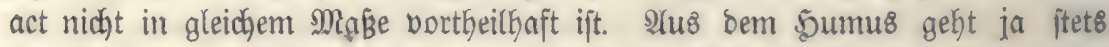
ein Strom bon Soklenjäure herbor, meldher ben Sauerftoff ber suft yon bem Samen abjoblieşt. Der Forftmann foll baker, went er jeine Culturjamen auf ifre Seimfähigéeit prüfen tvill, nicht gerabe eine Gumuşaltige (5roe ber= renoen. Sano, weldhem man es nidłt an greudjtigleit fehlen läßst, wirb biel idineller ein Rejultat liefern.

rsin Bra verbintbet fïh mit ben Beftanotheilen eines feften Rörpers nie

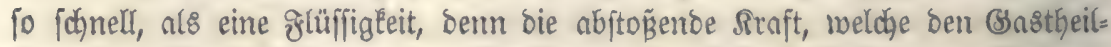
dyen eigen ift, tritt ber imnigen Berübung ber beiben Subitanzen binberno

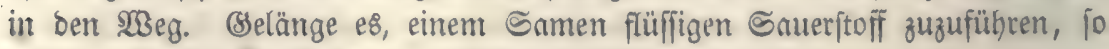
müßte offenbar bie Simung beffelben bejwleumigt werben.

(Es ift bis jest nod) nidjt gelungen, ben Saueritoff burdh (Eompreffion

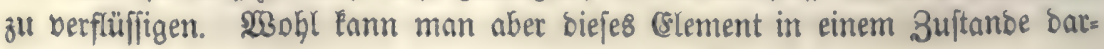


ftellen, weldyer nahe an ben ber Flüffigteit grengt, wenn man e8 aus $23 a f f e r$

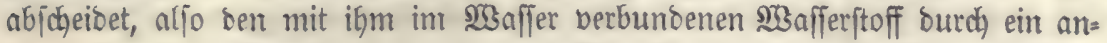

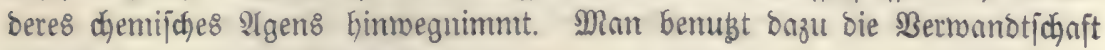
Des 5 ylors zum $\mathfrak{x a}$ afferftoffe.

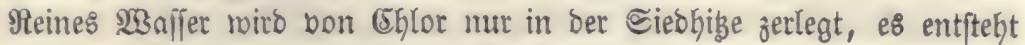

$$
\text { 이 } \mathrm{H}
$$

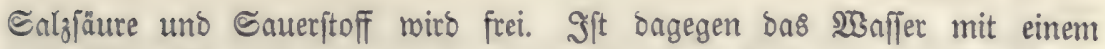
organiijchen Sïrper verumreinigt, fo erfolgt bie ßerbinoung bes C5flor8 mit bem 23 afferftoff auch bei gemöhnlicher Temperatur. Die organijche Subftanz befigt nämlich Bermanotichaft zum Snuerftoff; indem fie fich beffelben zu

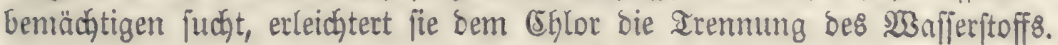

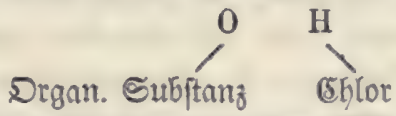

Der im stalus nascens aus bem flüffigen $\mathfrak{M a f f e r}$ freiwerdende Sau= erftoff muß gleidhjam als flüffig angejeben werben; er mirft, weil er eine in= nigere Berüfrung geftattet, weit kräftiger, als im gn\&förntigen 3ujtano.

Sumbolot fano, baß Samen bon Siefie (Lepidium salivum) in (હblor=

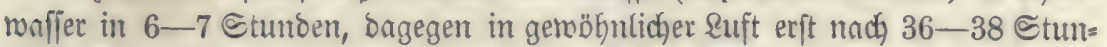
ben Eeimten. Sn erfterem bilbeten fie nach 15 ๔tunden $1,5 \mathrm{Mm}$. Lange 230 r zeldhen, wäbreno man fie bei ben andern faum bemertete.

(rin Ieig von Braunftein, Salzäure uno $\mathfrak{3 a f f e r , ~ i n ~ m e l d h e n ~ m a n ~ b i e ~}$ Samen legt uno onnn nuf $62^{\circ}$ bis $75^{\circ}$ Celi. erroärmt, joll nach Sumbolot

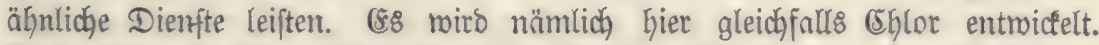
Braunfteit ift $\mathfrak{M r a n g a n f y p e r o r y d}=\mathrm{Mn}_{2}$; bringt mant ifn mit 2 গleq. Snlzjäure $\left(\mathrm{Cl}_{2} \mathrm{H}_{2}\right)$ und 23 nj]er zujammen, fo entjtegt zuetjt Mangandjlorio $\left(\mathrm{Mn} \mathrm{Cl} \mathrm{C}_{2}\right)$ uno $\mathfrak{3}$ affer $\left(\mathrm{O}_{2} \mathrm{H}_{2}\right)$.

$$
\mathrm{Cl}_{2} \mathrm{H}_{2}+\mathrm{Mn} \mathrm{O}_{2}=\mathrm{Mn} \mathrm{Cl}_{2}+\mathrm{O}_{2} \mathrm{H}_{2}
$$

Da8 gebildete Mangandhlorio kann als jolches in ber bize nicht bejtehen; e8 zerlegt fich in Manganchlorür uno in (5hlor, welches frei wiro.

$$
\mathrm{Mn} \mathrm{Cl}_{2}=\mathrm{MnCl}+\mathrm{Cl}
$$

In Sdjönbrunn brachte நumbolbt bie Samen von Clusea rosea, bei rbelchen man bie sinteitung bes Reimprozeffes bergeblich berjucht batte, mit= teljt biejes reigs jum 2lufgehen.

Berjuche, melthe ber Berf. mit mełrern Baum[amen anjtellte, füfrten

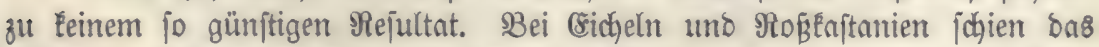
(5hlor bie Reimung mur in unbebeutentem Brabe zu bejohleunigen; Bucheln, હamen von Pinus sylvestris, Abies excelsa uno Abies pectinata in Eלflor= waffer gelegt, quollen zroar ftark auf, keimten bagegen gar nicht. 858 erlelärt fich bieje (Erjoheinung vielleicht burch Dent Delgehalt Der Samen. Das Del 


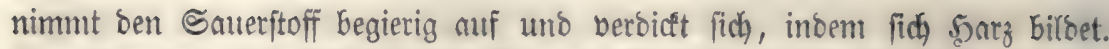

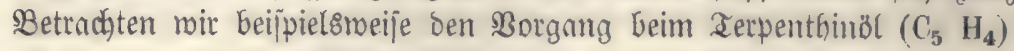
8 श्(eq. Terpenthinöl

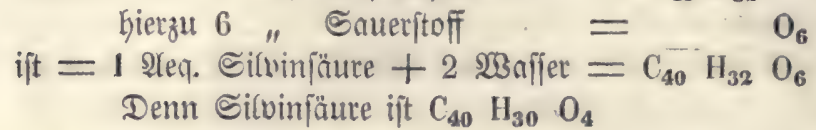
$=\mathrm{C}_{40} \mathrm{H}_{32}$

\section{b. Feuchtigfeit.}

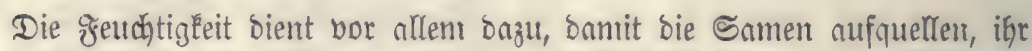
Bohumen bermełren und fomit bem Snuerftoff ber suft mehr âtigriffspuncte

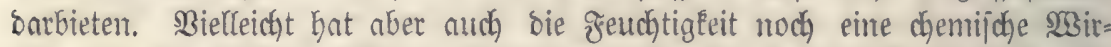

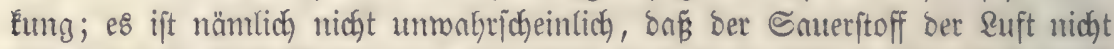

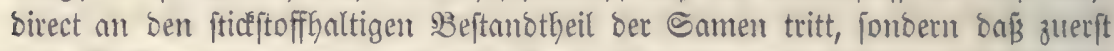
bns 233 affer zerlegt wirb, mornuf bem ber aus bem lefsteren freinerbento Enueritoff erft eigentlich bie 3erjebung der \$rotënberbinoungen im Eamen

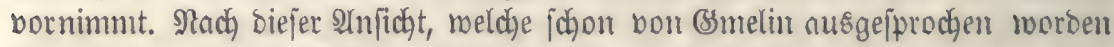
ift, würbe ber Sauerftoff ber Seuft ähnlidy, wie bas ç̧lor mirḱent.

\section{Drg. Subjtanz}

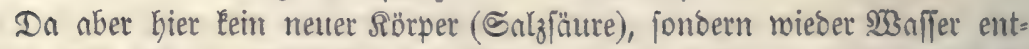

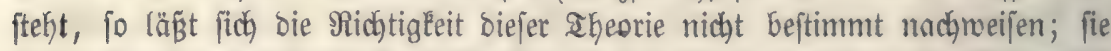

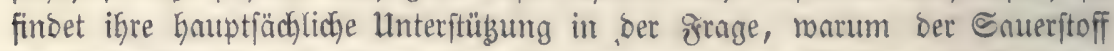
ber \&uft nidjt für fich alle:n, ofne bie (segenmart bon $\mathfrak{B a f f e r , ~ b i e ~ R e i m u n g ~}$ veranlaffer tönne.

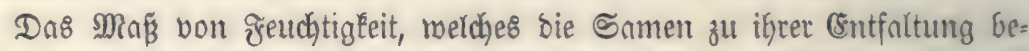

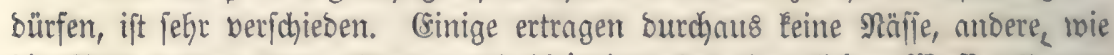
Die Samen von Vicia, Pisum uno biejenigen bet eigentlidgen 23 afferpflanzen

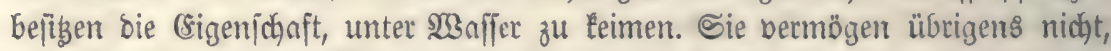
für fich) allein bas $2 \mathbb{3}$ affer zu zerlegen, fonbern nebmen cen Sauerftoff aus

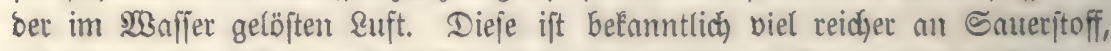
als bie gemöbnliche atmo/phärifhe suft, fie enthält nämlich anfatt 21 3olum=

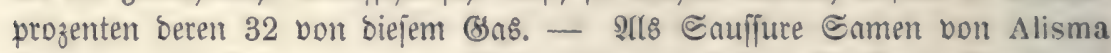

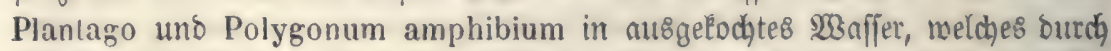

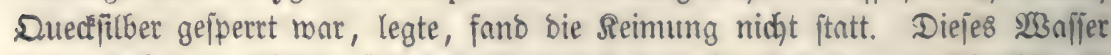
war burch bas Sieben jeines \&uftgebaltes betnubt worben. - Die ङamen bon Lemna erheben fich rährent ber Reimung an bie Dberflädye bes SWaffer\&; andere (d)werere Samen bleiben jebod) am Boben liegen.

Unneife Samen keimen oft fकhneller, als bolffänoig gezeitigte; es ift

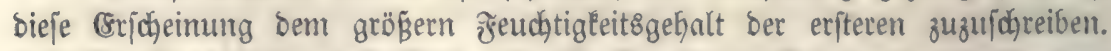
Snbefien ift es nicht bortheilhaft, unreife Samen zu culturen zu vertwenten, weil in biejen, wie ipäter ausfübrlid, nadggewiejen werben foll, nodh zu ronig 
2(mulon, Dertrin ober Del gebilbet ift. Auch find unreife Samen, eben me:

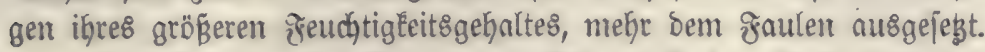

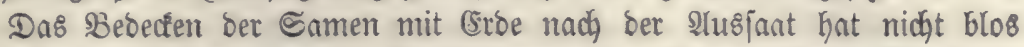

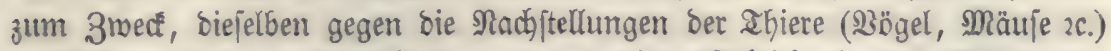

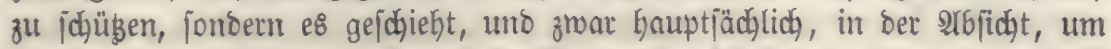

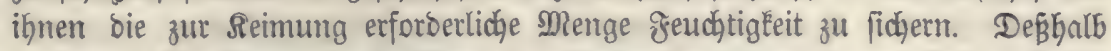

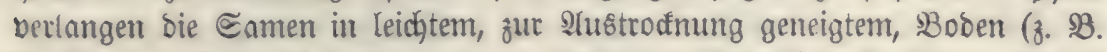

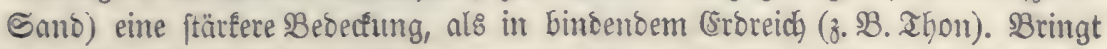
man aber bie Camen zu tief unter, fo feimten fie gar nicht mebr, meil fie bann von bem Saueritoff ber \&uft abgejchloffen find. Unterfudjungen über

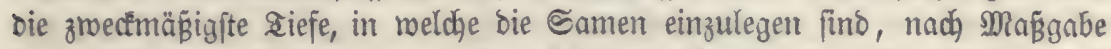

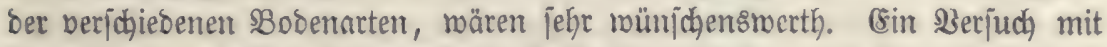

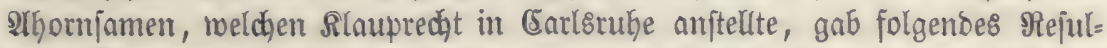
tat. Dben aufgejäet - ber $\$ 30$ ben war eine fanbige Bartenerbe - leimte

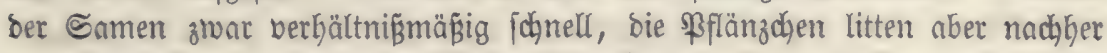
bon Irodenif̈ und gingen ber Mefrzabl nad) ein. (sinen 3oll unter ber (Erbe

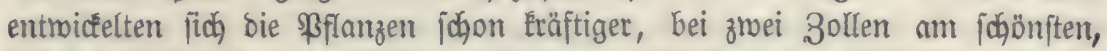
bei brei 3ollen ongegen blieben viełe aus. Schleiben bat Berjuche mit Sa: men von Agriculturgenäbj/en borgenomment. \&einjamen Eeimte bei 5 3oll Erobebectung gar nidht mehr, NBeizen entroicfelte fich bon 1 bis 3 unto 4 3oll immer fräftiger, je tiefer er lag, bon 5 bis 7 3oll oagegen immer ll̈m= merlicher. Bei 7 3oll blieben bie \$flanzen ofne Alebren', bei $8: 30 l l$ feimten fie gar nidat mebr.

MBie fobon bemerlt, ift ein zu tiefes Unterbringen ber Samen aus bem Srunbe nadytgeilig, weil biejelben bann nicht bie zur Reimung erforberliche

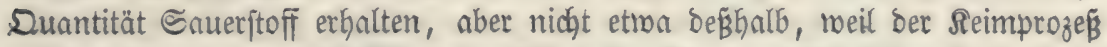

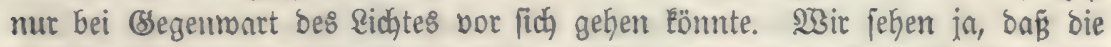
Samen fich ganz im Dunkeln entfalten. STuf ber moen Seite ift aber auds

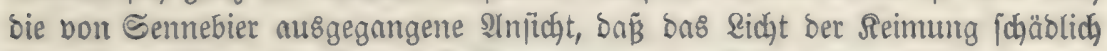

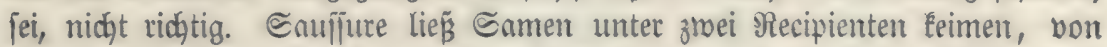
Denten ber eine burdjichtig war, währeno ber andere mur ein zerftreutes sidyt

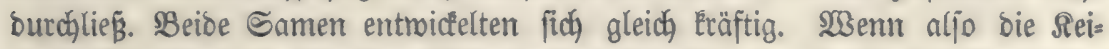
murg bei birect einfalfendem sichte gefindert wirb, fo ift bie urjache bavon

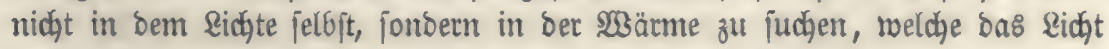
begleitet.

Bar oft exjeinen nach einer Soderung be\& Bobens, nach bem Roden ber Bäume 2c. an mandgen Drten Pflanzent, weldye jonjt hier fehlten. So

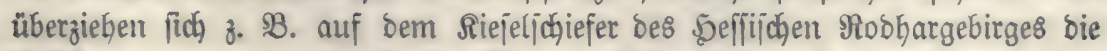
BBöjoungen bon neu angelegten 23 egen mit Digitalis purpurea (bem rothen gingerbut), auch menn bieje Pflanze in meiter (entfermung nicht borf́ommt.

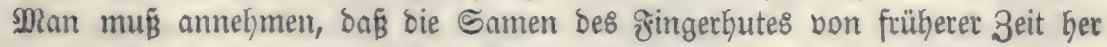

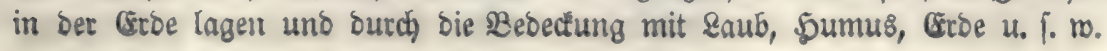


am Seiment gebinbert waren. 2Yuch bei Spartiun scoparium (ber Bejen= pfrieme) und bei senecio rulgaris (ber gemeinen Strelzmurz) bat man in berfelben Begent, forvie im Doenmalde bie nämliche Bemerfung gemacht.

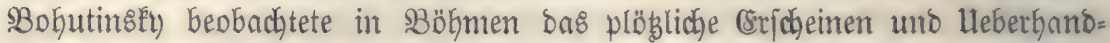

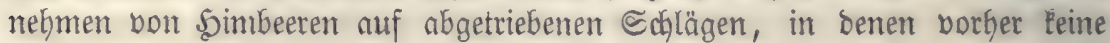
Simbeere zu jeben mar. (sir brachte (ङrbe aus 300 jährigen $B$ uchen=, Iannen=

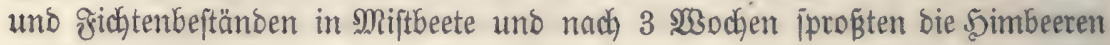
herbor.

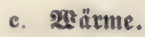

Der Reimprozeß ift von born Gerein blos dyemifdyer Natur; ber Snuer=

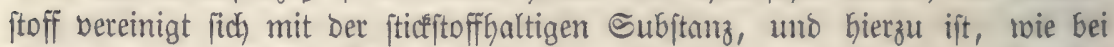

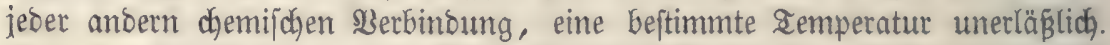

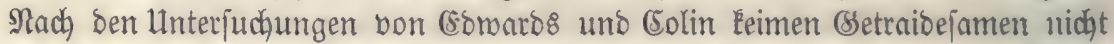

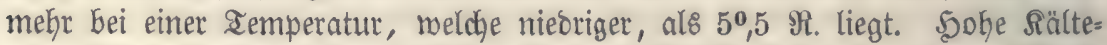
grabe jojaben ben gejörig abgetrodineten uno noch nicht geteimten Samen gar nicht, ober boch weit meniger, nls eine gefteigerte Şize. Nach ben beiben genamnten staturforjechern keimt (Setraibe nid)t mebr bei einer Iemperatur, meldhe $+36^{0} \Re$. überfteigt, mem jojon bei biejer Temperatur bie Reimltraft

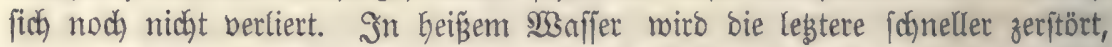
als in Dämpfen ober in trockener \&uft von ber nämlidhen 233 ärme, waht=

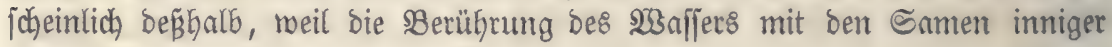
ift, als bie bon Dämpfen ober Bajen.

Uleber bie Srenzen ber Temperaturen, bei welchen bie Samen ber $23 a l d=$ bäume noch Eeimen, fint bis jebt nody Eeine birecten Unterjudjungen angeftellt

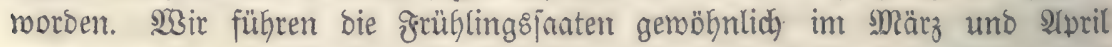
aนt, uno in biejen Monaten herricht im mittlern Deutichlano eine Temperatur

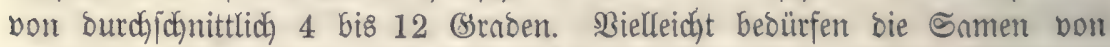
Denjenigen Şolzarten, beren Blätter fpät austreiben, einer größ̈ern $\mathfrak{3 a ̈ r m e ~ - ~}$ boch) ift bies blos eine Bernutfung, beren Bejtätigung bon genaueren Unter= fuchungen abjängt. - SWirb NabelGolzjamen bei einer Temperntur unter $44^{0}$ (5. ausgeflengt, jo leibet feine Reimfraft nicht, bei Anwenoung einter grö=

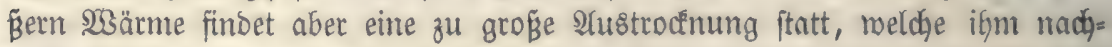
theilig toird.

Der Berlauf Des Reimactes ift bon einer gemifien $23 a ̈ r m e j u m m e ~ a b=$

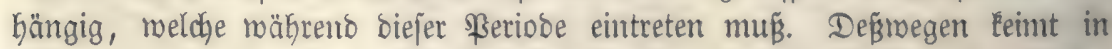
Schmeden bas Setraibe im April gejäet in 16-18, im Mai in 8-9, int Suni in 6-7 Tagen. - Da bie §rühlingŝnärme nur allmäblig in ben $\mathfrak{B O}=$ ben einoringt, fo brauchen bie Samen in ber Tiefe meht 3eit zum Reintell,

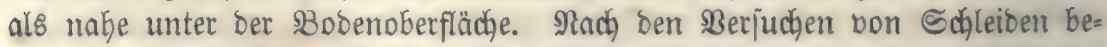
trug bei Betraibe uno süljenfrüdten ber Unterídied im 2lpril 10-14, im Juni 4-7 ฐage.

So menig bie Samen felbft bon orroft zu leiben haben, um jo empfinds 


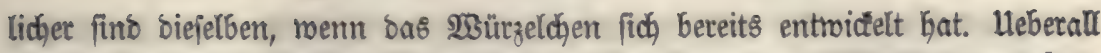

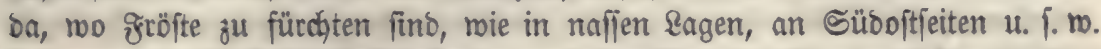

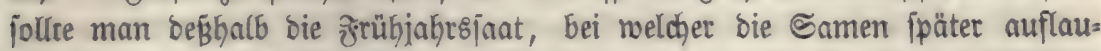
fen, ber Serbjtjant borziehen. Diejenigen Camen, weldje man gewöhntich nicht obennuf jäet, jonbern jorgfältig mit Eroe bebeưt, wie (sidheln, Saftanien,

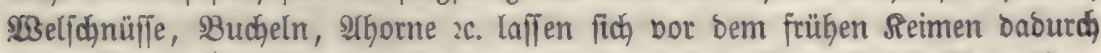

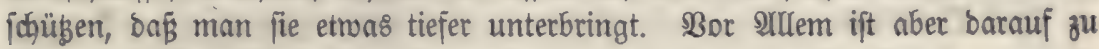
fehen, bas fie nidht hohl zu liegen fommen; hat man z. B. (sicheln unterge=

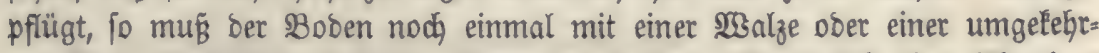
ten Egge überfabren werben. Denn im Booben pflangt fich eine Albnabme ber Iemperatur viel langjamer fort, al\& in ber \&uft, weil bie Eăltern \&uft=

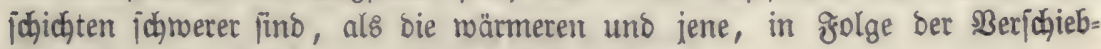
barkeit Der Easttheildhen, zu Boben finken können.

\section{Dauer ber Steimftaft.}

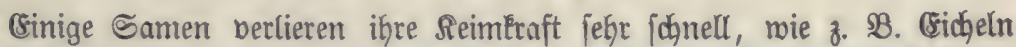
uno SBucheln; andere, zu benen borzüglich bie Betraibearten und auch einige ölthaltige gefjören, bemahren fie lange 3eit. Setraibe, meldjes man aus (sgyp=

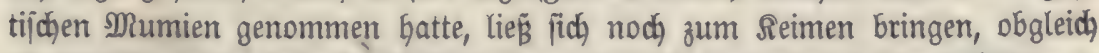
e8 ein Alter bon beinabe 3000 Jahren erreidht hatte. Im Durdhidnitt er=

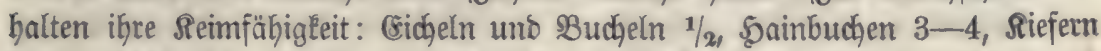

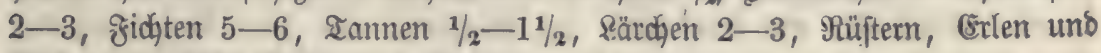
Birten $1 / 2-11 / 2$, গYhorn uno sidhen $2-3$ Jahre.

Dod) bängt bie Dauer ber Reimtraft feht bon ber BBehandlung ber Sa= men und der Methode ber Aufberwahrung ab. Unreife Samen nerlieren ibre

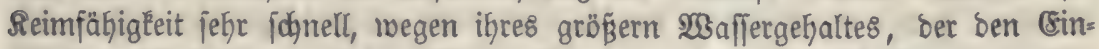

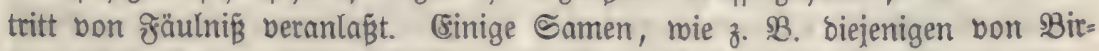

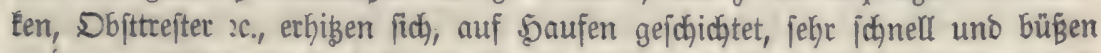
Dann an Reimeraft ein. (\&8 beginnt nämlid,), fo lange bieje Samen nod)

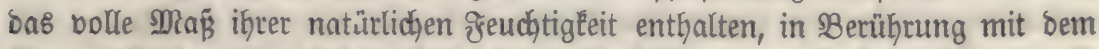
Sauerftoff ber Artmojphäre jogleidy bie 3erjegung ber ftidftoffhaltigen Sub=

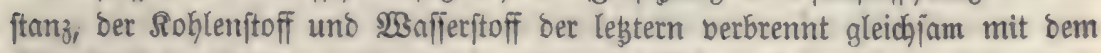

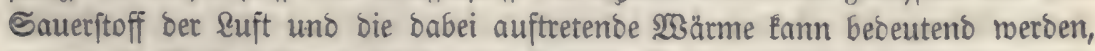
menn biele joldher Samen bidht auf einanber liegen. Diejer nadgtheiligen Crt= higung begegnet man, inbem man bie Samen bünn ausbreitet uno öfter\& umiçaufelt.

2Ule guten Methoben für bie 2Ufferoahrung ber Samen laufen barauf - hinaus, eine ober mehrece Bebingungen Der Reimung zu entfermen. Dahin gehört alfo, baß́ bie Samen gehörig abtrodnen, obgleidy fie auch nicht zu ftarł austrodtnen bürfen, meil fie fonft bas zur Seimung erforberliche Maß von geudhtigkeit berlieren. Nadhbem bie Samen lufttroden gemorben fino, bringt man fie in Bebälter, weldhe gegen bas Einoringen ber Freudhtigleit 


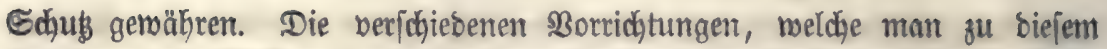
3mece ausgebacht hat, werben in ber "rorjtbenubung" abgebandelt. Beiläufig bemerken wir now, daß bas Bermengen ber Snmen mit Sobjlenpulber, wels

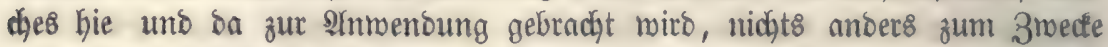
hat, als bie Samen trocfner zu erhalten; bie Rohle abjorbirt nämlich allen WBafferbampf; reldher mit ihr in Berübrung Eommt, fie berbichtet benjelben al ibret Dberfläd)e.

\section{3weiter Xbinitt.}

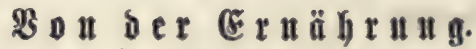

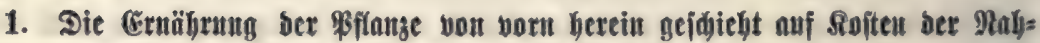 rungâtofite, weldie im Samen anfgeipeidjert finb.}

So lange bie Samen im Seimen begriffen find, und bis zur vollptänbi=

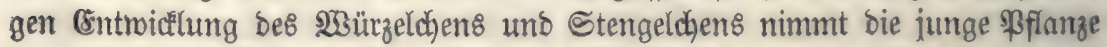

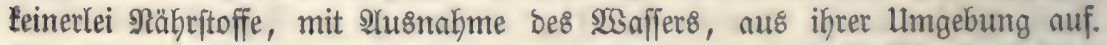
Man Eann Samen in Cijenoraht, in Rop̧hanren, ober auf Rojichpapier keimen laffen, in einer Altmojphäre, weldge ganz frei bon Soblenjäure ift. SW3urzel unઠ Stengel, fowie bie exften Blätter werben gebildet blos aus benjenigen Stoffen, melche bie sRatur in ben Samen jelbit niebergelegt bat. Das $\widetilde{S a}_{a}$

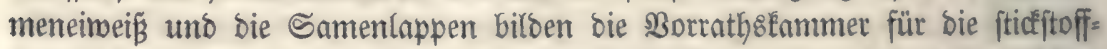
Galtige fowohl, als auch für bie fticfftofffreie ভubftanz. Den Sintheil, melchen insbejondere bie Samenlappen an ber Smährung haben, wies $\mathfrak{B}_{0}$ nnet (lln=

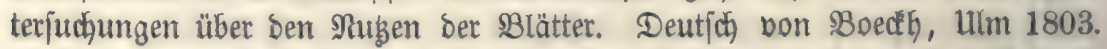
S. 110 ff.) burch folgenoen $\mathfrak{B e r j u c h}$ nach. "Sidh habe anfangs stuguit in ei=

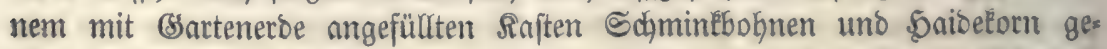
fäet. Sobals bie Samen aufgegangen maren, nabm id mehreren Sdymintbohnen bie Samenlappen, ebenjo mehreren \$aibefornpflanzen bie Samenblätter. Sid bebiente mid) bierzu einer (d)arfen Sdheere. Arnbere \$flanzen, forvohl ber

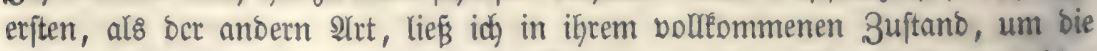
nötbigen ßergleichungen miftellen zu können. - Ungefäbr 12 Iage nachber Gabe idh bie erften Blätter ber Edymintébohnen, bie ifre Samentappen bebalten batten, gemeffen uno biejelben $3 \frac{1}{2}$ 3oll lang und eben fo breit gefunben; bie Blätter ber Sdymintébohne, bie ifrer Samenlappen bernubt waren, hatten aber nur eine Ränge von 2 3oll uno eine etroas geringere \$reite. \&ben bie-

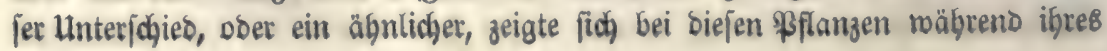


gangen $\mathfrak{M}_{3}$ achsthumb. Smmer fonnte man fie febre lecht unterid)etben. Die Edymintbohnen, bie in ifrem bollfommenen 3uftand geblieben maren, haben mehrere Blüthen getrieben, mehrere uno größ̈ere \$üljen angejebt, al\& biejenigen, weldhe ifret Eamenlappen beraubt worben waren. Das Arbfdyneiben ber Samenblätter hatte beim Saibelorn weit bemerlbarere Folgen, als bas शbnebmen ber Camenlappen bei ber Schminfbohne. Faft alle, meldje biefe Dperation ausgeftanden batten, fino zu Srunbe gegangen."

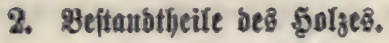

Die Stoffe, weldhe in ben Samen abgelagert find, reicjen nur eben

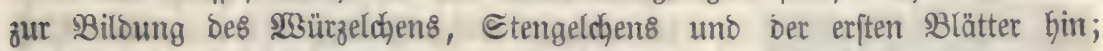
nachoem fie verbraucht find, ift bie Pflanze bezüglid if̧rer Ernäbrung uno insbejonbere if̧rer Maffenmełrung auf bie äuß̧ere umgebung angemiejen.

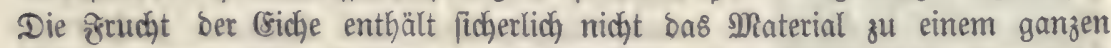

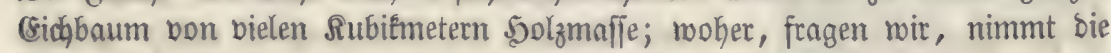
Pflanze bie Stoffe auf, mittelft beren fid ifgr 3olumen eine Zeit lang fort= währent vergröß̨̊ert?

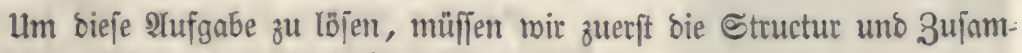
menfezung bes 5ूolze8 unterjuchen.

\section{a. Etructut bes \$olzes.}

Mit unbewaffnetem 2 ugge betrachtet, icheint bas $\mathfrak{S}_{0} l_{z}$ aus einer bald mefr, bald meniger bidaten, bon gröferen ober Aleiteren ßoren burchzogenen Maffe zu befteben. Unterjucht man aber bas $50 l_{z}$ mit einem Mifrojcop, fo bemerẗt man, Daß̈ es ein Aggregat bon jehr Eleinen zelten = ober röhrenförmigen Siörperçen iit.

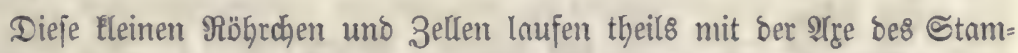
mes oder ber 3roeige parallel, theils ftehen fie minfelredyt auf biefelbe. Sm

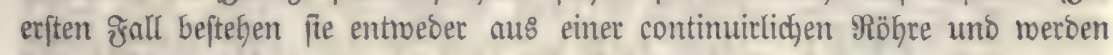

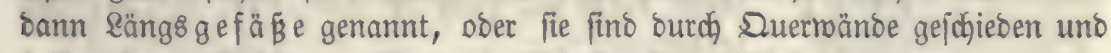
Geigen bann zellen. Sind bie Scheibemände fhief, fo nennt man ein 2ggregat bon foldhen Zellen Srosendyum, fino fie, was im 5olze feltener

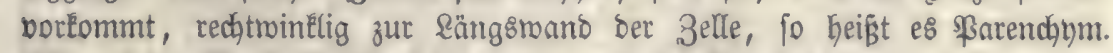
Die auf bie \&ängs = Sefäße ober Zellen rechtminflig ftehenoen Bellen werben Spiegelfajern ober IRarkftrahlen genannt. Sit, wie es häufig ftattfindet, eine

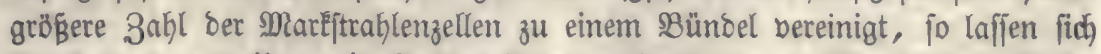

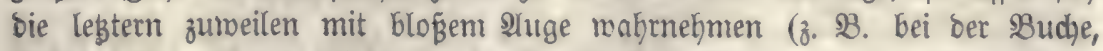
(Eidye); fie zeidynen fich bann burdy lebbaften Blanz aus uno führen baker

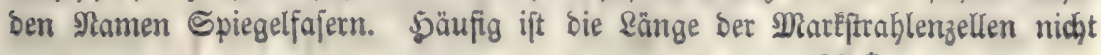



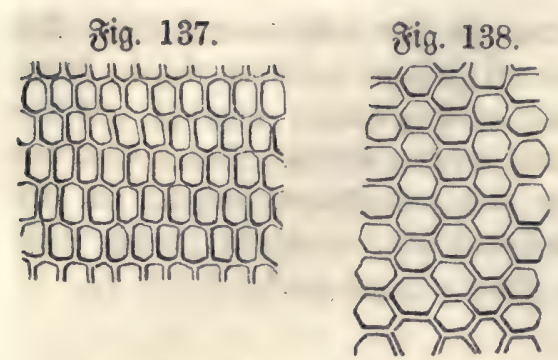

biel bebeutenber, als ifre șb̈he. Das Mark bejteht meift nur aus Zellen, welche eben fo breit, als God) und lang find. (\%̈ig. 137. ein Queridhnitt, Æ̧ig. 138. ein Rängb= idanitt burd' bas Mare ber \$latane bei 40facher \$ergröß̈erung).

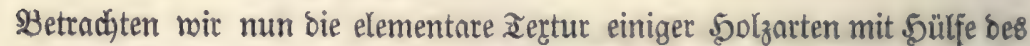
ஓig. 139.

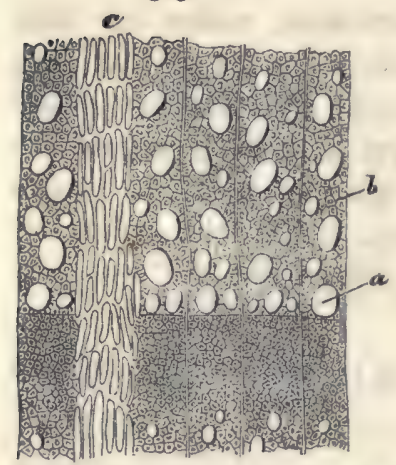
Miĺrojcops. જ̧igur 139 zeigt uns einen Duer=

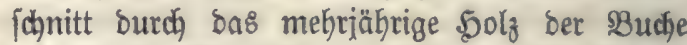
bei 40faç)er Bergröperung. Die runolidjen Deff= nungen, melche twir hier erblicfen, finto nidhts

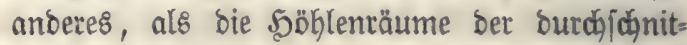

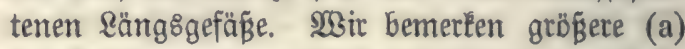
und Fleinere (b) Deffnungen; erftere gebören meiten bünnmanoigen (Sefäß̈en unઠ legtere engen bidmandigen $3 e l l e n$ an.

Bei Den reichen Solzarten fino die reiten (s)efäpe gemöbntich burch die ganze $\$ 2$ reite bes Jahrrings ziemlich gleidłmäzig vertheilt; bei ben harten Solzarten (Buche und (Eiche) beginnt bagegen ber neue Jahrring ftet8 mit weiten Ssefären uno enoigt mit engeren 3ellen.

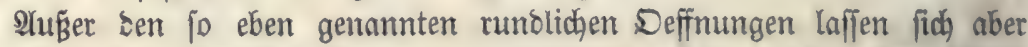

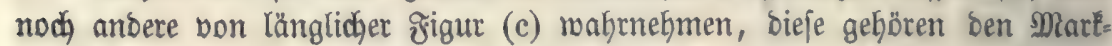
frahlenzellen an.

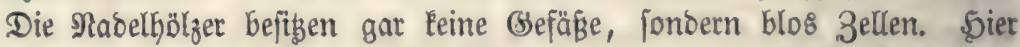
liegen aber bie weiten 3ellen nicht znoijoben ben engern bertheilt, jondern eв

ஓ̊ig. 140.

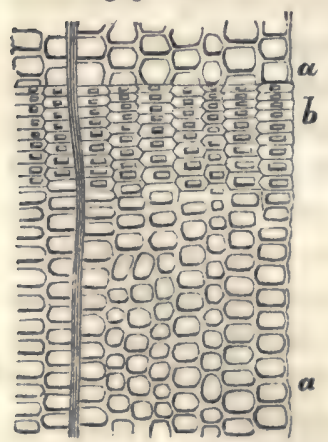

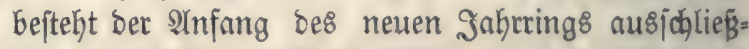
lich aus meitern, edigen 3ellen (a) und endigt mit engeren (b) bon gleicher Form (Fig. 140. Quer= jđynitt burch bas Solz ber Siefer bei 40 facher Bet= größzerung).

Da bie einzelnen Iheile Der Sahrtinge ziemtios gleidymäßig von Mlartitrablen burd)zogen fino, fo können bie legstern auch nicht alle aus bem Mart entipringen; es erzeugen fid mit jebem neuen Sahr: ring neue Mareftrablen, welche fich in Eeinem $\mathfrak{Z}^{u}=$ jammentang mit bem $\mathfrak{M a r k}$ befinden.

ঔübren wir nun einen Sdynitt burch irgend einen Diameter parallel mit ber 2rge bes Ctammes ober 3meiges, io erfent=

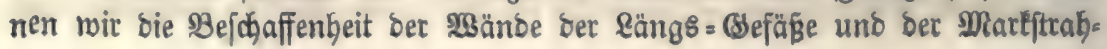




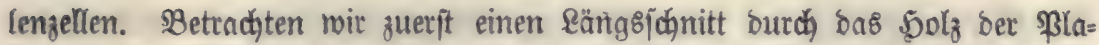
₹ig. 141.

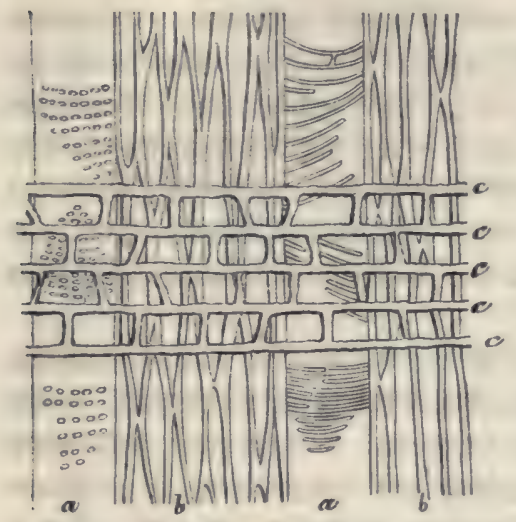
- tane (§ig. 141, bei 150 facher $\$$ ergrö= Berung). (Es ftellen a, a zmei reite (refäßie vor, ifre $\mathfrak{M a ̈ n \delta e ~ f i n d ~ m i t ~ z i e r = ~}$ liçen Billoungen bejegst, ballo beftehen fie aus Hleinen, mehr ober meniger tes gelmäß̈ig zufammengeteiheten Tüpfeln, ballo aus treppenartigen Duerftreifen.

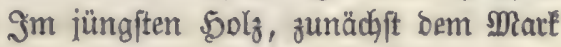

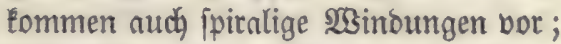
bieje fehlen aber burdjaus in ben Jahts ringen bes mebr als einjährigen 5ol= zes, jomie bei ben Nabelhölzern. b find bie engen prosendoymatifiden 3ellen. Sarendyymellen entbalten nut menige

જig. 142.

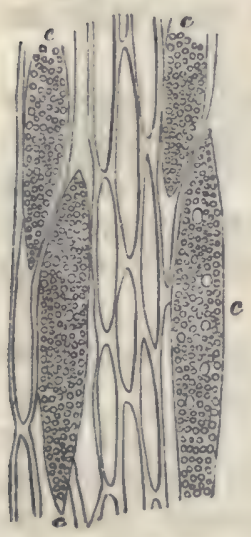

§ig. 143.

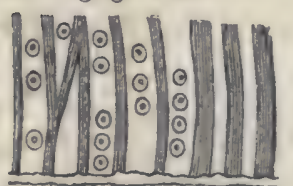

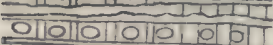
ollo

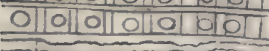

DIN NoloIII

nen rollen. Die 5olzarten, wie z. $B$. Sie (siche. $\mathrm{c}$ sftellt wie borfin beim Duerjunitt bie Markftrablen vor. Die leştern jebzen fich bis in die Rinoe fort und löfen fich nur im ærühjabr, wenn ber Saft in bie 'sBäume fteigt uno um Johannib, menn et zum zmeitenmal faft eben jo

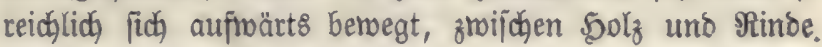
ßig. 142 zeigt einen Schnitt parallel ber Tangente bes Ulmfangs, bie Dvalen e jtellen Den Duerjodnitt butdh einige $\mathfrak{B}$ ünoel Marfiftrablen vor.

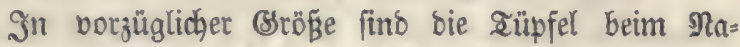
belholze entmidelt; ( ̧igur 143, عängsidhnitt burch) bas 5olz der Riefer im Sinn bes Diameters). Sie fino hier jorwohl ben Marfftrablenzellen, als auch ben Rängrgefäßien eigentfümlich, fommen aber bei leģtern nur auf ber Seite bor, weldye nach, ben Marêftrahlen Gin geridytet ift.

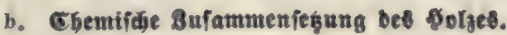

Die röhrenartigen (STementarorgane det Pflanzen fint in Der Mebrzahl ber Fälle feine urjprüngliçe $\mathfrak{B i l}$ bung, fonoern aus Zellen bon gleicher 5öbe uno Breite burd) Rejorption ber Querjdeiberänbe entftanden. Dieje Zellen bejtehen in ihrer erften IInlage aus einem ganz bünner \$äutchen, weldjes wir Membran nen= borfin genannten 3eichnungen auf ben $\mathfrak{W}_{\text {änoen ber }}$ 
Befäge erzeugen fid) erft fpäterbin surch) शrblagetungen aus ben Eaftbeftano: theilen.

Die Membran (aud) (seluloje genannt) ift intmer ftidftoffirei; fie enthält

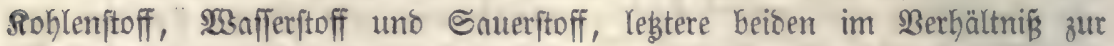
SWafferbildoung. Die grormel ift $\mathrm{C}_{12} \mathrm{H}_{10} \mathrm{O}_{10}$ aljo abjolut gleidj berjenigen

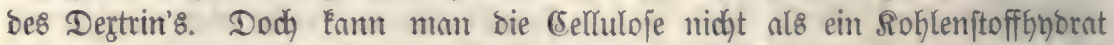
anjeben, benn $\mathfrak{W}$ afferftoff uno Sauerftoff fint in iffr nidyt als mirlliches

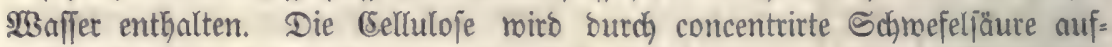
gelöft; fie färbt fich blau, menn man fic mit verbünnter Sdymefelfäure uno Soo bebandelt.

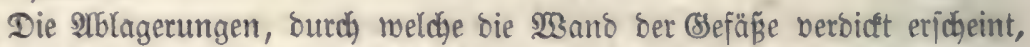
enthalten beim Solze neben Roblenftoff, Snueritoff uno 23 afferftoff imnter Stidftoff. Snoem fie bie Membran nicht burdyaus, fonbern nur ftellenmeije betleioen, entjtehen die jpiraligen, trepłyenförmigen, ringartigen э. Beichnun= gen; Iüpfel bilden fid, ba, wo bie शrblagerung entweber gar nicht, ober in

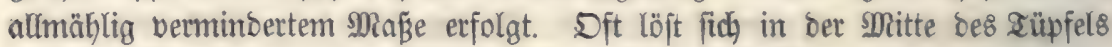

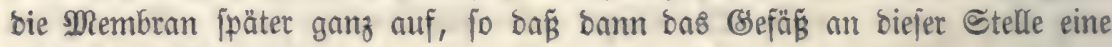
wirllidje Deffinung befibt.

Die

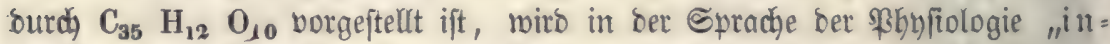
cruftirende Materfe" ober "Rignin" genannt. Sie untericheioet fich

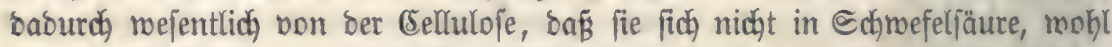

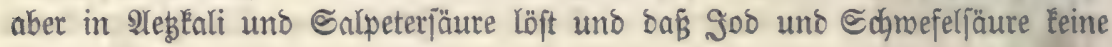
blaute Färbung bei igr herborbringen.

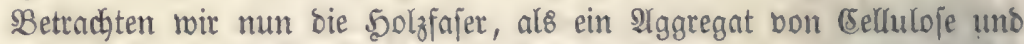

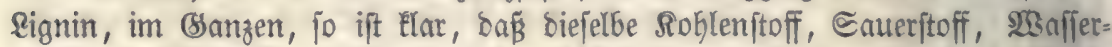
ftoff uno Sticfitoff entbalten mußs. Sierzu fommen aber, ronz rir bisher unerwähnt gelaffen haben, gemiffe unorganijđje ভubjtanzert, nämlich Sali, Natron, Ralk, Magnefia, Ihonerbe (?), Gijen, Mangan, Bhosphor, Shroefel, (BGlor, Siejelerbe. Diefe find aber biel mefyr in ber incruptirenton Materie, al\& in ber Membran entfalten; fie laffen fich bon ber \$olzfajer nur butch (sin= äpcherung bolfitänoig trennen.

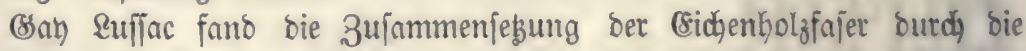
frormel $\mathrm{C}_{36} \quad \mathrm{H}_{22} \mathrm{O}_{22}$ auggebrüat; er überjah aber bei biejen 2Inalyfen ten

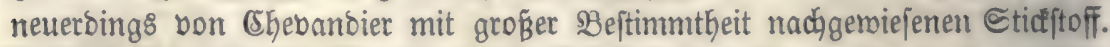
Da bas Sols mur ein 2lggregat bon Celluloje uno Rignin ift, fo Eam man

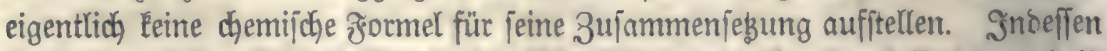
bietet ber Bebraudy berjelben in ber \$36yfiologie mandhe Bortheile bar und ift

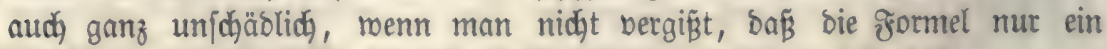

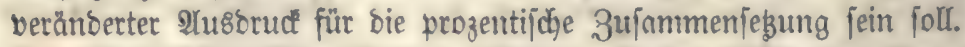

Nach ber obigen formel wären aud im Solze ber Sauerftoff und

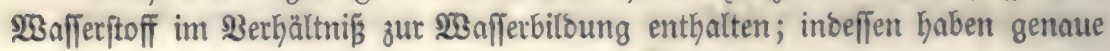




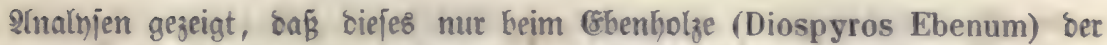

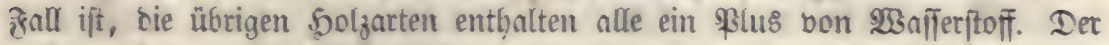

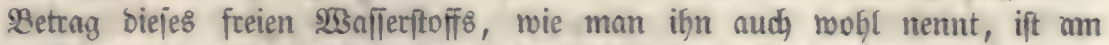
gröften bei bem barzreidgen Sabelfyolze und bei ben weidgen 5olzarten, wefz=

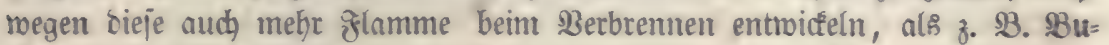
(b)en $=$ unto (sidjentyols.

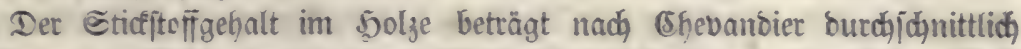

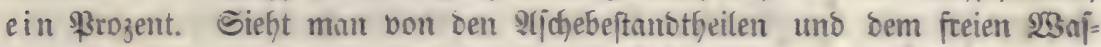
jerftofi, befien Sunntität bei ben meichen \$olzarten bi\& über $1 \%$ bom

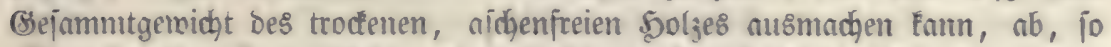

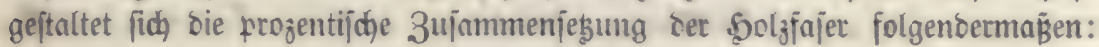

\begin{tabular}{lr} 
Soblenftoff & 51,65 \\
SBafferftoff & 5,26 \\
Sauerftoff & 42,09 \\
Stiditoff & 1,00 \\
\hline & 100,00
\end{tabular}

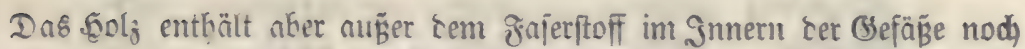

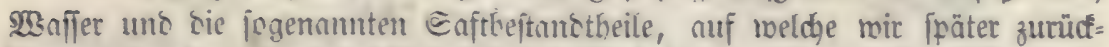

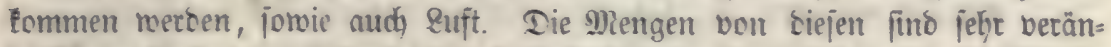

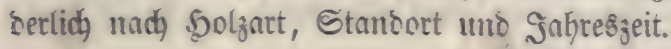

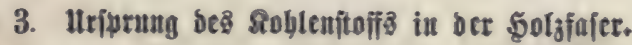

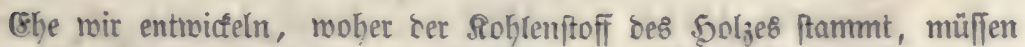
wir ben Etanspuntt feitifellent, von weldyem woir bei ben folgenton unterjud)= ungen ausgeben werben.

Die Chymie bुat die आuammengeiegten Rörper in ifre demente zerlegt,

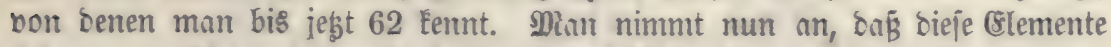
fid froar mit einanter berbinten, aber niddt in einancer übergeben Eönnen.

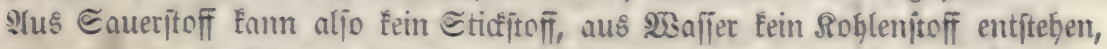

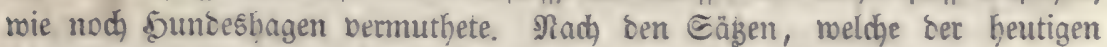

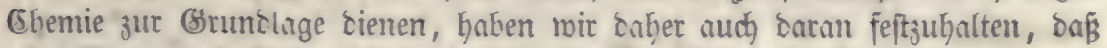
alle Elementarfofie, weldhe fith in ber Pflange finten, ihr als joldge von

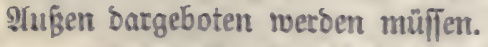

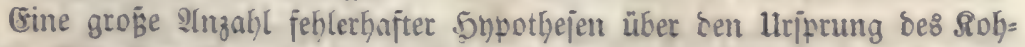
lenjtoffs fällt bon born herein in fich ơjammen, werm man ermittelt, mie

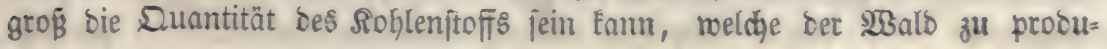
ziren vermag.

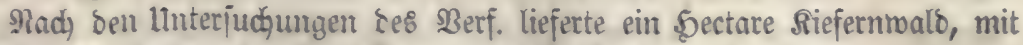

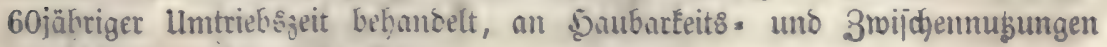
surdjichnittlidg folgenten (Ertrag: 


$\begin{array}{cccc}\text { Sdheitholz } & \text { Prügelholz } & \text { Stodthclz } & \text { Reisholz } \\ 8,10 & 1,60 & 1,13 & 1,81 \text { Stere, }\end{array}$

mobei zu Sdyeitholz alles \$olz über 125, zu Frügetholz bas bon $75-125$,

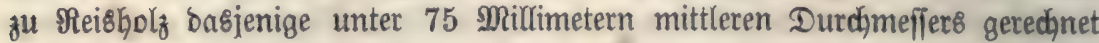
murbe.

Sin bem. vorliegenten gralle rogg 1 Stere getrodnetes Sdjeitholz 275,

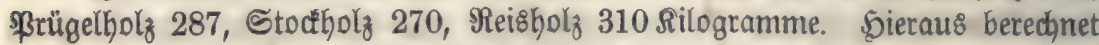

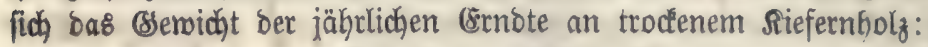

\begin{tabular}{|c|c|}
\hline Sodyeitholz & 2227,5 \\
\hline \$rügelfolz & 459,2 \\
\hline Stodtholz & 305,1 \\
\hline ßeisholz & 561,1 \\
\hline
\end{tabular}

Naḑ ben Unterfudhungen (5hebandiers entbält in 100 Theilen soblenftoff SBafferftoff Sauerftoff Sticfitoff

$\begin{array}{lllll}\text { Sdeitholz } & 52,15 & 6,16 & 40,59 & 1,10 \\ \text { \$rügelholz } & 52,15 & 6,18 & 41,09 & 0,58 \\ \text { アeisholz } & 50,97 & 6,02 & 42,41 & 0,60\end{array}$

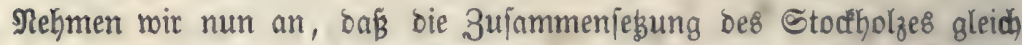

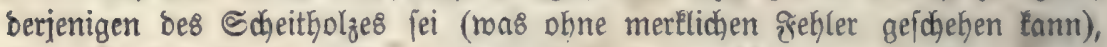
fo ergibt fich für bie jährlidje ßrobuftion bet verfochiedenen Eortimente pro Sectare

\begin{tabular}{|c|c|c|c|c|c|}
\hline & soblenftoff & 2Bafferftoff & Sauerftoff & Stiçiftof & \\
\hline Sdyeitholz & 1161,6 & 137,2 & 904,2 & 24,5 & Silogramme \\
\hline Prügelלolz & 239,5 & 28,4 & 188,7 & 2,6 & " \\
\hline Stoctholz & 159,1 & 18,8 & 123,8 & 3,4 & " \\
\hline \multirow[t]{2}{*}{ Reişolz } & 286,0 & 33,8 & 237,9 & 3,4 & $t^{2}$ \\
\hline & 1846,2 & 218,2 & 1454,6 & 33,9 & " \\
\hline
\end{tabular}

Ein நectare Sitefernmald probuzirt aljo unter ben angegebenen $\mathfrak{B e r b a ̈ l t s ~}$ niffen jährlich 1846, 2 Sil. Sohlenftoff.

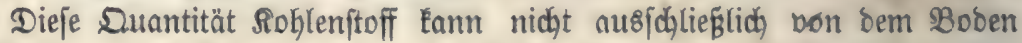
frammen.

Sn Sannober, an ben Ufern ber Dft = uno Norbjee, in ber Marl

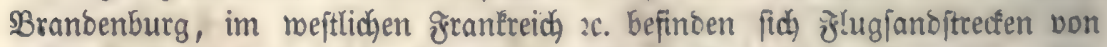

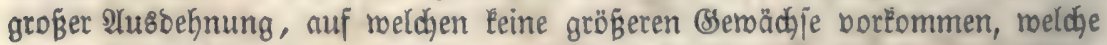
ben $\mathscr{B}$ oden mit Sumus bereidyern fönnten. Diejer Boben entfält oft fo menig

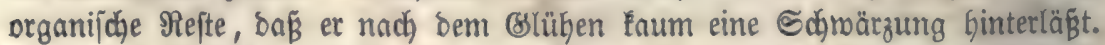

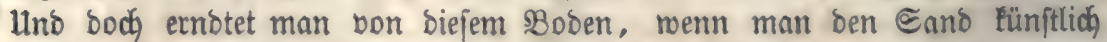
berubigt und ifn mit Siefern in (Eultur bringt, jährlid, eine Quantität Soblen= ftoff, bie ber oben angeführten febr häufig nidgt nachjteht. Diejer Roblenjtoff rübrt unmöglidh auళ bem $B$ Dben her. 
Die श्alde uno Rava, weldhe bie Bulfane auswerfen, ift betühmt wegen

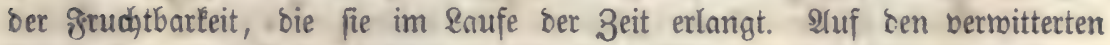

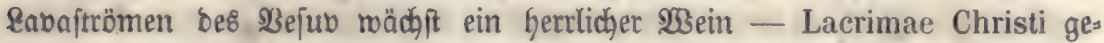
nannt. Im Val Demone am Yetna, auf alten \&abaftrömen, trifft man rie= jenbafte Saftanienbäume, untern anoern Den Castagno di Cento Cavalli,

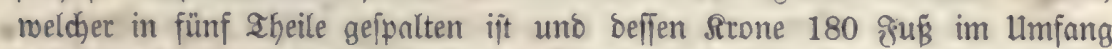

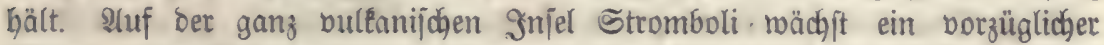
2rsein. Die 2liche und \&aba tommen aber frei von Roblenftoff aus bem Srater, weil bie Begentwart oon Sauerftoff uno eine fehr hohe Temperatur bie Roble nidgt unverbunben beftehen laffen, fie vielmehr in Rohlenfäure ummandeln würoen, welche als (Bas entweidjen müBte. Der Soblenftoff, meldhen bie Berwächle befizen, bie auf Eaba unb 2liche begetiren, Eamn nicht aus bem Boben frammen.

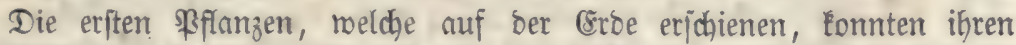

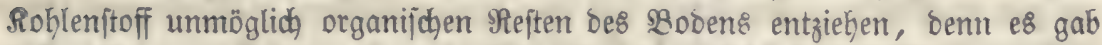
feinen Uthumus. Doer ift e\& benffar, baf ber Schöpfer zuerft abgeftorbene Dheile von Drganismen vor ben lebenoen erzeugt babe?

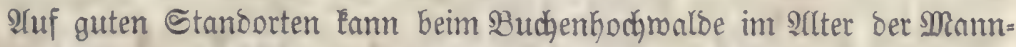
barkeit jährlich eine (srnote von 1000 Rilogrammen malbtrockenen \&aubes et= folgen. Nehmen mir an, es jei beim Atbetriebe eines Buchentodymalbes ber \&aubabrourf von 10 Jabren in noch unverweftem 3uftande exbalten, fo mür= ben fich auf einem \$ectare 1000 Rilogramme saub borfinoen, meldhes etro $6 \%$

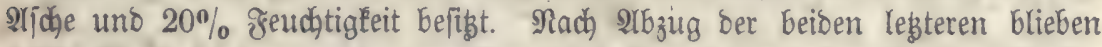

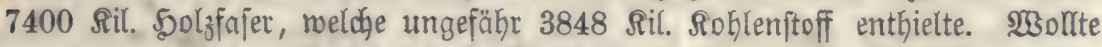

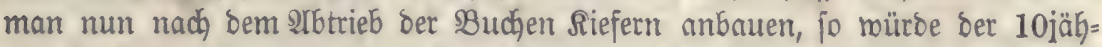

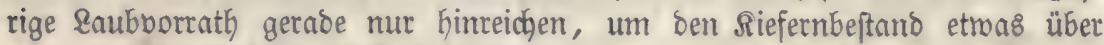

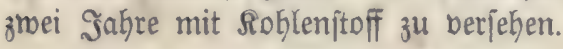

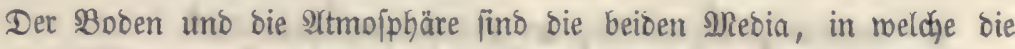
Pflanzen Gineinragen; ba der Roblenftoff im Boben zur Ernäbrung ber (seroächje nidht genügt, jo müflen wir jeine Duelle in ber 2 tmojphäre fuchen.

Reicht benn aber ber Rohleniäuregehalt ber Ruft hin, um bie 3 egetation auf ber ganzen (stbe mit Sohlenjtoff zu berjorgen? Die Întwort auf bieje

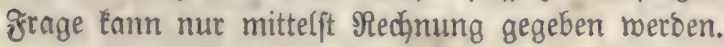

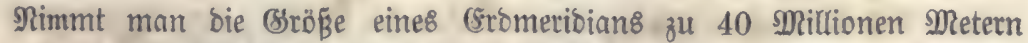
an, io ift bie Sberfläche ber Erbe, menn man legstere als bollfommene Rugel betrachtet, $509296000000000 \square$ Meter. Dentt man fidh, bie Crrbe jei an= ftatt mit·Ruft, mit Rueciftber bon bem am Meere herrjhenden Barometer=

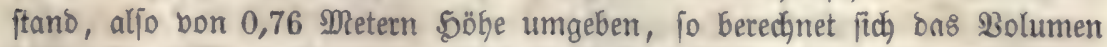
biejer Quediflbermaffe zu 387064960000000 (5ubilmetern. Das. ppezifijбe

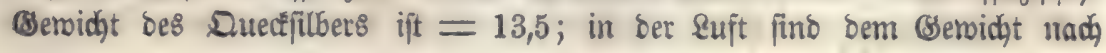


0,0008 Iheile Sohlenfäure enthalten; in leşterer hat man 0,2727 Rohlenftoff; hietaus ergiebt fich bas (semidyt bes in ber Soblenfäure ber suft befindlidjen Rohlenftoff\& gleidh 1139970000000000 Ril. obet circa 1140 Bitllionen Rilo=

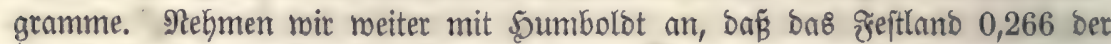
(stooberfläche betrage, fo berechnet fid bie 2tusbehnung ber zur \$flanzenpro=

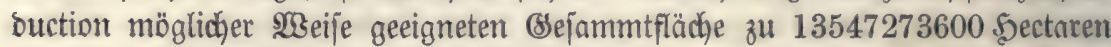
und bie Duantität bes auf berjelben erzeugbaren Roblenftoff zu ungefägr 27 Billionen Silogrammen, wobei aber angenommen murbe, baß̧ auf bem Sectare nidat, wie in bem borbin berechneten Beipiele 1846,2, fontern nod, mehr, nämlich 2000 Silogramme Sohlenftoff probuzint würben. Der Sohlens ftoffgebalt ber Atmojphäre würbe alfo hinreid)en, um bie Begetation bes ge= fammten Fejtlandes, bei einer jährlichen (Etzeugung von 2000 Ril. Rohlen= ftoff pro Sectare $\frac{1140}{27}=42,22$ Sahre lang mit sohlenjtoff zu berjełen.

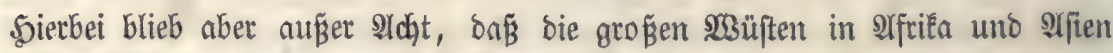
Feinen Pflanzentuths von 98 ebeutung befizen.

Die voritekenoe Redhnung betweift zur Benüge, baßß bie in ber artmo= fphäre ftets vorräthige Menge Sohlenfäure ben Bebarf ber 3egetation voll= ftänoig zu befriedigen bermag. §reilich würbe in 42 Sabren ber borhandene soblenjtoff abjorbirt jein, allein fajt fämmtlicher sobjenftoff, welcher aus ber

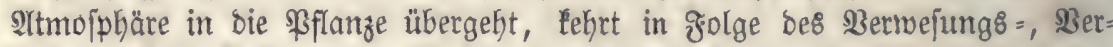

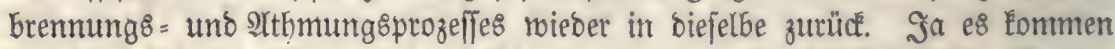

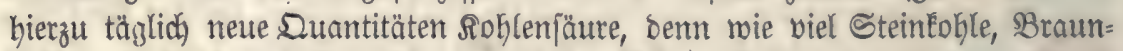
Fohle uno Iorf mirb fortmährent aus der Broe geföroert uno berbrannt!

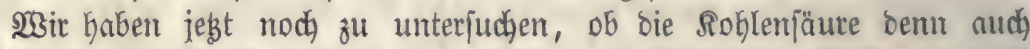
wirtlich von ben Siflanzen aufgentommen uno, im bejabenoen galle, in mel= der $\mathfrak{2}$ Beife fite affintilitt werbe.

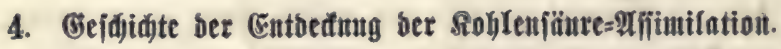

Sn Der Mitte be\& berfloffenen Sagrbunderts (1747) beobachtete Bonnet,

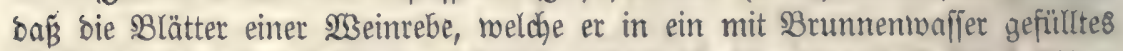

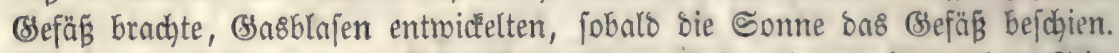
Sie famen theils aus ber Blattflädge felbjt, theils aber aud von ben Stie= Len uns 3weigen. Bejonbers ging bas (Sas bon ber untern Seite ber slätter aus. Mit Sonnenuntergang berloren fidh bie BBlajen; am folgenden Morgen, als bie Sonte ifre Strahlen auf bns SSlas narf, erjhienen fie wieber. Dies bauerte einige ange fort, bann börte bie (sthalation gänzlich auf.

Bonntet Gielt bas Bsas für gemöhnlidje suft, bie an ben sBättern fiod angebängt Gabe. (8r beftrich legstere roieberbolt mit eintem \$injel, um bie \&uft zu entfernen - ein Berfahren, meld)es er bei einem nnoern ähnliơnen Berjud̆ mit Erfolg angemanot hatte. Iroboem fano bie Basentwickelung ftatt. SIls 


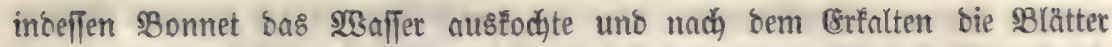

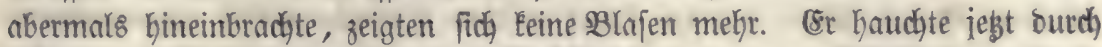

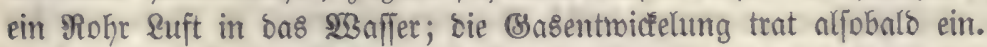

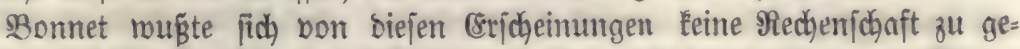
bert. Eeine Ertelärungen gingen von ber Borausfebung aus, die Blajen enthielten gemeine atmojphäriịdge suft.

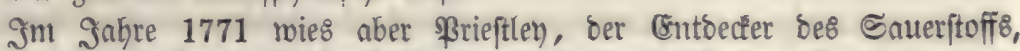

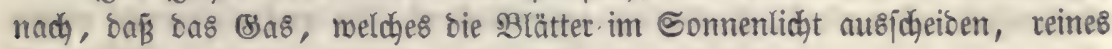
Drugen fei.

Sennebiêt etflärte 1792 ben uriprung bes Sauterfoffgajes, meldjes bie Bfianzen unter ben angegebenen \$erbältniffen bon fich geben. (Er zeigte, bafis

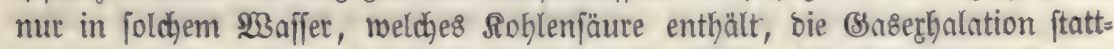

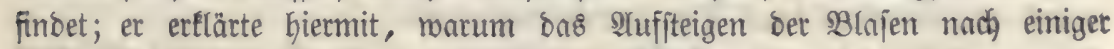
3eit aufbört; er wies nach, baß̈ bie Sauterftoffgasentwicfelung bann gerabe

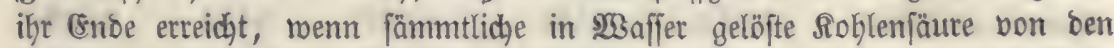

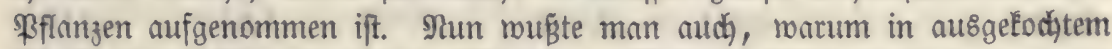
23 affer Eeine Blajen von ben Blättern auffteigen; bieję 2 affer mar burd

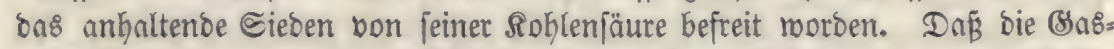
entrvidfung bon Neuem vor fich ging, ment Bontret \&uft in bas ausgetoct)te

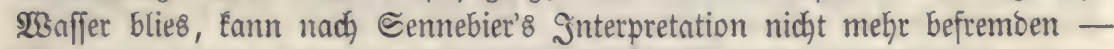
bie ausgenthmete suft enthält ja immer Roblenjäute.

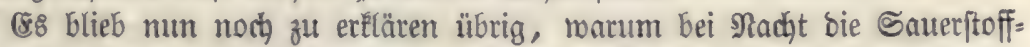
entroicflung ftille fteht. Sngentyoufs, inbem er bie Berjuche Bomet's forwobl

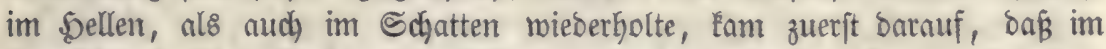

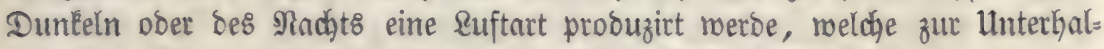
tung bes Âthmungs = unס Berbrermungsproseffes untauglich fei.

Der bon Bonnet angeftellte Berjud berweift, baß bie \$flanzen burdh

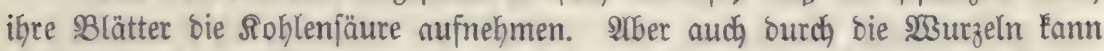

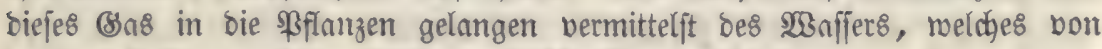
jenent aufgejogen wiro uno immer Roblenjäure entbält, neen es audi nur

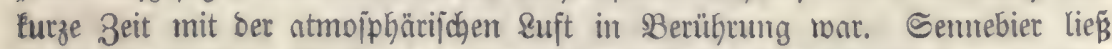

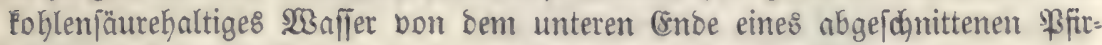

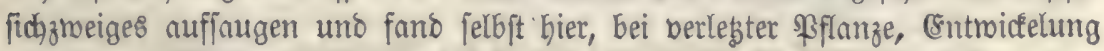
bon Sauerftoffgas.

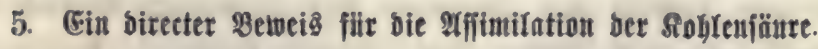

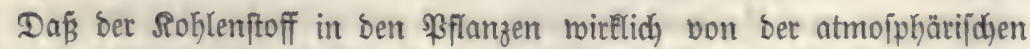
Rohlenfäure berrühre, brachte føjon Sauffure burd mefrere birecte Berjuche zur Evibenz. Dieje follen aber hier nidgt angefüfint nerben, meil biefelben,

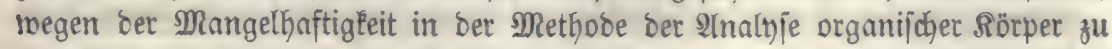

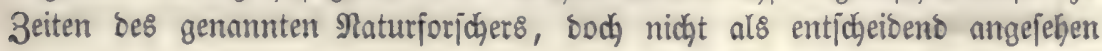




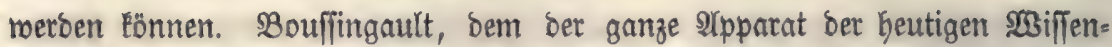
fidaft zu (Sebote fteht, hat bie Sauffure'idjen Berjuche mieber aufgenommen. (Er fäete fünf Ërbjen, zujammen 1,211 Eramme wiegeno, in Thon, welcher

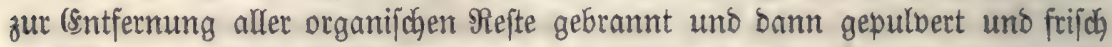
geglüft war. Nad) 30 Tagen waren bie Schoten reif. Die Dabon geerno=

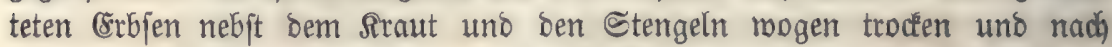

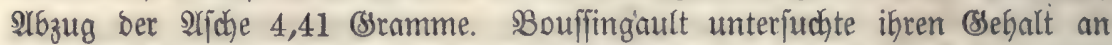

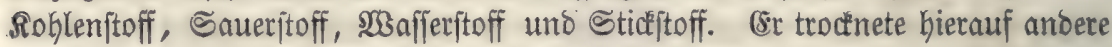

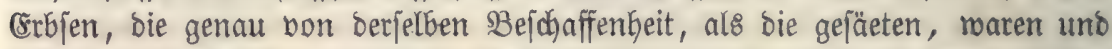

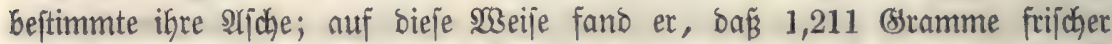

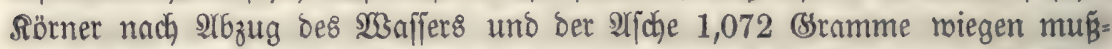

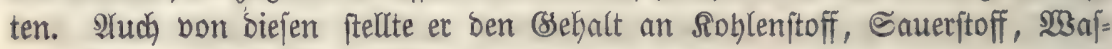
jerftoff uno Sticfitoff feft. Die Beredynnng ergab:

\begin{tabular}{|c|c|c|c|c|c|}
\hline & & Roblenftoff & Saueritoff & MBafferftoff & Stidfitonf \\
\hline Samen zut Saat & 1,072 & 0,515 & 0,069 & 0,442 & 0,046 \\
\hline Cennote & 4,441 & 2,392 & 0,289 & 1,645 & 0,115 \\
\hline Servinn burd) bie (5 & r 3,369 & 1,877 & 0,220 & 1,203 & 0,069 \\
\hline
\end{tabular}

(s\& raren aljo 1,877 Srammen Sohlenftoff aufgenommen worben, bie nur von ber in ber Aatmofphäre enthaltenen Sofylenfäure berrühren lonnten.

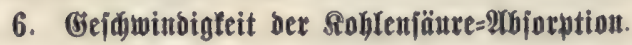

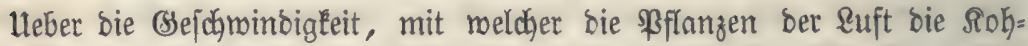

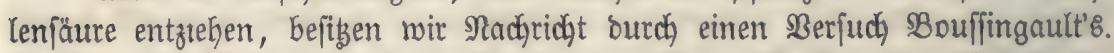

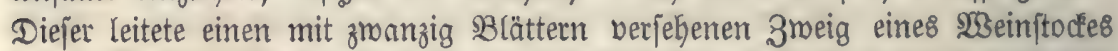
in einen Ballon. Durch eine geeignete Borridgtung Eonnte er bie äufiere Suft in ben Ballon treten laffen und bie ifrer Sohlenfäure beraubte roieber burch neue erfesen. Die suft augerbalb des 2rpparates enthielt 0,0004 Sohłenfäure; bagegen biejenige, meldhe mit ben $B$ lättern . Der 23 einrebe in Berührumg ge= wejen rar, nur 0,0001. (88 war in bier Stumben 60 sitern \&uft bie $\mathbb{R} 0 \bar{h}=$

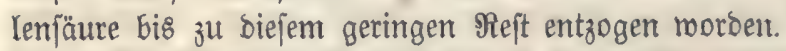

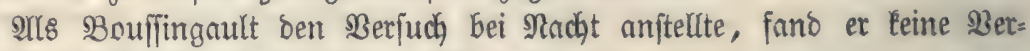

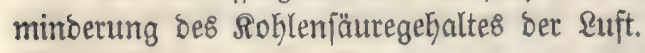

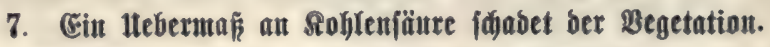

SBelch) mohlthätigen (sinflús bie Sohlenfäure auf bie Begetation aubs= übt, exgibt fich fehr beuttich aus folgendem fefr finnreichen Berfuch bon

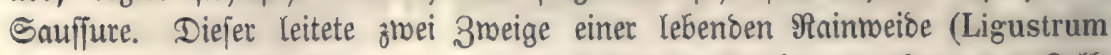
vulgare) in znei Ballone; in einen ber lebsteren brachte ex gebranten Salt,

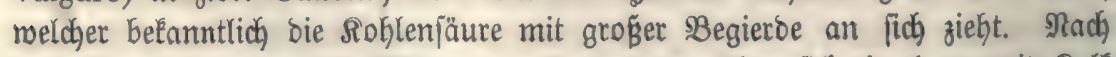

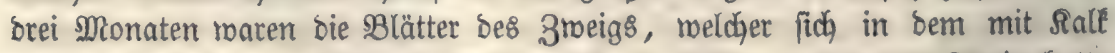

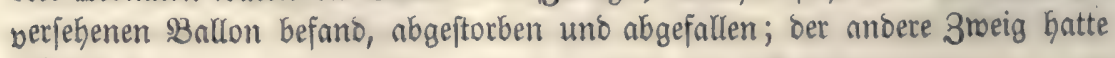
(id) erbalten. 


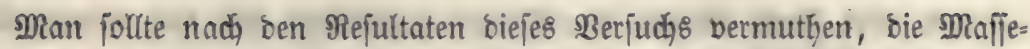

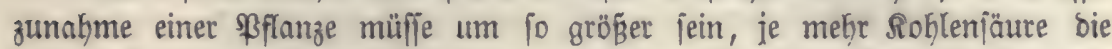
Buft enthalte, in ber fie fich befindet. Die Saufure'iden Berfuche beftätigen

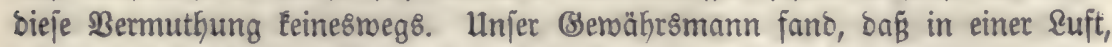

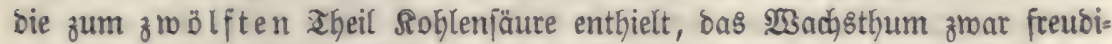

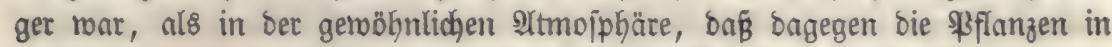
$1 / 4$ sobleniäure nur zehn Iage, in $1 / 2$ biejes bajes nur jieben zage lebten, nachber aber abjtarben uno berweletert.

Dieje Berjuche wurben im Sonnenlicht angejtellt; in fohmachem ober zerjtreutem sidht wirfte ein Uebermaß̈ bon Rohlenjäure nodj weit beroetblidher. In $1 / 4$ Gras erbielten fich bie sfflanzen nur 6 Iage, in $1 / 2$ nur 4 Iage.

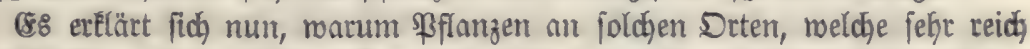
an Soblenfäure fino, nicht wohl begetiren tönnen. So erzählt Riebig von ben

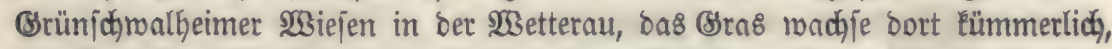
e\& zeige eine gelbe Frarbe; bies rühre unzmeifelthaft von ber Segenmart einer

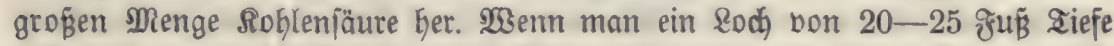

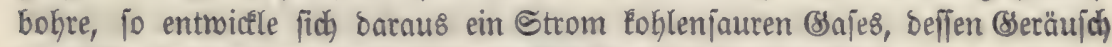
beim YU\&ftrömen man auf mełrere Schritte hin beutlich höre.

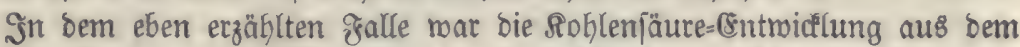
(Eroinnern eine ungemöhnlich reichliche; bie Siohlen[äure, weldhe ifren urjprung bem in 3erjebung begriffenen ફumus (\&aub, Moos, Unteräutern, den abge= faltenen bürten Baumzmeigen) berbankt, tritt mohl nie in foldhem MRaß̧e auf, Daßj fie ber Begetation jöäblich merben tönnte.

Den Roblenftoffgehalt eines zehnjährigen Raubabfalls haben wir borhin beijpielశ̊meije zu 3848 Rilogrammen betechnet; legtere exforbern, um Soblen=

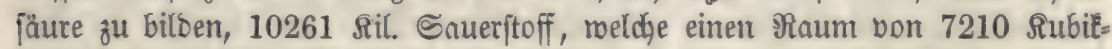
metern einnefmen. Die \&uftmaffe in einem 2 balo von 1 Sectare $(=10000$

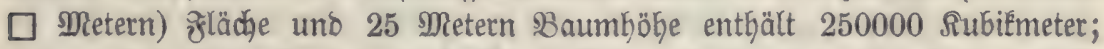

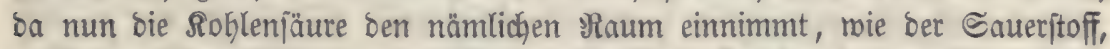
meldher zu ifrer Bildoung verwendet worden ift, fo twürbe bie ben obigen 3848 Sil. Roblenitoff entiprechende Roblenjäure bem $\mathfrak{B o l u m e n ~ n a c h ~} \frac{7210}{250000}=0,0029$ Der \&uftmaffe bes $3 a$ aldraumes betragen. 2(bbiren wir bieje 3ahl zu bem mittleren Rohlenfäuregehalt ber \&uft $(=0,0005)$, fo erhalten mir 0,0034 . $23 e n n$ aljo ber Rohlenftoffgehalt eines zebnjäbrigen \&aubabfalls fid auf ein= mal in Sohlenjäure bermanbelte, fo würbe legtere nur 0,0034 bon bem $\mathfrak{B}$ olu= men ber in bem 23 nlbraum enthaltenen \&uft ausmadjen. Da nun nad bem

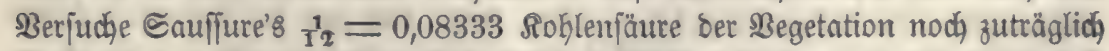

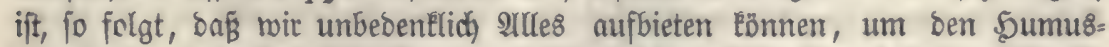

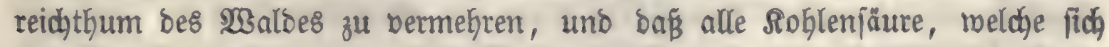

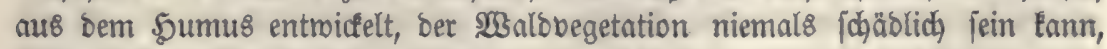
fonbern biejelbe begünjtigen muв. 


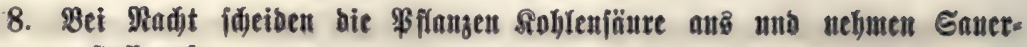 ftoff auf.}

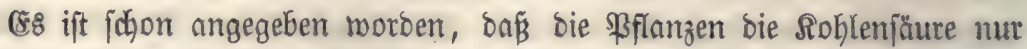

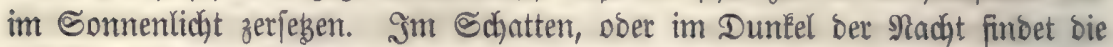

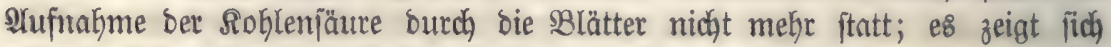
vielmehr, mas jehr mertwüroig ift, ber umgekehrte \$rozeß - bie ßftanze

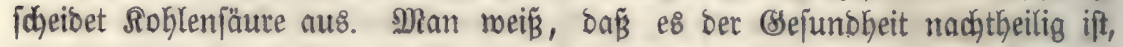
in 3immern bie Nacht zuzubringen, in meldyen Blumen fteben; es ift bie

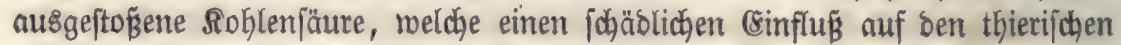
Drganismus aนเuีธt.

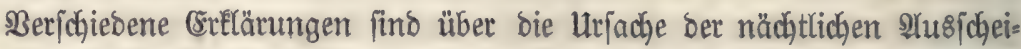
bung bon Roblenjäure gegeben roorben. (Sine jefr berbreitete ift biejenige,

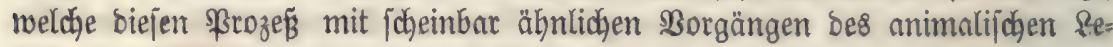
bens in श̂nalogie zu bringen gejucht hat.

Siebig war wohl ber erfte, welcher ben wahren Bruno biejes nuffallen=

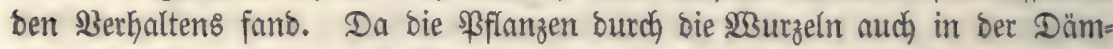

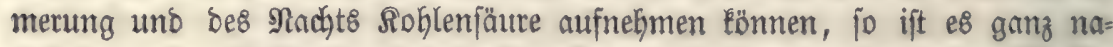

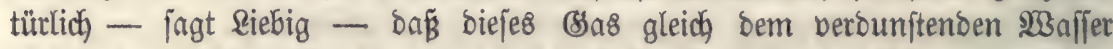

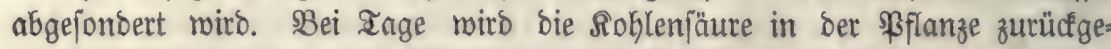
halten; Machts, wenn ber Arfimilationsprozeß aufhört, ift keine Urjache bor=

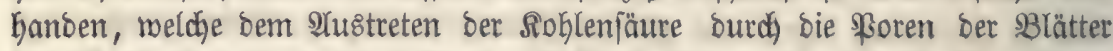

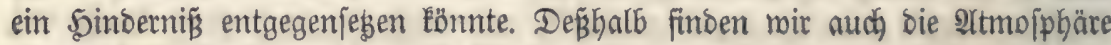

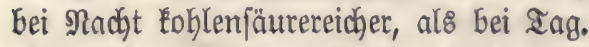

(ะs muß̈ Gier nod) einer andern, mit Beftimmtheit zuerit bon Sauffure

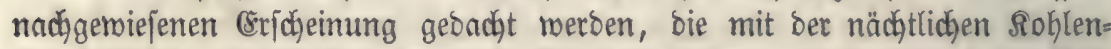
fäureergalation in Berbinbung gebracht worben ift - mir meinen bie 2uf= nahme von Sauerftoff, meldhe gleidgzeitig neben sem (sntweichen Der Sohlen= fäure bon Statten geht. Riebig ift mieber ber erfte gewejen, weldyer bie ur=

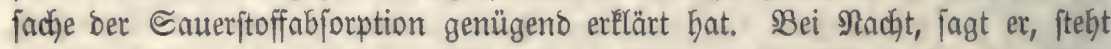

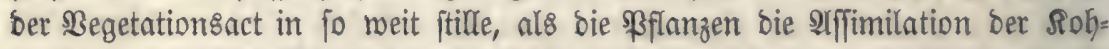

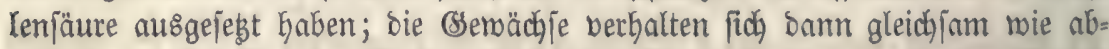

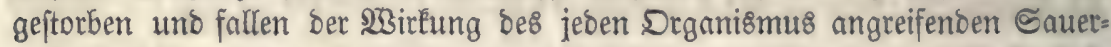

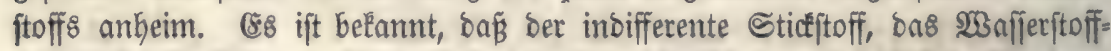

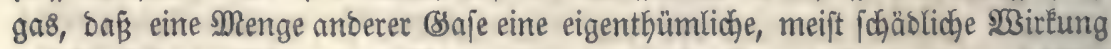

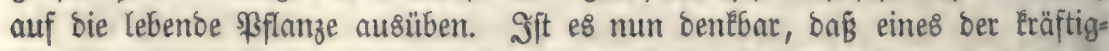
ften Ilgentien, ber Sauerftoff, mirfungzlos auf eine \$flanze bliebe, fo balo fie

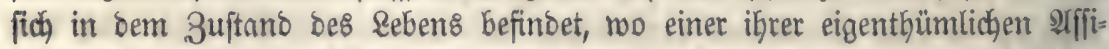

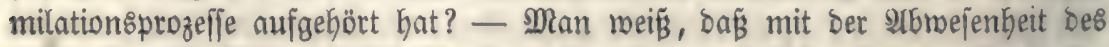

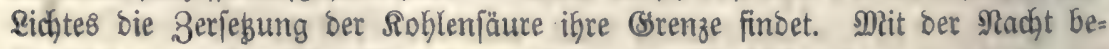

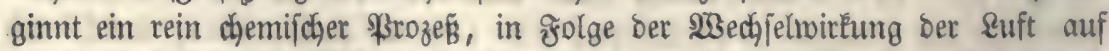

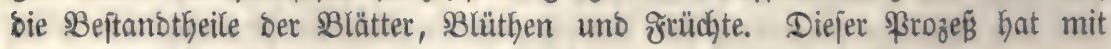
bem organifhen Rebenzproze巨́ in Der \$flanze nidgt Das geringfte gemein, benn 
ex tritt in bet tobten Pflanze ganz in berjelben Frorm auf, wie in ber leben=

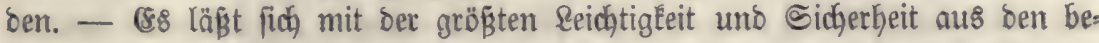
faunten Beftanotheilen ber Blätter berjodiebener Pflanzen voraus bejtimmen, melche bavon Den meiften Sauerftoff im lebenten 3uitano währen ber $\mathfrak{N G}=$ mejenheit bes Richtes abjorbiren merben. Die Blätter uno grünen Igeile aller

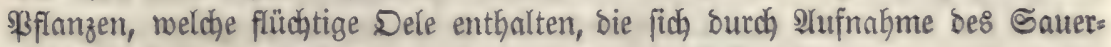
ftoff in 5arz verwandeln, werben mehr Sauerftoff aufnehmen, als andere, weldye frei babon find. Anbere wieber, in beren Safte fid bie Beftandtheile ber Salläpfel befinden ober ficfiftoffreidje Mraterien, werben mef̧r Sauerjtoff auf: nehmen, als bie, worin bieje Beftanbtheile fehlen. Die Beobadytungen Sauf jure's find entjheibende Berweije für biejes ßBerhalten; währent bie Agave

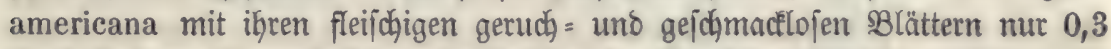
ifres Bolums Sauerftoff in 24 Stunden im Dunkeln abjorbirt, nefmen bie mit flüchtigem berharzbarem Del burchorungenen Blätter ber Pinuus Abies bie 10 fache, bie gerbjäurehaltigen ber Quercus Robur bie 14 fache, bie baljamigen $B$ lätter ber Populus alba bie 21 fadje Menge bes von oer Agave americana eingejaugten Saueritoff auf.

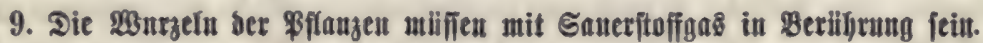

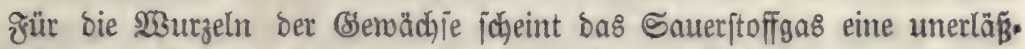
licke SBedingung bes Bejtełens zu jein; es miro von benjelben aufgenommen - zu meldjem 3roedse - ift unbefannt. હaufure fammelte \&uft, meldje mit $\mathfrak{W}$ urzeln in $\mathfrak{B}$ erührung genejen war, und fand fie jauerftoffärmer, als

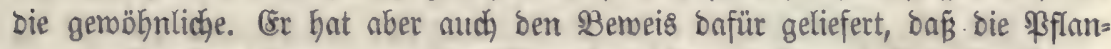
zen zu Brunbe geben, wenn ihre 230 urzeln nicht mit Gauerftoff in Berübrung

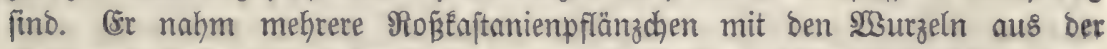

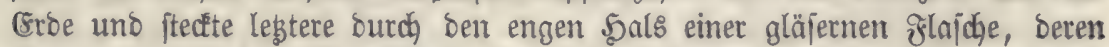

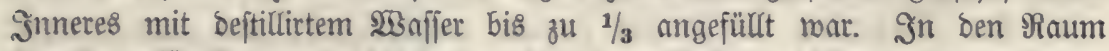

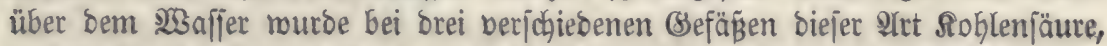

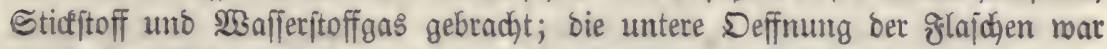
burdh Duectiflber geipert. Drei andere Bflanzen bon Aesculus wurben in

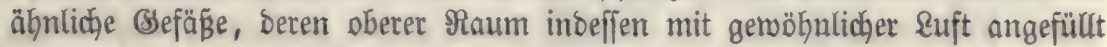
mar, gebradyt. Die Pflanzen, Deren 2 Suuzzeln mit Roblenjäure umgeben ma= ren, ftarben nach fieben ober adot Tagen, bie in bem $\mathfrak{W a f f e r f t o f f}$ uno Sticiftoff gingen etras (päter, nach 13 ober 14 Iagen, aber gleidjzeitig zu Brunoe.

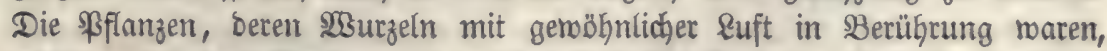
erfielten fich brei 230 oben, zu melcher 3eit Saufure ben Berjud beendigte, bollemmen frijch.

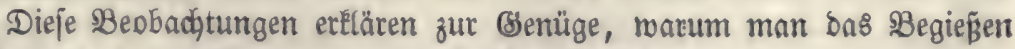
ber Sartenbeete im Sommer ununterbrodgen fortiesen muß̈, wenn man es einmal begonnen hat utro man nicht Befahr laufen roill, bie angebauten Bse=

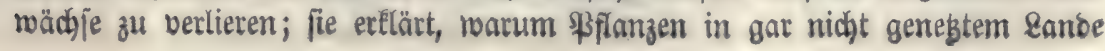




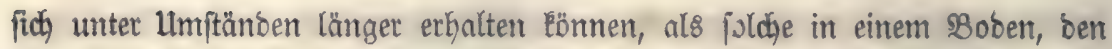
man nur eine Zeit lang begoß̈. (\&8 billoet fich) nämlich fogleich nach) bem ex=

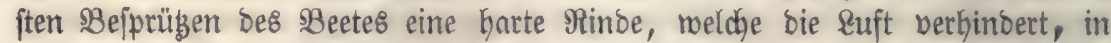

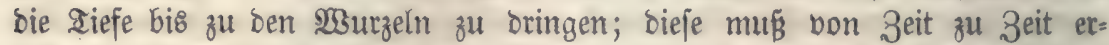
meicht merben, Damit bie \&uft wieber Bugang erhält. Das fortgejebte $B_{e}=$ gief́en hat aljo nidht blos ben 3roed, bie Bflanzen mit zreudhtigleit zu ber= fehen, jonbern aud ben eben fo midjtigen, ifren 23 urzeln Sauerfoff zuzu=

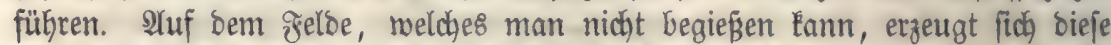

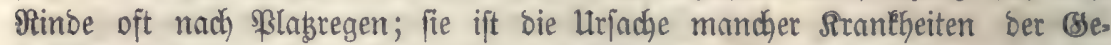

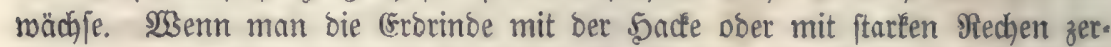
Hleinert, fo erreidyt man bie soderung bes Bobens nachbaltig und eben fo gut, als burd) fortgejestes Begiefien.

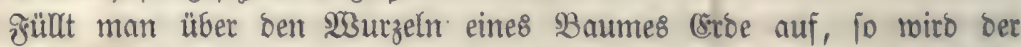
Saueritoff abgejdyitten, uno ber SBaum gebt zu Srunde, menn ex nicht bas Bermögen befitgt, eine hinreidhende 2 (nzahy bon neuen $20 u r z e l n$ aus dem mit (ribe bebectiten aheile bes ๔chaftes zu entwideln. SBlos burdh Aluffüllen von Eroe wurbe ber befannte ichöne Iulpenbaum zu Seibelberg zum 2rbjterben

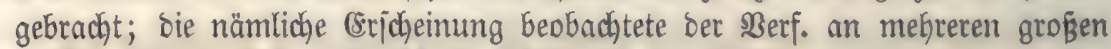

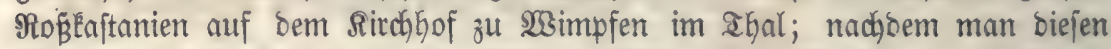
\$lab̧ planirt hatte, gingen die (đ)önen Stämme, welche bie einzige Zierbe bes \$lazes Gilbeten, binnen Jahresfrift zu Brunde.

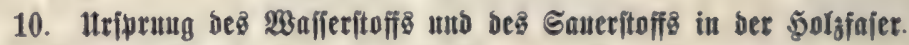

233 ir reben jest nicht von ber Saftfeudhtigleit, welche etwa $40-50 \%$

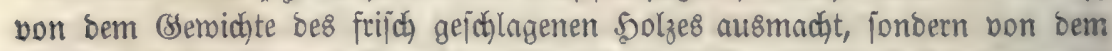
Wafferftoff uno Sauerjtoff, meldhe neben Roblenitoff uno Sticiftoff integrirento Beftanotheile ber 5olzfajet fino.

Der 23 afferftoff bes Solzes ftammt unzweifelhaft zum größsten Iheil

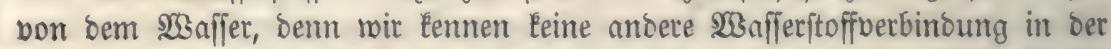

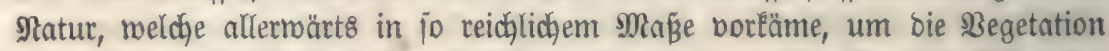

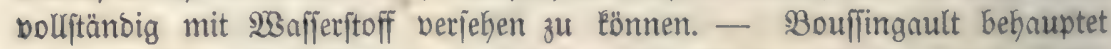
zmar, Soblenmafferftoffgas in bet \&uft nadhgemiejen zu haben, auds follen

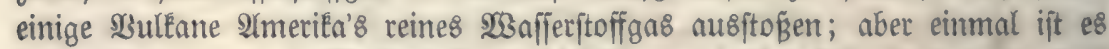

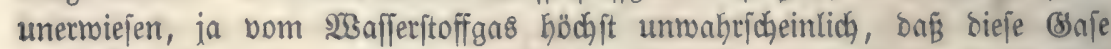
affimilirbar find, zum anbern ift ifre Menge fo unbebeuteno, bnß̧ wir bier gat

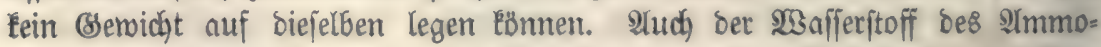
niaḱs Eann nidbt Ginreichen, um ben $\mathfrak{B f l a n z e n ~ a l l e n ~} \mathscr{W}$ afferitoff zut liefern.

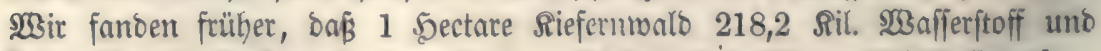
33,9 Ril. Sticfítoff probuziren Ënne. Dicjon 33,9 Rilogr. Stiçftoff entipre= wen nun, menn man ihn bom 21mmonial ableitet, 7,2 Silogr. 23 afferitoff

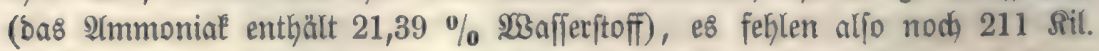

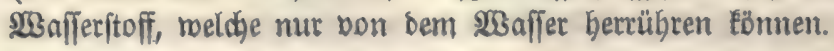




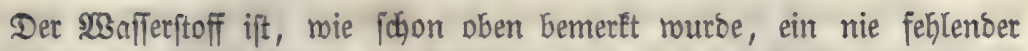
Beftandtheil ber Bflanzenfajer; er fommt ferner in ben organijoch Säuren und Bafen vor. (Sbenfo ift ber Sauerftoff jehr verbreitet, bod fehlt er in eini= gen Delen.

Unm uns eine Borftellung von ber Plffimilation biejer beiben Stoffe zu verjobaffen, wollen wir uns zuerjt an bie 3ujanmenjebung ber celluloje Gal= ten und nadher erjt bie Solzfajer im Banzen betrachten.

Die Frormel Der CEelluloje ift $\mathrm{C}_{12} \mathrm{H}_{10} \mathrm{O}_{\mathbf{1 0}}$.

Den Sohlenjtoff ber Celluloje Eann man ableiten aus 12 \&equibalenten

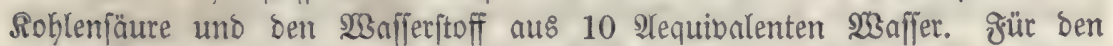

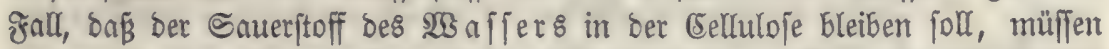
$2.12=24$ श्eeq. Sauerftoff ber Rohlenjäure austreten. SBirb aber ber Sauer= ftoff bes 2 affers nidht affimilitt, fonbern ber von ber $\Omega$ ohlenfäure herrüh= rende in bie 3 ujammenjebung ber Celluloje aufgenommen, fo müffen

\section{Sauterftoff bes $\mathfrak{W a f f e r 8}$ und}

\section{$24-10=14 \ldots$ Der Soblenjäure \\ in Summe 24 Sautertoff}

entroeidjen; es wirb aljo in beiben zällen bie sohlenfäure, freilich in bem einen gänz̧lich, in bem andern nur theilmeije, zerlegt.

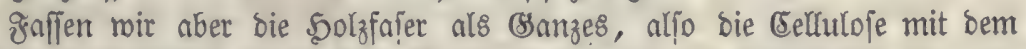
Rignin auf, fo bleiben bie \$erbältniffe bie nämtidhen, nur änbern fich bie Zah= lenmerthe. Sieft man von bem Sticfiftoff uno bem freien $\mathfrak{W a f f e r f t o f f ~} a \bar{b}$, fo

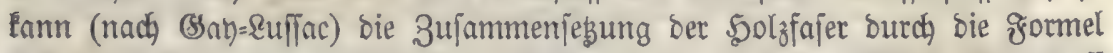

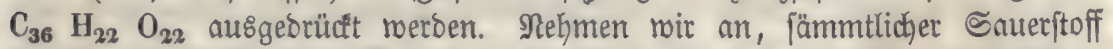

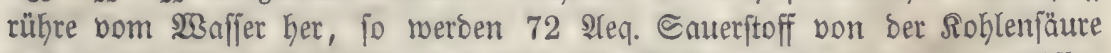

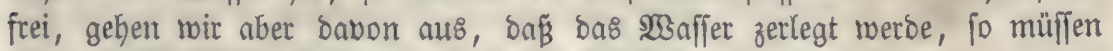

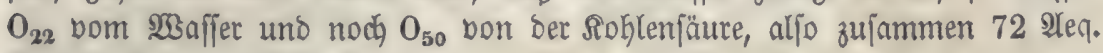
ธauerftoff ausigejdieben werben.

88 ift biel Darüber geftritten worben, weldjer bon biejen beiben 2 nfich $=$ ten ber Borzug zu geben fei. Man Gat zur IInterfitübung ber zmeiten SypD= theje angeführt, bie Sohlenfäure jei fojmieriger zerlegbar, als bas $23 a f f e r$.

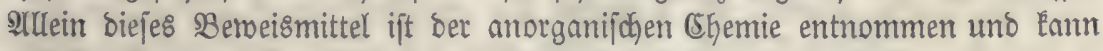
auf bie ßorgänge in Der lebenden \$Pflanze Keine Arnwentung finden. Da in ben beiben כ̧ällen, welche man unterftellen kann, gleichviel Sauteritoff ausige=

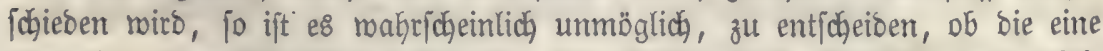

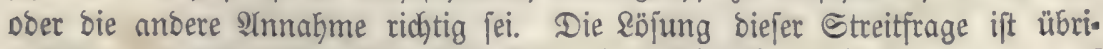
gens practijd ofne alles semidjt.

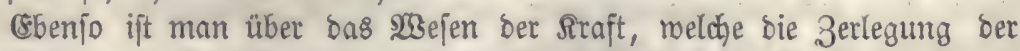
Sohlenjäure, ober, wenn man lieber mill, des $\$ 3$ affers zu Stande bringt,

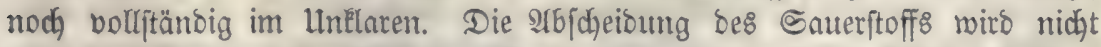

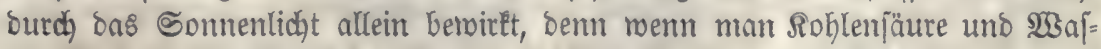
fer in einem (slasgefäßs Der Sonne ausjebt, jo findet bie Desortyotion nicht 


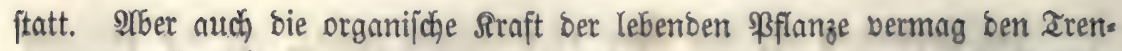

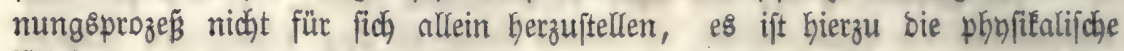
WSirkung des Sonnenlichts nöthig.

\section{Itriprung bes Stiditofię.}

Die Nadymeijung bes Sticfftoffs im Solze, namentlich feine quantita= tive Beftimmung, gehört mejentlich ber neueren 3eit an; borzüglich hat fich (5hebandier um biejen Begenjtand berbient gemadht. In ben હamen ber Pflanzen war ber Sticiftoff facjon früher aufgefunden worben, auch Gatte Payen gezeigt, bafí ber Saft vieler Serwächje, z. B. Der Sinde, bes łreigen=

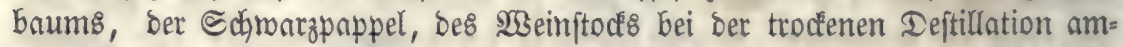
moniatalijąe Dämpfe liefere. 3u ber nämlichen Centbeckung war Riebig be= züglich bes arhornjaftes gelangt, als er biejen auf jeinen 3ucfergebalt unter= juchte. Die Menge des Almmoniaks, weldye der Saft beim Ilboampfen ent= mickelte, war fo beträchtlich, baß̉ Riebig anfangs bermuthate, e8̂ jei burch bie Bo\&byeit eines Menjchen Utrin in bie zum 2Huffangen bes Saftes unter bie Bäume geftellten Befäßze getommen, bis ihn jorgfältige Beobachtungen lehrs

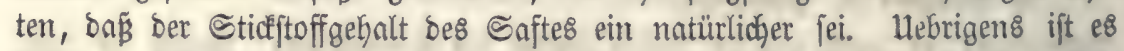

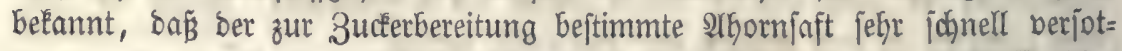

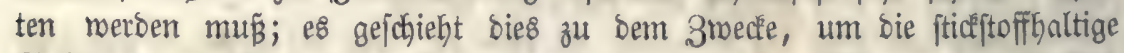

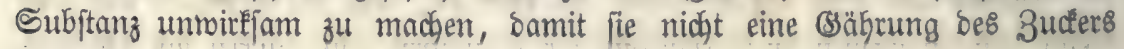
Gerborrufe.

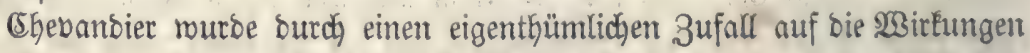
aufmerefam gemadjt, weldje die fticfftoffhaltige Subftanz im 5olze jelbjt her= vorbringt. \&affen wir ifn mit jeinen eigenen 230 orten reben: "Bei meinen erjten Analyjen (meld)e bie IInterjudyung ber elementaren Bejtandtheile bes

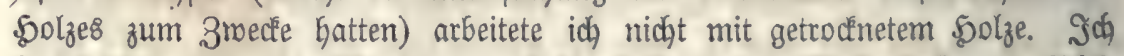

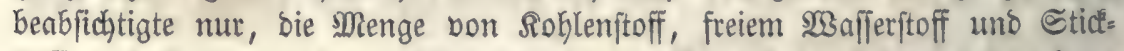

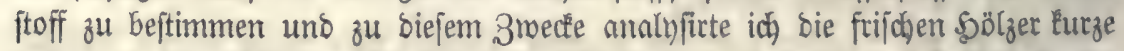

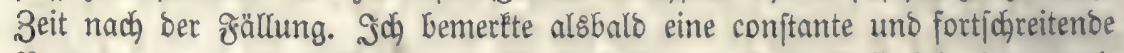
Beränberung in Dem Sehait an 23 afferftoff und Roblenftoff bei einem und

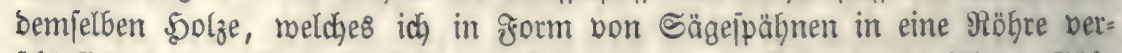

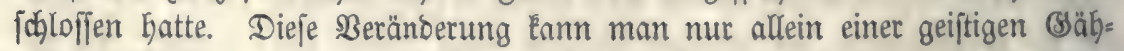
rung zuichreiben. Sie roar leidht zu erËenten, menn auch megen ber geringen Menge ber in (sähruutg begriffenen Materie nidjt anbers als burch) ben (se= ruch) fut beftimmen."

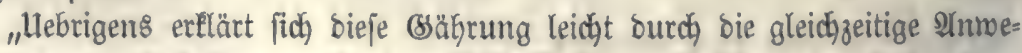
fenteit einer zuckerbaltigen uno einer ftidfitoffbaltigen Subjtanz im \$olze. Res= tere bertritt bie Stelle beళ Jerments."

"Um biejen mertwüroigen Umitanto aud) burdh Berjuche im (srogen fejt=

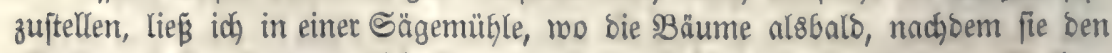
ISald berlaffen Gatten, gejdynitten nurben; Spähne bon entrinoten Budjen, 
5ainbudgen uno cidjen fammeln uno bradjte fie in entigen făffern in einen

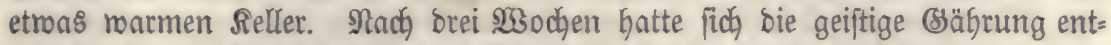

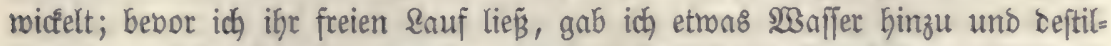
lirte bann bei j(broadjem reuer. SRach mehrmaligem Rectificiren erbielt idh

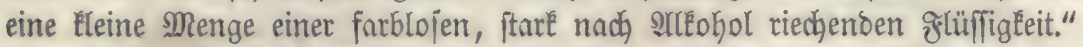

Bor noch nidat langer 3eit war man ber 2 nnjicht, ber Sticfifoff, wel=

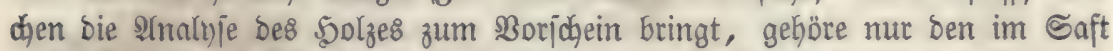
enthaltenen Broteinjubftanzen an, bis genauere Unterjudyungen nadiwiejen,

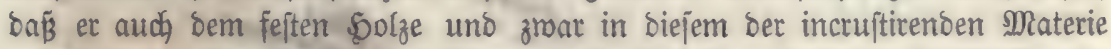

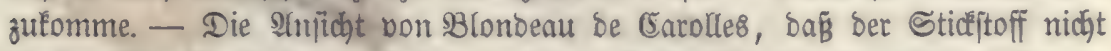
in chemijher Berbindung, jondern in freiem Bujtande vorbanden jei uno fich im

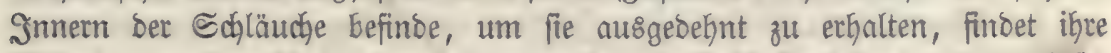

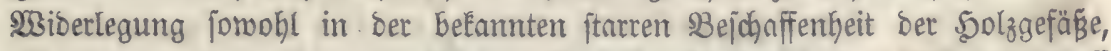

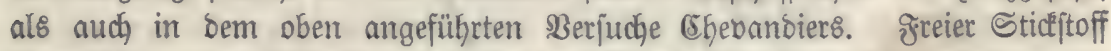
ift unfähig, eine ssäbrung, mie fie bon CGgebanbier beobachtet murbe, ein= zuleiten.

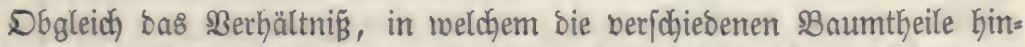

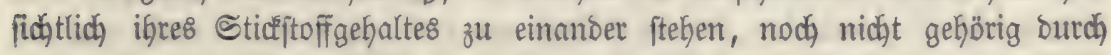
Unterfuchungen fejtgeitellt ift, jo weiß man boch, baßs alle biejenigen Drgane,

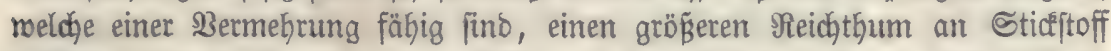
befigen, als bie bereits fertig gebildeten. $3 \mathfrak{u}$ jenen gehören namentlich bie cambiumzellen.

W3oher ftammt num aber ber Sticfitoff bes Şolzes?

Man war früfer ziemlid allgemein ber Alnficht, er roerbe birect aus ber Suft genommen, bon ber man ja weis, bä́ fie aus Sauerftoff uno Sticfftoff

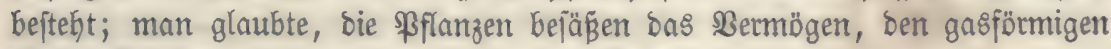
Sticfitoff fid anzueignen.

Dieje Annabme ift unridjtig, mie fobon Saufure burd, Berfudge be= miejen bat. Fr jagt:

"Idh habe bie Begetation bes Epilobium hirsutum mit bieler Sorgfalt jotwobl im reinen Sticfgas, als in ber atmoppärifßen \&uft berfolgt uno babei bie Berfahrungsart Prieftens, die er für biefen Berjuch vorjdreibt, ange= wanbt. Soh habe bie Ertperimente noch viel länger fortgefest, allein iḑ Gabe niemals eine Berminterung bes Stickgajes wahrnefmen fönnen, wenn idh bas Caueritoffgas, mas fich baraus gebildet Gatte, abzog. Das sämliche erfolgte bei allen übrigen (Semähjen, bie id̆ ben nämlichen \$roben unter=

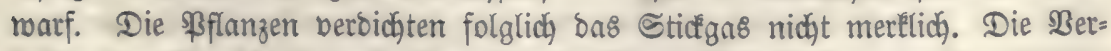

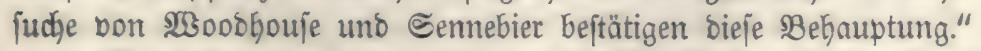

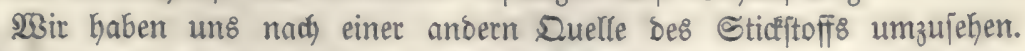

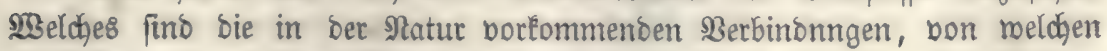
bie ßflanzen ben Stidftoff bezieken Ënnten?

Da bie \$olzfajer, wie wir riffien, Sticfftoff enthält, fo ift klar, baf 


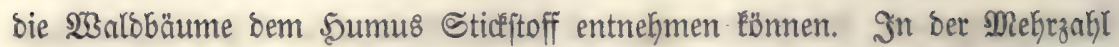

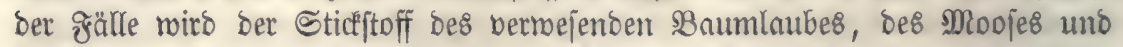
ber bünnen 3reige, welche von ben $B$ äumen abfallen, fich in ber form von

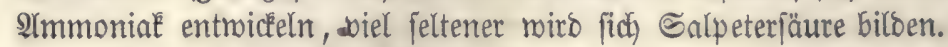

Rimmt man ben Sticfitoffgehalt ber trodenen Solzfajer mit (5Gebandier zu $1 \%$ im Mittel an, fo roürdent die 1000 Rilogramme, roeldye bas (Serwicht eines 10jäbrigen श्रbfalls von Buchenlaub ausmachen, nur 74 Rilogramme Stidfitoff entfalten, gerabe fo viel, um einen Riefernbeftand etroas über zrvei

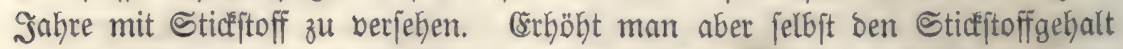
bes \&aubes nuf $5 \%$, fo mürbe er bod) nur auf 11 jafye ausreichen.

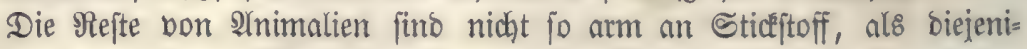
gen Der Begetabilien, allein eritere Émmen im 2 Balde nur in unbebeutender Quantität bor. Der Roth Der Thiere, weldhe, wie bas $233 i l \delta$, im SWalbe le=

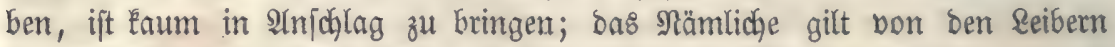
Der Infecten uno andern Eleinen Thiere, weldje im $23 a l b e$ berwefen.

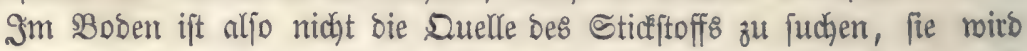
ebenfo, mie bei ber Sohlenjäure, in ber Ntmojphäre liegen, menn es nud

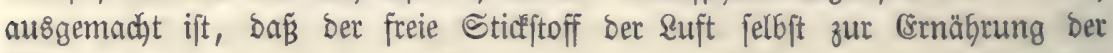
Pflanzen nicht bemugt merben fann.

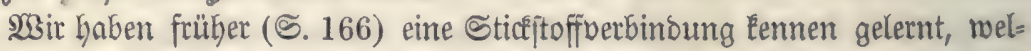

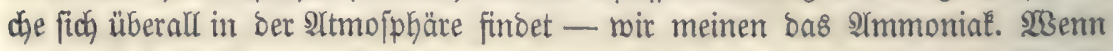
auch, nach) (Sräger, in ber \&uft nur 1/10000 2Ymmonin' entbalten jein jollte, jo macht bies boch für bie ganze 9tmojphäre etras über 14 ßBillionen mit einem Stidfiftoffgebalt von etmas mehr als 10 Billionen Silogrammen aus, währeno,

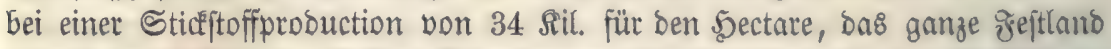

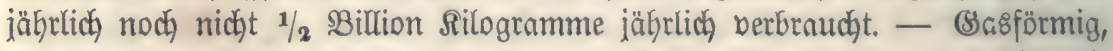

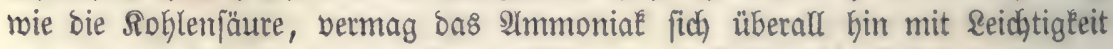
zu verbreiten, moburd eine locale $\mathfrak{A}$ (bjorption beffelben fofnell mieber ausge-

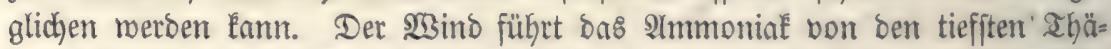
lern bis auf bie Spizen ber höchiten Berge, boch fajon allein nach bent Bes jes ber Diffufion Der Braje müß̈te es an jeben Drt im \&uftocean bringen.

WSie wohythätig Das 2 mmonial auf bie Begetation einwirkt, mies Davy Durd) folgenden Berjuch nach. (5r leitete biefes (sas, aus gährendem Mijte entwicfelt, unter bie $\mathfrak{B}$ urzeln eines $\Re$ ajens und bemertte bald eine auffallende Bejđjleunigung Desి $23 a$ actsthums.

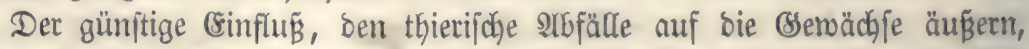

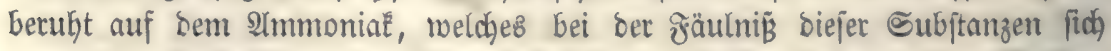

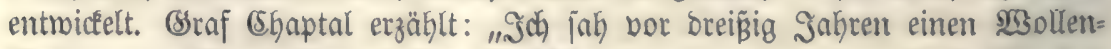
Gändler von Montpellier, Deffen 230 ajhbaus mitten in einem Jelde angelegt war, wobon er einen gropenen Theil in einen Barten umgemandelt hatte; er

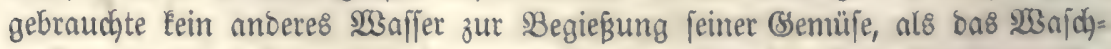

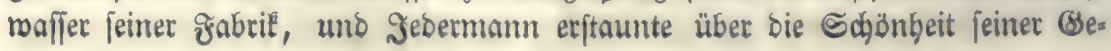




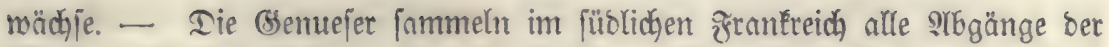
23olfenmeberei, um fie an bem Jufie ifgrer Dlivenbäume faulen zu laffen." EGenip, wie bie wollenen \&umpen, wirken die Sornipähne.

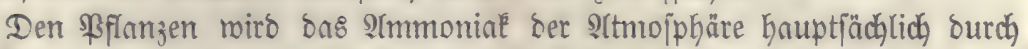

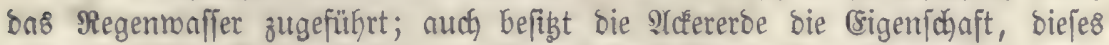
(S৯ร zu nbjorbiren. Şierin zeidynet fid) namentlid) ber Mergel aus; vom

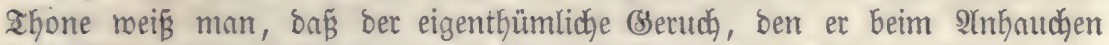

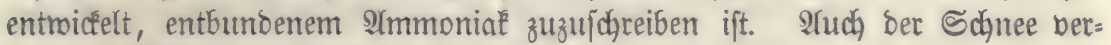
bidhtet viel \$Immonial an jeimer Dberflädhe.

Die Salpeterfäure fann bei meitem nidyt in Dem Maß̉e, wie bas $\mathfrak{Y}$ monint, als allgemeine Duelle bes Cticfftoffs angejehen merben, benn fie lommt bei weitcm nicht fo bäufig in ber Natur bor. Riebig fand unter 77

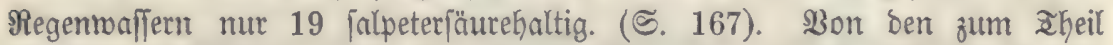

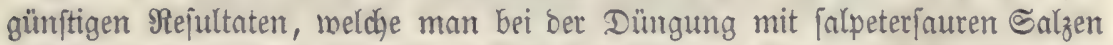

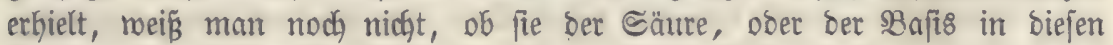
Salzen zuzuld jeiben jeien.

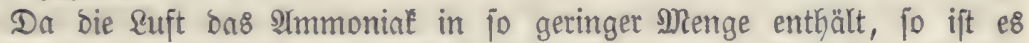

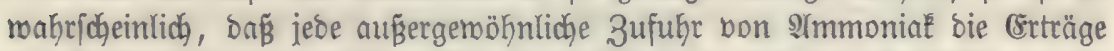
Des Bobens fteigen merbe. $S 6$ aber nicht, wie bei ber Srohlenjäure, ein

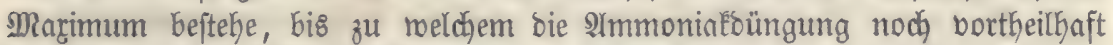
für bie (Semächje fei, barïber liegen noch Eeine birecten Unterjuchungen bor.

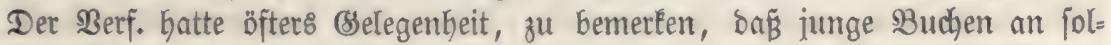

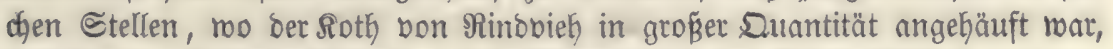
ausgingen. (Diftrict Silberberg bei Dbertamptabt im Doentwalbe). 
(8lftes $\Re$ ud.

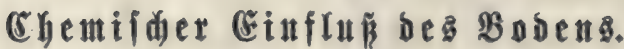

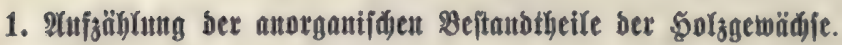

SWir Gaben bereits an einem anoern Drte ermähnt, baß bie Solzgemächfe

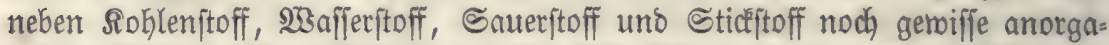
niface Bejtanotheile enthalten. Dieje fino Rali, statron, Sall, sBittererbe, IFonerbe, Sijen, Mangan, Sdynefel, \$hosphor, Siejelfäure, auch mokl zu= weilen Fुtuor, Soo, Brom uno Supfer.

Sn ber lebentoen Sfflanze Émmen die $\mathfrak{B a f e n}$ meift an organijche Säuren

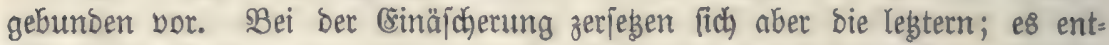
fteht Sohlenjäure, und bieje berbindet fich mit ben freigenorbenen Bajen.

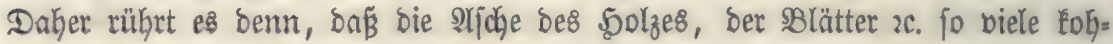
lenjaure Salge entfält.

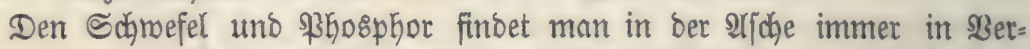
binoung mit einer $\mathfrak{B}$ nje al\& Sdjmefelfäure und \$hosphorfäure vor; es ift aber

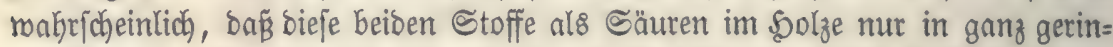

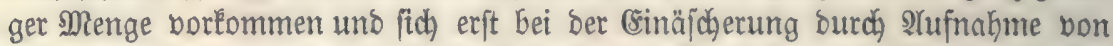
Sauerftoff aus ben zugehörigen Metalloiben etzengen. Sdymefel uno \$phosphor

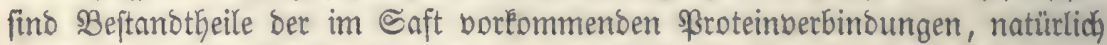
müfien fie aber auch ber incruftirenden Materie angebören, weil bieje ja nus Saftablagerungen entftanoen ift.

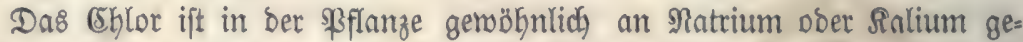
bunben. Die Riefelfäure commt entweber in Berbinbung nit Bajen (meift Sali ober গatron), Dber aud fiei vor. Im lestgenannten 3uftand kemerlt man fie im Buchenlaub; äjohert man biejes ein, fo seigen fich viele lleine

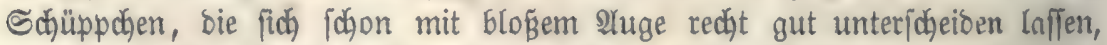
benn fie befizen oft $1-2 \mathrm{Mm}$. Durchmeffer. Dieje Schüppchen fino nichts anberళ alళ freie Siejelfäure, meldhe vorzüglich in ben \$lattrippen abgelagert mar.

Db bie ahonerbe wirellidy einen Beftanbtheil ber Solzaidhe ausmadje,

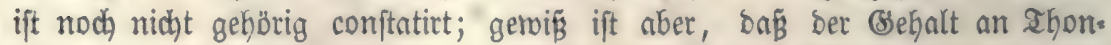
erbe, ben biele Irfdjenanalyjen angeben, entroeber von Staub, ober nur bou 


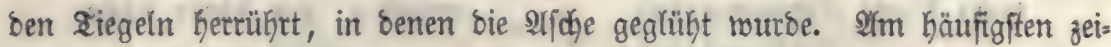
gen einen (sebalt an Thonerbe biejenigen Unterjuchungen, weldhe fich zugleids

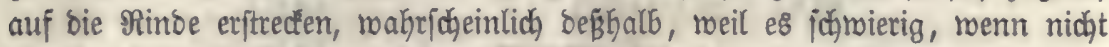
unmöglid, ift, bieje von anfäıgenden Staubtheildyen zu befreien. (orbmann

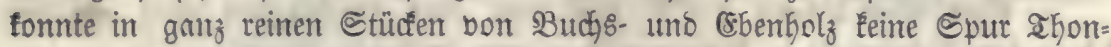
etbe entbecten, ebenjo wenig in reinen ๔amenajden (๔chubert). Begen ein

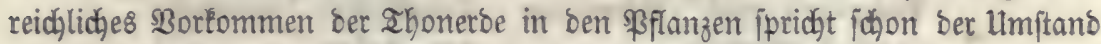

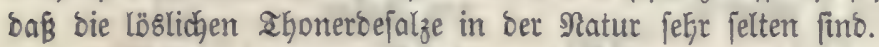

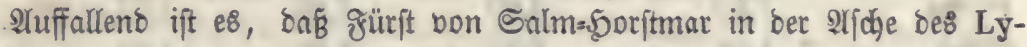
copodium complanatum 38,5\% Thonerbe gefunben Gaben will, mäkreno bie aljo bon 3weigen eines Juniperus communis, weldyer unmittelbar $\delta a=$ neben gemadjien war, in 0,35 Brammen nod) Kein Milligramm entbielt. Die=

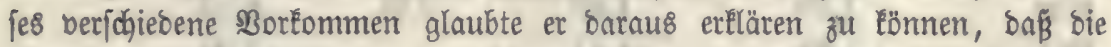

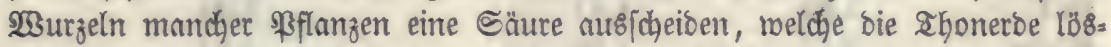

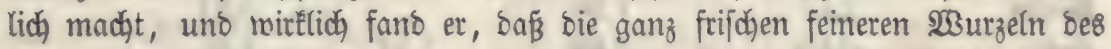
Lycopodium complanatum, frei bon (sroe nuf feud)te\& Ealmuspapier gelegt,

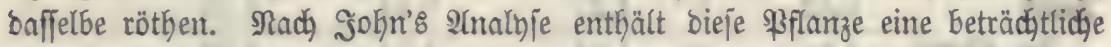
Menge effigjaurer Thonerbe, und in Nornegen benubst man biejelbe fogar als Beize zum Blaufärben mit $B$ laubolz (ङdubert).

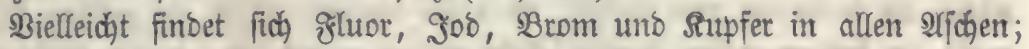
bie Duantität biejer Stoffe ift aber fo Hlein, baß̈ fie Eeine Beadatung, menig= ftens nicht für unjern 3roed, berbienen.

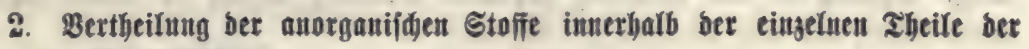 5̧olzgewǜific.}

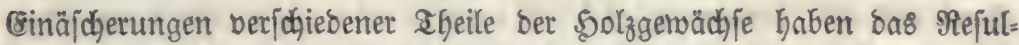

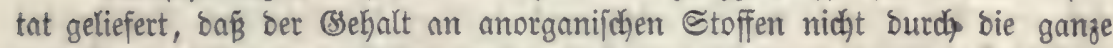
Solzpflanze bin ber nämliche bleibt, baß̈ er bagegen in jebem biejer Igeile ziemlich conftant ift.

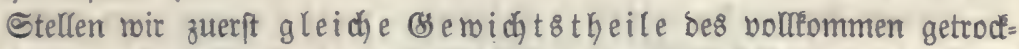

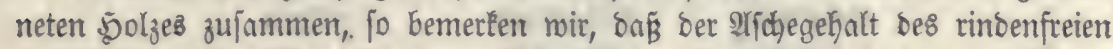

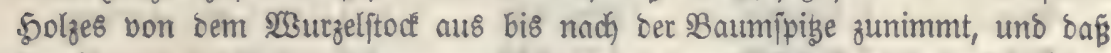
bie jünger gebildeten Drgane reidglicher mit ben arjobeftandtheilen verjehen fino, als bie älteren. So bat aljo z. B. Det Splint mețr 2lide, als bas Rernholz, bie jungen 3roeige haben mehr, al\& bas Stammbolz. Die \$lätter enthalten bei reitem mehr sliche, als bas eigentlidje \$olz; fie werben aber

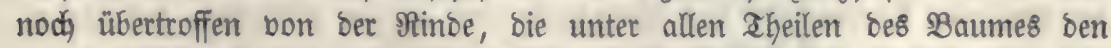

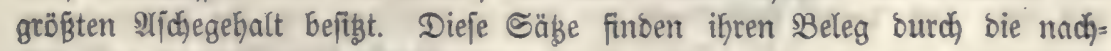
ftehenben Irnalyjén bon Sauffure.

1000 Fheile (sichenjtammbolz

" " Eidjeniplint
enthalten 2,0 2heile 2ricke

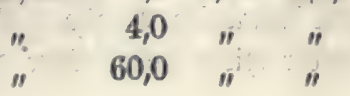


1000 Theile (Eichenzmeigholz

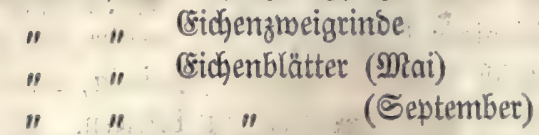

enthalten 4,0 Theile arjothe

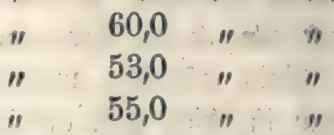

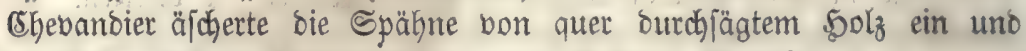
fano ben $2(j$ dijegehalt in $\Re r o z e n t e n$ ber ganz troctenen Materie

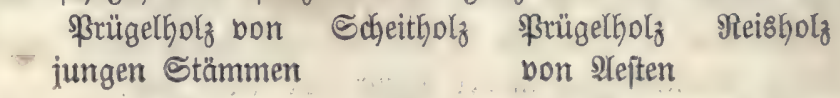

\begin{tabular}{|c|c|c|c|c|}
\hline Buthe & 1.02 & 0,9 & 1,26 & 1,77 \\
\hline Eiche & 1,45 & 1,58 & 2,00 & 1,82 \\
\hline Sainbudje & 1,29 & 1,69 & 1,84 & 2,08 \\
\hline SBinfe & 0,69 & 0,81 & 1,09 & 1,32 \\
\hline Arpe & 1,40 & 1,60 & 2,35 & 2,98 \\
\hline Erte & 1,35 & 1,41 & $"$ & 2,02 \\
\hline SBeibe & 2,11 & 1,90 & $"$ & 5,51 \\
\hline fridjte & 0,98 & 0,89 & 1,34 & 1,60 \\
\hline Riefer & 0,82 & 1,22 & 0,91 & 1,38 \\
\hline $\mathfrak{s m}$ Mitt & 1,23 & 1,34 & 1,54 & 2,27 \\
\hline
\end{tabular}

Siernady enthjelte aljo bas Srügelholz von jungen Stämmen mentiger

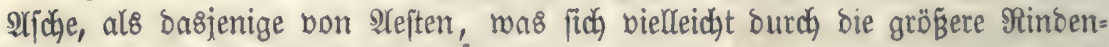

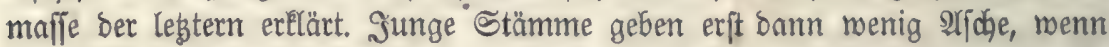

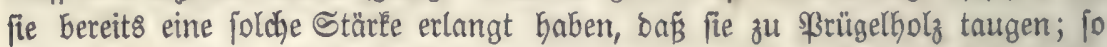

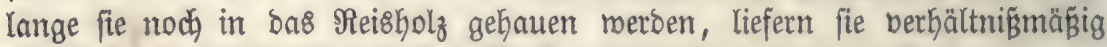
mehr erfde, als alle übrigen Sortimente.

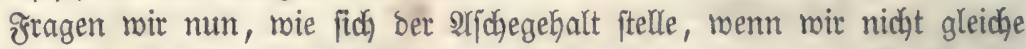
Serwichtstheile, fonbern gleidye $\Re$ a umtheile ber verfdjiebenen Sortimente

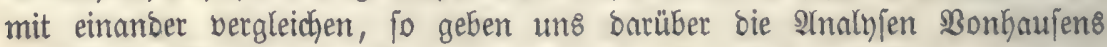

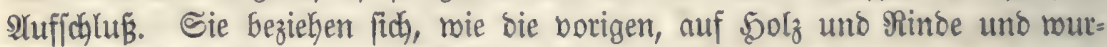
ben burdy Ginä|chern ganzer Stämme gemonnen.

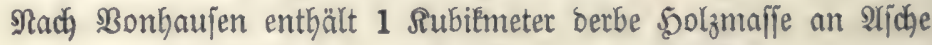

\begin{tabular}{|c|c|c|c|}
\hline & ङ(heitfolz & Prügeltholz & Rei8holz \\
\hline SButhe & 6,345280 & 10,236800 & 14,145920 Silogramm \\
\hline Siefer & 1,358848 & 1,715712 & 5,641920 \\
\hline
\end{tabular}

Das Prügelfolz rührte von शeften und ber Sdhaftipize her. - Dieje Zahlen

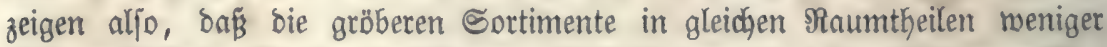

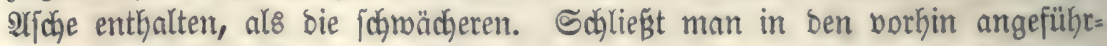

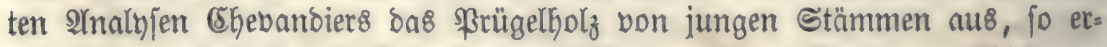

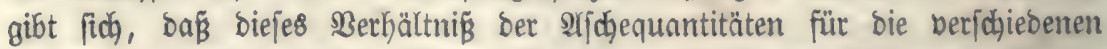

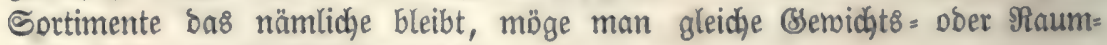
theile Solz mit einanber vergleidyen.

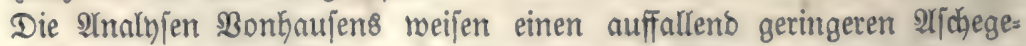
Kalt bei ber Siefer, gegenüber ber Budje, nady; eв jadpeint ein ganz allgemei= 


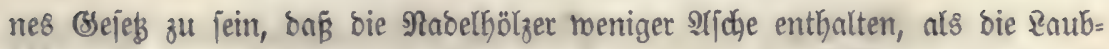
bölzer. Dagegen Ëann man nidjt jagen, dǻ bie weidjen \$ölzer weniger reid)

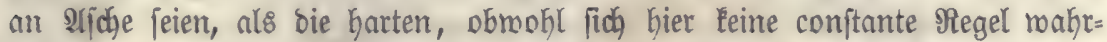

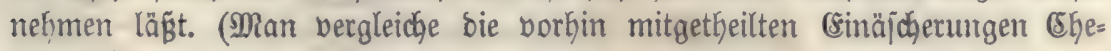
banbier8).

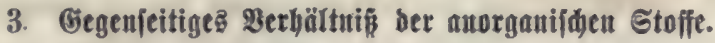

Betrachten wir bas Berkältnif́, in meldhem bie anorganijhen Stoffe

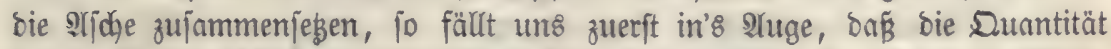

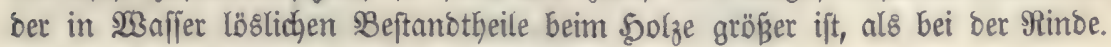
গWir wollen bierüber einige Zabłen geben.

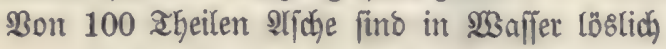

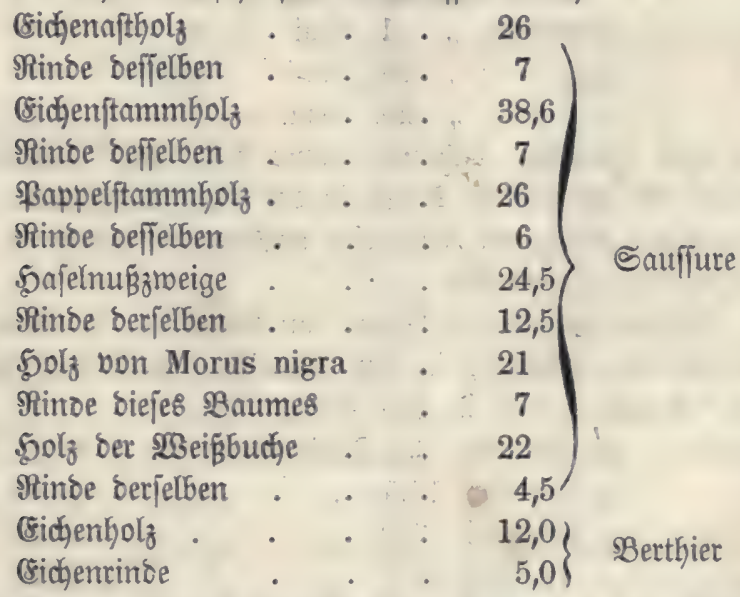

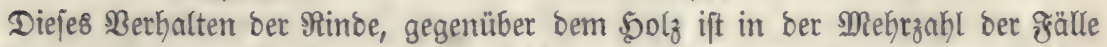

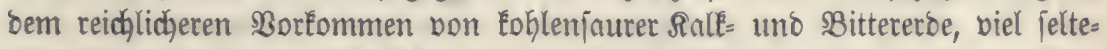
net aber, als mant gewöbntich annimmt, bemjenigen von phosphorfauren Sal= zen zuzujhreiben, wie bie nadjftebenten 3ablen berweifen

\section{Soblenjaurer Ralt uno \$\$osphorjaure}

\begin{tabular}{|c|c|c|c|c|c|}
\hline & & aute : & Sittererde & Salze & \\
\hline (sidgenaftbolz & & 12,25 & क & 28,50 & 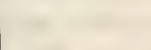 \\
\hline Pinbe beffelben & $\approx$ & 63,25 & : & 4,50 & \\
\hline Fappelyolz . & & 27,00 & ' & 16,75 & \\
\hline Rinbe beffelben & & 60,00 & & 5,30 & Sauाure \\
\hline 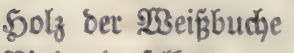 & & 26,00 & & 23,00 & \\
\hline Finde berfelben & & 59,00 & & 4,50 & 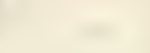 \\
\hline Butbentyolz & . & 57,28 & & 10,10 & \\
\hline Budjenrinbe & & 81,66 & & 4,67 & \\
\hline Iannentyolz & & 56,54 & & 9,1 & ettrol \\
\hline Tannentinbe & & 65,11 & & $12,67)$ & \\
\hline
\end{tabular}



Regel

Bei Morus nigra fant Sauाure eine ftärfere sibroeidjung bon biejer

$$
\begin{aligned}
& \text { Solf bon Morus nigra } 56,00 \quad 2,25 \\
& \text { Rinte : } 45,00 \quad 8,50
\end{aligned}
$$

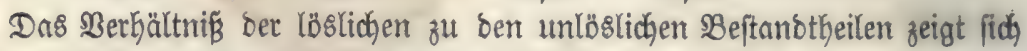
bei ben Blättern nach ber Safreszeit verjajieben. Nach ben ltnterjuchungen Snuffure's nefmen bie unlöslichen Stoffe gegen ben Serbft hin zu.

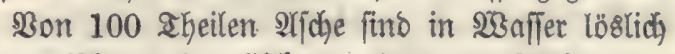

Blătter bet rich) bom 10. Mai 47

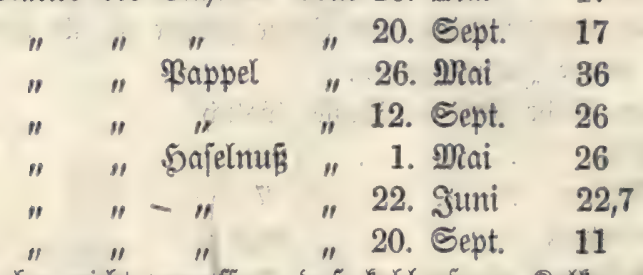

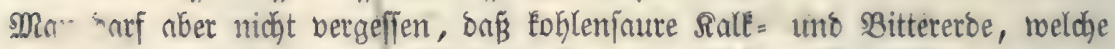

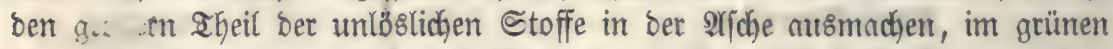
5olz al: flanzenfaure Salk $=$ und $\$$ Bittererbe bortommen, weldye in bem ohne= bin fauren $\Re$ flanzenfaft (öвlich) find.

Bei ben Blättern nimmt ber sebalt an Siefelfäure in bem Maß̉e zu, als jene an Eonfijtenz gewinnen, in Dem nämlichen Berhältniß́s nebmen aber bie allétien ab. Sauffure fanto in 100 Theilen aljose

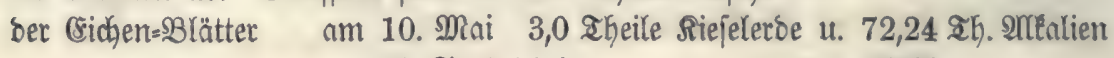

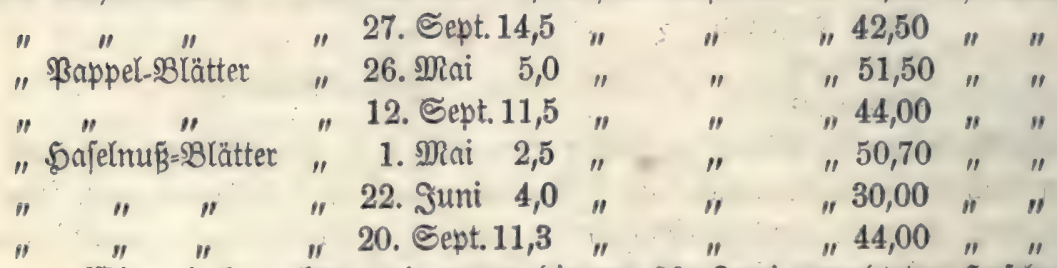

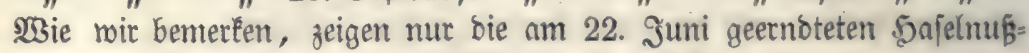

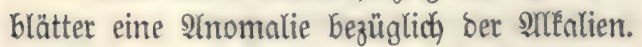

Bergleidjen wir ję̧t bns Berbältnif́s der anorganijchen Stoffe beridjiede=

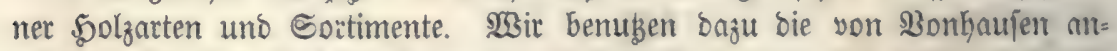

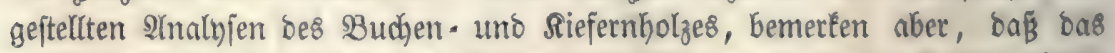

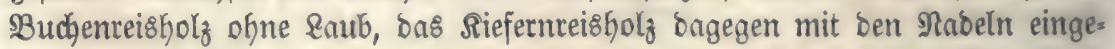

\begin{tabular}{|c|c|c|c|c|}
\hline \multirow[b]{2}{*}{ 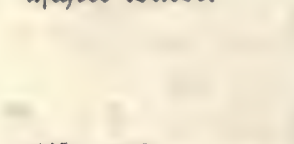 } & \multicolumn{4}{|c|}{$\begin{array}{c}\text { Suche } \\
\text { Solz mit } \Re \text { Rinoe }\end{array}$} \\
\hline & Sd)eitfolz & Brügelfolz & Reisholz (ohne & Raub) \\
\hline Eijenoryto & 0,520 & 0,268 & 0,592 & 3 \\
\hline Manganornouloryo & 0,925 & 1,073 & 0,592 & $=$ \\
\hline Ralferbe & 39,779 & 37,861 & 40,181 & \\
\hline
\end{tabular}
äphert nurbe. 


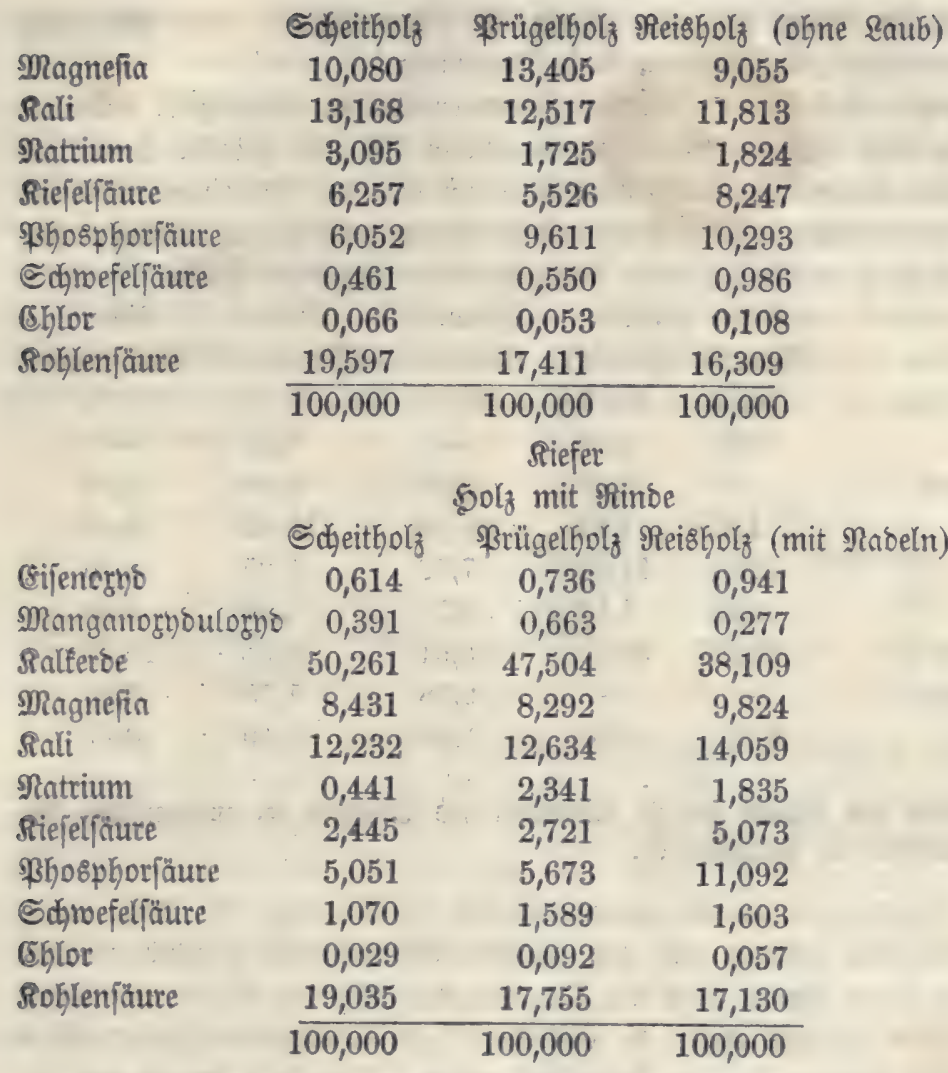

Ỹus Diefen 3ahlen ergibt fich Folgentes:

a) Eijen, Mangan uno Ehlor machen nur einen jehr Eleinen Eheil ber \$olzajdye aus.

b) Der Behalt an Salkeroe ift größ̈er bei ber Riefer, al\& bei ber \$Buche,

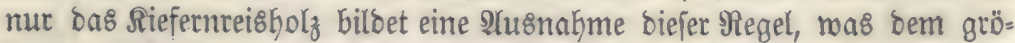

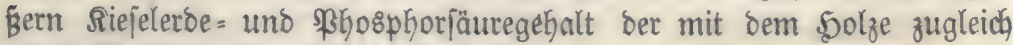

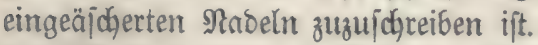

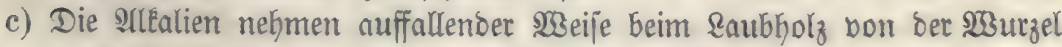

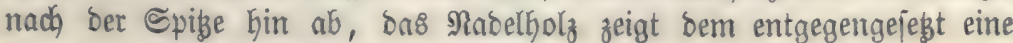
3 unahme in ber angegebenen Nidjtung.

d) Die Riejeljäuregehalt jteigt bei ber Riefer nach ber Spize Gim, auch bom

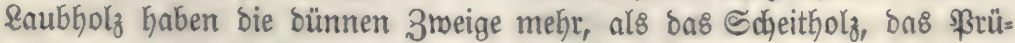
gellyolz bagegen befigt neniger, als bie beiben anbern Sortimente. Dodh

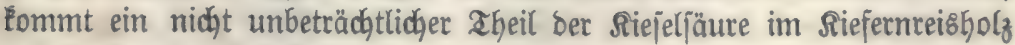
auf Soften ber Rabeln.

e) Die \$hosphorjäure fomohl ber Budje, als ber Siefer nimmt von bet 
WBurzel nach ber Spize hin zu, ebenjo bie Sdjwefelfäure; bas oblor zeigt kein daracteriftijches Berbalten in biejer Beziefung.

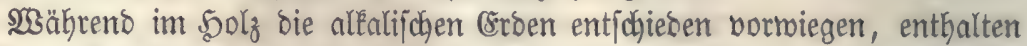

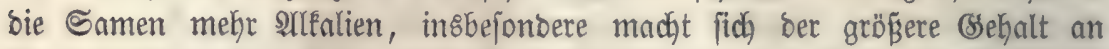

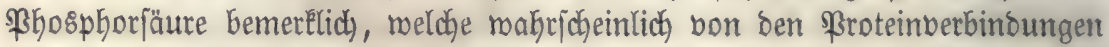

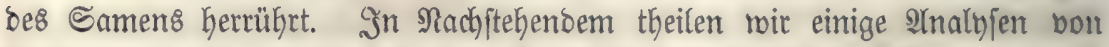
Baumjamen mit, welḑ) bas eben 2Yusgejprodjene beftätigen follen.

\begin{tabular}{|c|c|c|c|c|c|}
\hline & $\begin{array}{c}\text { Riefer } \\
\text { (ßolect) }\end{array}$ & $\begin{array}{l}\text { ङichte } \\
\text { (\$olect) }\end{array}$ & $\begin{array}{l}\text { 23allnǘ } \\
\text { (BSlaffon) }\end{array}$ & $\begin{array}{l}\text { Bucke } \\
\text { (Soudday) }\end{array}$ & $\begin{array}{c}\text { Cidje } \\
\text { (Rleinjobmiot) }\end{array}$ \\
\hline Sali & 18,61 & 18,57 & 27,12 & 18,13 & 51,73 \\
\hline Natron & 1,05 & 5,78 & - & 7,55 & - \\
\hline (5) Lornatrium & - & 0,49 & 0,80 & 0,69 & 0,78 \\
\hline salkeroe & 1,55 & 1,22 & 21,58 & 19,47 & 5,48 \\
\hline zalterbe & 12,57 & 14,34 & 7,72 & 9,25 & 4,45 \\
\hline (Eifenoryo & 2,51 & 1,12 & 0,73 & 4,59 & 9,90 \\
\hline \$hosphorjäure & 38,27 & 33,85 & 35,61 & 16,53 & 13,69 \\
\hline Schnefelfäure . & - & - & 2,28 & 1,75 & 2,23 \\
\hline Riejel[äure & 8,70 & 10,00 & 1,13 & 1,49 & 0,77 \\
\hline
\end{tabular}

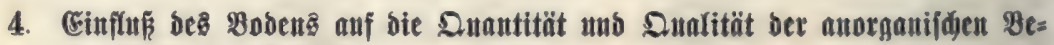

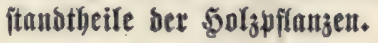

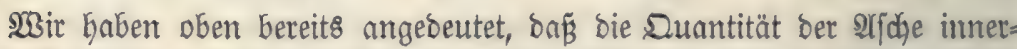
halb ber nämliçen Solzart uno bes gleichen Pflanzentheils ziemlich conjtant

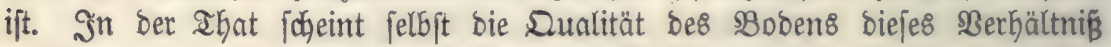
nidjt zu änbern. Diejes zeigen bie Unterjuchungen (Chebandiers, von reldhen

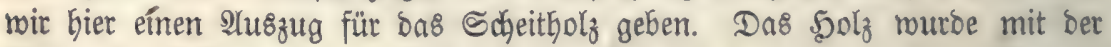

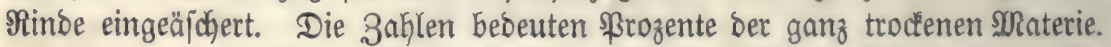

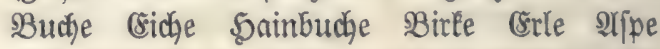

$\begin{array}{lllllll}\text { Bogejenjandftein } & 1,00 & 1,55 & 1,32 & 0,83 & 1,22 & 1,16 \\ \text { Bunter Sanoftein } & 0,85 & 1,54 & 2,20 & 0,88 & 1,78 & 1,61 \\ \text { Mujdyelkalé } & 1,12 & 1,66 & 1,55 & 0,72 & 1,23 & 2,04\end{array}$

Die Arbmeidfungen, weldhe bieje Zahlen erbliden laffen, fönnen unmögs=

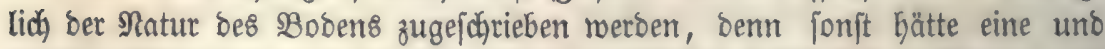

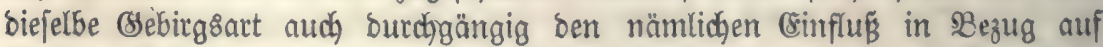
bie \$ermefrung ober Berminberung ber 2 fache äuß̈ern müffen. So fehen wir

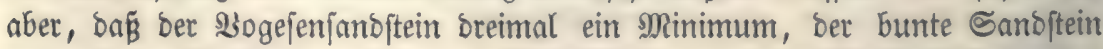
oreimal ein Marimum uno zroeimal ein Minimum, ber Mujchelfalle breimal ein Minimum Kerborbringt. Wollte man aber felbjt ber Anficht Guldigen, baß

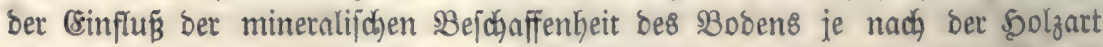

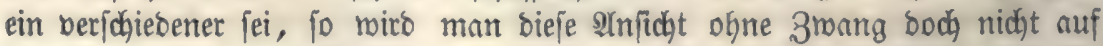
bie Sortimente außిbebnen fönnen. Sun ergibt aber bie folgende Iabelle, Daß̧ beim Sainbuchenjobeitholz ber bunte Sanbitein bas Marimum, ber $\mathfrak{B}_{\mathrm{D}}=$ 


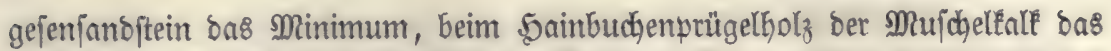
Marimum, ber bunte Sandftein bas Minimum ber 2ljofeproduction beroirft hat. Die Differenzen in Den obigen Zahlen Ënnen nur baḩer rühren, weil basjenige, was hier Scheitholz genannt ift, body nidjt \$olz bon ganz gleicher Etärḱe mar, indem man biejes Sortiment aus allem bemjenigen \$olz bilbet,

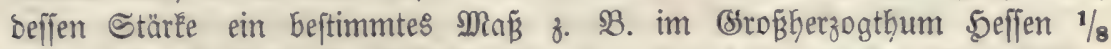

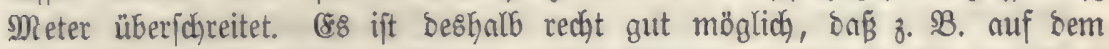

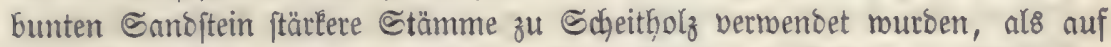

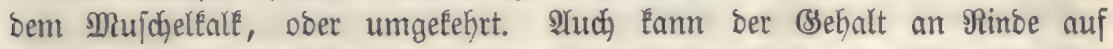

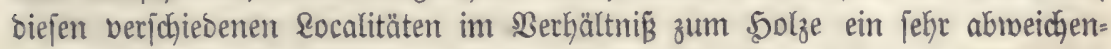
ber gewejen jein.

\begin{tabular}{lcc} 
& \multicolumn{2}{c}{ Sainbucke } \\
& Scheitholz & Prügelholz \\
Bogejenjanoftein & 1,32 & 1,82 \\
Bunter Sanoftein & 2,20 & 1,78 \\
Mujchelfalf & 1,55 & 1,93
\end{tabular}

$23 a 8$ aber bie Dualität ber 2ijchenbejtandtheile anlangt, fo äuß̧ert hierin Der Boben einen jebr bemerkbaren (Einflü, namentlich gilt bies bezüglich ber

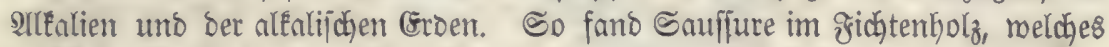

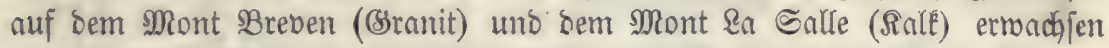
war, in 1000 Iheilen bet trockenen Materie 11,87 uno 11,28 Iheile 2ijo 3ahlen, die innerhalb der Srenzen ber Senautigkeit, melche bei (simäfcherungen ermartet werben fonn, mit einander fajt ganz übereinftimmen; oagegen ftellte

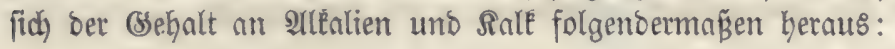

\begin{tabular}{|c|c|c|}
\hline & Sranit & Ralf \\
\hline Sohlenjaures sali & 3,60 & 7,36 \\
\hline Soblenjaurer Rale & 46,34 & 51,19 \\
\hline Sohlenfaure Bittereroe & 6,77 & 00,00 \\
\hline
\end{tabular}

2luf bem Raleboben war aljo in ber shat mehr sale bon bem 5olz aufgenommen worben, als auf bem Branitboben.

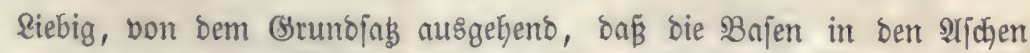

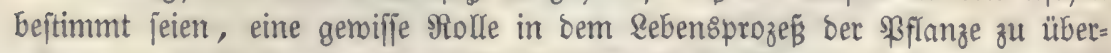
nefmen, glaubte ben relativen $23 i r k u n g s i v e r t h$ berjelben nach ifren 2lequiva=

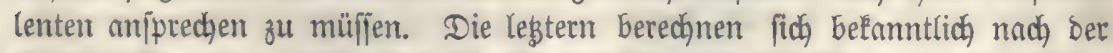
Sauerftoffmenge, meldye bas Metall braucht, um fich zu orybiren. Riebig

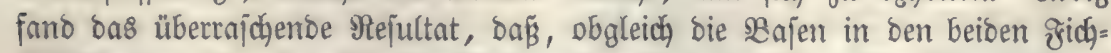
tenajden iu fefr abweidjenten Mengen vorḱommen, body bie Summe ifres Sauerfoffgegaltes, fo zu fagen, ganz übereinjtimmt. 
Fichtenafdje bom Granitboben

\begin{tabular}{|c|c|c|c|c|}
\hline Soblenjautres Sali & 3,60 & Cauerftoffgehalt bes & Ralis & 0,415 \\
\hline Sioblenjaurer Sinlé & 46,34 & " $"$ & Salfes & 7,327 \\
\hline হoblenjaure sittererbe & 6,77 & ber & Sittererbe & 1,265 \\
\hline
\end{tabular}

ङidjtenafde vom Saléboben

\begin{tabular}{|c|c|c|c|}
\hline Soflenfaures Roli & 7,36 & Saueritoffiebalt bes & Sali's \\
\hline Roblenjaurer Ralé & 51,19 & " $"$ & Sinlés \\
\hline Roblenjaure sBittererbe & 00,00 & & \\
\hline
\end{tabular}

9,008 und 8,95 find wirklidy Eaum von einanoer verjojieben, wenn man bie

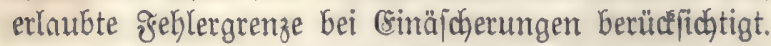

Das von Riebig aufgefundene Seres, baß ber Sauerftoffgehalt ber in

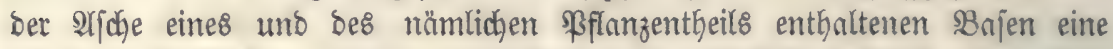

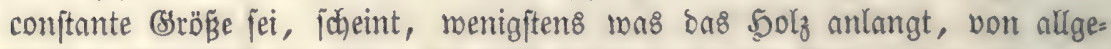

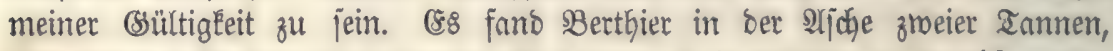
von berten I in bem Departement de l'Isère, II in Norwegen erwachjen war,

\begin{tabular}{lccrcc} 
& I & II & & I & II \\
Sali uno Natron & 16,8 & 34,8 & Sauerfoffgebalt & 3,57 & 7,7 \\
Sale & 29,6 & 13,6 & & 8,36 & 3,82 \\
Magnefia & 3,3 & 4,35 & 1,26 & 1,69 \\
\hline & & & 13,19 & 13,31
\end{tabular}

Dieje beiben 3ablen ftimmen faft abfolut mit einander überein.

\section{Utriprung ber anorganifoden Beitanotbeile in ben Begetabilien.}

Die nächjte Dutlle, aus welcher wir bie organifd)en Beftantotheile ber

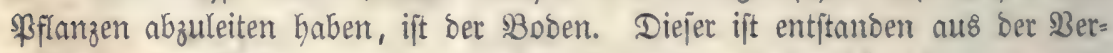
witterung ber Bejteine, weldhe bie fejte (8rorintoe urjprünglich) zujammengejebt

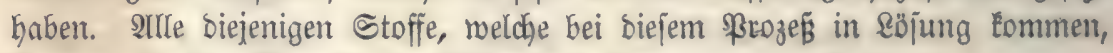
Eönnen von ben $\mathfrak{X}$ Gurzeln Der Pflanzen aufgenommen merben.

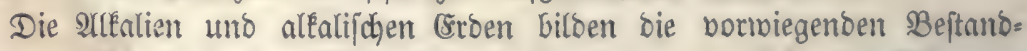
theile ber sljuche bes eigentlichen Solzes; fie find es, weldhe ber Boben in gröserer Mienge zu liefern hat.

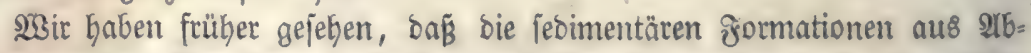
lagerungen von Sanbiteinen, Sialfen uno Bermitterungsprobucten ber fellos [pathe Doer ber ifnen berwanoten Mineralien beftehen, uno baв bie legtern in Den plutonifonen Billoungen immer enthalten finto. Rum befigen aber alle

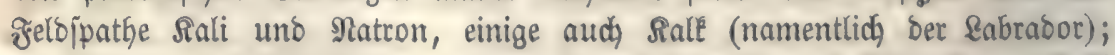

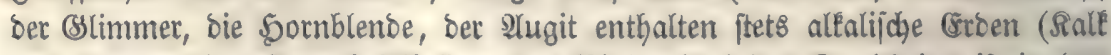

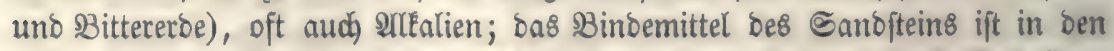

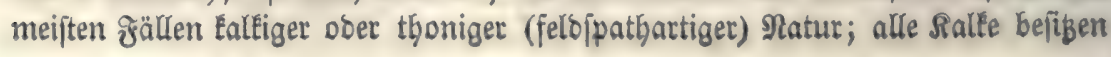




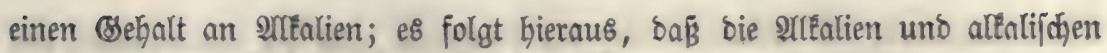
Eroen in jedem soben fich borfinden müffen.

Daí auch bie Siejel[äure, welche einen nidyt unbeträchtlichen aheil ber

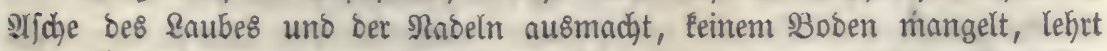

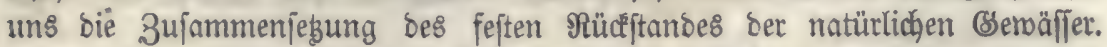
In Eeinem bon biejen hat man bis jest bie Riejeljäure bermip̈t, wenn es mur eine nicht zu kurze Strecfe über ben Boben gefloffen war.

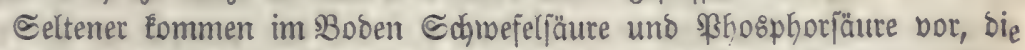
23 albbäume haben abet audj nidht fo viel von beiben nöthig. $203 e n n$ man bon einent bectare \$udjenmald jäbrlid 20 Sil. Salferbe ernotet, geminnt man erjt

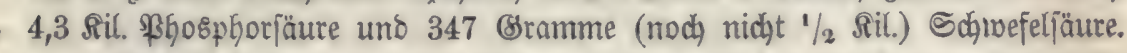

Das berbreitetfte ber jofwefeljauren Enlze ift ber (3yps, von ben phos: whorjauren ber 2lpatit uno $23 a$ arollit. Smmerhin Eommen aber biejelben (na=

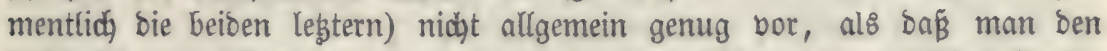

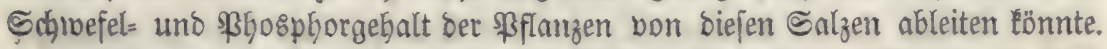

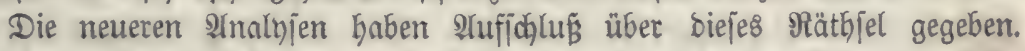
Bei genauerer Unterjuchung uno in beitete, fano man fait in jedem Bejtein einen, wenn auch nur geringen, (ses= halt an \$hosphor = uno Ed̆mefeljäure.

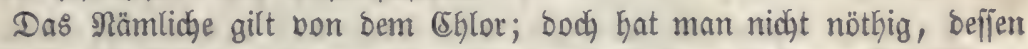

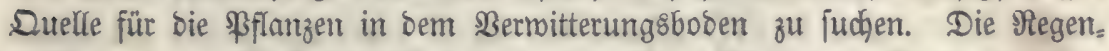
wolfen, beren $\mathfrak{B Z a f f e r \delta a m p f g e b a l t ~ z u m ~ g r o ̈ ß ̈ t e n ~ a h e i l ~ v o m ~ M e e r e ~ h e r r u ̈ h r t , ~}$ fübren fortwähreno groß̧e Quantitäten Sochjalz in bas sBinnenland ein, bie mit bem nieberfallenden Regenwaffer auf ben $B$ oben gelangen. Sbgleidh näm=

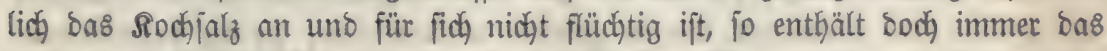
aus einer Sochjalzlöjung berbunitende 23 ajjer Spuren babon. Heber bem Meere jelbft ift ber Rochjalzgehalt bes $\mathfrak{3}$ afferbampfs am auffallenditen; Gier trübt bie \&uft jeberzeit falpeterfaure Eilberlöjung (es bilbet fieh unlösliches

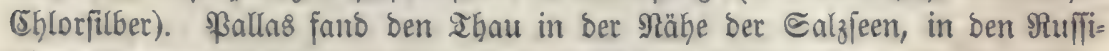

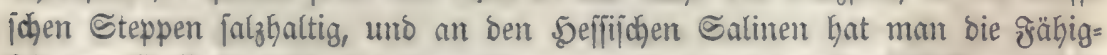

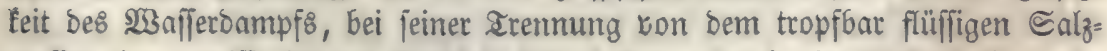
waffer eine gemiffe Menge Sodj]alz feftzubalten, burd birecte \$erjudye nad)= gemiejen.

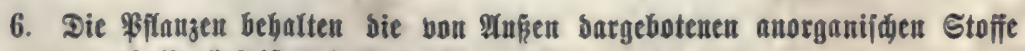

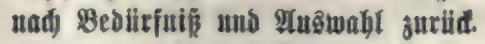

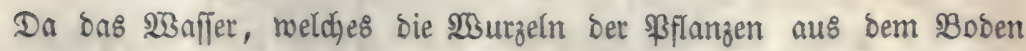

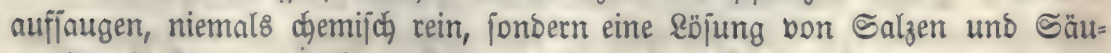

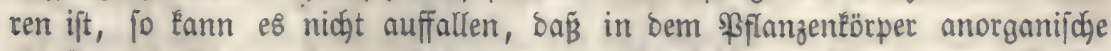
Stoffe gefunden merben. Das von ben Gerbächjen aufgenommene $23 a f f e r$ verbunjtet ja rieber, es nuf ein Iheil ber nicht flüchtigen Subjtanzen in ignen zurüableiben. Nun rirft fidh aber bie grage auf: fönnen bie fog. 


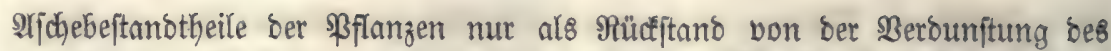
aufgejaugten $\mathfrak{B}_{\text {affers }}$ angejehen werben, Doer müffen wir biejelben als eine

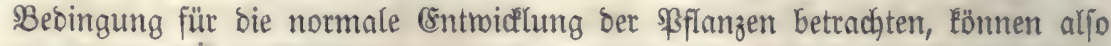

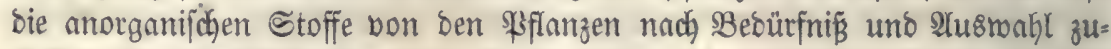
rüdfbef)alten merben?

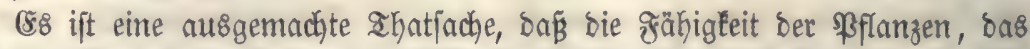

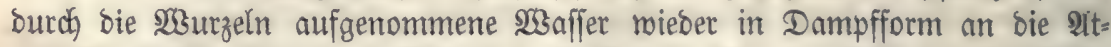

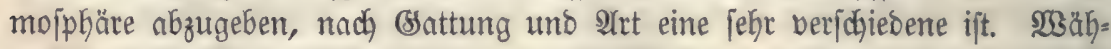

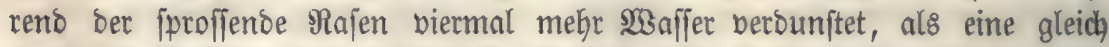

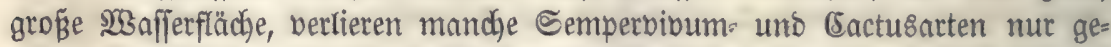
ringe Sputen ifrer Saftfeuthtigkeit. Nelymen wir nun an, es wütbe ben

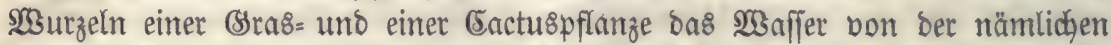

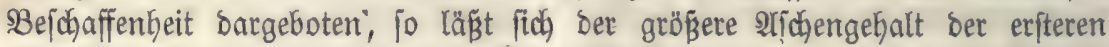
als folge ber vermebrten Berounjtung erElären.

Dffenbar ift bie Berounjtung bei ben Bflanzen ein rein phyfikalifaser

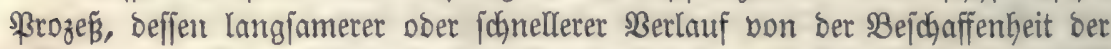
slätter und jungen Triebe, insbejonbere, wie wir fpäter jełen meroen,

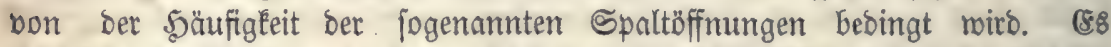

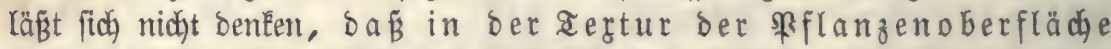
bie Bebingungen für bas 3 urüchalten bes einen ober bes an= bern berjenigen Stoffe getegen fei, weldhe burd) bas mittelft ber $\mathfrak{3}$ ur=

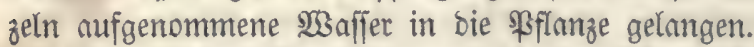

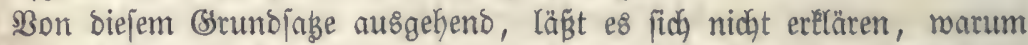

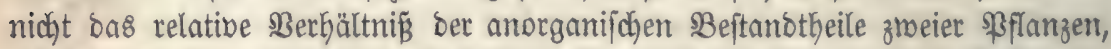
welche mit bem nämlichen $\mathfrak{W a f f e r ~ g e n a ̈ h r t ~ r o o r d e n ~ f i n d , ~ g e n a u ~ b a f f e l b e ~ b l e i = ~}$

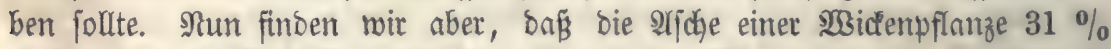
Sali uno $2 \%$ Riejeljäure enthält, rähreno die âlje eines biḑt baneben ge-

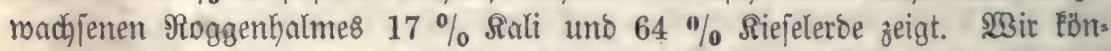

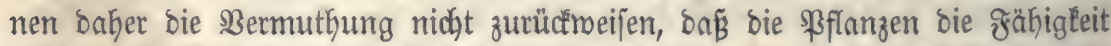

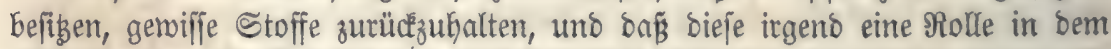
Drganismus, in Dem \&ebensprozeß̈ ber (remädhje fpielen. Dent wozu affi=

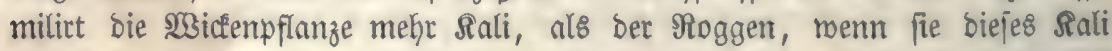
nidjt zu befitimmten 3medien braudyt? Die Staft jelbft, weldje bie 2lusmahl

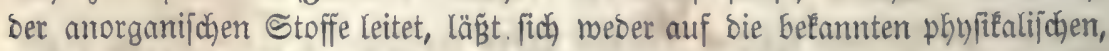
nod) auf bie ḑemifdjen Sräfte zurücfführen; wir müffen fie, fo lange igre Natur nicht genauer erforicht ift, als RebensËraft bezeidfnen.

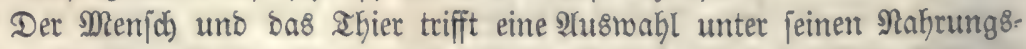
mitteln; Eönnen wir von ber \$flanze bas BSleiche annebmen? Bejigt aljo

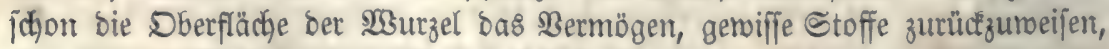

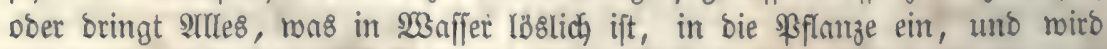

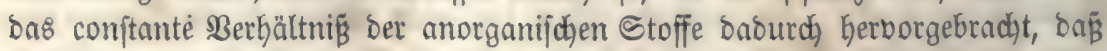
bie nidgt berwenbbaren Subjtanzen wieber aus ber \$flanze ausgejdieben 


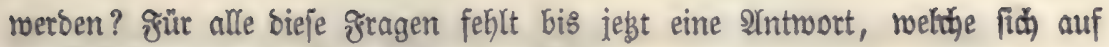

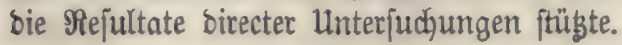

\section{Die anorganijuen Beitantheife ber Prfangen fint eine nothwenbige Be= bingung fiir bie normale Entwiatung berietben.}

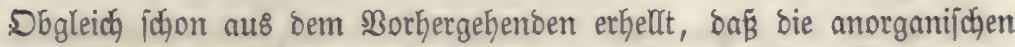
Stoffe, weldhe in ben ßfanzen gefunden werben, kein zufälliges ßorfommen

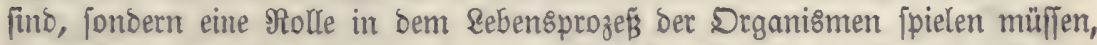
fo roollen mir boch noch einen birecten Berjudh anführen, weldher berseift, baß bie jogenannten 2 [jojebejtandtheile eine nothmendige Bebingung für bie nor= male Entroictlung ber Berwächje fino. Diejer SBerjuch rüthrt von SWiegmann uns ßolitorff her.

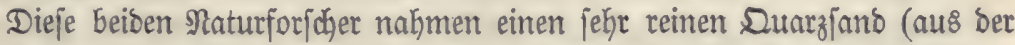

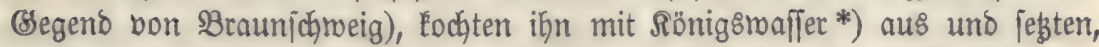
nachbem bie Säure uno bas, mas fich in ifye gelöft hatte, burch Wajchen ent= fernt mar, ber einen Sälfte biejes Sanbes organifje und anorganiijaje Sub= ftanzen in Dem Berbältnißz zu, in relchem fie bon Sprengel in einer frucht= baren Afdererbe gefunden worben waren. Ș 1000 Theilen enthielt bas von ifnen Dargeftellte Bemenge:

\begin{tabular}{|c|c|}
\hline Peinen Quarzโand & 861,26 \\
\hline Sdynefeljautes sali & 0,34 \\
\hline aroçnes soch jalz & 0,13 \\
\hline (Sebrannten Bups & 1,25 \\
\hline (Sejd)lämmte Streibe & 10,00 \\
\hline Sohlenfaure MRagnefia & 5,00 \\
\hline Manganorybo & 2,50 \\
\hline (Eijenorndo & 10,00 \\
\hline Allaunerbe, auธ 2llaun gefăllt & 15,00 \\
\hline \$5овphorjauren Ralt & 15,60 \\
\hline 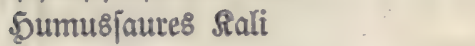 & 3,41 \\
\hline 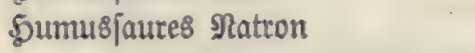 & 2,22 \\
\hline 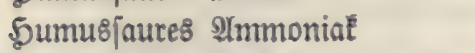 & 10,29 \\
\hline ఏૂumuริ|auten Salf & 3,07 \\
\hline Бุumuвิ|aure Talferbe & 1,97 \\
\hline 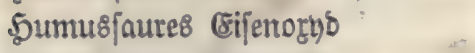 & 3,32 \\
\hline 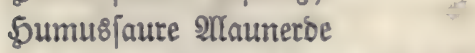 & 4,64 \\
\hline 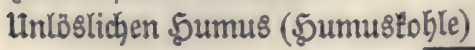 & 50,00 \\
\hline
\end{tabular}

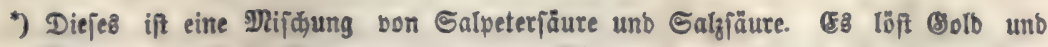
\$latin unter Entwictlung von falpetriger Săute auf, wobei biefe Dietalle in Bet= Seper, Bobentunde. 
Sed) Iöpfe bon 8 3oll Durdymeffer wurben mit reinem Sant un

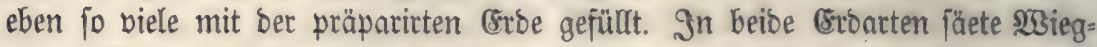

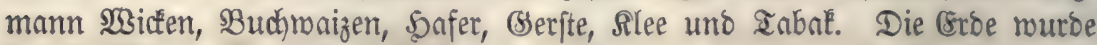
mit beftillirtém $2 \mathbb{B a f f e r}$ angefeuthtet.

In ben erften 8-10 Ingen zeigte bas $\mathfrak{3 a c h 8 t h u m ~ b e r ~ j u n g e n ~} \mathfrak{B}$ flänz= then Keinen Unterfojied, Dann aber wudjien bie in Funftlidjer (Erbe ben in rei= nem Sand erzogenen vor; ibre Blätter färbten fich ounfler und ifre salme uno Stengel murben ftärker uno fteifer. Sie blüften fämmtlich reidylid un fegten feimfäfjigen Samen an, während bie in ben blokßen Sano gejäeten Pflanzen nur zum Iheil blühten uno keinen frudhtbaren Samen berbor= brachter.

Man fieh̆t aus biejen Berjuḑen, baß̄ bie in ben Snmen niebergelegten

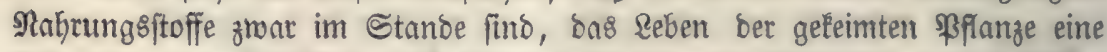

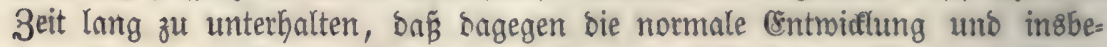
fonbere bie Samenprobuction nur erfolgen kann mittelft ber lözlichen Beftantotheile bes Bobens. Der \&uftitaub Eann biejelfen nidjt vertreten, Denn er roar ben in reinen Sanઠ gejäeten Pflanzen zugänglich, uno troboem entwictelten fich) sieje nidht volutänoig.

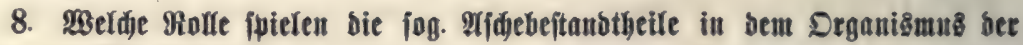 Brlauze?}

Die anorganifden Stoffe, weldye man in ben \$flanzen finbet, laffen fich in zroei grofie Gruppen bringen.

Die erftere, zu weldyer namentlich \$phosphor uno Sdfwefel geredhnet merben müffen, bebingen bie Sntegrität bes \$flanzentheils, meldhem fie angehören. Cie find förmlich in bie 3ujammenjegung beffelben eingetreten. WSozu bieje Stoffe bienen, miffen wir mit der größ̈ten Beftimmtheit. Artbu=

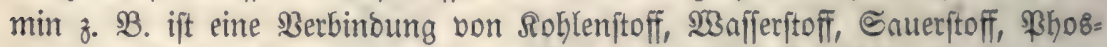
phor uno Sdjwefel; jebes von biefen (ETementen ift gleich wichtig für bie (5ons

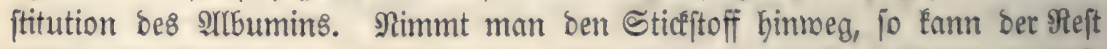
nicht mebr âtbumin genannt werben, aber eber fo renig verbient er bieje Bezeidynung ohne \$hosphor uno ভdynefel. 23ie feft z. BB. Der \$hosphor im Rleber an ben Rohlenftoff, $\mathfrak{B}$ afferftoff u. ז. m. gebunben ift, bemeift bie

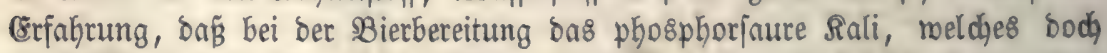

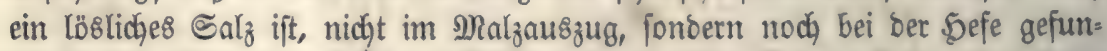

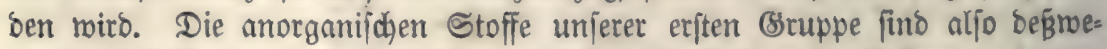
gen für bie Begetation notbroendig, weil fie wejentlid zu ber 3ujammenjegung gemiffer Pflanzentheile gehören.

binbung mit Bglor gebradit werben. Da in bem Boben foldae fhimerlöaridje Stoffe.

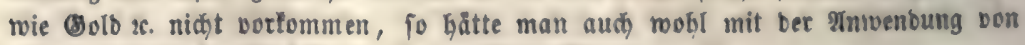

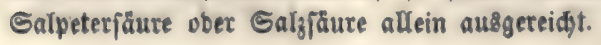


Indere anorganijacte Stoffe, aแs benen wir eine zmeite (sruppe bilden

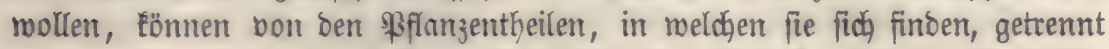

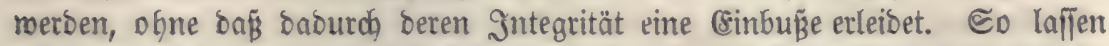

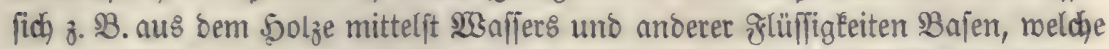

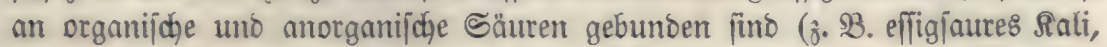

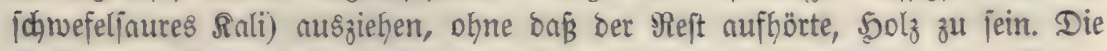
Entfernung biejer Eubjtanzen bat nidjt zur grolge, onß gleidjzeitig audy ber

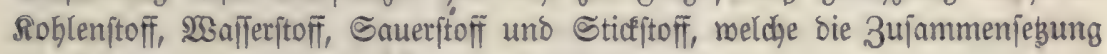
Der Solzfajer ausmachen, fich bon einanoer trennen.

$\mathfrak{B}_{3}$ z $u$ bienen bie anorganijd)en Stoffe ber zroeiten Sruppe?

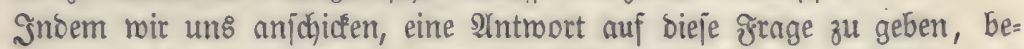
treten wir eines ber bunkeliten (S)ebiete ber Pflanzenphyfiologie. Riebig war

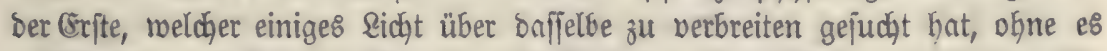

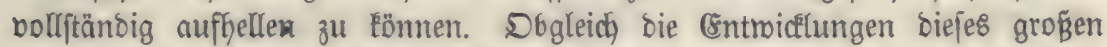

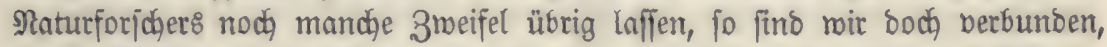
fie ausführlich mitzutheilen, benn fie find in ber ahat bie einzige (srtlärung, relche man bis jebt über bie Bebeutung oer angeführten 巨toffe für ben Bflanzenorganizిmus gegeben hat.

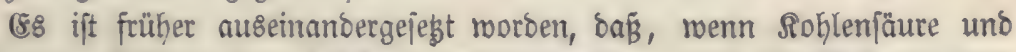

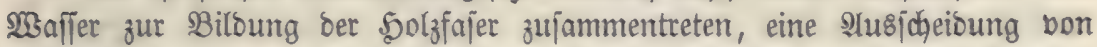
Eauerfoff exfolgt. (Seft man von ber 3ujammenjegung ber Eellulofe aus,

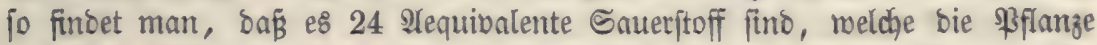

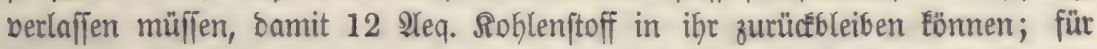

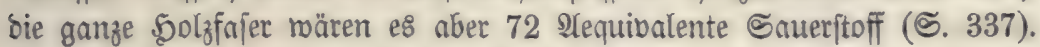

(s: ift mun nicht benÉbar, baß̈ bieje ganze bebeutenoe Quantität Sauer= ftoff auf einmal und in bem slugenbliaf ausgeftonen roerbe, in meldfem bie

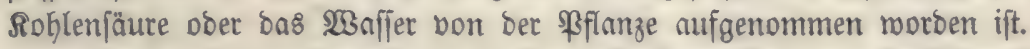

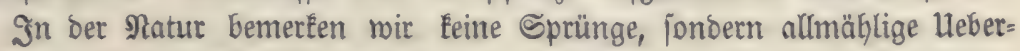
gånge, fromohl bom (sinfachen zum 3ujammengejegen, alв roie in ber umge=

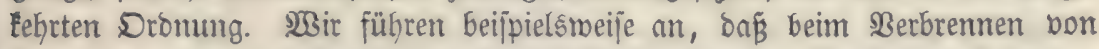

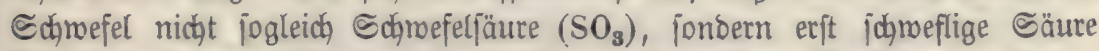

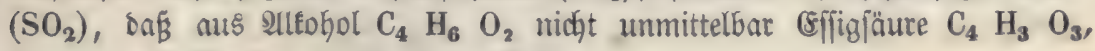
fonoern erft enfoebyo $\mathrm{C}_{4} \quad \mathrm{H}_{4} \mathrm{O}_{3}$ entiteht.

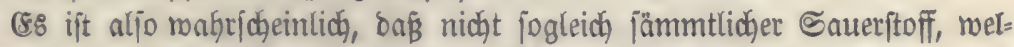

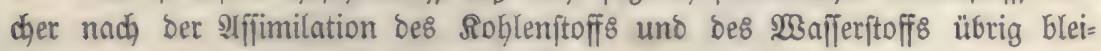

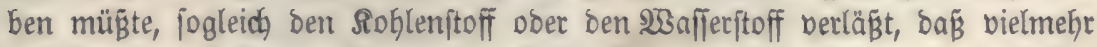

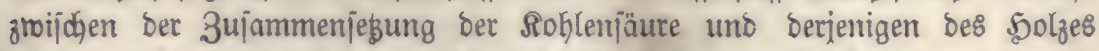
biele 3wijhenftufen liegen, weldhe aus Berbinoungen beftehen, Deren Sauer= ftoffgebalt in bem Mage abnimmt, als fie fid bem Solze näbern.

Dieje Innafme noürbe jegr geminnen, menn in ber Pflanze jelbft bieje

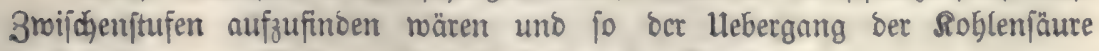

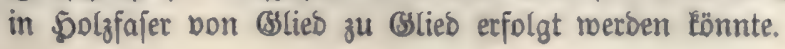


Dies ift nun bis jekt nicht in ber münjdgens?merthen Bolftänbigleit gelungen, mahrjdeinlich beß̧̈alb, meil ber Uebergang von einer biejer ßer= binoungen in bie andere in fehr kurzen Sinterballen erfolgt. Shalt man bagegen

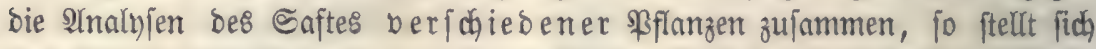
eime $\mathfrak{2} \mathfrak{n} z \mathfrak{a h l}$ von Sïrpern bar, beren Sauerftoffgehalt förmlids eine fallende

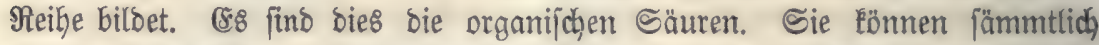

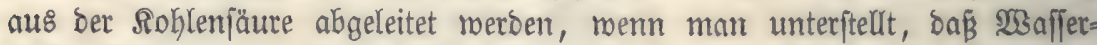
ftoff aufgenommen und Sauerftoff ausgegeben rerbe. $\mathfrak{X B}_{3}$ mollen bieje Deri=

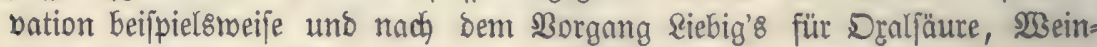

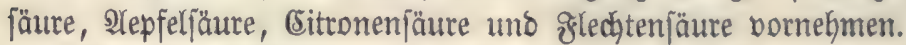

12 2leq. Sohlenfäure fins $=$ bierbon ab 6 Saueritoff bleiben 6 2)eq. mafferfreie Dralfäure Die Dralfäure exifitirt nidht in wafferfreiem Suftano, als Drals fäurehyorat enthält fie 1 श्Teq. $\mathfrak{2}$ affer.

6 Areq. Draljäurebyorat $=$ $\begin{array}{r}\mathrm{C}_{12} \mathrm{O}_{24} \\ \mathrm{O}_{6} \\ \hline \mathrm{C}_{12} \mathrm{O}_{18}\end{array}$ 24u\& Der Dralfäure entiftebt burdh 2lustreten von Saueritoff Wreinjäure uno 2 tepfelfäure

6 श्teq. Draljäurebybrat =

Giebon $a \mathfrak{b} 9$ Saueritoff bleiben 3 भeq. 2צeinfäure meiter ab 3 Sauteritoff

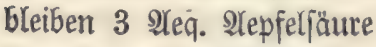
Gierbon ab 1 : bleiben 3 थeq. Bitronen[äure Gierbon 2 : 3 affer bleiben 3 গleq. F̊lechtenjäure $\begin{array}{llll}\mathrm{C}_{12} & \mathrm{O}_{24} & \mathrm{H}_{6}\end{array}$

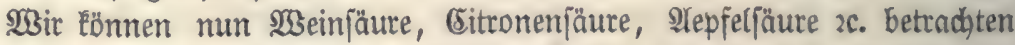
als Berbinoungen von Dralfäure mit Zucfer, Bummi, Âtmylon, Eellulofe u. 1. พ. 3. 28

6 SBeinjăure

$2\left(\begin{array}{lll}\mathrm{C}_{12} & \mathrm{H}_{6} & \mathrm{O}_{15}\end{array}\right)=$
6 Dralfäure + Eelluloje $\mathrm{C}_{12} \mathrm{O}_{18}+\mathrm{C}_{12} \mathrm{H}_{10} \mathrm{O}_{10}+\mathrm{H}_{2} \mathrm{O}_{2}$

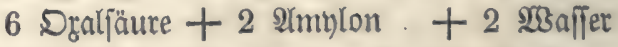

$$
=\quad \mathrm{C}_{12} \mathrm{O}_{18}+\mathrm{C}_{12} \mathrm{H}_{10} \mathrm{O}_{10}+\mathrm{H}_{2} \mathrm{O}_{2}
$$

6 Draljäure + trodener Aryornzuder +1 SBaffer

$=\mathrm{C}_{12} \mathrm{O}_{18}+\mathrm{C}_{12} \mathrm{H}_{11} \mathrm{O}_{11}+\mathrm{HO}$

6 Draljäure + trockener Draubenzuder

\section{$=\hat{B}_{12} \mathrm{O}_{18}+\mathrm{C}_{12} \mathrm{H}_{12} \mathrm{O}_{12}$}

- Durch Sinzutreten neuer Quantitäten 235 afferftoff Ënnen aljo alle bieje

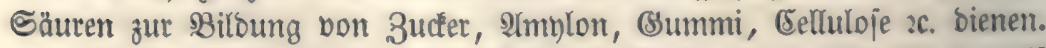

(6:s fragt fich num, ob IGatjachen Dafür iprechen, baß bie organifochen Säuren wirklid ben Lebergang in bieje Stoffe bermitteln. 
NBie ichon angebeutet nourbe, hat man in einer uno berjelben Pflanze

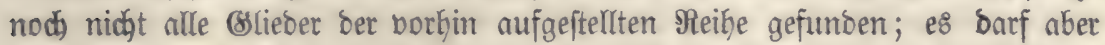

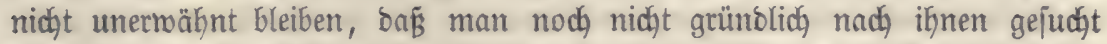
hat. Bon Riebig jelbjt ift $e \varepsilon$, fo biel mir wiffen, bis jeģt berjäumt morden, ben Sflanzenjaft auf bie ganze Rette ber Säuren, meldhe er in ifm bermuthet, zut unterjuchen. Dagegen füfint er folgende Benbadgtungen zur lunterftüung jeiner 2 infidjten an:

a. "Die unreifen grnudhte der $\mathfrak{B g e i n t r a u b e n ~ f i n o ~ m e g e n ~ i f r e s ~ S a ̈ u r e g e = ~}$ gehaltes ungenieß̧bar. Sm Sonnenliçt jobeiben fie Sauerftoff aus, uno jtatt ber Säure finden wir im 5erbjt 3udeer."

b. „2Sir jehen in ben grtühten bes $\mathfrak{B}$ ggelbeerbaum's auf bie $23 e i n=$ fäure bie 2repfel[äure, auf bie inuerftoffreichere Säure bie an Saueritoff ärmere

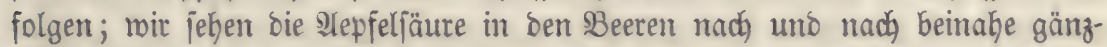
lich berfdhinden und finten an ifrer હtelle (summi uno હdhleim, bie vorher barin fehlten, uno ebenjobiel Crrünoe, roie wir für ben Hebergang bes $\Omega_{0} h=$

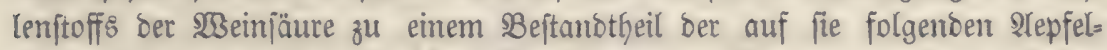
fäure haben, an bem rohl idgroerlid Semand zroeifelt, genau fo biel baben mir für ben llebergang biejer Єäuren in Zươer."

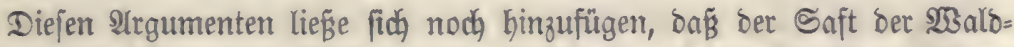

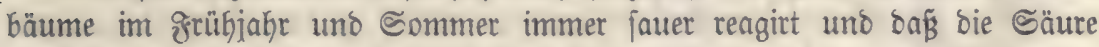

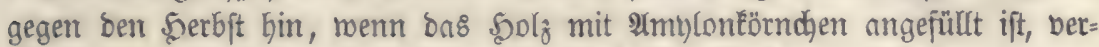

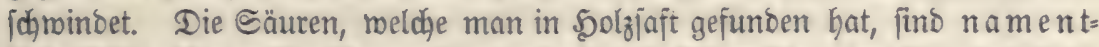

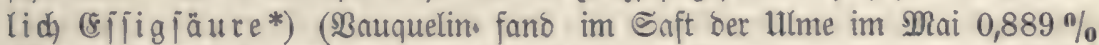

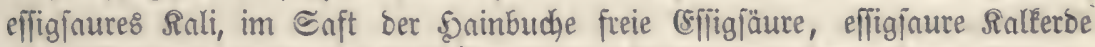

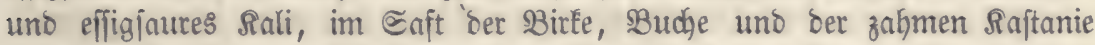

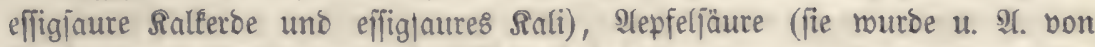

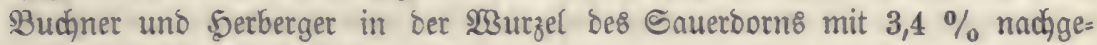
miejen), פBeinfäure unઠ (serbejäure.

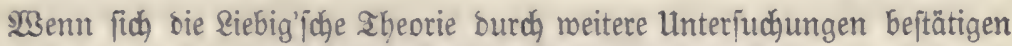
jollte, fo märe banit bns Dunfel, melches bisher über ber Billoung bes Şolzes

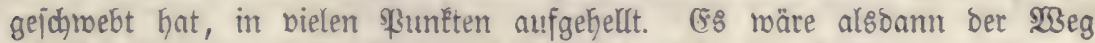
erleuchtet, sen bie soblemjäure zu surchnanbern hat, um in Silmylon, (Summi ober Zucter übergugehen. Sit man einmal bei biejen Eubjtanzen angefom= men, io madht bie Erelärung, wie fich aus ignen bas \$olz erzeugen kann,

*) Die Formel bes Effigåarefinbrate if $\mathrm{C}_{4} \mathrm{H}_{3} \mathrm{O}_{3}+\mathrm{H} 0=\mathrm{C}_{4} \mathrm{H}_{4} \mathrm{O}_{4}$; bieje

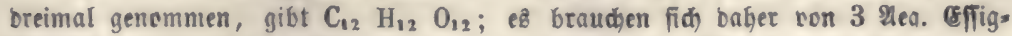

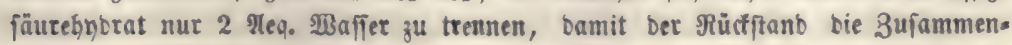
feģung ber celluloje erb̧alte. 


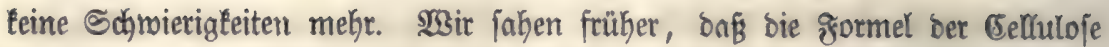

ijt. Dieje fitimmt mit berjenigen bes Derttins volftänbig überein; uno nefymen wir bie frormel be\& Imylons $\left(\mathrm{C}_{6} \mathrm{H}_{5} \mathrm{O}_{5}\right)$ Doppelt, fo baben mir $2\left(\mathrm{C}_{6} \mathrm{H}_{5} \mathrm{O}_{5}\right)=\mathrm{C}_{12} \mathrm{H}_{10} \mathrm{O}_{10}$ baher ebenfalts die cellulofe. 3ieht man bon ber gormel bes Slyornzuders 1 Aleq. W3affer ab, fo ift $\mathrm{C}_{12} \mathrm{H}_{11} \mathrm{O}_{11}-\mathrm{HO}=\mathrm{C}_{12} \mathrm{H}_{10} \mathrm{O}_{10}$

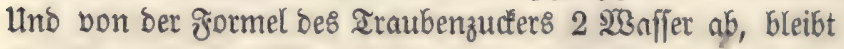
$\mathrm{C}_{12} \mathrm{H}_{12} \mathrm{O}_{12}-\mathrm{H}_{2} \mathrm{O}_{2}=$ aljo wieser celluloje.

$\begin{array}{llll}\mathrm{C}_{12} & \mathrm{H}_{10} & \mathrm{O}_{10}\end{array}$ $\begin{array}{lll}\mathrm{C}_{12} & \mathrm{H}_{10} & \mathrm{O}_{10}\end{array}$

(Es fojeint in ber Sib beffelben ift bas Marfftrahlengemebe und bie Rinbe, in Den Rängrge= fäßen fommt es nur jelten vor. Ulnterjudat man im frühjahr, menn bie

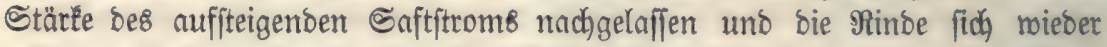
mit bem Solze verbunden hat, bie Mareftrahlenzellen, fo firbet man in ifhnen menig Stäremehl; im Sommer ift e\& fohon reichlicher borfanben, utno im

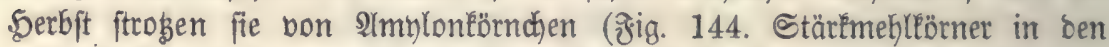
ə̊ig. 144.

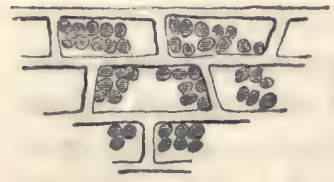
Maréftrablenzellen Der ßlatane). Das Nämlidje be= merțt man bei ben Blättern, if̧r Stärǩemehlgehalt ift im Serbjt, wenn fie abfallen, am größten, wees= wegen fie auch vorzüglich zu biejer gafhręzeit zu Zutterlaub geernotet werten, und ronn audh bas Bieb das Serbftlaub meniger gern frift, io meiß man bodh, baḱ biejes nahrhafter ift, als wenn es im Sommer bon ben Bäumen genommen roito.

Die Blätter ber \&aubGolzbäume fterben in unjeren Slimaten im \$erbfte mit bem sintritt einer niebrigeren Temperatur $a b$; fhon in bet Iürḱei, in (Sriedjenland, im fübliç)en Spanien find die \&nub̧ölzer wintergrün, bie sBlätter bleiben mehrere Sahre am Stamm figen, uno wenn fie abfallen, jo enthalten fie lein Stärḱemehl mebr, man kann fie mur zu Streu, nidht zur Nahrung für bie Shiere vermenton. Dieje Blätter haben ihr Stärkemehl an bas \$olz

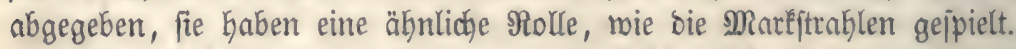

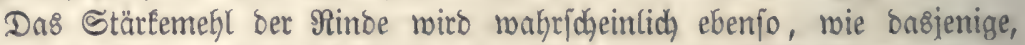
melches am Şolze aufgejpeichert ift, zur Billoung bon Selluloje vermanot,

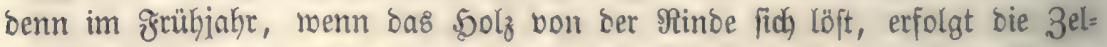
Lenbiloung von zrwei ๔eiten aus; e\& erzeugt fid ein neuer 5̧olgring uno zu= gleich eine neute Baftjctichte. Manche Solzarten enthalten auferorbentlid, viel

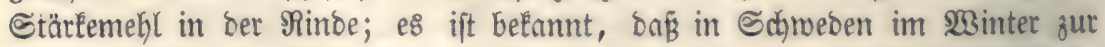

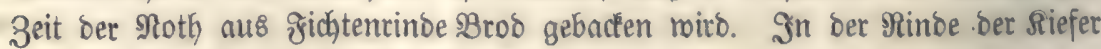
fano Du \$lenil 6\% Stärḱemebl.

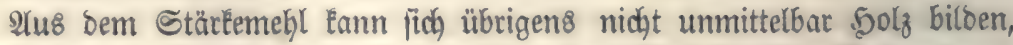

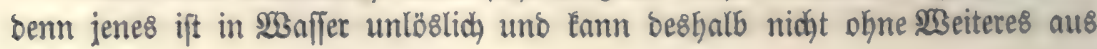




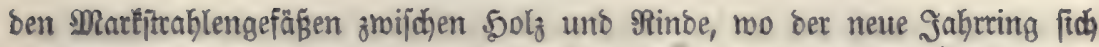

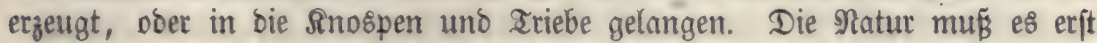
berflüffigen; fie bringt e\& zu bent \&nde in bie frorm bon Dertrin ober 3ucter.

Die Säfte von vielen $B a ̈ u m e n$ fint in ber Begetationszeit idjleimig, biejer Sdjleim hat genau bie 3ujammenjegung bes Dertrin's; anbere 5olz= arten enthalten im ₹rtütjabr 3udferjaft. Bei bem 215orn tritt er in fo bebeu= tenter Menge $(2-3 \%)$ auf, bafis man ifn wie ben $\Re$ ohrzudfer geminnt, uno

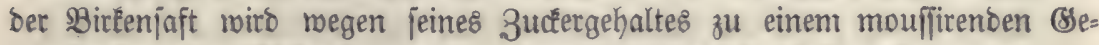
tränf́e, bem jog. Birfenchampagner, benugt. Sn biejen beiben Solzarten, bem SThorn uno ber Birfe, Gat ber Zudfer bie nämlidbe Beichaffentheit, wie im 3uctertoḩr, o. b. Feine formel ift $\mathrm{C}_{12} \mathrm{H}_{11} \mathrm{O}_{11}$. In ben Früchten bagegen

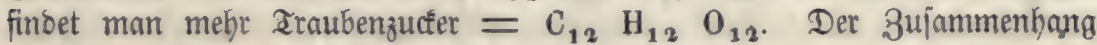

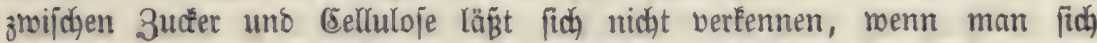

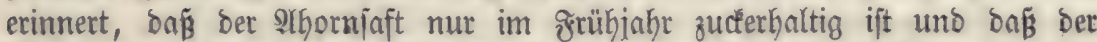

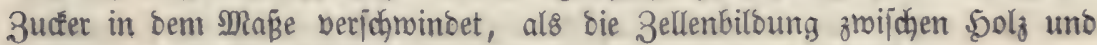
Rinbe uno bie Entwicfelung Der Rnospen uno Iriebe voridyreitet.

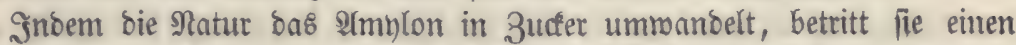
ummeg, benn bie 3ujammenjeģung bes Stärfemeble fteft ber Eelluloje näher,

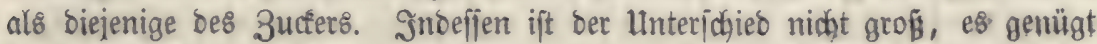

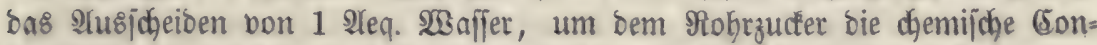
ftitution ber Celluloje zu geben. Sא̧äre Der Zudfer in ben Baumjäften Trau= benzuder, fo müpten 2 צeq. 23 nffer austreten.

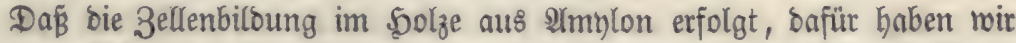
nod) einen Beleg in Dem Reimprozeß̧. Das Amylon bes Samens geht in 3ucfer über, läßt man ben Reim ber Sherite zu lang merben, jo ift ber

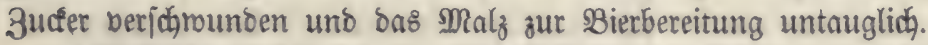

Bielleidht finbet bei ben Mabelhölzern ber Hebergang bes Âtmylons in

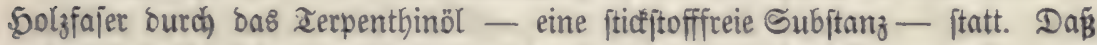
bas Stärfmehl fich in Fett vermandeln faum, jehen wir bei bem Mäjten ber Thiere, bie mit Rartoffeln gefüttert reerben, uno renn auch bie Borgänge im

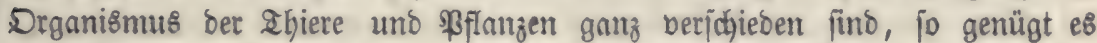

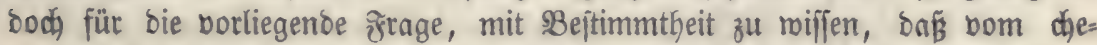

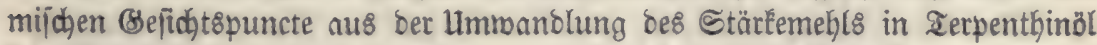

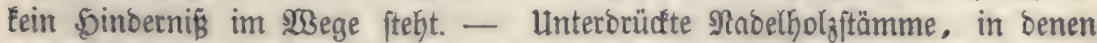
bie Rebensfraft gebroden ift, fino nicht vermögent, bas Rerpenthinöl in Şolz

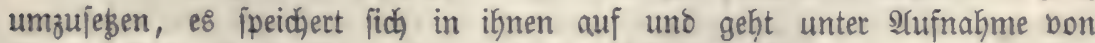

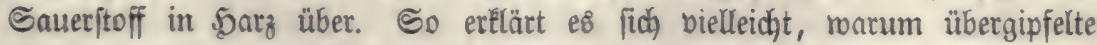
Stämme, bie längere Zeit im Drud geitanoen baben, fo tienreich find.

Sít.e\& nun wohl bie Rebensfrajt allein, melche die lteberführung bes

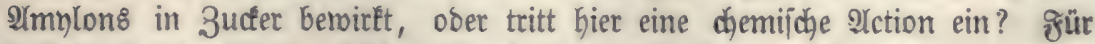
bas \$Borhanbenjein ber Legtern jprectjen bie \$orgänge bei ber Reimung; wir faben, baß 


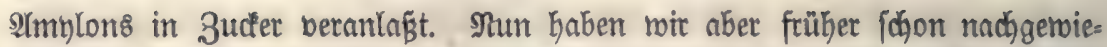

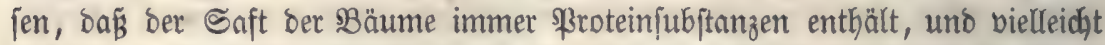
ftebt bie grof̧e Menge (rimeis, weldhe in bem abgelaffenen Athornjaft fo fannell bie meinige sähbrung herbortuft, mit ber silloung Des Z3utfers in einem en= gen Sujammenthange.

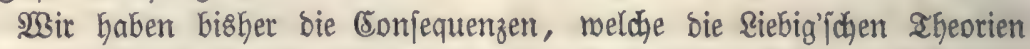

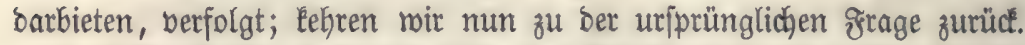

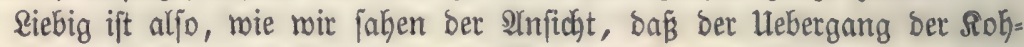

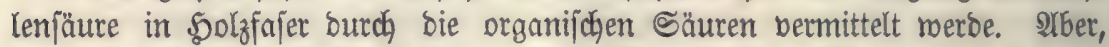
bemertt biejer grofe Naturforjober weiter, bie organifden Săuren find in ben Bflanzen felten in freiem 3ujtande vorbanden; fie find gebunden an sBajen. Die. Eoblenfauren Salze, welche man beim Berbrennen von Bemädsjen erfält, find als foldhe erft Durch) bie (sinäjcherung gebildet morben, fie roaren in ben Begetabilien entfalten al\& pflanzenfaure Salze. Die Säure murbe in ber

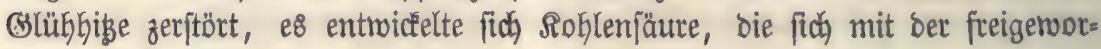
benen $\mathfrak{B a j e}$ berband.

WBenn bie Säuren frei in den Pflanzen borfommen, fo bemerlt man

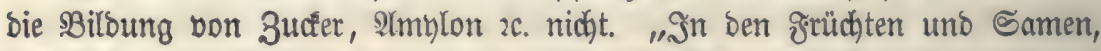
in meldhen bie Săuren frei, ס. ケ. nidjt als Salze enthalten find, wie bie Bitronenjäure in ben Bitronen, bie Draljäure in Den Richererbjen, bildot fich

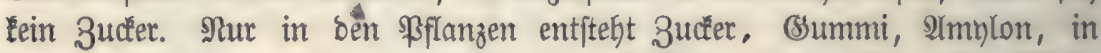
benen bie Säuren fich bereinigt finden mit $\mathfrak{B a j e n , ~ i n ~ w e l d y e n ~ f i c h ~ l o ̈ s l i d g e ~}$ Salze biejer Bajen befinden. Dhne bie Bsegenmart biejer legteren lann fid vielleidht eine organifche Säure, allein ohne bie Säure fein Zuớer zc. bildben". siebig.

ख3ären bie Mineralbajen mur zufällige $B$ eftandtheile ber Pflanzen, po

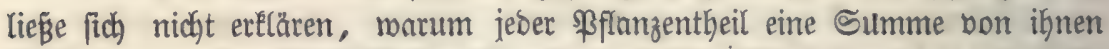

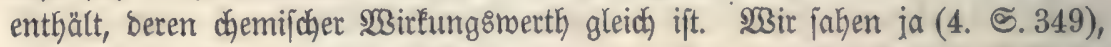

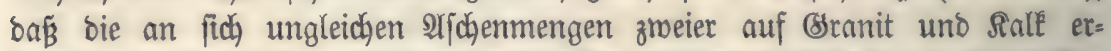
wachfener gichten boch gleiche Eauerftoffquantitäten ber Ba a en in fidg faffen.

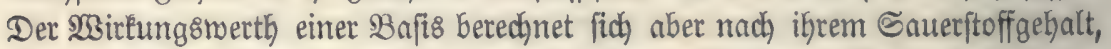

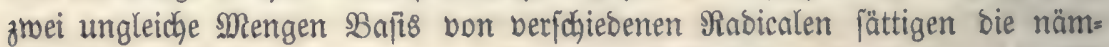
liçe Quantität Säure, menn nur ber Sauerftoffgebalt biejer $\$$ Bajen nicht bif= ferirt. 100 (Semidhtstbeile Schmefelfäure vereinigen fid mit 118 Sali zu ei=

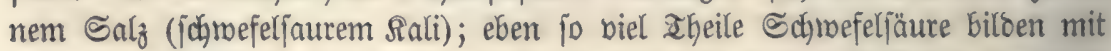

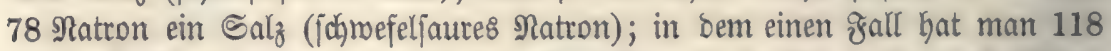

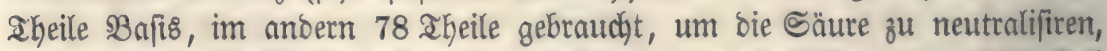
aber ber Gauterftoffgehalt ber beiben $B a j e n$ ift ber nämlidge, Denn 118 Sali enthalten 20 Saueritoff, 78 গatron enthalten gleidffalls 20 Saueritoff. Siebig.

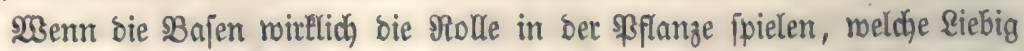

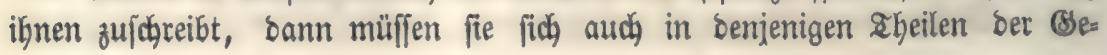




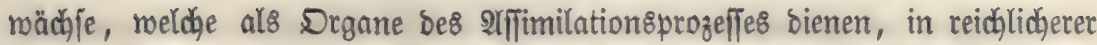
Menge finden, als in ben bereits fertig gebilbeten. Die Ânalnjen beftätigen

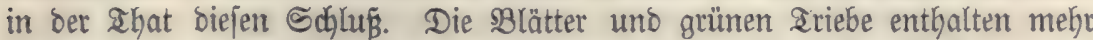

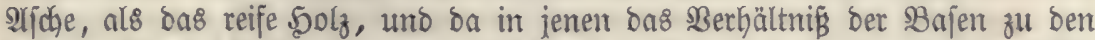
übrigen Beftandtheilen ber श्ajhe nidft Eleiner ift, als in biejem, fo ergibt fich,

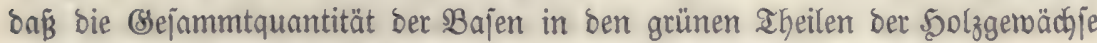

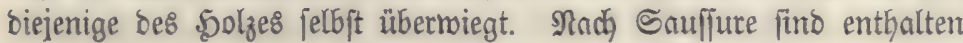

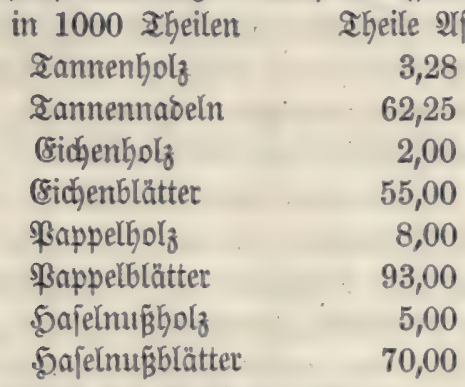

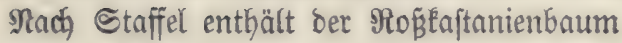

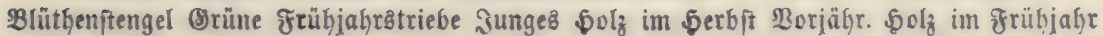
11,4 9,9 3,4 1,1 2lichenprozente, räbrend bas alte 5olz noch nicht $1 / 2 \%$ aljoje bejigt. Bon= haujen fand im Buchenreisholz 2,33 mal, im Rieferreisholz (mit Rnoeln) $4 \mathrm{mal}$ jo biel 2 jidje, als im Stammbolz.

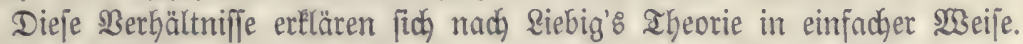
Das Stammbolz nar einmal jung, es enthält ja bie einjäbrige ßftanże. (šs muß aljo auch einmal reich an ben $2(j$ jhenbejtandtbeilen gemejen jein. $230=$ hin find bieje getommen? Nachbem fie bie 5olzerzeugung bermittelt Gatten, war ify Zroed erfüllt, bem reifen Solze tonnten fie nicht mefor nüben; bie

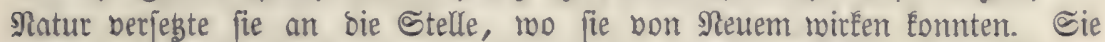
find, gelöft im Eaft, übergegangen in bie jüngeren Triebe, in bie Blätter uno Rabeln. So bermag eine Eleine Quantität bet anorganijchen Etoffe im

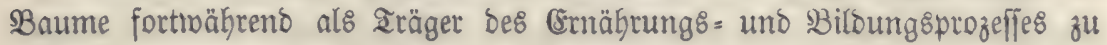
bienen.

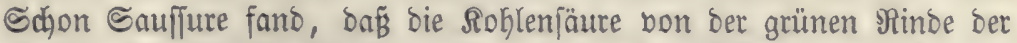

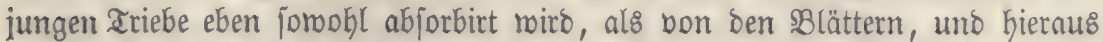

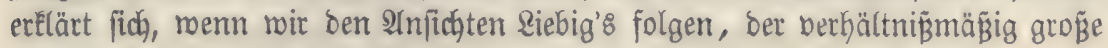
aljohengehalt ber jungen Rinde.

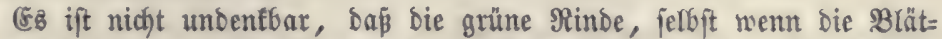

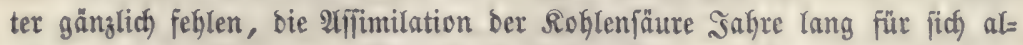

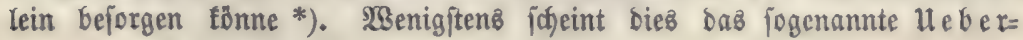

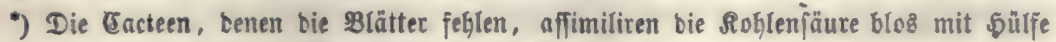
ber grünen Epibermiล bes Stammes. 


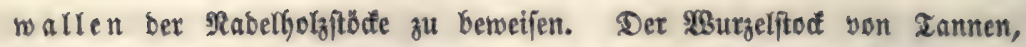
Fiddten und Rårdfen lebt oft nodh lange Beit fort, nad)bem ber Sdfaft ge=

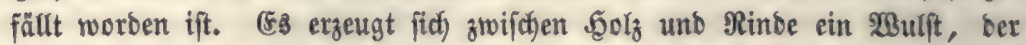

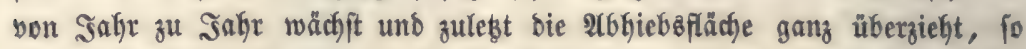

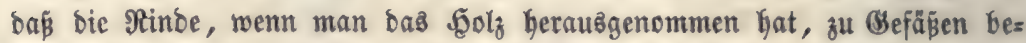

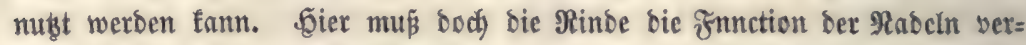
Fefen, benn man hat Stöffe bemerft, in Deren Utmgebung weit und breit fein $\mathfrak{B a u m}$ beffelben Benus fid bejant, ber burd Berbintung ber 2 Sur=

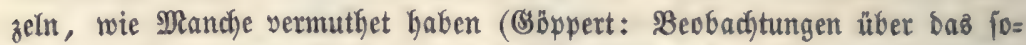
genannte Heberwalfen ber Tamnentöfé, Bonn 1842), Den Sto ex emährt

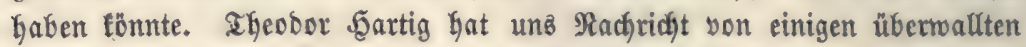
\&ărdjen gegeben, in beren näberer Hmgebung fid nur Juniperus - Sträudide befanden (Forft = und Iagdzeitung, 1844, 96). Dex Berf. felbft hat in

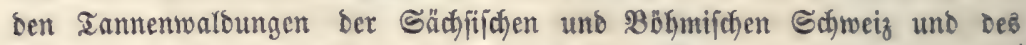

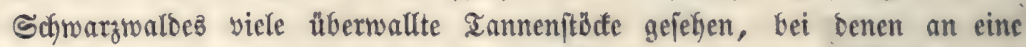
Berbinbung ber $\mathfrak{W}_{\mathfrak{S}} \mathrm{r}_{\mathrm{z}} \mathrm{Cln}$ mit andern Stämmen nicht im Entferntejten ge= bacht werben tounte.

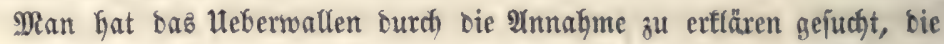

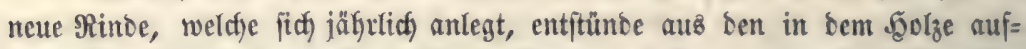

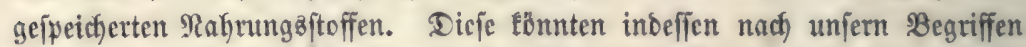

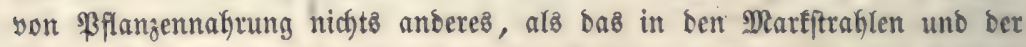

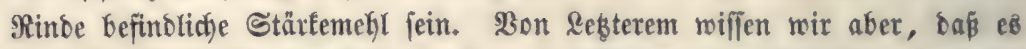
in jeoem frühjahr verzehrt, §. h. zur Billung yon Celluloje verwendet

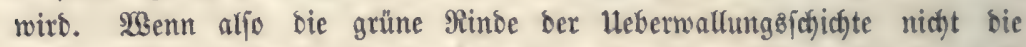
Fähigfeit bejäß̋e, Sohlenjäure aufzunthmen, und wenn biefe nicht innerhalk

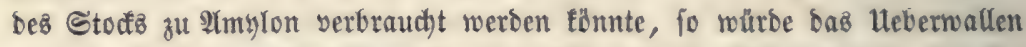
nur ein Sahr Yang ftattfinten fönnen. Dic jährtidje \$Sieberholung ber Er=

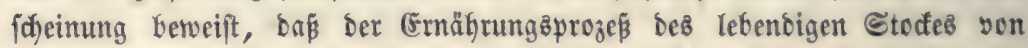
Demienigen ber unverftümmelten $\mathfrak{B}$ flanze nidjt verifjieden ift.

W3ir Gaben früher (6.) bie Jrage aufgetworfen, ob nicht vielleicht bas

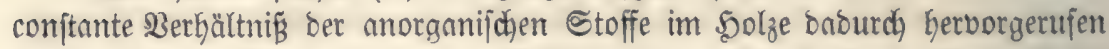

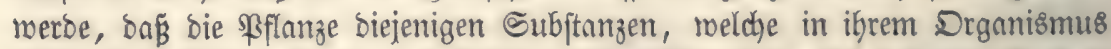
keine \$erwentung finben, nusjcheibet. Bielleidgt gelangt bieje grage zu ifrer

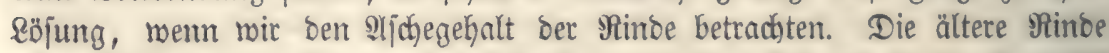
bieler 8 äume ift als ein wahres Gecret anzujehen; bie \$latane z. B. mirft fie jäbrlich ab; bei ber Siefer uno BBirf́e zeigt fich, menn auch in unvolltomm=

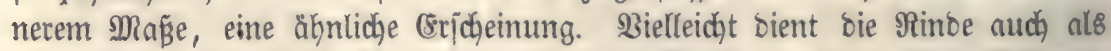

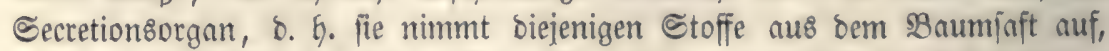
meldhe ausgefchieben werben follen. Darauf beutet joroohl bie Sograntung

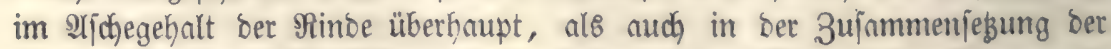

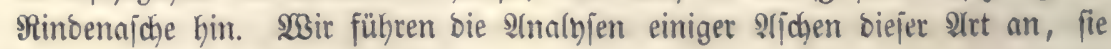
murben bon Sauffute unterfucht. 


\begin{tabular}{|c|c|c|c|c|c|c|}
\hline श1 & $\begin{array}{l}\text { Midje in } 1000 \\
\text { Sheilen ber } \\
\text { trocfenen } \\
\text { Pflange }\end{array}$ & $\begin{array}{l}\text { Ilfalien u. } \\
\text { Calze mit } \\
\text { alfalijøet } \\
\text { Bafis }\end{array}$ & $\begin{array}{l}\text { \$hos phorf. } \\
\text { Ralf und } \\
\text { Bittererbe }\end{array}$ & $\begin{array}{l}\text { Eijen, } f \\
\text { Mangan. }\end{array}$ & $\begin{array}{c}\text { Roblenjaute } \\
\text { Cerben }\end{array}$ & $\begin{array}{l}\text { Riejel } \\
\text { Erbe }\end{array}$ \\
\hline (sidgentinte & 60 & 28,50 & 3,0 & 2,00 & 66,00 & 1,50 \\
\hline Bappelrinde & 72 & 29,20 & 5,3 & 1,50 & 60,00 & 4,00 \\
\hline Бajelnü̧rinde & 62 & 56,70 & 35,0 & 0,12 & 8,00 & 0,25 \\
\hline 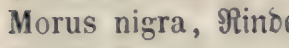 & toe 89 & 30,13 & 8,5 & 1,12 & 45,00 & 15,25 \\
\hline Sainbudbenrinbe & 134 & 34,88 & 4,5 & 0,12 & 59,00 & 1,50 \\
\hline
\end{tabular}

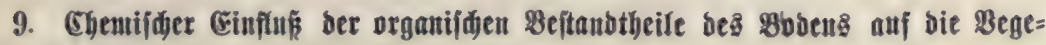 tation.}

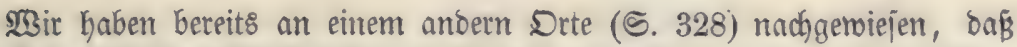

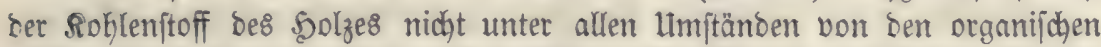
Reften im Boben abgeleitet meroen könne. $\mathfrak{S B}_{3}$ ir füfrten al\& Belege für un=

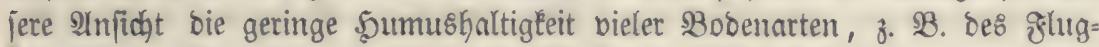
janbes, ber Raba sc. an, auf benen bod) bie Eultur ofne 9lnwentung orga= nifchen Düngers groß̉e Duantitäten Roblenftoff erzeugt. (s\& ift weiter be= rechnet roorben, baв̈ bie Menge Rrblenfäure, welche zu allen Zeiten uno an allen Drten in ber Irtmojphäre enthalten ift, vollftänoig genügt, um Den Be= wächjen jämmtlichen Roblenjtoff zu liefern, melchen jie bebürfen, baß́ jomit bie Sohlenjäure als bie allgemeinfte Suelle angejeben werben müfje, aus mel= dher bie sflanzen ben Rohlenftoff bejiehen lönmen.

গun wirft fidh aber bie frrage auf, ob ber Sumus al\& joldher bon ben Begetabilien aufgenommen rerben tönne uno of ex nicht etron auf foldsen

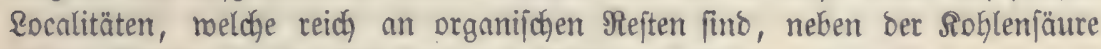
für bie Crrnägrung ber ßfflanzen von Bebeutung fei.

\section{a. Die Iö8 merben.}

Dás fejte, unlb̈sliche Stoffe, feien fie audh noch jo fein zertheilt, nicht

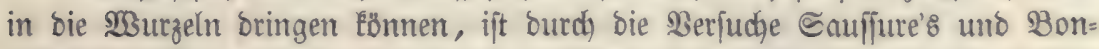
net's bemiejen rorben. Saufure ernäbrte einen Mnonat hinourd) breiṕig Pflanzen bom $\mathfrak{3}$ afferfnöterid) (Polygonum Persicaria) uno $\mathfrak{B f e f f e r m u ̈ n z e ~}$

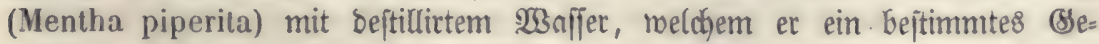
midgt bon jefr fein zertheiltem Riejel beigegeben hatte, Der burch etmas Zucfer= löjung in ber f̧üffigleit fupendirt erbalten murbe. (Er fand nad) Beenoigung

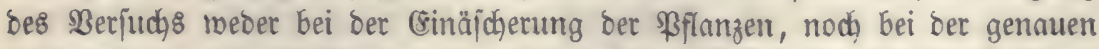

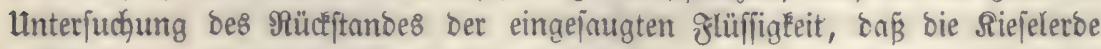

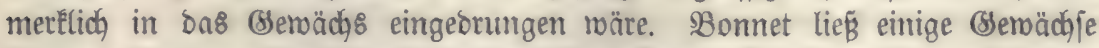
Tinte auffaugen; allein ber färbenbe nicht aufgelöjte Theil nurbe nur in einer unnägbaren Quantität eingejaugt. ( 5 r würoe in weit größ̧erer Mlenge burch 
bie vollemmenften giltrirgefäßse, bie wir irgeno herzuftellen bermögen, burch)= gegangen fein.

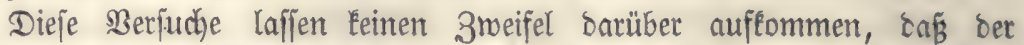

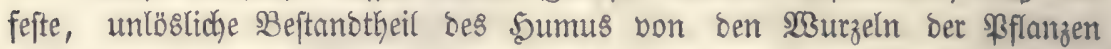
nicjt aufgenommen merben fönne.

(stras anders ift e\& aber mit bem Sุumus, menn er in eine lösliche

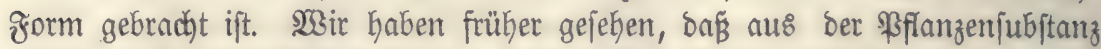

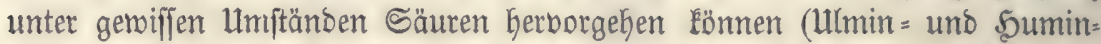

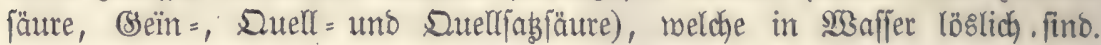

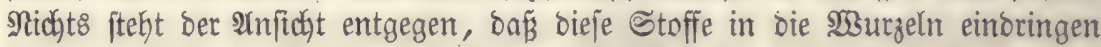
fönnen. Itm fo auffallénder ift bie bon Sauffure gemadjte Beobadytung, ba

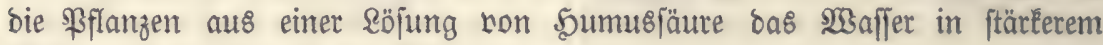
Maf̧e aufnehmen, als bie Săure.

Sauffure febte beftillirtem 23 affer $25 \%$ Dammerbe = Crtract (\$) fäure) zu und lięs in ber Mijchung Pflanzen von Polygonum Persicaria uno Bidens cannabina, żnei Sumpfgerwächje, begetiren. Nachbem bie \$flanzen bie Şälfte ber \&öjung eingeiogen Gatten, unterjuchte Saufure bie zurüçge= bliebene fłüffigkeit; er fano, Daß̉ Polygonum Persicaria nur 10\% und Bi-

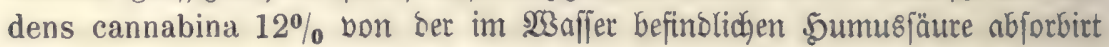
hatte.

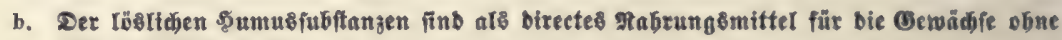 befonbere Bebentung.}

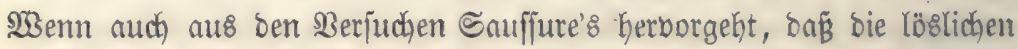
ఏumusfubftanzen bon ben Pflanzen aufgenommen berben fömten, fo idjeint

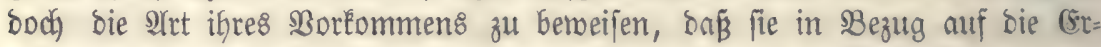
nährung ber (Semäd)fe bei meitem Keine fo hervorragende Slolle ipielen, mie bie Rohlenfäure; ę fprechen jogar gemiffe Beobadhtungen bafür, bafi fie ber Begetation föablidy find, fobald fie biejer im llebermaß bargeboten merben.

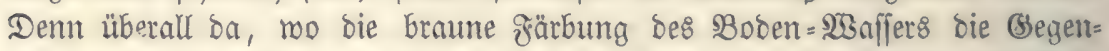

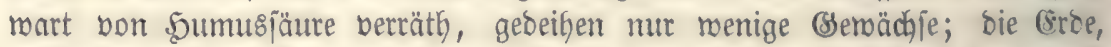

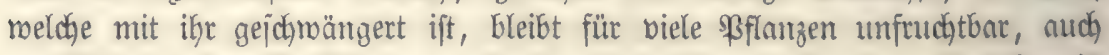

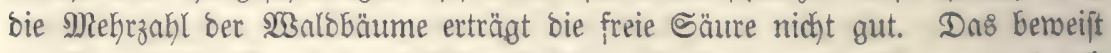
bie Eümmerlidye Begetation jelbit nuf foldyen Iorfmooren, meldjen man butch

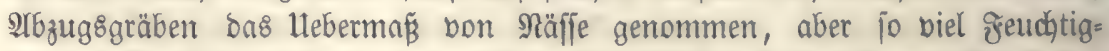

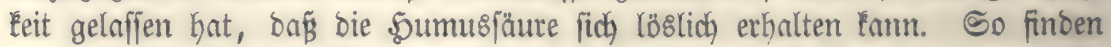

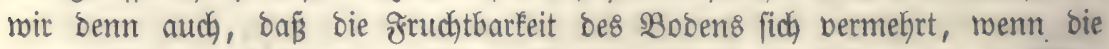

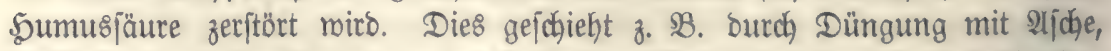

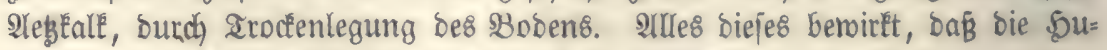

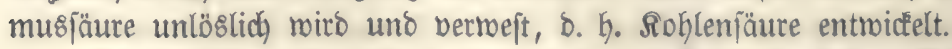

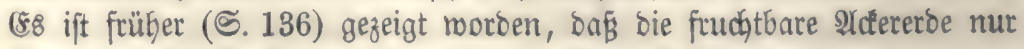

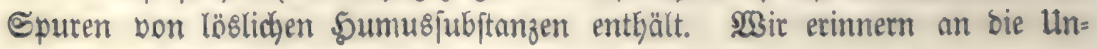




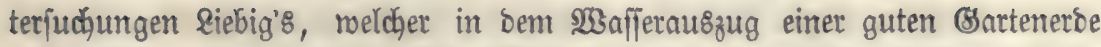
noch nicht roodoo an organijcher Materie fand, mir eximmern baran, bas bie Stalactiten in (Semölben uno Ђöblen humusiäurefrei fino, obgleid biefe

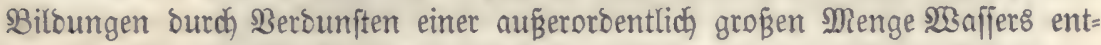

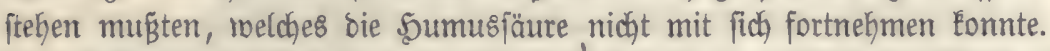

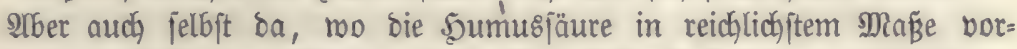
Ganben ift, Eann fie ben SPlanzen nicht allen Sohlenfitoff liefern, melchen bie=

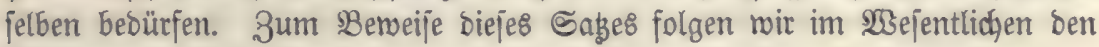
Irgumenten Riebig's.

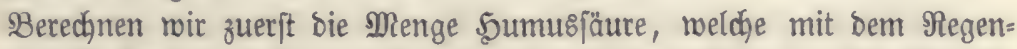
waffer in bie Pflanzen gelangen Eann, uno nefymen wir, um unjer Bemeis=

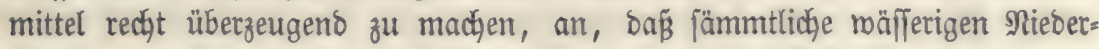
jóläge, welche räbreno ber Begetationzzeit auf ben Boben gelangen, von ben Sflanzen aufgejogen werben.

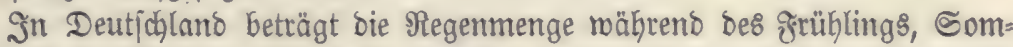
mers und Serbites ourchichnittlich 550 Mmeter, auf ben sectare fallen aljo 5500000 Silogramme $23 \pi$ fier. SRach Sprengel löft fidh bei $18^{\circ} \mathrm{C}$. in 2500

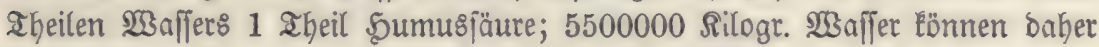
2200 Rilogr. Бumusfäure aufnebmen. Die von Mulber aus aorf bargeftellte Sumusfäure enthält $69 \%$ Roblenftoff; in 2200 sil. Şumusfäure finঠ aljo enthalten 1518 Sil. Rohlenftoff. SWir ernoten aber von einem Sectare Rie= fernmald auf Standorten bon mittlerer Bsüte über 1800 Sil. Sohlenftoff;

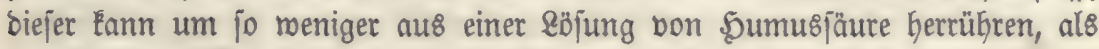
bon Regenmaffer, weldjes auf ben Boben Eommt, jogleidh ein grofier Iheil verounftet, ehe es von ben $23 u r z e l n$ ber $B$ äume aufgenommen miro. Dazu

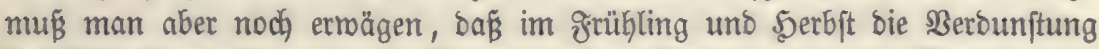

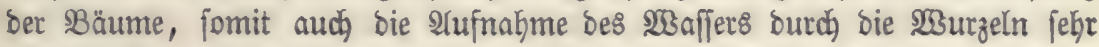
idfmady itt.

Da bie Şumusfäure mit ben Bajen lözliche Salze bilbet, fo konnte man auch mohl unterftellen, Dafi fie mit ben jog. 2rjchebeftandtheilen in bas \$olz gef́ommen fei.

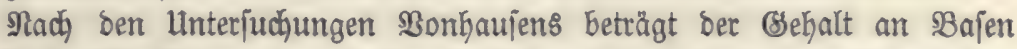
bon 3553 sil. Riefernholz, melçe jährlich auf 1 Sectare probuzirt merden,

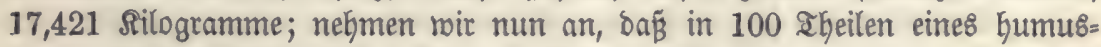
fauren Salzes 93\% 5umusjäure enthalten feien, io Eommen auf 17,421 Silogr. Bajen 2318 Ril. ફumusfäure mit einem Rohlenftoffgehalt von 1599

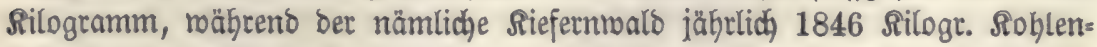
ftoff liefert.

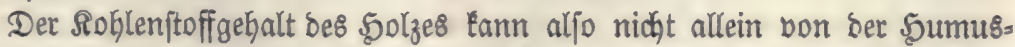

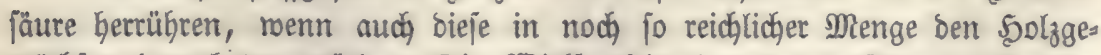

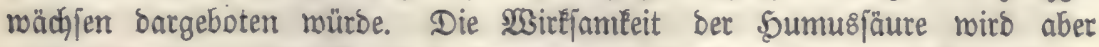

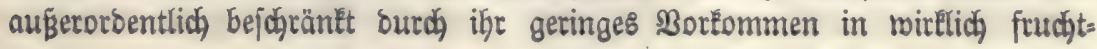


barem Boben, fowie burch Die (sigenjihaft, nad) bem 2lustrodnen ober Ssefrieren aus bem löstichen in ben unlöslichen Zuftand überzugeben.

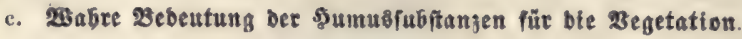

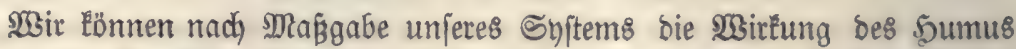
hier nur in chemifcher Beziefung abhantoeln uno verneijen Ginfichtlich ber

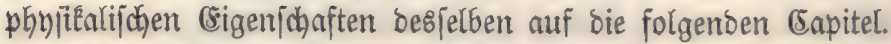

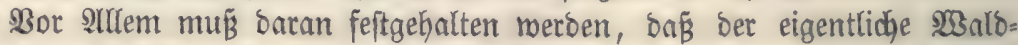
Gumus aus in Bermejung begriffenen Theilen von Drganismen, Gauptjächlich

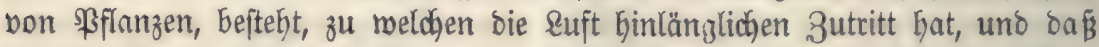
bie viel feltener borfommenben நumusfäuren fid faft immer nur an joldgen Drten finben, wo fich Iorf erzeugt ober erzeugen kann, aljo an jebr najfen Stellen, im 5odgebirg 4. \%. w.

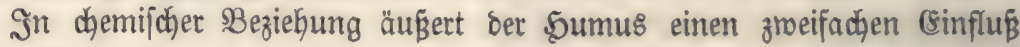
auf bie Begetation:

a. Die aus feiner 3erjegung herborgebenden gasfors migen und anorganifjen Stoffe tragen zur Ernäh= rung ber bero ăd je birect bei.

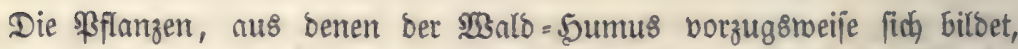
bejteben aus Zellengemebe uno aus anorganijoben Stoffen. Eriteres bildot bei

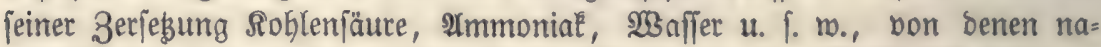

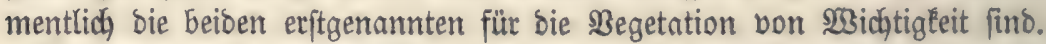

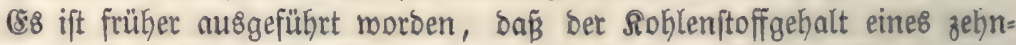
jährigen Raubabfalles im Buchentyodhmalbe bei weitem nidht hinreicht, um bie

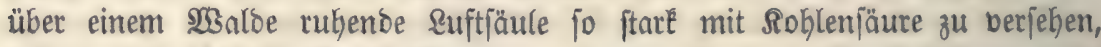

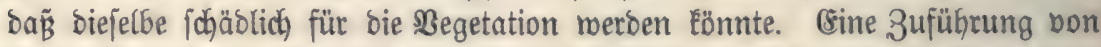
Roblenjäure in bie Iltmojphäre mit ben Mitteln, welche bem frorftmann zu Bebote ftehen, bleibt immer nüblich, wiro ftets eine Bermehrung bes \$olzzu= madjes zur Folge haben. Die Soblenfäure, meldje ber vernejente ફ̆umus entrwicelt, Darf baber niçt als überflüffig angejeben merden, fie vermebrt

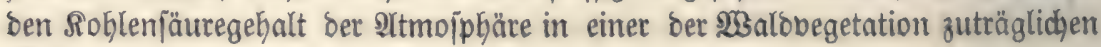
ISeije.

Daв Nämliḑe gilt, unt vielleidht in einem nod) Göberen (Srabe, von

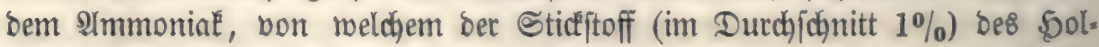
zeళ ftammt. Um biejen Sticiftoff Den felocrescentien zu geben, wentet ber

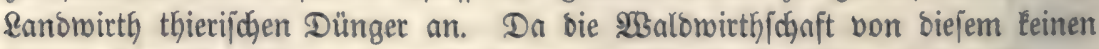

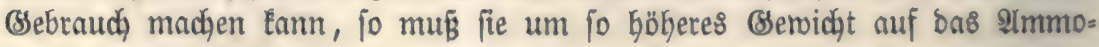

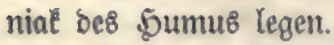

Whenn bie \$olzfajer bei ber Berwejung in ifhe einfadyen Beftanotbeile

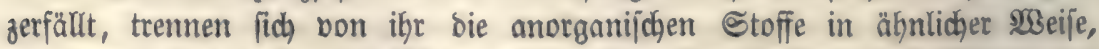

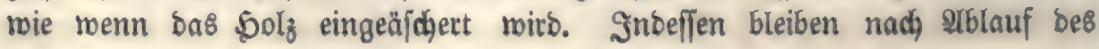




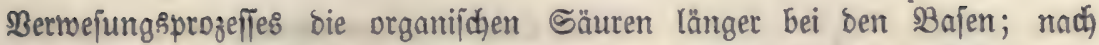
Berflü einer gemiffen Zeit findet man aber bods bie Bajen an Sobjenfäure gebunben; audh bie fieielfauren Salze mandeln fidh zum Iheil in Foblen= jaure um.

(sinerlei, weldye 2rnficht man über ben 3 mect hegt, zu bem bie anor $=$

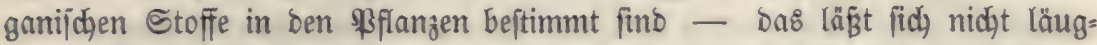
nen, bafi bie Pflanzen fie nicht entbehren können; bie Berjuche von NBieg= mann uno Bolftorff geftatten barüber nidht ben mindejten 3rweifel. Heberall Da, wo Mangel an ben löstichen anorganijchen Etoffen im Boben ift, roers.

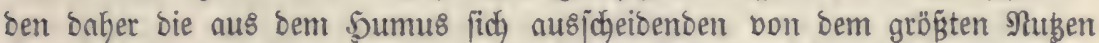
für bie Begetation jein, uto e\& roird in biejem Falle biejenige Şumusart am meiften leiften, weldhe aus joldhen Drganismen entftanden ift, bie biel aljohe uno namentlich in biejer bie felteneren Stoffe enthalten*).

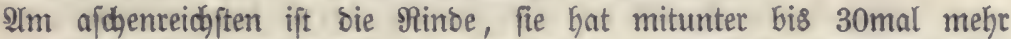

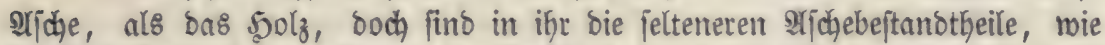
\$hosphorjäure, ¿djwefelfäure, Sllëalien gegen ben minber werthoollen Salk

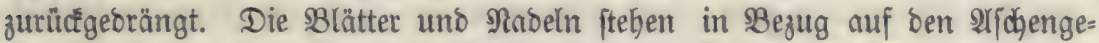
balt ber Rinbe nidgt viel nadh, übertreffen bieje aber bei weitem burdh ibren

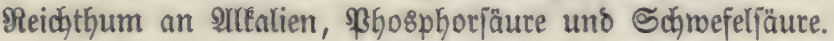

\begin{tabular}{|c|c|c|c|}
\hline & श्jogenprozente & Alléalien & \$Goвphorfäure \\
\hline (sichenrinbe & 6,0 & 28,5 & $\quad 3,0$ \\
\hline (Eic)enblätter & 5,3 & 72,2 & 24,0 \\
\hline Pappelrinte & 7,2 & 29,2 & 5,3 \\
\hline Bappelblătter & 6,6 & 51,3 & 13,0 \\
\hline gidotennabeln & 2,9 & 40,1 & 13,3 \\
\hline
\end{tabular}

Die bünnen 3meige zeid)nen fich bor bem ftärfern Solze burdh größsern

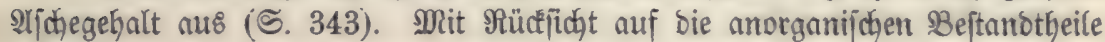
mürbe aljo baš \&ejęolz einen guten \$umus abgeben.

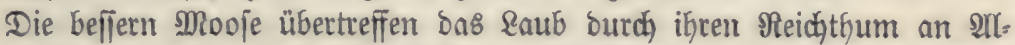

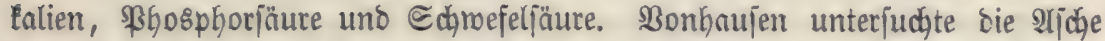
Don abgefallenem bürren Buchenlaub uno einem Moospoliter (aus $2 / 3$ Hypnum splendens, $1 / 6$ purum und $1 / 6$ tamariscinum beftegend) und fand von ben borgenannten Stoffen

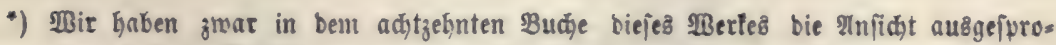

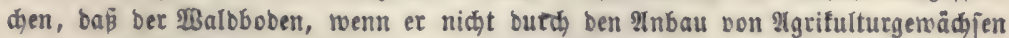
ausgejogen ift, genug anorganifde affimilirbare Stoffe enthält, um bie :Balos:

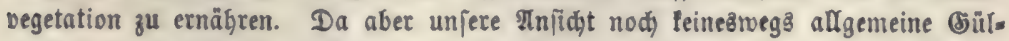
tigfeit exlangt bat, fo glaubten wir, um aud, ben Inbängern einer entgegenge=

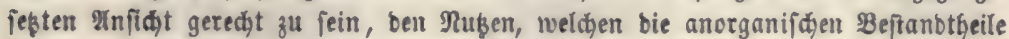

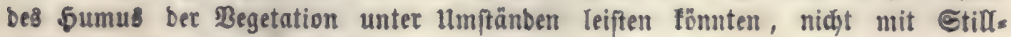

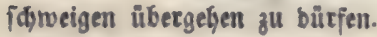




\begin{tabular}{|c|c|c|}
\hline an 2rlf́alien & $\begin{array}{c}\text { n Eaube } \\
6,21 \%\end{array}$ & $\begin{array}{l}\text { im Iloofe } \\
16,30 \%\end{array}$ \\
\hline " Phosphorjăure & 4,82 " & 11,24 " \\
\hline "Sdgrofeljäure & $1,30_{\prime \prime}^{\prime \prime}$ & 2,73 \\
\hline
\end{tabular}

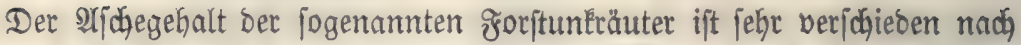

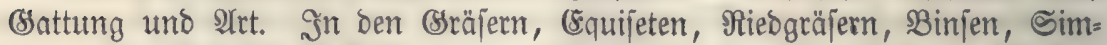

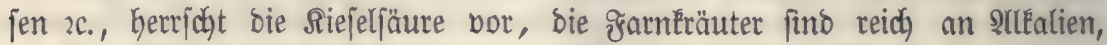
die Seibelbeere enthält ebenfalls eine nidjt unbedeutende Menge von biejen, fo wie von phosphorfauren (5rben. (Sauflure).

$\beta$. Die aus bem verwefenden 5umus jid entridelnde

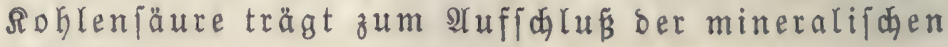
Beftandtheile des Bodens bei.

Der Boben ift aus ber Bermitterung Der Befteine entftanden; bei bem

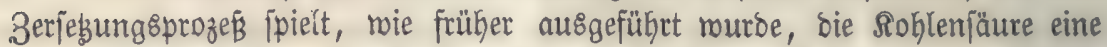

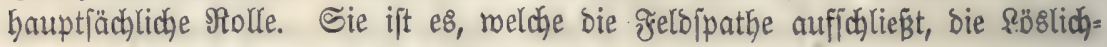

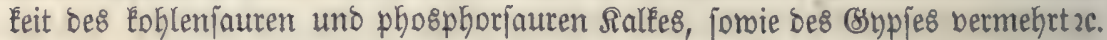

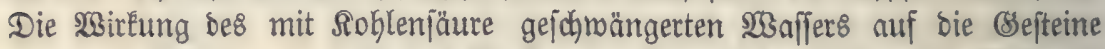
ift um fo kräftiger, je mehr bas $\mathfrak{W S}_{\text {affer }}$ von ify gelöft enthält. Die Mehrzabl

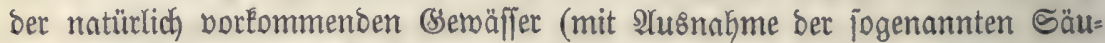

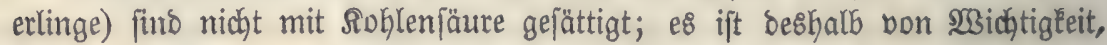

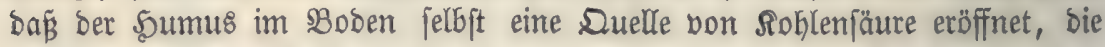
pogleich) von bem Waffer aufgenommen werben Eann. 3ur Beurtheilung bes

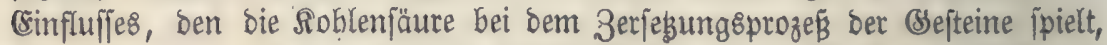

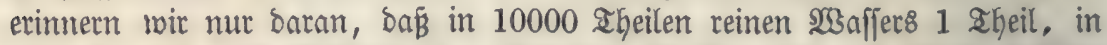
eben jo viel mit Roblenjäure gejättigtem $23 a f f e r$ aber 10 Theile Eoblen= faurer salê löslid find. 


\section{3rölftes $\mathfrak{B u c h . ~}$}

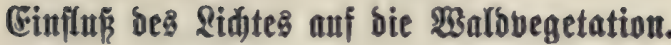

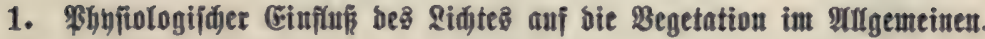

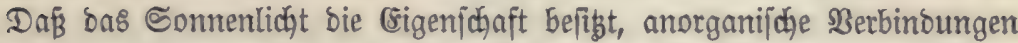

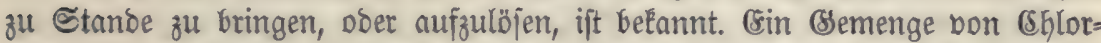

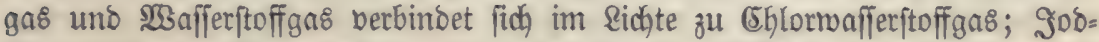

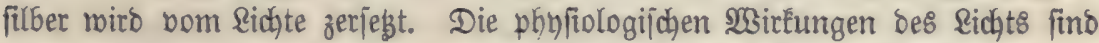

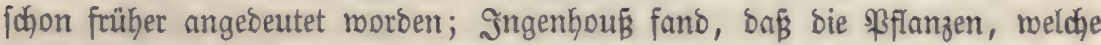
Rohleniäure aufgenommen Gaben, mur bann Sauerftoff ausbauchen, menn fie bom Somnenlichte getroffen werben. Dabei madat es nur in ber Sntenfităt

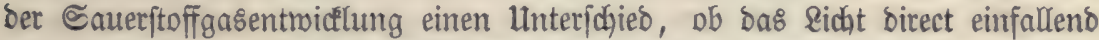
Doer gebrodjen ift. Das Mlondlidjt bermag nidht, bie 3erjegung ber Rohlen=

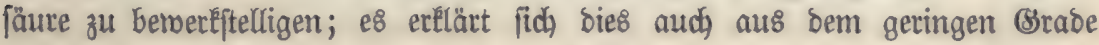
feiner Selligkeit, weldge nur $\frac{1}{300000}$ von Derjenigen Ses Sonnenlidates be= trāgt.

Die Sohlenfäure, weldhe für bie ßfflanzen megen ber Îneignung beళ Soblenftoffs fo midhtig ift, wirlt bod, nur fo lange woblthätig auf biejelben

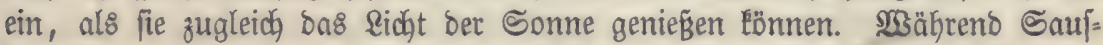

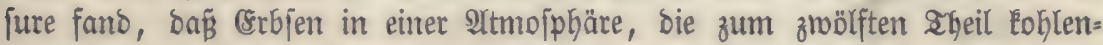
faures (sas enthielt, fröblich uno beffer, als in gemeiner suft muchjen uno

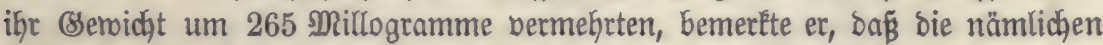
अflanzen 'bei berjelben Duantität Roblenjäure im Sdatten nur zebn Iage bas Reben friften Eonnten uno nur um 159 Millogramme an Berwicht zu= nabmen.

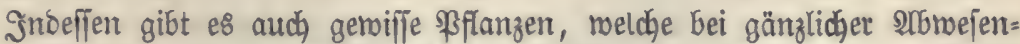
heit bes \&idytes vegetiren. Dieje gehören aber ben am niebrigiten organifitten Bruppen an. So findet man in ben Sdjadjten vieler Bergwerke SBilze namentlich aus Den (sattungen Byssus und Agaricus - melche biefes $\mathfrak{B e r}=$ Galten zeigen. Sn bem Snnern bon grüchten exzeugen firdh oft Sdhimmel=

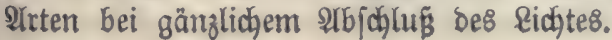


Dbgleid) bie böher organifitten (Semäd) je, insbejonbere biejenigen, weldye mit Samenlappen Keimen, sidjt zu ifrem (sebeifen forbern, fo ift boch bie Duantität, weldye fie bavon beoürfen, eine jefy verjojiebene nach (Sattung uno $\mathfrak{Y r t .}$ Die Dhnblattarten (Monotropa), bie $\mathfrak{B o g e l n e f t = \Re ( a g m u r z ~ E p i p a c t i s ~}$ Nidus avis, bie Stedfpalme Ilex Aquifolium z. \$B. madyfen mur im ๔dhatten; auch ber Seloelbeere fagt bå birect einfallende sidat nicht zu. Sie berliert

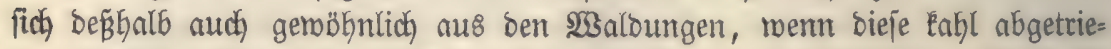
ben werben. Die Saibe (Calluna vulgaris) bagegen berjdymindet, jobald fie ftarl' bejchattet mirb.

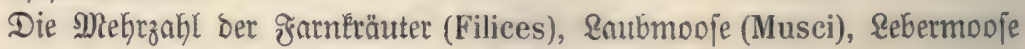
Hepaticae) unઠ Schnämme (Fungi) berlangen ebenfalls ein zeritreutes \&idht und nur menige bon ifnen, wie z. 2 . Trichostomum canescens, ericoides uno lanuginosum, mandje 9YTrten bon Polytrichum, madhen bierin eine $\mathfrak{A} u \&=$ nahme. Die Flechten (Lichenes) Dagegen merben ebenio oft auf Standorten, wo fie bem bixecten Ridjte ausgejest fino, als auch im Schatten gefunden.

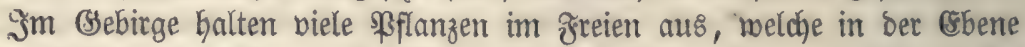
nur im Schatten gebeithen. So fino z. 33. Diele höhere Berge im 5aarz, int

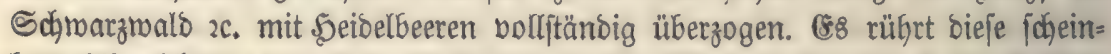
bare 2rbweidjung bon bem Berbalten in ber Bbene baber, weil im Bebirge

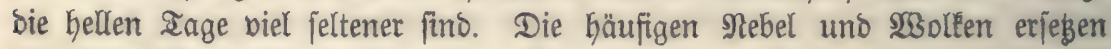
Gier ben Schatten ber 8 äume.

Bon bejonderem Binflü auf Die Frarben ber Blüthen uno das Befieber

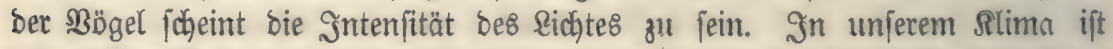

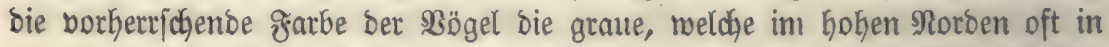
bie meiß̧e übergeht. In ben 2Aequinoctialgegentent zeigen bie Mehrzahl ber

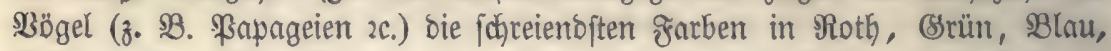

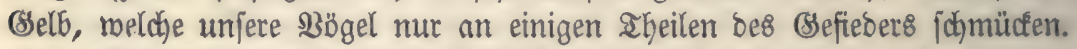

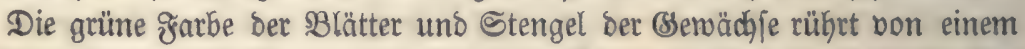
eigenthümlidhen garbftoffe - bem (5hlorophyll - her, weldhes in ben

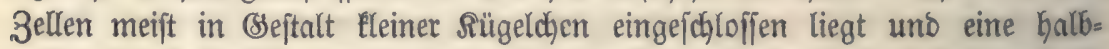

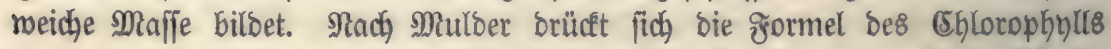
burdh $\mathrm{C}_{18} \mathrm{H}_{9} \mathrm{~N} \mathrm{O}_{3}$ aus; biejer Berbinoung ift aber immer nod) ein 23 adj8 von ber 3ufammenfegung $\mathrm{C}_{15} \quad \mathrm{H}_{15} \quad \mathrm{O}$ beigejellt. Säufig enthalten bie (5̧)loro-

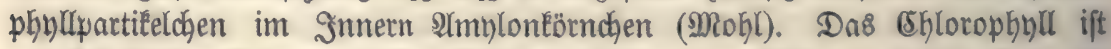
mur bei foldyen Pflanzentheilen fidhtbar, weldhe bem sidfte ausgejebt find; io Gaben z.!38. Die langen Iriebe ber Rartoffeln in Den Rellern eine bleidhe Fratbe,

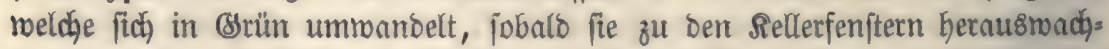

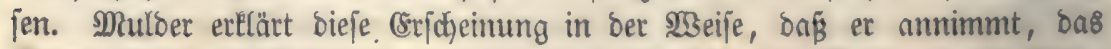

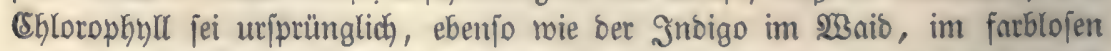

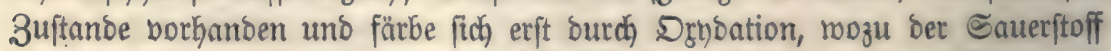

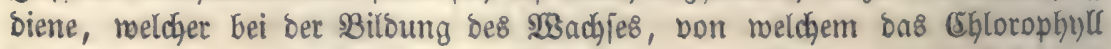

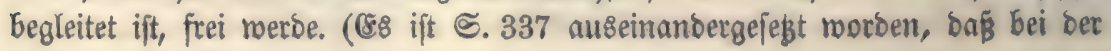




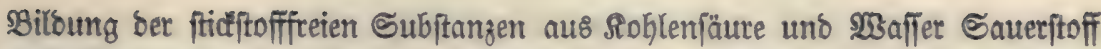

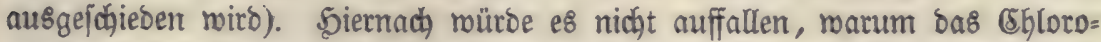
phyll erft bei Begenmart bon Ridht auftritt; wir wiffen ja, baß̧ bie Saueritoff=

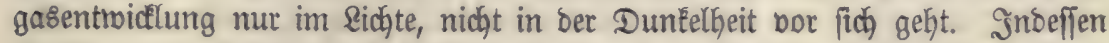

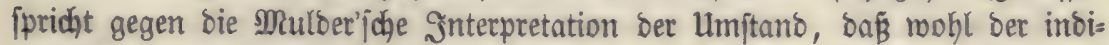

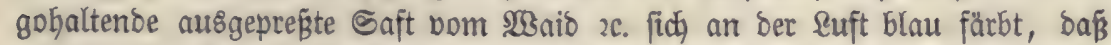
bagegen Der Saft bon \$flanzen, melche im Schatten getrieben baben, unter ben rämlichen ßerhältniffen Keine grüne Frarbe annimmt. Nur in ber leben=

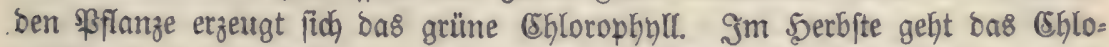
roplynll in ben SBlättern in einen gelben garbjtoff (Xanthophyll) über; ob Gieran eine De8sorbbation Sdyuld jei, ift nod nidht ausgemadyt.

Das EGlorophyll löft fich nidft in $23 a$ affer, eher fidon in 23 eingeift und

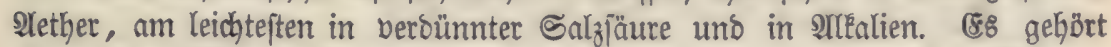

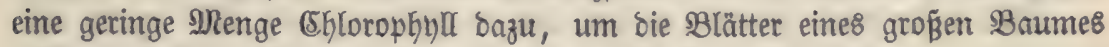
grün z̆ färben; Berzelius fano, bай bаzน 10 Bran binreidgten.

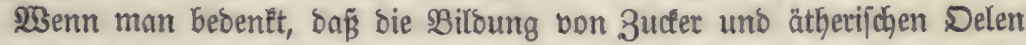

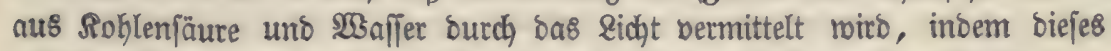
bie शlusfochoibung bon Sauerftoff aut ben beiben lestgenannten Stoffen be=

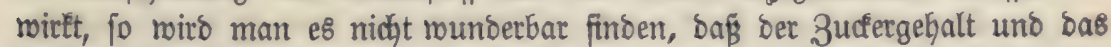
शroma mandher Früchte, namentlidh ber $\mathfrak{3}$ eintrauben, in foldhen Sabren zu=

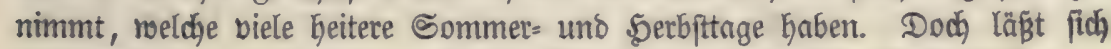

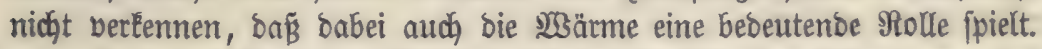

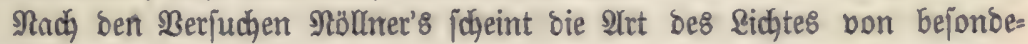

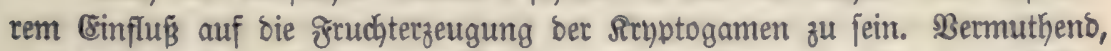

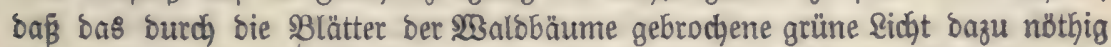

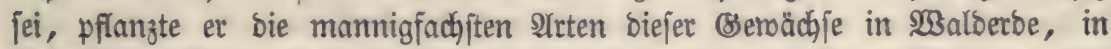

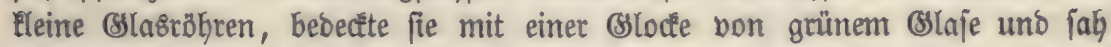

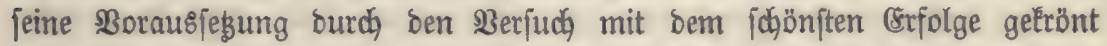

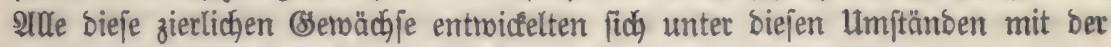
größ̈ten Heppigêteit, fie fegsten fuchtbaren Samen an. (Riebig).

Bon jeber bat man bem Mondlidat einen ganz bejonderen Einflus

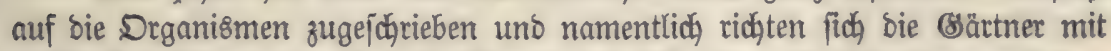
vielen Berridgtungen nady bem Stanbe bes Mnonbes. "Bemiffe Samen follen, bei zunebmentem Mono gefäet, beffer gebeiben, als wenn fie bei abnebgmen= bem Mono gefäet werben, $\mathfrak{B u r z e l g e t r a ̈ c h j e ~ f o l l e n ~ b e i ~ a b n e b m e n d e m ~ M o n o , ~ i n ~}$

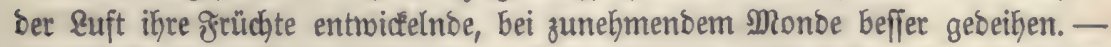

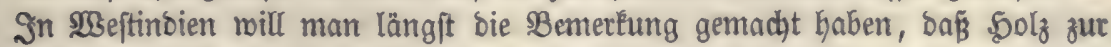
3eit bes \$3ollmonoes gefällt, meit leichter pringe uno faule, uno als शus=

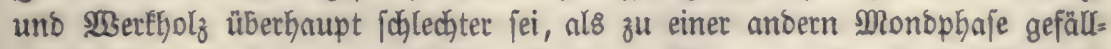

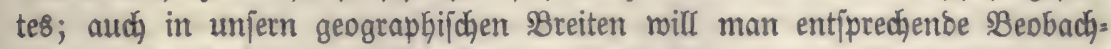
tungen gemadht haben; nad, 20 jährigen \$Beobadjtungen bom Dberförfter Sauer

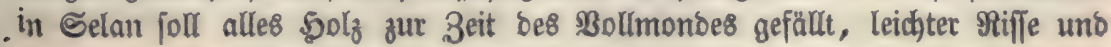


Sprünge belommen uno meit neniger 23 erth Gaben, al8 zur 3eit bes abneth=

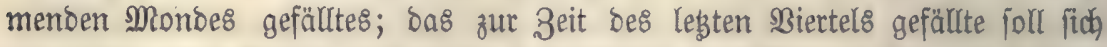
am beften zum Bauten uno allen Solzarbeiten bermehben laffen, es foll zu biefer Zeit am menigften Saft befizen" (ভchübler). (58 ift nidht ummöglid, Daß́ bie angeführten Erfoheinungen mit bem Stande bes Monoes zujammen= hängen; bodh verbiemen fie fo lange mit 3 orficht aufgenommen zu merben, bis ifre Beftätigung burch eine größzere 3ahl von \$Beobachtungen erfolgt. Shuch

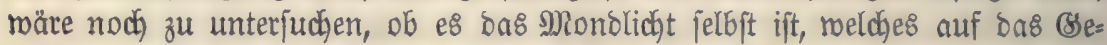
beifen ber Saaten, bie Dauer 2c. Des Şolzes eimmirkt, doer ob Diejer Csinflǘ

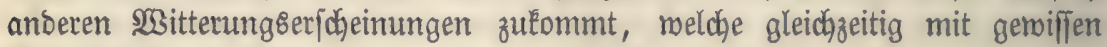
Monosphafen auftreten.

\section{Berfalten ber 20 arbbaututaten gegen baß Riojt.}

Wir haben oben bereit\& erroähnt, baß̈ bie Summe bon Ridht, meldhe bie

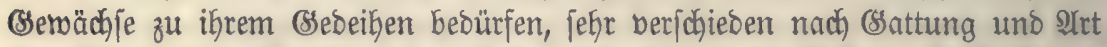

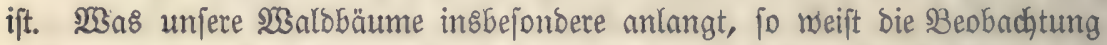
nach, Daß̧ Kein einziger bon ifnen burdh bie ganze Dauer feines \&ebens bin ben Schatten liebt; und menn aud einige eine theilmeife Bejdyattung nodh ertragen, fo merfen boch alle bie gröften Maffeerträge mur bann $a b$, wenn fie, bon einem gemiffen Altter an, ber bollen (sinmirfung bes Richtes blosge= ftellt find. Binige ongegen fommen in Der Sugent nuf unjubereitetem Boben nut im Sdjatten gut fort.

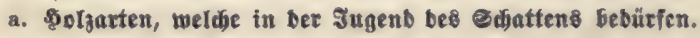

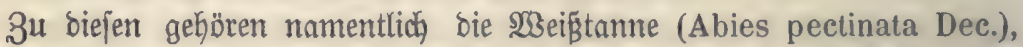

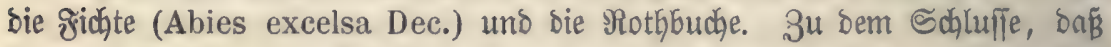
fie menigitens in ber frübeften Sugent uno auf unzubereitetem 930 ben bes Sdjattens bebürfen, ift man butch bie Beobachtung gelangt, baßz bieje Solz= arten im ङreien mittelft Saat nicht gut fortzubringen find, aud im §emel= (a)lagbetrieb nur bann gut gebeiben, wenn bei ber Schlagftellung burch eine

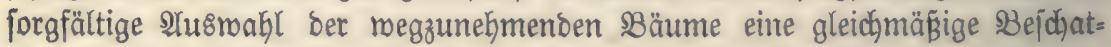
tung bes jungen ఇachwuchjes von Seiten ber ftehenbleibenden Stämme ker= beigeführt wiro.

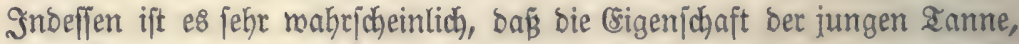
oithte uno Buche, mur im Sdyatten fich zu erhalten, weniger von ber (euch)= tenoen, als vielmehre von ber roärmenden Rraft ber Somenjtrahlen ab̧ängt. (58 iprechen gemichtige Srünbe Dafür, bafi ber Schatten biejen \$olzarten Gaupt= fächlich babutch mohlthätig mirb, weil in ifm bie, vorzüglich von ben Blättern ausgehenoe, Berounitung ichnächer ift. Denn alle bie genamten \$olzgemächie, welche auf unzubereitetem Boben im greien nicht fortfommen, wiberftehen

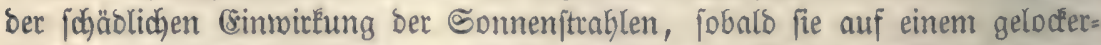

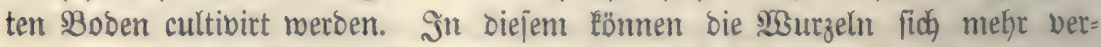

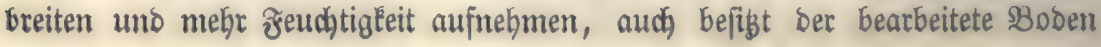




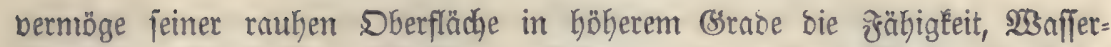

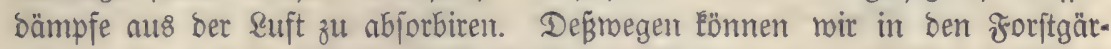
ten, in benen ber Boben mittelft Sacke uno Spaten ober mittelit bes Pflugs

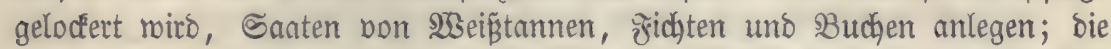
jungen $\mathfrak{B f l a n z e n ~ e r b a l t e n ~ f i c h , ~ o h n e ~ b a ß ̈ ~ m a n ~ n o ̈ t h i g ~ b a ̈ t t e , ~ i f n e n ~ k u ̈ n f t l i c h ~}$ Schatten zu geben.

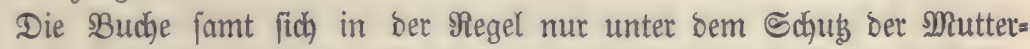

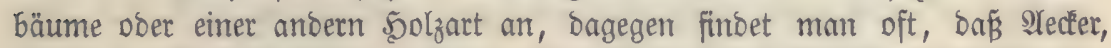

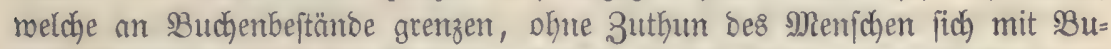

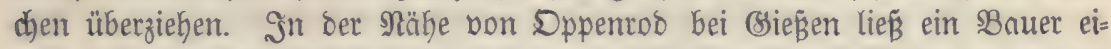

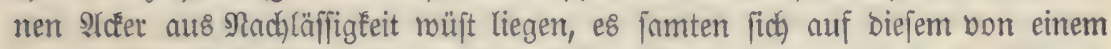

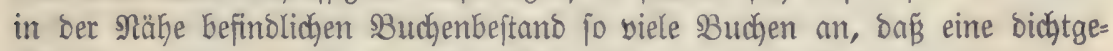
(d)loffene Solzung entftand. Die Bflangen ftroben von Bejuntheit.

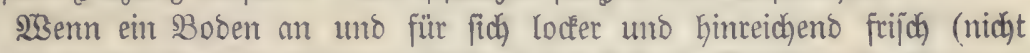

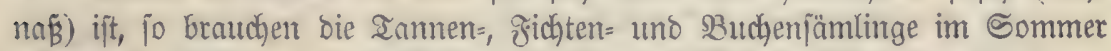
bei beitem nicht fo biel Schatten, als in trocenen sngen. Troboem bält man

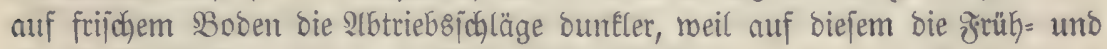
Spätfröłte bäufiger uno berberblicher fich einftellen.

In nebelreichen Bsebirgsggegentoen, in benen der fäufig bebectete Simmel

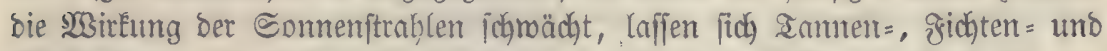
Buchenfaaten im greien eher fortoringen, als in ber (5bente. Doch ift bies

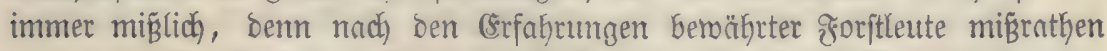
unter zehn Buchenfaaten, bie man in bem burch feine ftarken Nebel ausge= zeidhneten $\mathfrak{B o g e l s g e b i r g e ~ m a d j t , ~ g e m o ̈ b n l i c h ) ~ n e u m e , ~ u n o ~ z u ~ b e r ~ n a ̈ m l i c h e n ~ ( \& r = ~}$ fahrung ift man im 23 eftermalbe (פtaffaut), no ähnliche Berbältniffe ftattfinden, gelangt.

\section{b. Eolgarten, weldibe Echatten crtagen.}

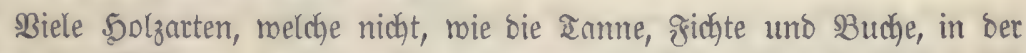
Sugeno ben ๔chatten gerabe verlangen, ertragen ifn bodt uno erfalten fich am \&eben, wäbreno anoere jelbit bei lichter Bejdattung eingehen.

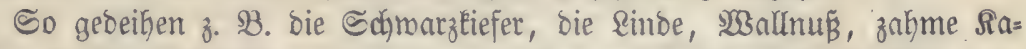

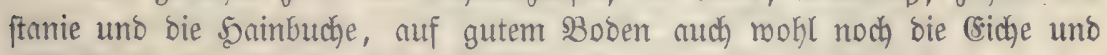
(siche in ber Sugento unter bem Schatten vorgemachjent Bäume, vornusge=

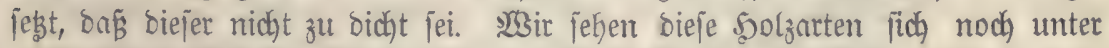
geid)loffenen Rieferbeftänden anjamen unto fich jo lange erbalten, bis bie fpä=

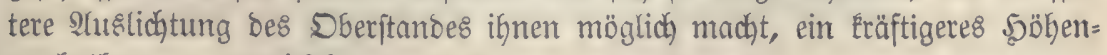
wadj8thum zu entwickeln.

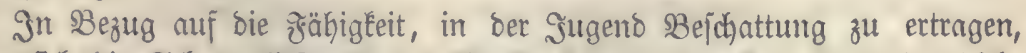

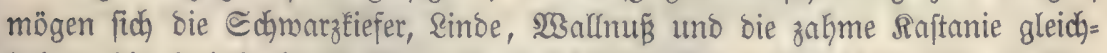

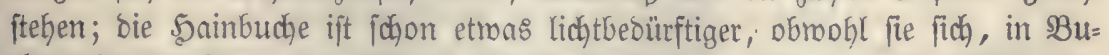

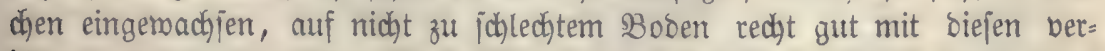

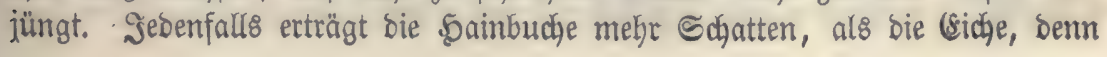




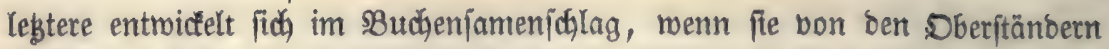
volfitänoig bejchattet ift, bei weitem nicht jo Fräftig, alz bie Đainbuche, e\& geht bie cridje unter biejen Ummitänoen geröbntich ganz ein.

Neuere Beobachtungen Gaben Den Berf. belebrt, Daß̧ bie sijhe auf eirrem

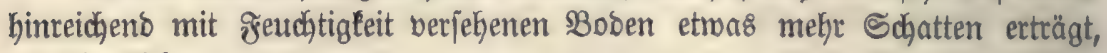
als bie (siche.

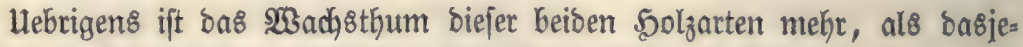
nige ber vorkergekenden gefindert, wenn fie im Sdjatten ftehen.

Bon Den IVhornen erträgt Der Stumpfahorn (A. pseudoplatanus) in ber Sugeno etmas mełr Sdjatten, als ber Spizahorn (A. platanoides), benn exfterer erhält fich in ben Buchenabtriebsichlägen eher unter bem Sdhatten ber

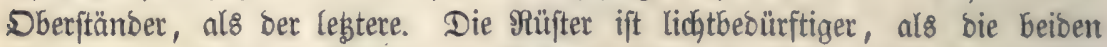
Ahornarten, benn fie lommt, in Riefernbeftänoe eingefäet, nicht fo gut fort, als bieje.

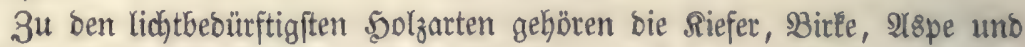

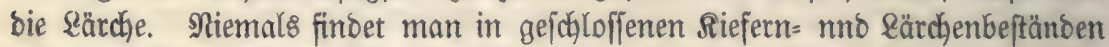

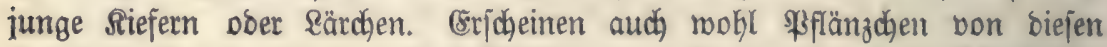
5olzarten hie und ba in folchen Beftäntoen, fo kann man feft berfichert fein,

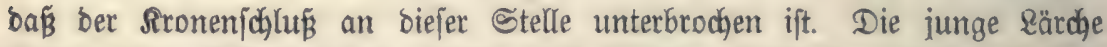
lommt aber felbft in jojon ziemlich ausgelidyteten Bejtänden nicht gut fort, uno bie junge Siefer zeigt überall oa, wo jie beidhattet ift, eine jefre fobroadhe

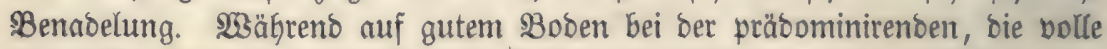

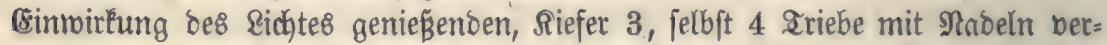
fehen find, ift bei unterbrücten, im Sd)atten ftehenoen \$flanzen gemöhnlid

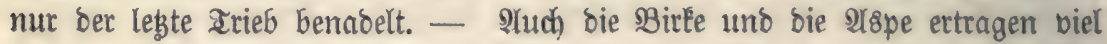

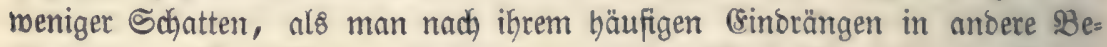
ftänbe vermuthen follte; mant miro bei genauerer Beobarthtung immer finden, bak bie Stellen, auf benen fie fid eimfinden, bon irgeno einer Seite her ober gerabe bon oben sidat erbalten.

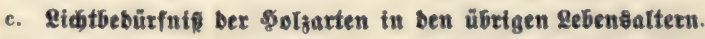

W3ie finon oben bemerlt murbe, berlangt Eeine einzige Baumart, nadt)= bem fie einmal bie 3eit ber Rinobeit überitanden hat, Bejwattung; Der (Einzel= ftamm gebeift am freubigften und legt ben größ̈ten 3 umadjs an, wenn ex bie volle Binmirfung Des sidhtes genieß̈t. Dagegen bejïgen einige Solzarten

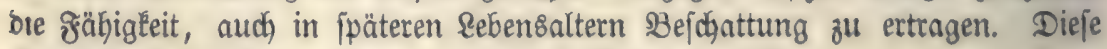

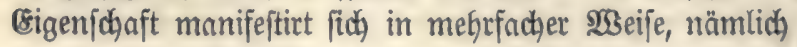

$\boldsymbol{\alpha}$. burd bidateren ober lidateren $\mathfrak{B} a \mathrm{um}$ jd lag,

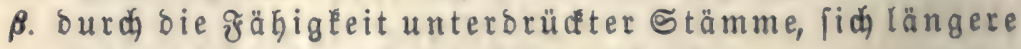
3 eit in lebendem 3 uftande zuerhalten.

$\mathfrak{B}_{\mathfrak{3} 8}$ zuerft bie 2 rt bes $\mathfrak{B a u m i c h l a g e s}$ anlangt, fo bebürfen offenbar biejenigen \$olzarten, welche eine bichte Sirone befigen, weniger Bidht, als joldge 
mit lidjtem sBaumidjlag. Denn bei exfteren erbält jebes $\mathfrak{B l a t t}$ im Snnern ber Rrone eine geringere Menge Ridgt: menn es nun troboem begetirt, fo beweift

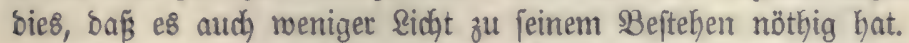

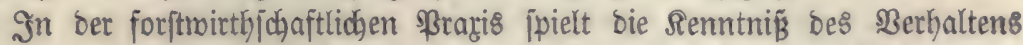

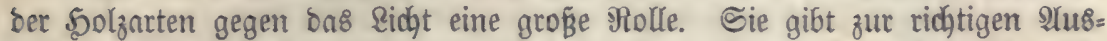
wahl vieler Setrieb8operationen Inleitung. Da wir nun bie Bäume bald in

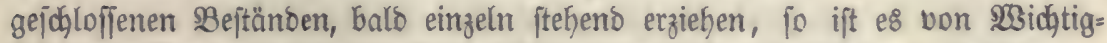
Feit, zu wiffen, mie fiḑ ber Baumjojlag unter biejen Umftänoen geftaltet.

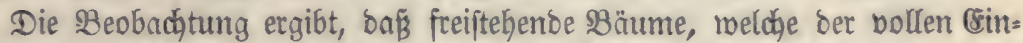

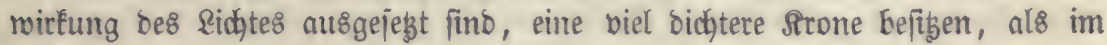
Schluffe. (\$s rühtt bies daher, weil in erifterem galle bas von allen Seiten zugänglidje Ridyt bie (5rzeugung von Blättern begünftigt. Seben mix ja body,

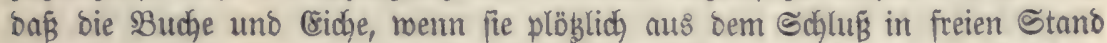

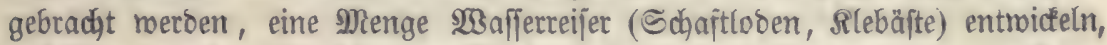
Daß̧ ein bon ber Durchforftung übrig gebliebener Ćtod entroeber gar feine,

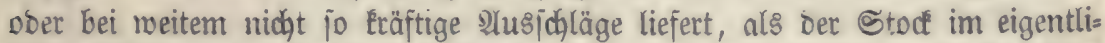

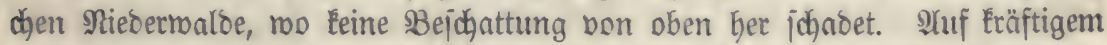
(tiefgrünoigem, locferem uno hinlänglid, frijchem) Boben meicht bahyer ber Baumidglag jelbft ber lidjtbebürftigern \$olzarten wenig von bem bet idjatten=

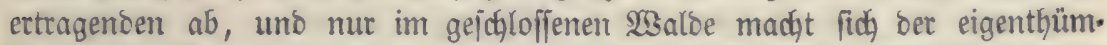
liche Baumjojlag jeber Solzart gelteno. Die Mehrzabl ber Altreebäume, an welchen wir cine bidhte Belaubung zu jehen gemobnt fino, ift im WBald ganz Dünnfronig. Dieß̈ gilt namentlich von Dem Ahorn, Den Dbftbäumen,

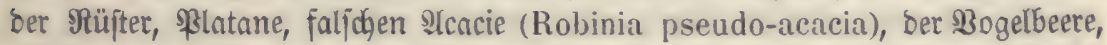

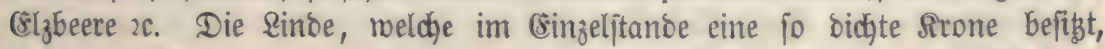

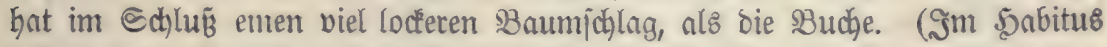

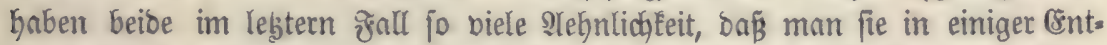

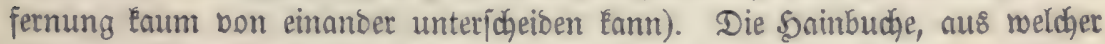

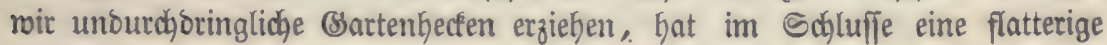
Beaftung.

Bon allen 5olzarten bejizen bie Tanne und gichte ben bidhteften Baum= idhlag. Doch ift biefer nicht etron in ber Bsebrumgenfeit ber einzelnen Ruirle zu juchen. Seber ber lejtern ift vielmebr in fich ganz licht, aber es ftehen an Der Sdhaftare viele Suirle über einanber, beren Sefte nicht in ber nämlichen

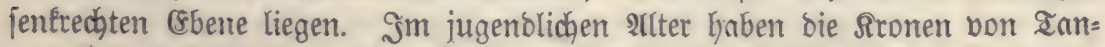

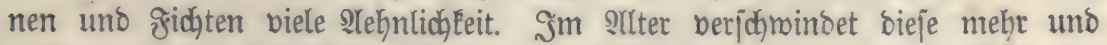
mejir, nur bas phramidale Injefpen bleibt ifnen gemeinjam. Die gridate be=

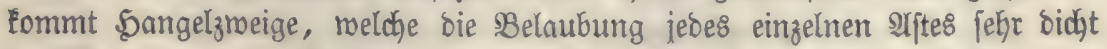

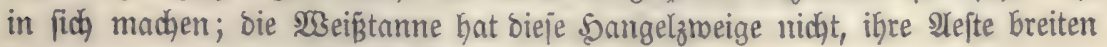
fidh in einen Gorizontalen Fäđjer au\&.

Bon Den Raubbölzetn Eommt Der bidjtefte Baumidjlag ber Budhe zu. Shre stone ift kuppelförmig. Die Rironen ber sinde, WBallmuß, zahmen Ra- 


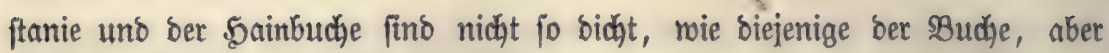
immer nody bidhter, als bie ber (ridge.

Der Baum[d]lag Der 2 Beymouthstiefer uno ber gemeinen Riefer meidyt bon bem ber Fidgte uno Tanne borzüglidh barin $a b$, baß̈ bei beiben bie frone nur aus menigen Suirlen befteft, meil bie unteren 2lefte früfzeitig abjterben,

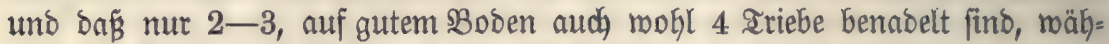

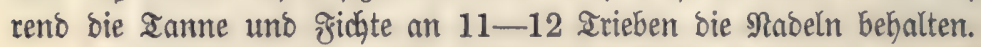

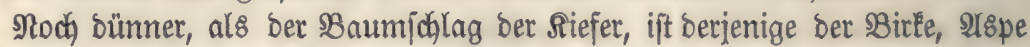

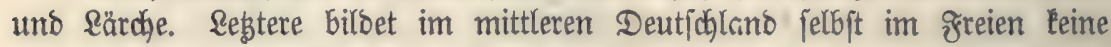
bidjte Srone; im gejhloffenen Stano erreicht fie aber gar bas Anjehen einer Berte, bie Spize befiłt nur menige Arefte.

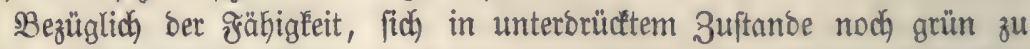
erhalten (Zählebigleit) ftehen bie Ianne und Fichte allen übrigen Solzarten boran; mahricheinlid) bermag aber bie sanne noch mebr Sdjatten (Drud') zo ertragen, als bie fichte. In ben Femeljhlägen bes Sdjmarzmalbes finbet

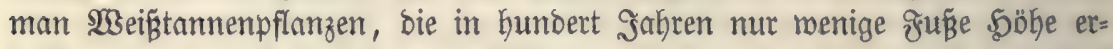

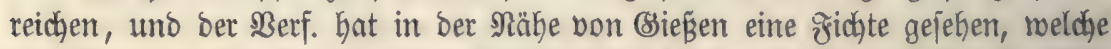

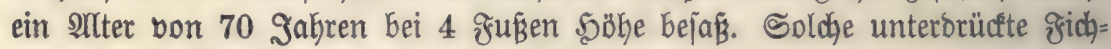

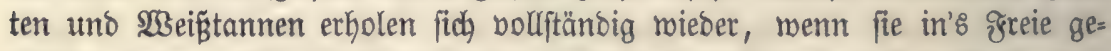

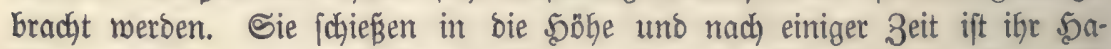
bitus gänzlich beränbert. Durdh bieje merefmürbige (sigenjohaft zeichnen fie fich) bor allen übrigen Solzarten auళ. Dieje ertragen robl alle Geitenjobatten menn nur bie Spize im bollen Richte fteht, aber fie gehen, menn leghtetes nicht ber Fall ift, nach eimigen Sahren ein; niemals entfalten fie, wenn aud bie Ueberjchirmung bor ifrem ÂAbjterben Ginmeggeräumt miro, ein fräftigeb \$ö= henmadysthum.

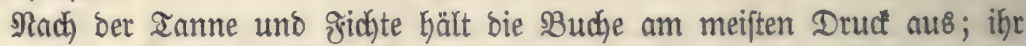
fteht in biejer $\mathfrak{B}$ zeziehung bie Sdhnarzliefer nidht biel nadh; bei legsterer beutet

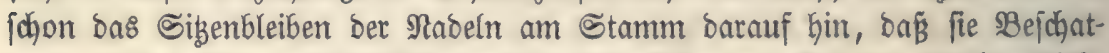

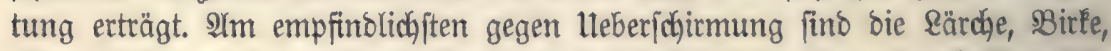

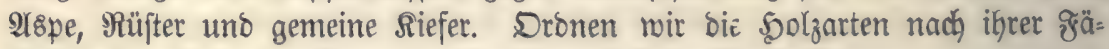

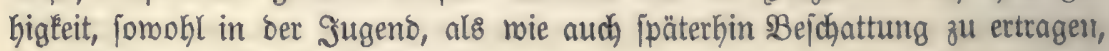

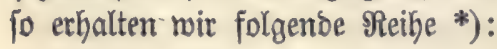

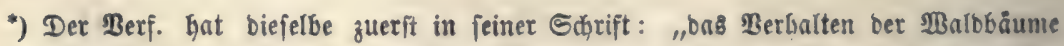
gegen Richt unb Schatten, Erlangen 1852, bei Cinfe" aufgejtellt unb hiet mur eine geringe 2tenberung an berfelben vorgeniommen. Der $\mathfrak{B}$ ater beß̊ $\mathfrak{B} e r f .$, (5. Seyer,

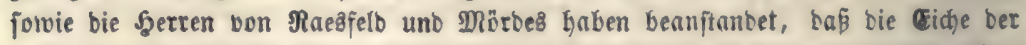
(5id) vorangeftellt fei. Reuere Beobadtungen in verisfiebenen Begenben von Deutich= Iano gaben bem Berf. bie Heberzengung, baßi alferbings bie Ejhe etwas mehr Sdjatten ettrage, alz bie (Eid)e, unb es ift bem entipredjent bie (rid)e in obiget

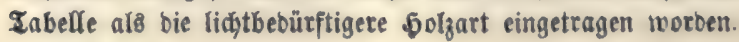


S3eistanne, gichte,

Buche, Ectroarzétefer,

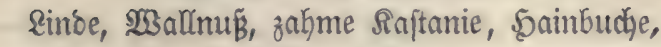

sidhe, sidje,

Bergahorn, Spizahorn, Dbitbaum, (srle,

Wetymoutbstiefer,

SSemeine Riefer,

Rüfter,

Birte, SYlspe,

Rärche.

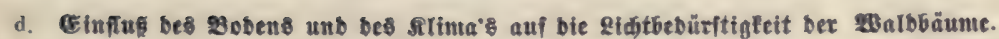

Die vorfin aufgeftellten Regeln fino ganz allgemeiner Siatur, fie bezieben fich) auf Bobenarten bon mittlerer (süte. Sit bie Stanbortshiejchaffenteit ber

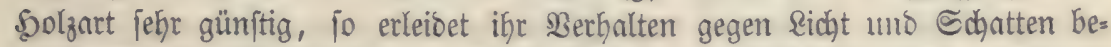
merkensmerthe Modificationen. Dieje bejtehen Gauptiächlich Errin, baß̈ bie

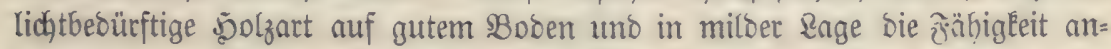

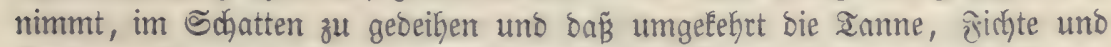
Buche, roldhe unter ben gemöhnlichen Berbärtnifjen in früher Sugeno Sdhat= ten verlangen, audh im Frreien fortfommen.

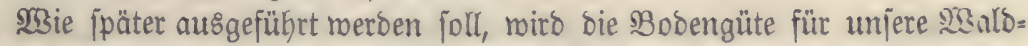

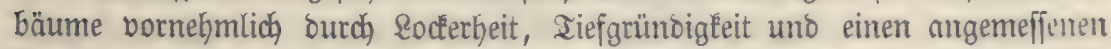

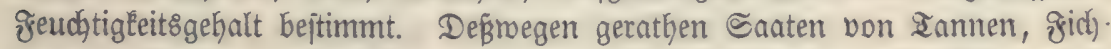

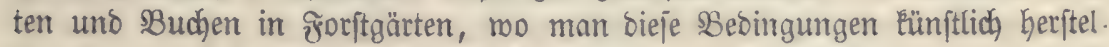

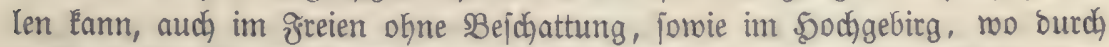

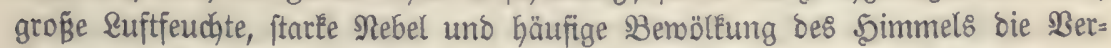

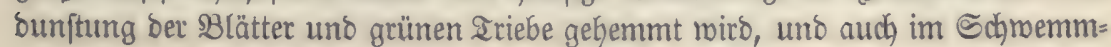

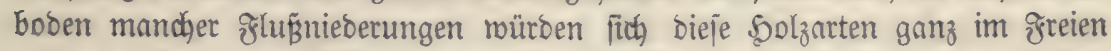
recht gut fortbringen laffen, menn fie nidht Gier ber Bejchattung zum ऽdyuss gegen bie an jolchen Rocalitäten Geimijळen grüf = uno Epätfröjte bedürftig wăken.

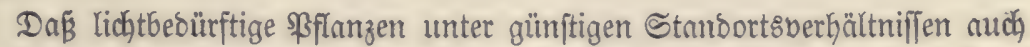

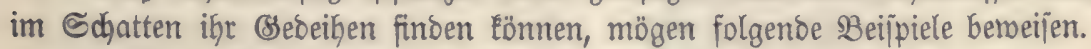

In ber milben, mit bem fruchtbarften Refmboben ausgejtatteten $\mathfrak{B}_{3}$ etterau (Brof̧herz. Seffen) fommen unter ben Dbftbäumen auf Dem felbe Sirtoffeln uno Cerealien io freubig fort, als ob ber ๔chatten ber saäume gar nidgt vor=

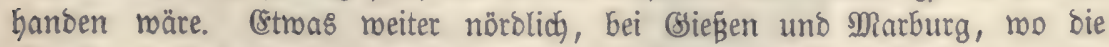
Qualität bes ßobens fich berringert, fino bie Echirmflächen unter ben Bäu= men tabl.

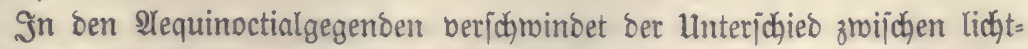
bebürftigen uno fohattenertragenoen Solzarten gänzlich. Sn ben Utroaldungen Sübamerifa's fommen alle \$Baumgerö̈dhje bicht unter einander bor. Unter 


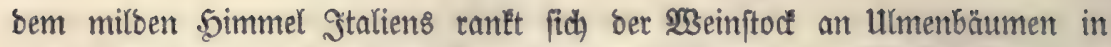
bie Sähe, inmitten bet Baumfrone erzengen fich nod) bie füseften arauben;

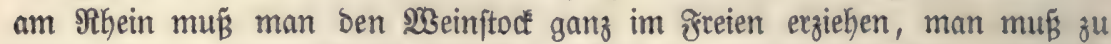

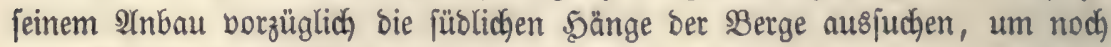
gute Früdgte zu erbalten.

Shetabe 10 , wie bie Bobenbearbeitung benjenigen \$olzarten, welche in

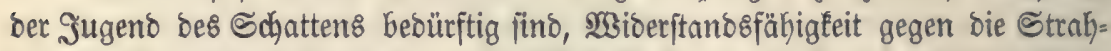

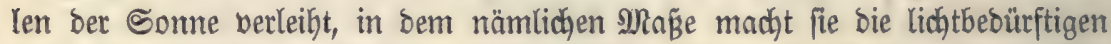

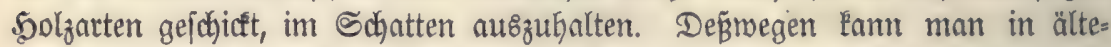

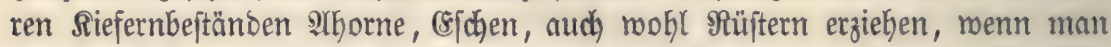

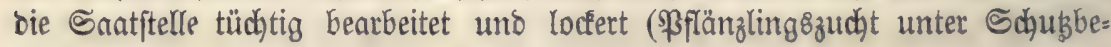
ftänoen).

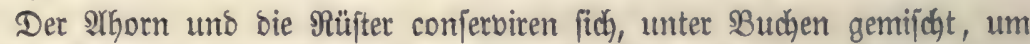

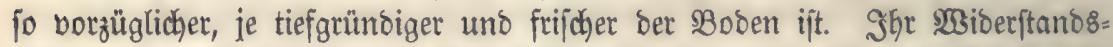
bermögen gegen ben bidhten Schatten ber Butche roächit in bem Stabe, als ihte Contwideflung lräftiget wiro.

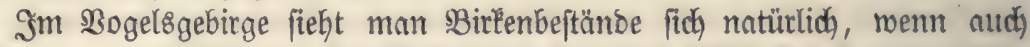
unbolléommen, berjüngen; Der Spizafjorn Eommt bajelbft bäufig unter bem

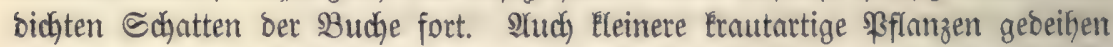

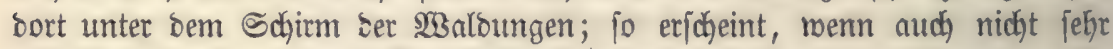

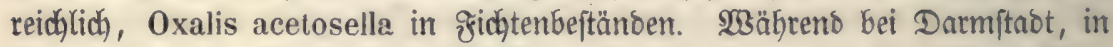
ebener Rage, ber Boben in gejdhloffenen Budbroaldungen nur mit bem abge= fallenen, trodfenen \&aub bebecft ift, wirb er im Bogelsgebirge bon Beroächjen Der mannigfadjiten $\mathfrak{2} r t$, wie von einem grünen Teppid), überzogen.

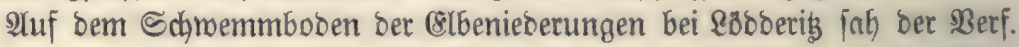
bie Rüfter als Interholz in Mittelwalbungen cultiviren. Dieje \$ehandlung würbe fie auf einem meniger tiefgrünoigen, weniger lodfern uno frijøen $B$ oden nidyt ertragen. 
Dreigehntes $\mathfrak{B} u$ (ో).

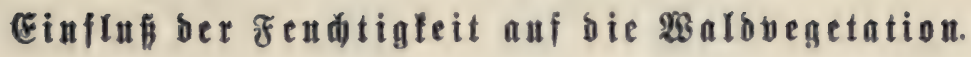

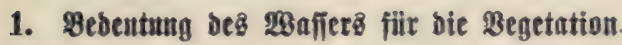

08 ift bereits an einem andern Drte, ats mir von ber 3ujammenjegung bes 5olzes hanbelten, ausgeführt morben, baß ber $23 a f f e r f t o f f$ fowohl ber

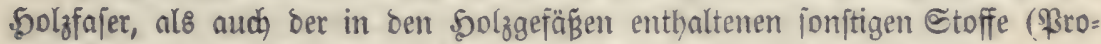

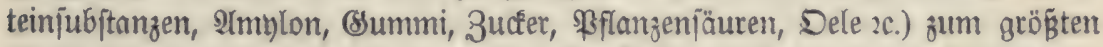

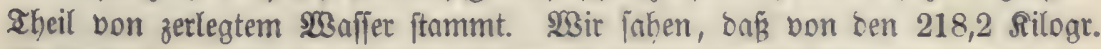

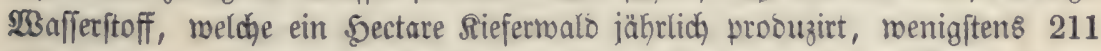

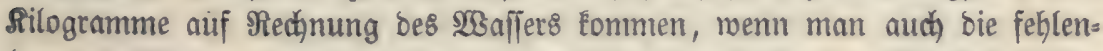

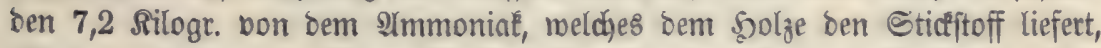
ableitet. Diejen 211 Rilogr. $2 B a f f e r f t o f f$ entiprect)en (ba bas $23 a f f e r ~ 11,11 \%$

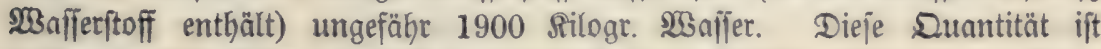
außierorbentlid, Elein, berglichen mit Derjenigen, welche während ber \$eges

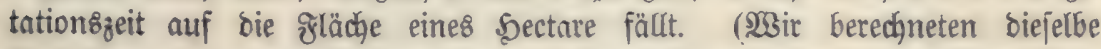

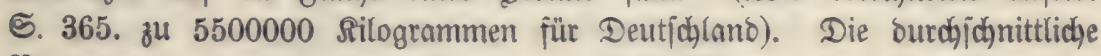

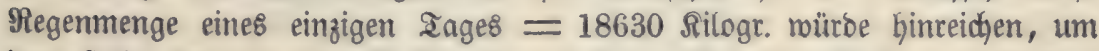

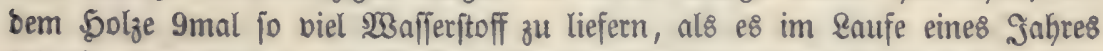

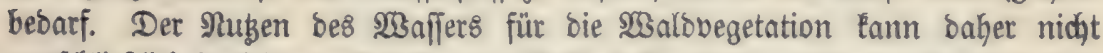

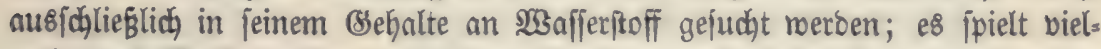

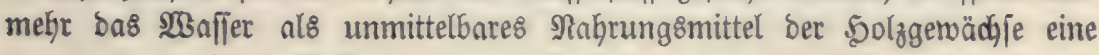
ganz untergeoronete Rolle.

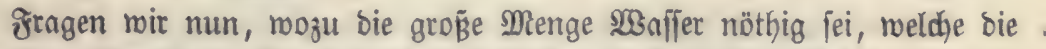
Pflanzen mäbreno der ßegetationszeit becürfen, jo kann bierauf bis jeşt nod)

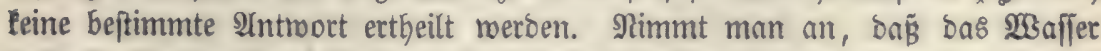

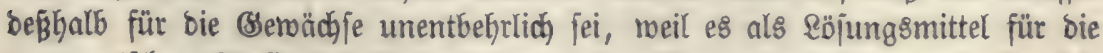
amorganijachen Stoffe bes SBobens biene, fo extlärt uns bieje an und für fich ridatige Unterftellung bods immer nody nidft, marum bie Pflanzen eine jo

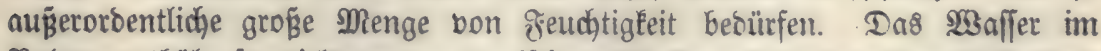
soben enthält fo biel an anorganifjohen Stoffen, baí ber Regenfall eines

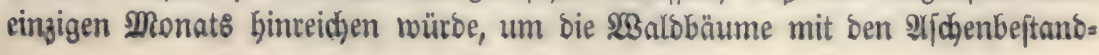




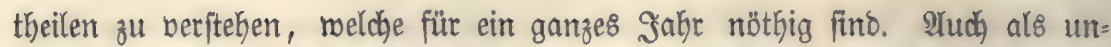

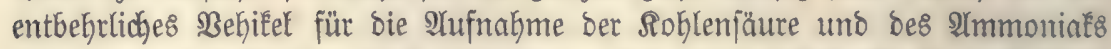

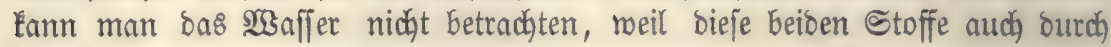
bie $\mathfrak{B l a ̈ t t e r ~ a u f g e n o m m e n ~ m e r b e n . ~}$

(s:s jajeint, bafi bie djemilichen Srozeffe, welche unter bem (sinfluffe ber

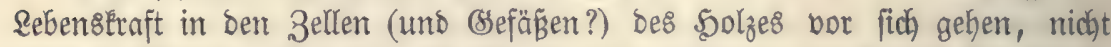

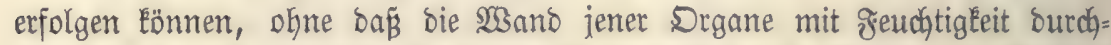

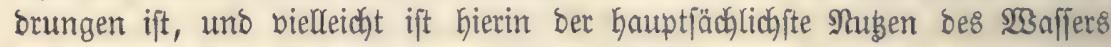
in Bezug auf bie $\mathfrak{B}$ egetation zu fucken. Dieje Snterpretation ift aber nichts anderes, als eine Stypotheje. SRad) Dem gegennärtigen Stande ber Pflanzen=

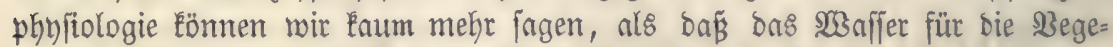

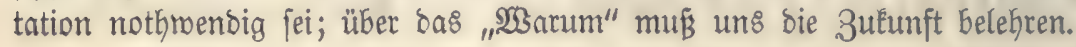

\section{Safteuditigfeit.}

Die 3etlen und Shefäßse, aus melchen bas Solz befteft, find inmen hohl

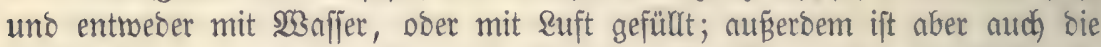

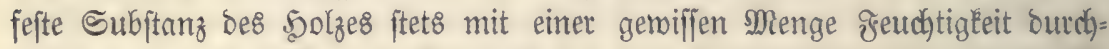

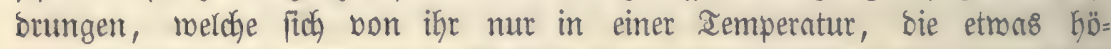

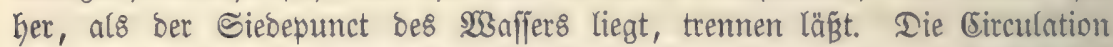
bes Saftes geht vorzüglich in ben jüngeren Solzlagen vor fich, uno bieje

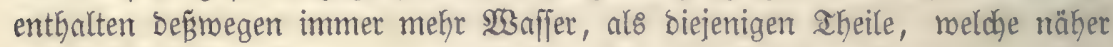
an ber Schaftare liegen; am trodenften ift gewöbnlich bas Mark.

fragen wir, zu welcher Sahreszeit bie größ̈te Menge Saft in ber $50 l z=$

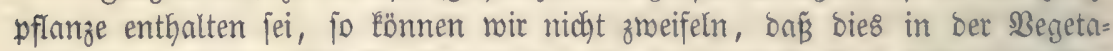
tionszeit ftattfinde. Indeffen fint nod) jo menig rationelle Unterfuchungen über

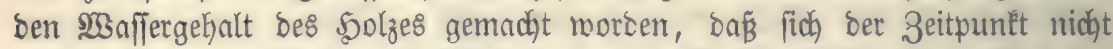

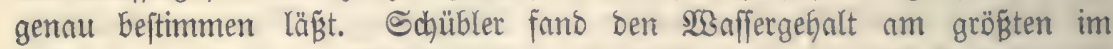
arübjahr; nad) einem Mittel mefrerer Berfuche nabm der Saftgehalt non

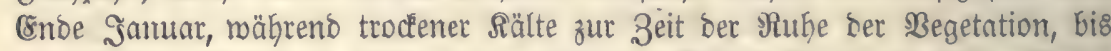
zum 2 Infang 2lpril\& um $8 \%$ zu; er ftieg im Mittel bei 5 zu biejer Unter= fuchung bienenoen $B$ äumen (Fraxinus excelsior, Acer pseudoplatanus, Aesculus Hippocastanum, Corylus avellana, Abies excelsa) von 39,2 bi $47,2 \%$ ober nahe um $1 / 5$ Der uriptünglichen Duantität.

Menn man bie IIngaben in ben Refyrbüt)ern bergleidft, io jollte mant glauben, ber $N_{3}$ affergebalt ber einzelnen 50 lzarten jei auferoroentlich verjochie=

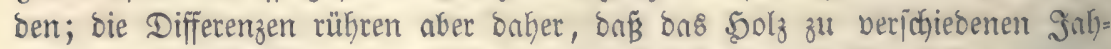
reszeiten unterjucht rourbe. Sie werben fich bödhit rabrfointich auf einen

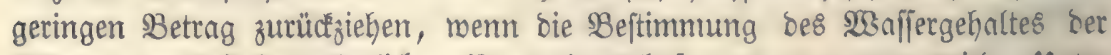
Bäume zur Zeit ber nämlichen Begetationsphajen borgenommen wiro. Unter

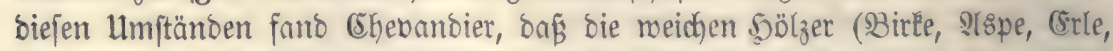

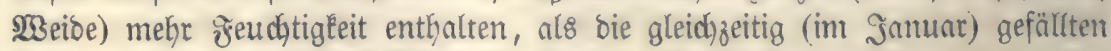

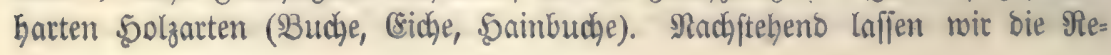


fultate von Sartig's uno Sönig's Unterfudungen über ben $\mathfrak{B a f f e r g e h a l t ~ e i n i = ~}$ get Solzarten folgen. (58 fanben

\begin{tabular}{|c|c|c|c|c|c|}
\hline & Sartig & Rönig & & 5artig & Rōnig \\
\hline Fagus sylvatica & $39,7 \%$ & $42,0 \%$ & Alnus glutinosa & $41,6 \%$ & $50,0 \%$ \\
\hline Carpinus Betulus & 18,6 & 35,5 & Tilia europaea & 47,1 & 49,0 \\
\hline Quercus Robur & 34,7 & - & Populus tremula & 43,7 & 48,0 \\
\hline$" \quad$ pedunc. & 35,4 & 40,0 & Abies pectinata & 37,1 & 44,0 \\
\hline Acer pseudopl. & 27,0 & 37,0 & Abies excelsa & 45,2 & 48,0 \\
\hline Ulmus campestris & 44,5 & 41,0 & Pinus sylvestris & 37,7 & 48,0 \\
\hline Fraxinus excelsior & 28,7 & 38,0 & Larix europaea & 48,6 & 48,0 \\
\hline Betula alba & 30,8 & 40,0 & & & \\
\hline
\end{tabular}

Benuben mir bieje 3aflen zu nichts, als um bie Brenzen zu beftimmen,

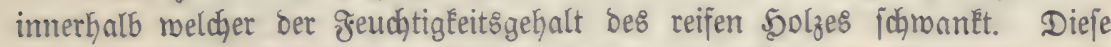
betrngen alio 18 bis $50 \%$. Windere fanden aber für ons Macimum nod' Göhere 2 Berthe, jogat bis $60 \%$.

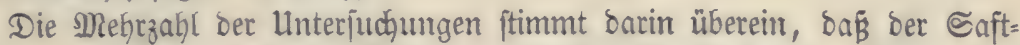

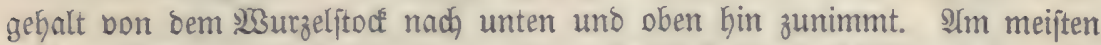
Eaft enthalten bie $\$ 3$ lätter uno grünen Triebe. Nady Schübler haben bie jüngeren 3roeige oft Doppelt fo biel $23 a$ jer, als bas ältere \$olz; bei einem

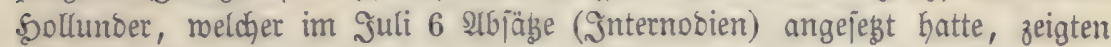
bie einzelnen 3rijchenjtücte von eitter 3lattausbreitung zur andern in ber Mienge ber wäj]erigen Beftandtheile folgende Berjachiedentheiten. Der $\mathfrak{B a f f e r =}$ gehalt

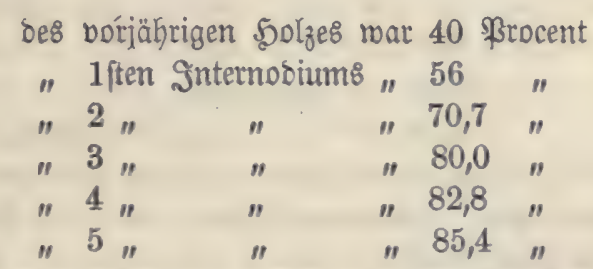

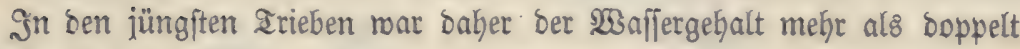
io groß̧, als im borjäbrigen $50 l$.

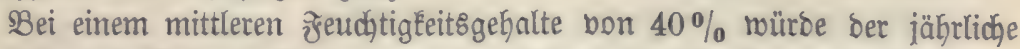
3umachs eines Riefernwalbes, Den wir früher beijpielsmeife zu 3551,9 Rilo=

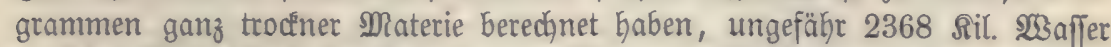
in fich faffen; bie \$olzmaffe eines 60jäfrigen Beftandes enthielte unter ber nämlichen Ânnahme 142116 Silogramm $\mathfrak{3 a}$ affer. Dieje Duantität lönnte

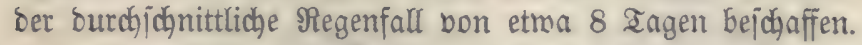

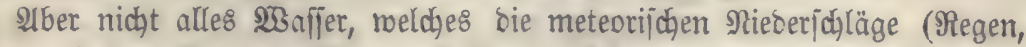
Schnee :c.) bem Boben zufütyren, ift für bie Pflanzen verwendbar; jebr viele

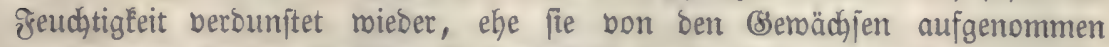

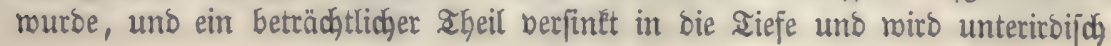




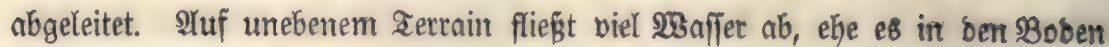
eingebrungen ift.

Dalton berechnet, baß $1 / 3$ bes im Flüggebiete ber Ihemie niebergefallenen

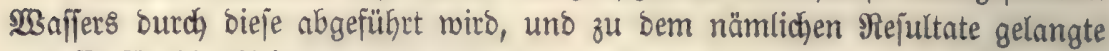
Daufe für bie Seine.

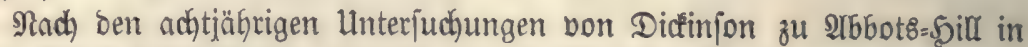

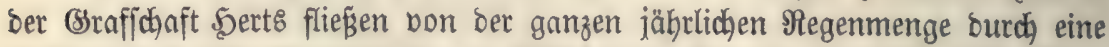

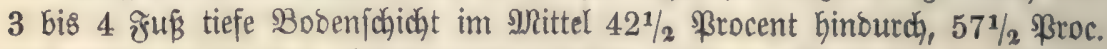

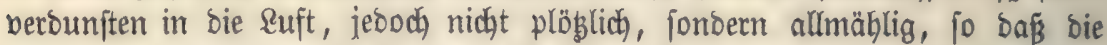
Berbunitung nidft unmittelbar bom Boben aus, fonbern aud bon ben Bflan=

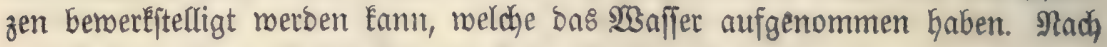
Den Sabreszeiten geftaltet fid ber $\mathfrak{3}$ organg folgentermafen:

\begin{tabular}{|c|c|c|c|}
\hline Monat & $\begin{array}{l}\text { Serfictert } \\
\text { ßroc. }\end{array}$ & $\begin{array}{l}\text { Berounitet } \\
\text { ßroc. }\end{array}$ & $\begin{array}{c}\text { Regenmenge } \\
30 \text { lle }\end{array}$ \\
\hline Samuat & 70,7 & 29,3 & 1,847 \\
\hline Zebruar & 78,4 & 21,6 & 1,971 \\
\hline Mărz & 66,6 & 33,4 & 1,617 \\
\hline Stpril & 21,0 & 79,0 & 1,456 \\
\hline Mai & 5,8 & 94,2 & 1,856 \\
\hline Suni & 1,7 & 98,3 & 2,213 \\
\hline Şuli & 1,8 & 98,2 & 2,287 \\
\hline श्tuguit & 1,4 & 98,6 & 2,427 \\
\hline September & 13,9 & 81,1 & 2,639 \\
\hline Detober & 49,5 & 50,5 & 2,823 \\
\hline ఇobember & 84,9 & 15,0 & 3,837 \\
\hline December & 100,0 & 0,0 & 1,641 \\
\hline Mittel & 42,3 & 57,6 & 26,614 \\
\hline
\end{tabular}

Daß̧ aber bieje 3ahlen nur für einen einzigen F̆all gelten uno baß̊ bie

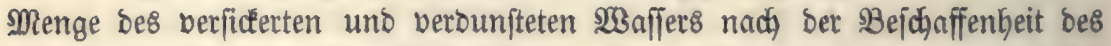

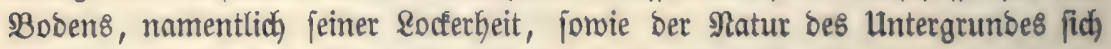
abänoert, braudyt mohl nur angedeutet fu werben.

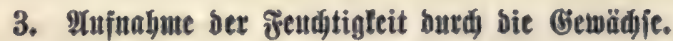

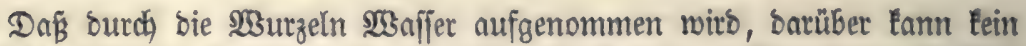

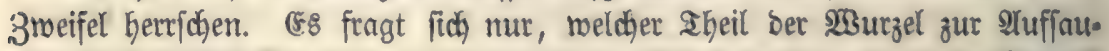

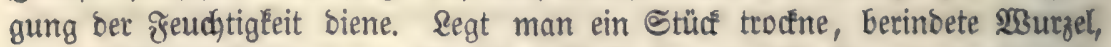

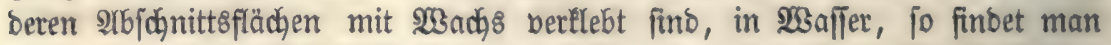
nach einiger 3eit, bas biejes in bas $50 l z$ eingebrungen ift. 888 ift aljo ge=

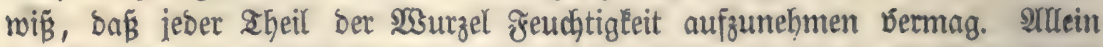
bas 2 huffaugen geht um jo langfamer von Statten, je mehr bie $23 u r z e l$ mit abgeftorbenem Zellgemebe belleibet ift, uno ziejt man bie Menge bes burds

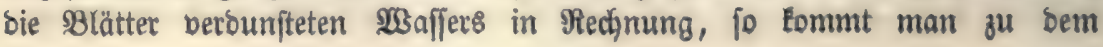




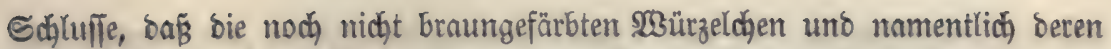

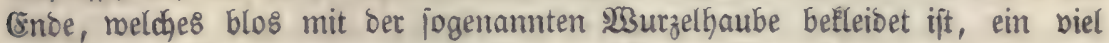

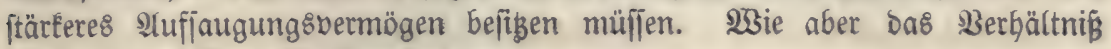
jei, Darüber feglen alle Unterjuḑungen.

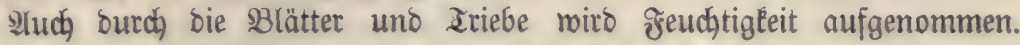

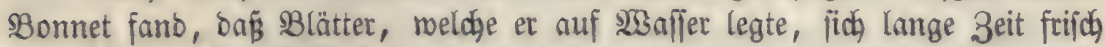
erbielten, uno Burnett mies bas von ben Blättern bes ichmimmenoen \&aid)=

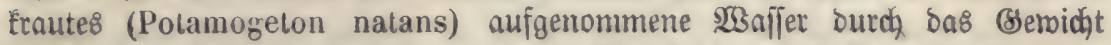
nach. 2(uch oas in Dunftform in ber 2 tmojphäre enthaltene $\mathfrak{W a f f e r ~ E a n n ~}$

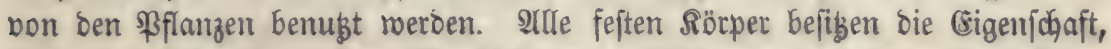
(B)aje uno Dämpfe an ifrer Dberflädhe zu berbichten; went ein trodentes Blatt fich in ber \&uft befindet, jo wiro jeine Dberfläche nach einiger 3eit mit einer,

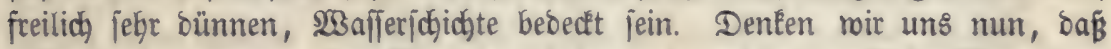

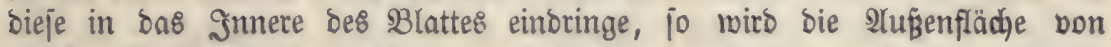

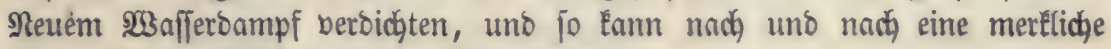

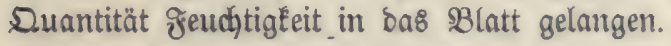

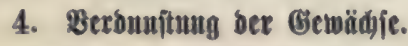

Nimmt man eine Pflanze, ohnte fie zu verlegen, aus ber (stbe und jebst fie einige Zeit ber \&uft aus, fo verminoert fich ibr (Semidht, meil bas in bet Pflanze enthaltene tropfbar flüifige 23 affer berounftet. Die Dberflädhe Der

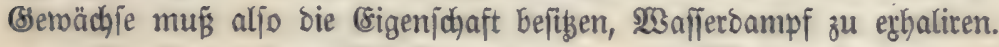

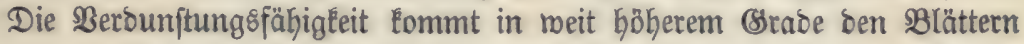
und jungen arieben, alz ben berinbeten Ifeilen bes Baumes zu. Duhamel bu Monceau verpidgte die beiben Mbhiebsflädhen eines 31 Pfund 3 Unzen

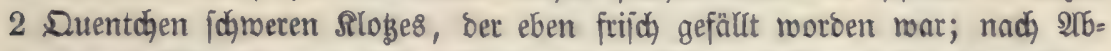

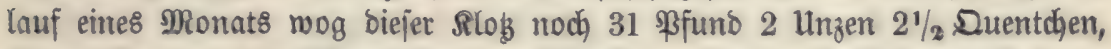
Gatte aljo nur $7 \frac{1}{2}$ Quentchen an (Semicht berloren, obgleidh er auf einem

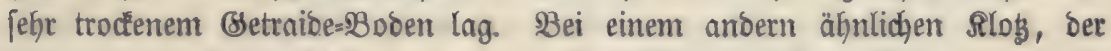

Æigur 145.

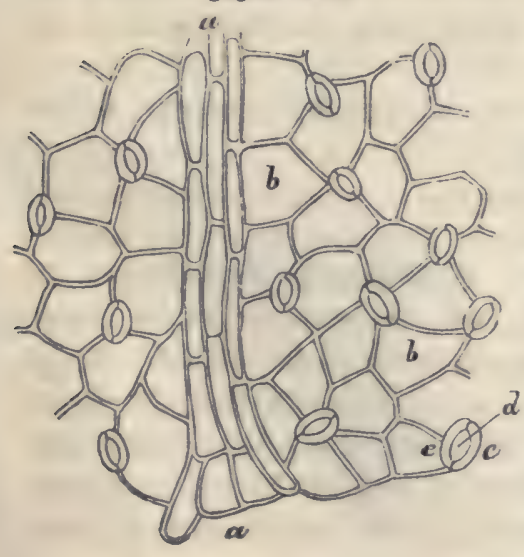

aber nicht berpicjt toorben war, Gatte bas (semidyt um 1 \$s funo abgenom= men.

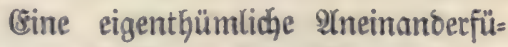
gung ber 3ellen auf ber Dberflädye ber Blätter erleichtert bie (rrbyalation bes WBafferbampfs. Rojt man von ber $\mathfrak{H}_{\mathrm{n}}=$ terjeite eines \$latanenblattes ein feines Sclyeibchen ab (osig. 145), io bemerlt man bie langgeftrecten 3 ellen ber Blattmerben a; zmijeden ben legsteren liegen größ̈ere Zellen $b$ uno an Diejen bfters zmei balbmonoförmige 3ellen c, $c$, reldye eine suncle d zroidgen fids 
laffen. Diefe sücée febt fich eine Strecfe weit in bas Snnere bes 2 Blattes fort bilbet aljo eine förmliche 2 Lumünoung für baffelbe. Man nennt d bie Spalt= öfnung des $\mathfrak{B l a t t e s ~ u n o ~ c ~ c ~ b i e ~ S p a l t o ̈ f f i n u n g z z e l l e n . ~}$

Arte \&aubholzbäume tragen bie Spaltöffnungen auf ber Unterjeite ber

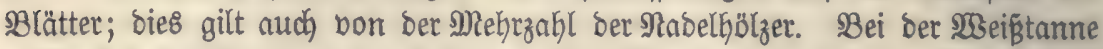
ช. B. find biefelben auf ben beiben meiñen Streifen befindlid, melche bie un= tere Fläche ber Nabel ber Ränge nach überziehen; bie Fichte und Riefer ent= balten bie Spaltöffnungen auf allen Seiten ber Nabeln in ebenjoldhen Strei= fen, meldhe mit ber Arte ber গabel parallel verlaufen. Die Samenblätter ((Sotylebonen) ber SSemächfe tragen bagegen bie Spaltöffrungen meift auf ber oberen, bem sidate zugekebrten Seite.

Sinige \$Sbyfiologen Gaben bie Berounftung blos von ben Spaltöfnun= gen abhängig machen wollen; bies f̧heint aber aus bem Grunbe nidgt ridgtig

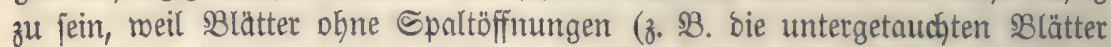
mancher $\mathfrak{W a f f e r p f l a n z e n ) ~ a u d h ~ F e u d j t i g k e i t ~ b e r o u n f t e n . ~ S e g t ~ m a n ~ n a ̈ m l i d h ~}$ joldje 3 lätter autier Communication mit bem $23 a f f e r$, fo bertrodnen fie nach

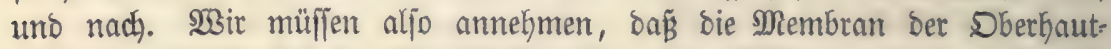
zellen an uno für fich sie cigenfohaft befige, ben flüf!igen Sintalt ber 3ellen in Dunftform entweichen zu laffen. Dafür fpricht audh ichon ber Umftano, baß̈ bieje Membran am lebenten Blatte mit Feudtigkeit burdhorungen ift, welche berjofwinbet, wenn man fie (bie Membran) vom Blatte löft. Da bie

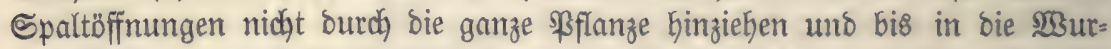

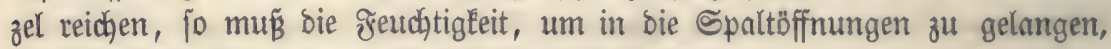
bie Membran Der angrenzenden Bellen burdjoringen.

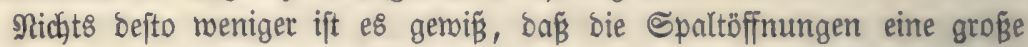

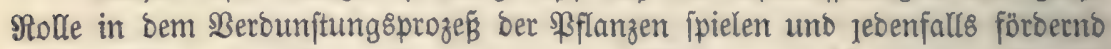
auf Denfelben einwirken. Denn Diejenigen Pflanzen, meldke (wie z. $\mathfrak{B}$. Die (Eraffulaceen) beftimmt find, monatelang auf einem trodenen Terrain ofne

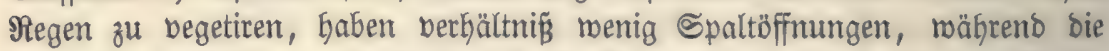
untere Blattfläche ber Durch ifre ftarke ß3erdunftung ausgezeidgneten SBudge mit Spaltöffnungen über\{äet ît.

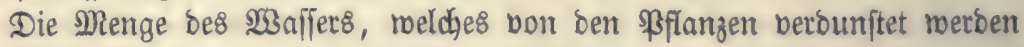
Eann, hängt $\mathfrak{a} \mathfrak{b}$ :

\section{a. Son Cattung unb 9rt.}

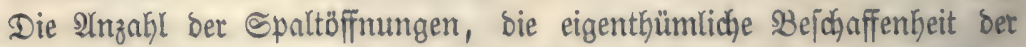
Membran, welche bie Dberfläche belleibet, audh bie imrere Tertur Der Zellen, welche ein mehr Doer minter rajh)es frortbenegen bes Saftes geftattet, mögen

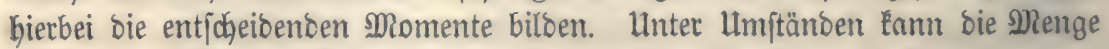

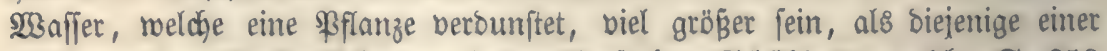

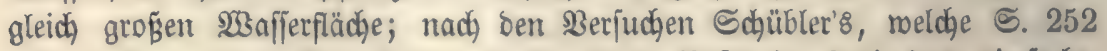

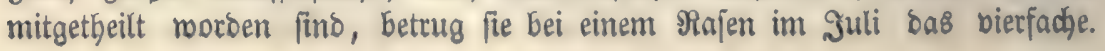




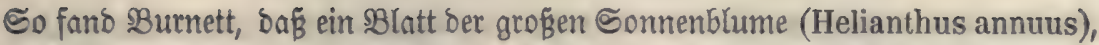

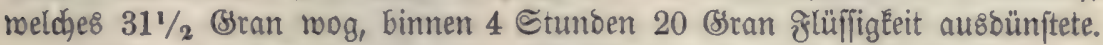
Heber bie Berdumftung unferer $\mathfrak{2 B a l b b a ̈ u m e ~ f i n d ~ b i s ~ j e b t ~ n o c h ~ m e n i g e ~}$ Interjuchungen angeftellt worben, biejelben fino audy mit auBerorbentlichen Sdanierigfeiten verbumben. Rlaupred)t uno Schübler fanben bie Menge bes

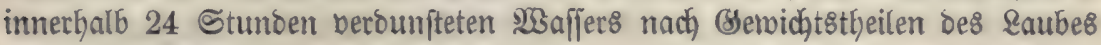
ober ber Rabeln:

\begin{tabular}{|c|c|c|}
\hline Solzart & $\begin{array}{l}\text { Rlaupredtt } \\
\text { (Iuni, Suli) - }\end{array}$ & $\begin{array}{c}\text { Schüblet } \\
\text { (அug., Sept.) }\end{array}$ \\
\hline Budje & 36 & 46 \\
\hline Cicthe & 37 & 45 \\
\hline Birte & 29 & 44 \\
\hline Erle : & 43 & - \\
\hline Siefer & 11 & - \\
\hline ofichte & 10 & 17 \\
\hline ISBeistanne & 12 & - \\
\hline Eäróge & 18 & 31 \\
\hline
\end{tabular}

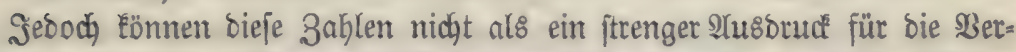
Dunftung, wie fie am Baume ftattfindet, angejęen werben, weil bie Blätter

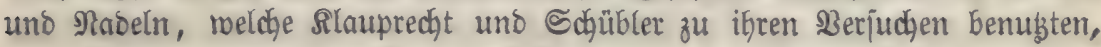
bom Stamme getrent, aljo jebenfalls in einem abnormen 3uftande maren.

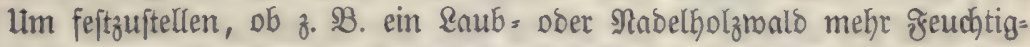

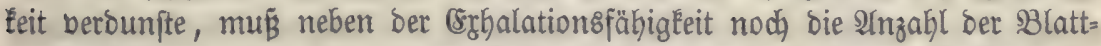

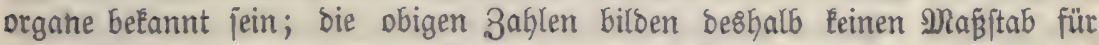

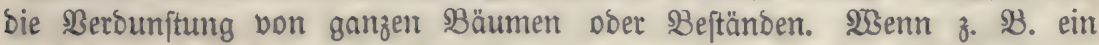

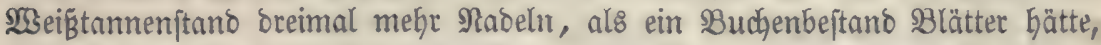

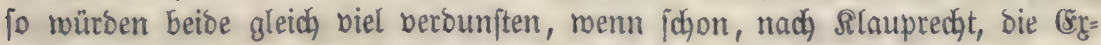

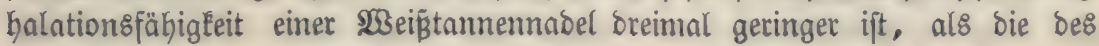
Buchenlaubes.

\section{b. Zon bem \&ebentalter ber Gewädjfe.}

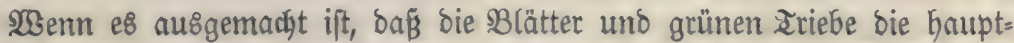

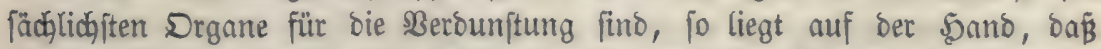

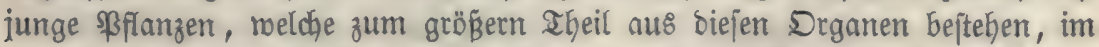

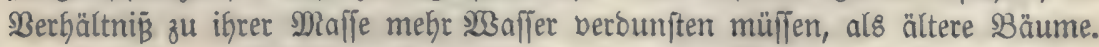
Sn ber That, es ift beľannt, wie fęr bie jungen Bflanzen unjerer Eulturen

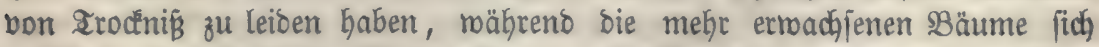

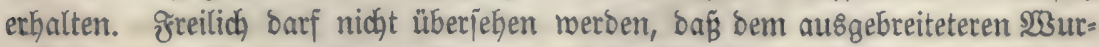

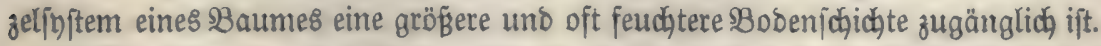

2lbgejehen von ber Remperatur ber \&uft 2 . Cogeint bie ßerbunftung im ğrübjabr, menn bie slätter nod) zart find, am ftärếten zu fein. Späterbin nimmt biejelbe in Dem Make $a b$, als bie Dberhaut ber 2 lätter fidh mit 


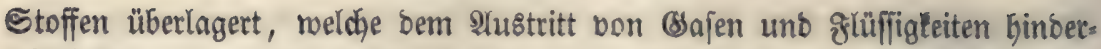
(id) fint.

WSie früher auseinandergefegst nurbe, enthält ber Saft ber Bäume zu gemiffen Zeiten Deçtrin, Zucfer, Zerpenţinöl sc. Die beiben erftgenannten Subjtanzen treten mit bem $\mathfrak{M a f f e r , ~ i n ~ m e l c h e m ~ f i e ~ n u f g e l o ̈ j t ~ f i n d , ~ b u r d y ~ b i e ~}$

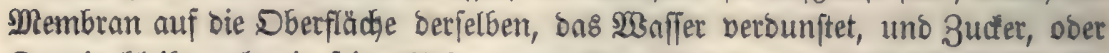

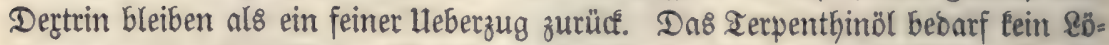

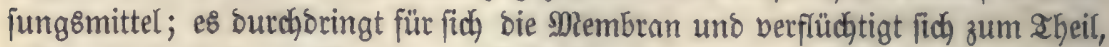
mäbrent ein anberer IGeil unter 2ufnahme von Saueritoff in Sarz ühergeht.

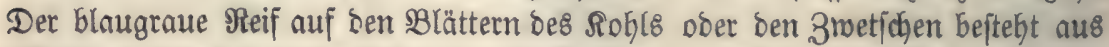

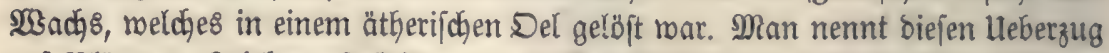

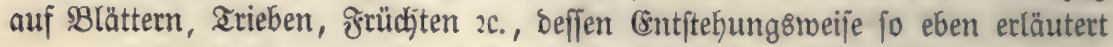

Æig. 146.

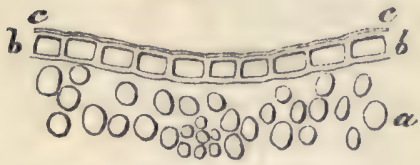

murbe, bie (Euticula. §ig. 146 ftellt ben Queridhnitt burch einen Theil bes Suchen= blattes bei 200 façer-Bergröß̈erung bar. a find bie 3ellen im Snnern, b bie Dberbaut= zellen bon ber Interjeite bes Blattes. Das feine Stridfelchen ce über Ser Bellenreihe bb ift bie Cuticula. (ss ift begreif= lich, baß̈ bie Buticula bejonoers bann, wenn fie von madhb = ober harz=

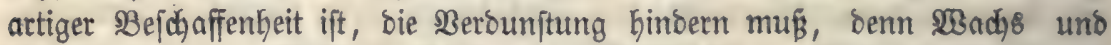

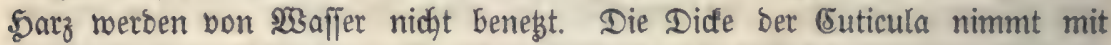
bem 2llter ber Blătter $2 c$. zu und ift aljo mit bie 1trjache, ronrum bie Ber=

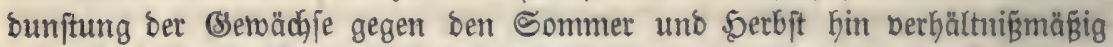

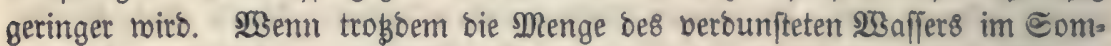

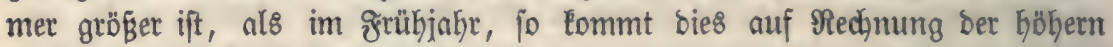
Zemperatur in ber wärmeren Sahreszzeit.

(58 if an einem andern Drte (ङ. 372.) bie Ânficht ausgefprodien mor=

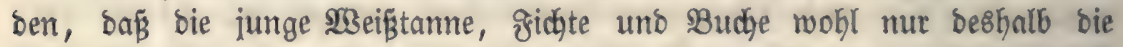
bolle cinmirkung ber Sonnenitrablen nicht ertragen fönnen, weil fie burd) bieje zu einer übermäßigen ßerounftung gereizt werben. Inoem bie Sonne

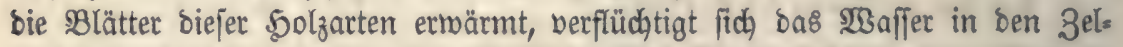
len; es entrueidyt in frorm bon Dampf. Die (Empfindlich)eit gegen bie Cons nenftrablen nimmt aber im Spätfommer uno 5erbft ab, und man E⿱onnte zu biejer Sabrezzeit bie Pflanze ganz freiftellen, wenn nidgt bie grrühfröfte zu

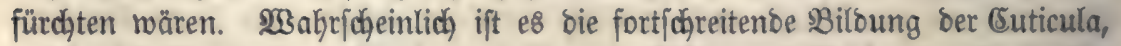
meldye bie Berbunftung bet jungen నanne, Fidhte uno Budge im Raufe der 23egetationzzeit ermäßigt. Sn ber Ibat bemerlt man bei ben Iannen = unb ङidjtennabeln, weldje mit hellgrüner Farbe aus ber aufbredt)enten Inofpe

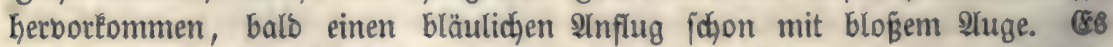

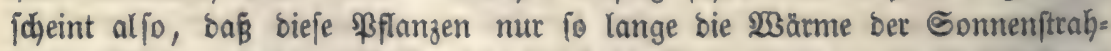
len zu fürdjten haben, als fie nidbt burdh bie Cuticula gegen bie \$3erbunftung

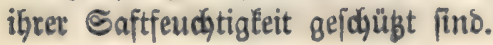


Man nimmt allgemein an, baß̈ bie Nabelfblzet wentger 23 affer ver=

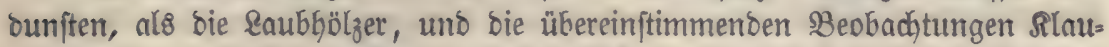

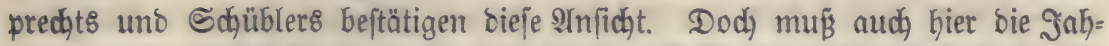
reszeit wohl betüdfichtigt werben; Rlauprecht ftellte feine unterjuchungen im

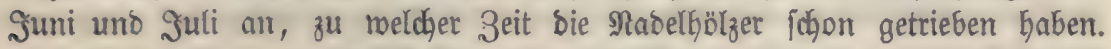

\section{Æig. 147.}

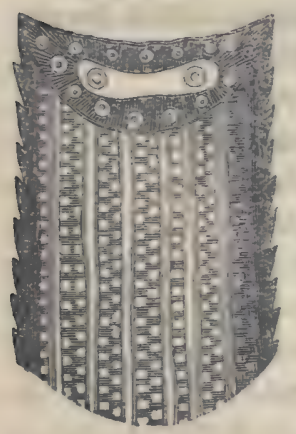

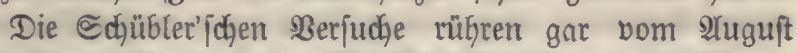

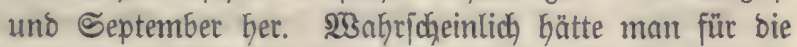
Tamne und gichte andere 3ahlen gefunden, menn man bie Beobadjtungett in ben Mai verlegt hätte. Hebrigens erElärt ber Terpenthingehalt Der Nabelfölzer bie geringe Erchalationsfähigkeit ber leģtern zur senüge, nenn man gleidhzeitig bas beadgtet, was über bie Biloung ber Buticula gejagt rurbe. 2Uud bie geringe Berounjtungsfähigleit, reldhe Rlauprecht für bie Riefernabeln nadggemiejen hat, joheint in einer ftarken (Euticulajobichte ifren Srund zu baben. BBei einer unberfegrten Siefer= nabel ift bie ganze Dberflädge mib einem blaugrauen Reif bebectt, ber bon Garziger $\mathfrak{B} e j$ daffenheit ift. Betradjtet man ifn mit bem Microjcop (ङigur 147, bei 15fadjer Bergröperung), fo löft et fich in lauter einfache ober boppelte Streifen auf. Dieje enthalten bie Epaltöfnungen.

ঔigur 148.

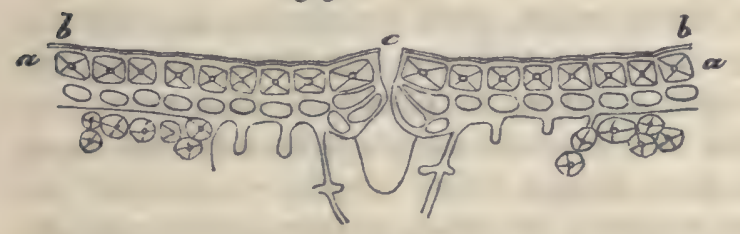

Iuf einem Dueridnitt (ঔig. 148, bei 200 facher Bergrōperung) erbliát man über ben Zellen aa bet Eppibermis bie cruti= cula $\mathrm{b}$ b als ein feines Stridgelchen. e ftellt eine Spaltöfnung bor.

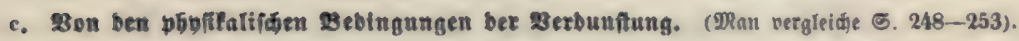

Sieffer gehören bie Temperatur, bie suftfeudgte, Der \&uftoruct, ber \&uft=

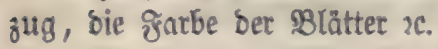

Durch eine erhöhte Zemperatur Eann bie Berbunftung in zroeifacher

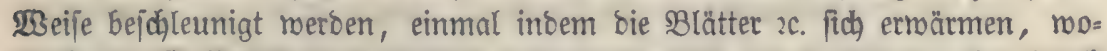
burch iffr 23 affergehalt in Dampf berwanoelt wiro, zum andern aber burdh Srmärmung ber Ruft, melche bie \$flanze umgibt. Regteres hat zur folge, baß

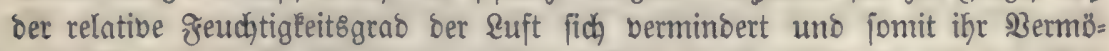

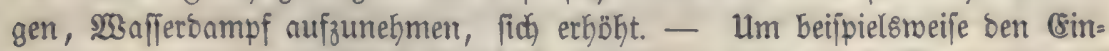

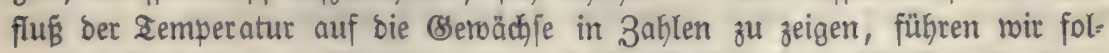
genden Berfuch von Sdjleiben an. Diejer fäete Safer uno Slee in einen

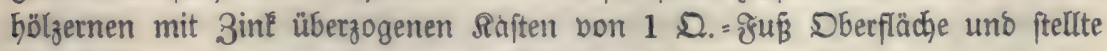
ben Saften auf eine feb̆r genaue $B$ tüdenmage; jeben Iag wurbe bie bet: 


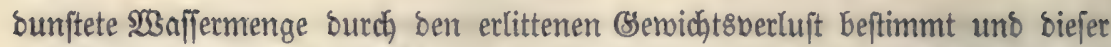
Berluit burch Begiegen erjegt, nobei ber Bobenraum in bem 3ujtande eines gemöhnliçen guten nicht ausgebörnten sanoes gehalten murbe. Der Rilee und Safer entwidfelte fich Keinesmegs jefr üppig regen ber febr unpaffenden

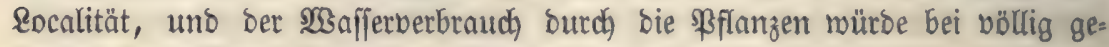
funber Entwicklung bei meitem bebeutender ausgefallen jein.

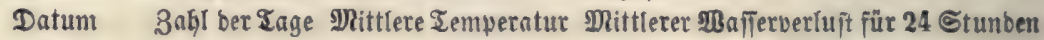

1) Ilpril 12-19 9

2) Ipril 29-Mai 8

$11^{\circ}, 55$

3) Mai $8-11 \quad 3$

12,52

4) Imai $27-29 \quad 2$

17,43

5) Mai 29- Suni 13

14,00

6) Suni $7-8 \quad 1$

17,28

55,00 Bramme

7) Şuni $12-14$

18,66

8) Suli $19-21$

21,40

9) $\mathscr{2}$ ug. $10-14$

21,40

59,50

102,66

95,00

133,01

126,00

227,50

18,00

305,00

190,50

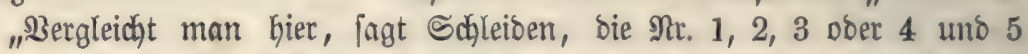
ober 8 und 9 , jo zeigt fid in biejen Rejultaten, Daß bie Mienge bes von ben

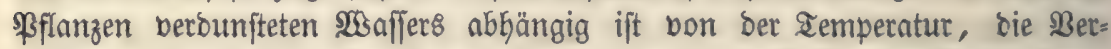
gleid)ung von 3,5,9 ober 7 uno 8 zeigt, wie bie (Srößze Der ßerounftung mit ber allmähligen (sntrwicklung Der Bflanze und ifrer B̉attfläche fteigt, endlid) bie Bergleidungen von 5 und 6 zeigen ben (sinflǘ Der \&uftfeuch= tigkeit auf bie Berbunftung, indem am 7ten und 8ten Juni nadj fehr hef=

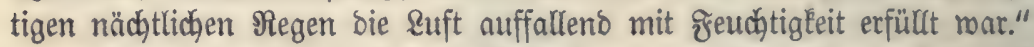

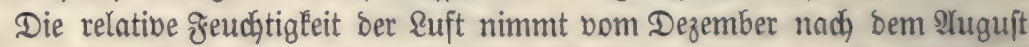
$a b$, in meldyem Monat fie ifren Eleinften 23 erth erreidyt. - Die suft auf Bergen ift an heitern aagen trockener, an trüben bagegen feudder und im

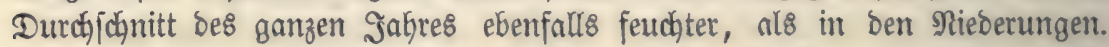
Drte an ber See geniésen einer feuchteren \&uft, als Drte im SBinnentanbe

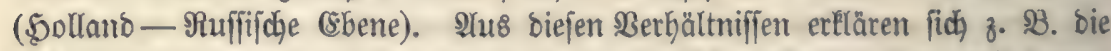

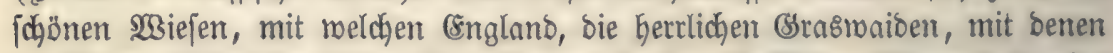

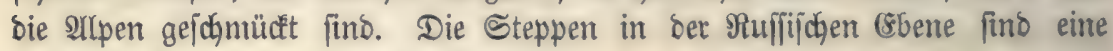
nothrwentige frolge ber troçenen $\mathbb{E}$ uft.

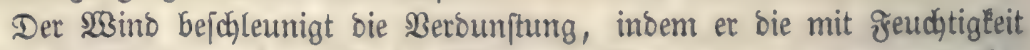

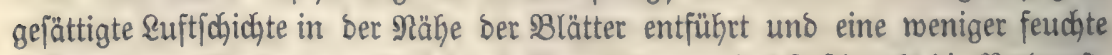
\&uft an beren Stelle jęst. Daḱ burch Berminderung bes \&uftoruc'8 bie Berbunfts ung begünjtigt wiro, ijt S. 250 ausfüffrlich erörtert woorben. - Dunfel ge= färbte $3 B$ lätter $2 c$. merben burdì) die Somnenftrablen ftärker errwärmt, als joldge mit hellerer garbe, fie laffen baher ifre greudhtigkeit leidhter fahren.

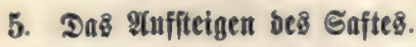

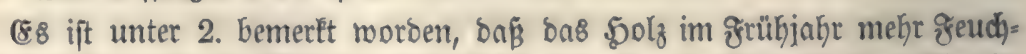

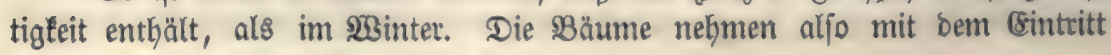




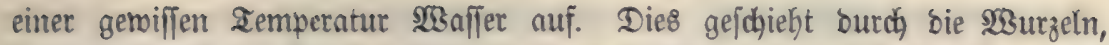
denn viele Bäume find im grühjahr nod blattlos, während bas 5olz bereits mit Saft angefüllt ift.

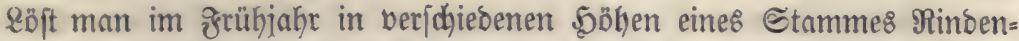

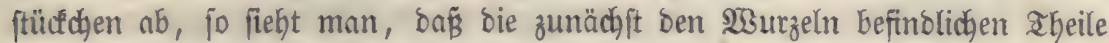
frïher Saft füfren, als bie 3roeige in ber Srone, baß̈ aber aud bieje nach uno nach mit greuchtigfeit erfülrt merben. Schneibet man zur geeigneten 3eit

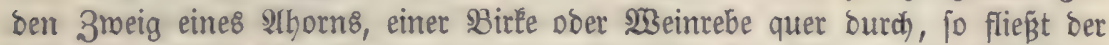

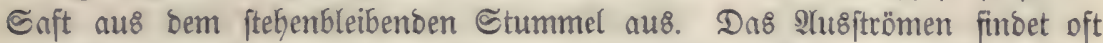

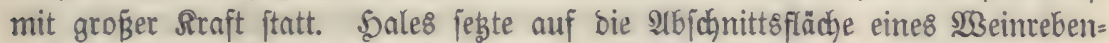

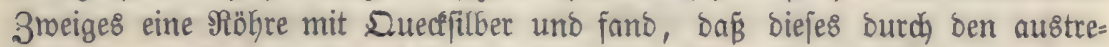
tenden Saft auf 38 3oll 5öhe gehoben wurbe, was einem Drud von faft 11/2 2Ytmojphäre gleidfommt. STus allem biejem geht herbor, baß̉ ber Saft

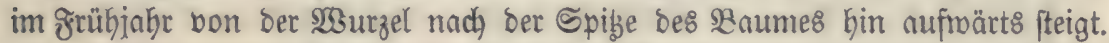

Man hat bas Auffeigen des Safte\& burch bie Capillarität ber Zellen zu extlären gejudbt. Sn ber Ihat lafjen fich bieje als jefr feine Saatröbrchen betradăten. Doch genügt bie (Enpillarattraction Éeinesmegs, um ben Saft bis zu ben Spigen groger SBäume emporzufeben, benn nach ben Berjuchen von

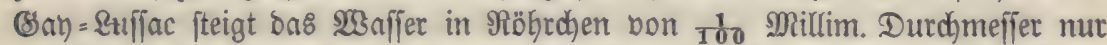
3 Meter hoch. Daß̂ es bie Saarröhrdjentraft nidgt ift, weldje das Aluffteigen bes ๔afteళ bemirft, zeigt bas ßerfalten gefällter Stämme; einige 3eit nad̆ Dem Sieb fteigt $\mathfrak{W a f f e r , ~ i n ~ m e l d j e s ~ m a n ~ b i e ~ A b h i e b r f l a ̈ d y e ~ t a u c h t , ~ n i d j t ~ m e h r ~}$

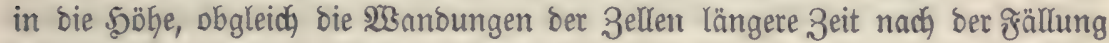
Eeine $\mathfrak{B}$ eränberungen erleiben, weldhe fie zum Serborbringen ber Capillarer= jobeinungen untauglidh machen ểnnten.

Man hat fich baher nach andern urjachen bes Eaftauffteigens umzu= jehen; wir finden biejelben theils in ber jog. (snoosmofe, theils in ber Ber= bunitung.

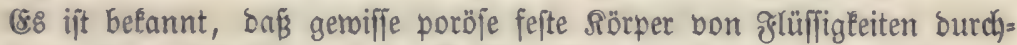

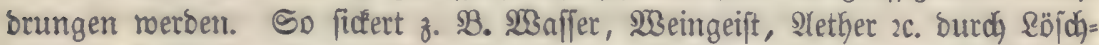
papier (giltriren). Andere Subjtanzen bagegen, beren \$oren feiner find, ge=

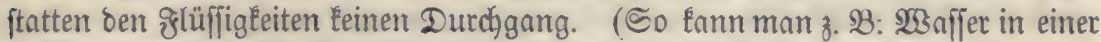

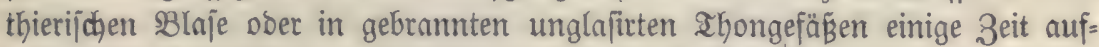

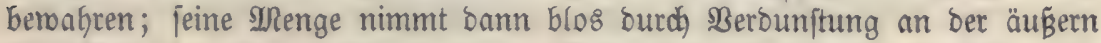
Dberfläche ber bon innen benebten $B$ (aje ober bes \$łons allmählig ab). Sier ift bie Anzief)ung ber feften Ifyeildyen, weldhe eine \$ore umgeben, gegen

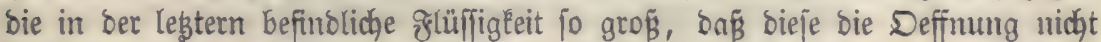
berlaffen Eann. Destwegen faugt fich z. B. Der gebrannte ahon voll 233 affer, abet et läpt eô nidat burdafickern.

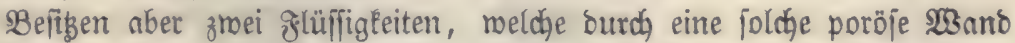

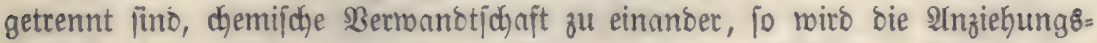
kraft ber feften Iheile gegen bie flüfifigen burdh bas sBeftreben, fich chemifh 


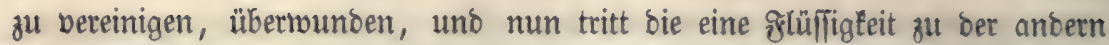
über. Diejer ßorgang, meldjen man "Enoosmoje" nennt, murbe zuerft bon Fijojer uno Dutrodjet beobadjtet.

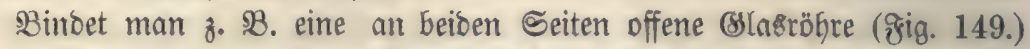

ঔig. 149.

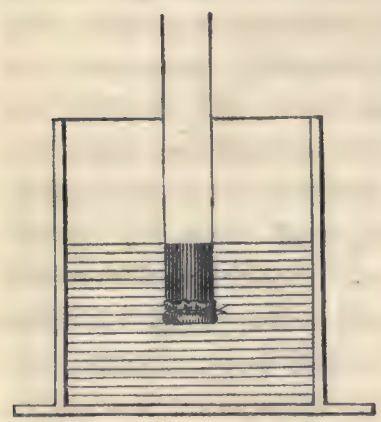

an ber einen Seite mit Blaje zu, gibt man bier=

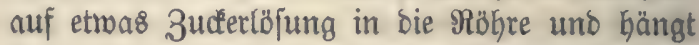

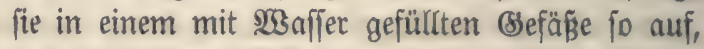

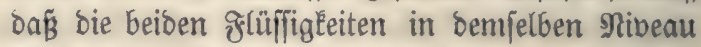

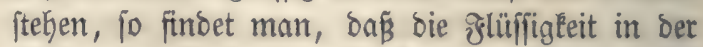

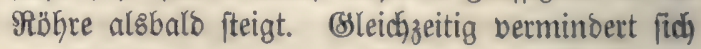

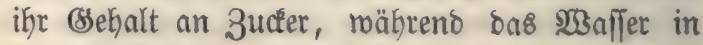

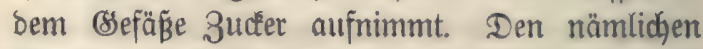
Borgang beobadhtet man, wenn ftatt bes , Buders Srummi, Derctrin Doer Einein in bie Röbre ge= bracht wirb. Dodf zeigt fich in jo ferne ein lun=

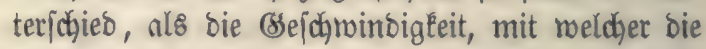

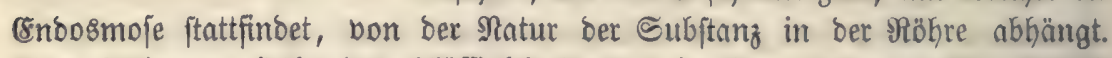

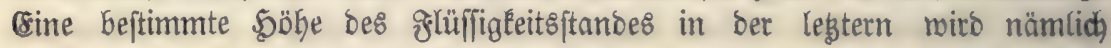
bei 3ucker in 2,11, bei simeis in 2,3mal weniger 3eit, als bei summi et=

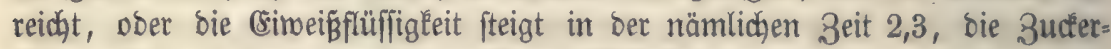
löjung 2,11 mal jo hod), als bie Summiflüffigkeit.

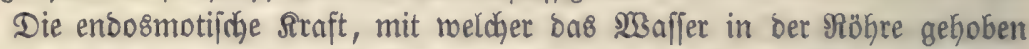
wirb, ift Göb)ft bebeutent. All 8 Dutrodhet ftatt ber borbin ermähnten gernoen RöGre eine mit Dopperter Sitummung antoandte, neldje an Der Srümımung

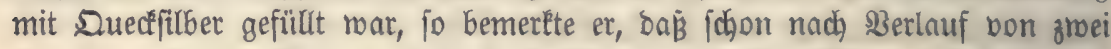

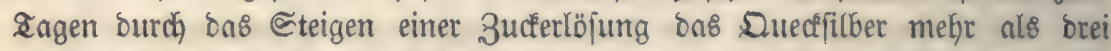

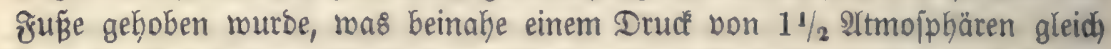

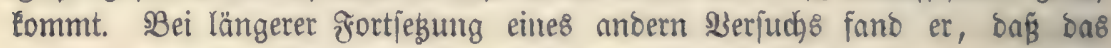

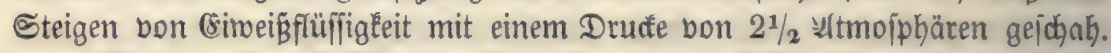

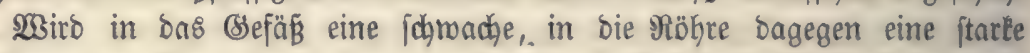

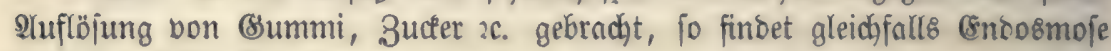

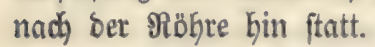

WBie früher angegeben murbe, enthalten bie 3ellen bes \$olzes Ctärf́e= mehl und fticfitoffbaltige Eubftanzen. Sm grühjabr, bei bem Eintritt einer

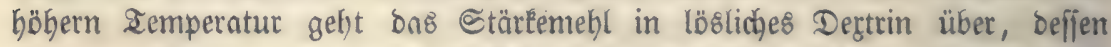
3ujammenjegung ganz genau gleich berjenigen bes (summi's ift. Cobalo biejes

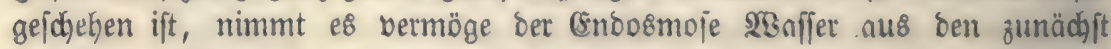
liegenben 3ellen auf. Slun hat man gefunben, ban bie Didate bes Enftes mit ber \$öhe über ber (rrbe wädjit. Soffmann tiohrte am 8. März eine

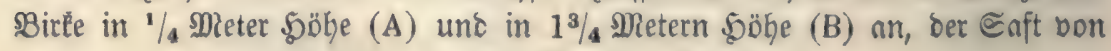
A batte ein Bemidyt bon 25,712

B " " 25,717 


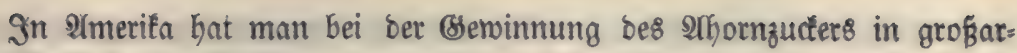

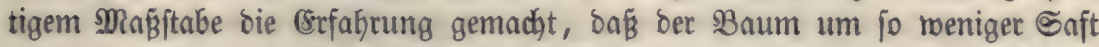
gibt, je höher man ihn anbohrt, baß̈ bagegen ber legstere um fo reidger an 3 ucter wirb.

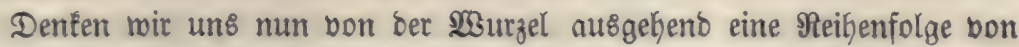

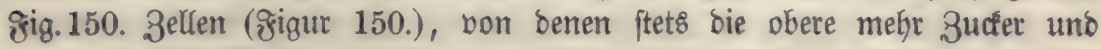

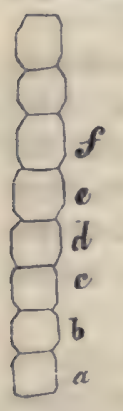
fticfiftoffbaltige Subftanz entbält, als bie untere, jo miro zuerfit a

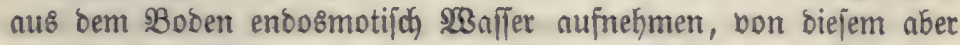
alsballo einen aheil an $b$ abgeben. Nun verabfolgt $b$ Fłüfligkeit an

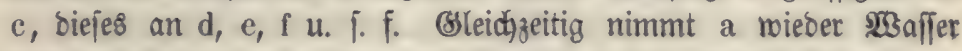
aus bem Boben auf. So entiteht ein fortwährender Saftftrom von

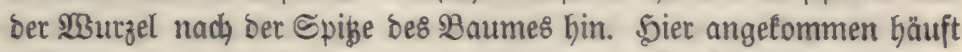

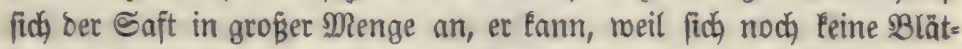
ter entmicfelt Gaben, nicht burch Berbunitung auళ bem Baum ent= meichen, uno bie Epannung roädfft immer mebr, ba ber grö̈̈ere Bsebalt ber 3ellen an 3udfer, Degrtrin und ftidftoffbaltigen Sub=

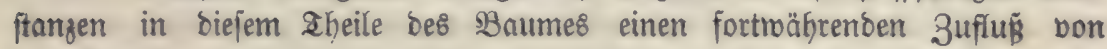

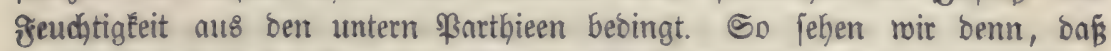
ber Saft mit grofier Bsewalt ausftrömt, jobalo woir einen 3weig abjojneioen.

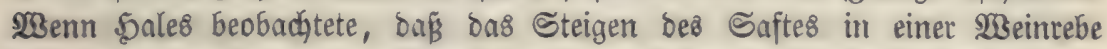
mit einem Druct bon $2 \frac{1}{2}$ Altmojphären bor fich gehe, jo fintet bies in ber

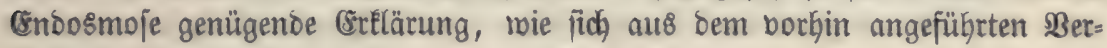
juche bou Dutrodget exgibt.

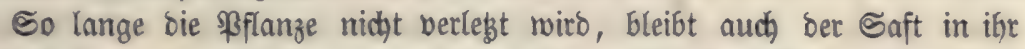
zurüagehalten, aber bie હpannung bauert fort. Sie berwirlt, baß̈ ber ङaft

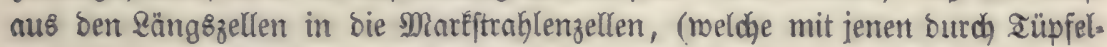
D̈frungen in Berbindung ftehen) Gineingepreß̈t wirb; nun fofminoet ber $3 u=$ fammentyang ber Marffitrablenzellen an ber Stelle, wo bieje 3ellen am

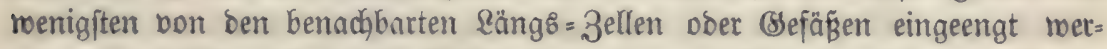

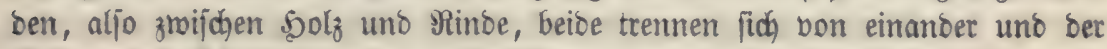

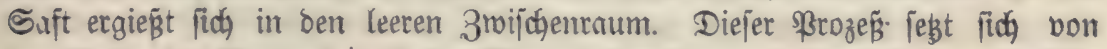

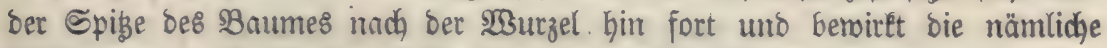
rricheinung, als ob ber Saft eine eigene rüdéläufige Benegung bon oben nad) unten befize.

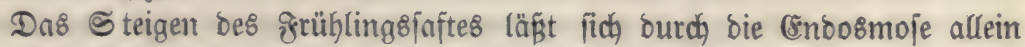
ertlären; nicht jo bie mähreno ber übrigen Begetationszeit fortonuernoe (st= hebung bes Snfteళ von ber 13 urzel nach bem (Sipfel bin. (58 mü bier

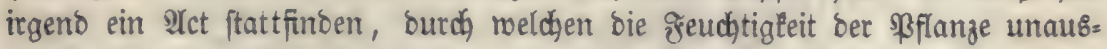

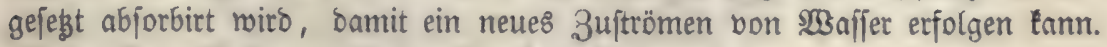
Diefen $\mathscr{2} c t$ erblidén wir in ber $\mathfrak{B}$ er $b$ un fitung.

Denfen wir uns die an ber Dberfäđdje ber Blätter uno grünen Stengel

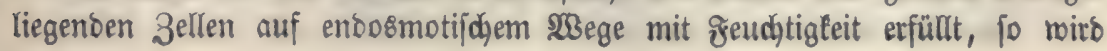


biefe burch ben Berbunftungsprozes berminbert werben; e\& befinbet fich jest

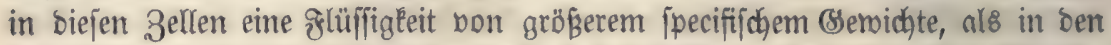
angrenzenben Zellen, bieje merben aljo greuthtigleit an jene abgeben. În ber

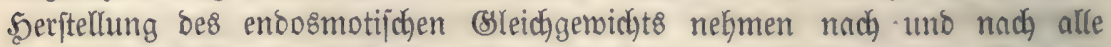
Bellen bes $B$ numer 2 nntheil, weldye mit ben oberen in Berbinoung ftehen;

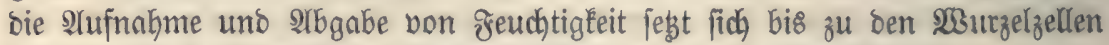
fort, welche ihrerfeits bie Freuchtigkeit aus bem Boden empfangen.

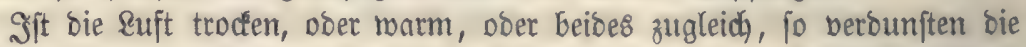
(Semächje mehr Freuchtigkeit, als unter entgegengejebsten Berbältniffen. Sann vom Boben aus Eein (Srjał bes verdunfteten Saftmaffers erfolgen, etron meil

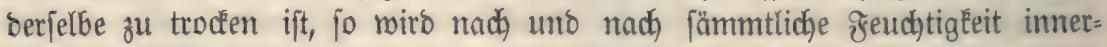

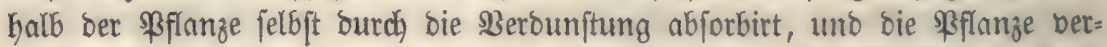
melft. Der ado tritt um fo fchneller ein, je größzer die Arnzahl ber beroun= ftenden Drgane (BRlătter $3 c$.) ift.

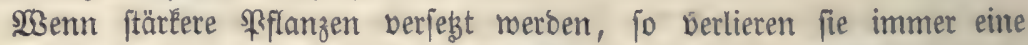

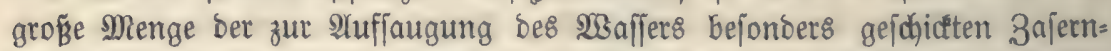

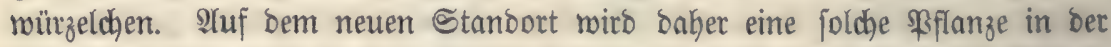
nämlichen 3eit nicht fo viele Geuchtigkeit aus bem $B$ oben aufnehmen können,

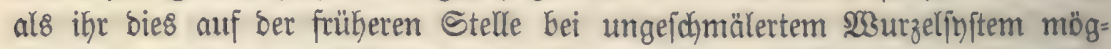
(id) war. aritt nun ein trockener, bie Berbunjtung begünitigender Sommer ein, fo geben bieje Pflanzen zu Brunde. SBill man fie retten ober gleids

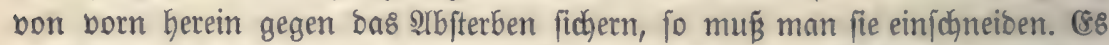
entwideleln fich Dann nicht po biele S3lätter, als menn alle 3meige erfyalten ge-

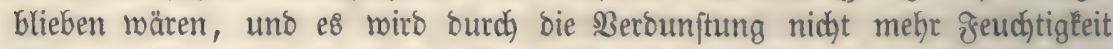
hinweggenommen, als bie menigen $\mathfrak{3} u r z e l n$ zuzufüfren vermögen. Das

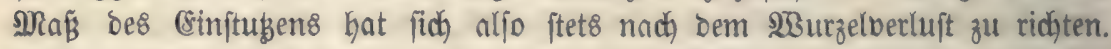
Daher erelärt e\& fid benn aud), marum \&aubbolźftummelpfinnzen faft immer ficherer anjhlagen, al\& foldye mit ganzem @d)afte*). - Dert nämlidjen Effect erzielt man, menn man e\& bahin bringt, baßß ber $\mathfrak{B}$ aum an benjenigen

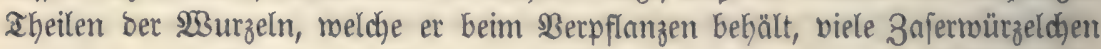

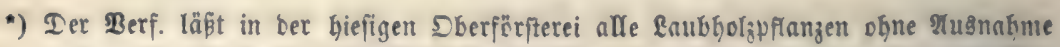
einftuben, und zwar merben fie in ber Regel ganz abgeworjen; nur für Froptftellen, auf weldyen inmer frärfere sfftanzen bermenbet werben, bleibt ein Stü beళ

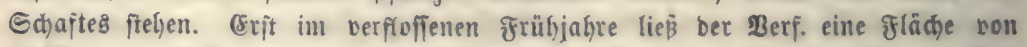
60 Morgen mit Buctenfitumuelpflanzen, meld)e 2 centimeter über bem Boben abge= morjen morben waren, befflanzen; tiefe (5ultur zeigt ein rorzüglides Beteiben. -

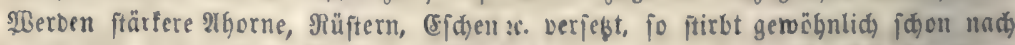

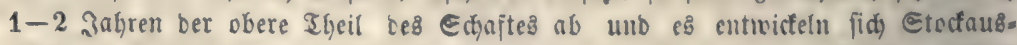
(ळ) äge; nıan ifit bann genštbigt, bieje zu entfernen, ober ben nbgeitorbenen Theil

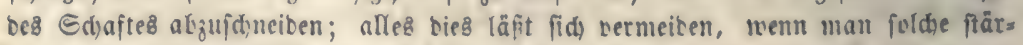
fere Stämmd)en gleid) von vornberein tüd)tig einftubt, ober, mas nod beffer ift, über bem $\mathfrak{B u r z e l f t o c t ~ a b w i r f t . ~}$ 
austreibt; bies gelingt ant beften in ber $\mathfrak{B S e i j e}_{\text {, bn }}$ man $1-2$ Jahre bor bem SBerpflanzen bie Sauptmurzeln in paffender (sntfernung bom Stamm

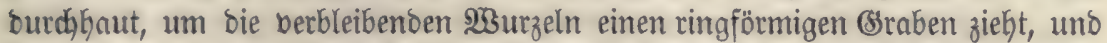

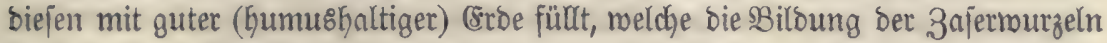
begünftigt. Diefes Słerfafren ift aber mur bei foftbaren Ctämmen, Dbftbäu= men ac. anmentbar.

Da bie 2luffaugung ber Bobenfeudftigleit hauptjächlich burch bie feinen

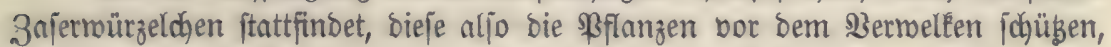
fo muß̈ auf ifre Erzeugung alle Sorgfalt bermanot merten. Beim $\mathfrak{B e r}=$

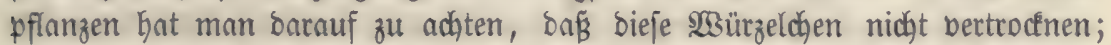
benn ift bies einmal gejohehen, fo können fie ifre Functionen nidjt mefhr ber= ridyten, uno bie Sflanze leibet jo lange, Gis fie roieber neue Zajermürzeldyen gebilbet bat, borzugsmeije burch trodine $\mathfrak{B}$ itterung.

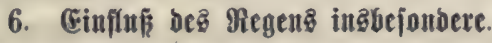

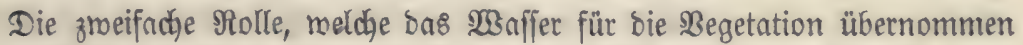

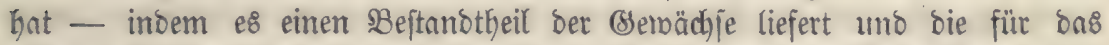
Reben nothroendige Menge Saftfeuchtigéeit bejchafft - wiro vorzüglich burd, ben

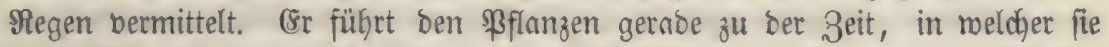
am meiften freuchtigkeit bedürfen, alfo im đrtilfjabr uno Sommer, bas $23 a$ affer

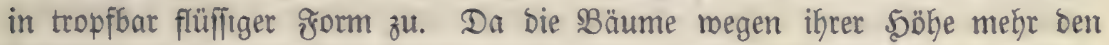

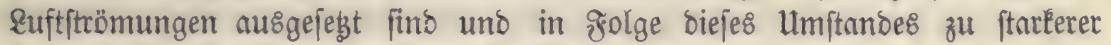
Berbunjtung angeregt werben, fo find die Regenniederjhläge gerabe für bie

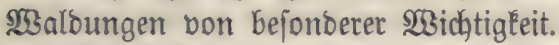

Die günftige 2 Sirkung Deళ Regens für bie \$egetation wird beftimmt

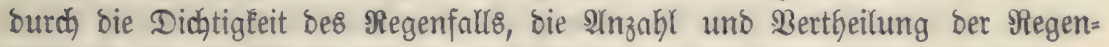

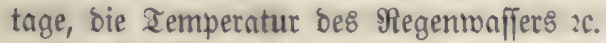

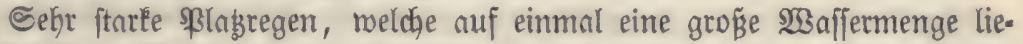

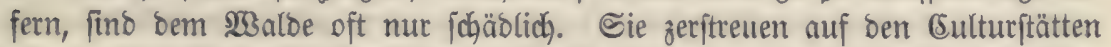
bie mit keiner ftarken Grobebectung verfebenen Eamen, namentlid auf ๔and= boden und Bauland, jhrnemmen auf geneigtem Terrain bie Eamen in bie Tiefe

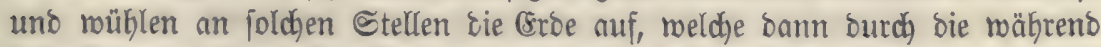

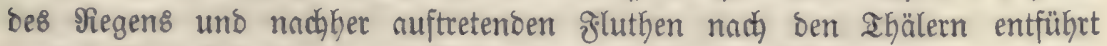
wirb. Banz bejonbers berberblich) metben bie \$lagregen ba, wo eine geneigte

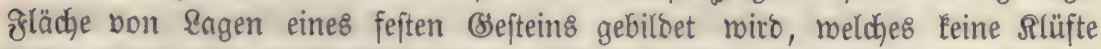
befist, burdh bie bas $23 a f f e r$ nach ber riefe abziehen fönnte. Sier bleibt alles Regenmaffer auf ber Dberfläche uno erzellgt oft in ganz kurzer 3eit badjäbn=

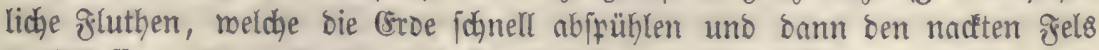
zurüctaffen. Dieje Sadjtbeile lafjen fich ba, mo bie Mittel vorbanden find, in Der $\mathfrak{W}$ eife auf ein geringere\& $\mathfrak{M} \cap \tilde{B}$ zurüdfführen, baß̄ man an foldhen Bergmänoen Gorizontale Ternffen mit Bräben anlegt, weldhe bas 233 affer feit=

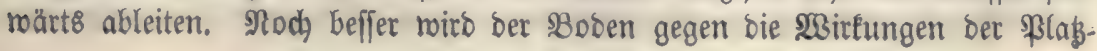


regen burdh bie $\mathfrak{W a l b u n g e n ~ g e f d u ̈ h t , ~ w o b o n ~ w i r ~ a n ~ e i n e m ~ a n b e r n ~ D r t e ~ a u s = ~}$ fübrlicher bandeln wollen.

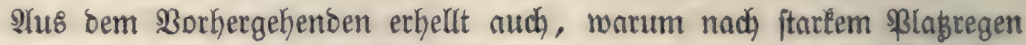

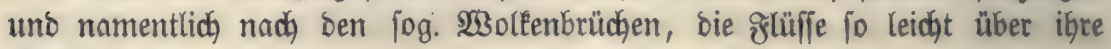
Ulfer treten.

Die fanften Stridjregen, weldye keine groß̋e $\mathfrak{B a f f e r m e n g e ~ a u f ~ e i n m a l ~}$ bringen, mirḱken jełr günjtig auf bie Begetation, wenn fie längere Zeit an= bauern. Sie bringen nach) und nach in ben Boben uno bis zu beträdhtlicher Diefe ein, ofne ifn zu verwunben; baburch werben bebeutende $23 a f f e r m e n g e n$ im (8roreich) aufgejpeidhert, weldhe bei nadhfolgender trodener $233 i t t e r u n g$ ben Semächjen nachbaltig zu Sute fommen. $320 n$ geringerem Nugen find bie Staubregen, zumal, wenn fie nur kurze Zeit anthalten; gemöbnliơ bringen fie nidyt tief in bie Brobe ein, ober berflächen fich auf ben Blättern ber SBäume.

Branz bejontors wohlthätig für bie Begetation icheinen die Bemitterre= gen zu fein, wie fich an Dent frifcheren (Srün, welches bie SSerwächfe faft augen=

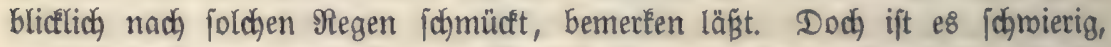

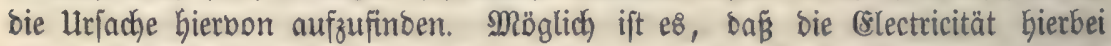

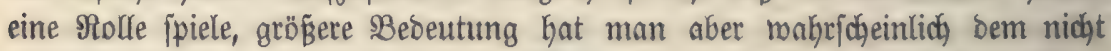

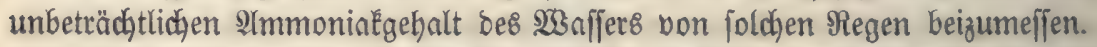

Iuch) bie vermehrte \&uftfeuchte, meldye noch längere 3eit nach Beendi=

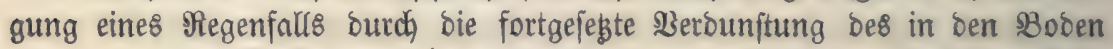
eingebrungenen $\mathfrak{B a f f e r}$ erzeugt wiro, übt einen rohlthätigen (sinflü auf bie 23egetation au8.

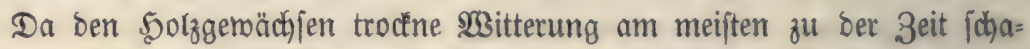
Det, in weldger ifre SBlätter uno Nabeln borzüglid) zur Berounftung ge=

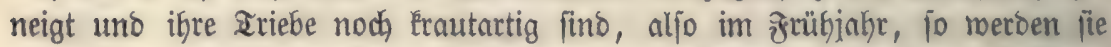

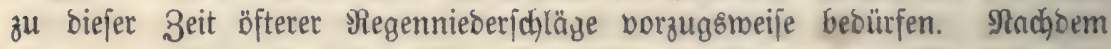
einmal bie (5uricula fidh gebilbet hat, läß̈t bie Berbunftungsfähigkeit nad), uno nun tönnen fie fid fichon eher bei trodnem sBetter erbalten. Im berbjte, wenn Die Rraft bes begetntiven Rebens fidd) verminbert, wiro ein

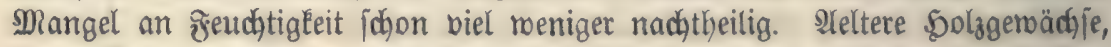

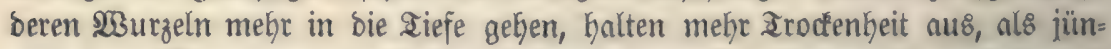
gere, beren $2 \mathfrak{B}$ urzeln nody nicht fo tief eingebrungen fino, ferner tiefrourzelnoe, wie

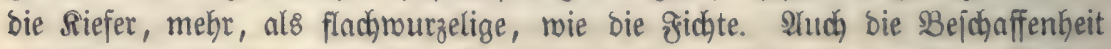
bes 3 obens ift hier von sinflus. Bobenarten, weldje pine grofie wafferhal= tenibe Sraft befitzen, wie z. B. Der Sehm, beoürfen jeltener ber Befeuchtung, als (Erbarten, welche leidjt austroçnen, wie z. B. Ser Eanb. 2Uf tiefgrünoigem Boben, weldyer ben \$olzgewädbjen geftattet, längere $\mathfrak{2 3 u r z e l n ~ z u ~ b i l d e n , ~ b a u e r n ~}$

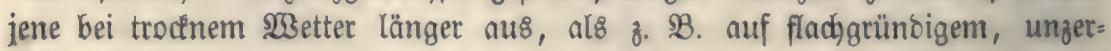
Elüftetem ซ̌els.

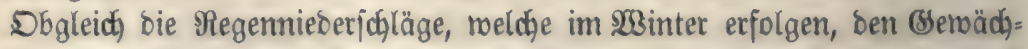
fen nidht augenbličtich. zu Sute Fommen fönnen, fo geben fie barum bod 
nicht ganz für bie \$egetation berloren. Denn bie Winterfeudjtigkeit fammelt jich im Boben an, fie fteigt im frübjabr uno Sommer, wenn bie oberen Ero=

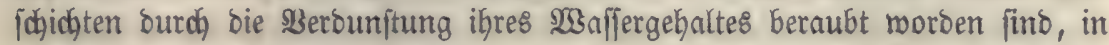

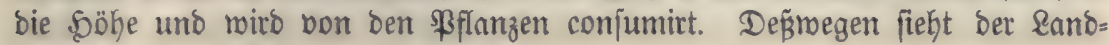

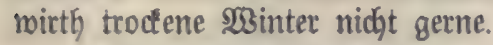

Die \$olzmaffenprobuction einer \&ocalität miro nicht gernoe burch eine

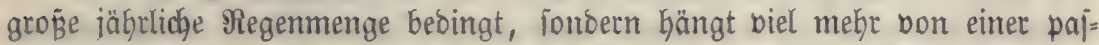

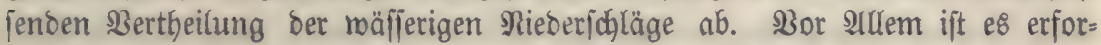

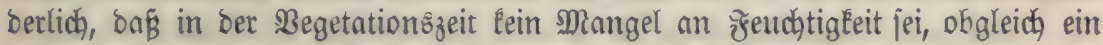
Ueberman eben jo jehr jobabent tam, weil in biejem Falle bie Iemperatur

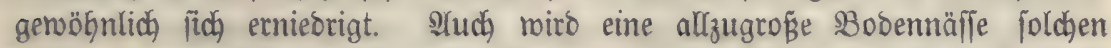

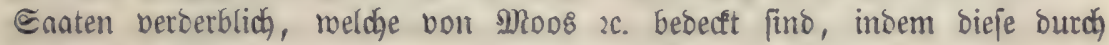
รăulniñ ไeioen.

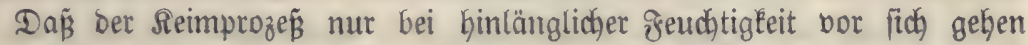

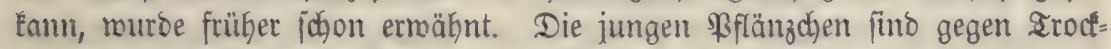
niß̧ bann am empfindlidjiten, wenn fid) eben bie Blätter ber (Eoty)lebonen

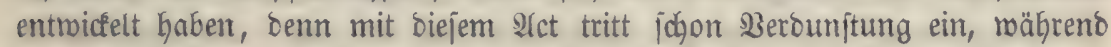

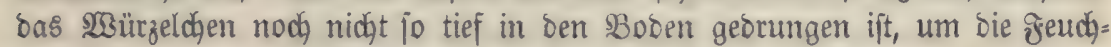

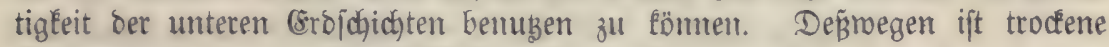

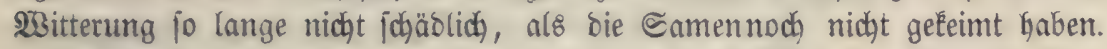

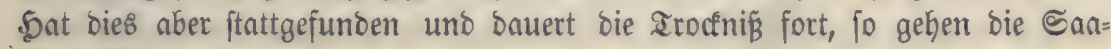
ten leidgt zu Brunbe.

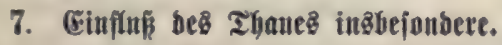

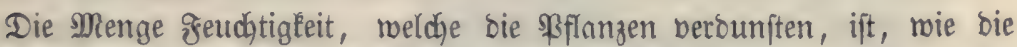
früher mitgetheilten Berjuche ๔atleiben's uno Echübler's zeigen, nicht unbe=

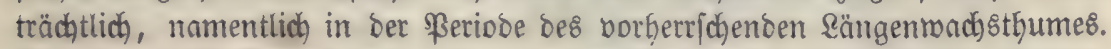

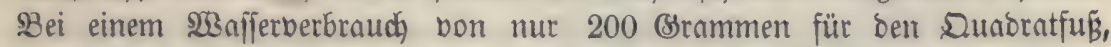
wie Edhleiden beim Safer und Rlee beobadgtete, mürben innerbalb 24 Stun=

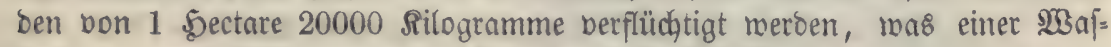

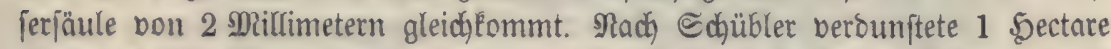
Raịen täglich 100000 Silogramme, entipreçeno eimet $\mathfrak{W a j f e r j a ̈ u l e ~ v o n ~} 10$ Millimetern.

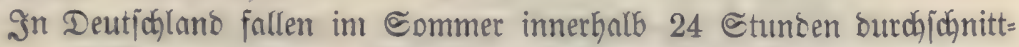

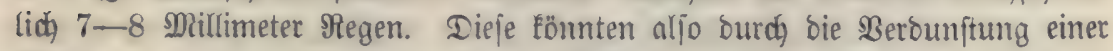
WBieje in meniger al8 einem Inge abjorbirt werben; nachber würbe e\& an

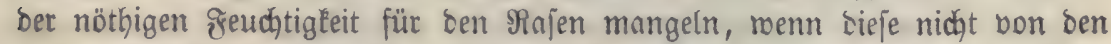
tieferen (srbjojichten bejchnfft müroe. Allein gar oft trodfnet im ๔ommer, wenn

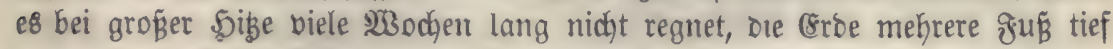

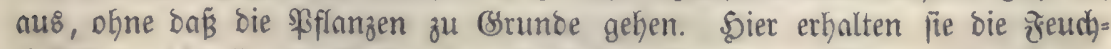
tigkeeit, meldhe fie zur Berbunftung kebürfen, Durd) ben Shau. Die Bebin= gungen für bie Billung beffelben find im borbereitenden Iheil bargelegt noorben. 


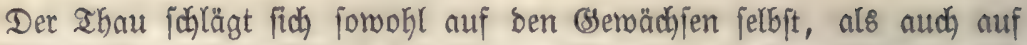
bem soben nieber, aber ftets in reichlicherer Menge auf exiteren, namentlich ben grünen aheilen berfelben, meil biefe ein grö̈̈ere\& 23 ärmeausftrahlung:

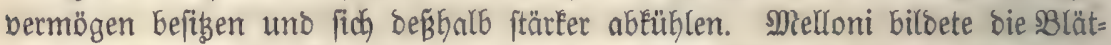
ter von Ulmen und Bappeln aus blankem Metalfblech) nach) und feste jene, roie bieje, ber nädtlichen Straflung aus. Die Temperatur be\& Metalls blieb untberänbert, biejenige der grünen $B$ lätter fan $3^{0}$ unter bie ber umgebenden

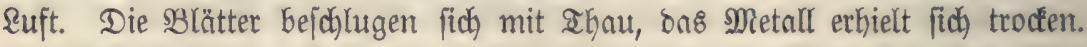

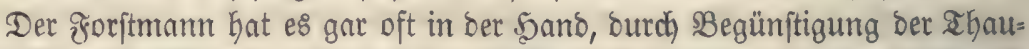
nieberjchläge bie \$flanzen mährend der trockenen Sommermonate zu erbalten.

Sn ben Şerjüngungsiçlägen betleiben fich bie Mutterbäume, menn e\& Raubhölzer find, leidjt mit Sdjaftloben (Wrafferreifern), in ร̧olge ber freieren Stellung uno bes auf Den Schaft fallenoen Sonnenlidytes. Dieje Sdyaft= loben merben auf trocfenen Stanoorten bem Interwuctbs fobäblich; wie man gemöhnlich jagt, baburdh, bas fie ben jungen Pflanzen ben Ihau rognehmen.

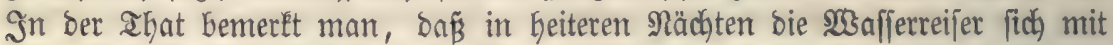
Ihau bejchlagen, währeno ber Unternudys tročen bleibt. Die Beobachtung ift richtig, aber bie bon ifgr gegebene refflärung eine faljche.

\section{ঔigur 151.}

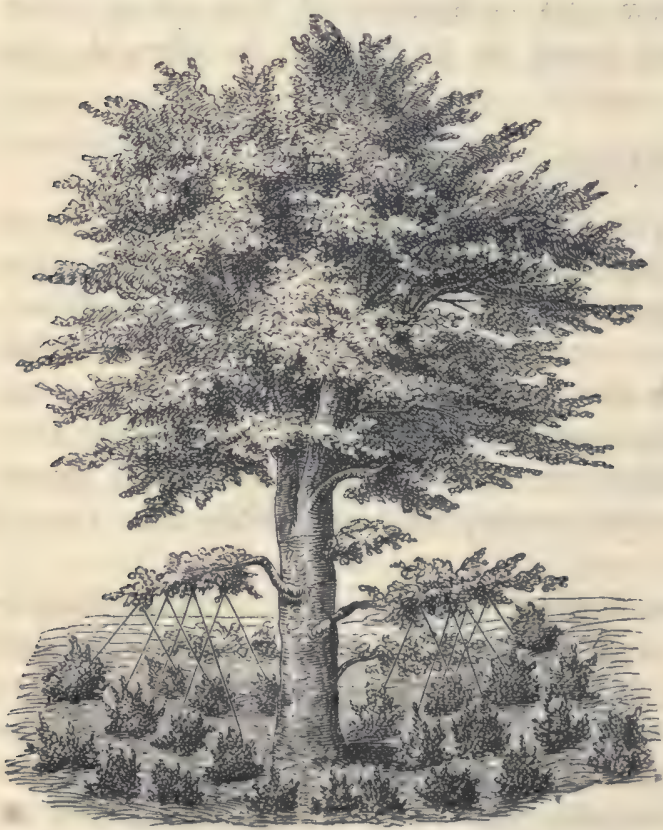

Wie wir früber jaben, liegt eine unerläß̈liche $\mathfrak{B} e$ oingung für bie SBilbung besీ Tyaues baxin, baß der zu bethauende (segen= ftand eine nieberere Semperatur, als bie umgebente suft an: nimmt. Bei ben Pflanzen miro bieje Bebingung baburd' Yeidyt erfüult, weil ibr $2 \$ 3 a ̈ r m e n u 8=$ frahlung8verntögen basijenige Der \&uft übertrifft. Befinbet firch aber über ber ßfflange ein (regenitant, weldher bie aurge= ftrablte 2Bärme wieber reflectitt, fo tann fie fich nicht bis fum Thaupunt abeüflen. In biejer WBeife- mirft \&. $\mathfrak{B}$. Der bebecte Simmel, reébalb eв bei biejem nidjt thaut. Den nämlidjen Effect bringen bie Sdbaftloben Der Nutterbäume in ßerjün=

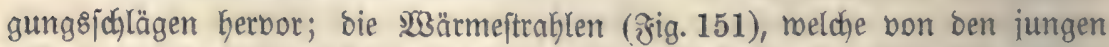
sflanzen ausgehen, werben wieber auf fie zutüdgeworfen; ifre remperatur

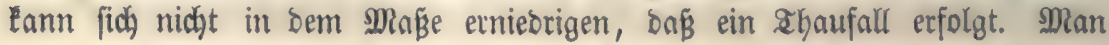




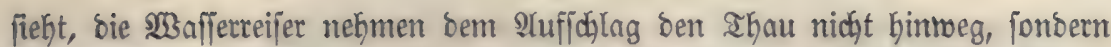
fie erhalten die Pflanzen über der zum (sintritt bes IGaupunfts nöthigen Temperatur. WBill man biejen Mip̈ptand bejeitigen, jo hat man bie MBaffer= reifer zu entfernen. Die Snftrumente, rolche fid) hierzu eignen, werben im 23albbau bejdyrieben.

Dft fichon hat man bie Beobachtung gemadht, Daß Pflanzen auf bera= ftem Boben und trodenem Standort nidht gebeigen, bafi fie fich aber mieder

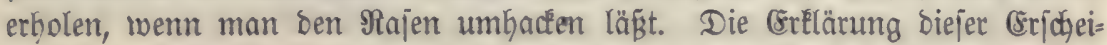

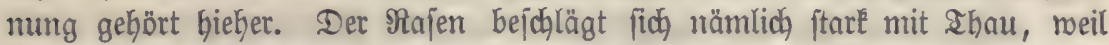

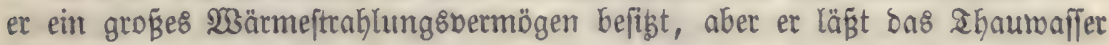
nicht bis zum Boben gelangen und in ihn eintoringen; fo bleibt biejer troden.

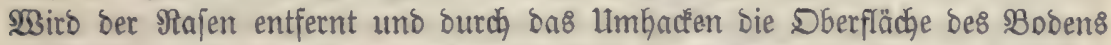
gleichzeitig rauh gemadyt, fo erhält bie (5roe ben Ihaunieberjojlag unmittelbar uno, meil raube Rörper mehr $\mathfrak{3 a ̈ r m e ~ \delta u r c h ~ S t r a b l u n g ~ v e r l i e r e n , ~ i n ~ r e i d s ) = ~}$ licjerem Maß̧e.

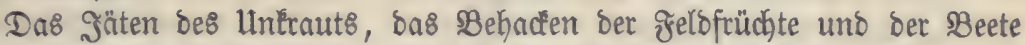
in ben כroriftgärten hat ftets vermehrte \$hauniederjobläge auf bem Boben im Befolge.

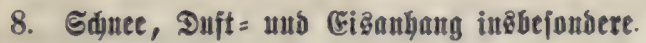

Wrie im $\mathfrak{B}$ orbereitenten Theile angegeben murbe, erzeugen fid Sdhnee

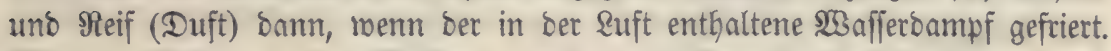

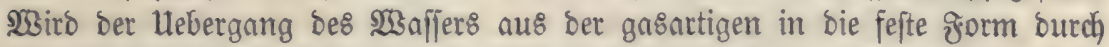

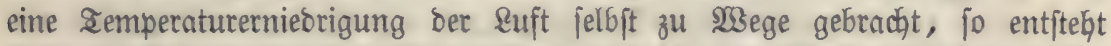

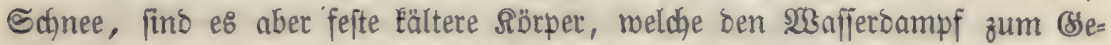
frierent bringen, fo nennt man bas 2lggregat bon Bisteryftallen, weldber fidh an ifnen anlegt, Duft, Seif, গaubreif $2 c$.

Der (risanfyang entîteht bann, wenn ber Wafferbampf Der Suft fich an

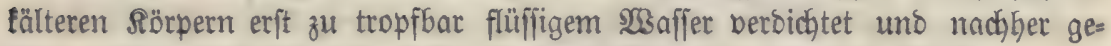
friert. Gr enthält leine Sityftalle, fondern biloet eine amorphe Maffe.

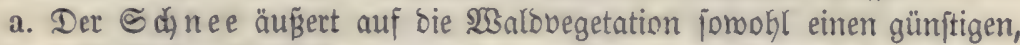

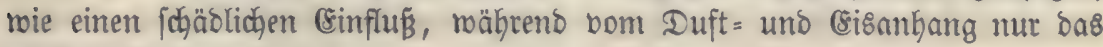
legtere gejagt werben fann.

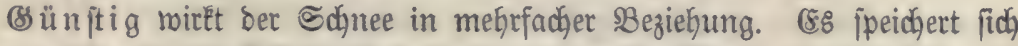

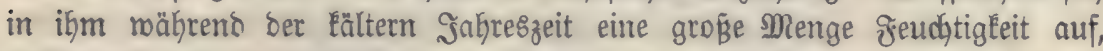

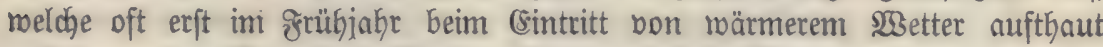
uno bann bem Boben bie für ben Sommer erfordertiçen säffe verteiht. $\mathfrak{A m}$

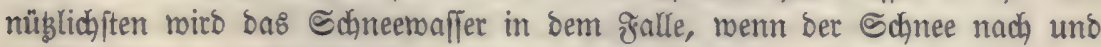
nach) aufthaut, wäbrend ein rajober Albgang beffelben oft (srbabjpühlungen

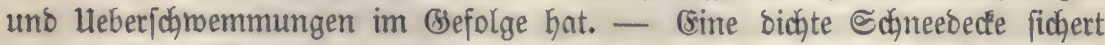
bie jungen Pflanzen in Beriünungsfolägen gegen bie Bejōäbigungen, melche biejelben beim 2̂tbtreiben, Aufarbeiten uno Iransportiren bes \$olzes 
erleiben Ë̈nnten, unto biejer Bortheil madyt fich namentlid, ba geltent, wo

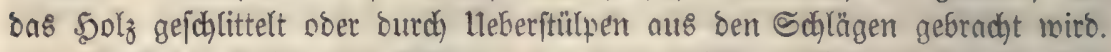

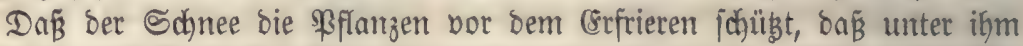

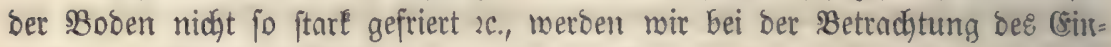

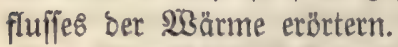

Die fwäblichften $233 i$ kungen bes Sdhees beftehen in bem jogentann=

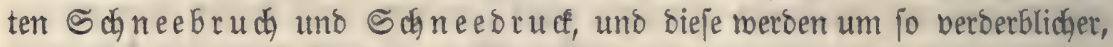
menn fich bazu nodh Duft= und (sisanthang gejellen.

Sdhneebruds und Saneebruct, unter meldhen man bas Umbrechen ober Ummlegen von einzelnen Bäumen ober ganzen Baumgruppen verfteft, treten für fich alleir nur bann ein, wenn ber Sdynee, menigitens bon vornberein, in

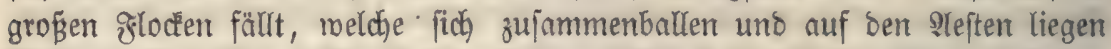
Gleiben, währeno ber bünnflocfige Sdynee keinen Salt auf oen Zmeigen finbet, aljo auf biejen fich nicht in größgeren Quantitäten an häufen Eann.

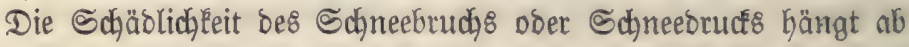

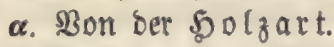

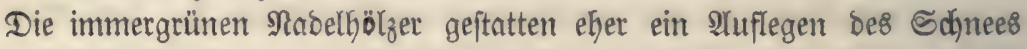
auf ben benabelten 3weigen, als bie zut Zeit bes Sdjneefalls knhlen \&aub= bölzer uno bie Rärche. Déprogen ijt aud ber Edyneejchaden bei biefen un=

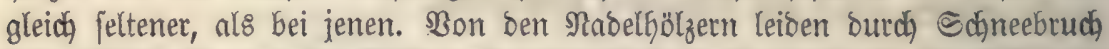
am meiften bie gemeine Riefer uno bie Schnarzfiefer, meil fie ein brüchiges \$olz befigen.

\section{B. Bon bem Solzalter.}

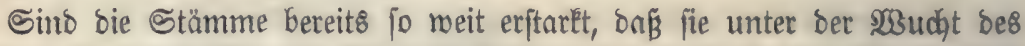
auf ifynen laftenden Sahnees fid nidjt biegen können, fo werben fie entweder

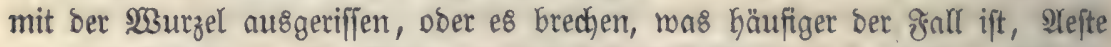
Doer ber Schaft ab. Die Stelle, mo lebsteres gejojiefht, liegt, je nady ber Stärké,

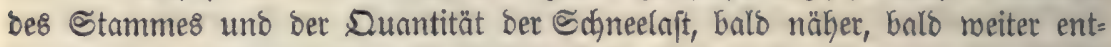
fernt bon ber Spize. SBei fefre ftarken Stämmen werben oft nur bie Sipfel ausgebrochen, währeno bei bünneren Stämmen bie SBruchftelle felbft bis zu

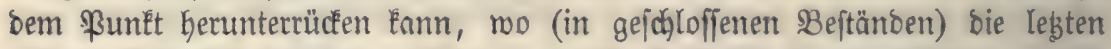

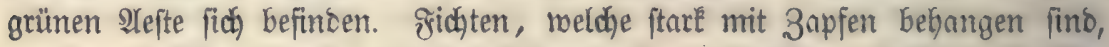

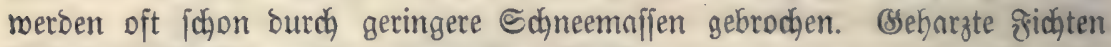
berften gemöhnlidy an Den augelnditen Stellen.

In jüngeren Beftänden, in weldhen bie Bäume nody bidhter ftehen, bres chen ebenfalls entmeder einzelne ๔tämme, ober e\& werben ganze Baumgrup: pen, bie oft eine flädje von mehreren 2 ren bis zu $1 / 8-1 / 4$ Sectare eimmehs= men, vertheilt burdh ben Beftano hin, zu Boben gebrüat, robei aber gemöhn= lid) einzelne Stangen aud) gebrodjen werben. In Bsertenjÿlzern legen fiod aber oft ganze Beftänbe unter ber $\mathfrak{2 3 u d a t ~ b e s ~ S c h n e e ' s ~ n i e b e r , ~ o b e r ~ e s ~ b r e c h e n , ~}$

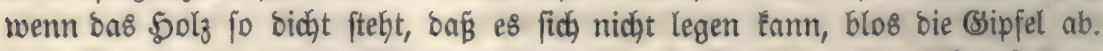
Quff ftar geneigten Flächen uno im \$od)gebirg, too ber Sdyneefall an 


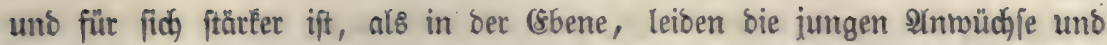
(5ulturen bäufig burdh ben jogenannten ङ Gier, namentlid, menn ex zu thauen anfängt, in eine nach abmärts gehenoe Bewegung unb brüdft babei bie \$olzpflanzen, meldge er überlagert, in ber

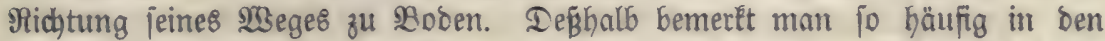

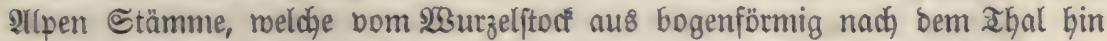
gefrümmt fino, währeno ber Schaft meiterhin getabe in bie Söhe fteigt.

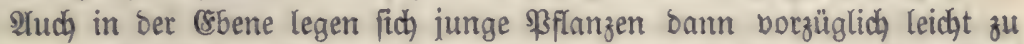
Boben, wenu zroijhen ignen tin ftarter (Srasmudgs ftattfinbet. Das Bras wirb bom Sdhnee gebrüdt uno nimmt bie \$flarzen mit zur Ẽrbe Gernieber. Eäpt man bas bras im 5erbjt, wo es fu Streu redht gut vermenbbar ift,

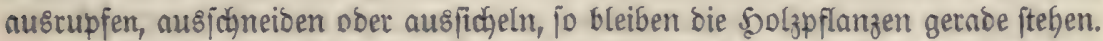

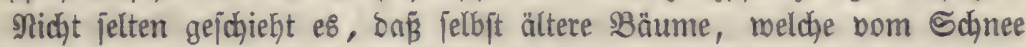

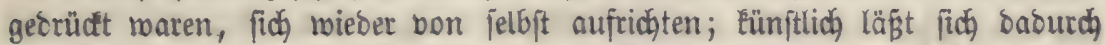

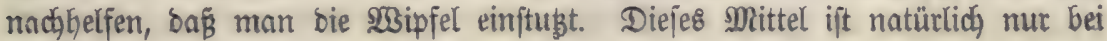
Eaubbolz von \$agen.

r. Bon ber Meereshöhe.

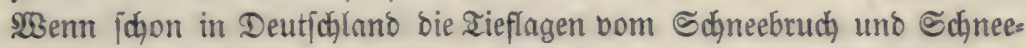

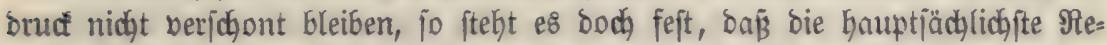
gion bes ๔djneejd)abens zmijdjen 300 uno 800 Metern Meereshb̈he begriffen ift. 23eiter hinauf find bie $B$ eftänoe ichon gepicherter, weil in ben 5odhlngen

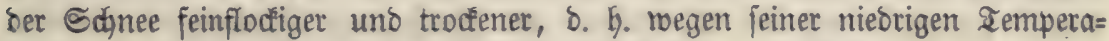
tur meniger zum Sdymelzen uno Zujammenballen geneigt ift.

d. Bon Der Erpofition und bem 2 inde.

Iuf Sübjeiten wirb feinflodiger Sdynee leidjter von ben Sonnenjtrablen

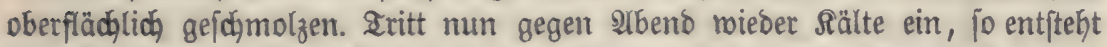
eine fejte Irujte, auf reldyer eine grofie Menge Sdhnee fïh ablagern Eann. -

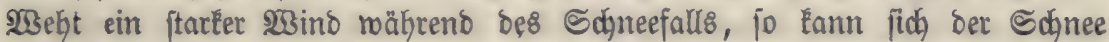
auf ben 2leften nidat anbäufen, meil er beitänoig abgejdüttelt mirb. Dod, leibet in biejem galle auf hügeligem ober bergigem Ierrain oft ber bem $\mathfrak{W}_{\text {in }}=$ zuge entgegengejejte (sinhang, uno zroar gernoe beßhalb, weil et bor bem Minde gejdübt ift. Diejer treibt nämlid, wenn er an ber $\mathfrak{B}$ ergmanto Ginauf=

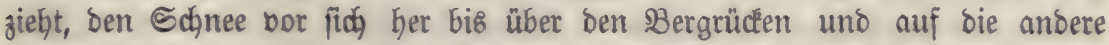
Geite bes 2165ang8, no ber Sdhnee mit aller 234 dht auf bie Bäume brüdt, meil ber jest nadjlaffente $23 i n d$ ifn nidht zerftreuen fann. - Stellt fich bet WBind exft bann ein, nadjoem bie $3 B$ äume bereits mit Sdqnee (namentlid) feft= gefrornem) belaben find, fo ift bie Bsefahr bes ๔dhneebruchs größ̈er, weil jebt burdh) ben bie Seite getüat betben Eann.

8. Bon bem bidgteren ober lideren @tand ber $\mathfrak{B}$ äume, bet $\mathfrak{B a} a$ lobehandlungsart 2 .

Die 9 äume roberftehen bem Sdhneebrud uno Sdyneebrud um fo eher 
je kräftiger fie ermadjen fino. Da nun bei mehr freiem Stanbe bie Sdjäfte

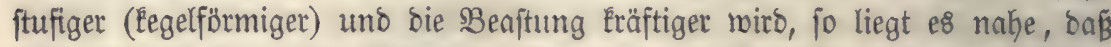
bicht aufgefd)offente Saatbeftänbe, mögen fie auf künftlichem ober natürlichem

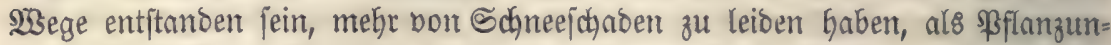

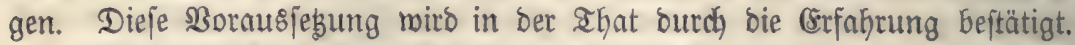

Siernus laffen fich bie Mittel ableiten, meldye man zu ergreifen hat, um

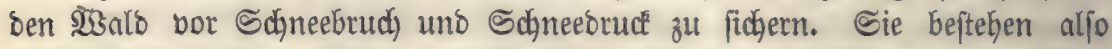

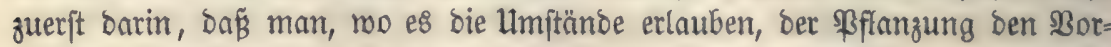

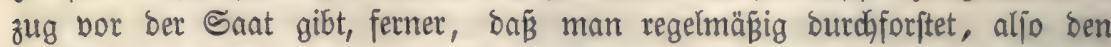
श्A

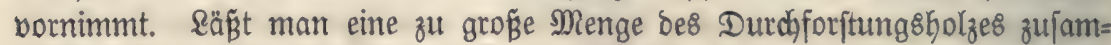
mentommen und wiro biefes náchber auf einmal genught, fo legen fich bie übrigbleibenden jdymanken Stangen jołon burdh bas eigne Bsemidat um; mie viel mełr alio, menn fie nody mit Sdfnee belajtet find. Nur ba, mo bie Durchforftungen in gröB̈eren 3eitinterballen ausgeführt merben, fam es

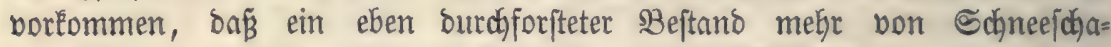
Den leibet, als ein nicht burchforfteter. - Mijchbeftänoe von foldjen Solzarten, weldye eine verichiebenartige Beaftung befigen, wiberjteken bem Sdynee leidyter, als reine Seftänbe, benn in eriteren find Dem Sinzelftamme bie Bebingungen zu einer Fräftigeren Entroičlung geboten. So hat man be=

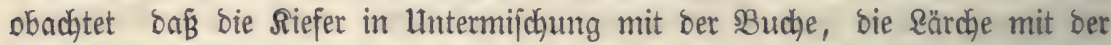

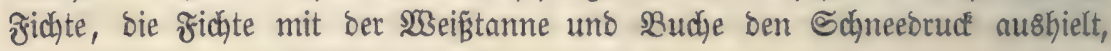
ohne bejoßjobigt zu werben.

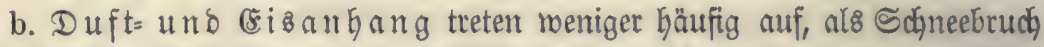

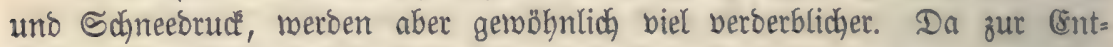
ftefung Des Reifes und (SLatteifes erforberlich ift, Daßs bie remperatur ber

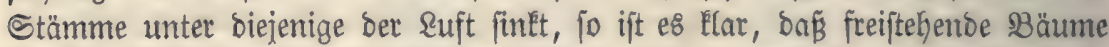
mefr vom Duft= und sizantyang zu leiben Gaben, als foldhe im geidjloffenen

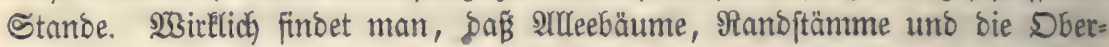
ftänoer in Mittelmaloungen biefen beiben Meteoren vorzugsweife unterliegen.

Die Mapregeln, weldje man anwenden muß, um bie ફolgen bes Duft=

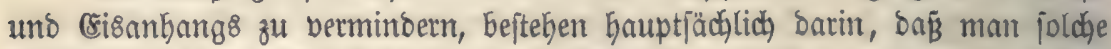
Betriebsarten vermeibet, bei welchen bie Bäume freiftehend erzogen merden (Mit=

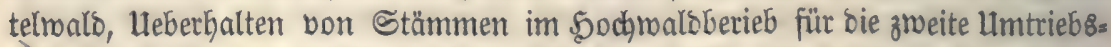

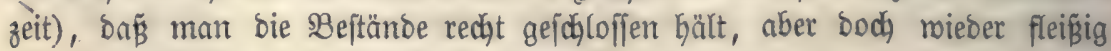
genug burchforftet, um einen möglichft fräftigen $\mathfrak{B a u}$ ber (sinzelftämme zu erzielen.

Arlle bieje Borḱehrungen bermögen aber nidjt, bie Beftänoe gegen ben

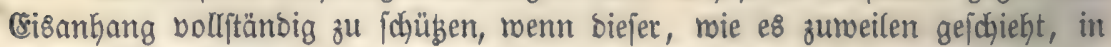

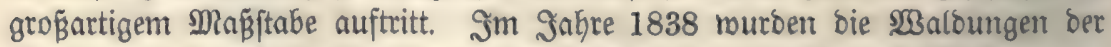

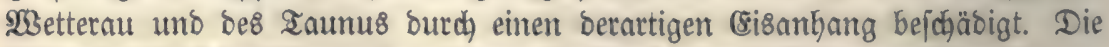
Eiszapfen, weldhe fidh an ben 2leften ber 38 uchen uno Gidyen anjebten, batten 


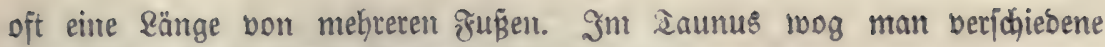
Repte uno bas an ifnen hängende (sis unt fant:

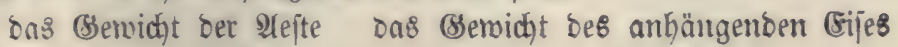

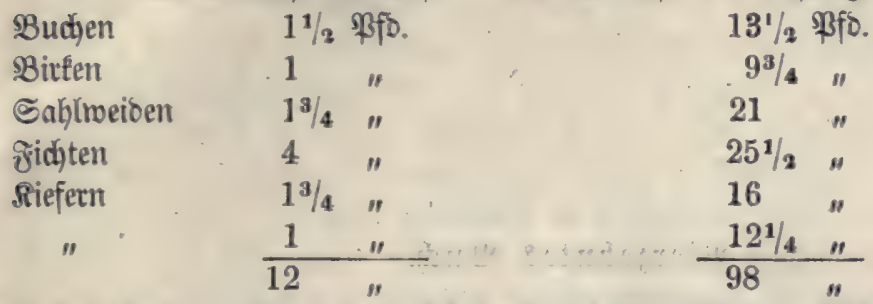

Das 50 lz trug aljo Das 8-9 fache jeines Betvichtes an (sis.

Denft man fich nun alle $\mathscr{Y}$ ejte eines 8 aumes in biejer $23 e i j e$ mit (Eis überzogen, jo begreift man, baßi jelbft ber ftärfite Stamm einem joldhen (Sis= anhang Keinen $23 i b e r i t a n \delta$ zu leijten vermag.

\&uftzug berfindert bie Biloung bes Raubreifs und bes Blatteijes, in= bem bie närmere \&uft bie Temperatur ber Eälteren Iheile bes Baumeళ, mit meldhen fie in Berührung Eommt, erhöht. Şat aber ber Duft= uno Sisanhang fich) einmal erzeugt, bam bermehnt ber $23 i n \delta$ bie Befahr, inbem er ben Sdawer= punft bes belajteten SBaumes auf bie Seite juiebt.

Dem Duft = unt Eisanţang fïto nicht blos bie Nabelhölzer, fonoem audh) bie Raubbolzarten ausgejest.

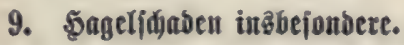

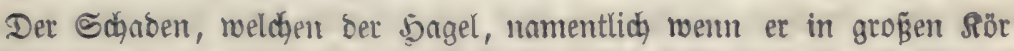

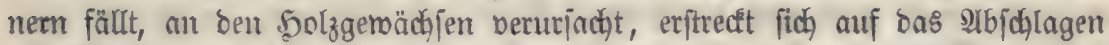

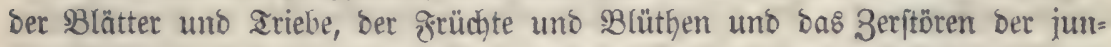

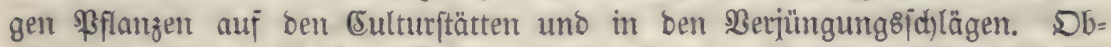

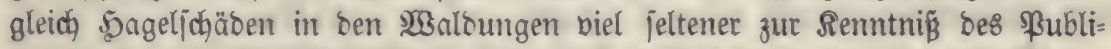

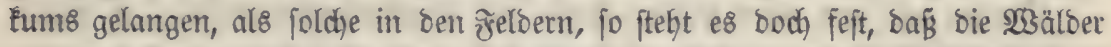

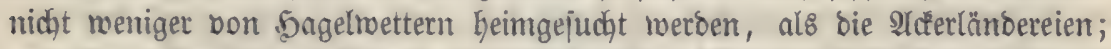
nur ijt ber Berlujt auf lebstern gewöGnlich viel größ̄er, meil jelbft ber einiährige

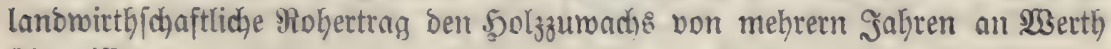
übertrifft.

Bei ber zneifelhaften Entitefungsont bes நagels bält e\& fodmer, ein

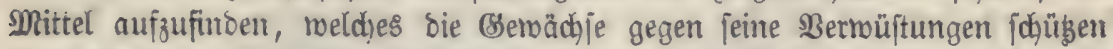

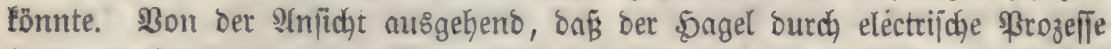
Gerborgerufen werbe, hat man an manchen Drten Stangen, ähnlidh ben $\$ B l i b=$ ableitern, aufgerichtet, um bie Electricität zu entfernen. Dieje Borriḑtung ift

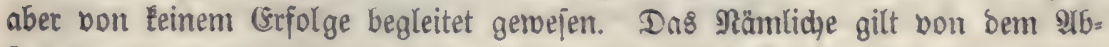
fettetr bon Ranonen ic. 


\section{Bierzebntes $\mathfrak{B}$ ud.}

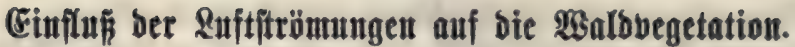

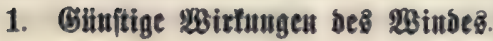

s. Suftwedfer.

Mie früher gezeigt murbe, entnehmen bie (Semächje ber \&uft zroei me= fentliche Nahrungsftoffe - bie Rohlenjäure und bas Âmmoniat. Da beibe nur in begrengter Quantität in ber 2ltmojphäre entbalten find, fo roürben bie sffanzen bald ifre Umgebung bon biejen zmei Gajen gereinigt Kaben, wenn nicht fortwähreno eine 3ufubr bes berbrauḑten Platerials ftattfänoe. Diefe miro berwirft Durch bie Diffuifon Der Baje, in meit böherem (srabe aber burch, Den $\mathfrak{B}$ Bino.

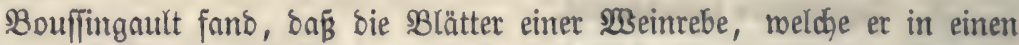
8Lasballon eingefübrt hatte, bie suft fajt gänz̧lich iłres Rohlenjäuregehaltes beraubten, wie grof aud bie Bejdyminoigleit Der \&uft roar, roeldye er ben

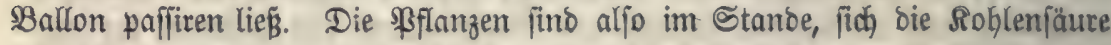

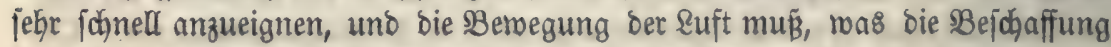
ihres Sauptnahrungsftoffi anlangt, günjtig auf fie eimbirken.

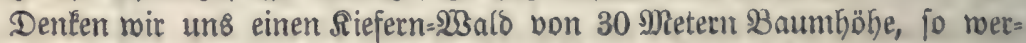

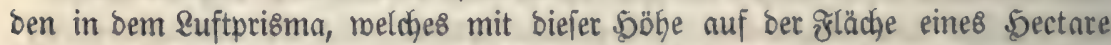
fich aufbaut, 234 Rilogramme Rohlenfäure und in biejen 64 Ril. Soblenjtoff

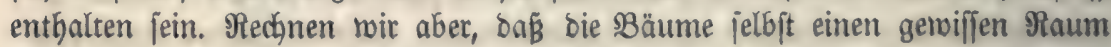
einnebmen, ben wir beiläufig ž 310 cubitmetern beranid)lagen wollen, fo

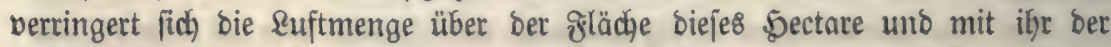
Roblenitoffgehalt auf 60 Rilogramme. Unterftellen wir weiter, baß bie bena= belten 2Yejte, weldhe bie Albjorption ber Rohlenjäure vollziehen, Den britten

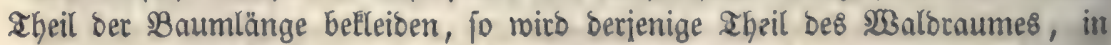
welchem bie 2lffimilation ber Sohlemjäure bor fich geht, 20 Sil. Rohlenjtoff

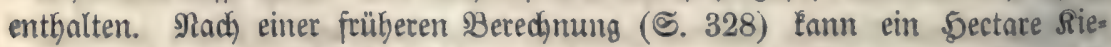
fernmals ber Ruft jäfrlic) 1846 uno (menn man bie Begetationszeit gleich 180 Iagen jest) täglid etroas über 10 Sil. Soblenjtoff entziehen. In zroei Zagen wirb aljo unter biejen Berbältniffen bie \&uft, melche bie 3neige um= 
gibt, ihret Sohlenfäure beraubt jein, unઠ nun mußs eine Ruftftrömung eintre= ten, meldhe rieber neue Soblenjäure zuführt, menn niçt ber (stnährungsprozeß in Stoctung gerathen foll.

$23 i r$ jehen aljo, on wenoige Bebingung Des \&ebens uno Bebeibens ber Bsenädje ift.

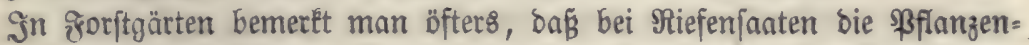
reiben am Fand ber Beete auffallent ktäftiger fich entroićeln, als bie von

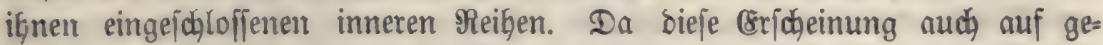

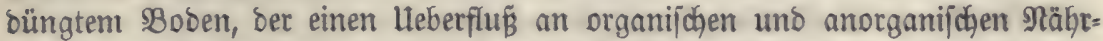

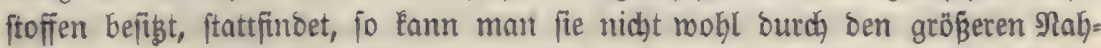

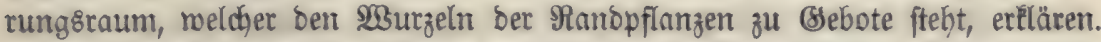

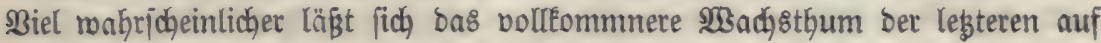

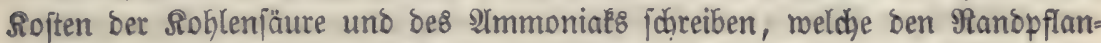
zen immer zuerft burdy ben $\mathfrak{W i n} \delta$, ber bie Beete beftreidht, zugeführt merben. Da nadh ben Berjudien von Bouffitgault bie 21bjorption ber Sohlenjäure (uno aud) mohl bes 2 mmonial's) burd, bie \$flanzen jo auserorbentlich fohnell

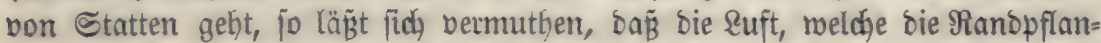

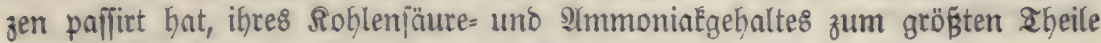
beraubt ift, bis fie an bie mittleren Reiben ber \$imnenjant gelangt.

Das Eräftigere Wadhsthunt ber Ranoftämme höherer Beftänbe beruht nur zum Theil auf ben nämlichen lurjachen, hängt aber mohl hauptjächlich

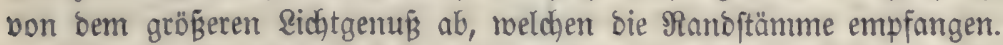

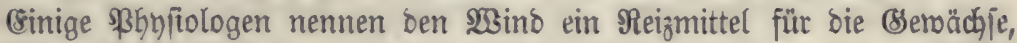
fie baben aber unterlaffen, zu ertlären, was unter einem joldsen zu verfteben

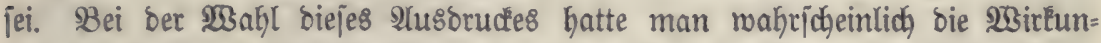
gen im Yluge, meldhe Bemürze uno andere Stoffe auf ben thierifchen Drga=

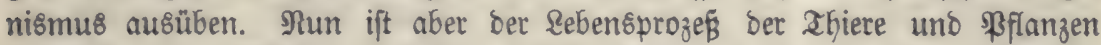

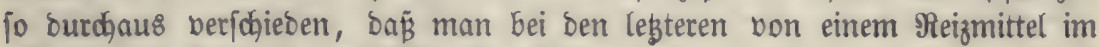
Simme ber exfteren gar nidht fprechen kann.

\section{b. Einfuf ber \&uftetron}

CEs ift bier nidgt ber Drt, bie Bebingungen ber Befrudhtung ber (Be= rächje ausführlich) ž erörtern, weil biejes in bas (Sebiet ber eigentlichen \$flan=

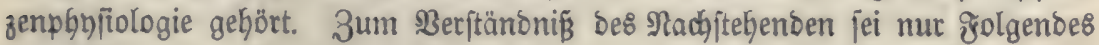
bemertit.

Die Beftuchtung einer $\Re_{f l a n g e}$ finbet ftatt, wenn ber Samenjtaub (\$ol-

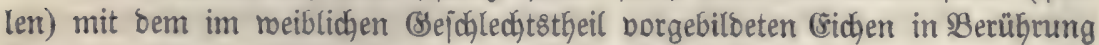
tommt. Regtere ift bei ben nadtjamigen \$fflanzen (3. B. Den Coniferen) eine unmittelbare, bei benjenigen ßflanzen aber, bei welden bas (sidhen von einer

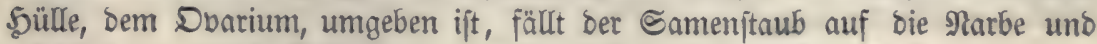
wäbjit Dann, ourdh Bitoung von Zellen, bis zu bem (Eidhen bin.

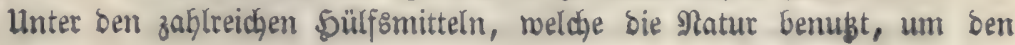


Samenitaub zu bem meiblidyen (Heichlechtgtbeil ber ßflonzen gelangen zu laj= fen, nimmt ber $\mathfrak{3}$ int eine wiḑtige Stellung ein. (5r Gebt bie Eleinen \$ollen= Eörner von bem Staubbeutel auf und führt fie ben zu befutudtenden (Eich)en zu. WBie meit ber Samenftaub burdh ben $\mathfrak{B}_{\text {ind }}$ transportirt werben Ë̈nte, fieht mau an Dem jogenannten Schnefelregen, ber nur auళ ßollentörnern, namentlich von Coniferen, befteft. So fiel z. B. zu Anfange diejes Sahrhun=

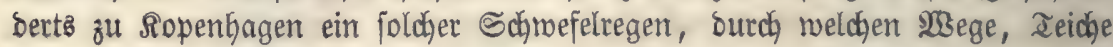
uno Dächer mit einem gelben Staube bedectit murben. (Er ftammte bon ben

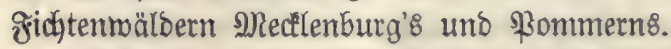

Die Bermittlung bes 2 efruchtungsgef häftes burch ben 23 ind ift bor=

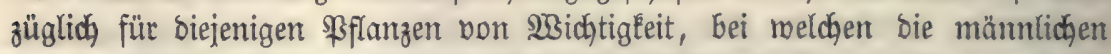
uno weiblichen Blüthen auf verijhiebenen Stämmen fitzen. Alber auch bei Den einfäufigen $\Re$ ftanzen ift fie von Bebeutung, indem es bei biejen nicht jel=

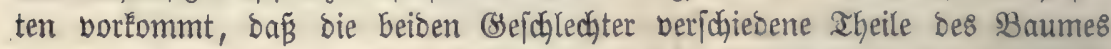

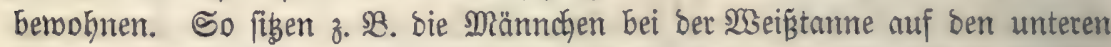

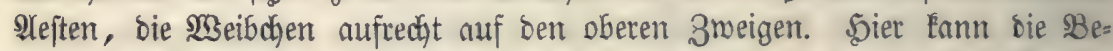

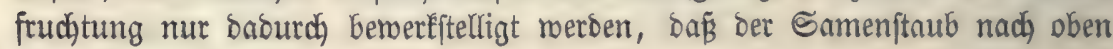
hin gefübet wiro.

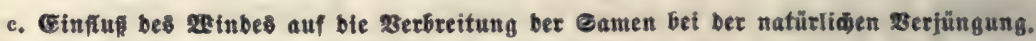

Die natürlicje Berjüngung ber Beftänoe burch Samen Eann in zmeifa= cher $23 e i f e$ geicheben. (Entweder man bält auf ber zu bejamenton glädje eins zelne Bäume (\$MUtterbäume) über (eigentlid)er Femelbetrieb uno Femelī)lng=

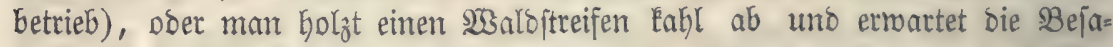
mung von einem angrenzenden Beftano (Rahlfablagbetrieb mit natürlic)er Berjüngung). Sm legteren Falle wirb ber Same burd ben 233 ind bon ben

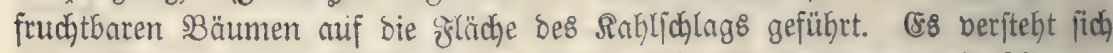

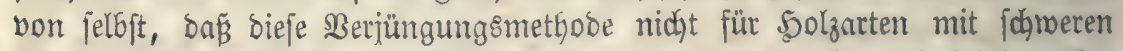

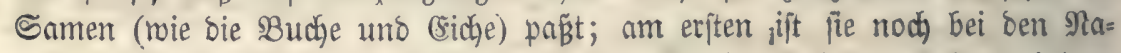

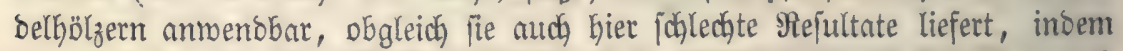
einestheils bie sejamung ơ ungleichmäв̈ig ausfälut, mberntbeils aber nuđ̆

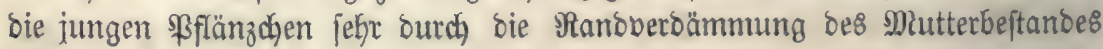
leiben.

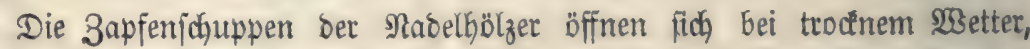

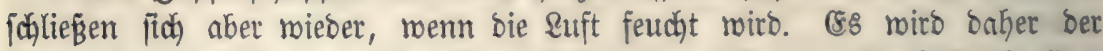
Same bornefgmlids mit ben trodfenen Dftrinden abfliegen. Dod, ift bie (snt= fernung, bis zu weldjer nod) eine binreichende Bejamung erfolgt, nidgt groß;;

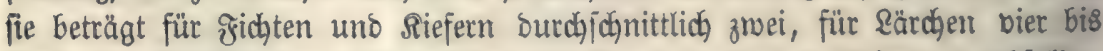

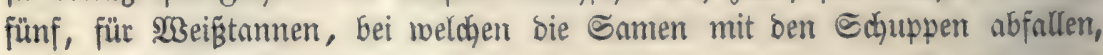
kaum eine Stammlänge.

d. פefeitigung bex sobennälí.

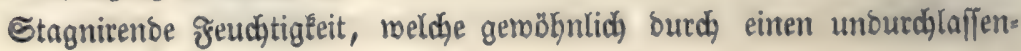


ben Itntergruno Doer burd) eine niedere Temperatur beranlaģt mito, tönnen

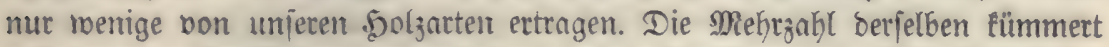

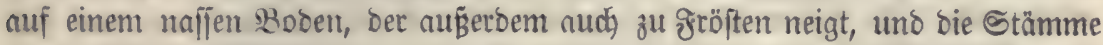
toerben leidgt rotbfaul.

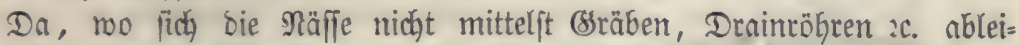
ten läß̈t, Gietet Beförberung bes Suftzuges ein vortreffliches Mitter, um bns

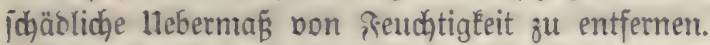

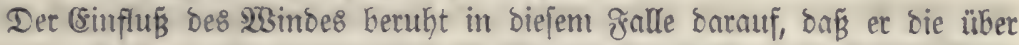
tem naljen Bocen fefmebende, mit 2 Bafferbampf gejättigte \&uftichichte hin= regnimmit uno an ifre Stelle eine trodene bringt, weldhe bie Fähigleit befibt,

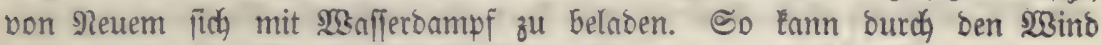
nach unঠ nadh bie Bobenfeuchtigfeit gänzlich aufgezebrt werben.

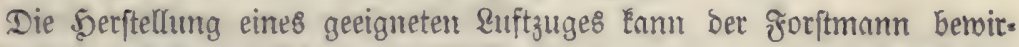

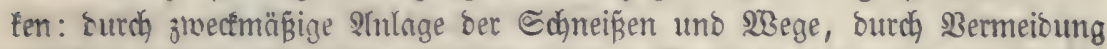

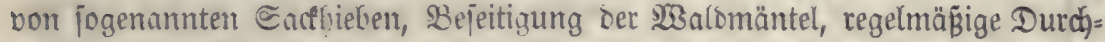
forftungen, (entfernung ber (jonft nübliçen) Bobenfträucher, Ânlage geregelter

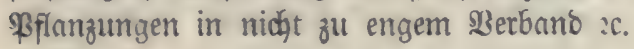

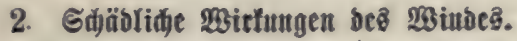

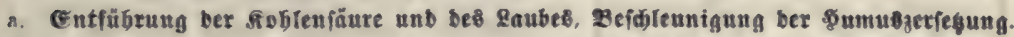

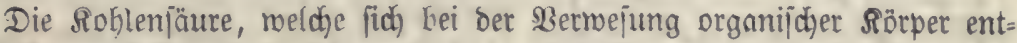
roictelt, Ingert fitf), meil fie jofmerer als bie \&uft iit, um bie in Zerjebung be= griffene Subftans und theilt fich ber \&uft nur ganz allmäblig burch Diffuiton mit; jo lange jie abet ien vernejenden Sörper ungibt, jobliefit fie biejen bon bem Eauerítoff ber \&uft ab, was eine Unterbrechung bes \$ermejungsprozeffes

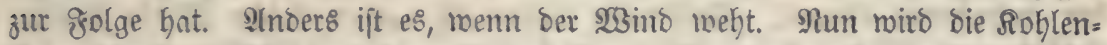

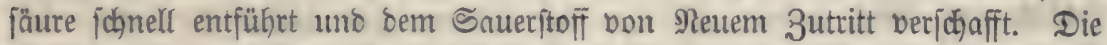
Bermejung geht jebst wieber bon Ctatten, menn e\& nicht an zentchtigkeit man=

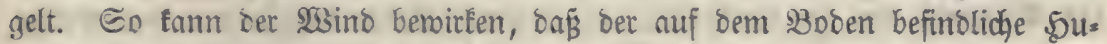
mus fich fodnell betzefrt.

SBie mir ipäter jehen meroen, jpielt bie aus bem bumus lich ents

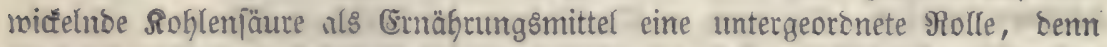

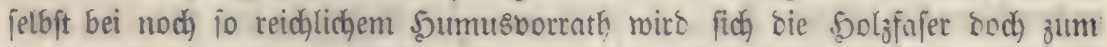

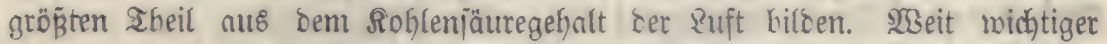

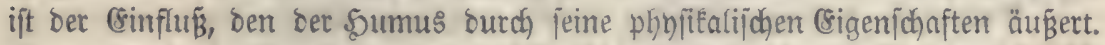

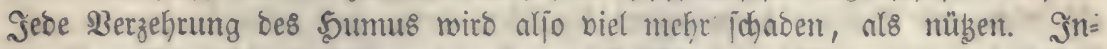
bem ber $\mathfrak{B i n}$ bie 3erjebung bes Sumus bejolentnigt, übt er einen nachthei= ligen (sinfluß auf bas Bereifen ber 23 aldoeyetation aus.

In ben Rnubholżbeftänoen berubt bie Shumuserzeugung vornelimlich auf bem abfallenten Saumlaube; aud Diefes wiro butch ben $23 i n$ entroeder aus:

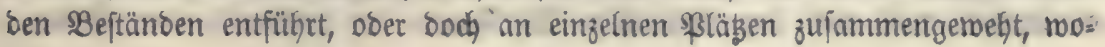


burd) andere entblöft roorben. Sluf ben leģteren ergibt fich bann ein Zumadbs: ausfall, weldher nidht mieber burdh bie 3urwachsmebrung auf ben erfteren

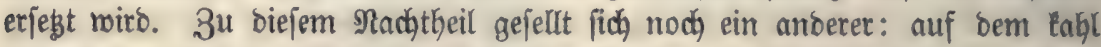
geworbenen Boben fohlägt bie natürliche Berjüngung felten gut an.

\section{b. Fubtrodnenbe \$inbe.}

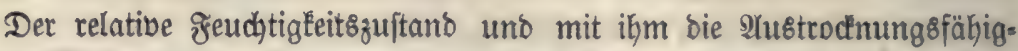
feit bes 2 Binoes richtet fid einmal nach ben Simmelsgegenton, aus weldyen ber $\mathfrak{B}$ ind Eommt, zum andern nady bet Sabreezzeit.

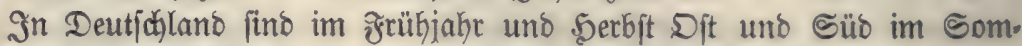

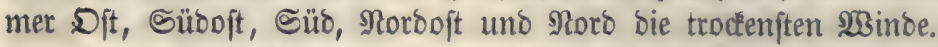

₹ig. 152.

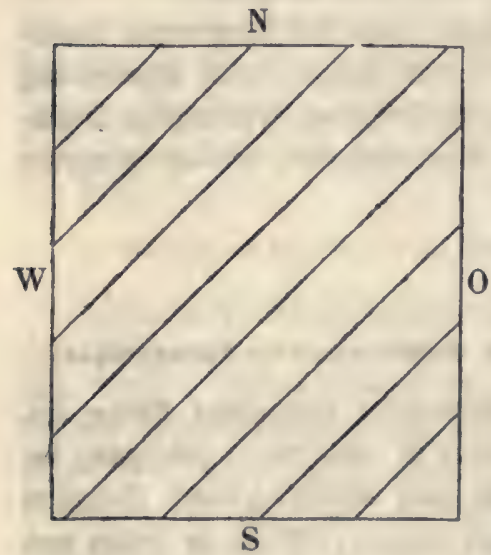

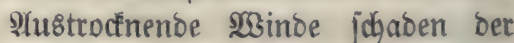
Walbuegetation in "zweifact)er $\mathfrak{B e i j e}_{\text {, butch }}$ Berflüdytigung Der nöthigen Bobenfeudb:

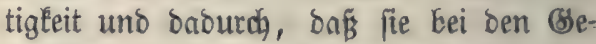
mächjen eine übermäfige $\mathfrak{B e r \delta u n f t u n g ~ G e r = ~}$ vorrufen. Dieje Sadatheile madhen fidh bejonbers bei ben Culturen bemerlbar. Aeltere \$olzgemächje merben in unjerm Elima burdh trodene 233 into felten zum Atbjterben gebradht, mohl aber im 3uradas zurüctgejęt.

Bon ben austrodnenben $\mathfrak{B}$ inben leiben namentliá) eben geteimte Saat

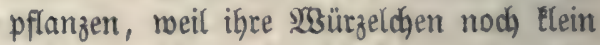
fino uno nicht viel Freuchtigłeit aus Dem $\mathrm{BD}=$

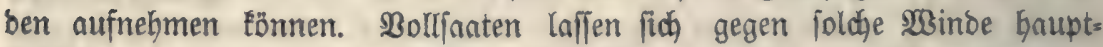
(äd)lich) nur burd) tieferes (sinlegen ber Samen uno zeitige Bornabme ber

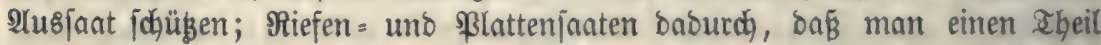
bes 2lbraums bon ber (Eulturftelle an biejenige Sante besfelben bringt, meldye

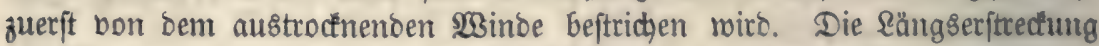

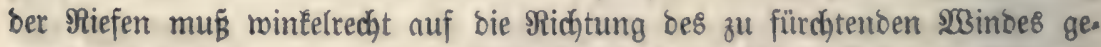
nommen werben. Da nun in Deutjolano im grtüjabr Djt uno Süb bie

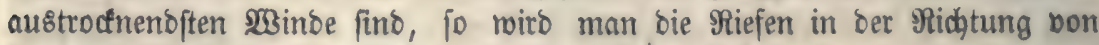
Norboft nach Sübmeft anzulegen baben. (જig. 152).

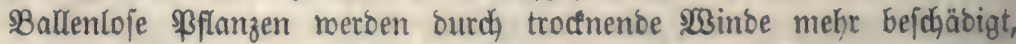
als foldhe mit 3 allen; Denn erftere bebürfen einige 3 eit, bis fie angenourzelt fino uno aus bem sBoben Feudigtigfeit aufnehmen Eönnen. Smmerhin ift es nüblid), bei Ballenpflanzen Den Rochballen fo bor bie eingelegte \$flanze zu

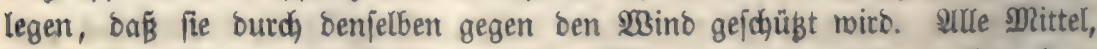

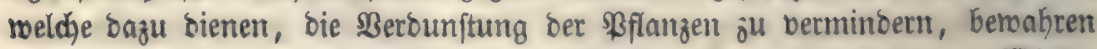

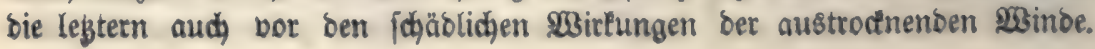


Sierber gehört namentlich bas Bejdyneiben ber 3meige uno felbft bes Sdhaftes

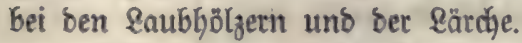

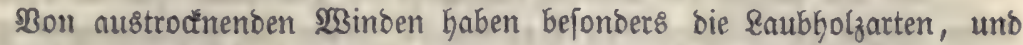
unter biejen borzüglid bie SRothbuche zu leiben. Б口olzgetwädjje mit fteifen,

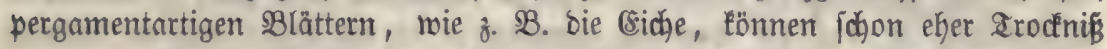

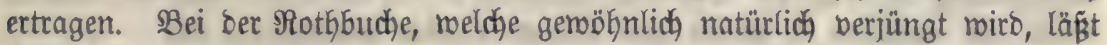

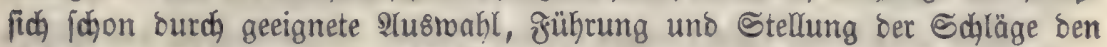
Befafyren, weldhe austrochnende $\mathfrak{B i n b e}$ ben jungen \$flanzen bringen, borbeu=

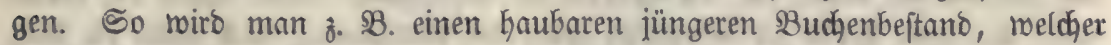

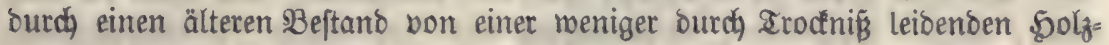
art geidübt ift, vor biefem berjüngen.

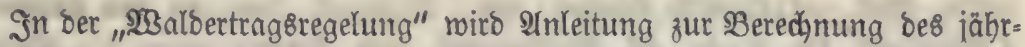

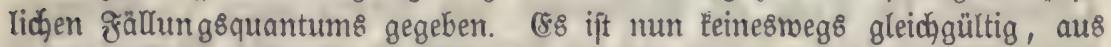

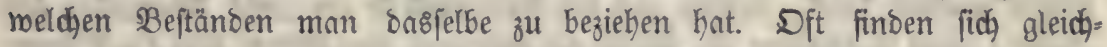

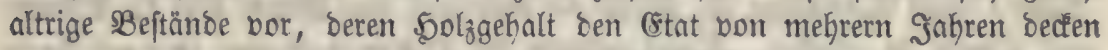
lann. Bei ber \&B/ung ber grage, an welche Etelle eines jolchen Beftandes

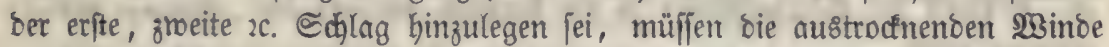

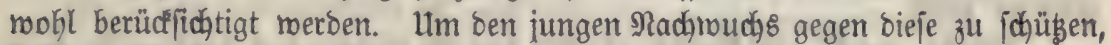

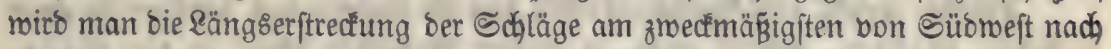

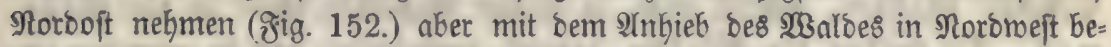
ginnen und in Süboft aufgören; zugleidy barf man bie 21uहlichtung, nament=

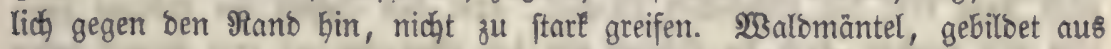
foldhen 5olzarten, weldye bis zum Boben herab lange Zeit beaftet bleiben (Jichte, Weiṕtante) geben eine bortefflidge Sdhugmebr gegen bie trochenten SBinde ab.

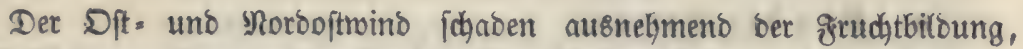
einestheils regen ibret austrodnenten (sigenjobaften, fobann aber audh regen

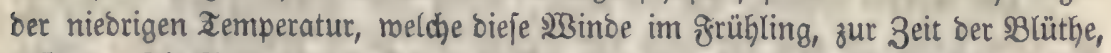
befigen. Die Samenftaubzellen enthalten eine eigenthümlidje zeuchtigkeit; fobals fie bieje berloren Gaben, taugen fie nidbt mehr zur Befruchtung. Nady Shaer

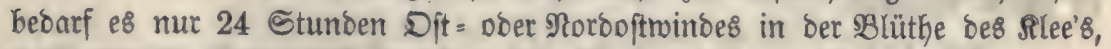

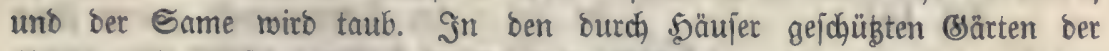
Stäbte uno Dörfet getäth das Dbft faft aljäbrlich; mähreno auf ben freien, bem $\mathfrak{X}$ Bino zugängliçen şöhen viel öfter Mifiernoten erfolgen.

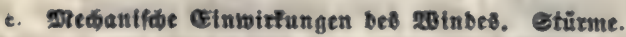

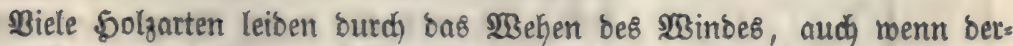
felbe nidat gerabe in Sturm ausartet. So nimmt o. $\mathfrak{B}$. bie \&ärdje in bet

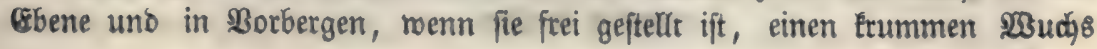




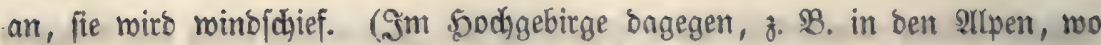
fie nur jehr kleine Sahrestriebe bildet, wädjit fie gerabe auf).

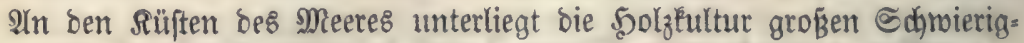
feiten wegen ber falzfübrenten Eeeroinde, Deren faft unausgejegtes $23 e h e n$ nur menige 98 aumarten ertragen, ohne zu Kümmern, ober ganz zu verberben. Merfwüroig ift, baß ber Seenino unmittelbar an ber Rüjte nicht jo jojäblid)

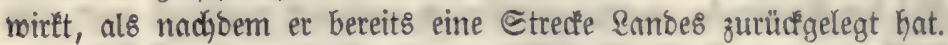

2Bie langiährige (srfahrungen ergeben Gaben, miberiteht an ben Sürftent

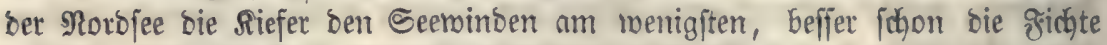

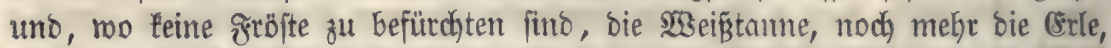

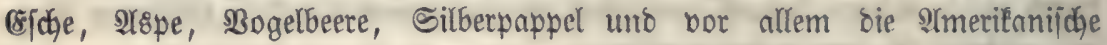
Pinus alba. Dod üft bie (5xpofition nno bie (Configuration ber Rüfte aud)

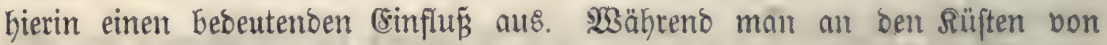

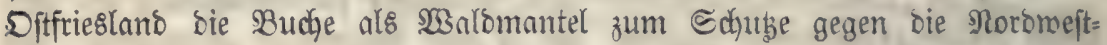

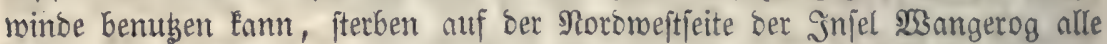
Bäume ohne 2 Lusnahme ab, fobald fie anfangen, ihre $23 i p f e l$ über bie Dämme uno Dünen zu erheben. Dabei nehnen bie Blätter bald eine idymarze farbe

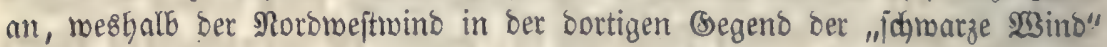
genannt wirb.

WBinoe, meldye eine SBejdymindigleit bon 20 Metern unt batüber in einer

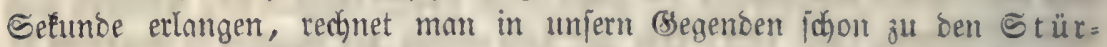

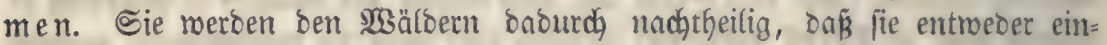
zelne 2(ejte von ben Stämmen trennen, ober ben Sd)aft ber Bäume iplit=

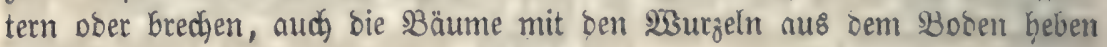
(jog. $25006[e)$,

Die Befahr ber Minde bängt $a b$ :

\section{a. Bon ber bolzart.}

(sin Sörper befinbet fid) in Ruke, wem fein Sdymerpuntt unterftütst

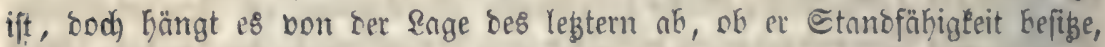

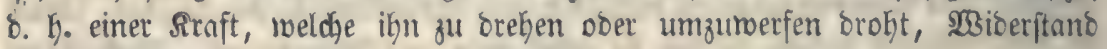
zii leiften vermöge.

ஓig. 153.

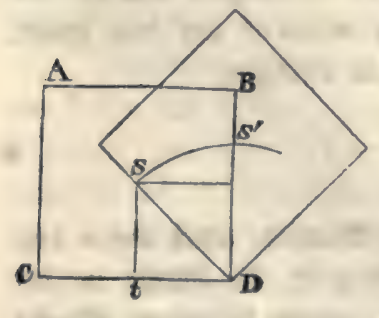

(5s jei $\mathrm{s}$ ber Echmerpunlt irgento eines

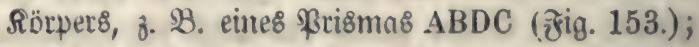
foll bas ßrisిma auf bie Geite BD gclegt wer= ben, fo muв basielbe fo georeht werben, dás ber Enoepuntt 1 Der von Dem Sdyroerpunett $s$ aus gezogenen Berticalen s $t$ außrerbalb ber $\$ 3$ afis $C D$ fälit. (s mur aljo s ben Bogen $s$ s' bejdjrei= ben, baber ber Sdhwerpuntt s um $s^{\prime} D-s t$ geboben werben. 
ঔig. 154.

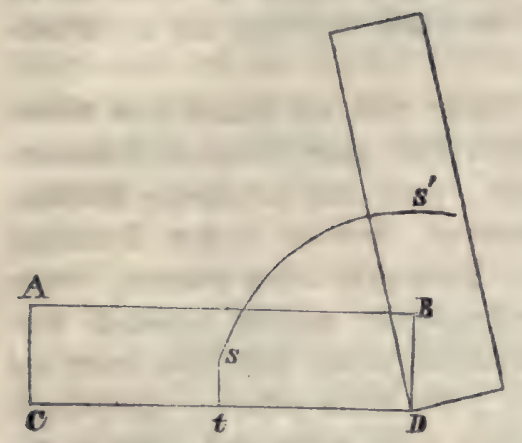

Denten mir uns nun ftatt bes bori= gen Prismas ein anberes von gleidjem Gervidgte, aber größ̄erer Brunoflädhe

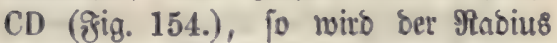
D s, mit weldyem ber Bogen ss' zu bejdreiben ift, gröber ausfallen, aljo muth $s^{\prime}$ böher über $s$ liegen, folglid)

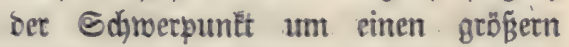
Betrag gef̧oben werben müffen, bamit

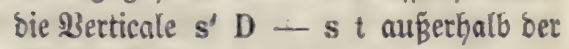
Bajis CD falle.

Nehmen wir brittens an, bie vorige Maffe jei in ein \$risma von fleineret Эilg. 155.

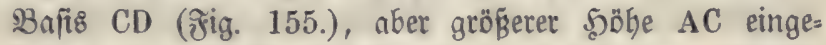
Eleibet, jo wirb bier ber $\$$ Bogen ss' viel flacher ausfallen, Daher aud, $s^{\prime} D-s t$ Eleiner jein, als in bem erften gralle.

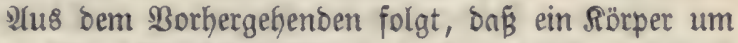
jo mehr Stanofäbigkeit befißst, je größzer jein Bemidjt uno jeine Bafis ift uno je tiefer jein Sdfmerpuntt liegt.

Sit ein Siöper in bie ortoe eingelaffen, fo fommt auß̈er ben eben erwähnten Umitänoen nodh ber Druct zur Spradje, meldyen bie (robe gegen ben berjentten aheil ausübt.

Man Earn obne merflidfen Jehler anneלmen, Daß̈ die Rejulticende a b biejes Drucfes burch bie Mitte a bes

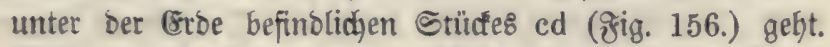
WBirtt mun auf ben aus ber (5rbe Gerborragenden Theil cg eine Sraft ef in einerlei Sinne mit ab, io tritt bann (sleidggemidht ein, menn ac. $a b=$ ce. ef. Sit bagegen ce. el $>$ ac. ab, io miro ber Rörper um ben \$untt c georeht und aus ber Eroe gerifjen.

stlle Bäume lafjen fïh) nls bebel nnjehen, beren einer Edjentel von bem Sdafite gebilbet wiro, währento

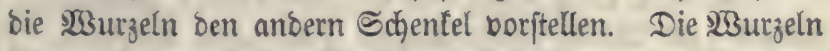
fönmen in zrveifadger 23 eije zur Befejtigung des Baumes bienen, einmal, indem fie, roie bie Ingmurgeln, eine Bajiz abgeben, um meldhe ber Sdjwerpuntt bes Baumes georeht metben mü̈, wenn lebterer fallen joll (noie oben

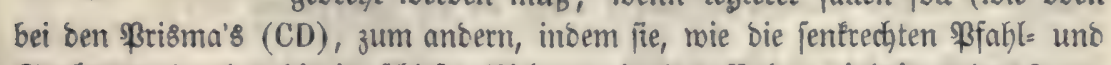

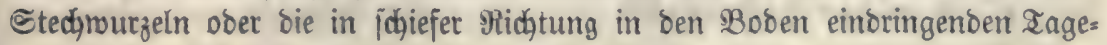
rourzeln burd, ben Druat ber fie umgebenden (Erbe feftgebalten werben. Sin Baum mirb bann ganz bejonbers feft ftehen, wenn er neben einer tief gehen 
ben \$fahlmurzel noch weit ausftreichenoe Iagmurzeln befizt. Snoffen hat bie

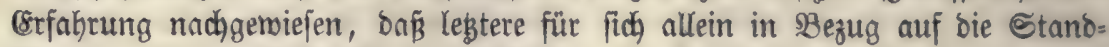
fähigketeit nidat fo viel leijten, als exftete.

Se länger ber Sdjaft ijt, um fo leidjter wirb ein Baum vom Minbe umgemorfen merben können, benn er bietet igm einen längeren Sebelzarm

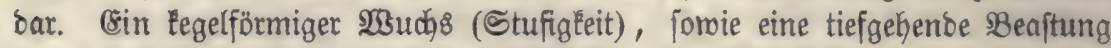
uno bünne frone fichern gegen ben Winomurf, weil bei foldhen Stämmen ber Sdnwerpunțt näher nm Boben liegt. Dešnegen leiben $B$ äume, meldhe regelmäß̈ig nach bem Sopf = uno Sdhneibelfolzbetrieb zugleidh behanoelt mer= ben, weit wentiger bon Stürmen, als Stämme, weldje man von unten auf längs bes Schaftes hin mit Belaffung einer bicfen Srone entaftet. Frreiftehende Stämme, weldhe ftufig aufwachjen und tiefer herab benftet find, werben we=

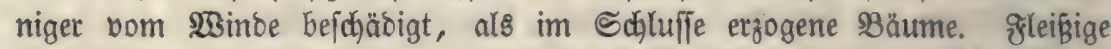
Durchforftungen gehören zu ben vorzüglichjten Sduszmaß̈regeln gegen bie

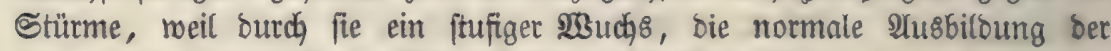
Rrone un eines Eräftigen 23 urzelfyjtems beförbert roirb.

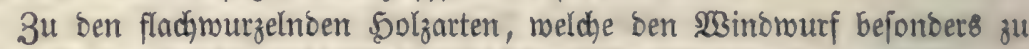

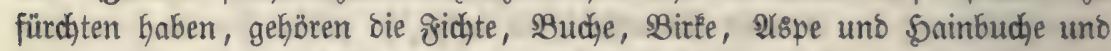
bie borgenannten \&aubhölzer, namentlid, bann, menn fie aus Stoct $=$ ober

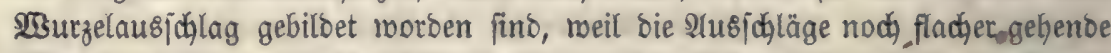

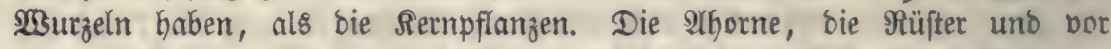
allen bie sidhe wiberftehen ben Stürmen vortrefflid, weil fie eine bollénmen entmiçelte \$fablmurzel belizen.

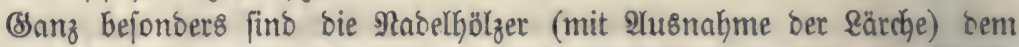

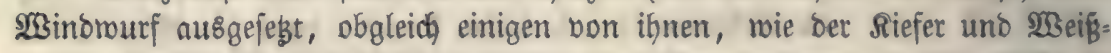
tanne, die \$faflnumgel nicht mangelt. Der 8runo babon ift einestheils in ber Sdaftböbe, weldye bieje \$olzarten erreichen, zum andern aber in bem

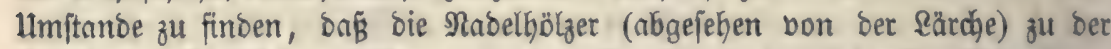
3eit ber gefäfrlichfiten Stürme, in Den 2lequinoctien, mit voller Belaubung berfehen pino, weldge, wie bas Segel eines Sdiffes, bem Wint eine grop̈e 2(ngriffifläche barbietet.

\section{B. Bon bem 5olzalter.}

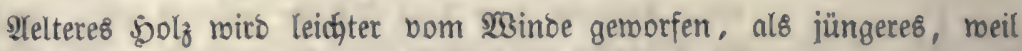
exftere\& bem $23 i n$ be einen längern Şebel8arm barbietet. Desmegen hat man

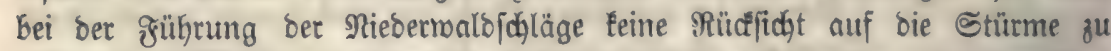
nebmen uno ift aljo nidat gebinbert, benjelben eine foldje Lage zu geben, bafis

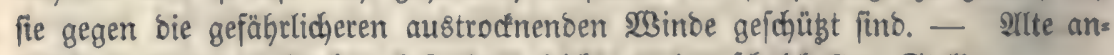
brüchige Stämme brechen bejonbers leidjt an ber fäabfaften Stelle.

\section{$\boldsymbol{\gamma}$. Bon ber Sărezseit.}

W3ie im 3orbereitenten Theile angegeben wurbe, wehen in unjern bses genben bie ftärfften Stürme in ber \&lequinoctialzeit, aljo gegen bas leģte 
Drittel ber Monate Mărz uno September. Den Eaub̧ölzern werben bejon=

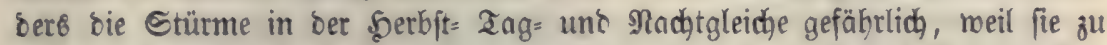
biejer Zeit noch faft alle iffe slätter befizen. Hebrigens ift bas sintreten ber

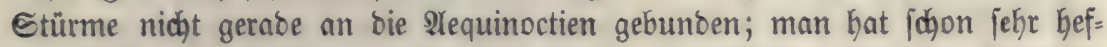
tige Drfane beobadatet, meldhe fich mitten im $\mathfrak{W B}_{3}$ inter ober im Sommer zeigten.

\section{d. Bon bet cribebung über die Reeresfähe.}

Die Walbungen im Sochgebirge finb, wenn ifnen nidht burdh vorra=

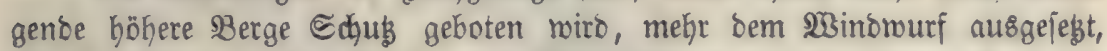
als bie $\mathfrak{M}_{3}$ alder in ber (Ebene. Der $\mathfrak{B B}_{3}$ ino erlangt auf ber legtern megen ber

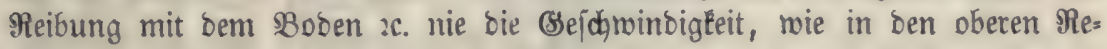

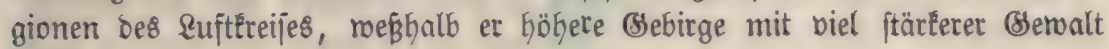
trifft.

\section{Bon bet Erpofition.}

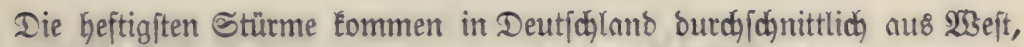

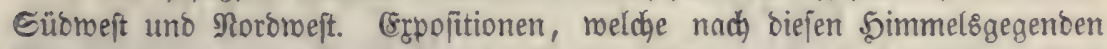
Ginneigen, merben baher borzugstreife ben Stürmen ausgejest jein. Dodh ereignet e\& bistreilen auch, Daß̉ jehr ftarf́e Stürme nus anbern Simmels. gegentoen weben. Begen bieje Laffen fidh freilid leine Bortebrungen treffen,

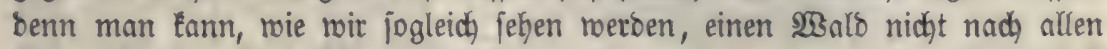
Seiten hin bor ben Stürmen johüß̧en. (\&s genügt, welun er bor berjenigen

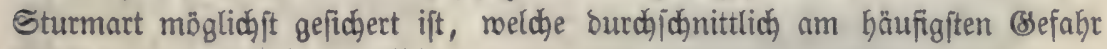
bringt.

Im Bebirge wird, wie mir im 3 orbereitenden Theil bemerkten, bie Sturm=

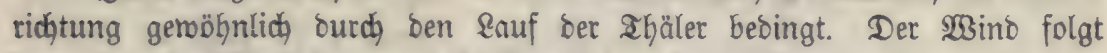
bem 3ug ber ßertiefungen bes Serrains. In Rüjtengegenden geben bie Stürme faft immer bon bet See aus.

Die Mrafregeln, welche ber छorftwirth zu ergreifen bat, um bie $\mathfrak{W a l}=$ bungen vor ben berberblictjen folgen ber Stürme ficher zu ftellen, beziehen

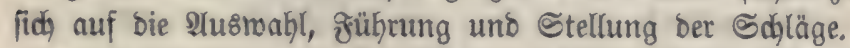

So mirb man 3. B. einen jüngeren haufaren $B$ eftano, weldher burd) einen älteren bon einer tiefrourzelnoen \$olzart gegen bie 23 indridhtung hin gebeçt ift, bann zuerft verjüngen, wenn jener aus einer \$olzart befteht, mel= d)e ben Stürmen leicht unterliegt. Snoem mir biejes Berfahren antathen, ję̧en wir voraus, baß̈ burds bas Ueberhalten des älteren Beftandes fein be=

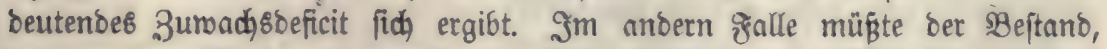

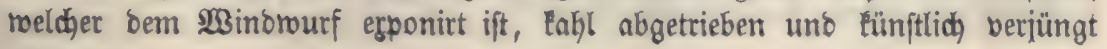
nerben. 
ஓ̊̀ig. 157.

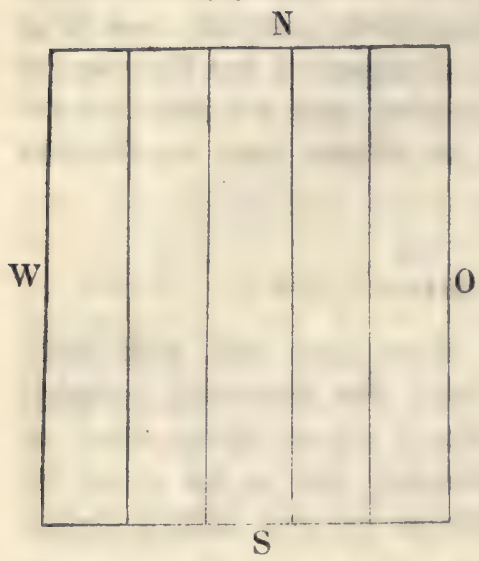

Sar oft befipt ein Beftand eine folche

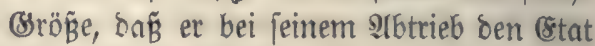
füt mehrere Sabre ober Rerioben bectt. Sier fidjert man ben Bejtandesteft, ber nact) Bornabme einer Jahres= ober Beriobenfälung berbleibt, baburd) gegen ben

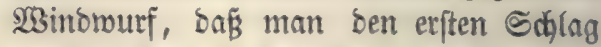
an berjenigen Bejtanosjeite anlegt, meldje ber Sturmridjtung entgegengejest ift. So \%. B. woiro man ben Beftand (§ig. 157.), wenn ex von 23 eftitürmen zu fürchten Gat, in ber Ridutung bon 0 nach W, aljo in Diten anfauten uno bie Rängser= ftrectung ber Schläge bon Norben nach Süben ridyten, bamit bei bem $30 r i d$ reiten ber Schläge nach 23 eften Gin an

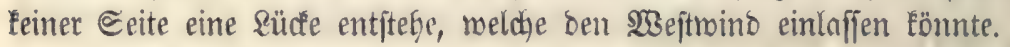

Fig. 158.

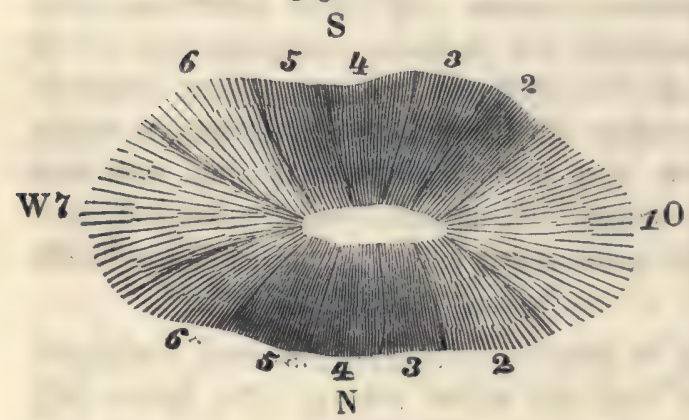

Die fo eben ertheilte $\mathfrak{B o r}=$ (d)rift gilt aber nut für bie Ebene. Im Sebirge, wo man die Sd)läge wegen ber 5olz= abfubr in geraber \$idytung bon bem früe nad, bem (sipfel fin

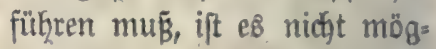
lid, mit ben Schlägen nach parallelen sinien borzuict)rei= ter. Sier legt man (§ig. 158.), menn 8 . $\mathfrak{B}$. SBęt der Sturm=

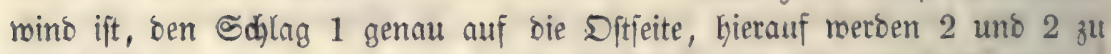
beiben Seiten von 1 angebauten, uno fo fährt man mit ber Edjlnganlnge

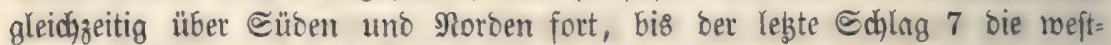
liche (Erpofition erreich)t. Stets mǘ aber bie Suppe zuerft veriüngt werben,

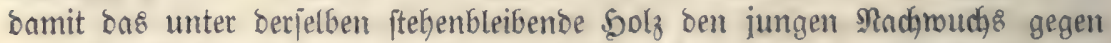

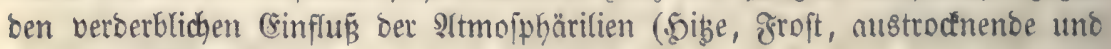
und falte $23 i n \delta e)$ j(dükse. 
Ґ๋ig. 159.

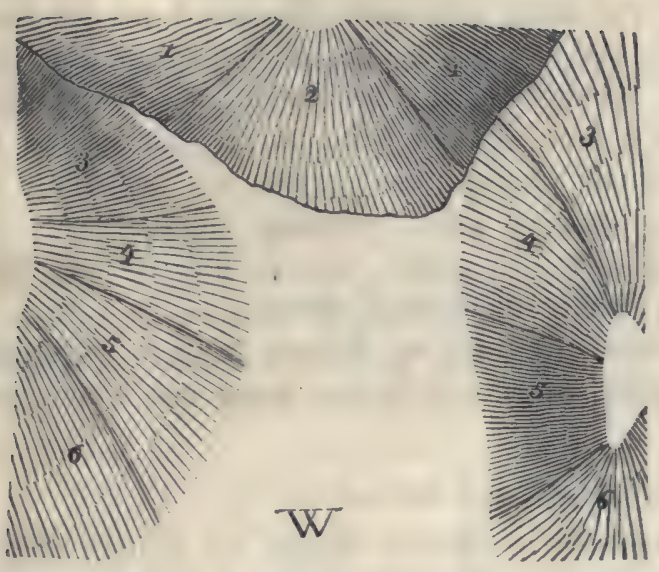

Sat ein Shal jeine श्थ münoung nach) ber Sturmge= geno bin, jo beginnt man mit ber ๔ḑlaganlage oben int (se= birge nno jest ben Бieb nad ber Maunoung bin fort (ঔig. (159.).

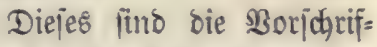
ten für sie Behanolung ber einfacheren そälle. Sm ßebirge, two ijolirte \&agen mit $\mathfrak{T h a ̈ l e r n}$ uno Blatenus mechjeln, jebt (ïc) bas Berfahten, um bie Beftänoe gegen bie ๔türme zu fohüben, aus ben eben ange=

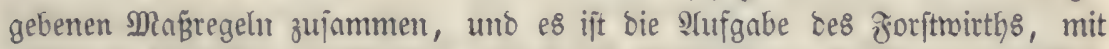

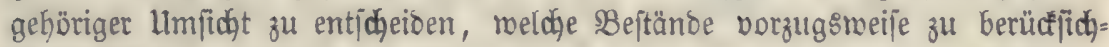
tigen fint.

\section{Q. Bon bem श्रbodungs grabe.}

Bäume, weldhe auf einer geneigten $B$ obenfläche ftehen, werben bom

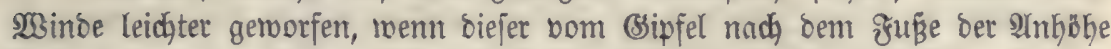
hin, als renn er in umgefehrter sidytung weht. (\$8 beruht bies auf meh= rern Brünoen. Ginmal ftehen bie Bäume auf geneigtem Boben getwöhnlid nicht fenfrecht zur Sorizontalen, fonbern fie Gängen etrons nads bem ơuge

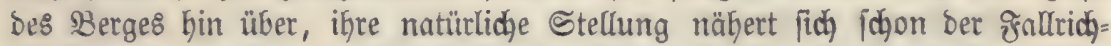
tung; zum Alnoen wiro bie Rraft bes 2 Binbes, weldger bon unten unb fait Æig. 160.

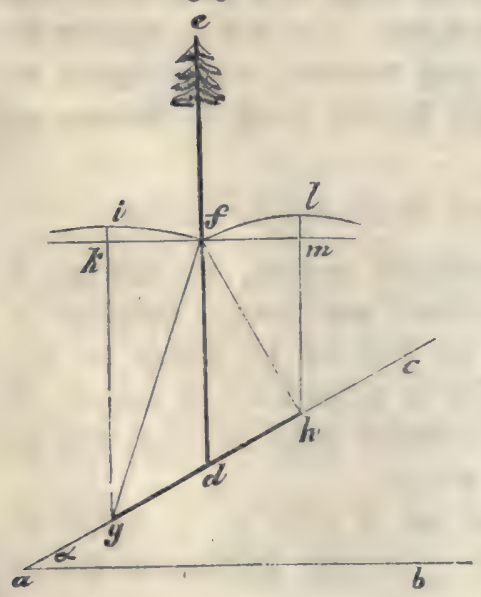

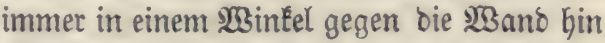
einfällt, burd̆ bie Reibung an bem Boben geidhnächt, währeno ber vom Bsipfel tom= mente Wint meift parallel mit ber Boben= flädje weht; brittens ift aber bie 5öhe, um meldge ber Sdhrerpunft bes 3 aumes ge= foben werben muß́, bamit biejer zum gall gelange, fleiner, wenn ber Baum nach un= ten bin, als wenn et nadh oben hin ge= worfen werben joll. (\&s jei a b (ङig. 160.)

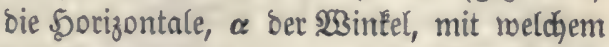
die Bergruand a c gegent bie Sorizontale geneigt ift, de ein Stamm, f jein Sdywer= punlt, $\mathrm{d} g=\mathrm{d} h$ jeien zrwei Zagmurz̧eln. Solf ber Baum nadj unten bin fallen, jo 


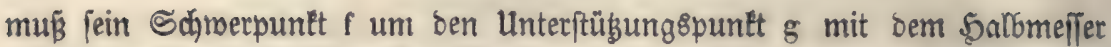
$\mathrm{g} f=\mathrm{gi}$ ben Sireisbogen fi befdreiben; zieht man nun von $f$ aus ber 50 .

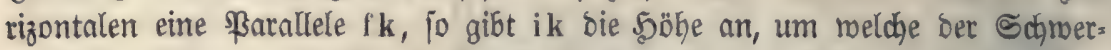
puntt $\mathrm{f}$ gehoben merben muß̧, bamit bie bon $\mathrm{f}$ aus gefällte Berticale außier-

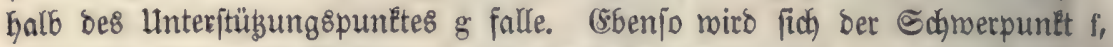
menn ber $\mathfrak{B a u m}$ bie 2 nhböhe himauf gemorfen merben foll, um ben \$unEt $h$ mit bem \$albmeffer fh brehen und bie Söhe 1 erreichen müffen. Nun ift

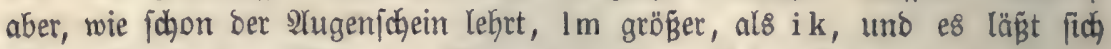
bieళ aud mit ben Gäben ber Elementarmathematif beweijen. -

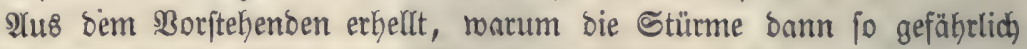
meroen, wenn fie ben Bipfel eines Berges überjotritten baben und Dann wieDer thalabräato meben.

\section{$\eta$. Bon ber Bejdaffengeit bes Bodens.}

Iuf flad)grünoigem, unzertlüftetem $B$ oben lönnen bie Băume leine

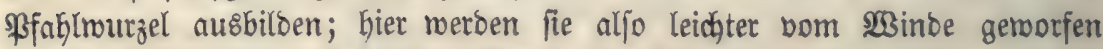
merben, besgleidjen auf lockerem Sand ober Moorgrund, weil bieje zu wenig

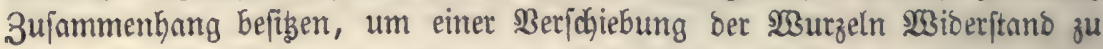
Ieiften, went ber 2 Bind ben Stamm nach ber Seite hin brüat. Nefynlidy ver=

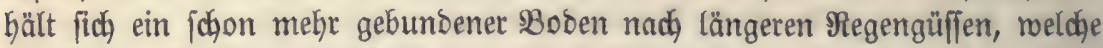

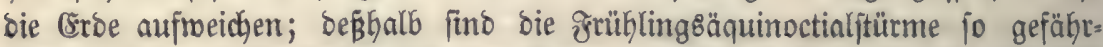

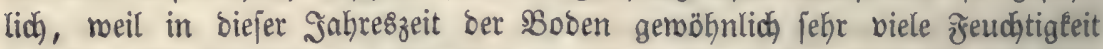
enthält. Şit ber Boben gefroren und bamit Der 3ujammentang ber (5ro= theildgen ftärter gemorben, io roiberjteben bie Bäume bem 2 Binomurfe biel eher.

\section{Bon ber umgebung.}

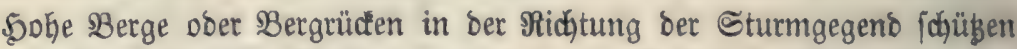

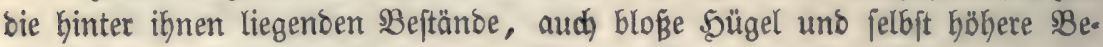

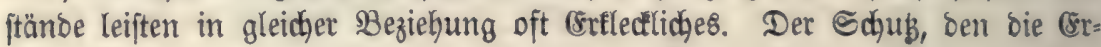
hebung bes Bobens gerwährt, wirs bann nodh bermefrt, wenn legterer be=

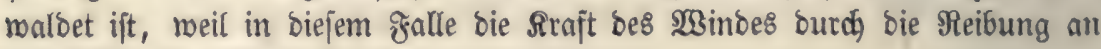

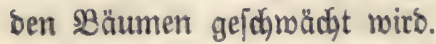

¿. Bon ber Betriebsart und ber 23 aldbehandrung.

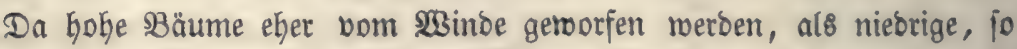

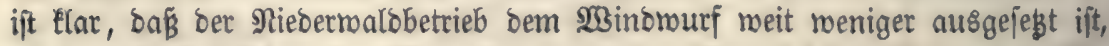
als ber 5odymaldbetrieb. Man braudyt in ber That bei ber Anlage ber Rie=

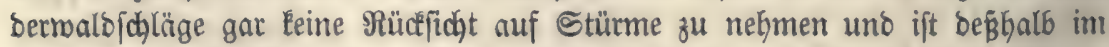
Stande, bie Sdhläge jo zu führen, baß bie sohben gegen bie ihnen viel ge=

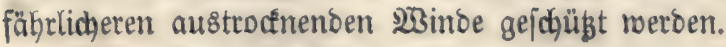

Die Stanofäbigkeit ber sBäume nimmt um jo meł̆ zu, je ftufiger ihr

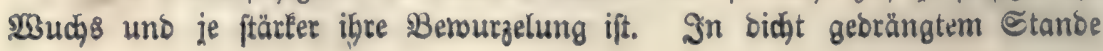


wito ber Baumjohaft mehr walzenförmig uno bie 2rftberbreitung beginnt exft

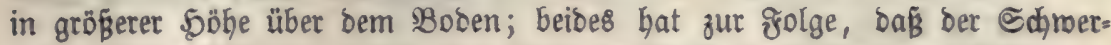

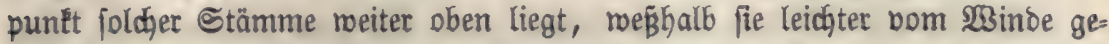
roorfen uno, io lange fie nod johroant find, eher umgebogen roerben, als bie

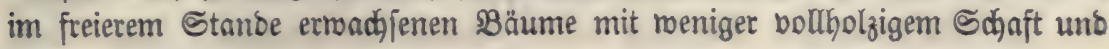
tieferer Beaftung.

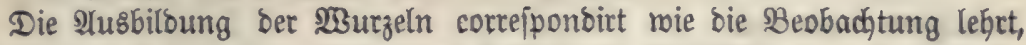

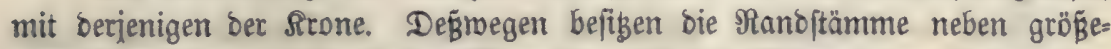

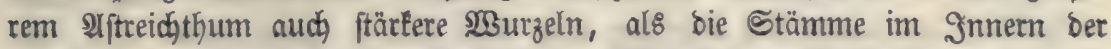

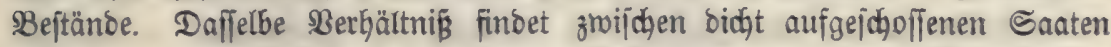
und ben, geroöhnlid in reiterem Berbanbe angelegten, Bflanzbeftän= Den ftatt.

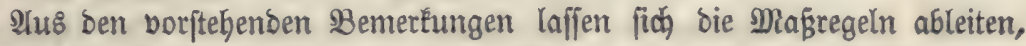
melobe ber grorftwirth in Anmenoung zu bringen hat, um bie Befahren bes 23 inbmurfs von ben $23 a l$ ungen fern zu balten. Sie befteben aljo zubör=

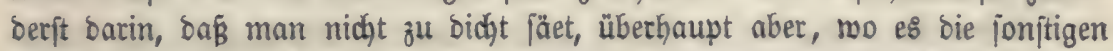

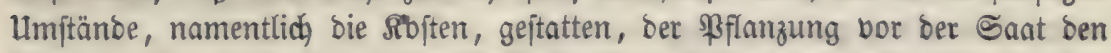

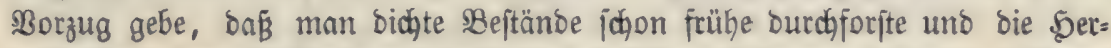

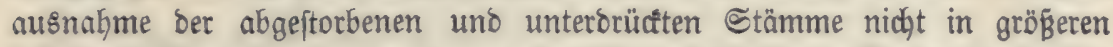
3eitintervallen, fondern fo oft, als thunlich, roiederḩole. Werben, mie bies

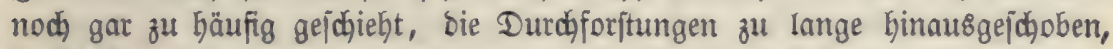

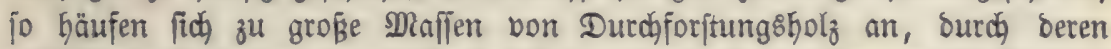

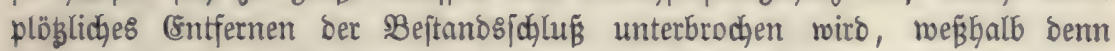
polche Beftänoe kurze Zeit nach Der Durchforftung dem \$3inonurf am erften unterliegen.

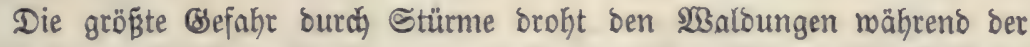
ßeriobe ber natürliçen Berjüngung, reil zu biejem 3mecte die Befitänoe gelichtet werben müffen. WSit haben oben angegeben, wie man bem $2 B_{i n} \delta=$

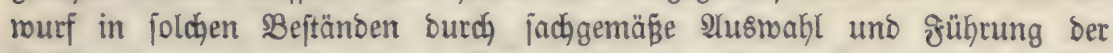
Edhläge begegnen, ober ifn boch wenigitens verminoern fönne, unઠ müffen

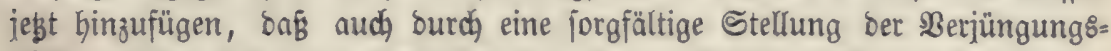

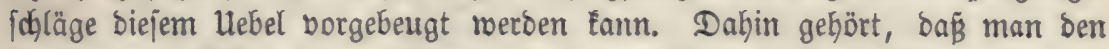

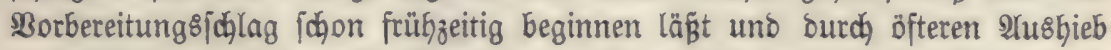
ber zur Bejamung ungejojicten ober von bem $23 i n b e$ bejonbers leidjt zu be=

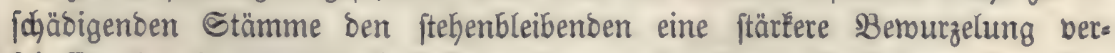

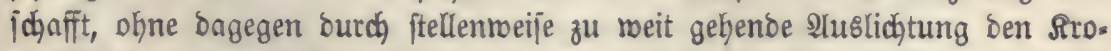

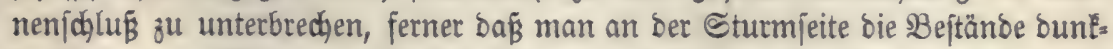

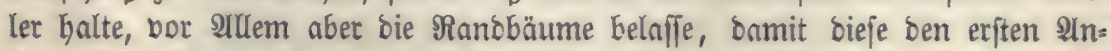

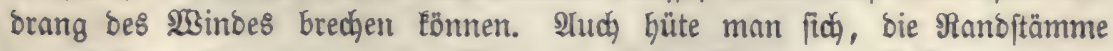
zu entajten. Denn wenn ber $\mathfrak{W}$ sind einmal im Rande eine Deffnung gefun= ben hat, io gelingt es ifm viel eher, bie idhlechtbenurzelten Stämme im Innern bes Beftandes nieberzumerfen. 


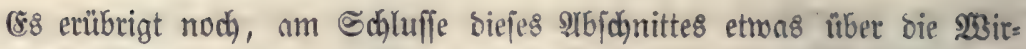
belminto zu jagen.

Die Keftigften Drkane in ber Keifen Zone fino ftets MSirbelminte, und zroar werben bieje burd, zmei \&uftitrömungen berurjad,t, weldge fidh parallel, aber in entgegengefebter Ridjtung neben einanber fortberwegen. Dabei rüctt ber Mittelpuntt ber Drehung ftetig borwärts, inbem er auf jeinem $\mathfrak{B}_{\text {ege eine }}$ Bogentinie bejdureibt.

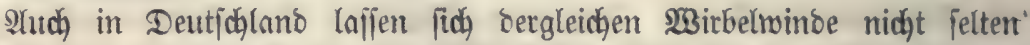
beobachten, fie bebnen fich aber hier nicht über eine fo grofie frtäche aus, wie

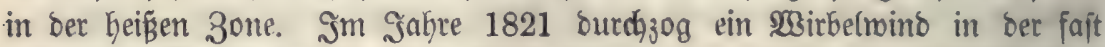

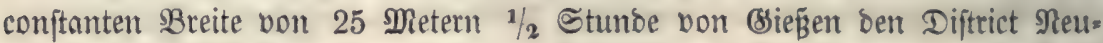

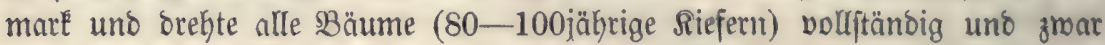

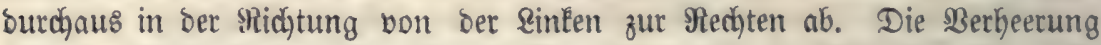

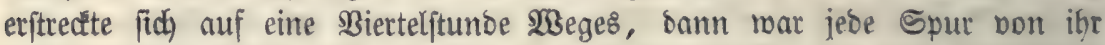
veridymunden.

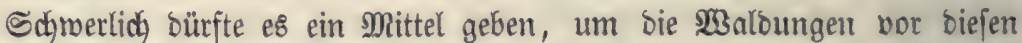
gefährlichen $233 i r b e l f t u ̈ t m e n$ fiçer zu ftellen. 


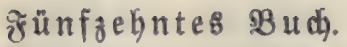

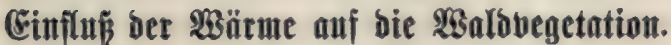

\section{Cinleitung.}

Bon Den (sinflüffen, weldhe bie Meteore nuf bie \$egetntion äusern,

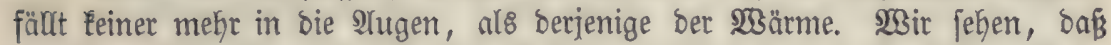

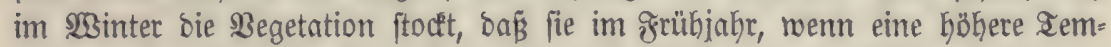
peratur eintritt, mieber erroacht und im 5erbit, menn bie $\mathfrak{S B a ̈ r m e ~ a b n i m m t , ~}$ von ఇeuem in Stillitano geräth.

Ireten im ortühjahr, nachoem bie Begetation bereits erroncht ift, Ealte

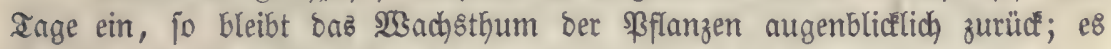
fest fich aber fort, jobald bie Temperatur wieber in's Steigen kommt.

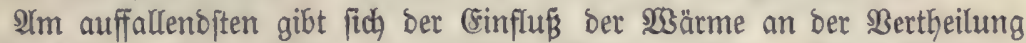

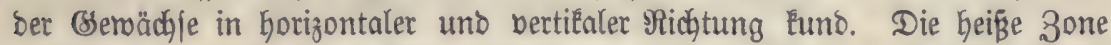
enthält nidht allein bie meiften Snoibibuen, fonbern befitst audy ben größ̈ten

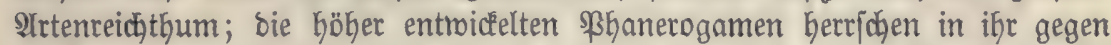

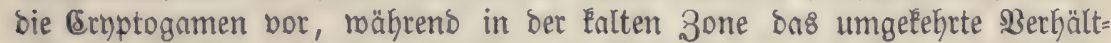

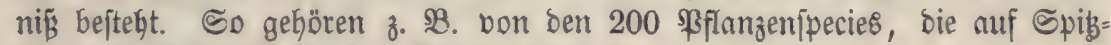
bergen borlommen, $2 / 3$ ben (Eryptogamen an.

Steigt man von ben Süften bes Broñen Deenns in ber Nähe bes

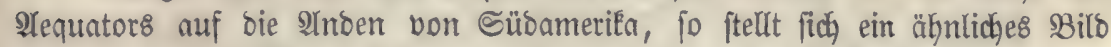

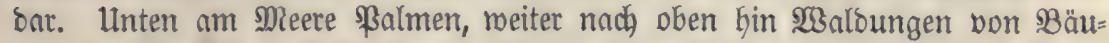

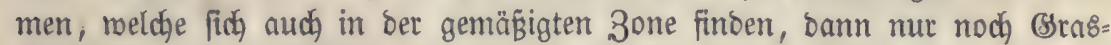
länbereien, zuleģt fłlechten uno Mooje bis zur Brenze bes emigen Sdhnee's

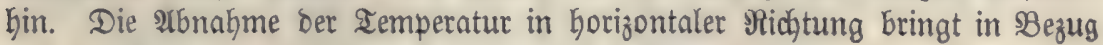
auf bie Begetation faft ben nämlichen Effect Gervor.

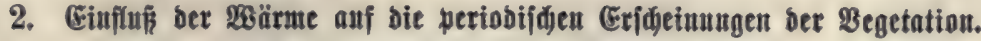

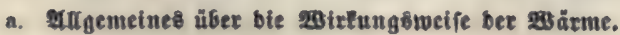

Mie Sebermann betannt ift, Gängen bie periobijdhen (Erfidjeinungen ber

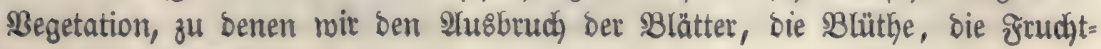


reife und ben $B$ lätterabfall, in gerviffem Sinme auch bie Reimung rechnen, von ber Temperatur ab. WGie lebtere Gierbei mirke, Darüber fino roir burch= aus noch nicht im Slaren; da übrigens bie periobijohen (srjcheinungen alle

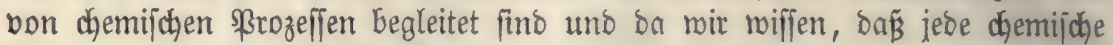
2Yction - fei es nun eine Berbinoung, ober eine Zerjełung - von einem beftimmten $\mathfrak{2}$ ärmegrad bedingt miro, jo ift menigitens einiges sidat auf bie Wirkungen getworfen, welche bie Temperatur bei ben genannten periobijकhen (Erjheinungen ber Begetation Kerborbringt.

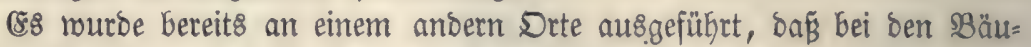
men bie Entfaltung ber Snoppen mit bem Steigen bes Saftes eintritt. Der

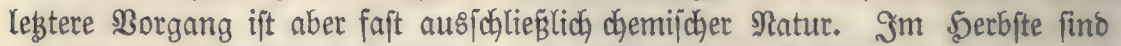
bie Markftrahlenzellen des 5olzes vollgepfropft bon Stärf̈emehlë̈rndyen; im

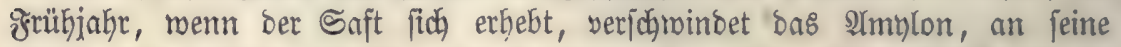

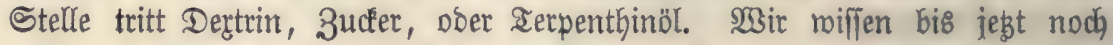
nicht mit Sidjerheit bie Urjache anzugeben, burdy melche bas 2 Imylon in bie lestgenannten Stoffe vermanbelt wirb, menn es idjon wafjricheinlich ijt, bas bie fticfftoffyaltige Subjtanz ber Zellen biejen Hebergang bermittelt. Sollte

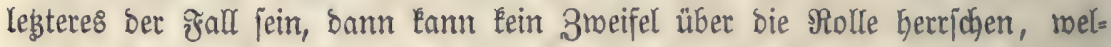

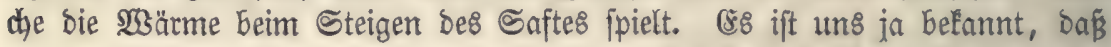

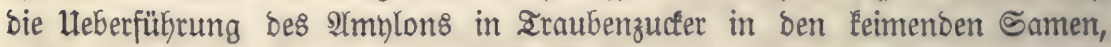
melche burch eine 3erjegung ber fticfiftoffyaltigen organijchen Subftang berwirlt miro, mur bet eimer gemiffen Iemperatur erfolgt. Stud alle übrigen Metho= Den, um Stärkemehl in 3ucter zu vermandeln, wie z. B. Die 2Ynmenoung

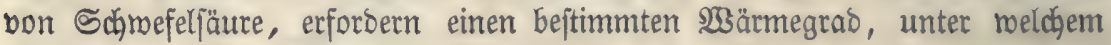
Det Prozeß nicht von ftatten geht.

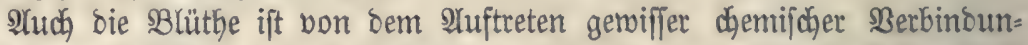
gen (z. B. flüchtigen Delen) begleitet, welche ifg eigentfüumlid fino. Noch

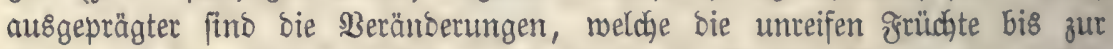

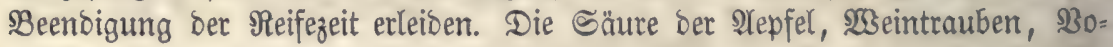

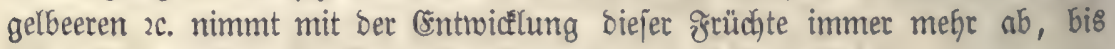
fich zulegt an ifrer Stelle 3ucker, Dertrin, ober Schleim findet.

Şaben wir uns nun bavon überzeugt, baß̄ bie $W_{3}$ ärme eine Bebingung für bie Sebenserfcheinungen Der Gemärbje bilbet, fo kann e\& uns nicht auffal=

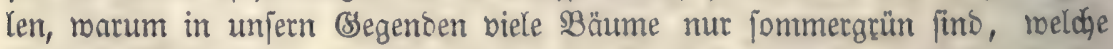

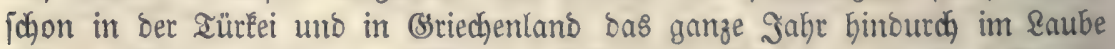
ftehen. In ben rärmeren Slimaten fallen bie Blätter zomar ebenfalls ab, nadjoem fie ifre gunctionen erfüllt baben, allein mittlermeile billon fich fohon

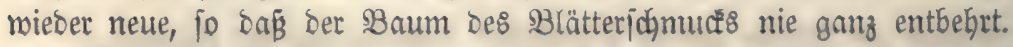

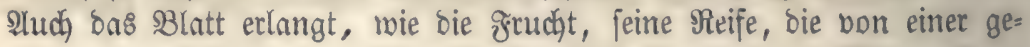
miffen Iemperatur abbängig ift. Sat bieje gefeblt, mar aljo z. BB. ber Som= mer Ealt, fo fallen bie Blätter oft gar nidht ab, fontoern bleiben, felbjt menn fie Durdh bie Säte bes 2 Binters zu Srunde gehen, nod) lauge an ben 3meigen 
Gängen, ähnlich mie bie slătter von unterorücteten Stämmen, meldhe megen

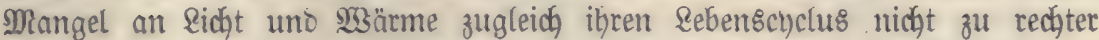

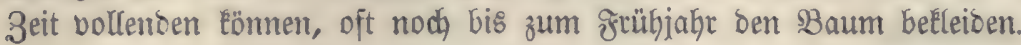

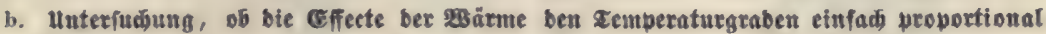 feien.}

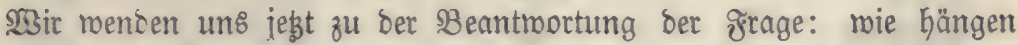
bie periobijdyen (srjheimungen bes vegetativen \&ebens von ber föhe ber Ien=

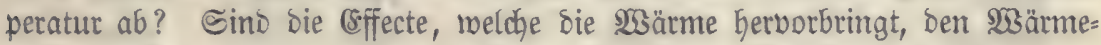
graben einfach proportional, ober findet ein anderes $\mathfrak{B}_{\mathrm{B}} \mathrm{erkältni \xi \beta}$ ftatt?

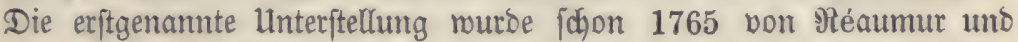
Fpäter von Cotte uno 9roanjon gemadht. Bouffingault unternahm es, ifre

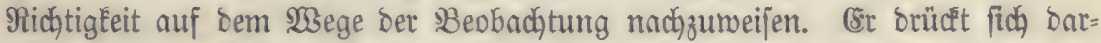
über folgendermaffen aus: $23 e n n$ irgento eine \$3Gaje bes \$flanzenlebens ge-

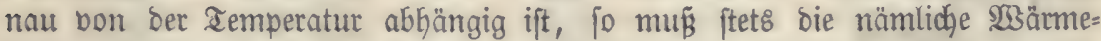
fumme an Dem Drte ber (Sultur erreidt werden, bis bieje \$shaje eintritt, einterlei, meldyes bie sage biejes Drte\& jei. Sierbei ift aber natürlich ange=

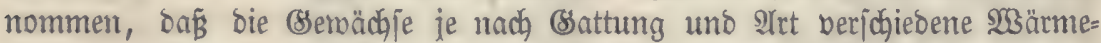

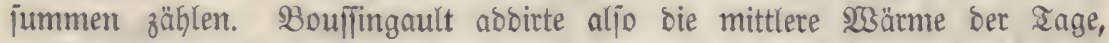

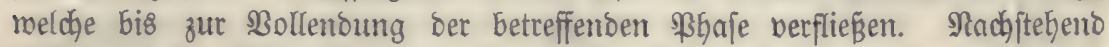
theilen mir bie $\mathfrak{W}$ ärmejummen mit, weldye fid nad) feinen Beobachtungen

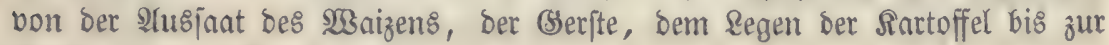
Cernote biejer grtühte ergeben.

\section{NBaizen.}

Drte

Bectgelbronn in Eljaß

Sommetwaizen

Winterwaizen

Bari\&

MBinterwaizen

Singiton (New פyorE)

WBinterwaizen

Sommerwaizen

(Eincinnati (DGio)

Sommermaizen

Dutindugui (am श्lequator)

Sommerwaizen

Sormeto / Benezuela

Irugillo $\{$ Sommerroaizen

Mäblbau|en in হhüringen

WBinterwaizent

a. Dauer ber CuItur. b. Mittl. Temperatur. c. \$robuct auß a. b Tage 
Bectjelbronn

Wintergerfte
Sommergerf
Nlais : "
Negupten "
Singfton "
Sumbal "
Santa=ðé " "

a

122

92

137

90

92

168

122

(8)erfte.

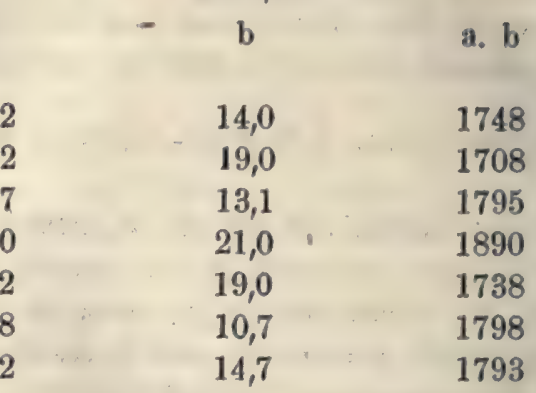

sartoffel.

Erjąí 1836

" Durchifunitt

Alais

Mühlhaujen (รhür.)

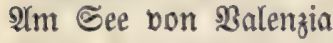

Meriba (Borbilleren)

Santa =₹ré

Binantura (am 2́ntijaná) b

157

183

183

133

120

137

200
18,2

18,2

21,1

15,56

25,5

22,0

14,7

11,0 a. b

3039

2944

3228

2078

3060

3060

2930

3036

3192

- 3180

Cambugan (am (Eotocache, Alequator) circa 11 Monate ? Bujuqui baj. circa 200 I. $\quad 15,5$

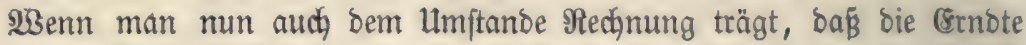

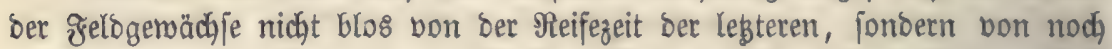

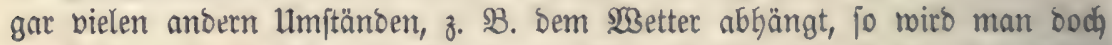
bie Differenzen, reldhe bie Bouffingault'jenen 3ahlen für eines und basfelbe

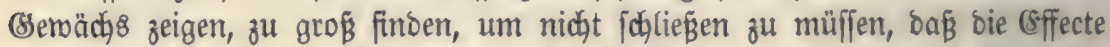
Der $\mathfrak{3} 3$ ärme ben remperaturgraben nidjt einfady proportional jeien. Dies lebrt aud fichon folgenbe fimple Betradhtung. Man habe an zmei angen binter einanber bie remperatur bon $8^{0}$ beobachtet, an einem britten Inge bie

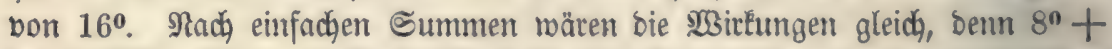

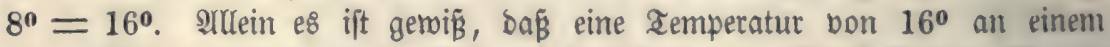

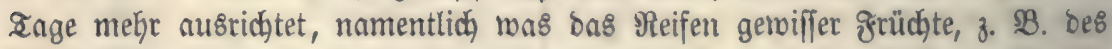

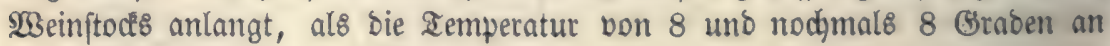
grwei aufeinanberfolgenten Tagen.

\section{c. Boraแซ์ ber Duabrate ber Iemperaturen.}

Um ben eben berührten 2Tnjtano zu bejeitigen, nahm Ruetelet bypothe:

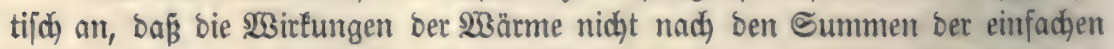
Temperaturgrabe, jonbern nady ben Summen ber quabrirten Iemperaturen 


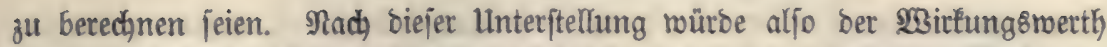
von zmeimal $8^{0}$ nicht 16 , jondern $8^{2}+8^{2}=64+64=128$, Der $\mathfrak{W}_{\text {Sittungs: }}$ merth von $16^{0}$ aber $16^{2}=256$ fein, es mürbe baher eine einmalige Iempe= ratur von $16^{\circ}$ ber $\Re$ egetntion boppelt fo viel nügen, als zroei auf einander= folgenoe Temperaturen bon je 8 Sraben. ITugenidjeinlich fommt bie Quete-

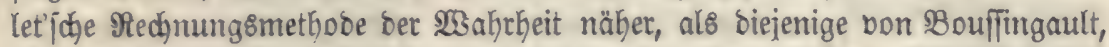

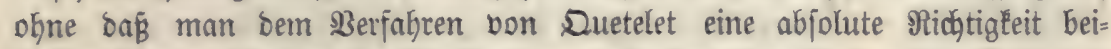

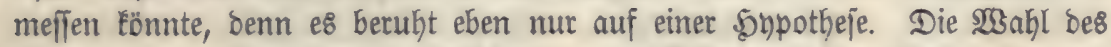

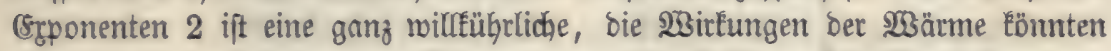
eben jo gut einer andern Botenz proportional jein. Die Beobadtungen, weldhe Quetelet anjtellte, um jeine Zählmethobe zu redhtfertigen, iprechen zrwar

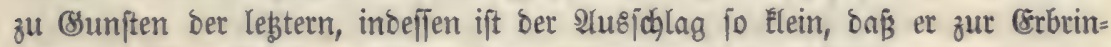
gung bes Berveijes łaum für geeignet befunoen werben bủrfte.

Quetelet berechnete, bañ bie Summe ber einfadjen Iemperaturen, meldhe fich vom erften frofffreien Iage bis zum (Eintritt ber \$Blüthe ber Syringe et= geben, 476, bie હumme ber Quabrate ber Iemperaturen 4296 beträgt. 3ählt man nur, jagt Duetelet, in irgeno einem andern Jahre von bem nämlichen

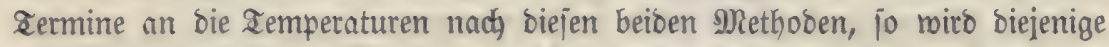

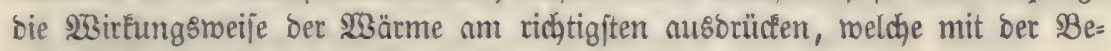
obachtung am genauejten übereinjtimmt.

शach) Quetelet follte bie Suringe blühen

im Sabe nad) ber Summe

Der eimfachen ber quabriten fie blühte aber wirtlich Semperaturen

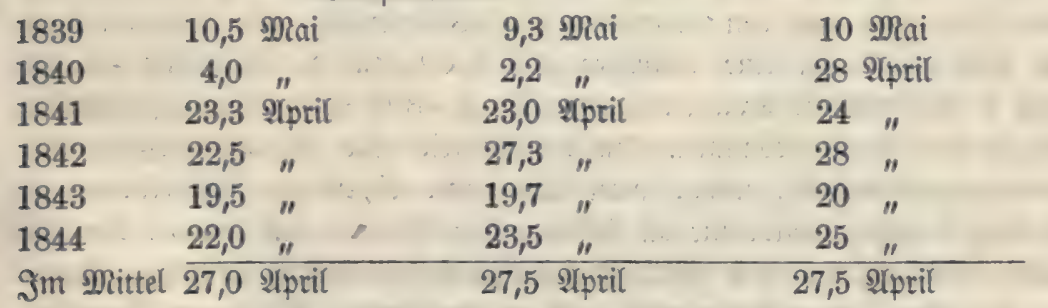

2Bie man fieft, ftinımt bie Rechnung !nach quabritten Temperaturen ge= nauer mit ber Beobactung überein, als biejenige nach eimfachen Zemperatu=

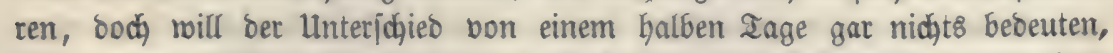
benn Seber, weldjer jđłon einmal verjudyt hat, die Blüthezeit irgento einer

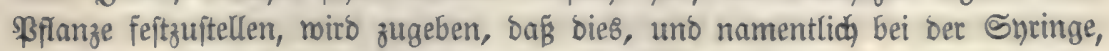
nicht genau auf einen halben $\mathfrak{I} a g$ benerlftelligt werben Eann. Die folgenden Beipiele, in weldyen a bie Summe ber Duabrate, b ber einfadyen Tempera=

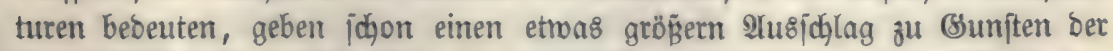
Quetelet'juen sypotbeje, fint aber gleidffalls nidgt volléommen entidheibent. 
grudtreife

Fragaria vesca

\section{1}

\section{$1842 \quad 1843$}

1844

Inittel

Sbeobachtet 24 Mai

1 Suni 15 Suni

a 1200024

(b 102228

Ribes rubrum uno

Ribes nigrum

(beobadatet 9 guni 12

a 1440029 M) 11

b 1170

5 ฐันni 10

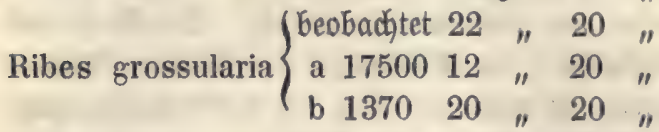

17

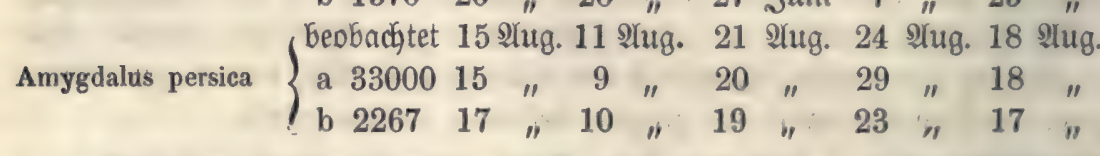

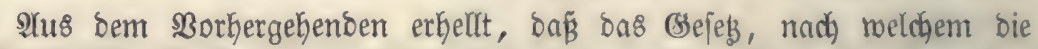

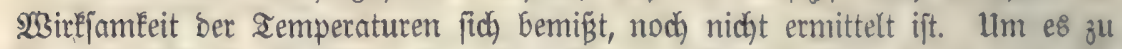
finoen, müffen nod) viele anoere snppotbefen aufgeftellt und burch eine zahl= reiche Reife von Beobadjtungen geprüft merben.

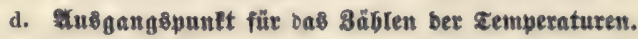

$23 e n n$ man bei bem Summiren ber Temperaturen nad bem Berfahtent bon (Sotte ober Quetelet biejenigen Temperaturgrabe, meldje über bem (Be= frierpunct liegen, als pofitiv, biejenigen unter 0 aber als negativ zäblt, fo un= terftellt man, baß́ alle pofitiven aemperaturen ben Gintritt ber betreffenden Begetationsphaje begünftigen und baßs alle negatiben Temperaturen ein fohon

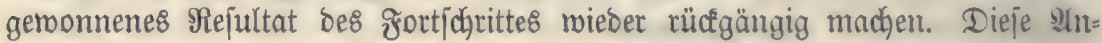

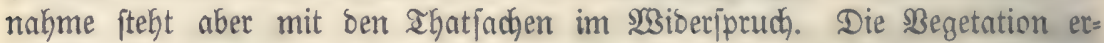
wacht nicht gerabe bei einer Iemperatur bon $0^{0}$, für bie Mehrzahl ber Ge= mächfe ift eine mittlere Sagestemperatur von 6 -8 Srnben über 0 erforberlich, bamit fie in's areiben Eommen. Itm ben (sintritt einer ßegetationspbaje ridftig vorauszubefitimmen, müpte nian baher nur biejenigen zemperaturen in

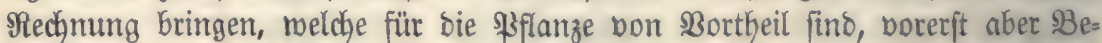
obachtungen über bas nod̆ zuträgliche Iemperaturminimum anjtelten. Ebenjo räre mit ben aemperaturen unter $0^{0}$ zu berfahren. Diejenigen (Setwädjle, melche Iemperaturen unter $\mathbf{0}^{\circ}$, ohne zu erfrieren, ertragen, werben burch

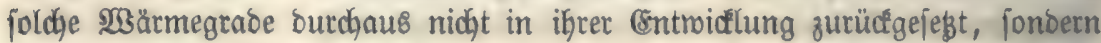
nur aufgehalten; bie dhemijachen Beränoerungen bes Belleninhaltes gerathen in's Stoden, fegen fich aber mit bem (sintritt höherer Iemweraturen nugen=

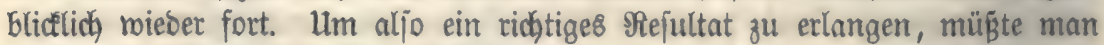

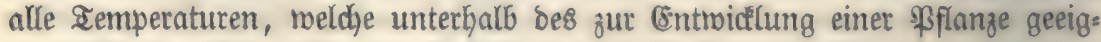

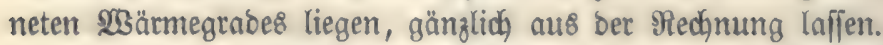

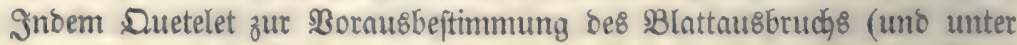
Umftänden aud) ber Blüthe) bie Iemperaturen vom erften froftfreien Iage an 
zäblt, vermeibet er Glos bie negativen Iemperaturgrabe, aber nicht bie pofitiben, weldye unterbalb bes für bie $\mathfrak{B}$ egetation nodh zuträglichen Iemperatur= minimums begriffen find. NYus biejem SBerjehen find bie Differenzen żwijoben

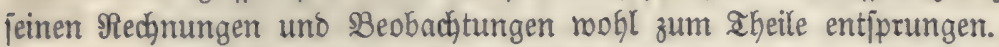

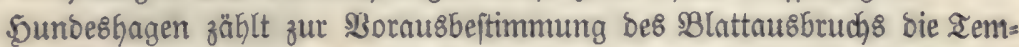
peratur vom $B$ lätterabfalle im Serbfte an burch ben ganzen $23 i n t e r$ Gin=

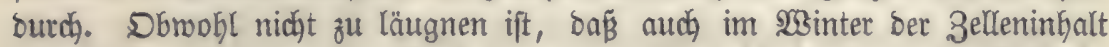

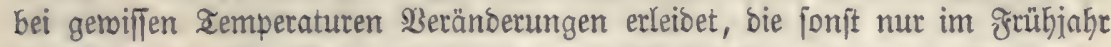

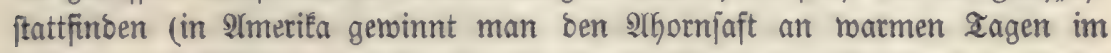

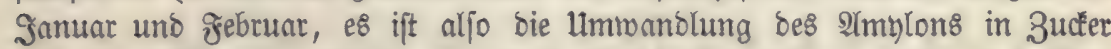
ichon im 23 inter vor fich gegangen), jo find ooch bie Temperaturen bes $23 i n=$

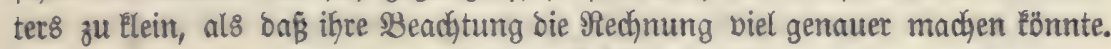

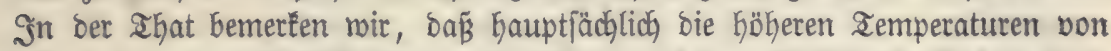

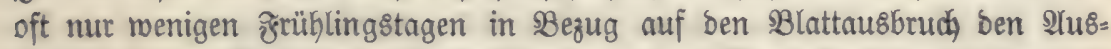
idflag geben. WBie menig bie Temperaturen bes 2 sinters mirfen, jeben wir

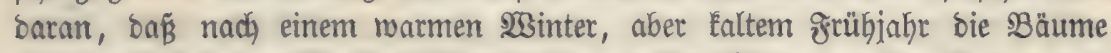

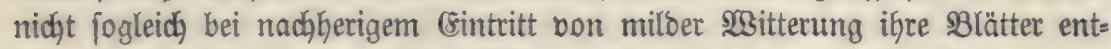

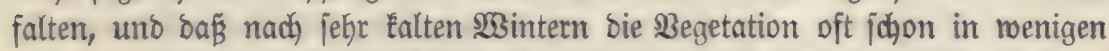

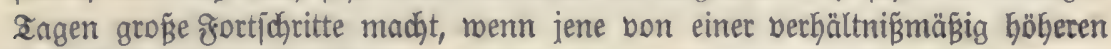
Temperatur begleitet fint.

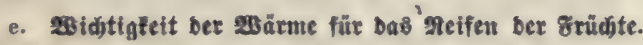

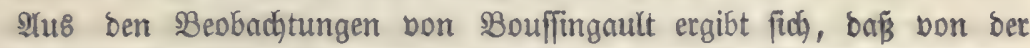

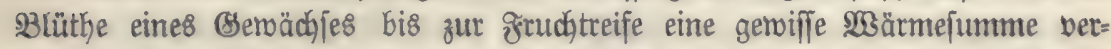

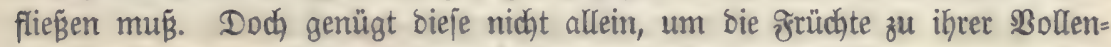
bung zu bringen; hierzu finઠ außerbem noch beftimmte böbere Iımperatur= grabe exforberlid. Sonoon unt franefurt am Main baben biefelbe mittlere

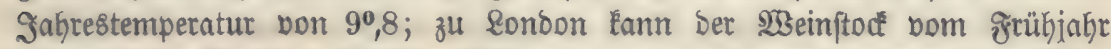

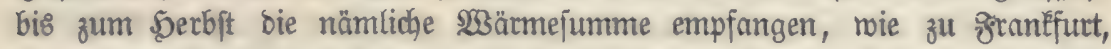
und bennod, find bie Trauben in Englano zut 2 seinbereitung untauglich.

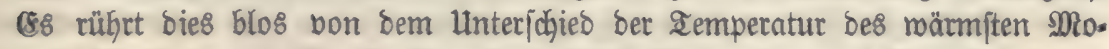

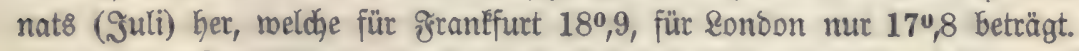

Bei unjern Bäumen reerden bie Blüthetnofpen ein Sahr früher gebil=

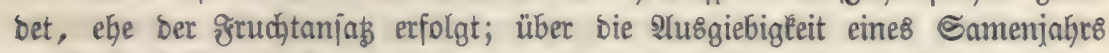
enticheibet baher bie remperatur von zrwei Sommern. 88 müffen hier zmei (rreigniffe zujammentreten, um ein brittes möglids zu madjen, uno ba zujam=

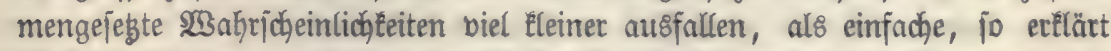
es fich leidht, warum jogenannte Bollmajten fo jelten find. ఇebmen wir bei= ipielsmeije an, in irgeno einer Bregento trete alle a Jahre ein fo warmer Som= mer ein, wie er zur fruchtbiloung erforberlidy ift, fo wirb bie $23 a b r f d$ einlid)= feit, baß̉ ein genoiffes Jaht einen foldgen Sommer erfält, $=\frac{1}{a}$ fein. Die 


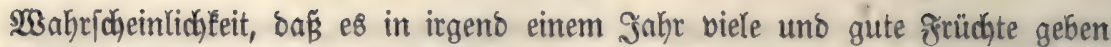
werbe, was aljo von zwei aufeinanoer folgenten warmen Jabren abjängt, ilt aber $=\frac{1}{a} \cdot \frac{1}{a}=\frac{1}{a^{2}}$; wenn \%. B. $a=4$ ift, fo tritt nur alle 16 Sabte eine reichliche Samenernote ein. Möglich, ift $e 8$, baf̈ bie $\mathfrak{B}$ lüthenënofpenbil= bung andere Temperaturen erforbert, als bie fruchtreife; in biejem જall ift

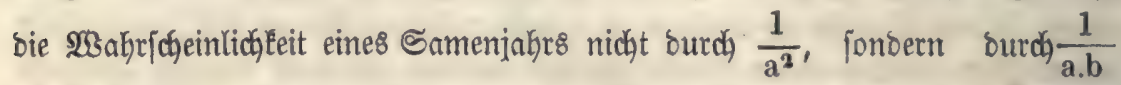

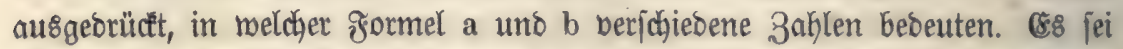
3. 98. $a=4, b=6$, io ijt $\frac{1}{a \cdot b}=\frac{1}{24}$, was fagen will, baji nad, ben

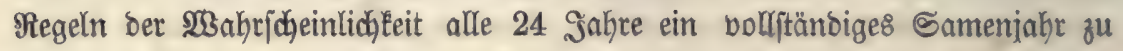
ermarten jei.

greiftehenoe Bäume tragen häufiger uno reidhlidger Samen, als foldhe in gejobloffenen Beftänben, weil hier ber (sinzelftamm nidht fo viele şärme erf̧ält, als ba, no bie Sonne eime größ̈ere $3 a$ hl von Blättern treffen kann.

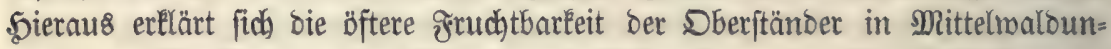

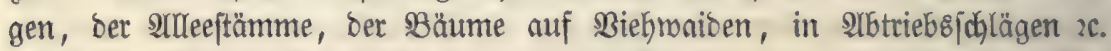

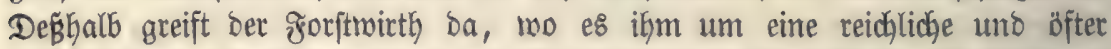

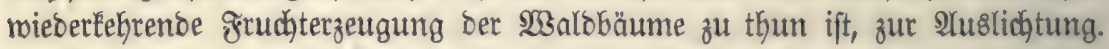
(Borbieb bei der natürlidjen Berjüngung). $D b$ das Connenlidgt in Bezug

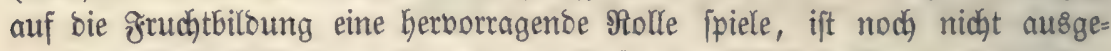

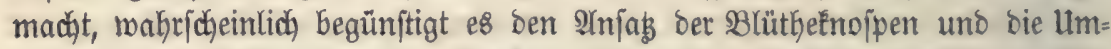

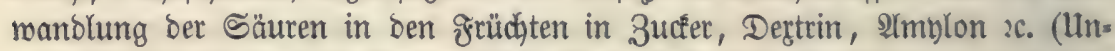
reife ortüchte icheiden im Sonmenlidjte Sauerftoff aus. Sauffure).

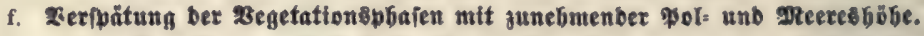

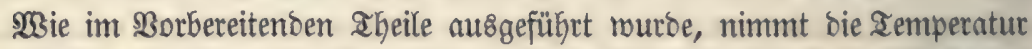
$a b$, je meiter ein Drt bom Slequator entfernt ober über ber Meeresfläche er=

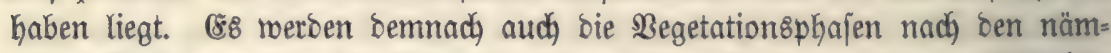

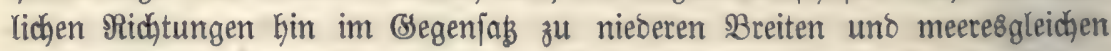
sagen fich verfpäten. Da aber bas (Sefej Ser Temperaturabnatyme nadj bem ßol uno ben höheren Regionen bes \&ufttreijes hin nidjt blos von ben ma=

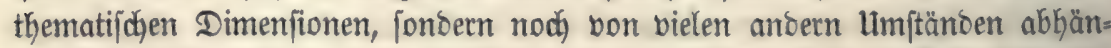

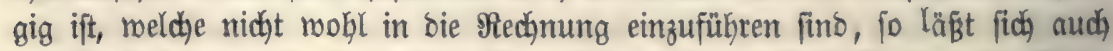

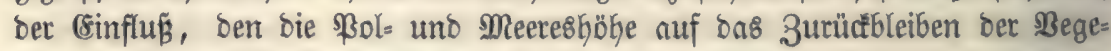
tation äufert, nicht für jeben Drt im Bornus beftimmen.

Die (Sigenţümlichkeiten bes Rüften= uno Binnenlanbelima's madhen fid

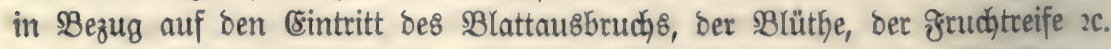
in auffallentem Mafie geltent. Sänber, weldhe in ber Näbe ber See liegen, haben wärmere $2 B$ inter, als Drte tief im Continente, Dagegen fino regtere

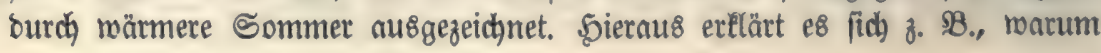


in Briuffel (mit 20,5 Wintertemperatur), roo ber 1 Beinftod früfer austreibt, als in Ungarn, f. B. Dfen (mit 0,06 Mintertemperatur), bie Trauben zur Meinbereitung nicht benubt werben ënnen, während man in Ungarn bor=

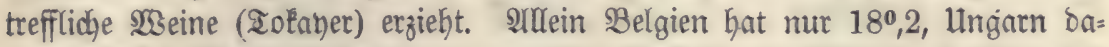

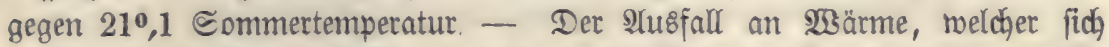
burch bas johiefere 21uffallen ber Sonnenftrahlen in höheren Breiten ergibt, mirs zum Theile wieber erjegt Durdh bie längere Dauer bes $\mathfrak{I} a g e 8$ uno ber

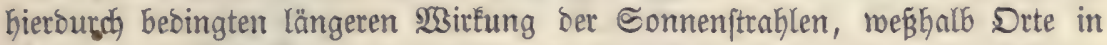

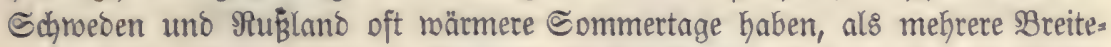
grabe tiefer gelegene Drte in (England. Daher fommt e\& Denn, baß̈ bie (5rnote

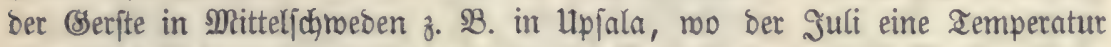
von $17 \%$ befigt, burdy/d)nittlich 10 aage früber eintritt, als in England, mo

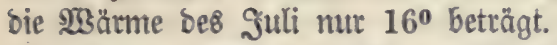

Bon groß̧em (Einfluffe auf bie Bollendung ber Begetation\&phyajen ift ber

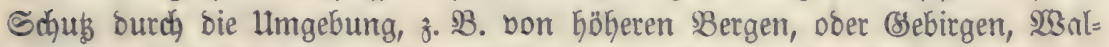
Dungen zc. Dieje berwirken oft mehr, als eine um mehrere Brabe jüblidgere Enge.

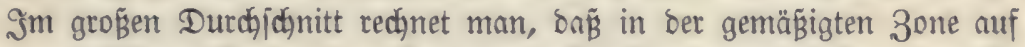

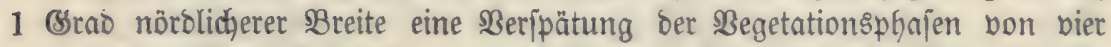
Iagen fommt. Dodh ift bies, wie bemertt, nur eine Durdjidnittszahl. In Franefurt am Main idhlagen bie sBäume oft acht bis vierzehn Iage früher

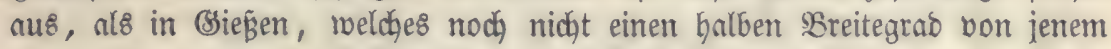
entfernt liegt; biejer Unterjofied ift bem Sdyuge zuzujd)reiben, meldyen bie Berge bes zaumus dem im ahale gelegenen ¡ranlffurt gemähren.

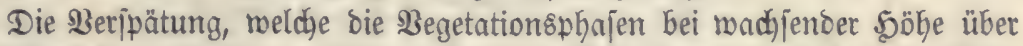

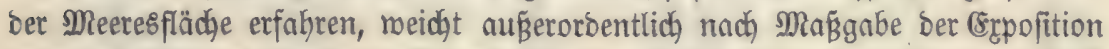
und bes Schuzes burch die llmgebung ab. Daker fann es vorfommen, dafis an einem höher gelegenen Drte ber Blattausbrudh), die Blüthe 2 . früher ein= treten, als in einer viel tieferen \&nge. 3ur Beftätigung biejes ธałes mögen einige bon $\mathfrak{W}_{\text {effely }}$ mitgetheilte IIngaben, welche bem (Sebiete ber Defterrei= childen $\mathfrak{A}(p e n$ entnommen jimb, bienen. 
离

हี

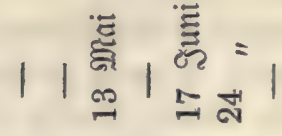

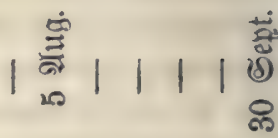

돋ㅇ

$\left|\begin{array}{l}\text { हี } \\ \text { เू }\end{array}\right|$

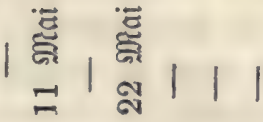

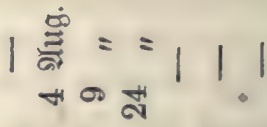

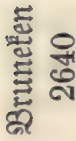

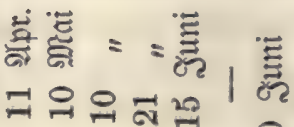

오

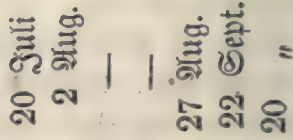

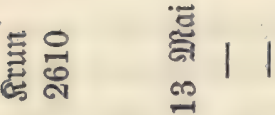

1111 离

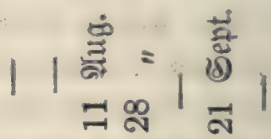

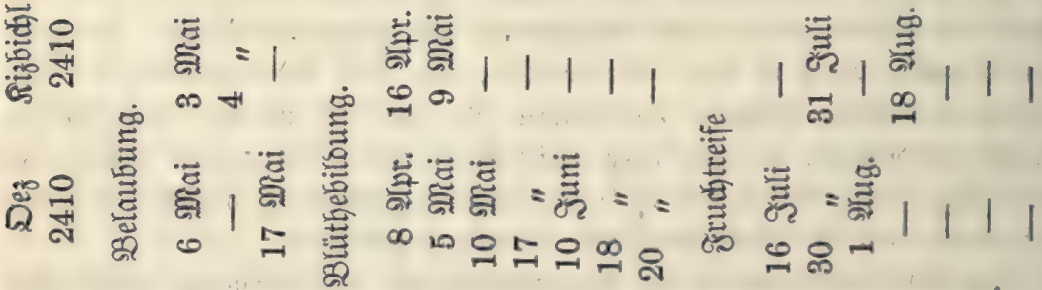

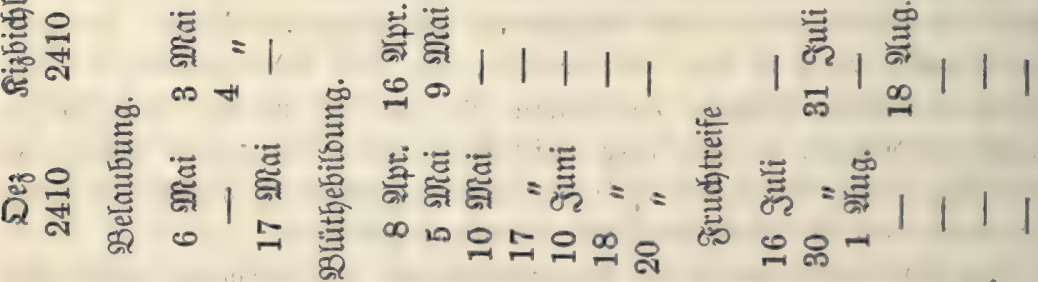

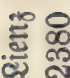

हैं $=$

$\infty=\infty$

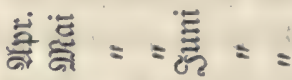

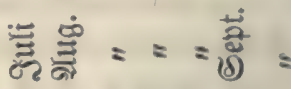

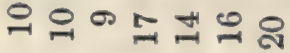

네

릉 ᄚ

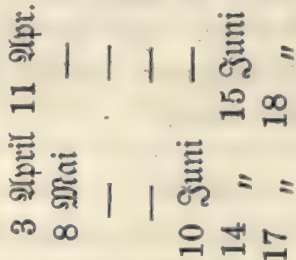

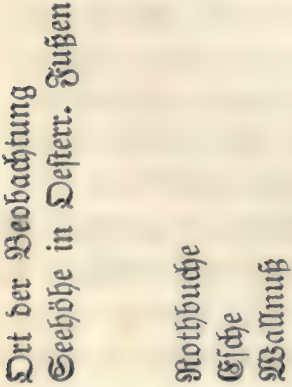

हृँّ

류요

हूँ

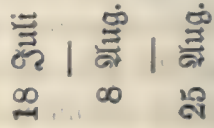


Nach ben sBeobadtungen, welche $B$ erghaus in ben Sahren 1833-34 in Eachjen aufjeichnete, berjpätet fich für 333 Meter Errhebung über ben Meeresీ|piegel

bei

\begin{tabular}{|c|c|}
\hline Wintermaizen & um 22 \\
\hline Poggen & " 13 \\
\hline Safer & " 20 \\
\hline Berfte & $\| 22$ \\
\hline Sartoffer & " 23 \\
\hline
\end{tabular}

bie Grmote

um 22 ?age

$\begin{array}{rrr}\text { " } & 22 & \\ \text { " } & 14 & \\ \text { " } & 22 & \text { " } \\ \text { " } & 5 & \end{array}$

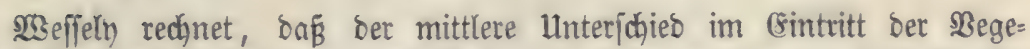
tation8phajen für je 200 Meter Seehöhe etwa 6 Tage beträgt. Dies ift aber nadi b'2ubuiffon bie 5öhe, weldye in ben Artpen einer Iemperaturabnabme

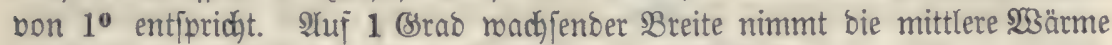
um $0^{n}, 6$; aljo auf 1,66 srad 3 reite um 1 bollen (3rab bes Thermometer8

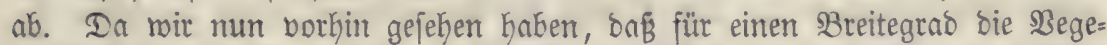
tationsphajen um etro 7 Inge zurüubleiben, fo folgt, bnfí eine gleiche Iem= peraturberminberung in vertifaler ßidhtung, faft ben nämlidhen Effect in $\mathfrak{B} e=$ zug auf bie periobijchen Erjdyeinungen ber Begetation herborbringt, wie in borizontaler. Michtung.

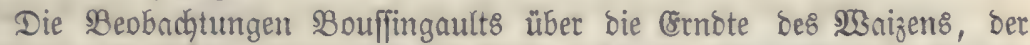
Berfte und Sartoffeln zeigen, wie bie Zeit, weldhe ein Berwädjs braudit, um eine $\mathfrak{B e g e t a t i o n s p h a j e ~ z u ~ v o l l e n d e n , ~ m i t ~ b e r ~ B r e i t e ~ z u n i m m t . ~ D i e s ~ L a n n ~ n a s ~}$ türlid nicht anbers fein, benn menn bie mittlere Tagestemperatur geringer miro, fo ift eine grögere 3akl von aagen erforberlid, bamit bie nämliche

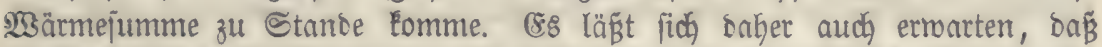
bie ipät ermadjenbe Begetation ber Sodjgebirge längere Zeit bebarf, um eine befitimmte $B$ haje zu erreichen, als bie \$flanzen in ber Ebene. $23 i r$ laffen zur

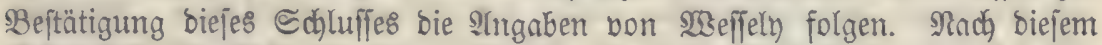

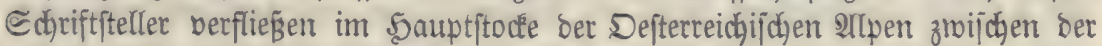
Blüthenbiloung uns frudhtreife

\begin{tabular}{|c|c|c|c|}
\hline $\begin{array}{l}\text { Seehöhe in } \\
\text { Defter. ₹unken }\end{array}$ & Ririche & SWinterroggen & Gserjte \\
\hline $1500-2000$ & 51 Tage & 44 Tage & 44 Iage \\
\hline $2000-3000$ & $69 \quad$ & $46 \ldots$ & $47 "$ \\
\hline $3000-4000$ & 78 & 47 & 47 \\
\hline $4000-5000$ & - & 50 & 48 \\
\hline $5000-6000$ & - & 56 & 51 \\
\hline
\end{tabular}

WBir Gaben oben darauf aufmerEjam gemadyt, mie jehr bie Şäufigfeit

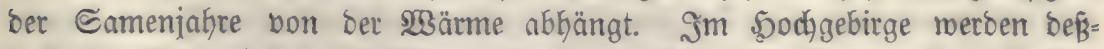
halb bie Eamenjatire biel jeltener eintreten, als in ber (Ebene. Nadh SEeffelty erfolgt bei ber ঔ̊idyte ein zur natürlichen Berjüngung genügender Samenabfall 
Sn einer Meeresfïhe

von Dejter. §ußsen

1000
2000
3000
4000
4500
5000
5500
6000

in Norbabfalle und im Souptifoct" ber 2 Ilpen innerbalb 3 Jabren

$\begin{array}{lrl}" & 4 & " \\ " & 6 & " \\ " & 8 & " \\ " & 11 & " \\ " & - & " \\ " & - & " \\ \text { " } & - & \end{array}$

im Sübabfalle

ber Illpen

innerbalb 3 Jabren

$\begin{array}{lrl}\text { " } & 4 & \text { " } \\ " & 5 & " \\ \prime \prime & 6 & " \\ " & 7 & \prime \prime \\ " & 8 & " \\ " & 11 & \end{array}$

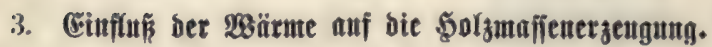

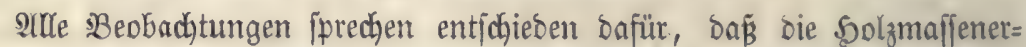
zeugung unter fonft günftigen Berbältniffen burdh bie $\mathfrak{B a ̈ r m e ~ b e j o l e u n i g t ~}$

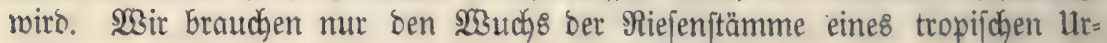

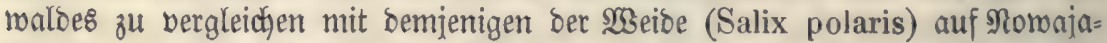
Semlja, bie in Gunoert Sahren fid Eaum 16 Centimeter über ben Mroosirajen erkebt, in roeldyem ber Eriechende Stamm fidh berbirgt, ber oft erft in Der boppelten 3eit eine Dicfe von 4-5 Centimetern exlangt.

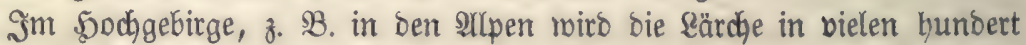
Jahren oft nicht jtärker, als auf einem ihr zujagenden Boben bes glachlanos in einem balben Sabrbundert.

Dagegen ift e\& eine ausgemadyte Thatjadje, baß̈ in ben Ealten Ragen

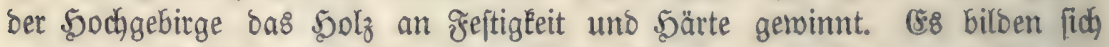
bie weiten Bsefäfe ober 3ellen bes frühlingsholzes in geringerer $3 a b l$ aus,

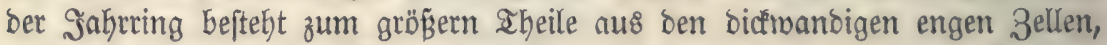
weldye bei bem in Der (Bbene erroadjenen 5olze mehr an ber bem centrum

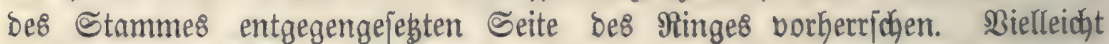

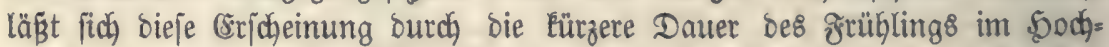
gebirge erllären. Der Uebergang vom $\mathfrak{W}$ inter zum Sommer ift bier viel

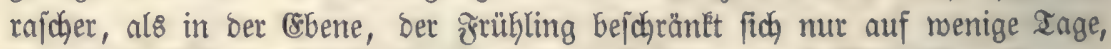
in weldyen fich eben fo wenige ber weiten 3ellen ober Befäge billoen tömnen.

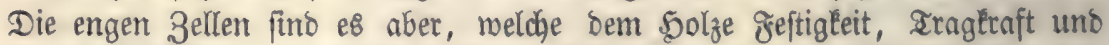

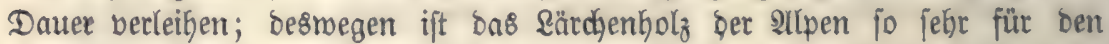

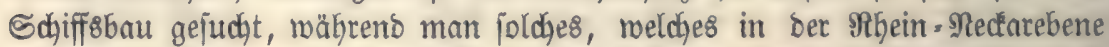

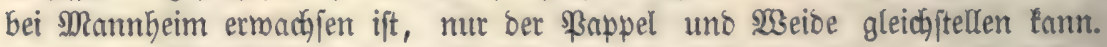

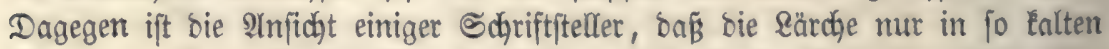

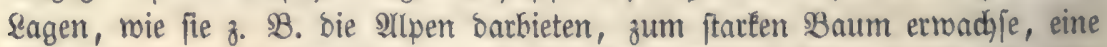

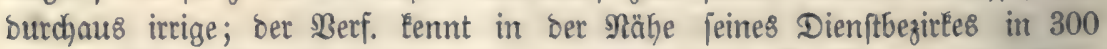

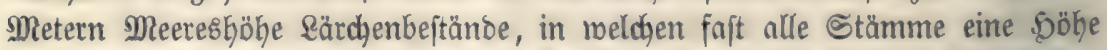
bon 30 Metern uno eine Stärlée von $1 / 2 \ldots 3 / 4$ Metern aufzumeijen haben,

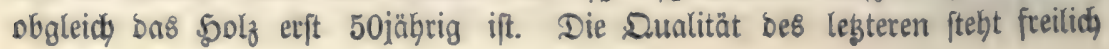


Derjenigen ber ellpenlärche etwas nach, ift aber noch immer vortrefflidh gemug,

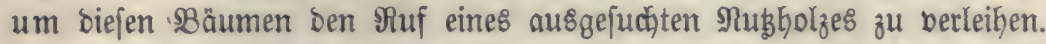

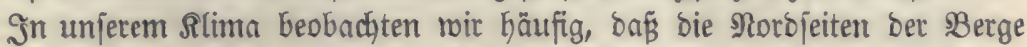

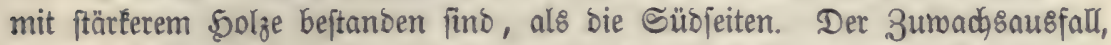

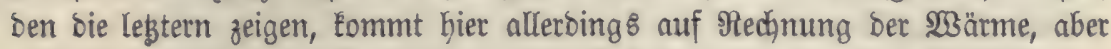

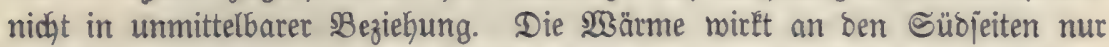
beşhalb nadytheilig auf bie \$olzmaffenerzengung ein, meil fie bie Feudjtigkeit

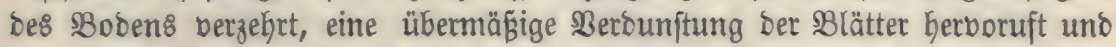
Den 5ุmu\&, namentlid) bie abgefallenen bürren \$(ätter fo meit austrod́net,

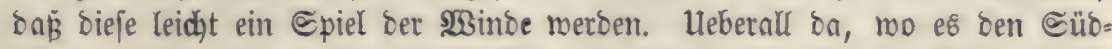
jeiten nidht an natürlicher Feuchtigfeit mangelt, no z. SB. Der SBoben burch

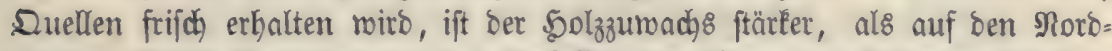
jeiten. Diefez \$erbalten hat ber Berfaffer zum öfteren im ๔dymarzmals beo= baditet.

(58 gibt leine Baumart, ja man Kann jagen, Keine Pflanze, meldhe in

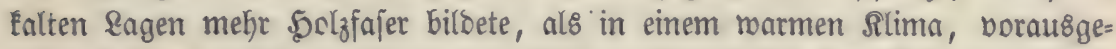

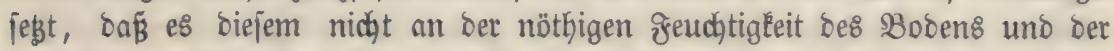

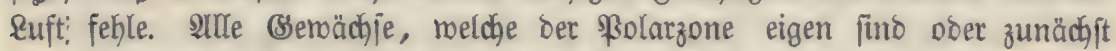
Der Sdhneegrenze im şodhgebirge mohnen, find an biejen @tanoort nicht

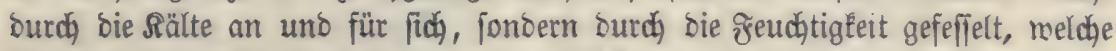
ifnen bort fu Bebote ftebt ober ifnen felbit, megen ber geringen SBerounftung, erbarten Bleibt. SBringen wir dieje Sflanzen in bie feudste 2ltmofphäre eines

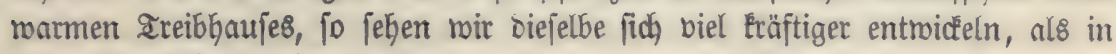
igrer eigentliçen \$eimatb̆.

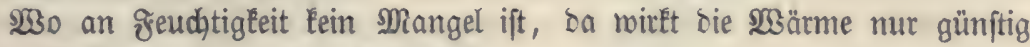
auf bie MRaffenerzeugung Des 5olzes ein.

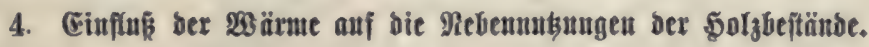

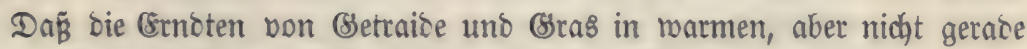
trodenen \&agen beffer ausfallen, als auf Ealten હtantorten, ift eine aubige= madhte Sadje.

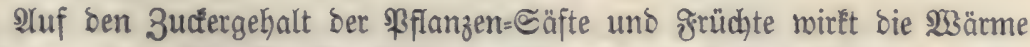
verjojieben ein. (8s gibt (semächje, meldye nur in heif́en Slimaten 3ucker liefern, mährend bei andern bie Crgiebigkeeit an 3udfer abnimmt, jobald fie aus der gemäßigten in bie Geifie 3one gebradat metben. 3u cen erfteren

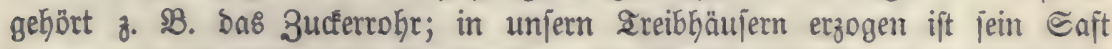
ărmer, als berjenige der Runfeltübe. Die 2lepfel uno Birnen bagegen ver= lieren in ber heigen 3one an Eüße. Der 3uffergehalt bes 2Akornjaftes ift in joldhen Begenden am größ̈ten, welche neben recht narmen હommern Ealte

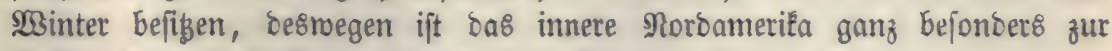
Cultur ber auf 3udfer zu benugenden श्रhorne gefobidt.

Der Behalt ber (8id)enrinbe an Sserbjtoff joheint im jüblichen Deutjoch= 


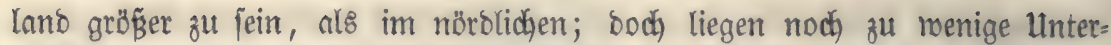

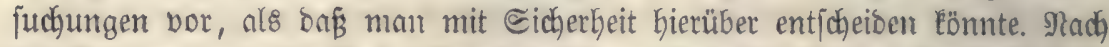
Den Srfahrungen bes Berf. ift im mittleren Deutichland ber Berbftoffigehalt

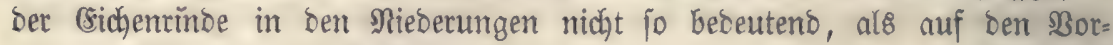
bergen uno in etwas etponirten \&agen.

Die Sinoppern etzeugen fich nur in Segenden mit warmen Sommern.

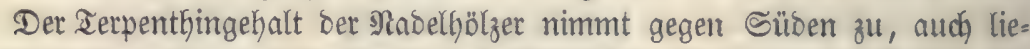

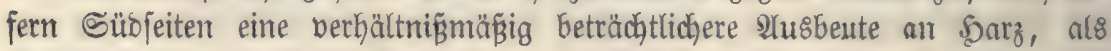
Rorbjeiten.

\section{Gike.}

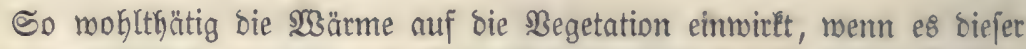
nidjt an Feuthtigkeit mangelt, eben fo jobäblid, wiro fie im entgegengejess= ten galle.

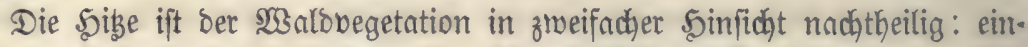

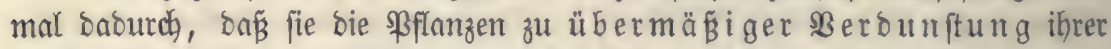
Freuchtigeit reizt, zum andern megen der 248 tro

2lm meiften leiben burch) bie Sizge biejenigen Solzarten, meldhe ichon an

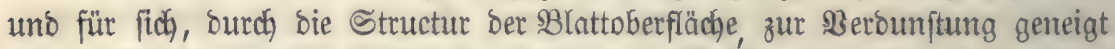

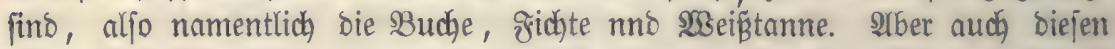

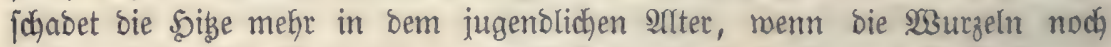
nidat tief in Den Boben eingemurzelt fint. Dafs fladimurzelnto Solzarten, namentlidh auf einem nidyt tiefgrünoigen Boben ber size eher unterliegen,

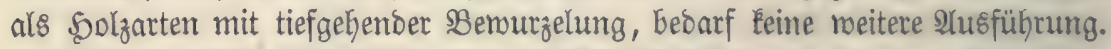

(sine erhöhte Temperatur ber Ruft im Schatten miro ben Bemödjjen bei meitem nidht jo nachtheilig, als bas birecte Aluffallen ber Somnenftablent,

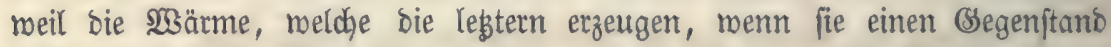
treffen, viel größer ift, als bie aemperatur, melche bie \&uft felbit annehmen

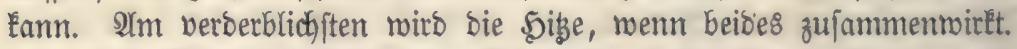

Die $\mathfrak{3 a ̈ r m e , ~ w e l d y e ~ e i n e m ~ R o ̈ r p e r ~ b u r d h ~ b i e ~ S o n n e n f t r a b l e n ~ m i t g e t h e i l t ~}$

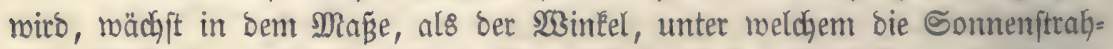
len auffallen, einem red)ten fid nähert. Daher leiben bie ßffanzen burch bie

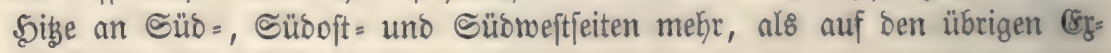
pofitionen unt auf ebenen Ragen.

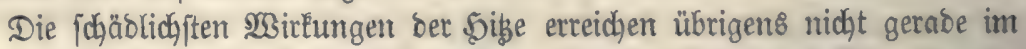
Sommerfolftitium, aljo im legten Drittel beళ Suni, ifren Göchften Betrag, menn fobon bie Sonne zu biefer Zeit am hörhiten fteht; bie Berkeerungen ber Dürre treten bielmehr am ftärêften ourchjobnittlich im Suli uno felbft im Suguft

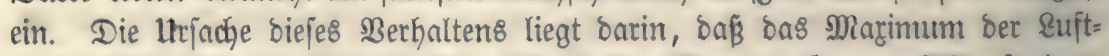

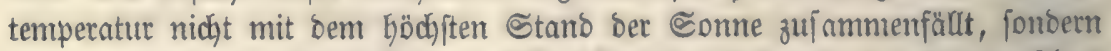
etwa einen Monat päter erfolgt. Bis bahin hat fid) zwar bie Somme fohon

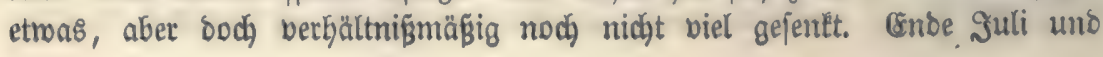


SYnfang Qluguft bilden aljo bie \$eriobe, in welcher eine foldhe Zemperatur ber \&uft, uno ein boher Stand Der Conne zujammentreffen. Um bieje Zeit hat

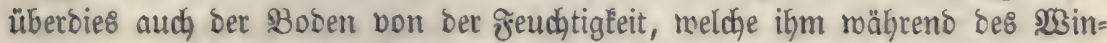
ters unઠ bes früblings zu Iheil geworben rar, ichon biel berloren, menn

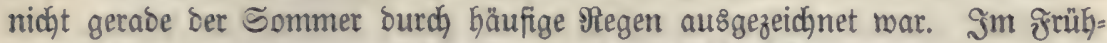
jabr find zroar bie jungen SPFlänzchen nodh biel jofroädher benurzelt, als im Sommer, trog Dem rafft bie Düre in Der leģteren Safrezzeit eine größ̈̈ere

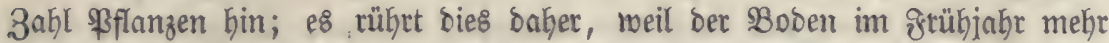
Feuchtigkeit befỉst, als im ๔ommer. Siermit joll übrigens nicht gejagt jein,

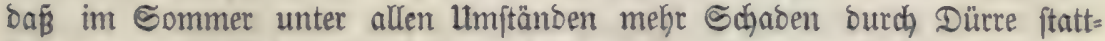
finbet, gar oft ift bas grühjafy trodfen und ber Sommer feucht, in biejem

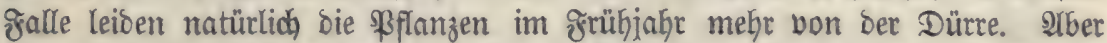
im gropen Durchidhnitt fterben bodg im Sommer, uno zroar rnoe Suli uno

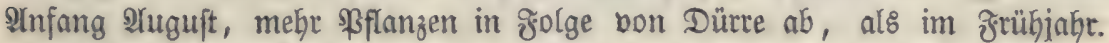

2lm verberblidyiten reerben bie Sonnenftrahlen ben 5olzpflanzen bann, menn fie bieje bon zmei Seiten zugleich treffen, nämlich einmal birect (a)

§igut 161 .

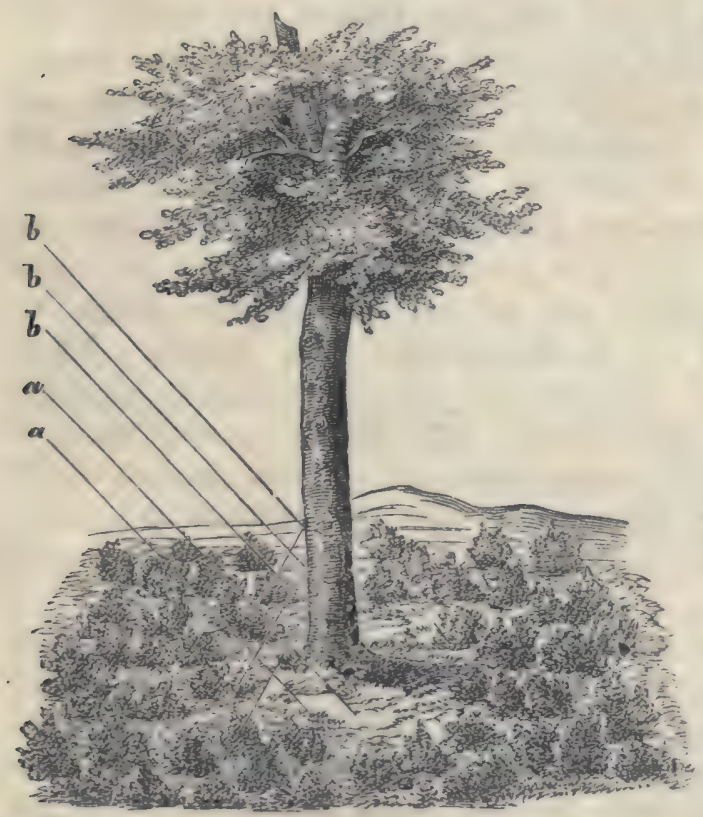

(ə)ig. 161.) und bas an= bere $\mathfrak{M a l}$ Durch) Reflerion (b). Diejer Fall ereigntet fich am băufigften in ben

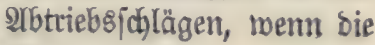
Mutterbäume z̆ll lange üGergebalten werben uno enotidi) jo lidat zu fteben fommen, bafi bie Sonnen= frablen bie Stammrinde birect treffen tonnen. Sift bieje nun glatt ober hat fie, wie bei ältern 28 udjen uno 2 Seistannen uno bei Birfen ber Jall ift, eine Gelle garbe, fo wirlt fte mie ein Spiegel, fie gibt bie Somentitrablen (b) in

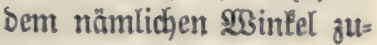
rüc, in welchem bieje ber Rinbe zugef́ommen waren.

So wirb benn in ber unmittelbaren Umgebung bes Mutterftammes eine fajt

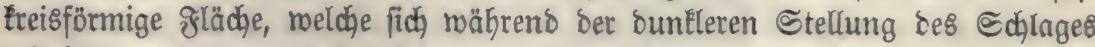

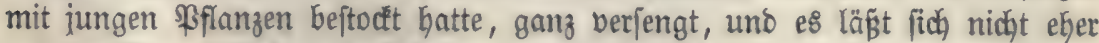
auf Derfelben Eultiviren (gejchroeige benn eine natürlidge Bejanumg erwarten), bis ber bie Eonnenftrablen reflectirende Mutterftamm entfernt morben ift. 


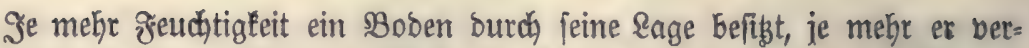
möge feiner 3ujammenjegung gejchicft ijt, fich in bem 3ujtano ber ofrijकe zu erbalten, um fo meniger haben bie auf ifm rackjenben \$flanzen bon einer

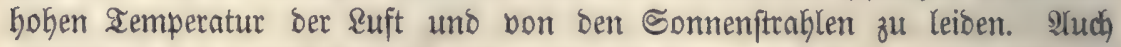

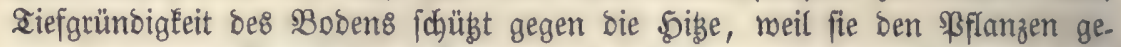
ftattet, längere $\mathfrak{3 u r z e l n ~ z u ~ b i l d e n ~ u n \delta ~ m i t ~ b i e j e n ~ b i e ~ u n t e r e n ~ f r i f c h e r e n ~ ( 5 r \delta = ~}$ idhichten zu etreidyen.

Sit ein Boben mit Bras ober Unfraut überzogen, fo nimmt biejes bie

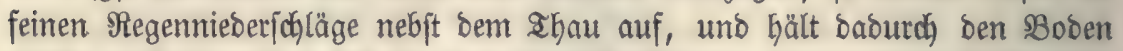
trodfen. Daker laffen fid bie \$olzpflanzen vor ben verberblidfen $23 i r k u n g e n$

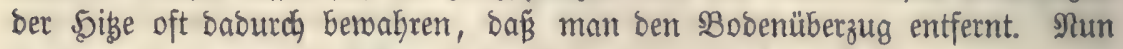

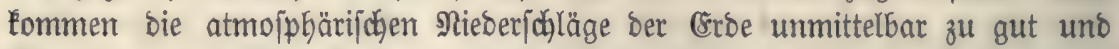

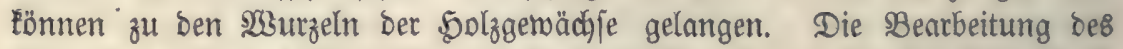

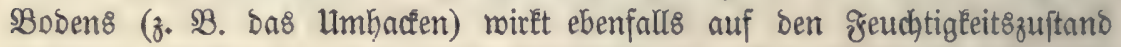
besfelben günftig ein, die rauke Dberfläcje ber (stoe ftrahlt গadyts mehr

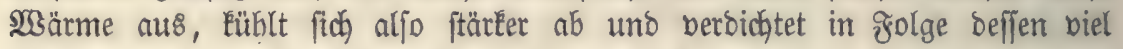

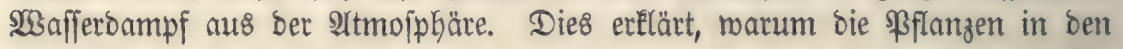
そorftgärten, mo ber sBoden gelockert uno bom Unfraut frei erhalten roiro, meniger von ber Dïrre zu leiben Gaben, ats bie culturen auf bem unzube= reiteten Boben ber $\mathfrak{S a l \delta b i f t r i c t e . ~ D e m ~ B e r f . ~ f i n o ~ S a n o f t r e d f e n ~ b e f ́ a n n t , ~ a u f ~}$ melchen sie Saat ber Riefer jährlich burdh Die Dürte einging; fie gelang erft bann, als ber Boben burch den Bau bon \$adffrüchten oberfläd)lich rauly ge= madht morben mar. Den nämlidjen Dienjt leiftet-ba\& jog. Surzhacfen auf Kahlen, unbejamt gebliebenen Stellen in Den Arbtriebsjojlägen; Der Berf. batte vielfnch) Belegenheit, zu beobachten, mie auf ben wunogemachten ßläłsen ber

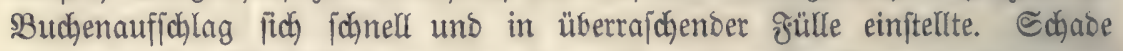

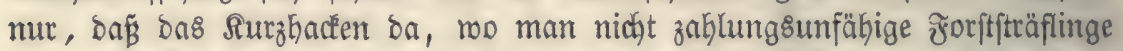

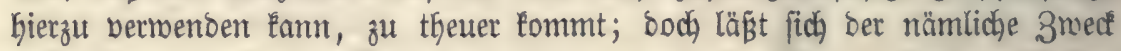

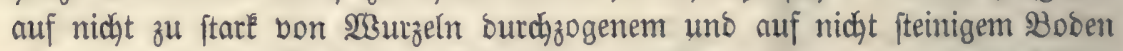
auch burd) ben Umbruch bon Sdyweinen erreichen, Der entroeber ganz toften= frei oder jogar noch gegen eine Bergütung von Seiten ber (sigenthümer biejer shiere exfolgen fann.

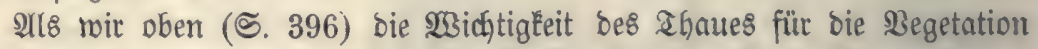

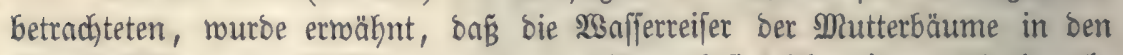

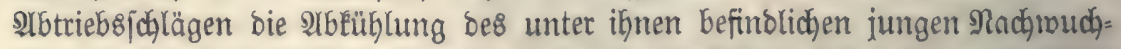

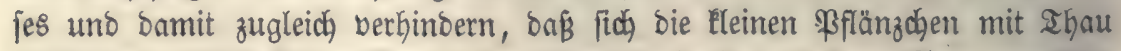
bejdjlagen. Natürlich müffen joldje Pflanzen in ben trodenen Sommermona=

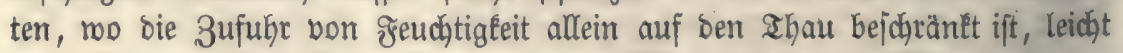

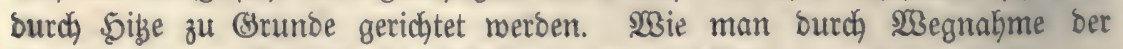
WSafferreifer bem Uebelftande abhilft, murbe gleidhfalls angegeben.

Ueberḩaupt tritt auf trockenten Standorten, mo leine Fröjte zu befürchten

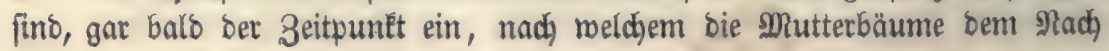




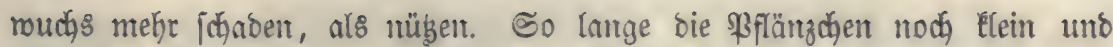

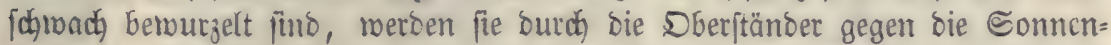
ftrablen gejchübt; fiaben fie nber einmal fich mehr ausgebilbet, hat fich bas

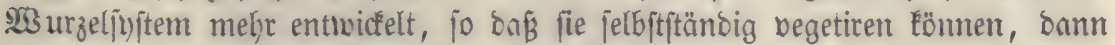
werben ifnen sie Miutterbäume mur nadhtheilig, indem fie bie feinen Regen=

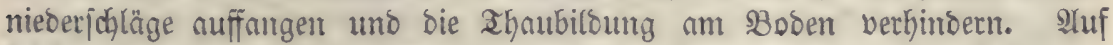

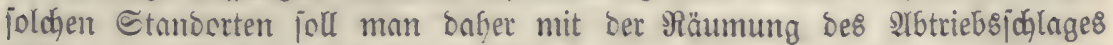

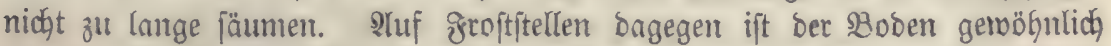
aud) feucht ober menigitens frijd, hier fohabet trodene 23 itterung bent jungen Pflanzen weit weniger, uno die Mutterbäume löınen zum 厄chus gegen bie

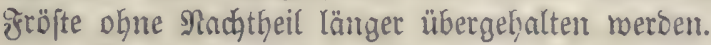

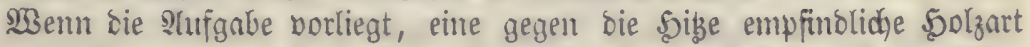

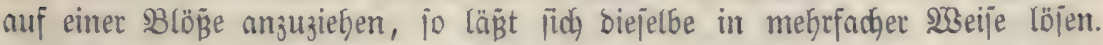

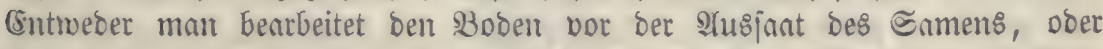
man baut borber eine 5olzart an, welche von trodener 23 itterung und ๔on=

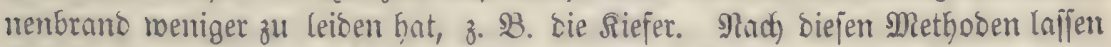
fich Buchen=, Jichten= uno 23 eis̄tamenjaaten an joldhen Drten aufforingen, wo Eein förmlidjer Dberitano borbanben ift. ఇoch bejer erreidht man aber jeinen

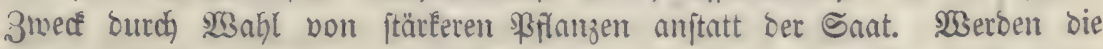
Bfflanzen mit sen Ballen eingejegt, jo lege man ben sodjbalten bidht neben

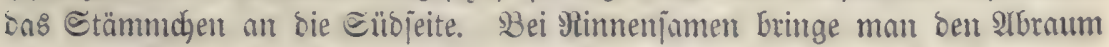
eben bakin.

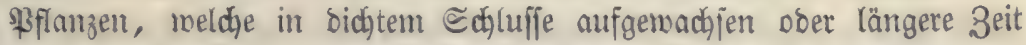
überjojimt gemejen find, geben leidyt ein, wemn fie in's greie berjebt met= ben, wo bie Conne ungehinbert auf fie einwirfen Eann. Eoldhe Pflanzen

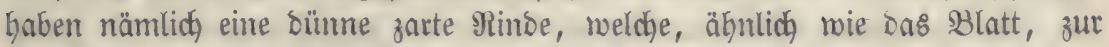
Berbunftung ber હaftfeudytigkeit jefr sisponirt ift, währenঠ bei ben bon Ju=

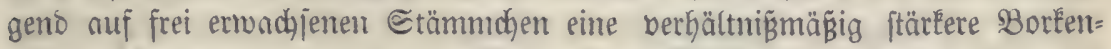

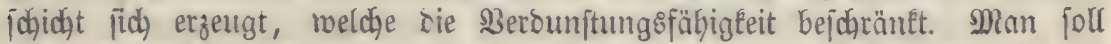
saber auf joldhen Socalitäten, melche ber Eonme jehr exponirt find (子. B. auf

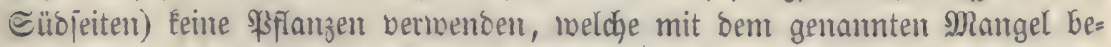
haftet funt, ober erft eine ausbauembe Solzant auj ber Culturftätte anziełen, reldye jenter zun Edube gegen bie Eonnenhige bient. Edyneller fonmt man zun 3iele, renn man cie Pflanzen bor bem Sinjeben über ber $2 \mathfrak{S u r z e l}$ abrvirft, boch) gilt bies mut für Raubbölzer.

2lber audh nod) ältere Eremplare bon mehreen 5olzarten, zu benen na=

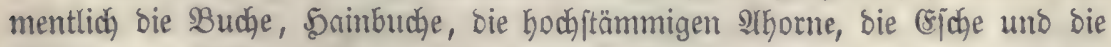

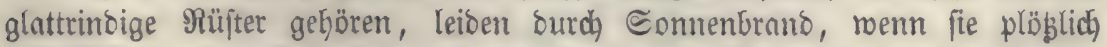

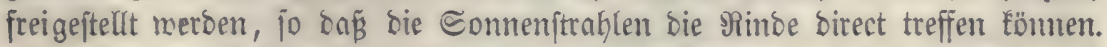

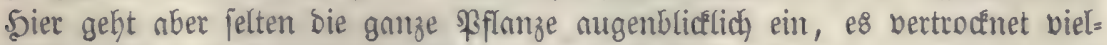

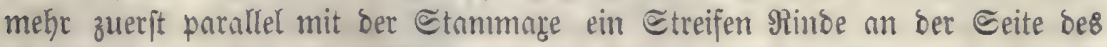
Baumes, weldher nm ftärejten von ber Eonne getroffen witb, uno löft fich 
nach) unb nach ab. Das 5ूolz mirb bnourd blof gelegt uno fault leidat ein,

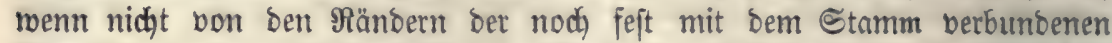

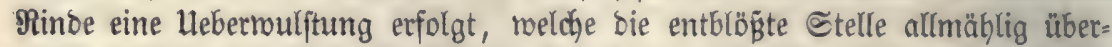
bect. Man nennt biefe (Erfheinung $\Re$ inbenbrand; fie zieht bas 2 rbjterben

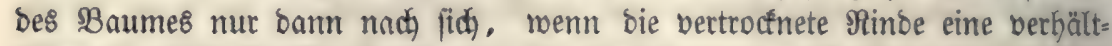

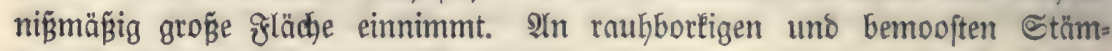
men fommt bet Rinbenbrant nidyt vor.

IIm ben Sinbenbrand zu berhüten, barf man, namentlid, auf unge=

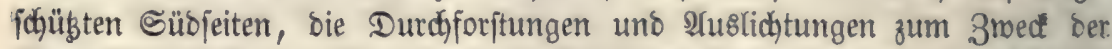
Samenid)lagftellung nidłt zu ftark greifen, man balte bielmegr ben Sieb von vorn berein ganz fdhroah, wieberhole ifn aber bfter, bamit bie Rinto nadh und nady exftarlft uno zulegst bie bolle Einmirkung ber Sonnenjtrablen obne

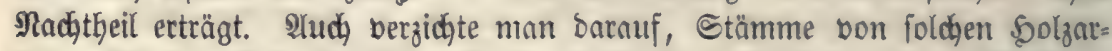

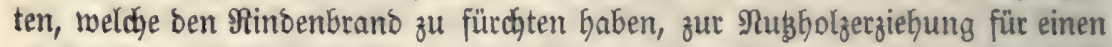
zmeiten Umtrieb überzuhalten. Ueberhaupt hat bas Uleberbalten ber $\$ 3$ äume nod andere Mififtänoe im SSefolge; werben nämlich joldye Stämme im saufe ber Umtriebszeit jobabaft uno müffen fie entfernt merden, fo wiro baburch bas junge 50 oly in ber Umgebung biejer Stämme bló geftellt uno leibet nun,

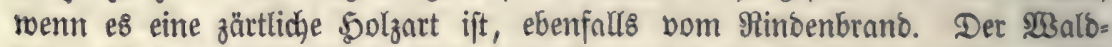
bau gibt übrigens Mittel an bie Sand, um ftarkes Solz in gefwloffenen

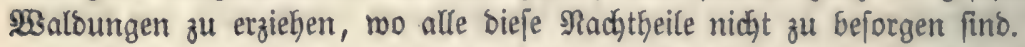

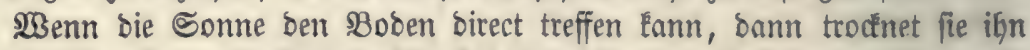

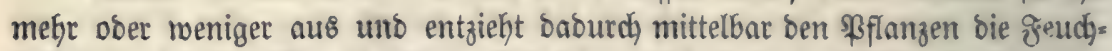
tigkeit, welche biejelben zu ifrem Beftehen nöthig haben. SRidgt alle (5roarten

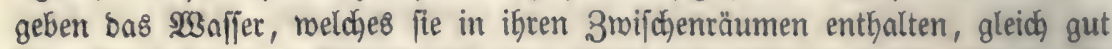
$\mathrm{ab}$; alle gebumbenen Bobenarten, wie Thon uno Rebm, bewahren bie geudh=

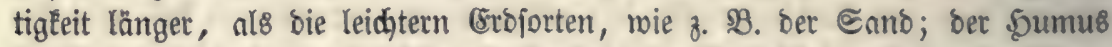

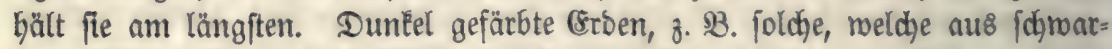
zem, toblebaltigem Ihonjobiefer entftanden fino, erroärmen fid zu eirtem böhern Iemiperaturgrabe; als Eroen mit heller z̧arbe. IInter gemiffen Ber= Gältniffen lann eine beractige Temperaturerböbung ermünjdht fein; io überftreut

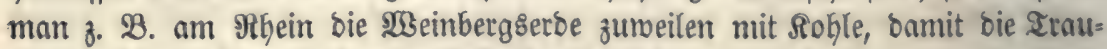
ben aud in weniger rarmen Jahrgängen reifen.

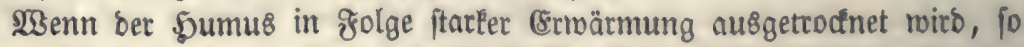
verlieren bie Subjtanzen, auz meldjen er befteht, aljo bie gragmente bon

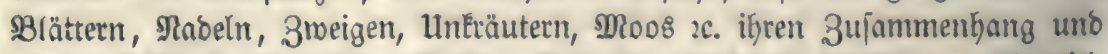
merben leidht ein Spiel ber 23 inde. Daburd) bermagert ber $\$$ Boben uno mirb

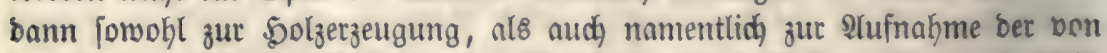
ben Bäumen fallenoen Baumjamen ungejdjictit. Dieje Bobentaumagerung tritt bann bejonbers in hohem Brabe ein, wenn bie Sonnenftrablen von mehrern Seiten ber ben Şumus treffen fönnen, wozu, wie (d)on oben nusgefühtht

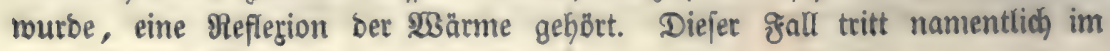




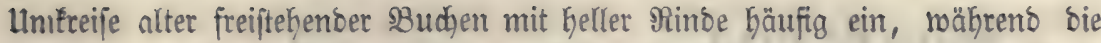

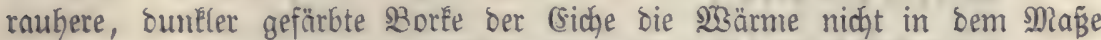
reflectirt. Ier Berf. Eennt eine zu Ianowirthidhaftlidjer Zwijd)ennubung ver=

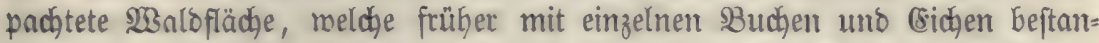
ben war; now gegenwättig, nachoem bie Bäume bcreit\& mehrere Jahre ge=

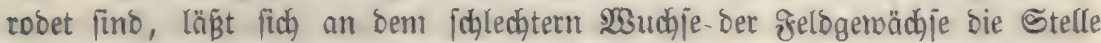
beurtheilen, no eine Buche geftanden Gatte.

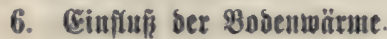

Se tiefer man bon ber Dberflädhe bes sBobens abruärt\& fteigt, um fo

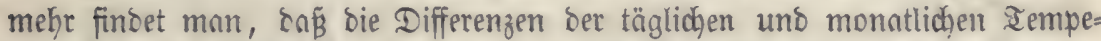

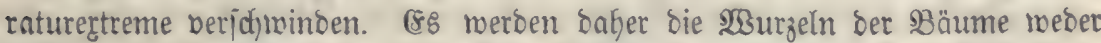
bon fo hohen :3ärntegraben, noch von fo ftrenger Rälte getroffen werben, als bie oberirbijaten Theile des Stammes.

Die Edłromkungen ber täglid)en uno monatlidjen Iemperatur berfpäten

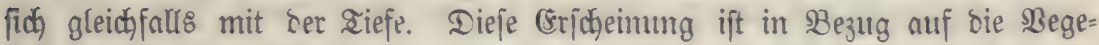
tationscauer von Bedeutung. Denn erftere miro, fo läßt fid vermuthen, bei

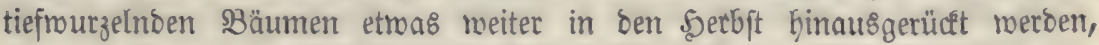
mährend ber $\mathfrak{B}$ lattausbruch fräter erfolgt.

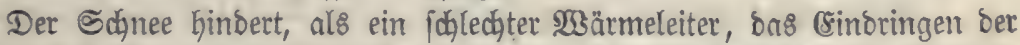

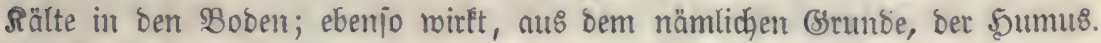
Destwegen friert ber Boben, wenn er mit einer bohen Edjichte Edynee ober

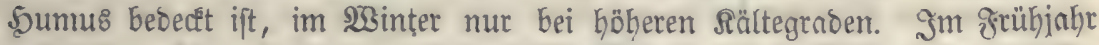

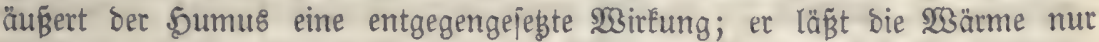

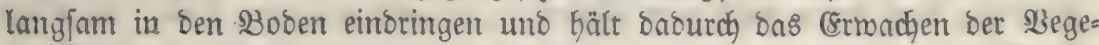
tation jurüc\%. Diejer llmiftano ift für joldfe Drte, meldhe oft von Spätfröften

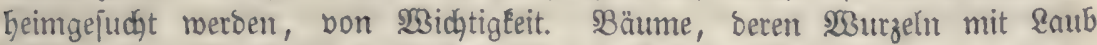

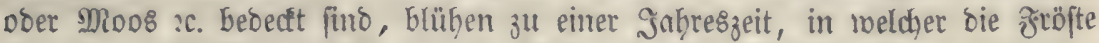
bereits borübergegangen fins.

\section{7. ซึroft.}

\section{A. 20 นี}

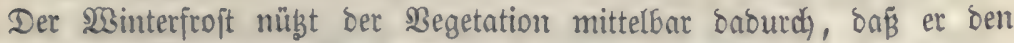
Boben locfect. 23enn bas $23 a f f e r$, mit weldyem jeoe Cronat mebr ober we=

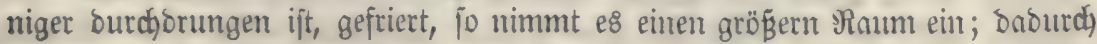
rberden bie Iheildyen ber (Erbe von einander getrennt. Die burd) bent orroft

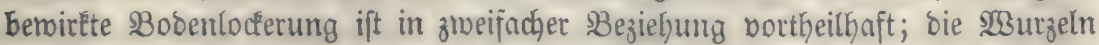

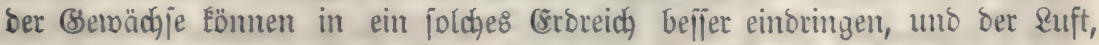

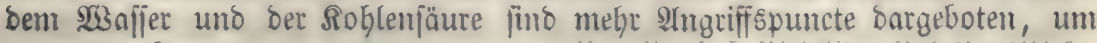
bie Gropartifeldyen zu zerjegen. 


\section{B. Oxaben bes รroftes.}

\section{a. शlgemetnes über ben Crfrierto bet ben Pfinzen.}

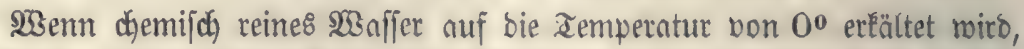
fo geht e\&, einige menige 2 (usnahmsfälle abgered)net, aut bem flüffigen $3 u=$ ftand in ben feften über. Sfft aber bas $\mathfrak{W a f f e r}$ mit andern Etoffen berun= reinigt, welche in ifm aufgelöft fint, fo liegt ber (5rftarrungspuntt unter $0^{0}$.

Då $50 l z$ enthält zu allen Zeiten æreuchtigkeit, welche fich theils in ben 3ellen uno Befäpen, theil\& aber auch in Den $23 a ̈ n d e n$ berjelben befindet. Bei einer remperatur, weldhe nur menig unter $0^{0}$ liegt, merben bie Säfte ber (Seroädjife feft.

Diejer 3ujtand berurjacht aber nidht bei allen ßflanzen ben ros. Die

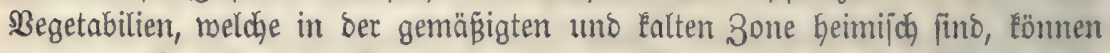
unter gemiffen Berbältniffen weit niebrigere Temperaturen ofne Sdyoden er=

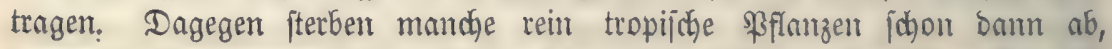
wenn bie Temperatur menige Brabe über bem Befrierpunft fteft. So geft 子. $\mathfrak{B}$. Ocymum basilicum immer ein, went bie $\mathfrak{X}_{3}$ äme unter $+5^{0}$ fintet. Dieje Siflange ijt jodon feit 1548 in (sngland eingefüfrt, uno bod hat fich ihr Berbalten gegen bie Temperatur nod) nicht geändert.

Man war früher Der Arjicht, ber Erfriertod beruhe auf

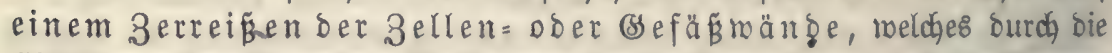

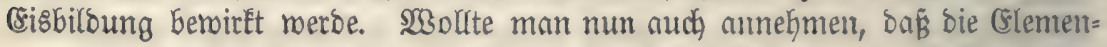

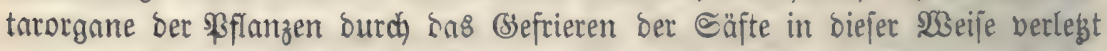

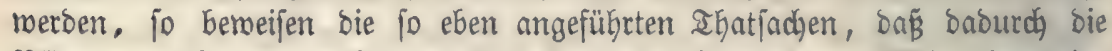
Pflanzen nod) lange nidht zum Albjterben gebracht werben. Afllein bie borige Annahme ift aud) ganz unridftig, benn (söppert hat burdh genaue anatomijobe

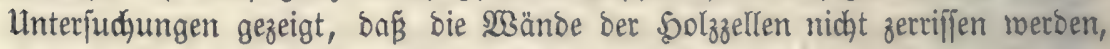
auch menn ifgr flüifiger Snbalt burd)nus in ben feiten 3 uftand übergeht.

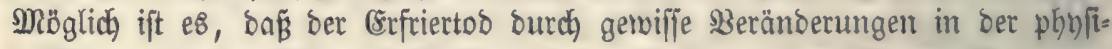

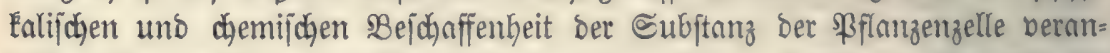
laß̧t wird; weldhes aber biefe Beränderungen feien, bnrüber miffen wir bis jest noch jo viel, wie nidhts. Sूunbe\&hagen hält ben Erfriertob für eine "eigen-

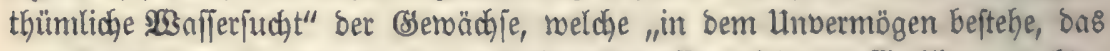

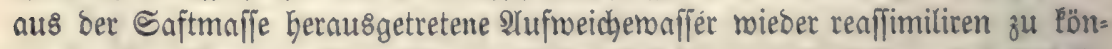

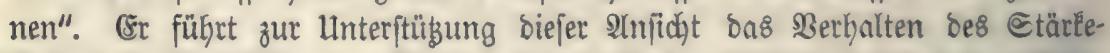
Eleifters in ber Rälte an. $23 \mathrm{emn}$ nämlich bieje ๔ubftanz gefriert uno bann mieber aufthaut, io wirb fie zum Rleben untaugliob, eire helle räfferige

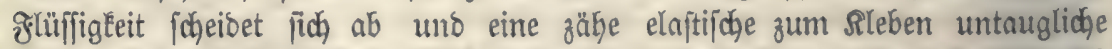
Maffe bleibt zurüct. Begen bieje, von Bogel beobadgtete, Thatjadje läßjt jich nichts einmenoen, allein es ift entichieden faljd, fie zu berallgemeinern. Shus bielen in ben ßflanzen borf́ommenten hyoratifitten Säuren wiro bas $23 a$ affer beim (sefrieren nidyt ausigejdieben; wir füfren als Beleg z. 2 . bie Draljäure 


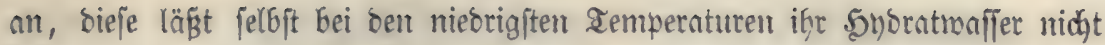
fahrent.

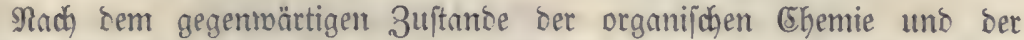

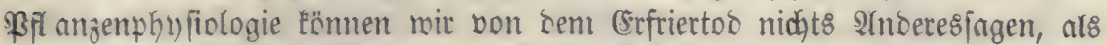

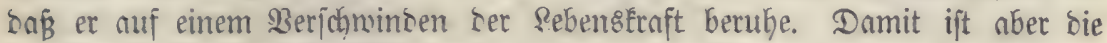
(5rjd)einung lange nod) nicht erflärt, benn bieje Proraje ift meiter nicht\&, al\& eine Ulmidyreibung bes 230 otte\& Iob.

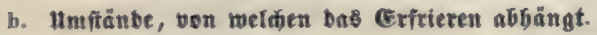

\section{a. Temperatur.}

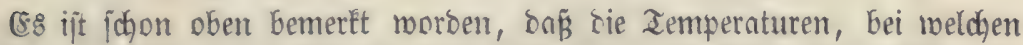

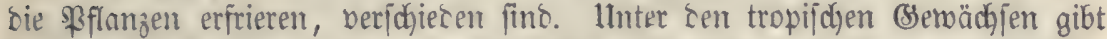

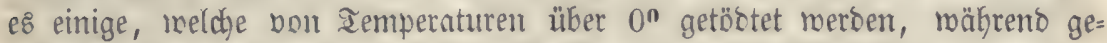

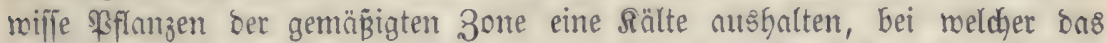

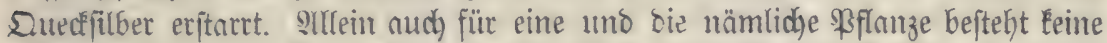

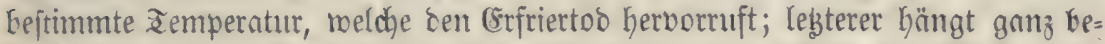
joncers bon rem 3uftante ber Bntwicflutg $a b$, in iveldyem die \$sflanze zur 3eit bes groftes fidy befinbet.

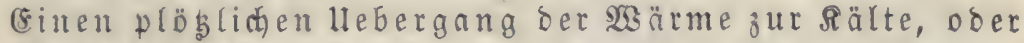
umgefehrt ber $\mathscr{R}$ äte zur $\mathfrak{2}$ ärme fönnen bie Pflanzen meit meniger ertragen, als viel ftärtéere Sältegrabe, wenn bieje allmählig eintreten unt in

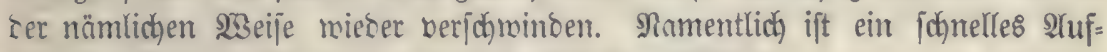
thanen gefrorner Pfflanzen ober beren Iheile gefälyrlich.

\section{B. Sakreszeit.}

Sü̈er ber Saftzeit halten bie in ber falten umo gemäfigten 3one heimija)en 5olsgewädje mitunter fefr hohe Sältegrate aut, bagegen jterbent bie Blätter uno nod nidat berbolzten Iriebe oft bei ber Temperatur bes Ge= frierpuntetes ober renige Grnoe unter $0 \mathrm{ab}$, ja es gehen von ren zaärtlichen

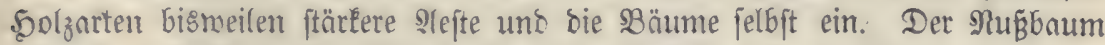
leibet im nörolichen Ieutichlnno, 10o jeine grtürdte jelten reifen, meniger bon

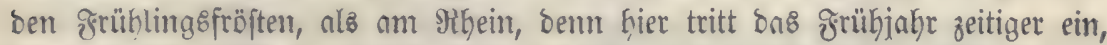

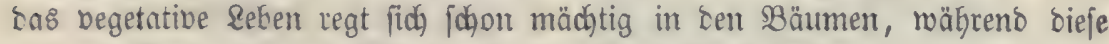

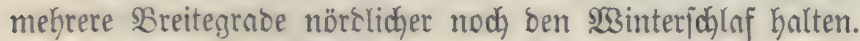

Der gröfte Edyaben, ben ber groft anridftet, findet aljo meniger bei

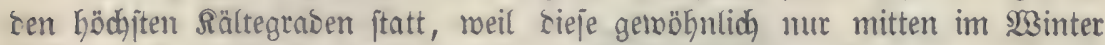
borfommen, wo bie Begetation nod nidjt erwadht ift.

Die gröjte, weld)e bie \$flanzen während ber Begetationşzeit treffen,

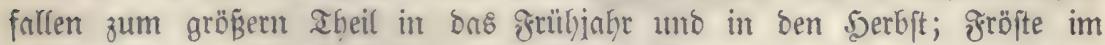

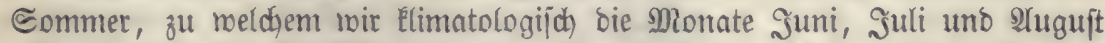

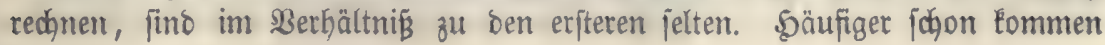




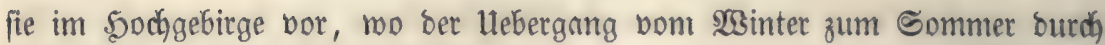
ein viel Łürzeres grühjabr erfolgt.

Die Früblingsfröfte nennt ber forjtmann gewöhnlich "Spätfröfte,"

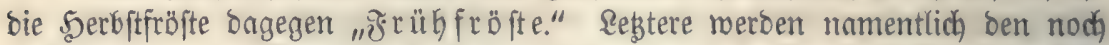

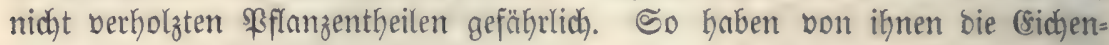

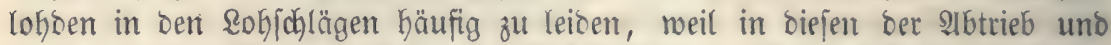
fomit auch der 2 Sieberausfchling ber Stöffe fpäter erfolgt, als in ben gemöhn= licken Nieberwaldungen. Nuch im Sodjgebirg ift bie Begetation megen bes

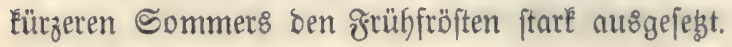

$\boldsymbol{\gamma}$. zagezzeit.

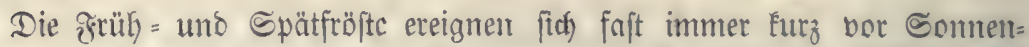
aufgang, meil zu biejer Zeit bas Minimum ber Iemperatur eintritt. 33on einem Spätfroft fann mur bann bie Rebe fein, wenn bie Temperatur am Iage bereits fo hoch) geftiegen mar, sak bie Begetation firk entmicfeln founte;

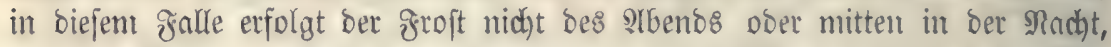
meil bie $2 \mathfrak{G a ̈ r m e ~ n a c h ~ S o m n e m u n t e r g a n g ~ n u x ~ a l l m a ̈ h l i g ~ a b n i m m t ; ~ e \& ~ g e f j o ̈ r t ~}$ aljo in frühling nothmendig bas Minimum ber täglichen Temperatur bazu,

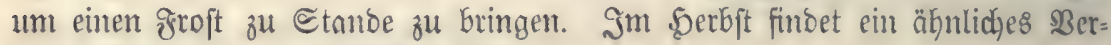

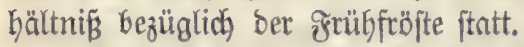

(serwöhnlich) ift aber bie Ienperatur ber Bflamsen, menn fie bon ben

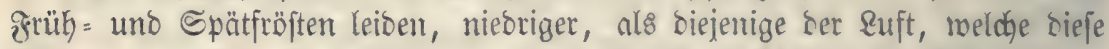
Ffflanzen umgibt. Das (Exfrieren erfolgt nämlich nicht $\mathfrak{b l o s}$ burch bie niecre Iemperatur, melche die \&uft den Bflanzen mittheilt, fondern burdh bie eigene

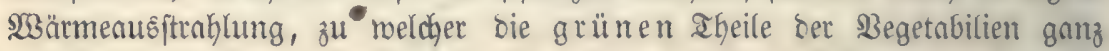

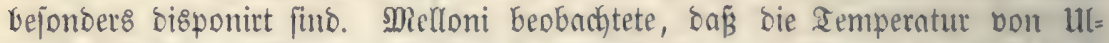

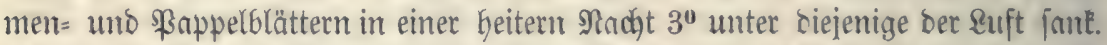
Şieraus erelärt e\& fich alio, narum im grühjabr uno serbft oft nur bie grü= nen Theile der (Serwächje mit Reif bebeât fino.

\section{d. $\mathfrak{B}$ itterung.}

ซึigut 162.

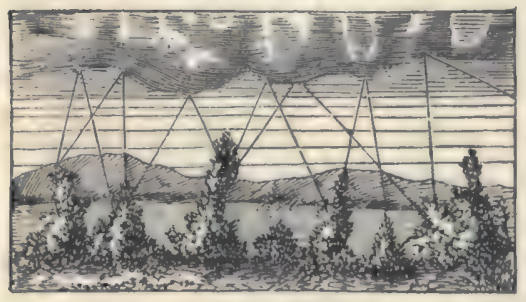

Rach Dem fo eben Rorgetragenen miro man es begreiflich firoen, warum bie grüh = unto Spätfröfte fo jelten bei bebeditem $5 i m m e l$ auftretent.

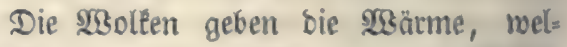
d)e bon ben Bflanzen autgeftrablt wirb, mieber jutüd (ஓిigur 162.); еళ fant aljo in biejem gralle ein groft nur burdh einent falten 20 into Gerbor:

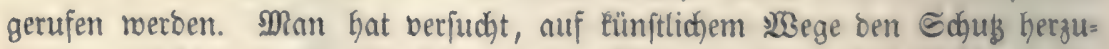
ftellen, weldhen ber bebectte Simmel ben Pflanzen gegen bas (Erfrieren ge= 
räbrt, uno unter ben Mitteln, weldhe zu biejem Znect angewenoet worben fint, nimmt ber $\Re$ a $u$ d) eine borzüglidje Stelle ein. WBie uns Bouffingault erzäblt, Tegen bie Eingebornen bon Dberpert, weldye bie hohen Ebenen bon (5uzfo berwohnen, feudtes Stroh Doer Mift in Brano, um Raud zu erzeugen

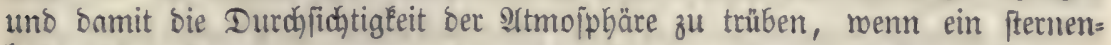
Geller Simmel uno eine roenig beregte \&uf̣t einen öroft befürdhten laffen. Das eben angegebene Mittel zur 3̧erhütung bes froftichndens läßt fich wokl

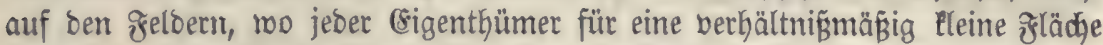
zu forgen hat, umb auch in §orftgärten, ober muf kleineren Eulturftellen an=

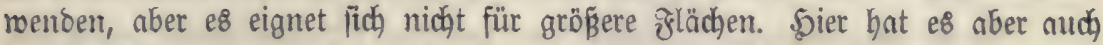

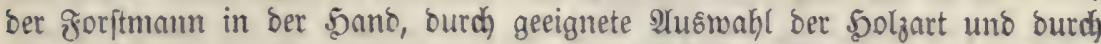

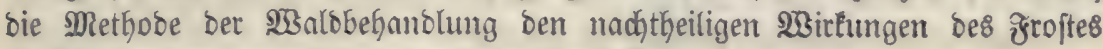
zu begegnen, rovon fpäter bie Rebe fein foll.

Alud bei berwegter $\&$ uft tritt in ber Regel kein froft ein. Wie

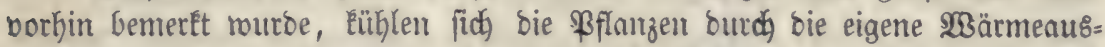

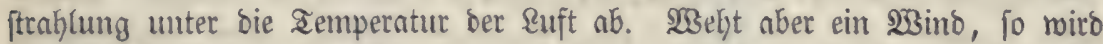
Die erf́altete Pflanze fortwäfrento nit wärmerer \&uft in Berührung gebradht,

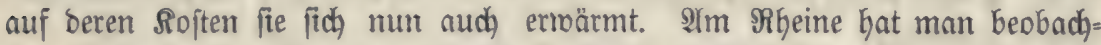

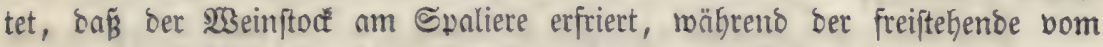
grofte nicht bejhäbigt mirb. Das lommt baker, weil ber nicht angebunoene

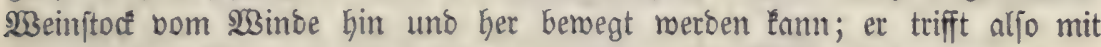
einer gröfiern Menge warmer \&uft zujammen. Die $\mathfrak{S B i n}_{\text {be }}$ bringent nur bann grojt, wenn fie eine niebrige Iemperatur befigen. Diejer Frall tritt aber ver= hältnifmääßg felten ein; gemöhnlid ift ber Wino höher temperirt, als bie Pflamzen.

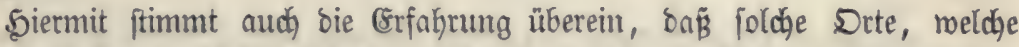

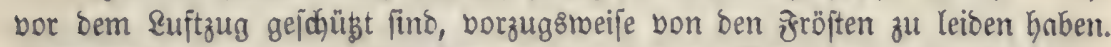

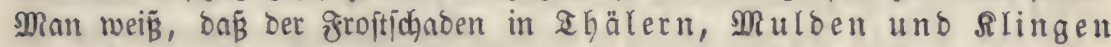
geröbnlid) beträdtlider ift, als ouf ben freiliegenden Söhen in ber Umgebung biejer Bertiefungen, wenn fhon im ardgemeinen bie 2empera= tur mit ber Crrbebung über bie Meeresflädge nbnimmt. Bei Aleineren நöhen=

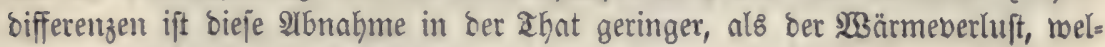
den bie \$flanzen burdh Strablung exteiden.

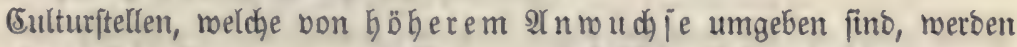
bejonbers häufig von ben grüh = uno Spätfröpten heimgejudbt, nament=

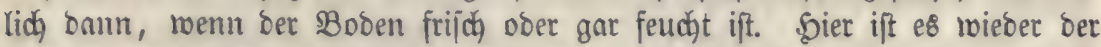
Mangel an Euftzug, melcher bas (sintreten bes ₹roftes begünftigt. Stellt

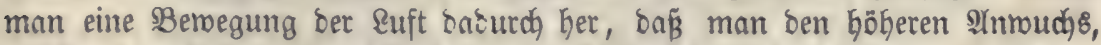
meldyer ben Bulturort umichlieğt, hie uno ba lidgtet ober abtreibt, jo bleiben bie gröfte aus.

5ohes bidates (s)

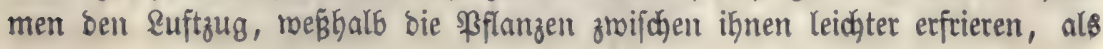


felbft auf ganz nactem Boben. Desimegen wentet man als mittel gegen ben groftichaben bei jungen (Eulturen mit Bortheil ons STGmät)en, S6ficheln,

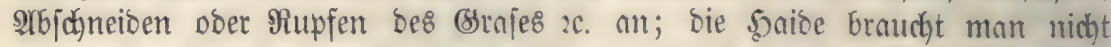
ganz zu entfernen, e\& genügt, weun fie mur fo licht burdjunft wiro, bon ber

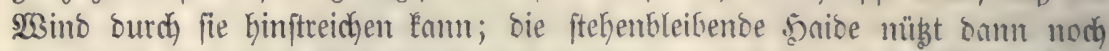
ben angebauten 50 olzpflanzen, indem fie bie von biejen antgeftrablte 23 nuffält uno wieber zurücógibt.

\section{E. Бolzart und 5olzalter.}

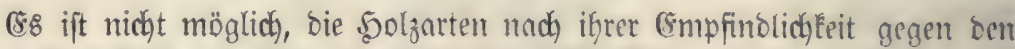

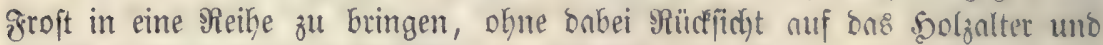
ben sentwicklungszuftano Serjelben zu nebmen.

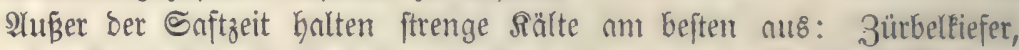

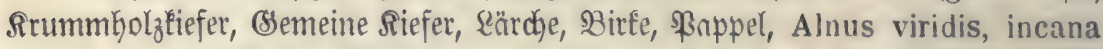

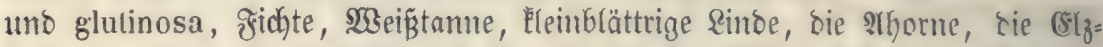

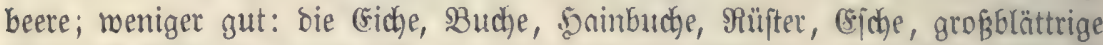

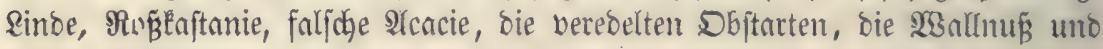
zahme Raftanie.

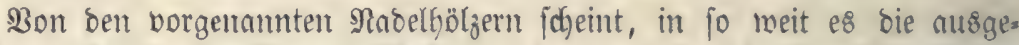

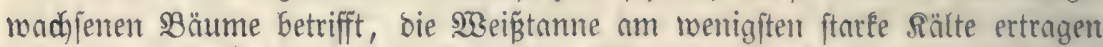
zu Ëmuen. Co gingen it bem ftrengen $\mathfrak{S B}_{\text {intet }}$ von $1788 / \mathrm{sg}$, als bie Sälte

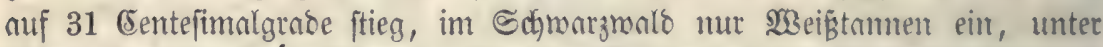

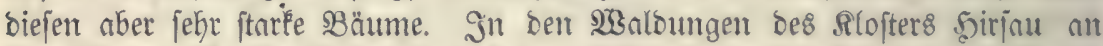
Der গagold etfroten allein 46 Sägetonnen, 54 gemeine 60er, 138 gemeine 50er 2 .

Sm Sahte 1829 mutse in hiefiger (Segento bie Beobathtung gemadht,

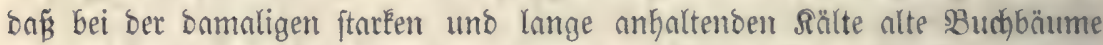
nur auf uafjen ভtanoorten erfroren, rabridyeinlich beblalb, meil bie

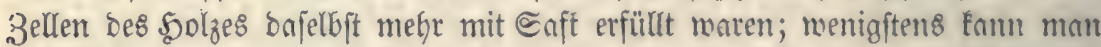

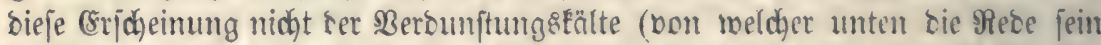
mirb) zujdreiben, meil ber Bofen fdjon Intge vorker, ehe bie hobe Rälte ein= trat, gefroren war.

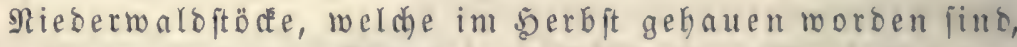

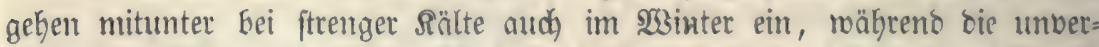

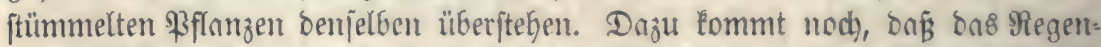

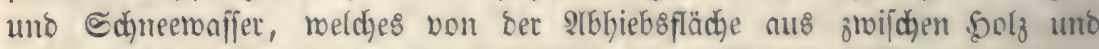
Minbe einbringt, went e8 gefriert, bie Rinbe vom Eduafte ablöpt.

Gunge Bflanzen jind gegen ben groft weit empfinblider, als ältere.

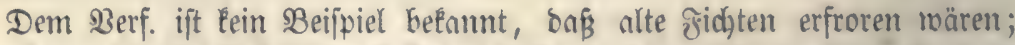
aber erft am 25. Arpril bes verfloffenen Jahres gingen ifnt mefrere bundert jechejährige. Eichten burch ben froft zu Srumbe, obgleidy biejelben nody nicht 
getrieben hattent. Lleberbaupt gibt es mokl Heine Sholzart, weldye nidyt in ber

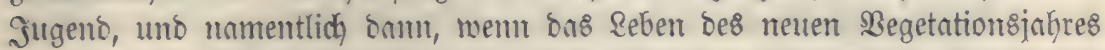
fich mieber in ifg zut regen begimt, bor groftidjaben fidjer wäre. (s: Gerrjat

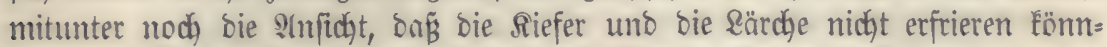

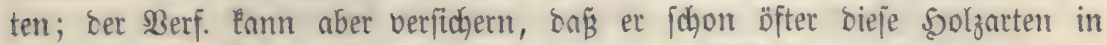
jugendidjem stler erfroren gefunden hat, er jah jogar, baß̈ bei bem

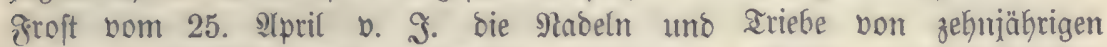
Siefen uno fiebenjäbrigen \&ärchen total bom ₹roite getöbtet worben

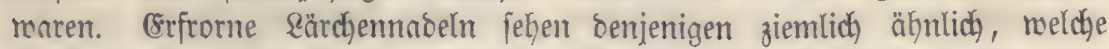
burch ben grañ ber Earbe bon Tinea larieinella nusgehöhlt worben futb, Inffen fich aber bou siejen surdh bie mefyr gelbe §arbe unterjdyeiben. Die einzige Solzart, an weldher ber Berf. bis jebt nod Éeinen Froitichaben zu benerfen selegenheit hatte, ift bie 23 ermouthefiefer.

Diejenigen 5olzarten, weldye als Bäume vom j̧roft getöbtet werben

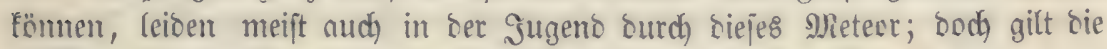

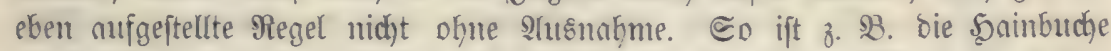
in ber Sttgento gegen ben ₹roft menig empfindlidy; nau fann fie baher

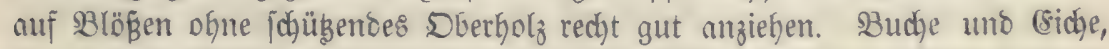
Tanne uno gicbte werben in ber Sugeno am Gäufigften vom froft heimge= fucht. Refhrt biejer alljährlid), ober bod) oft mieber, uno erfrieren bie (Endrtiebe bes Cd)aftes uno ser Zroeige, fo erbält bie \$fflanze nad) und nad) ein bujod=

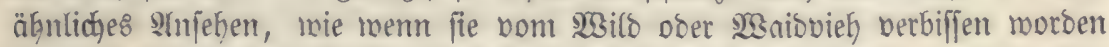

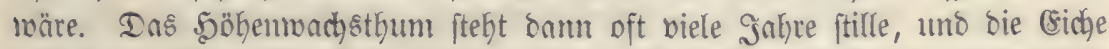
geht babei oft zu Brumbe, wenigftens entmidfelt fie fich felten zu einem ichö= nen Strmm, wenn fie längere 3eit bom froft gelitten hat, mähreno bie

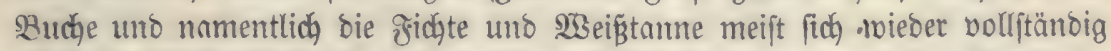
erholen, jobalo fie nidjt mehr vom grofte berübrt werbeh. Die umitänoe, unter weldhen lebteres geichieft, merben wir jpäter kennen lernen.

Die Baumblïthen find gegen ben groft empfindlid, fie leiben bon bemielten bei Temperaturen, weldhe ben s(ättern nod) feinen

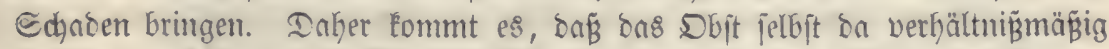

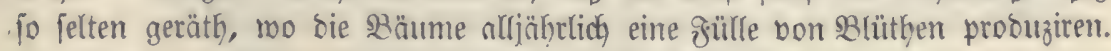

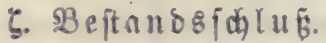

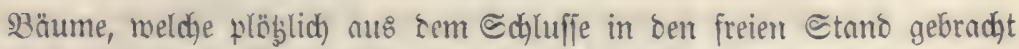
werben, erfrieren bei geringeren Sältegraben, als joldje, weldhe an ben freien Stano getwöfnt funt. Das ift ber (Sruno, warum bie Enftreitel, meldye man beim Mittelmaldbetrieb ïberbält, leidgter ber Rälte unterliegen, als bie viel jüngeren (aber verfolgten) Sohben nuf ben nämlidjen Stanoorten. Man foll

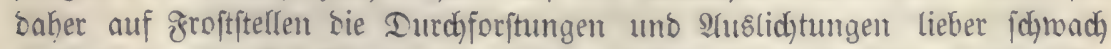
greifen, aber biejelben bifters mieberholen - eine Regel, welche aud in bielen anbern Beziefungen Bendftung verbient. Inbeffen bezieht fidh bas fo eben 
ïber ben 'Groft Bejagte mehr auf bie zärtlidgen, frembländijoben Solzarten

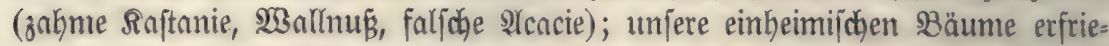
ren, wie borfin bemertt murbe, went fie einmal ermadjien find, nut bei un. getwöhnlich hohen Rältegrnben.

Junge Bflanzen Dagegen, welche unter bem Shube eines Dberitandes erzogen uno bann in's ?reie gebrad)t wurben, leiben bäufig burch grröfte

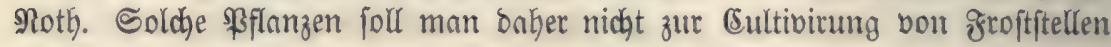
berwenten.

WBie wir oben ausgeführt baben, liegt eine Sampt=llrjadje für bas (8r= frieren in ber nädhtlichen $\mathfrak{B a ̈ r m e a u s | t r a h l u n g , ~ z u ~ w e l d h e r ~ b i e ~ g r u ̈ n e n ~ I f j e i l e ~}$ ber Begetabilien vorgüglich bisponirt find. Da fid) bieje sigenjohaft ber Bflanzen mun einmal nicht bejeitigen läß̈t, fo hanbelt es fich barum, ifuen bie verlorene $\mathfrak{S a ̈ r m e ~ w i e b e r ~ z u ~ g e b e n . ~ D a , ~ w o ~ b i e ~ B e r j u ̈ n g u n g ~ e i n e s ~} B \mathfrak{B}=$ ftandes burth ben Samen erfolgt, melcher von ben ftehenbleibenoen sBäumen

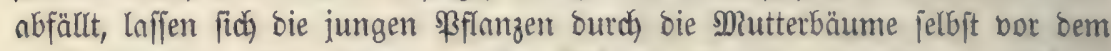
Froft jđüüen. Die Sronen biejer Stänme ftrablen nämlich bie 233 ärme zurüct, weldhe bon bem jungen Arnmudbs nusgegeben wirb. Sn weldgem

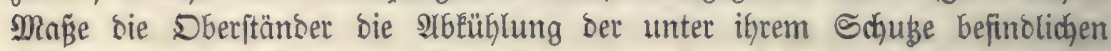

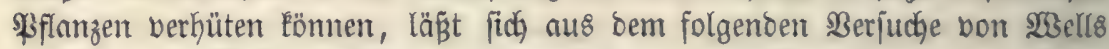
entnehmen. $\mathfrak{B e l l s}$ befeptigte in ben Boben eines Brasplabes vier Heine Stäbe von 16 rentimetern \$öhe uno zog über bie Spize berfelben, meldhe

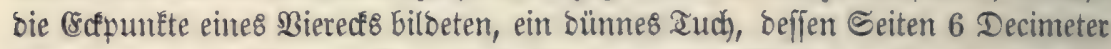

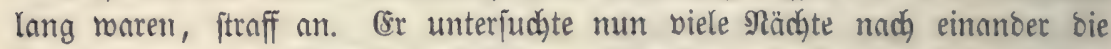
zemperatur bes joldhergeftalt befdirmten (srajes uno fand biejelbe allemnl Göher, als bie bes naken unbebecten Brajes, wenn biejes fälter, als bie suft

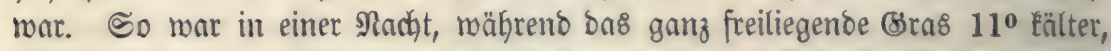
als bie \&uft mar, bieje nur um $3^{0}$ wärmer, als bas bebecfte (Sras; berjelbe Unteridhied fand in einer andern Nacht ftatt, als bie \&uft $14^{0}$ märmer, als

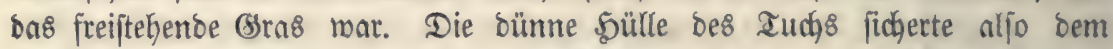
(Sraje bas einemal eine um $8^{\circ}$, bas anderemal eine um $11^{0}$ Gögere Iempe= ratur. - 2lber jelbjt bann, menn ber fchübento Begenftano nidht parallel mit bem Boben, fonbern perpendicular bon biejem aus angebracht ift, ftrablt er

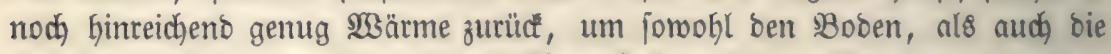
auf ifm befindlichen Kleinen Bervächje auf einer höheren Iemperatur zu ex=

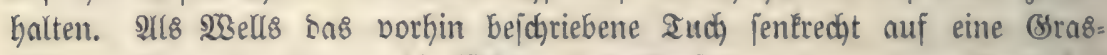

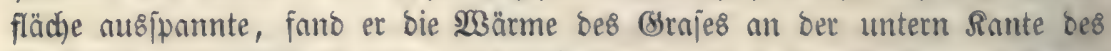
Tuches $4^{0}$ und felbjt $6^{0}$ höher, als biejenige bes in einiger esntfermung bavon befinoliçen ungédüüten סrajes.

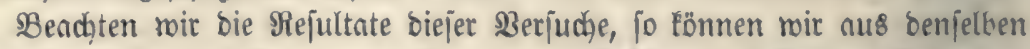

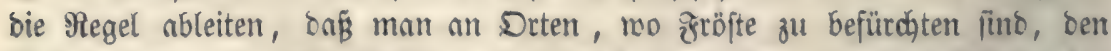
Bejamungs = uno 216triebsichling jo bunlel zu halten uno ben Abtrieb bet Mutterbäume fo lange hinauszujdjieben habe, als es bas \&idgtbeoürfniß ber 


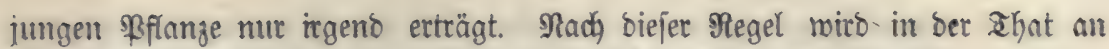
vielen Drten idgon jeit Innger Zeit gemirthid)nftet; im Bogelsgebirge, wo ber s8ocen aus einem zähen Refm mit groß̈er wafferhaltender Sraft befteht, nuf bem häufig gröjte borkonmen, hat mant bie Berjüngungsonater ber Budhen.

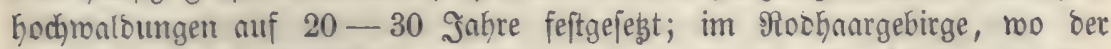

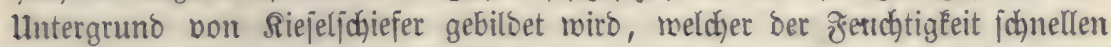
2lbzug geftattet, treibt man oft jefon mit $3-5$ Jabren ab, nachoem bie Ber= jüngung angejchlagen ift.

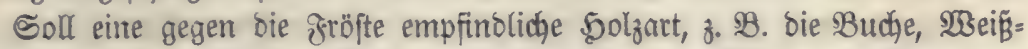
tanne ober Fidjte, auf einer Blöge cultivirt reeroen, weldje ben Jröjten ectpo= nirt ift, jo baue man zuvor eine antere Solzart an, weldhe vom frofte me=

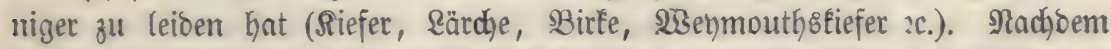

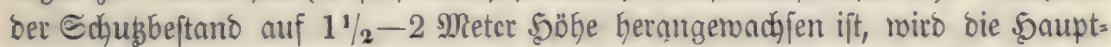

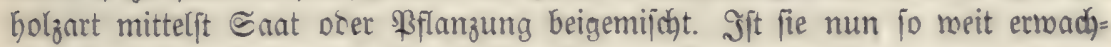

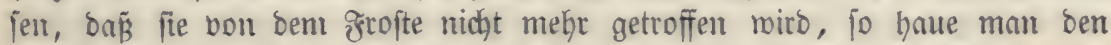
Ed)ubbejtano nad) unt und entmeder ganz aus, ober man laffe fo biele

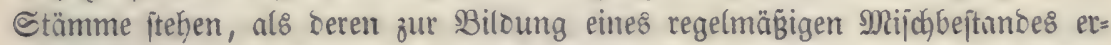
forcerlich fint. Sierbei fonmt es natürlich ontauf an, ob bie bornngebaute

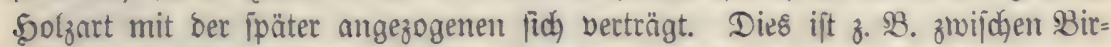
fen uno Fichten nicht ber Fall, währens bie Birfe uno bie Buche recht gut mit einander fortfommen, vorausigejegt, baß̧ bie sirke nicht zu reichlich beige= niijd) jei.

ๆ. Bejdaffenteit bes Bobens.

(8\& gibt gemiife Eocalitäten, welche ganz bejonbers zu irrö/ten geneigt

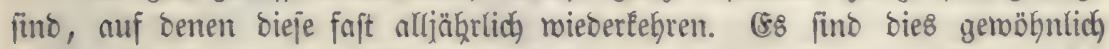
feudfe Stellen, mo bas $2 B a f f e r$ in Folge einet tiefern Rage bes \$odens fid) anjammelt uno wo zugleich ber nöthige Ruftzug mangelt, un bie żeuchtigḱeit

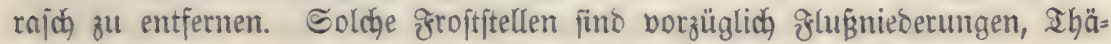
ler uno Mulden, Der Frojt miro hier surdh ben $\mathfrak{B a ̈ r m e b e r l u f t ~ e r z e u g t , ~ w e l = ~}$

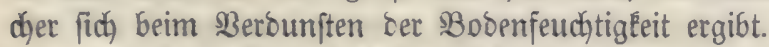

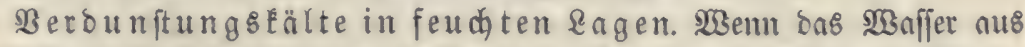
bem flüffigen 3 uftano in ben bampfförmigen übergeht, jo befnt $e \&$ fich be=

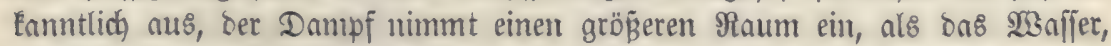
ats weldyem er fid) gebiliset hat. Die Bolumsvermebrung wirb berwirft burds

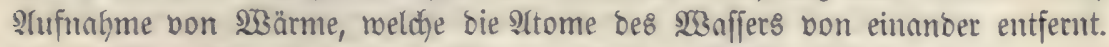

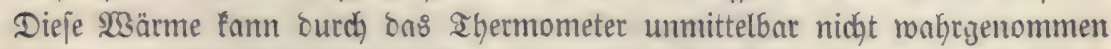
merben, fie ift latent, eben meil fie baz̆ bient, bamit bie aheildgen bes Dam= pfes fich nicht mieber näbern uno 2 Baffer bilben. Ulm 1 Rilogramm $\mathfrak{W a f f e r}$ von $100^{\circ}$ in Dampf von 'Der nämlichen Iemperatur zu bermandeln, bebarf man eben to viel $23 a ̈$ äme, al8 um 1 Silogranmm 23 nffer bon $0^{\circ}$ auf bie Temperatur von $536^{\circ}$ zu bringen. Da\& $\mathfrak{1 3}$ affer bercunftet audh bei Iempe= raturen, weldfe unter ben Siebpunct liegen, bie latente 263 ärme bes Dampfes 


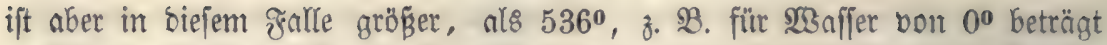

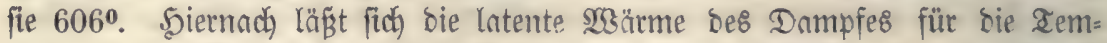
peraturen zroifhen $0^{0}$ und ber Siebhige surch Interpolation fincen. Co ift

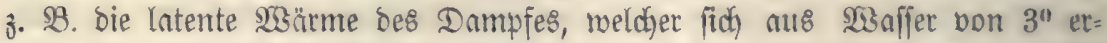
hebt, 604 (genauer 603,9), Das fagt alfo, baß̉ man mit ber 23 ärme, melohe

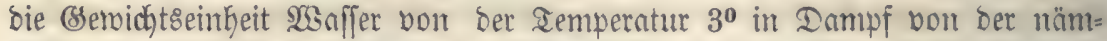

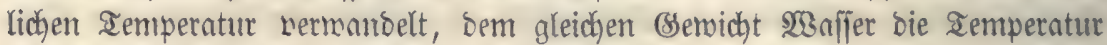
$604+3=607$ ertheilen fönnte (ङ. ๔. 181).

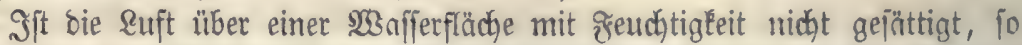
berounftet fo viel $\mathfrak{B a f f e r , ~ b i s ~ b e r ~ ๔ a ̈ t t i g u n g s p u n c t ~ e i n g e t r e t e n t ~ i f t . ~ D i e ~} \mathfrak{B} a ̈ r m e$, meldye bie Dampfbiloung erforbert, wirb in biejem - Jalle theils aus ber um= gebenten Buft, nod) mebr aber nus bem $\mathfrak{W n f f e r ~ f e l b j t ~ g e n o m m e n , ~ b o n ~ m e l = ~}$

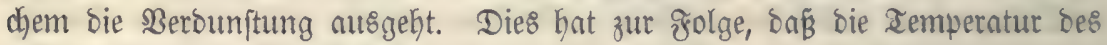

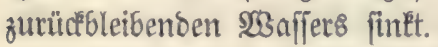

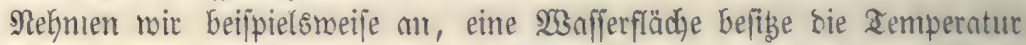

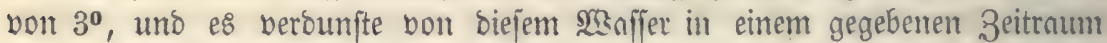

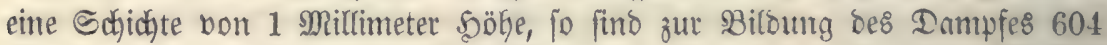

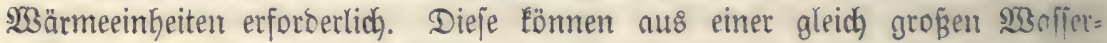
fläche von 604 Millimetern Iiefe genommen metben, wenn beren Temperatur um $1^{0}$, ober bon $\frac{604}{3}=201$ Millimetern, wenn beren Iemperntur um $3^{\text {o }}$ (ïd) ernieorigt. Die Bersunftung\&Eälte von $3^{0}$ müroe fich aljo 201 Millimeter ocer ungefäfr 2 Decimeter tief fortpflanzen. Ifllein ter Boben, auf meldyent umjere $2 B$ aldbäume cultivirt merden bönnen, ift felten mit einer fo bohen 23 affer=

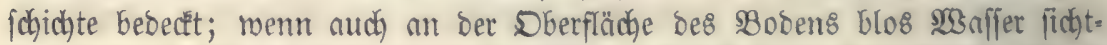
bar ift, fo fängt boch bald unter bem Epiegel beffelben bie fefte Croferume an,

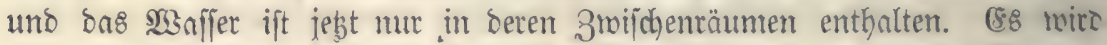

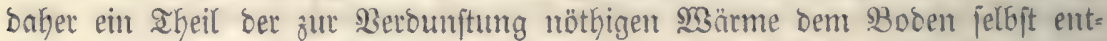

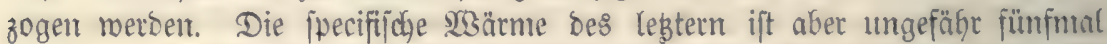
geringer, ats biejenige bes $2 \mathfrak{B a f f e r 8 , ~ \delta . ~ h . ~ m e n n ~ d i e ~ a e m p e r a t u r ~ v o n ~ 3 . ~} \mathfrak{B}$.

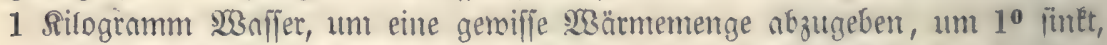

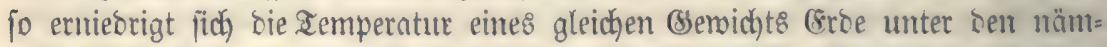

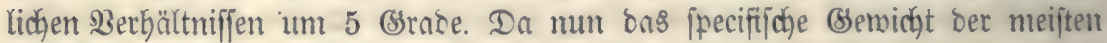
Croen $=2,5$ iit, fo mürbe fich bie Berounftungefälte im Boben $\frac{5}{2,5}=2 \mathrm{mal}$ fo tief fortpfianzen, al: im 23 affer.

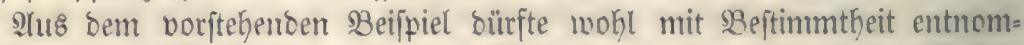

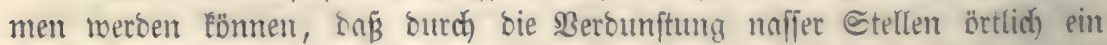

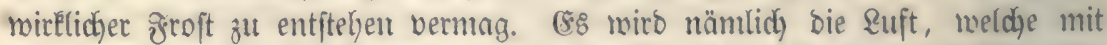

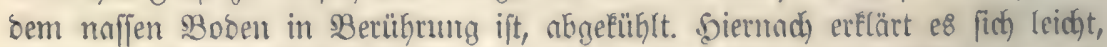
marum it feudgten f̧lünieberungen, in Mulden uno Rlingen, in agälern, weldye menig sefäl befiben, warum nuf fobmerem ober un= 


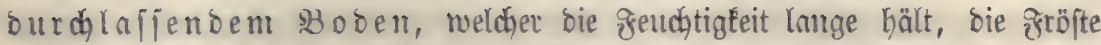
eine fo bäufig eintretente (srid)einung fino.

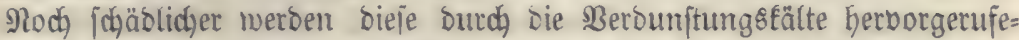

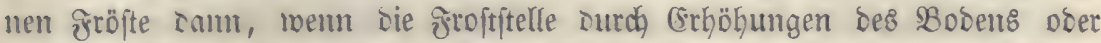

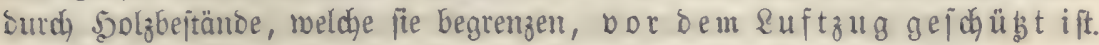
Die Eluft, weldye sie froftlocalität umgibt, ift nämlich immer wärmer, nls bie üher bem naffen Boben rugente ๔djichte ber Stmojphäre; fom nun ber Wint ungehintert über bie froffttelle binjtreichen, fo wiro er bie falte suft

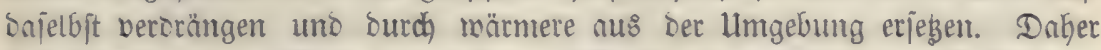

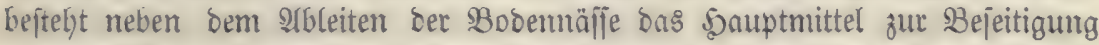

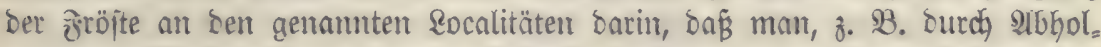
zen eines $23 a l \delta j t r e i f e n s$, etron in Edjueipenbreite, einen gehörigen \&uftzug bet= fterlt, überbaupt alles basjenige entjernt, was ber Euftbenegung im $\mathfrak{3 e g e}$

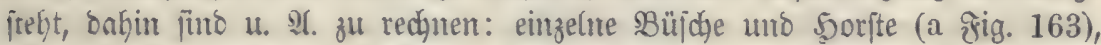
jomie in rie groftftelle fineimagende 3ungen (b) von bem angrenzenben, mit

\section{ङ̧ig. 163.}

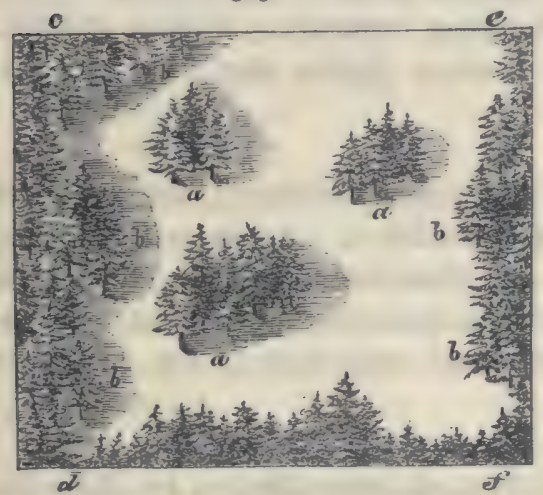

höherem Solze beftodten, Beftanoe. alle cieje 5inderniffe müfien Ginmeg=

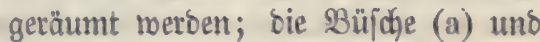

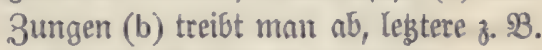
nad) zrwei Sinien, bie man fid bon $\mathrm{c}$ nach $d$ und von e nach $f$ gezogen ben= Fen Eann. Pfuch an bem unteren SRande lię̧en fich) nodh einige 3ungen neg=

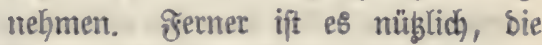
Ränber ber angrenzenten $B$ eftänbe un aud) wohl biefe jelbft burdh ifre ganze शTu8behnung bit zu entaften. Dieje Mapregel if namentlid bann von

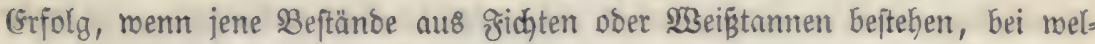
chen sie 21ejte bis tief an Ctamme Gerab fiben zu bleiben pflegen *).

5öhe, bis zu rold er bie Berounftung seälte fid eriftedt.

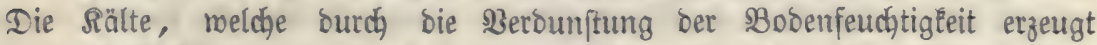
miro, theilt fidh, wie vorfin Gemerft wurbe, ber über ber nafjen ofläche ruhen= ben \&uft mit und ftimmt auch beren Temperatur hernb. Da aber bie Fort=

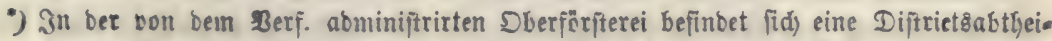
lung ,Biegenacter" genannt, an beren einem ente eine Blöpe liegt, auf nelḑer iक̧on feit langer Zुeit alljährlich werfud)t nurte, Jiđ̆ten zu cultiviren, bie allein

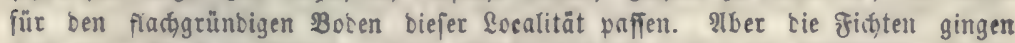

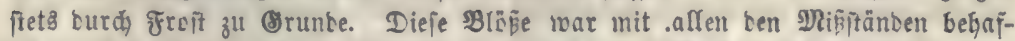

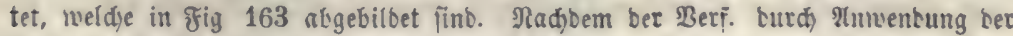

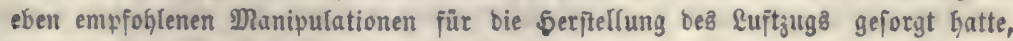
bracte ber Froft leinen Shaben mebr. 


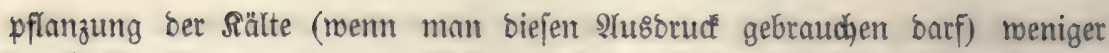
burdh) Strahlung, als burch Reitung erfolgt, fo eritrecte fich bie Temperatur:

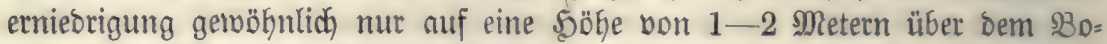
ben. Die Bflanzen exfrieren baber nuf foldten naffen Stellen nur fo lange, als fidh ifre Bsipfel uno Triebe noch innerbalb ber groftregion, wie wir fie nennen möchter, befinden. Saben fie biefelbe eimmal zurüdgelegt, fo ent=

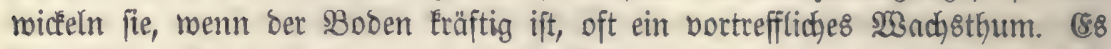

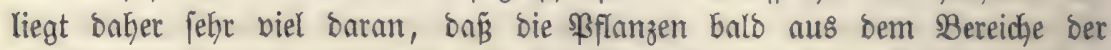

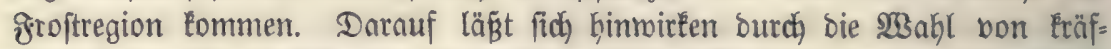

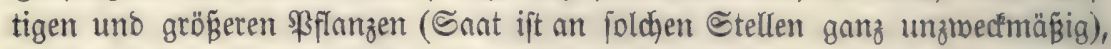
bie man, um das Alnjhlagen zu fichern, uno um eine Unterbrechung bes

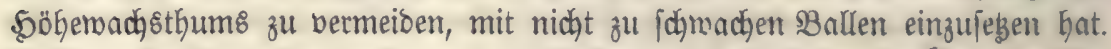
Bei ben \&aubholzpflanzen Eommt es häufig bor, baß̈ fie burdh offtere groftbe=

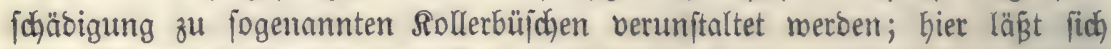

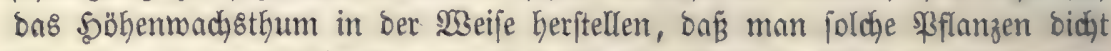

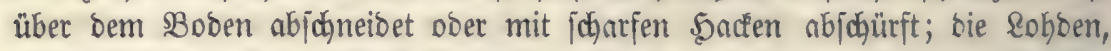

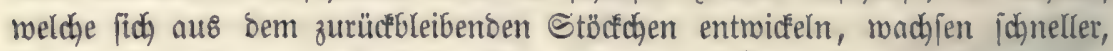
als bie Sernpflanzen uno fino oft in menigen Sabren über bie Jroftregion binaus.

\section{Erpofition.}

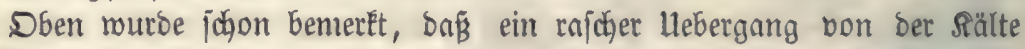

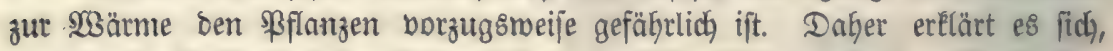
marum bie fröpte fo oft auf ben Dft= uno Süboftjeiten auftreten. În jolchen Erpofitionen follte man baher Eeine zärtlicken \$olzarten anzief)en, ober wenig= ftens vorker eine bauerbaftere anbauen, unter beren Sdjuge fid baun jene cultiviren lä

\section{c. Meereşöhe.}

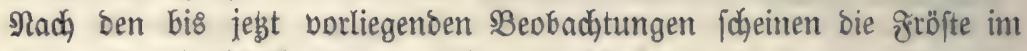
5od)gebirge eben fo bäufig, menn nidyt nod) bäufiger aufzutreten, als in ber (Ebene, namentlid) Eommen bie ortühfröfte oft bor weil ber Uebergang von

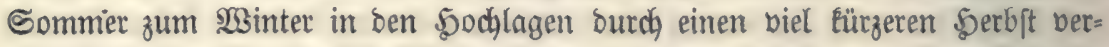

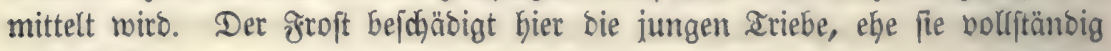
verfolgt fint.

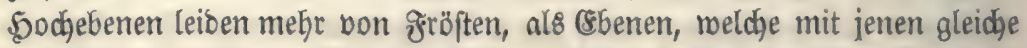

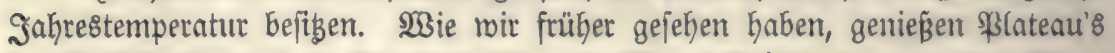

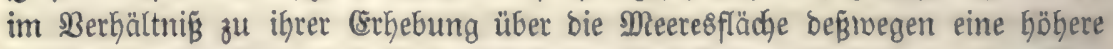
Temperatur, weil bie Ruft hier mit einer groß̈en $B$ obenoberfläche, bon welcher bie burch bie Connenitrablen bemirf̂te Crrwärmung ausgebt, in Berübrung ift.

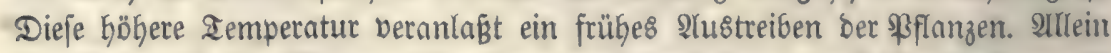

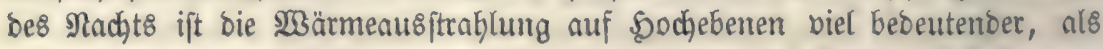
in ben Dieflagen, weil bie \&uft über jenen bünter ift, aljo bem Durchgange

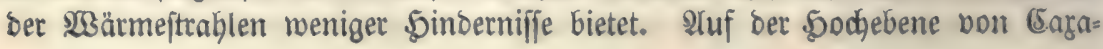


marca in $\Re e r u$, weldje bei einer Meereshöhe vost 1660 Metern eine mittlere

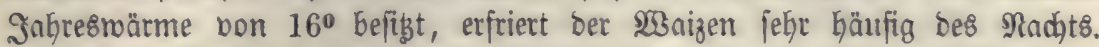
5umboldt jah Gier bei Inge im Schatten bas Thermometer auf $25^{\circ}$ iteigen, währeno es bor Somnennufgang nur $8^{0}$ gezeigt hatte. Man fiebt hiernus, meldhe bebeutenoe Iemperaturbifferenzen auf 5ochebenen vortommen.

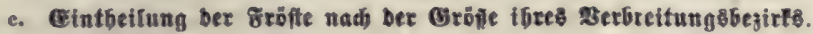

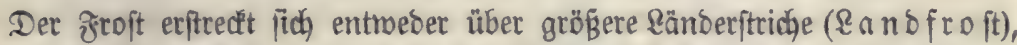
Doer über Eleinere fläd)en ( wenn nad, vorangegangener warmer $23 i t t e r u n g$, weldhe bas begetatibe Reben

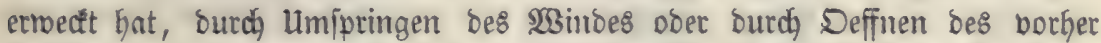
bebeåten Simmels plöglid) eine (Erniebrigung ber Iemperatur eintritt. Die Eocalfröfte bagegen, meldye ganz beftimmte Stellen einbalten, auf benen fie

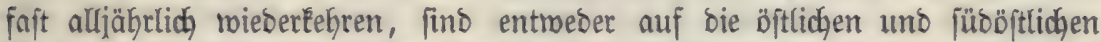

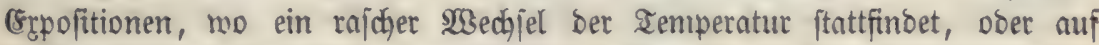

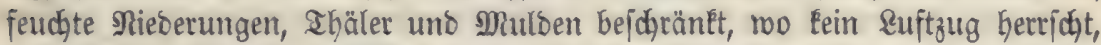

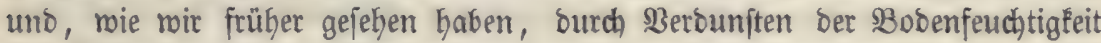

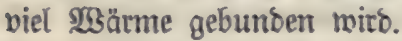

\section{d. Eroftrifก.}

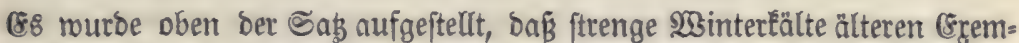
plaren von benjenigen 5olzarten, reldge in unjern Begenoen Geimijid funo, ober aus höheren Breiten ftammen, jelten töbtlich mirb. Dagegen bewirft fie bei mandyen SBaumarten, Daß̃ biejelben parallel mit ber Sdhaftage Sprünge erbalten, bie man groftriffe ober (Siв́lüfte nennt. Dieje tönnen in zmeifacher 23 eije entfteben.

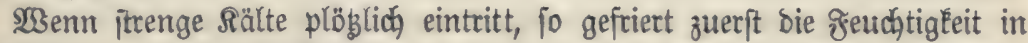

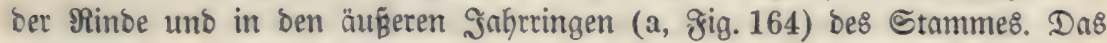

ə̧ig. 164.

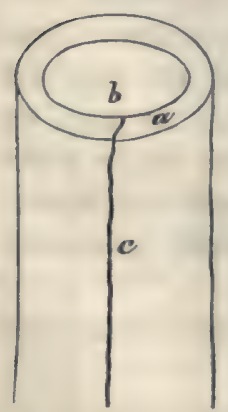
(sis, weldjes fich) bildot, nimmt nun zroar einen gröfíferen

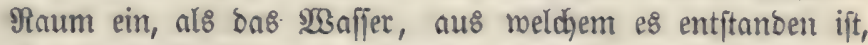
allein es zieht fich, wenn bie Sälte unter $0^{0}$ finlt, forträlb= reno zujammen, gerabe ebenjo, wie bie fefte Subjtanz ber

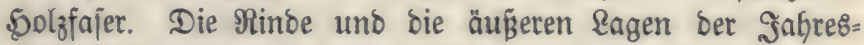
ringe (a) werben baher einen Drud gegen bie inneren $\mathfrak{b o l}_{3}=$ lagen ausüben. Dringt nun bie Rälte noch meiter in ben sBaum ein, fo gefriert aud bie greudftigleit in ber übrigen 5olzmaffe, bas (sis befnt fich um bus 1,0525 fache bes $\mathfrak{B O}=$ lumens bon temjenigen bes $23 a f f e r 8$ aus uno äusert einen Druct gegen bie bereits gefrornen Jahrringe uno gegen bie Rinde. Da bieje aber nidgt nadggeben Eönnen, meil fie jelbjt zujammengesogen werben, fo tritt, wenn der Drud bon innen nad్ außien

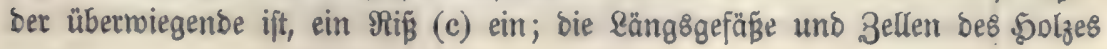


berlieren ifren (ohneoies jofwachen) peitlichen 3ujammentyang, fowie benjenigen mit ben Marefftrahlen, uno berften von einander.

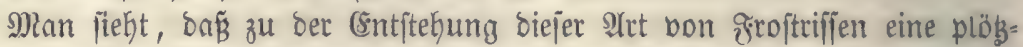
lid)e (stniebrigung ber Iemperatur elforberlich ift; bringt bie Rälte allmählig in ben Baum ein, fo laffent fich bie nody nidjt ftart geworbenten imteren Solz=

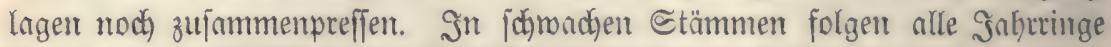

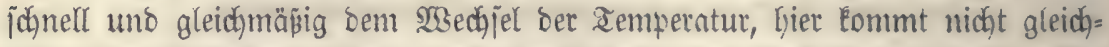
zeitig eine 3u|ammenziehung nach innen uno eine 2lusbefnumg nach auß̧en

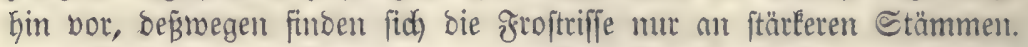

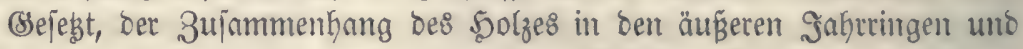
Der Rinde fei ftark genug gemejen, um bei plöblichem sefrieren ber innern Jahrringe beren Druct zu wioerftehen, to wird ber legtere nidyts seitomentiger

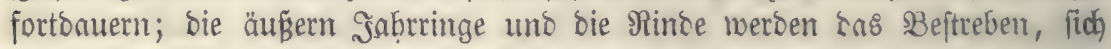

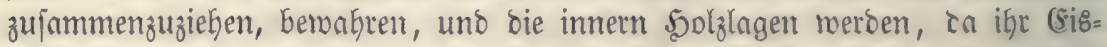

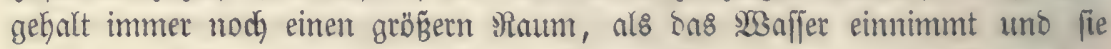

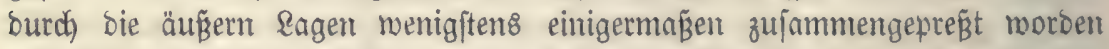
fint, fich auszubebnen fuchen, wenn fchon bns ßolumen bes (sijes bei Ten= peraturen unter $0^{0}$ Eleiner ift, als im Moment Des Befrierens. Eobald nut

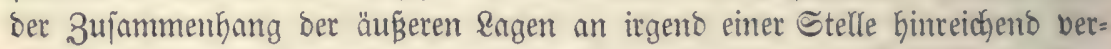
minbert wirb, fo belvirkt bie 3ujammenziefung biejer \&ngen uno bas 94

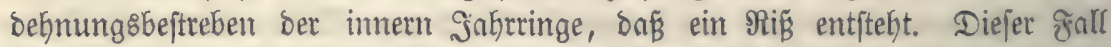
tritt z. B. Dann ein, menn bie eine Seite bes Sdhaftes plöblid, etwa bon ben Strablen ber Morgenfonne, erwärmt wirb, es entfteft alsosmun an ber

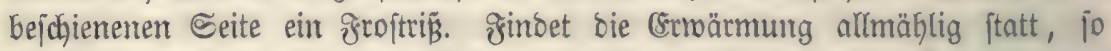

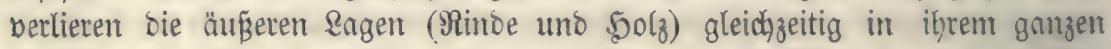

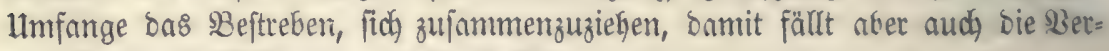
anlaffung zur siltoung eintes groftriffes reg.

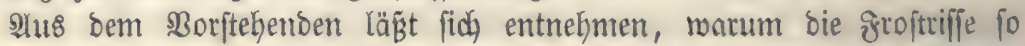
Gäufig auf Sübofțeiten uno an freiftebenden Stämmen, bortommen. ôroftriffe an $B$ äumen in gejefloffenen Beftänoen, weldje nicht ber Morgenionne erpo: nirt find, für inmmer mur bie Folge von plöblich eintretenter Rälte. ఏier geht aber bas Springen bes \$olzes mit viel größerer (semalt vor fich, oft

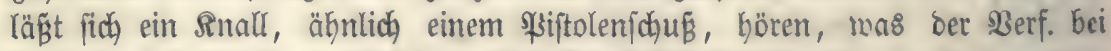

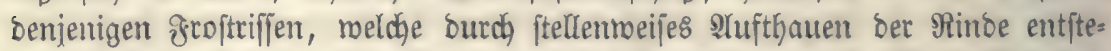
Gen, niemals wahrnebmen konnte. Das sinallen erfolgt meift bes Nadhts, vorzüglidh kurz bor Sonnenaufgang, zu meldher Zeit bie Sälte gewöbntid iちren Gödhften Srad erreidjt.

Die Ærroftriffe Eommen überbaupt meift im Nad)winter vor, wesn bas Solz içon anfängt, fidu mit Saft zu füllent.

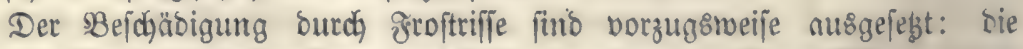

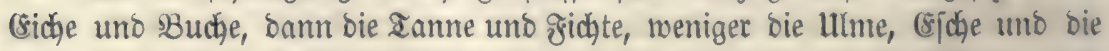
IfGorne, jomie bie Riefer. Birken leiben mohl gar nidht bon benfelben, aud) 
bei Bappeln fommen fie äuB̉erft jelten vor, mierongl fie bon bem Berf. einige Mate bei Pop. italica beobatytet worben fint. Bon Den beiben (Eidgenarten ift Quercus Robur nehr zu frrojtrifien geneigt, als Q. pedunculata, ras mohl auf ber größ̈ern Epaltigkeit ber erfteren beruht. Etämme, welche plöb̆s=

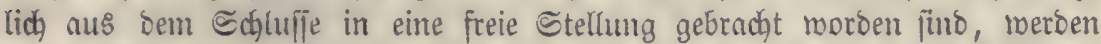

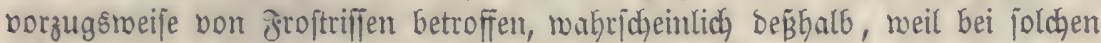

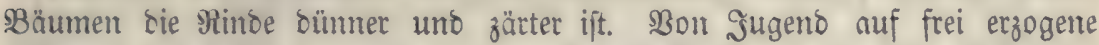

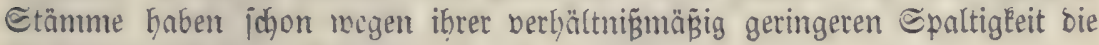
Æroftrifịe weniger zu fürdhten.

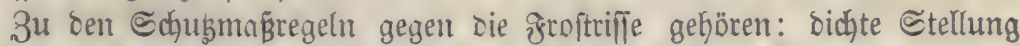

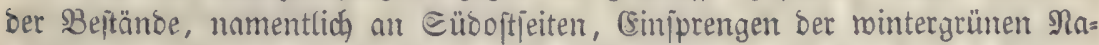
Delgölzer in bie Enubholzbeftünoe, (Erziehung der ftärtéeren Scolziortimente in gejđloffenen Bejtänoen mit höberen Umtriebszeiten (aber mit päterer Bei=

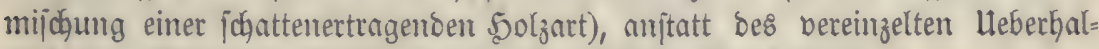
tens von Stämnten für bie Dauer einer zmeiten Utmtriebszeit.

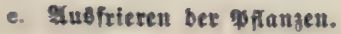

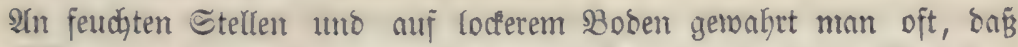

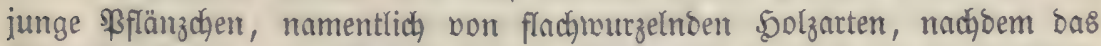
(Eroreich gefroren uno plöblich wieber aufgethaut war, mit ganz ober theil=

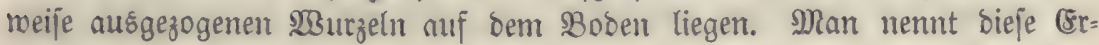

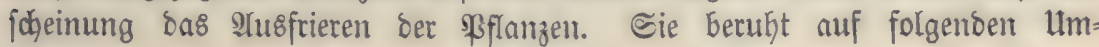
ftänoen.

Wenn plögliche Sälte eintritt, fo bas nidyt fämmtliche Grbe, weldje

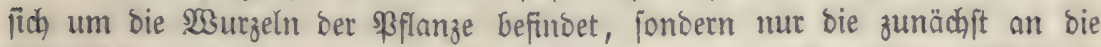

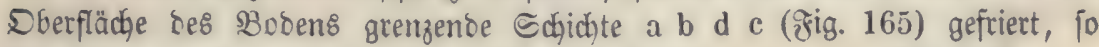

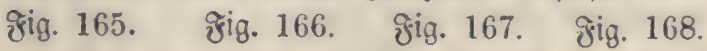

ஓेंg. 169.
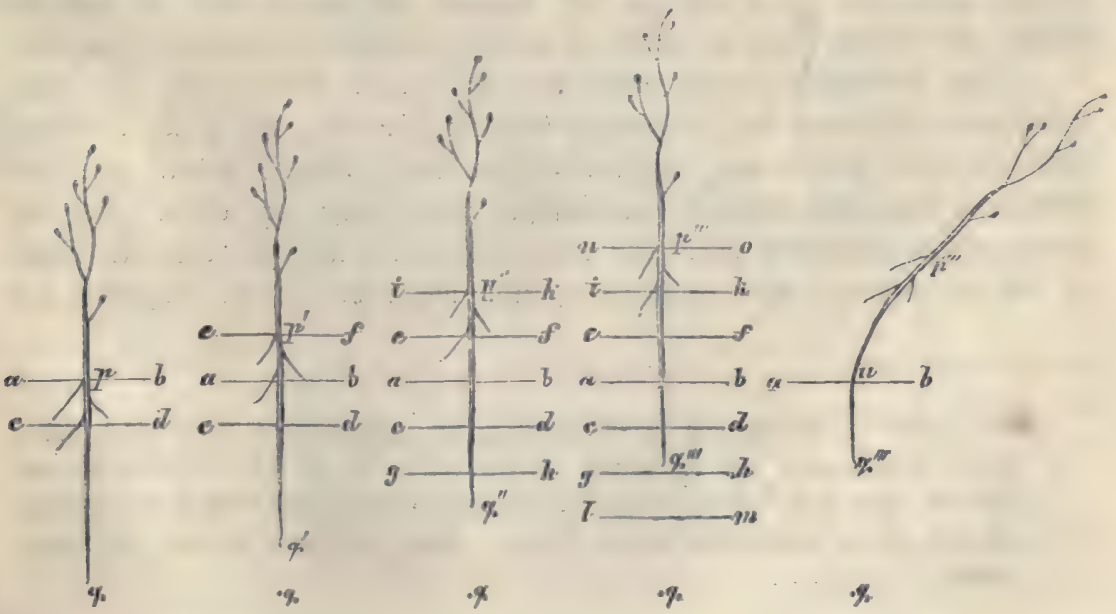

seyet, sobenfunde. 


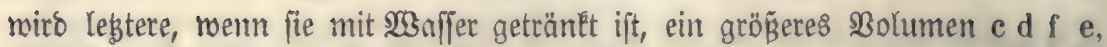

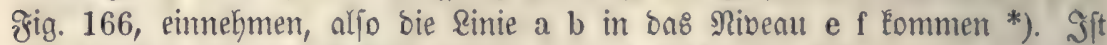
nun bie (srbe in ber Echichte abdc an bas Pflänzchen feftgefroren, bagegen bie unter ber sinie ed befintliche (sroe nod) weich, fo Kebt fid, das \$Plänz=

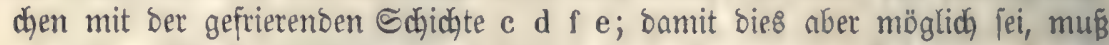

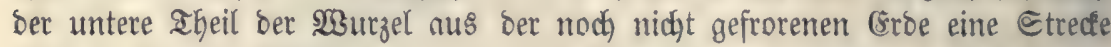
lang ( = Dem Betrng von $q^{\prime} q=a e$ ) nuggezogen werben. Friert nun neuerbings nody bie (Erojchichte $\mathrm{c} d \mathrm{~h} g$, (きig. 167.) jo befnt fie fich aus, und hebt bie bereit8 gefrorne Echichte; bas Bolumen ber gejammten gefror:

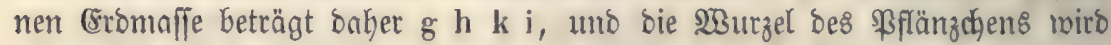
abermals um eine (Sröffe $q^{\prime \prime} q=$ ie atsgezogen. Snchbem aud) nod bie Schichte g h m I (ङig. 168.) gefroren unt mit biejet bie gefammte (5tomaffe auf ons Bohum I m o n gebradht morben ift, befinbet fich ber ßsunct $p$,

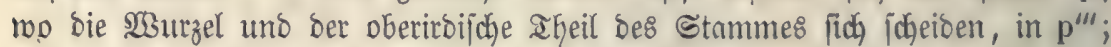

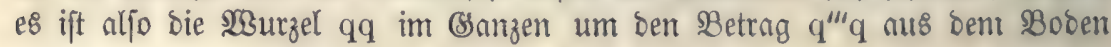
gezogen worden.

IGaut mun ber Boben blos oben auf, mäbrend er bei q"' nod mit ber

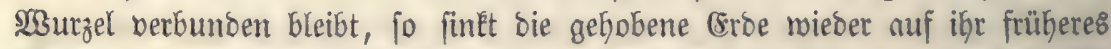

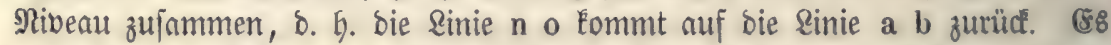

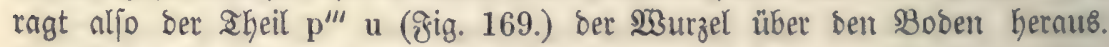
Die Pflanze legt fich bann gemöhntich um, weil $\mathrm{p}^{\prime \prime \prime} \mathrm{u}$ ein Theil ber bieg= fameren $\mathfrak{S} 3$ uzzel ift.

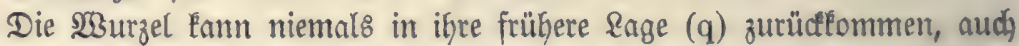
wenn ber Boden auf einmal bis zu jeiner ganzen Diefe aufthaut, weil bet untere Theil ber 23 urzel nidyt gemug Steifigfeit befigt, um in bie Eroe ein= zubringen.

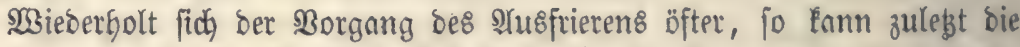

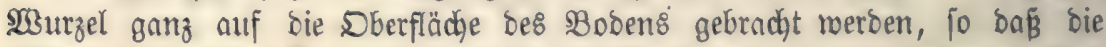

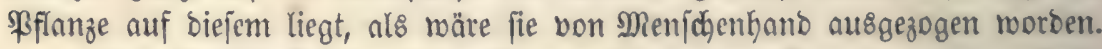

Dด8 SHEfrieren Eommt meift nur bei jungen Exemplaren ber flact)=

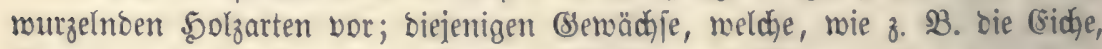
jojon im erften Gabre eine tiefgekende \$fahlmurzel bilben, haben bon bem Autffrieren nur unter befonoers ungünjtigen $\mathfrak{B e r h a ̈ l t n i f f e n ~ z u ~ l e i b e n . ~ B e i ~ b e n ~}$ tiefrourzelnden Solzarten wirb ber untere Theil ber 203 urzel burd ben Druat Der auf igr laftemben oroe feítgehalten, uno renn bie oberen Sojidjten bes

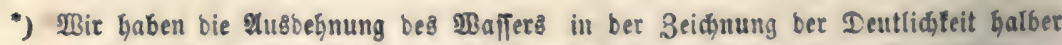

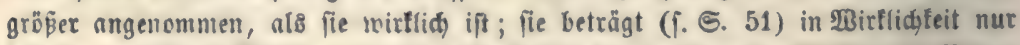

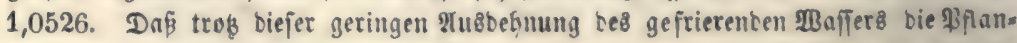
zen vom gropte ausgehoben werben tönnen, herubt auf einer urfade, bie fogleid, erörtert werben wirb. 


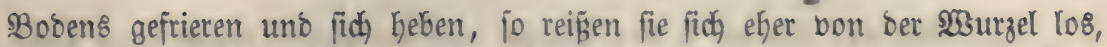

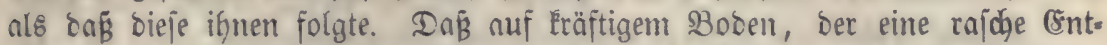
miaklung bes 233 urzelinjtems von vorn berein begünitigt, audi bie flachmur=

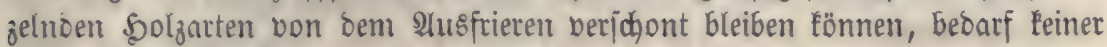

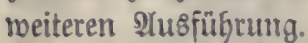

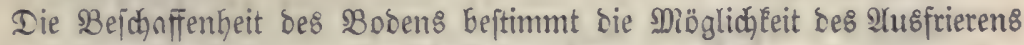

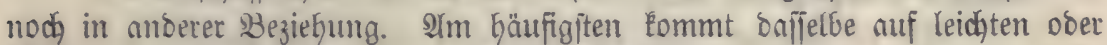

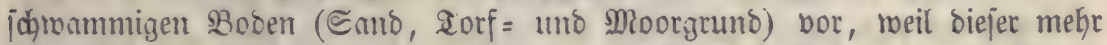

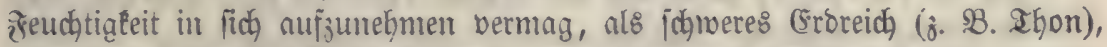

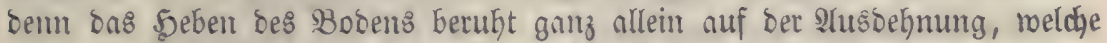

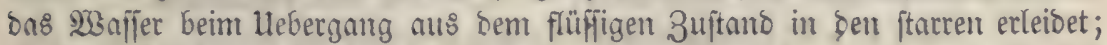

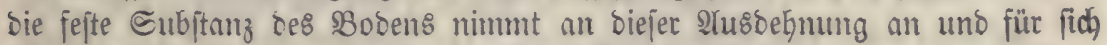

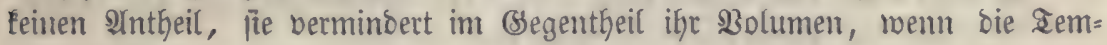
peratur finft.

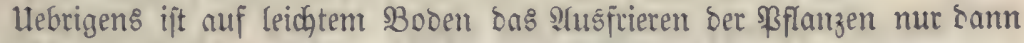

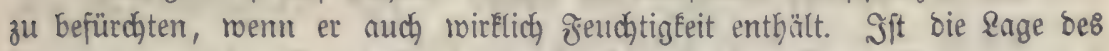

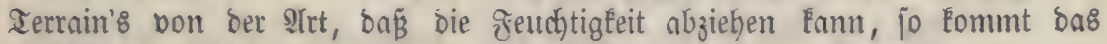
Ituşrieren nicht bor. Reß̧teres ift überhaupt mehr auf Ihalvertiefungen, 'Mulben 2c. bej̄jränift.

Betrod"neter, unbenarbtet Boben ift bem 21usfrieren bejonders unter=

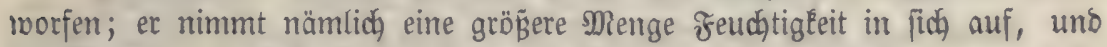

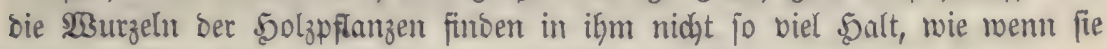
mit ben 93 urzeln bon (3rab 2 c. 2c. beridhlungen find.

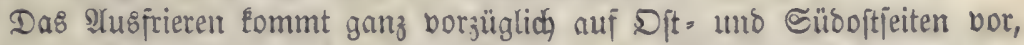

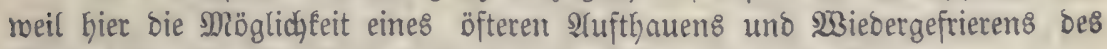
Bobens gegeben ift. STuf nördlichen Expofitionen, no ber Boben nur einmal gepriert, ift bas ŜAsfrieren eine jeltene Erjofeimung, bie mur bann eintritt, wenn Das 2 setter fich b̈fters ănoert.

(Sine Decte von Enub ober Schnee jhügt bie Bflanzen vortrefflich gegen

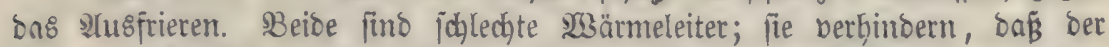
Boren ftark̂ gefriere, ober öfters aufthaue. In reldhent Mage bie günjtige

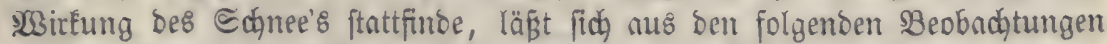

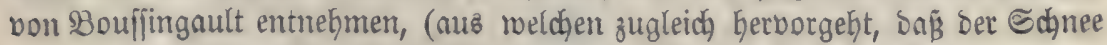

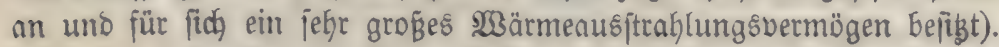

Boulingault fekste ein Ifbermometer auj cine 0,1 Meter biffe Sdinee lage, weldye feit eintem Monate ein mit $\mathfrak{B a i z e n}$ beftellte Felo befleibete,

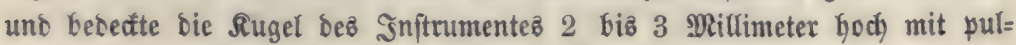

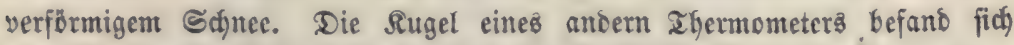

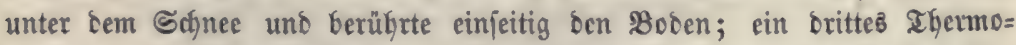

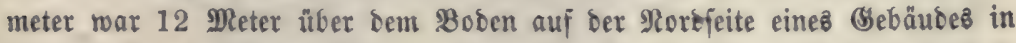
freier \&uft aufgehängt. IN ben Tagen ber Beobadjtung wurbe bas Felo youlfommen von ber Sonne bejditenen. 
$\mathfrak{A m}$ 11. Februar 5 Uhy 2(6ents war bie Sonne bercits eine Galbe Stunde Ginter bem Gebirge veridfnunsen; ber 5̧immel war unberedt, bie \&uft fehr ruhig. Daz Ihermometer unter bem Sdynee żigte $0^{0}$, baz auf bem Edfnce - 10,5, Dab in freicr 2 uft $+20,5$. Tie Sonne war faum Ginter bie Berge gefunfen, als bic 2lusftrahlung yon ser Dberfläche bez Schnee's mafirnehmbar nurbe.

2m 12. Februar war bie Radjt fethr fohen, ber Şimmel wolfenloz

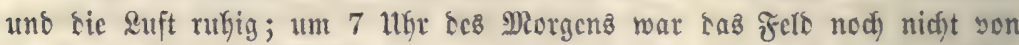
ber Sonne beffjienen. Dab Tharmometer unter fom Schnec zcigte - 30,5 , Das Ihermometer auf bom Sd)nee - $12^{0}$, sā frete Ihermometer $-3^{n}, 0$.

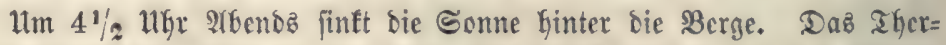
mometer unter bem Sdynce zeigt $0^{0}, 0$, bas Thermonter auf bem Edince $-1^{0}, 4$, bas Thermometer in frcicr \&uft $+30,0$.

$\mathfrak{2 m}$ 13. Februar, um 7 thyr Morgenz bebcefter Simmel, Ruft etwaz berogt. Ifermometer unter scm Sidnee - 20,0, Thermometer auf Dem Schnee $-8^{0}, 2$, freies Ihermometer $-30,8$.

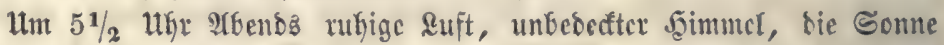
feit einiger Beit untergegangen. Ifyermometer unter bem Sdhnce $0^{0}, 0$, freicz Ihermometer $+4^{0}, 5$.

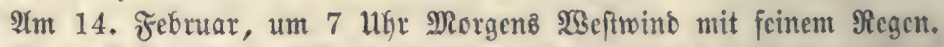

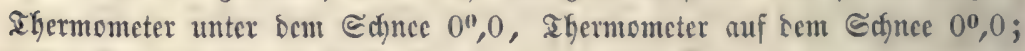
in ber freien suft $+20,0$.

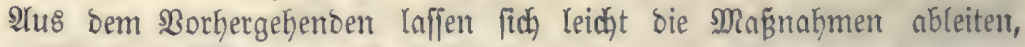

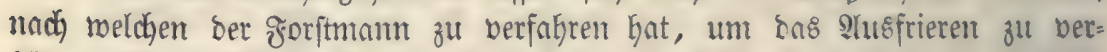

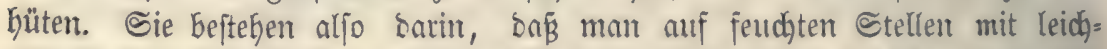
tem Boben Keine fladjwurzelnden Solzntten cultibire, ober boch, mem bies

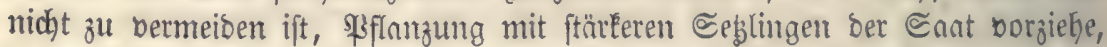
baß́ man ben Sablichlagbetrieb in Berbindung mit Etodroden, wemn thun=

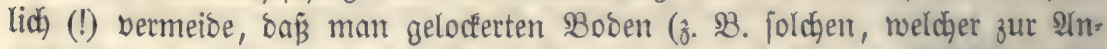

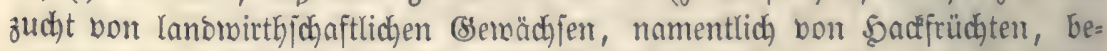

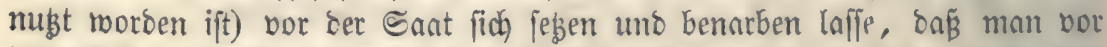
Dem 2 ntbau bon fladjwurzelnoen $50 l$ zarten ticfinurzelnoe anziebe, Iamit bieje

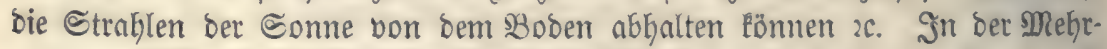

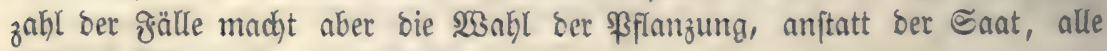
bieje Borfichtımañregeln entbehrlich. 
Sed)รehntes 2 ud.

\section{(E)}

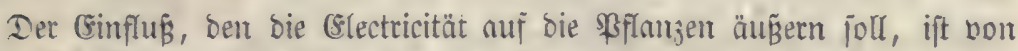
einigen Echriftftellern feht n̈bertrieben soorben. Die Zeit liegt nicht ferne, in welcher mant eine grofe 3nht ber (Erjheinungen bes vegetativen Rebens, von

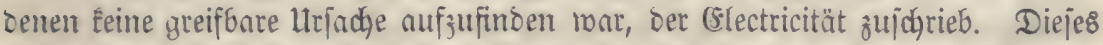

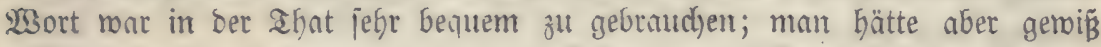
aufridytiger gehanoelt, wenn man e8 lieber roeggelnffen uno ohne WBeiteres

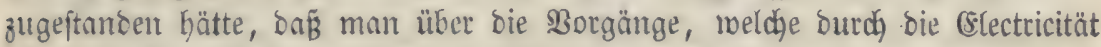

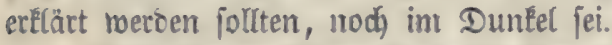

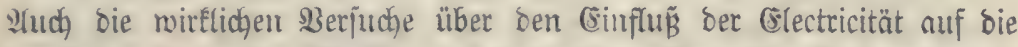
Pflanzen jüto nit grofier Borjicht aufzunehmen. Bsar oft rügren fie bon Eoldten her, welche anfiänger der Electricität8 = Theorie waren uno Den Ber= juch mit ber sibjicht anjtelten, burch ifn ben Berweis eines vorher ausge= iprochenen ๔ages liefern ju mollen. Man ift in ber Ifat berechtigt, ein

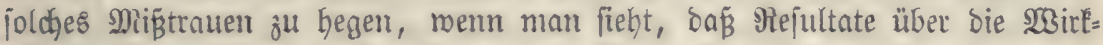
ung Der (Electricität veröffentlicht worben finŁ, melche andere Beobad)ter unter den nämlichen Umitänden niçt wieber zu erbalten bermodgten.

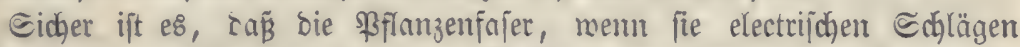
nusgejegt wiro, auf einige 3eit ifre (stafticität verliert. So fallen o. $\mathfrak{B}$. die Blätter von Mimosa pudica burd) (Slectripiren zu[ammen uno richten jich erjt nach einigen Iagen wieder auf, wie ber Berf. zum öfteren beobadjtet

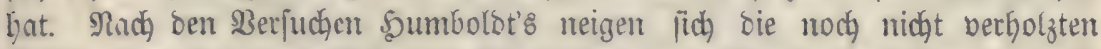
Blütţenftengel von verjobiebenen (Semächjeı augenblicflich abroärt\&, menn fie von einigen electrijojen $\Xi$ d)lägen getroffen werben.

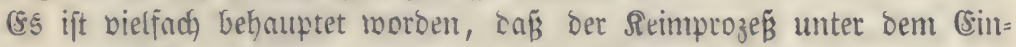

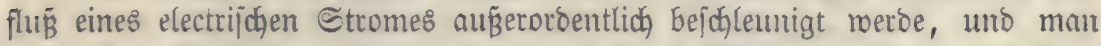
mill surch Berjuche gefunden baben, baí electrijïte Cenffamen 11 Inge frilfyer gefeimt hätterr, als niçt electrijüte. Co lange indoffen keine contro= lirenden Berjuche angejtellt woorsen find, möge man bieje Ŝngaben als jwei=

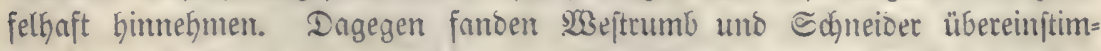

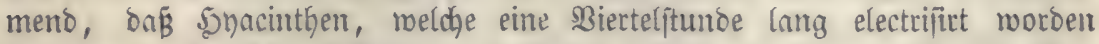
waren, im Dunfeln :2lüthen entroidfelter. Siernach ichiene aljo bie Blec=

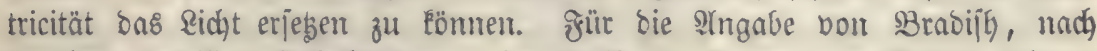
reldjer electrifitte 2abafipflanzen innerb̧alb 21 Iagen zur Blüthe gelangt 
rören, liegt aber keine beftätigende Beobadjtung vor, inbeffen gehört eine

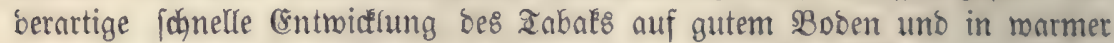
Eage, auch ohne sinmirk̈ung ber (Electricität, nicht zu ben હeltenkeiten.

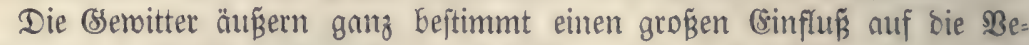
getation; mur ift 'es zmeifelhaft, $\mathrm{ob}$ berjelbe nuf ber electrijchen $\Re$ atur ber

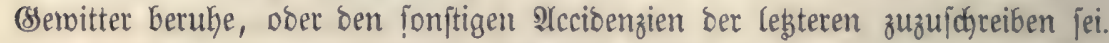
Die Bervitter treten gemöhnlidy bann auf, roenn es längere 3eit nidht gereg= net hat, mittlermeile fammelt fiç) in ber \&uft biel Stnub, Rohlenfäure uno Immonial an, weldje bann burdh ben Bemitterregen zur Erbe gefüthrt mer=

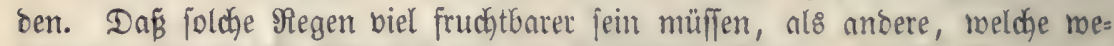
niger bon biejen Stoffen enthalten, liegt auf ber Saario.

Der 2 ligh uno bas 23 etterleuchten foll ber siüthe fohaben. Im Doen= malbe ift man allgemein ber Inficht, baß̉ ber in ben Sacfwaldungen gefoute Budjwnizen in gemitterreidgen Sommern uno namentlich bei p̈fterem 23 etter= leuç̧ten taub blüfye.

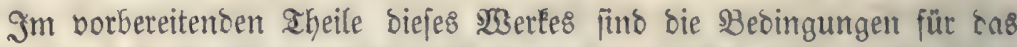

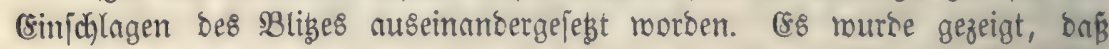
ber Blip vorzugsmeife bie guten \&eiter ber Crlectricität aufjucht. Da bas

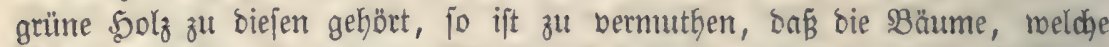

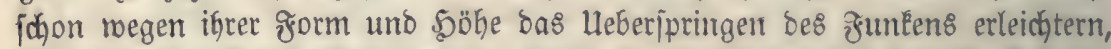
Bfter vom Blike getroffen merben. Diez ift in ber Ihat ber fall, uno bie

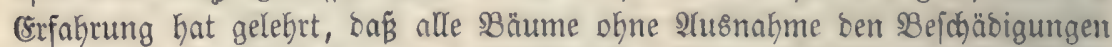
bes $B$ liges unterliegen Ënnnen, wiemohl einige Solzarten mehr, andere weniger bon ifnen zu leiben haben. Möge es uns erfaubt fein, über biejen intereffan=

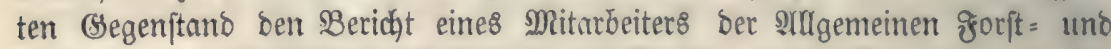
Sagozeitung von 1850 unjern Rejern borz̆ü̈fren.

"Dem Einfdylagen Des Blizes am meiften untermorfen find bie sabel=

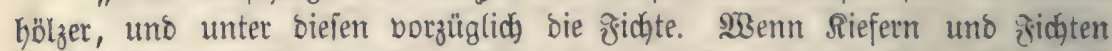
beifammenjtehen, fo fochlägt ber Bliz efyer breimal in eine gichte, als einmal

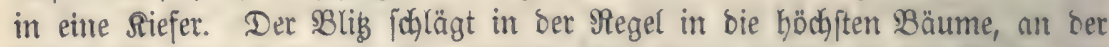
ganzen sänge besి Stammes ununterbrochen Gimunter bis in bie (sroe; nur wenn er einen ftarken 3meig auf feinem 253 ege trifft, baum fäbrt er wohl ben 3weig entlang rechtwinflig abwärts. 2(ud) finbet man bei gebreft etwadbje=

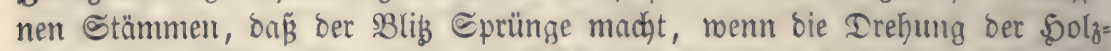
fajern, beren Eängsirichtung or am liebjten folgt, feiner verticalen (Eilfertigkeit zu hinberlich ift."

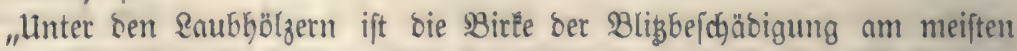
unterworfen. Sier ijt ber graphitfarbige હtreifen, weld)en ber Blig allen Stämmen (\&aub = uno Nabelfblzern) ohne Nu\&nahme ertheilt, Enum ober gar

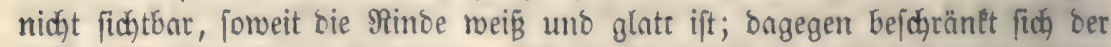
Blig, pobnlo ex an bent unterent rififigen aheil bes Etammes Eommt, nid)t

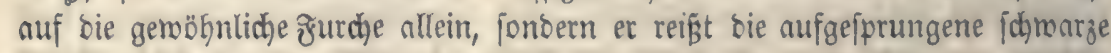
Borfe rings um ben Stamm mit ab uno wirft fie rabfpeichenartig ftrablig 
oft 40 bi: 50 Sdhritte meit. Nidyt felten fehlt an Dem untern rififigen Stnmmtheile bie Splintfurche gänzlich, uno joheint auts ber rings abgenor=

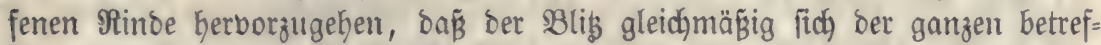
fenden Ctammoberfläche bemächtigt babe. Dben fo wenig, mie unten ent= fteht aber ein Epalt im Birfentholze, diejes bleibt bielmehr, einige lnsge= riffene Eajern abgerechnet, felbjt unbejöäbigt."

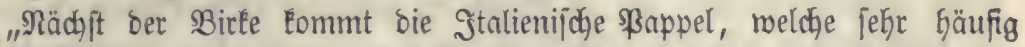

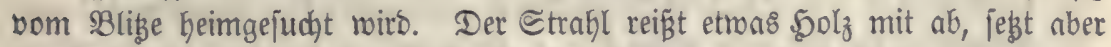

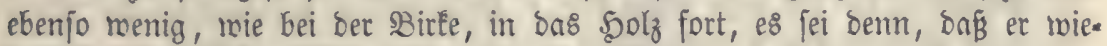

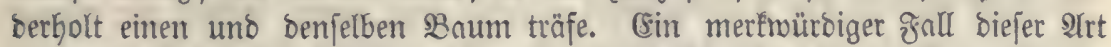
ereignete fich in ben 1820er Jahren vor ben Alugufthore zu Braumfdyeig. Sier befindet fich an ber Chauffee eine boppelte ßappel=słlee, beren Bäume, etroa gleichzeitig gepflangt, fo ziemlich gleidhe \$öhe baben mögen. Deffen

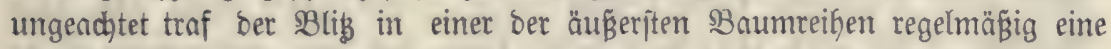

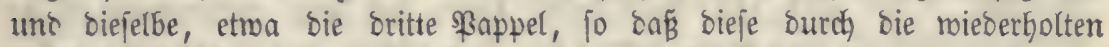

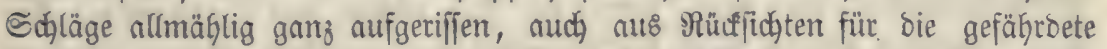
Raffage entfernt werben, uno einer jungen \$appel \$las madjen muste, weldhe

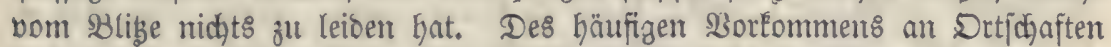

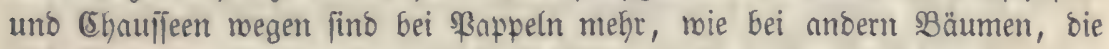

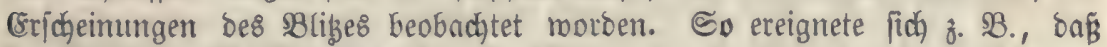
bei Sorft, zwijđ)en Burgoorf uno \$annover, an einer mit Pappelbäumen

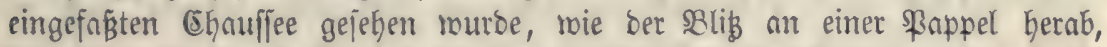

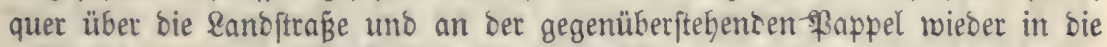

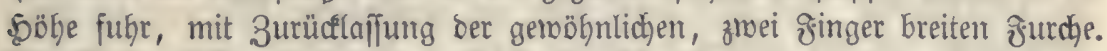
Mir ift ein Sall belannt, mo eine Stalienijhe \$appel etroa einte Ruthe weit

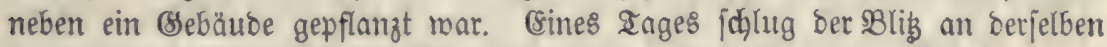

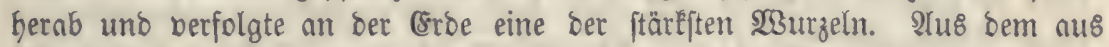
(sid)entyolz conftruirten (srunoe Des ifm hier in ben $23 e g$ tretenten $230 h n=$

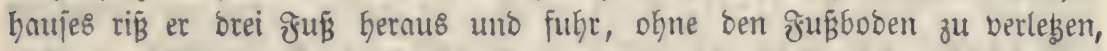

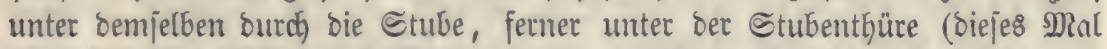

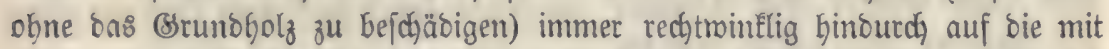

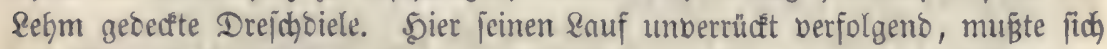

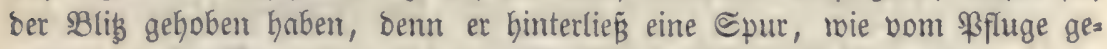

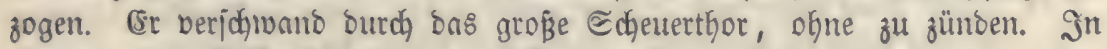

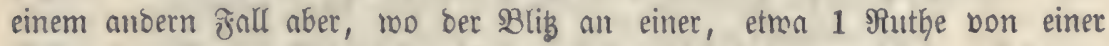
Sdheune entfernten Pappel Gerablief, verließ̈ er bieje bei eintem fid bem Scheuer=

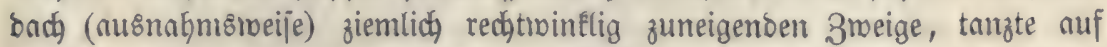
bemịelben binaus unter bns Dach uno ftecfte bas gange Ssebäube in Brano."

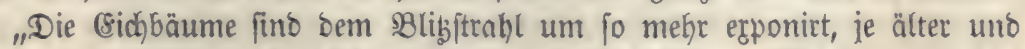

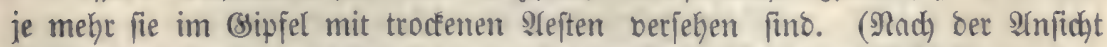

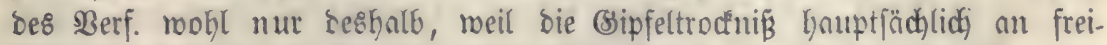
ftehenden Bäunten borfommt). Der Blig fegt baran hinab und reipt außer ber Borke aud einige Solzfajern mit fort, ohne dem solze zu jugaben.

$(D a=$ 
gegen erzählt ber Berichterftatter fpäter von einer andern 90jährigen (sidhe,

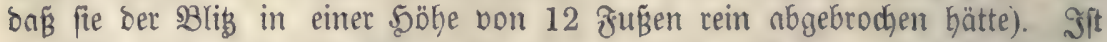
bie (sidje bon unten bis oben hohl uno an beioen (enden aufgejchloffen, fo

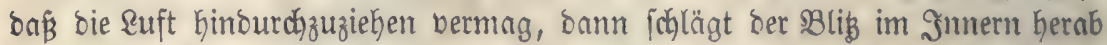
uno zümbet und zerftört leicht ben ganzen Stamm."

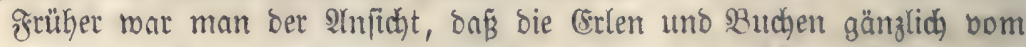
Blize verjdjont blieben, uno es rourbe oft gerathen, bieje Bäume in ber ミähe

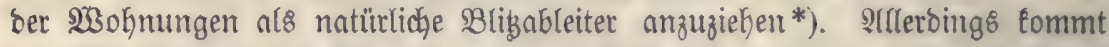
ber Blibjeflng bei ber (Erle feltent bor, v. Ball will in jeinen mebr als 30000 \$ectaren umfaffenden Dienftbezirḱen niemals bon einem foldhen bernommen baben; Dagegen gebt aus ber folgentoen, bon unjerem serichterjtatter mitge=

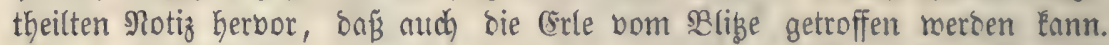
IIn einer Felbhecfe in ber গähe von Sona, erzählt berjelbe, befand fich eine

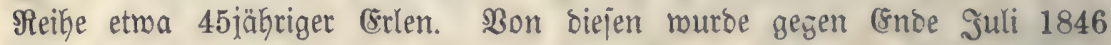
Margens 5 lthr eine von oben Gerab burd) ben Bliz̧ jprungmeije in ber Borke aufgeriffen, und bann, foweit ber $\mathfrak{B}$ oll reichte, rein abgebrodjen. Ten

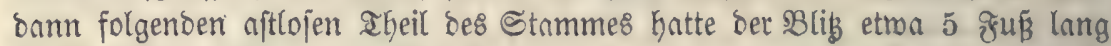
in Splitter zeridalagen, weldhe Esum zu finben maren. Unten nber mar ein

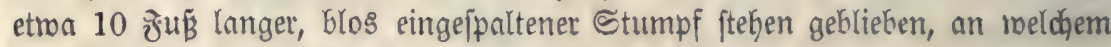

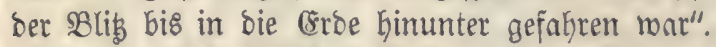

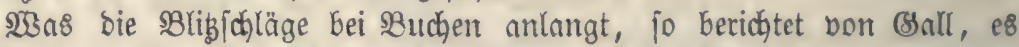

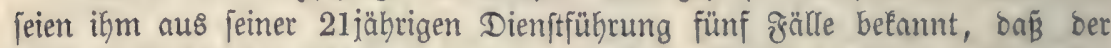

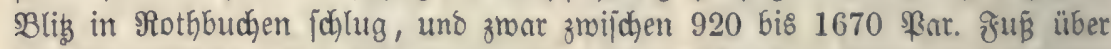

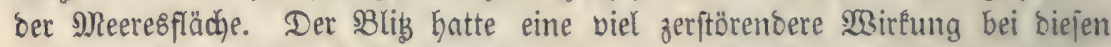

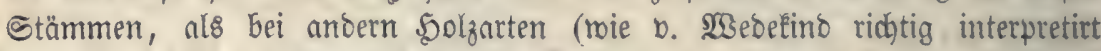

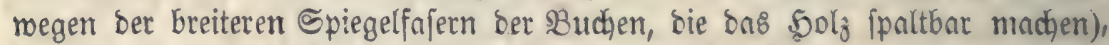
benn es tourden hierburd) fehr ftorke alejte herabgejdymettert, bie zum Iheil einen Durdfmeffer bon 17-20 (Eentimetern Gatten. Der erftere Stamm war

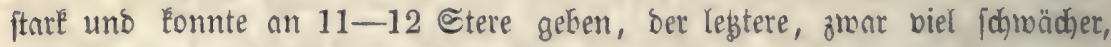
mor bngegen aller AYefte nuf einer Ceite beraubt, no ber Bligftrahl berunter= fuhr; aud musten beioe Stämme, an benen ber હdbaft zum Theil getiorften, ba\& folgente Salje gefälut merben.

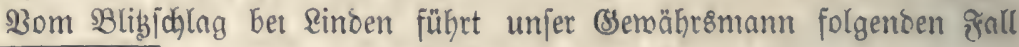

*) Tiejen 3wed mürte man üfrigens verjeblt haken, tenn zu Brib̧ableitern taugen

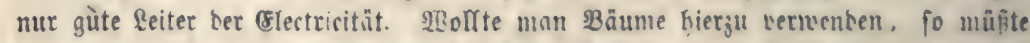
man gerabe biejenigen wählen, welche am bäufigften rou \$Bligg getroffon merben, fie aber in eine foldje Entfernung bon ben शRobnungen pflanzen, baßj fie zmar bell

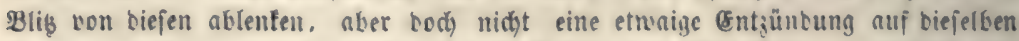
übertragen fönnen. ३̧ebenjalls wäre bieje 2irt vou Blibableitern eine febr un:

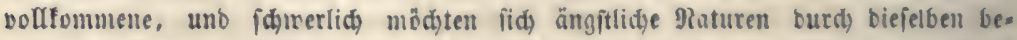

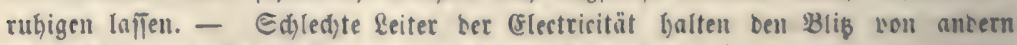

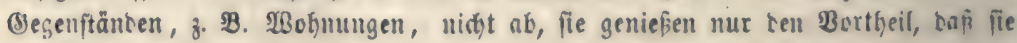
felbft meniger leidit getroffen werben, wenn ein anterer guter feiter in igrer Siähe fiid) befinbet. 


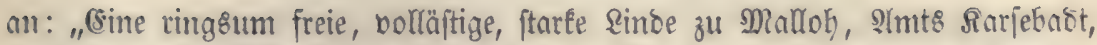
murte bor einigen Gabren bom Bliłg getroffen, begetitt aber ungead)tet ber erlittenten Borfte heiter fort. Merfwüroiger $23 e i f e$ verbreitete fich ber Sd)lag nicht allein berjengent über ben zwijchen ber sinde und bem 2330 hnthulje

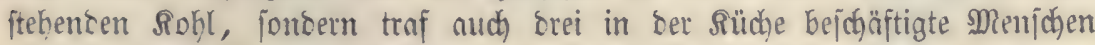
uno brei an ber andern Ceite ber Rinbe bor einem S23agen haltenbe Pferde, mährent ber neben ber geöffneten Sausthüre ftehente Förfter unberüfgrt blieb. Die umgejunEenen Menjchen uno Pferte Eamen wieber zut Befunnung."

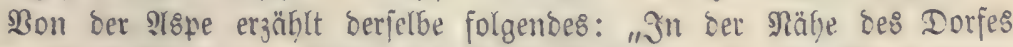

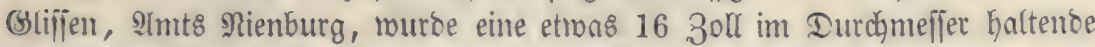

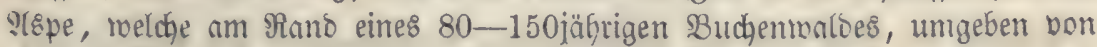

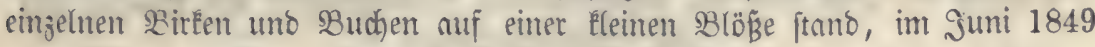
vom 3 lizge getroffen. Co meit bie Slejte hernbjapen, fah man nur bie ge= röbulidge ơurdhe, bem untern Theil bes Ctammes mar aber nicht allein ringšum bie Borke genommen unઈ zum aheil 185 Edfritte weit umher ge= ichleutert, jondern bas Etammbolz war surdymeg zerjplittert uno riedenartig zujammengebreht. 233 egen bes berbliebenen 3110ammenthangs Der Theile bauerte e\& nod) etrua vierzebn ange, bis ber Stamm umjant." Bon ber

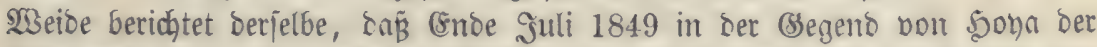

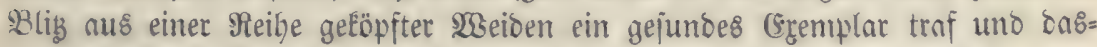

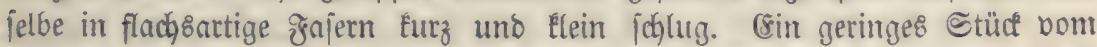
Stamm mit einigen Aleften uno melkén $B 3$ lättern war übrig geblieben. SRach

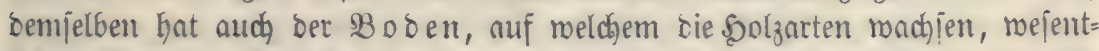

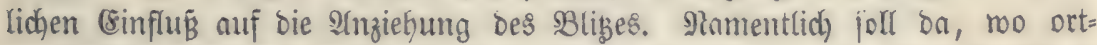
fteinbaltiger Llntergruno (æajeneijenjtein) borf́ommt, wie an vielen Drten in ben Saibegegenten, Blifjichlag an ber Iagezorbunutg fein. "Eine etron $60 j a ̈ h r i g e$ berktüppelte (fichenpflanzung auf einem etron einen Morgen um=

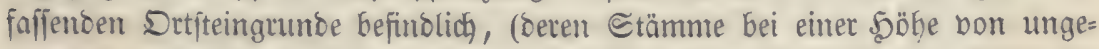

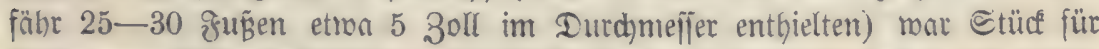

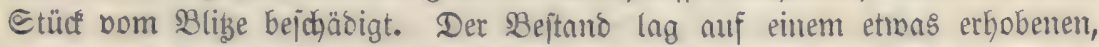
mit ftruppiger Saibe betwachjenen Boben. Hingsum ran ebenter \$nger mit

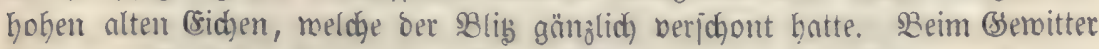
flohen ortskunoige Sirten jente Rtüppelpflanzung wie bie Bejt, weil bort

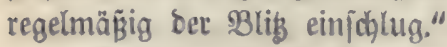

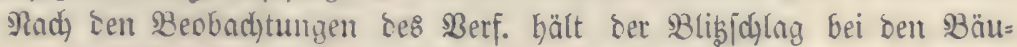
nten Eeine befítimmte Şimmelśgegento ein. DG bie Bäume in ebenten Bsegen=

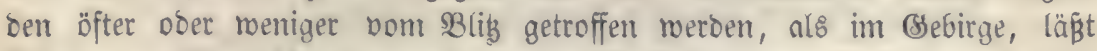
fid) regen Mangels an bergleidjenden SBeobad)tungen bis jegt nod) nicht

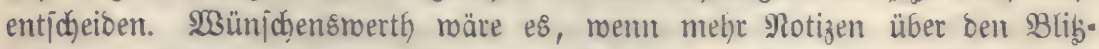
ichlng bei Bäumen aus beriddiedenen Begenden gejammelt würben; dieje

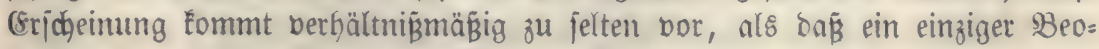
bnd,jter bas nöthige Material auforingen Ë̈nnte. 
Siebzehntes 8 ud

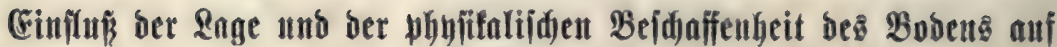 bie $\mathfrak{B a l}$ suegetation.}

Madjbem mir erörtert Gaben, welche Molle bie Atmojphäre, bie Meteore uno bie d)emijhen Bejtanotheile bes Bobens in Bezug nuf bie 23 nlopegeta= tion jpielen, Gleibt uns nod) übrig, Den (sinfluf ber Enge uno der phyfiéalijden Bejdaffenheit bes Bobens z̆ müroigen.

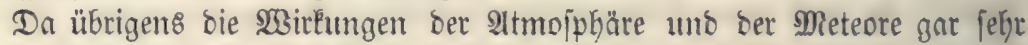
von bem Boden abyängen, fo lonnte e\& fidy nidht fehlen, baßs bieles hierker

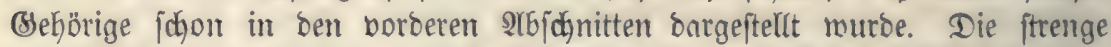
Sonberung ber Materien, rwie fie im Borbereitenden Iheil ftattfand, connte

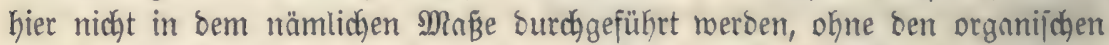
3ujammenting bes Stoffes zu Bunfen ber formellen Bebandlung theilweije aufzuheben. Die berichiebenen Irgentien Des Pflanzenlebens, jo meit biejelben

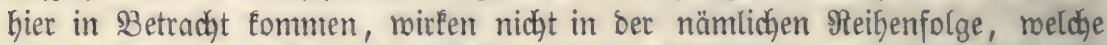
bie fdrriftlidye Darftellung Der fyftematifden Dromung Galber einzubalten ge= zmungen ift; 2 Bärme, Feudjtigleit, Euftftrömung uno noch fo bieles ândere vereinigt fid), um bie Broducte bes begetnbilijhen Drganismus hervorzubrin= gen. 23ollten wir nur einigermaffen ein Bild von biejem 3ufammentrirfent

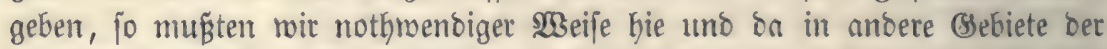
Darjtellung Ginübergreifen. So ift e\& benn gef́ommen, onß̧ wir hier meniger Reues vorzubringen, als bielmehr bas in ben vorberen 2rbjonitten rejagte, meldyem an bem gegentoärtigen $\mathfrak{B l a g e}$ jeine juftematijche Etellung gebührt, zu

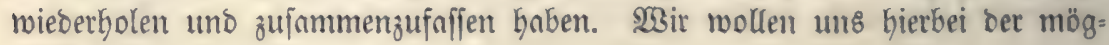
lichften Rürze befleigigen.

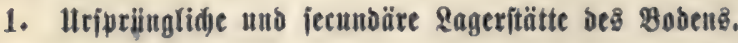

Das jogenamnte nufgefdyemmte \&and ift gewöhnlich tiefgrünsiger, bie (Eropartiteldhen fino feiner zertheilt uno berwittern bę̧̧alb leidjter, als bei foldt)em Boben, weldyer unmittelbar aus ber 3erjegung bes unter itm liegen= Den Befteines herborgegangen ift. Der aufgejdhivenmese Booen geftattet baher

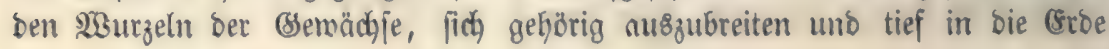




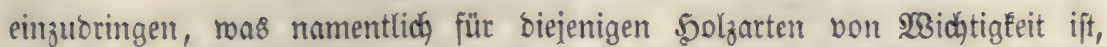

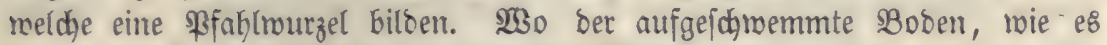

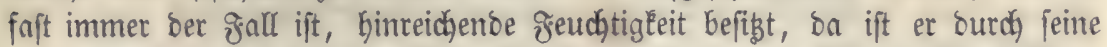

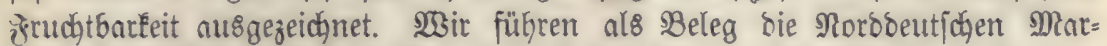

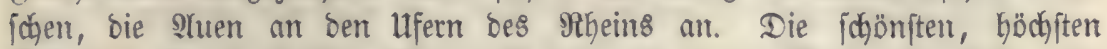
(Eichen machjen in joldhem Boben (Inoblaudbsaue am Rhein, bie Eidhentoal=

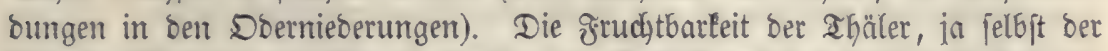

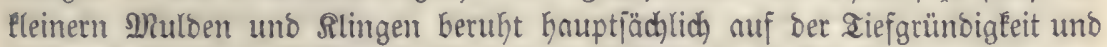
feinen 3ertheilung bes $\mathfrak{B}$ obent, ber an biejen Drten jeine jecundäre \&nger= ftätte gefunoen hat. $23 e n n$ bas aufgejhnemmte \&ano bäufig von @pätfröften zu leiben hat, fo fommt bies meift auf Rechnung ber bertieften \&age, relche eine slnjammlung ber greuchtigkeit begünjtigt.

\section{2Burgerfobenraum und Itntergrumb.}

FłLadjgrünoiger Boben hinbert bas (sinoringen ber 2 surgeln in bie Diefe;

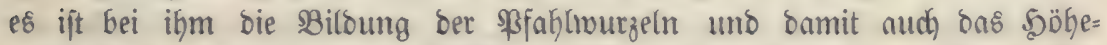
mad)githum bieler \$olzarten (Gichen, Riefern zc.) aufgebalten. (Er trod́net leidyt aus uno erforwert eine tiefgehende SBobenbearbeitung.

(sin unburchlaffender Untergruno, weldher entweder bon plaftifchem afyon, oder bon Jjeljen, noer von Rajeneijenftein gebildet miro, ift ber Baumbegeta=

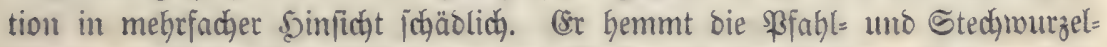
bilounz, verhinoert bas (sinoringen bes 23 affers in ben 30 oent uno berurjad)t

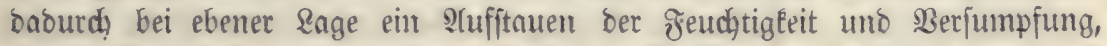

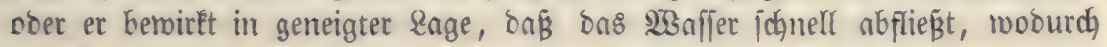

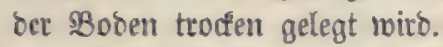

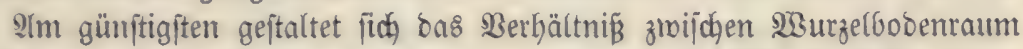

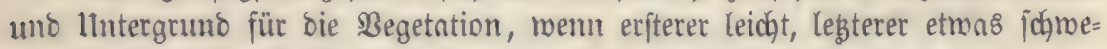

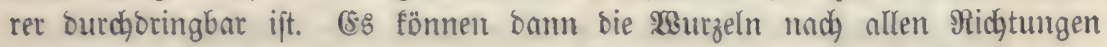

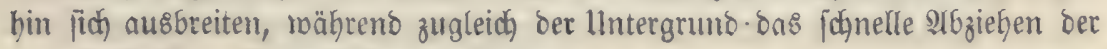
atmojphärijchen Niederjd)(äge verbindert.

\section{Dieflänber.}

Die Tiefänoer funo mit ben beridfiedenartigften Boobenjortent ausgejtattet.

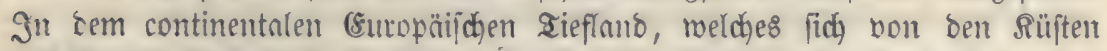

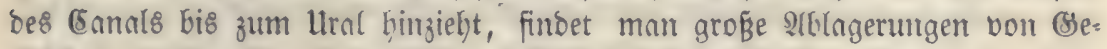

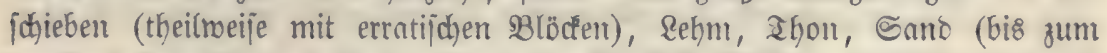
feinförnigiten §lugjanto hin). (Eine eigenthümliche Bobenart, weldge nament=

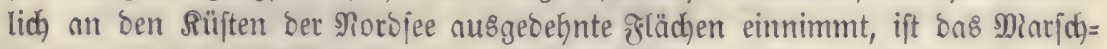

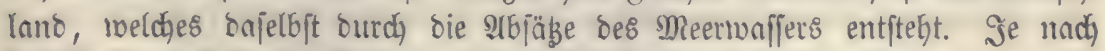

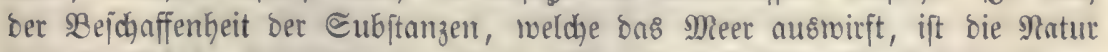

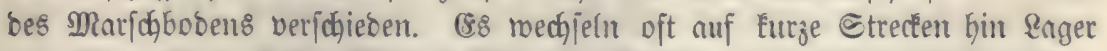

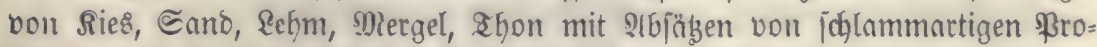
bucten. Die leșteren fino megen ifrer feinen Bertheilung, weldge eine idhnclle 


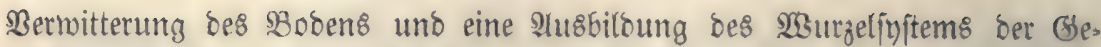

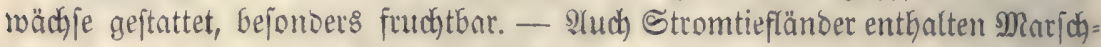
boden, nur ift hier bie 3ujammenjebung ber 2rbhgerungen nod) mehr bem $23 e d y$ fel untermorfen.

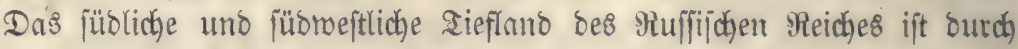
eine eigenthümliche Bobenart - bie jogenannte Schnarzerbe - ausgezeich)=

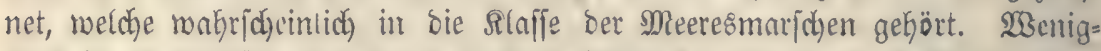

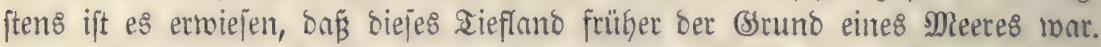
Die ভdymarzerbe enthält neben jegr feinzertheilten Mineraljubftanzen $6-12 \%$ organijue Materie.

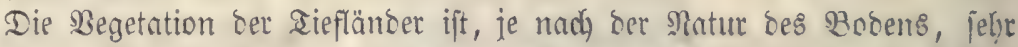
verifhieben. 130 ber Boten aus unturchlaffendem Ifon befteft, ba bitben

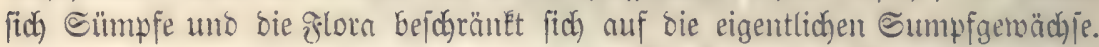
Bei Den Sanbobragerungen fommt es sarauf an, ob ter Untergruno feucht ober trocfen fei. Im erfteren golle ift bie (5ultur möglich, menn mut bie

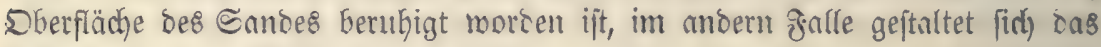
Ierrain zu einer 23 üjte (

Die Stromtiefänoer fino gemöhnlid) burdh Sügel ober Berge gegen muthe

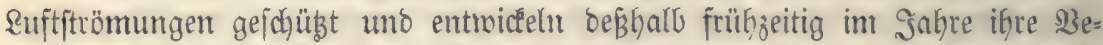
getation, ongegen leioen fie häufig bon હpätfröften, meldje bem größern frentch-

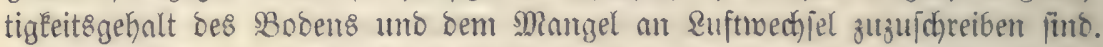
Die au\&gedefynteren Meeres = uno bie continentalen Tiefln̈ber bagegen find

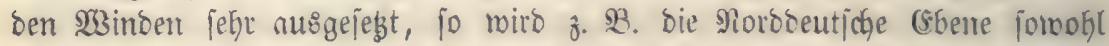

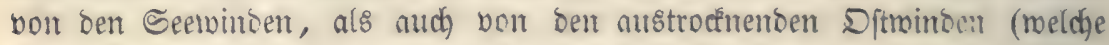

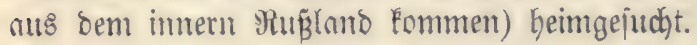

\section{Géchirgąläther.}

Mit wadjentoer Meere\&höhe treten eime Menge ßeränoerungen im Slinı ein, welche bemirken, Daßß bie Begetation ber Bebirge von berjenigen ber Dief= länoer abweicht.

Die mufallenojten Ericheimungen im Pflanzenleben werben burch bie

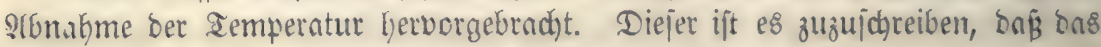

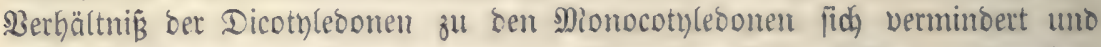

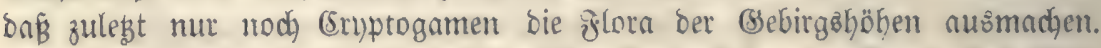
Aber lange borker, ehe bie bicots)ledonijdyen Srautpflanzen aufhöten, fint fojon bie Baumgetwähje berifhwumben.

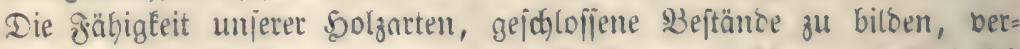

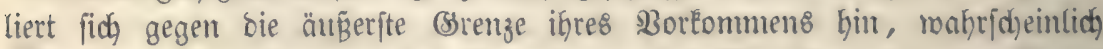

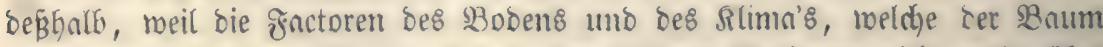

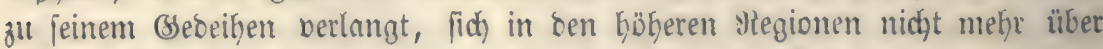
ganze Flärthen fint, jondern mur nu einzelnen Functen findent.

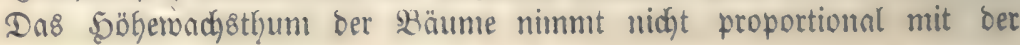


(sthebung über bie Meeresfläd) ab; oft trifft mun in sen (Gebirgen nicht

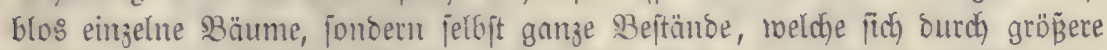

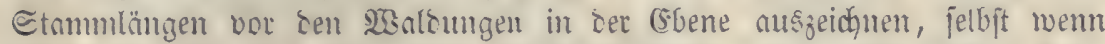

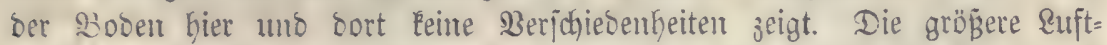

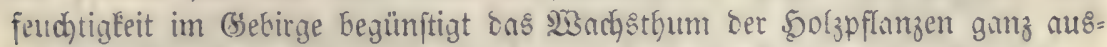

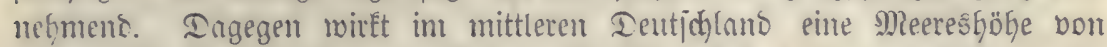
600 - 700 Mietern fichon metellich nadjtheitig auf bus Rängewad)sthum ber

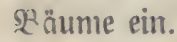

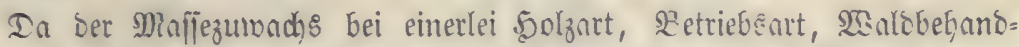

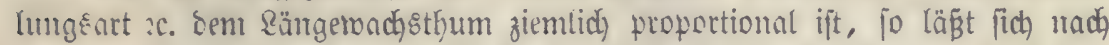

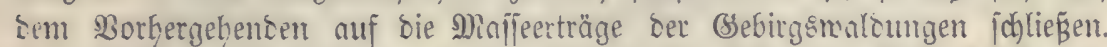

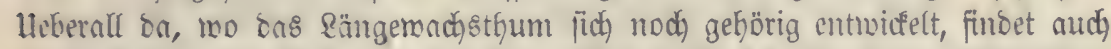
ein entiprechenter Majlezunachs ftatt. Co ergab fich bei einem Crtragsver=

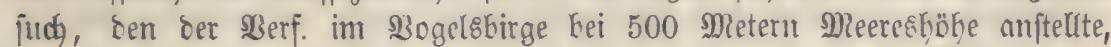

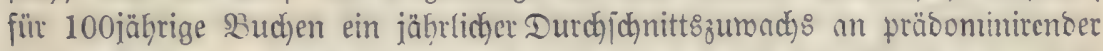
5olzmaffe bon mebr als 6 Cteren pro 5ectare, besgleichen bei einem andern

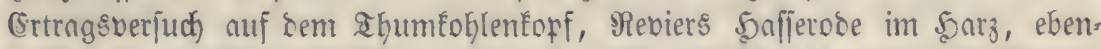
falls bei ungefähr 500 Metern über Der Meeresfläche in eintem 97jäbrigen

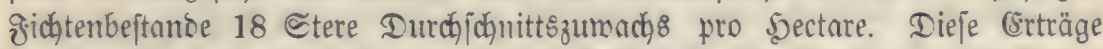
ftehen, roie mant fieft, berijenigen bon 8 eftämben in ber (s.6ente nicht nad). Bei Sclzmaffeerträgen von biejem Belang bleibt auch ber 3umachsgang im

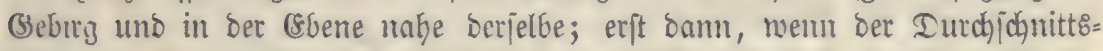
zumnchs auf einen bebeuteno Eleineren Betrag fich rebuzirt, tritt Der Fall ein,

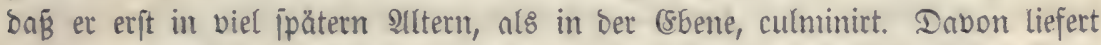
u. I. die Rärdje cin Beippiel; bei 100-200 Metern Seeböhe erfolgt Der

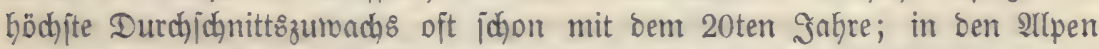
bagegent, bei 1400-1500 Metern Seebölye, erit nach Dem 80-100ten Sabre.

Die Säufigeeit ber Enmenjabre ift in ssebirge viel geringer, als in ber

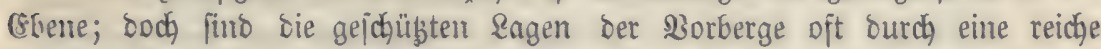

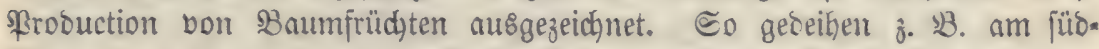

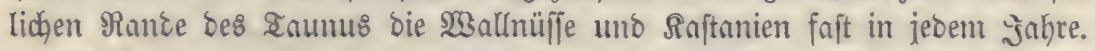

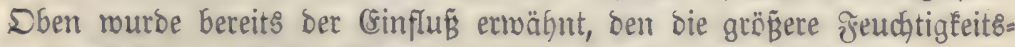

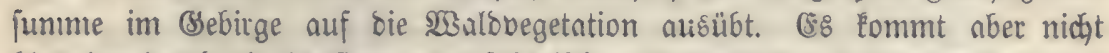
blos ber burch bie Gäufigen atmojphärijd)en SRieberjhläge hervorgerufene grö=

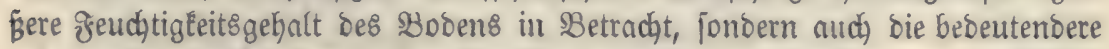

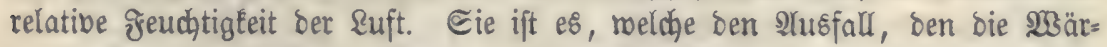
meabnahme im Bebirg in Bezug auf bie \$olzmaffenprobuction berwirken Eann, menigftens bis zu einer gemilifen (Erbebung über bie Meeresfläche bin róeber ausgleidht. In ber gröвern \&ufffeudgtigkeit ift bie urjache zu juळhen, roarum

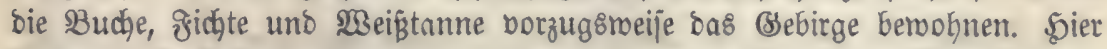

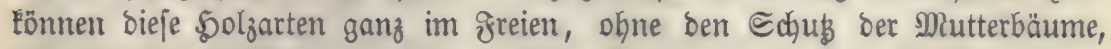
fich natürlich fortpflanzen, Gier roadjen fie in ber Sugeno fogneller empor 


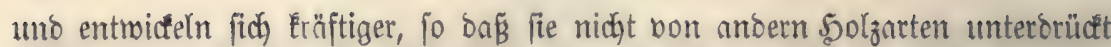
meroen Ëounen. Der größrere relative Seudutigkeit\&gehalt ber \&uft uno ber häufiger umzogene Simmel erlauben im Bsebirge, bie vorgennmten Solzarten im frreien mittelit ভaat anzuieben, was in ber (sbene, wenigitens auf nidht zubereitetem Boben, felten gelingt.

Der grö̈̈ern Menge an \&uft = uno BBobenfeuchtigkeit ift es ferner zuzu= fafreiben, warum in ben Borbergen bas abgefallene Baumlaub jo idyell ver: weit. Dagegen miro wieber in ben höberen Ragern ber Bebirge bie \$umus= biloung burch bie Ifonakme ber remperatur vergögert; legstere, forvie bie ftagnirente Feuchtigkeit bes SBodens, welche wegen Mangels an $23_{3}$ ärme nidht verbunften fann, geben Beranlaffung zur Brzeugung bon aorfmooren.

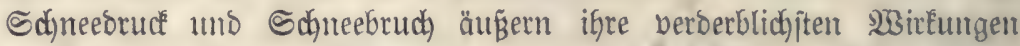

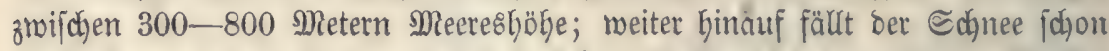
feinfloceiger uno trodener uno bäuft fich beş̧alb nicht in größzeren Maffen auf Den 3roeigen der Bäume an. Duft = uno Crizanbang treten mebr in ber (stene, als im Sebirge auf.

Die Befahr bes 23 inomurfs hängt im Bebirge fehr bon ber Configura= tion bes Bobens, bem Schus burdy vorragende größ̈ere Berge 2 . $a \bar{b}$. Bont

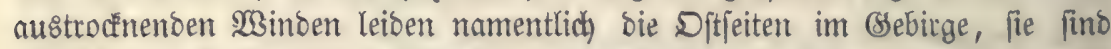

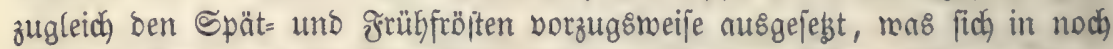
Göherem Ssrabe auf bie Süboftjeite bezieht. Siłge und Dürre wirken meḅt an ben Sübjeiten ber Berggebänge.

Der Boben ift in Den Thälern gewöhntlict) tiefgrünoiger, als auf bem

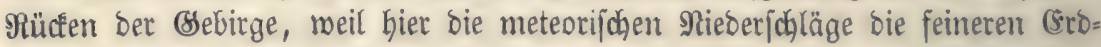
theildyen ablöjen und in bie Iiefe jämemmen.

Betradyten wir nun noch ben (sinflü, den bie Frorm uno Bolumber= theilung Der SSebirge auf bie Begetation äuß̈ert.

Bei kegelförmigen, parabolijđ)en uno kugelfegmentartigen \$ergen Fommt

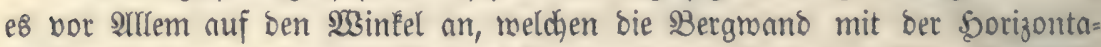

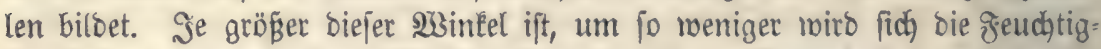
feit Galten uno um fo leichter bie (5rbe bon ben Bergmänoen aus in bie

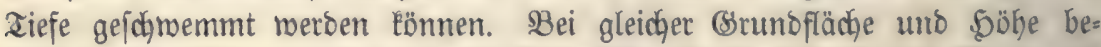

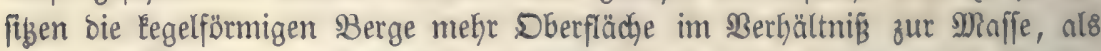
bie parabolijhen und fugeliegmentartigen, jente werben onkjer melyr $\mathfrak{B}_{3}$ ärme butch) Strahlung und Mittbeilung an bie Ruft abgeben. Da bie Epizen ber łegelförmigen Berge Durdh Bäume, weldhe auf ber Bergrwand ftehen, nur menig gegen Sonne uno $2 \mathfrak{3 i n} \delta$ gefdjübt merben fönnen, fo ift auf ifnen bie (6ultur, namentlich von foldjen \$口olzarten, welche zu ftarker Blattauboünftung geneigt fino, mit Sdjwierigkeiten verbunoen.

Sörner fino gemöhnlich unberwalbbar; baffelte gilt von ben factoff an=

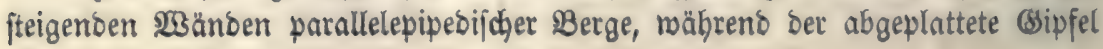




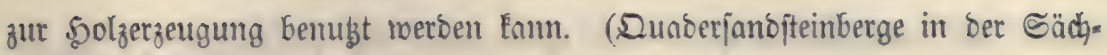
fildjen હdjweiz).

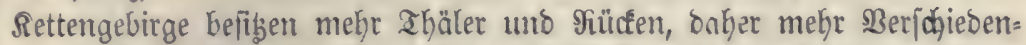
Eeiten im Boben und in ber Begetation, als Maffengebirge. Bei jenen Eommt Alles Darnuf an, nach weldher Simntrlsgegento hin bie Retten verlaufen. Sift

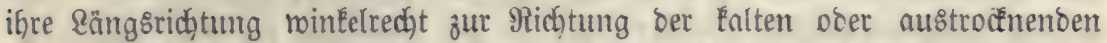

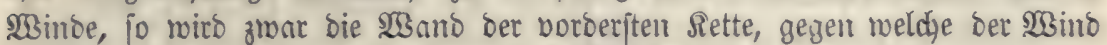

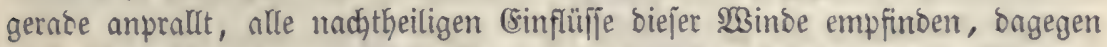

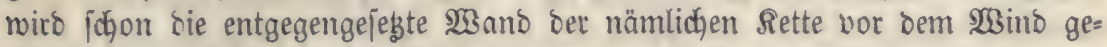

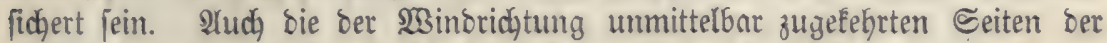
übrigen Retten merben burdh bie erjte Sette, namentlid) wern bieje etmas

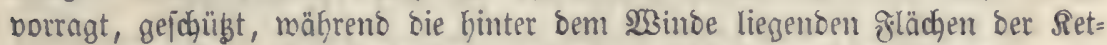
ten gemöbnlich ein herrliches Slima erbalten, melches bas frühzeitige (Ermachen ber Begetation, jomie bie Blüthenbiloung uno frudjtreife, bie (sultur eroti=

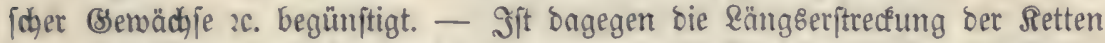

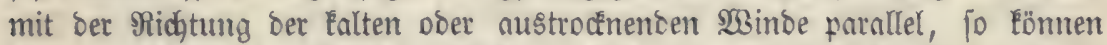

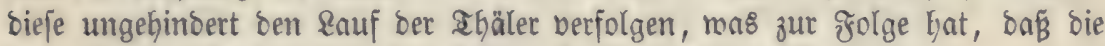
Segetation auf keiner bon ben beioen Ihalmänben geoeift.

\section{5odjebenen.}

Dieje bejigen eine böhere Gahrestemperatur, als ijolinte Berge, bagegen werben fie, ment ifre Erhebung über bie Meeresfläche bedeutend ift, oft bon

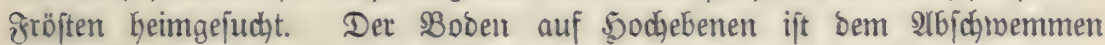
Durch bie Meteormaffer meniger ausige|̣egt, leibet aber bäufig burch Berjum= piung. Die Mlebrzahl ber Sochebenen enthält ausgebebnte Torflnger.

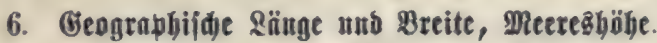

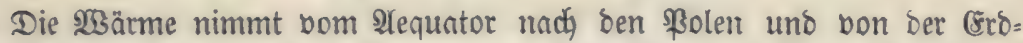
Dberfläche nach ben höheren Regionen bes \&uftEreijes Giu ab, inbeffen ift bie

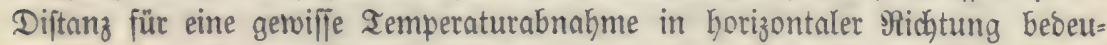

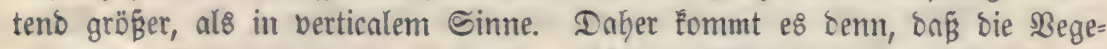

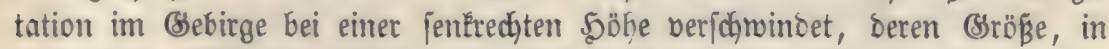
borizontaler Ridhtung aufgetragen, nodh nidht eine Berminberung ber Tempe= ratur um ben Betrag bon $1^{0}$ bewirlt.

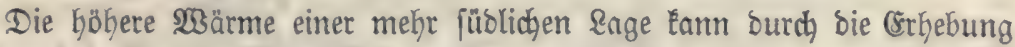

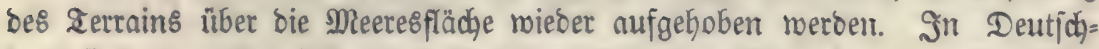
lano findet bon ber $D i t=$ und Norbjee bis ju den 2 llpen hin eine allmählige Steigung bes Randes jtatt; auf ber \&inie bon Ctraljuno nad) Mändjen nimmt bie Temperatur nur um $\mathbf{1 0}^{0}, 2$ zu. Altein München liegt 500 Neter über Straljunઠ.

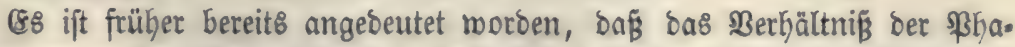
nerogamen zu ben (5ryptogamen in bem Maß̉e Eleiner wiro, als bie Jabres= 
wärme mit zunehmenter $\mathfrak{B o l}=$ und Meeresbäbe fich verminbert; e8 murbe

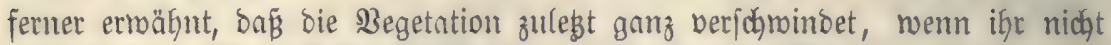

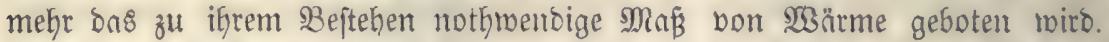

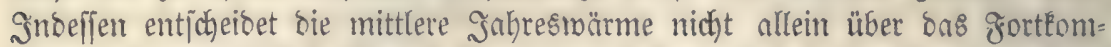

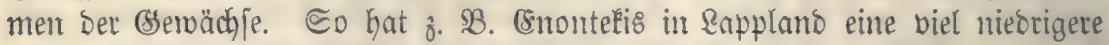
mittlere Gafrestemperatur $\left(-2^{n}, 7\right)$, als ber St. Botthard $\left(-0^{0}, 8\right)$, uno ood finbet man bei (Enontefis nod) Jichten, währento die Epige bes (sottharbber= ges keine Baumgerwächje aufzumeijen Gat. झllein bie Sommertemperatur bon

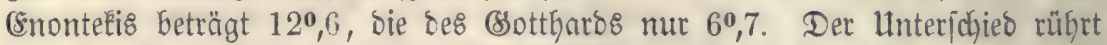
baker, weil bie Eonne in ben höhern Breiten währento des Eommers länger

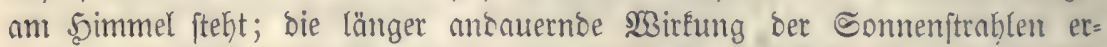
jegt hier Dasjenige, mas jenen, megen bes johieferen zufforlens, an Sntenitität fehlt.

Die Albnahme Der $\mathfrak{B a ̈ r m e}_{\text {ift }}$ Der \$olhöhe nicht birect proportional. Die

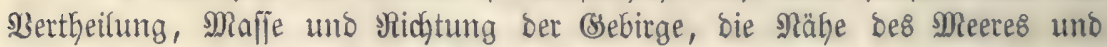

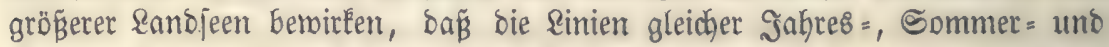

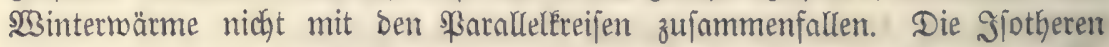
gehen im Snnern ber Continente zu höheren Breiten binauf, als an ben Rü=

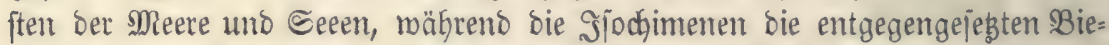

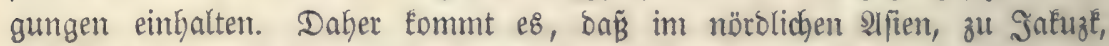
bei - 90,7 Sabrestemperatur noch Sommergerjte gebnut werben Eann, ob= gleich, ber Boben felbft im Eommer bindurch) in ber Riefe bon einem Mieter

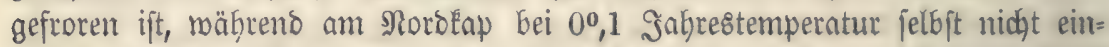

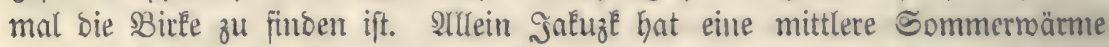
von 170,2 , bas গorbéap nur von $6^{0}, 4$. Dagegen geftatten Drte an ber Gee bie lleberminterung zärtliç)er Ssemädje im freien. ๔o erfriert z. $\mathfrak{B}$. zu Du=

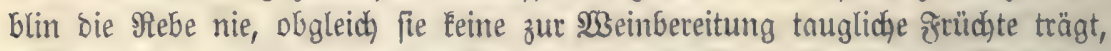

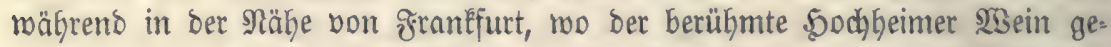
zogen wirb, ber M̉einftocf b̈fterళ bom groft bejchäbigt wiro; allein Dublin

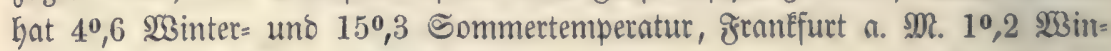
ter $=$ und 180,3 Sommertemperatur.

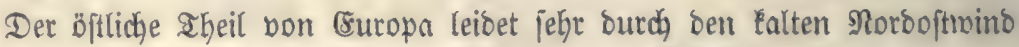
uno ben nustrocknenoen, im Sommer fehr marmen Ditwino. Dagegen arten

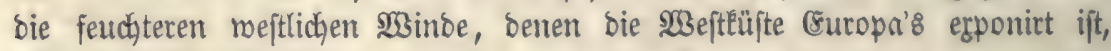
b̈fter zu Stürmen auళ.

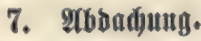

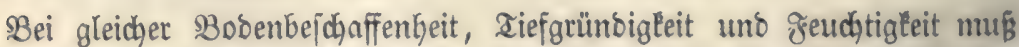

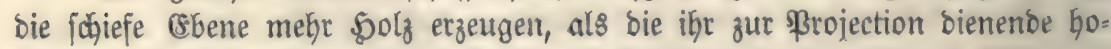

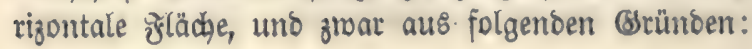


รૈig. 170.

a. Die fidefe Ebene AC ift im

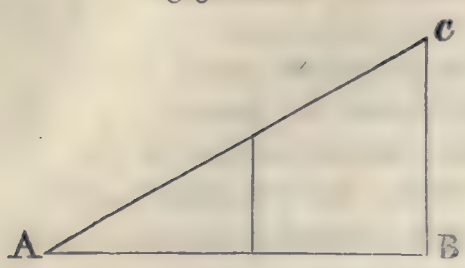
Berhälnifis bet Gecante fu 1 grö= Ber, als bie Gorizontale oläde AB, benn eह ift (æig. 170)
A B : $A C=1$ : sec. $A$

Bei gleidger Pflanğmeite fönnen aljo auf A C mebr Pflanzen Slag finoen, als auf A B.

Berbăltnißz ber

Neigungsminkel 5orizontalen zut jöiefen Cobene

\begin{tabular}{|c|c|c|}
\hline $0^{\circ}$ & 1 & 1,00000 \\
\hline $5^{0}$ & 1 & 1,00382 \\
\hline $10^{\circ}$ & 1 & 1,01543 \\
\hline $15^{\circ}$ & 1 & 1,03527 \\
\hline $20^{\circ}$ & 1 & 1,06417 \\
\hline $25^{\circ}$ & 1 & 1,10338 \\
\hline $30^{\circ}$ & 1 & 1,15470 \\
\hline $35^{\circ}$ & 1 & 1,22077 \\
\hline $40^{\circ}$ & 1 & 1,30541 \\
\hline $45^{\circ}$ & 1 & 1,41421 \\
\hline
\end{tabular}

Bflanzenmenge pro Sectare bei 1 Meter Pflanzmeite 10000 10038 10154

10353

10642

11034

11547

12208

13054

14142

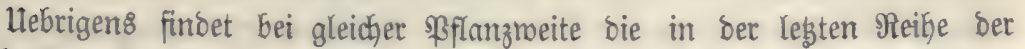
borftebenten Tabelle angegebente \$flanzenmenge nur bann auf ber fochiefen

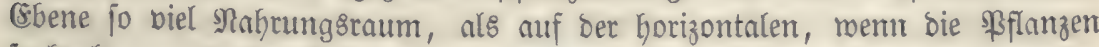
jentrecht zur jobiefen (Sbente jtehen. Befizen fie bagegen eine zur Sorizontalen Jig. 171. jenfrechte Stellung, fo bietet bie ichiefe Fläche nicht mebr গałrungsiraum Dar, al\& bie horizontale, weil jegt bie legtere burch bie \$rojectionen a $b^{\prime}, b^{\prime} c^{\prime}, c^{\prime} d^{\prime}, d^{\prime} e^{\prime}, e^{\prime} l^{\prime}$ vorgeftellt wird (ঔig. 171).

Bielfache Unterfudhungen haben ge= Lehrt, Dañ bie Bäume auf einer jodiefen (sbene zrour nidjt gerabezu jentredst auf ifge ftehen, aber aud nicht mit ber 5ori= zontalprojection einen rechten $\mathfrak{M B i n}_{\mathrm{k}} \mathrm{l}$ bilben. Sie neigen fid etwas, wenn aud nur menig, mit ibrer Spige nach bem

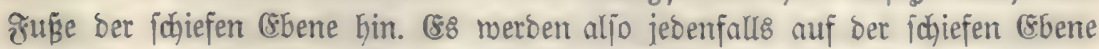

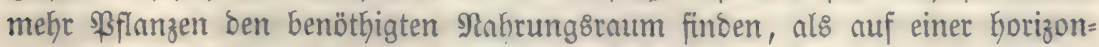

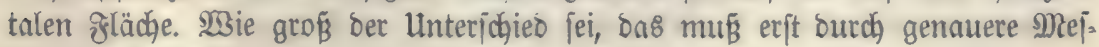
jungen feftgeftellt reerben. 
b. शHf ber fdiefen \&bene erbält die (sinzelpflanze megr gidnt, als auf ber horizontalen gläde.

Stehen mebrere Bflanzen auf einer Sorizontalebene neben einander, io mirb nur bie bem Boben entgegengejeste Afomölbung ter Rtone bie bolle (Sin=

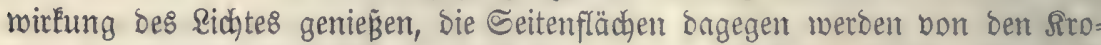
nen ber angrenzenten Bäume befichattet roerben. Auf ber fobiefen Ebene ift

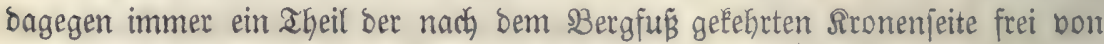
aller $B$ ejedattung.

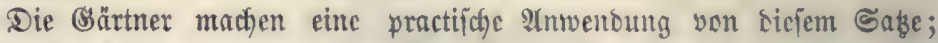

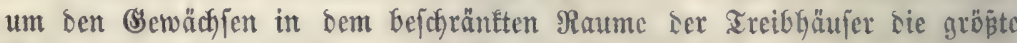
Summe yon Ridgtgenuß zu veridfaffen, ftellen fie jent über einander auf eine tünftictje Terafie.

Wenn trobs ben unter a und b, aufgefülyten Momenten in ber Mehr $=$ zahl ber Fälle geneigte Eagen meniget Solzmaffe probuzicen, at\& ebentes Ier=

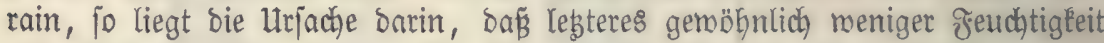

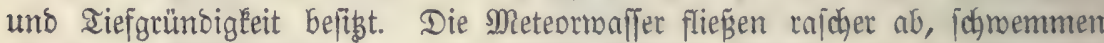
bie feinen crotbeildsen von ben ichiefen glächen fimunter in die Gbene bet Thäler und laffen fie Gier liegen.

Die Interfudungen, weldhe bis jegt angeftellt worben find, um ben größ̈ern

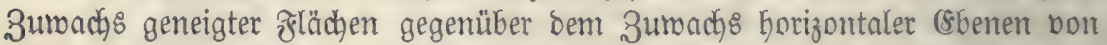

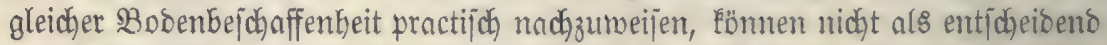
angefeben merben, weil mir bie Factoren ber Booengüte nod) zu wenig Een=

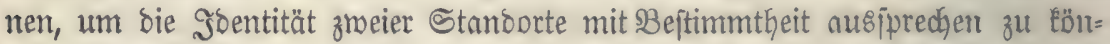

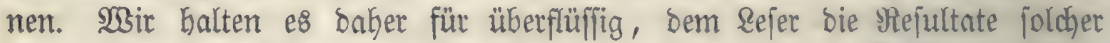
Unter|uthungen mitzutheilen. Dasijenige, mas unter a uno b über Den grö= Bern 5olzzumachs auf geneigten flächen gejagt worben ift, beruft leoiglich auf theoretifchen 2 tnfichten, uno es wirb noch lange bauern, bis es gelingt,

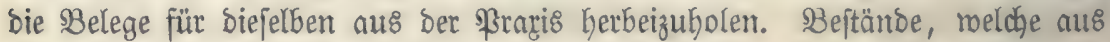
natürlicker Beriüngung Gerborgegangen fino, eignen fich zu folchen Ltnterjuch)= ungen nidjt im Minoeften; es Ënnen nur foldhe ₹rorftorte bazu benubst wer=

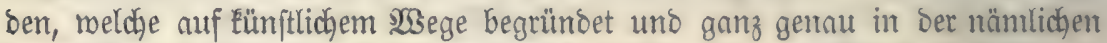
Wreife behanbelt morben find. Sat ja bod ficjon ein ungleiches Beftociung: $=$ verhältnif́s auf Eocalitäten von einer uno berjelben Bobentbejohaffentheit bie beridjtedenften 3umachsergebniffe zur ærolge!

(S)eneigte Flächen fezen ber Benrbeitung des Bobens und Der Crnote ber erzogenen ßrobucte Sdynierigleit entgegen; namentlidy kommen bieje bei

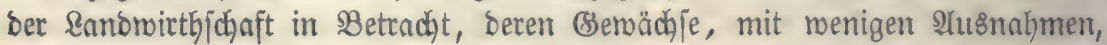
auf einem von ber fruchtbaren Bobenfrume entblöften Boden, wie er gemöhn=

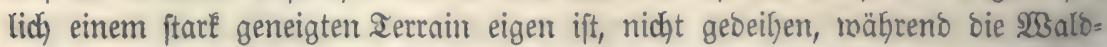
bäume nod auf nadtem ģels vegetiren Ënnen, menn berjelbe nur zerelüftet

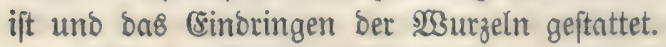

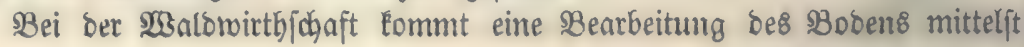


Biehgeipann fehr jelten vor, ober fie läßst fid ood immer umgeben; bie Rano= rirthjichaft ift bagegen (abgejehen bom eigentlidyen Bartenbau uns ber (Sul=

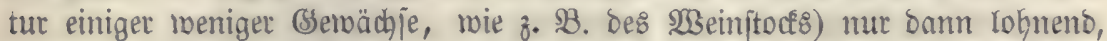
menn ber Umbruch des \$Bobens un das Unterbringen bes ๔amenz mit Bei= hülfe von Bieh, anftatt surch Menjehenthano, geidhehen Énn. Der sleigungs: minkel ber jobiefen f̊lächen, auf Denen bie 2Igricultur nod) betrieben wer=

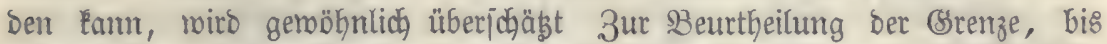
zu weldher eine Bearbeitung Des Bobens mittelit Zugvieh nod, ausführbar

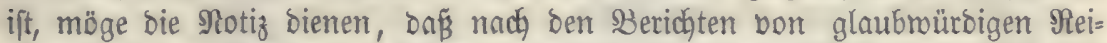
jenben bie Maultbiere in Epanien belaben nur nody auf einer Reigung von $29^{\circ}$ gehen. Der $\mathfrak{K B i e f e n b a u ~ f a n n ~ a u f ~ f t a ̈ r e ́ e r ~ g e n e i g t e m ~ T e r r a i n ~ a u s g e l l b t ~ w e r = ~}$

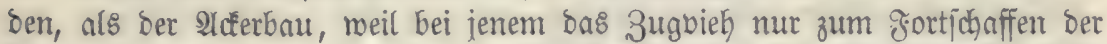
Ernote gebraucht miró uno bieje leid)t an bie mit einem geringeren (Sefäll berjełenen 2rbfubrmege gebradgt merden kann. Indeffen erforbert bie SWGiejen= cultur boch auch bie Sanoarbeit bon Menjichen, und wo bieje nidgt meb̧r mit

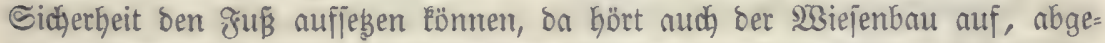

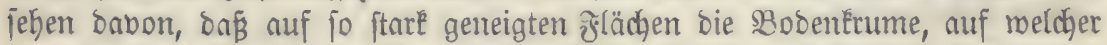

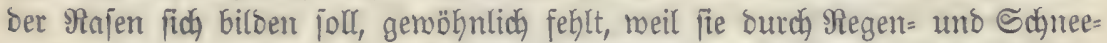
waffer abgeidhnemmt roirb. Nach ben Ermittlungen bes um ben Straß̈entbau

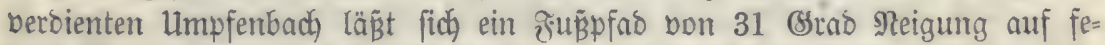
ftem SBoben nur mit Mühe erfteigen, uno bies möd)te auch bie Brenze für ben 2 Siejenbau jein, bie inbeffen für lodferes (storeich bei einer nodh geringeren Neigung ftattfindet. Dieje Brenze mürbe biel tiefer liegen, wenn bie Irbeiter

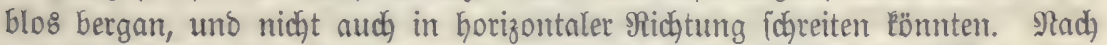
Sprengel follen bie bejten 2 ß3iejen in ber Sdymeiz uno in Iyrol jelten $15^{\circ}$ Neigung überiteigen, uno über $20^{\circ}$ Ginaus ber Boben nur noch als 23 eibe bemugt merben. Der Berf. hält bieje 2lngaben für jebr ridbtig, er bermutfyet,

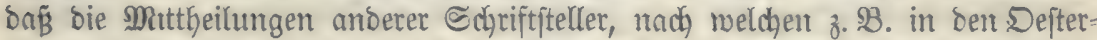

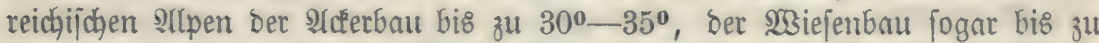

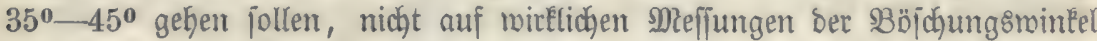
beruken.

2930 Die Bobenbearbeitung mittelft ber Sadfe ober bes von Menichen gezogenen 2 adol's beivereftelligt mirb, wie 8. B. Beim Sactwaldbetriebe, da

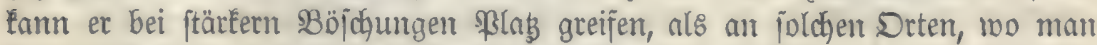
Den mit Ifieren befpannten $\mathfrak{B F}$ flug anmentet.

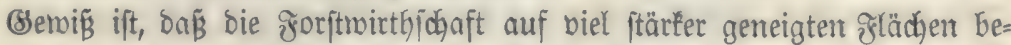

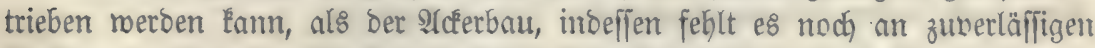
Meffungen über bas Marimum des Reigungstrinfels, bei meldhem eine be=

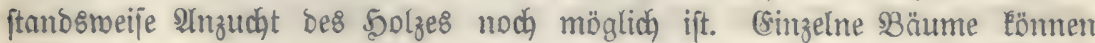
felbjt nod) auf ganz jenfredgten $\mathfrak{B}$ änoen (子. B. Mrauern) Stanbraum finben;

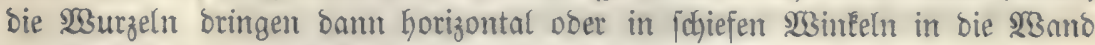
ein, Der Stamm madjt über bem $563 u r z e l j t o d$ eine Biegung uno geft in ver- 


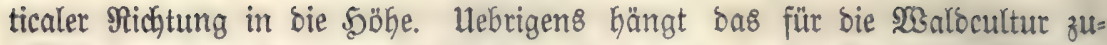

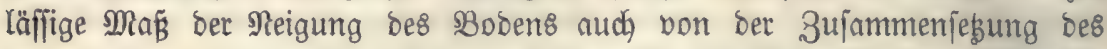

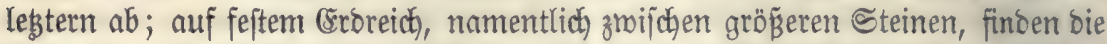

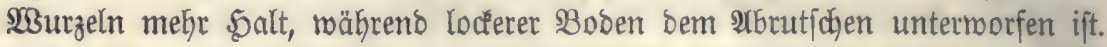

\section{Expofition.}

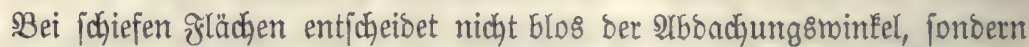

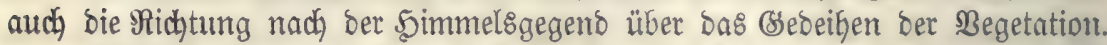

Sübliche \&agen trocénen ftärêer aus, als nördliche. SYuf jenen ermacht

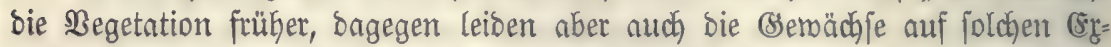
pofitionen öfter bon ðröften, wemn nach vorausgegangener narmer Witterung

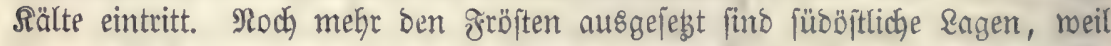
Gier ber Ulebergang Der Rälte zur $\mathfrak{3 a ̈ r m e ~ e i n ~ p l o ̈ b l i c k e r ~ i f t ~ u n o , ~ m i e ~ r o i r ~ f r u ̈ = ~}$

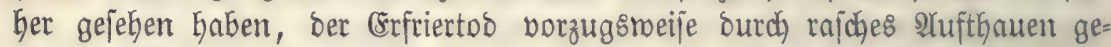
frorner Sfflanzentheile herbeigefüfyrt mirs. - Im Bsebirge fteigt (mit einzel= nen 2 Yusnahmen) Die Begetation Gö̆her an Den Sübjeiten empor, al\& an nörb= lidjen 2 IbGängen.

Deftliche Erpofitionen leiben in unjerem Rlima bor Allem burch aus $=$ trochnende Winde, bleiben Dagegen mebr von ben Stürmen verjohont.

Den Süomeffeiten fehlt e\& gewöhnlich nicht an Fueuchtigkeit, weil ber

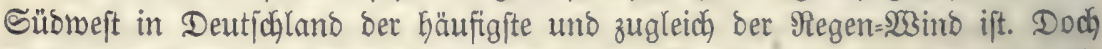

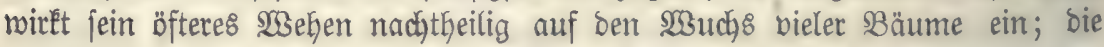
Stämme biegen fich nach, Der Dem 2 Sind entgegengeję̧ten Seite und erbalten

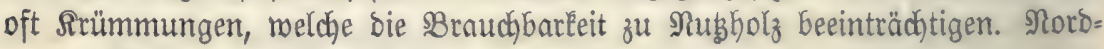
meit =, NBeft= umb Sübmefteiten werben überbies bon ben Stürmen am meiften heimgejucht.

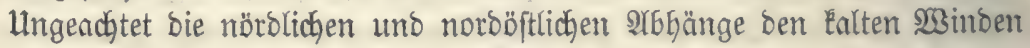
vorzugstreife ausgefegt fint, io zeigen fie boch in Deutjolano, uno nament=

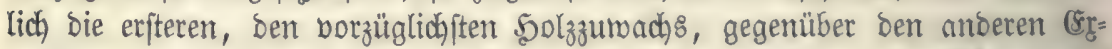

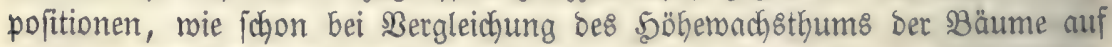

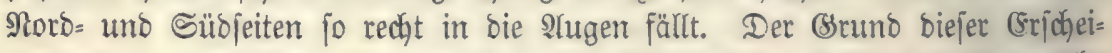

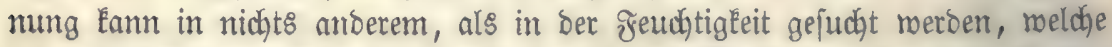

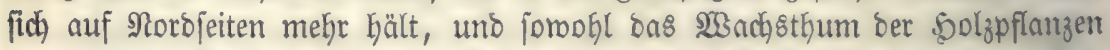
unmittelbar begünftigt, als audh bie ßerwitterung bes Bobens beförbert. Rei=

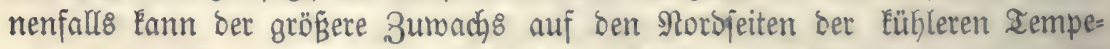
ratur beigemeffen werben, bent bas 5olzrnachsthum auf Sübjeiten fteht jenem nicht nach, wenn nux an reuchtigleeit kein Mangel ijt.

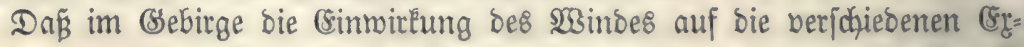
pofitionen burch ben \&auf ber Fyäler abgeändert mirb, Gaben wir bereit8 frï= ber entmidelt.

\section{Bhyiffalijüe Ceigenidinfen ber Bobenarten.}

Bon bem hierher Bebörigen ift Geteits Sieles in ben borberen शrbjhnit= 


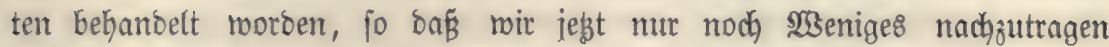
baben.

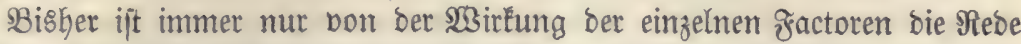
geroejen, uno wir baben es ben folgenden Sapiteln vorbebalten, zu ent= fcheiden, meldye bon biejen Gactorent in Bezug auf bie $23 a$ aldogetation von

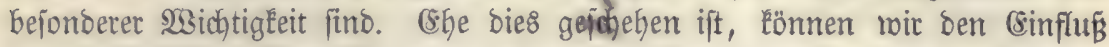

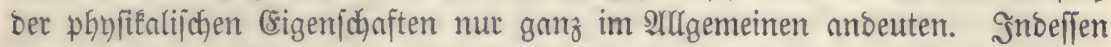

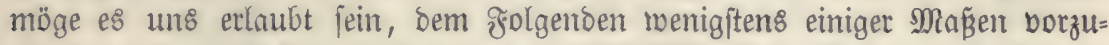

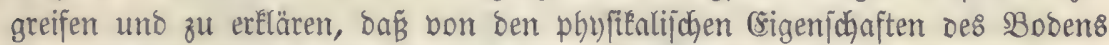

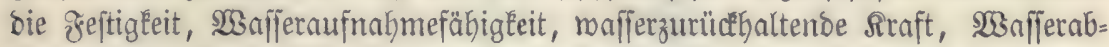

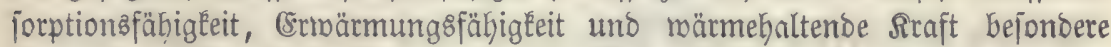
Beadtung berbienen. WBir mollen nun Biniges über bieje Bigenjidhaften an= geben, behalten aber, wie bemertt, bie ftrenge uno umfaffenbe 23 üroigung Derfelben bem lebten Theil biejes suaches vor.

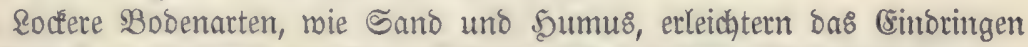

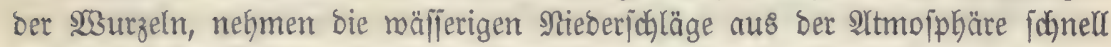

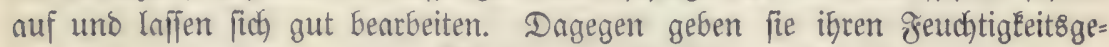
balt bei troctner oder warmer $23 i t t e r u n g$ auch wieber leidjt ab, werden in ge=

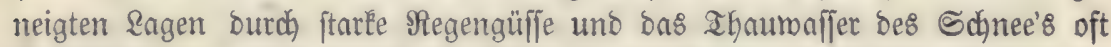
abgeidnemmt, auch) frieren bie sfflangen auf ifnen (namentlich auf humojer (Eroe) bismeilen auళ.

Fefte Böben nefymen bie nieberfallenden Meteormaffer nidyt leidyt auf;

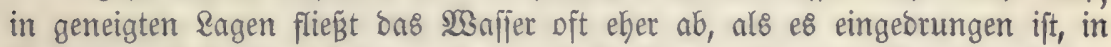
Bertiefungen bleibt e\& ftehen uno berurjadjt Berjumpfungen. Dagegen Kalten fefte Bobenarten bie eimmal aufgenommente ₹eudhtigleit länger an. SSeringe Regennieberjhläge nüben einem feften $\Re_{0}$ ben, nenn er einmal trocfen geroor= Den ift, nur wenig, bagegen wiberitegt er länger ber Sonnenfige uno ben austrodenenten NBinoen, wenn er einmal gehörig angefeuchtet morben ift. Das

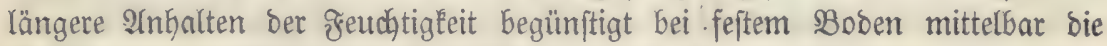
(Entipthung ber grüh)= uno Spätfröfte.

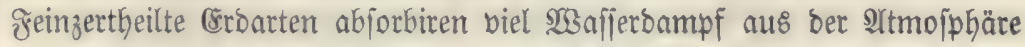
- eine Eigenjchaft, bie ben Pflanzen namentlid) währeno ber trochnen Som= mermonate zu Bute Fommt.

Die Farbe bes Bobens fann eimen günftigen, mie ungünftigen Einfluf

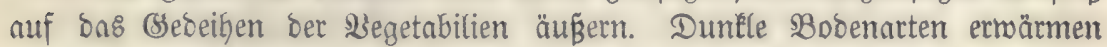

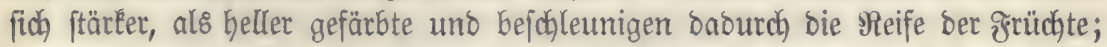

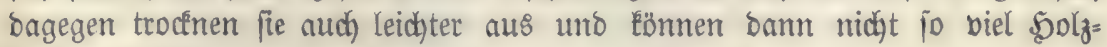
maffe probugiren.

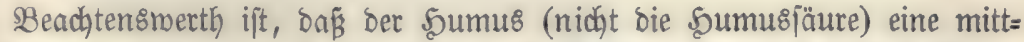

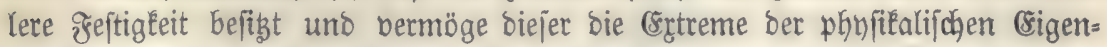
idhaften bes sodens berminbert. (sin sBoden, weldyem reichlich) Sumus beige= mengt ift, wirb baher ber Mpehrzahl ber \$flanzen am meiften zulagen. 


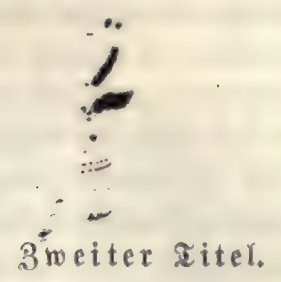

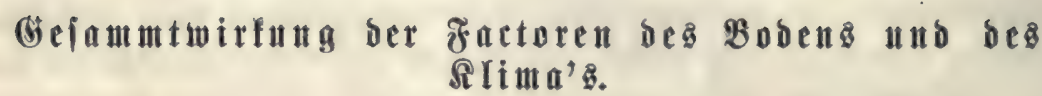

शchtzehntes 8 u市.

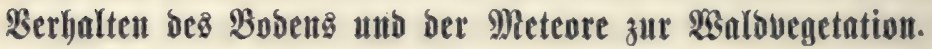

\section{(E) $\mathfrak{i} \mathfrak{I}$ e it}

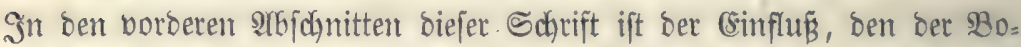

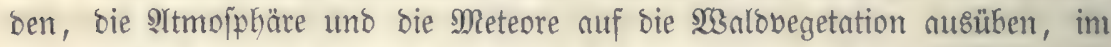

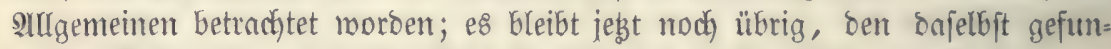

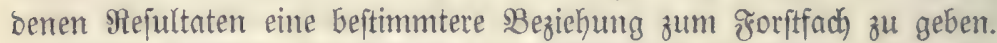

Die forftlict)e Bobenkunbe uno Rlimatologie finden ifre Anneentung

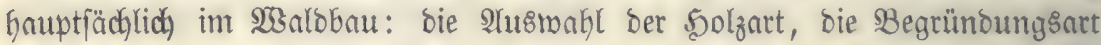
ber Beftänte, iłre Erzzięung uno Berjüngung Gängen ja ganz uno gar bom Boben und Slima $a b$.

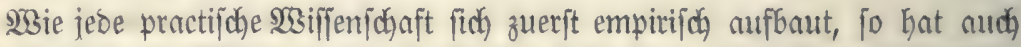

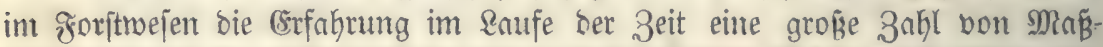

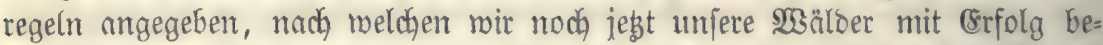
mirtbjchaften. Die nusgezeichyneten Männer, von welchen unjer Keutigę Sy=

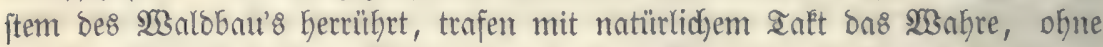
für bie Middtigkeit ifrer Säge einen andern Bemeis, als ben ber eigenen lleberzengung ž baben.

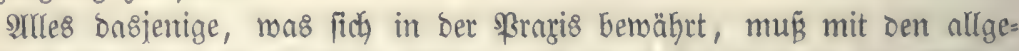

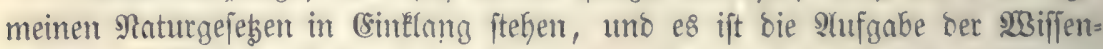

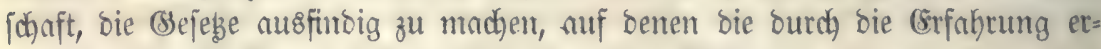

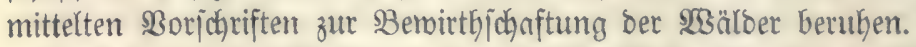

Saben wir erft einmal bie miffenfidaftliche (Srunolage ber beftehenten

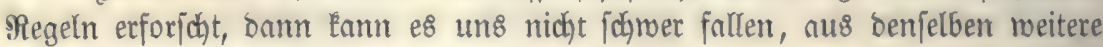
mubbringenbe zolgentungen abzulleitert.

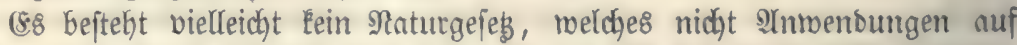
bas practifde Reben geftattet, uno menn e\& uns bi\& jegt nody nidht gelungent 


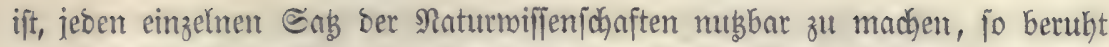

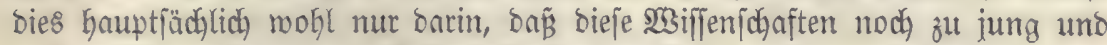
noch nicht genug in ben Sänoen Derjenigen fint, welche nach ber Art iłres

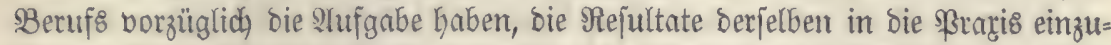

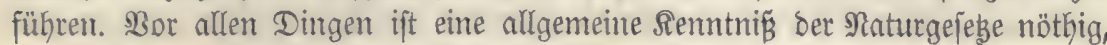

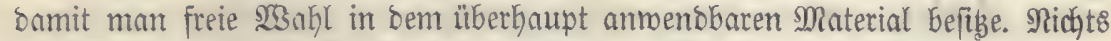

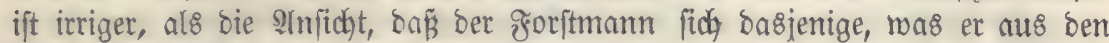

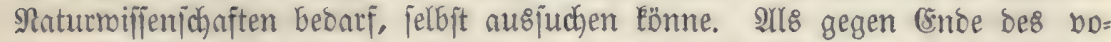

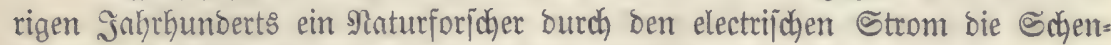

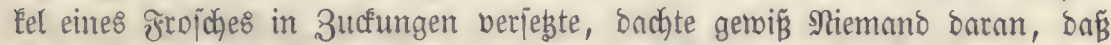
bie nämliche Rraft fünfzig Sahre päter ę möglich machen mürbe, einen (ses= banfen in einer Secumbe breimal um bie croe zu jagen. So findet jeoes

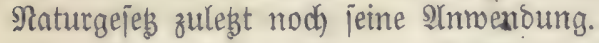

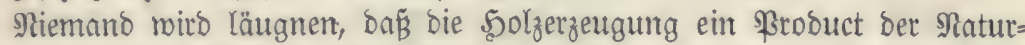
Eräfte jei, uno baí fie fich vermebren laffen müffe, wenn wir e8 -einmal ber=

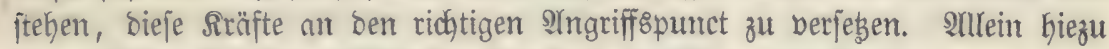
ift, wie Eemerl̂t, eine umfaffende Renntnif́s berjelbent nothmendig.

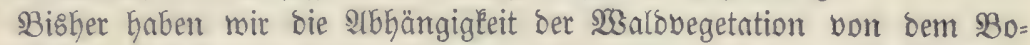
belt unઠ bem Slinta nur ganz im aflgemeinen befandelt; jebt wollen wir

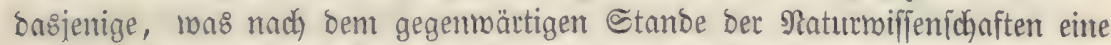
ummittelbare llebertragung in bie forjtliche Praris geftattet, bejonders ber= ausheben.

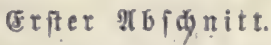

\section{Begriff ber forftiden Stanoortgite.}

\section{Borbemerfung.}

Dbgleidh Der Boben, bie Stmojphäre und bie Meteore einen grofien

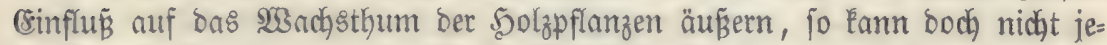
bem von biejen gactoren eine gleiche WGichtigeeit bei ber Beurtheilung ber forft=

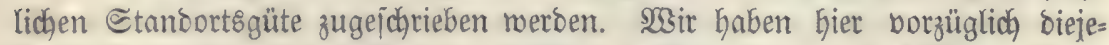

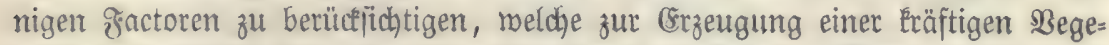

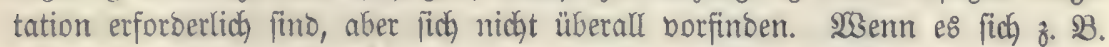
barum hanbelt, bie SBüte irgento einer Rocalität z̆l dharacterifiren, fo merben

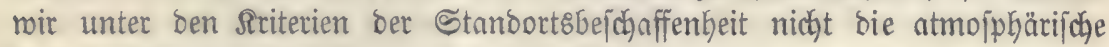
suft erwähnen, weil bieje ja nirgenos fejlt.

Die BBeurtheilung ber Standortsgüte findet in ber practijchen ફorjtmif=

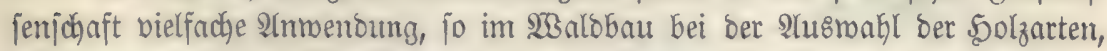

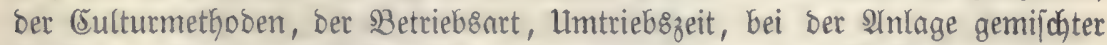

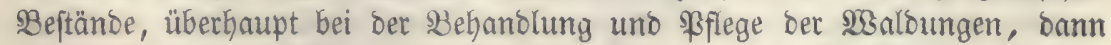
aber auch in ber ซrorftagation bei ber Bonitirung, um bie fünftigen \$olzet= 
träge bon nod) niçt Gaubaren SBeftänoen ober anzubauenden $2 B$ löß̈en zu be= ftimmen.

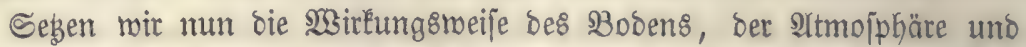
ber Meteore als befamt voraus uno fragen wir: burd) welche (sigenidhaften biejer brei groß̈en (Sruppen, weld)e die Algentien bes Bebeikenళ ber Begetation

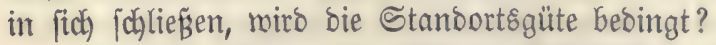

utm biefe grage mit abjoluter Sidjerbeit zu lö|en, müffen toir un\& ferne von allen theoretifchen Speculationen balten, mir müffen unjere ङdylüffe blos

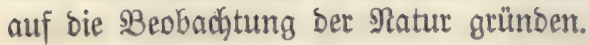

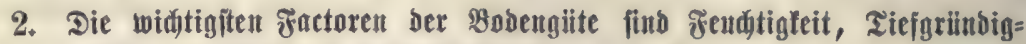

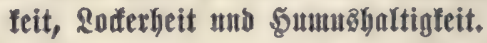

Der BRegriff ber forftlichen Standort\&güte ift ein relativer; er bängt von ben Zmecten $a \mathfrak{b}$, zu welchen bas Solz erzogen werben poll. So Eonnte z. $B$.

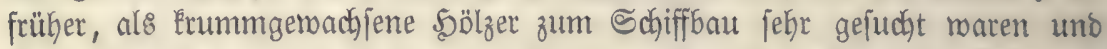
theuet bezahlt wurden, ein magerer Boben, auf meldjem fich foldye Sitünnten öfter zu erzeugen pflegen, als gut angefprochen merben, obgleidy auf ifym ber Maffezumachs gering war. Indeffen gejört das eben angefüfrte sBeippiel zu

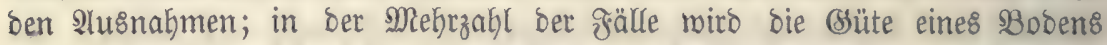
banach bemeffen, ob auf ibm bie Beftäno grof̉e Maffenerträge abnerfen uno

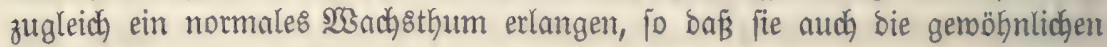

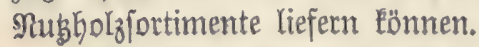

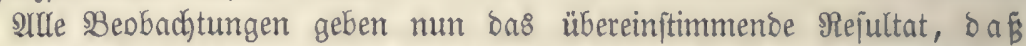

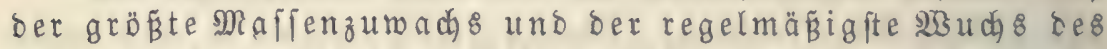
5olzes auf einem folden Boden erfolgt, welder tiefgründig, hinreidend loder un humu\&haltig ift und zugleidq einen dem Bedürfnib der betreffenden Solzart entipredienden Grad don geudtigeit bejigt.

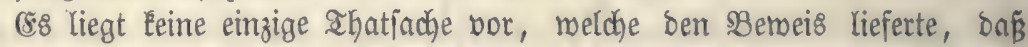
irgend eine Solzart auf einem tiefgrünoigen, binlänglich) locfern uno mit feucd)=

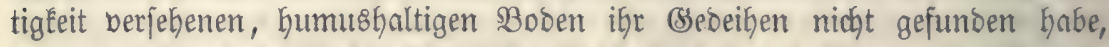

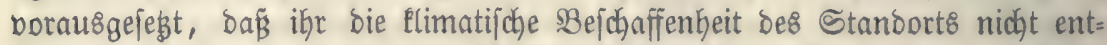

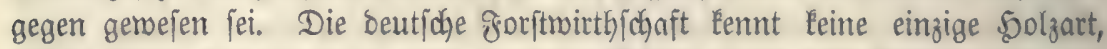
welche einen flachgrünoigen Doer trockenen $B$ Doden einem tiefgrünoigen bon an= gemefึenem žeudtigkeitsgehalte vorzöge.

Betrachten mir nun bie $23 i r k$ ung ber einzelnen Factoren ber \$Bobengüte etroas genauer.

\section{a. Tiefgründigtett.}

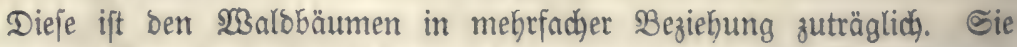
geftattet ben 203 urzeln in bie siefe zu bringen, was namentlich für biejenigen

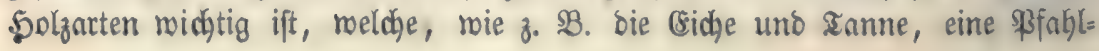


murzel Gilden und in ber $\Re$ egel keine bedeutenden Şöhent erreichen, wenn

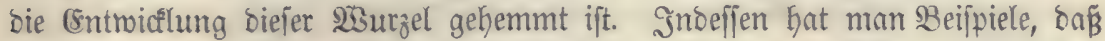
Dieje 50 lzarten auch auf einem flachgrünoigen Boben nody ein anjefnliches

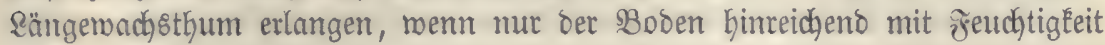
berjeken ift.

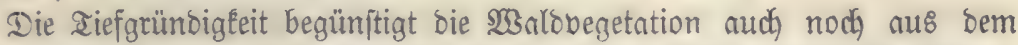
Grumbe, weil fie biejer eine nadhyaltige Bezuggquelle bon Feuchtigleit eröffnet.

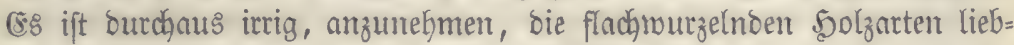
ten einen flach)grünoigen Boben. Selbit bie Fichte und bie Buche, melche bock gemifis eine flache Bemurzelung befigen, gebeiben am beften nuf eintem tiefgrünbigen $B$ oben.

Den flachgrünbigften Boben liefert gemöfnlidy ber plaftijdye Ityon; feine

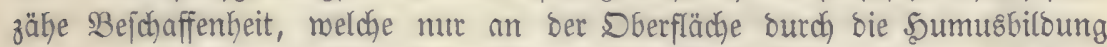

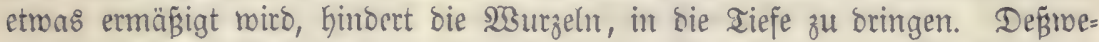
gen eignet fich biejer Ihon am nentigiten zur (Exziebung von (sidhenthod)wal=

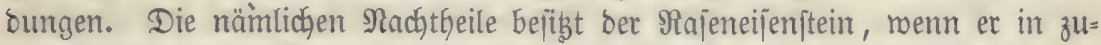
fammentbängenden $\mathfrak{B l a t t e n}$ bicht unter ber Dberfläche bes Bobens lagert; faft

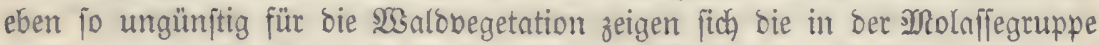
vorÉommenten Rie\&lager, wenn bie einzelnen Brocken burch) ein eifenhaltiges Cement berbunoen find.

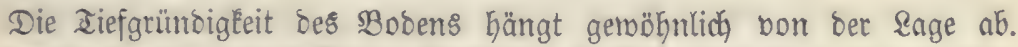
2uf ebenem Terrain, it IGälern, Mulben und Flingen merben ober mutben

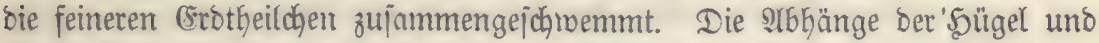
Berge fint viel öfter fladgrämbig, weil bie Meteornafjer fortmährent bie (stbe ablöjen und fie nach ben unteren Regionen entfügren.

\section{b. Soderbeit.}

Sn einem loceten Boben erzeugt jīh bei hinreidfentem Freudftigleits=

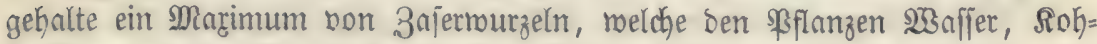

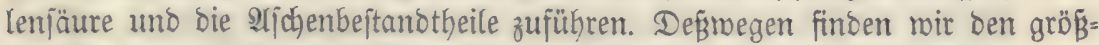

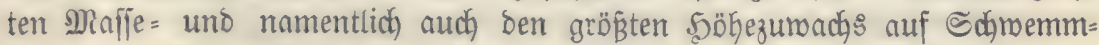

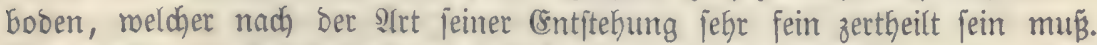

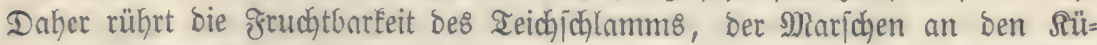
ften bes Meeres 2c. Die herrtiche Baumbegetation, melche man auf frifchem

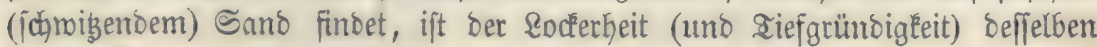
beizumeffen.

Dbgleidh bie hö ch ft en Maffeerträge, weldhe biz jest beobadhtet murben, nur einem Boden bon gehöriger Rocferbeit zutommen, jo unterliegt e\& bod Keinem 3meifel, baß̧ bie Beitänoe auch noch auf einem SBoden, welcher blos

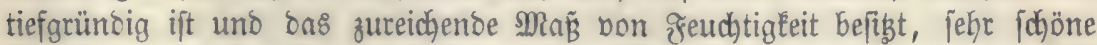

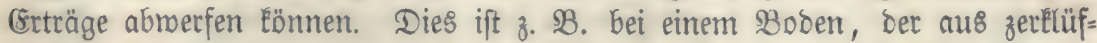

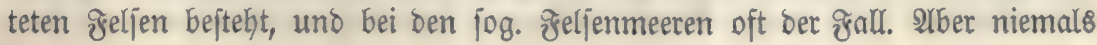




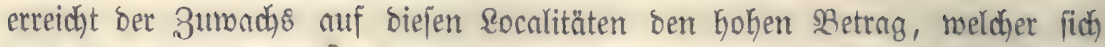

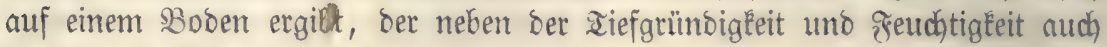
Rodferkeit befitzt.

Ulebrigens bürfen mir nicht bergeffen, zu ermähnen, baß̈ eine allzu groß̈e

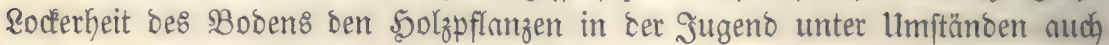
nachtheilig werben kann. Sie begünjtigt nämlich bie Bermefynung ber jöhäb=

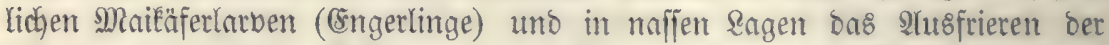

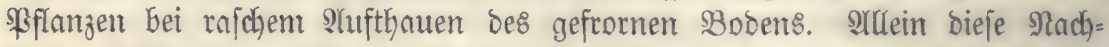
theile verfatwinten fpäter mieder, und merden baun burdy ben Bortheil ber größ̈ern Mafjenerzeugung überwogen.

\section{c. Feutitigfeit.}

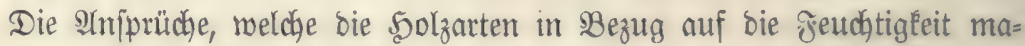
chen, fint auperorbentlich veridjieben.

Die Mefrzabl unferer Walbbäume geocifyt am bejten auf einem flos

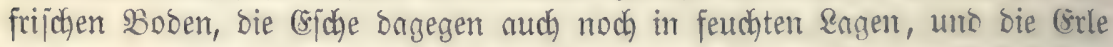
verlangt gerabezu einen naffen Boben. Irockenteit Des SBDoens fagt keiner Solzart zu, bod) mird fie noch am erjten von ber Riefer uno ber Birfe er= tragen. Die 3ogelbeere (\$berejd)e) ift bie einzige Solzart, melche an iffem

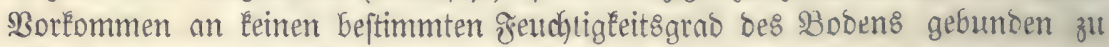
fein fajeint, bod) gebeibt fie ant beften auf einem blos frijhen (Eroreid).

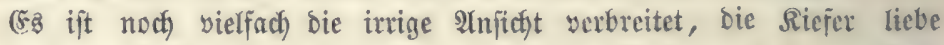

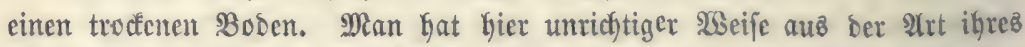

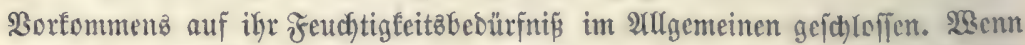
bie Riefer fich) häufig auf troffenen Stanoorten in großen Beffänoen findet,

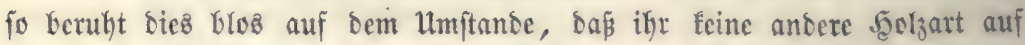
folche Rocalităten zu folgen vermag. SGer fid Davon überzeugen will, baß

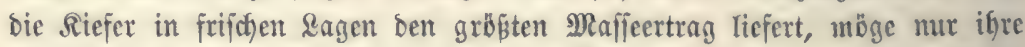

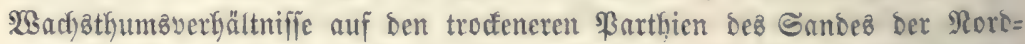

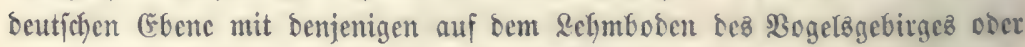
auf $\delta \mathrm{em}$ fodwiţenten Sanbe ber Main = Rgeinebene vergleidfen.

Der F̧etthtigkeitsgebalt bes \$Bodens bängt vornehmlid) von zmei llm= ftänoen ab: nämlich) bon jeiner 3 ufammenjełung uno von feiner sage. Der Boden in Bertiefungen (z. B. Mulden, Rlingen, Thälern, Nieberungen an

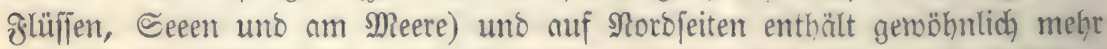

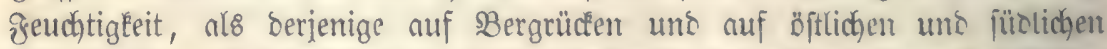
Expofitionen. Daher fonmmt e\& besu, Daß́ auf ben erftgenaunten Socalitäten

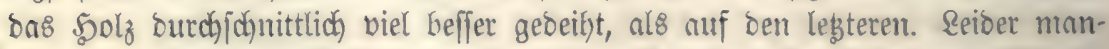

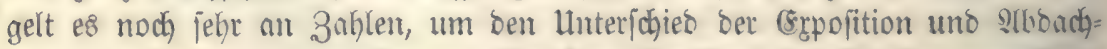

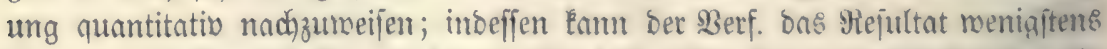
eimer Unterjutrung bieten, welche er in siejer Beziehung angeftelft hat. (ir beftimmte im Sabr 1851 outch) ipecielle Solzmanfenaufuabme ben Durdh= 


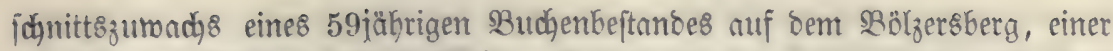

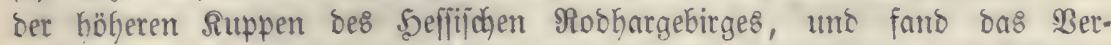

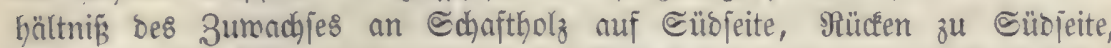

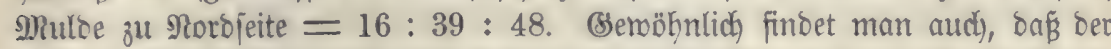
Boben nuf ben Norbjeiten tiefgrünbiger ift, bies rührt baher, weil bie Feuct)= tigleit bie 3erjebsung Ser Befteine beförbert.

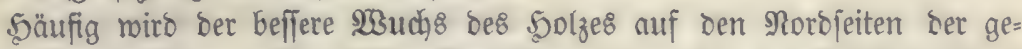

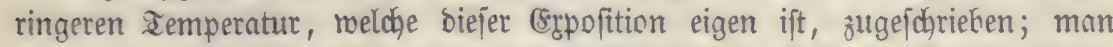
lieft von mandjen Sgolzarten in ben Rehrbüchern ber Forftbotanile, fie liebten

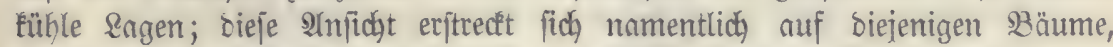

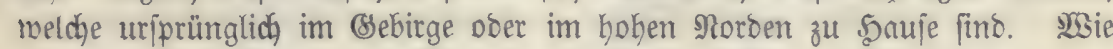
wir aber fohon früher ausgeführt haben, ipricht aldes gegen bie Atnnahme,

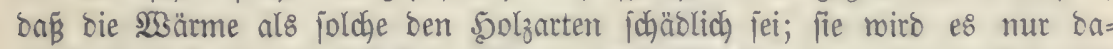

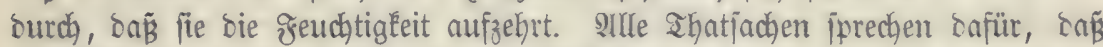

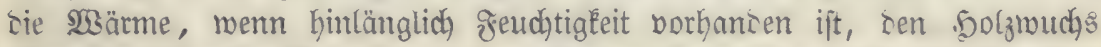
eben jonohl unterftügt, als fie ber übrigen ßegetation juträglidh ift. Bon

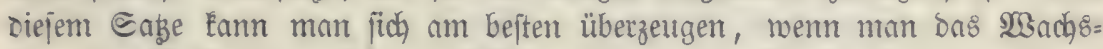
thum der Beftände an foldhen jüblichen Sängen, melche burch Ueberriejelung frijch erbalten werben, beobachtet.

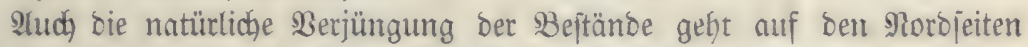
gemöhnlich beffer bon Statten, al\& auf ben übrigen Expofitionen. SBenn

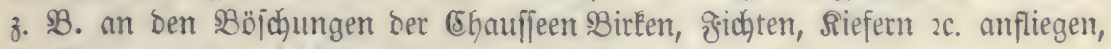
io ift immer bie nörbliç) Ceite boller beftanoen.

In trodinen \&agen zeigt fich auf Böben mit groser mafferbaltenoer

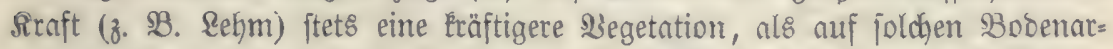
ten, weldye zum 24ustrochnen geneigt fino; indeffen carf man nidht annefymen

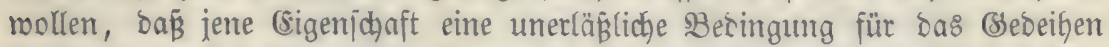

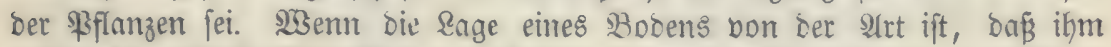

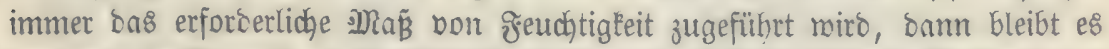

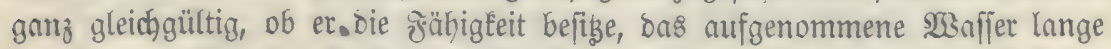
an fich) zu halten. Dep̈megen fömuen z. B. auf locferem ๔andboben in

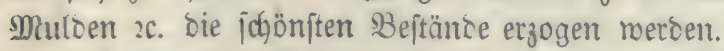

Feljen uno Eteine, weldye den Boden bedecten, erjdymeren zron oft bie Bornahme ber Culturen, begümítigen aber bas $23 a c h s t h u m$ ber $8 a ̈ ı m e ~ d a=$

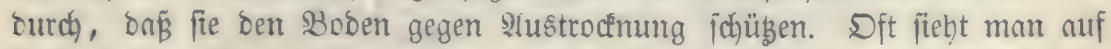
Eocalitäten, melche faît mur Eteine enthalten, bie herrlichjten Bäume machjen. Der Berf. Eennt eine Begent, in weldyer die Sandlente einftmals verjudten, ifje zelder butch (Entfernung ber Eteine, meldhe auf benjelben in grofer 3abl in= gen, frudbtbarer zu madhen; zu ifrem stadytheil muste fie aber getrahren, ban

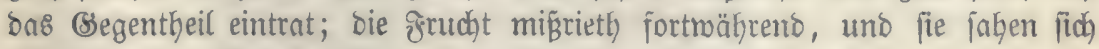
genöthigt, bie Steine wieber an ifgre હtelle zu juaffen.

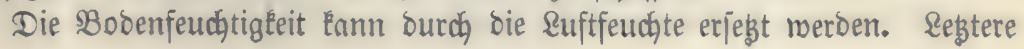


ift namentlich benjenigen \$olzarten jef̧r zuträglidy, meldge, wie z. SB. bie sBuche, zu ftarker 3 Battausoünitung geneigt fino. Daker idhreibt fich u. $\mathfrak{A}$. Das treff= liche Sebeiben Der $\mathfrak{B u c h e n ~ i m ~ B o g e l o g e b i r g e , ~ i n ~ b e n ~ m i t t l e r n ~ \Re e g i o n e n ~ b e s ~}$

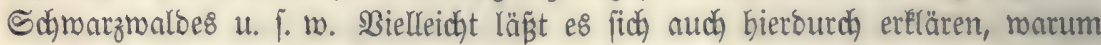
bie Buche im mittlem Deutjd)land mehr bie Borberge, al\& bie Gbenen be= robint.

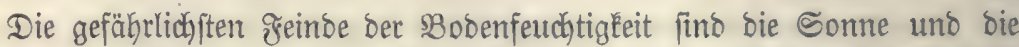
Winbe, namentlich bie trod'nen Ditminoe. Die meijt geringe Standortsgüte Der Süס = unt Der Ditfeiten wirס Durch Diefe beiben umptänoe bebingt.

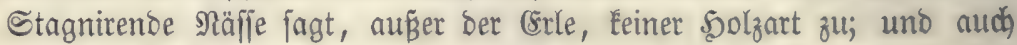
jene, fowie bie $23 e i b e n$ gebeihen beffer an fließendem 23 affer.

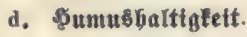

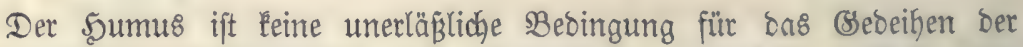
Waldoegetation; Dieje erreicht auch jchon bann einen hohen (Srno bon

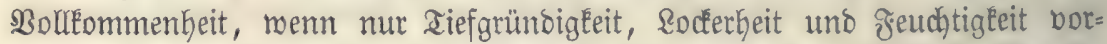

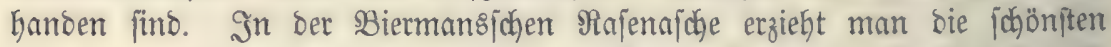

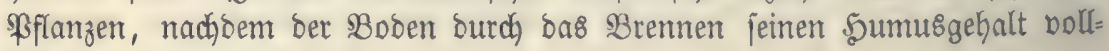
ftänoig berloren Gat.

Ylber ber Sumus mirb ba jefr widhtig, wo eine ber brei genannten Bebingungen ber Bobengüte feflt. Denn buth eine hinreichende Echichte ঔigur 172.

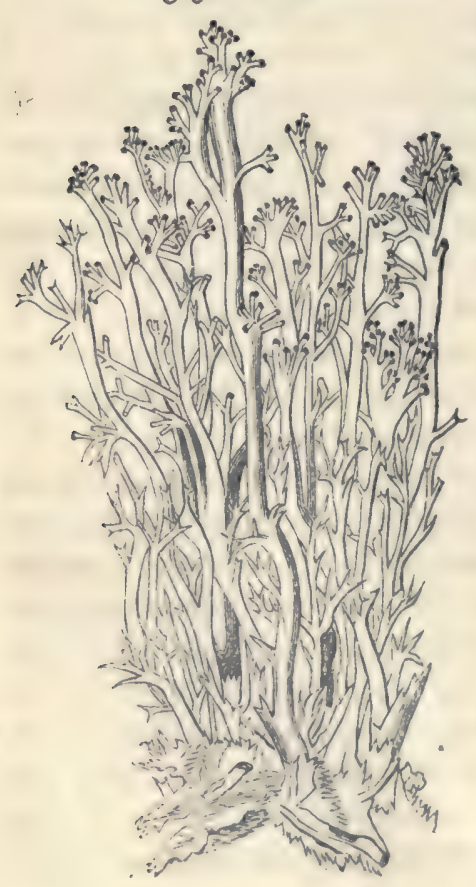
Sumus genoinnt ber Boben an Tiefgrïn= bigkeit und Rockerkeit, auch berizt ber ఏu=

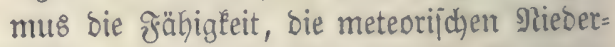
fochläge leicht aufzunefymen unto fie lange

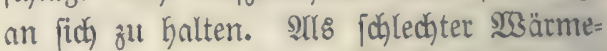
leiter jojübt er überfaupt ben Boben ge= gen 2 Iustroct̆mung.

İneffen żeigen fich nur biejenigen $5 u=$ musarten roohlthätig für bie Begetation, melḑe fich bei bollftänoigem 3utritt ber \&uft gebildot baben, nidjt allzulocer funto, uno Eeine roadjsartigen Beftanotheile ent= Galten. Die eigentliç̧en sumusfăuren, melche niemals in frudt)tbarer serde, fondern mur in aorfmooren, Sümpfen :c. bortom=

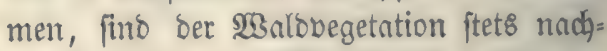

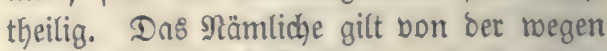

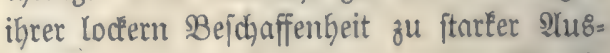
trocknung geneigten jogenamnten Ctaub= erbe (bie fich) borzüglich) aus Cladonia rangifarin a bildet) uno vou bem tradss= Galtigen \$aibe= uno \$aibelbeerfumus. 
Sumus, melcher ftart mit (serbjäure imprägnirt ift, berbält fich gegen

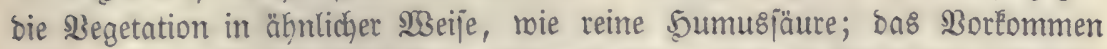

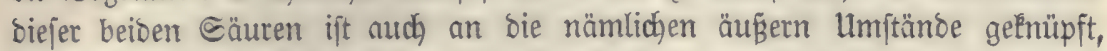
benn sie B̆erbjäure bleibt nur bann längere Beit untberänbert, wenn fie burch SBaffer vor bem Saueriftoff ber 9ltmojphäre gejchügt ift - im andern Frall mürbe fie raich in B̧allusfäure übergeführt merben.

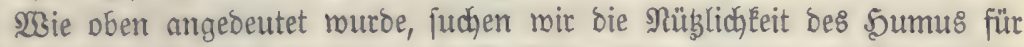

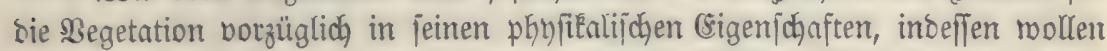

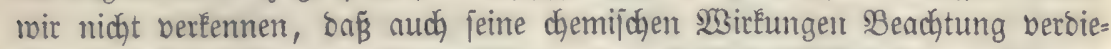

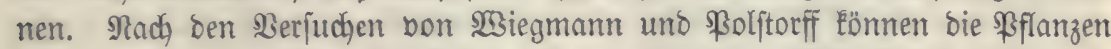

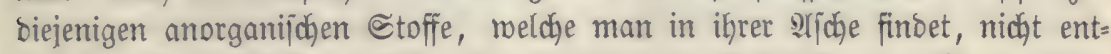
befren; ohne biejelben roürben fie ifre normale (Entroidlung nicht erreidfen. Eicherlich werben aber bieje anorganijden Etoffe ben \$sflanzen am bollépm. menften burch ben Şumus geliefert, benn lebgterer hat fich ja aus Begetabilien

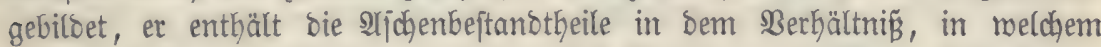
fie bie \$flanzen bebürfen, uno bazu noch in einer leidjt auffdyließ̧baren form. Hebrigens barf auf bie anorganifđen (Etemente bes Şumus nicht all= zuviel (Servicht gelegt merben; wie fpäter nachgemiejen meroen foll, ift ber

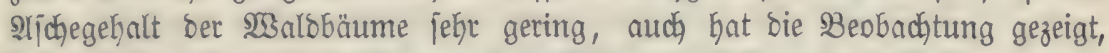

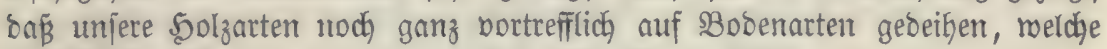
verbăltniß̧mäß̆g arm an anorganijąen ভubjtanzen fint.

(Bine größ̈ere Bedeutung Ëönte man iđjon Dem Bohlenftoffgebalte des

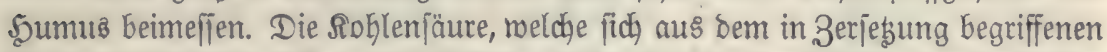
S.umus entrideflt, liefert, mie früher gezeigt trurbe, einen nicjt unmejentlichen

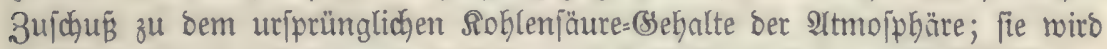

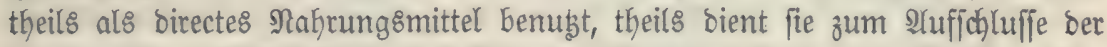

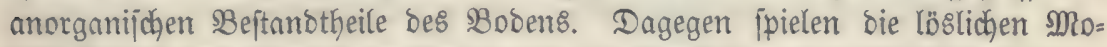

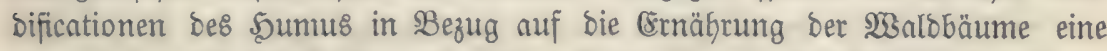

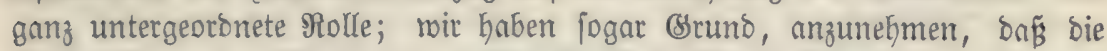

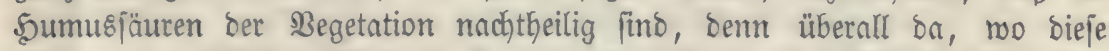

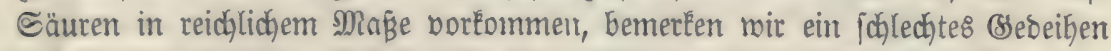

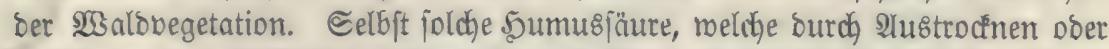
(Befrieren ihre Röslich)eit berloren hat, beligt noch manche nachtheilige (Eigen=

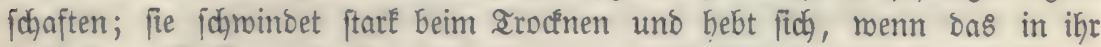

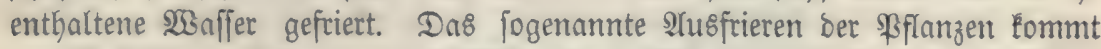

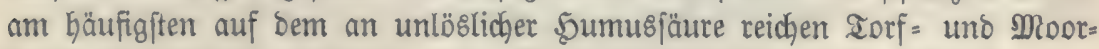
boben vor.

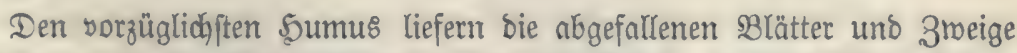
Der Bäume; in Nabelfyolzbejtänben tragen bie Moofe, weldjes fich auf bem Boben erzeugen, fo lange ber Baumfronenjduús meber alfzu bicht, nodh atzu

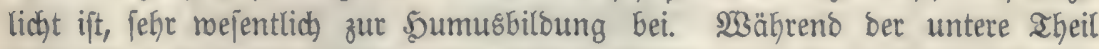

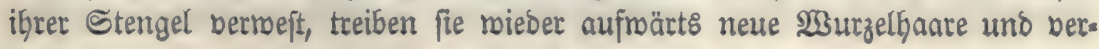


längern fich an ben Epizen. Die borzüglichiften Mooje gebören ber (Sattung Hypnum (29fmoos) an. SKir nennen bon biejer bie Ŝrten: H. purum, splendens, Schreberi, triquetrum, praelongum, loreum, brevi- et longirostre, crista-castrensis (legteres mehr im Bebirg, als in ber (sbene vor= fommento), myurum; auf feudteren હtellen finten fich H. cupressiforne, tamariscinum, squarrosum, undulatum, auf trocfneten: H. rugosum, lutes-

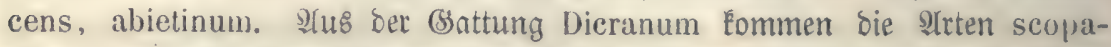
rium, majus und undulatum ben eben genannten Hypnum-2rten in ifren (sigenjidaften ziemlich gleich. Bon ben \&ebermoojen find Jungermannia asplenoides, nemorosa, tribbata, albicans gleid,falls müglich. Die auf unffem Boben machjenten Irten bon Hypnum, wie H. cuspidatum, nitens, trifarium, aduncum, filicinum, Dicranum glaucum, berfohiebene Iften von Polytrichum, Mnium, Sphaynum, Bryum, Climacium begünftigen bie Iorf= billoung uno berf̧̧ließ̌en ben Boben ber natürlidjen Bejamung, wirken aljo

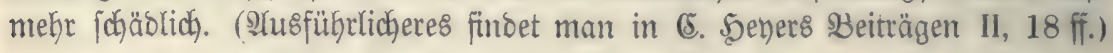

\section{Intere Anfifinten iber bie Factoren ber \$obengüte.}

Sn Dem Borkergehenden haben wir nachzumeijen gejucht, daßs bie Büte des Bobens in forftlicher Beziefjung, namentlich) mas bie (Erzeugung bes hödh)=

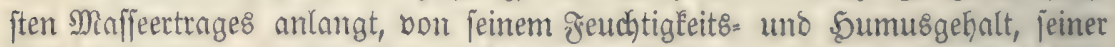

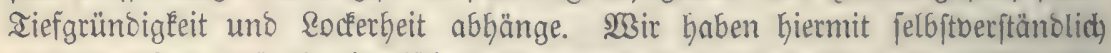

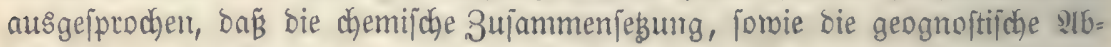
ftammung bes 3Bobens mur in jo fern über bie ssüte beffetben enticheiben, als fie auf bie borfin genannten gactoren influiren. Da aber andere Edyrift=

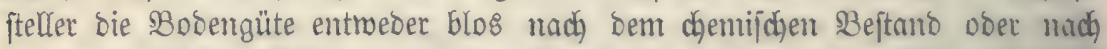
ber geognoftifon Srbftammung bemeffen Gaben mollen, jo müffen wir bieje von ben unjern abmeidjenden Infichten etraas näber betradjen.

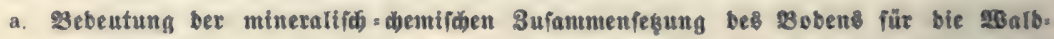 vegetation.}

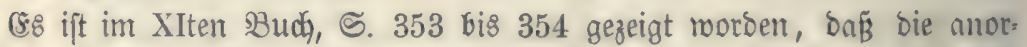
ganijchen Beftanotheile bes Bobens für bie S3egetation abfolut nothmentig

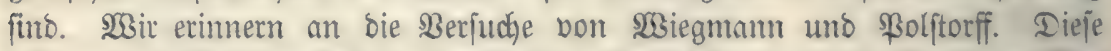

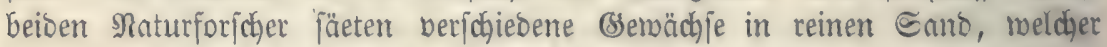
Durch) Säuren jeines (sebaltes an löslichen Mineraljubjtanzen volljtänoig be=

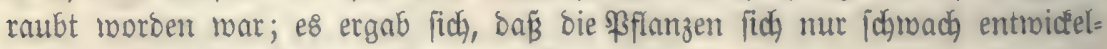
ten uno keine Eeimfähigen ธamen anjesten.

(58 finto weiter bie Riebig'jhen Iheorien angeführt morben, welche es

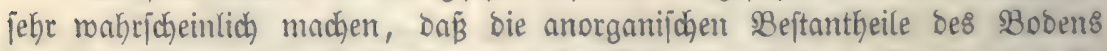
bie Uebetfüfrung ber Sohlenjäure in Solzfajer vermitteln. Die \&anbrirthe menben fodon feit langen Sahren Düngftoffe an, weldje rein nnorganifd)en Urjprungs fino, uno, mie bie Erfahrung gelehrt hat, bie (Erträge ber givloer

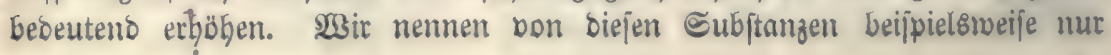




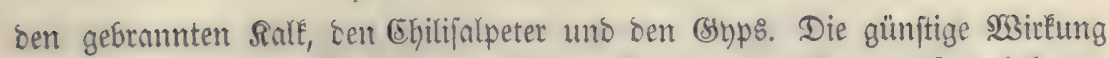
Des legsteren auf oen Rlee uns bie übrigen Reguminojen ift genugam befannt.

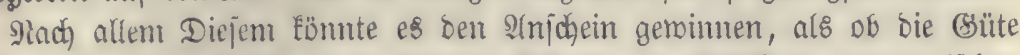

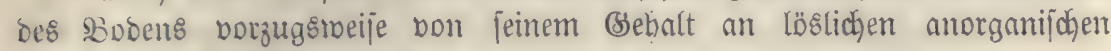
Etoffen ab̧ängig jei.

Dhne 3roeifel jpielen bie anorganijchen SBeftantbtheile bes 30 obens in

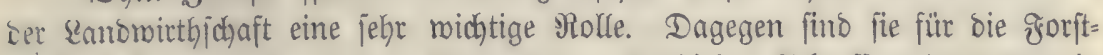
mirthjofaft bon meit geringerer Bebeutung. 3u biejem હd)luffe gelangt man in Der Ibat, wern man bie Betrieb8operationen Der Sgricultur mit benen ber

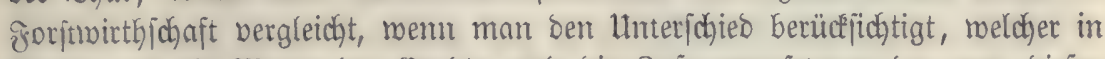
sBezug auf bie Mienge Der Emote und bie 3ujammenfegung ber von biefen beioen Bemerben erzengten Broducte befteht.

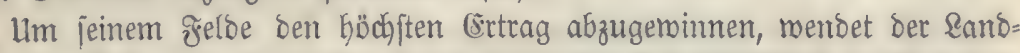

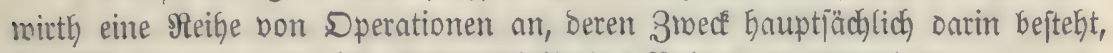
Die löslidjen anorganijchen Beftanotheile bes sBobens zu vermehren.

$\alpha$. Die Düngung. Die (Semächje, melche den Bsegenftano Des SYcker= banes bilben, fino Durch bie fortgejebte cultur in einen 3uftano gebracht mor= ben, welcher bon ifrem urfprünglichen bedeuteno abrweicht. Die Mehrzahl

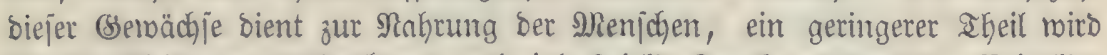
für bie Rleioung, Beleuchtung uno induftrielle 3wedfe angezogen. Bei allen

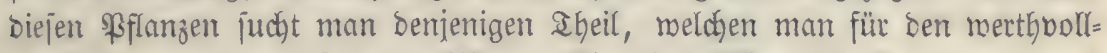

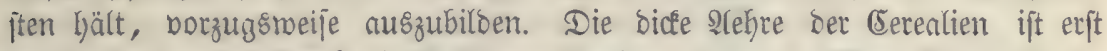
in \&aufe Der Zeit Dutch bie Cultur entitanden, Denn in Alfien, ifrent Bater= lambe, untericheident fich) unjere (ssetreibearten, was ben Şabitus anlangt, nicht von ben gemöhnlichen Şräfern. Die Rartoffel erzeugt in (Ehili, wo fie Geimijọ iit, uur erbjengrope Snollen; nach Darmin joll ber Ertrag eines ganzen

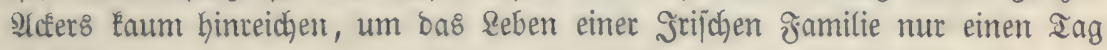
ou friften.

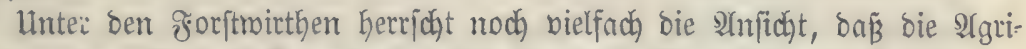
cultur meniger Roklenjtoff probuzire, als bie Forjtmifjenjofaft. Dieje Meinung berubt auf einem Srrthum. Bruffingault ernotete auf feinem Sut zu Bechel=

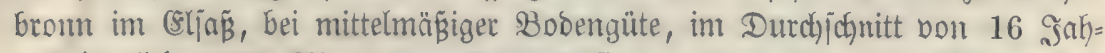
ren jährlich 1720 Rilogramme Sohlenjtoff pro Sectare - ein Ertrng, Ben wir uur von sabelfolz=, niemals Eaubholzwaloungen erzielen. Der sehalt

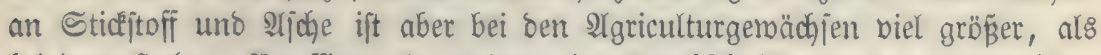
bei bem ఏolze. Bouffintgault ernotete im Durchjodnitt von 16 Sabren jähr= (ich 53 Silogramme Etiçitofi uno 214 Silogramme an anorganijojen Eub=

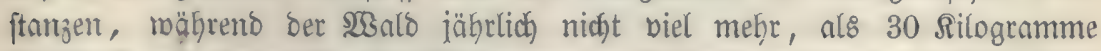
ভtiçjtoff uno etroas über 50 Rilogramme an 2ichenbeftanotheilen zu probuziren vermag.

Bei ber Ranomirthjohaft bleibt bie (Erzeugung bon Betreibe immer ber Sauptzmed bes (Semerbes. Das Stroh ift Durch feinen Gebalt an Mineral- 


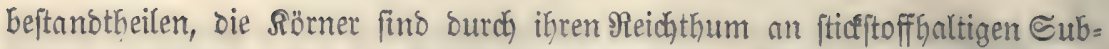

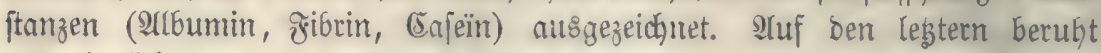
bornebmlich ber safyrungsinetth Des Betreides.

Wenn e\& mun zlwar ber Cultur im Raufe ber Zeit gelungen ift, gemiffe Theile ber lanomirthichaftlichen (semäch je zu einer abnormen Bröß̈e Keranzu= billon uno badurch ben Srtrag des geldes an ben merthpollen Stoffen, meldye jene Theile enthalten, bebeutend zu erböhen, fo fann es fich auf ser

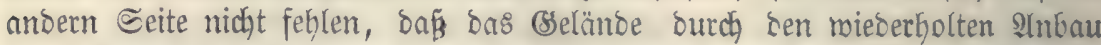

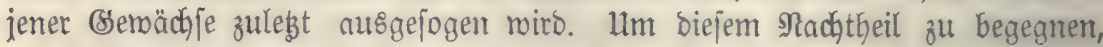
um ftets mieber neue Ernoten bon eben fo grofiem Belang, als bie frïgeren zu erhalten, hat man fich genöthigt gejehen, biejenigen Etoffe bem Booen

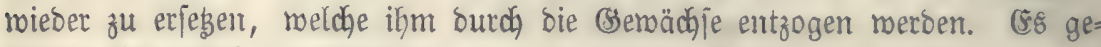
fojieht bies burdh bie Düngung.

Seit frühefter Zeit hat man mit Dem beften (Erfolge bie Ercremente ber Thiere zur Düngung angewandt. Dieje Orcremente enthalten in Der Ihat zum grỉ=

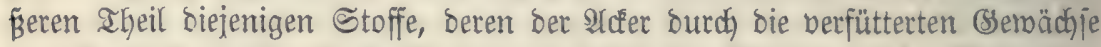
beraubt morden ijt. Das Csinzige, mas bei ber Ernährung der Animalien

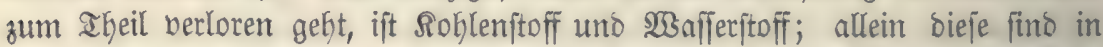
Bę̧ug auf bie Düngung von geringer Bebeutung, ba jener von ber Soflen= fäure ber Ruft und biejer von Dem $23 a f f e r$ in finreichender Mnenge geliefert merben kann.

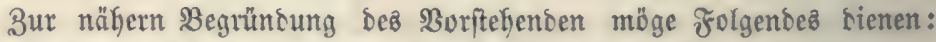

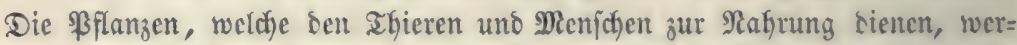
Den theits verbaut und gehen cann in sab Blut über, theils werden fie aber fogleidh als unmaffimilirbar surdf bie (Excremente ausgejofieber. Die

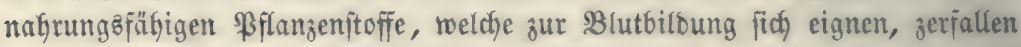

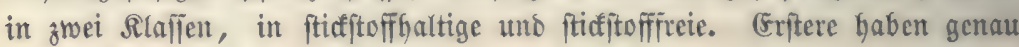

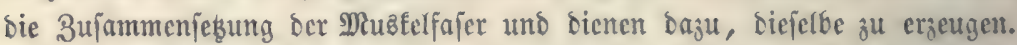

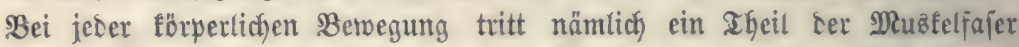

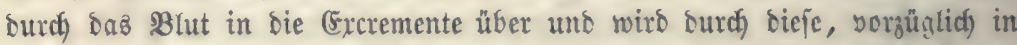

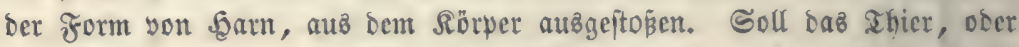
Ser Menjó zu neuer Rraftäuperung fäbig gemadjt werben, fo muß ein

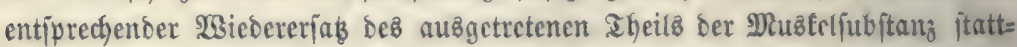

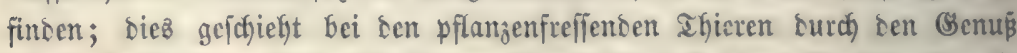
ber fitifftoffhaltigen Beftandthcile ber Begetabilien, bei bem Menidyen fowohl

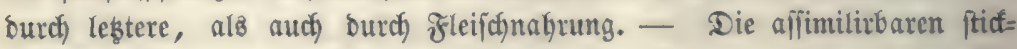
ftoffireien Materien ber Pflanzen (Stärfemehl, Dextrin, Fett 2c.) werben

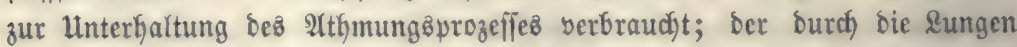
eingenommene Gaueriftoff Der Ruft verbintbet fid) mit bem Rohlenftoff unt

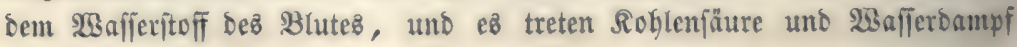
burch) bie \&unge aus.

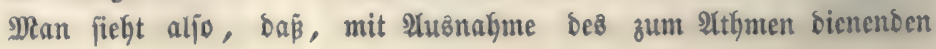




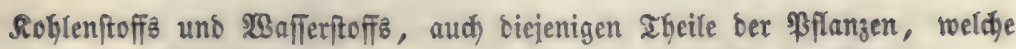

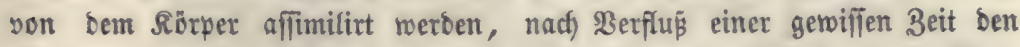

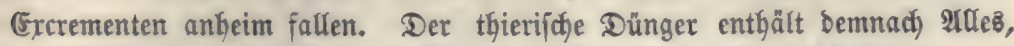

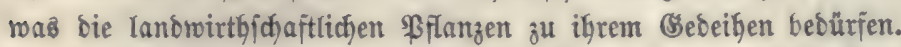

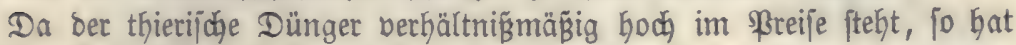
man berjucht, ifn burch andere mohlfeilere Stoffe zu erjeben. Bon biejer ärt ift 子. B. Der Riebig'īhe ßatentoünger. Snbeffen Eommt ber legtere, mie

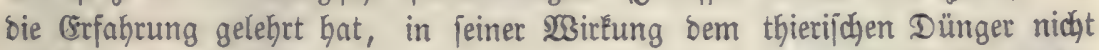

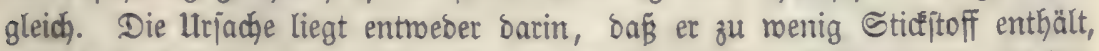

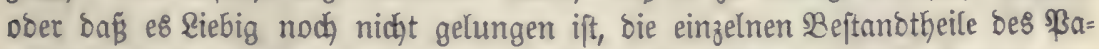

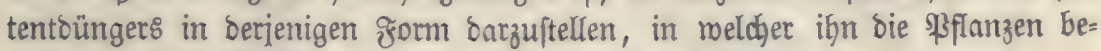
hufs bet श्ञfimilation verlangen.

B. Die Beaderung. Die rilomachjenden Pflanzen entnehmen bem Boben fo biel von jeinen löslidyen $B$ eftanbtheilen, als beren im Umtreife ber

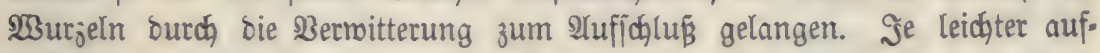
jळhließ̧bar ber Boben ift, um jo üppiger gedeihen bieje \$flanzen. Die 2lgri=

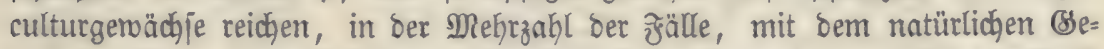

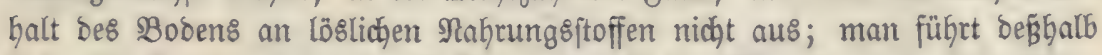

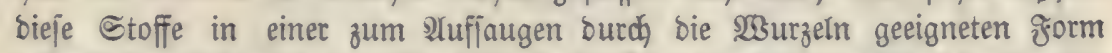
mittelft bes Düngers zu. In bem Berbraudye be\& lestern läßjt fich aber ba=

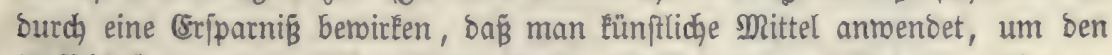
2ufichlǘ ber mineralijchen Bejtanortheile bes Bobens zu beförbern. Dies ge=

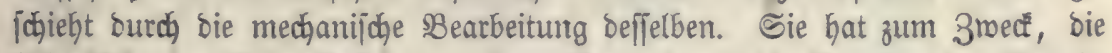
Dberfläche ber Bobentheilchen zu vergröß̈ern, Damit bie IIgentien ber Bermit= terung, uno unter biejen namentlich die Roblenjäure, mehr Berührungspuncte

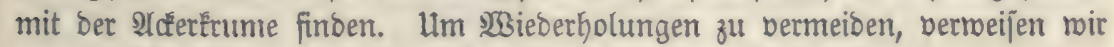
wegen biejes Begenjtandes auf ben Borbereitenden Theil, S. 77.

Wir fino übrigens reit babon entfernt, behaupten zu wollen, baß̈ bie Beacferung uur zu bem vorbezeichneten 3 medfe biene. Man nimmt fie auch nodh

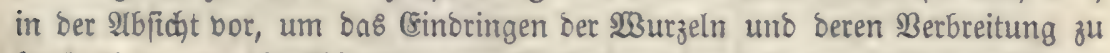

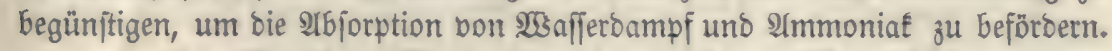

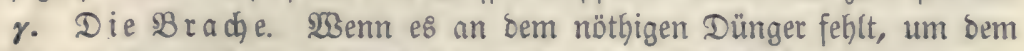
Felbe bie Stoffe, welche es burch den 2 nbau bon (seroädhjen berloren hat, fogleich rieber zu erjegen, fo fieht man fich gezroungen, Die Cultur einige 3eit rufyen, ober, mie man jich ausbrüat, ben Boben brad, liegen zu lafjen, Samit fich in Folge bes Bermitterungsprozeffes roieber ein Bortath bon affimilirbaren Nahrungsftoffen in ber \&dererbe anjammeln Eann. Die 3eit

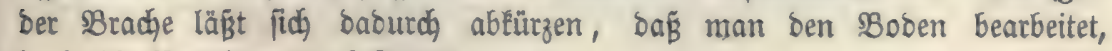
๖. Ђ. Die $\mathfrak{B e r w i t t e r u n g ~ b e f o ̈ r b e r t . ~}$

d. Die 23 edjelmirthid)aft. (Shemijhe Analyjen baben bas Re=

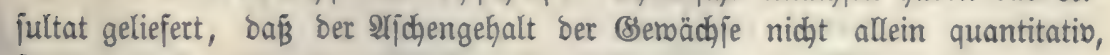
jonbern auch qualitatio berichieben ift; indem man bie 2rjogen bon ganzen 
Ernoten berechnete, fand man, bafi die Pflanzen bem Boben ungleidhe Mengen ber veridhiedenen श्ajhebeftanotheile entziehen.

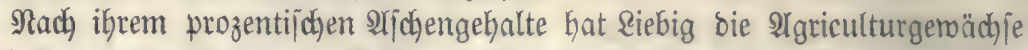

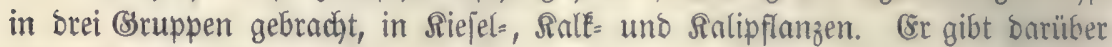
folgenbes Sdjema:

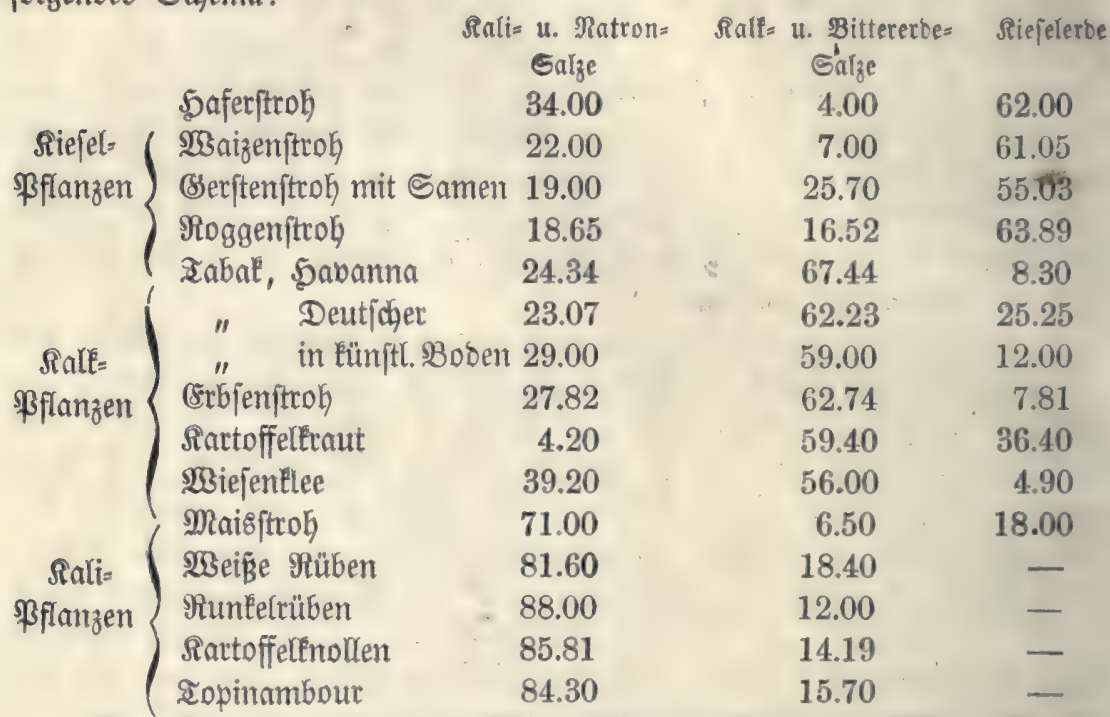

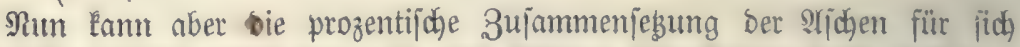
allein nicht barüber enticheioen, ob eine Pflanze Den Boben mebr ausjange,

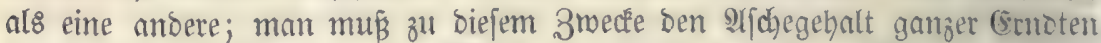

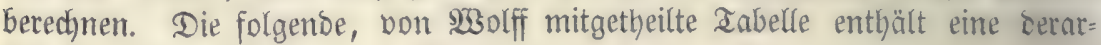
tige $3 u$ ammenftellung.

Ertrag

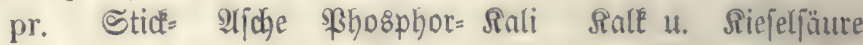
Sectare ftoff fäure Sagnefia

sil. Sil. sil. sil. sil. sil. sil.

SGaizen

Sïrner

Stroh

^oggen

\begin{tabular}{lrrrrrrr} 
Rörner & 1600 & 30.6 & 27.7 & 13.1 & 9.3 & 4.0 & 0.6 \\
Stroh & 3800 & 13.3 & 152.0 & 4.0 & 29.6 & 10.0 & 101.1 \\
\cline { 2 - 7 } & $\mathbf{5 4 0 0}$ & 43.9 & 179.7 & 17.1 & 38.9 & 14.0 & 101.7
\end{tabular}

Berite

Rörner

Stroh

Sebalt oer Emoteerträge an

\begin{tabular}{rrrrrrr}
2000 & 36.8 & 35.0 & 16.9 & 10.5 & 6.0 & 0.5 \\
5000 & 15.0 & 225.0 & 9.2 & 42.1 & 12.4 & 158.6 \\
\hline 7000 & 51.8 & 260.0 & 26.1 & 52.6 & 18.4 & 159.1
\end{tabular}


Bebeutung ber minecalijđen 3ujammenfeşung besి Bobens.

(Ertrag

pr. Stid: 2liche Bhosphor= Sali Salle $u$. Siefeliäure Sectare ftoff Ril. Ril. Ril. jäıte

sil.
Magnefía

Ril. Ril. תil.

Safer

\begin{tabular}{lrrrrrrr} 
Sörner & 2000 & 37.4 & 70.0 & 17.5 & 11.2 & 7.7 & 29.4 \\
Stroh & 4000 & 12.0 & 240.0 & 7.7 & 62.8 & 24.0 & 130.0 \\
\cline { 2 - 7 } & 6000 & 49.4 & 310.0 & 25.2 & $\mathbf{7 4 . 0}$ & 31.7 & 159.4
\end{tabular}

Sautbohnen

\begin{tabular}{lrrrrrrr} 
Rörter & 2000 & 82.2 & 63.8 & 21.8 & 28.7 & 8.7 & 0.4 \\
Stroh & 3000 & 36.0 & 150.0 & 15.0 & 36.0 & 54.0 & 15.0 \\
\cline { 2 - 7 } & 5000 & 118.2 & 213.8 & 36.8 & 64.7 & 62.7 & 15.4
\end{tabular}

Erbjen

$\begin{array}{llllllll}\text { Rörnex } & 1500 & 53.1 & 37.7 & 11.4 & 16.6 & 6.0 & 0.6\end{array}$

Stroh

\begin{tabular}{rrrrrrr}
3000 & 53.7 & 150.0 & 11.3 & 40.5 & 54.0 & 6.0 \\
\hline 4500 & 106.8 & 187.7 & 22.7 & 57.1 & 60.0 & 6.6
\end{tabular}

Wiicfen

$\begin{array}{lllllll}\text { Rörnet } & 1500 & 65.3 & 45.0 & 15.3 & 18.5 & 5.9\end{array}$

ङtroh

\begin{tabular}{ccccccc}
3000 & 51.0 & 165.0 & 14.9 & 33.0 & 75.9 & 12.2 \\
\hline 4500 & 116.3 & 210.0 & 30.2 & 51.5 & 81.8 & 12.2
\end{tabular}

Raps

\begin{tabular}{lrrrrrrr} 
Rörner & 2400 & 80.0 & 96.0 & 41.3 & 24.8 & 26.8 & 1.2 \\
Stroh & 4500 & 13.5 & 189.0 & 11.3 & 58.6 & 56.7 & 7.6 \\
\cline { 2 - 8 } & 6900 & 93.5 & 285.0 & 52.6 & 83.4 & 83.5 & 8.8
\end{tabular}

$\begin{array}{llllllll}\text { SRunfelrüben } & 40000 & 96.0 & 384.0 & 23.0 & 172.6 & 43.8 & 21.5\end{array}$

$\begin{array}{lrrrrrrr}\text { BLätter } & 10000 & 28.0 & 188.0 & 12.2 & 75.2 & 30.1 & 13.2\end{array}$

$\begin{array}{llllllll}\text { Rartoffeln } & 20000 & 82.0 & 204.0 & 23.1 & 105.1 & 14.7 & 114\end{array}$

$\begin{array}{llllllll}\text { Sileeheu } & 6000 & 130.8 & 390.0 & 24.6 & 105.7 & 120.9 & 20.7\end{array}$

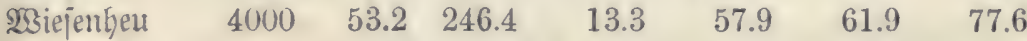

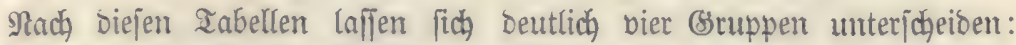

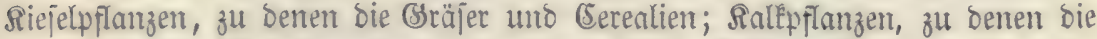

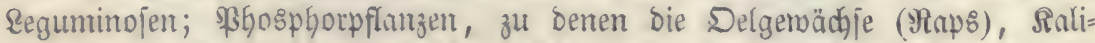

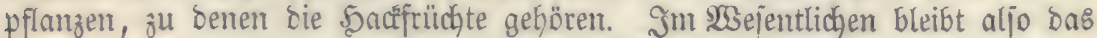
3ermögen, Dem Boben bejtimmte Bejtanotheite zu entziełen, ons nämliḑe, mag man blos bie prozentijche 3ujammenjebung ber slidjen, Doer bie vollen Ernoteerträge vergleiç一n.

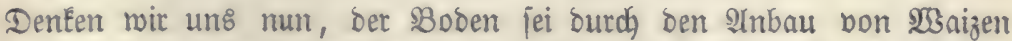
jeines (Bebaltes an löslicher Siejeljäure beraubt worben, fo wiro er bod) nodh ôun Ânbau bon ơrbjen tauglich jein, denn bieje braudsen nur wenig Riejel= fäure, aber bejto megr Ralk. Sat Der \$oben fich an biejem erjegöpft, fo Eann 


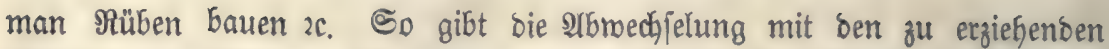
Sflanzen ein Mittel an bie Şanb, um bem Boben fortwährend gute Ernoten

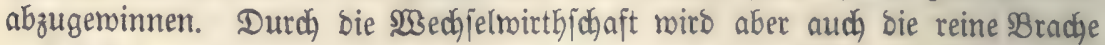
entbebrlich gemadht, denn man Eann näbrend ber Brachzeit eine \$flanzenart bauen, meldje blos jolche Stoffe braucht, beren bie fpäter cultibirenden (Se=

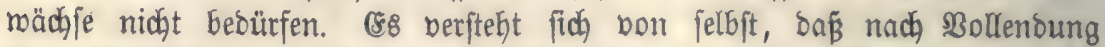
einer Rotation eine Düngung eintreten mú̈, meil jegt ber Boben gänzlich erichöpft ift.

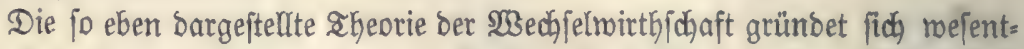
lich auf ben qualitativen uno quantitativen Unterjojies in bem 2rjogegehalt

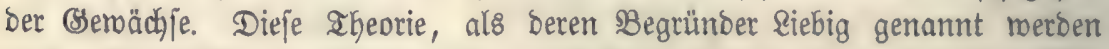
mus, ift indeffen in neuerer Zeit angefochten morden. Man hat ifre Midh= tigkeit aus bem Grunbe bezmeifelt, meil e8 nicht gelingen mollte, bie Boben= Fraft burd) Düngung mit benjenigen anorganijohen Stoffen, melche ifm burch irgend eine Sflanzenfpecies entzogen morben fino, mieber Kerzuftellen. $203 e n n$ e\& z. $\mathfrak{B}$. Der Mangel an Riejelfäure ift, fagte man, melche uns berbietet, zmeimal hinter einanoer $\mathfrak{W}_{3}$ aizen zu bauen, fo muß lez̧teres boch zuläfig jein, wenn man nach ber erften $\mathfrak{B g}_{3}$ izenernote bem Boben bie fehlende Rie=

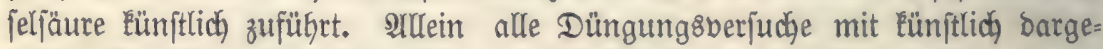
ftellter Riejelfäure find fehlgejojlagen, folglich Eann es nidjt ber (sntzug von

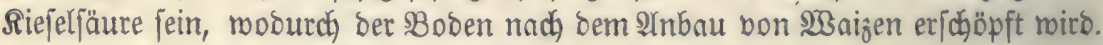

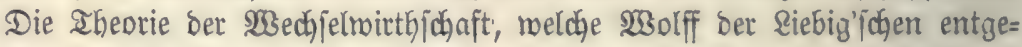

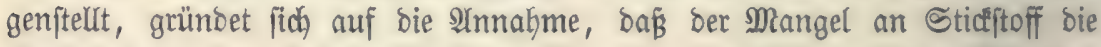
Sauptur|ache ber Bobenerfäppfung fei. Er unterftellt, einigen \$flanzen, wie z. B. Den Sacffrüchten uno Dem Rlee, fomme borzugstweije bas $\mathfrak{B e r}=$ mögen zu, den Sticfftoff ber Atmojphäre mittelft ber sBlätter fich anzueignen, räbreno andere $\Re$ flanzen, z. B. Die Cerealien mehr barauf angewiejen feien, ben im Boben enthaltenen Sticfiftoff burd bie 23 urzel aufzunefymen. Die

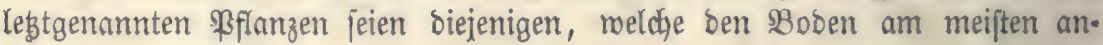
griffen.

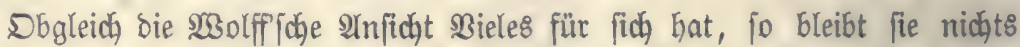
Defto weniger eine Sypotheje, deren Beftätigung burdh Berjuche erft abge= martet merben mußs. (Sanz abgejeben bon ber objchmebenten Streitfrage ijt

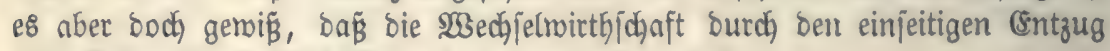
von Beftandtheilen bes Bodens herborgerufen wirb.

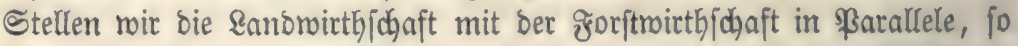
fälut uns auf, bas bie legtere befteht, ohne bie in ber \&anbroirthichaft ge=

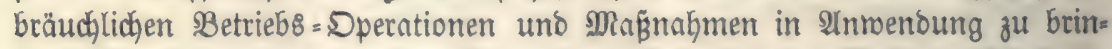

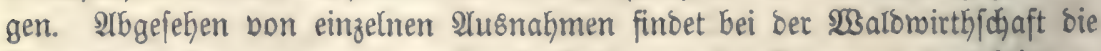
Bobenbearbeitung nur zu bem Zroedfe ftatt, um bie Samen unterzubringen. Man will biejelben burd) bie Bebectung Der Croe gegen bie গachftellungen

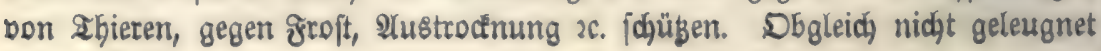




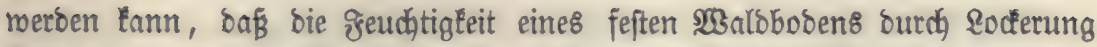
fich bermefren läst, io fteht boch auf ber andern Seite bas feft, dapi bie

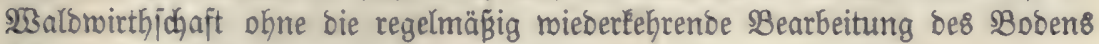
fidi erhalten fann.

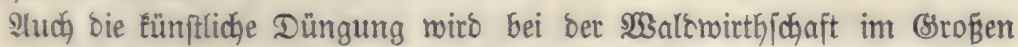
nicht in 2fnmenoung gebracht. Doch barf nicht überjehen werben, baß ber Jorftwirth bie erzogenen Benäbjje nidat fo rein abernotet, als bies von Sei=

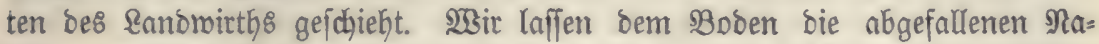

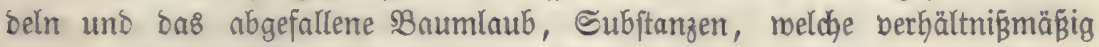
reidi an anorganijoben $B$ eftanotheilen finto.

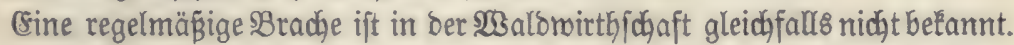

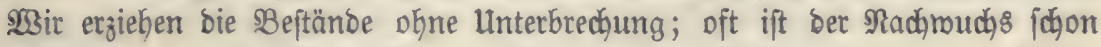
vorhanten, ehe bie Mutterbäume entfernt morben find.

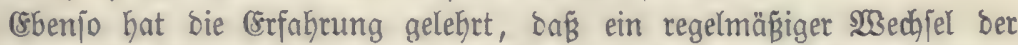
ఏolzarten nicht nöthig ericheint. Irn bielen Drten werben ßuchen=, Fichten=,

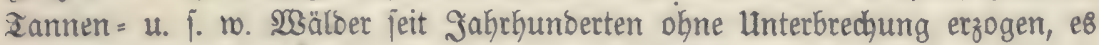

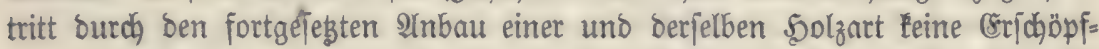

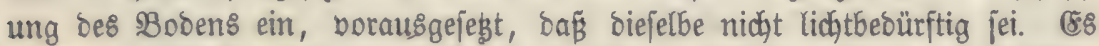
ift jogar conjtatirt, baß ber Boben in Buchen=, gichten = ober Tannenbeftän= ben fich in bem Mafe beffert, je länger bieje Solzarten cultivirt merben.

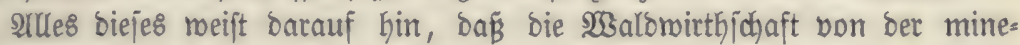

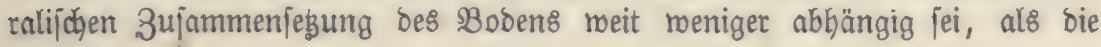
श्रgricultur.

3u bem nämlidfen ๔djluffe gelangt man aber audh, menn man bie

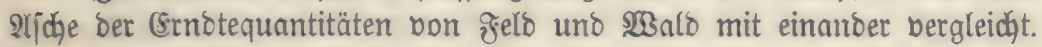

Bonfaujen äjdjerte eine 80 jährige Riefer uno eine 100iäfrige Budbe

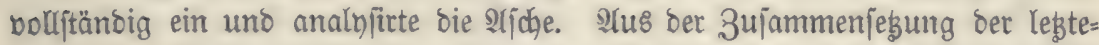

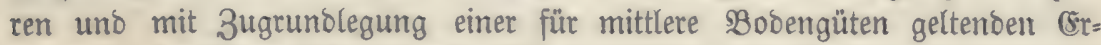
tragstafel berechnen fich folgende slichequantitäten, melche bie borgenannten

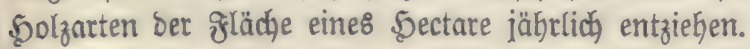

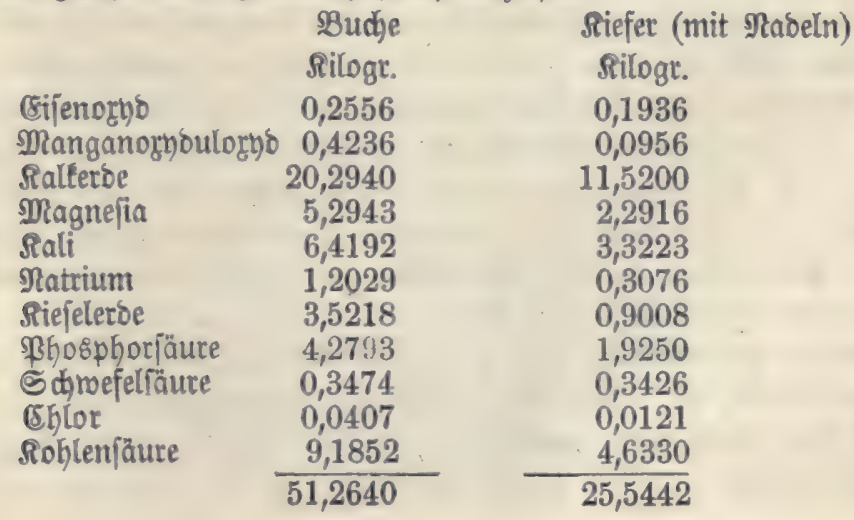




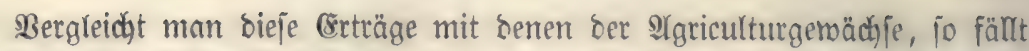

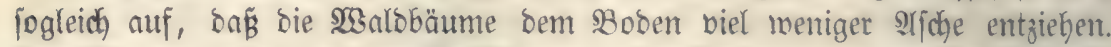
Der $23 a i z e n t$ liefert 5 mal mehi arjche, als bie Buche uno 10 mal mehr, als

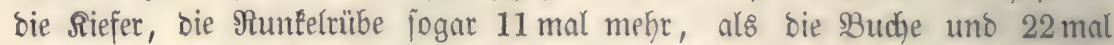

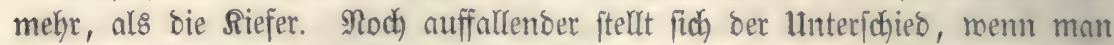

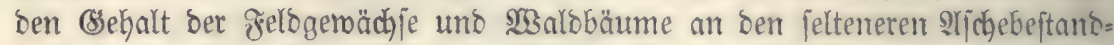

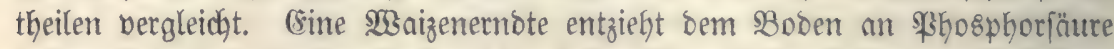
jechsmal fo viel, al\& bie $B$ uche, $12 \mathrm{mal}$ jo biel, al\& bie Riefer, an Riejelfäure $45 \mathrm{mal}$ jo viel, als bie Buthe unt $177 \mathrm{mal}$ fo viel, als bie Siefer. Eine

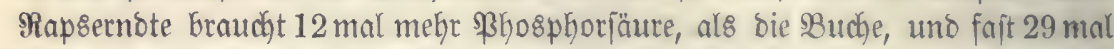
mehr, als bie Siefer bem Boben entnimmt. Cine Rumkeltübenernote enthält

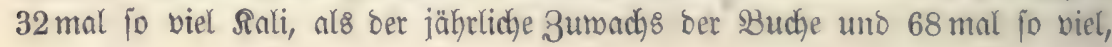
als berjenige Der Riefer.

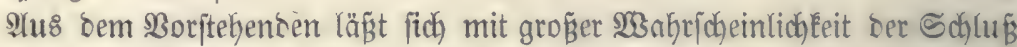

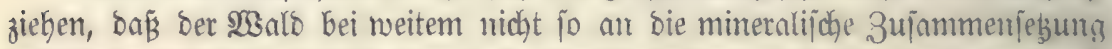

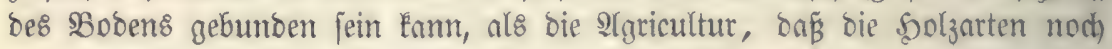
mit einem Boden borlieb nehmen merben, meldyer zu arm an affimilitbaren anorganijwen Subjtanzen ift, um ber Ranomirthjchaft lohnende Erträge zu veriprechen.

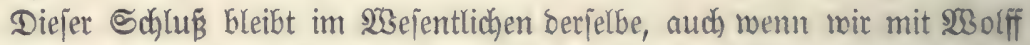

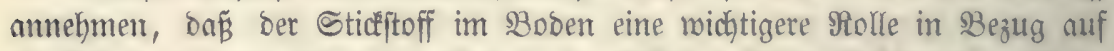

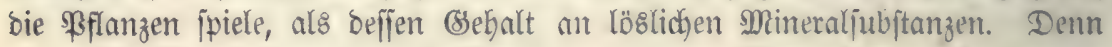

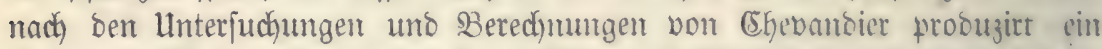

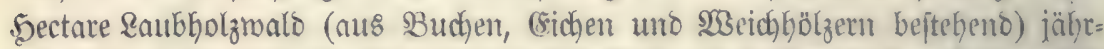

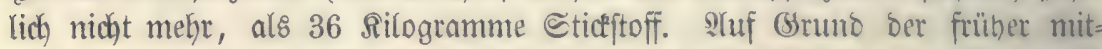

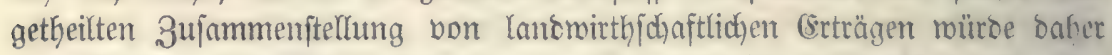

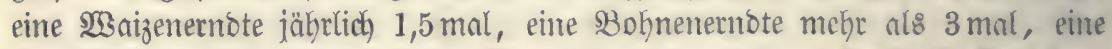

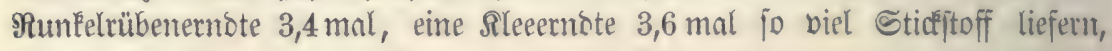

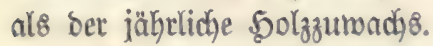

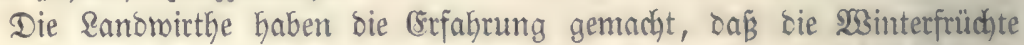

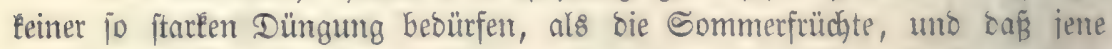
überhaupt nod) auf einem Boben bon geringerer mineralijcher Iraft georifent.

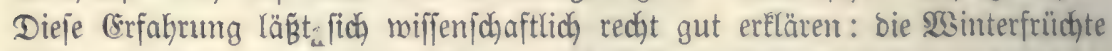

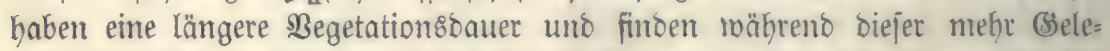
gentheit, fich bie nöthigen arjobeftandtheile angueignen; rie Sonmerfrüchte bagegen müffen in Kurzer Zeit eine eben fo grof̧e Menge von anorganijoken Stoffen aufrehmen; onzu ift erforberlich, ons Der Boben entweber türatig ge= büngt, ober leidjt auffichließ̈́ar jei.

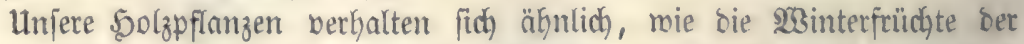

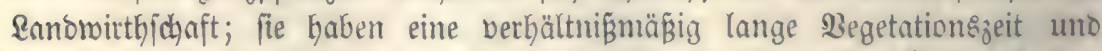

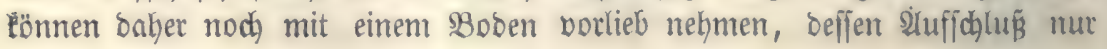
langfam erfolgt. 


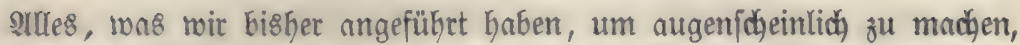

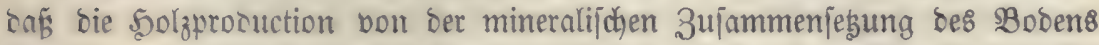

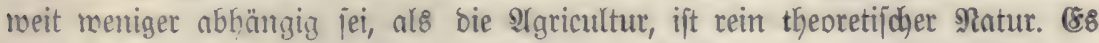
fehlt inceffen nicht an proctijohen Belegen zur Bejtätigung unferer Snfidjten.

Eehen wir uns eiumal banach um, wie fich biejenigen sBöben, weldhe arm an löslichen anorganijchen હubjtanzen fimb, gegen bie Walbuegetation berfyalten.

Dhnitreitig gehört ber Cand, in meldgem Qunarz ober (stimmer bor=

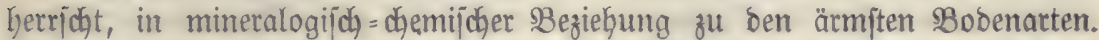
Der Duarz enthält ja fajt mur Riejelerde und Bijen= oder Manganoryb, uno

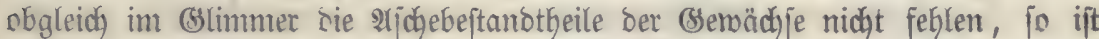
cod bieje Mineralipecies fo johner aufichlieģbar, fie trost fo hartnädig ben

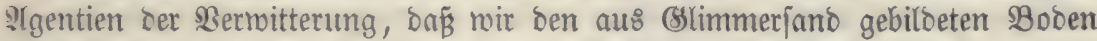
umberingt als arm bezeidhnen Eönnen. Deffen ungeadtet finoen wir auf bie= jen beiben ธanoarten, mögen fie nun rein ober bermengt borf́fommen, bie

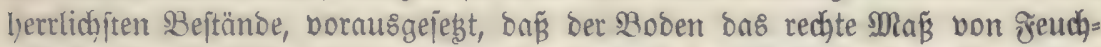
tigfeit befige, jomie e\& bie einzelnen ఏolzarten berlangen. Der $\mathfrak{B e r f}$. fübrt

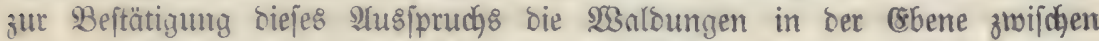

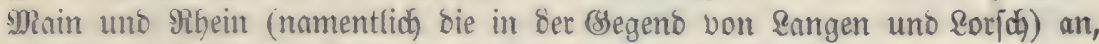

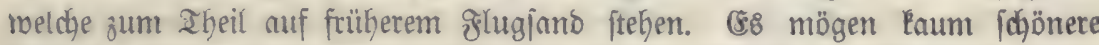

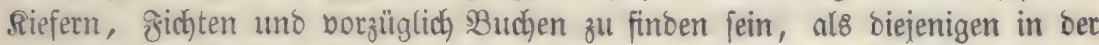
Main = Mhein = Cobene.

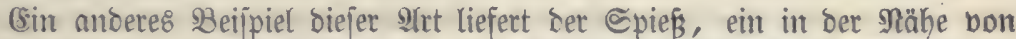

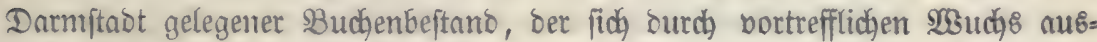

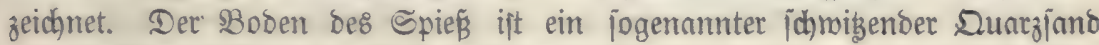

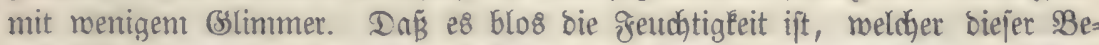
itand jein fröhliches Bebeifyen berbanft, l lägt fich aus ben wefftidy bon Darm= ftact befindlichen Riefemsijtricten beurtheilen, weldhe auf trodenerem Sand bon Der nämlichen mineralijoben Bejdgaffentheit jteben. Sier bleibt felbft bie genüg= I

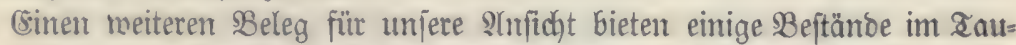
1118. Ins Iaunusgeftein gehört in bie Bruppe bes Dunrzit'8, jhon ber

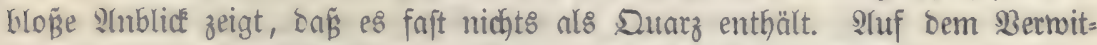
terungsboben biejes (Sejteins wachjen vortreffliche sBuchenbejtänoe mit einge.

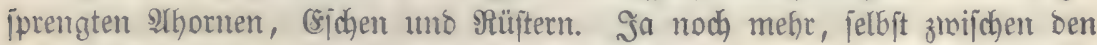
naưten Steinen in ben jogenannten Feljenmeeren bes Inumus vegetiren \$1horne

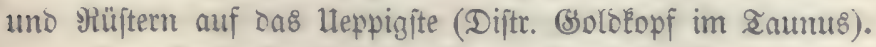

Der Duaberjanoftein, weldyer boch ofnftreitig zu benjenigen Sanbftemen gehört, bie am wenigften Bindemittel befiben, ergeugt in frijden Ragen aus. gezeidhnete $B$ ud

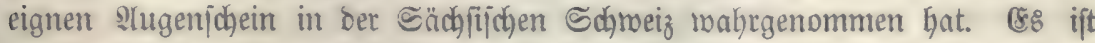

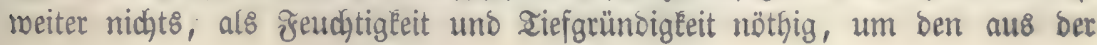


Berwitterung Des Quaberjanbftein's gebildeten Boben zur ßrobuction bon

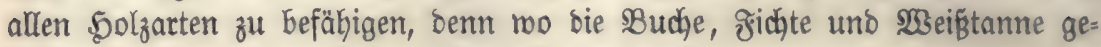
beiben, da lommen auty bie andern Solzarten fort.

Das Rejultat ber fo eben mitgetheilten Beobachtungen läuft aljo auf ben Saj̧ hinaus, baś jeber \$Boben, meldjer fich in jeinem natïrlichen 3uftande befinoet, genug anorganijobe Stoffe enthält, um bie \$olzbeftänbe mit biejen

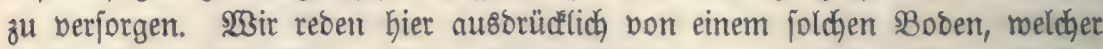

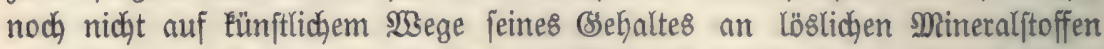

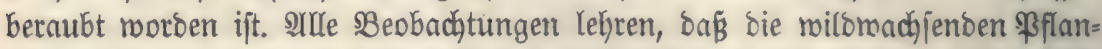

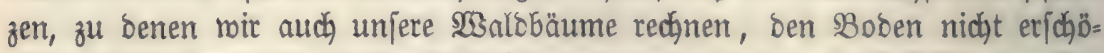
pfen, wohl kann aber biejer gall eintreten, menn man mit Beifülfe ber $B e=$

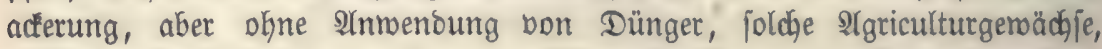
meldhe grof̈e 2̂njprüche an bie mineralijchen Subjtanzen bes Bobens machen, längere Zeit cultibirt. Bor ofngefähr zmanzig Sahren wurbe ein (sidjenbe=

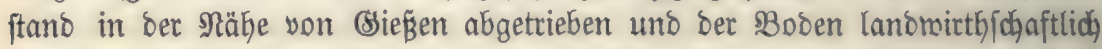

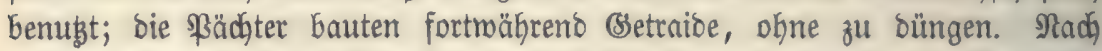
Berlauf von fünfzehn Sahren war ber $B o b e n$ fo ausgejogen, daßs es fid nicht mefr erlohnte, ben SSetraibebau fortzujesen; man fing nun wieber an, ridjen zu cultiviren, allein auch bieje famen auf bem ausgemergelten sBoben

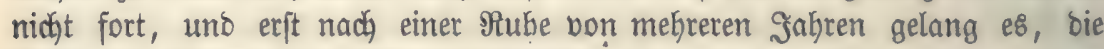
gläche mit Siefern in Cultur zu bringen.

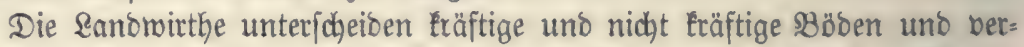
ftehen unter jenen foldhe, weldhe des Düngens längere Zeit entbehren Ë̈nnen.

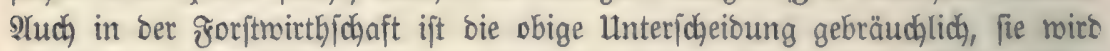
aber hier in boppeltem Sinne angetwandt. Sinige nennen einen SBoben föon bann Eräftig, wenn er überbaupt zur Solzproduction fehr geeignet ift; 2rnoere begreifen unter fräftigen Böben foldje, welche bns Streurechen gut ertragen.

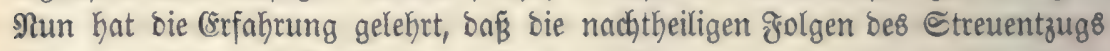
fid namentlich. auf ๔andboben gelteno madjen, und man hat bies bem ge= ringen ssehalt bes Sandes an löslichen anorganijchen Subftanzen zurechnen

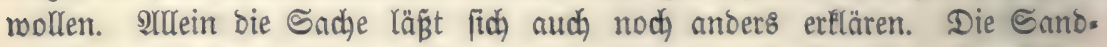

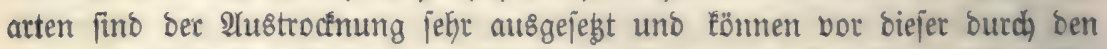

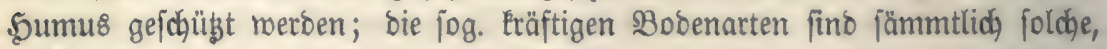
weldhe eine grofie rafferhaltenoe Rraft befizen; ber Streuentzug mirb alfo bei ifnen nidat fo leidht eine 2lustrocfnung lyerbeifübren. WBir jeben baher, Daßß bie nadhtheiligen folgen bes Streurechens auf Canbboben fich ebenjomohl

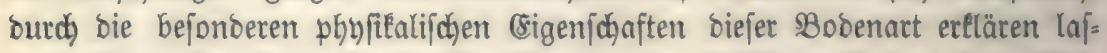
jen. Siernach würbe aljo bie Bezeichnung eines fräftigen Bobens hauptjäch= (id) burch beffen $\mathfrak{B e r f a l t e n ~ g e g e n ~ b i e ~ F r e u d j t i g l e i t ~ g e g e b e n ~ f e i n ~ u n o ~ m i r ~ w u ̈ r = ~}$ ben bie (sintheilung ber Bäben in arme uno reiche, je nady ifrem sebalt an affimilirbaren anorganijøgen Stoffen, bezüglich ber $\mathfrak{N 3 a l b b a ̈ u m e ~ f a l l e n ~ l a f f e n ~}$ muีfกา. 


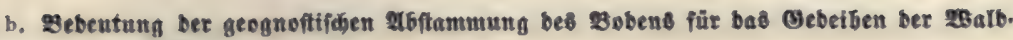 negetation.}

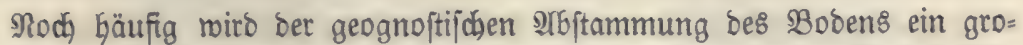

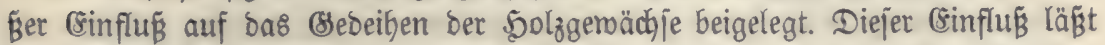
fich allerbings nicht läugnen. (s\& fragt fich nur, $\mathrm{Db}$ ein uno baffelbe Matter= geitein bei ber Bermitterung ftet\& einen $\$ 30$ ben bon ber nämlichen (Süte Ger= borbringt.

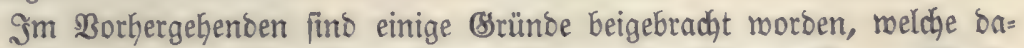

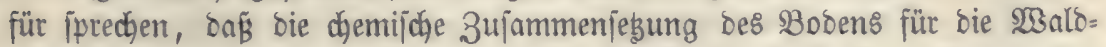

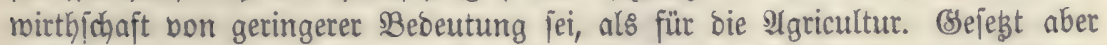

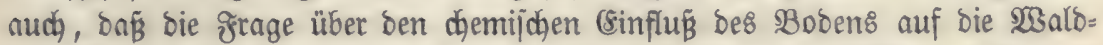
vegetation noch offen fei, fo föınen wir bie Fractoren ber (süte be\& Bobenళ

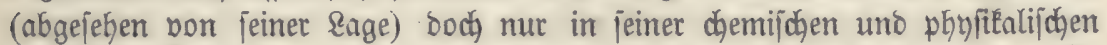
Bejofffentheit juchen. (ss bliebe nun zu enticheiben, ob jebe (Sejteinzart, meldye ber Beognoft mit einem bejonoeren Namen bezeidnet, ftets einen Boden bon

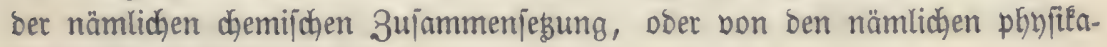
lijdjen Eigenidjaften liefert.

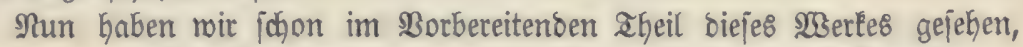
baß́s bie Beognojten (sefteine von ber verjojiebenartigiten 3ujammenjebung unter einem und demjelben Nament bereinigen. Co gibt es z. SB. Sornblen= ben, reldhe Allealien enthalten, uno 5omblenten, melche bavon frei find; es gibt Syenite mit Drthoflns = uno anbere mit Rabraborfelsjpath. Der eine Syenit Eann alfo unter Umftänoen einen falléarmen, ber anbere einen Earférei= Wen $\mathfrak{B}$ oben bei ber Berwitterung liefern. Noch gröfer ift ber Unterichied, mas ben (sebalt Der Mineralien an ben feiteneren Bobenbeftandtheilen, z. B. Der \$hosphorjäure, anlangt. (8\& gibt ærelojpathe, meldhe jebr reid, baran find,

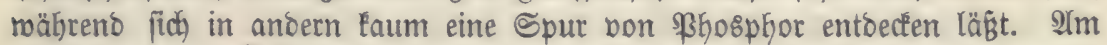
bebeutenojten ift bie Differenz bei ber 3u[ammenjegung ber Balke. Der Berf.

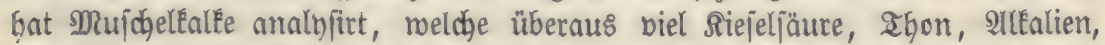
\$hosphorjäure, (Sijen $2 c$. enthielten, währeno andere fich faft al\& reine foblen= faure Salkerbe exgaben.

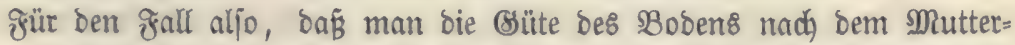
geftein beftimmen roollte, müßte man nicht allein bie 3 abl ber geognoftijchen

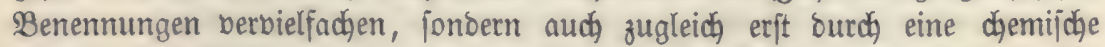

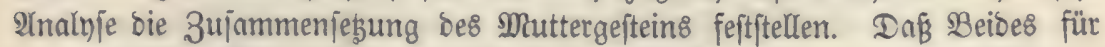
ben practijhen (sebraud unthunlich ift, berfteht lich ohne weitere Âsführung.

Bejegt aber audh, man Eenne bie demijche 3ujammenjegung bes Mut= tergejteints ganz genau, io läßjt fich aus biejer noch Eeinesnegs bie 3ufammen= [esung bes Betwitterungsbodens bemeffen. (s8 fommt bier borerft barauf an, mie weit bie 3erjegung bes Befteins nor fich gegangen ift, uno bann wäre nod' zu ermitteln, $0 b$ bie Beftandtheile beffelben an Drt und Stelle

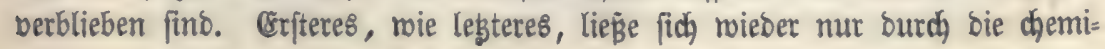


foche Ŝnaltrle, uno audh mittelft biefer mur beiläufig, beftimmen. Denn menn auch) bie $2 B i f f e n j d$ aft is möglich mad)t, jesen siörper in foine clementarbe= ftandtheils zul zerlegen, fo ift fie bod) nodh meit Enbon entfernt, bei einer Menge verjojiebenter Eubftanzent angeben zut E⿱丷m) in welcher Form jese bon biejen fich befinte.

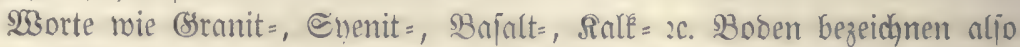
blos bie Yrbftammung, aber burchaus nidht bie djemijche 3ufammenjebung biefer Bodenarten.

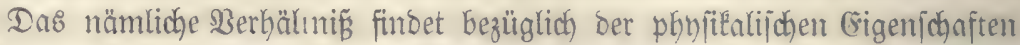

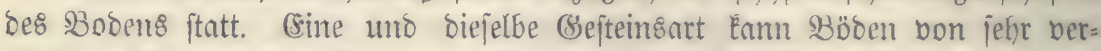

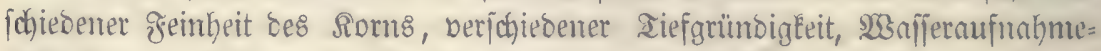

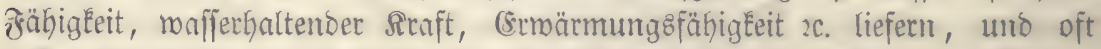

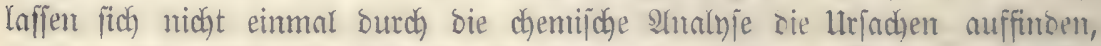

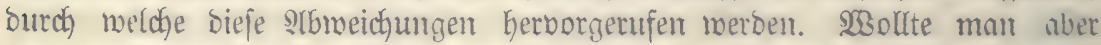

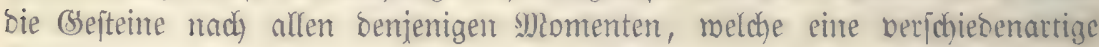
Bermitterung bemirken, unterjd)eisen, fo mütse man mit Iaufenden von slla= ment nicht ausreichen. Dabei fonment noch) eine Menge Unifänoe in Betracht, weldye unjerer $2 \mathfrak{B a f y n t h m u n g ~ g a ̈ n z l i d ~ e n t g e h e n . ~}$

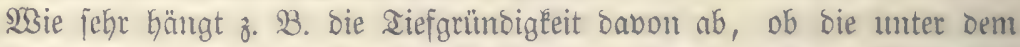

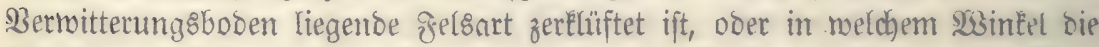

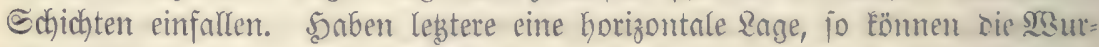
zeln nicht einsringen, Das $23 a f f e r$ fammelt fidh an uno verurjacht 23erjumpí=

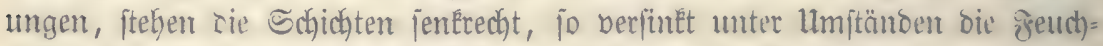

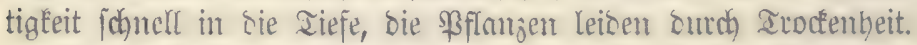

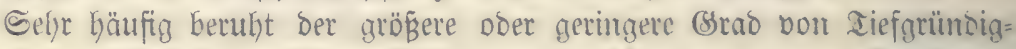

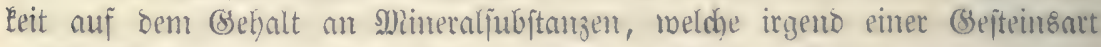

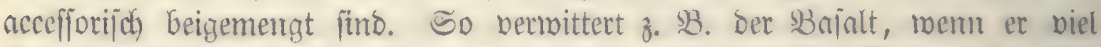
Dlivin enthält, biel johnelter, als wem er an biejent Minteral arm ift. Dii 3erjeb̧arket des ǰeldipaths bängt rejentlich von jeinem Bsebalt an (sijen= oryboul ab.

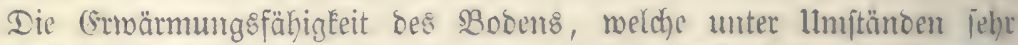

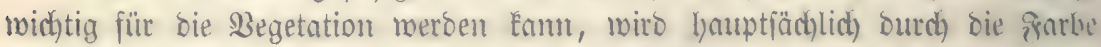
bes Miuttergefteins beftimmt. Die Farbe wedt)felt aber, felbjt bei einem und bemielben (Seftein, oft ganz nup̈eroroentlid).

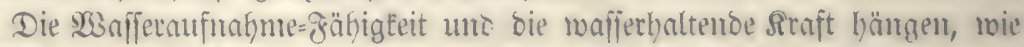
wir früber gejeben bowen, vornelymlich bon sem (stabe ter Zertheilumg ab, in relcher bie \$ortifeldyen bes SBobens fich befittoen, uno bieje Zertheilung

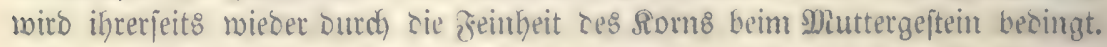

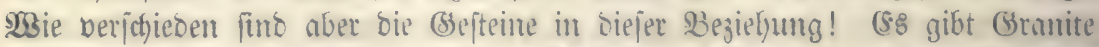

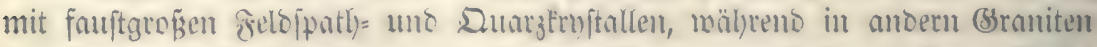

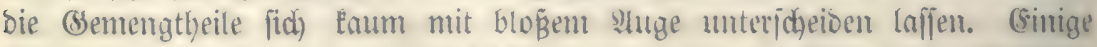
Porphtre enthalten viele, andere hörhft menige voer gar Eeine Duarz=Siryftalle. 


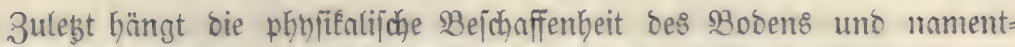

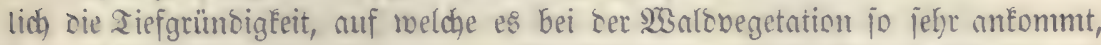

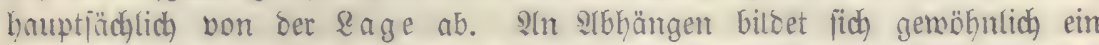
flad)anrünsiger Bosen, weil bie (srotheildyen surde) sie nieberfallenden Meteor= maffer in bie Diefe gefdrommt merden; in sen Mittien :c., mo sie (Sropar= tifeldhen abgejegt merben, erzeugt fich ein tiefgrünoiger Boben. Co fonn eine unc biejelbe Gejteinsont, je nach ber Slerflächengeftaltung bes Terrains, \$2D̈ben von jehre beridjiesener Diefgrünoigkeit liefern.

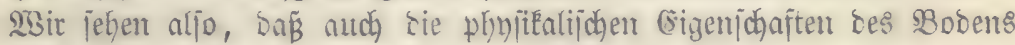
fich) nidyt nach) Dem Miuttergejtein bejtimmen Laffent.

Iie Refrbüther ber Bobenfunce pflegen bei jeder (Befteinsart bie Bejchaf=

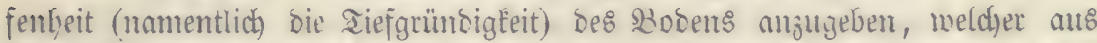
Bermitterung eines joldhen Gefteins fid) bilden joll. Dieje sungaben beruhen

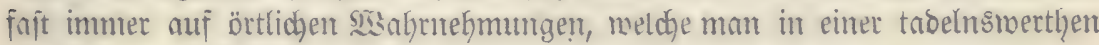
SBeije generalifitt bat.

So lieft man in fajt allen @chriften über forittiche Bodenfunte, Der Ba= jatt liefere ein überaus frudjtbares (storrich), welches oer erften Bodentlaffe

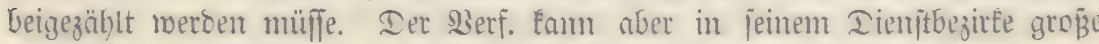
Etrecten bon sajaltbooen nufzeigen, beffen Bsitte geringer ift, als biejenige bes trodéeniten flugiande\&.

(Sinige @dyriftiteller funs aber nod) weiter gegangen; ïe baben neben jecter Bejteinsart nicht blos sen Boben, meldyer ms ibje entpringt, nebjt jei=

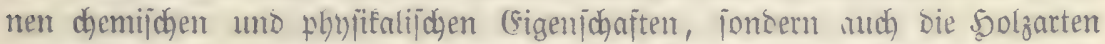
angegeben, meldye auf einem joldyen Boben bejonsers gut geveiben jollen. Ja man bat fich jogar noch nuf feirere Epecialitäten eingeloffen, man bat Den

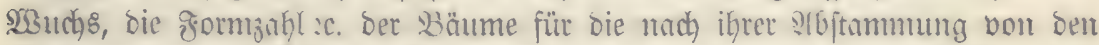

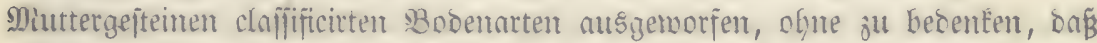

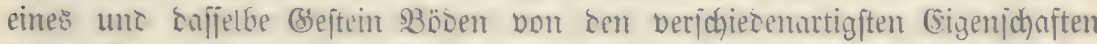
liefern Eann. Dieje ģeblgriffe rügren zum Iheil saher, weil mun glaubte, es

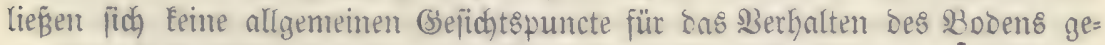

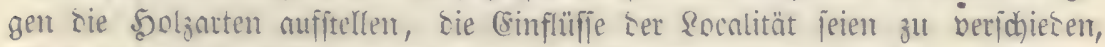

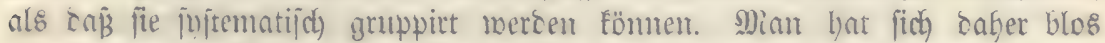

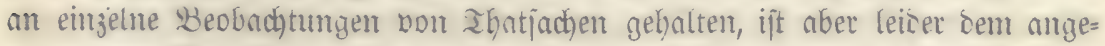
nommenten stuntojage mieser untreu getworben, indem man es़ nicht bei zer

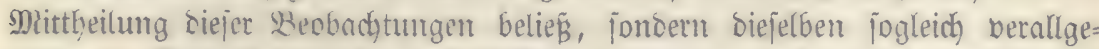

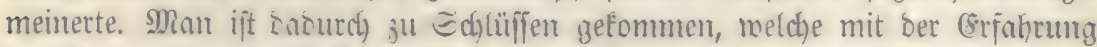

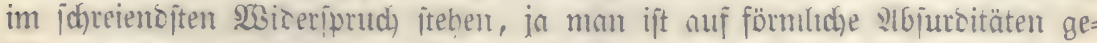

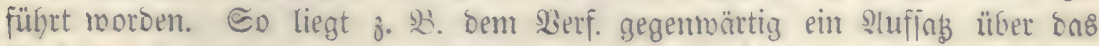

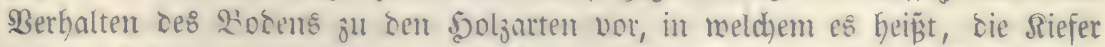

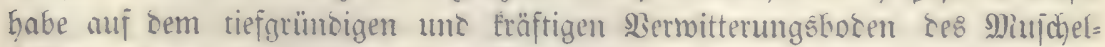

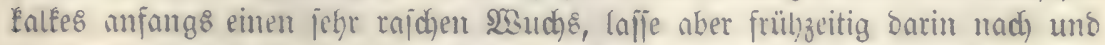
fönne baber auf einem joldyen Bosen nut in einem furgen lumtriebe bortheil= 


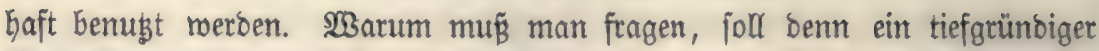
Boben ein balbiges Sinfen bes 3umachjes zur Folge haben? Sit benn bie

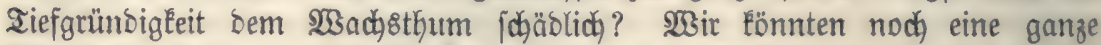
Reike bon foldyen grundofen Behauptungen auffübren, weldye fid in bie Riteratur ber forftidjen BobenEunde eingejchlichen baben, und entmeder ber theoretifcten Speculation, ober ber Sucht, zu generalifiren, ifren Urfprung ber= DanÉen.

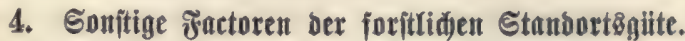

Bisfer haben mir die Stanoortsgüte blos in fo meit betradytet, als fie von bem Boben abfängt; es bleibt uns jest nod) übrig, bie Factoren be\& תitima's zน würbigen.

Der tiefgrünoigfte, humofefte, frifhefte Boben mird keine Begetation Gerborbrigen, menn er fich über ber Sdyneegrenze befindet. Sollen bie einzel=

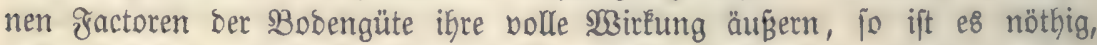
dás fie bon ben Meteoren in einer angemeffenen $233 e i f e$ unterftügt merben. MBir wollen nun biejenigen Meteore nennen, von meldyen bas (sebeigen ber 3 allobegetation vorzüglich ab̧ängt.

\section{a. 2 ärme.}

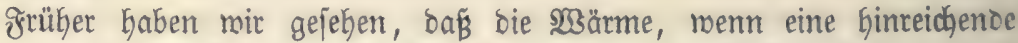

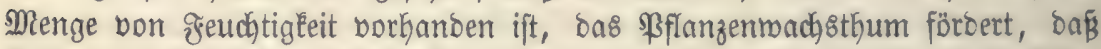

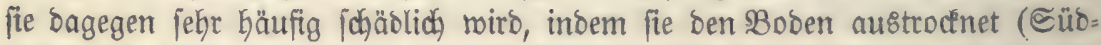

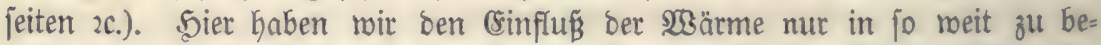
tradhten, als biejelbe eine sBebingung für das frortéommen uno Bebeifen der $\mathfrak{B a l b v e g e t a t i o n ~ b i l b e t . ~}$

(58 murbe Dben bereith angegeben, Daß́ bie vier Fractoren ber Boben=

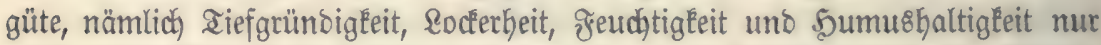
bann einen (sffect Gerborzubringen bermögen, menn bie Iemperatur bes Stant= ort8 einer Solzart biejer angemeffen ift. Wir baben nun zu fragen: in melcher

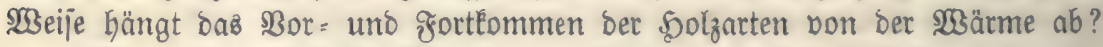

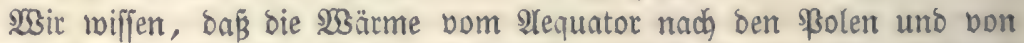
ber Meeresfläche nach ben böberen Regionen bes \&ufttreifes hin abnimmt,

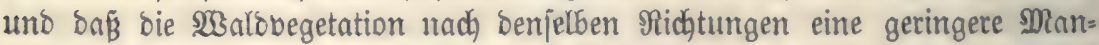

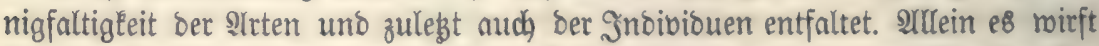
fid) nun bie neue grage auf: rid)tet fid bas Frottemmen und (sebeifen ber 5olzarten nadh Der mittleren Sabrestemperatur, ober nad ber Sommer= ober

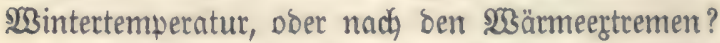

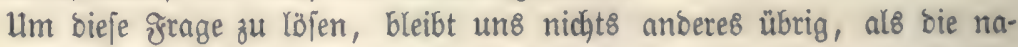
türliche Berbreitung Der Solzarten zu Betrad)ten, Denn bis jebst find nod) Eeine (5ulturberjudje angeftellt morben, um bie 23 irtungsweije ber $\mathfrak{2 B a ̈ r m e ~ z u ~ e r = ~}$

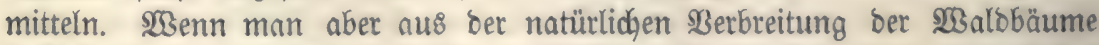
Shlüffe in ber geodaten Beziehung ableiten roill, fo tann bie\& nur mit ber größ̈ten Borfidht geldeben. Denn wenn irgento eine \$olzart an einem ge= 


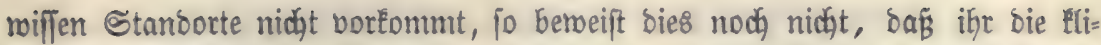

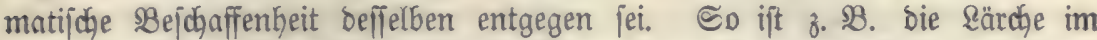
BogelEgebirge uriprünglich nicht beimijch genejen, fie roiro bajelbit noch nicht länger als 100 Sabre cultivirt. Und bod) rächjt sieje 5olzart bajelbft biel

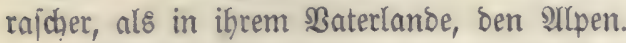

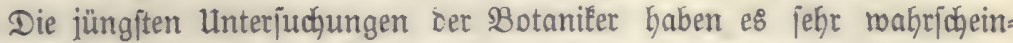

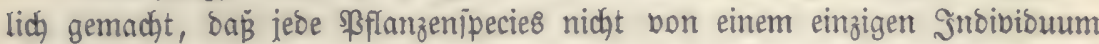

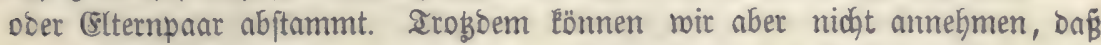
jebe socalität, weldye zur \$robuction einer beftimmten Sflanzenart tauglid iit, aud jogleidy beim Beginn ber jesigen geologijohen Periobe mit berjelben

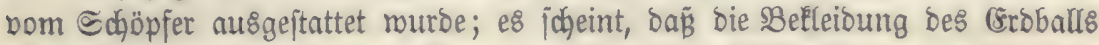

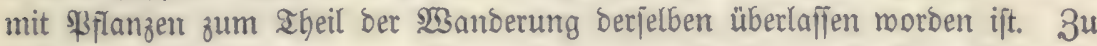
biejem Echlufie gelangt man johon, wenn man überlegt, baß̈ nicht alle Iheile Der Erobberfläche gleidzzeitig eine joldhe 3obenbejchaffenheit Gaben Eonnten,

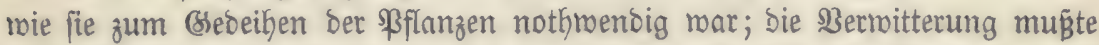
viele Socalitäten im Raufe Der Zeit beränoern, eł̧e fich eine Slegetation auf

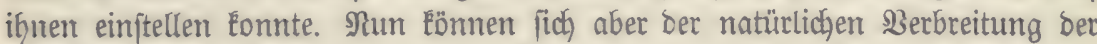

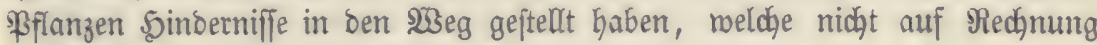
Det $\mathfrak{X}$ ärme gejeģt werben bürfen.

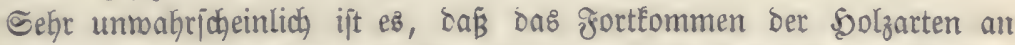

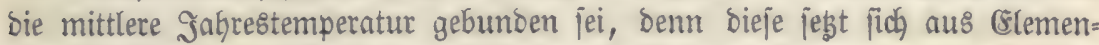
ten zujammen, weldje jegr abmeidjent auf bie Begetation einmirken. 3mei Drte von gleidher mittlerer Sabrestemperatur Ënnen höchit verichiedent ธom= mer, und $\mathfrak{B}$ intertemperatur befigen. Bergleidjen wir in biejer Beziefung 3. B. (Enontefis in Rapplano (Eei $68^{\circ} 40^{\prime}$ n. Br.) und ben St. Sottharo $\left(46^{n} 33^{\prime}\right.$ n. 98 r.). Eriteres hat eine mittlere Jahrestemperatur von $-2^{0}, 7$,

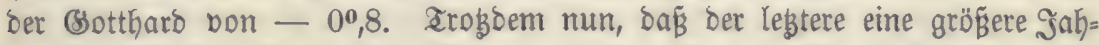
restwärme befigst, ift er jeber Baumbegetation baar, räfreno bei Enonteliz

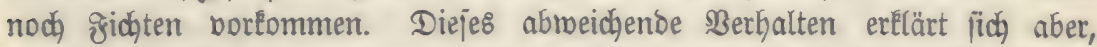
menn man bie Commertemperatur vergleicht, melche für (Enontȩ́is $12^{0}, 6$, für ben Bottharo nur 60,7 beträgt. Die gichte ift eine 50 lzart, melche bie

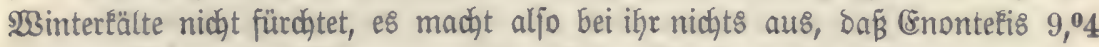

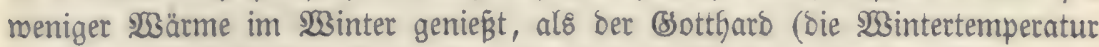
von Cnontefis beträgt - 170,0 , bte bes (Sottharo - 70,6). Edjon aus

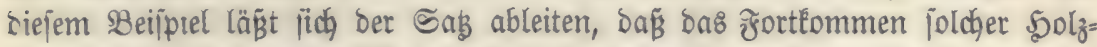

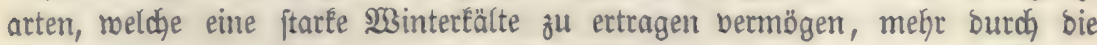

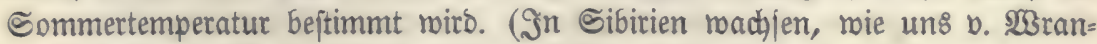
get beridjtet, WBeiden auf gefromem Boben, ber nur wägrend ber Sommer= monate ein paar 3oll hodh aufthaut). 2ndoere 5olzarten bagegen, wie z. $B$.

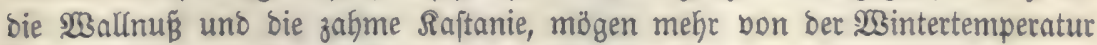
ober vielmeł̆ bon den Rälteerttemen abjängen.

Zut Bollenoung jeiner Segetationsphajen (BBlattausbrudh, Blüthe, 


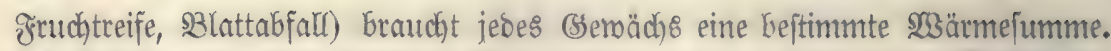
(ss ift baher eigentlid) nicht bie Commtertemperatur, jonbern bie s[3ärnte ber

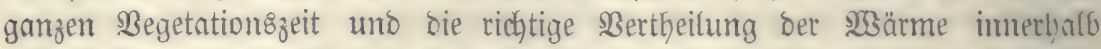

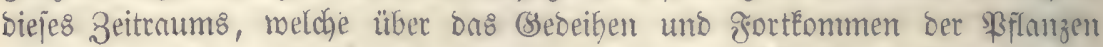
enticheibet. Die natürliche fortpflanzung Der (Semächje Gängt überbies von

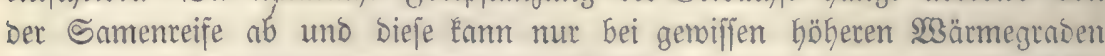

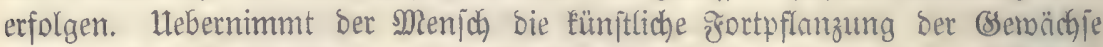
(indem er z. S. Die Samen aus füblicheren Slimaten bezieft, no biejelben

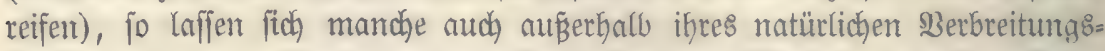

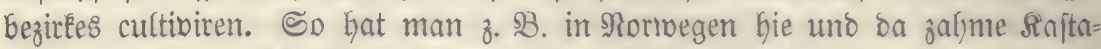
nien angebaut, weldye cin recht Eräftiges 233 ach)stbum zeigen, allein fic nuiffen auf kïnftlidyem $\mathfrak{B}_{e}$ ge fortgepflanzt werben, weil ifre Samen nidgt reifen.

(s:8 ijt johon bie Jrage aufgeworfen morben, ob eine \$ffanze an niebri= gere Rältegrade allmählig gemöhnt werden Eönne. Sach ben bisherizen

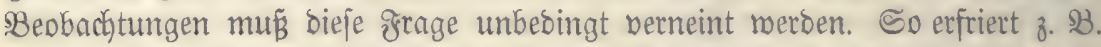
Oxymum basilicum, meldjes fofon feit 1548 in (sngland cultivirt birb, regel=

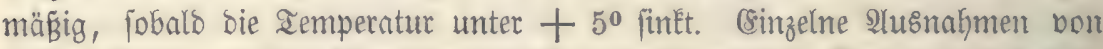
biejem sejebse, melche bismeilen geltend gentacht murben, find nur icheinbare.

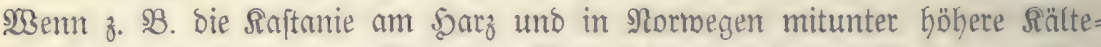

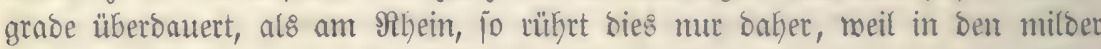

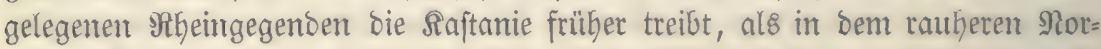
Den. 233ie wir fdhon an einem andern Drte gejehen haben, werben bie gröfte Den Bäumen vorzugstweife bann gefährlich, wern bieje bereits int ভnfte ftehen.

2uch) bie \$Bobennärme übt einen (sinflufis auf bie Berbreitung ber (Be= mächje aus. So Eommen z. B. auf ben heifen fumnrolen ber bulfonijchen Snlel Sichin zmei Sfffrnzen, Cyperus polystachius unઈ Pteris longifolia, bor, weldye man mur nody in Sicilien uno sffrifa fintet, uno in einen bon marmen Duellen gebildeten See Ungarns mächit die Sotoşhume, weldhe zur

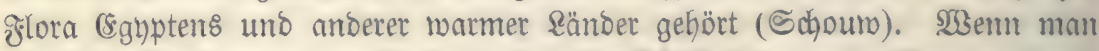

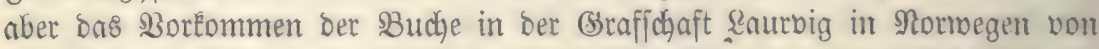

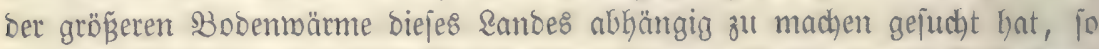

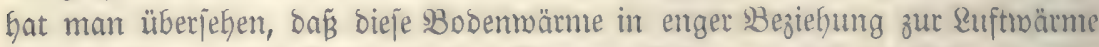

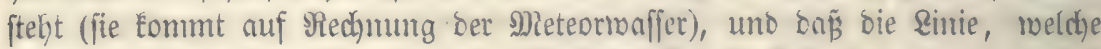
ben Serbreitungebezint Der Buthe in Rornegen uno Schneben begrengt, mit ber Siptherme bon \&aurvig zu[ammenfällt. (\$\& ift aljo gar nid)t nötbig, bie

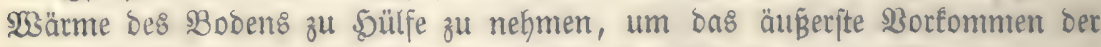
Buche in গtorwegen, gegenüber bemjenigen in Schneben, z̧u ertlären.

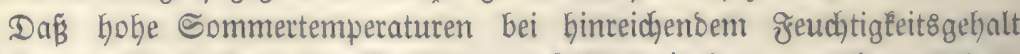

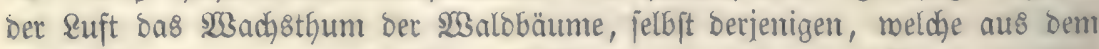
Sochgebirg ftamment, unterftüben, ijt fohon an einem andern Drte angegeben worben. 
Die vorftehenten Betradgtungen liefern folgente Mejultate.

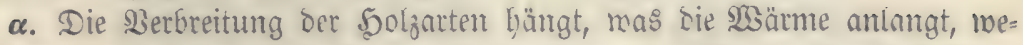
niger bon ser mittlum Sobrestemperatur, ats non Der Iemperatur Les હom= mers, ober bielmetro ber Slegetationszeit, ab.

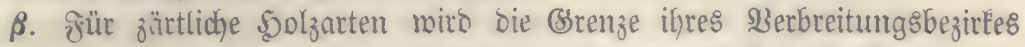
surdh bie niebrigite Iemperatur bes $\mathfrak{3 i n t e r s}$ ober Der ভaftzeit beftimmt.

$\gamma$. Die Cultur genifijer Solzarten Eam fich nod auf Begenten erftrecfen,

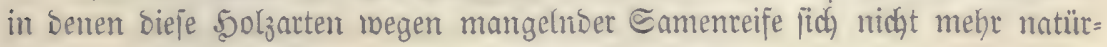
lid, fortpflanzen.

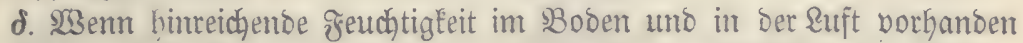
iit, jo Gindern Goke Eommertemperaturen ben Inbau norbija)er ober auछ bem \$od)gebirg ftammenter \$olzarten nicht.

\section{b. Ruftfeuditigleit.}

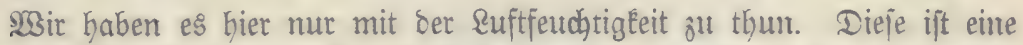

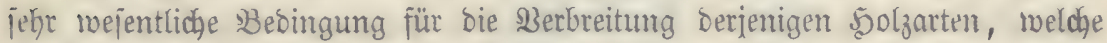

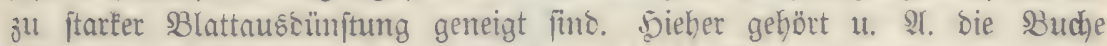
Wir jełen, baß biejelbe mefr bie $\mathfrak{B}$ orberge als bie (šbenen bemohnt, unt glau=

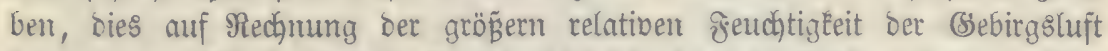

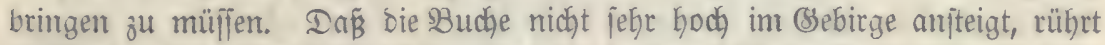

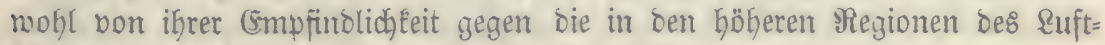
Ereijes Gerridhenden nieberen Iemperaturen her.

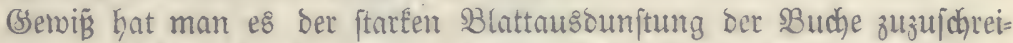

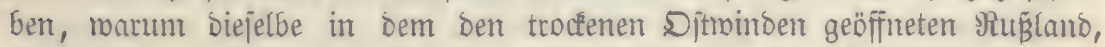
fowie in ben Sbenen von Epanien, tem jüblichen Frantreich uno bon Stalien nicht vorfommt. Shenigftens foheint sies baraus berborzugeben, weil fie

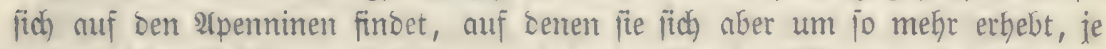

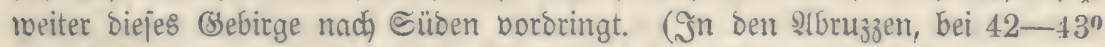
B Breite trifft man bie Buche in Beftänden bei 4000 , in Sicilien bei 6000

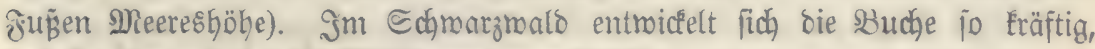
¿ñ fie hie und ba bie $23 e$ eiṕtanne unterorüctt.

Die feften 5lyorometeore wirken ber Berbreitutg mandher Soljarten entgegen. So geft 3. 3. Die Riefer in ben Ulpen nicht jo hod im sebirg

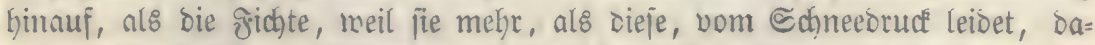
gegen erftredt fitch bie Sieferngrenge nörolich $\left(69^{\circ}\right)$ meiter, als bie Brenze ber

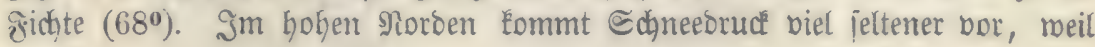
ber Edynee feinfloatiger fălut.

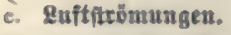

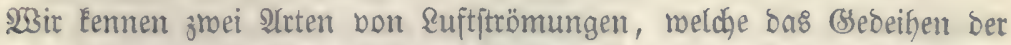
Solzarten bei ber vorzüglichften Bobengüte hinoern Ënnen; Dies fint bie Stürme

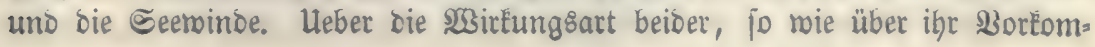


men auf beftimmten Rocalitäten, ift an bem gegörigen Drte bas Nöthige ge= fagt worben.

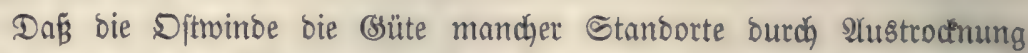

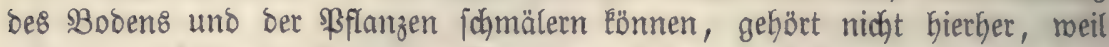
wir gegenmärtig nur biejenigen Meteore zu bebandeln haben, meldbe bei bem

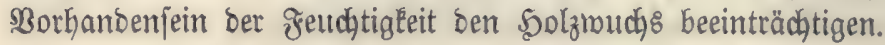

3 weiter มื

\section{Corbaltug und Mebrug ber foritliden Standortagite.}

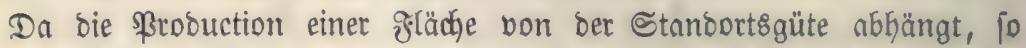
hat ber grorjtmann Alles, mas in jeinen Rräften fteht, aufzubieten, um biejelbe zu erbalten und zu bermebren. Der Ranbwirth wendet zu bem nämliçen 3mecke mehrere, zum aheil fehr Foftpielige, Dperationen an; er büngt feinen Ida'er und untermirft ifn jährlich einer tiefgehenden Soderung (Beackerung). Der Froritmann ift nicht im Stande, poldje theure Manipulationen in 2Tmendung

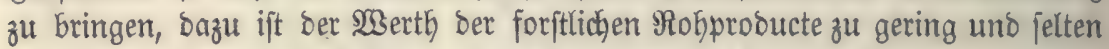

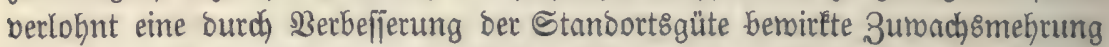
bie ftattgehabten Soften, menn dieje nicht jehr unbebeutend find. Sn ber Pfalz beträgt ber Belbrwerth bes Rokertrags bon 1 Sectare Tabal oft 400 -

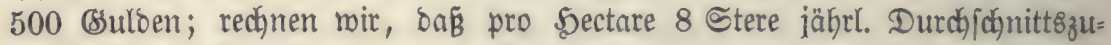
machs an $B$ udjentholz mit einem $23 e r t h e$ von 6 fl. pro Stere, aljo von 48 fl.

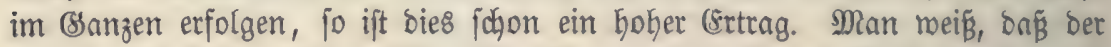

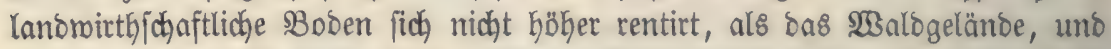
menn erfteres auth meift einen gröferen Sapitalmerth befist, als leşteres, io fieht man boch ein, bẩ nuf jene $400-500$ fl. fich biel mehr \$roductions=

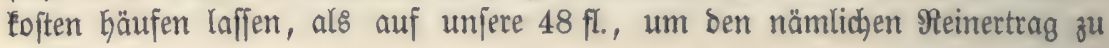
erzielen.

Die Maßregeln, melche ber Frorftmann zu ergreifen hat, um bie Büte bes 23 aldbobens zu erfalten und zu vermehren, beftehen meniger in bejonoe=

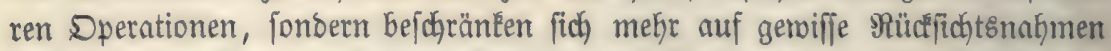

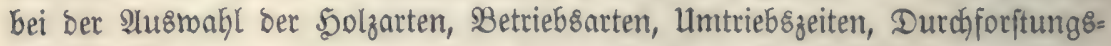

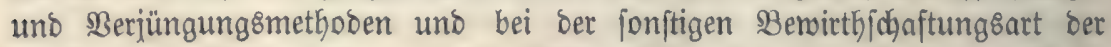

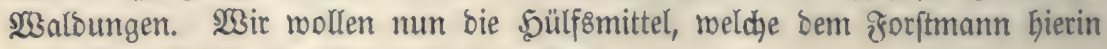
zu Bebote ftehen, im (sinzelnen betrachten.

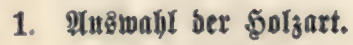

Mie oben gezeigt wurbe, wirkt ber sumus baburd) günitig auf ben Boten ein, neil er beffen Riefgrünbigkeit uno \&ocferkeit vermehrt und zugleich

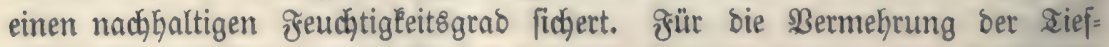

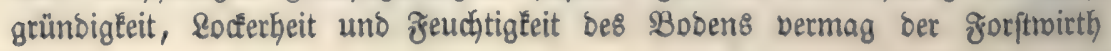




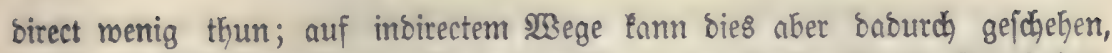

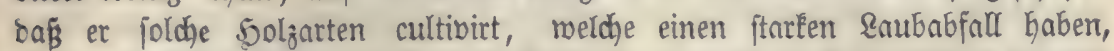
ober bie Sumuserzengung jonft begünjtigen, und beren Rronenichluß po biḑt

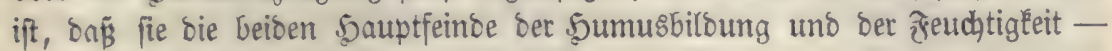
bie Sonne uno ben 2 Sino - abhalten.

Soldhe 50 olzarten fino borzugstweije biejenigen, melche Echatten ertra= gen, aljo bie হanne, Fidjte, Buche, Sdymargtiefer, Sainbuche, Sinbe,

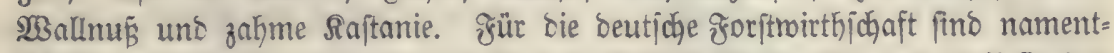

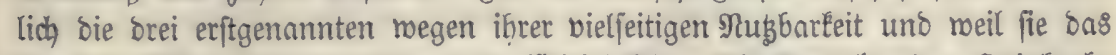

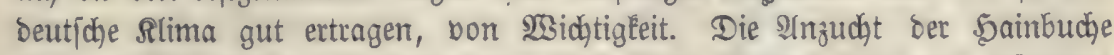

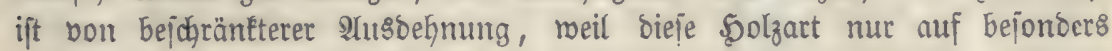
günftigen Gtanoorten gebeift.

Auch bie gemeine Riefer uno bie عärdbe tragen bis zu einem gemififen \&ebensalter hin zur Befferung bes Bobens bei, weil fie einen ziemlich ftarÊEn

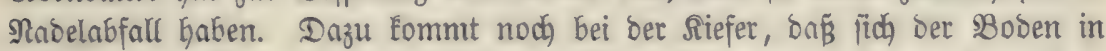

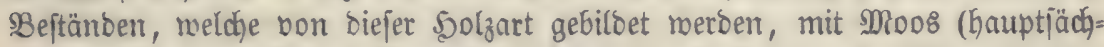
lich den Hypnum-I(tten) überzieft, welches die Stelle bes abgefallenen Raubes ber Raubraldoungen bertritt. Alllein bie Riefer uno bie \&ärche fangen ichon frühe an, fiod auszulichten, und es berfanmintet mit biejent 3eitpunft zugleids bas Moos in ben Riefernmaldungen; bieje beioen Solzarten fino aljo nicht geeignet, bie $\Re_{0}$ dengüte auf bie Dauer zu erbalten uno zu vermebren. Noch meniger fin bazu biejenigen $\mathfrak{B}$ aumarten befähigt, welche wir früber al\& lidyt=

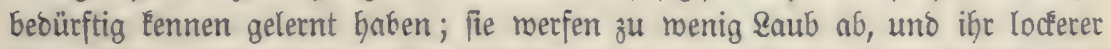

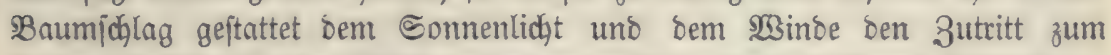

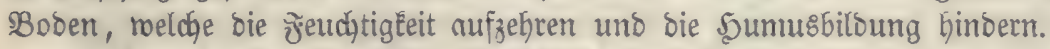

Theorie ber reinen $B$ eftänoe. Soll eine Solzart in reinem Beftande auf bie Dauer cultivirt merben, jo muß biejelbe einen bidgten $B$ anum= fajlag befigen. Die Buche, jichte uno Tanne Eann man Sabrtaujente lang auf einer uno berjelben fläche erziegen, bie Bobenfraft nimmt nicht ab, jon= bern fie bermebet fich mit jebem Jabre.

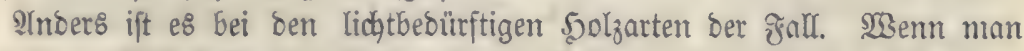

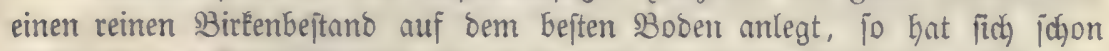

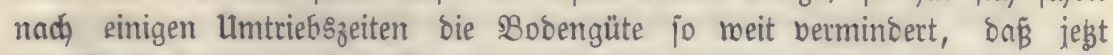

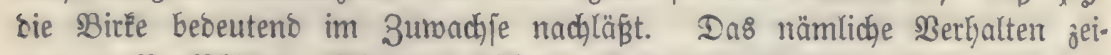

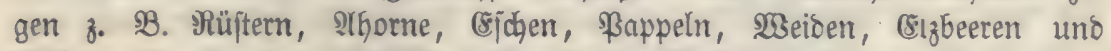

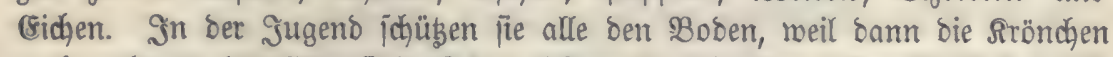
nod) nabe an ber (stoe finb; fpäter lidjten fie fich aber aus. Sie laffen fitc) baher nur ba mit Erfolg auf bie Dauer in reinen Inftänden etzieken, too bie Natur auf einem andern 23 ge für bie Sinftanobaltung ber BobenEraft

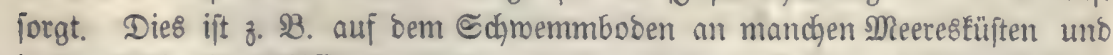

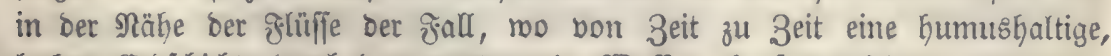

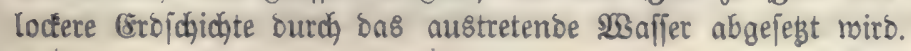


Die Sd)warzerle fommt p̈fters in reinen $\mathfrak{B} e$ ftänoen vor uno Eann audh, obgleidy fie eine lidgtbebürftige .5olzart ift, in foldyen gebulbet merben. Denn bie Socalitäten, auf meldhen bie Erte gebeift, Gaben von einer Bobenausma= gerung, Gervorgerufen burch Den lichten \$Baumichlag ber auf ifnen erzogenen Solzarten, nicht8 zu bejorgen. Die (Srle liebt, wie mir früher gejehen haben, naffe Stantorte; an folchen Stellen ift Der Berwejung bes abgefallenen \$aum=

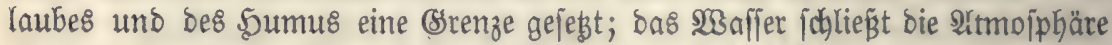
$a b$, und ber menige Sauerftoff, weldyer neben Sticfiftoff im $23 a f f e r$ gelöft ift,

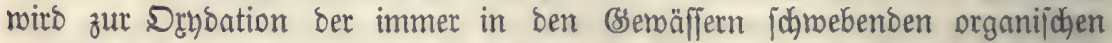

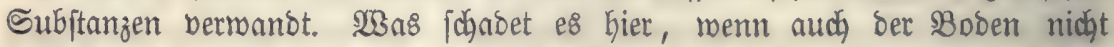

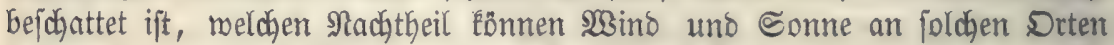
bringen? Feudhtigkeit ift im Uebermaßje borhanoen uno bas saub fann nicht entfübrt werben, benn es fintt jogleich im $23 a$ affer unter.

Theorie der gemifd ten Beftände. Diejenigen Solzarten, meldje zu reinen Beftänסen nidyt taugen, müffen in gemijoten Beftänoen erzogen werben. Die vorkerrichenbe 50 olzart in biejen muß eine bon ben jojattener=

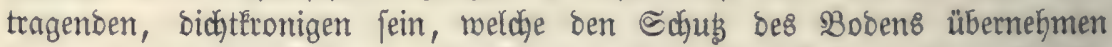
Eann. Die lichtbebürftigen, DünnEronigen Solzarten bürfen nur einzeln ein= gefprengt werben. (sine horftrweife Untermijo)ung empfiehlt fidh nicht, neil bei

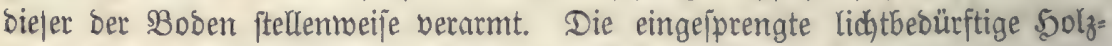

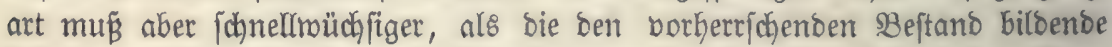
fdjattenertragende fein, bamit fie nidjt von biefer unterbrücft merbe. 3mei

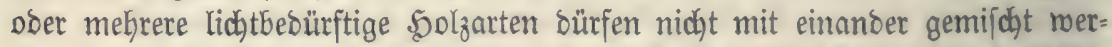
Den, benn erftens berarmt ber Boben in Beftänoen, weldye nur aus lichtbe= bürftigen 5olzarten beftehen, und żweitens müroe bie eine lichtbebürftige bon ber andern unterbrüat werben.

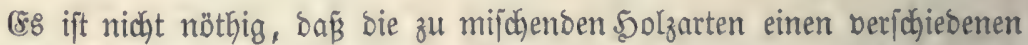

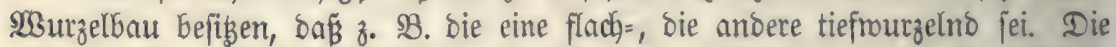

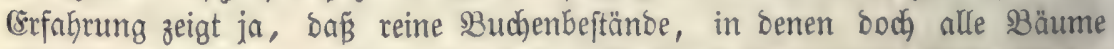

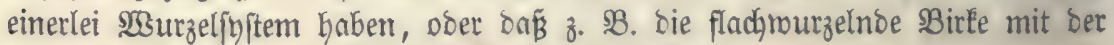
flachrourzelnoen Buche gemijedt, recht gut gebeihen.

Man hat bie Beobachtung gemadht, bǻ bic - lichtbebürftigen Solzarten

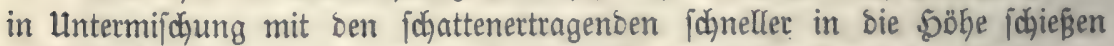

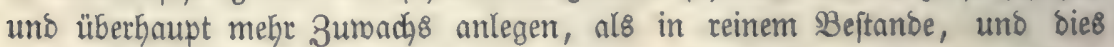

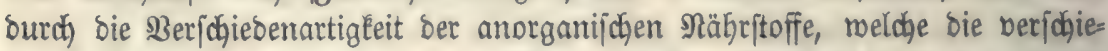

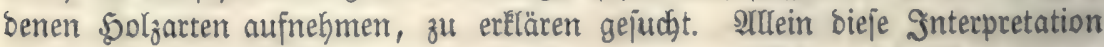

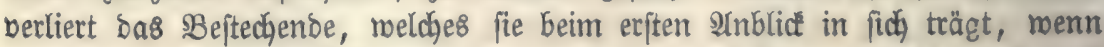

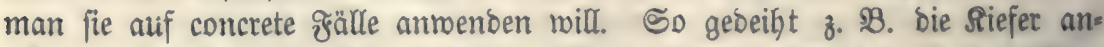

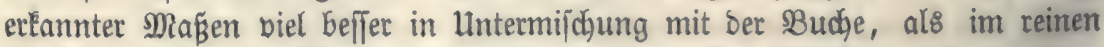

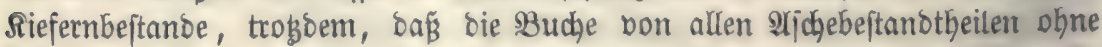

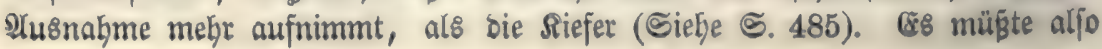


nach jener Theorie bas $23 a c h s t h u m$ ber Riefer burch bie Buche gehindort mer= ben, während bie Beobachtung bas regentheil nadymeift.

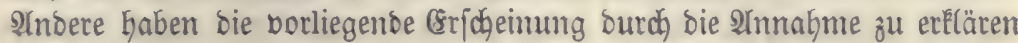

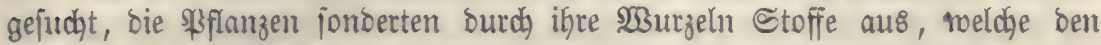

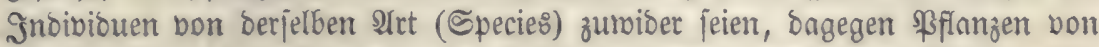

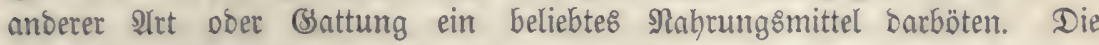
(Seroädje follten fich bierin ähnlich wie die Thiere verfyalten, bon benen man

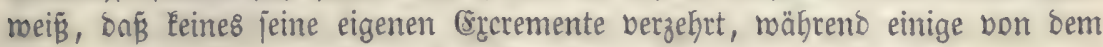
Sothe anderer Ifiere leben. Sndeffen hat man hier die Innalogie zu meit

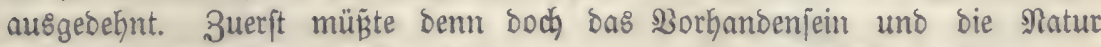

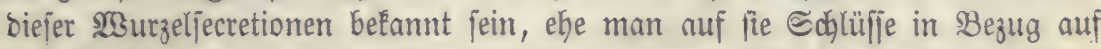

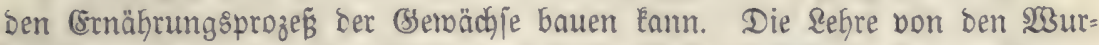
zeljecretionen ift bis jest nichts anderes, als eine Sypotheje, bie gar Keinen

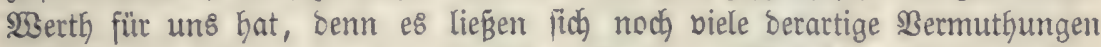

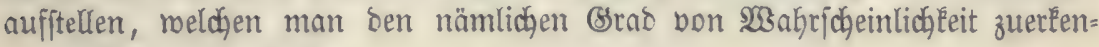
nen müste, wie jener.

Das beffere Bebeifen ber lichtbebürftigen \$olzarten zmijhen ben ichat= tenertragenten Eann man auf eine ungeznungene $13 a i j e$ aus Der Ratur biejer

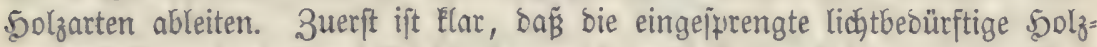

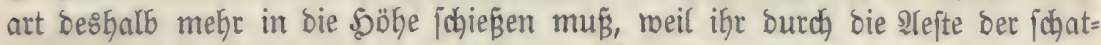
tenertragenden, welche jene umgeben, bas jeitwärts einfallente Richt entzogen

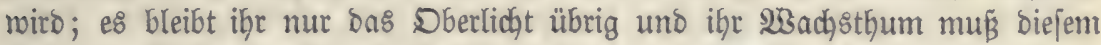

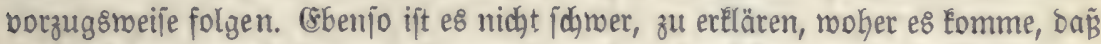

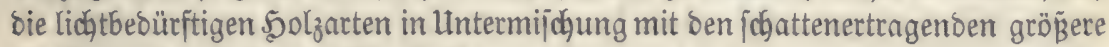

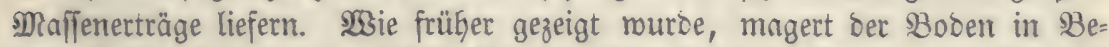
ftänoen, melche rein aus lichtbebürftigen (bünnfronigen) Baumarten bejtehen, aus; übernimmt aber eine johattenertragenbe (bidjteronige) Solzart ben Schus ber Bobenteraft, fo fann natürlid, bie lidttbebürftige in Untermijchung mit ifg beffer zumachjen. Wir jeben aljo, baf bie borliegende frage burch bas $\mathfrak{B e r}=$ halten ber \$olzarten gegen bas sicht vollemmen aufgehellt wirb, uno in ber

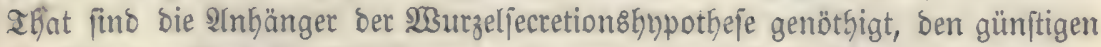

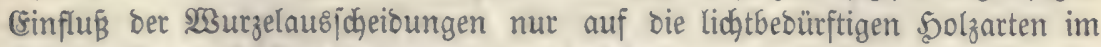

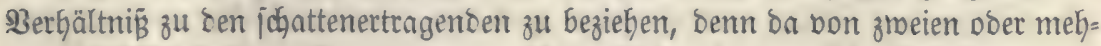
reren lichtbebürftigen 3 Bumarten, meldje mit einander gemijojt find, immer bie

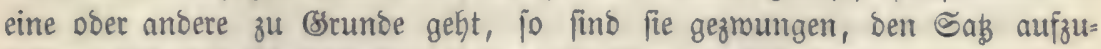

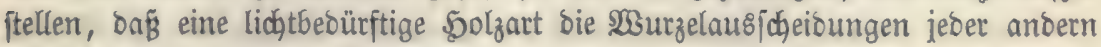
lidjtbeounrftigen \$olzatt niḑt extrage.

Эnoeffen zieben nidht blos bie lidhtbedürtigen Solzarten bon ben ichat=

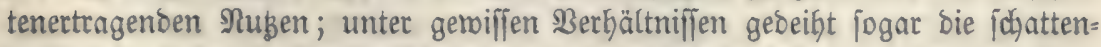
extragenbe beffer in Untermifchung mit einer lidłtbebürftigen, als im reinen

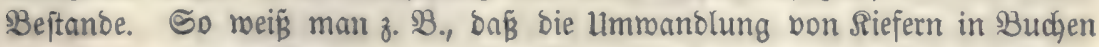

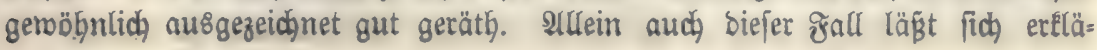




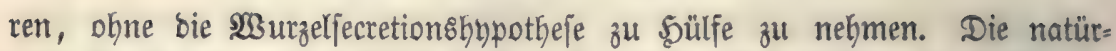

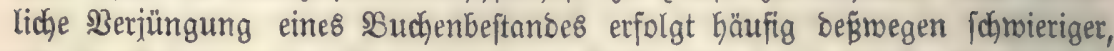
als bie (Erziełung ber \$uche unter ber Riefer, meil bie natürliche Berjüngung

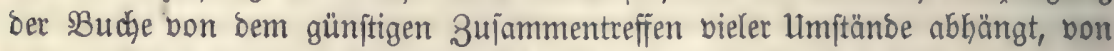
benen oft ber eine ober ber anbere fid) nidjt zur rechten Zeit einftellt. Sat man

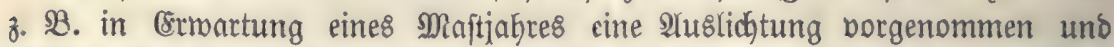
bleibt biefes längere 3eit aus, fo vermagert ber $\mathfrak{B}$ oben unঠ jpäterfhin fohlägt bie ßefamung nicht mehr an. WOollte man, wie bort bei Der Riefer, bie

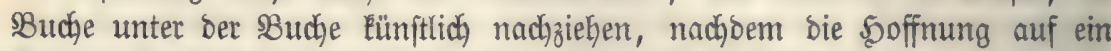

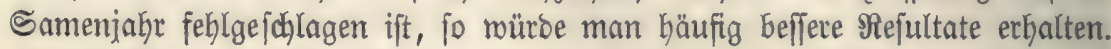

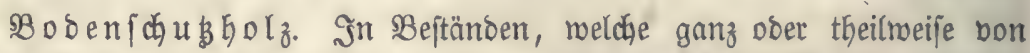
lichtbeoürftigen Solzarten gebilbet werben, überzieft fich ber $S_{0}$ oben, nament-

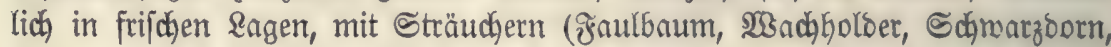
Simbeeren zc.) Dieje (semächje bienen zum Schuge bes ßBobens gegen Some und $\mathfrak{W}$ ind, fie müffen jorgfältig erbalten werben. Man fürobte nicht, es

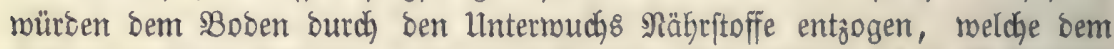

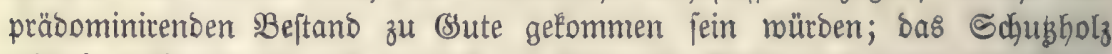
wiro ja nidyt genubst, es bermeft an Drt uno Stelle uno nübt bem Dber= $\mathfrak{h o l}_{z}$, indem e\& ben Boben mit Sumus bereidjert.

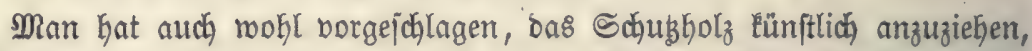
und bazu bie fojattenertragenden Baumarten (Ianne, Jichte, siuche, Sain=

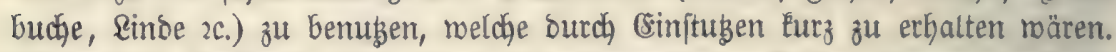
Illein bieje Maß̃regel wirb jelten bie aufgemenbeten Soften lohnen, reil bie

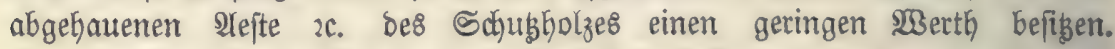

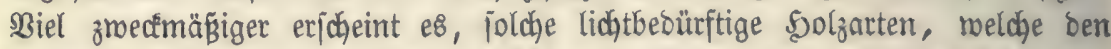
Boben auf bie Dauer nidjt zu johühen vermögen, idhon gleidh bei ber $\mathfrak{B} e$ ftandsbegrünonng mit fojattenertragenden zu mijchen, ober, roenn fie Geteits in reinen Beftänoen vorbanden find, fie in johattenertragende umzumandeln. NBgenn z. B. ein reiner Riefern= Doer (Eichenbeftand fich fo weit gelichtet hat,

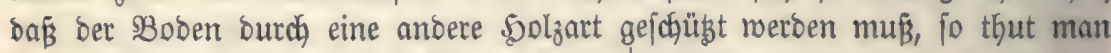
beffer, biefe gerabe in bie söbe madhjen zu laffen, anftatt fie eimzuftugen. Die Siefern Doer (siçen werben bann nach und nach berausgenommen, und

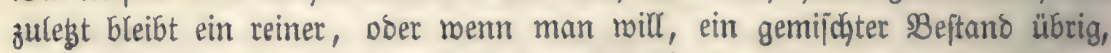
in welchem bie ntachgezogene \$olzart vorkerricht.

23 alsmäntel. 3um 2Ỷbhalten Des 23 inoes, weldyer bas abgefallene

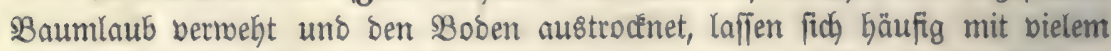

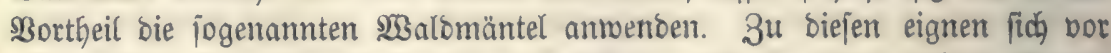
allen andern \$olzarten bie Tanne uno Fidhte, weil fie einen bidjten Baum. iळhlag befigen, uno bis zu höhern Rebentialtern auds noch am untern abeil bes Schaftes benftet bleiben. Zwei bis brei Baumreiben merben in ber

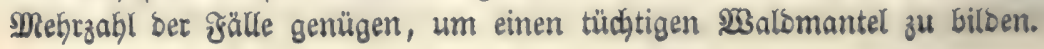




\section{Maß ber Seftantoesoidite.}

Wie mir oben gejehen Faben, fchügen bie idattenertragenoen 5olzarten ben sBoben auf bie Dauer besivegen am meiften, weil fie eine bichte Belau=

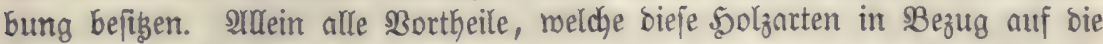
Ertbaltung ber Bobenteraft bieten, gehen verloren, menn man fie nidjt ge= idiloffen erziegt.

(5otta uno nad ifym nodh mefrere andere Edriftiteller wurben burdh

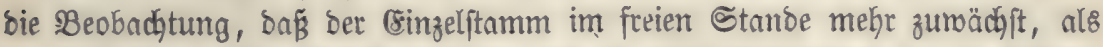

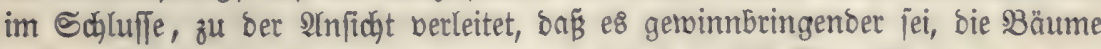
nicht, mie es 85. \&. Sartig angerathen hatte, in gejohloffenen Beftänoen, fon= bern fo räumlich zu erziehen, dás jeber Strmm bon allen Seiten her bas Sidht geniefien tỏnne.

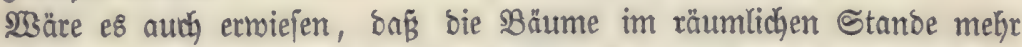

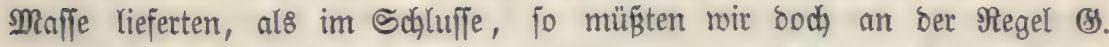
8. Sartig's fepthalten. Denn bie Erfahrung hat gezeigt, baßz ber Boben

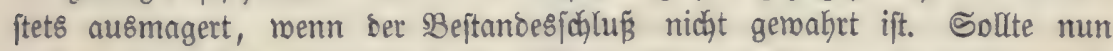

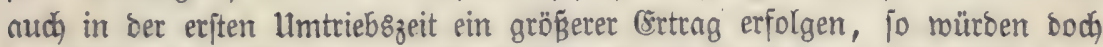
bie fpätern Utmtriebszeiten un jo neniger ergiebig ausfallen. (858 bleibt baher überall $\delta a$, mo, wie in Stantsmaloungen, bie Nahbaltigkeit als exfte $233 i r t h=$

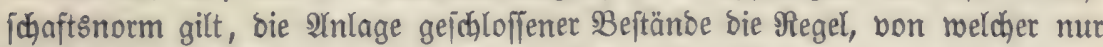

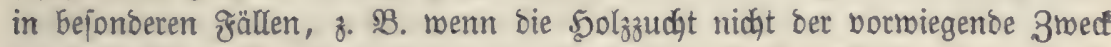

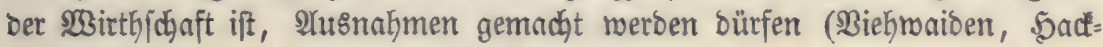
maloungen $2 c$.)

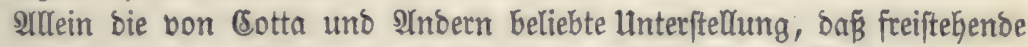

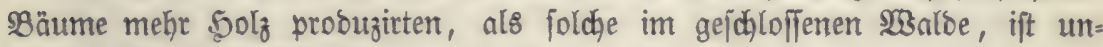

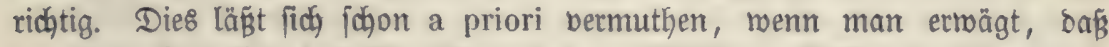

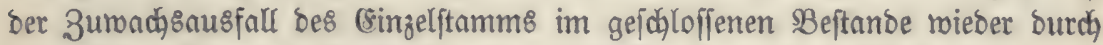
bie größ̈ere Stammzahl gebecft mirb. Indellen kann biefe Bermuthung nur bann practijaten Werth Gaben, menn fie burdh mireliche comparative linter=

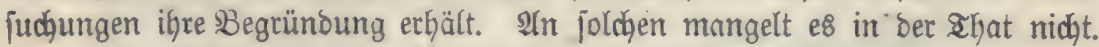

Bor aditunozmanzig Sahren legte Der $\mathfrak{B a t e r}$ be\& $\mathfrak{B e r f}$. Siefermpflanzungen in berjobiebenen Berbänben in ber शlbficht an, um zu ermitteln, bei weldher Bflanzmeite am meiften 5olzmafle erzeugt werbe. 3ur Berjuchsftelle nurbe eine Fläche bout mebr als 12 ఏectaren benubt. Sm Sagre 1851 unterjuthte

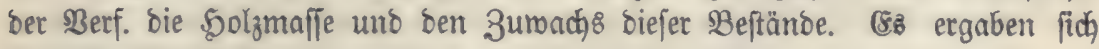
folgente $\Re$ ejultate:

Pflanzmeite

1,0 Meter

1,5 "

2,0 "

2,5 "

3,0 "
Durdjidnitt8zumadjs im 25ten Jahre

11,32 Rubifmeter Derbmaffe pro 5ectare

9,52

8,58

8,52

7,06

"
"

$\begin{array}{lll}" \prime & \text { " } & \text { " } \\ \text { " } & \text { " } & \text { " } \\ \text { " } & \text { " }\end{array}$


Man fiebt aljo, daß̉ ber Crtrag mit ber Pflanzmeite abnimmt. Der

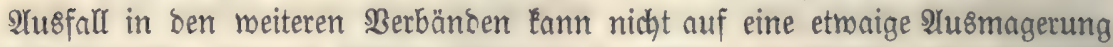
Des Bobens gejchoben merden, benn bie fr. Jläche mar Blöge, ehe fie culti=

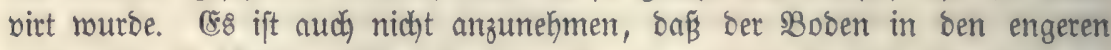
Berbänden jo fojnell gebeffert worben jei, um biejem llmftano ben böheren

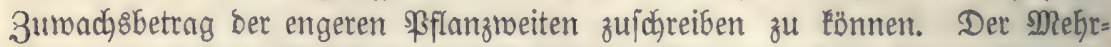

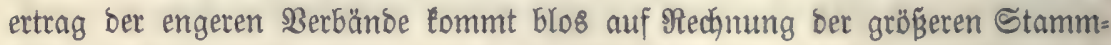
zabl.

Alls ber Berf. Den 3umadhs eines gleichaltrigen Saatbeftanoes neben

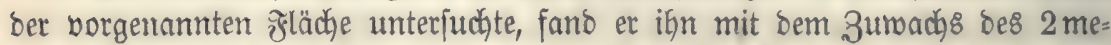

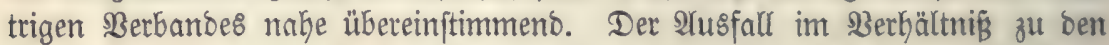
Berbänסen von 1,5 uno 1,0 Metern rührt ofnzmeifelhaft baher, weil Caat= beftänoe felten jo vollfommen find, als Pflanzbeftänoe; in ber That bielt es

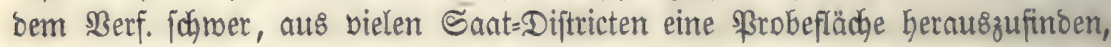
welche nicht ftellenweife mangelbaft beftocit gemejen wäre.

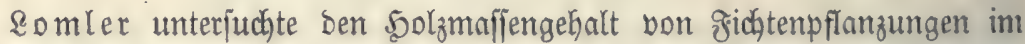

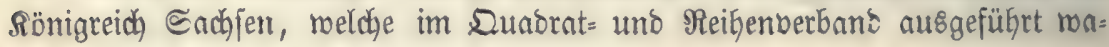
ren. (Er gelangte of folgenocn Rejultaten:

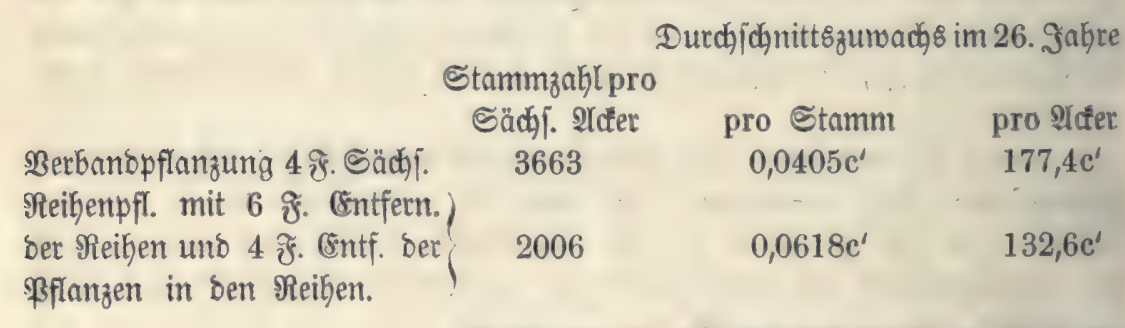

Berbanopflanzung 4. ঔ. ธäđł

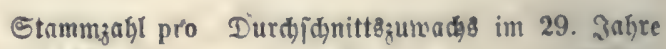
Săd)f. ICtet pro Stamm. pro Itefer

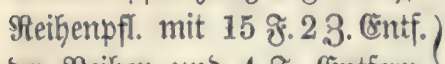

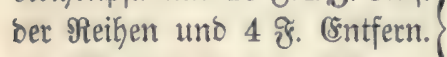
bet Pflanzen in ben Reiben

3854

1155 $0,0371 c^{\prime}$ $175,4 c^{\prime}$

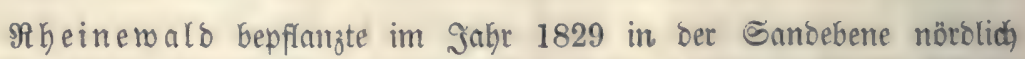
von Mannheim 12 hell. Morgen mit Siefern in 3-14 fußiger (\$eiा.) Sflang=

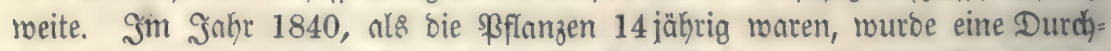
forftung borgenommen uno zugleidh ber Solzgehalt ber 12 9lbtheilungen be=

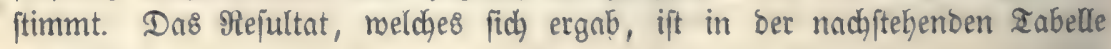
verzeidnet. 


\begin{tabular}{|c|c|c|c|c|c|c|c|c|}
\hline \multirow{3}{*}{ 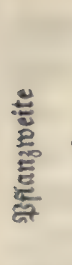 } & \multicolumn{3}{|c|}{ Stammabl } & $\begin{array}{l}\text { Dimen } \\
\text { Des Domin } \\
\text { Beftar }\end{array}$ & $\begin{array}{l}\text { fisnen } \\
\text { tirenben } \\
\text { ntegs }\end{array}$ & \multicolumn{3}{|c|}{ 5olzgefialt (Geñ. RFE.) } \\
\hline & 5auptbe= & $\begin{array}{l}\text { Durdiforitet } \\
\text { und }\end{array}$ & Sunme & $\begin{array}{l}\text { Durdinm. } \\
\text { in }\end{array}$ & Länge & Sauptoe: & Nukung im & Summe \\
\hline & ftanb & Togang & & $\begin{array}{c}\text { Brufthobe } \\
3 \text { oll }\end{array}$ & Fัญ์ & ftant & $\begin{array}{l}\text { Sabre } \\
1840\end{array}$ & \\
\hline $\begin{array}{c}\qquad \hat{\beta} \dot{\beta} . \\
\mathbf{3}\end{array}$ & & 622 & 3500 & 2 & 18 & 1141 & 380 & 1521 \\
\hline 4 & 2074 & 698 & 2772 & $2^{1} / 2$ & 18 & 933 & 346 & 1279 \\
\hline 5 & 1518 & 198 & 1716 & $21 / 2$ & 19 & 1129 & 336 & 1465 \\
\hline 6 & 1190 & 45 & 1235 & $2^{3} / 4$ & 19 & 997 & 356 & 1353 \\
\hline 7 & 836 & 99 & 935 & $2^{3} / 4$ & 18 & 690 & 296 & 986 \\
\hline 8 & 674 & 61 & 735 & $2^{3} / 4$ & 18 & 576 & 306 & 882 \\
\hline 9 & 532 & 20 & 552 & 3 & 18 & 627 & 290 & 917 \\
\hline 10 & 436 & 20 & 456 & 3 & 18 & 526 & 360 & 886 \\
\hline 11 & 378 & 7 & 385 & 3 & 16 & 418 & 380 & 798 \\
\hline 12 & 308 & 2 & 310 & 3 & 15 & 326 & 252 & 578 \\
\hline 13 & 244 & 17 & 261 & $31 / 4$ & 15 & 304 & 218 & 522 \\
\hline 14 & 240 & 3 & 243 & $31 / 2$ & 13 & 321 & 238 & 559 \\
\hline
\end{tabular}

Die menigen 2 nomalien, melche bie borjtehende Ertragsmeife zeigt, mö=

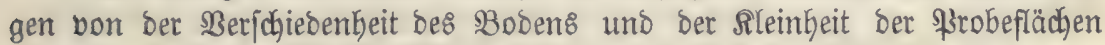

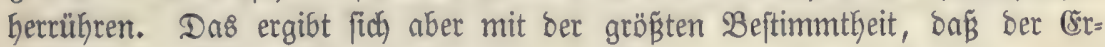
trag mit ber Pflanzroeite abnimmt.

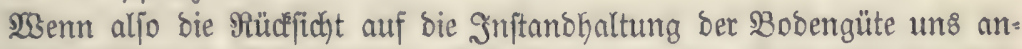
räth, bie Beftänoe in bollemmenem Sdyluffe zu erziehen, fo werben mir hier=

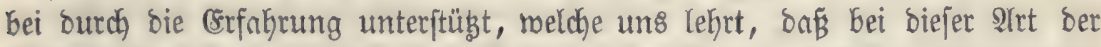
Beftandserziełung zugleid) Dem Boben bie Göchjten (Erträge abgemonnen merben.

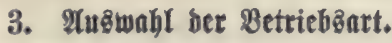

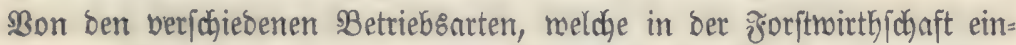
geführt find, üben nidht alle eirten gleid) günftigen (sinflußs auf bie (rrbaltung uno Megrung ber Stanoort8güte aus.

Diejenigen Betriebsarten, Bei weldyen ber Boben offter Blosgelegt miro, nie ber \$odjmald=Sinhlid)lagbetrieb, ber Nieber= und Mittelmaldbetrieb, erhal=

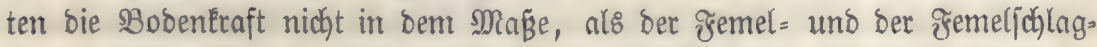
betrieb, bei melchen der Boden ftet8 burdh Şolzpflanzen gejđüßjt bleibt. Seber

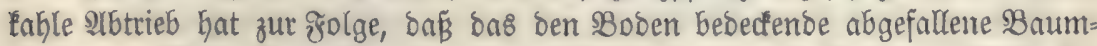

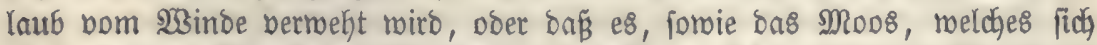

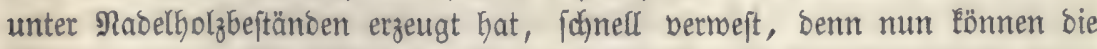
Meteornaffer, reldhe früher bon bem Rronenoache aufgefangen wurben, unge= Ginoert zum Boben gelangen. \&aub uno Moos tragen bann am meiften zur 
Snftandhaltung uno Bermehrung ber Diefgrünbigfeit bei, wenn fie noch nicht

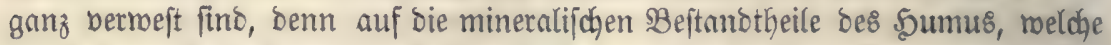

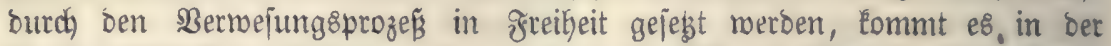

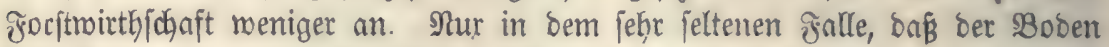

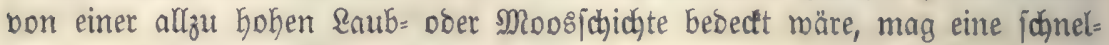
lere 3erjęung berjelben erwünjht fein.

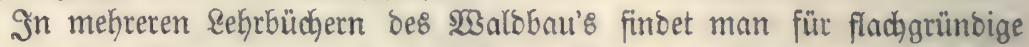

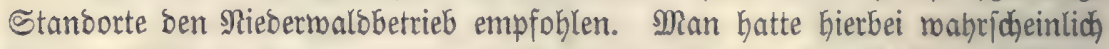
nur bie (Eiche im 2luge, welche allerbings gemöhnlid Kein Söhentoadhsthum

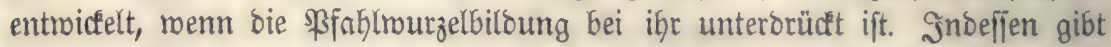

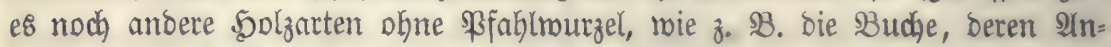

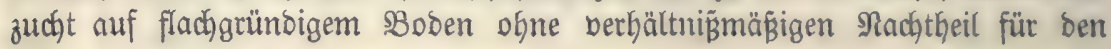
Söhemuchs gelingt.

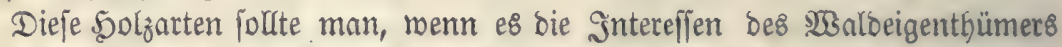

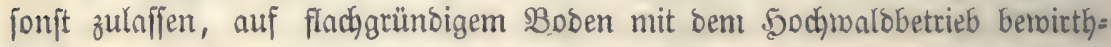
(c) aften, Denn leģterer ift weit mefr, als ber Niebermalobetrieb, geeignet, burch)

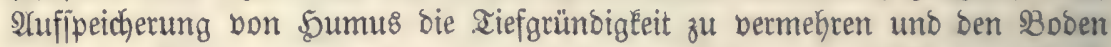

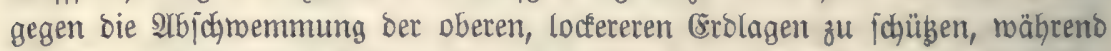
bie glad)grünoigkeit des sBobens, namentlid) in geneigten sagen, bei jebem 2Abtrieb Deb গiebermalbes burch bie nieberftürzenben Meteormajfer beförbert wirb.

Die gebräudylicyjte Solzart für ben Niebermalobetrieb ift belanntlich bie (siche, theils megen bes werthoollen Ertrags an sohrinbe, theils megen ifhes

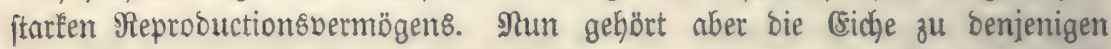

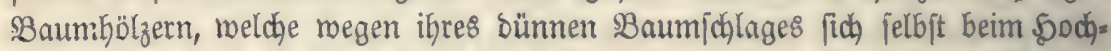

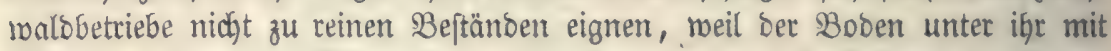
Der Zeit vermagert. SWie viel reniger kann baher bieje 5olzart im \$ieber= malbe die Bobentraft erhalten! Man follte baher ftet\& bafür forgen, baß́ in bie (Eid)ennieberwaldungen nod, andere, bobenbeffernoe 5olzarten eingepprengt

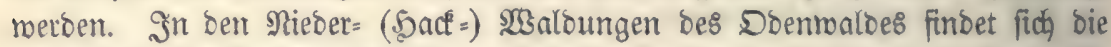
Sajel als natürliche (Bejelljofafterin ber (sidje. (\&\& bürfte fich empfeblen, bie

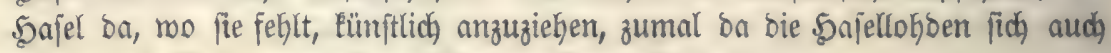

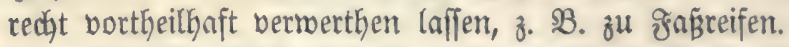

Der F̌emelichlagbetrieb (mit natürlidłer BZerjüngung ber übergehaltenen Mutterbäume) zeidhnet fïch nber nur bann burch feine J̈ähigkeit, bie Boben= fraft zu erfalten, vor bem Niebermald =, Mittelwald = unt Siablichlagbetriebe

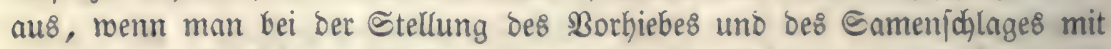

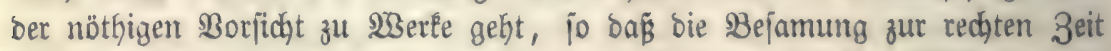
uno in geförigem Maß̉e erfolgt, uno wenn überhaupt bie Dertlichleit ber na=

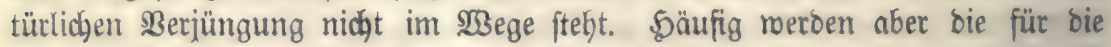
Bejamung vorbereiteten ๔๙) täten, benen man e\& gleid bon born herein mit Beftimmtheit bätte anjeben 


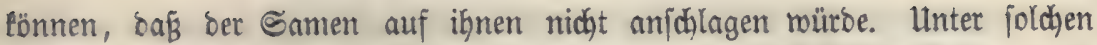
llmftänden leiftet ber Sablidslagbetrieb mit jofortiger künftlicher (Eultur mehr fïr bie (Erbaltung ber Bobentraft, als ber Fremelid)lagbetrieb.

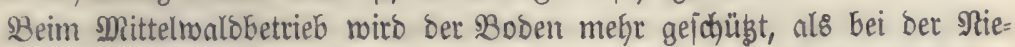
bermalomirthichaft; inseffen find bie $\Re$ ortheile, melche man in jener Simficht von Len Dberifänbern in ben Mittelmaloungen zu ermarten Gat, Gäufig über=

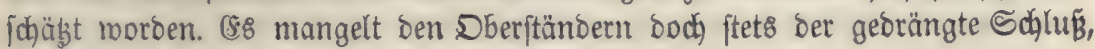
in meld)em bie ßBäume eines \$odhroaldes fid befinden.

\section{Ilntriebฮิzeit.}

Surze Umtriebzzzeiten baben Den Nachtheil, baß̈ bei ifnen ber Boben zu oft blosgelegt wirb; bagegen magert aud bei hohen Umtriebszeiten ber 30 bent leicht aus, meil alle Solzarten in Göberem allter fich lidyt zu ftellen pflegen. IIm früheften erfolgt bie natürliche $\mathfrak{A} u \&$ lichtung bei ben lichtbebürftigen $\mathfrak{S O l}_{\mathbf{z}}=$ arten. Dȩ̧́alb follte man bieje \$olzarten bann, wenn man eine Doer bie anoere von ihnen, wie z. 8 . Die Siefer, in teinen \$Beftänben erziegt, mit nie= Derem Untrieb bemirthjonften, ober, was für bie srhaltung ber Bodenfraft nod) vorzüg(idjer uno aud öfters zugleich lucrativer ift, bald eine bobenbei= jernde johattenertragende Solzart (Buche, Tanne, Fichte) einjprengen. Die Erziebung von fehr ftarEem (sichentbaufolz läpt fich, obne Befäbroung ber Bobentraft, nur in ber borgebachten 2 Seife erreichen.

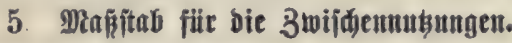

Unter ben 3mijchennugungen verifteht man alle Gälungen, weldje ben eigentlichen Şaubarkeit\&hieben vorangeben, unter ben Durdyforftungen inßbe= jonbere begreift man die Serausinahme des bürren und unterbrücten Solzes.

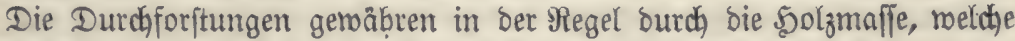

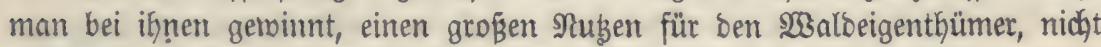
minber beadhtenstwerth ift ber Sortheil, welchen Der $\mathscr{2}$ uşieb bes bürren umb

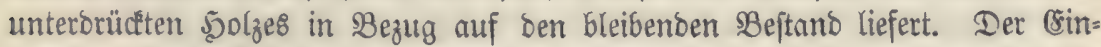
zeljtamm in biejem erjtarkt rajcher, weil ifm mun mebr sidht zufommt; in zolge beffen wiberfteht er zugleid) ben (sefahren bes 23 inowurfs, Sdynee= bructio ac. Keidhter.

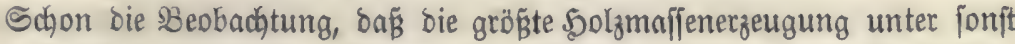
gleiçen Umftänoen bon ber Stammzahl abhängt, leitet auf bie Regel hin,

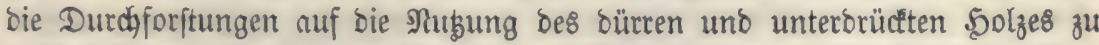

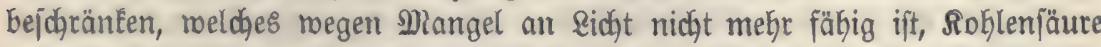

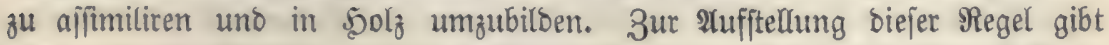
aber auch bie SRüceficht auf Die Inftanohaltung ber Bobenteraft Beranlaffung. Ueberall ba, no ber \$eftanoesjoblü unterbrochen ift, wirfen bie Sonne uno

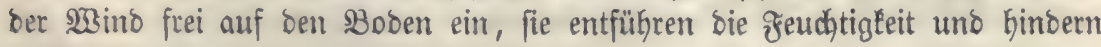

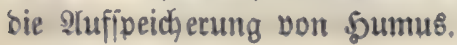


216meidfento von biejer Regel, welche zuerft mit voller Bejtimmtheit uno Slarbeit bon Eeorg \&uowig Sartig ausgefprodgen morben ift, ertheilte Sein= riḑ) Eotta bie Borjdarift, zu ben Durdhforftungen aud̆ biejenigen Stämme beizuzieben, von benen, roenn fie audh nodh nicht böllig unterbrücft feien, bodh

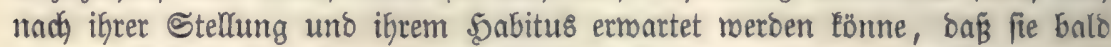
eingehen müroen. Solche "beherrfdhte" Stämme jollten alfo zugleich) mit ben bürren uno unterbrüctten entfernt reerben.

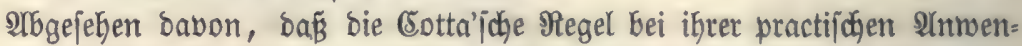

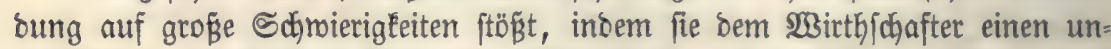

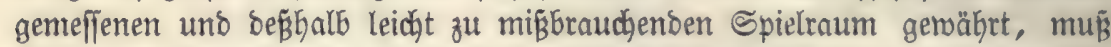
fie aber aud wegen ber Nachtheile, welche ifre Befolgung in Bezug auf bie Bobenfraft Gerbeifüfren würbe, berworfen merben. Denn ausgenommen ben

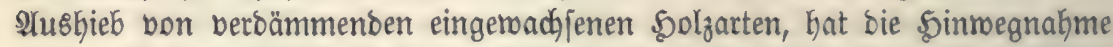
bon noch) nidht unterbrüdten Stämmen ftets eine Unterbrechung bes sitonen= ґூ)

\section{Ratiirlidie uto timfltidie Berjïngutg.}

$23 i e$ unter 3. angegeben, erbält fich bie Bobentraft bei natürlidger $\mathfrak{B e r}=$

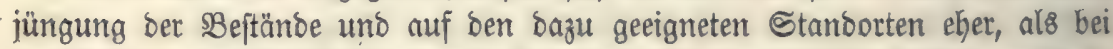
ber Ânlage von Sablfchlägen uno ber burch fie gemöbnlid) bebingten fünft=

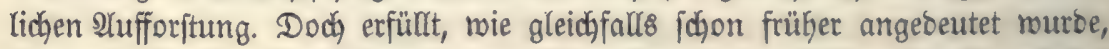
bie natürliche Berjüngung nur bann igren 3 weck, wenn fie redhtzeitig erfolgt. Bleiben bie ausgeliçteten Beftänbe längere Zeit liegen, ohne baß ein Samen=

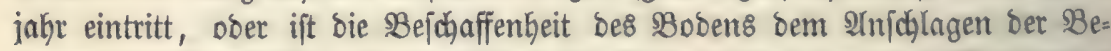
famung nidjt günftig, fo vermagert ber Boben unter bem unvollfonmenen Sdjube ber Dberitänber meit mehr, als beim Sabljhlagbetriebe uno fogleid nachfolgenoet fünftlicher cultur.

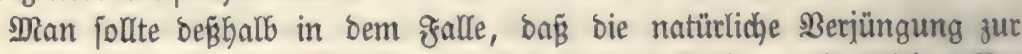

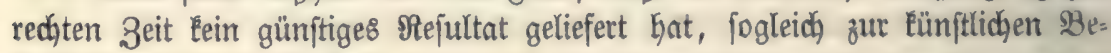
ftandsbegrünoung id̆reiten.

$\mathfrak{A}$ m menigiten eignen fich zur natürliçen Berjüngung burd) Samen bie lichtbebürftigen $\mathfrak{D}_{0}$ lzarten, und in ben bon ignen gebildeten Samen= uno $2 b_{3}$

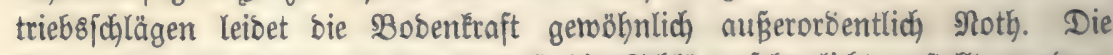

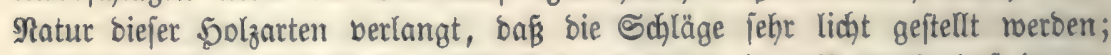

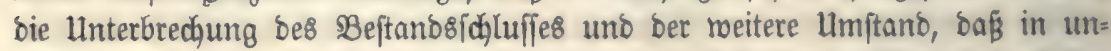

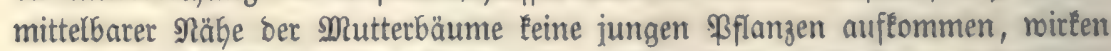

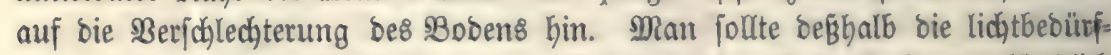

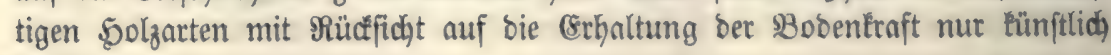
periüungen.

\section{20edjiel ber \$olzarten.}

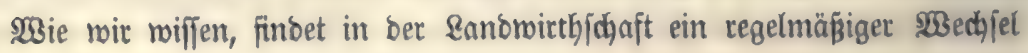


mit ben anzubauenben $\Re$ flanzen ftatt. Die Erfahrung hat gelehrt, bafí bie

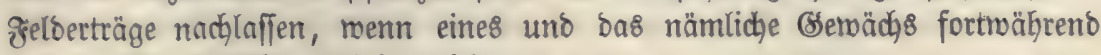
auf berfelben fläđhe cultivirt roiro.

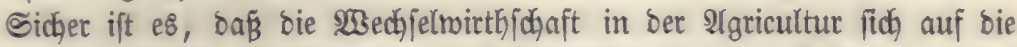

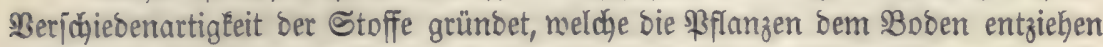
- einerlei, ob man unter biejen Stoffen bie Mineralbeftandtheile ober ben Sticfitoff berftehe - benn burch 2Inmentung von Dünger Eann man ben

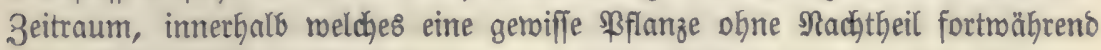
(i⿱亠凶禸) anbauen läß̄̈t, verlängetn.

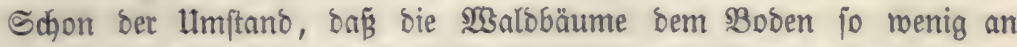

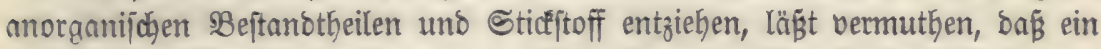

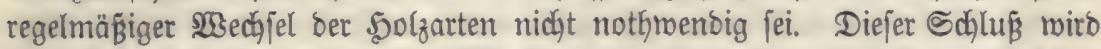

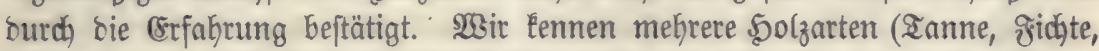
Buche ic.), melche jeit unborbenellichen Zeiten gemifife Stanborte ofne ltnter=

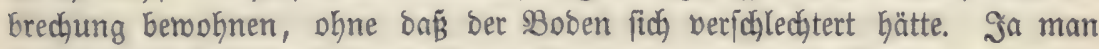

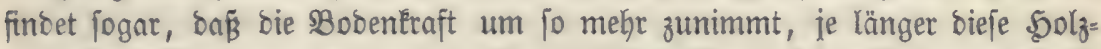

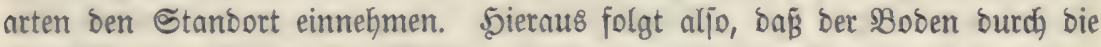

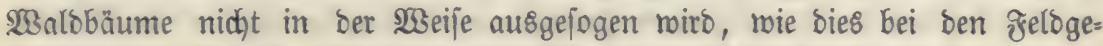

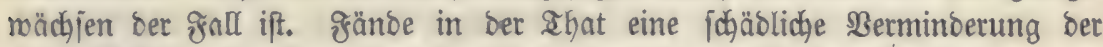

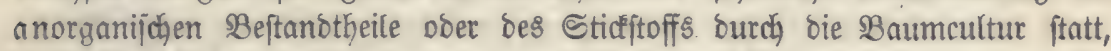
fo müßte fich jene auf einen geringeren Betrag zurüaffübren laffen, wenn man bie Bäume nidht, mie es bis jeşt üblidy ift, geidloffen, fonoern räumlich er-

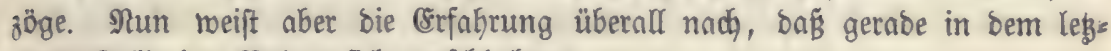
teren Falle ber Boben fich beridjlechtert.

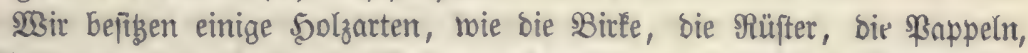
bie Nhorne 2c., unter benen ber Boben ausmagert, wenn man fie längere 3eit

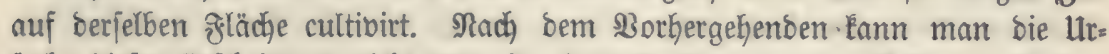

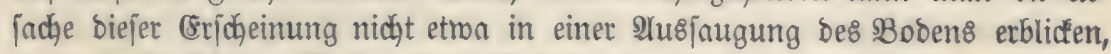

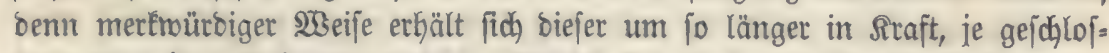
fener man jene \$olzarten erzieht. Uebereinjtimmeno mit ben \$Beobaditungen, melche man Ginfichtlich ber Berjchlechterung bes Bobens bei ben bichtfronigen Baumarten, wenn bieje räumlidh aufroadjen, gemadjt hat, muв man anneh̆= men, baß̧ bie oben genannten 50 lzarten blos megen ifres bünnen Baum= (đ)lags bie Bodenfraft nidjt zu iđüben uno zu mehren vermögen. Sie rer=

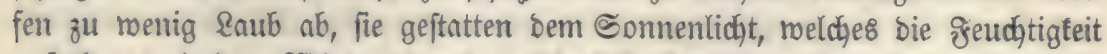

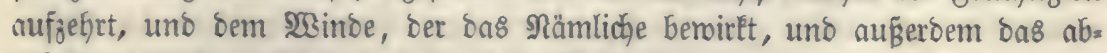
gefallene \&nub entfüfrt, Zutritt in bie $\$ 3$ eftänoe.

Sit bie Sobengüte burdh ben reinen 2 nbau einer biefer \$olzarten, wel= d)e man ftets wur in gemijojten Beftänoen ergieben folte, bermindert roorden,

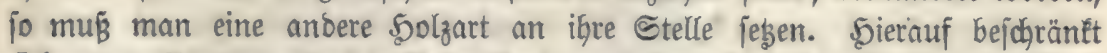

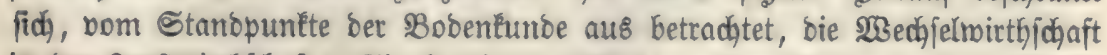

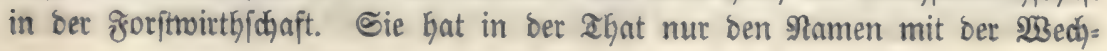




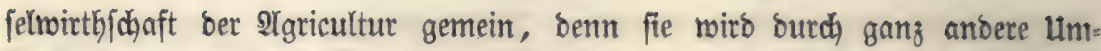
ftänbe Gerborgerufen. Wenn man fich bei ber 21usmahl ber 5olzarten ftet8

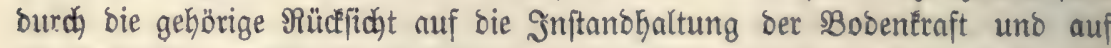
bie Anfprüche, weldye bie Solzarten an ben Boben madhen, leiten ließ̧e, uno wenn alle Srrungen in legsterer Şinficht unbermeiblich wären, fo mürbe ein

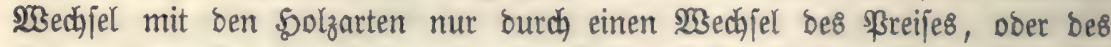

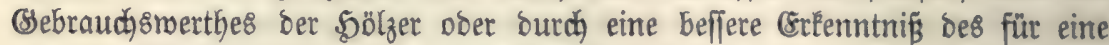
\$olzart fich eignenten Stambortes bebingt werben Eömnen.

Sat fid) einmal bie Umwandlung einer Solzart in eine andere als noth) menoig herausgeftellt, fo kann man fobon burch bas zur ummandlung einzu= baltende Berfabren fehr mejentlich auf bie Berbefferung ber Bobenfraft ein= wirken. Soll eine bichtéronige Solzart, z. 2B. weil ibr ber Stanoort nidht angemefien ift, burch eine bobenbeffernoe lichtbedürftige erfebt noerben, fo mufis man jene erft rein abtreiben, ehe man mit ber (5ultur beginnt. Denn mollte

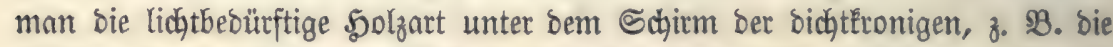
Siefer unter ber siuche, cultibiren, jo rürbe jene nidjt anjchlagen, aljo ber Boben noch längere Zeit unbejdÿ̈gt bleiben. Riegt bagegen bie Alufgabe bor, an bie Stelle einet bünmEronigen \$olzart eine johattenertrngende zu bringen, fo mird man jene borerft, jo meit es überfhaupt thunlid, ift, überhalten uno unter ifrem Schuge bie fohattenertragenoe anbauen. Artsbann trägt bie zu verbrängente Solzart neben bem neuen Annudhje immer nod) zur Deçung

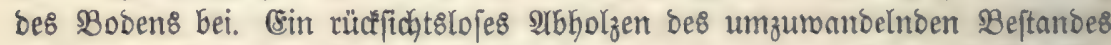
mürbe einestheils bie Bobenfraft idjwächen, zum andern aber auch bie श्थn= zudjt ber johattenbedürftigen $50 l$ zart erjoberen.

Sn ber Natur laffen fich bälfig Ummanolungen von eimer Solzart in eine andere beobachten, weldye ohne unmittelbares (sinjidyreiten bes Menjhen

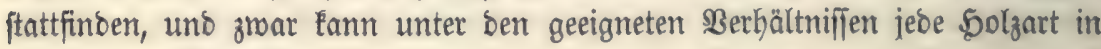
jebe antere übergehen.

IIm bäufigiten wiro bie natürliçe Umwandlung ber Solzarten burch

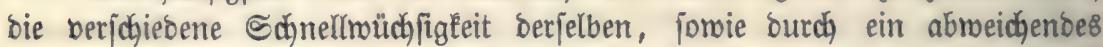
Berbalten gegen sidjt uno Schatten bebingt. Bon biejem (Sejicht8puntte aus=

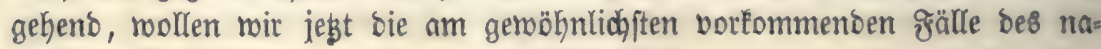
türliçen $\mathfrak{W}$ edjielz unjerer Baumarten betrachten.

Sommen zroei ober mehrere fojattenertragente Solzarten neben einander auf

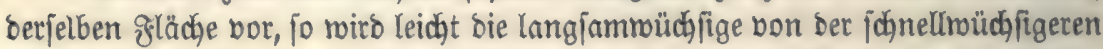

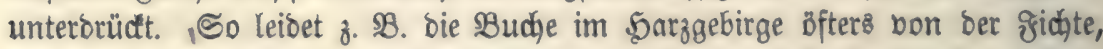
namentlich auf einem burdy Streurectyen entÉtäfteten Boben, Noth, weil bort

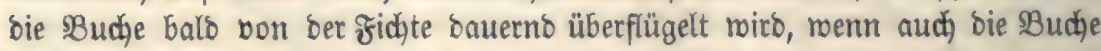
in früber Jugent einen ßorpprung bor ber Fidjte befitgt. In einigen \&agen

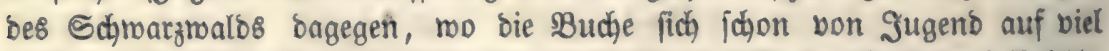

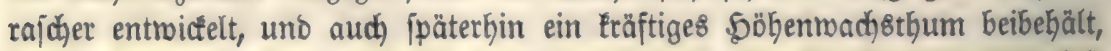

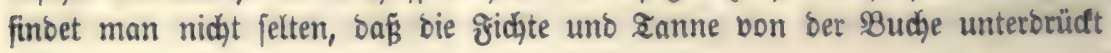




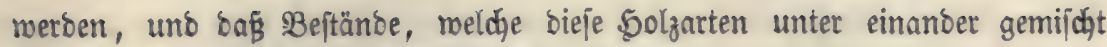
enthalten, in reine Buchenbeftänbe übergehen.

Schattenertragente 50 lzarten mandeln fich in lichtbebürftige in znei

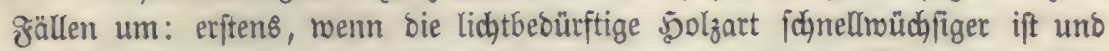
fich in einen aus jकattenertragenoen Solzarten gebildeten Beftano reichlida einbrängt; zmeitens, wenn ber Boben burch Bichtftellung, Streuentzug ober anoere Itrjachen jo entleäftet moroen ift, bas fich bie ungenüg/ame ichat= tenertragende 5olzart auf ihm nidht mehr zu halten vermag. Schlägt hiet

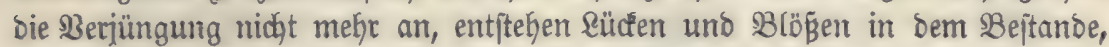
io fann fich auf biejem eine lidhtbebürftige \$olzart, melche meniger 2 njprüche

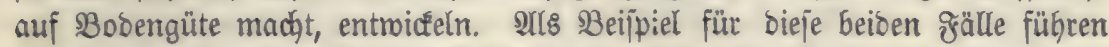
mir bas oft zu beobachtente Berbrängen ber Budje burdh bie jogenannten Weidjhölzet an.

Sind zmei lidhtbebüritige $50 l$ zarten mit einanber gemijdht, fo geht, menn ber sBoben nicht aujerorbentlich fräjtig ift, jtets bie langjammüchjigete ein.

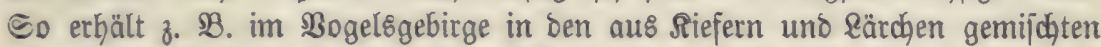
Beftänben zuleğt bie \&ärche bie Dberhano, rährend ber Berf. auch ben um= geteftrten gall auf bem trocknen Sanbboben einiger Begenben bon Norb= beutichlano, no bie Riefer p̈fter ichnellmüchjiger ift, als bie Rärche, zu beobach)= ten Gelegenbeit batte.

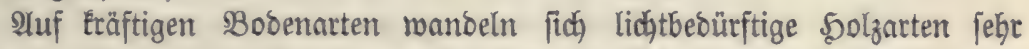
häufig in idattenertragende um. Dieje brängen fidh in jene ein, uno rad)= jen mit ifnen in bie Söhe; fommt nun bie 3eit ber natürliç) Berjüngung,

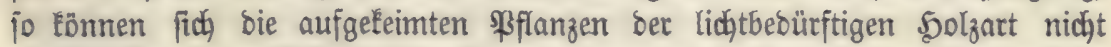

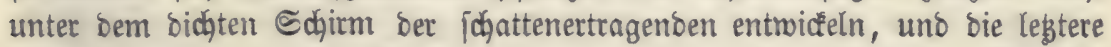
bildet jodann ben borberrijhenden ober gar einen reinen Beftand. Arls Bei= jpiel für bieje 2ltt ber llmmandlung nennen mir bas Berbrängen ber Siefer

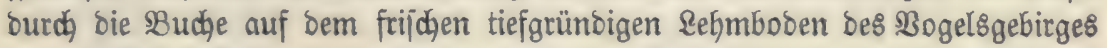
uno 2 sejterwaloes.

In allen biejen gällen exfolgt, was mir mohl zu beadten bitten, ber 23edjfel ber 5olzarten niemals baburch, baß̈ etran eine berjelben ben Boben

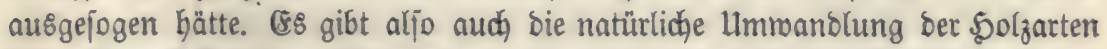
feine Beranlaffung zur Şegrünoung eines regelmä s̃igen wechjels mit ben 5olzarten; biejer bleibt, mie wir oben ausigeführt Gaben, ftet\& nur auf einige

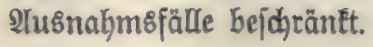

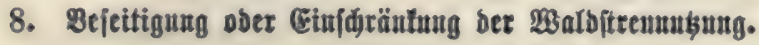

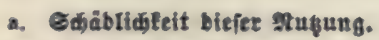

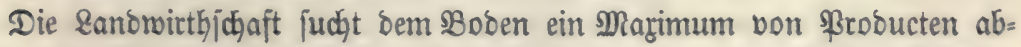
zugeminnen; fie entziebt bemjelben eine Summe bon anorganijoben Subjtan=

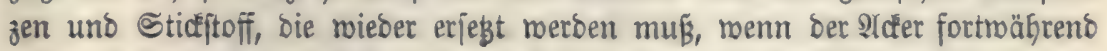
reidge Grnoten liefern joll. Nur auf jebr menigen Rocalitäten bermag ber 
Boben biejen Erraja felbjt zu leiften; im andern Falle wirb er burch bie fünftliche Düngung bewerffelltigt. Die Bobenbearbeitung Eann blos bie int

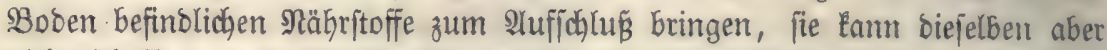
nicht (chaffen, uno bie Bracke, weldye bie Meögliç)eit gibt, bon 3eit zu

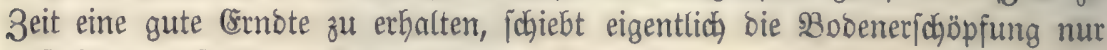
nuf einen entfernteren Beitpunct binaus.

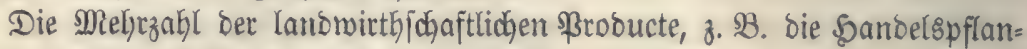

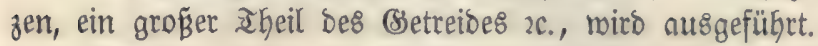

Ulm bem frelbe bie Stoffe, weldje es hierdurch berloren hat, mieber zu erjeben, bebarf beşhalb jebes Sut, bas fich in Stand erhalten will, eine ge=

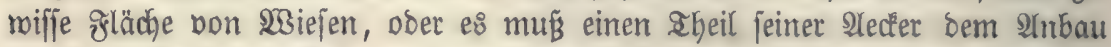

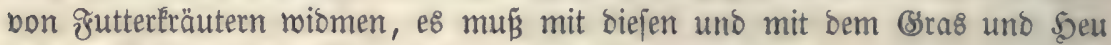

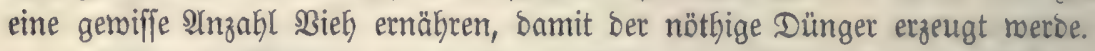

Fehlen bie $\mathfrak{B i e j e n , ~ m i e ~ z . ~ B . ~ i n ~ B r e b i r g a g e g e n t e n ~ m i t ~ e n g e n ~ I h a ̈ l e m , ~}$

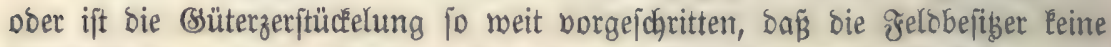

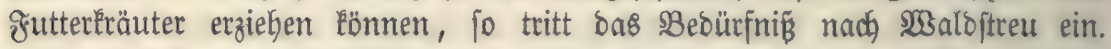
Diefe wirb Dann namentlidh bon Den Rleinbauern berlangt, welohe genötfigt find, ify Stroh zum Iheil Doer ganz zu verkaufen, um fich baare Mittel zu berichaffen.

Die Streuanforberungen werben, wie fich von jelbft verfteht, am grös̆ten

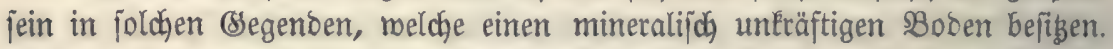

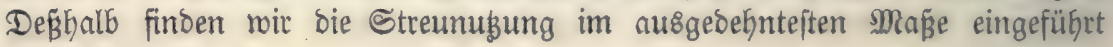
auf Sanbboben.

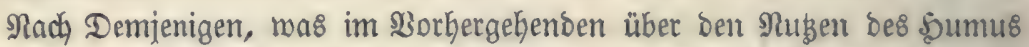

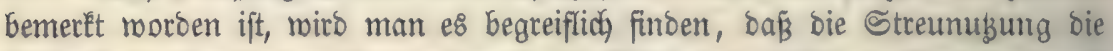

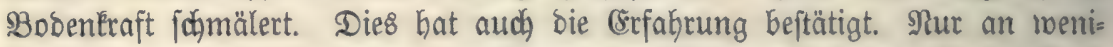

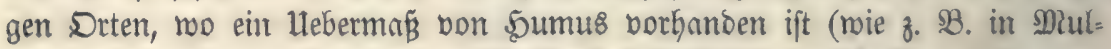
Den, in benen bas zujammengemehte saub fich oft jehr anbäuft), möchte eine theilmeife (nie eine gänz̧liche) Entżief)ung ber Streu ohne Echaben jein.

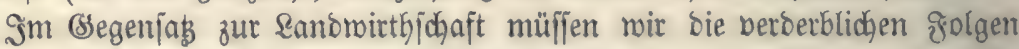
Der Streumuzung in Bezug auf ben $\mathfrak{B}_{\text {ald }}$ nicht in einer 3 erminberutg ber

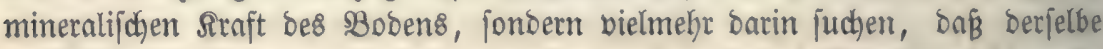

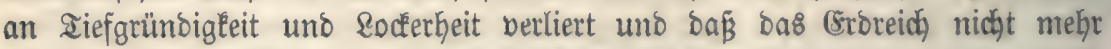
gegen bie Berflüchtigung ber greuchtigkeit gejobüht ift. Dazu fommt nod,

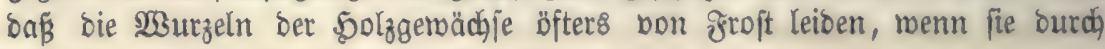
bas Streurechen blosgelegt rorben find.

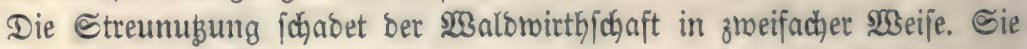
erjdgwert auf einem SBoben, welcher von ifr gelitten bat, bie Berjüngung

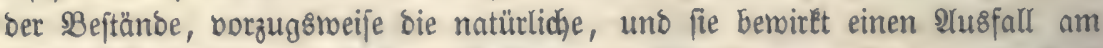

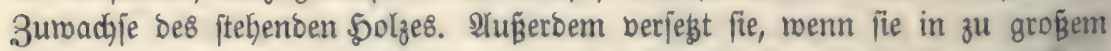
Mage aubgeübt wiro, bie $B$ eftänbe in einen franlbaften 3 uftano, uno offnet

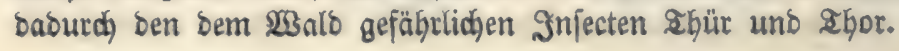




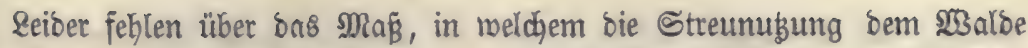

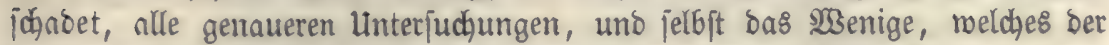
verbienjtbolle Sunteshagen zur \&öjung biejer grrage beigebracht hat, kann nicht als entijheibeno angejȩ́en mercen.

ulm sie Schäbliçfeeit der Streumugung quantitatio feftzuftellen, reidht man mit blofgen Beobachtungen nicht aus, e\& müffen förmlid comparative Interjudjungen unternommen werben. Bor allem ift e8 nöthig, fidf barüber

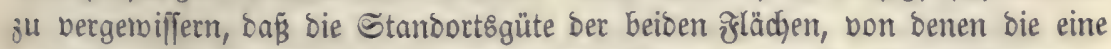

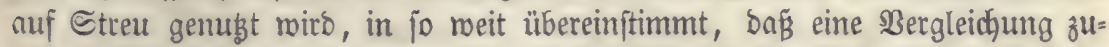

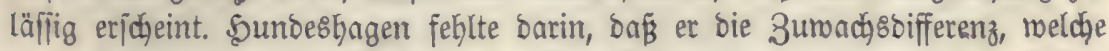
ein auf Streu benugter Bejtand im Begenjas zu einem anbern, in reldjem ons Ctreurechen unterblieben war, zeigte, ganz auf Rechnung ber Streu= mugung ichrieb, obne fich vergerwiffert zu haben, ob ber Zumachs ber beiben Beptände bor Dem Eintritt ber Streunubung ber nämliçe mar. Selbft wenn man im ভtande wäte (roas übrigens bei ber jebigen 24t8biloung ber forft= liçen Bobentunde uno Rlimatologie gerabezu unmöglid ift), bie joentität

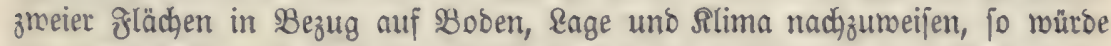

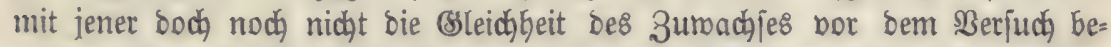
wiejen jein, weil bie f̧olzmafjenerzeugung eines Beftandes nidyt blos von ben Jactoren ber Ctnmoort\&güte, jonbern auch - jelbft bei ber nämlidhen \$olzart

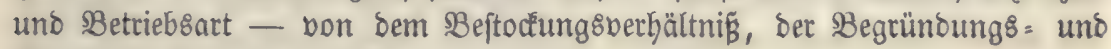
WBaldbehandlungsiant ab̧ängt.

Snoeflen ift e\& nidjt nöthig, baß̈ berjenige Bejtano, meldher intact blei= ben und zur Bergleichung mit bem andern, auf Streu zu nugenden Beftand, bienen joll, bor bem Beginne bes Berjuches genau ben nämliçen 3umadjs, wie biejer, zeige; es ift nur erforberlich, baß̈ ber 3umadjs gang ber beiben Beftände berjelbe jei. Şft diejes der Fall, Dann läst fich ber erjte Bejtano ftet8 als $23 e i f e r$ für bas normale 2 adjsthum bes andern benusen.

Dentén wir uns (જ̊ig. 173) Den Zumadjsgang ber beiben Beftänbe

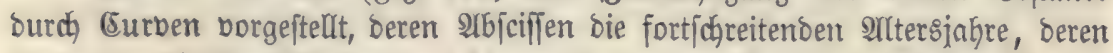
Drbinaten bie Durdhjidnittszumadjie, melche jenten entiprechen, borjtellen, jo wirb

ङ̊ig. 173.

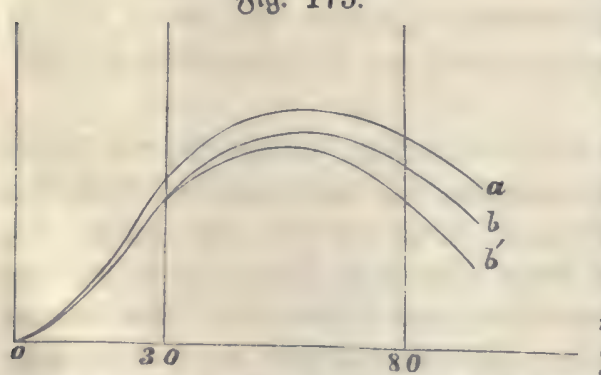
Der Beftand a bann als $\mathfrak{W}$ eijer für b bienen fönnen, wenn bie Curbe b ber (surbe a ăhnlich ift. शehmen mir nun an, bie Zumadyscurbe bes auf Streu benugten 8 Beftander b jei b', jo merben wir blos beim Beginn Des Berjudjes eine Drbinate von b erbalten, fpäter tb̈nnen wir blos bie Droinaten bon a und $b^{\prime}$ beobadaten. Sift es aber ausgemacht, baś a uno b

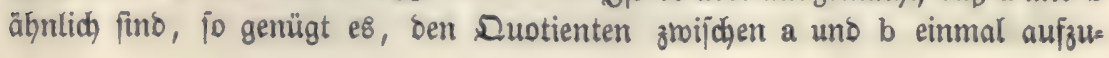


puchen, um mit Şülfe beffelben uno ber jeberzeit burch eine solzmaffencuf = nahme leidgt feftzuftellenten Droinate bon a bie Droinate bon b zu finoen.

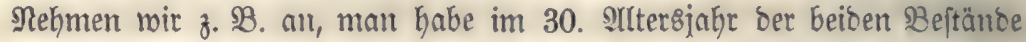
Den Durchichnittszumachs bon a pro Morgen $=100$ Eubiffüen, Den bon $b=90$ cubifupen gefunden; nun jei $b$ auf Streu bembt worben und jein 3umadbs Gieourdh auf ben Betrag von b' gejunten. Sm 80. Jafice Gabe

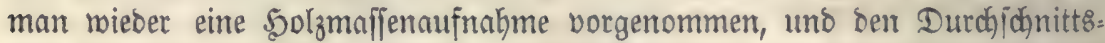
zumadjs bon $a=120$, von $b^{\prime}=92$ gefunden, fo rürbe ber 3unadjs von $b^{\prime}$ wenn Eeine Streu genubt worben wäre $=\frac{90}{100} \cdot 120=0,9 \cdot 120=108$ gemejen fein. (Er mar aber in $23 i n t e l i c)$ Eeit $=92$, folglich Gat ber Strentent=

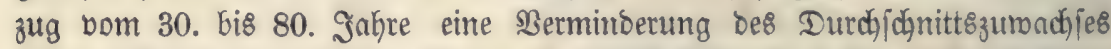
um ben Betrag von 108-92=16 CubiffuBen verurfact, uno bie sau=

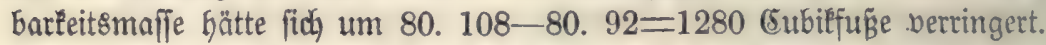

Man miro jelten in einem Beftande zmei Probeflädhen von angemeffener

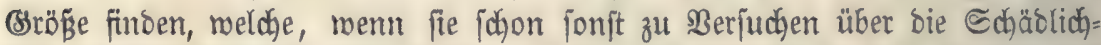
feit bes Streurechents geeignet fino, bod aud zugleid vor bem Beginn bes Berjuches genau den nämlichen Durdj/d)nittszumadjs befizen. Dies ift aber

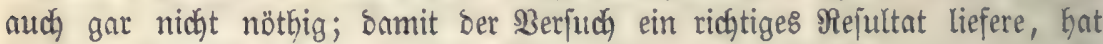
man nur barauf zu jehen, baśs ber 3uwađhsgang ber nämliche jei; bann läß̨t fid) mittelft bes peben angegebenen Berfahrens leidgt ausfinoig machen, wel= den 3umadys ber bem Streutentzug untermorfene Bejtano im normalen $3 u=$ ftanoe gehabt bätte.

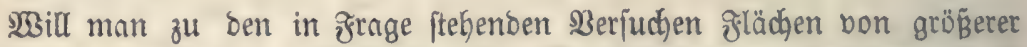

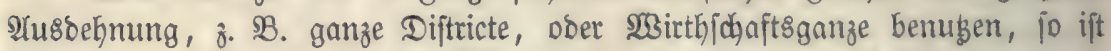

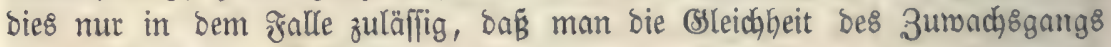
ber zu vergleichenten flächen vorker genau nad)gemiejen yabe. Dies miro

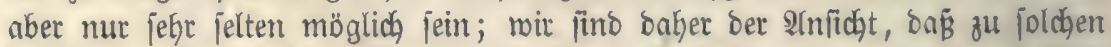
Berjuchen Kleine, bidat neben einanter liegenoe Flächen von etra $1 / 4-1$ Đec= tare fid viel mehr eignen.

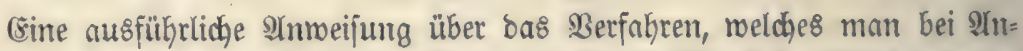
ftellung von Berjuchen über bas Streurechen einzuhalten bat, fintot man in

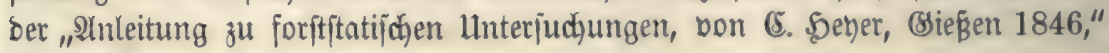
ธ. 162.

Sunbeshagen ift bis jebst ber (sinzige gerwejen, welcher fich) mit Unter=

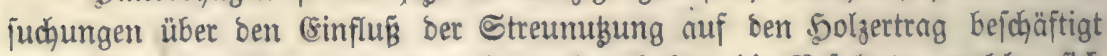

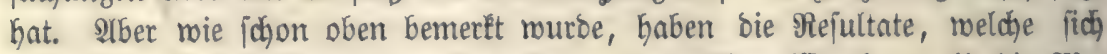

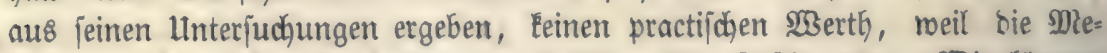
thobe, nads weldher Sunbeshagen arbeitete, eine falfaje mar. WWir tönnen

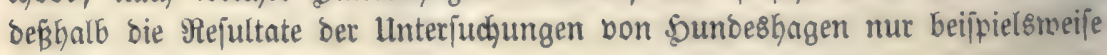
anfübren. 


\begin{tabular}{|c|c|c|c|c|}
\hline Betriebsart & & & odyroals & Mittelivald \\
\hline Solzart, Boden zc. & 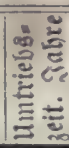 & $\begin{array}{r}\text { Sau } \\
\text { Sanoftein }\end{array}$ & $\begin{array}{l}\text { idhen auf } \\
\text { Salte u. Bajalt }\end{array}$ & $\begin{array}{l}\text { Budhen auf 巨anto } \\
\text { ftein und Salle }\end{array}$ \\
\hline 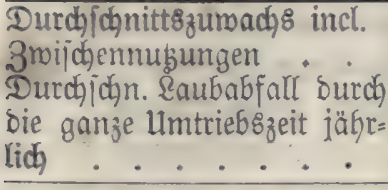 & + & 60 凡bf. & 15 Entt. & $\begin{array}{l}40 \text { Rbf. } \\
18 \text { Entr. }\end{array}$ \\
\hline 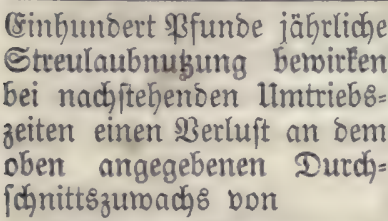 & $\begin{array}{r}100 \\
80\end{array}$ & 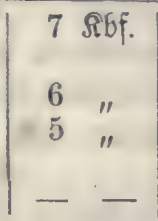 & $\begin{array}{ll}5 & \Re b f . \\
4 & \prime \prime \\
3 & \\
- & -\end{array}$ & $\begin{array}{l}- \\
- \\
2-3 \text { RGf. }\end{array}$ \\
\hline
\end{tabular}

Die Säbe, weldhe 5undeshagen über ben (sinflü bes Streurechens auf ben Solzertrag ausgejprodhen hat, fint zum Iheil nichts anberes, als bie (5on= jequenzen feiner 2rnfichten nuf bem Bebiet ber forfitidjen Bobenfunde; bie menigften grünoen fich auf birecte Interfuchungen. SWir laffen bieje Säbe bier folgen.

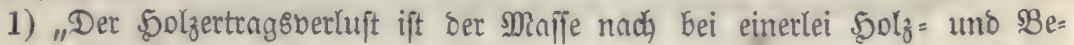
triebsart unס BDodengüte Der Streumenge umberändert proportional, bie

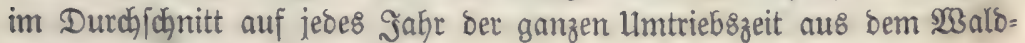
beftanbe -entnommen wirb."

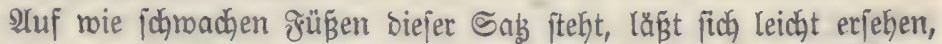
menn man annimmt, e\& merbe bie fänmtliche Etreumenge auf Sant= ftein im Betrag von 20 (Enttn. jährlid, dem $\mathfrak{B G a l}^{2}$ entnommen. Der

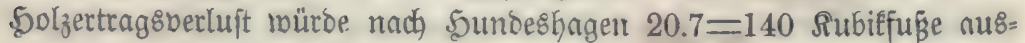

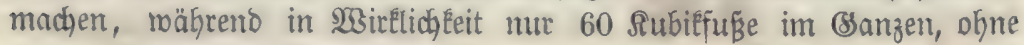
Stceuentzug, zumadj]en.

2) u. 3) "İe frijher ber Boden ift, um fo roeniger beträgt ber burdh einer= Lei Streumenge bemirkte Ertragsiverluft."

4) "Ie fohlechter (bejonders trociner) Der SHoben ift, um fo früher und ftär= Eer werben nicht blos bie grolgen des Streurech)ens bemerêlidh, fondern

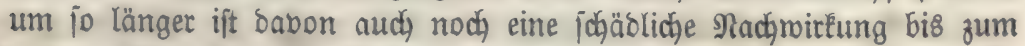
ipåtern Inter bin zu befürdoten."

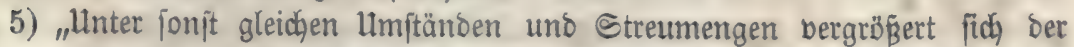
Solzertragsverluft in ziemlich gleichem Berhältnifife, mie bie \&ängen ober 3eiträume der Umtriebszeiten länger merben."

6) "Bei einerlei Boben und Solzart ift ber mit gleidgen Ctreumengen ber= bunbene ફolzertragsberluft in bem ßerbältnißß von $2: 4$ Doer auch $3: 4$ 


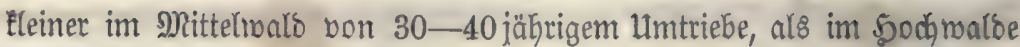
bei 80-100 jäfr. Itmtriebe."

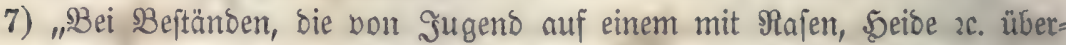
zogenen SBoben im lichten ocer freien Ctande berlebten, roie z. B. Bflan= zungen $2 c$. , hat fich bis bahin noch kein Ertragsvertujt fogar für ben gall bemerellidh gemadjt, al\& man benjelben allen Saubabfall entziegt."

8) „Shngenchtet junge 5̧olzbeftänoe noch flacher als ältere nurzeln, fo

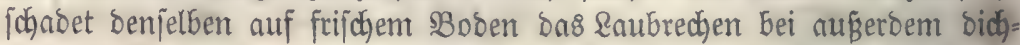

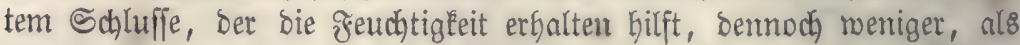

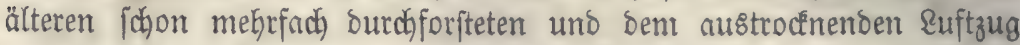
mehr geofffneten Bejtänoen; umgelefyrt berhält fich bies aber auf jojlech)= tem und uriprünglich fchon trocfenem Boben uno Rage."

9) "Der Dem BBoden burch bie Streumuzung zugezogene Siraftwerluft ift

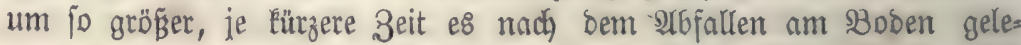
gen hat."

Sbgleich einige von biejen Säben plautibel erjdheinen, fo beoürfen fie boch alle ber $\Re$ eftätigung burch directe comparative Unterjuchungen. So lange biefe überhaupt fehlen, foll man fich jebes Urtheilz über das $\mathfrak{M}$ a

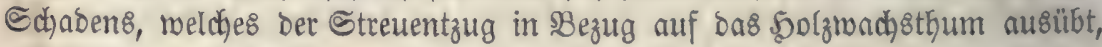
enthalten.

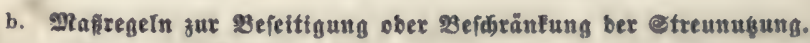

Das Streuredjen grünbet fich entroeber auf Berectitigungen, ober es ift

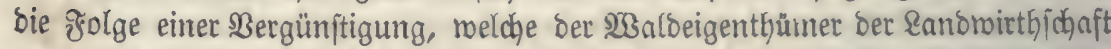
an foldhen Drten gemährt, no e\& Derjelben an Den nöthigent Streumitteln mangelt.

In bem erften F̧alle ijt bie gänzlidłe Bejeitigung be8 Stteurechens nur

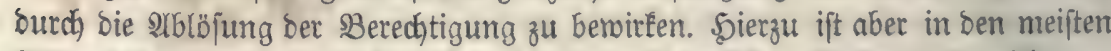
ঔällen die (sinmilliguntg bes sBerechtigten erforbeclid). Sollte biefe nicht er= folgen, fo ift es bod bäufig möglid), bas Mañ ber Streunußzung fo meit zu

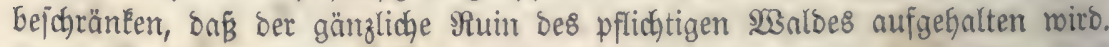

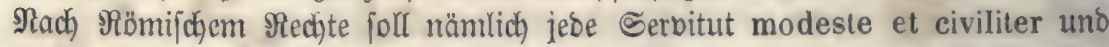

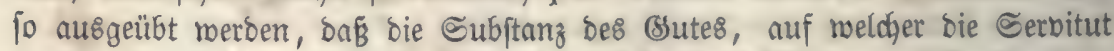

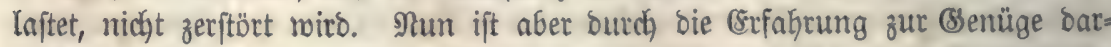

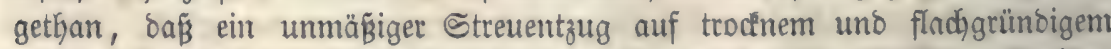
Ierrain ben Boben zulebst gänjlich) ungeidjiưt maḑt zur natürlichen Berjün= gung und jogar zut 5olzerzeugung. Sier Łann aljo ber $23 a$ aldeigentbümer verlangen, baßi bas Streurechen nidht altjäbrlid, fonbern in gemiffen, nicht zu

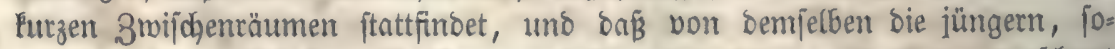
wie bie zur natürlicjen Berjüngung beftimmten älteren Beftäntoe verichont bleiben.

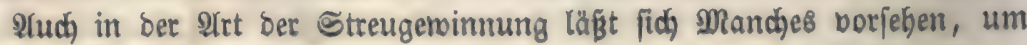




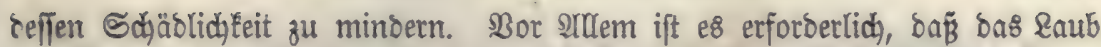
nidjt bis zur nadten Grbe hin entfernt roirb, weil bas neunbfaltende $\mathbb{R} a u b$

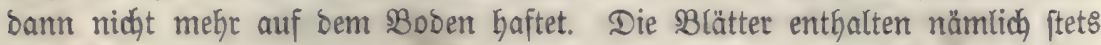

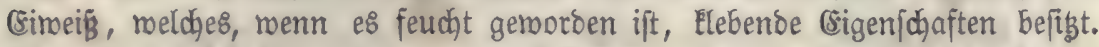
(ss verbinoet fich baher das neat abgefallene \&aub viel eher mit bem bereits

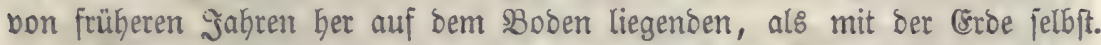

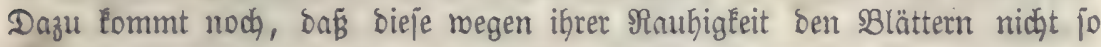

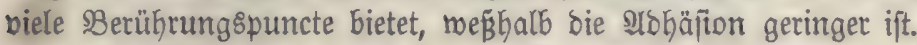

Die Arnwenoung von eijernen Rechen, ftatt hölzernen, hat ben grofien

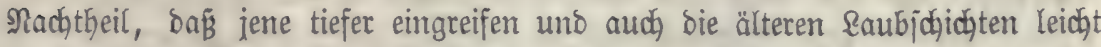
megnefmen. Man jollte bef̧alb überall $\delta a$, no es thunlich ift, mur ben ses braudh von hölzernen Rechen zur Streugeminmung zulaffen.

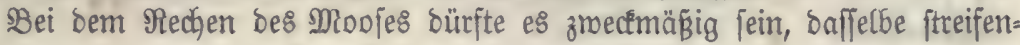
reife regzunefymen, bamit auf ben entblöiten ๔treifen bas Mpos bon bem frehen gebliebenen aus fid regenteriren farm.

(sin eigentliches, unabrveisbares. Beoürfniß für bie Ranomirthjchaft bildot

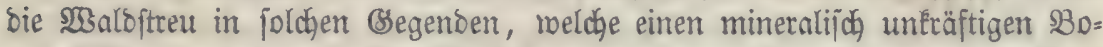

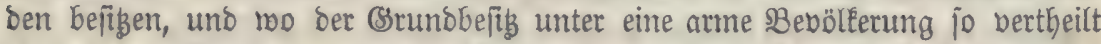
ift, Dá̉ ber Eingelne entweder nicht genug Stroh erziejt, ober boch genöthigt ift, baffelbe zu berlaufen. Shatjächlich finden mir bas streurectyen in ausgge= behnteftem Maß̉e eingefübrt auf Sanoboden, namentlid) auf bem (Sebiete bes bunten Sanditeins uno im (sebirge, no bas Beoürfnifi nad) Streu fid ge=

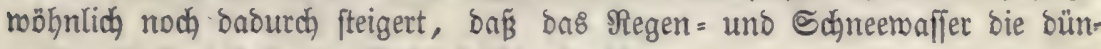
genden $B$ eftandtheile ber 2 recker leicht abjpühlt.

Unter ben eben gefofilderten Berbältnif]en ift e\& meift urmöglich, bas Ctreurechen ganz zu bejeitigen, ofne bie Ranbmirthjohaft zu ruiniren. Coll

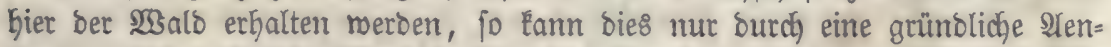
berung in ben incialen Berfältniffen ber Bemobner foldjer Segenoen gefdue= Gen. Maffenhafte 2(usmanoerung, ment es nöthig ift mit Unterftübung auf

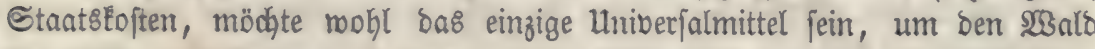
gu retten.

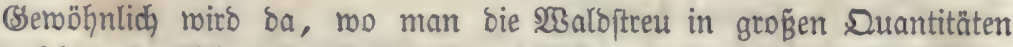
begehrt, Eein orbentlicher Sauş̧alt mit bem Dünger getrieben. Meift find bie Dungftätten fehr mangelhaft eingerichtet, nidyt gepflaftert uno bem Ŷulaugen

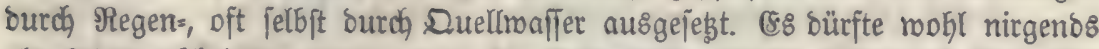
als Särte ericheinen, menn man bie Ertaubniß̈ zum Streubezug ftets an bie Crridłtung einer znectmäß̈gen Dungftätte Enüpfte.

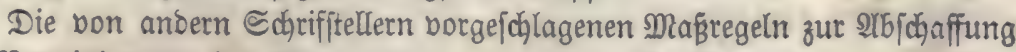
Dber $\mathfrak{B e r m i n \delta e r u n g ~ b e t ~ C t r e u n u b u n g ~ - ~ r i e ~ z . ~} \mathfrak{B}$. Bermehrung uno $\mathfrak{B e r}=$ befferung ber natürlichen $23 i e j e n$, bie Zuhülfenab̧me vun Etreujurrogaten $2 c$.

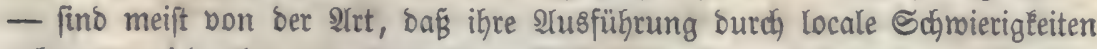
gebemmt wirb, ober volt bem guten $23 i$ llen ber Streuconjumenten ab̧ängt. 


\section{Seriftellung eine geeigueten $\mathfrak{M a n ̃}$}

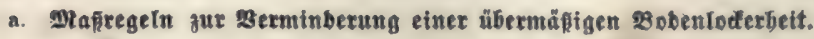

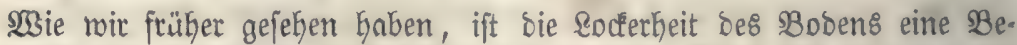
bingung für bie (Erzielung Der hödfften Maffenerträge. Dies gilt aber nur für

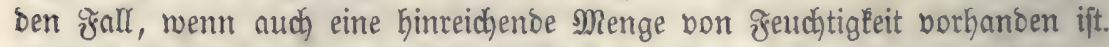

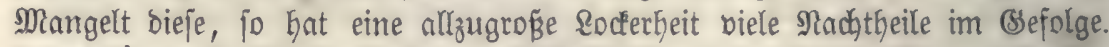
Die Bflanzen leiben in Der warmen Sahreszeit surch Irodfniß́, ber Boden wirb an Arbfängen leidht bon ben Meteorwaffern in bie Tiefe gejhyemmt,

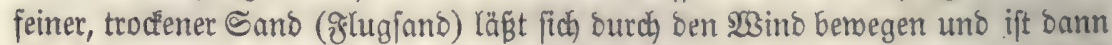

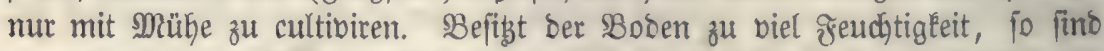

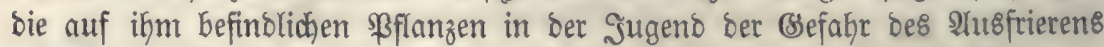
unterworfen.

Die Mittel zur Befeitigung einer übermäß̈igen Bobenlocferheit bejtehen: in ber $\mathfrak{A}(n z$ zud

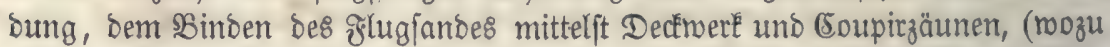

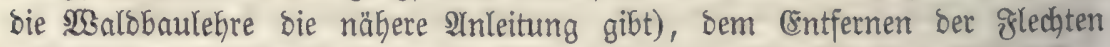
und jonftigen (semächje, aus meld)en bie jogenannte Stauberbe fich bildet,

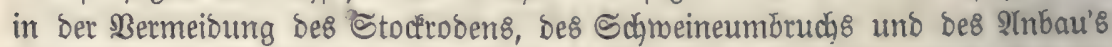
von lanowirthjidjaftlichen (semähjen, melche eine Bearbeitung bes Bobens mit $2 \mathfrak{3 e r E g e u g e n ~ e r f o r b e r n . ~ D a ̊ ~ i n ~ b e r ~ A l g r i c u l t u r ~ g e b r a ̈ u d j l i d j e ~ F e f t m a l z e n ~}$ bes Bobens mirb fich in ber Frorftrinthjefaft nicht anmenben laffen.

\section{b. MRapregein zut Berminberung einer allzugrofen sobenfeftigleit.}

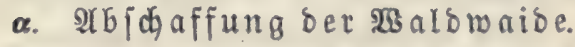

Die Behütung ber $\mathfrak{x a l b f l a ̈ c h e n ~ m i t ~ B i e h ~ ( n a m e n t l i d y ~ \Re i n o b i e h ~ u n d ~}$ Sferben) Gat auf eimem nidjt binbigen Boben eine Bermehrung ber Sockerheit

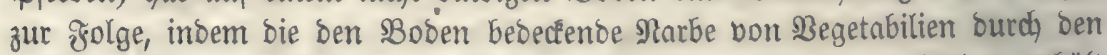
Iritt ber Thiere zerftbur wird. (sin an fich fejon gebunbener Boben erhält

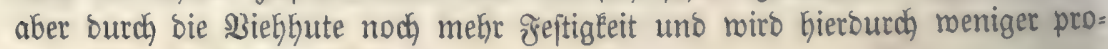
ouctio für bie groritmirthichaft.

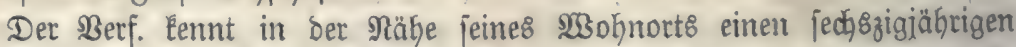

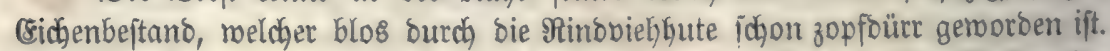

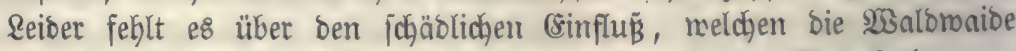
auf ben \$olzmuchs äuß̈ert, gänzlich an birecten comparativen Unterjuchungen. WBir find baher nidjt im Stande, etwas Genaueres über bas Maß́ biejer ङ(häbliç)eit anzugeben.

\section{B. $\Re u$ rzhacten.}

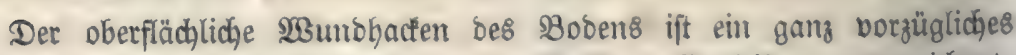

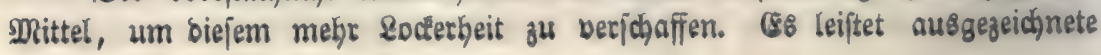


Dienfte bei frrengem (sroreich an foldyen Drten, auf weldyen ber Sumus megen

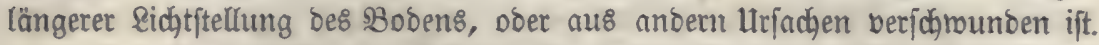

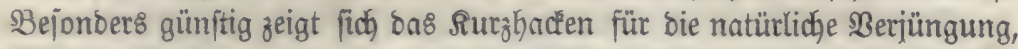

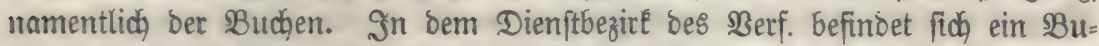

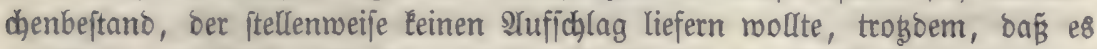
an Miaft nicht febite. Nachbem man bieje Stellen oberfläblich mund gebadt batte, Eejamten fich biejelben viel vollfommener, als in allen übrigen Sheilen ธев Beftanbes.

Das (sinzige, was einer ausgebehnteren Antwentung Des Rurzhadens entgegenjtegt, ift bie Rojtipieligkeit biejes ßerfahrens. Man madht bon ifm genöhn= lid) nur bann Bebrauch, menn man über eine hinreidhenbe $3 a b)$ von Frorft=

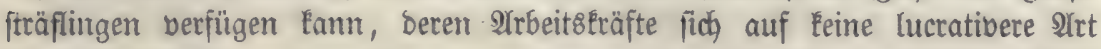
berwertben laffen.

\section{r. Umbrud mittelft zahmer Schreine.}

Birliger, als ourch das Rurzhaden, läß̈t fid bie Bobenlockerung ourdh ben llntbrudh mitteljt jafjmer Schmeine beroirfen, ja man erfält fogar öfters nod) ein Sadhtgelo für bie Beftattung ber Schmeinehute. Nur auf fteinigem

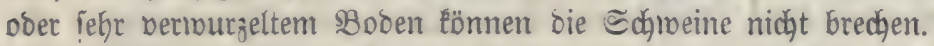

\section{d. Sainen bes 9 obenz.}

Das Sainen bejteft darin, Daß́ man ben Boben jammt jeinem Ueber= zug abplaggt unt bie \$laggen, wenn fie troden geroorden fino, brennt. Bei

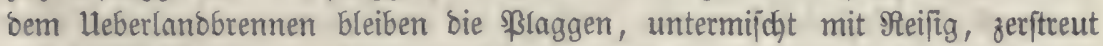
auf ber Flädje liegen, bei bem Schmoren werden fie auf Şaufen gejebt uno

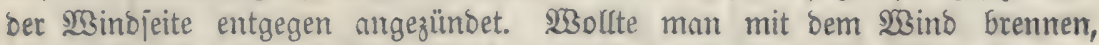
fo mürbe fich das $50 l_{3}$, meldjes man in bie 5aufen einjidichtet, eher ver= zebren, als oas Durchglüfen ber \$laggen ftattgefurben hätte.

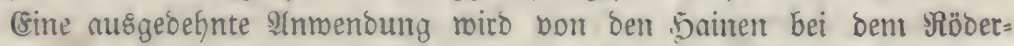
lantbetriebe uno bei bem Dacémalobetriebe gemadht; fier findet baffelbe aber

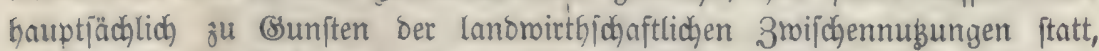

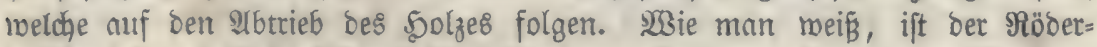

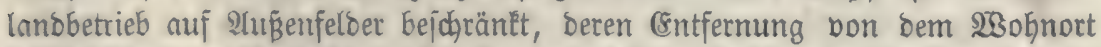

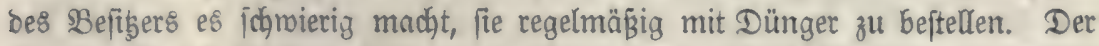
Sactwaldbetrieb bagegen miro - abgejehen bon andern Motiven, beren (5r= örterung nidgt bierher gefjört - Durdh einen Mangel an Dünger herborgeru= fer. Bei biejen beiben Betriebsarten foll aljo bas Sninen bie Düngung erjegen. Difenbar merden durch bie Dperation bes Brennens Dem SBoden Feine büngenten SBeftandtheile zugefüthrt, meldhe ex nicht fochon gebabt hätte, e\& Eann aljo bns Brennen ber \$laggen, Des Feifig's sc. zu Keinem andern 3roed bienen, als um bie näfrenden Bejtanotheile biefer ๔ubftanzen fobnell in einen

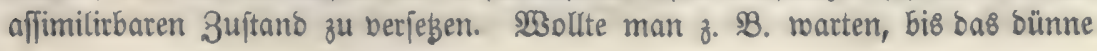


Reifig, melches auf Dem Schlage zurüctbleibt, verweit ift, fo mürbe ber

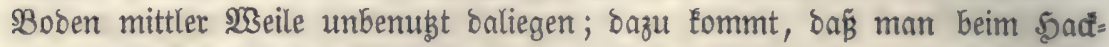
marbbetrieb mit ber grudytbeftelfung eilen muß̈, weil fonft bie soben empor=

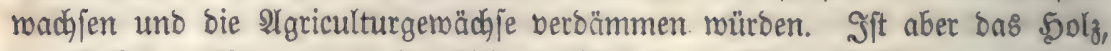
ber Unträuterüberzug zc. eingeäjchert, fo find bie Mineraljubftanzen frei ges

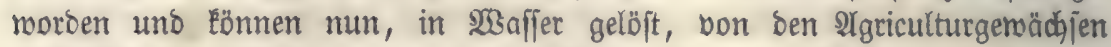
aufgenommen werben.

Durdy bas Brennen wirb aber auch ber Boben felbft aufgeidhloffen, menn er, was faft immer ber fall ift, Thon uno Salk enthält. SBie bie (refahrung

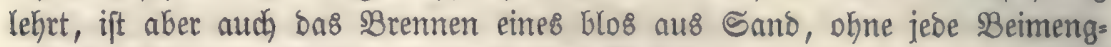
ung von Ifon Beftehenden Bobens ohne Nuben.

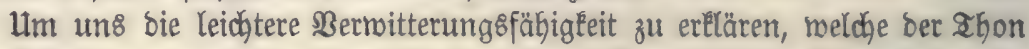
erlangt, menn er mit Salf geglüht miro, müffen mir uns baran erimnern,

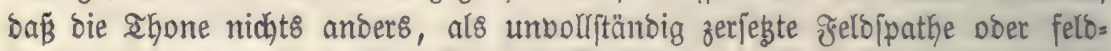
[pathartige Mineralien find, und bä́ bie Silicate fich um jo leichter burdh

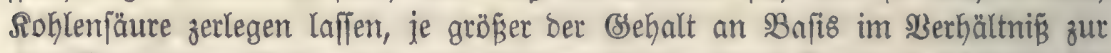
Siejelfäure ift. छslüht man ein Ifyonerbefilicat mit Salk, jo bemädhtigt fidł biejer eines aheiles ber Riejerfäure, uno nun kann bie Rohlenfäure bie Rie= jeljäure leidjt austreiben. SBei biejer (selegenbeit werben aber auch bie im

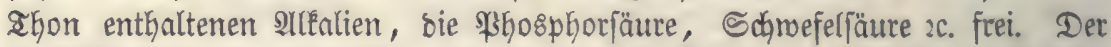
nämliche 230 rgang zeigt fid

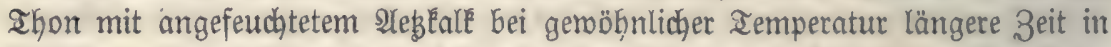
Berüfrung fid befinbet. Sa jelbft in einer Mengung bon ahon mit Eoblen= faurem SalE zerjebt fich ber Shon leidgter, als ohne bie segenmart bes Sarlejalzes - und hierauf berufht höd)it makricheinlich bie günftige $233 i r k u n g$ bes Mergels bei Der Düngung ber Felber.

In neuerer 3eit hat man bas Sainen bazu angeroandt, um fid ein

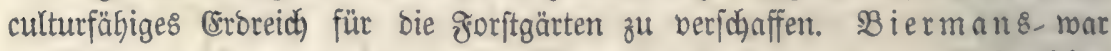

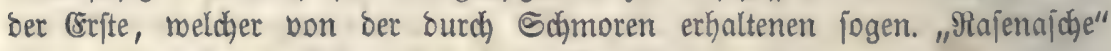
einen ausgebehnten (sebraud in biejer Beziehung madjte.

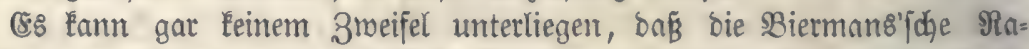

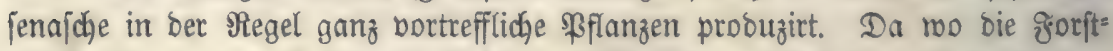

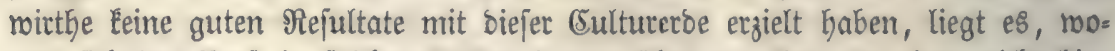
bon fich ber Berf. in folchen öällen immer überzengt bat, an einer nidgt hin=

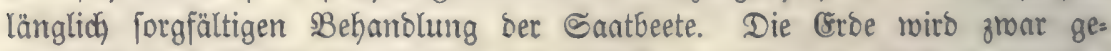

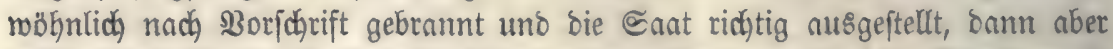

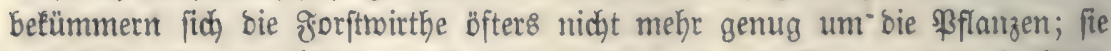
unterlaffen bie burdfaus erforberlidge Reinigung ber Sämpen von lintraut, uno wenn nachker bie Pflanzen in biejem erficten und verberben, fo miro

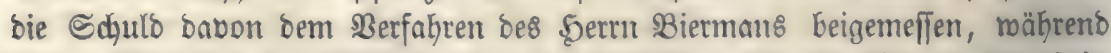

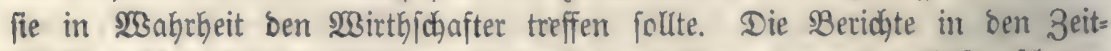

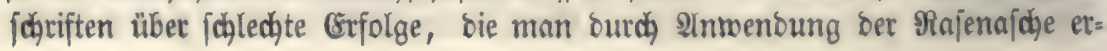




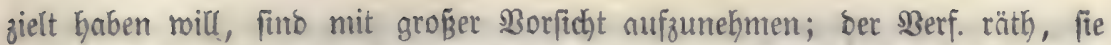

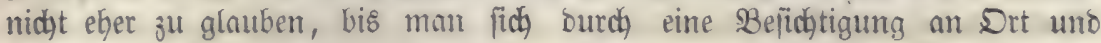
Stelle bout dem roafren Sadyperbalt überzeugt bat. So fennt ber 3 Berf.

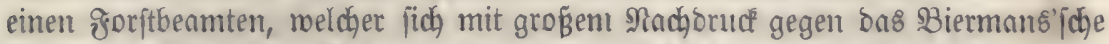
Berfabren offentlich erelärte, meil es ifm nicht habe gelingen mollen, gute

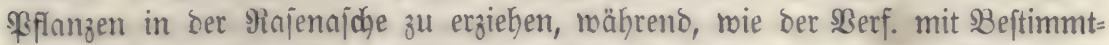

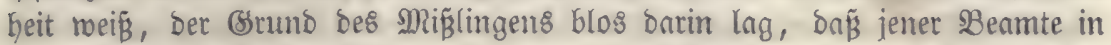
bie nod) marme rijoje fäete.

Cefr oft ift man geneigt, ichledhte (Erfolge, weldhe man mit biejem Ber= fahren gehabt hat, auf sechnung ber Rocalität łu feben, mähreno fie nur ber

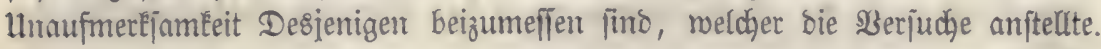

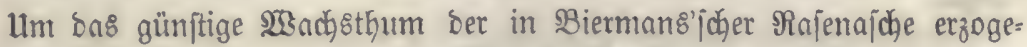

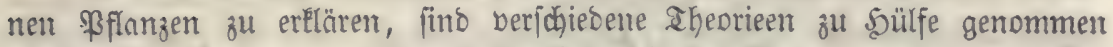
morben. Diejenigen, weldfe bie grudhtbarkit bes Bobens nad) feinem (Se= Galte an anorganiijhen löslichen Eubitangen beurtheilt miffen mollen, Gaben

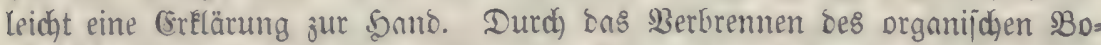
benüberjugs uno bes Reifigs wito - jo jagen fie - eine großse Menge bon

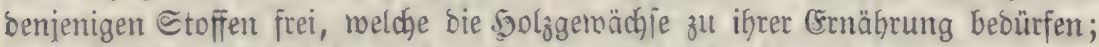

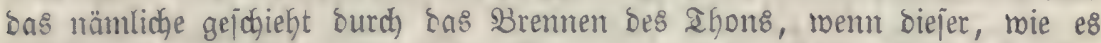
faft inmer ber jall ift, einte BReimengung von ßalf entbält. Dieje Snterpre=

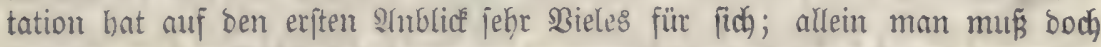

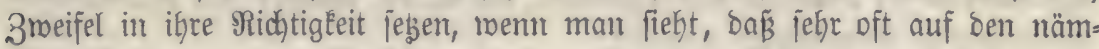

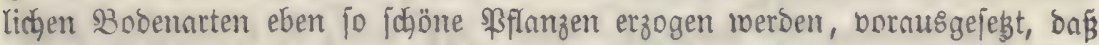
man bas (Eroreich, ebenjo gründlich bearbeitet habe, als bies nach bem $\mathfrak{B e r}=$ fabren von \$Biermans gejchieft. Dann lefyrt aber auch cie Beobachtung, forwie

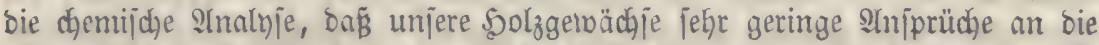

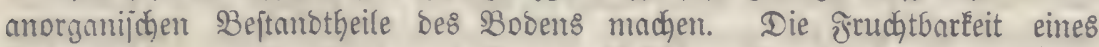

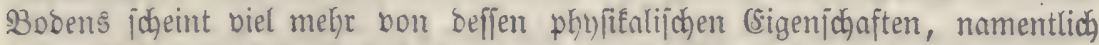
jeiner Liefgrüntoigkeit, Socferbeit uno jeinem jeudhtigkeitsgebalte, abzuhängen,

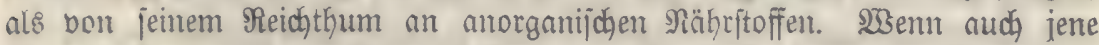
(Eigenjidaften nur bazu bienen jollten, um bie 2lufjaugung ber Mineraljub=

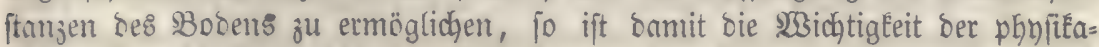

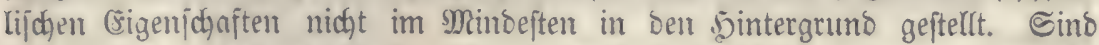

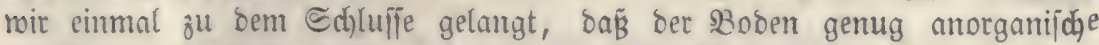
Etoffe in affimilirbarer form erḅalte, um sie $\mathfrak{3 a}$ alovegetation zu ernähren fo föunen mir ben $\mathfrak{W e r t h}$ Deffelben tod offentbar nur banach beurtbeilen, ob jeine jonftige Bejchaffentheit eine *ufjaugung biejer Stoffe in Ginreidyentem Maß̉e geftatte. Wir merden aljo Earalif hin geführt, bie (süte bes s3obens

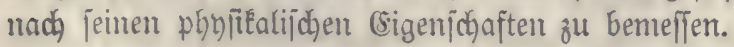

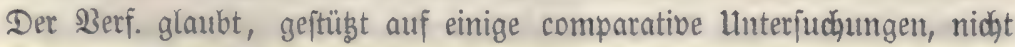

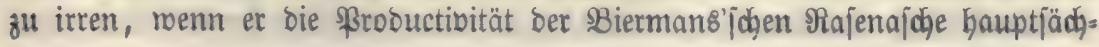




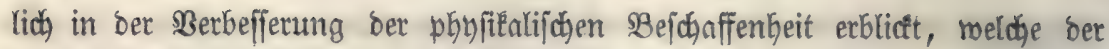
Boden burdy bas Brennen erleibet.

Bobenlodertheit ift eine ber erften Bebingungen für bie 8rziebung guter Fflänzlinge, ohne biefelbe bilbet fich nie ein reiches Syftem von 3ajertourzeln

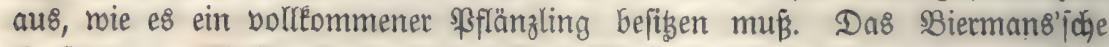
Berfahren berfoufft aber in hohem (Srabe Bobenlocferheit. Dies gilt namentlich

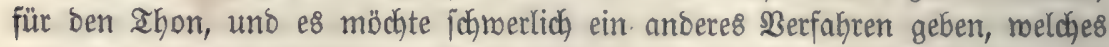

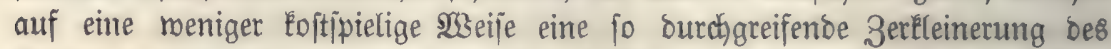
Thons bemirfen fönnte, als eళ burch das sBrennen gejohieht. Diejenigen $\mathfrak{B}_{\mathrm{D}}=$ benarten, welche fchon an und für fich ein binreichendes Má̧ von soderbeit befigen, wie z. 3. Der Sand, werben burch bas ßBrennen nicht wejentlich ver= beflert.

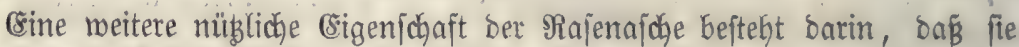
bie greudjtigkeit leidjt aufnimmt, uno lange anbält. Sie ift ganz bejonoers geidjiçt, bie in ber \&uft enthaltenen 2 afferbämpfe zu conoenfiren. Dies be= ruht einestheils auf ber feinen Bertheilung ber Eroe, zum andern auf bem

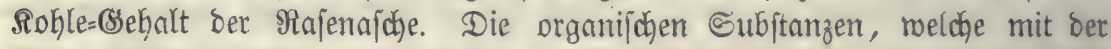
Eroe geglüht merber, berbrennen nie volfftändig, es bleibt immer ein Theil

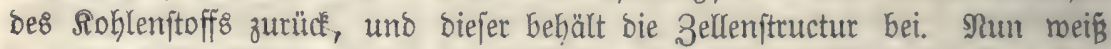
man aber, baf bic Soble in biejem Falle eine grofie Suantität Bas ober Dampf zu abjorbiren vermag. (sin jebr läftiges Ilnfraut auf ben Biermans'= fichen Beeten ift Funaria hysrometrica, ein Moos, welches fich nur ba zeigt, wo es nie an J̌euchtigleit mangelt.

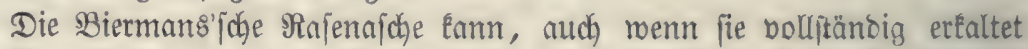

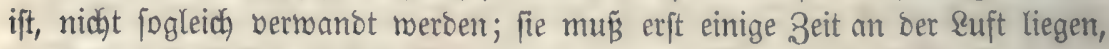
bamit ber Aegžalé, welcher fich beim \$Brennen gebildet hat, Rohlenjäure an=

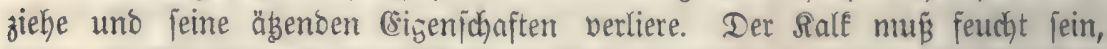
menn er fich mit ber Soblenjäure berbinden foll; aus biejem (stunbe fieht man e\& gerne, menn bie aljhe leidjt beregnet mirb. Man barf biejelbe nicht fogleidh nach bem Brennen bid)t zu[ammenjallagen, meil fonjt bie Sohlenjäute nicht zubringen Eann. T2m beften jegst man bie sljche auf Saufen und bebecitt

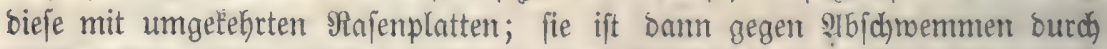

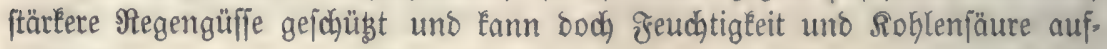
nelgmen.

c. Bobenbearbeitung bei ber angudt bou Fgriculturge= wăd fen auf $\mathfrak{W} a$ logruno.

Im Borbergehenden haben wir bereit\& zmei forftliche Betriebsarten ken=

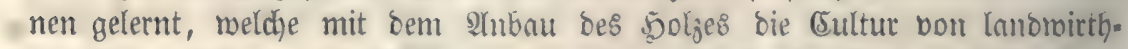

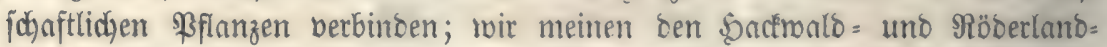

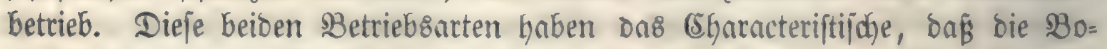
Denbearbeitung am Enoe bet Umtrieb8zeit burch \$ainen bemirft wirb. IIn 


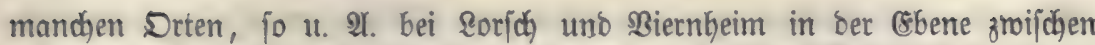

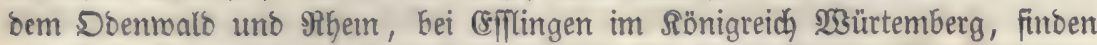

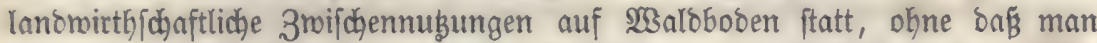

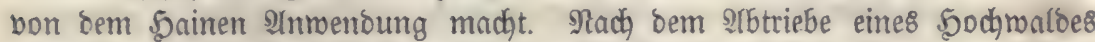

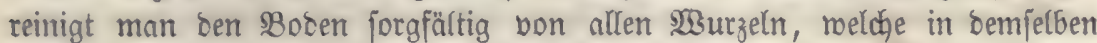
zurüafgeblieben fino, uno bearbeitet jebt bas (ordreich) mit ben in ber Rano= mirtbidaft gebräuchlidhen Sinftrumenten, insbejonoere mit oem $\mathfrak{B f l u g e . ~ R a c h = ~}$ bem einige Safre lang Betraibe uno Sandfrüb)te (Sartoffeln, zumeilen aud) Inbat) gezogen morden fint, tritt mieder bie f̧olzcultur ein. Dieje furbet

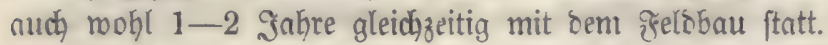

Man Fat gegen bie oben geidjilberte Berbinoung ber Eanbwirthjhaft

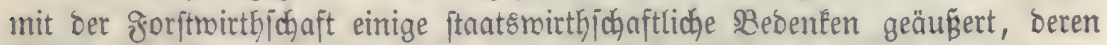
23üroigung übrigens nicht Gierber gehört. Bom Ctan£punte ber Bobentunde

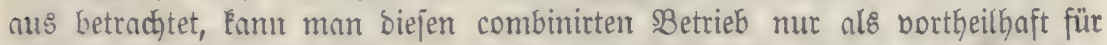

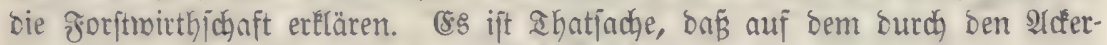
baut gelocferten Boben ganż bortrefflictje Solzpflanzen etzogen merben, wovon

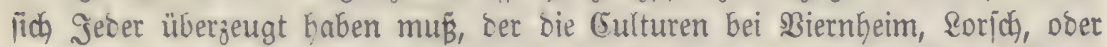

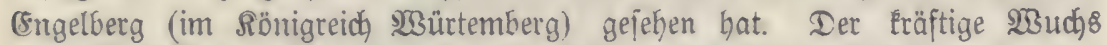
ber Solzpflanjen in foldhem Boden läpt fich nur butch bie Rocferung, meldhe

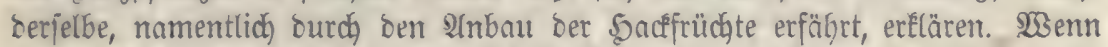

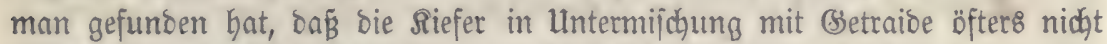
gebeiht, fo rüfyrt bies nicht etroa bon ber Bobenloderung. fondern bavon her, bав̈ bie Riefer keinen ๔dhatten ertragen fann. Im Freien angezogen, fommt bie Siefer auf gebautem \&anbe eben jo gut, wie jebe andere \$olzart fort.

Die Bortheile ber Bobenloderung berjhminden aber in bem łalle wie=

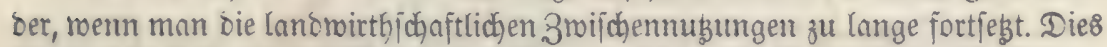
fann nicht befremben. Wie mir wiffen, entzieben die Igriculturgemädje bem Boben meit mehr anorganijohe ๔ubjtanzen, als bie \$olzgenächje; jo kam es

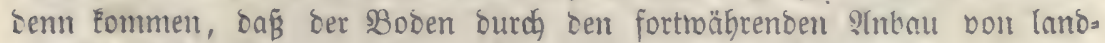
wirthichaftlichen SPlanzen jeinent ganzen Borrath an löslichen anorganijchen Bejtanotheilen verliert uno nun jelbft fein Şolz mehr zu probuziren vermag. Im meiften jaugen Infok uno Betraibe ben Boben aus, Rartoffeln jobaden in biejer Sinjidat meit weniger.

Bon Seintrid) (Eotta ging bie Soee aแв, nuf geeigneten @tanborten ben

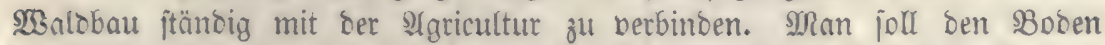
erft eimige 3eit blos zum Strbau bon 2lgriculturgemächjen bemuben, dann

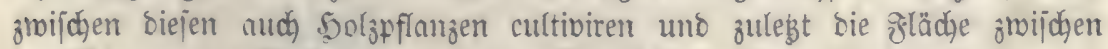

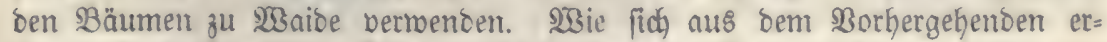

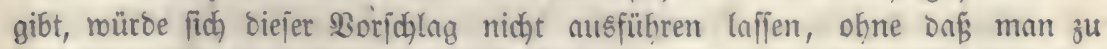

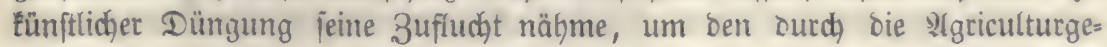
mädjje ball erjöppften Boben zur 5erborbringung bon neuen Ernoten zu 
befäbigen. Der AYnmenoung bon thierifhem Dünget in 2 Balde ftehen nber

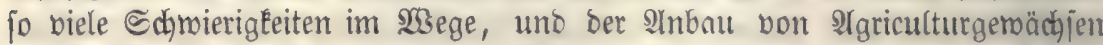
zwijhen bem Solze ift roegen ber mühjamen Bobenbearbeitung und noch aus bielen anbern Esründen, beren Črörterung nicht lierher gehört, jo wenig lu=

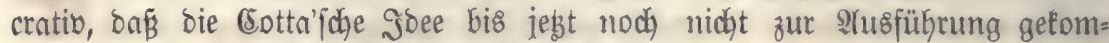

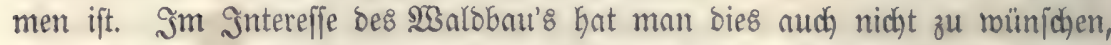

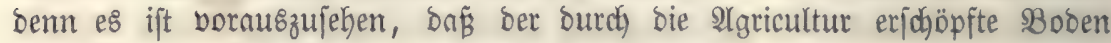
gänžlich untauglich zur \$olzproduction rerben roürbe.

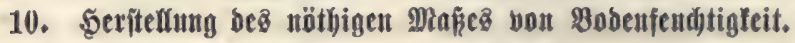

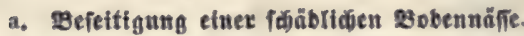

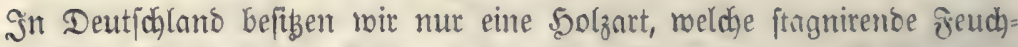

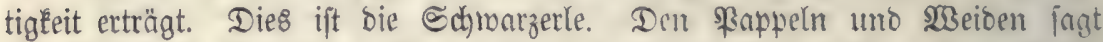
nur fliefendes 23 affer zu; fie gebeifen an biejem inmmer beffer, als in Süm=

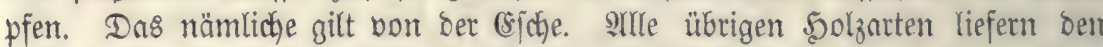
größzten Maffezumadys auf einem nut frifchen Bóben. Die Riefer uno bic Birke ertragen nod am erften trodíne Stanoorte.

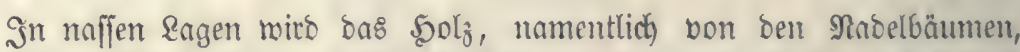
gemöhnlid rothfoul. Die natürliche Beriüngung, porvie bie cernote be\& Şolzes ift an foldyen Rocalitäten vielen Sdymierigéeiten untermorfen. STuß̈erbem er=

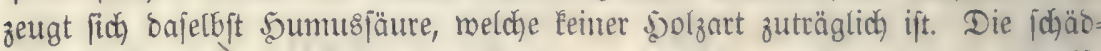

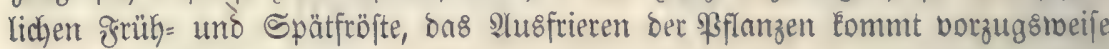
nuf najןem Boben bor.

$\alpha$. Urjadien Der Bobennäfe.

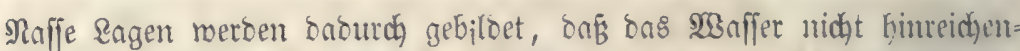

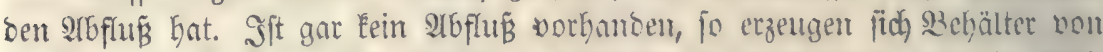

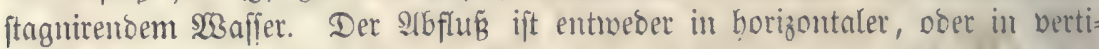

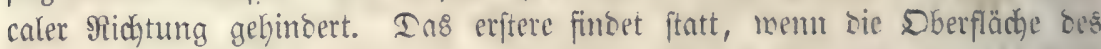

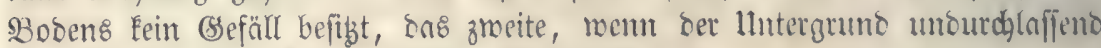
ift. Sit find bieje beiben Şinderniffe vereint.

\section{Die Rälfe tann herrühren}

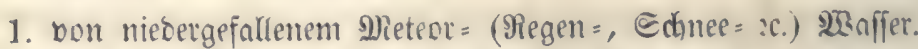

2. Bon Quellmaffer. Die Duellen entiteben nus bent nieberz̧efallenem Waffer; bies gilt jelbft, weun aud) nur mittelbar, für sen felten borfommen=

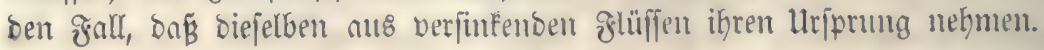

Bon bem Regen=, Edynee = x. 23 affer, weldyes auf ben Boben gelnngt, verounitet un ein Theil; bas übrige fliefit entweder von ber Dberflädge bes 
(Eroreidy jogleidy ab und nach ben tiefer gelegenen Strllen, aljo in bie Bädue, grïffe Seen uno Meere, ober es bringt in ben Boben a (§ig. 174) ein,

ঔ̊ig. 174.

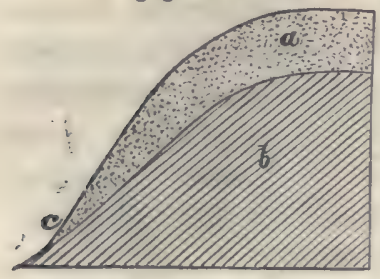
menn biejer locker genug ift, um bas 2 saffer aufs

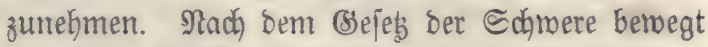

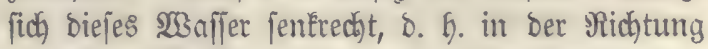
bes (stobalbneffers, abroärts undzroar jo range, bis es auf eine undurchlaffende @djichte b (z. $B$. unzerltüftete Jelien, IGon zc.) ftopit. Sat biaje eine geneigte Rage, jo fliefit bas $\mathfrak{M}_{3}$ affer auf berjel= ben ab und fommit bei $c$, mo bie undurdifaffente

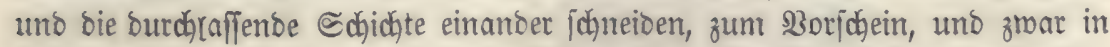
lebsterem gralfe nad, Dem gleidhfalls auf Der allgemeinen (Sravitation berubenden

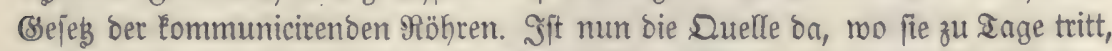

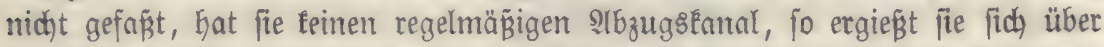

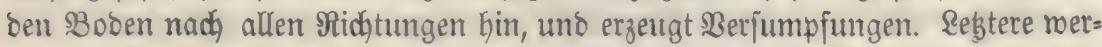

эrig. 175.

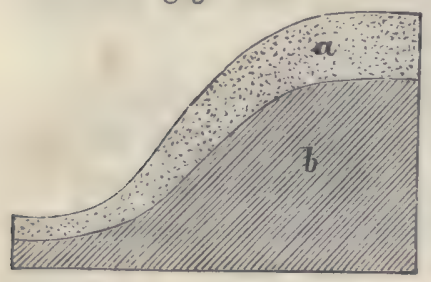

ঔig. 176.

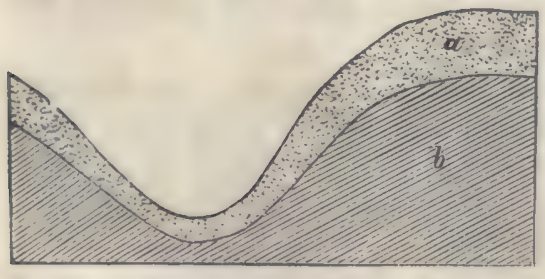
ben aud bam gebilbet, wenn bie undurdylaj= iente Chichte aus ber geneigten Rage in bie horizontale übergeht (gig. 175), ofne bie Dutchlaffente Schidhte zu junetoen; ons $23 a j=$ fer Gat bann Feinen Frall melir, e\& fteigh aufs

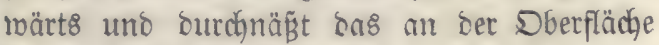
liegente (Groreid). Noch jichlimmer ift es, menn

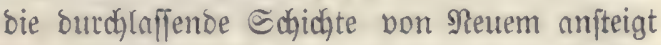
(รig. 176.), weil jebst bas $\mathfrak{M a f f e r}$

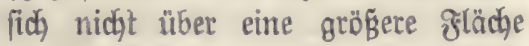
berbreiten Eann, jonoern innerfalb Der Bertiefung bleiben muß́.

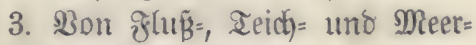
maffer. Das đ̇uñwaffer erbält nur baburch Bernegung, bá̃ es nuf einer jơjefen (sbente ïth) befindet. Je ftär=

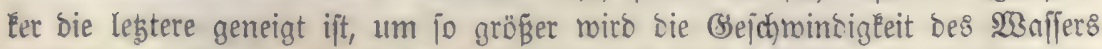
ausfallen, weil bas relative Bsemidht eines nuf einer jebiefen Ebene befindichen

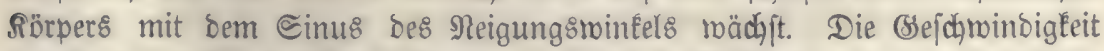

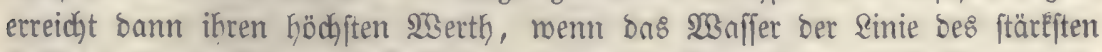

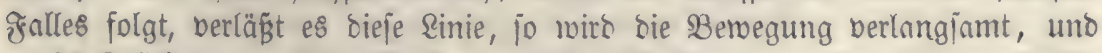

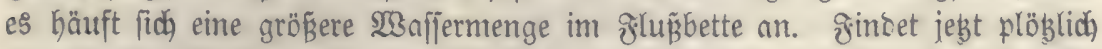

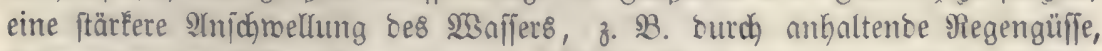

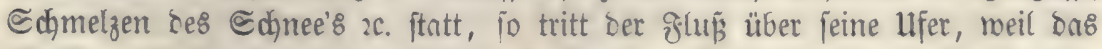

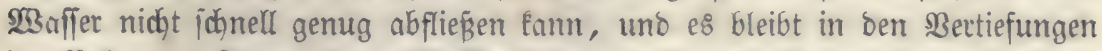

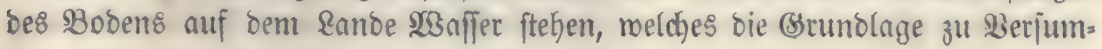




\section{§ig. 177.}

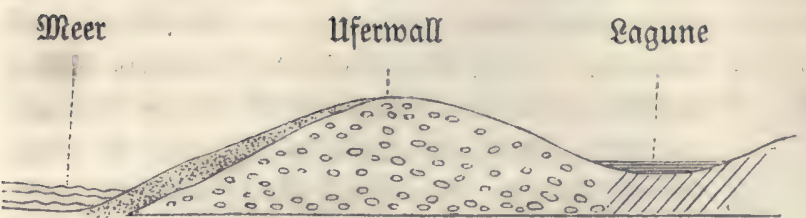

pfungen billoet. \&eg= tete etzengen fich auch, bei bem lleber= treten bon Ieidhen, Seen uno jelbft beim Meere. Die \&agunen (જig. 177.) geben hierbon ein $\mathfrak{B e i}=$

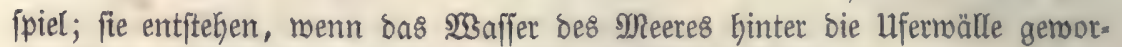
fen mirb, und nidjt mieber zum Meere zutüaffiégen fann.

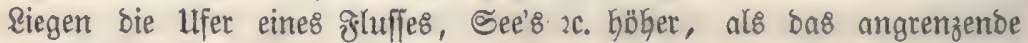
Sand, fo bringt bas $\mathfrak{W a f f e r}$ bei hohem Stande bon unten auf an bie Dber= flädje bes Bodens und bleibt fo lange ftehen, bis ber $23 a f f e r f t a n \delta$ mieber $a b=$

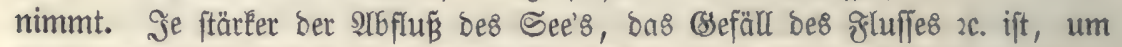
fo fonneller miro fich folches Seifmaffer, mie man es mennt, berlieren.

\section{B. YGleitung bes $\mathfrak{B a f f e r s}$ in offenen (Sräben und $\Re a=$ nălen.}

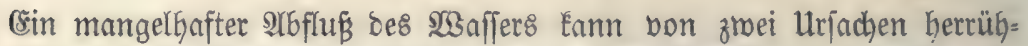

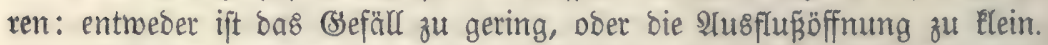

Im erfteren zralle hat man nackzulehen, ob nicht nach irgend einer all=

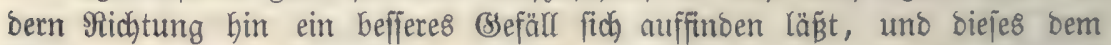

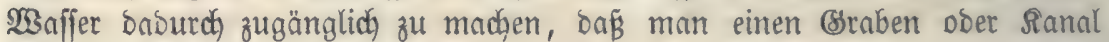
ziegt und Den Damm burdjfticht, melcher biejes Befäll bisher ben 23 affer

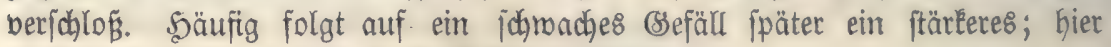
genügt es, wenn man exfteres gehörig vertieft.

grüffen berfdafft man ein größseres (sefäll, menn man bie stümmen

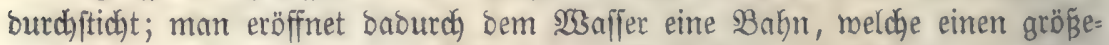
ren Neigungsminkel befigt, ober fürzt Den $253 e g a b$, Den baffelbe zu burchlaufen Gat. Eagumen Eann man entmeder nady bem Eande ober nach bem Meer

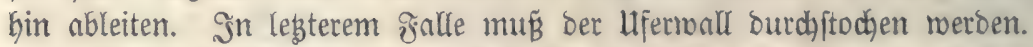

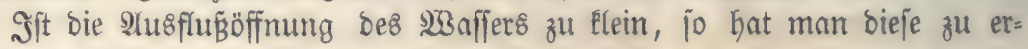
meitern.

Bei ber SYnlage von (Entwäfferungen reid)t man gemöhnlid mit einem

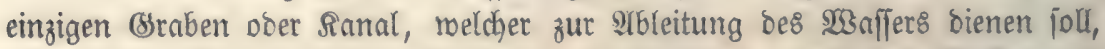

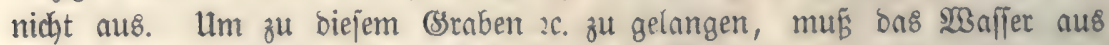

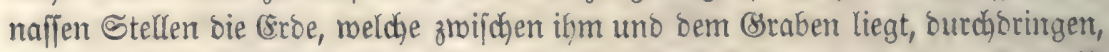

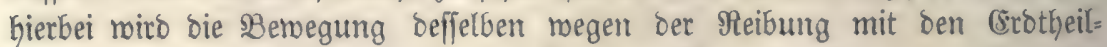

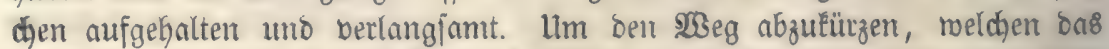

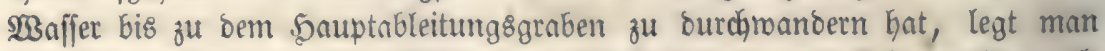
bon ben naffeften Stellen (Iümpeln, Waffergallen) aus Eleinere Sammel= 


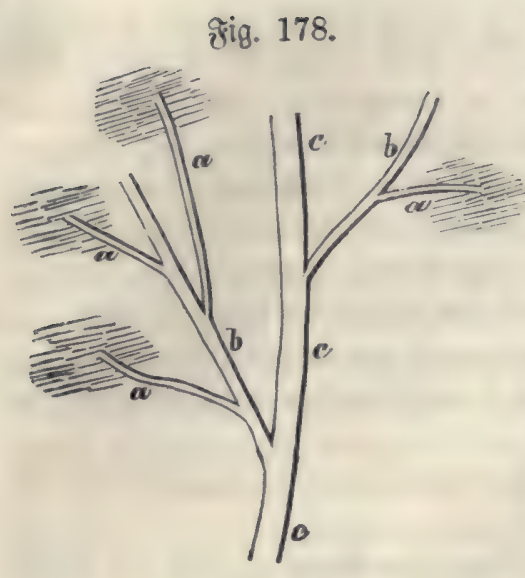

(Sräboben a (જ̊ig. 178) an uno verei= nigt bas 2 affer, melches biejelben auf= genommen haben, in einem etwas grö= Beren 3uleitungsgraben $b$, ber onffelbe enolich Dem Sauptableitungsgraben c zu= fübrt.

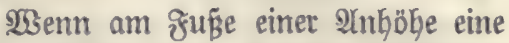
Berjumpfung ourch Quellen entitanden ift, fo Earn man biejelbe ganz einfach in ber 23eife bejeitigen, bais man ftatt mebrerer ธammelgräbchen blos einen a (‡ig. 179) runo um bie 2tntöbe anlegt uno aus biejem bas $23 a f j e r$ unmittelbar in ben 5auptableitung8ggraben b einfübrt. (58 ஓig. 179.

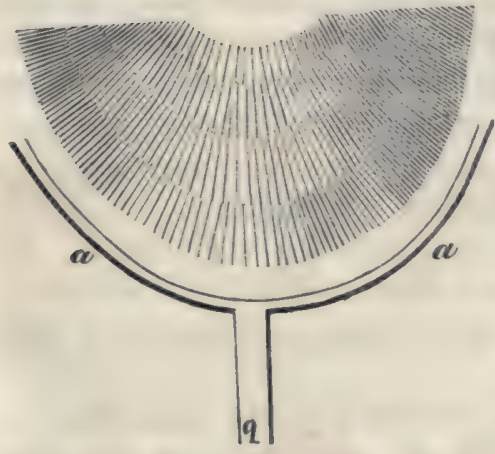
lammelt fich bann bas 2 Saffer, rwenn e8 von ber Inböke Gerabfommt, in a unb verbreitet fidf nidjt weiter bon berjelben.

Die Ridjtung ber Braben uno Ranăle ergibt fich idyon aus ber sinie, weldhe das bei hohem Stande abflieğenbe $\mathfrak{W a}$ affer ein= iळlägt; um ganz ficher zu gehen, be= ftimmt man aber bei größereat Entwäfle= rungsarbeiten bกรి (sefäll nod) mittelift ber $\mathfrak{B a f f e r m a g e . ~}$

Das Befäll für bie 2lfzugsgräben be= fitimmt fich rad, ber Menge bes abzulei= tenoen 2 affers und nad, ber Bejuaffen=

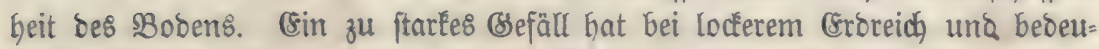

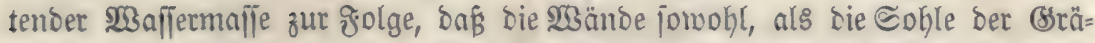

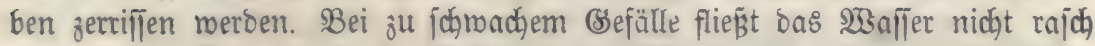
genug $a b$, meil es burch bie Reibung ober Slobäfiton am Boben feitgehalten rirb.

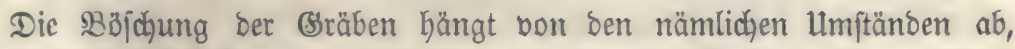

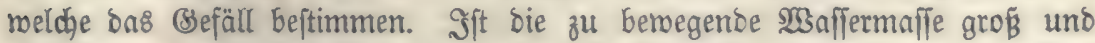
Der SBoben loçer, jo Gat man ben (Sräben eine ftärkere Ylusladung zu geben, als unter umgetéteten Berbältniffen. 2Uuf bintendem Boben reidjt man mit

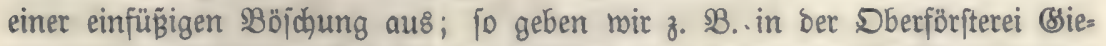
B̈en ben gemöhnticjen entrwäfferungsgräben, von benen wir jäbrlich biele tau=

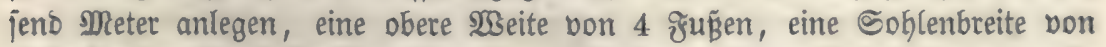

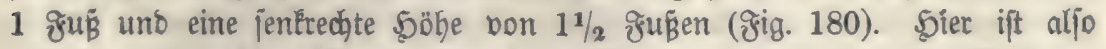
$\mathrm{ce}=\mathrm{ag}=\frac{\mathrm{cd}-\mathrm{ab}}{2}=\frac{4-1}{2}=\frac{3}{2}$, femer $\mathrm{a} e=11 / 2=\frac{3}{2}$, alfo 
Æ̊ig. 180.

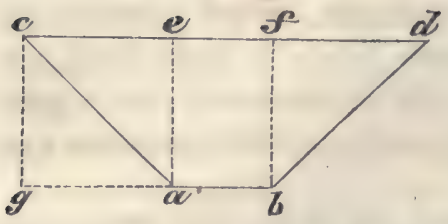

c g : ag $=\frac{3}{2}: \frac{3}{2}=1: 1$. Dieje Frorm ber Sräben bat fich in saufe ber

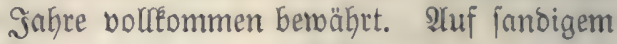
Terrain erbalten bie Bräben aber eine grö= Bere obete 23eite, bamit fie nidjt jo balb burdh ben Sand zugeidyemmt roerben,

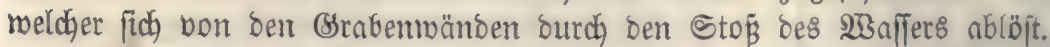

Bei Ranälen bepflanzt man bie Uferwämbe zur beffern BBefeftigung nod mit Weibenftectingen Dber belegt fie mit Fajahinenwellen, bie man burdh ein=

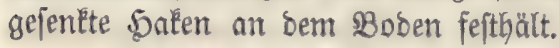

$\boldsymbol{\gamma}$, Ableitung Des Waffers in Unterorains, Drainröhren, ober mittelft Berjentung.

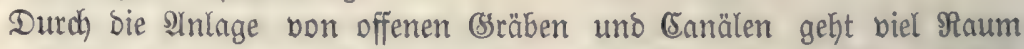

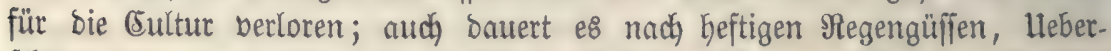
fonnemmungen 2c. oft zu lange, bis ber Boben gehörig troden gelegt ift. Die=

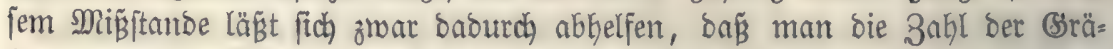
ben vernebrt, allein bann würbe die fläche bes culturlandes noch neiter ber:

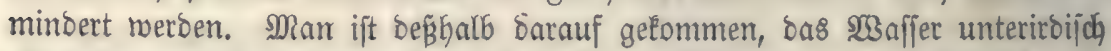
abzuleiten. Diejen 3roed erfüllt forohl bie 2rnlage von unterbrains uno bie eigentliche Drainage, al\& audh bie Berjentung Des $\mathfrak{W a f f e r z ి . ~}$

శig. 181.

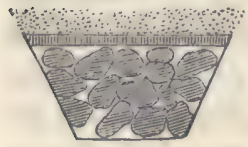

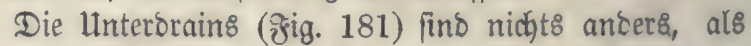
(Sräben, meld man mit Steinen ausfüllt, uno mit Steint= platten ober in beren (Ermangelung mit Reijig. uno nad)= Ger mit rerbe bedectt.

3ur eigentlichen Drainage, weldhe gegentwärtig in

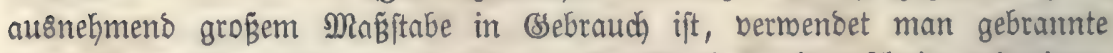

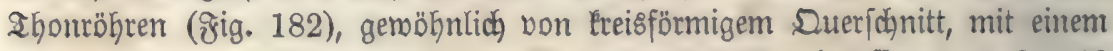

ঔig. 182.
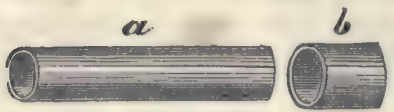

Durdmeffer von $2-18$ (Sentimetern uno einer Ränge von 30 bis 45 cents timetern. Dieje RB̈bren

werben einfach an einander geftog̈en und an ber \$erbinoungsfitelle burch eine Eleinere, aber weitere Röbre b von gleichem Material (Muff) zujammenge= Galter.

Man unterfheibet Rebenbrains unb Saupt= ober Sammelorains; erftere

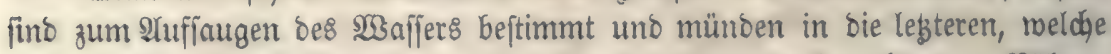

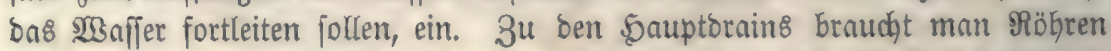

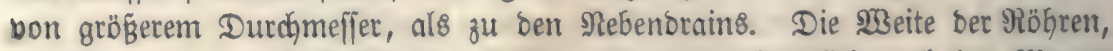

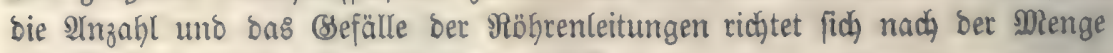
bes $\mathfrak{2} 3$ affers, melche abgeleitet werben folr.

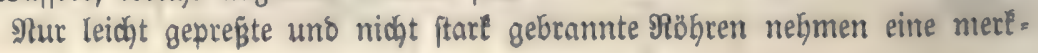




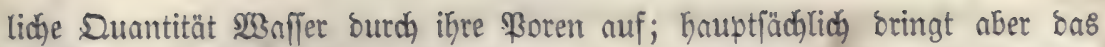

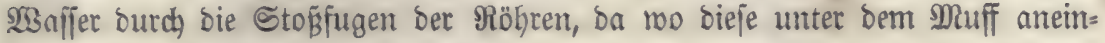
anber grenzen, eir.

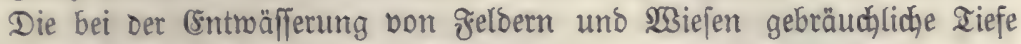
für bie Draintöhren beträgt $60-120$ Centimeter; Die Đauptorain\& fommen etwas tiefer, als bie Rebenornins zu liegen.

Somohl bie eigentlidge Drainage, als aud bie Itnterorains fömen in

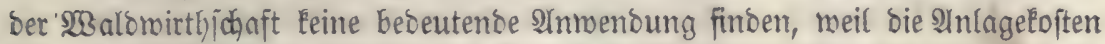

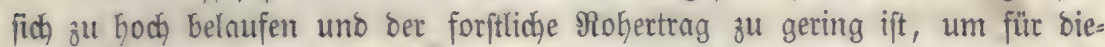
jelben ein Alequibalent zu bieten. Die Entmäfferung eines Sectare Ranbe\&

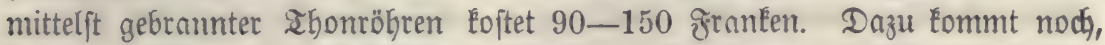

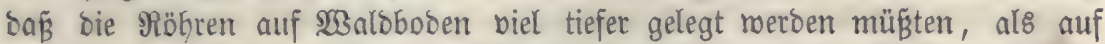
Ydeerlant, weil jonft biejelben beim IImgraben ber Bäume, beim Roben ber

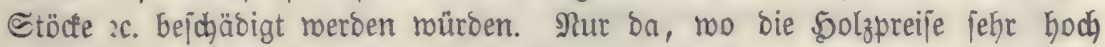
ftehen, E⿱丷ounte fich bie Drainage vielleidjt empfehlen. - Man hat biejelbe für Frorftgärten borgejchlagen. Arllein aud hier ift fie entbehrlich, meil ber Forft= wirth bei ber $23 a h l$ ber socalität für joldhe Gäarten faft immer einen grofien Epielraum hat uno leicht §lächen auffinoen wirb, weldhe Eeiner Entroäfferung bebürfen. Der einzige gall, auf meldhen fid bie Arnwenoung Der Drainage

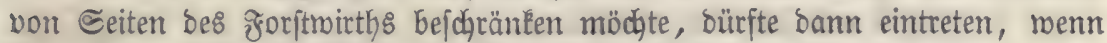

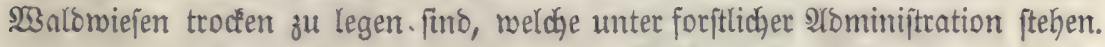

gig. 183.

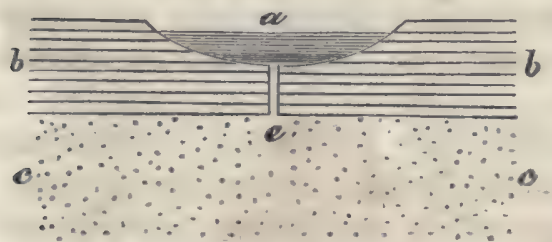

(S⿱乛⿻上丨 Eommt zumeilen vor, baß́ bei naffen Stellen a (ð̊ig. 183) unter ber undurdhlaffenocn ङdhidjte b, mel= die bie Berfumpfung bemirlt, eine burchlaffente c fich befindet. Şier tann man bie säffe unterirbifd ab= leiten, wenn man bie unoutchlaffente Shaidfte bei e Durchbohrt. Diefes Berfahren ift neuerbings in Grantreich öfters mit orfolg in Ânwenoung ge= bracjt morden.

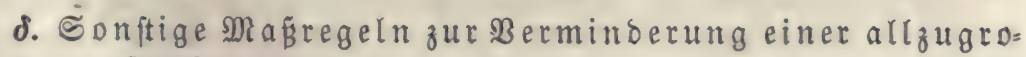
Ben $B$ odenfeudtigeit.

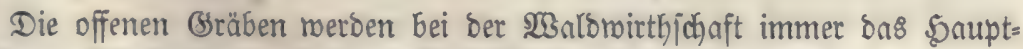
Mittel zur Arbleitung ber Bobennäffe bleiben, außzerbem läät fid) aber auf bie Berminderung ber leşteren nody burdh bie YYrt ber $\mathfrak{B a l b b e h a n d l u n g ~ e i n w i r k e n , ~}$ 3. B. baburdh, daßs man an naffen Gtellen bas 5olz nicht jo bicht ergieft,

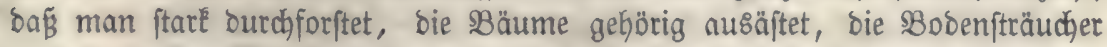

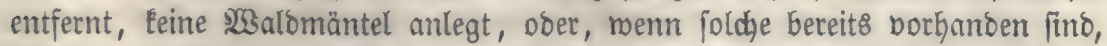

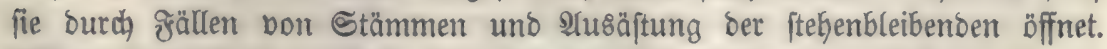

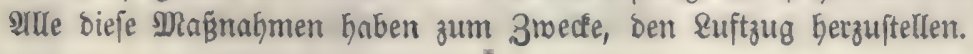




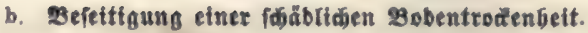

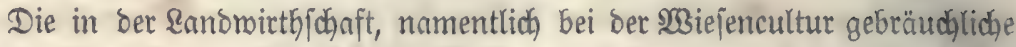

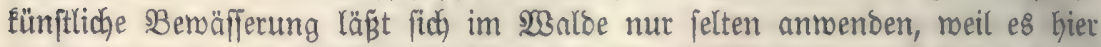

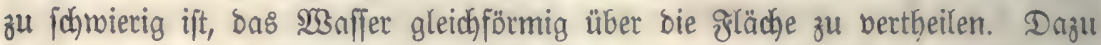

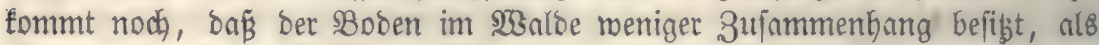
bie mit einer (Graहnarbe bebedten $\mathfrak{W i e f e n , ~ u n o ~ b a h e r ~ b e m ~ 2 b j c h m e m m e n ~ u n = ~}$ termorfen ift.

Die Maßregeln, welche ber Forftman! zu ergreifen hat, um eine grö= Bere Bodenfeudjtigleit im sigalde Gerzuftellen, beftehen Gauptfädhlich in bem Entgegengejegten von bemjenigen, maŝ unter $\delta$. über die Bెejeitigung Der

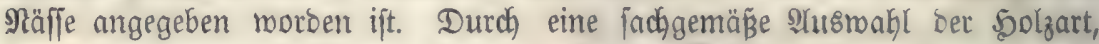

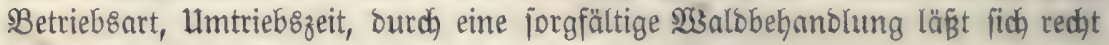
gut auf bie Crrbaltung ber Bobenfeudjtigkeit einwirken.

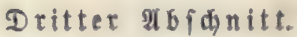

\section{unteriudug ber foritioli Standortigute.}

(Bonitirung).

\section{Begriff utb Bwed ber Bonitinut.}

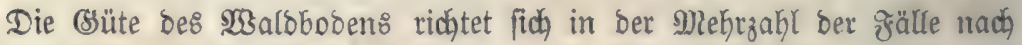

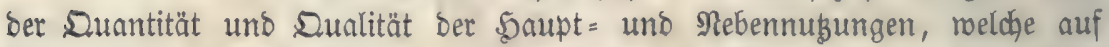
ifm erzogen merben Ënnen; bie Bonitirung ber Stanbortsgüte fällt Daher mit Der Borau\&befitimmung Der (Erträge zujammen, weldje irgend ein Stano= ort makridheinlicher 2 Seije liefern mirb.

Die Bonitirung. findet ihre Gauptjächlichjte Ŝlnwenoung im $\mathfrak{3 a l d b a u}$

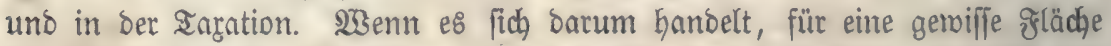

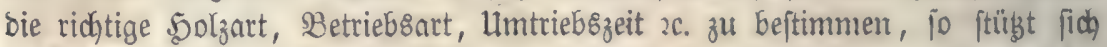

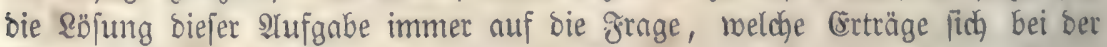
S⿱⺈

In ber Taration ift bie Bonitiung ganz unerläplich, um bie Saubar=

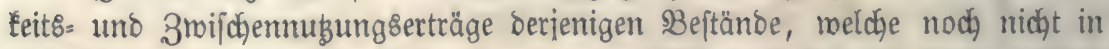
bas Arbtriebsalter getreten find, fo wie von $B$ löB̈en, melche angebaut roerben jollen ober Ënnen, zu ermitteln.

\section{Berfabren zur Bonitirum.}

\section{a. Directe แnterfudung ber ซactoren ber Otanbortogüte.}

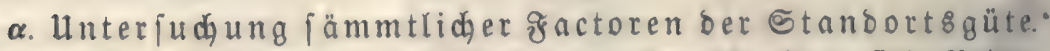

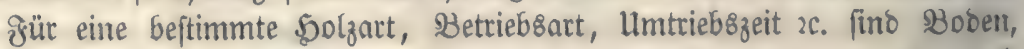
sage uno Silima bie conítanten Bebingungen bes \$̧olzmadysthumb, aljo auch ber Crrnoteerträge; zu jenen ftänbigen §actoren tommen nod) einige andere, 
melche nicht fo regelmäß̈ig auftreten, mie z. $B$. Injectenjchaben, feuter zc. Die Unterjudhung biejer Factoren gehört nidjt Gierher; ber (Einflü, neldhen fie auf

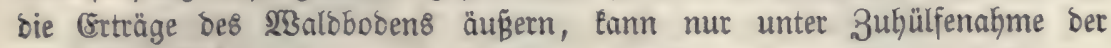

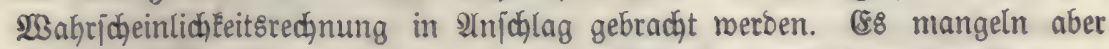

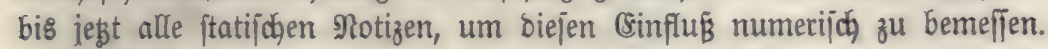

$203 a 8$ bie Factoren von Boben, Eage uno Slima anlangt, fo Eennen wir bon biejen menigitens biejenigen, weldje für bas \$ Jolzmachsthum entichei=

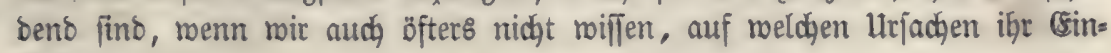
fluß berubt.

(58 fragt fich nun, 06 man burd) birecte Unterjudfung jener gractoren ben Ertrag irgend eines ๔tanoorts ermitteln Ënne.

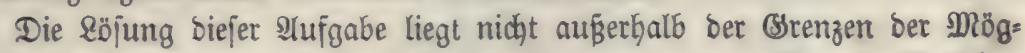

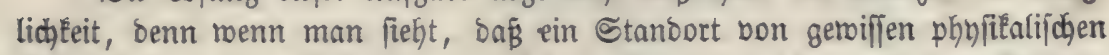
Cigenjohaften einen \$olzertrag = a Gerborbringt, weldher nur Das \$robuct jener Bigenjichaften ift, jo muв man burch Unter[uchung ber Factoren ber

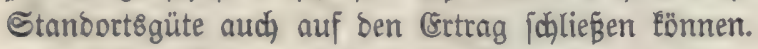

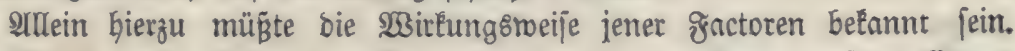
Man bätte borerft nötbig, zu riffen, wie jeoer einzelme ซactor auf ben (Ertrag influirt.

W3enn man eine nod jo genaue Bejhreibung bon Boben, \&age und Slima irgend einer socalität angefertigt bat, jo ift bod, Eein froritmann in ber

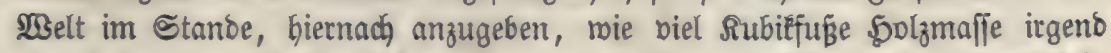

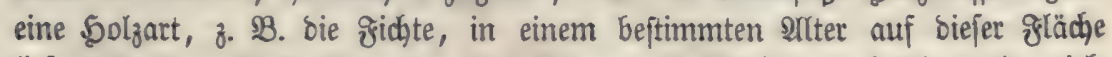

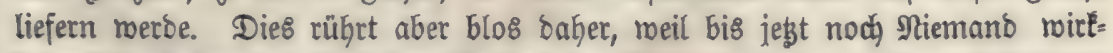

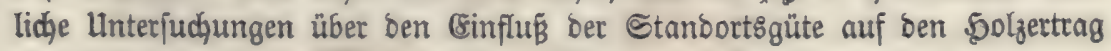
angeftellt hat.

Cinige Grtragstafeln enthalten zroar eine Bejdreibung von Boben,

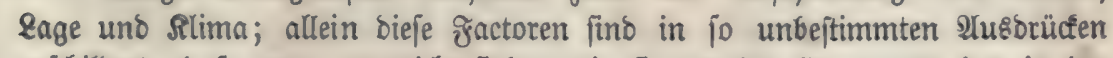
gejdildert, bas man gar nidjt fieht, wie fie an Der Erzeugung ber in ber Etragstafel angegebenen \$olzmaften betheiligt fino.

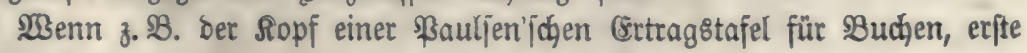
Bonităt, Lautet:

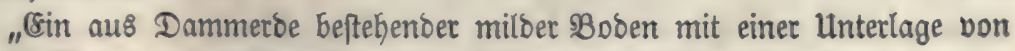

SalEpteinent ober Mergel in einer kühlen uno frijđen \&age,"

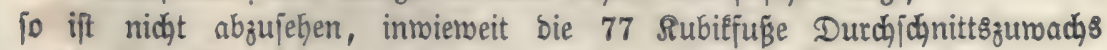

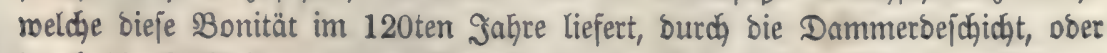

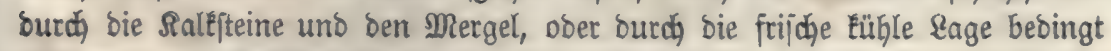
merben (ganz abgejehen bavon, baś in ber ßauljen'joben BBejchreibung biele an= bere gractoren bes \$olzzumachjes gar nicht aufgeführt fino). Man Eann, mit einem Worte, auళ Dem Sopf jener (Ertragstafel uno bem beigefügten \$olzer=

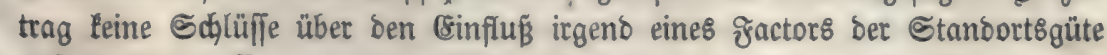
auf bie ఏolzmaffenerzeugung ableiten, fo baß̉ man etroa angeben lönnte, wie 


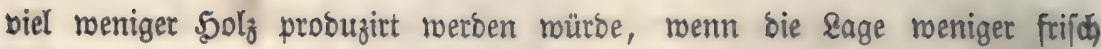
wäre.

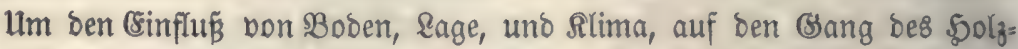
zumachjes zu ermitteln, müßte man in einem normal bejchaffenen $\mathfrak{W}_{3}$ alde alle Factoren ber Stanoortв̈güte, aljo z. B. Die mittlere Temperatur, den Bang

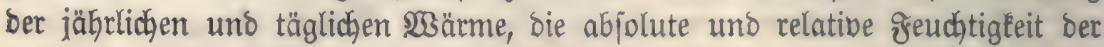

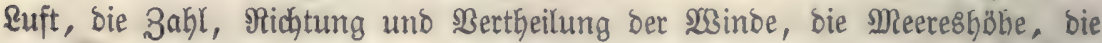

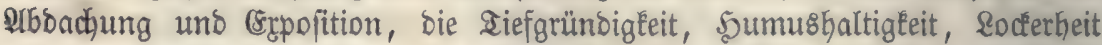

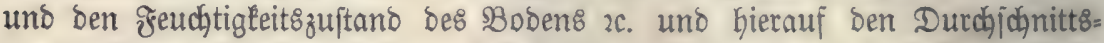
zumachs des auf biejem Standort Befindlichen 5olżbeftanbes unterjuchen. Diejer

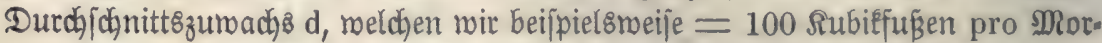
gen annefmen mollen, ift ohnzmeifelhaft ein \$robuct aller jener factoren.

Nun müB̈te mon einen andern Beftano ausjuchen, meldher in Bezug

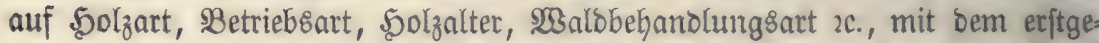
nannten Beftande übereinftimmte, und Defien Factoren ber Stanbortsgüte bis auf einen einzigen genau bie nämlichen rären. Der eine abroichenoe gactor fei, z. B. Die Arbsadjung, fie betrage Gier 20, Dort 15 Srabe. Der

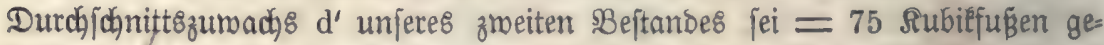

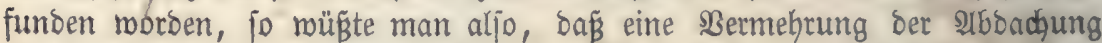
um 5 srabe einen 3uwadjsausfall von $100-75=25$ subiefüen ober von 25 ßrozenten bemirte.

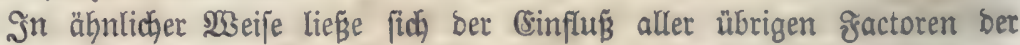
Stantortsgunte beftimmen.

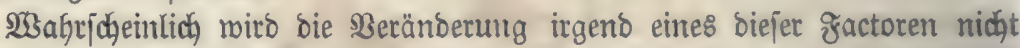
überall ben nämlidben (Effect in Bezug auf Den \$olzzumactb herborbringen;

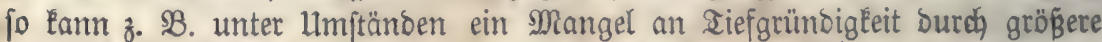

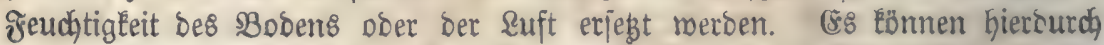
febr complizirte ßerbältniffe entftehen, meldje unjere Ilufgabe erjoftveren, aber unlö86ar ift fie barum noch nidht gemoroen.

Bis jest fehlen indeffen alle vorbereitenoen Unterfudungen, um aus Den Factoren ber Standortsgüte unmittelbar ben Ertrag ableiten, ס. ந. boni=

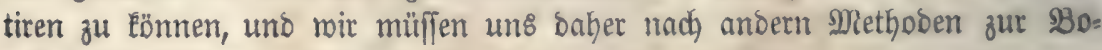
nitirung umjehen.

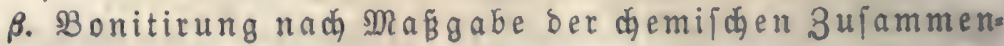
үęung bes $B$ odens.

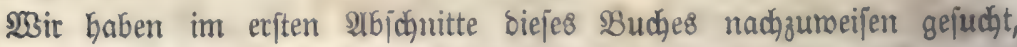

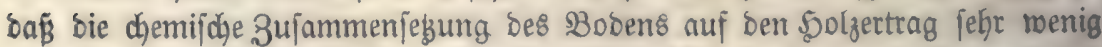
ober gar nicht influirt, weil unjete \$olzgerwächje eine geringe Cumme von anorganifchen Stoffen aus bem \$Boben aufnebmen, uno jeber $\$$ Boben genug von biefen enthält, um ber $133 a l \delta b e g e t a t i o n$ iłren vollen Bebarf liefern zu

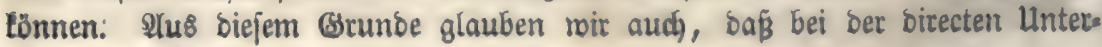




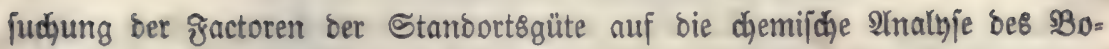
bens gar leine Rücoficht zu nebmen jei.

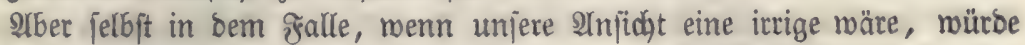

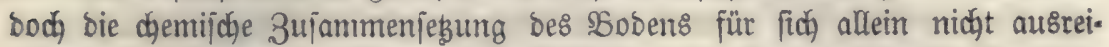
dhen, um bie Stanoortogüte zu djaracterifiten. Der Ertrag würbe immerfin

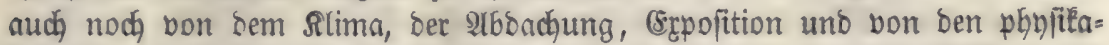

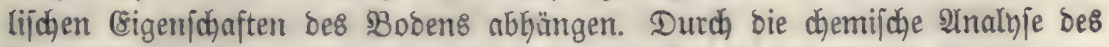

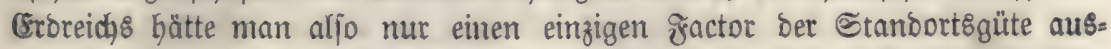
findig gemadht. Siernach müge man ben $223 e r t h$, roldhen bie dgemijoje un=

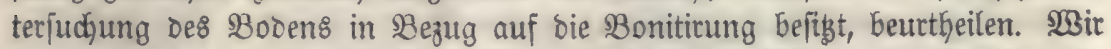
fino genöthigt, bem borliegenden (Segenftanbe einige 2hufmerkfaméeit zu mib=

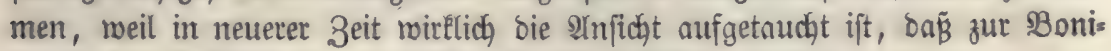

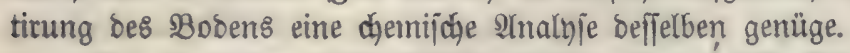

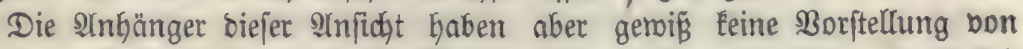

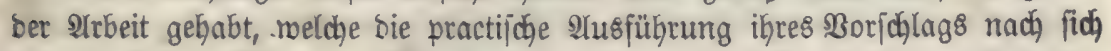
gieben wütoe. Sebe nur einigermafien genaue djemifhe Bobenanalyje erfor= bert wenigitens 14 Iage 3eit, wie ber $\mathfrak{B e r f}$., meldyer fich) längere Zeit mit

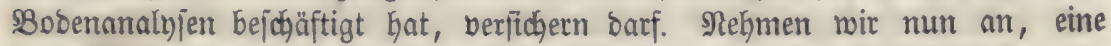

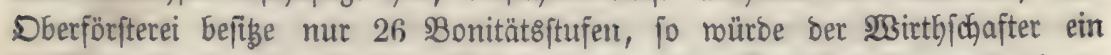
bolles Эabr baz̆ brauchen, um die Bobentanalyjen für feinen 9rominiftrations=

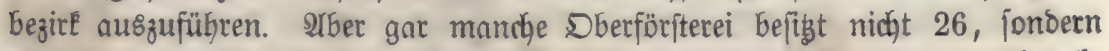

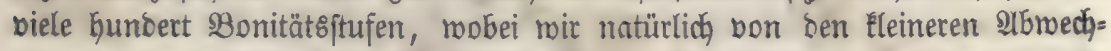
felungen in ber djemifdjen 3ujammenjebung bes Bobens, meldie faft bon Sdyritt zu Sdyritt ftattfinoen, abgejefen baben.

Diejenigen bon unjeren sejern, welche fidh eine genaue Renntniß bon bem Berfahren berjofaffen wollen, weldyes man bei ber quantitativen dhemi= ichen Inalyfe des \$Bodens einzuhalten Gat, bermeijen mir auf bie borzügliche

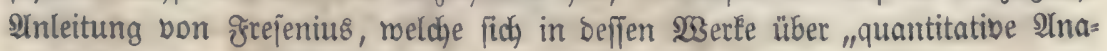
Inje" fintoet.

Für Diejenigen, meldhe nidjt im dyemijohen saboratorium gearbeitet baben, aber bod einen, menn auch nur oberflädglidgen Begriff von einer Boben= anthlyje zu erlangen wünjđjen, mollen roir ganz kurz aubeinanderjegen, wie man quafitativ bie 3u|ammenjebsung bes Bobens ermitteln fann, uno bemet: Een hierzu, daßs bie Methobe ber quantitativen Analyje mohl zumeilen, aber nidht immer, mit bem für bie qualitative Unterjudjung geeigneten Berfabren übereinftimmt.

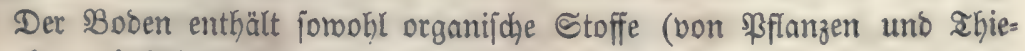
ren), als aud Mineraljubjtanzen.

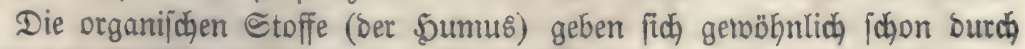
Den blofien Ânblide zu.erËennen. Sit wenig Sumus borbanten, fo weift man ifyn nad, indem man bie Eroe mit Eoblenjaurem Sali (ober auds Natron)

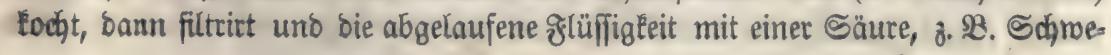




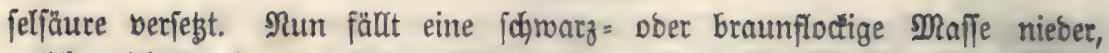

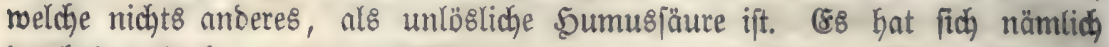
burch bas Sochen mit Dem Âtléali ein humuriaures Salz gebildet; gibt man jęt ๔d)mefelfäure zu, fo miro biejes Salz zerlegt; es entifteht idjmefeljaures

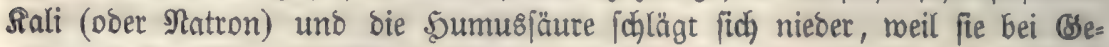
genmart einer Mineralfäure unldstich in $\mathfrak{B}_{\text {affer ift. }}$

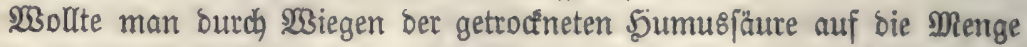

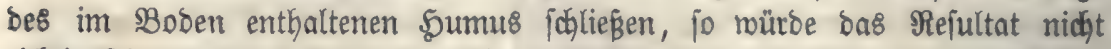

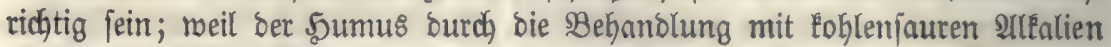
in jeiner 3 ujammenjęung verändert roorben ift.

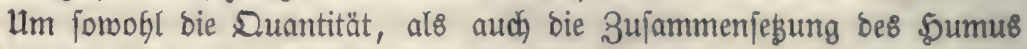
im Boben ganz genau zu erfabren, bazu gibt es nur eine einzige ridgtige Me=

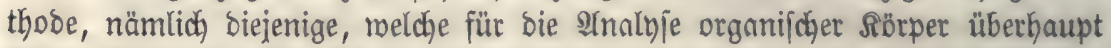
üblich ift, uno weldhe fich barauf gründet, baß̉ man ben Rörper mit Supfer.

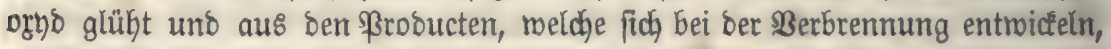
bie 3u[ammenfesung bereçnet. (88 würbe uns zu weit füfren, wenn wir biefe Methobe hier im Binzelnen betrachten wollten; fie ift in jebem Rebrbuda ber analytipchen (Shemie (子. B. in bemjenigen von grejenius) bejphrieben. Dieje Methode jeşt aber voraus, baß́ man ben Roblenjäuregehalt ber lohlenjauren Salze bes Bobens borker beftimmt habe, bamit man nidyt bie Sohlenfäure,

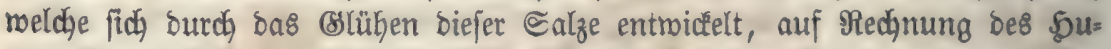
mus bringe. Alud auf etmas Siryftall = und 5ybratwaffer ber anorganifichen

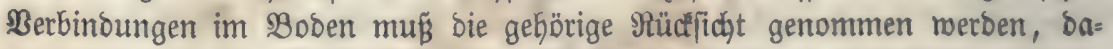

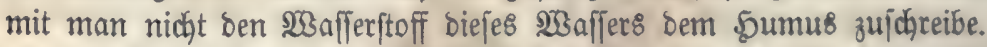

Wollte man bie Menge des Sumus blos burdh ben Serwidatsberluft beftim= men, weldhen bie zu unterjuchende (srbe bor uno nady bem slühen zeigt, fo würbe bas ఇejultat nicht richtig ausfallen, roeil einestheils bei bem \&lühen

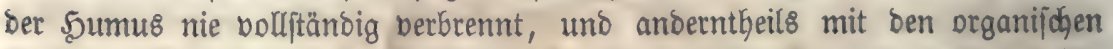
Subftanzen aud bas Srtyftallifations: und stybratraffer ausgetrieben wirb.

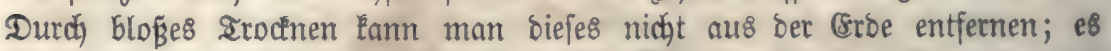
entmeicht erft bei einer remperatur, meldye fohon zerftörend auf ben 5umus

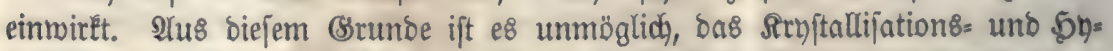

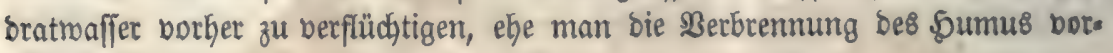
nimmt.

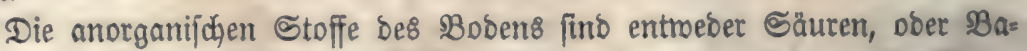
jen, obet Salze. ltm fie zu beftimmen, bringt man bie Crrbe in 2lufbjung

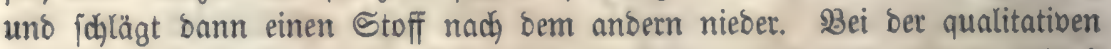
Innalyje ift bies b̈fters nicht nöthig, hier Gat man auch nod andere Mittel, um bie in ber ঐuflöiung enthaltenen ङubjtanzen zu erfennen.

Die Cilicate im Boben (z. B. Der ahon) löfen fich gerwöbnlid exft bann, nadjoem man fie mit 2ltealien ober Saryt geglüht bat. Man wenbet zu biefem 3rode gemöbynlich Baryt an, meil bie Erobe nur feḅt felten an uno 


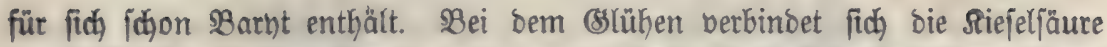

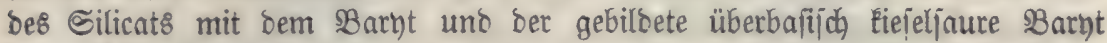

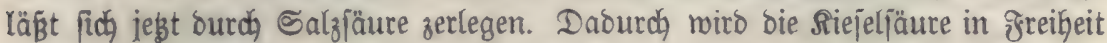
gejegt. Sie erjobeint in ærorm einer Ballerte. Srod"net man jest bie ganze Maffe, fo miro bie Siejelïäure in Säuren uno $\mathfrak{3}$ affer unlöslich; man Eann fie baher abjcheiden, wenn man ben übrigen $\mathfrak{T h e i l}$ ber geglühten Maffe mit Salziäure auflọ̈t.

Sn ber \&öjung befinoen fich) nun alle Bajen uno Säuren der Crroe, aubfoflieglich der Riejelfäure. Man jegt zu biejer \&öjung Sohnefelammonium, leğteres joblägt (sijen, Mangan, phosphorjaure Eroen und Thonerde nieber.

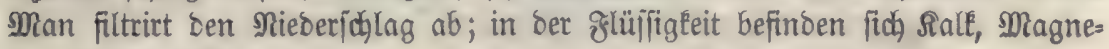
fia, Rali uno నatron.

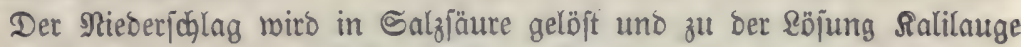

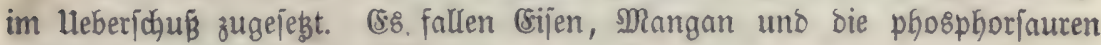
Erben. Belöft bleibt bie atonerbe.

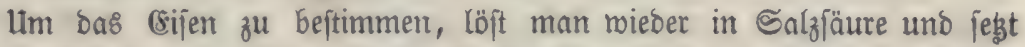

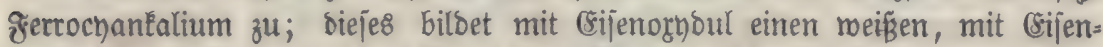
oryo einen tiefblauen Mieberjojlag. Das Mangan läß̈t fich finden, wenn man

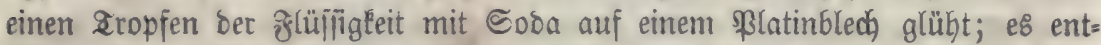
fteht manganjaures গatron, meldges an jeiner grünen そarbe lenntlich ift. Bon Der Beftimmung Der \$hosphorfäure merben mir nadher handeln.

Utm bie Shonerbe, weldje vorbin in \&öjung blieb, nod gentuer nadzu= meijen, neutralifirt man $\delta a \delta$ in ber \&lüjifigeeit enthaltene Sali mit Salziäure

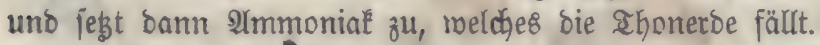

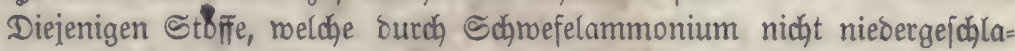
gen rurben, fin

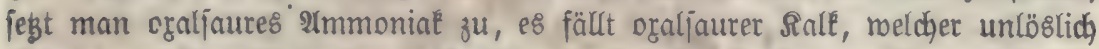
ift, nieber. Die 9Ragnefia ichlägt man mit phosphorjaurem 2lmmonial als phosphorjaure Magnefia nieder. Nun Gat man noch Sinli und Natron in ber

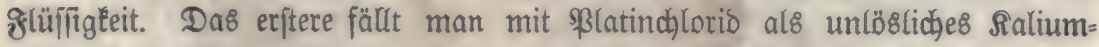

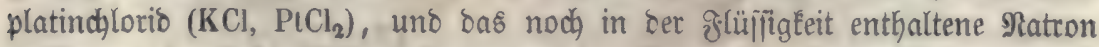
meift man burd bie Eäthrofirflamme nach. Bringt man nämlich etras bon

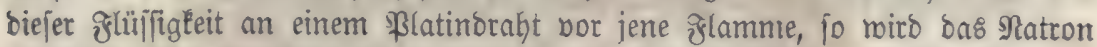
zuerft zu Natrium rebugirt, berbrennt aber bann mieber mit Sauerfitoff zu Natron, nobei fich bie Flamme beutlich gelb färbt. Dieje grarbe gibt bas

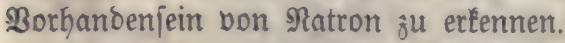

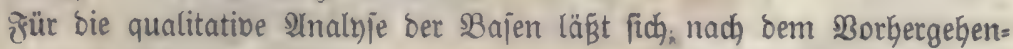
ben folgenter Schema auffitlen:

2uf 3ujaß von Sdjoefelammonium

fallen I

Eifen, Mangan, Zhonerbe, phosphorjaure croen. bleiben gelö) II Salé, Magnefía, Rali,

Natron. 
Die in I gefälten Stoffe weroen in Salzfäure gelölt; zu ber \&öjung jebt man salilauge im lleberídub

$$
\text { (Es fallen } \mathrm{A}
$$

Gifen, Mangan, phosphorjaure

$$
\text { Eroen. }
$$

Man löpt in Salz[äure uno reift nach)

a) Sijen mit frerrocyantáalium

b) Mangan burch (slüken mit હoba nuf einem \$latinblect.

\section{\&̈̈jung II}

a) Salf wiro mit oraljaurem 2 tmmonial nadgemiefen.

b) Magnefia riro mit phosphorjaurem P(mmoniak nadggetwiejen.

c) Sali miro mit \$latindylorio nachgemiejen.

d) Natron ertbeilt ber \&D̈throhrflamme eine gelbe そärbung.

Beftimmung ber Säuren. Wiie die Riefelfäure nadhgemiejen mirb, ift bereit8 oben gezeigt worben. 2Yüer biejer fommen im Boben nodh Soblen=

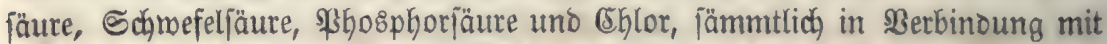

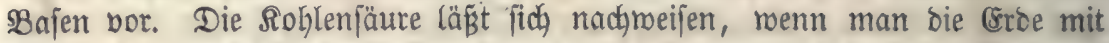

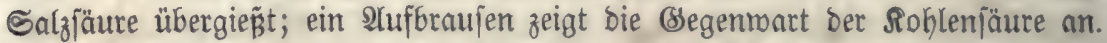

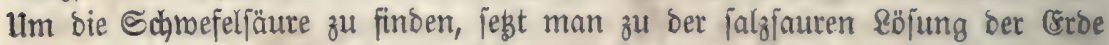

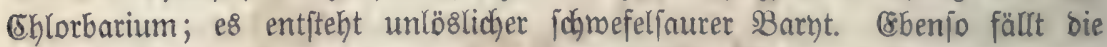

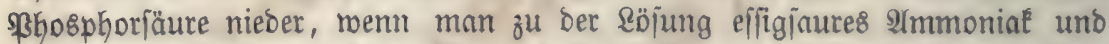
(Eijenthlorio gibt, es entiteht phosphorjaures (sijenoryd, meldyes in Eifigiäure unlöslich ift. Das chlor findet man, wenn man bie söjung mit falpeters

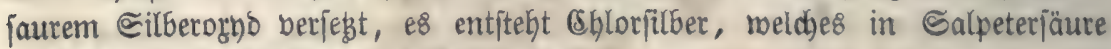

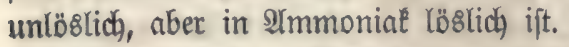

Snoem wir in Borjtehenoem eine Methode zur qualitativen Sinalyje bes Bobens mittheilten, hatten wir nux ben 3wed", Dem 2̂nfä̈nger einen beiläufi= gen Begriff von ber Sache zu geben. (58 gibt andere Methoden, weldae

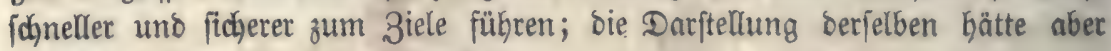
meniget unjerem 3roecfe entiprodjen.

\section{b. Sonittrug bes 8 obent nad feinem vegetabilifiben ueberzuge.}

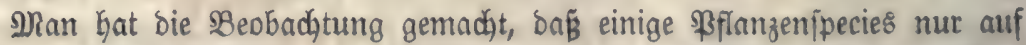
Böben von einer beftimmten mineralijosen 3uiammeniebung vorḱommen, ober bod) Dieje Bobenarten borzugstweije berwohnen. Man hat hiernad bodenftete uno bobenbolde ßflanzen unterjdieden uno biejes Bortommen zur Bonitirung be६ 3 obens benusen rollen.

Gndeffen finoet bie Bobenftetigfeeit nur für jeğr wenige Bobenarten ftatt; am beftimmteften ift fie ausgeprägt bei ben kochjal $z=$ uno Eallerbebaltigen Böben, neniget fichon beim Sanbe. Bobenftete Pflanzen für ben Ihon uno

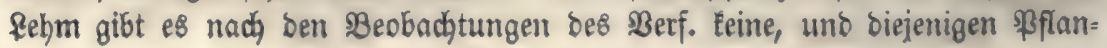


zen, weldhe $z$ o. B. auf bem ahone bfter exjdeinen, als auf anderen Bobenarten,

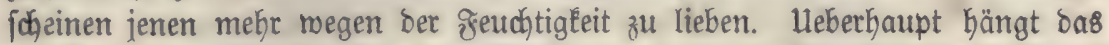

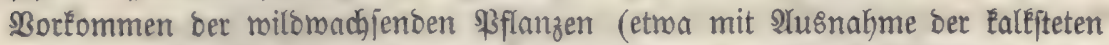

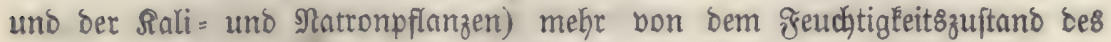
Bobens, als von beffen mineralijoter 3ujammenjegung $a b$.

Selbit wenn aber auch bie Saupt=8Bobenarten, melche wir unterjojieben baben, ihre bodeniteten \$flanzen befigen follten, fo mürbe uns bies nicht viel

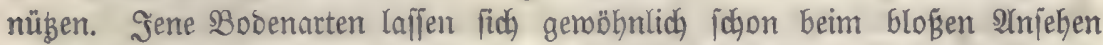

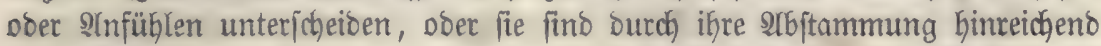

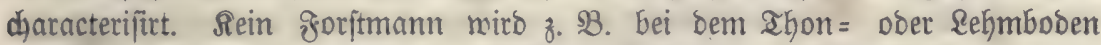
nach ben auf ifnen machjenden Fflanzen juchen, um bieje BBobenarten zu ertennen.

3ur Unterfijeioung ber Bodenarten leiften uns aljo bie bobentyolden jomohl, als bie bobenfteten SPflanzen einen nut jefir geringen Dienjt.

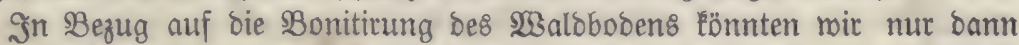
von ber Erfoheinung Der boceniteten Bflanzen Bebrauch madjen, wenn bieje

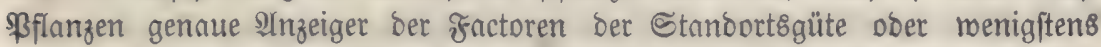

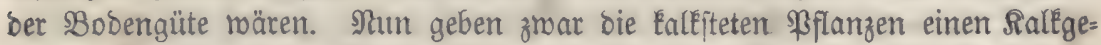

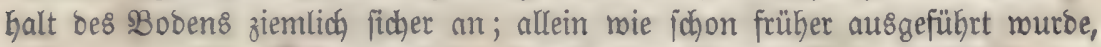

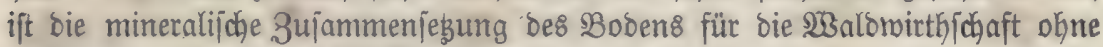
Bebeutung, und was biejenigen Pflanzent anlangt, welche an einen gemiffen

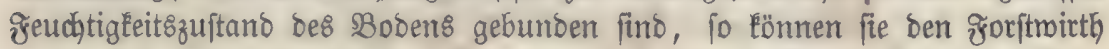

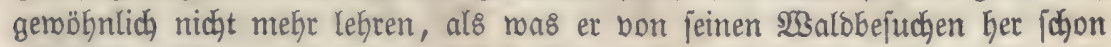
ohnebies meip.

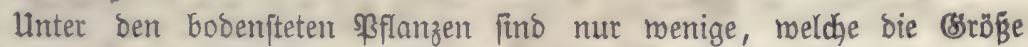
eines Straudases erreidhen; fie befizen Eeine tiefgehente 2 Burzeln uno lönnen

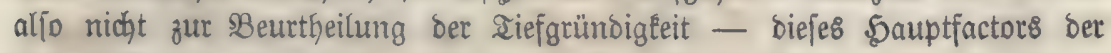
Bodengüte bemugt werben.

(sinige $\$$ Pflanzenarten, wie z. B. Digitalis purpurea, Epipactis Nidus avis, Atropa Belladonna etc. zeigen gemöhnlich einen Sumurgehalt beళ

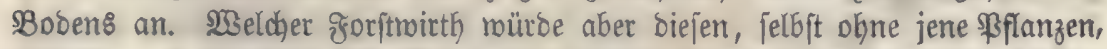
niđht bemerten! Das Nämliche gilt von ben Sumpf = unঠ Iorfgemächjen; Whem roird das Borhandenjein eines ธunpfes ober Torfgrundes entgeben!

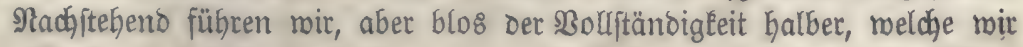

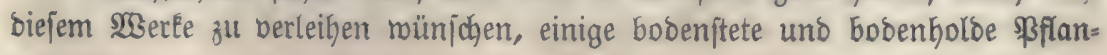
zen an.

Einen Behalt bes Bobens an Chlornatrium zeigen an: Salsola kali, Salicornia herbacea, Glaux maritima, Chenopodium maritimum, Triglochin maritimum, Rumex maritimus, Atriplex litoralis, Artemisia marilima, Plantago maritima, Glyceria maritima.

Ralfitete Pflanzen fino: Geranium columbinum, Coronilla coronata, Reseda lutea, Rubus saxatilis, Hieracium saxatile, Gentiana cruciata, 
Rhododendron hirusutum, Plantago montana, Sessleria coerulea, Phleum Micheli. Dieje Bflanzen tommen aber nicht blos auf einem Boben, melcher burdh Bermitterung von fohlenfauren Sale entitanoen ijt, fonbern auf allen Bobenatten vor, meld)e viel Salk enthalten, wie z. 2 . auf $\mathfrak{B a j a l t , ~ ( b e f l e n ~}$ Salégehalt fich von bem \&abrabor = Felsipath herjojreibt).

Ralegolde Pflanzen find: Gentiana ciliata, Anthyllis vulneraria, Veronica urticaefolia, Sedum Telephium, Primula veris, Vinca minor, Alchemilla alpina, Epipactis latifolia. Luzula maxima.

Sanbboben lieben: Elymus arenarius, Arundo arenaria, Carex arenaria, Festuca ovina, bromoides, duriuscula, Aira canescens, Statice Armeria, Plantago arenaria, Jasione montana, Dianthus arenaria, CalIuna vulgaris, Sarothamnus scoparius, Pteris aquilina.

2uf Zhonboben tommen Käufig vor: Stachys palustris, Lathyrus tuberosus, Sonchus arvensis, Tussilago Farfara, Hieracium grandiflorum, Thlaspi campestre, Serratula arvensis, Bromus giganteus, Dactylis glomerata.

Ginen Gumu\&haltigen Boben lieben: Digitalis purpurea, Urtica urens, dioica, Senecio vulgaris, Jacobaea, Epilobium angustifolium, Impatiens Noli tangere, Datura Stramonium, Fumaria officinalis, Epipactis Nidus avis, Lunaria rediviva, Lithospermum purpureo-coeruleum, Atropa-Belladonna, Arum maculatum, Asarum europaeum, Mercurialis perennis etc.

Die Torfgerbähje Gaben wir bereit\& $\subseteq$. 73. genannt.

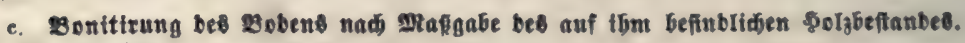

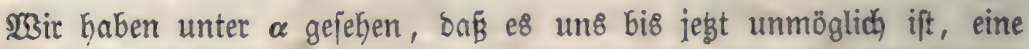
Bonititung bes $B$ obens burd birecte Unterfudjung ber gactoten yon $B$ oben,

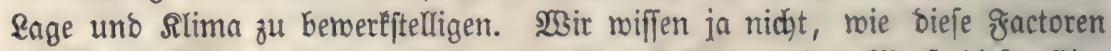

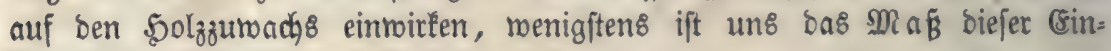
mirtung unbefannt.

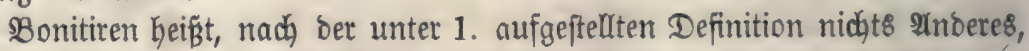
als ben Şaubarleitsertrag beftimmen. Diejen Eann man aber am einfachftén aus ber gegenwärtigen Solzmaffe bes Beftanbes felbft ableiten, benn in leģ=

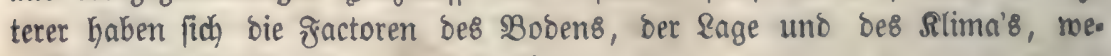
nigitens zum Iheil, idyon ausgejprochen.

Die unter $\alpha$ gejohilderte Methobe will jene gactoren birect unterfuchen, uno nad ifnen ben \$aubarkeitzertrag einer gläd)e bemeffen. Der Solżbeftano ift aber bas \$robuct der rinnirfung bon Boben, \&age uno Slima; feinte 5olzmaffe gibt in einer 3 abl ben (sejammteinfluß aller jener berfofiebenen Agentien ber Stanbort8güte zu erf̌ennen.

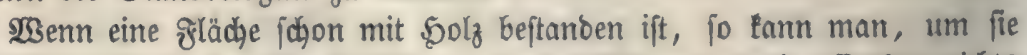

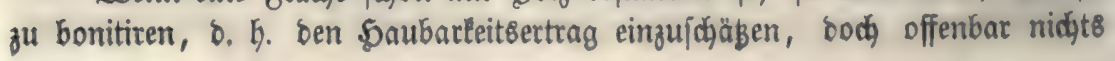


befferes thun, als fragen: Wie baben fich Boben, sage uno slima in bem Solzbejtanbe ausgejprodyen?

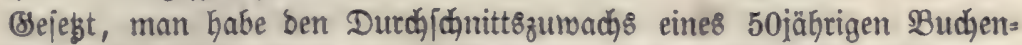
beftanbes gleich 47 cubiffufien pro Morgen gefunben, fo wiffen wir, baß

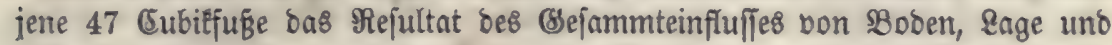
Rlima fino.

Nebmen wir nun weiter an, man habe bie Mafle eines anbern $B$ udben-

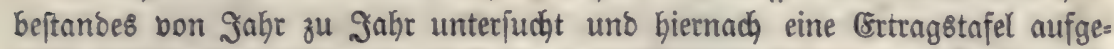
ftellt, nefymen wir weiter an, bieje Crttrigstafel meife für bas 50te Sabr eben=

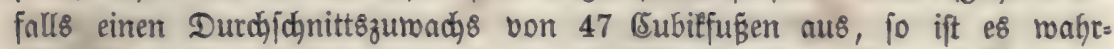

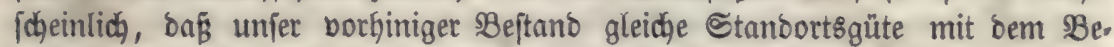
ftanoe, für meldjen bie Certragstafel entworfen ift, befitge. Dort, wie bier, haben Boben, \&age und Rlima im 50ten Jabre einen Durdjichnittzumadjs

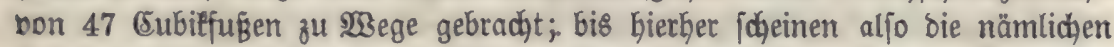

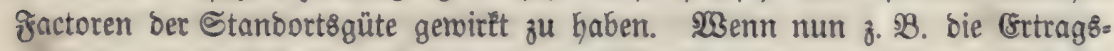

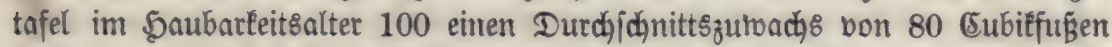

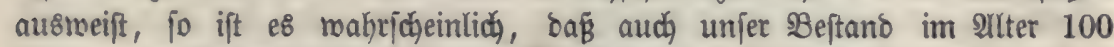
einen Durdhfdnittszumadhs von 80 (Eubiffupen liefern werbe.

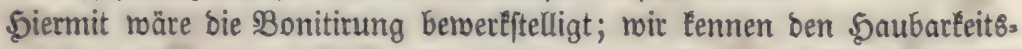
extrag, uno auch bie Durdfforftungen laffen fich aus jener 8rtragstafel ent. nebmen.

W3ir Gaben es oben blos als mabricheinlid) Gingeffellt, bá̈ eine (sleidh=

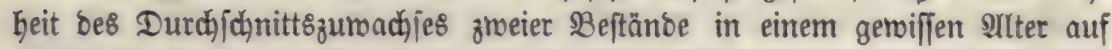

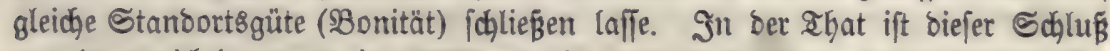
nur bann ridhtig, wenn jenes 2̂Ater nidgt meht meit bon bem \$aubarkeitsalter

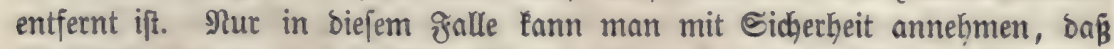

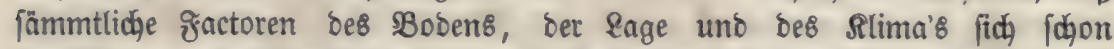

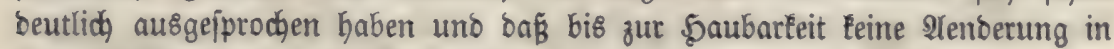

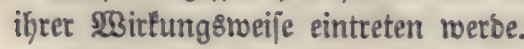

Itm unళ beutlidget auszubrücten, wollen mir ein sBeipiel von einet joldgen Qlenberung anfübren.

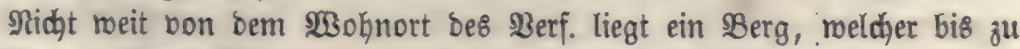
450 Metern Meereb̧öbe anjteigt. Diejer Berg ift, fonie bie 8bene, aus welcher er fich erhebt, mit $\mathfrak{B}$ udjen beftanden. Man hat nun bie Beobadhtung

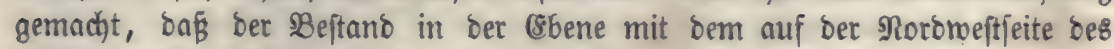

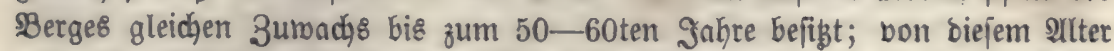
an änbert fich aber bas Berbältniß̄, bie Etangenbölzer auf bem \$erge fan=

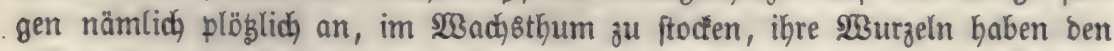
felfigen Untergrund erreidat, mähreno ber Bejtand in ber (Ebene nod) frỏblich fortmädfit. SBie man fiebt, waren bie Factoren ber Stanoortsgüte bis zum 50-60ten Jabre gleidh, nun änberte fidh ein einziger, bie Tiefgrünoigleeit.

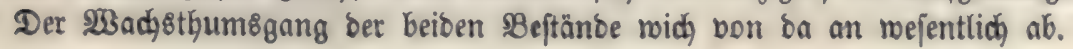


Sätte man aljo ben \$aubarłeitzertrag des Beftanbes auf bem serg nad) einer für ben $B$ ejtano in ber (Ebene entworfenen (8rtragstafel einjöäzen mollen, to müroe man einen Frehler begangen haben.

Wir fehen baher, bá̈ man bei ber Bonititung nad) Ertragstafeln im=

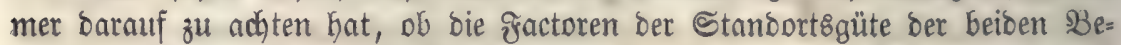
ftänbe übereinftimmen. Um eine ßergleichung anftellen zu Ënnnen, müß̈te bie

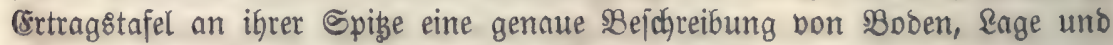

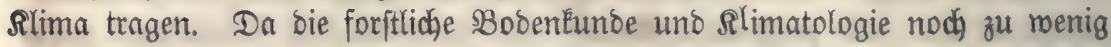

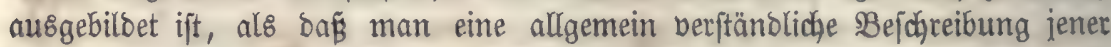

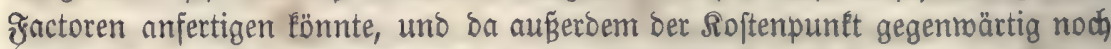
verbietet, jene sBejdyreibung auf eine methooijche unterjuchung zu grünoen,

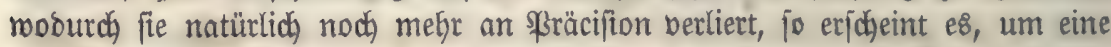
möglichft richtige sonitirung ơ bewerk̂ftelligen, nothmentig, zaß ber mit bie= fem (sejd)äft jid) Befaffende mur foldhe Ertragstafeln anmendet, meldye ex jelbjt entworfen bat. Dieje Bebingung, fo getedhtfertigt fie aud fein mag, läßzt fich indeffen nicht immer einbalten, nomentlich nicht in bem ơalle, wenn man bie

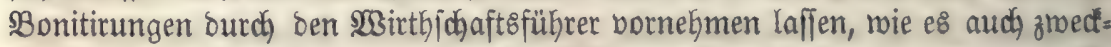
mäв̈ig ift, uno nicht ein eigens auf bas (5ejđäft eingeübtes ßerjonal verwenden will.

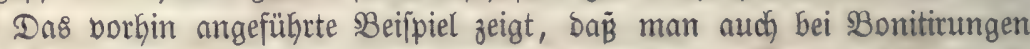
nach) (Ertragstafeln Unterjuchungen über ben Cinfluß Der Factoren ber Stant=

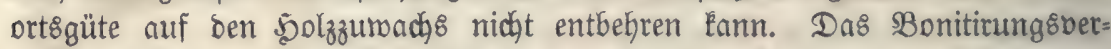

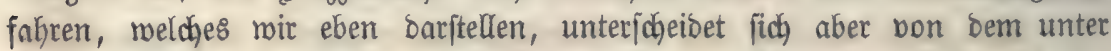

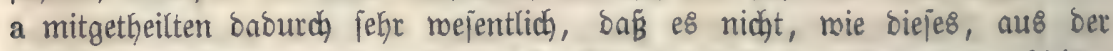
Unterfud)ung jebes einzelnen Factor8 der Standort8güte ben \$̧olzertrag ableiten

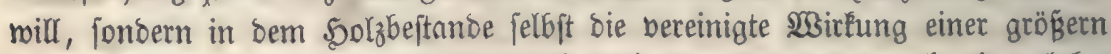
3 ahl biejer Fractoren erbliat, aljo aud biejenigen æactoren noch einmal be= fonbers in Rechnung ninmt, weldhe ber Crtragstafel und bem zu bonitiren= ben $\mathfrak{B}$ eftano nicht gemeinjofyaftidi find.

23 ir haben bis jegst bas Berfabren ber Bonitinung jo bargeftellt, wie

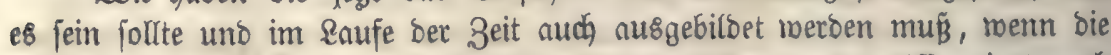

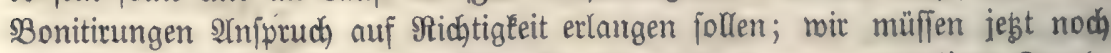

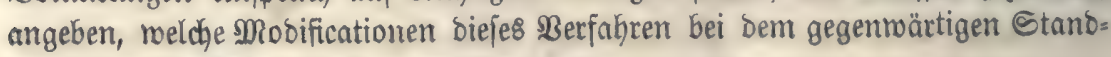
punct ber forftmirthidjaft zul erleiben Gat.

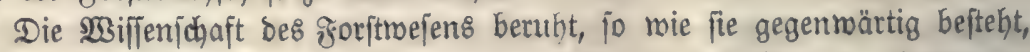
mebr auf Beobachtungen, als auf birect angeftellten Unterjuchungen. Desinegen

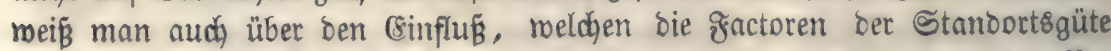
auf ben 3umadys haben, nur fo viel, als man bein Durdywandern ber $B$ eftände eben ohne befondere Mühe raburnehmen fornte; über bas Mlä́ jenes Einfluffes meiß̈ man aber gar nichts

Salten wir zum sBeleg biejes Sabes das oben angegebene speipiel feft.

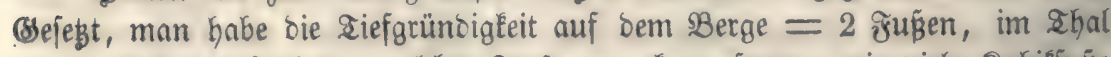

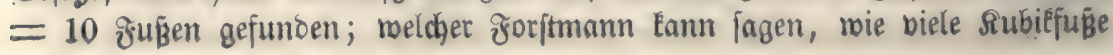




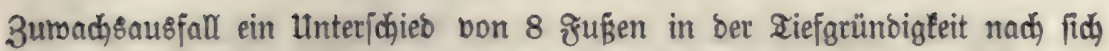
ziehen miro? (88 mangelt burdjaus an IInterjudfungen, um bieje frage be= antworten zu E⿺辶nnen.

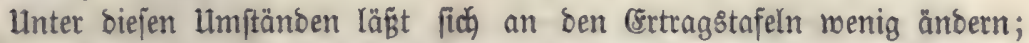
man ift genöthigt, ben நnubarkeettertrag ber Tafel gerabezu für benjenigen bes zu bonitirenden Beftanoes gelten zou laffen, wenn nur ber jemeilige Durd)=

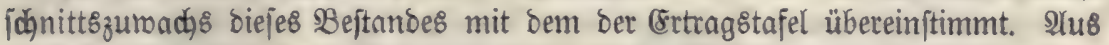
benjelben Brünoen ift auch gegennärtig eine SBeidreibung bon Boben, Rage uno Rlima am Ropfe ber Ertragstafeln ohne allen Nuzen. Denn reer wäre

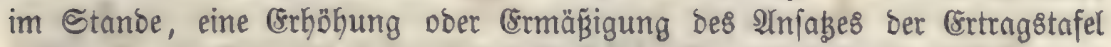

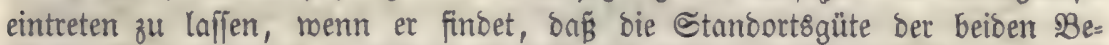

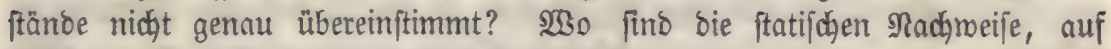
welche er feine 9 fenderungen grünben will?

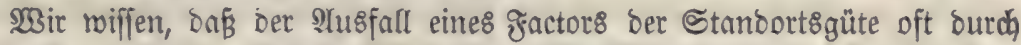
einen andern exjegt werden Eann. Diefer gall Eann eintreten, ohne baf́ mir ben andern factor genau zu beftimmen bermödaten. Sift es hier nidat beffer,

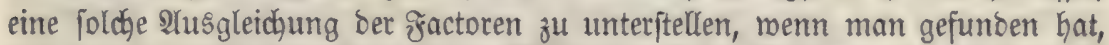

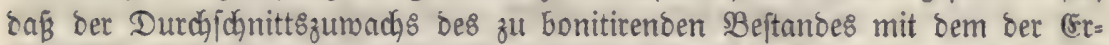
tragstafel übereinftimmt, als fich in Mutbmaß̧ungen zu ergeben, benen jeber reelle $5 a l t$ fehlt?

Das Einzige, was mir bei bem gegenmärtigen Stanopuntt bes frorft=

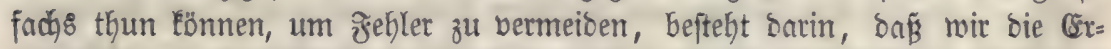

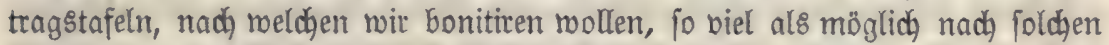
Beftänoen entwerfen, weldge fich nake bei bem Drte befinten, wo bie Boni= tirung borgenommen werben joll.

Begreiflicher $23 e i j e$ reidht man auf joldhen Socalitäten, wo bie Stands. ortżgüte mechjelt, niçt mit einer einzigen (Erttagstafel aıเร; ев müffen becen io viele aufgeftellt merben, alร fich 2lenberungen in Der Standort8güte bemer=

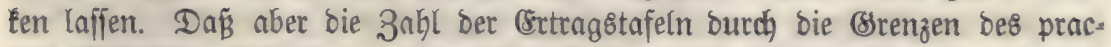
tijđ) Möglichen beftimmt werben, braucjen mir blos für 2lnfänger zu bemet:

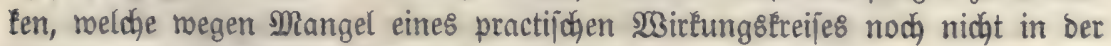
\&age waren, einen Begriff bon jenen Srenzen zu erlangen.

2uf ichledhten Stanoorten ift nidht allein ber 3uwadys geringer, als unter günjittgen Berbältniffen bes \$obens uno bes Silima's, fonbern e\& tritt

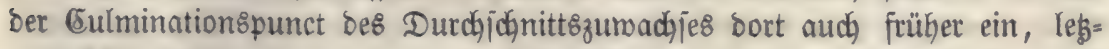
terer bält meniger lange an und finẗt früher, als bier. Diejer Ulmitano ift für bie 3ahl bet Ertragstafeln borzugstweije entidheibent.

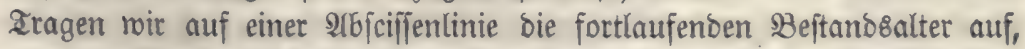
erheben wir auf biejen शlbicifien bie entiprechenden Drbinaten ber Durchjichnitts:

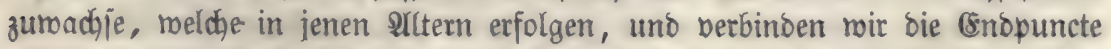

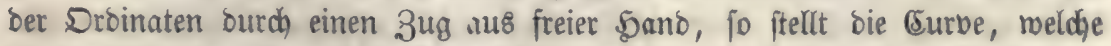

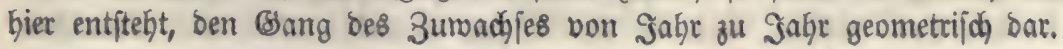


Atte bieje 3umadiscurben fint einanber blos bann ähnlid, wenn fich bie Droinaten ber einen burd) Multiplication mit einent ftänoigen Coefficien= ten (ooer Quotienten) aus ben Drbinaten ber andern ergeben. Ueberall, mo 2rebnlichleit ber curben ftattfinbet, reidyt man mit einer (srtragstafel aus, benn ber betreffende Quotient läşt fich ganz einfach finden, wenn man ben

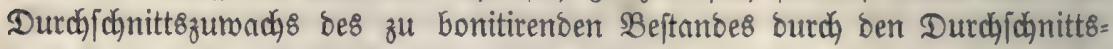
zumachs der Crtragstafel bibibirt. Wir Graudjen aljo mut bann neue (5r= tragstafeln zu entwerfen, wenn bie Curben anfangen, bie 2Yehnlichkeit zu verlieren.

Beiest, man habe orei (Ertragstajeln entroorfen, melche im 50. Jahre

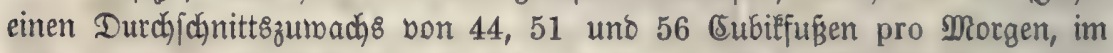

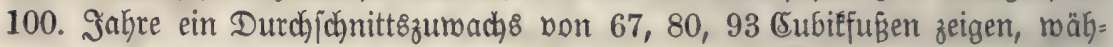

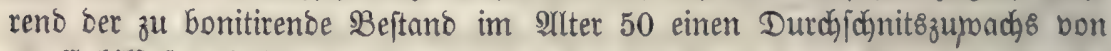

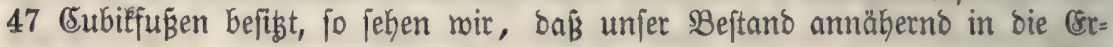

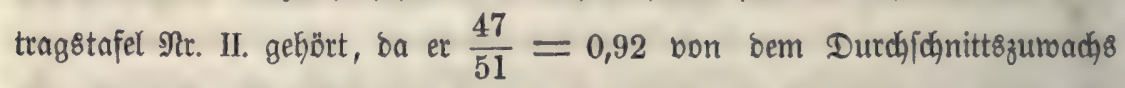

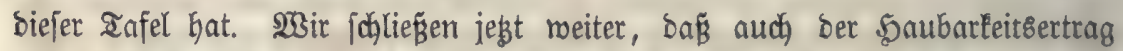
unjers Beftandes nur 0,92 bon bemjenigen ber Iafel betragen, Demnach) $=80.0,92=73,6$ jein werbe. Dieje 2lmnahme ift vielleicht nicht richtig;

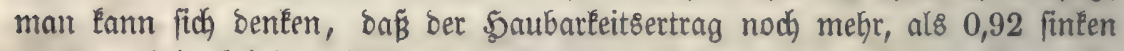
werde; allein bei bem Mangel an jtatijhen Notizen wiro uns bieje $\Re$ Bermuth)=

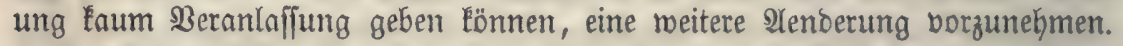
Nach) meldjem Maspitab mollte man bieje audy eintreten laffen?

Da bie Bonitirung fich mur auf bie Standortøgüte, und nicht auf bie

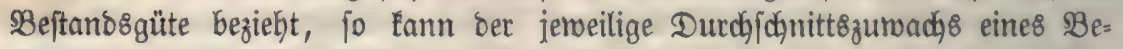
ftandes nur bann zur Aluffindung Der Crtragstafel Benubt werben, wern bies

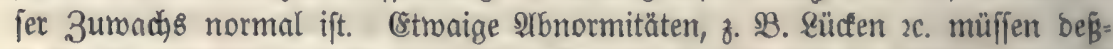

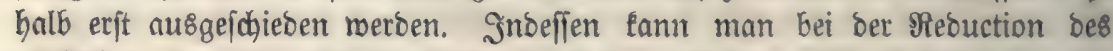
wirflichen Durch/chnitt8zumachjes auf ben normalen nicht vorfichtig genug

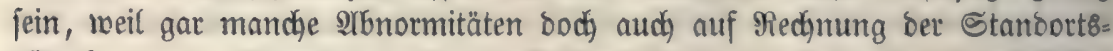

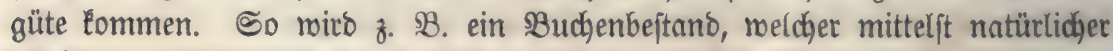
Berjüngung begrünot morben ift, nur auf ganz bejonberz guten Stanoorten eine gleidymäв̈ige uno volle Beftodung befïgen. 2330 llte man Gier bie Eleineren

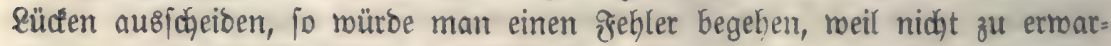

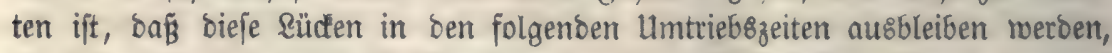

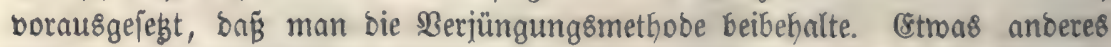
ift e\&, ment bie \&ücten Durch ftarken grebel entftanden fino uno man mit

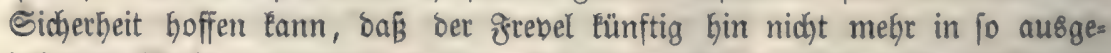

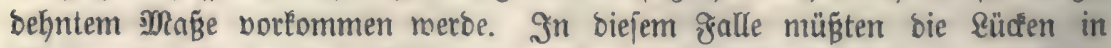

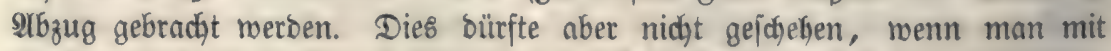

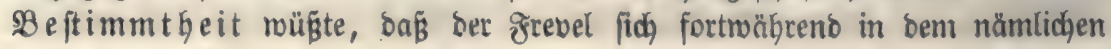


Magifabe wieberholen merbe. Bei ber Serechnung bes normalen 3uroadjes

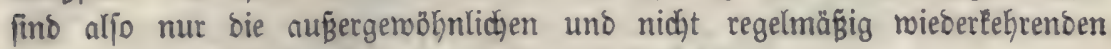

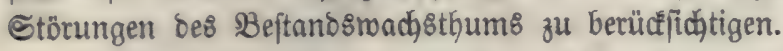

Bisber wurbe bas Berfahren ber Bonitirung für foldhe Beftänoe ges

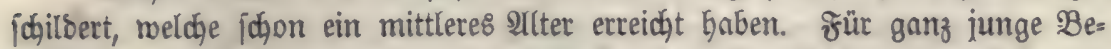

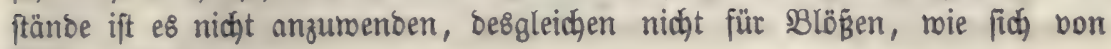
jelbit verjtebt.

Bei ganz jungen Beftänden ift bie 2lufnahme bes Durdjidgnitt8zumad).

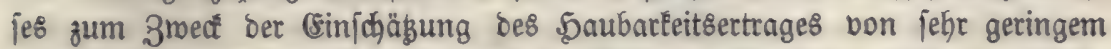

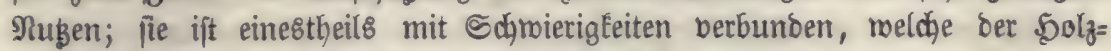

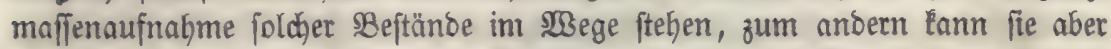
aud), wenn man ihr Bebeutung beilegt, zu unridgtigen Sonitirungen führen. Mandge Factoren ber Bobengüte treten mur in ber Sugend auf, anoete gün= ftige ober idäbliche (sinflüffe berjd)ninden ipäter. (Ein mit Siefern untermijळ)= ter gichtenbeftand fann im jugendliçen Alter geringen 3umadjs befizen, wenn er burch bie Uleberjobirmung ber borgemachjenen Siefern leibet; nadh bem

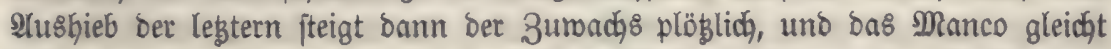
fich, rwenn ber Boben gut ift, in fpäteren Safren mieber auళ. Noollte man

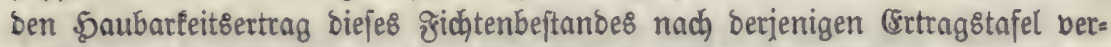

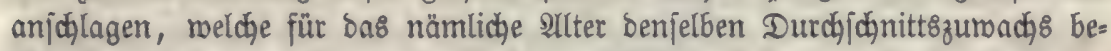

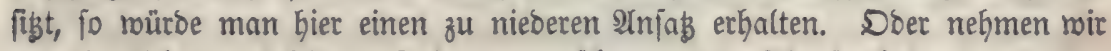
an, bie ¡idgten wüchjen auf einem angejohremmten, jehr fruchtbaren, aber et=

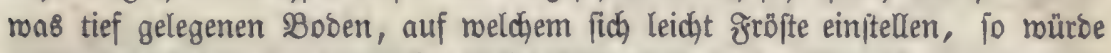

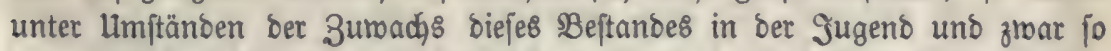

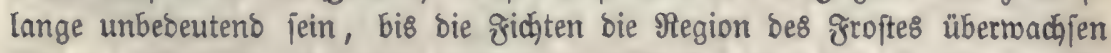
bătten. \&itten fie, roie bies bäufig ber Fall ift, nach Dem fie eine getwiffe

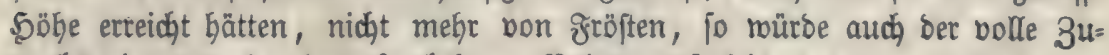
radis eintreten, ber bem fruchtbaren sBoben entipridyt.

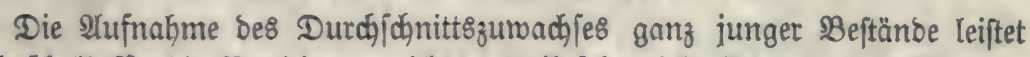
aljo beß̧̧alb fûr bie Bonitirung nichts, meil jehr viele Crtragstafeln fich ben= fen laffen, weldhe bis zu einem gemiffen Sllter bin zu[ammenfallen, fpäter aber mertlid auseinantergeben.

Sier jajeinen wir aljo boch mieber auf bas unter a angegebene $\mathfrak{B}$ erfab= ren ber Bonitirung Gingemiefen zu fein. 2्Alein ba uns, wie oben bemerltt wurbe, alle Renntnif bes (Sinfluffes, ben bie Factoren ber Stanoortsgüte auf

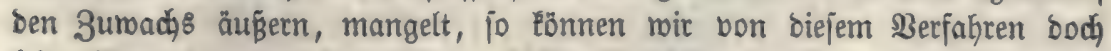

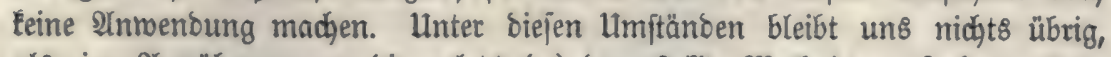
als eine 2Innäherung an bie zulegt (c.) bargeftellte Methobe zu juchen. Dieje Innäberung bemirken mir baburch, baß̉ roir nidjt unmittelbar aus ben burch

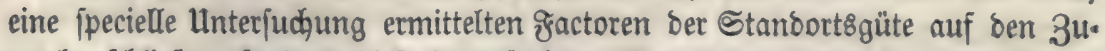

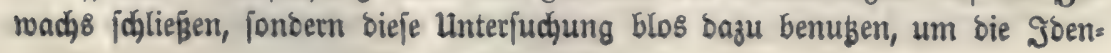




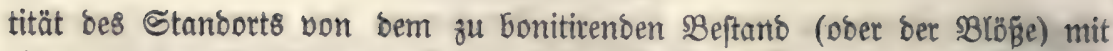
einem andern Standorte, auf bem ficts ein Beftano bon borgerüaterem SUlter befindet, nactzumeijen. Nach ber \$olzmaffe dieles lesteren Beftandes mürbe man aljo bie entipredjende (stragstafel ausmählen.

Bei Betriebrregulirungen unઠ bei $\mathfrak{W a l \delta m e r t b r e c h n u n g e n ~ f o m m i t ~ e 8 ~ f a f t ~}$ immer vor, baß̈ junge Bejtänoe uno Blöß̈en zu bonitiren fino.

Sier find aljo Senntniffe aus ber forftlichen Bobentunde und Sitimato= logie unentbefrlich, uno bies ift bielleidyt ber widgtigite Dienft, weldjen bieje

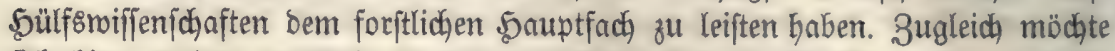
fich hieraus ber practijche Nugen ber Bobentunbe uno Rlimatologie, jonie

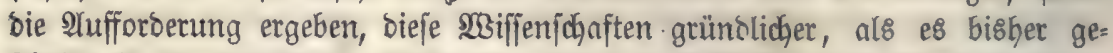
ichehen ift, zu betreiben, namentlich aber bie शYtusbildoung berjelben burch bi= recte Unterjuchungen zu förbern. Mit blogien Beobaditungen, welche man

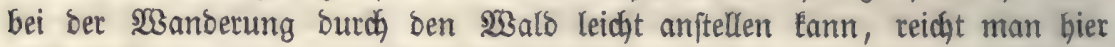
nidit aus.

Bisher hat man bei Bonitirungen zwar aud gemb̈hnlidhe Ertragstafeln benust, aber zur 24usmahl ber leştern öfters nidgt bas richtige ßerfabren an= gewanot.

Statt nach bem Durdjidnittszumadjpe bes zu bonitirenden, Dber eines

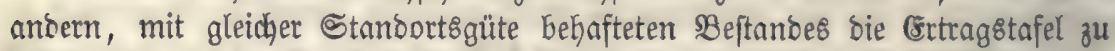

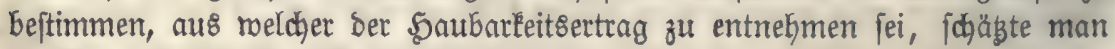
bie Ertragstafel ohne 2 Beiteres ein.

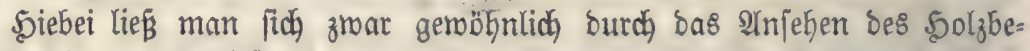
ftandes Yeiten; war biejes jehr gut, fo nahm man z. B. Die Srtragstafel Nr. I.

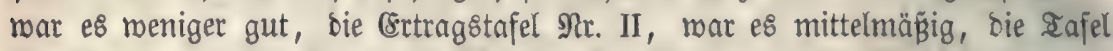

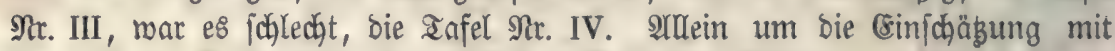
nur einigem Srabe bon Benaugléeit ausfübren zu Ënnen, müßte man ein ganz genaues Bilo von ben Beftänden im Siopf haben, aus melchen bie Ma:

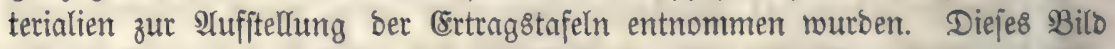

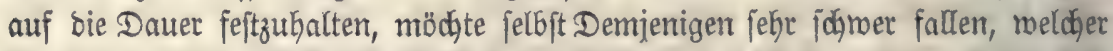
bie (Ertragstafeln felbft aufgeftelat hat. NYüerbem bängt aber ber Solzgehalt

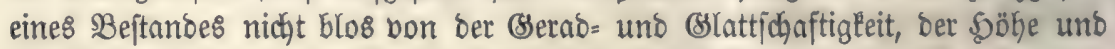
Bollyolzigleit ber Stämme, fondern auch von ber Stammzahl pro Morgen

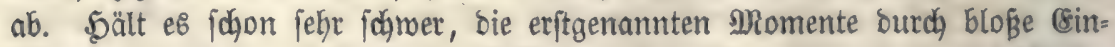

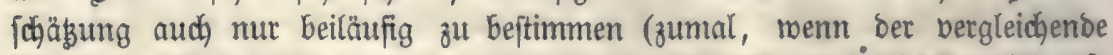
Masitab nicht in natura, fonbern nur in ber (sinbildung borbanden ift), fo ift es boch gerabezu unmöglich, bie Stammizahl anbers, als burch 3ählen ber Stämme zu ermitteln. Sat man fich aber einmal hierzu verftanton, fo wirb man am beften jogleich bie Situppe anlegen und ben Maffengeb̧alt bes Beftandes aufnefmen.

Bei jungen Bejtänoen ober Blöß̈en ließs man Einjobläge in ben Boben 


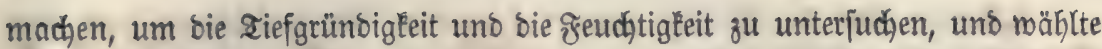
Giernad bie (strngstafel aus, bäufig ohne zu wiffen, tafel berzeidynete Beftano auf einem \$oben von ber nämlichen হiefgrünoigéeit,

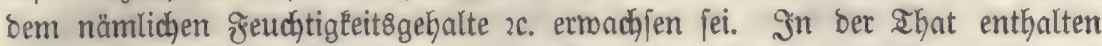
bie meiften Brtragstafeln Eeine Befdreibung bes Bobens; man befït aber gar leine Brtragstafeln, in welchen alle Factoren Der Stanbort8g hute angege= ben roären.

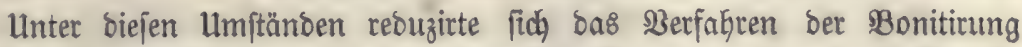

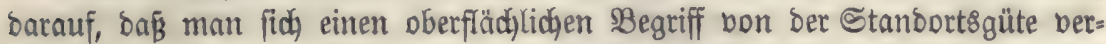
jojaffte und hiernach ben Boben in beftimmte Slafjen, ohne jeben genaueren

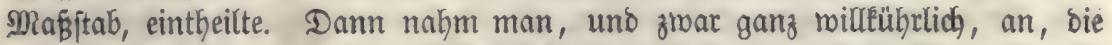
Estragstafeln, nach reldyen bie Bonitirung ausgeführt merben pollte, entfpräs dyen ganz genau jenen eingebilbeten Bobentaffen. Man legte biejen, wie

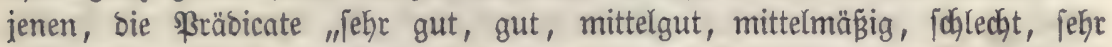

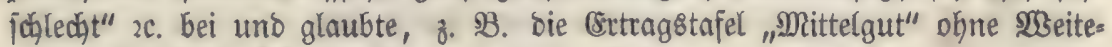
re\& anmenben zu bürfen, wenn man ben $\mathfrak{B}$ oben für "mittelgut" erkannt hatte. Man fieht mohl ein, bafi e\& bei biejem Berfafjen nothmentig ift, ben Ertragstafeln Namen zu geben, benn ohne bieje mürbe jeber 2Inhalt8punft

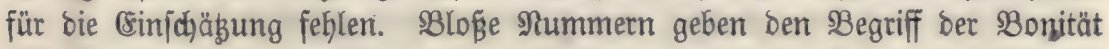
bei reitem nidjt fo beutlich an; menigitens gehört einige Zeit bazu, ebe man

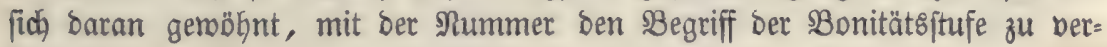
binben.

(88 Kann mohl keine mangelhaftere Methode zll Bonitiung geben, als bie oben bargeftellte. SRicht nur, baß̧ fie jeber Berläffigkeit barüber entbehrt, ob ber mit einem Der obengenannten \$räbicate bezeidjnete Stanoort auch mit ber gleiḑbenannten (Ertragstafel übereintommt, fonbern eళ fehlt auch) gänzlich

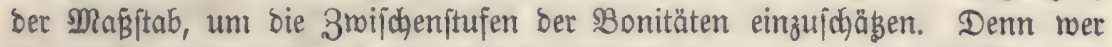

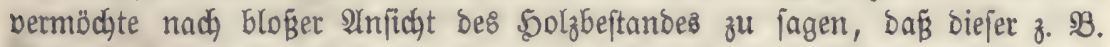
0,92 bon ber \$aubarkeitsmaffe der einen Doer ber andern Ertragstafel liefern merbe? Und bod Eann bie Afbreichung von 8 Prozenten, wie bas Dben angefübrte Beijpiel zeigt, unter Umitänoen einen bebeutenden Ěrtragsausfall berwirfen.

Bei Dem Berfafren ber Bonitirung, weldyes wir von vornberein unter c empfohlen haben, fälut die Benamung der Bonitätsftufen Ginweg. Es ge=

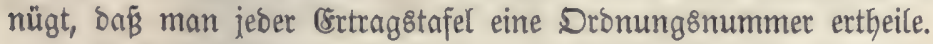

Defters ift johon bas Berlangen ausgeiprodjen worben, man möge fid) über eine allgemein gültige Benamung ber Bonitätsftufen vereinigen. Selbft

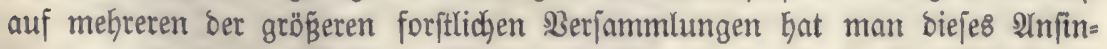

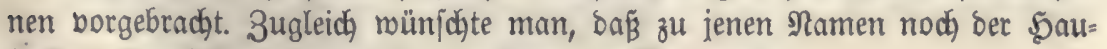
barkeits=Durdjidnittszumadjs Doer (strag gefügt nerbe.

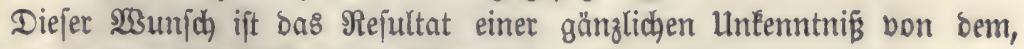
was man unter ",3onität" zu veriftełen bat. 
Dffenbar find bie Erträge unjerer 5olzarten fehr berfdicéen nach bem Stanborte. So wirb man z. B. in einer (Segent, weldhe borzugstreije troctes nen Sanbboben befibt, Den Srtrag ber Riefer auf ben etwas frifdheren sagen als "fehr gut" bezeidhnen, wäbreno er für eine anoere (segent, in meldyer es Dem Boben ftellenteije nie an Feuchtigleit mangelt, im Berbältniß̈ zu ben

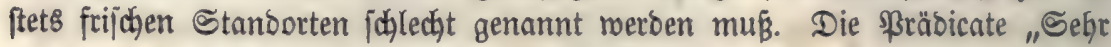
gut, gut" ac. Gaben nur eine ganz relatibe Bebeutung.

2luch bie 3ahl ber Bonität\&fifufen hat man feftgeftellt miffen wollen.

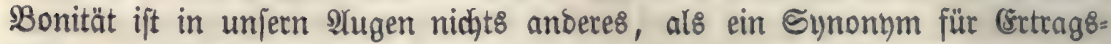
tafel, uno bie $3 a b l$ biejer hängt wieder von ber \&ocalităt $a b$. Es müffen fo biele Etrtragstafeln entworfen werben, als fich 2Yenderungen im 3umachsigange

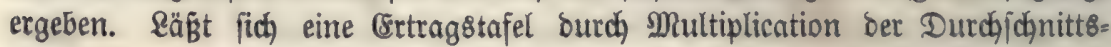
zuraadje mit einem ftänoigen (Eoefficienten aus ber andern (8rtragstafel ab= leiten, fo ift eine bon beiben entbehrlidg gemorben. (88 tönnen nur foldhe (8r= traggrcutben paffiren, welche einanoer nidht ägnlid fint. Die $3 a b l$ ber $S_{D}=$ nitäten richtet fid baher nad, ber 3abl ber nidgt ähnlichen Ertragstafeln, welche man für eine gemiffe \&ocalität entwerfen muß̈. SYln bem einen Drte fann man mit eizer einzigen (Ertragstafel ausireicjen, roähreno man an bem andern Drte brei Crtragstafeln ober Bonitätsffufen aufftellen muß̈. 
Reunzehntes $B$ ud.

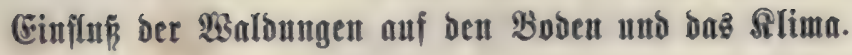

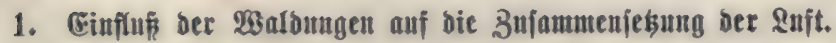

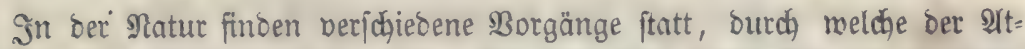
mophbäre ๔auerftoff entzogen wirs. (s\& find bies vorzüglich cer Berbren-

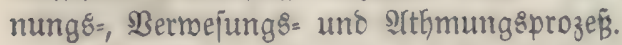

SGgleidh bie Berbrennung uno Bermejung fich onrin wejentlich unter= ïheiben, baß̧ bei erfterer ber Sauerftoff ber \&uft auch birect an ben Sohlen= ftoff ber berbrennenden organijchen ๔ubjtanz treten Eann, mähreno bei ber

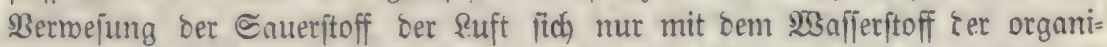
iकhen Eubjtanz berbintot, jo ftimmen bie keiden Brozeffe boch barin überein,

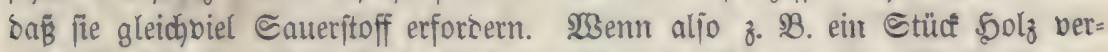
wejt, jo beonrf e\& Der nämlichen Menge Sauerjtoff, um eine gemiffe Ruan=

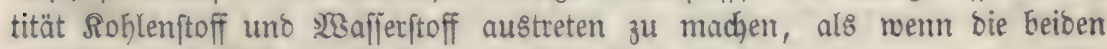

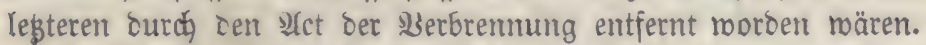

Die Menge Saueritofi, melche Duroh ben Itthmungeprozes conjumirt mirb, ift nicht unbedeuteno. Der Menjob braucht in Durdjidynitt täglich ein Silogramme Caueritoif; menn nun, mie man gewöfnlich annimmt, auf ber

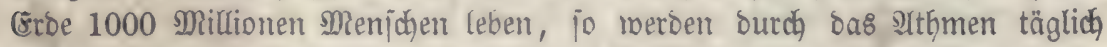
1000 Millionen Silogramme Saueritoff abjorbirt. Der Sauerftoff, Den ber 2thmungsprozen ber Zhiere erfordert, sürfte eben fo biel, menn nidht nod, mebr, betragen.

Betrachtet man bie Quantität bes Sauerftoff', welche ber Qerbrennungs:=

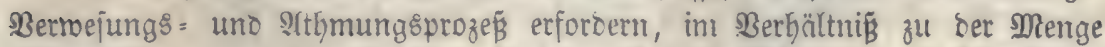
Eauerftoff, welche bie ganze IItmofphäre enthält, jo fieht man, bas jene nur einen jefr Eleinen Brudjtheil von biejem ausmadjt. Unter Der Şorausjejung, baß́ die Berbremung uno Bernejung breimal po biel Eauerftoff conjumiren, als ber Atthmungeprozes, berechnet Dumas, baß̧ bie \&uft nach Alblauf eines Sabrbunberts nut $\frac{1}{134000}$ ihres Eaueritofigehaltes berloren haben merbe.

Wie gering sieje Suantität auch) jei, fo (teht bod) fejt, Daßs eine fort= wäbrende (sntziebung bon Sauerftoff bie \&uft im Raufe ber 3eit verberben 
mus. $23 e n n$ bies in 100 Sabrent noch) nicht bemertlich ift, fo tritt es biel= leicht in 500, in 1000 Jahren Kerbor, uno da wir bis jegt Eeinen (sirund

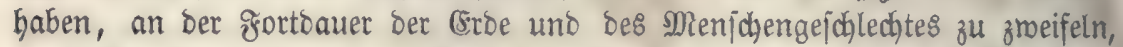
fo müfjen wir amnebmen, oaf̈ irgeno eine fpätere (senerntion bie sachtheile einer Berjchlechterung ber \&uft empfinden werbe.

Die Natur hat bafür geforgt, baßi ber Berluft an Sauerftoff, reldgen

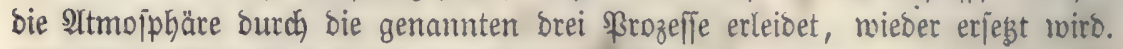
Der Erjas findet ftatt burch ben Begetationsprozeß

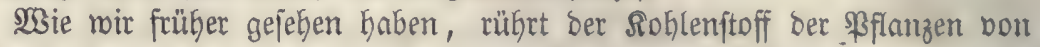
ber Rohlenjäure Der suft her. Die Serbädhfe nehmen Sohlemiäure auf, zerle= gen bieje, behalten ben Sohlenitoff uno geben ben Saueritoff in Basform mieber von fich.

(Sigentlich exfatten mur Der Berbrentnungs = uno Der 2ltfmungsprozeß ber \&uft bie bolle Quantität von Roblerjäure zurück, welche fie burch ben

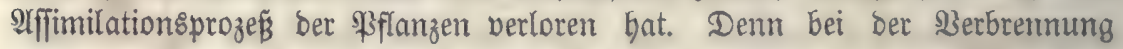

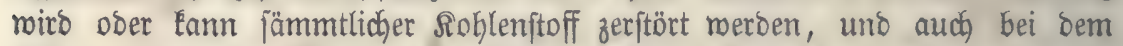
Ŷthmungsprozeffe tritt bie ganze Menge Rohlenftoff, welche bie Antrimalien be=

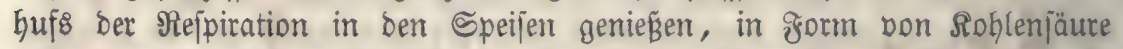
wieber aus, menigjtens ift biejes bei gejunden, ausgemadjenen Menjojen uno

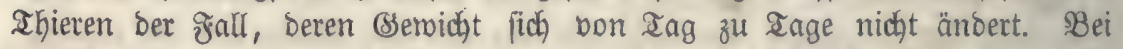
ber $\mathfrak{B e r m e j u n g ~ D a g e g e n ~ b l e i b t ~ f t e t 8 ~ e i n e ~ n i c h t ~ u n b e t r a ̈ c h t l i c h e ~ Q u a n t i t a ̈ t ~}$ Iob=

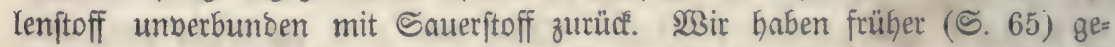

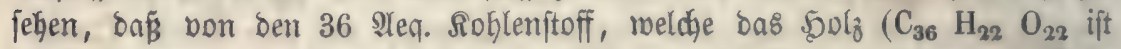
bie 3 ufammenjebung ber \$olzfajer) enthält, nur 11 Ireq. in Form von Soh=

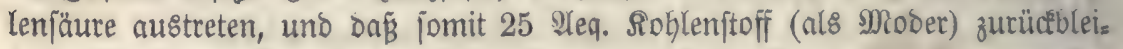
ben. (\&8 kann aljo aus der Rohlenjäure, welche z. B. ein \$ffund berneftes

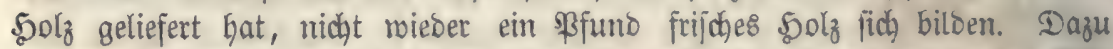
mären noch 25 Ieq. Sohlenjäure erforberlich. 3u Der Erzeugutg von 1 S\$F 5olz wiro aljo die Rofjenfäure von meht als brei Pfunben vermeften \$olzes berbraucht. Demnach berminbert fidh Der Sohlenfäuregebalt ber \&uft Durdh

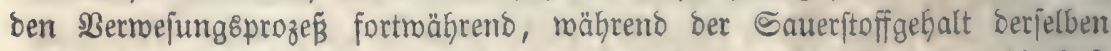
zunimmt. $23 a b r i c h e i n l i c h$ miro aber ber \$Berluft an Soblenjäure, ben bie \&uft

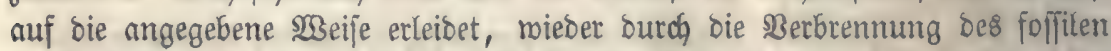

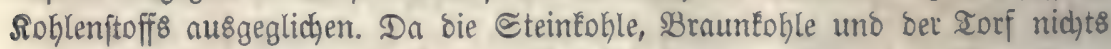
anoeres, als ber Sohlenftoff fino, meldjer bei einer unvolftänoigen $33 e r m e j u n g$

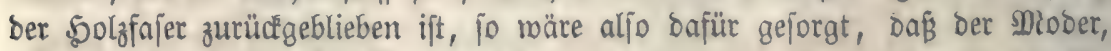
ober ein 2equibalent beffelben, wieber in Form bon Soflenjäure in bie alt= mo|phäre zurücffęrt.

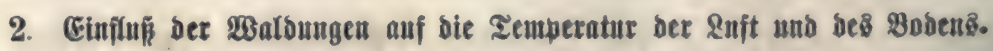

23ie wir früber gejefen haben, abjorbirt bie \&uft mur ronig bon ber

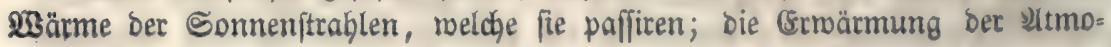


iphäre geht vorzüglich von bem Boben aus, nachbem fich biejer burch bie aufe gefallenen Sonnenftrablen erroärmt hat.

\section{a. Einfu ber 20 albungen auf bie Eommertemperatur.}

Im gejhloffenen $\mathfrak{B a l d e}$ eömmen bie Somnenfrablen nidjt bis zum $\mathfrak{B O}_{0}$ ben gelangen, fie treffen zumeijt mur bie fronen ber Bäume. Dieje wiro aber bon ben Commenjtrahlẹn nicht in bem Maßje errärmt, wie ber Boben,

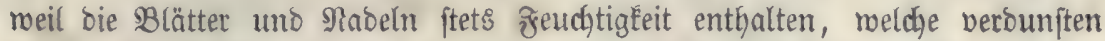
Eantr. Die $\mathfrak{1 3 a ̈ r m e , ~ w e l d h e ~ d i e ~ E o n n e n f t r a h l e n ~ b e n ~ S B a ̈ t t e r n ~ z u f u ̈ b r e n , ~ w i r \delta ~}$ aljo bazu berbraudjt, um die Saftfiüfifgèt in Iampf zu berwandeln. Der Dampf entweidht mit ber nämlichen àmperatur, welche bas $2 B a f f e r$ befist, aus bem er fich entroidelt. Die von ben Sontnenftrablen ben 8 lättern zuge= fübrte $\mathfrak{B a ̈ r m e ~ i f t ~ a l j o ~ l a t e n t ~ g e t o o r d e n ~ ( B B e r g l . ~ ๔ . ~ 1 8 0 ) . ~}$

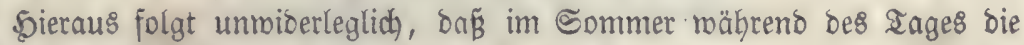

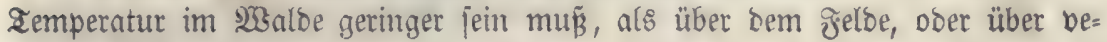
getationslojen grächen.

WSas nun aber das Maßs ber Temperaturoifferenz anlangt, fo mangeln Gierüber zuberläfitge Beobachtungen. S(uch) ergibt fich aus \$3orftefienoem nod lange nicht, ob überhaupt bie Eommertemperatur in mälderteichen segenden gegenüber maloarmen ober malblojen geringer ift, benn im $23 a$ aloe kühlt fíd,

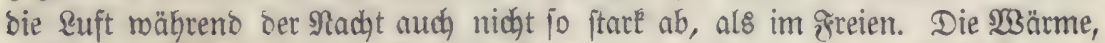
welche ber Boben uno bie \&uft ausftrahlt, wiro mieber von ben Stämmen,

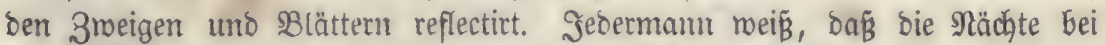
bebectem Simmel nicht jo Ealt fino, als menn ber Simmel Elar ijt, weil bie

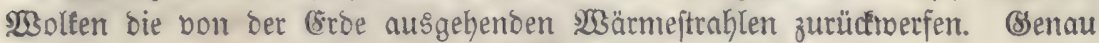

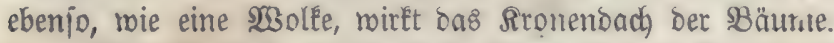

Die Ibatjadje, Daßs es im Sommer bei ange im $23 a$ alde tübler, bei

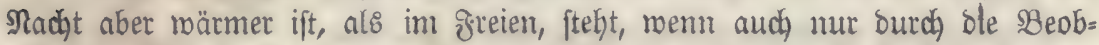

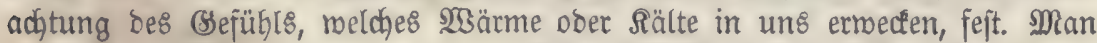
jucht an Geipen Sommertagen ben Eüblen $23 a l d$ auf, und wer bie sacht

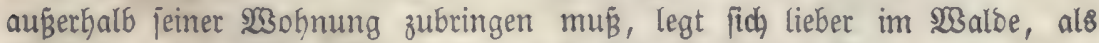
im freien gelbe nieber, weil er roeif, bnß̈ es bort rärmer ift.

2lber - wie johon oben bemerft wurbe - man ift, jo lange genaue 2emperaturbeobachtungen fehlen, nicht im Ctanbe, mit Beptimmtheit zu jagen,

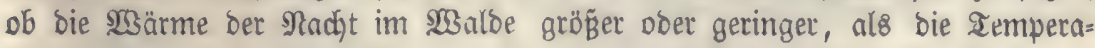
turetniebrigung bei Iage jei.

Die io oft ausgeprodjene SBehauptung, dap malbreidhe Segenden tüh= lere Eommer befiben follen, als roalbarme ober maldoje socalitäten, ift alfo bis jest nidgt im Seringften etwiejen.

\section{b. Ftnfuf ber 2Balbungen auf bie 2Bintettemperntur.}

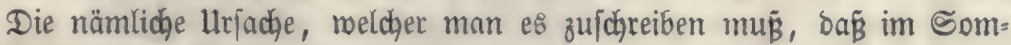

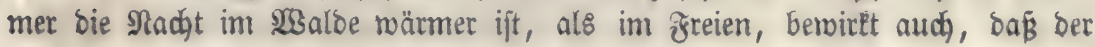




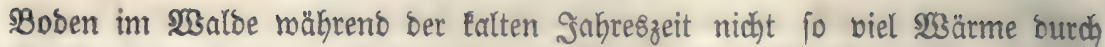
Alusftrahlung berliert, als bies beim felbe ber Fall ift. Dazu Eommt nod, baß̧ das \&aub, MNoos und überhaupt Der Sumus, meldher den SBoben in ben

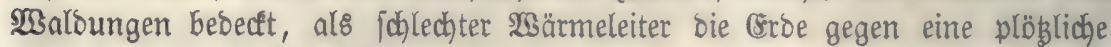

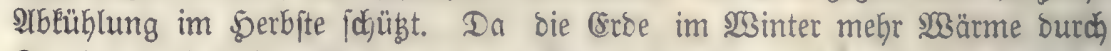
Strablung einbübt, als ifg bon ber Comne zugeführt wiro, fo ift es mahr=

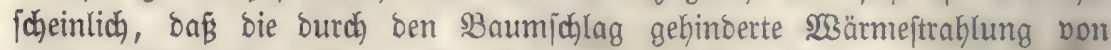

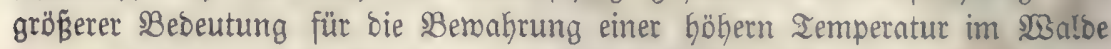

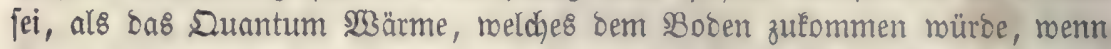

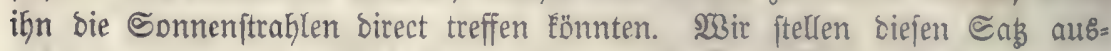
brüctich nur als roahridseinlid Gin, roeil alle pofitiben seobachtungen

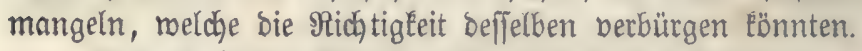

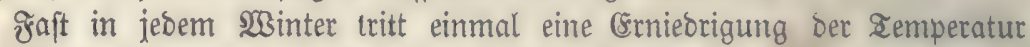

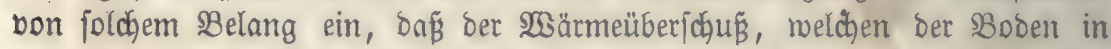

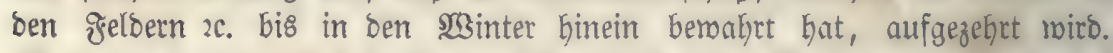
Sit biejes gejheben, hat fich bie Iemperatur im sisalde uno im freien

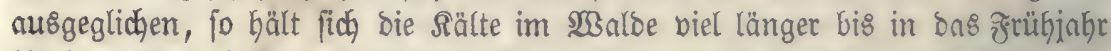
binein. Denn jest berfindert Der Baumichlag, baß̈ bie Sonnenjtrablen ben

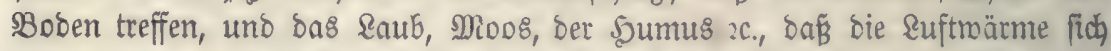
bem Boben burdh \&eitung mittheilen Eann. Daher bautert ber $23 i n t e r$ int Walbe etras länger an. $233 e r$ Gätte noch nicht beobachtet, wie oer Schnee unter ben $S_{B}$ äumen in $\mathfrak{W B}_{3}$ alde oft viele 230 ochen fpäter roeggeht, als im freien

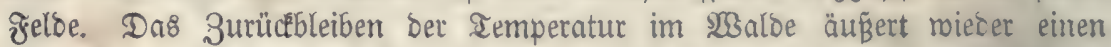

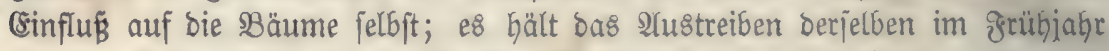
zurüc.?. Diejer Umitano ift für die $\mathscr{B}$ alobegetation vielleicht von Bortheil, e\& merben Daburch bie $B$ eịchäbigungen ber Spätfiöite geminoert.

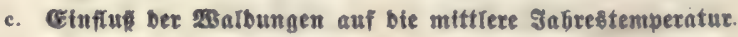

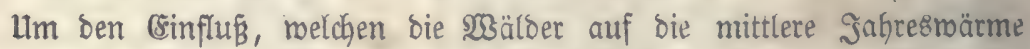
äuß̈ern, zu beftimmen, gibt e8 brei Metfoben. Man Eanu nämlich biejen

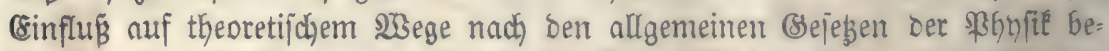
meffen, ober bie Temperatur bervalbeter uno nicht beroaldeter Bsegenden ber= gleichen, ober ermitteln, ob ourch $\mathfrak{B S a l b a u s r o t t u n g e n ~} \mathfrak{B e r a ̈ n d e r u n g e n ~ i n ~ b e r ~}$ mittlern Sahrestemperatur berwirft worben fino.

Rach Dem 32orkergebenden ift es noch unbeftimmt, ob bie NSaldungen bie Sommertemperatur erniebrigen uno bie 233 intertemperatur ergöhent. (58 läßjt fich baber auch nicht angeben, welchen (sinflü bie SBälber auf bie mitt= Lere Jahrestemperatur äußern. 233 äre es aber auch ausgemacht, onấ in raldo= reicjen Bsegenden bie Sommer kühler, bie $\mathfrak{B i n t e r ~ b a g e g e n ~ m a ̈ r m e r ~ j e i e n , ~ a l s ~}$ in raldofen ober waloarmen Ränbern, fo müroe man immer nodj nidht ent=

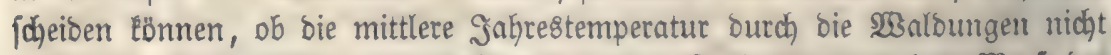

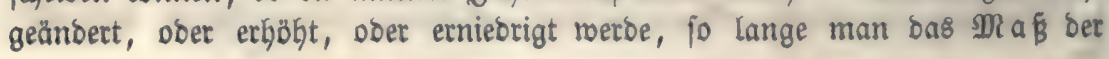


Temperaturbifferenzen nod) nidgt kennt, weldhe burch ben $\mathfrak{M a l d}$ im Sommer und $2 B$ inter berwirtt werben.

(sin Umitano, welchen wir bisfer noch nicht ermähnt haben, trägt bazu

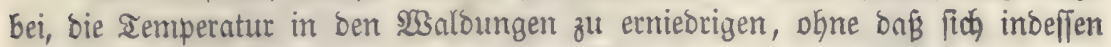

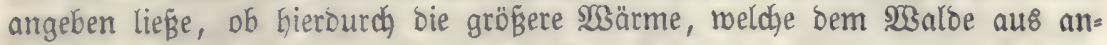
bern, vorbin angeführten, Urjachen zufommt, ganz abjorbirt, ober ob jogar Gierburd bie mittlere Sabrestemperatur maloreicher (segenden unter bas mittel bon maldarmen Drten herabgeftimmt merde. SBSir meinen bie ftagnirende

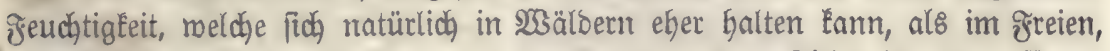
meil fie bort vor bem \&uftzug und ber Sonne mehr geichügt ift. Sm offenen

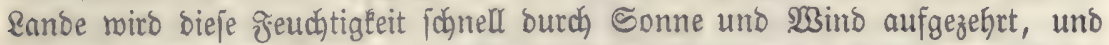

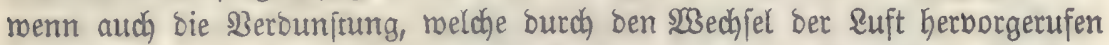

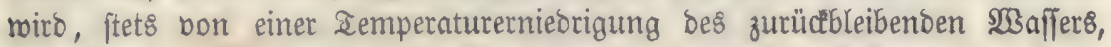
bes 3 obens und ber mit biejem in Berührung ftehenden \&uft begleitet ift, io bauert boch die Siälte nidat lange an, fie mirb burch Sonne und \&uftzug ries Der aufgehobert. Inters ijt es aber, menn bie Berrunftung ber ftagnirenden zreuchtigleit bas ganze Jahr hinourch mährt, uno menn zugleiḑ ber 3utritt . von närmerer suft gebemmt ift; in biejem ₹̊alle miro bie Semperatur ber naffen 引läche in einem fort heruntergeftimmt. 2lber - wie jofon oben be=

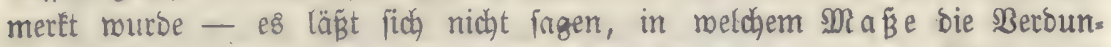

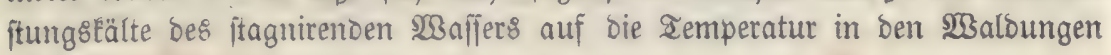
eimmirtt.

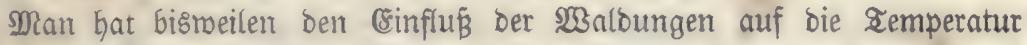
Dent Des Meeres gleichgeftellt. UUtein Diejer 3 ergleid) ift ganz ungegrünbet. Das Meer zeigt im Sonmer blos destoegen eine nieberere Temperatur, als

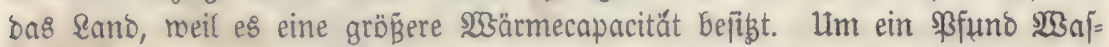

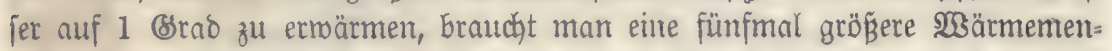
$\mathrm{ge}$, als um einem $\mathfrak{B f u n d}$ trodner croe biefelbe Temperatur zu ertheilen. Das W3affer des Meeres nimmit megen jeiner Durchfichtigḱeit bie $\mathfrak{W a ̈ r m e , ~ m e l c h e ~}$ ihm Durch bie Somnenftrahlen zugeführt wiro, jum größten aheil auf, nur ein Hleiner Theil geht Durdh bie an ber Dberfläche ftattfindende ßerbunfung berloren; im 23 alde mird aber alle 233 ärme der Sonnenjtrablen, meldye das sitonendach treffen, jur Derbunftung ber in Den Blättern ic. enthaltenen

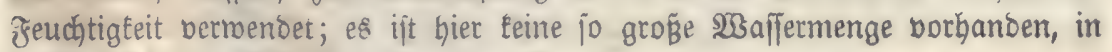

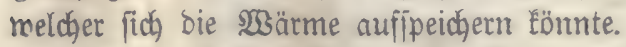

W3enn das Meermaffer im 2 Binter märmer ift, als bie (srbe auf bem Feftlanbe, fo rüfrt bies baher, meil bas Meer im Saufe bes Commers über:

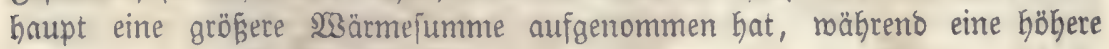

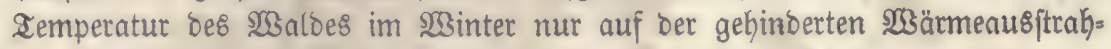
lung beruben tönnte.

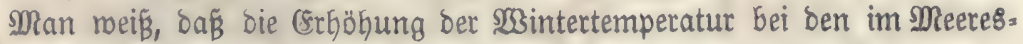

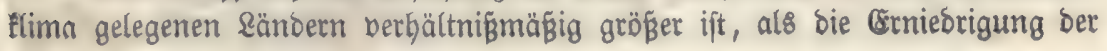


Sommertemperatur. Artes biejes ift burdh birecte Beobaditungen am Ther= mometer erwiejen. Daher erflärt e\& fïh) ganz einfad), warum bos Meeres= flima eine böhere mittlere Jahrestemperatur, als bas continentalflima zeigt.

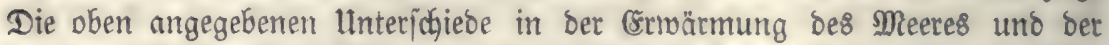

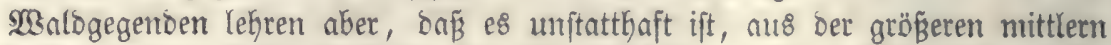
Sahrestemperatur der 'Süftenlänber eine ebenfolche größere Jahreswärme für bie $\mathfrak{W} 3$ aldogegentoen ableiten gu mollen.

Die zweite von ben vorbin angefüfyten brei Methoden zur Beftimmung bes (sinfluffes, melchen bie 23 altungen auf bie mittlere Sabrestemperatur äußeen follen, ift vorz̆̈glich, von Moreau de Sonnes befolgt worben.

Moreau be Gonnes, weldyer im Sahr 1825 eine Edjrift über ben Ein=

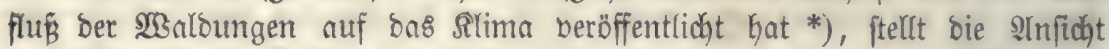

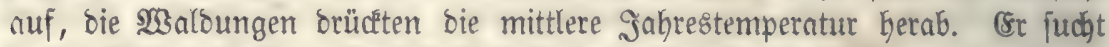
biejen Saz̧ baburch zu beweijen, daf́ er bie mittlere remperatur bon Drten in malbreiden uno walbarmen ober malklojen Gegenten, aber unter berjelben geographilchen Breite, vergleicht.

Die Rejultate, zu meldyen Morenu be Sonnes gelangt ift, Eönnten nur bann als entidjeibeno betrachtet werden, menn berjelbe fämmtliche binflüfe

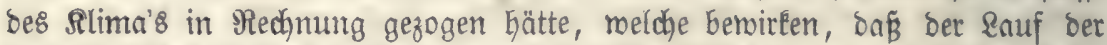
Sipthermlinien von ben Barallelfteijen ber Brobberfläche abmeichen. Das hat aber biejer Sdyiftfteller gänglich unterlaffen.

arle bie Beifpiele, welche Moreau be Sonnes gemäblt hat, zeigen nur

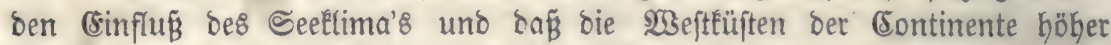
temperirt find, als bas Innere ober bie Dftküften Derịelben. Die\& rührt, mie

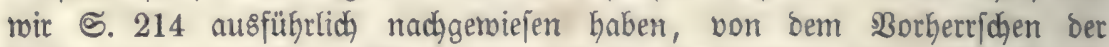
feudhtroarmen weftlichen Minbe auf beiben Semifphären ber. Mloreau be

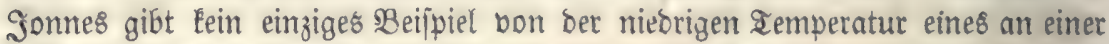

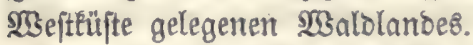

Da bie Sdyrift bon Moreau be Gonnes bei bielen ærorftrirthen, meldye nid)t bie zur Brüfung jener Sd)rift nothmendigen meteorologijden Senntniffe

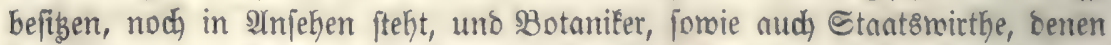
bie Eigenthümlidjéten bes $2 \mathfrak{3 a l b e s}$ fremo fino, fid) auf biejelbe öfters nod) zu beziehen pflegen, jo halten wir es ber Mïhe werth, einige ber Gerborra=

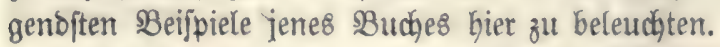

"\$aris, fagt Moreau be Jornes, liegt unter 4850' Breite; Regens= burg unter $48^{\circ} 56^{\prime}$ Breite; bie mittlere Iemperatur ber erfteren ๔tnot beträgt $11^{0}, 8$; bie ber zreiten 80,7 , mithin Unterjedied $3^{0}$. Die $\mathfrak{M a l \delta u n g e n ~ b e b e c t e n ~}$

-) Die Echrir̆t füht cen Titel: Recherches sur les changemens produits dans l'état physique des contrées par la destruction des fôrets Bruxelles 1825 . Gie

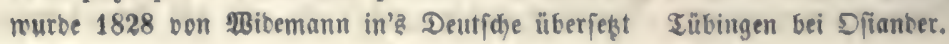


beinnhe ben britten Theil von Bayetn; menn man bagegen, um bie 2ušbeh= mung berjenigen zu jobägen, melche in bem Eanbftrid liegen, welcher \$aris umgibt, bie Departements der Ceine, ber Ceine und Marne, ber Seine unb

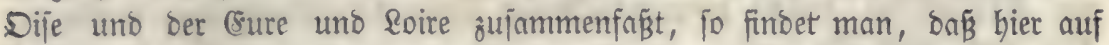

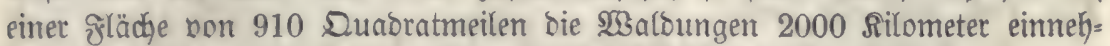
men, was nidht einmal ben adgtzehnten aheil berjelben ausmadbt."

"Brïlfel liegt unter $50^{\circ} 50^{\prime}$ und $\mathfrak{B r a g}$ unter $50^{\circ} 05$; bie mittlere $\mathfrak{2} \mathrm{em}=$ peratur deళ erftern Drt\& beträgt $11^{0}$, bie bes zmeiten $9^{0}, 7$; der Unteridjié ift 1,93 ober beinabe 2 strabe. Die 2 Baldungen bilben mehr, als zrei Sie= bentheile, ober beinabe ben britten Theil von 3 b̈hmen, wäbrent fie hödjtens ben achten Theil bes - Brüfier untgebenten - Eandes bebecten."

In berjelben 2 Beije vergleidht Mroreau be Jonnes Reyben in Sollano und SBerlin und bringt Sen Unterichied der Iemperaturen, melcher $3^{0}, 17$ zu

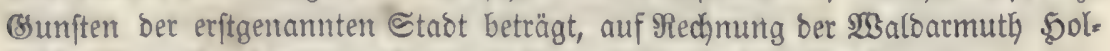
Lanbs gegenüber bem zum britten Theil mit $\mathfrak{1 3 a l \delta}$ bebecften \$reupen.

AUle bie vorangefüthrten Beippiele zeigen nicht ben Cinflǘ ber $23 a$ aldun= gen, jonbern ben ber Gee auf bie mittlere remperatur.

In Den folgenden Beippielen rührt die geringere Iemperatur bon ber Eage an einer Diftïfte ber.

"Neapel liegt an ben Ufern bes Mittellänbijchen Meeres unter $40^{\circ} 50^{\prime}$,

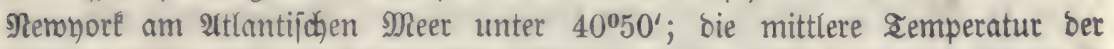
erjteren biejer Stäbte beträgt $19^{\circ}, 5$, bie ber zmeiten $12^{\circ}, 1$; ber Unterjojied ift alfo $7^{0}, 4$. In Stalien fino bie $\mathfrak{S B a l o u n g e n ~ b e i n a k e ~ g a ̈ u r z l i d ~ z e r f t o ̈ r t ; ~ i n ~ b e n ~}$ Bereinigten Stanten bebeden fie den größ̈ten Theil bes \&andes."

In biejem Beipiel ift jogar ganz überjehen, baßs bie Ditküfte von 9lmes rifa, an weldher Nembork liegt, auch fohon an groperer 233 aldarmuth leibet. Sollte bies aber zu ber 3eit, als Moreau be Tonnes fdrieb (1825), nod)

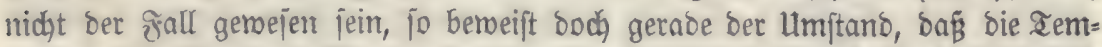
peratur von Remobork fich bis heute nicht geänoert hat, baß̧ bie niebere mitt=

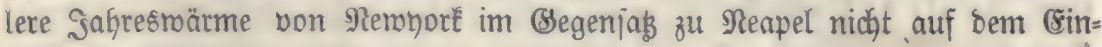
fluffe ber $\mathfrak{W a l}$ aldungen berubt.

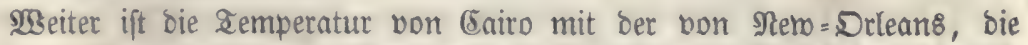
Temperatur bon Gurinam mit ber bon St. Rouis am Senegal verglidgen.

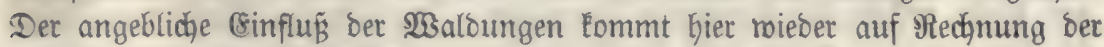
Eage an einet Difticjen Rüite.

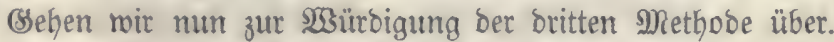

Man Gat bie den $\mathfrak{M}_{3}$ arbungen zugeichriebene $\mathfrak{B} e$ eänderung ber Tempera= tur aus ben Beränberungen folgern mollen, melche bas Rlima von Deutich) lano jeit ben Zeiten der Römijogen Subafion erfahren haben joll. Tacitus

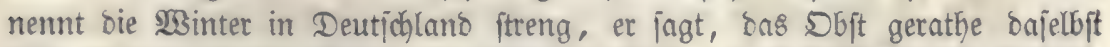
nicht (Germania frugiferum impatiens). গach Den Begriffen bon Zacitub,

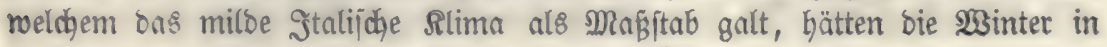


Deutjhlano mohl bis zum heutigen Zage nichts bon ihrer Strenge berloren, uno nas bas Mißrathen des Dbftes anlangt, fo gift es jegt noch bei uns viele Gegenden, weldhe gar Kein Dbjt produziren. Fuch jelbit in benjenigen \&agen von Deutichlant, welche borzugŝneife zur Dbitzud)t geeignet fino, getäth das Dbft Dodh nidht alle Sahre.

(Es ift nicht gerabe unmahricheinlich, Daß̈ bas Silima bon Deutichlano

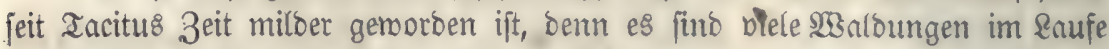
ber Sahthunderte ausgerottet und zu Slufertano angelegt worben; mit ben $23 a ̈ l b e r n$ beríçmanion zugleich manche Sümpfe uno jonjtige Befälter ftagni=

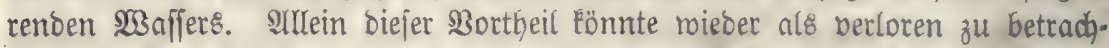

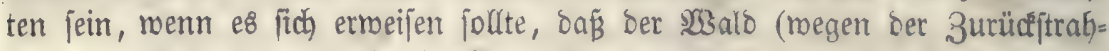
lung ber Bodennärme ac.) bie $\mathfrak{M i n t e r k a ̈ l t e ~ e r m a ̈ f i g t . ~}$

Die Bemeije, welche man baf̣ür beizubringen gejucht Gat, baß̈ bas slima

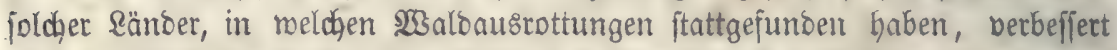

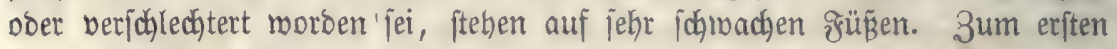
lägrt fich eine Beränoerung der Temperatur roohl nicht ohne bas Ihermonieter befitimmen, ein Snjtrument, weldye\& exft feit hunbert Sahren in einer zu ge= nauen Temperaturmeffungen geeigneten $\$ B$ ejchaffentheit angefertigt miro. $923 \mathrm{enn}$ man aljo unterjuchen rvill, ob bie Temperatur fich im Saufe der Zeit geän. bert habe, fo mufis man fich nach andern Methoden umjeken, um bie Iempe=

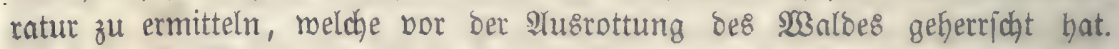
'Man Kat bierzu bie periobijchen (sijc)einungen bes begetativen \&ebens, jomie bas \$zorkmmen bon gemiffen \$flanzen benubst, von benen man reiß, meldjer

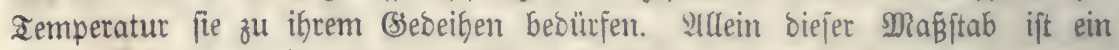

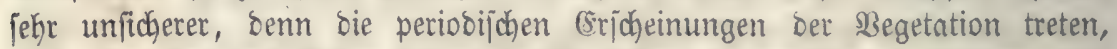

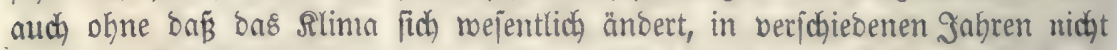
zu ber nämliçen 3eit ein; man müß̈te aljo Durchjichnittsmertbe aus früheren 3eiten baben, an benen es aber gänzlich mangelt. Was bie geographiiche Berbreitung ber Pflanzen anlangt, jo hängt bieje nicht Glos von ber Iempe= ratur, fondern auch bon 30 oden $x$. ab, und es Eann baker Der Berbreitungsbezitt' einer Pflanze im \&aufe der Zeit getwedjjelt haben, obne baf́s bie Iemperatur einer Slenberung unterworfen gewejen .märe. Ŝußerbem fino bie (Betwächje,

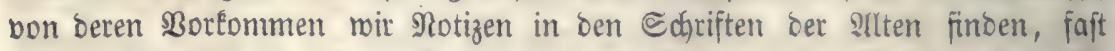
nur foldhe, meldye ber Algricultur angebören. Se nach ber Stufe, auf roeldge jich bieje befano, muşte auch bie Berbreitung Der künftlich angebauten \$flan=

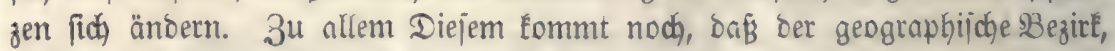
innerbalk beffen bie Berbreitung einer Pflanze, fich berogen Eann, nicht bon einem genau beftimmbaren Zemperaturgrabe abhängt, jondern eine größ̈ere Inzabl von Braben umfáft.

3um 3meiten bliebe noch übrig, feftzujtellen, ob wirflich eine $23 a l \delta a u s=$ rottung ftattgefunden habe. Dies miro aber gemöhnlid unmöglich jeir. SBis

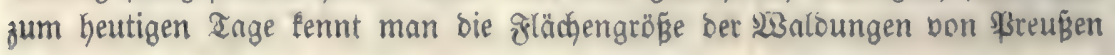


uno Defterteid nicht genau, roil bie 13 albungen nods nidat alle bers meffen fint. 23oher rollte man aljo wiffen, ob bie $23 a l$ bungen von Egyp= ten, Doer gar bon Ditindien fich bermindert Gaben! Und bodh hat man ans gefliche Remperaturveränberungen in biejen \&ändern yon ber Alusrottung ber

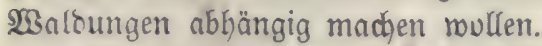

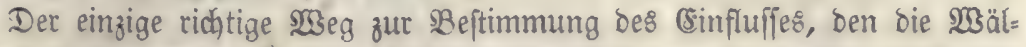

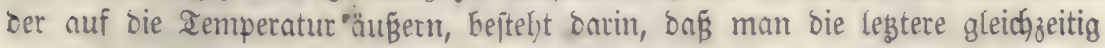
an zivei Burtten, von benen ber eine innerbalb einer compacten $23 a$ alomaffe, Der andere im greien jich fefinbet, mittelft be\& Dhermometers unterjucht, babei

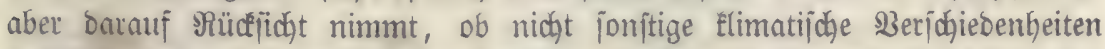
jmijchen biejen beiben \$unften bejteben, meldhe an uno für fid jojon eine Afrreichung ber Témperaturen berurjachen Ëmmen.

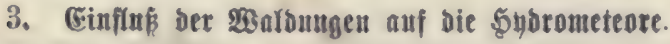

\section{a. Cinfu仿 Der 20albungen auf bie regenmenge.}

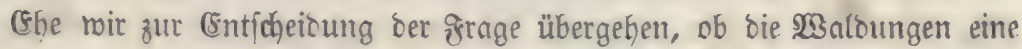
Bermebrung ober ßerminderung ber atmojphärifden Nieberjaläge berwirfen tönmen, haben mir uns an bie Besingungen zu eximnern, unter meldjen foldhe Nieberjóläge überhaupt exfolgen.

23ie ๔. 248 bemerlt morden ijt, befteht für jede Iemperatur ein Marimunt bon $23 a f f e r b a m p f$, weldhes bie Ruft aufzunehmen vermag. Sift biefes Maçimum borbanden und fintt jebt sie Temperatur, jo tritt ein Iheil bes Dampfes in ben flüifigen 3 uftano über, uno es entifteht, je nach ben umftän=

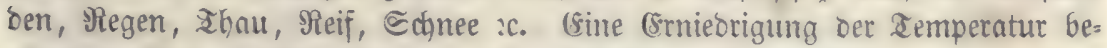

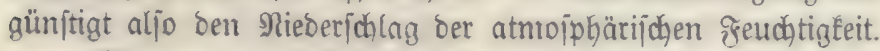

$233 e r d e n$ zmei Ruftichichten, melche beibe vollftänoig mit Dampf gejättigt fins, mit einander, gementgt, io mirb efenfalls ein Iheil bes Iampfes in füffigem 3uftano abgejojieben, weil bie Marimn von Dampf, melche bie \&uft bei Eeftimmten Demperaturen aujz̧unehmen bermag, in einem ftärferen $\mathfrak{B e r}=$ bältnifie, als bie zemperatuten madjen. Wasenn fich aljo bie berichiebenen

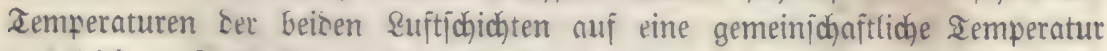
ausgleichen, io bleibt ein Ueterichuß̈ bon Dampf, ber ausgeichieben nerben murg. Ia es fam jogar ein Stieserjolag erfolgen, auth menn sie beiten Euftichichten nicht voljtänoig mit §ieudhtigkeit gejättigh, bagegen verjajieben

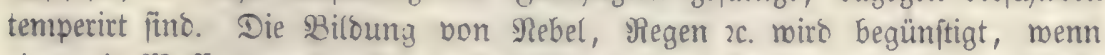
eine mit $\mathfrak{W a j i e r \delta a m p f ~ b e r i e h e n e ~ B u f i t i d i d t e ~ e i n e ~ a n d e r e ~ t r i f f t , ~ m e l d g e ~ e b e n f a l l s ~}$ 23affetbampf entbält.

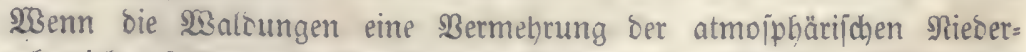
id)läge bemirfen jollten, fo fönnte bies alio rnourdh geidjehen, onf fie eine

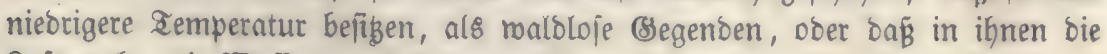

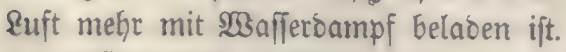

Wå nun bic Remperatur in ben $23 a ̈ l$ bern anlangt, jo haben wir unter 
2. gejehen, baß̈ biejelbe allerbings zu gemiffen zages= uno gahreszeiten gerin= ger, als über bem freien gelde ift. Die $23 a l \delta u n g e n$ könnten alfo im ธom=

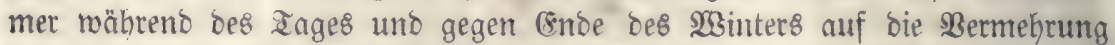
ber Regenmenge einmirken. Inbers verfält es fich bagegen in ben Sommer=

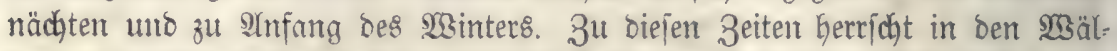
bern eine Göhere Iemperatur, als im freien, weldye bem 3uftanoefommen

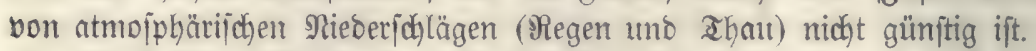

Um alpo zu beftimmen, ob bie 23 aldungen auf eine Betmehrung ber Regenmentge einmirken, müß̈te man bie \$lbmeichungen, weldye ber (sang ber

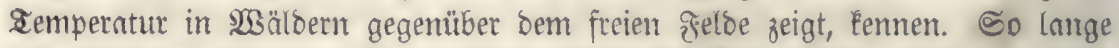
aber hierüber Eeine comparatiben Beobadytungen borliegen, fund mir auper

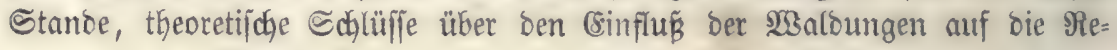
genmenge zu zieken.

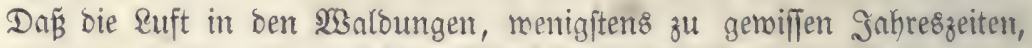
eimen höheren relativen Feudhtigkeitsgehalt befibt, als im freien, focheint ziem=

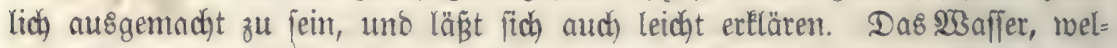

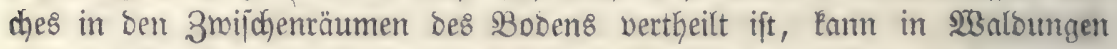
nicht io id)nell berbunften, weil es gegen sie birecte (sinmirkung ber Sonnen=

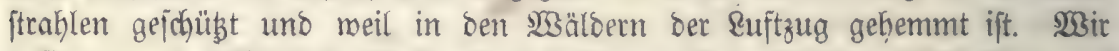

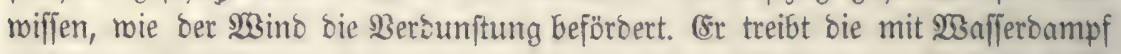
gejättigten \&uftichichten fort uno fringt an beren Stelle nente, trociene Ruft, melche befähigt ift, abermats şafferdampf aufzunefmen. Sun ift, wie Seber

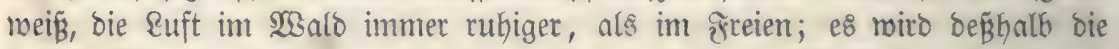

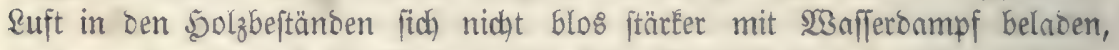
fontern es wito aud bie Bodenfeudtigkeit nidht auf eimmal aufgezefrt mer= Den, aljo fortwähreno die Berounjtung unterbalten E⿱丷nnen.

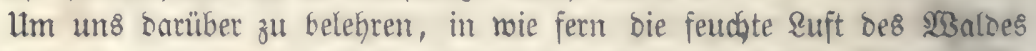
Den (sintritt Des Fegens begünjtigen fönne, braud)en wir Glos bie ichon früher

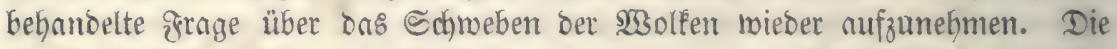

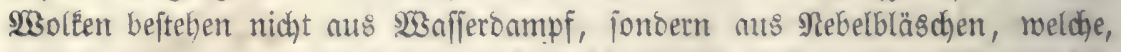
meil fie ichnerer al\& bie \&uft fimo, fortwäbreno fich jenten, aber mährenঠ bes grallens burd) ben bon ber (stoe auffeigenden warmen, reip. trocfenen suft= ftrom mieber aufgelöft, b. \%. in Wafferbampf vermandelt werben. Dr biejer

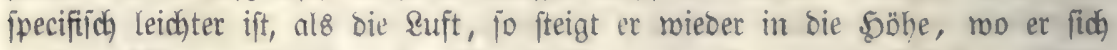

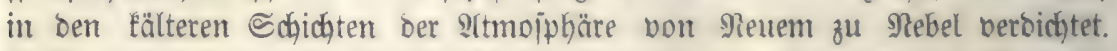

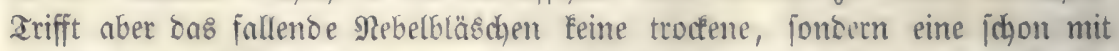
f̧eudjtigkeit gejättigte Ruft, fo löjt e\& fich nidjt wieder allf, fondern tommt

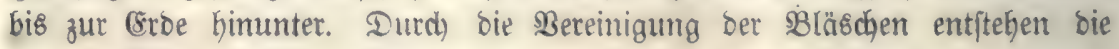
Regentropfen.

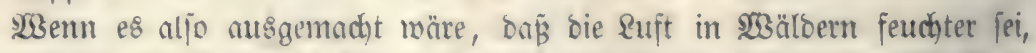

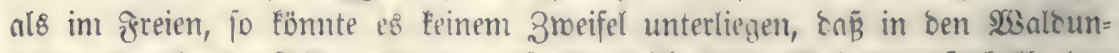
gen mehr Siegen fällt, als unter fonft gleidjen Umftänden auserbalb des 
WBalbes. Diejenigen Solzarten, meldhe zu ftarfer Blattausbünftung geneigt

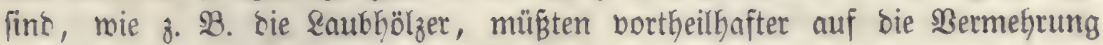
ber Regenmenge einmirfen, als bie Rabelbölzer, bon Denen man annimmt,

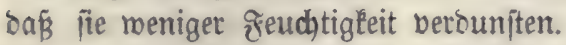

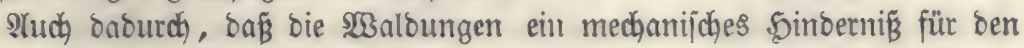

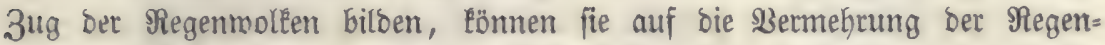

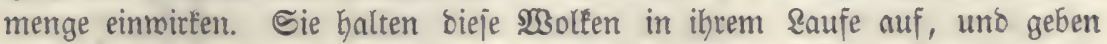

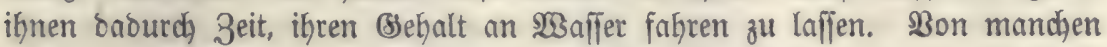
Drtert, 8. 3. Bergen in Sorwegen, Seibelberg ac. meif man, baß fie bie

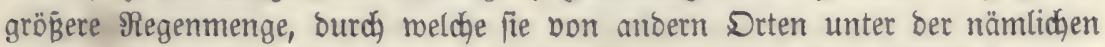

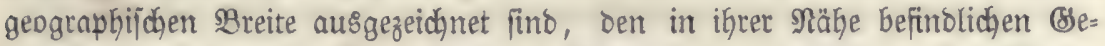

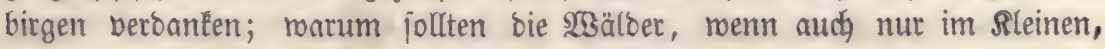
nicht eine ähnlidge $23 i r$ tung hervorbringen können?

rches Iasjenige, mas mir bisher angefüht baben, madyt ef frar mahr=

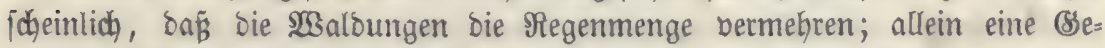
mifbeit in biejer Beziefung geben unfere Srgumente bei weitem nods nidgt. So lange wir feine pofitiben 3ahlen über bie Iemperaturernieorigung uno

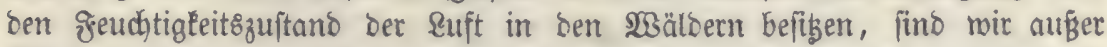

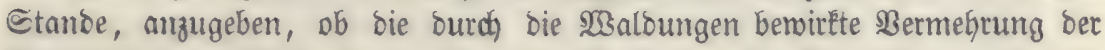

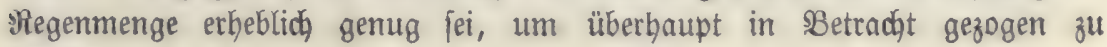
merben.

Man follte nun benten, bie vorliegente grage lię̧e fich ganz einfach

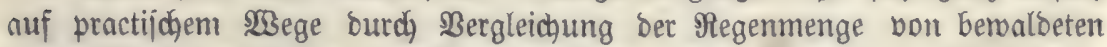

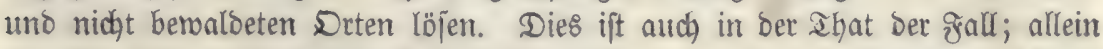
bie bis jegt borffandenen Materialien reidjen zu einer foldyen Bergleidjung nicht aus. (58 müffen bazu bejonbere Unterjudungen angeftellt merben, bei

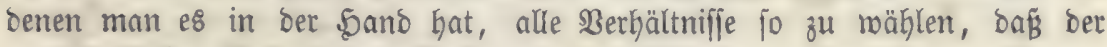

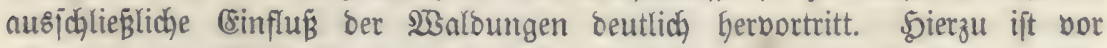

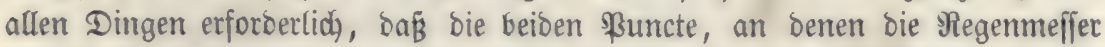
aufzuftellen find, nid)t zu meit auseinanberliegen, weil man fonft feine sese

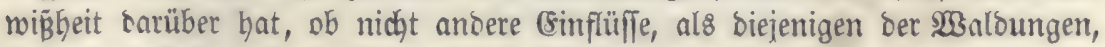
mitgerwirkt haben.

In Ermangelung birecter Unterfuchungen Gat man fich bisher barauf

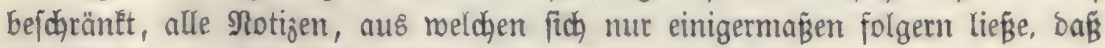

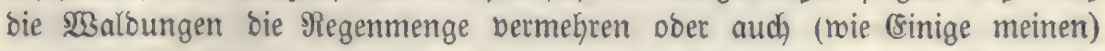
berminoern, zujammenzujuchen, leiber aber mehr auf bie Zabl, als auf bie Sdjärfe ber shelege gejehen. Man Gat die Riterntur bes Alterthums burd)=

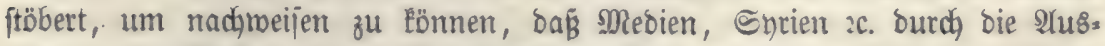
rottung ber $\mathfrak{W a ̈ l b e r}_{\text {ein }}$ trocfenes Slinia erbalten haben, ohne bie geringite

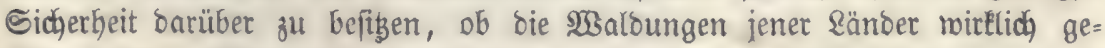
litten haben. Xber aud angenommen, ba B biejes ber fall gemejen jei, jo ift es immer nodh nidgt ermiejen, ob bie 23erminderung ber $23 a ̈ l$ eer jene $\mathfrak{B e r}=$ 
änbetungen im Slima betwirth babe, ober of bie legteren nidgt andecen Urjachen zugefdrieben werben müffen.

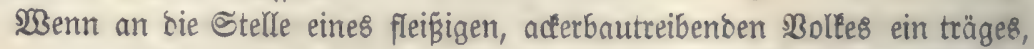
ober ein nomabifitendes tritt, fo getvinnt, mie fid leid)t begreifen läşt, bie Dberfläch)e bes früher cultivirten Eanbes ein ganz anderes 2lnjeben; ftatt be=

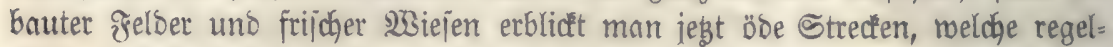
los mit milomachjenden Pflanzen, Seiben 2 . Keftanden find, die ben Cinbrud"

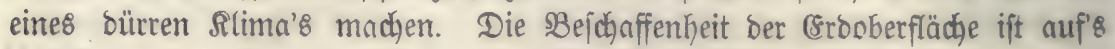
innigite an ben sang ber (Eultur bes Menichengejकlechtes gefunden.

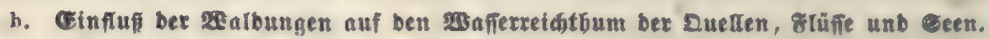

Uuf Den $\mathfrak{W}_{3}$ afferreidhthum ber Duellen*) (bemnach audh ber Bädhe,

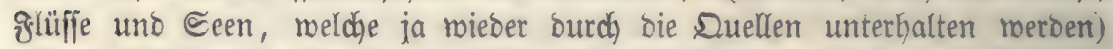

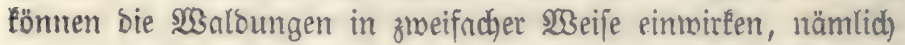

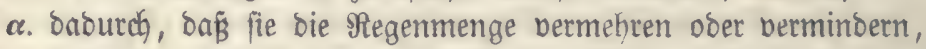

$\beta$. Daburth, baf́ fie bie niederfallenden Meteorroaffer aufnehmen uno etft nach und nach an ben Boben, namentlich an bie tieferen sagent beffelben,

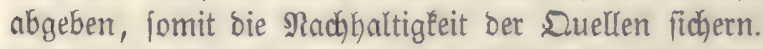

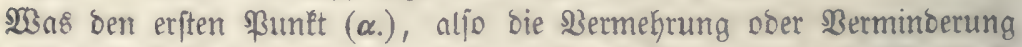

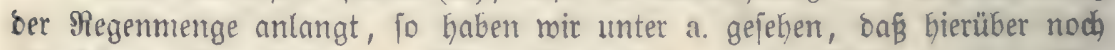

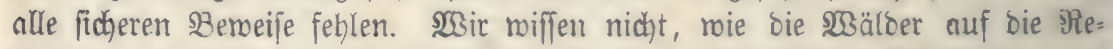
genmenge einwirken, uno wenn es audy, bom theoretijohen Stanopunct aus

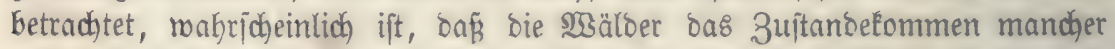

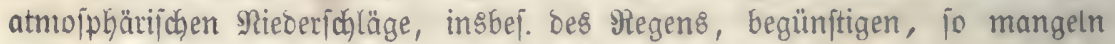

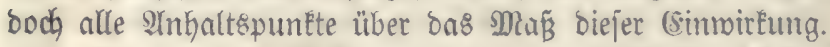

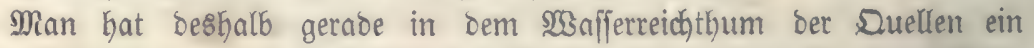

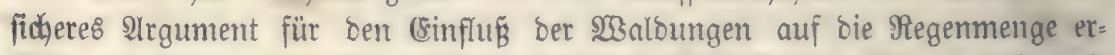
blicten zu bürfen geglaubt, aber, wie mir jogleidh fehen merben, nicht mit

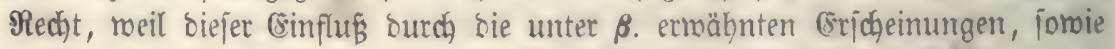

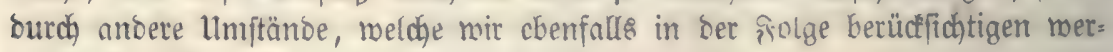
ben, wieber verocelt merben tann.

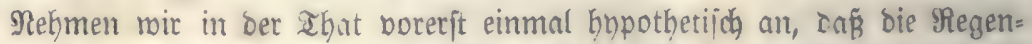

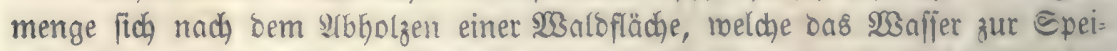
fung einer Quelle liefert, nidyt berminbere, jo witb bod, bie Cergiefigleit ber

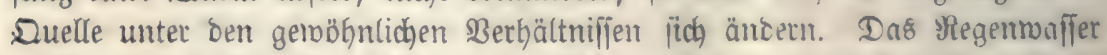
reldyes fich fonft in ben Blättern ber 3 Bäume fing uno nach uno nach auf

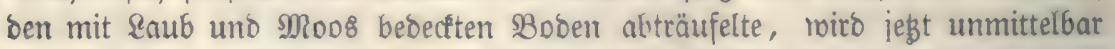
nuf Den Boben gelangen unt bon biejem eher abfließen, als e\& eingebrungen ift. Dies bezieht fich borzugsmeife auf bie fteileren \&agen, wo nach bem albtrieb

*) Thre entfetung, f. S. 522. 


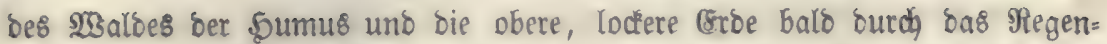
unt Sdineeroafer abgefpult mitb.

Die Abfholzung eines 2 aldes mürbe aljo in Dem angenonimenen æralle

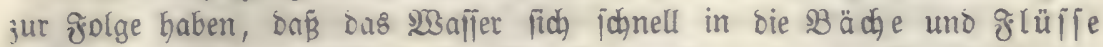
begibt uno bieje periobijch ftarf anjohnellen macht, aber bie Ergiebigfeit ber Quellen, welche Gauptiächlich bon bem in bie Grobe verfintenden $23 a f$ er abbängt, miro nachlaffen - alles biejes, mie mir mobl zu benchten bitten, ohne Daß̧ fich Die Regenmenge geänbert hat.

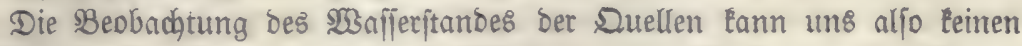

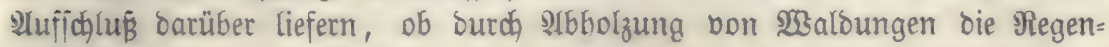
menge fich berminbert babe.

Бierzu fommt noch, daß auf abgeholzten Flächen ein grofier sheil bes

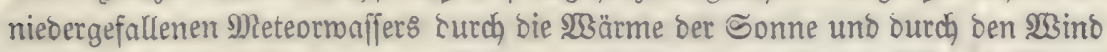
aufgezehrt mird, ehe es in ben Boben eingebrungen iit, während biejes $\mathfrak{W}_{\text {affer }}$

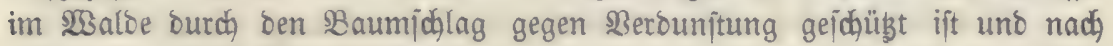
und nadh in ben s8oben fidern tann.

Die Iheorie ipridht aljo bafür, oañ jomohl bie (5rgiebigéeit, als auch

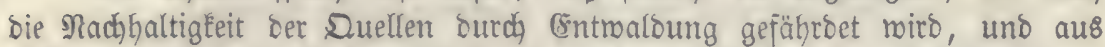

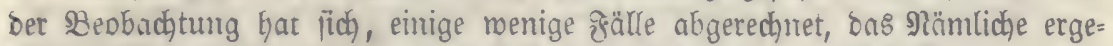
ben. Wir E⿱丷onnten eine groge 3abl bon belegenten seipipielen aus allen Theilen ber Eroe anfüfren, bejđränken uns aber auf die Dittheilung einer einzigen bon $B$ ouflingault überlieferten Beobachtung, melche mir besmegen als

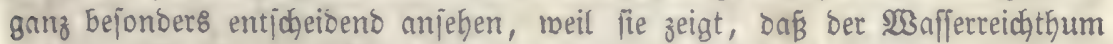

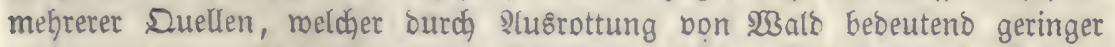
getworden war, fid bon Neuem Gerftellte, nachbem eine SKieberbewaldung ftattgefunden Gatte. Salten wir uns an bie eigenen $2 B$ orte Bouffingault's:

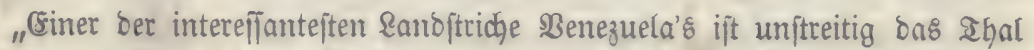
bon Aragua. In geringer Entfermung bon Der Rüfte gelegen, uno begün= fitigt burch ein marmes Rlima uno einen Boden bon beippiellojer forucht= barkeit, bereinigt eริ alle Culturgenächje, Die fïch für bie నropenländer eignen; auf Den Şügeln, weldhe in ber Mritte Des Thals fich erheben, fieht man nidht

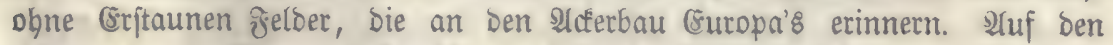

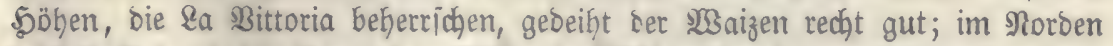

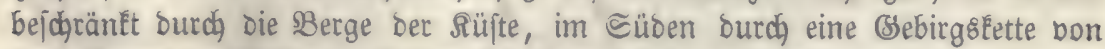
ben Elanos gejojieben, findet fich ons Ihal von ঐragua im Diten uno

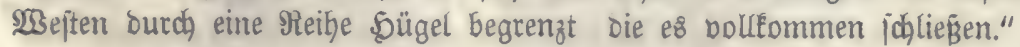

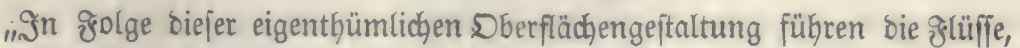

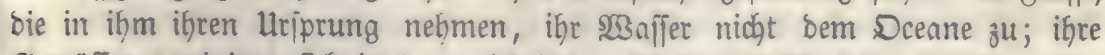
(semäffer vereinigen fid in bem niebrigften Theile bes ahales und bilden Gier in ifrer Bereinigung den jejönen See bon Iacarigua ober Balencia. Diejer See, ber nach D. Sumbolot an 2llusbebnurg ben bon Reufdhatel übertrifft, 
liegt 439 Meter über bem Meer; jeine \&änge beträgt ungefähr 10 Sieue\&, feine größte Breite überjteigt nicht $2 \frac{1}{2}$ Rieues."

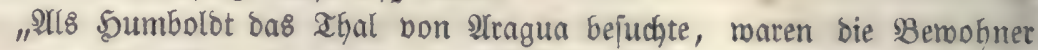

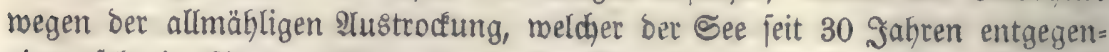
ging, fehr in Sorge. (\$\& genügt in ber That, bie bon ben älteren Sd)rift= ftellern gegebenen $\mathfrak{B e j}$ đjreibungen mit feinem gegentoärtigen 3 uftande zu ver:

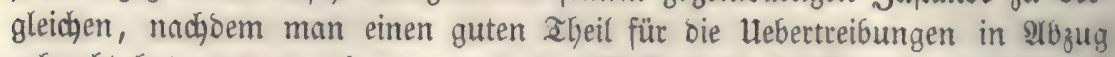

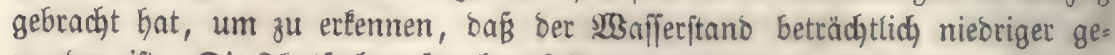

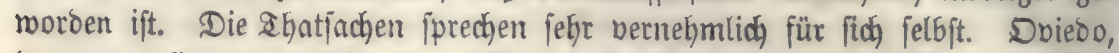
ber gegen (Enbe des fechszefynten Sahrhunderts bas ahal bon Aragua fo oft

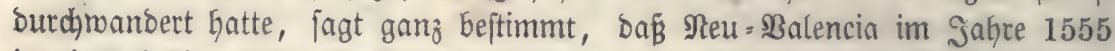
in einer halben \&ieue Entfernung vom See bon Iacarigua gegrünet rooroen

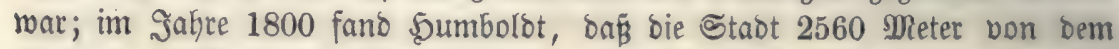
Gejtabe des ธees entfernt lag."

"Das थ̂njeben bes Terrains gibt hierfür neue Belege. Бügel, meldhe fid in ber Ebene erheben, fübren nod) beute den Namen Injeln, den fie bamals mit vollem Rechte ttugen, als fie nodh vom $23 a f f e r$ umgeben raren. Die burch bas 3urüdmeichen bes ๔ees trocken gelegten sänbereien waren in bewunberungstwüroige Eulturen von Baummollenftauben, Bananen uno 3ucterrohr vermanbelt. Nahe am ufer bes Cees erbaute 230 hnungen jahen

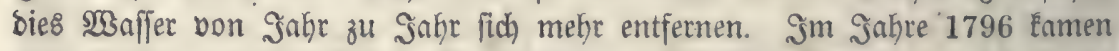
neue §njeln zum Borjhein. (Sin wichtiger militärijher \$unct, eine 1740 auf ber Injel ber (Eabrera erbaute §eftung befan〉 fids Damals (1796) auf einer

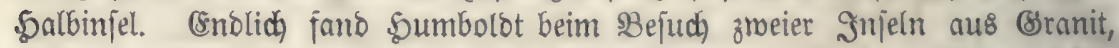

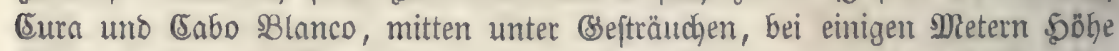

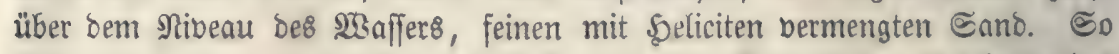
befitimmte uno unzroeibeutige Thatjacken musten Seitens ber (selebrten bes

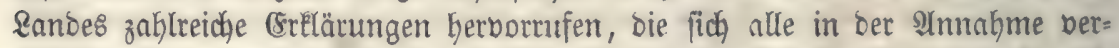

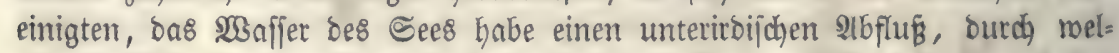
d)en Daffelbe in ben Deen gelange. Sumbolbt bermarf bieje \$typothejen, und erelärte nach einer grünolichen Unterjuchung ber Drtsperbältniffe bie fort= jajreitenoe Berminderung Des Iacariguajees aus bem Urbarmachen grö̌er Streçen \&anbes, weldjes feit einem balben Sahrbumbert in bem Thale bon Îragua ftattgefunben hat."

"Seit Dviebo, Der wie alle (Ehronifen/chreiber, über bie Berminterung

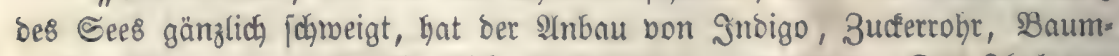
wolle, Cacao eine aukerorbentlidje Ansbehnung gewonnen. Das Thal von Arragua Gatte im Jabre 1800 eine fo bidjte BebölÉerung, wie bie beftbeböl=

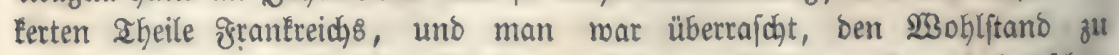
erblicten, ber in zablreichen Dörfern biejer gewerbthätigen segend Gerrjobte.

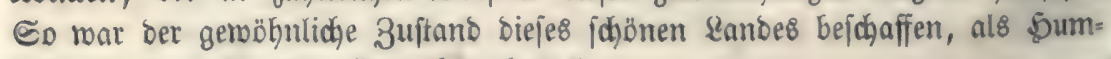
bolot bie Sacienoa bon Cuta beroognte." 


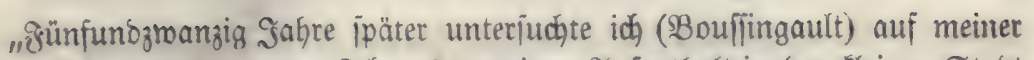

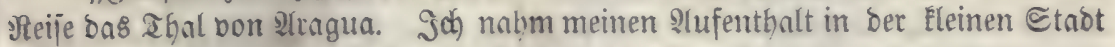
Daracay. Geit mefrern Jahren Fatten sie SBemohner bie Beobachtung ge=

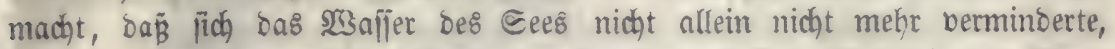
fonbern jogar ein merklliches Steigen ronbrnehmen laije. Ränbereien, unlängít

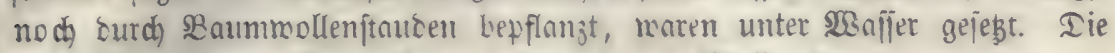

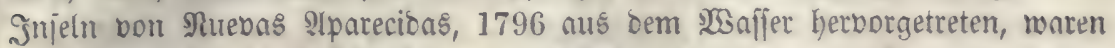
bon seuem für bie ๔chifffahrt zu gefährlichen Untiefen gemorden. Tie Rano=

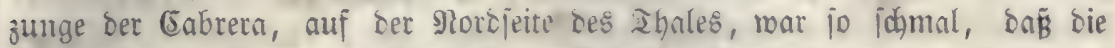

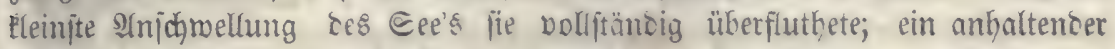

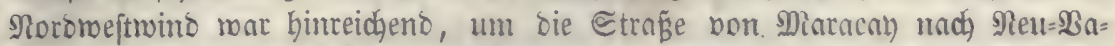
lentia mit $23 a f f e r$ z̆ bedećen. Tie von ben lijerbemohnem jo lange gehegten Befürdjtungen hatten igre Ratur beränbert; es mar nicht mehr bie böllige Austroçnung bes Sees, was mit Sorgen erfüllte. Mian fragte fich, ob bieje

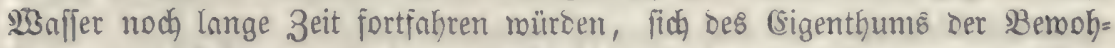

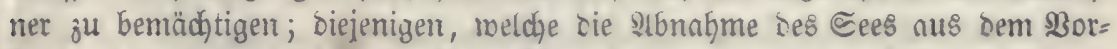
handenjein unterirbijcher (canäle erllärt hatten, maren genötbigt, bieje zu

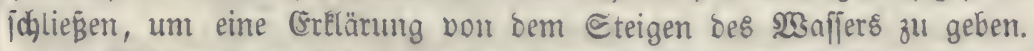

„233ährend ber bis zu diejer 3eit verflofienen 22 Jahre batten idymere politijche Ereignifie das \&ano heimgejucht; Benejuela gehört nicht mefr Epas

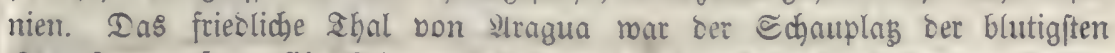

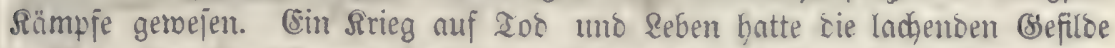
zerîtört, iłre Bevölferung becimirt. Beim erften SRuf nad) lunabhängigfét

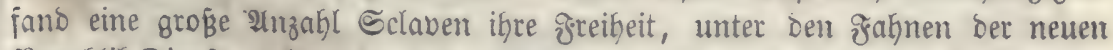

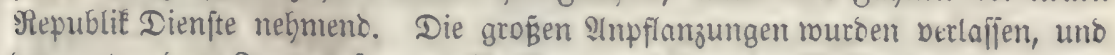
ber unter ben Iropen jo unaufbaltjam vorbringende SSald Gatte in Eurzer 3eit einen I heil bes \&anoes, weldhes Dienjohen ifm burd) eine längere, als

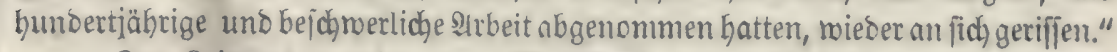

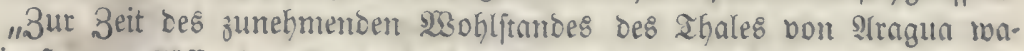
ren bie Sauptzuflïje des Cees abgeleitet, uno zu Bewäfferungšnnlagen be=

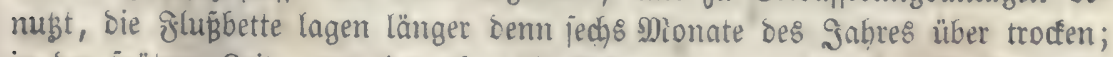

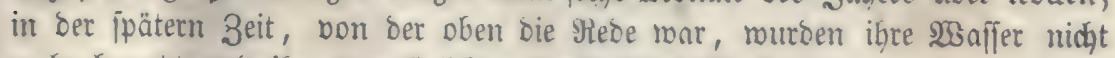
mehr benugt uno i̧̧rem natürlichen saufe überlaffen."

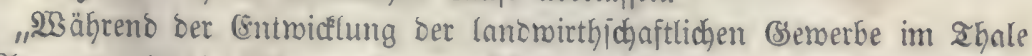
Don Alragua, als bie Urbarmadjungen fich berbielfältigten uno ber Snbau im

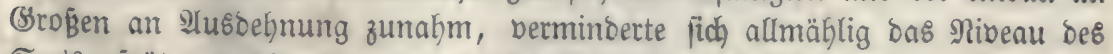
See's; ipäter, mährend einer unglüçsiohneren, glüctichermeije mun überitan=

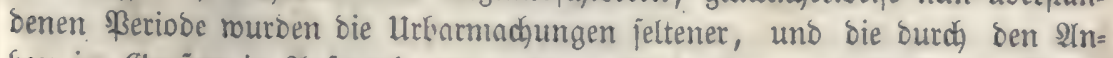

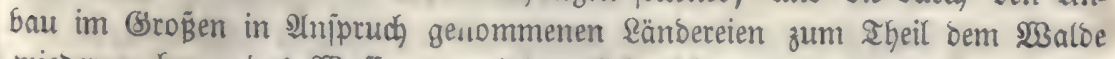
riedergegeben; bas $\mathfrak{W a f f e r}$ berminoert jïh nidht mebr und nimmt bald eine nidat mehr zneideutige fteigende Bemegung an."

Wir legen, wie idyon oben bemerkt murbe, auf bie borítehenbe,

DDI 
Bouffingault mitgetheilte Beobachtung besmegen io biel semicht, weil fie ebenjomohl ben negativen, wie den pofitiven (sinflüs ber 23 aldungen alf bie

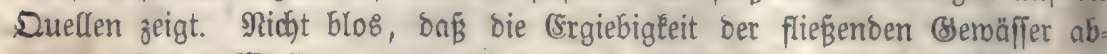
nahm, als ber $23 a$ ald ausgerottet rurbe, fie ftellte fich auch roieder her, nact)=

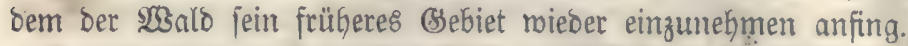

Die übermiegende Mehrzahl ber Beifpiele, welche die Klimatologijohen

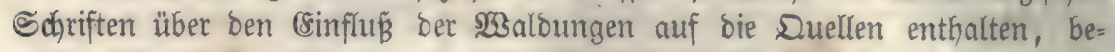

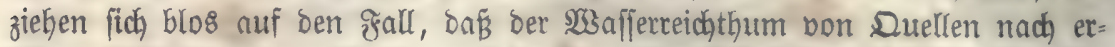
folgter Urbfolzung bon Wälbern fich vermindert habe, Dber basi bie Quellen ganz ausgeblieben feien. In allen biejen Beifpielen Ërnnte jenes (sreignißß

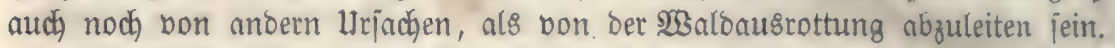
$\mathfrak{U m}$ - Den (sinflǘ bes 233 albes unmiberlegbar barzuthun, Gätte man aud)

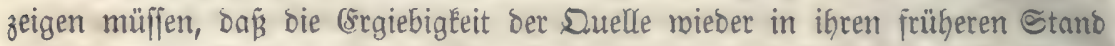
zurückgetreten jei, wie e\& von Bouffingault in bem Beifpiele bom Cee $\mathfrak{T a c a}=$ rigua geidjeben iit.

Nidyt ourch eine grofie Menge, jonbern burch bie Sichtigleit oer SBei= fpiele laffen fitch sBeneife fübren, uno bie Echriftiftller, melche fich bemüht haben, Die nadjtheiligen Frolgen ber 2 albausrottung zu berweijen, müroen beffer getfan haben, reenn fie fith blos auf bie borfin erzählte Beobachtung Bouf=

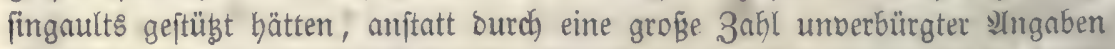

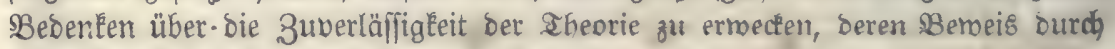
jene 2ngaben geliefert werben follte.

Mïge man fida), wenn e\& gilt, ben jo michtigen Einflǘ ber 23 aldungen nuf bie Suellen z̆u ermitteln, inseünftige nicht barauf bejchränken, die Beobachtungen fo aufzunefmen, wie jie ber 3ufall bietet. Die frorftmirth= fojaft gibt genug (selegenfyeit, um mirtliche Berfuche anzuftellen, bei benen

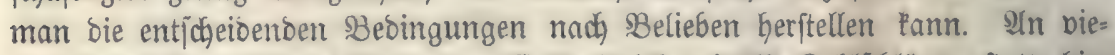
len Drten Deutichlands findet ber $W_{3}$ aldabtrieb mittelft Rablid)lägen ftatt, hier lieģe fich bie vorliegentoe frage leid)t enticheiben, weil man nicht blos bemer=

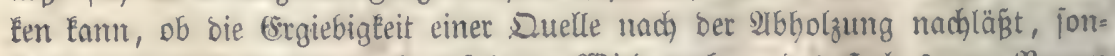

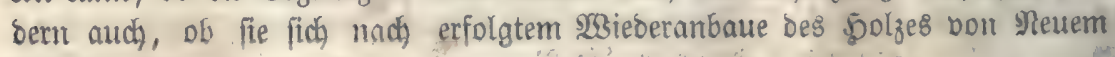
einftellt.

Die bon Bouffingault mitgetheilte Beobadhtung bom See zacarigua

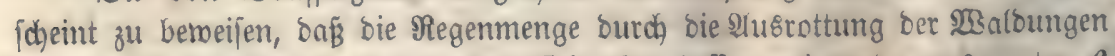
bermindert worben ijt; wenn man fid aber befien eximert, was unter $\beta$

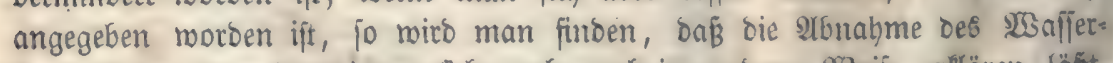

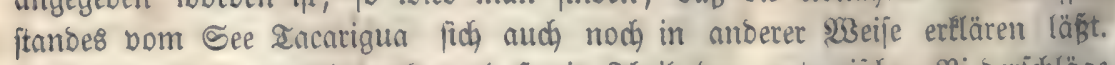

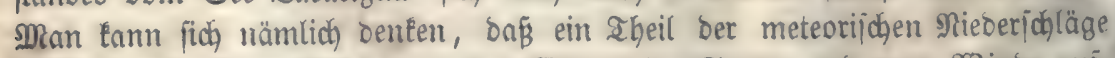

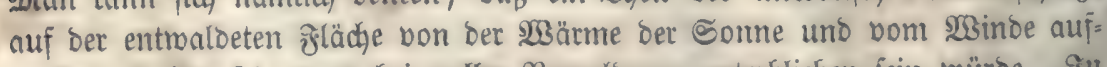
gezehrt worden jei, was bei boller $\$$ Beroaldung unterblieben fein toürbe. In Der בhat führt Bouffingault nod, ein Beippiel an, weldhes zeigt, baß́ eine

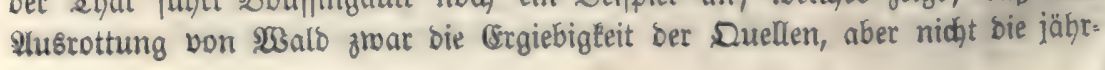




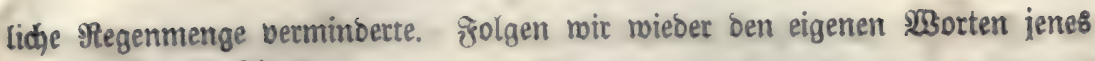
gropien Naturforiders.

1Das metallfübrende (sebirge bon Marmato liegt in ber $\Re_{\text {roving }} \Re_{0}=$

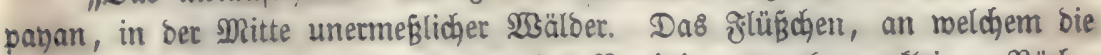

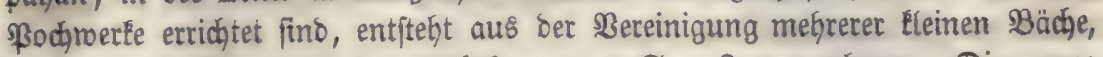
bie ifre (sntitebung auf ber इochebene von San Jorge nehmen. Die ganze Begens oberhalb bes (8tabliffements if ausnebmeno bidht mit 23 ald be. madis] $\left[e^{. \prime}\right.$

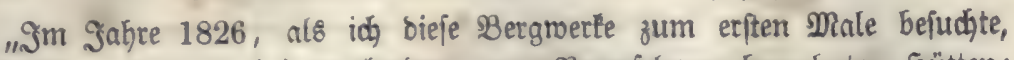

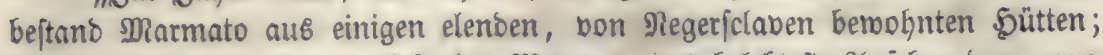
1830, als ich ben Drt berließ̧, bot Marmato Das belebtefte Ánjẹen bar; man

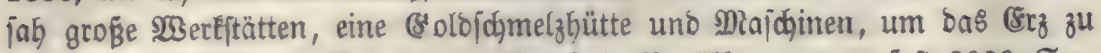
zerfleinern und zu amalgamiren. Sine freie BeböltEerung bon faft 3000 Ser=

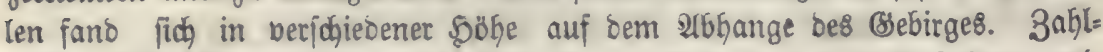
reidje 5oljichläge fanben ftatt, joroofi zur (stbauung ber Majdainen uno

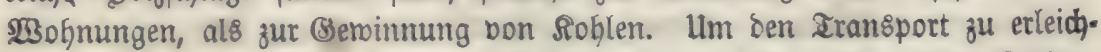
tern, batten bie Cabläge auf ben \$odjebenen von ๔an Sorge ftattgefunden. Der Abtrieb hatte Eaum zmei Sahre gebauert, als man bemertte, baß̈ bie

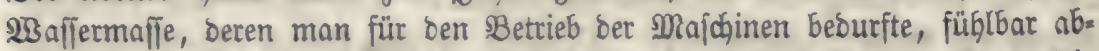

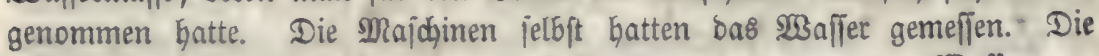

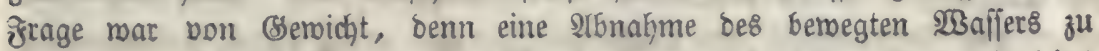
Marmato würbe ftet\& von einer 2 bnabme an probuzirtem Bolbe begleitet fein."

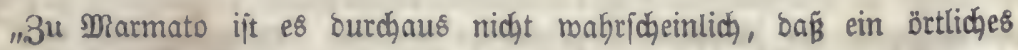

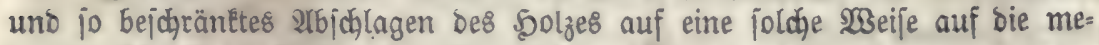

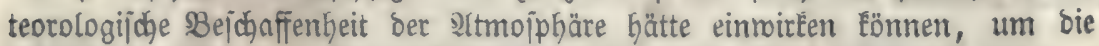

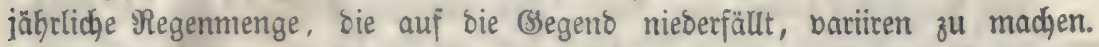

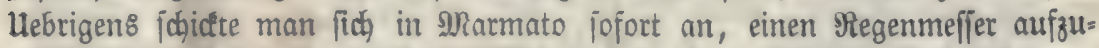
ftellen. Dbgleid, die Soljichläge fortgejest roorben waren, jo erfielt man

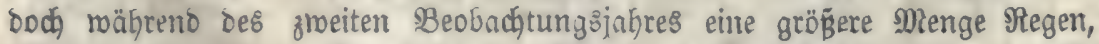
als im erịten Jafyre, ofne daß̈ man Gierbei eine merelliche 3unabme ber bes

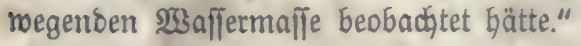

"Ohne 3weifel find zmeijährige Beobadhtungen für bie Beftimmung ber

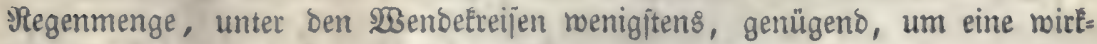

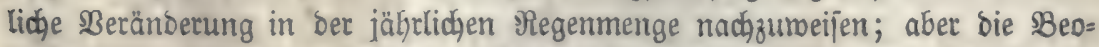

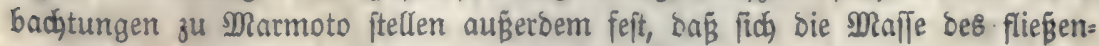
ben $23 a f f e r 8$ bermindert hatte, obgleidh die Regenmenge im zmeiten \$afh biel bebeutenber gewejen wat."

Die beiben Beijpiele, roldhe mir uadh der 9lutorität Bouffingault's ange= fübrt baben, zeigen aljo übereinfțimmeno, Daß̈ bie Crgiebigkeit ber Quellen

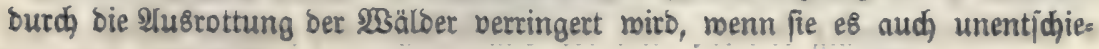


ben Iaffen Doer gar unmabricheintich machen, ob jene (Erfcheinung auf einer

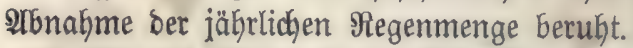

Bei bet Mehrzahl Der Deutfchen Flüffe mill man eine Albnabme be\& W3afferftandes gegen früher mahrgenommen haben, wie folgenbe, von 3 Berghaus entworfene 3ufammenftellung zeigt.

\begin{tabular}{|c|c|c|c|}
\hline \multirow{2}{*}{$\begin{array}{l}\text { Namen } \\
\text { Der } \\
\text { જtuื }\end{array}$} & \multicolumn{3}{|c|}{ Mittlerer $2 \mathfrak{B a f f e r f t a n d}$} \\
\hline & $1811-1820$ & $1821-1830$ & $1831-1835$ \\
\hline Rhein & $8^{\prime} 9^{\prime \prime}, 30$ & $8^{\prime} 9^{\prime \prime}, 30$ & $7^{\prime} \quad 8^{\prime \prime \prime}, 00$ \\
\hline SWEejer & $\ldots \ldots$ & $3^{\prime} 4^{\prime \prime}, 94$ & $2^{\prime} 11^{\prime \prime}, 39$ \\
\hline Elbe & $6^{\prime} 1^{\prime \prime}, 69$ & $6^{\prime} 9^{\prime \prime}, 53$ & $5^{\prime} 10^{\prime \prime}, 01$ \\
\hline Dber : & $3^{\prime} 1^{\prime \prime}, 42$ & $3^{\prime} 1^{\prime \prime}, 69$ & $2^{\prime} 10^{\prime \prime}, 40$ \\
\hline IEfeidjpel & $4^{\prime} 10^{\prime \prime}, 62$ & $4^{\prime} 6^{\prime \prime}, 28$ & $3^{\prime} \quad 0^{\prime \prime}, 36$ \\
\hline Memel & $7^{\prime}, 0^{\prime \prime}, 28$ & $7^{\prime} 9^{\prime \prime}, 82$ & $7^{\prime} \quad 2^{\prime \prime}, 31$ \\
\hline
\end{tabular}

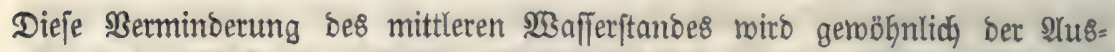

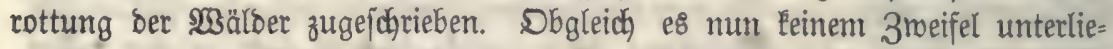

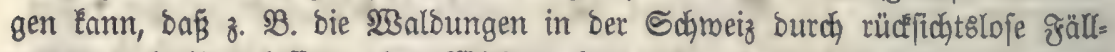
ungen und unterlaffung des Wsieberanbautes im saufe biejes Jahrhunberts auferorbentlich gelitten haben, fo ragen wir bod nicht, uns mit $2 B$ eftimmt=

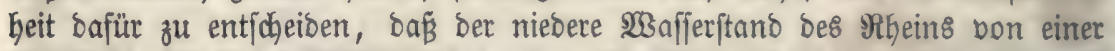

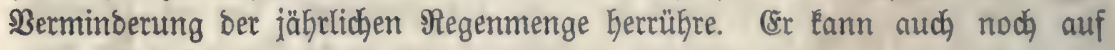
anbern urjachen beruhen.

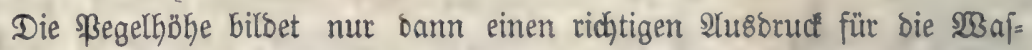
fermenge eines ơluffes, wenn bie uffer hod genug fino, um ein slustreten

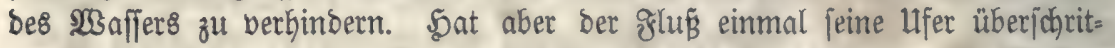

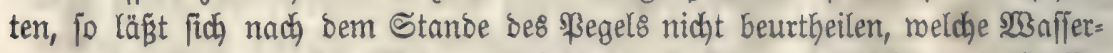

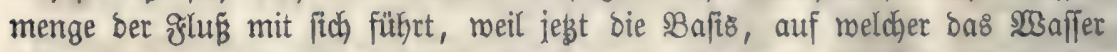
fich) bemegt, größß̈er geworben ift. Denken wir uns nun, bie 2Yusrottung ber

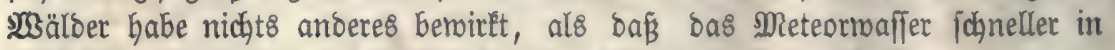
bie ơlüffe bineingelangt, fo werben von 3eit zu Zeit Ueberfornemmungen

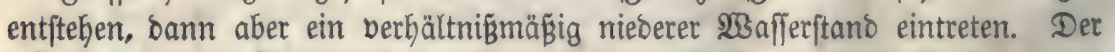
für bie Dauer einks Sahres berechnete mittlere $\mathfrak{S}_{3}$ afferftand wiro finken, ohne

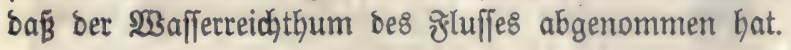

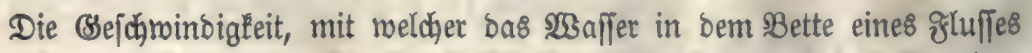

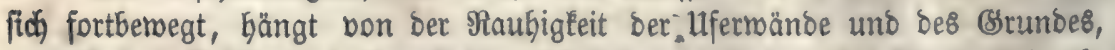
ganz bejonders aber bon ber Neigung Des legsteren gegen bie \$orizontale ab. Bezeidjnet $\alpha$ ben seigungsiminfel, fo ift gsin. $\alpha$ bas relative Semidht, meldjes

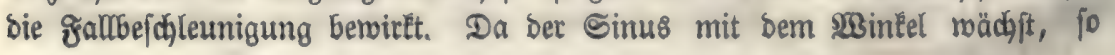




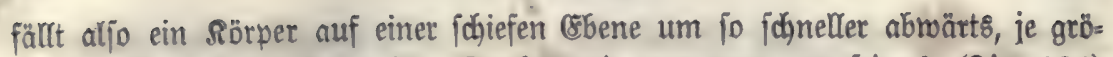

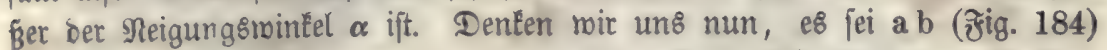

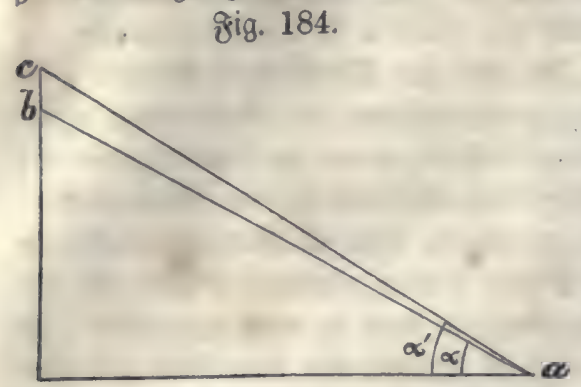
bie urpprüngliche Eage bes f̧luf̧bet= tes, a c beute bie Crob̈hung an, welche baffelbe burch eine von bem

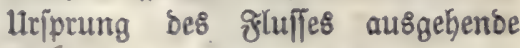
Berjantoung exfabren babe, jo wirb, meil jegt bet Meigungsininfell $\boldsymbol{\alpha}^{\prime}$ gro"= Ber, als $\alpha$ ift, bas $\mathscr{W}$ afier idhneller fliefien uno eine gegebene $23 a f$ er: maffe $m$ fich rajder über bie sinie a c

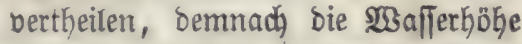

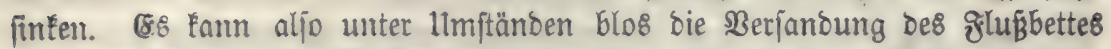

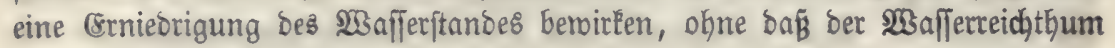

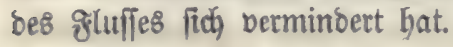

3u allem Diejem fommt nodh, baß̈ man gar nidft mit Beftimmtheit

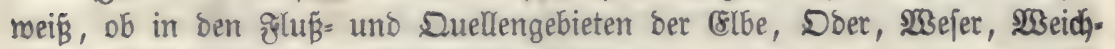
fel 2 . $23 a l d a u 8$ rottungen ftattgefunden baben.

W3ie oben gezeigt rutrbe, tragen bie $23 a$ aldungen zur Unterbaltung ber

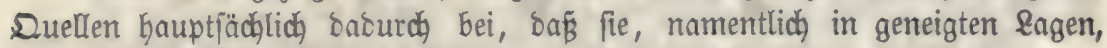

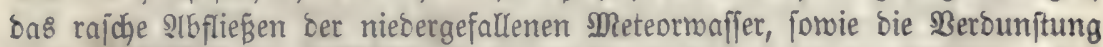

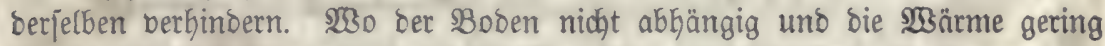

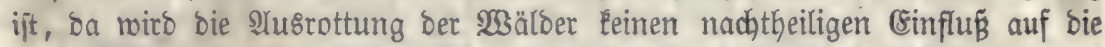
Duellen äußern. Diejer §all tritt auf ben \$lateau's ber 5odagebirge ein.

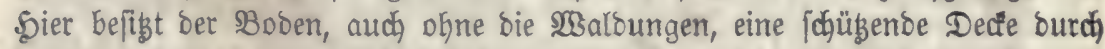

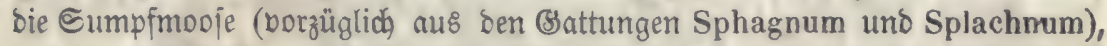
meldye bas Regen= und Edneemaffer aufnebmen, und bie Berbunftung ift burch eine niebere remperatur gehemmt. Unter den angegebenen \$erbältniffen

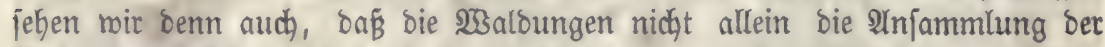

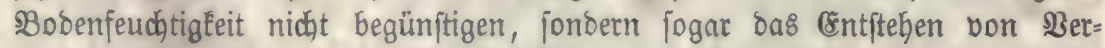
fumpfungen Ginbern. (s\& wiro nämlich an foldhen Drten bie Berbunftung meniger von ber Temperatur (roeil biefe an und für fich gering ift), als viel=

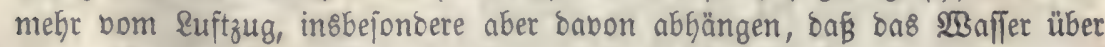

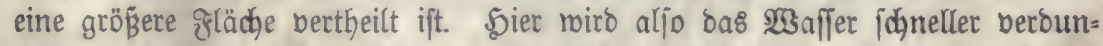
ften, menn es an best Blättern 2c. Der Bäume haftet, al\& renn es auf bem Boden fich befindet. Entjoheidende Beobachtungen über Sumpfbiloung unter

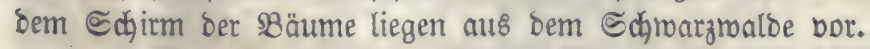

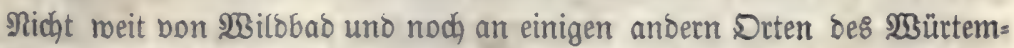

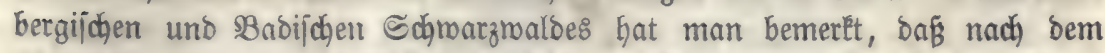

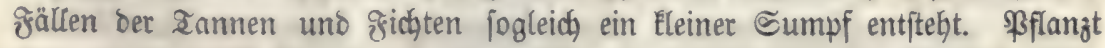
man einen neuen Baum auf bie Stelle, fo berfdrminoet ber Sumpf mieber 


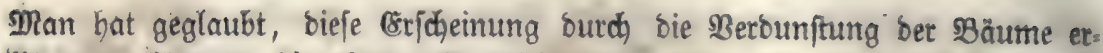
flären zu Können; bies tann aber nidjt ridjtig jein, benn in ber sbene finoet

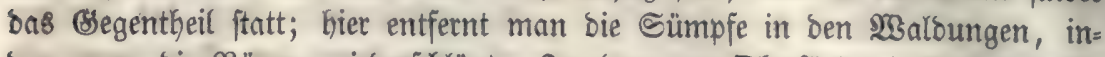

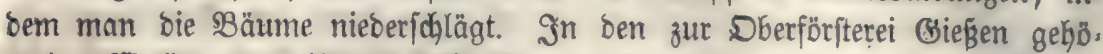

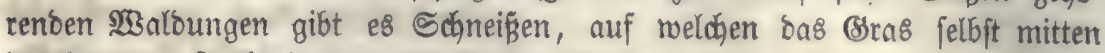
im Sommer feudht ift, und nur bann abtrocknet, wenn bie angrenzenden $B_{e}=$ fänoe gefällt werben. Die oben angefübrte (Exidjeinung im Sdymarzmalde

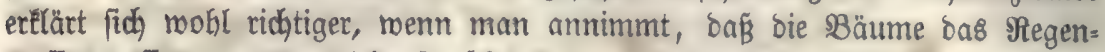
traffer auffangen und nidht fo idhnell zum Boben gelangen laffen. (\&8 bet= theilt fich hier auf eine größgere Dberfläd)e und fann jo eher verbunften. Sit bagegen tein Baum vorhanden, fo wirb eళ jogleid, von bem Boden, insbej.

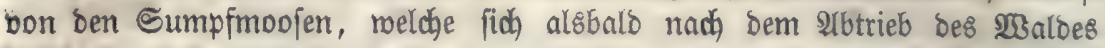
erzeugen, aufgenommen und berounftet nun wegen ber Eleineren Dberfläche biel langjamer. 2xlles biejes findet aber nur an foldgen Drten ftatt, wo bie Berbunftung an uno für fich burch eine niebere Zemperatur ber Euft erichnert

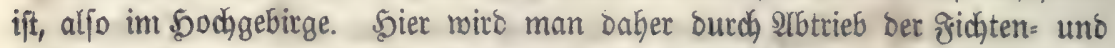

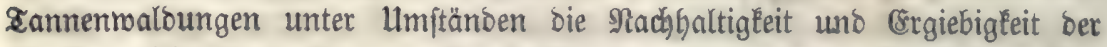
Quellen nicht ftören k̈̈nnen. Die liđatfronigen \$olzarten, z. SB. Riefern, Eär=

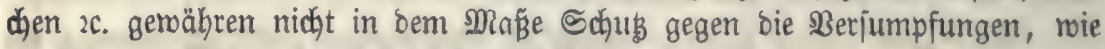
bie bis zum soben berab beafteten gichten und rannen.

In foldhen Sebirgen, welche Éeine Sümpfe enthalten, ober wo ber $\mathfrak{B D}_{0}$ ben, menn er blosgelegt moroen ift, fich nidht fogleid mit aorfmoojen be-

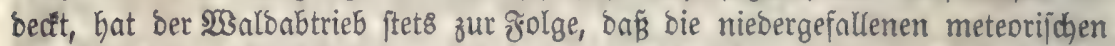

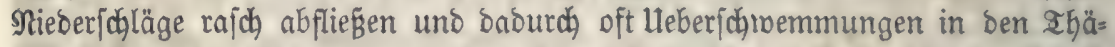

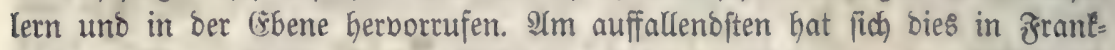
reich) gejeigt, nachbem 1789 in ber Assemblée constituante und 1793 ourch ben Conbent ber ßerf́auf eines grofien Theils der Staatsmaldungen uno bie Sheilung ber Bemeinbenaldungen becretirt morben mar. Un bas burch ben 2ntauf verausgabte (sello jo ichnell als möglid) wieber zu erlangen, hieb man

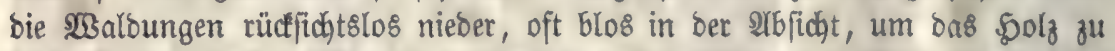

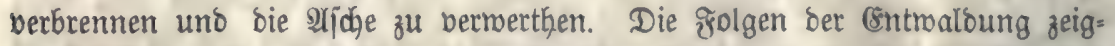
ten fich fehr bald. Napoleon ließs als erfter (Eonjul burch ben Minifter bes Snnern bie Berichte ber \$räfecten Gierüber einholen. Alus allen Departes menten liefen Slagen ein. Man nollte gefunden Kaben, baß̧ bie Bäche unb F्ञlüfle bald trocken lagen, bald in bie furdhtbarjten Ueberjhmemmungen ausarteten,

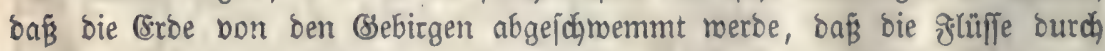
Sejohiebe beritopft mürben 2 c. Samentlich hatte man bie $28 i l$ bung ber log. (Się̧bäd)e (lorrents) beobadjtet, meldhe man früber taum tannte. Dieje Bießs=

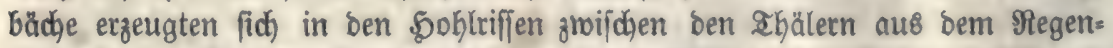

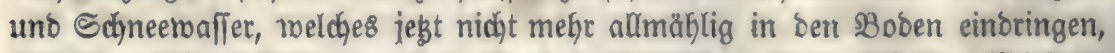

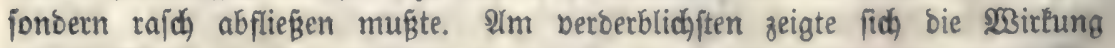

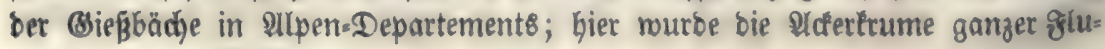




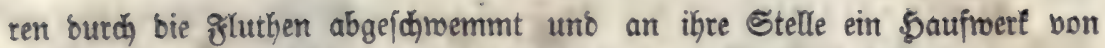
(Seftein8brocen gebradgt, weldae bie 2argicultur ummöglid) mad̆ten.

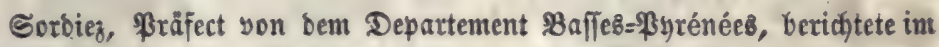
Jahy 1804 an bie Franzöpifá) Regierung: „bie Berge nehmen, feitbem fie

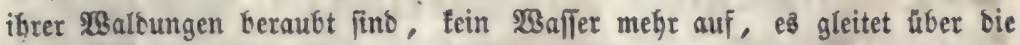

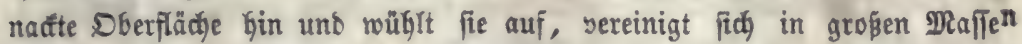

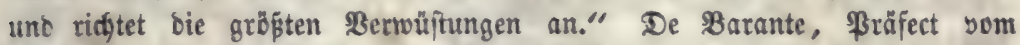

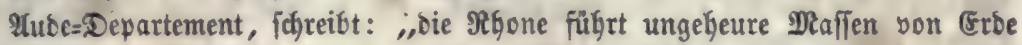
mit fidf, weld)e fie abjest. Die bem \$flug geobffneten Berge werten bald nur nod) nadte, unfudytbare Feljen aufauweifen baben; jebe Frurdje ift ein Craben geroorben; bie Dammerbe wirb burd) bie ftarfen Regen in bie Fluffe gefübrt, lagert fid in ben unteren PartGien berfelben ab unt brwirft baburd

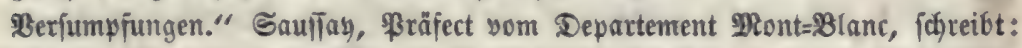
„Dab Befeb vom 10. Febr. 1793 aber bie Theilung ber Bemeinoegüter,

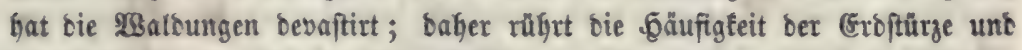

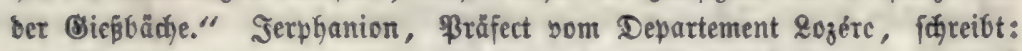
"Durdh ben 2 tbtrieb ber Bemeinberwalbungen wirb bie (Erte an ben $26 b a ̈ n=$

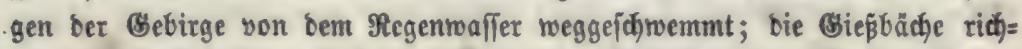
ten jebes Sałr bie größten Berkeerungen in ben Cevennen an." Faudjet,

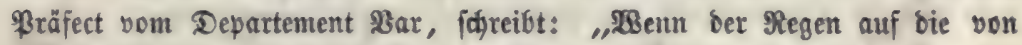

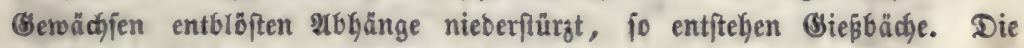

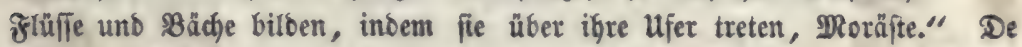

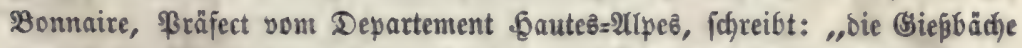
furdent bie Seiten ber Bebirge, bei bem geringiten Bewitter wadyjen fie an,

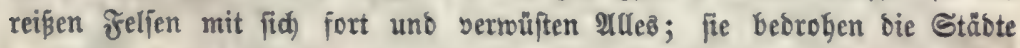

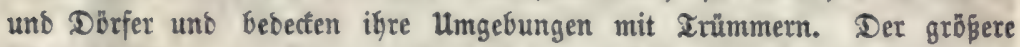
Theil ber Berge war yor nod) nidht langer 3eit mit fabönen $\mathfrak{B a l b u n g e n t}$ bebcatt, jekt zeigen bie nadten (sipfer nur nod') unwirthbare Feljen. Ueberall

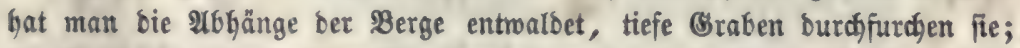

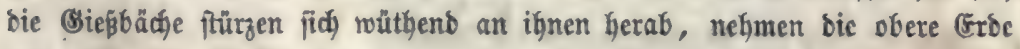

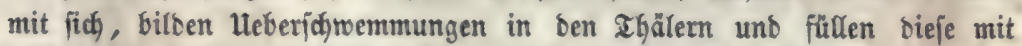

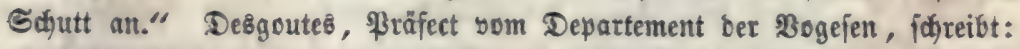
„bie Ueberfd)wemmungen fint häufiger, als jemalb, bie शRab tritt oft uีber ihre ufer."

\section{e. Einfufie ber Balbungen auf bie Eawinen.}

Nad) Saftbofer entitehen bie Eawinen niemals butd) 3ujammenrollen,

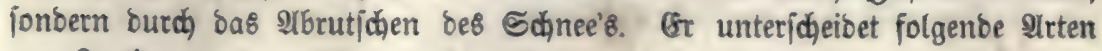
bon Bawinen:

a. Staublaminen; fie bilben fidh, wenn bie Sdgneemaffe an einem Betgabbang zu rutfden beginnt uno in Staub auffiegt. 


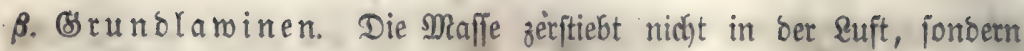
rutīht gejd)loffen bormärts. menten.

$\gamma$. Sleticherlaninen. Sie bejtehen aus geboritenen Sletjoterfrag=

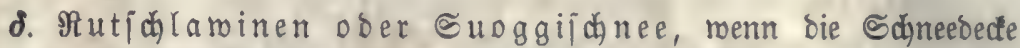
auf meniger fojiefem Boben nidht zum Fallen ober Eostreisen fommt, fondern langlam über bie sroe rutjht und hinter jebem Begenitano, welcher ber betwegten Maffe roiberfteft, fich antyäuft, Gis er bem Druck meidst, ober ber Sdunee fidh an ifm theilt.

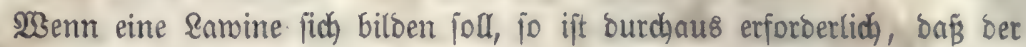

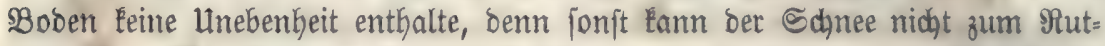

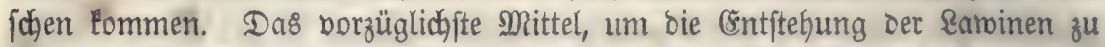
berhinoern, befteht aljo barin, Daß̈ man bem Boben künftlid, Unebentheiten ber:

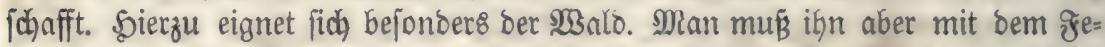

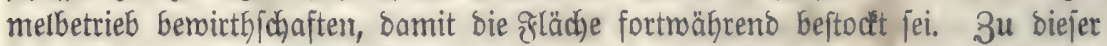
Betriebsart eignen fich nur bie fohattenertragenden 5 b̈lzer, aljo namentlich bie

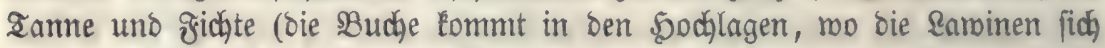
bilden, gemöhnlid nidyt mebr fort). 2Huty ber Niebermaldbetrieb mürbe ganz gut ben obigen 3roed exfüllen, menn mur bie (sidje, melche allein zu Sdylag= holz auf bie Dauer taugt, im 5odhgebirge fortzubringen wäre.

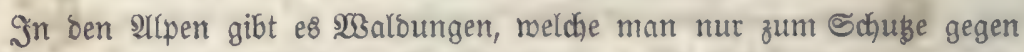

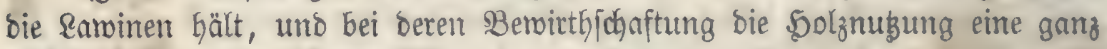
untergeoronete Rolle fpielt. Man nennt fie Bannmaloungen.

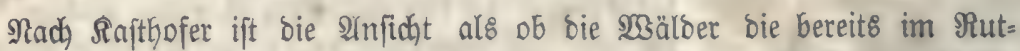
fwen begriffenen \&aminen aufhalten Ë̈nnten, eine irrige. Selbft ber ftärffte WGald joll bem Drudfe bes in ber Bemegung begriffenen ๔anne's nidat zu miberftehen bermögen. Die 3 Bannwalbungen könnten fomit mur bazu bienen, um bie ßillung ber \&aminen zu berfinbern.

\section{Cinfur ber 23 aldungen anf bie 23 inte.}

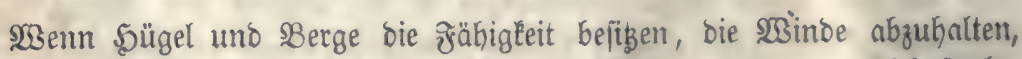
ober beren Ungejtüm zu brechen, fo müffen bie $23 a l$ oungen, namentlich joldje,

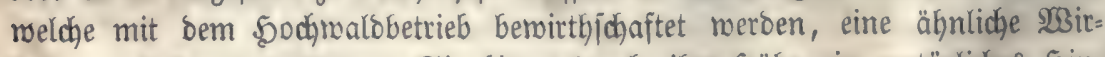

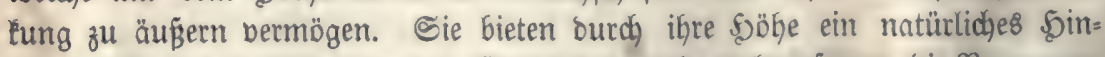

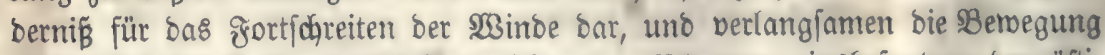

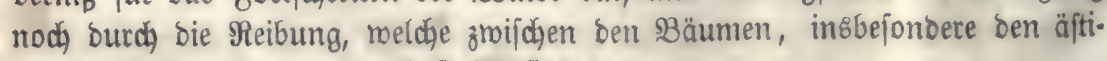
gen Baumeronen, uno ber \&uft ftattfinbet.

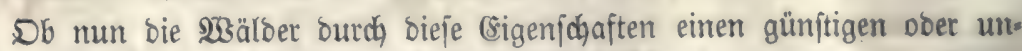

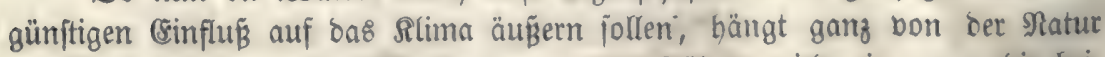
ber $\mathfrak{W}$ inde $a b$, beren sauf fie bemmen. Sm Süben mirb ein gegen bie bei= 


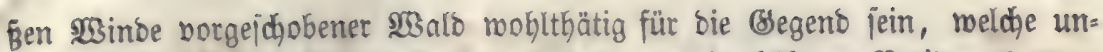
mittelbar hinter bem 23 inde liegt, rähreno man in höheren 8 reiten es gerne

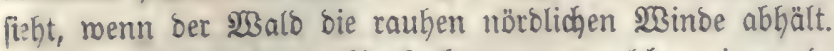

¿s fehlt nidht an Beobadatungen, meldhe zeigen, baß̈ bie 23 albungen

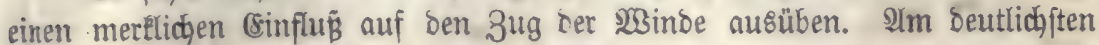
trat Derfelbe in franfreid Gervor, nachoem bie Staatsmaloungen berfauft, viele Bemeinderwaldungen getheilt uno in Folge biejer beiben limitänoe viele

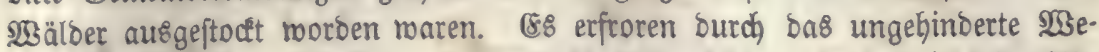

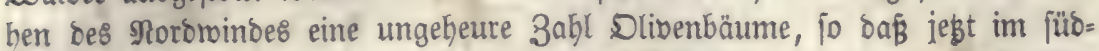
liçen frrankreich) bei weitem nicht mehr foviel Dliven gewonnen werben tön= nen, als bieß por ber Pebolution ber frall war. 2lud jegt ift ber 2Tnbau bes

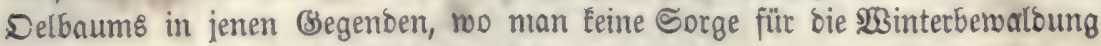
getragen hat, mit groß̧en ๔chmierigkeiten berbunoen.

Sn Deutichlano hat man an vielen Drten beobachtet, DaB das Dbit nicht mehr gerieth, wenn ein 23 ald niebergejohlagen wurbe, ber bie rauken Norbminde abgebalten Gatte. Um menigitents ein Beifpiel zu geben, nennen

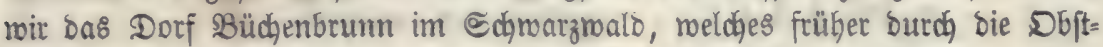
cultur ausgezeidhnet mar, no aber bas Dbft jogleidh zu mifreathen anfing, nachbem man einen Rablfieb borgenommen Gatte. W3ahridfeinlid mirb ber

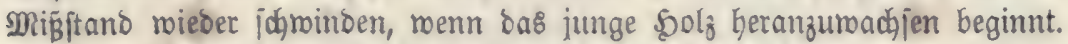

In Amerifa jollen bie Djt = uno Norboftwinbe immer reiter borbringen,

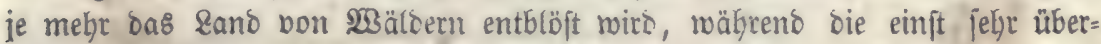

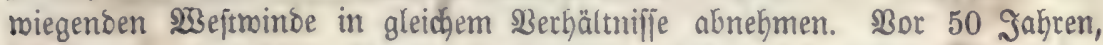
jagt Williams in jeiner Siftory of Bermont, weheten bie Ditroinde Laum 10 13 ङranz. MReilen landeinwärt\&; iest jpürt man fie im frühlinge oft in 20, und in Bermont jelbft in 27 Meilen (Entfermung bon ber Süfte (\$Bronn).

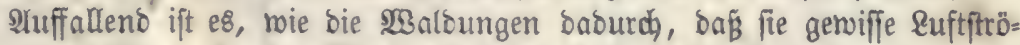
mungen abhalten, auf ben Befundheitรzuftand ber Bewohner von mandjen Begenden einwirken. So nimmt man an, baß̧ bie Yusoünftungen ber \$on=

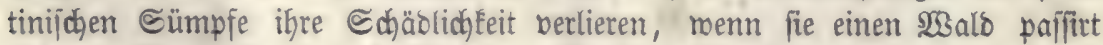

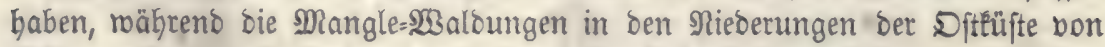

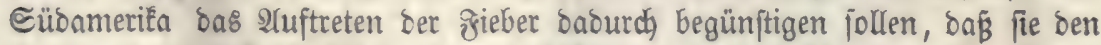
Euftzug hemmen, der bie feuchten હdhidaten ber Armojphäre über ben Sümpfen entfernen Ëbnnte. Man johlägt bie $\mathfrak{B a}$ aldungen in biejen Begenten nie= ber, um legtere bemohnbar zu madjen.

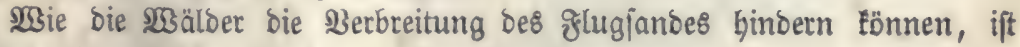
früher beteitร etroähnt worben. 


\section{8}

\section{If}

5. $133.3,4$ b. o. lieb $25-50 \%$ ftatt $25-25 \%$.

5. 195. 3. 8 v. แ. " Iemperatur um 12 uตr.

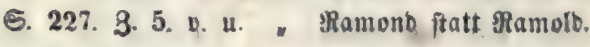

5. 476. 3. 2. ๖. u. "rangiferina itath rangifarina. 

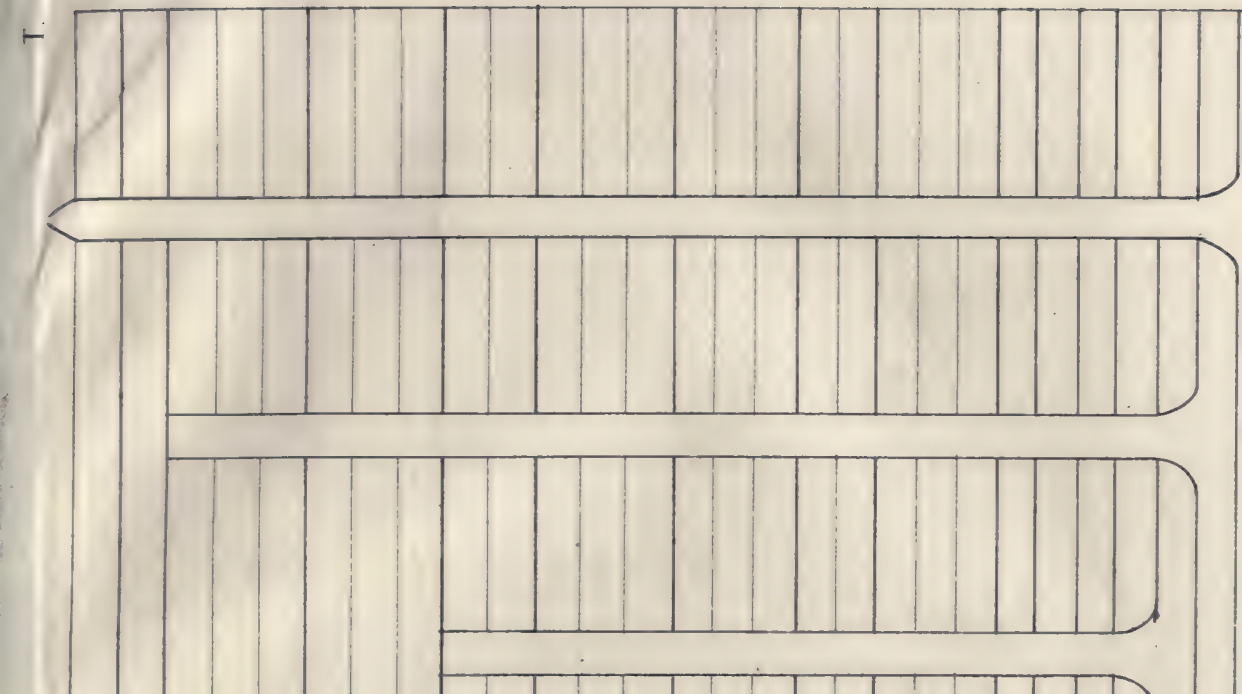

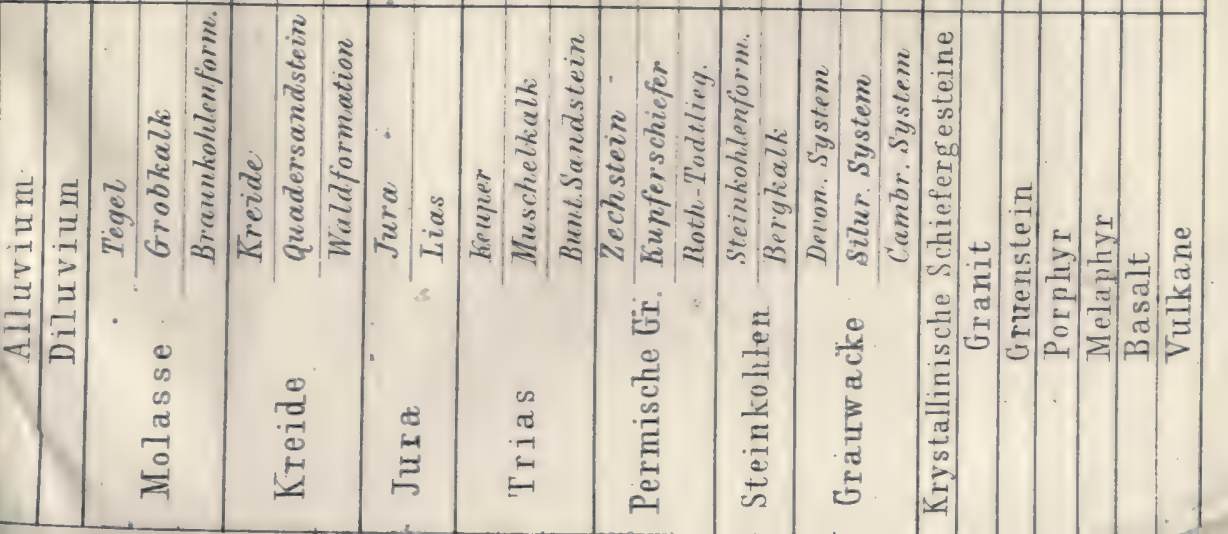









\section{LIBRARY \\ UNIVERSITY OF TORONTO}

S

598

$\mathrm{H} 47$
Heyer, Gustav

Lehrbuch der forstlichen Bodenkunde und Klimatologie

\section{BiolMed}

PLEASE DO NOT REMOVE CARDS OR SLIPS FROM THIS POCKET 
